


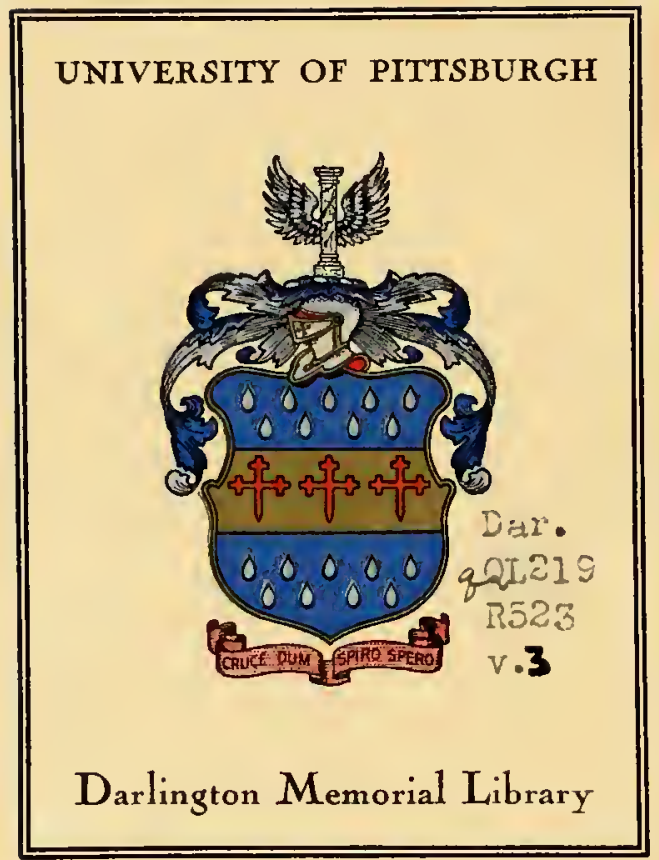


. 
Digitized by the Internet Archive in 2009 with funding from University of Pittsburgh Library System 




\section{F A U N A \\ B O R E A L I - A M E R I C A N A; OR THE \\ Z O O L O G Y \\ OF THE \\ NORTHERN PARTS}

OP

\section{B R I T ISH A M E R I CA:}

CONTAINING DESCRIPTIONS OF THE OBJECTS OF NATURAL HISTORY COLLECTED ON THE LATE NORTHERA LAND EXPEDITIONS UNDER COMNAND OF CAPTAIN SIR JOHN FRANKLIN, R.N.

PART TIIIRD.

\section{TH E F I S H.}

B Y

JOHN RICHARDSON, M.D., F.R.S., F.L.S.,

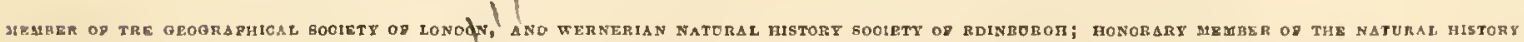
WOEIETY OP MONTREAL, ANL LITERARY AND PHILOSOPHIOAL SOCIETY OF OOEBEO; POREION MEMBER OP THE GBOORAPHICAL GOOIETY

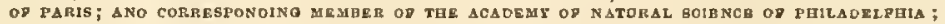

SURGEON AND NATURALIST TO THE EXPEDITIONS.

ILLUSTRATED BY NUMEROUS PLATES.

PUBLISHED UNDER THE AUTHORITY OF THE RIGHT HONOURABLE THE SECRETARY OF STATE FOR COLONIAL AFFAIRS.

L O N D O N :

RICHARD BENTLEY, NEW BURLINGTON-STREET. 



\section{TABLE OF CONTENTS.}

\section{INTRODUCTION}

Page ix

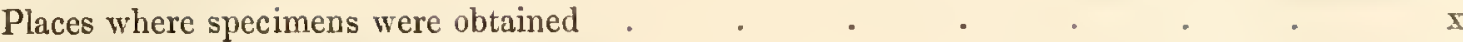

Orders of Fish established by Cuvier . . . . . . . . . . . . xii

M. Agassiz's arrangement (note) . . . . . . . . xiii

\section{OSSEOUS FISHES.}

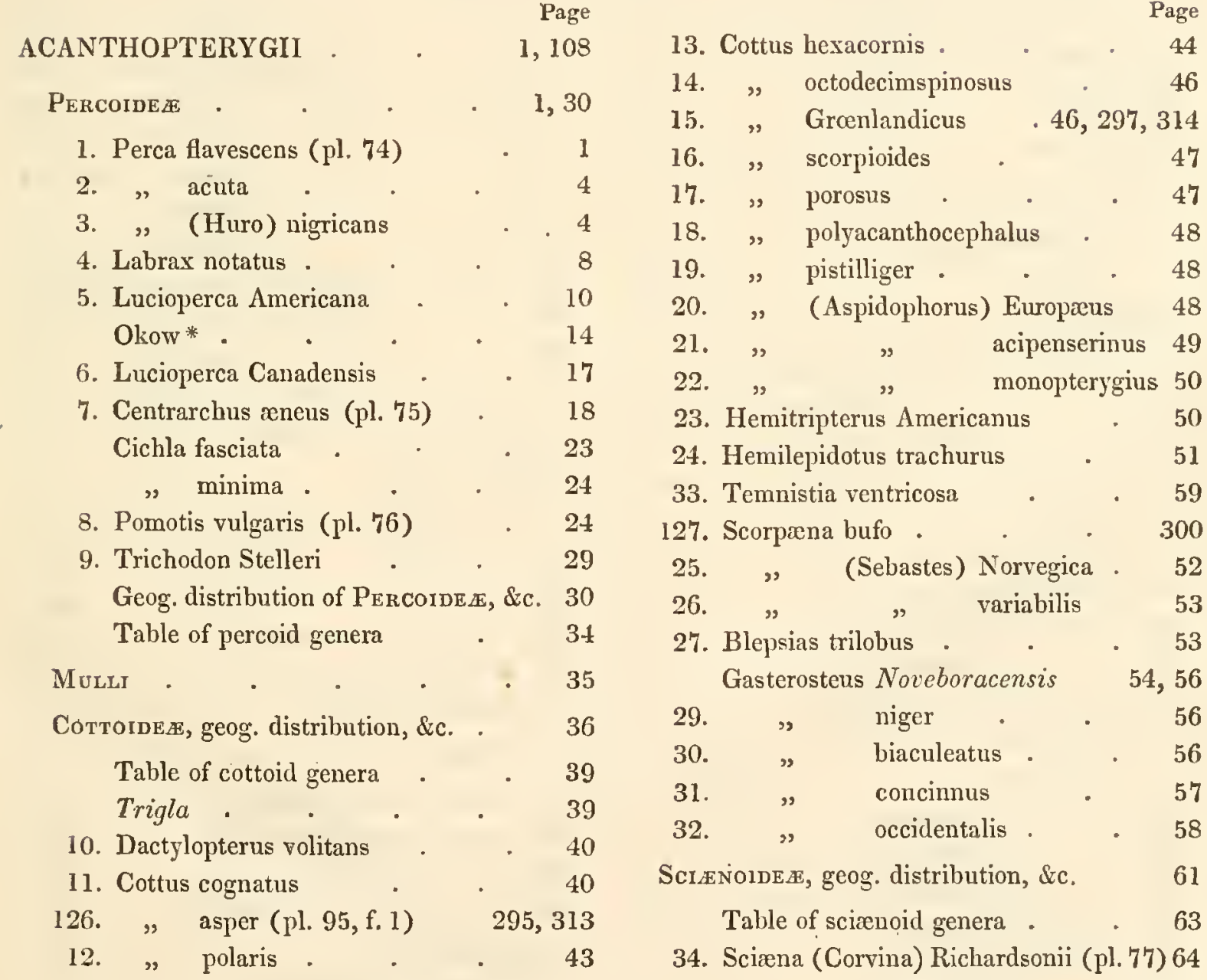

* The receipt of specimens of the Okow since the sheets describing it went to the press prove it to be the Lucio-perca Americana. 
35. Sciæna (Corvina) oscula . . 68

36. „(Otolithus) regalis Sciana (Otolithus) Drummondii $\quad 70$

SParoidea . . . . 70

Manoidex . . . . 72

Chemodontoidea $\quad$. . . 73

Anabasideet . . . 75

Scomberoidea Tribes, geog. distrib., \&c. 76

Table of genera . . $\quad 78$

37. Scomber grex et vernalis . $\quad 80$

Second tribe of Scomberoidex . 81

38. Notacantlius nasus $\quad$ - $\quad$. 82

Third tribe of Scomberoideæ . . 82

Fourth tribe of ditto . . $\quad 83$

39. Zeus (Lampris) guttatus . . 83

TANIOIDEE . . . . 85

Siganotdex . . . . . 86

MUgILOIDEE

Tetragonurus Cuvieri . . 87

$\begin{array}{llll}\text { Atherina } & \text {. } & & \end{array}$

GoBIOIDE

40. Blennius (Clinus) punctatus . 88

41. " " lumpenus . 90

42. " (Centronotus) gunnellus 91

Butter-fish . . . 93

Pustulated blenny . . 93

Zoarces . . . . $\quad .93$

43. Blennius (Zoarces) polaris . 94

44. Anarrhichas lupus . . 95

45. $\quad$ minor . . 96

Gobius, sub-genera, \&c. . . 96

Callionymus . . . 97

Platyptera . . . 97

46. Chirus monopterygius . . 98

47. " decagrammus . . 99

48. " octogrammus . . 100

49. " superciliosus .. . 100

Chirus lagocephalus . . 101

" hexagrammus . . 101

Hexagrammus Stelleri . 101
Batracholde . . . . 102

Thutinameg . . 103

50. Lophius (Malthe) cubifrons (pl. 96) 103

LABROIDEA . . . . 106

United States' species . . I I07

Fistularoidex . . . 107

Remarks on Acanthopterygil . 108

MALACOPTERYGII ABDOMINALIS 109

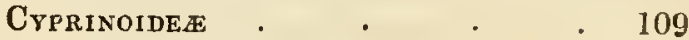

North American species $\quad$. 109

51. Cyprinus (Abramis) Smithii (woodcut) . . . . 110

128. " " balteatus . 301

52. " (Catastomus) Hudsonius 112

129. " " reticulatus 303

$53 . \quad " \quad$ Forsterianus 116

54. " " $"$ Sueurii 118, 303

$55 . \quad " \quad$ " aureolus . 119

56. " $"$ nigricans 120

57. $\quad$ (Leuciscus) gracilis (pl.78)120

58. " " chrysoleucas 122

130. ", " caurinus 304

131. " " Oregonensis 305

Exoglossum nigrescens $\quad$. 122

ESOCIDAE . . . . 123

United States' species . $\quad 123$

*53. Esox lucius . . . 124

*54. " estor . . . 127

*55. Scombercsox scutellatus . . 128

*56. Brazilian pike . . . 129

*57. Exocætus exiliens . . . 129

Siluroidex . . . . 132

Unitcd States' species . . . 132

*58. Silurus (Pimelodus cænosus . 132

$59 . \quad, \quad$ nigrescens . 134

60 . ",$\quad$ borealis . 135

Salmonoldes . . . . 137

Trouts or true salmon . $\quad$. 137

* These six numbers were inadvertently repeated. 
European trouts 139

Salmo salar (pl. 91, f. 1) . 140

Salmon trout (pl. 92, f. 2) $\quad 140$

Hirling . . . 141

Sowin (Salmo Cambriscus) (pl.91,

f. 2)

141,306

Nith trout (S.trutta) (pl.92, f. 2, 5) 142

Loch Leven trout 143

Salmo ferox . . . 144

" fario $(\mathrm{pl} .92, \mathrm{f} .3) \quad$. 144, 307

Char or Torgoch (pl. 92, f. 5) 144

61. Salmo salar

145

62. " Scouleri (pl. 93) . 158, 223

63. " Rossii (pl. 80 \& pl. \$5, f.2) 163

64. , Hearnii . . . 167

65. " alipes (pl. $81 \&$ pl. 86, f. l) 169

66. „ nitidus (pl. 82, f. $1 \& 86$, f. 2) 171

$6 \%$ \# Hoodii (pl. 82, f. 2 ; 83, f. 2 ;

$$
87, \mathrm{f} . \mathrm{I}) \quad \text {. } \quad . \quad 173
$$

68. „ fontinalis ( $\mathrm{pl} .82, \mathrm{f.} 1$; 87, f. 2) 176

Greenland trouts

178

69. Salmo namaycush (pl. $79 ; 85$, f. 1 ) 179

70. , Mackenzii (pl.84; 94, f.1) 183, 309

Mountain or Speckled trout . 178

Columbia River salmon @ 162, 217

Common salmon (Lewis and Clarke) 162

Red char

Salmon trout

(ditto) 162, 223

(ditto) 163,225

82. Salmo quinnat . $\quad$. $\quad 219$

83. " Gairdneri . . . 221

84. " paucidens . . 222

85. " tsuppitch . . . 224

86. " Clarkii . . . 225

Salmon of New Caledonia . . 214

Trouts of ditto . . . 307

71. Salmo (Osmerus) eperlanus . 185

72. „, (Mallotus) villosus . 187

87. " " Pacificus . 226

73. " (Thymallus) signifer (pl. 190) 190

74. " : thymalloides 194

Coregoni, observations on . 310
75. Salmo (Coregonus) albus (pl. 89.

Page

f. 2, 94, f. 2, A. B. c.) 195, 311

$\begin{array}{llllr}76 . & & & \text { tullibee } & 201,309 \\ 77 . & " & n & \text { Artedi . } & 203 \\ 78 . & " & & \text { quadrilateralis }\end{array}$

(pl. 89, f. 1) 204

79. " " Labradoricus 206

80. " " $\quad$ lucidus (pl.90,f.1 $) 207$

81. " " harengus (pl.90, f. 2) 210

Salmo (Coregonus) fera 213

Vandesius* 207,213

Clupeonde . $\quad$ •

United States' species . . 229

88. Clupea harengus . . 229

89. Hiodon chrysopsis (pl. 94, f. 3,

$$
\text { A.B.C.) - . 232, } 311
$$

90. „ tergissus . . 235

91. Amia ocellicauda . . 236

92. Lepisosteus Huronensis . 237

MALACOPTERYGII SUBBRACHIATI 241

Gadoidex . . . . 241

United States' species . . $\quad 241$

Kamtschatka ditto . . . 242

93. Gadus morrhua . . 242

94. " callarias . . . 244

95. " Fabricii . . 245

96. " ogac . . 246

97. " (Merlangus) carbonarius 247

98. " " polaris - 247

99. " (Lota) maculosus . 248

100.,$\quad$ (Brosmius) flavescens . 252

101. " (Phycis) punctatus (wood-cut) 253

102. Macrourus rupestris . . 254

Platessoinex $\quad . \quad$. $\quad 255$

United States' species . . 255

North-west American species - 256

103. Pleuronectes (Platessa) stellatus . 257

104. " (Rhombus) glacialis 258

DrscoBoli . . . . 260

* This specific name is adopted from Sibbald's Scatia Illustrata. In the Number of Yarrell's British Fishes, which has just appeared, it is called Coregonus Willughbii. 


\begin{tabular}{|c|c|c|c|c|c|c|c|c|c|}
\hline & & & & & Page & & & & Page \\
\hline 105. & Cyclopteru & s lumpus & - & - & 260 & 111. Anguilla rostrata. & . & & 267 \\
\hline 106. &, & minutus & - & & 262 & 112. Ophidium viride & - & - & 271 \\
\hline 107. & $"$ & spinosus & - & . & 263 & 113. Saccopharynx ampullac & ceus & & 271 \\
\hline 108. & 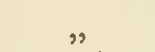 & ventricosu & s & & 263 & 114. Ophidium stigma & - & - & 273 \\
\hline 109. & $"$ & (Liparis) & commul & & 263 & 115. $"$ Parrii . & & & 274 \\
\hline EснE: & NEIDEE & . $\quad \because$ & . & & 265 & 116. Ammodytes lancea & - & . & 275 \\
\hline 110. & Echeneis $n$ & laucrates & . & . & 266 & LOPHOBRANCHII & & & 276 \\
\hline LA & COPTERY & GII APOI & ES & & 267 & PLECTOGNATHI & . & - & 277 \\
\hline ANG & ILLIFORME & & . & - & 267 & United States' species & & & 277 \\
\hline
\end{tabular}

\section{CARTILAGINOUS FISHES.}

\section{CHONDROPTERYGII ELEUTHERO-} POMI

StURIOnIDE E . . . 278

United States ${ }^{2}$ species . . 278

Lovetsky's arrangement of Sturgeons 281

117. Acipenser transmontanus $\quad 278$

118. $\%$ rubicundus . . 284

131. " Rupertianus . . 311

118. Chimæra . • . 285

CHONDROPTERYGII TREMATOP-

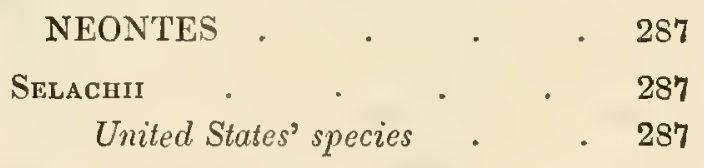

119. Squalus (Carcharias) vulgaris . 288

120. " $\quad$ " Terræ novæ 289

121. " (Selache) maximus . 291

122. " (Spinax) acanthias . 291

132. " (Scymnus) gunneri . 313

123. Raia fullonica . . . 291

Cxclostomata . . . 292

124. Petromyzon tridentatus . 293

125. " fluvialis . . 294 


\section{LIST OF PLATES.}

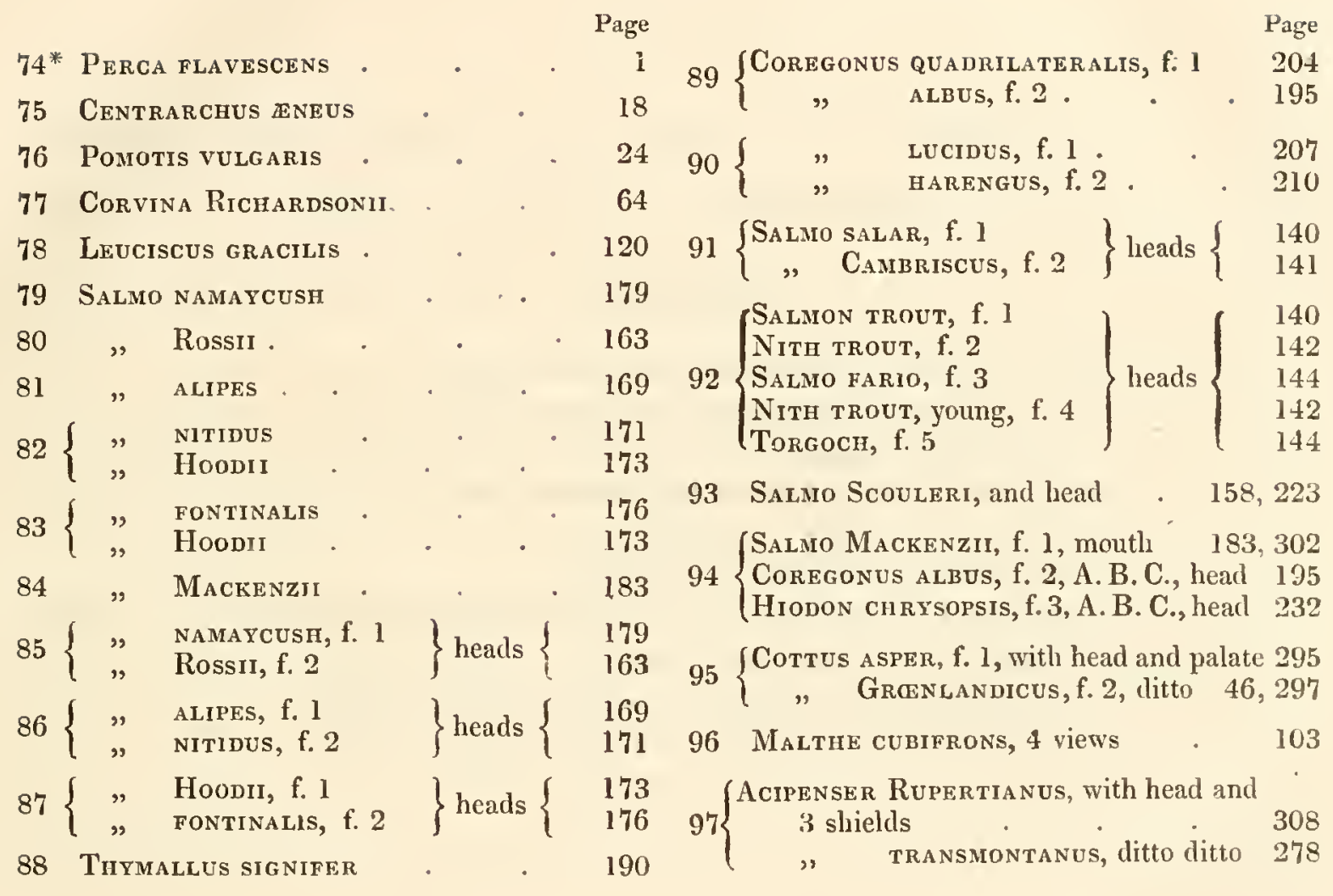

All the above plates were executed with strict fidelity to the specimens placed before him by Mr. Wateriouse Hawkins. Nos. 89 and 90 are etched on copper, 94, 95, 96, and 97, are drawn on zinc, and the remainder are lithographed. Two wood-cuts, printed with the text, are from slight sketches, after nature, by Lieutenant-Colonel Hamilton Smith. Figures of Catastomus reticulatus, Forsterianus, and Sueurii, will appear in the Natural History Appendix to Captain Back's forthcoming narrativé. 


\section{ERRATA}

Page 30, line 9, after " five hundred " add "twenty-one."

10, for " twenty-seven" read "forty-seven."

- 34, in two last columns of the table, for " 111 " read " $131 ;$;" and in line of totals, for " 327 " read " 347 ," and for " 501 " read " 521 ."

_ 80, line 1 , for " [36]" read " [37]."

_- 145, line 3, for "Wynn" read "Wynne."

- 174, line 3 from bottom, for "shorter labials" read "longer labials."

- 194, line 1, for " tahn" read "than."

241, line 2 from bottom, before " maculata" insert "Lota."

- 271 , lines $6,8,12$, and 13 from bottom, dele "very." 


\section{N T RODUCT I O N.}

Notwithstanding the high rank which our countryman Ray occupies in the annals of Natural History as a founder of systematic ichthyology, that branch of science has been greatly neglected in this country,-yet Britain owes much of her wealth to her fisheries; and her seamen, traversing the ocean in all directions, are familiar with the finny inhabitants of almost every river in the world, as well as with the wonders of the deep. While the fish of the English seas were imperfectly known, it was not to be expected that those frequenting the waters of a remote colony would be more fully described; and, in fact, this volume of the Fauna owes comparatively little to the labours of previous writers in respect of the determination and description of species, though the arrangement and generic groups are adopted wholly from Cuvier. Forster, in the Philosophical Transactions of 1773, gives an account of four Hudson's Bay fish, three of which he erroneously identifies with European species; and he is the only ichthyologist that I have been able to cite respecting the fish which sport in the sea-like lakes and magnificent rivers of the portion of North America lying north of the St. Lawrence, and exceeding the whole of Europe in extent of territory. There is, I believe, no scientific account of the Canada fish, with the exception of M. Le Sueur's and Dr. Mitchill's descriptions of a few lacustrine species. Some of those inhabiting the seas of Newfoundland are included in the published volumes of the Histoire des Poissons, by Cuvier and Valeuciennes. Fabricius's and the work last mentioned are my authorities for the Greenland fish, and I am indebted to the Appendices to the late Arctic Expeditions for those found on the northern shores of America. Pallas, Steller, and Tilesius have described the fish inhabiting the sea of Kamtschatka, and such of them as are known to range over to the Ame- 
rican coast are included in this Fauna. Eschscholtz's description of a fish taken in Norfolk Sound is quoted, and as I cau refer to no work containing any notice sufficiently detailed and accurate to determine the species, or even the genera, of those in the waters of New Caledonia, the popular accounts of voyagers and travellers, who have visited that country, have been occasionally transcribed at some length, to supply the want of scientific information.

The specimens described and figured in the following pages were chiefly collected by me at Cumberland House in latitude $54^{\circ}$, at Fort Enterprise in. latitude $64^{\circ}$, and in the Arctic Sea at the mouth of the Coppermine River in latitude $67^{\circ}$, on Sir John Franklin's first journey*; at Penetanguishene on Lake Huron in latitude $44^{\circ}$, in Great Bear Lake in latitude $64^{\circ}$, or in the canoe route between these places, on his second journey; and in the following quarters by the exertions of others, viz., on the Labrador coast of the Gulf of St. Lawrence, from whence I obtained a collection of the Salmon and Coregoni of the Mingan and Musquaw rivers, prepared by Mr. Cuming; of the Hudson's Bay Company; at Penetanguishene, where Mr.Todd, surgeon of the Naval depot, procured me a suite of specimens which I submitted to the inspection of Baron Cuvier, together with those obtained on Sir John Franklin's second journey; and in the Albany River district latitude $51^{\circ}$, from whence $I$ have very recently received a series of fresh-water fish in excellent condition : in addition to these, Dr. Gairdner, surgeon of the Hudson's Bay Company's establishment, at Fort Vancouver, ou the Oregon or Columbia River, sent me a cask full of specimens, which, though much damaged on the voyage, have, with the aid of his valuable notes, furnished the only means I possess of obtaining a knowledge of the fish of that river, and enabled me to understand in part the popular descriptions given in Lewis and Clarke's narrative; Dr. Scouler, of the Dublin Institution, presented me with a curious salmon, which he obtained on the coast of New Caledonia; and I am indebted to Peter Warren Dease, Esq., for several kinds of trout from the interior of that country; by the kindness of Captain

\footnotetext{
* The fish observed on Sir John Franklin's first journey are described, and a few of them figured, in the Appendix to his Narrative; but the specimens, which would have been of great use for comparison with those afterwards obtained, were destroyed by vermin during my absence on the second journey.
} 
James Ross I have had the opportunity of describing and figuring the salmon procured by him on Sir John Ross's recent expedition; and still more lately I have obtained some useful specimens of the heads of tish, prepared by Mr. King during Captain Back's overland journey*. It will be observed, that these different collections consist almost exclusively of the fresh-water, or anadromous species, that supply a principal article of diet to the natives and residents in the fur-countries, the smaller kinds which escape through the pretty wide meshes of the gill-nets in ordinary use there having been mostly overlooked. I am, however, indebted to John James Audubon, Esq., the celebrated American ornithologist, for a small but interesting collection, made on the coasts of Newfoundland; and Lieutenant-Colonel Hamilton Smith favoured me with sketches and notes of several Canada fish. But even with these advantages the work must be considered as very defective in marine species, and by no means complete even in the fresh-water ones. As it was not until after I returned to England from Sir John Franklin's last expedition that I entertained the idea of publishing a work of this nature, I had no inducement to avail myself of the opportunity which was afforded by our journey through Canada and the State of New York, for the collection of materials in aid of such an undertaking; and my numerous subsequent attempts to remedy this deficiency, by procuring specimens through correspondents, have been unsuccessful, except in the instances above mentioned. Upwards of four humdred species of European fish are described in the Histoive des Poissons, or noticed in the Règne Animal, and it may be fairly inferred, that a still greater number inhabit the fresh waters of British America, or the Atlantic, Arctic and Pacific seas which bathe its shorest. The present work contains only one hundred and forty species, so that much remains to be accomplished by resident naturalists; and with the view of facilitating the labours of those who may undertake

- Many of the specimens, having arrived at different periods, and when the printing of the work was considerably advanced, could not be noticed in their proper places, and their descriptions have therefore been introduced either at the end of the families to which they belong, or in the Appendix; but an attempt has been made to remedy this irregularity by arranging the table of contents.

+ De Witt Clinton estimates the species of fish in the United States at four hundred, and Dr. Mitchill describes one hundred and seventy that are brought to the market of New York. 
- the task, I have endeavoured by minuteness of description, aided by correct figures, to render their recognition of the fish already named more certain. I have, also, in consideration of the difficulty of procuring books in remote districts, entered more fully into generic details than is usual in a local Fauna, and likewise given compendious notices of most of the families mentioned in the Règne Animal, borrowing largely not only from that work, but also from the Histoire des Poissons. Cuvier divides the class in the following manner:-

\section{First Series. FISH PROPERLY SO CALLED.}

A. Upper jaw formed externally of intermaxillaries and moveable labials; and posteriorly of a palatine arch composed of palate bones, pterygoid processes, jugal, petrous, and squamous bones, constituting a sort of interior jaw as in birds and snakes, and furnishing posteriorly an articular cavity for the condyle of the lower jaw.

a. Gills in leaves.

Order 1. Acanthopterygit. (vide p. 108. F. B. A.)

2. Malacopterygit abdominales. (p. 109.)

3. Malacopterygil sub-brachiati. (p. 241.)

4. Malacopterygil apodes. (p. 267.)

b. Gills in tufts.

5. Lophobranchit. (p. 276.)

B. Labials soldered to the intermaxillaries : palatine arch united to the cranium by suture and not admitting of motion.

6. Plectognathil. (p. 277.)

Second Series. CHONDROPTERYGII or CARTILAGINOUS FISH.

A. Gill openings of the ordinary form, having a moveable gill-plate. (El.Eutheворомі.) (р. 278.)

7. Sturionidez. (p. 278.)

B. Canals communicating with gills having fixed edges, and opening exteriorly by one or several holes. (Trematopneontes.) (p. 287.)

8. Selachiı. (p. 287.)

9. Cyclostomata. (p. 292.) 
As this arrangement* is very different from the quinary one advocated by Mc Leay, the nomenclature of that gentleman and his followers, which is adopted in the second volume of this Fauna, is inapplicable here, and Cuvier's names are therefore given to the various groups, except in a few instances, where the French term used by him did not readily admit of a direct Latin translation, as in the case of "Poissons Plats," for which Platessoidea is substituted.

I gladly avail myself of this introductory chapter to notice the kindness of various gentlemen by whom I have been assisted in the progress of the work. In the first place, I have to express my gratitude to the Right Honourable Lord Glenelg, Secretary of State, for his recommendation of an additional grant in aid of the publication, and to William Hay, Esq., Under Secretary for Colonial Affairs, for his efficient support of my application, and invariable personal kindness whenever I have had occasion to address him. I lave likewise to express my obligations in an especial manner to Captain Pelly, Governor of the Hudson's Bay Company, and Nicolas Garry, Esq., Deputy Governor, for the liberality with which they have always promoted my endeavours to illustrate the zoology of the furcountries; also to James Keith, Esq., of La Chine, and to the other gentlemen already named, to whom I am indebted for specimens of American fish. My thanks are also due to the following gentlemen, who procured for me, in most instances with considerable difficulty and trouble, specimens of European fish for the purpose of comparison, viz. : Dr. Graham, F.R.S.E., Professor of Botany, Edinburgh; Mr. Scobie, of Kioldale, Sutherlandshire; Mr. John Burnet of Dumfries ; P. J. Selby, Esq., F.R.S.E., of 'Twissel House ; G. A. W. Arnott, Esq., F.R.S.E.; Captain Barou, Royal Engineers; John Lloyd Wynne, Esq., of Coëd-Coch, Denbighshire; the Rev. T. W. Booth, Vicar of Friskney, Lincolnshire, and W. Yarrell, Esq.,

\footnotetext{
* Professor Agassiz, of Neufchâtel, has recently given to the world an entirely new arrangement of fish, founded chiefly on the form and structure of the scales, upon which he establishes four orders:-1. CTEnoïnians, which are the Acanthopterygii of Cuvier and Artedi, with the exception of those which have smooth scales, and with the addition of the Flat-fish, or Platessoidea, removed from the Malacopterygii. 2. Crcloïnans, which are priucipally Malacopterygii, but take in also the smooth-scaled fishes excluded from the Acanthopterygii. 3. Gavoïdans, comprising the Lophobranchie, Plectognathii, and Sturionidece, together with a great number of extinct genera. 4. Placoïdrass, which are the Selachit and Cyclostomat a of Cuvier.
} 
whose beautiful, able, and accurate work on British Ichthyology, now in the course of publication, will, it is to be hoped, be a means of reviving, in this country, a taste for that branch of natural history. Lastly, I have again to acknowledge the attention of the officers of the British Museum, whenever I have had occasion to consult its library, or natural history collection, and particularly that of my friend J. E. Gray, Esq., upon whose valuable time I have had occasion frequently to draw very largely. Part of the specimens described in this work were, as I have already mentioned, examined and named by the truly illustrious Cuvier, and I would gladly have submitted the rest to his inspection as they arrived; but in common with other naturalists, and the civilized world in general, I have had to deplore his death, which, notwithstanding the vastness of his labours in zoology, must be considered as premature for the interests of science; though we look with confidence to his able coadjutor, M. Valenciennes, for the completion of the unrivalled Histoire des Poissons. I may also notice here, the deaths of two naturalists to whom the former volumes of this work are much indebted. 'Their walk in science was indeed far beneath the lofty platform which Cuvier constructed, but they were unrivalled in the paths they chose for themselves. I allude, in the first place, to Mr. David Douglas, to whose researches in North California, and on the banks of the Columbia, we owe many of the most beautiful hardy flowers which ornament our gardens. He perished miserably in the Sandwich Islands, by falling into a pit in which a wild bull had been previously taken, where the infuriated animal gored him to death. Thomas Drummond, of Forfar, the other gentleman whose loss I have to record, was my friend and associate on Sir John Franklin's second expedition. An enthusiastic admirer of animals and plants, he was eminently qualified for a collector of objects of natural history, by an extreme quickness and acuteness of vision, and a wonderful tact in detecting a new species. His favourite pursuits were carried on under circumstances of domestic discomfort and difficulties, that would hare quelled a meaner spirit,- the contemplation of the works of God on the mountain top, or in the bosom of the forest, serving to soothe the sorrows of his wounded mind. In his company, and by his aid, most of the birds described in the second volume of 
this Fauna were procured : by his unremitting industry and strenuous exertions a very great proportion of the plants included in Dr. Hooker's Flora Boreali-Americana were obtained; and the Musci Americani*, published on the same plan with his beautiful Musci Scotici, will be a lasting monument of his activity and penetration as a cryptogamic botanist. After making very large collections of plants in various parts of the United States, and in the province of Texas, he died in the Island of Cuba, where he had landed on his way to the Florida Keys.

* In two volumes quarto. 



\title{
NOR'THERN ZOOLOGY.
}

\author{
PART III. \\ P I S C E S.
}

ACANTHOPTERYGII.

PERCOIDEA.

\author{
[1.] 1. Perca flavescens. (Cuvier.) American Perch. \\ Family, Percoideæ. Genus, Perca, Cuv. \\ Yellow perch (Bodianus favescens). Mitchill, Ph. Trans. New York, i., p. 421. No. 7. \\ Sмiтн, Fish of Mass. \\ Perca flavescens. Cuv. Reg. An., ii., P. 133. \\ La perche jaunâtre d'Amérique (Perca flavescens). Cuv, et VAL, ii., P. 46. \\ Plate lxin.
}

'Tuis fish has a close resemblince to the river Perch of Europe. Our specimen was taken in Lake Huron, where it frequents steep banks and affords much sport to the angler from the eagerness with which it snaps at the bait. In the month of May it spawns and then resorts in great numbers to the mouths of rivulets. It does not, as far as I could learn, exist in any of the streams that flow into Hudson's Bay or the Arctic sea, and most probably it does not range farther north than the 49th or 50th parallels of latitude, between which the rivers that fall into the chain of Great Canadian Lakes originate. Dr. J. V.C. Smith, author of a popular work on the Fish of Massachusetts, enumerates the Perca fluviatilis among the fish of that State, but he has most likely been misled by the report of anglers who have mistaken the P. flavescens for it. It is certain, that no naturalist who had the opportunity of comparing these two species with one another, would have placed them in different genera, as Dr. Smith has done. Dr. Mitchill includes in Bodianus fish of several genera together with the subject of this article, which is a true perch; while under Perca he places only Labrax lineatus and Centropristis nigricans of 
Cuvier. The mistake of confounding the American perches with their European representative is a very excusable one, where opportunities of comparison do not exist; and Baron Cuvier, after describing $P$. flavescens, $P$. servato-granulata, and $P$. granulata, which inhabit the Atlantic streams of New York and the neighbouring States, adds "Elles seraient certainement confondues avec le nôtre, par un voyageur qui les observerait chacun isolément et sans pouvoir en faire, comme nous, un rapprochement et une comparaison immédiate."

\section{DESCRIPTION}

Of a specimen taken at Penetanguishene, Lake Huron, May, 1825.

CoLour.-General tint of the back greenish-yellow ; of the sides golden-yellow with minute black specks; and of the belly whitish. Nine or ten dark bands descend from the back to the sides, and taper away towards the belly; the alternate ones are shorter, and on the tail and shoulders they are less distinctly defined : the longest band is opposite to the posterior part of the first dorsal fin, on which there is a large black mark.

FORM.- - The body is moderately compressed, its greatest thickness being somewhat more than one half of its depth. Its profile is oblong, tapering more towards the tail, which is nearly cylindrical : its greatest depth is at the ventrals, and rather exceeds one-fourth of the total length, caudal included.

The head constitutes two-sevenths of the total length, and its height, at the eye, is equal to one-half its length, from the tip of the snout to the point of the gill-cover. The forehead is flat, but appears depressed, owing to the convexity of the nape. The snout is a little convex. The orbits are lateral, distant more than one of their own diameters from the tip of the snout, and more than two diameters from the point of the gill-cover. The jaws are equal. The mruth descends as it runs backwards, its posterior angle being under the centre of the orbit.

'ГеЕтн.-The intermaxillaries, lower-jaw, knob of the vomer, and edge of the palate-bones, are covered with very small, straight or slightly-curved densely-crowded teeth (en velours). The vault of the palate, posterior part of the vomer, and the pointed tongue, are smooth.

GirL-covers.-The preoperculum is narrow; its upper limb rising vertically forms a right angle with the lower one; and its erge is armed with small spinous teeth, those on the lower limb being directed forwards. The bony operculum terminates in a narrow sub-spinous point, beneath which there are three denticulations, with grooves running backwards from them. An acute-pointed membranous flap prolonged from the margin of the suboperculum conceals these parts in the recent fish. The edge of the interoperculum and posterior part of the suboperculum are minutely denticulated. The edges of the humeral bones are slightly grooved and denticulated, the denticulations being more obvious in some individuals than in others.

SCaLEs.-There are sixty scales on the lateral line, and twenty-two in a vertical row between the first dorsal and centre of the belly. The scales are rather small, their bases truncated and furrowed to near the middle (striées en éventail) by six grooves corresponding to eight minute lobes of the margin. A narrow border of the outer rounded edge is very minutely 
streaked, producing teeth on the margin, visible under a lens. The length and breadth of a scale, taken from the side, are about equal, being two and a half lines. A linear inch measured on the sides or belly, longitudinally, contains twelre scales, the scales on the belly having, however, less vertical breadth. On the back an inch includes seventeen or eighteen. The asperity of the scales is perceptible to the finger, when it is drawn over them from the tail towards the head. The lateral-line is thrice as near to the back as to the belly, and is slightly arehed till it passes the dorsal and anal fins, when it runs straight through the middle of the tail. It is marked on each scale by a tubular elevation, which is divided irregularly by an oblique depression.

Fins -Br. $7-7 ; D .13 /-1 / 13 ; P .14 ; V .1 / 5 ; A .2 / 8 ; C .17 \frac{5}{5}$.

The first dorsal commences a little posterior to the point of the gill-corer and to the pectorals : its fourth and fifth rays are the highest : the first ray is slender and not half the height of the second; the last ray is so short as to be detected only by a close examination. The second dorsal commences a quarter of an inch from the first, the space between them being occupied by two or three inter-spinous bolies without rays: its first ray is spinous, and is closely applied to the base of the second, which is thrice as long, distinctly articulated * and divided at the tip: the remaining rays are all divided at their summits, but at their bases the articulations are obsolete. The pectorals originate opposite to the spinous point of the operculum; they are somewhat longer than the ventrals, which are attached opposite to the second spine of the first dorsal. The anal is rounded: its first ray is one-fourth part shorter than the second, both being spinous: the succeeding rays are articulated and branched, the fire anterior ones being longer than the second spine, the others becoming snccessively shorter : its termination is opposite to that of the second dorsal. The caudal is distinetly forked, its base is scaly, the scales advancing farther on the outer rays and covering one-third of their length.

\section{Diarensions.}

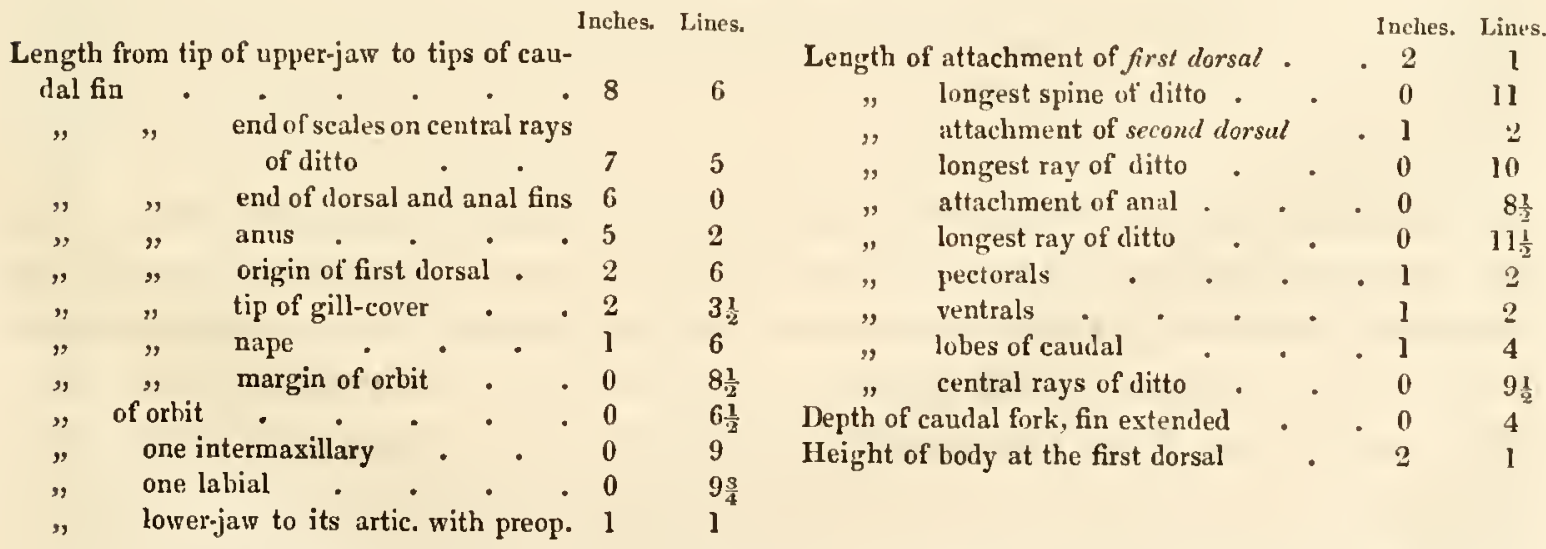

Our second specimen, nearly of the same size, has only seven vertical lateral bands, with merely a little clouding in place of the intermediate shorter ones. Mr. Todd informed me that some specimens were covered with small black spots.

* In the Histoire des Poissons, the two first rays of the second dorsal are described as spinous; but in our two specimens they are as we have mentioned. Our specimens were seen and named by Baron Cuvier. 
La perche à museau pointu (Perca acuta). Cuv. et VAL., ii., p. 19, pl. 10.

This species was found in Lake Ontario, by MM. Milbert and Le Sueur. It strongly resembles the $\boldsymbol{P}$. flavescens, but its lower-jaw is proportionably longer, and its snout more pointed. It wants the black spot on the first dorsal.

Perca gracilis (Cuv. et Val., p. 50) is probably also a Canadian fish, but it has hitherto been found only in Lake Skaneateles, on the New-York side of Lake Ontario. It also resembles $P$. flavescens, but its preoperculum is not denticulated; the spine of the second dorsal is very short and slender, and the spot on the first dorsal small.

\section{[3.] 1. Perca (Huro) nigricans. (Cuvier.) The Huron. \\ Family, Percoideæ. Genus, Perca. Sub-genus, Huro, Curier. \\ Le Huron (Huro nigricans). Cuv, et Vas, ii., p. 124, t. 17. Cuv. Reg. An., ii., p. 135.}

Baron Cuvier established this sub-genus on the inspection of a solitary specimen which was prepared for me by Mr. Todd at Penetanguisbene, on Lake Huron. In the analytical table of genera, given in the Histoire des Poissons, it stands among the Percoideæ having their ventrals, containing only five soft rays, situated under the pectorals; seven rays in the branchiostegous membrane; two distinct dorsal fins, or one fin divided into two by a notch extending to its base ; and all the teeth small and crowded like the pile of velvet (dents en velours). The specimen is a dried one, of the right side of the fish, and contains only six branchiostegous rays, nor is there a trace of another ever having been inserted into that limb of the os hyoides; yet in his description the Baron enumerates seven. Mr. Todd counted only six in the recent fish. The Baron says that the Huron would possess all the characters of the Perch, if it were not devoid of denticulations on the bones of the head and shoulder, and particularly on the preoperculum*. Few fish of the family, he observes, possess this smooth-edged preoperculum, and, in fact, on reviewing the characters of his genera and sub-genera, we find, that of that

\footnotetext{
* The want of denticulations in the preoperculum is considered to be merely a specific distinction in the Perca flavescens, Cuv.
} 
division which has the ventrals placed under the pectorals, the small genera of Etelis, Aprion, Grystes, Aplodactylus, Bryttus, and Chironemus, alone resemble the Huron, in having the preoperculum without either crenatures, denticulations, sharp points, or spines: some Pomoti, however, have the crenatures of this bone scarcely perceptible, and in Pomatomus its edge is finely ciliated. Of the Percoideæ whose ventrals are jugular or abdominal, Aphritis, Bovichtus, Splyzacua, and Paralepis, have also a smooth preoperculum; Trachinus and Pereis have two or three small bony points which are not perceptible through the soft parts, and Percophis has the edge of its bony preoperculum even, but there is attached to it a narrow border of dentated membrane. It would be easy, the Baron observes, to modify the characteristic phrases of the larger generic groups, so as to include the Huron and other similarly-isolated species; but this practice would lead to the erroneous belief of there being a more intimate connexion between these aberrant species and the types of the groups than actually exists; and as he aims at expressing, even by the subdivisions of his families, the affinities of the different beings composing then, it is more in accordance with his plan to give to every peculiar form a proper generic name. A smooth tongue is one of the characters of the genus Perea, which we have not been able to identify in the Huron, that nember having been removed from our specimen, as has also the branchial apparatus. Mr. Todd mentions two plates of teeth on the superior pharyngeal bones and one on the lower. The figure in the Histoire des Poissons represents eleven soft rays in the second dorsal, three of them in dotted lines; there are only eight now existing in the specimen, but the skin immediately behind the last one is a little damaged, and from the contour of the fin, one is induced to think that at least one posterior ray has been destroyed.

This fish is known to the English settlers on the borders of Lake Huron, by the name of Black bass-the word "bass" being almost synonymous with perch. The same appellation is given, at New York, to the Centropristis nigricans, to which our fish has a general resemblance. The Huron is highly esteemed as an article of diet, its flesh being white, firm, and well-flavoured, and it is, in fact, considered to be the best fish that is caught in the lake during the summer months. It haunts deep holes at the mouths of rivers or edges of banks, and readily takes a hook baited with a small fish, or a piece of white rag trailed after a boat, as in fishing for mackerel. It does not exist to the northward of the Great Canadian Lakes. 
DESCRIPTION

Of the dried specimen.

Form.-Profile elliptical, the ellipsis commencing acutely in the somewhat pointed chin and conical head, but passing gradually into the thickish tail. The depth of the body is greatest under the first dorsal, and appears to be about equal to the length of the head, or one-third of the total length, excluding the caudal. Head flat above, covered with scales as far as the posterior margin of the orbit: the forehcad shows a slight median ridge with a more prominent lateral one, aud there are many fine streaks on the upper margin of the orbit. The anterior sub-orbitar bone is marked by some short diverging ridges, and the under and posterior margin of the orbit is more distinctly roughened by many small irregular prominences. The orbit is circular, situated close to the forehead, and two of its own diameters and a half above the articulation of the lower-jaw: it is also a diameter and a half behind the extremity of the upper-jaw, and four diameters from the point of the suboperculum, or most posterior part of the gill-cover. The mouth acquires a somewhat vertical aspect, from the chin, or tip of the lower-jaw, projecting about a quarter of an inch beyond it, and from its opening descending from the plane of the forehead at a considerable angle as it runs backwards; the articulation of the lower-jaw is opposite to the posterior margin of the orbit. The labials have a lengthened triangular form, the narrow apex only passing under the edge of the sub-orbitar bone: the posterior dilated and truncated extremity projects considerably beyond the tip of the intermaxillary, and extends farther back than the orbit : it is further widened by the addition of a superior piece, or apophysis, whose corner is rounded. There are no pores in the lower-jaw, but two circular openings of canals in the bone are visible through the dried skin which covers them.

TеEтн.-The opposing surfaces of the intermaxillaries and lower-jaw are covered with densely-crowded, curved, fine card-like teeth, or, as they ought perhaps to be called, in conformity with Cuvier's nomenclature, rather coarse "dents en velours"- the dental surface being broad anteriorly, and narrowing to a point behind. The transverse, anterior, projecting extremity of the vomer, and the outer edges of the palate-bones, are armed with finer teeth "en velours," the dental surface of the latter narrowing to a point posteriorly like those of the mandibles; there is, however, a detached but contiguous patch just beyond this point on the edge of the palate. 'The whole vault of the palate is smooth. The tongue, as we have already mentioned, has been removed, and if Mr. Todld's account of the pharyngeal teeth be correct, they are not distributed into the same number of patches as in the perch.

GILL-covers.-Preoperculum having a narrow upright limb, covered with smooth skin, there being a single small scale only, just above its angle: the lower limb is wider, and has three scales in a single row, which does not cover half its surface: the whole edge of the bone is smooth and even, with the exception of a very shallow wide notch at the base of the upper limb. The interoperculum is comparatively broad, its depth exceeding that of either the preoperculum or suboperculum; it is covered by a row of ten scales, which leave its under border naked. The bony operculum has an acute, oblique notch in its posterior 
margin producing two thin points: the lower point is closely applied to the apex of the suboperculum, forming with it one thin obtuse plate, which, together with the upper point, are concealed by the membrane which borders them. The under margin of the suboperculum is slightly waved, forming two obscure lobes. As in many, or perhaps in most, of the percoidere with scaly gill-covers, the margins of the pieces composing them are covered with smooth skin: there is even a wider naked space than usual behind the points of the operculum, ancl the anterior border of that bone is as wide and prominent as the limb of the preoperculum to which it adjoins. The forehead, snout, infra-orbitar bones, and margins of the orbits, mandibles, labials, branchiostegous membranes and edges of the different opercular bones, are corered with smooth skin; the rest of the head, inchuding the temples and top of the cranium as far as the linea rostri basalis*, are clothed with tiled scales. The bones lining the posterior edge of the gill-openings are likewise scaleless, and their edges, though undulated, are destitute of spines or serratures. The nape is supported by a median ridge of the cranium, and a thin lateral one on each side equally high. There are also several inter-spinous bones anterior to the first dorsal. The Branchostegous membrane contains six curved rays, the anterior ones cylindrical, the posterior ones becoming more and more flat and wider.

Fins.-Br. $6 ; D .6 /-2 / 8$ ? ; P. $15 ; V .1 / 5 ; A .3 / 11 ; C .17 \frac{7}{7}$.

The pectorals consist of fifteen rays, the first of which is short, and its articulations very obscure, being visible only at the tip and with a lens. The ventrals are attached directly under the pectorals, and contain six rays, of which the first is spinous and one-third shorter than the succeeding ones. The first dorsal consists of six acute spinous rays, having the connecting membrane notched between them : the first ray is one-third shorter than the third, which is the longest, and stands about an inch behind the insertions of the pectorals and ventrals : the fourth and fifth are nearly as long as the third. The second dorsal is one-third higher than the first, and commences nearly an inch behind the posterior insertion of the membrane of the latter: the two anterior rays are spinous and separated by membrane,the first of them equal in height to the corresponding ray of the first dorsal: the third ray is simple but articulated; the succeeding ones are branched at the tips, and nearly equal to each other, the seventh being, however, rather the highest : the fifth ray is opposite to the anus, and the tenth (it is not certain whether this be the last or not, as the specimen is injured) is opposite to the fifth of the anal. The anal contains fifteen rays, the two first of them shorter, spinous, and very acute: the branched rays equal those of the dorsal in height: the first spinous ray stands half an inch belind the anus. If the fish, exclusive of the caudal-fin, be divided into three parts, the head will form one, and the first spine of the anal will stand at the commencement of the third. The space between the anal and caudal considerably exceeds that occupied by the attachment of the former. The caudal is somewhat rounded and very slightly emarginated: its base is covered with small scales, which terminate by an even line rounded off on the three exterior rays, while they cover the accessory short rays, abore and below, to their tips, thus producing a notch at each end of the line.

Scales. - The scales are rather large, the exterior edge forming a segment of a circle and

* Linea rostribusalis illa esl, qua per marginem orbita posteriorem transtersim ducilur.-Nis.sson. 
being quite smooth, the sides almost parallel, and the base truncated and crenated in correspondence with ten or eleven furrows which diverge from the centre like the sticks of a fan. There are sixty scales on the lateral line, exclusive of about nine smaller ones, forming a continuation of the same row on the base of the caudal, and twenty-six in a vertical row beneath the first dorsal, of which seven are above the row which forms the lateral line. A linear inch measured along the sides includes five scales and a half. The scales on the gill-covers are a little smaller than those on the body: those on the cheeks are still less, and the scales on the caudal, and on the space before the ventrals, are the smallest of all. A scale taken from the lateral line under the first dorsal is four and three-quarter lines wide and three and a half lines long. The lateral line runs parallel to the curvature of the back and is distant from the belly : it is marked by a tubular elevation on each scale.

CoLour.-Back and sides dark, with a faint longitudinal streak through the centre of each row of scales. Belly yellowish white.

\section{Dinensions}

Of the prepared specimen.

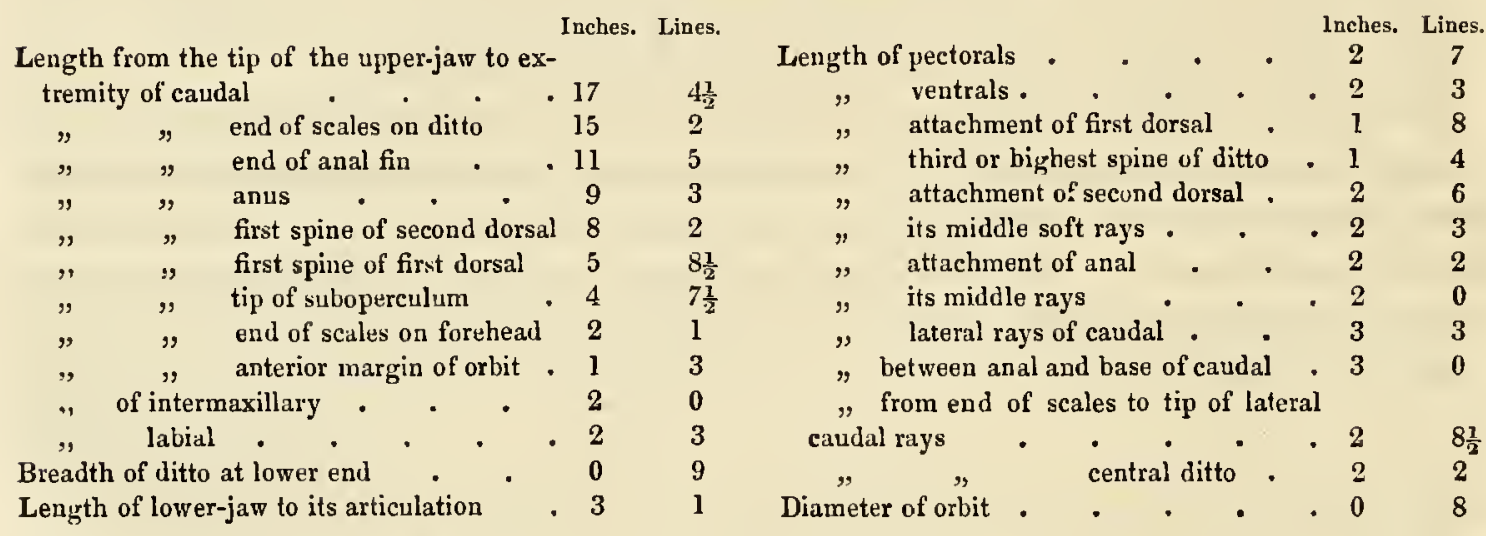

\section{[4.] 1. Labrax notatus. (Smith.) The Bar-fish, or Canadian Basse.}

Family, Percoideæ. Genus, Labrax, Cuvier.

Labrax notatus. Lieutenant-Colonel C. H. Smiтr. Mss.

The genus Labrax, or Basse, belongs to the same section of Thoracic PerCOIDEx with Perca, from which it is distinguished by scaly gill-covers that terminate in a double spinous point, the want of denticulations on the sub-orbitars, subopercula, and interopercula, but principally by parts of the tongue being rough like a file with a crowd of extremely small teeth. Cuvier remarks, that the Basse has so close an affinity to the genus Perca, that it might be termed Sea-perch with more propriety than Serranus, which has much less resemblance to the perches in 
organization. The common Basse of Europe (L. lupus) spawns in bays of the sea, preferring those into which rivulets of fresh water flow; but it occasionally ascends rivers, and the lupi of the Tiber, taken between the two bridges, were in rogue, at some periods, with the epicures of ancient Rome*. The Rock-fish, or Striped Basse (L. lineatus) of New York, frequents the coasts of that state all the year; but, as Dr. Mitchill informs us, " the greatest run is in the fall. Instead of going away on the approach of winter, the Striped Basse seeks refuge in bays, ponds, and recesses, where he may remain warm and quiet. Here the fishermen find him and make great hauls during the coldest season, when many are brought to market in a frozen state." The dread of cold was ascribed, by the ancients, also to the lupus, and Cuvier thinks that their opinion is founded on facts ; but I should judge that the Striped Basse, at least, seeks quiet rather than warmth, by quitting the sea in winter, for in northern climates the temperature of the ocean exceeds that of shallow bays or rivers in the winter-time. Had Dr. Mitchill observed that the Basse resorted to the southern states in greater numbers, or launched out into the Gulf-stream, in the cold season, we might have attributed its movements to a love of a higher temperature; but if its clange of residence be not owing to its food being more abundant in the bays and rivers at the periods of its resort to them, it probably arises simply from the fact, that it prefers still-water to the turbulent waves of the ocean, excited by frequent storms. Cuvier has stated the matter more simply, and perhaps more correctly, in saying that this fish ascends rivers in the spring to spawn, and in the winter for the sake of shelter. I do not know how high up the St. Lawrence the Bar-fish goes, but the river ceases to be salt far below Quebec, where the fish is taken. Many of the lupi are covered with brown spots, and these were noticed by Cuvier to be females: it would be interesting to know if the different sexes of the American Basses have peculiar markings. The $L$. notatus derives it name from the resemblance of its spotting to musical characters. Lieutenant-Colonel Smith has obligingly furnished me with the following note respecting it.

"The Bar-fish of the Canadians at Quebec differs from Mitchill's Basse ( $L$. lineatus, Cuv.), in being much more robust, and in being marked with rows of spots, five above and five below the lateral line, so regularly interrupted and transposed as to appear like ancient churchmusic. The back is brilliant with iridescent green, gold, and pink colours: the sides silvery. Head covered with strong scales. On the lateral line, which is quite straight, I reckoned fifty-eight scales."

$$
\text { "Fins. }-D 9 /-1 / 12 ; P . \quad \text { ?; V. 1/6;A. 1/12;C. 17." (Smith in lit.) }
$$


The lupus, which the L. lineatus closely resembles in structure, contains seventy scales in a row, between the gill-opening and caudal-fin. The most remarkable character of $L$. notatus appears to be the solitary spine in the anal, all the other species having three. As to the six soft rays of the ventrals, the same number is represented in Mitchill's plate of lineatus, while Cuvier reckons only five, in conformity with the division of Percoideæ to which the genus belongs; but it often happens that the last ray is divided to the base, thus causing six to appear in the recent fish, though in the dried specimen, or skeleton, the exact number is easily ascertained by counting the joints. L. lineatus has eight or nine longitudinal streaks on a side, one of them corresponding to the lateral line. In the more robust form, and in the strong scales of the head, the Canadian Bar-fish resembles the L.mucronatus of the United States and the West Indies, and the L. multilineatus of the Wabash. The latter species has sixteen narrow, black, longitudinal lines on the flanks. Nothing is said of the habits of the latter; but if it ascends the Wabash in the winter time, it must have quitted the warm climate of the Gulf of Mexico, and its movements might in that case be ascribed, by some, to its love of cold or temperate waters. $L$. notatus is the most northern known American species, and if it frequents no higher latitudes than the Gulf of St. Lawrence, or the 50th parallel, its range northward is about equal to that of the L. lupus, which has been noticed on the sonthern shores only of Britain, though but rarely.

\section{[5.] 1. Lucro-perca Americana. (Cuvier.) The American Sandre.}

Fanil.x, Percoideæ. Genus, Lucio-perca, Cuvier.

Le Sandre d'Amérique (Lucio-perca Americana). Cuv, et VAl., ii., p. 122, pl. xvi.

Picarel. Setteers on Lake Huron.

The genus Lucio-perca also belongs to that division of Thoracic Percoideze having seven branchiostegous rays and two dorsals, but it stands in a subdivision which is cliaracterized by the presence of long canine teeth, in addition to the ordinary ones "en velours." The species of this genus, like those of Perca* as restricted by Cuvier, are probably all inhabitants of fresh-water exclusively, for though a $L$. marina of the Black Sea is noticed in the Histoire des Poissons, it is included in this genus with doubt, being known to Cuvier only by the description

* Perca-trutla of the Hist. des Poiss., which was caught in Cook's Straits, New Zealand, is afterwards deseribed as a Centropristis, and will, Cuvier thinks, prove to be the type of a peculiar genus. 1 t is not said whether $P$. Plumeri and $P$. marginalu were taken in the sea or not; all the rest are fresh-water species. 
given of it by Pallas, who considered it to be a Labrax. Exclusive of this uncertain species, there are three others which are each peculiar to a separate quarter of the Northern hemisphere. The European one, L. sandra, is found in the rivers and lakes of the north-east parts of that quarter of the world, and in the rivers that fall into the Caspian, being, however, unknown in Great Britain, France, and Italy. In this species there are no scales on the cheeks, lower part of the operculum, or suboperculum, and the preoperculum is the only piece of the gill-cover that is dentated, or shows spinous points. The vomer is armed only with teetl "en velours ;" and there are one hundred and twenty scales in a row between the gill-openings and the caudal-fin. The Asiatic species ( L.volgensis) inhabits the rivers and lakes which fiow into the Caspian Sea, has smaller and less unequal teeth than the preceding, but larger scales, there being only ninety in a longitudinal row. The cheeks and the gill-covers, with the exception of the suboperculum, and the limb and lower edge of the preoperculum, are covered with small scales. The $L$. Americana differs remarkably from these two in the tip of its bony operculum, being a sharp point or spine, showing, as Cuvier observes, that this sort of arming furnishes a character of very secondary importance. Other distinctive marks will appear in the detailed description which follows. The specimen described in the Histoire des Poissons was procured by M. Milbert from the fresh-waters of New York, but no account is given of its habits: ours is from Lake Huron, and was prepared by Mr. Todd at Penetanguishene. This gentleman states that it spawns in A pril and May, when it collects in numbers about the mouths of rivers. It takes a hook readily, and its flesh is white, firm, and wholesome.

\section{DESCRIPTION}

Of a dried Lake Huron specimen, identified by Curier.

Form-lengthened. The profile of the back is straight from the shoulder to the second dorsal, it then inclines slightly towards the tail, but also in a straight line*. The anus is under the fifth and sixth rays of the second dorsal, and just posterior to the middle point, between the gill-opening and base of the caudal. The centre between the tip of the snout and end of the lateral line is under the eleventh ray of the first dorsal. Head.-The inclination of the forehead equals the sloping upwards of the under-jaw, thus giving a conical profile to the head, its apex formed by the extremities of both jaws being obtuse. The orbit is large and oval, and is placed once and a half the length of its axis behind the tip of the upperjaw, and three lengths from the apex of the gill-cover. Each labial is composed of a single strong bone without any supplementary piece: it is dilated towards its extremity, and its under edge curves round the tip of the intermaxillary: it does not reach quite so far back as

* Mr. Todd states the body to be "roundish and thicker upon the back, but sharper ahout the belly." The reverse of this is indicated by the section represented in the Hist. des Poiss. 
the articulation of the lower-jaw, or posterior margin of the orbit, which are opposite to each other. The anterior suborbitar is marked by five or six flat ridges radiating from a centre, which, when the soft parts are dried up, appear as denticulations on the edge of the bone.

GiLL-Covers.- The preoperculum has the form of a thin crescent, with its ascending limb very slightly undulated but entire, and its lower edge deeply serrated, producing six or seven coarse teeth slightly directed forwards. There are some scarcely perceptible crenatures on the edge of the interoperculum. The operculum and suboperculum together form an equilateral spherical triangle. The former ends in a pretty strong flat spine, which is the extremity of a thin, though strong ridge, that strengthens the bone internally, but is even with the surface above; the edge of the bone above the spine is cut away by a deep sloping notch, whose upper corner is a thin acute point, situated half an inch behind the tip of the spine, and an inch above and behind the membranous apex of the gill-cover: the under edge of the operculum forms a slightly convex perfectly even line. The suboperculum has, also, an even edge, which is bordered by a membranous flap that extends beyond the spine of the operculum and conceals it. The notch of this bone is also covered by the soft parts. The supra-scupular, scapular, and humeral bones are devoid of the slightest indentation or crenature*; they are also scaleless, but the edge of the upper one is a little waved, and projects slightly on the side of the nape. There are irregular patches of small scales on the posterior part of the frontal bone, the temples, cheeks, operculum, and suboperculum; the posterior margins of the latter pieces, the whole interoperculum, and the head between and anterior to the orbits, are covered with smooth skin.

TEETH.-The intermaxillaries are armed posteriorly with a single, close, even row of very short curved teeth, with, on each side of the snout, a long, strong canine tooth, whose point fits into a depression of the lower-jaw ; and on the extremity of the jaw, between the canines, there are five or six smaller conical teeth. On the under-jaw and edges of the palate-bones there is also a row of minute, crowded teeth, and just within them a series of large teeth, similar, and mostly equal in size, to the upper canines: each limb of the lower-jaw contains about twelve of these, and each palate-bone eight: they stand, generally, about the breadth of their bases apart from each other, but the lower canines, or foremost pair on the lower-jaw, are separated by a wider space from those behind, and shut in just anteriorly to the upper canines. The first pair on the palate (one tooth on each bone) is the largest of all. The transverse extremity of the vomer is injured in our specimen, but it appears to have been furnished with small teeth in the middle, and with one larger one on each angle, of which the sockets remain, and are as wide as the sockets of the lateral teeth of the palate $\dagger$. The vault of the palate is smooth. The tongue has been cut away.

* In the fig. in Hist. des Poissons they are serrated.

$f$ In the Hist. des Poiss., this species is simply said to resemble the European Sandre in its dentition. The teeth of the latter are thus described :- "Les máchoires sont garnies d'une baude très-étroitc de dents en velours, parmi lesquelles il y en a un rang de coniques et pointues encore assez petites à la machoire supérieure, et déjà plus grandes à l'inférieure et aù. palatins: deux de ces dents aigü̈s en avant à la mâchoire supérieure, quatre à l'inférieure, et deux en avant de chaque palatin plus grandes encore que les autres, forment de véritables canines; mais à la ligne transiersale du vomer il n'y en a que de petites en velours. La langue n'en a point, elle est libre et douce. Celles des pharyngiens sont en cardes." 
Fins. $-B r .7 ; D .14 /-1 / 21 ; P .13 ; V .1 / 5 ; A .1 / 13 ; C .17 \frac{11}{11}$.

The first dorsal is arched and contains fourteen spinous rays. In our specimen the third, fourth, and seventh are the longest, the fifth and sixth, though acute, being rather shorter, probably from thcir growth having been accidentally impeded: the first stands over the tip of the gill-cover and insertion of the pectorals, and is not half so high as the third, but longer than the thirteenth, and twice as long as the fourteenth. The second dorsal commences an inch, or seven scales breadth, posterior to the membranous termination of the first, or to the middle point between the end of the snout and tips of the caudal: its rays are longest from the third to the seventh, the posterior ones becoming gradually shorter: the first is very short and appears to be spinous, the two next are simple but articulated, and the remainder are branched at their summits : the twenty-two rays are supported by twenty-one interspinous bones. The anal terminates opposite to the nineteenth ray of the second dorsal: three or four scales are interposed betwixt it and the anus : its spinous ray is very short and closely applied to the second, which also appears, at first sight, to be spinous, but its articulations are perceptible through a lens". The ventrals are situated a very little posterior to the pectorals, and contain fire thick articulated rays, with a spinous one closely applied to the lower half of the first. Caudal slightly crescentic at the extremity, composed of seventeen rays, with eleven additional short ones at the base abore and below.

SCALES.-The scales are of a form approaching to semi-orbicular, but more or less oblique; a narrow border round the uncovered portion is rough, with little crowded points sensible to the touch, but which require the aid of a lens to render them visible; the truncated base is marked irregularly with a variable number of crenatures corresponding to faintly impressed, nearly parallel streaks. There are ninety scales on the lateral line $\uparrow$, and forty in a vertical row just behind the ventrals-eleven of them above the lateral line. The latter is almost perfectly straight, and is on a level with the upper edge of the gill-cover. The scales above it are not only smaller than those on the sides, but also more closely tiled, so as to appear much smaller when in situ; they are also rounder with nuch less obliquity. The ordinary scales terminate on the base of the caudal by a semicircular outline, and there are also some very small ones on the membrane beyond, extending farthest between the outer rays. A scale from the back measures two lines and three quarters, both in length and breadth. On the sides they are about three lines and a half wide by three lines long. A linear inch measured on the sides includes seven scales; on the back there are nine or ten in an inch.

Colour.-Mr. Todd describes the back as dark, the sides dark yellow, and the belly whitish. In the dried skin the scales, as low as the lateral line, appear blackish-green, with very narrow pale exterior margins. On the sides the dark colour is confined more to the base of each scale, producing an obscure reticulation. There is a black patch on the membrane of the three posterior rays, and traces of dark clouding on other parts of the fin, particularly behind the first ray.

\footnotetext{
* Cuvier marks the rays of this fin $2 / 11$, but our specimen shows the above very distinctly. The second dorsal is also marked $1 / 20$ by him.

+ Between each pair of scales proper to the lateral line, the edges of two adjoining scales intervene and overlap. There are one hundred and twelve scales in the row immediately beneath the lateral line.
} 


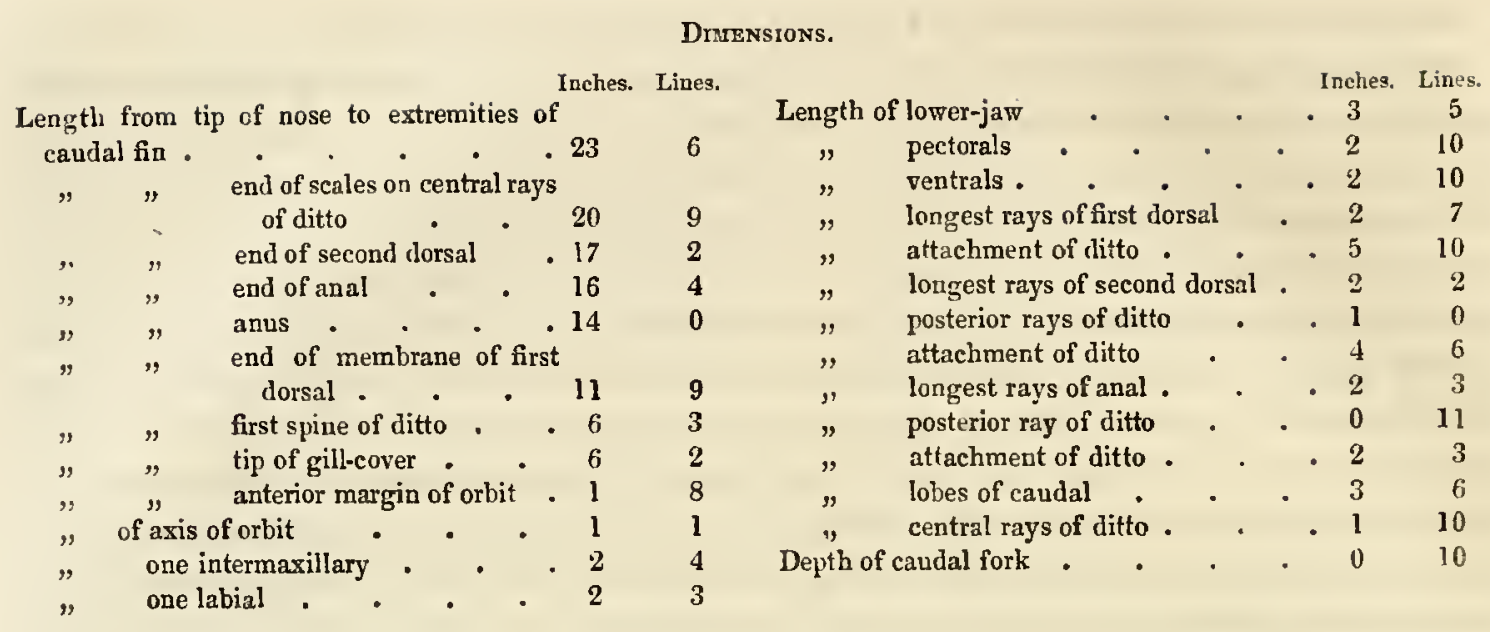

\section{The Okow, or HoRn-FISH*}

The Okow inhabits the rivers and lakes of the fur countries up to the fifty-eighth parallel, and is, in all probability, the same species with the $L$. Americana. Specimens that I prepared at Cumberland-house, in 1820, would have enabled me to decide this matter, but, as I have mentioned in the preface, they have been accidentally destroyed; and on referring to my original notes of the characters of the recent fish, I perceive a few discrepancies betwixt them and the description in a preceding page of $L$. Americana, particularly in the position of the anus being under the commencement of the second dorsal, and not under its fifth ray. As the notes in question, though carefully drawn up, were my first attempt at ichthyological description, I do not found much upon them, but I deem it safer to place them before the reader, rather than to run the hazard, on the one hand, of creating a nominal species, or, on the other, of confounding two together, and thus producing an error in our account of their geographical distribution and habits. My notes, moreover, contain an account of the viscera, which is omitted in the Histoire des

\section{Poissons.}

The Okow spawns in May, soon after the ice breaks up. At that period, and during the summer months, it is taken abundantly in gill-nets; but as it is seldom or never seen in the winter, it very probably passes that season in the deepest recesses of the lake. It is a well-flavoured, delicate fish, though, being too poor to

\footnotetext{
* Perca fluviatilis, var.?? Rich. Fr. Journ,, p. 725, An. 1823.

Okow, Crees, Picarel, or Dorè, Cañdians. Flom-fish, Fur-traders.
} 
please the palates of those who have been accustomed to feast upon the White-fish (Coregonus allus), Mathemeg (Pimelodus borealis), or Sturgeon, it is very often abandoned to the dogs, with whom, for the same reason, it is no favourite. Even an Epicurean ichthyophagist would relish it when fried; but from the scarcity of lard, butter, or suet, this is not an usual mode of cooking in the fur-countries.

\section{DESCRIPTION}

Of recent specimens taken in Pine-Island Lake, lat. 54, May, 1820.

CoLour.-Back and sides greenish-grey alternating in small spots with king's yellow: belly whitish. First dorsal beautifully streaked and clouded with different shades of yellowish-brown, and marked on the three posterior rays by a dark patch of venous-blood red. The second dorsal, the pectoral, and caudal fins are coloured and dotted like the back, the lower tip of the caudal being, however, whitish. The ventrals and anal are white, the latter also tinged with red, and both marbled with king's yellow. The top of the head is coloured like the back, and the cheeks present some shades of light cherry-red. The irides are lilac-purple, streaked with pearl-white, and the inside of the mouth is bluish-white, with a coating of nacre shining through in patches. The scales are rough on their exterior edges.

Form.-Body compressed and oblong; the back sinks slightly at the end of the first dorsal, and the latercl line, which is parallel to it, has a corresponding depression. Anus situated rather before the commencement of the posterior third of the fish, exclusive of the caudal. Head.-When the jaws are closecl, the profile of the head is a cone, whose apex, including the tips of both mandibles, is rather obtuse. The anterior nasal openings have small opercular margins, shaped like the ear of a mouse, and placed so as to catch the stream of water when the fish mores forwards. The eyes are large and prominent. The mouth is rather large, its gape extending backwards with a curve dowuwards as far as the centre of the orbit. The jaws are equal in length, the somewhat pointed extremity of the lower one fitting into a depression formed in the more obtuse upper one.

ТЕктн.-The two largest teeth of the upper-jaw project one on each side of the snout, like the canine teeth of some quadrupeds, and are visible when the mouth is shut: they stand on the intermaxillaries, which are further armed with small teeth in a single crowded row. The lower-jaw presents, on each limb, a series of teeth like the upper canines, set rather widely, and the intervals are occupied by minute ones. The edges of the palate-bones, and the transverse ridge of the romer, are armed like the lower-jaw. All the long conical teeth are very acute and have their points inclined backwards. The tongue is smooth, has a triangular form, and its tip is free, or projects considerably into the moutl. The three inner branchial arches are set with a double row of tubercles covered with small teeth; the outer arch has one row of tubercles, and also a row of rakers half an inch long, armed on their interior surfaces with a multitude of hook-shaped teeth. The superior and inferior pharyngeal bones are likewise rough with innumerable minute teeth.

GiLl-covers. - The preoperculum has a prominent semicircular edge, which is armed with irregular tooth-like processes. The rest of the gill-corer is triangular, its apex being a mem- 
branous flap. The operculum is armed with a spine which scarcely projects through the skin, and also with three smaller points, visible only when the skin dries. The interoperculum and suboperculum are unarmed, and the latter is terminated by the membranous tip of the gillcover. The supra-scapular is rough with a projecting edge, and the humeral bones hare also a prominent edge which is toothed. There are various patches of scales on the top of the head, cheeks, and gill-covers, and the frontal bone exhibits several furrows through the thin integuments. The Branchiostegous membranes overlap each other al their insertion into the isthmus, and contain seven cylindrical curved rays.

Fins.-Br. $7 ; D .15 /-21$ or $22 ; P .14$ or $15 ; V .1 / 5 ; A .1 / 12 ; C .16$ or 18.

The first dorsal has fifteen spinous rays. The second, commencing an inch behind the termination of the other and over the anus, contains twenty-one or twenty-two rays. The caudal fin is crescentic at its extremity, and is partially scaly towards the base.

\section{VISCERA.}

On laying open the abdomen the liver appears lying transversely on the stomach and cæca : a triangular flap hangs from its centre, but it is not otherwise divided. The bile is pale; the duct of the gall-bladder opens into one of the cæca The osophagus is distinguished internally from the stomach by its longitudinal folds : it is short, and before it is slit open appears to be continuous with the first intestine, the stomach looking like a little bag attached to the side of the canal. The lining of the stomach has a light red colour, and being more ample than the exterior coats, is disposed in large crowded and convoluted folds : the pylorus is near the cardiac orifice, the greater part of the stomach being a blind sac. About an inch below the pylorus three caca * open into the intestine, which they equal in calibre. Their structure is similar to that of the intestine, consisting of a peritoneal coat with longitudinal fatty bands, a muscular coat with longitudinal fibres, a firm gelatinous coat, much thicker than the others, and an internal lining disposed in very minute folds. The intestine makes two convolutions, in the second of which its coats become gradually thinner and its calibre less, until it terminates in the rectum by a circular projection or valve. The rectum is short, and its diameter is equal to that of the gut near the stomach. The spleen lies in the first duplicature of the intestine. The air-bladder is forked at its upper end, and a small duct, proceeding from its middle, terminates in the same cacum with the gall-duct $\dagger$. There are a number of redcoloured fatty substances attached to the lining of the air-bladder.

* L. sandra has four cæca.

$\dagger$ This passage stands so in my notes. I acknowledge that my dissections being carried on in cold weather, and in an apartment into which the light was admitted through a small parchment window, I may have mistaken a fold of peritoneum, or a band of vessels, for a duct. But if the duct really terminates in the cæcum, it seems to furnish an argument against M. Agassiz's opinion of the air-bladder being an organ of respiration, almost equally strong with that derived from the entire absence of that viscus in many fish. 


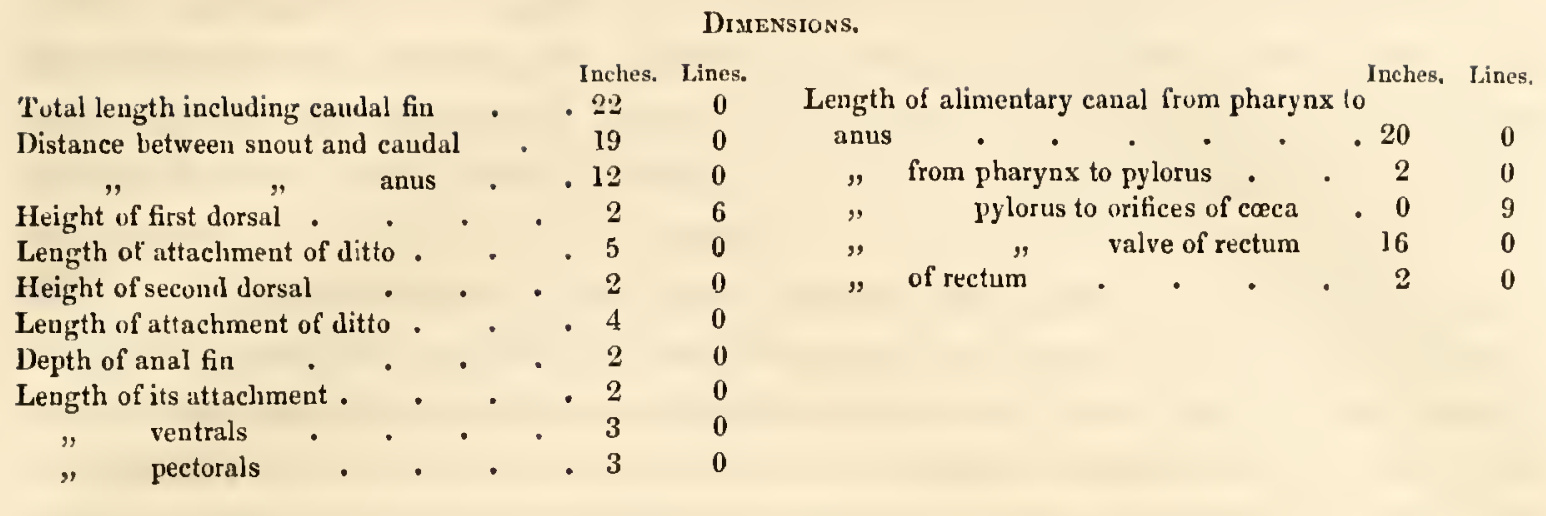

Lieutenant-Colonel C. Hamilton Smith made a drawing at Quebec of a Lucioperca which has some of the peculiar characters of the Okow, and which he thinks is either a marked variety of $L$. Americana, or a distinct species. "It is known by the name of Poisson doré. The specimen was fourteen inches long, its anus situated exactly beneath the first spinous ray of the second dorsal, and the fourteenth ray of that fin opposite to the termination of the anal. The colour of the fish was deep gold-yellow, with the black mottles running irregularly and obliquely downwards from the back towards the belly and tail, being quite in a contrary direction to the strealis represented in the figure of L. Americana, in the Histoire des Poissons. There is a black spot behind the first ray, there is another before the last of the anterior dorsal, and there are five longitudinal streaks on the second dorsal, but none on the caudal or ventrals. No spine was observed on the gill-plates." (Sniтh in lit.)

\section{[6.] 2. Lucio-perca? Canadensis. (Smith.) Canadian Sandre.}

Lucio-perca Canadensis, C. H. Sмитн. Grıf. Cuvier, x., Pl. 1, p. 275.

This fish, well-known at Quebec under the name of " Green pickering," is very different from any described species of Lucio-perca, so much so, that we are rearly to join with its discoverer in suspecting that it may prove to be the type of a peculiar genus. In L. Americana the under margin of the bony operculum is perfertly even; but in the Green pickering it is armed with four remarkable, acute spines, similar to the one that terminates its point, and nearly as large. The preoper.culum appears to liave no serratures that show through the soft parts. The first dorsal commences with a strong spine, which is higher than the succeding ones, 
and stands farther back than the corresponding spine of $L$. Americana. The second dorsal resembles the anterior one in its first ray, which is spinous, being the lighest, the succeeding articulated ones gradually diminishing in altitude. The two fins are equal in height, while in L. Americana the posterior one is lowest. In profile, the resemblance of the Green pickering to the Sandres is pretty close, but it presents a very dissimilar section of the body. Lieutenant-Colonel Smith remarks, that it has a strong similarity in form to the Aspro vulgaris, though it cannot rank in the same genus, as its dentition is totally different, nor does its likeness to that fish extend to the form of its jars and caudal. We have been favoured with the following extract from Lientenant-Colonel Smith's original notes respecting this interesting species.

"The specimen was caught at Quebec in the month of October, and measured about fourteen inches in length. The back was broad and flattish, its breadth nearly equalling the depth of the body. The gape large, extending to the eyes; the teeth strong, obtuse and standing singly. Nostrils double. Edge of the gill-plate armed with a row of five spines, which do not extend beyond the bordering membrane. Head scaly and the body rough, and stiff with very small scales. The two dorsals have an interval between them, and the first is marked with three rows of large, round, black spots; the second with four streaks of the same colour: the tail is lunate, with a half-black bar on the upper and lower rays:-these three fins, together with the pectorals, having a yellow ground colour. The anal, commencing under the seventh ray of the second dorsal, is ochre-yellow: the ventrals are rounded and have a bright orange tint. The irides are black with a golden ring. The upper part of the body is dark olive-green, the lower whitish, joining the black by a waving line: there are a few pale yellow spots below the lateral line which curves downwards.

"Fins.-P. $12 ; V .1 / 5 ; D .12 /-1 / 17 ; A .12 ; C .17 . "$ (Sмітн in lit.)

\section{[7.] 1. Centrarchus eneus. (Cuvier.) Bronzed Centrarchus.}

Family, Percoideæ. Genus, Centrarchus. Cuv, et Vai., t. vii., p. 456.

Cichla ænea, Le Sueur. Jour. Ac. Sc. Phil,, ii., p. 214. An. 1822.

Le centrarchus bronzé (Centrarchus aneus). Cuv. et VaL., iii., p. 84, Pl. 48.

\section{Plate lxxv.}

This fish inhabits Lakes Huron, Ontario, and Erie, frequenting, during the summer months, shady places, under high banks or shelving rocks. It preys upon cray-fish, worms, and the larvæ of coleoptera, and is very voracious, not sparing the young even of its own species. Our specimen, which was procured at Penetanguishene, was submitted to the inspection of Baron Cuvier, who made the fol- 
lowing remark upon it. " Cychla anea de Le Sueur, Centrarchus aneus, Nob." Since that period, however, the seventh volume of the Histoire des Poissons has appeared, wherein the genus Centrarchus is revised by M. Valenciennes, and some changes made in the specific names, in consequence of many more specimens having been sent to him from various parts of the United States. In the third volume it is said, "Les centrarchus ont le corps ovale, comprimé, un dorsale unique, des dents en velours au machoires, au-devant du vomer, aux palatins et sur les bases de la langue; le préopercule entier; l'angle de l'opercule divisé en deua pointes plates. Nous les avons nommés centrarchus ou anns épineux, ì cause du nombre assez considérable des épines de leur anale, qui va a cinq ou six, tundis que dans la plupart des genves voisins il n'est que de trois." In the seventh volume this character is modified as follows:- "Nous avons vu deux espèces de centrarchus qui n'ont que trois épines à l'anale, comme c'est l'ordinaire chez le plus grand nombre les acunthoptérygiens; mais ce genre n'est pas moins facile cependant à recomnaître par l'absence de dentehures au préopercule et surtont parce que des dents en velours ras existent sur les palatins, le vomer et la base de la lingue." (p. 456.) Bryttus is distinguished from the preceding genus solely by the want of teeth on the tongue; and Pomotis is known from both by the tongue and palate being smooth, the preoperculum shightly toothed, and the operculum ending in a rounded, membranous ear-like lobe. Some of these characters*, so far from being of generic importance, will scarcely serve to distinguish species; and it will be seen, by the description given below, that our specimen of Centrarchus aneus has the preoperculum distinctly serrated or denticulated. It appears, therefore, to us, that it would be more convenient and better to re-unite the three genera into one, which will stand in the division of Thoracic Percoideæ having five soft rays in the pectorals; fewer than seven branchiostegous rays; only one dorsal; and no canine teeth.

On comparing our Lake Huron specimen of Centrarchus aneus with the description of the species in the Histoire des Poissons, the only discrepancies are, that there the anal is said to commence opposite to the sixth dorsal spine, while in Le Sueur's original figure, as well as in our specimen, it begins opposite to the tenth; no notice is taken by the Baron of the singular oval plate of teeth on the centre of each palate-bone, and he says, "c'est à peine si l'on peut dire qu'il $y$ " une dentelure au préopercule." The edge of the preoperculum, in our specimen,

\footnotetext{
* Even the character of teeth on the palate is of little importance as a generic distinction in some families of fish. See Thymallus signifer, which resembles the Common Grayling very closely in its general form, but differs from it in having palatine teeth.
} 
has been cleared by insects, and the serratures are very evident; while the description in the Histoire des Poissons was taken, most probably, from fish preserved in spirits, and, consequently, with the soft parts entire. Le Sueur also describes the gill-covers as without spines or denticulations. The Baron states the scales to be “striées en éventail, à huit crénélures ;" whereas we observe fourteen or more crenatures. M. Le Sueur's figure represents a more elongated fish than our specimen. I have been particular in noting these minute and apparently trivial differences, because of the following passage in the Histoire des Poissons, which requires that the species of the individual we have to describe should be determined with the greatest possible precision.

"Le centrarchus que nous désignions sous le nom de sparoïde (t. iii., p. 88, et pl. 48,) c'est trouvé parmi les poissons recueillis dans l'expédition si hardie du Capitaine Franklin. Il avait été pêché dans le lac Huron: les naturels le donnèrent au Docteur Richardson sous le nom anglais de 'rock basse.' Nous avons reconnu que cette espèce n'est pas le véritable labre sparoüde de $M$. de Lacépède; ainsi nous l'appellerons le centrarchus à six épines (centrarchus hexacanthus, Nob.), et nous reporterons le nom de sparoïde à l'espèce qui nous est récemment parvenu et qui a, comme le dessin original de $M I$. Bosc l'indique, neuf épines à l'anale." A mistake has here occurred as to the origin of the specimen now called $C$. hexacanthus, which was not procured by us, but was very likely sent by M. Le Sueur from the Wabash (see Hist. des Poiss., t. iii., p. 88). The only one we saw is the one described at length below, and which, as I have mentioned above, was labelled $C$. ceneus by the Baron himself: it was then returned to us, and could not have been examined by M. Valenciennes in his revision of the genus. C. hexacanthus is readily distinguished, not only by having but six dorsal spines, but also by the great length of the soft portion of the anal, and many other particulars which will at once appear on comparing our figure with $\mathrm{t}$. xlviii. in the Hist. des Poiss. M. Le Sueur's original name of nigro-maculatus might have been retained instead of the new one of hexacanthus, had it not been applicable to most species of the genus.

DESCRIPTION

Of a dried specimen from Lake Huron.

Form.-Body short and much compressed : its profile oval, the back, however, more arched than the belly, with a short strap-shaped tail issuing inmediately behind the dorsal and anal fins; the profile descends in a rapid curve from the dorsal to the snout, with a slight gibbosity between the orbits. The length, excluding the caudal fin, is a little more than twice the height of the body at the fore part of the dorsal, where it is greatest. 
The Head measures a little less than one-third of the total length, including the caudal fin, and is twice the length of the tail, from the anal to the end of the scales. Eyes large and rather prominent, placed about a diameter of their orbits apart from each other, the same distance from the tip of the upper jaw, and also from the articulation of the lower one, and two diameters from the tip of the gill-corers *. The infra-orbitar bones form an irregular, uneven plate before the orbit, but merely a narrow margin beneath it. The cheeks are rather large, and are entirely covered with scales. The snout is short and obtuse. The mouth, when closed, descends obliquely towards the articulation of the lower jaw, which is opposite to the centre of the orbit: its orifice commences in the axis of the pectoral fins, and is about twice as much below the ridge of the back, as it is above the rin of the belly. The intermaxillaries form the whole upper margin of the mouth. The labials project more than half their length from under the antcrior infra-orbitar plate, are strong, become gradually wider towards their lower ends, which are truncated and cover the corners of the mouth. The under jaw has a little depth vertically at its extremity, forming a kind of chin when the mouth is closed: there are five orifices in each limb of the bone communicating with an internal canal, two of the holes on each side of the chin being connected with pores in the recent specimen. The two jaws, the snout anterior to the centre of the orbits, the infra-orbitar bones, the labials, preoperculum, some ridges and margins of the other opercular pieces, and the branchiostegous membrane, are corered with smooth skin, but the rest of the head is scaly.

TЕEтh small, short, not very acute, but numerous and crowded like velvet pile (en velours ras) into stripes or plates, which cover the edges of the jaws and chevron of the vomer to the breadth of a line. The outer edges of the palate-bones are covered by a narrower band of rather shorter teeth, and there is an oval patch of them, a quarter of an inch long, near the midldles of these bones. Our specimen has lost the tongue.

GilL-COvers. - Preoperculum having its upper limb ascending vertically, nearly at a right angle to the lower one, which is shorter and wider. The anterior edge of the bone is elevated, its surface is uneven, and its inferior margin is very regularly and distinctly denticulated with fine grooves running upwards from between the teeth. In the recent specimen these are concealed by the smooth skin. The interoperculum has a row of scales along its upper border, which are partially covered by the serrated edge of the preoperculum: the under part of the bone, exceeding the scales in breadth, is smooth with an even edge. The suboperculum is very small and of a triangular form: its upper angle is covered by two small scales; its lower border is smooth. The operculum, forming by far the largest part of the gill-cover, is also triangular, its posterior apex terminating in two thin lobes or plates separated by an acute notch: the upper of these plates is truncated; the lower one projects farther, is more acute, and is slightly jagged, or obscurely crenated on its under edge-these plates are edged with a membrane which lengthens them out and alters their form a little, at the same time concealing the crenatures. The anterior border of the operculum is raised into an eren smooth ridge, which has a row of three scales between it and the slightly-overlying edge of the preoperculun.

* The eye is considerably larger than in the Pomotis described in a sulsoquent page. 
The posterior flat points or plates are also covered with smooth skin, but the bordering membrane, and all the rest of the operculım, are scaly. The supra-scapular, and bones lining the posterior margin of the gill-openings, are smooth and toothless.

The Scales have their exterior edges forming a segment of a circle, their sides parallel, and their bases truncated : exteriorly they are smoath to the naked eye, but under a lens their surfaces and edges are covered with minute teeth: on the covered bases there are diverging furrows with fourteen corresponding crenatures of the edge: the size of 'the scales is greatest on the sides, smaller on the back, belly, and tail, and smallest on the head, particularly the cheeks: they cover the occiput, terminating between the eyes. One from the sides is nearly five lines wide, and rather more than four lines long. The lateral line follows the curve of the back at the distance of an inch. It contains forty-three or forty-four scales, and there are forty in a longitudinal row on a line with the tip of the gill-cover. A vertical row under the beginning of the dorsal contains twenty-one scales.

Fins.-Br. $6 ; D .11 / 11 ; A .6 / 10 ; P .14 ; V .1 / 5 ; C .16 \frac{2}{2}$.

The dorsal commences a little behind the base of the pectorals, and just anterior to the tip of the operculum: its eleven anterior rays are spinous, very acute, and gradually increase in height from the first, which measures four lines to the sixth, which is nine lines in height: the soft rays are an inch and a quarter long, and the outline of that part of the fin is rounded. There are three interspinous bones anterior to the first dorsal spine, but no vestige of rays belonging to them. The ventrals stand opposite to the third dorsal spine; and the anal, beginning opposite to the tenth, contains six strong, tapering, and very acute spines, the fifth of which, being the longest, measures nearly an inch : the soft part of the fin is one inch and a half deep, and is rounded-three or four of its rays are posterior to the last ray of the dorsal. The caudal is very slightly two-lobed, unless when spread to the utmost, when it is almost even: its length equals the part of the tail behind the dorsal, or constitutes one-sixth of the total length of the fish. The bases of the caudal, dorsal, and anal, are scaly for a short space.

Colour.-Not having had an opportunity of examining a recent specimen, I am indebted to Mr. Todd for the following clescription of the colours:- "Back dark; sides honey-yellow, with a quadrangular black mark on the base of each scale, sometimes including the tip of the overlying scale. These marks are most distinct on the sides, where they form rows." M. Le Sueur says, "The general colour is brilliant coppery, with irregular spots of a blackishbrown, and olive upon the back, the head, and opercula ; the jaws, lips, and throat are black; thorax bluish-grey: these colours, which are very beautiful during life, disappear when it dies, and become of a bluish-grey, brown, or black; lateral scales with their base and extremity black, so as by their junction they produce the lines of black spots which ornament this fish. Pectoral, ventral, and anal fins marbled with reddish-brown and blue; the anal and dorsal have a black border with their bases dark brown, the rays distinguished by their light colour; the soft part of the dorsal is maculated with small irregular spots. Pupil dark blue; iris red and black." 
DiMensions.

Length from tip of snout to extremities of

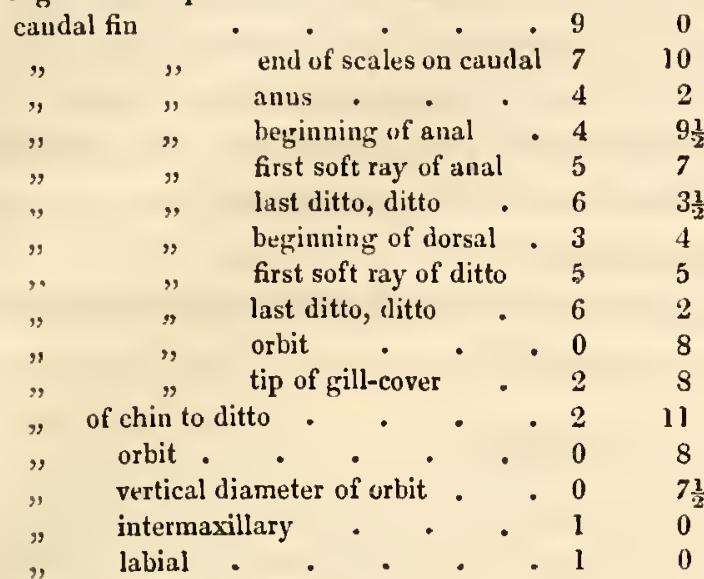

Length of lower jaw to its articulation with the preoperculum . $\quad . \quad$. $\quad 1 \quad 4$ $"$ attachment of whole dorsal $\quad 3 \quad 8 \frac{1}{3}$

" $\quad$ spinous part of ditto $2 \quad 4$

" highest dorsal spine $\quad$. 0 9 "soft rays . . 114 attachment of anal . $\quad . \quad 2 \quad 1$ " of soft rays of ditto 1 a soft rays of anal . $\quad . \quad 1 \quad 5$ pectorais.$\quad 116$ ventrals . $\quad . \quad$. 115 caudal from scales on longest rays 1 fi ditto from origin of longest rays $\quad 1 \quad 10$ eentral rays of caudal from their base 1 o

Greatest heigbt of body - . - . 3 8

Vertical diameter of tail . . . 1 1

Distance between anus and first aual spine 0

M. Le Sueur has described, in the Journal of the Philadelphia Academy of Sciences, two Lake Erie fish, which he associates with his Cichla anea, the Centrarchus aneus of the preceding article. The presence of palatine teeth excludes them from Pomotis, but as he does not mention whether the tongue be toothed or not, nor the presence of serratures on the preoperculum, it is impossible to say whether they belong to Centrarchus or Bryttus, or even to the same group. We abridge M. Le Sueur's descriptions. His first species resembles Pomotis Cateshei (Cuv. et Val.) in the streaks on the gill-covers, but differs from it in its palatine teeth, and from all the species of the group described in the Histoire des Poissons, in its transverse bands on the sides.

\section{Cichla fasciata. (Le Sueur.)}

Fonm.-Body compressed, tapering at the two extremities, three and a half times as long as the head, by one length in depth. Head narrow, scaleless between the eyes and upon the snout, which is short. Jaws large, truncated posteriorly, intermaxillary long and narrow. Inferior jaw hardly longer than the superior one, mandible strong, enlarged, spoon-shaped.

ТеЕтн very small, numerous, card-like on the jaws, palate, and extremity of the vomer.

Fins.-Br. $6 ; P .18$ to $20 ; V .5 ; D .10 / 15 ; A .3 / 12 ; C .17^{8}$.

Dorsal fin high, rounded behind, arched before, and very low at its junction with the soft part. Anal rounded shorter than the soft part of the dorsal. Caudal slightly emarginated with rounded lobes.

Scales rounded, not toothed, rather irregularly placed, large on the sides, smaller on the back, small on the back of the neck, very small under the belly, on throat and cheek, and a 
little larger on the preoperculum and suboperculum; there are also very small ones between the rays of the anal and caudal fins. Irateral line undulated, oblique.

Colour general brownish-olivaceous, deep and fuliginous on the back, lighter on the sides, the middle of the scales brown, the margins black; anal fin greenish, the posterior part of the dorsal and caudal violaceous, abdomen and throat bluish and violaceous, thirteen, fourteen, or fifteen transverse brown bands on the side, a little deeper than the general tint; the opercula are also traversed with many olivaceous bands. When the fish dies the colour changes, and is then sometimes all blue or black, and the bands disappear.

Length eighteen or twenty inches. It is one of the best fishes in Lake Erie, and is salted. It is taken at all seasons of the year by the seine or hook and line.

\section{Cichla minima. (Le Sueur.)}

Form.-Body very long, sub-compressed, elevated before the dorsal. Head arched, very large. Eye very large. Teeth very small in many ranges on the jaws and palate. Mouth large.

Scales very small. Lateral line straight in the middle of the body. Colour cleep grey, tinted with bluish on the back, with metallic reflexions on the sides and abdomen, and with points, or small black and brown spots on the abdomen and back, and a spot on the neck.

Fins.-Br. ?; D. 9/14; P. ?; V. ? A 3/10;C. 17 to 18 .

Dorsal fin long, divided into two equal parts, the anterior of spinous rays much lower than the soft part, which is rounded. Anal large, equal to the posterior part of the dorsal. Pectorals large, placed very low near the operculum. Ventrals much smaller than the pectorals, and placed exactly beneath them. Caudal subtruncated.

LENGTH nine lines. Lives in the small lagoons of tranquil water which discharge by narrow channels into Lake Erie.

[8.] 1. Ponotis vulgaris. Northern Pomotis.

Family, Percoideæ. Genus, Pomotis. VAL. Hist. des Poiss., vii. p. 454.

Plate lixivi.

This fish frequents the sheltered inlets of Iake Huron and the ponds in that vicinity, concealing itself, in the summer time, beneath the broad leaves of the nuphar and water-lily*, where it may be readily taken with a hook baited with a small fish or worm. I found fragments of fresh-water shells (helix, planorbis, limneus, \&c.) in the stomachs of several individuals which I examined. In the third volume of the Histoive des Poissons, Baron Cuvier referred a number of specimens which

* Catesty says of the species he detected in Carolina, the original of the Labrus auritus, Linn., that it covers itself with mud or sand, and is therefore called "ground-perch." 
he had receiver from various parts of North America to a species which he designated vulgaris, and our Lake Huron ones were examined among the rest and returned to us under that appellation. As has been mentioned, however, in the preceding pages, M. Valenciennes found it necessary, on receiving an additional number of good examples from different localities, to distribute them into several species, and to revise the characters of the genus Pomotis, of Centrarehus, so closely allied to it, and to constitute an intermediate genus, which he named Bryttus. He says, "Les pomotis seront ceux des poissons de ce groupe qui auront quelques denteheres plus ou moins marquées au bord du préopercule, les palatins et la langue lisses et sans dents. Ils n'ont de dents que sur le chevron du vomer. Le nombre des rayons épineux de l'anale ne sera plus qu'un caractère secondaire; car nous: avons déjà parlé d'un pomotis qui a quatre épines à cette nageoire." The dentition furnishes, in fact, the only means pointed out of distinguishing these three genera*, for we have already seen that our specimen of the Centrarchus aneus his its preoperculum as conspicuously denticulated as the Pomotis vulgaris tigured in the Histoive des Poissons, though the latter is described by the Baron as displaying this character more distinctly than its congeners. On the other hand, the pomotis described below, has the denticulations very slight indeed, and in one specimen scarcely perceptible. Our Lake Huron eximples also want the crenatures of the upper huneral bone, represented in the Histoire des Poissons (t. xlix.) ; their bodies are more nearly orbicular in profile, the greatest depth equalling the distance between the preoperculum and the posterior part of the dorsal and anal fins; the ventrals are under the third or fourth dorsal spine, while in the figure referred to they are opposite to the first spine of the dorsal, and the numbers of the scales differ as well as the rays of the fins. These discrepancies were perhaps sufficient to have authorised me to give a new specific name to the Lake Huron fish which ippears to be the most northern of the genus, but our figure was engraved previous to the publication of M. Valenciennes' revision of the genus under the name by which Cuvier had himself labelled the specimen, and I have therefore, for the present, continued to it the appellation of vulgaris. Correct and minute descriptions of recent specimens are particularly necessary to complete our knowledge of this group of Percoidea, owing to the rapility with which the fish composing it lose their brilliant colours after death. M. Valenciennes describes his $P$. vulgaris as having no colourerl streaks on the cheeks, and this, if there be no mistake,

* In the operculum ending by two points, and in the smallness of the suboperculum, $C$. aneus differs remarkably from our $P$. vulgaris, whose operculum enls in a round lobe, and the suboperculum is prolonged so as to form the under maryin of the gill-cover. Wie do not know how far these characters prevail in other specics. 
would at once distinguish ours; but his observations necessarily relate to specimens preserved in spirits, and his correspondents may readily have committed errors in their accounts of species so similar to each other. His Pomotis Catesbei "se distingue de toutes les autres par les lignes brunes et obliques des joues," but its form is lengthened. In ours the side of the head is ornamented by alternate wavy lines of azure blue and gall-stone yellow. I have to remark, that my account of the colours was noted down after comparing the fresh specimen with Syme's book of colours, but that the artist, having no other guide than my brief description, has fallen far short of the beauty of the original tints and markings. Our figure, however, does every justice to the form of the fish, and agrees minutely with the measurement of the specinen, in which no traces remained of the original brilliant colouring. Mr. Todd was informed by the natives, that many small land-locked lakes or ponds, in the vicinity of Lake Huron, contain no fish whatever but the Perca fluviatilis and this pomotis.

\section{DESCRIPTION}

Of a recent specimen taken at Penetanguishene, April 20, 1825.

CoLour. - Back and sides for a short space below the lateral line blackish-green, thickly interspersed with ill-defined, roundish spots of deep bluish-grey and gall-stone yellow (one on the middle of each scale), and also with some obscure tints of indigo-blue. On the cheeks and gill-covers the blue tints are brighter, approaching to azure, and are disposed in longitudinal wavy lines alternating with gall-stone yellow. The lower parts of the sides are lighter than the back, and exhibit sone greenish reflections with larger and more distinct roundish spots of yellow. The belly presents the pure gall-stone yellow without spots. On the tip of the gill-cover there is a large bluish-black spot, edged posteriorly with bright scarlet. The irides are silvery shaded with yellow.

Form.-Profile broadly oval, the anterior apex rather acute and formed by the lower jaw, which projects slightly beyond the upper one: the posterior apex of the oval is lost immediately behind the dorsal and anal fins in the slightly tapering tail, whose height is one-third of that of the body. The height of the body is greatest at the fourth or fifth dorsal spine, where it measures three inches and three quarters, and the long axis of the oval, from the chin to the setting-on of the tail, is five inches and a half. The height is to the whole length, excluding the caudal fin, as 3.7 to $7^{*}$. The body is much compressed; its greatest thickness is on a level with the tip of the gill-cover, or in the middle of the height, and does not exceed an inch : the ridge of the back is acute, the belly is obtuse, being nearly an inch broad. The lateral line is arched, gradually though slightly approaching the back as it recedes from the operculum, until it arrives opposite to the posterior part of the dorsal fin: it is there broken by two or three successive descents of a scale's breadth each, and afterwards takes a straight course along the middle of the tail : it is marked out by a tube on the basal half of each scale.

* In P. vulgaris (C. et V., vii., $\mathrm{P} .465$ ) " sa hauteur fait la moitié de sa longueur, la caudale non comprise." 
The Scales adhere firmly to the skin and are rather large. On the sides and tail there is no great difference in their sizes; on the gill-covers, though more rounded, they are nearly as large, but the cheeks, ridge of the back, and flattened surface of the belly, are covered with smaller scales; while the smallest of all are on the bases of the fins and on the membrane connecting their soft rays. The form of the scales is the segment of an oval approaching to a semicircle-their bases are very evenly truncated, and are marked with fifteen or sixteen faint furrows or lines, corresponding to minute crenatures of the margin-the rest of their surface appears rough under the lens, particularly towards their exterior semicircular margins. A scale taken from the side measures four lines longitudinally, and five transversely. A linear inch, measured on the side on a line level with the tip of the gillcorer, contains nearly eight scales, and there are thirty-eight in all, in that row, exclusive of four or five small ones on the caudal fin; there are forty-two or forty-three on the lateral line, also excluding the latter. At the greatest depth of the body there are twenty-two scales in a vertical row, of which six are above the lateral line, and twelve between it and the first ray of the ventral, with three scales for the half breadth of the belly.

HEAD small, forming one-third of the length of the fish, excluding the caudal fin. The scales of the nape terminate on a line with the posterior erlge of the orbits; the rest of the upper surface of the head, the infra-orbitar bones, the mandibles, the preoperculum, the inferior margins of the other bones of the gill-cover, and also the anterior ridge and ear-like tip of the operculum, and the branchiostegous membrane, are smooth; the otlier parts of the gill-corer and the cheeks are scaly. All the bones lining the gill-openings posteriorly, and those supporting the pectoral fins, are without serratures on their edges: the anterior surface of the latter is covered by a row of scales. The orbits, exactly circular, are close to the forehead, and more than their own diameter above the articulation of the lower jaw, one diameter from the tip of the snout, and two from the tip of the gill-cover. The anterior infra-orbitar bone is rather large, has a rhomboidal shape, with the lower angle rounded off, and is marked with irregular ridges and furrows. The nostrils, situated in the angle between the eye and snout, have their two orifices rather distant from each other. The mouth is small: the intermaxillaries, forming its upper border and attached to the snout by pedicels, are capable of a slight protrusion. The labials, proportionably much smaller than in Centrarchus aneus, slide under the sub-orbitar bone, leaving only a fourth part uncovered. The lower jaw shuts in before the intermaxillaries, giving the commissure of the mouth nearly an angle of $45^{\circ}$. The articulation of the jaw is opposite to the anterior margin of the orbit. There are no pores on the lower jaw, though there is a canal in the bone with two orifices covered by skin.

TEЕтн.-The opposing surfaces of both mandibles are covered with small teeth crowded closely together; the outer ones are nearly cylindrical and rather obtuse, the inner ones more awl-shaped, slender, and acute. The vomer forms a strong, horse-shoe shaped projection, chevron, or gorget, and is armed like the jaws. The palatine bones and tongue are smooth. On the upper pharyngeal bones there is a pair of triangular plates of teeth "en pave?" there being forty or fifty cylindrical teeth with flat crowns in each triangle; behind which there is a pair of smaller irregular plates of morc minute teeth. On the inferior pharyngeal bones 
there is one pair of rectangular plates of teeth similar to the anterior plates above, and, like them, larger than the teeth on the jaws. The branchial arches are each furnished with a pair of rows of very small tubercles, which are rough with teeth so minute as to be invisible to the naked eye.

GiLl-covers.-The upper limb of the preoperculum, descending almost vertically, terminates by a curve in the lower one, whose inferior border is scarcely crenated, being only slightly and ninutely undulated. The interoperculum has a row of scales adjoining the overlying border of the preoperculum, the largest scale being opposite to the angle of that bone. The suboperculum, instead of being snall and triangular, as in centrarchus aneus, is long, and is attached to the whole under edge of the operculum: it is covered by a row of scales which leave a narrow under border naked. The operculum is triangular with the posterior apex rounded : in the recent specimen this rounded tip is lengthened out by membrane into the coloured ear-like appendix from whence the generic name is derived. The anterior margin of the operculum rises into a smooth ridge, between the lower end of which and the angle of the preoperculum there are two scales, being a continuation of the row which exists on the interoperculum. The under margin of the operculum also forms a smooth line betwixt the scales on its surface and the row covering the suboperculum.

Fins.-Br. $6-6 ; D .10 / 12 * ; P .13 ; V .1 / 5 ; A .3 / 10 ; C .176$.

The branchiostegous rays are considerably curved; the posterior one is flattened, the others are nearly cylindrical. The dorsal fin commences opposite to the tip of the gill-cover and base of the pectorals : the ten spinous rays occupy nearly one-third more space than the twelve articulated ones, but the latter are considerably higher. Three interspinous bones without rays fill up the space between the first dorsal spine and the thin, elevated occipital crest which supports the ridge of the nape. The first ray of the pectorals is spinous, though as slender as the others; it is about half the length of the longest soft ray. The ventrals attached opposite to the fourth dorsal spine consist of five articulated rays, supported anteriorly by a moderately stout spinous one one-third shorter. The anal fin commences a quarter of an inch behind the anus, and terminates opposite to the last dorsal ray: its three first rays are strong, somewhat compressed, awl-shaped acute spines, of which the third is twice the length of the first, but scarcely half as long as the articulated rays that follow : the outline of the fin is rounded. The caudal fin is slightly sinuated at the extremity with rounded lobes. Small scales cover its outer rays two-thirds of their length, but they extend only a short way on the central rays.

\section{INTESTINES.}

Stomach a roundish sack bent up on the osophagus and having its internal coat longitudinally plaited : the pylorus is wide, and is surrouuded by a collar of six cylindrical, obtuse creca each an inch long. The gut is a cylindrical tube bent twice upon itself between the pylorus and anus : its coats, like those of the stomach, are rather thick, and its lining also forms longitudinal folds.

* Another specimen has only eleven soft rays, but it has an additional short spine at the beginuing of the fin. 
DIMENSIONS

Of the Lake Huron specimen.

Length from tip of lower jaw to end of caudal
foclies. Lines.
f

\section{[9.] 1. Trichodon Stelleri. (Cuvier.) Steller's Trichodon.}

Fasilu, Percoidex. Genus, Trichodon. Cuvier.

"Trachinus trichodun. PALL., Zoogr., t. iii., p. 235." TiLesıus, Mêm. de Pétersb., iv., P. 466, Pl. 15, f. 8. An. 1813.

Le trichodon de Steller (Trichodon Stelleri). Cuv. et Var., iii., p. 154.

Anamchlyk. Aleutians.

The genus Trichodon, first indicated by the unfortunate Steller, stands in Cuvier's system among the Thoracic Percoidea, which have five soft rays in the pectorals, fewer than seven branchiostegous rays, and two dorsals. Pallas and Tilesius, suppressing Steller's genus, ranged the only known species as a Trachinus, or Weever; but the Weevers in the Baron's scheme of arrangement are Jugular Percoider, and have besides the operculum armed with a remarkable spine; while in Trichodon that bone ends in a flat point, and the preoperculum is armed with four or five strong spines. The lateral direction of the eyes distinguishes Trichodon from another genus of the same division with the Weevers, namely, Uranoscopus, to which its flat liead and vertical mouth give it a resemblance. The position of its ventrals again under the pectorals, and the want of scales, seem to ally it to Cottus; but its cheeks are not mailed by the sub-orbitars, which form only a narrow border to the orbit.

The only Trichodon hitherto discovered inhabits the most northern part of the Pacific, being found both on the American and Kamtschatdale coasts, and abounding particularly at Unalaschka. It resembles the Weevers in its habits, buries itself in the moist sands at low water, and is dug up by the natives with their 
hands. The females deposit their roes in holes in the sand, where the males fecundate them, and it would appear that the parents look after their offspring, as they are often dug up in the same pits with their little ones.

We shall conclude our notices of the Pencoide w with some general observations on their geographical distribution. Previous to the appearance of the Histoire des Poissons such an attempt would have been entirely futile, and even that splendid memorial of Cuvier's transcendent genius, a model for works on Natural History, does not afford all the data we require, but is to be considered as merely a frame-work to be filled up by future observers. It contains five hundred species of this family, three hundred and twenty-seven of which, or about twothirds of the whole, are inhabitants of the Indian Ocean and warmer latitudes of the Pacific: forty-nine frequent the eastern sile of the Atlantic (including the Mediterranean), and one hundred and eighteen have been detected on the American side of that sea, the greater part of them within the tropics. Few of the Percoidea attain high latitudes. Perca vulgaris, one of the most northern, exists in the Siberian rivers which fall into the Icy Sea; Lucio-perca sandra, Acerina vulgaris, and Trachinus draco, are found as high as Sweden; and Labrax lupus* reaches the Danish coast. In the New World the Lucio-perca Americana (or rather the Okow, if it be a distinct species) is the only one that has a range northward at all approaching to these $\dagger$, for in America the true perches are not so arctic as the Sandre, though in Europe they are more so. Eight other percoid fish, described in the preceding pages of this Fauna, inhabit the St. Lawrence, or the Great Lakes from which that river issues, but none of them go to the north of the fiftieth parallel, while the Okow extends to the fifty-eighth. One species of perca is found in Patagonia, and Trichodon Stelleri inhabits the sea of Kamtschatka, stretching over to Russian America.

Before speaking more particularly of the distribution of forms, or the range of species, it is advisable that we should enumerate the fresh-water genera, though the line of division betwixt them and the oceanic ones cannot be drawn with precision, because some genera, composed mostly of fresh-water species, contain one or two which exclusively inhabit the ocean + ; or, on the contrary, a marine genus

* In page 10 the southern shores of Britain are assigned as the northern limit of the range of this species, on the autho. rity of the Hist. des Poissons; but Professor Reinhardt enumerates it among the Danish fishes, in a paper recently read before the Natural History Society of Copenhagen.

+ The Okow does not, however, exist in the rivers that flow into the Polar Sea.

$\ddagger$ All the East-Indian Dules inhabit the fresh waters, but the two American species are found in the Caribbean sea. 
may include one or more fresh-water species*. Even the species cannot be strictly arranged as belonging to salt or fresh-water, several that habitually reside in rivers or lakes occisionally straying to the sea or into tidal waters $\uparrow$; while of the marine species, some are regularly anadromous, ascending the rivers every season to spawn, others quit the sea occasionally, only, entering the fresh waters in quest of food or shelter at uncertain periods + Allowing for these cases, then, fourteen of the sixty genera which compose the family may be said to belong to the fresh waters, namely, Aspro and Acerina peculiar to Europe; Huro, Grystes, Aphrodederus, Bryttus, Pomotis, and Centrarchus, found in North America $\oint$; and Ambassis, Aphrites, and Dules, belonging to the East Indies. Perca has species in Europe, Asia, the Indian Archipelago, North America, and in the West Indies; Lucio-perca has one representative in Europe, another in Asia, and a third in North America ; and Grystes has one species in the rivers of Carolina and Georgia, and another in the Macquarrie of New Holland. Lates may be considered either as a fresh-water or marine genus, one species existing in the rivers of Northern and Tropical Africa, and two others in the sea and rivers of the East Indies $\|$. It may be gathered from the preceding paragraphs, that in temperate climates the majority of percoideæ are found in rivers or lakes, while within the tropics there is a vast preponderance of marine species.

After the above cursory review of the fresh-water genera, an equally compendious notice of the marine ones, that are common to various districts of the ocean, will enable us to single out the genera or modifications of the percoid form, which have the widest distribution. Serranus (which includes a fourth part of all the species in the fimily) is much more common within the tropics than elsewhere, but it is known in the Mediterranean, on the Atlantic coasts of Europe, Africa, and of North and South America, in the Red Sea, the Indian Ocenn, Polynesia, and sea of Japan, though not on the Americin side of the Pacific. Labrax, which contains only seven species (some of which are littoral or even ascend into fresh waters), is also widely diffused, having representatives in the Mediterranean, on the European, and North and South American coasts of the Atlantic, in Polynesia and the

* Twenty species of Apogon are marine, while A.thermalis has the very extraordinary residence of warm fresh-water springs.

† Perra vulgaris has been taken in the Solway firth, and is reported by Pallas to inhabit the Caspian Sea. Lucioperca sandra. and the common pike, are also said by the same naturalist to remain in a bay of the Caspian even in the spawning seasun, without entering the neighbouring rivers, althongh there is no obstacle to their ascending them.

I As some species of Labrax, or Basse. Centropomus frequents the mouths of rivers.

\$ Two of the genera are not exclusively Nurth American. Pomotis has a Brazilian species, and Centrarchus a WestIndian one.

II Lieutenaut Allen found a Lates in the Niger, exactly resembling that of the Nile and Senegal, and Mr. Collie observed a species among the Loo Chuo Islands. 
northern Pacific, but none in the African Atlantic, Red Sea, or Indian Ocean. Ten other genera, containing one hundred and fifty-eight species, are common to the warmer latitudes of the Atlantic, Indian and Pacific Oceans, viz.: Plectropoma, Mesoprion, Polyprion, Centropristis, Priacanthus, Myripristis, Holocentrum, Uranoscopus, Sphyrana, and Polynemus*. Dules, which we have already mentioned as an East-Indian fresh-water genus, is not exclusively so, as two species exist in the Caribbean Sea. Pingruipes has one species in the Brazilian Sea, and another in the sea of Chili. Rypticus, confined to the Tropical Atlantic, has one species peculiar to the Brazils, and another common to the Caribbean Sea and Cape Verd Islands. Trachinus has species in the Mediterranean, and also in the European Atlantic as far north as the Cattegat. 'The remaining genera are either peculiar to a single district of the ocean, or consist of only a solitary species each, and will be mentioned in the subsequent paragraphs.

We have next to notice a few facts respecting the range of individual species. It were to be wished that we could throw an additional interest into this inquiry, by pointing out the peculiarities of organization by which certain species are adapted to inhabit a variety of climates, while others thrive in very confined localities only; but our acquaintance with the habits and anatomy of oceanic tish is by far too slight for such a task. One might be led $\dot{a}$ prior $i$ to imagine, that as the ocean affords, as it were, a high way so easily traversed by the finny tribes, many species would be common to both sides of the Atlantic, yet this is far from being the case. Not one of the percoidex of European seas has hitherto been detected on the North American coasts, and there are but four which cross the Atlantic even in the warmer latitudes. These are Holocentrum longipinne, which has been taken on the coasts of Carolina, the West Indies, and South Americe, and also off the islands of Ascension and St. Helena: Sphyrana picuda, which occurs in the Gulf of Mexico, in the sea of Brazil, and at Goree, on the coast of Africa: Polyprion cernuum, which ranges from the Mediterranean to the Cape of Good Hope, crosses to the Rio de la Plata, and is found also at Queen Charlotte's islands in the Pacific: and lastly, Rypticus saponaceus which has been taken at Martinique and among the Cape Verd islands. Two species double Cape Horn, or at least they exist on both the Atlantic and Pacific sides of South America, namely, Centropomes undecinalis, which frequents the mouths of rivers in the IVest Indies, Brazils, and Peru: and Bovichtus diacanthus, which has been taken off Tristan d'Acunha and on the coast of Chili.

* Polynemus approximans was observed by Mr. Collie on the cuast of Cakifornia. (App. Beechey's Voy., p. 57.) 
One species may be supposed to travel round the Cape of Good Hope, viz., Apogon rex-mullorum, which exists in the Mediterranean, among the Canaries, in the Indian Ocean, at the Marian Islands, New Guinea, and New Holland, but has not hitherto been discovered in the American seas. It is, however, by no means certain that a species which is found on both sides of a continent, or at a succession of distant places, actually exists in the intermediate seas, or traverses them, for Uranoscopus scaber is common to the Mediterranean and Indian Ocean, without having been detected in the Atlantic; and there are species of other families which frequent the Mediterranean coasts of Egypt, as well as the Red Sea, though they are unknown in other districts of the ocean. The range of the percoidea, and of many other Acanthopterygii, is much greater in the Indian Ocean and warmer parts of the Pacitic than in the Atlantic. 'Thus species which exist in the Red Sea, at the Seychelle Islands, and the Mauritius, range by the Indian peninsulit and archipelago to New Guinea, the north coast of New Holland, and through the Polynesian group to Otaheite, and even to the Sandwich Islands. A continuous coast, or a chain of islands lying nearly in the direction of the zones of equal temperature or parallels of latitude, seems to favour the spreading of a species over it great extent of ocean. The shores of the Atlantic, which have a direction the reverse of this, afford no such facilities to the nigration of fish, the beds of sargasso, or sea-weed that occur in the lower latitudes being but in imperfect substitute for islands, and available to those fish only which feed on or near the surface.

Having made these very general remarks on the diffusion of the genera, and on the range of individual species, we have next briefly to notice the forms peculiar to different quarters. Europe has five genera proper to itself, Aspro and Acerinu, inhabitants of fresh waters, and Pomatomus, Trachinus and Paralepis of the sea: add to these Pentaceros, frequenting the Cape Verd Islands, and Apsilus the Cape of Good Hope, and we have seven different forms, containing in the aggregrate fifteen species peculiar to the east side of the Atlantic. The genera proper to North America all belong to the fresh waters, and are, Huro, Aplurodederus, Bryttus, Centrarchus, and Pomotis ; while the Gulf of Mexico and Brazilian seas contain Pinguipes and Percophis, in all nine forms and twenty-one species peculiar to the American side of the Atlantic. Centropomus and Bovichtus are proper to South America, but they occur in both oceans. Aplodactyhis is peculiar to the sea of Chili. Trichodon has been found in the Kamtschatdale Seit only, and Niphon nowhere but in the sea of Japan. The Red Sea, Indian Ocean, Polynesian and Australian seas, or the lands which they wash, contain twenty-three percoid genera, not known to exist in the Atlantic or its arms, the Mediterrancan. 
Black Sea, Baltic, and Hudson's Bay; nor in the Pacific north of the tropics. The following list of their names exhibits the number of species belonging to each, amounting in the aggregate to one hundred and thirty-one.

\begin{tabular}{|c|c|c|c|c|c|c|}
\hline Etelis & 1 & Priopis & 1 & Therapon & . 13 & Rhynchichtys \\
\hline Enoplosus & 1 & Grammistes & 2 & Datnia & 3 & Beryx. . \\
\hline Diploprion & 1 & Diacope & . 36 & Pelates & 3 & Trachichtys \\
\hline Apogon* . & 20 & Aprion & 1 & Helotes & 1 & Percis . \\
\hline heilodipterus & 3 & Cirrhites & 6 & Nandus & 1 & Aphritis. \\
\hline mbassis & 12 & Chironemus & 1 & Sillago & 7 & \\
\hline
\end{tabular}

\begin{tabular}{|c|c|c|c|c|c|c|c|c|c|c|c|}
\hline GENERA. & 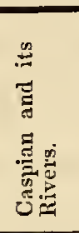 & 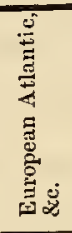 & 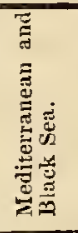 & 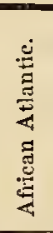 & 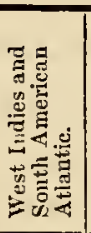 & 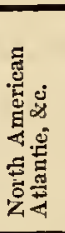 & 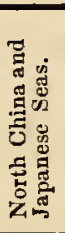 & 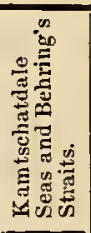 & 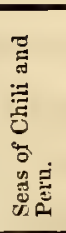 & 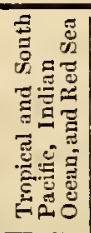 & $\begin{array}{c}\text { Totals } \\
\text { of } \\
\text { Species. }\end{array}$ \\
\hline Perca.. . . . . . F & 1 & 1 & 2 & 0 & 2 & 5 & 0 & 0 & 0 & 2 & 11 \\
\hline Labrax $\ldots . . A$ & 0 & 1 & 2 & 0 & 1 & 3 & l & 0 & 0 & 1 & 7 \\
\hline Lates...... A & 0 & 0 & 1 & l & 0 & 0 & 0 & 0 & 0 & 2 & 3 \\
\hline Centropomus . & 0 & 0 & 0 & 0 & I & 0 & 0 & 0 & 1 & 0 & 1 \\
\hline Lucio-perca . & 2 & l & 1 ? & 0 & 0 & 1 & 0 & 0 & 0 & ॥) & 3 or 4 \\
\hline Huro ... & 0 & 0 & 0 & 0 & 0 & i & 0 & 0 & 0 & 0 & 1 \\
\hline Niphon & 0 & 0 & 0 & 0 & 0 & 0 & 1 & 0 & 0 & 0 & 1 \\
\hline gon ...... & 0 & 0 & 1 & 0 & 0 & 0 & 1 & 0 & 0 & 20 & 21 \\
\hline Pomatomus $\ldots$ & 0 & 0 & 1 & 0 & 0 & 0 & 0 & 0 & 0 & 0 & 1 \\
\hline Aspro . . . & 0 & 0 & 2 & 0 & 0 & 0 & 0 & 0 & 0 & 0 & 2 \\
\hline ranus. . & 0 & 2 & 6 & 7 & 31 & 2 & 3 & 0 & 0 & 85 & $13 \imath$ \\
\hline Plectropoma . . . & 0 & 0 & 0 & 0 & 5 & 0 & 1 & 0 & 0 & 9 & 15 \\
\hline Mesoprion . $\mathrm{S}$ and $\mathbf{F}$ & 0 & 0 & 0 & 3 & 18 & 0 & 0 & 0 & 0 & 28 & 49 \\
\hline Acerina . . . . F & ] & 1 & 2 & 0 & 0 & 0 & 0 & 0 & 0 & 0 & 3 \\
\hline$\ldots$ & 0 & 0 & 1 & 1 & 1 & 0 & 0 & 0 & 0 & 1 & 1 \\
\hline ntaceros. & 0 & 0 & 0 & 1 & 0 & 0 & 0 & 0 & 0 & 0 & 1 \\
\hline Centropristis & 0 & 0 & 0 & 0 & 4 & 2 & 1 & 0 & 0 & 3 & 10 \\
\hline ystes . . . F F & 0 & 0 & 0 & 0 & 0 & 1 & 0 & 0 & 0 & 1 & 2 \\
\hline$\ldots$ & 0 & 0 & 0 & l & 0 & 0 & 0 & 0 & 0 & 0 & 1 \\
\hline Rypticus : . & 0 & 0 & 0 & l & 2 & 0 & 0 & 0 & 0 & 0 & 2 \\
\hline lodactylus & 0 & 0 & 0 & 0 & 0 & 0 & 0 & 0 & 1 & 0 & 1 \\
\hline Centrarchus ...F & 0 & 0 & 0 & 0 & 1 & 6 & 0 & 0 & 0 & 0 & 7 \\
\hline Pomotis . . . . . F & 0 & 0 & 0 & 0 & 1 & 7 & 0 & 0 & 0 & 0 & 8 \\
\hline yttus ....F & 0 & 0 & 0 & 0 & 0 & 3 & 0 & 0 & 0 & 0 & $\cdot 3$ \\
\hline hrodederus . . . F & 0 & 0 & 0 & 0 & 0 & 1 & 0 & 0 & 0 & 0 & 1 \\
\hline iacanthus . . . & 0 & 0 & 0 & l & 4 & 0 & 2 & 0 & 0 & 8 & 15 \\
\hline ules . . . . F & 0 & 0 & 0 & 0 & $2 S$. & 0 & 0 & 0 & 0 & $9 \mathrm{~F}$. & 11 \\
\hline chodon . . . & 0 & 0 & 0 & 0 & 0 & 0 & 0 & l & 0 & 0 & 1 \\
\hline ripristes . & 0 & 0 & 0 & 0 & 1 & 0 & 1 & 0 & 0 & 10 & 12 \\
\hline locentrum & 0 & 0 & 0 & 3 & 3 & 1 & 0 & 0 & 0 & 14 & 19 \\
\hline achinus . . . . & 0 & 2 & 4 & 0 & 0 & 0 & 0 & 0 & 0 & 0 & 4 \\
\hline guipes . . . . & 0 & 0 & 0 & 0 & 1 & 0 & 0 & 0 & 1 & 0 & 2 \\
\hline$\cdots$ & 0 & 0 & 0 & 0 & i & 0 & 0 & 0 & 0 & 0 & 1 \\
\hline ichtus. & 0 & 0 & 0 & 0 & 1 & 0 & 0 & 0 & 1 & 0 & 1 \\
\hline Uranoscopus . & 0 & 0 & 1 & 0 & 1 & 1 & 0 & 0 & 0 & 9 & 11 \\
\hline Sphyræna . . . & 0 & 0 & 1 & 2 & 3 & 0 & 0 & 0 & 0 & 5 & 10 \\
\hline & 0 & 0 & 3 & 0 & 0 & 0 & 0 & 0 & 0 & 0 & 3 \\
\hline Polynemus..... & 0 & 0 & 0 & 3 & 1 & 1 & 0 & 0 & 0 & 9 & 14 \\
\hline \multirow{2}{*}{ Gen.peculiar to India, \&c. } & 0 & 0 & 0 & 0 & 0 & 0 & 0 & 0 & 0 & 111 & 111 \\
\hline & 4 & 8 & 28 & 24 & 85 & 35 & 11 & 1 & 4 & 327 & 501 \\
\hline
\end{tabular}

OBs. The letter $\mathrm{F}$ follows the names of the genera which are wholly or mostly inhabitants of fresh water. A points out those whose species are anadromous, ascending occasionally into rivers; and $\mathrm{S}$ signifies sea or marine species.

* One species of Apogon is, as we have already mentioned, found in the Mediterranean as well as in the Indian Ocean. 
The preceding table presents a general view of the diffusion of the Percoidere. IVe have found it convenient to divide the ocean into nine districts, the divisions being made, as far as we could, to suit the distribution of this family of fish. 'To shorten the table, twenty-two genera peculiar to the Indian Ocean and tropical regions of the Pacific, enumerated above, are omitted, the aggregate number of their species merely being inserted. The fresh-water species are includer under the head of the seas into which the rivers flow.

Cuvier, considering the Muld to have some relations to the Percoider, has placed them as an appendix to that family, though he says they constitute a perfectly natural genus, which is so isolated that it may be considered as a peculiar family in itself. The genus Mullus is distinguished from other groups of Acanthopterygrii by two distinct dorsals; large and easily detached scales on the head and borly: but principally by two barbels attached to the chin or symplysis of the lower jaw. The term Mullus is retained for a sub-genus which wants teeth on the upper jaw, and that of Upeneus is given to one which has teeth in both jaws. Mullus, in its geographical distribution, is confined to the Black Sea, Mediterranean, and European Atlantic, including the Baltic. Upeneus has twenty-seven species in the Red Sea, Indian Ocean, and Pacific*, inchuding the seas of Australia and Japan: four in the West Indies and Brazils, and one at the Cape Verd Islands, but none of either sul-genus belong to North America.

* A new species of Upeneus is indicated in Mr. Bennett's Appendix to Beechey's Voyage, as occurring at Oahn, one of the Sandwich Islands. 


\section{CO'TTOIDEA.-MAILED.CHEEKS*.}

'T'HIs family, having many characters in common with the Percoideæ, is distinguished by the sub-orbitars being united to the preoperculum, and so expanded as to cover a large part or the whole of the cheeks. A family likeness prevails among the fish possessing this cheek-mail, notwithstanding the various forms of the head, that result from its greater or less development. In one group of genera, the hearl has the form of a cube or parallelopiped; in another it is round or depressed ; in a third it is compressed; and a fourth group is composed of fish of it hideous aspect, having a large or even monstrous head and vertical eyes. Gasterosteus, though belonging to this family, because it has the cheeks protected by the sub-orbitars, does not enter any of these four groups, there being neither spines nor tubercles on its head, nor anything very striking in its form : in this genus the first dorsal is replaced by free or detached spines. Monocentris, which has a large cuirassed head, and the whole body protected by scales of stony hardness, forms a genus apart, whose affinities, owing to our iguorance of its anatomy, are unknown : it resembles the gasteroste $i$ in its free dorsal spines. The percoid genus Uranoscopus approaches this family in the development of the sub-orbitars, but they are united to the temporal bone posteriorly, and not to the preoperculum.

'The only forms among the Cottoidea that have anything like a general distribution are the larger genera of Trigla, Cottus, Aspidophorus, Scorpæna, Sebastes, and Gasterosteus, containing the majority of the whole species. Minous, Pterois, Apistes, and Synanceia, belong to the Indian Ocean, a single species of each of the three latter extending to the Pacific. Platycephalus and Pelor are also genera of those seas, a greater proportion of their species, however, extending to the more temperate latitudes of the Pacific, three of the former existing on the extra-tropical coasts of New Holland, and four with one Pelor in the sea of Japan. The Japanese Sea also nourishes some forms peculiar to itself, as Oplichthys, Bembras, and Momocentris, and the sea of Kamtschatka alone produces Blepsias and Hemilepidotus. Peristedion is peculiar to the Mediterranean. The European Atlantic possesses no cottoid form exclusively; but on the American side, Hemitripterus

* Joues cuirassées. (Reg. An.) Cuvier has not furnished us with a Latin equivalent to this plirase, which might be

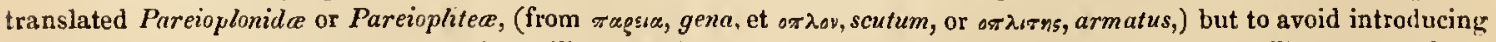
a new term, I have used Cuttoidece, which will be readily understood, being derived from the most familiar genus of the fainily. 
is widely spread in the higher northern latitudes, Cephalacanthus is proper to South America, and Prionotus is common to both these districts. The habitat of Tanianotus is unknown, and it is consequently scaree, and most probably fouml only in one locality. Of the twenty-five generi, therefore, which compose the family of Cottoidex, sixteen are peculiar to certain limited portions of the ocean : and eight of the remainder have species in two or more distinct districts. Hoplostethus has one Mediterranean species, and the only known specimen of a second was taken from the stomach of a shark, caught in the Atlantic at some distance from the coast of South America. Agriopus has one species not uncommon off the Cape of Good Hope, and another in the sea of Chili. Sebastes has species in the Mediterranean, and also in the Atlantic, Indian, and Pacific oceans: this form, which approaches nearer to the Percoidere than the other Cottoideæ, having a very general distribution. Aspidophorus has several species in the more northern latitudes of the Paeific, and on the European and American sides of the North Sea. The Trigla are known in the Mediterranean, on both sides of the northern Atlantic, at the Cape of Good Hope, in the Indian Ocean, the Australian Sea, and in the seas of Japan and Kamtschatka*. Cottus, a genus either littoral or frequenting tidal estuaries, with some entirely fresh-water species, has a very wide distribution in the northern hemisphere, existing in the rivers and lakes of Europe, Asin, and America, in Lake Baikal, the Icy sea of Asia, the Baltic, the North Sea, English Channel, the seas of Iceland, Greenland, and Baffin's Bay, the Polar Sea, on the Atlantic and Pacific coasts of North America, and in the seas of Kamtschatka and Japan; but it is unknown in the Mediterranean and more southern districts of the ocean. Scorpana, again, is comparatively a tropical gents, most of its species being inbabitants either of the Red Sea, the Indian Ocean, and Archipelago, or of the Polynesian seas; it is known, however, also in the Mediterranean, in the Atlantic, on the European side from the English Channel to the Canaries, and on the American side from the United States to the Brazils; it bears, like its subgenus Sebastes, a close resemblance to the Percoider. Gasterosteus, consisting principally of anadromous species, has a wide range in the northern hemisphere, heing found in the rivers of Europe, Greenland, and America, in the Baltic, both sides of the North Atlantic, and in the sea of Kamtschatka. A new species has even been detected at Otaheite by the naturalists of Captain Beechey's Experition, though there is none mentioned in the Histoire des Poissons, as occurring in the southern hemispliese.

* A species of 'rrigla is mentioned in the Appendix to Captain Buechey's Voyage, as occurring in the harbour of Rio Janeiro, but it was most probahly a Prionolus, purhaps the punctalus, which is known to exist there. 
The range of individual species is more remarkable in this family than in the more extensive one of Percoideæ, as is evident when we consider the number of species which cross the Atlantic, and in this respect there is some analogy between the Cottoidea and some of the higher classes of animals, it having been observed that the quadrupeds and birds common to the Old and New Worlds are species that have a high northern range. Trigla pini exists in the Mediterranean, on the Atlantic coasts of France, and at New York. Dactylopterus volitans is common in all parts of the Mediterranean, and ranges on the American coast from the Brazils to the banks of Newfoundland, probably pursuing the course of the Gulf Stream. Aspidophorus Europaus is found in the Baltic, English Channel, the Iceland Sea, and Davis's Straits. Scorpana porcus ranges throughout the Mediterranean, and from the English Channel to the Canaries, and it also occurs at New York. Sebastes Norvegicus extends from the sea of Norway to that of Greenland and the Gulf of St. Lavrence. It seldom approaches the surface, living habitually at a great depth. Gasterosteus leiurus, which may be reckoned an anadromous fish, prevails all over Europe, and has been taken in the Baltic, and also in Greenland, if one of the very nearly resembling American species has not been, in the latter case, confounded with it. The G.trachurus has probably an equally extensive range. Cottus gobio, a fresh-water species known throughout Siberia, and in Europe from Italy to Sweden, is, according to Fabricius, also an inhabitant of Greenland; but we need careful comparisons to establish the identity of the Greenland species : our C. cognatus, which can scarcely be distinguished from $C$. gobio, inhabits Great Bear Lake. C. quadricornis is common to the Baltic, the Icy Sea at the mouth of the Jenisei, and Lake Baikal. Besides some that have already been particularised, several Cottoideæ are common to the Mediterranean and Baltic, particularly of the genus Trigla, as T. lineata, hivundo, lyra, gurnardus, and cuculus; and also Scorpena scrofa. Cottus scorpius, C. bubalus, and Gasterosteus Spinachia are common to the Baltic and North Sea; while Platycephalus fuscus has an extensive range in the Pacific, being found at Port Jackson, Otaheite, and Japan.

But one specimen of the very singular genus Oreosoma has been seen. It was brought from the Atlantic by Péron. The cheeks are but very imperfectly covered by the sub-orbitars, hence it scarcely belongs to this family, though it appears to have a greater affinity to it than to any other. 


\begin{tabular}{|c|c|c|c|c|c|c|c|c|c|c|c|c|c|c|}
\hline GENERA. & 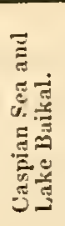 & 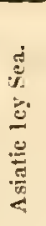 & 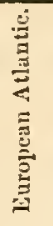 & 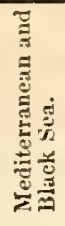 & 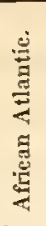 & 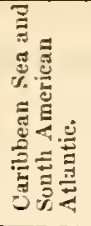 & 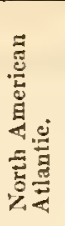 & 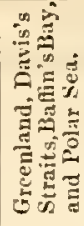 & 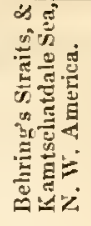 & 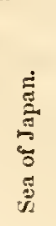 & 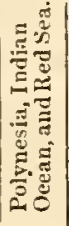 & 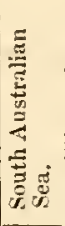 & 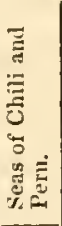 & $\begin{array}{l}\text { Totals } \\
\text { of } \\
\text { Species }\end{array}$ \\
\hline (Trigla .... & 0 & 0 & 7 & 8 & 4 & 0 & 1 & 0 & 0 & 0 & 5 & 1 & 0 & 15 \\
\hline Prionotus... & 0 & 0 & 0 & 0 & 0 & 1 & 3 & 0 & 0 & 0 & 0 & 0 & 0 & 4 \\
\hline I. \{ Peristedion . & 0 & 0 & 0 & 1 & 0 & 0 & 0 & 0 & 0 & 0 & 0 & 0 & 0 & I \\
\hline Dactylopterus. & 0 & 0 & 0 & 1 & 0 & 1 & 1 & 0 & 0 & 0 & 1 & 0 & 0 & 1 \\
\hline Cephalacanthus & 0 & 0 & 0 & 0 & 0 & l & 0 & 0 & 0 & 0 & 0 & 0 & 0 & I \\
\hline Cottus . . . & 2 & 1 & 4 & 0 & 0 & 0 & 3 & 5 & 10 & 1 & 0 & 0 & 0 & 22 \\
\hline Aspidophorus . & 0 & 0 & l & 0 & 0 & 0 & 0 & 2 & 6 & 5 & 0 & 0 & 0 & 9 \\
\hline 11. Platycephalus . & 0 & 0 & 0 & 0 & 0 & 0 & 0 & 0 & 0 & 4 & 15 & 3 & 0 & 21 \\
\hline Oplichthys . . & 0 & 0 & 0 & 0 & 0 & 0 & 0 & 0 & 0 & l & 0 & 0 & 0 & 1 \\
\hline Hemitripterus. & 0 & 0 & 0 & 0 & 0 & 0 & 1 & 0 & 0 & 0 & 0 & 0 & 0 & 1 \\
\hline Hemilepidotus. & 0 & 0 & 0 & 0 & 0 & 0 & 0 & 0 & I & 0 & 0 & 0 & 0 & 1 \\
\hline Bembras... & 0 & 0 & 0 & 0 & 0 & 0 & 0 & 0 & 0 & I & 0 & 0 & 0 & l \\
\hline Scorpæna . & 0 & 0 & 3 & 2 & ] & 5 & I & 0 & 0 & I & 12 & 0 & 1 & 20 \\
\hline Sebastes . . & 0 & 0 & l & 1 & 2 & 0 & 1 & 1 & 1 & 3 & 3 & 0 & 0 & 11 \\
\hline Pterois ... & 0 & 0 & 0 & 0 & 0 & 0 & 0 & 0 & 0 & 0 & 7 & 0 & 0 & 7 \\
\hline 11. Tænicnotus. . & 0 & 0 & 0 & 0 & 0 & 0 & 0 & 0 & 0 & 0 & 0 & 0 & 0 & 1 \\
\hline Blepsias . . • & 0 & 0 & 0 & 0 & 0 & 0 & 0 & 0 & 2 & 0 & 0 & 0 & 0 & 2 \\
\hline Agriopus. . . & 0 & 0 & 0 & 0 & 1 & 0 & 0 & 0 & 0 & 0 & 0 & 0 & 1 & 2 \\
\hline Apistes.. & 0 & 0 & 0 & 0 & 0 & 0 & 0 & 0 & 0 & 0 & 13 & 1 & 0 & 14 \\
\hline linous . . & 0 & 0 & 0 & 0 & 0 & 0 & 0 & 0 & 0 & 0 & 2 & 0 & 0 & 2 \\
\hline IV \{ Pelor .... & 0 & 0 & 0 & 0 & 0 & 0 & 0 & 0 & 0 & 1 & 4 & 0 & 0 & 5 \\
\hline$V \cdot\{$ Synanceia $\cdot \cdot$ & 0 & 0 & 0 & 0 & 0 & 0 & 0 & 0 & 0 & l & 5 & ) & 0 & 6 \\
\hline MIonocentris . & 0 & 0 & 0 & 0 & 0 & 0 & 0 & 0 & 0 & 1 & 0 & 0 & " & 1 \\
\hline Hoplostethus . & 0 & 0 & 0 & 1 & 0 & 1 & 0 & 0 & 9 & 0 & 0 & 0 & 0 & 2 \\
\hline \multirow[t]{2}{*}{ Gasterosteus . } & 0 & 0 & 6 & 5 & 0 & 0 & 6 & 3 & 1 & 0 & 0 & 0 & 0 & 17 \\
\hline & 2 & 1 & $2 \cdot 2$ & 19 & 8 & 9 & 17 & 11 & 2] & 19 & 67 & 5 & 2 & 168 \\
\hline
\end{tabular}

Trigla, placed by Cuvier at the head of the family, is, in fact, the genus in which the sub-orbitars most completely cover the cheek, these bones being articulated anteriorly to the snout, projecting more or less beyond it, and united so firmly posteriorly to the preoperculum that it moves along with them. It belongs to the group having a parallelopipedon head and two dorsal fins, being, with its two sub-genera, distinguished from the rest of the group by the presence of free rays under the pectorals. The Trigla, as we have noticed in the preceding pages, have a wide range in the Mediterranean, and on the European side of the Atlantic, from the Canaries to Norway. One species, at least, ranges also to the American coast, for a Trigla pini, or one so like it that no distinguishing marks could be perceived in the prepared specimen, was sent to Baron Cuvier from New York; and as this species ranges on the European side as high as the Dutch coast, it is probable that it extends on the American one to Nova Scotia or Newfoundland; but until it has been actually detected on the coasts of British America, it would not be proper to enumerate it in our Fauna. The sub-genus Prionotus, distinguished by the presence of palatine teeth, en velours, belongs entirely to America, and though three of the four known species reach New York, yet their 
range being to the Southern states, and some of them to the West Indies and Brazils, it is not so likely that they go northwards beyond the influence of the Gulf Stream.

\section{[10.] 1. Dactylopterus volitans. (Lacep.) Common Dactylopterus. \\ FaMiLy, "Joues cuirassées." Genve, Dactylopterus. Cuvier. \\ Trigla volitans. Lins. Le Dactyloptere commun. Cuv, et VAl., iv., p. 120.}

The genus Dactylopterus differs from Trigla and its two sub-genera, Prionutus and Peristedion, in the different shape of the helmet-like casing of the head, which is long and broad, but flat and of small depth: the sub-orbitars do not project on the sides of the snout, neither do they entirely cover the cheeks, while the preoperculum is so connected with them, that instead of being entirely fixed, it retains sufficient mobility to point its enormous spine, when required, as a defensive weapon: the operculum is unarmed; the teeth confined to the jaws are small, rounded, and low, like paving stones ("dents en pavés"): there are only six branchiostegous rays; the ventral fins bave only four soft rays (an unusually small number in Acanthopterygious fishes), and the supernumerary rays under the pectorals, instead of being free, are united by membrane into a kind of parachute equalling the body in length. The whole body is cased in large hard scales, which rise into longitudinial ridges in various parts.

The common species enters into our list as it occurs on the coasts of Newfoundland. It ranges also through the seas of the United States, and is particularly abundant in the Mediterranean, but does not appear to frequent the British Channel or the Atlantic coasts of France. A second species exists in the Indian Ocean and Archipelago.

\section{[11.] 1. Cottus cognatus. (Richardson.) Bear Lake Bull-head.}

Fanir.y, "Joues cuirassées." Genus, Cuttus. Linn. et Cuv.

The genus Cottus is characterised by a large depressed cuirassed head, variously armed with spines or tubercles, a more slender, tapering, almost naked body; two dorsals either quite distinct or very slightly united; ventrals of three or four rays 
only under the pectorals; six branchiostegous rays; and teeth on the forepart of the vomer, but none on the palate bones. 'The stomach is an obtuse sac, the pylorus is surrounded by from four to eight crea, the ovaries have a blackish colour, and there is no air-bladder belonging to the fish of this genus. Platycephulus: differs from Cottus in having a still more depressed head, which is also differently cuirassed, large abdominal ventrals of five rays, a row of sharp palatine teeth, seven branchiostegous rays, and a scaly body.

The Cottus which forms the subject of this article was taken in considerable numbers in the clear waters of Great Bear Lake during the month of May, at which period it resorts to the stony shallows to spawn. Specimens which we sent to Baron Cuvier were returned with the remark, that they belonged to a species of Cottus, and were "tres semblables aux C. gobio*", and they indeed correspond in most particulars with the extended description of the latter in the Histoire des Poissons. I have since compared these specimens minutely with an English golio, kindly lent to me by Mr. Yarrell, and the principal difference that I have been able to detect in the American fish is the greater height of its dorsal and anal fins. 'There is also a discrepancy in the number of the rays, but this can scarcely be accounterl a specific distinction, since different individuals of grobio show equally extensive variations. The Bear Lake specimens having been long in spirits have lost much of their colour: but the following particulars may still be noter. In $C$. gobio the rays of the pectorals are variegated with rings alternately dark and light; in cognatus the colour is almost uniform, but varies in intensity in different individuals. In one small female specimen of the latter, however, there is a slight indication of these rings, and its body likewise is marbled in a more lively manner than the rest, having a greater resemblance to gobio. 'The males are darker than the females in the American as well as the European species. The specimen which we have described in detail was the largest we obtained, and was selected for description from its being exactly of the same length with the gobio with which it was compared.

\section{DESCRIPTION}

Of a male specimen taken in Great Bear Lake, lat. $64 \frac{1 \frac{1}{2}^{\circ}}{2} \mathrm{~N}$., May 26,1825 , and a comparisou of it with an English C. gotio.

Form.-Head corresponding exactly with that of gobio in size and shape, except that the mouth is rather larger: it forms one-third of the whole length excluding the caudal, and it is

* Cuvier, speaking of $C$. minutus of Pallas from the sea of Ochotzk, says, "Sa ressemblance avec lespèce commune de nos eaux douces est telle que nous n'oserions ren distinguer," and I should have thought in a similar way of C. cognatus; but as Cuvier did not cunsider it to be the same with the common species, although greatly rescmbling it, it appears safer to give it a distinct appellation. 
as broad as it is long: its height is two-thirds of its breadth. The jaws are equal. There are no conspicuous spines on the head, but the preoperculum ends posteriorly in a little point that is bent upwards, and is concealed in the thickness of the skin. The operculum terminates in a rounded process, whose membraneous ed ging has two acute angles.' There are six slender cylindrical rays in the branchiostegous membrane: in gobio the rays are stronger and flatter. The membranes can be inflated: the isthmus, or space between their insertions, measures half an inch. Body moderately compressed, and tapering gradually from the broader head to the caudal fin : its greatest height, which is at the beginning of the dorsal, is nearly the same with its transverse diameter there, but the compression is more decided towards the tail, whose thickness at the insertion of the caudal is little more than half its depth. The belly and under surface of the head are flattish, the back is more acute, particularly the posterior part of it. The anus, situated precisely as in gobio, is rather nearer to the snout than to the insertion of the caudal. There are no scales, the body and head being covered with soft skin. The lateral line consists of a series of little depressions with raised margins, and runs parallel to the ridge of the back, and nearer to it than to the belly.

ТеЕтн.-The intermaxillaries, lower jaw, and vomer, are armed with short teeth, en velours. The tongue is smooth, very broad, short, and fixed.

Fins.-Br. $6 ; P .15 ; V .1 / 4 ; D .8 /-18 ; A .14 ; C .15$.

The pectoral fins are large and fan-shaped, their longest rays, as in gobio, equalling the head in length. They are all articulated and unbranched. The ventrals, arising a little behind the pectorals, contain five rays; the first of which, a slencler spine laalf the length of the others, is so closely applied to the succeeding articulated one as scarcely to appear distinct until the integuments are removed. Cuvier describes gobio as having one spinous ray in each ventral, and only three articulated ones; but in Mr. Yarrell's English specimen these fins correspond exactly, in the number of their rays, with cognatus.

The first dorsal commences a little farther back than the ventrals, and exactly at the same distance from the snout as in gobio, but it extends about a line farther along the back, and contains two more rays than in that species. All the rays are very slender and flexible, but not articulated, and are connected to their tips by a delicate membrane. The longest measures one-third of the height of the body. The second dorsal arises within less than a line of the first, and has an attachment twice as long, reaching to within three lines of the insertion of the caudal. Its rays (eighteen) are articulated and simple, except the two central ones, which are very slightly forked. [The English specimen of gobio has only six rays in the first dorsal, but Cuvier says they vary from six to nine: and the second dorsal has sixteen rays all articulated and simple, though Cuvier describes the last ray as forked, and some of the others as branched. There is a space, measuring two and a half lines, between the first and second dorsals, and their rays are one-third shorter than the corresponding ones of cognatus.]

The anal fin, similar in form to the second dorsal, has fourteen rays all articulated and simple. It commences opposite to the sixth ray of the second dorsal, and does not reach quite so near to the caudal fin. The caudal unites with the tail in a straight line, and contains fifteen rays, all more or less forked. It forns one-sixth of the total length as in gobio. 
CoLour. - The under surface is silvery-grey minutely spotted with dark brown : on the sides the dots are intermingled with crowded irregular blotches of the same colour, and on the back and top of the head the colour is dark brown, nearly uniform, few spots of the light colour appearing.

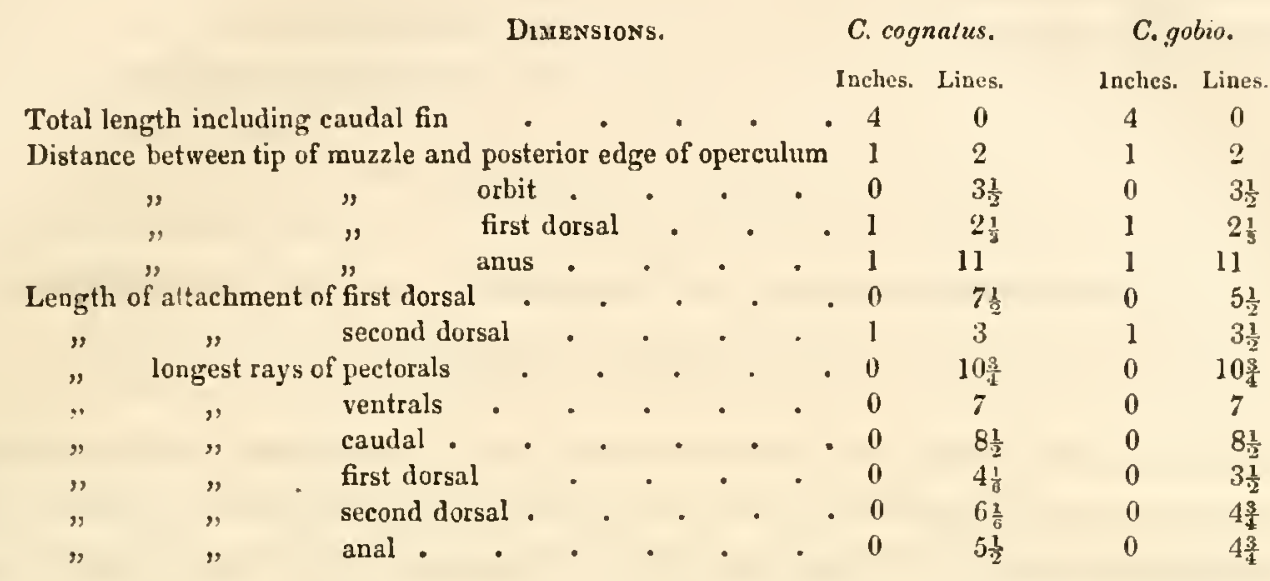

Some individuals of $C$. cognatus, which are full of roe, measure only two and a half inches of total length. All our specimens agree with each other in the number of rays in their fins. There are four pretty long caca round the pylorus, and the viscera correspond with the description of those of C. gobio in the Histoire des Poissons. The stomach contained fragments of dytisci, and of other fresh-water insects and crustacee, and also of some small fish.

\section{[12.] 2. Cottus polaris. (Sabine.) North Georgian Bull-head.}

Cottus polaris. SABıne, App. Parry's First Voyage, cexiii. J. C. Ross, App. liii.

This species is compared by Captain Sabine to C. gobio, but that has the head almost unarmed. It agrees with C.claviger in the number of rays in the dorsals, but its rentrals are described as having more rays than usual in this genus. Captain J. C. Ross informs us that it seldom exceeds two inches in length, and that it is very abundant on the east side of the peninsula of Boothia, affording a plentiful supply of food to the numerous water-fowl which breed there.

"Cottus capite spinis duabus, operculis spinis quatuor armatis."

"A species of Cottus, similar in habits to C. gobio, was rery abundant on the shores of North Georgia (lat. $75^{\mathrm{a}}$ ), inhabiting the pools of water left by the tide, and the mouths of small rivulets by which the snow on melting found its way to the sea; the largest individual did not equal two inches in length; the head is more compressed and not so much flattened as in the Cottus quadricornis, and is armed with two strong spines placed before and between 
the eyes: the gill-covers are also armed with four strong spines; the pectoral fins are larger in proportion than those of $C$. gobio, and the upper jaw rather exceeds the lower; the lateral lines are furnished with a series of small tubercles directed backwards : colour light, with clusters of minute dusky spots.
"Fins. - D. 6-13;
P. $15 ;$ V. $5 ; A .14$.
C. 14." (SABine, l.c.)
8-13;
$15 ; \quad 5$;
15.
12 to 14
(Capt. J. C. Ross.)

\section{[13.] 3. Cottus hexacornis. (Richardson.) Six-horned Bull-head.}

Cottus hexacornis (Six-horned Bull-head), Richards., Frankl, Journ., p. 726. An. 1823.

Numerous specimens of this fish were caught in a net set in the mouth of a small river near the Coppermine, and the following description is drawn up from notes written on the spot:-The subsequent calamities which befel that expedition having occasioned the loss of all the specimens, no actual comparison has been made with other species; but after an inspection of the Cotti brought home by Captain Beechey, and an attentive perusal of the Histoire des Poissons, I an satisfied that it differs from all other described species in the form of the horns, or processes which arm the head, and in other particulars. From the peculiar shape of these horns in our species, it might bear the name of claviger, still more appropriately than the one so termed by M. Valenciennes.

The individuals that we caught retained life long after they were drawn from the water, leaping vigorously over the sands, and when touched inflating the head. In this operation the branchiostegous membrane is distended, and the several pieces composing the gill-covers are separated by the extension of the intervening membranes. Our Canadian voyageurs were both astonished and alarmed by these fish, and termed them Crapauds de mer, probably from a kind of croak they uttererl when first handled

\section{DESCRIPTION}

Of eight or nine recent specimens taken at the mouth of 'Tree River, near the Coppermine, lat. $67^{\circ} 12^{\prime} \mathrm{N}^{\top}$ orth. July 23rd, 1821.

Size.-A bout seven inches in total length.

Colour.-Of the upper aspect a clouded admixture of brocoli-brown and olive-green tints: of the belly white. The fins are streaked with bluish-black. Irides tinged with red.

Form.-Head large and depressed. Eyes large. Six club-shaped, or rather nail-shaped processes stand erect on the top of the head : their summits flattish, minutely cancellaterl, and scabrous. The smallest pair stand between the nares: the largest over the posterior angles of the orbits; and the third of intermediate size on the occiput. The mouth is capacious. 
Its margins are formed by the intermaxillaries and lower jaw. The maxillaries hare an elongated wedge-form, and lie in a membrane behind the intermaxillaries. Both jaws and the romer are set with bands of fine teeth, en velours. Tongue obtuse and smooth, as are the palate and maxillaries. The preoperculum is armed beneath with three strong clivaricated spines, the posterior onc, which measures half an inch, being the longest. The gill-covers are composed of several bones connected by membrane, and armed on their exterior edges with four or fire small spinous teeth. The bones which support the pectoral fins are also armed with small spines and have sharp rough edges. The branchiostegous membrane contains six slender cylindrical curved rays. The Body is much narrower than the head, and tapers to the insertion of the caudal fin. The anus is situated midway between the mouth and the caudal. The lateral line is rough and runs near the back-above it there is a row of smal! orbicular, scabrous, bony plates, the row being doubled opposite to the second dorsal. There are no other perceptible scales.

\section{Fins.-Br. 6. $\quad P .16: \quad V .3 . \quad D .7-13 . \quad A . \quad$. C. 12.}

The pectoral fins are sub-orbicular and contain sixteen rays, none of them branched. 'The upper ray is scabrous throughout. The others are scabrous only near their micldles. 'The ventrals, soft and whitish, have three rays, of which the first is the strongest, but none of them are spinous*. The first dorsal commences posterior to the pectorals and terminates opposite to the anus. It has seven simple rays. The second dorsal is larger and has thirteen rays. Its commencement and termination correspond with those of the anal, and most of its rays are scabrous. Both dorsals are rounded or arched. The anal fin occupies about two-thircls of the space between the anus and caudal, commencing near the former. This fin becomes slightly lower or less decp posteriorly. The caudal is cuneiform and has twelve rays, most of them forked.

OBs. In the forn of the bony processes, on the top of the head, this species approaches closely to $C$. quadricornis of the Baltic; but it does not appear, from the descriptions I have consulted, that there is a distinct pair on the nasal bones of the latter. There are also differences in the form of the spines of the preoperculum, those of $C$. hexacornis being quite sinuple, while in the other they are truncated, or divided at the point. In the C. quadricornis, also, there is a thick spine on the supra-scapular bone, which is likewise truncated; while in C. hexucornis, that bone, the humerals, and the gill-covers, are merely armed with small spinous teeth. And the rows of scales on the body are clifferent.

It appears to me likely, that the C. quadricornis, Sabine (Zool., App. to Captain Parry's First Voyage, p. ccxiii), may be really the C. hexacornis. Captain J. C. Ross, who considers it to be the same with the $C$. scorpioides of Fabricius, says that, though very abundant on the Greenland coast, it is more rare in the higher latitudes, but several were taken on both sides of the peninsula of Boothia. The natives prize it highly as an article of food, preferring it to cod-fish or salmon. The Esquinaux of Boothia call it Kaneeol, the same name which the Greenlanders give to $C$. Gronlandicus.

* It is possible that a small spine might be attached so closely to the first ray of the ventral as lo escape my observation, or, as Cuvier says of the ventrals of C. scorpius, "Elles sont étroites, ef leur Epine est si intimement ume à leur premier rayon inuu, qu'elles puroissent n'uroir que trois rayons" 


\section{[14.] 4. Cottus octodecimspinosus. (Mitchill.) The Sculpin.}

Scorpius Virginianus, Willoughby, t. x., 15.

Le Grand Chaboisseau à dix-huit épines de l'A mérique du Nord. Cuv, et Var, iv., 181,

This species has been confounded by several naturalists with the European C. scorpius, but it is quite distinct and of a considerably larger size. Its preopercular spine is longer than in that species, its point equalling or surpassing the spinous extremity of the gill-cover. The spines of its dorsal are, also, strong and pungent, instead of being flexible; and it differs much in its viscera from the European species. The stomach is a large thin bag, and the six cæca are so short as to look like a fringe: in $C$. scorpius the coats of the stomach are thick, and the pylorus is surrounded by eight cæca. The Sculpin* abounds on the coasts of the United States, and is also plentiful at Newfoundland. It is a pity that Cuvier did not retain the original specific name given by Willoughby, who figured it correctly ; it is preferable to octodecimspinosus, which may lead to error, there being, in fact, twenty spines on the head. C. scorpius has exactly the same number, ten on each side, viz., one at the nostril, one over the orbit, one on the nape, three on the preoperculum, one on the operculum, one on the suboperculum, and two on the scapular bones.

Fins.-Br. $6 ; D .8$ or $9 /-1 / 15 ; A .14 ; C .12 ; P .18 ; V .1 / 3$. (Hist. des Poiss.)

\section{[15.] 5. Co'ttus Granlandicus. (Cuvier.) Greenland Bull-head.}

Cottus scorpius. Fabricius. Fauna Groenlandica, p. 156.

Le Chaboisseau du Grouland (Cottus Groenlandicus). Cuv, et VaL., iv., p. 185.

Kaniok. Groinlanders.

It has been usual to enumerate the quadrupeds and birds of Greenland as belonging rather to Europe than America ; but the fish existing in Davis's Straits, even on the Greenland side, associate more naturally with the American ones. The $C$. Gronlandicus is known only by Fabricius's description, which agrees well with the Sculpin of the United States above mentioned, except that he counts only sixteen spines on the head and shoulder, and mentious obtuse, rough tubercles 
on the cranium, but no spines. It is abundant in all the bays and inlets of Greenland, but prefers a stony coast clothed with sea-weed. It approaches the shore in spring and departs in winter. It is very voracious, preying on every thing that comes in its way, and pursuing incessantly the smaller fish, not sparing the young of its own species, and devouring crustacea and worms. It is very active and bold, but does not come to the surface unless it be led thither in pursuit of other fish. It spawns in December and January, and deposits its red-coloured roe on the sea-weed. It is easily taken with a bait, and constitutes the daily foor of the Greenlanders, who are very fond of it. They eat the roe raw.

Fins.-Br. $6 ; D .10 /-17 ; A .14 ; C .17 ; P .17 ; V .3 . \quad$ (Fauna Grcenl.)

\section{[16.] 6. Cottus scorpioides. (Fabricius.) The Pokudleek.}

Le petit Chaboisseau du Gronland (Cottus ssorpioides). Cuv. et VAL., iv., p. 187.

'This species, according to the description given of it by Fabricius, approaches some of the European species, and a comparison of specimens is required to estiblish it as distinct. It is named "Pokudleek" by the Greenlanders, and frequents muddy places near the mouths of rivers, preferring brackish water.

The rays of its Fins are D. $10-15 ; A .12 ; C .15 ; P .15 ;$ V.3. (Fauna Grønl.)

[17.] 7. Cottus porosus. (Valencienmes.) Porous Bull-head.

Le Chaboisseau poreux (Cotfus porosus). Cuv, et VaL., viii., p. 498.

This species resembles the $C$. scorpius of Europe in the armature of the top of its head and gill-covers, and $C$. Gronlandicus, or scorpioides, in the great number of its dorsal rays. A specimen, six inches long, was taken in Baffin's Bay, which had sereral hundreds of very small shrimps in its stomach.

$$
\text { Fins-Br. } 6 ; D .11-1 / 16 ; A .13 ; C .17 ; \text { P. } 18 ; V .1 / 3 \text {. (Hist. des Poiss.) }
$$


[18.] 8. Cottus polyacanthocephalus. (Pallas.) Many-horned Bull-head.

"Cottus polyacanthocephalus. PaLL. Zoogr. Ross., p. 133, No. 104, pl. 23."

La cotte à tête très épineuse. Cuv. et VAL., iv., p. 177.

'This species was taken on the north-west coast of America, in the 60th degree of latitude, off Cape St. Elias, by Billings. It approaches to quadricomis in its characters, but its opercula are better armed.

Fins. $-D .10-1 / 14 ; A .12 ; P .17 ; V .4 ; C .15$; and some small ones.

(Hist. des Poiss.)

[19.] 9. Cottus pistilliger. (Pallas.) Antleved Bull-head.

"Cottus pistilliger. PaLL., Zaogr. Ross, t.iii., p. 143, pl. 20, f. 3 and 4."

Le Chaboisseau à bois de chévreuil. Cuv. et VAL., iv.p. 193.

This very curious Bull-head, which resembles $C$. diceraus in some of its characters, is found at Unalaschka, and also on the Kamtschatka coast.

Fins. -D. $9 /-13 ; A .16 ; C .13 ;$ P. $18 ; V .1 / 3$. (Hist. des Poiss.)

Cottus diceraus of Pallas, and C. claviger and ventralis found by $\mathrm{Mr}$. Collie at Kamtschatka, and described by Mr. Bennett in the Natural History Appendix to Captain Beechey's Narrative, and also in the Histoire des Poissons, together with C. Mertensii and C.marmoratus of the latter work, may possibly exist on the eastern as well as on the western entrance to Behring's Straits; but as they have not been actually detected on the American coast, they are not entitled to a place in the Fauna of that country.

[20.] 1. Cottus (Aspidophorus Europaus.) (Cuvier.) The Pogge.

Genus, Cottus. Sub-gemus, Aspidophorus. Cuv, Lacer.

L'Aspidophore d'Europe (Aspid. Europeus). Cuv, et Val., iv. p. 201.

The Aspidophori are considered, in the Regne Animal, as forming merely a sub-genus of Cottus, from which they are distinguished by the want of vomerine 
teeth, and by the body being cased in large keeled, angular scales, and acquiring thence the form of a slender, many-sided pyramid. 'The latter character gives the Aspidophori a totally different aspect from the Cotti. The only species that has been discovered in the European seas, is well known to naturalists as the Cottus catrupractus of Linnæus. It is very abundant on both sides of the English Chamnel, particularly on the Lincolnshire coast, and ranges northward to the Cattegat and Baltic, and westward to Iceland and Greenland. Its occurrence on the Davis' Straits' side of the latter country entitles it, according to the plan of our Fauna, to be mentioned here.

'This speeies varies in length from three to six inches. The anus is far forwards, and the body. between it and the hinder part of the anal and'second dorsal, is octagonal; the slender tail and the forepart of the body are hexagonal; the mouth opens transversely under the muzzle, and there are small barbels, or fleshy points, covering the whole surface of the branchiostegous membrane, the corners of the mouth, and border of the interoperculum; there are two at the extremity of the snout, and a minute one before each orbit.

Fins $-B r .6 ; D .5-7 ; A .7 ; C .11 ; P .15 ; V .1 / 2$. (Some specimens have only six rays in the second dorsal and anal.) Hist. des Poiss.

\section{[2l.] 2. Cottus (Aspidophorus) acipenserinus. (Cuvier.) Sturionic Aspidophore.}

L'Aspidophore esturgeon. Cuv. et VAL., iv., p. 207.

This species is common at the Island of Oonalaschka, and on the coast of Kamtschatka. It passes under the name of lisitza, or the "fox," among the Russians, and of koschadanguisch among the Aleutians. It is distinguished from the preceding by many characters, the most striking of which are the want of barbels on the branchiostegous membrane, and the numerous polygonal plates, marked with stelliform streaks, which cover the breast before the ventrals; while in the European species that part is covered by four plates only, arranged in a square form.

$$
\text { Fins._Br. } 6 ; D .9 /-8 ; A .8 ; C .11 ; \text { P. 17; V. 1/2. (Hist. des Poiss.) }
$$


[22.] 3. Cottus (Aspidophorus) monopterygius. (Cuvier.) Aspidophore with one Dorsal.

L'Aspidophore à une seule dorsale. Cuv. et VAL., iv., p. 224; vi., p. 554, t. 169.

The two preceding Aspidophori have the second dorsal commencing close to the end of the membrane of the first, and the mouth situated rather behind the tip of the snout; three other species, with approximated dorsals, are described in the Histoire des Poissons, but they have the under jaw longer than the upper one, and the snout meither projects beyond the mouth nor supports spines. Three species also are described with their dorsals some distance apart, and these have the jaws of equal length, and thick spines in the first dorsal.

The species we have now to notice is distinguished from all others by having only one dorsal placed in the middle of the body, over the anal, both these fins consisting of few rays, all flexible, the first ray alone not appearing articulated. It is the most slender of the genus, the height of the body, at the ventrals, not exceeding one-fifteenth of the total length. Before the dorsal the body is four-sided, or if the facets produced by the keels of the scales be taken into account, eight sides may be reckoned : the tail is six-sided. The snout projects beyond the mouth.

Fins.-Br. $6 ; D .1 / 4 ; A .1 / 4 ; V .1 / 2, C . \quad ; P .11$.

This Aspidophore was supposed, by Bloch, its first describer, to come from India, and it was named by Lacépède Aspidophoroide Tranquebar; but it has lately been discovered to be an inhabitant of the Greenland Seas, so that this sub-genus belongs entirely to the Northern hemisphere, and chiefly to the higher latitudes. (Hist. des Puiss.)

\section{[23.] 1. Hemitripterus Americanus. (Cuvier.) The Searaven.}

Fanily, Cottoidex. Gexus, Hemitripterus, Cuvier.

Acadian Bull-head. Penn., Arct. Zool, ii., p. 118. No. 101.

Yellow Scorpæna (Scorpana flava). Mitchill, Ph. Trans. New York, i. p. 382, t. 2. f. 8.

L'Hemitriptère de l'Amérique (Hemitripterus Americamus). Cuv. et VAL., iv. p. 268.

'The genus Hemitripterus is considered by Cuvier as exactly intermediate between the Cotti and Scarpana, the two distinct dorsals with the broad head giving it a resemblance to the former, while its many and various tentacula, or barbels, and its palatine teeth, bring it near the latter. The head is bristled, 
spinous, and garnished with many shreds of shin; and the first dorsal is so deeply notched, that three dorsals have been reckoned by some. Only one species is known. It attains the length of two fect, and inhabits the cod-banlis on the coast of New York, Nova Scotia, and the Gulf of St. Lawrence, where it is often taken by the hooks set for cod-fish. Its skin is soft and finely granular, with little conical tubercles scattered over the back and sides. The flanks have a bright carmine tint, at least in certain localities, as at the Magdalene Islands.

Fins.-Br. $6 ; D .15-12 ; A .14 ; C .12 ; P .18 ; V .1 / 3$. (Hist. des Poiss.)

[24.] 1. Hemlepidotus trachurus. The Hiekejak.

Family, Cottoider. Genus, Hemilepidotus, Curier.

"Cottus trachurus. Pall., Zoogr. Ross., t. 3, p. 138, pl. 25."

This is another genus intermediate between Cottus and Scorpana; but which has, on the whole, more affinity to the latter. In the form of the head, and in the distribution of its spines, there is a resemblance to the Cotti; but in the solitary dorsal, and the teeth on the palate bones, as well as on the vomer, it partakes of the characters of the Scorpana: it is distinguished at once from both genera by two broad longitudinal scaly stripes on each side alternating with stripes of smooth shin : the scales become visible as the skin dries. Captain Billings obtained one specimen among the Kourile Islands, and another on the American const, where the species was observed also by Steller, who says that the inhabitants of the Aleutian Islands name it liekejak. Pallas described Billings' specimen, and Cuvier states the description to agree exactly with his $H$. Tilesii, except that it gives two rays more to the soft dorsal, and that a division is mentioned between the first three spines of that fin and the eight succeeding ones. The rays of C. Tilesii are $B r .6 ; D .11 / 18 ; A .1 / 14 ; C .12 ; P .17 ; V .1 / 3$. Steller gives the following anatomical details of those he examined. The liver had three lobes and many biliary ducts, but no gall-bladder was detected. The stomach of an individual, a foot long, was no bigger than an acorn, and it contained a small Hounder, some crabs, and a madrepore. There were five pretty long cacu at the pylorus. (Hist. des Poiss.) 


\title{
[25.] 1. Scorpena (Sebastes) Norvegica. (Cuvier.) Northern Sebastes.
}

\author{
Family, Cottoideæ. Genus, Scorpæna, Linn. Sub-genus, Sebastes, Crv. \\ Sea Perch. . Penn., Br. Znol, iii., p. 349, pl. 59, f. 2. \\ La Sebaste septentrionale (Sebastes Norvegicus). Cuv, et Val., iv., p. 327.
}

'The Scorpana have a strong resemblance to the Cotti in possessing a large spiny heat, large pectorals, and, in part, the thick simple rays of these fins, but they differ in the compressed form of the head, the undivided dorsal, and in the presence of palatine teeth. They have seven branchiostegous rays. The clumsy head and soft spongy skin of the Scorpana give them a hideous aspect, and the spines with which they are armed are formidable to those who attempt to handle them. Setting aside the bony armour of the cheeks, the spines of the head, and the simple inferior rays of the pectorals, they have much aftinity with some of the percoideæ, particularly Grystes and Centropristis. None of the true Scorpænæ are mentioned by authors as existing within the limits which we have assigned to our Fauna, but the Scorpana porcus, which has an extensive range in Europe, throughout the Mediterranean, and from the British Chaunel to Teneriffe, occurs also at New York.

We have, however, to notice two northern species of Sebastes, a sub-genus, which possesses all the characters of Scorpcena, except that the head is scaly, is less studded with spines and crests, and wants the skinny shreds or appendages. The resemblance of the Sebastes to some of the Percoider with a solitary dorsal is such, that they have been considered as congeners by naturalists of the first rank. The Sebastes Norverica inhabits the Icy Sea and Northern Ocean. It is plentiful on the Norway coast, and is found at Iceland, Greenland, in the Gulf of St. Lawrence, and off Newfoundland. It inhabits the deepest bays of South Greenland, and does not approach the shore, except when driven thither by tempests. It feeds upon the pleuronectes cynoglossum, and readily takes a hook. Its flesh is dry but agreeable. The Greenlanders eat its lips raw, and were formerly accustomed to use its spines as sewing needles. It lhas a swimming bladder, which the Scorpænæ have not, and which does not exist in all the Sebastes.

Its colour, when quite fresh, is a bright carmine, which is paler towards the belly, and mixed with brown on the back; there is likewise a blackish mark on the tip of the gill-cover. In form this Sebastes resembles the perch, that is, its body is somewhat compressed, and its profile oblong, the dorsal and ventral curves being slightly convex; the mouth is oblique and the lower jaw projects a little. The posterior sub-orbitar bone sends a process obliquely back- 
wards towards the preoperculum, which it does not quite reach, so that we can scarcely saly that the cheek is mailed. The whole fish is clothed with small rough scales, eren to the extremity of the snout and on the labials, the only naked parts being the branchiostegons membrane and the posterior borders of the gill-opening, inctuding the base of the pectorals Belts of minute scales cover the basal halves of the vertical fins.

Fiss.-Br. $7 ; D .15 /-15 ; A .3 / 8 ; C .14 ;$ P. $19 ;$ V. 1/5. (Hist. des Poiss.)

The Mediterranean possesses a species of Sebastes which differs from the above in a few characters, and at the Cape of Good Hope there is one which very closely resembles the northern species, and another which is more like the Mediterranem one. There are two or more in the Indian and Polynesian seas, and several in the sea of Japan. The following one is from the sea of Kamtschatka.

[26.] 2. Scorpena (Sebastes) variabilis. (Cuvier.) The Tockoo.

La Sebaste variable (Sebastes variabilis). Cur. et VAL., iv., p. 347 .

This Sebastes has the head less armed than any other species; there are not even crests on the cranium, or over the orbits, and no teeth on the sub-orbitars: the preoperculum has five short, obtuse teeth, and the operculum two points. That it belongs, however, to this genus is evident from the narrow process which the posterior sub-orbitar sends towards the preoperculum, and which may be felt through the skin, and also from the nine simple rays of the pectorals. Fins D. $13 / 15 ; A .3 / 9 ; C .17 ; V .1 / 5 ; P .18$, of which nine are simple. It is taken plentifully among the Aleutian Islands, and is named kakootsheek ly the inliabitants, and tockoo on the American coast. Vancouver found a "sea-perch" at Port Discovery, in the Straits of Juan da Fuca, which may be this species; but the name is too vaguely applied by sailors to render even the genus anything nore than conjectural.

[27.] 1. Blepsias trilobus. (Cuvier.) Three-lobed Blepsias.

Fasir., Cuttoideæ. Gexus, Blepsias. Curier.

Le Blepsias trilobé (Blepsias trilobus). Cuv. et VAL., iv., p. 375, pl. 90.

The spiny preoperculum, compressed head, mailed cheek, palatine teeth, short, simple, and half-detached lower rays of the pectorals, and fleshy appendages 
of the snout, connect this genus with Scorpana, from which, however, it is distinguished by its five branchiostegous rays, and its high dorsal divided into three unequal lobes, as in Hemitripterus ; whilst the compressed head prevents it from entering the latter genus. The detailed description of the species in the Histoire des Poissons is founded on the examination of two individuals which were taken on the north-west coast of America by Merk. Steller observed the same species at the entrance of the sea of Ochotsk. The general aspect of the fish recalls that of some Blennies with which it was associated by Steller. The skin is destitute of scales, but is rough, with fine grains, which appear to be disposed in three longitudinal stripes, separated by very narrow intervals. The specimens were five inches long.

Fins.-Br. 5;D.7/24;A. 20;C.11;P.11;V.1/3. (Hist. des Poiss.)

Another species (B. bilobus, Cuv. et Val.) occurs in Awatska Bay, Kamtschatka. It lias been described and figured as the type of a new genus by Mr. Bennett, in the Natural History (Appendix) to Captain Beechey's Voyage, under the name of Peropus bilobus, on account of the form of its dorsal, indicated by its specific name, and its six branchiostegous rays; in other particulars Peropus coincides almost exactly with Blepsias. In P. bilobus there is a short spine over the nostril, and there are six fleshy appendages to the lower jaw, and two to the upper. The skin is hispid with short rigid bristles without any smooth stripes. Its Fins contain $\boldsymbol{B r} .6 ; D .7-21 ; A .19 ; C .13 ; P .14 ; V .1 / 3$. The following anatomical particulars are from Mr. Collie's notes. Air bladder wanting. Stomach a large membraneous sac. Caca several, ventricose. Intestinal canal short. Liver light clay colour. (App. Beech. Voy., p. 59, pl. 16, f. 3.)

[28.]

\section{Gasterosteus. Burnstickle.}

Gasterosteus aculeatus. Fabricius, Faun. Grænl., p. 169.

Kakilisak. Greenlanders.

'This genus wants the family aspect of the Cottoidex, for the sub-orbitars being smooth, and not distinguishable through the integuments, the cheek-mail is not apparent, neither is the head armed with tubercles or spines. The dorsal spines are detached, each having a separate menbrane, and the pelvic bones are united to the more than ordinarily large humerals, so as to form a kind of breast-plate. The ventrals, situated posterior to the pectorals, are almost entirely formed of their 
single spinous ray, and the gill-rays do not exceed three. The Burnstickles, or Sticklebacks, are the smallest of European fresh-water fishes, and probably also the nost abundant, as they exist in ilmost every rivulet and piece of water. 'They are active, lively little fish, and when any obstacle obstructs their way, will leap at foot out of the water, in endeavouring to surmount it. They are exceedingly voritcious, and commit great havoc in fish-ponds, where they devour vast numbers of young fish at the instant of their exclusion from the roe. The G. aculcatus (L.), or the 'Three-spined Stickleback, the largest species, abounds in every corner of Europe*, and even extends to Greenland, if the Kakitisak of Fabricius, above referred to, be actually this species, and not one of the very similar American ones. This author states, that it inhabits every pool and rivulet of Greenland, and even those into which the tide enters, feeding on worms and aquatic insects. In Europe two species were long confounded under the appellation of aculeatus, until Cuvier distinguished them by the names of G. trachurus and leiurus.

In both species the forepart of the back is covered by five bony plates, on the second, third, and fifth of which stand the three dorsal spines. The third spine is sometimes wanting, and at other times the fourth plate gires origin to an extra spine. The flanks are protected by in series of oblong plates having their axes vertical: in G. trachurus these plates are continued along the sides of the tail, there being in all twenty-five or twenty-six, exclusive of five small ones that cover the keel of the tail and render it more prominent; in G. leiurus the six anterior plates only are present, the posterior parts of the fish being smooth.

Fins.-Br. $3 ; D .1 /-1 /-1 /-10$ or $11 ; A .1 /-9 ; C .12 \frac{4}{4} ; P .10 ; V .1 / 1$.

Fabricius says that the Kakilisak seldom exceeds the little finger in length, that its forehead is marked with black in form of a spade, and its anal fin contains ten soft rays besides the spine: in other respects he refers to Artedi's description (Sp., p. 96), which is that of G. trachurus.

Five other European three-spined Burnstickles are described in the Histoire des. Poissons, and there is one in the sea of Kamtschatka, which, at the summer solstice, ascends the rivers of Awatska, Paradunca, \&c., in such dense shoals that it may be taken up with a pitcher in equal quantity with the water itself. It is named G. obolarius $t$, but the detailed descriptions of Steller, Pallas, and Tilesius do not indicate any characters so decided that Cuvier could pronounce it to be a distinct species. It derives its name from the smooth silvery spot which intervenes

* In certain places it ajpears occasionally in enormous shoals, so that it is taken for the purpose of manuring the land. A labourer, hired by a Lincolnshire farmer to collect it in the river Welland, at the rate of one halfpenny a bushel, earnel four shillings a day. (Bril. Zool.)

† "Obolarius aculeatus, STetr.er, Mss." "Gusteracanthus calaphraclus, PAl.l.. Fuun. Ross." Gasterosteus calcphraclus, Truesic's, Ném. de l'elersb., iii., p. 225. 
between the pectorals and gill-openings, having the form of a piece of Greek money. It has thirty-one vertebræ and the same number of lateral scales. The four dorsal spines are serrated. 'The Kamtschatdales collect it to serve as food for their dogs, and they also prepare excellent white soup with it for themselves.

G. Noveboracensis is, as the name indicates, a New York species.

It has a very strong resemblance to the $G$. trachurus, its most obvious peculiarities being the narrow dorsal.plates, the more prominent keels of the tail, and the position of the lateral line, which is nearer to the back.

Fins.-D. $1 / 1 /-1 / 11 ; A .1 / 8 ; C .12 ;$ P. $10 ; V .1 / 1$. (Hist. des Poiss.)

[29.] 2. Gasterosteus niger. (C'uvier.) Black Burnstickle.

L'Epinoche noire (Gasterosteus niger). Cuv. et VAL., iv., p. 503.

This species, which has also an armed tail, inhabits Newfoundland. It has at more elongated form, and more slender spines than its European representative. Its lateral scales amount to thirty-three, and its colour throughout is blackish. (Hist. des Poiss.)

\title{
[30.] 3. Gasterosteus biaculeatus. (Pennant.) Two-spined Burnstickle.
}

\author{
Gasterosteus biaculeatus. Forster, Cat. Mitcmul, Phil. Tr., New York, i., p. 430, pl, 1, f. 10. \\ Two-spined Stickleback. PenN., Arct. Zool., ii., p. 132, No. 147. \\ L'Epinoche à deux épines. Cuv. et Val., iv., p. 503.
}

This Stickleback is said, by Dr. Mitchill, to inhabit the salt waters of New York, and to consort with the Killifish, or Cyprinodons. M. Pilaye sent it from Newfoundland to Cuvier. It is one of the smallest of the genus, Dr. Mitchill assigning it a length of scarcely an inch, and the Newfoundland specimen measuring only seventeen lines.

It is distinguished from the other species by a sharp flat tooth on the external base of each rentral spine, the European species having simply an enlargement there. Notwithstanding its name, it has three dorsal spines, the third being small and joined to the soft dorsal.

Fins. -D. 1/1/ - 1/12;A.1/8;C. 12;P.9;V.1/1. (Hist. des Poiss.) 
Pennant mentions the Three-spined Stickleback as very plentiful at Hudson's Bay (Arct. Zool., ii., p. 132, and Intr., p. cxci), but it did not come under my notice, and as the species in that naturalist's time were but imperfectly discriminated, its reference to G. aculeatus must be doubtful. Hutchins speaks of Sticklebacks three inches in length, which constitute food for the pike and turbot.

\section{[31.] 4. Gasterosteus concinnus. (Richardson.) Tiny Burnstickle.}

\section{Uswæ-atheek-àsheesh. Crer Indians.}

This diminutive species, perhaps the smallest of fresh-water fishes, is found at the commencement of summer in ponds and rivers, and is supposed to be washed out of the lakes by the floods of melted snow which occur at that period. It ranges fiom the Saskatchewan in lat. $53^{\circ}$, to the Great Bear Lake in the 65th parallel, and probably through a still greater extent of country. In 1820, many sledgeloads were taken from a small pond in the vicinity of Cumberland-house for the purpose of feeding the dogs. Although it has a strong general resemblance to G. pungitius, or rather lavis of Europe, it exhibits differences which justify us in considering it as a distinct species. It has a still smaller size than G. lavis, a more slender and elegant form, stronger and higher spines, and lower second dorsal and anal fins, the portion of the tail behind these fins being thinner as well as longer.

\section{DESCRIPTION}

Of specimens taken at Great Bear Lake, lat. 641 N., and comparison with an English specimen of $G$. lavis, belonging to Mr. Yarrell.

Form.-Similar to that of G. lavis, but the head smaller, being only a fourth part of the total length, and the body, and especially the tail, more slender. The mouth is also smaller, and the teeth, although perceptible to the touch on both jaws, are much less conspicuous than those of lavis. There are no scales whatever on the body. The lateral line is a straight furrow until it passes the anal fin, when it rises into a very slender ridge that keels the tail. The anus is equidistant from the snout and end of the tail : in G. lavis it is a little farther back. The abdomen is protected by a bony cuirass, formed posteriorly by the bones of the pelvis, and anteriorly by two narrow cubital bones which join in an acute angle behind the median insertion of the gill-membranes. In concinnus the posterior angular point of the pelvic bones is narrower but stronger, and the space enclosed by the cubital bones is triangular: in lavis this space is triangular only towards the apex, the two bones being parallel postcriorly. The smootb space between the insertion of the pectoral and the gill-opening is smaller in concinnus, its nine dorsal spines are both stouter and longer, and the triangular. 
membrane which is attached to each of them posteriorly, is thicker and larger than in lavis. In both species the seventh and eighth spines are smaller than the preceding ones, and the ninth, which is contiguous to the second dorsal, is rather longer than any of the others: in concinnus it is only one-third lower than the second dorsal; while in lavis it is two-thirds lower. The second dorsal and anal begin and terminate opposite to each other, and have similar triangular slapes: the posterior angle of these fins in lacvis is more prolonged or acute; while in concinnus the fins have an equilateral outline, in consequence of their attachments being shorter, and the naked tail longer. In concinnus the soft dorsal has nine rays-in lavis it has eleven. Contiguous to the anal fin of the former there is a separate spine, furnished with its proper membrane, like the dorsal spines, the largest of which it equals in size: in lavis this spine is comparatively small. The ventrals are each represented by a spine articulated to the pelvic bones, and a small triangular membrane in which there is imbedded a very indistinct soft ray: the ventral spines do not reach quite to the point of the abdominal cuirass in either species. All the spines, both dorsal and ventral, are moveable, and none of them are serrated. The caudal fin is even at the end and has an elongated wedge shape.

CoLour nearly as in G. lavis, olive green, with a silvery belly, and the whole body and soft parts of the head speckled with black dots.

$$
\text { Fins.-Br. } 3 ; D .1 /-1 /-1 /-1 /-1 /-1 /-1 /-1 /-1 / 9 ; A .1 /-9 ; P .10 ; C .12 \frac{2}{2} ; V .1 / 1 \text {. }
$$

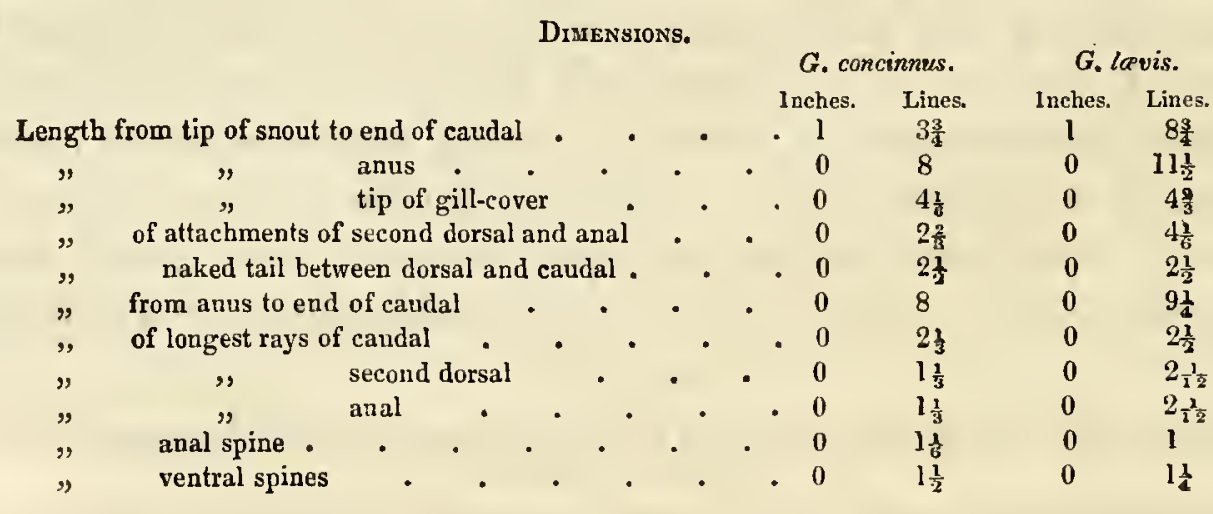

\section{[32.] 5. Gasterosteus occidentalis. (Cuvier.) Newfoundland Burnstickle.}

L'Epinochette de Terre Neuve (G. oceidentalis). Cuv, et VaL., iv., p. 509.

This species, which was discovered in Newfoundland by M. Pilaye, is very like the nine-spined Stickleback of Europe with an armed tail : its form is merely more lengthened. Fins.-D. $8 / 9 ; A .1 / 9 ;$ C. $12 ;$ P. $11 ; V .1 / 11$. (Hist. des Poiss.) 


\title{
1. Temistia ventricosa. North-west Notehfin.
}

\author{
Faurx, Cottoider. Genus novum, Temnistia * prope II emilepidotum. \\ Blepsias ventricusus. Escisciroltz, Zwol. Allas, drittes heft, p. 4, t. 13. \\ B. curpore fusco; faciis quatuor flexuosis maculaquc posticá rubris; abdomine inflato albo \\ fuscoque marmorato; pinnis pectoralibus faciis tribus hepatinis pallidisque alternan- \\ tibus. Escil. I. c.
}

'This fish frequents the north-west coast of America, having been taken in Norfolk Sound, and off the island of Sitcha, by the Russian Expedition under Captain Kotzebue. Eschscholtz states it to possess all the characters of Blepsias, but though it does in part correspond with the short notice of that genus in the Règne Animal*, it differs both in habit and in structure from the only two species of Blepsias hitherto diseovered. It belongs to that group of Cottoideæ which is characterised by the compressed form of the head, and has much resemblance in external form to Hemilepidotus and Scorpæna, between which it will probably stand in a natural arrangement. It is separated from the former by its body being wholly scaly, and the presence of barbels on the head; and from the latter, by having only five gill-rays and a three-lobed dorsal. The want of scales on the bead distinguishes it from Sebastes, and its habit, which is very unlike that of it blenny, its long pectorals and scaly body, detach it from Blepsias. The other Cottoid genera, with compressed heads, are still more dissimilar in external characters to this fish: Pterois has seven gill-rays, and is remarkable for the extreme length of the rays of its dorsal and pectorals; Apistes and Minous are armed with a large, moveable, sub-orbitar spine; Agriopus has a scaleless body and unarmer, imperfectly cuirassed cheeks; and Hoplostethus has its deep body protected inferiorly by lieeled scales, and six soft rays in its ventrals. We have, therefore, ventured on giving Eschscholtz's fish a proper generic name; but as the Zoologischer Atlas contains no account of its dentition, nor any anatomical details, we shall not attempt any further enumeration of the characters of the genus, than what may be gathered from the following description of the species, which is compiled partly from the text of the work just cited, and partly from an inspection of the plate.

* Th. rspew, scindo, et igisv, velum.

† Les Blepsias ont la lểe comprimée, la jouc cuirassée, des barbillons charnus sous la mâchoire inféricure, cinq rayons au.s ouies, de très petites ventrales, et une dorsale très haute, divisée cn trois pardcs echancrures. Règ. An. 


\section{DESCRIPTION.}

Form.-The head is much compressed, the eyes large, lateral, and closely approximated, as in Hemilepidotus. The intermaxillaries appear to be capable of some protrusion, and to be connected with the snout by a whitish membrane; immediately behind which, on the upper surface of the snout, there is a pair of brown, short, cylindrical processes, and before the eyes two pairs of white ones, all of them said to be tubular. There are three pairs of short, slender, acute barbels on the lower jaw; a thick one with a fringed end on the lower extremity of the labial, and one like it, though smaller, on the lower part of the cheek. The plate also represents six prominent, obtuse, though small teeth (or, perhaps, barbels) on the margin of the sub-orbitar bone; three large acute teeth, or spines, and two intervening small ones, on the preoperculum; a notch on the margin of the suboperculum; and an acute angular tip to the gill-cover. The head is entirely naked; but the body is covered with large tiled scales, which are described as being roundish, finely toothed, and biggest on the sides, where there are fifty-eight in a longitudinal row. The form of the body is that of a Hemilepidotus, or Scorpæna, exclusive of the greatly-inflated stomach or belly, which is pendulous and henispherical. The dorsal fin commences a very short way behind the nape, and extends nearly to the caudal : it is supported by thirty-one rays, all spinous, and is notched anterior to the twelfth ray, by the gradual decrease of the six preceding ones. There is another, but less decided notch at the third ray, the membrane of which reaches only to the iniddle of the following ray. The rays of the anal, pectorals, and ventrals, are also represented as spinous, or at least simple, the caudal ones alone being forked at the tips. The ventrals are long and slender, and are supported by five rays, the first of which is short and closely applied to the next. The caudal is slightly rounded at the end.

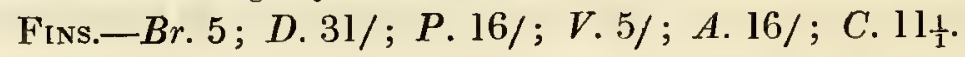

CoLour.-The head is mostly brown, the body is also brown, with scattered darker spots, and four transverse, broad, waved red bands, the first of them crossing just before the dorsal: there is also an imperfect band, or large patch, of the same colour, between the dorsal and upper base of the caudal. The belly is white, studded laterally with brown spots, which towards its middle diminish to specks. The dorsal, anal, and caudal are reddish, the two former being marbled with brown. The pectorals are marked transversely with three dark reddish-brown bars, and as many alternate pale ones. 


\section{SCIANOIDEA:}

THE members of this family have almost all the external characteristics of the Percoideæ : the spiny or denticulated operculum : the toothed or armed preoperculum: the double, deeply-notched, or single dorsal: the scaly body; and even the divisions of the family which spring from the various combinations of these characters are but repetitions of those into which the Percoider are distributed. The distinctive character of the Scianoidea is the total absence of vomerine and palatine teeth. Moreover, the cavernous structure of the cranium, and arched form of the head, and especially of the nose, give a peculiar physiognomy to the fish of this family, which is rarely observed in the Percoider: the scales, also, are less rough, and extend more generally over the head and vertical fins: but these latter characters are not so essential as the perfectly toothless palate, and are, indeed, mostly present in the percoid genus Polynemus. The Scirenoideæ have much resemblance to the Percoideæ in their internal structure, also, though their air-bladders exhibit a greater variety of forms, being in many species complicated with hornlike processes, or branched or fringed appendages, which Cuvier thinks have some connexion with the grunting noises that the Sciænoidere emit in a more remarkable degree than even the gurnards. The Sciænoidee are numerous, have similar habits to the Percoideæ, and are equally useful to man, almost all of them furnishing a wholesome food, and many being remarkable for their exquisite flavour.

Cuvier divides the Sciænoideæ into two series, the first of which is characterised by a double or divided dorsal. The Maigre (Sciana), Corvina, and Umbrina. three Mediterranean fish, are types of the principal genera of this series : severil smaller genera are associated with them; and all have the cranium heightened by salient portions, the lower jaw pitted with conspicuous pores, the soft dorsal proportionably long, the anal, on the contrary, very short, the preoperculum denticulated, at least in the younger individuals *, the bony operculum terminated by two flat points and seven branchiostegous rays; in short, they have a close resemblance to the perches, except that their palates are quite snonth. Moreover, their dorsal

\footnotetext{
* This must be understood with some latitude, for $\boldsymbol{N e b}$ ris and Eleginus, of this series, have the preoperculum smustl. wr, as Cuvier says of that of the latter, "très entier." In the second series, Glyphisodon, Etroplus, and Heliases. also want Jenticulations on the preoperculum.
} 
spines are robust, the scales strong as in the perches and spari, and the whole head is scaly. Many of them have their pharyngeal teeth "en forme de pavé," like the labri; but they differ from the labri in wanting the double lips, and in having cæcal appendages to the pylorus. Their air-bladder is very large, and is furnished, in many of the species, with appendages of very curious forms. The presence or absence of canine teeth, the form of the snout, and the existence or want of barbels on the lower jaw, serve to characterise the minor divisions of the first series. The second series is composed of genera which have a single continuous or very slightly-notched dorsal. They differ more from each other than those of the first series, and it is among them chiefly that combinations of characters analogous to those of the Percoideæ occur. Three genera, having seven gill-rays, constitute one subdivision, and are distinguished from each other by the number of pores on the lower jaw, or the presence or absence of scales on the vertical fins. Another subdivision, comprising the Sciænoideæ with fewer than seven rays in the gill-membrane, is broken into smaller groups, which are characterised by the form of the lateral line, according as it is continuous or interrupted, or by the presence or absence of simple rays in the pectorals, and by the preoperculum being smooth or toothed.

The Cottoideæ, notwithstanding the peculiarity of their mailed cheeks, form the connecting link between the Percoideæ and Sciænoideæ. Thus the cottoid Sebastes are so like the percoid Serrani in form, as to be often mistaken for them, and the Scorpænæ and Sebastes have palatine teeth like the Percoideæ; while other Cottoideæ, the Synanceiæ for example, have the smooth palates of the Sciænoideæ.

When we speak of the families in reference to the distribution of the majority of their forms and species, the Percoider may be considered as belonging principally to the South Sea and Indian Ocean, the Cottoideæ, as affecting the higher northern latitudes, and the Sciænoideæ as being more peculiarly an American family, for more than one-third of the genera are proper to the Atlantic shores of that continent, and there are only eight of the thirty* which compose the family that have not one or more species there. The genera peculiar to America are, Ancylodon, Nebris, Lepipterus, Boridia, Conodon, and Eques, inhabiting the intertropical districts, and Leiostomus, Pogonias, Micropogon, and Hamulon, common to them and the seas of the United States: all these have two.dorsals and

\footnotetext{
* Cuvier includes thirty-one genera in the family, but the origin of Lonchurus, which consists of one, or perhaps two, species, is unknown. Eleginus, a genus of the Indian and South seas, and one of the eigbt which have no representative on the Atlantic side of America, has a species on the coast of Chili.
} 
seven branchiostegous rays. Scolopsides, Amphiprion, Premnas, Dascyllus, and Etroplus, which are peculiar to the Red Sea, Indian Ocean, and Polynesia, have one continuous dorsal, and fewer than seven gill-rays. Diagramma and Pomecentrus, which have also seventeen or eighteen species each in these seas, have also a single dorsal, but the former has seven gill-rays. Maquaria, containing is solitary species which inhabits the Macquarie, a river of New Holland, belongs to the same subdivision with the genera peculiar to the Polynesian seas. We have enumerated eighteen genera, twelve only remain, and of these Sciana, Otolithus, Corvina, Umbrina, and Pristipoma, typical forms of the Sciænoideæ that have seven gill-rays, and all but the last, having a double dorsal, are the most widely diffused, as the subjoined table shows. Glyphisodon and Heliases, which have the widest distribution among the genera with fewer than seven gill-rays, have smooth preopercula, and are aberrant forms leading to the Sparoideæ, or in some points of view to the Labroideæ.

\begin{tabular}{|c|c|c|c|c|c|c|c|c|c|c|c|c|}
\hline \multicolumn{2}{|r|}{ GENERA. } & 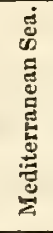 & 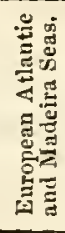 & 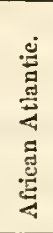 & 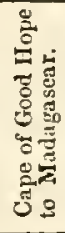 & 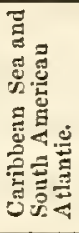 & 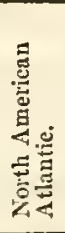 & 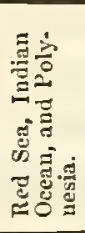 & 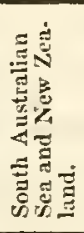 & 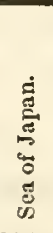 & 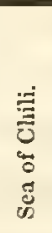 & $\begin{array}{c}\text { Totals } \\
\text { of } \\
\text { Species }\end{array}$ \\
\hline \multirow{16}{*}{ I. } & Sciæna . . . & 1 & 1 & - & 1 & _ & - & 1 & _- & _- & - & 3 \\
\hline & Otolithus . . . & - & - & 1 & i & 8 & 2 & 5 & - & - & - & 15 \\
\hline & Ancylodon ... & - & - & - & - & 2 & - & - & - & - & - & 2 \\
\hline & Corvina $\ldots$ & 1 & - & 4 & - & 4 & 4 & 19 & - & 1 & - & 31 \\
\hline & Leiostomns . . . & - & - & - & - & 1 & 2 & - & - & - & - & 2 \\
\hline & Larimus . . . & - & - & 1 & - & 1 & - & - & - & - & - & 2 \\
\hline & Nebris ..... & - & - & - & - & $i$ & - & - & - & - & - & i \\
\hline & Lepipterus. . . & - & - & - & - & i & - & - & - & - & - & i \\
\hline & Bonidia..... & - & - & - & - & 1 & - & - & - & - & - & 1 \\
\hline & Conodun .... & - & - & - & - & i & - & - & - & - & - & i \\
\hline & Eleginus .... & - & - & - & - & - & - & 1 & I & - & 1 & 3 \\
\hline & Eques ..... & - & - & - & - & 3 & - & - & - & - & - & 3 \\
\hline & Umbrina . . . & 1 & 1 & - & - & 4 & 1 & 4 & - & - & - & 10 \\
\hline & Pogonias . . . & - & - & - & - & 2 & 2 & - & - & - & - & 2 \\
\hline & Microjogon . . . & - & - & - & - & 3 & 2 & - & - & - & - & 3 \\
\hline & Hæmulon .... & - & - & - & - & 11 & 2 & - & - & - & - & 13 \\
\hline \multirow{7}{*}{ II. } & Pristipoma . . & - & - & 7 & 1 & 11 & 1 & 13 & - & 1 & 1 & 35 \\
\hline & Diagramma . . & - & - & - & - & 1 & - & 18 & - & 1 & - & 20 \\
\hline & Lobotes...... & - & - & - & - & 2 & 1 & 2 & - & - & - & 4 \\
\hline & Scolopsides . . . & - & - & - & - & - & - & 19 & - & - & - & 19 \\
\hline & Cheilodactylus. . & - & - & - & 2 & 1 & - & - & 1 & 1 & 3 & 7 \\
\hline & Latilus . . . . & - & - & - & - & i & - & 2 & - & - & $i$ & 4 \\
\hline & Maquaria... & - & - & - & - & - & - & - & 1 & - & - & 1 \\
\hline \multirow{8}{*}{ III. } & Ampihiprion . . . & - & - & - & - & - & - & 13 & - & - & - & 13 \\
\hline & Premnas . . . & - & - & - & - & - & - & 3 & - & - & - & 3 \\
\hline & Pomacentrus . . & - & - & - & - & 2 & - & 17 & - & - & - & 19 \\
\hline & Dascỵllus. . . . & - & - & - & - & $\overline{-}$ & - & 3 & - & - & - & 3 \\
\hline & Glyphisodon .. & - & 1 & 1 & - & 3 & - & 26 & - & - & - & 30 \\
\hline & Etroplus .... & - & - & - & - & - & - & 3 & - & - & - & 3 \\
\hline & Hleliases . . . & - & 1 & - & - & 1 & - & 5 & - & - & 1 & 8 \\
\hline & Totals. & 3 & 4 & 14 & 5 & 65 & 17 & 154 & 3 & 4 & 7 & 262 \\
\hline
\end{tabular}


Few forms, or even species, exist in the European seas. Sciana and Umbrincs have each a species common to the Mediterranean and Atlantic coasts of Europe, Corvina, one peculiar to the Mediterranean, and Glyphisodon and Heliases, one each in the sea of Madeira, making but five European species in all. None of the Sciænoideæ appear to have a wide range; none cross the Atlantic, and none are common to that sea and either the Indian or Pacific oceans.

\title{
[34.] 1. Sciena (Convina) Richardsonit. (Cuvier.) The Malasheganè.
}

\author{
Fanil., Sciænoideæ. Genus, Sciæna. Sub-genus, Corvina. Cuvien. \\ Le Corb de Richardson. Cuv. et Val., v., p. 100. \\ Malasheganeh. Cree Indans.
}

\section{Plate lxxvir.}

Corvina belongs to the first series of the Scianoidea, or those which have a double dorsal fin and seven branchiostegous rays. We have here followed the Règne Animal in considering this series as constituting one large genus, named Scicna, and divided into sub-generic groups, which are raised to the rank of genera in the Histoire des Poissons. The characters of the series, or of the extended genus Sciana, are given at some length in a preceding page (61). Corvina differs from the sub-genera Sciana and Otolithus, in the robust form of its anal spine, and from the latter by a second character, viz., the want of canine teeth: the albsence of barbels on the lower jaw distinguishes it from Umbrina and Pogonias. 'The teeth of Corvina also, when closely examined, present a peculiarity of distribution; they form stripes "en velours" on both jaws, but the outer rows, though even and pointed, are stronger than the others. Boridia and Conodon have the form and other exterior characters of Corvina, but differ in the teeth, the latter having a row of conical teeth exterior to the stripe " en velours," and Boridia, the jaws armed with several rows of short, thick, blunt teeth, which ally it to the Sparoidea, and render it a connecting link between that family and the Scianoidea. The form of the air-bladder varies considerably in different species of Corvina, being quite simple in some, while in others it sends out horn-like processes which are pointed, branched, or even fringed. The remarkable drum-like noise which the Maigres, or true Sciænæ have the power of producing, at a considerable depth in the water, has not been ascribed to the Corvinæ. In some Corvinæ the preoperculum has merely a slightly undulated edge, in others it is denticulated or even 
decidedly spiny. By far the greater number of the species are inhabitants of the sea exclusively, some have been observed to enter the rivers of India and Africa, but not to ascend beyond the tidal waters; the two species which occur in our Fauna are inhabitants of fresh water only, being found in the Canadian lakes above the falls of Niagara.

'The Malasheganè inhabits Lake Huron. It is taken in the Georgian Bay, on the north side of that lake, during the summer months, in gill-nets set in deep water, or by hooks baited with worms. It feeds much on cray-fish. It is a firm, white, well-tasted fish, but never fat, and requires much boiling. It is called "Sheep's-head" by the Anglo-Canadians, probably for the reason that the same appellation is bestowed on the Sargus ovis in the United States, viz., from its having an arched nose, and " some smutty shades of colour on the face*." I had no opportunity of examining the intestines of the Malasheganè, though $I$ can bear testimony to its excellence as an article of food, in which respect it may be compared to the turbot of Europe. My specimen was prepared by Mr. 'Todd.

\section{DESCRIPTION}

Of a specimen taken at Penetanguishene, on Lake Huron.

Form.-Profile, exclusive of the short and rather deep strap-shaped tail, irregularly oval: the curre, from the snout to the dorsal fin, is quadrantal and abrupt, the head and shoulders being very prominent. The greatest depth is at the attachment of the ventrals, where it exceeds a third of the total length including the caudal. The head is rather small, and higher than long; the forehead flattish, the snout short, the lower jaw projecting a little, the mouth cleft nearly as far back as the centre of the orbit, and the lips somewhat flabby and sparingly protrusive, but folding back when closed. Eyes lateral, situated more than two cliameters of the orbit from the extrenity of the snout and one abore the mouth: the irides are silvery. The nostrils are near the eyes, and the anterior opening is the smallest. There are four pores beneath the end of the lower jaw, apparently leading to cells in the bone, but none are perceptible on the muzzle, at least in the dried specimen.

Teetr.-The opposing surfaces of both jaws are corered with small, slender, erect, crowded teeth, the exterior row, and a small cluster on the tip of each jaw, being of a larger size, thougls similar in form: "the outer ones have their points rounded, but from their slenderness they appear acute: there are also two patches of teeth on the upper pharyngeal bones, and two on the lower." Mr. Todd,-_(who does not describe their form, though it is probable that they are "en gros pavés ronds," as in the nearly allied C. oscula.) Tongue pointed and smooth.

GILL-COvers. - The posterior edge of the gill-corer is irregularly curved, the tip of the suboperculum forming a small projecting angle on a line with the upper ray of the pectoral fin. 
and there is a rounded lobe about midway between this and the upper angle of the operculun. The preoperculum is broad below, but its upper limb, rising at a right angle, becomes gradually narrower. Its whole free edge, that of the interoperculum, and of the suboperculum anteriorly, are finely denticulated, and the teeth, being the tips of very short marginal ridges, are very conspicuous in the dried specimen. The anterior border of the operculum, to the width of half an inch, is scaleless and marked with fine vertical streaks : the under margin of the bone is concealed by scales, and there is a deep rounded notch on its posterior margin which is also covered by membrane and scales, but a rounded lobe above the notch, and another below, are more evident from their edges being finely ridged and somewhat denticllated : the tip of the suboperculum is closely applied to the lower lobe and passes it a little. The bones lining the posterior edge of the gill-opening are scaleless and have smnoth edges: the humeral bone is remarkably large and cavernous, the cavities occupied by a net-work of fibres. There are seven branchiostegous rays, all somewhat flattened; the first ray is one inch and a half long, the last one measures above four inches.

Scales.-The whole head except the lips, intermaxillaries, labials, branchiostegous membrane, and anterior border of the operculum, is scaly, the scales varying much in size, small and large being crowded together. The scales of the body are also unequal in size, though mostly very large and strong, particularly on the sides, where their general form is that of a square or rectangle, with the exterior side a little convex, and the two outer conners rounded off : many are somewhat oblique, the lower side being the longest. The smallest scales, excepting those on the fins, are on the humeral bone, and next those on the top of the head and before the dorsal. There are fifty-three or fifty-four scales on the lateral line, exclusive of fourteen or fifteen very small ones on the base of the caudal; and about twenty-eight in a vertical row behind the pectorals, eight of which are above the lateral line. A scale taken from under the posterior third of the first dorsal and beneath the lateral line, is seven lines long by eight and a half wide, and is marked with about ten furrows, which converge towards the centre, but do not meet: the corresponding crenatures are not prominent, the basal edge being nearly a straight line : the middle third of the exterior slightly convex edge is crowded with fine ridges, visible under the lens, and apparently jointed, but the whole edge appears smooth to the naked eye and to the touch. A linear inch measured lengthwise on the sides, includes from three to six scales, according to the place that is chosen. The lateral line follows the curve of the back at the distance of one-third of the height of the body, until it comes opposite to the middle of the anal, whence it runs in a straight line through the centre of the tail, and is continued between the middle rays of the caudal for more than half the length of that fin. It is formed by a small tubular ridge,which divides, in a radiated manner, on the outer border of the scale, into several irregular winding branchlets. The anus is at the commencement of the posterior third of the fish excluding the caudal.

Fins.-Br. $7 ; P .15 ; V .1 / 5 ; D .9 /-1 / 18 ; A .1 / 7 ; C .17 \frac{4}{3}$.

'The pectorals taper to a point and are considerably longer than the ventrals, or than the rays of any of the other fins. The ventrals are attached a little farther back than the peetorals, their upper ray being opposite to the under one of the latter, or nearly under the fourth 
dorsal spine. The ventral rays are robust: the first is bony, and is about two-thirds of the height of the second, which is the longest, and, like the remainder, repeatedly divided towards the tip. The first dorsal conmences about a spinc's breadth posterior to the tip of the gillcover, and nearly as much anterior to the pectorals: its rays are very stout, compressed, acute spines; they gradually diminish in height from the fourth ol longest to the ninth, which is about one-third as high, but almost equally robust: the fifth equals the second, and the first is very short, obtuse, involved in membrane, and closely applied to the base of the second. The membrane is scolloped between the rays, and is attached to the first ray of the second dorsal for about one-third of its height, the two fins not being distinct but merely separated by a notch. The second dorsal is higher than the first: it contains nineteen rays, the first of which is spinous, and is rather more than half the height of the succeeding soft rays, but equals the serenth spine of the first dorsal; the soft rays are forked at the tips. A low process of membrane is prolonged for about two inclies beyond the last ray of the sccond dorsal, in which there are imbedded eleven obtuse cartilages, or rudimentary rays, which increase in lengtlı as they are more posterior, from one line to three and a half: they have twelve interspinous bones*. The base of the dorsal fins is covered with small scales which gridually encroach on the rays as they are more posterior: the two or three first rays of the first dorsal are visible their whole length; but the ninth, and all the rays of the second dorsal, are more than one-third imbedded in the seales; the prolonged membrane of the latter is scaleless. The anal is supported by a very robust, tapering, bony ray, deeply grcored behind: there is no short spine anterior to it: the first soft ray is about one-third longer, the remainder decrease gradually in length, the last one being shorter than the bony ray. All the soft rays are repeatedly divided at their summits. The caudal terminates evenly, its corners being slightly rounded off: its rays begin to divide below the middle into five or six branches.

Colour.-Top of the head and the back greenish-grey, with darker bands descending * short way from the latter: sides ash-grey with silvery tips to the scales : belly cream-yellow.

Disensions.

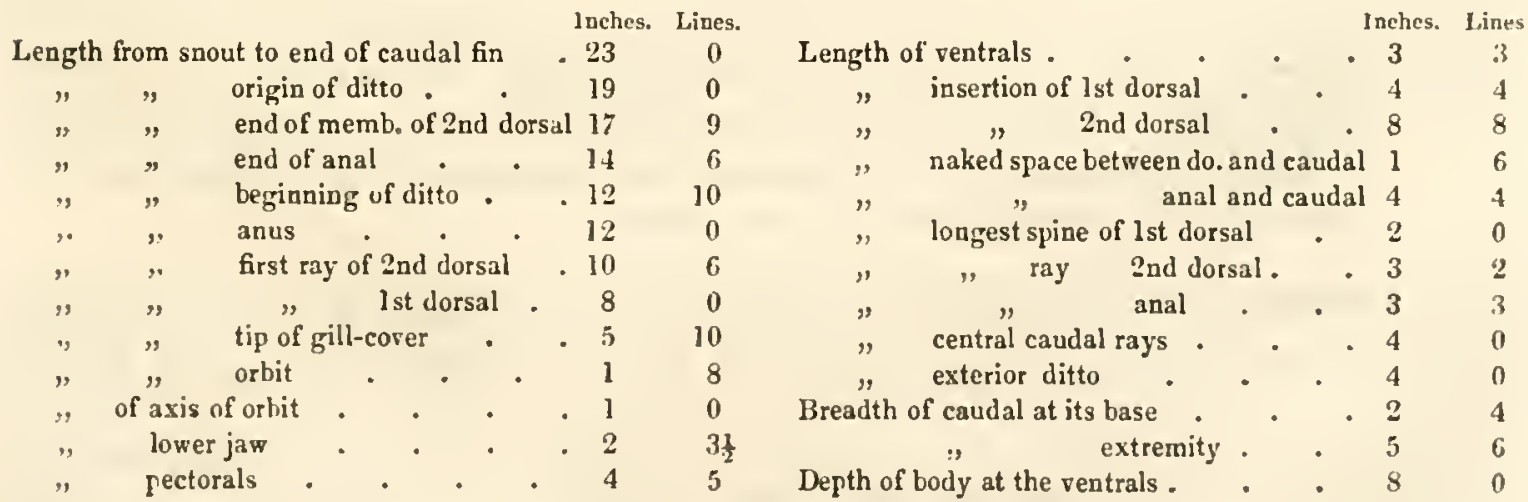

* I detected the rudinentary rays by softening the membrane and dissecting it after the specimen was returned to me by Baron Cuvier. 
[35.] 2. Sciena (Corvina) oscula. (Le Sueur.) Le Sueur's Corvina.

Sciæna oscula, Le Sueur. Jour. Ac. Sc. Phil., ii., p. 252. An.1822. Pl.

Le Corb dẹ Le Sueur (Corvina oscula). Cuv, et Val., v., p. 98.

This fish inhabits Lake Erie*, where the specimens taken by M. Le Sueur had their stomachs filled with fragments of river shells of the genera Cyclas, Paludina, \&c. This fresh-water species resembles the Corvina nigra of the Mediterranean in its form, though its nape swells out still more.

Its usual size is about seventeen inches in length, by nearly five in height. There are five pores on the lower jaw, and its pharyngeal teeth are large, round, and flat (en gros pavés ronds), serving to bruise the shell-fish on which it feeds. The stomach is a large, round, blind sac, and there are seven thick caca at the pylorus. The intestine is almost as wide as the stomach, but its coats are very thin. The air-bladder is very large, without appendages, and is covered with nacre. M. Le Sueur describes the colours of some specimens which he found on the beach, where they had been left by the fishermen, as "bluish-grey on the head and caudal-fin, drawing upon black on the snout and above the eyes, more grey towards the back and above the pectorals: all the other fins are of a lighter grey: there were some red tints on the cheeks, and a yellowish reflection on the sides of the back, tail, and opercula; the abdomen beneath the throat was white." (Le Sueur, $l: c$.)

[36.] 1. Scima (Otolithus) Regalis. (Cuvier.) The Squeteague.

Faylly, Sciænoideæ. Genus, Sciæna. Sub-genus, Otolithus. Cuv. Règ. An.

Scuteeg, or Weak-fish. 'Sснов̈рғ, Berschr. einiger Nord, \&c., viii., p. $169 . \quad$ An. 1778.

Johnius regalis, ScuneIden, Syst. Ichlh. Blochii, p. 75. An. 1801.

Labrus̀ squeteague (Weak-fish), MıтснцL,, New York Tr., i., p.396, pl. 2, f. 6. An. 1815.

L'Otolithe royal (Otolithus regalis). Cuv. et VAl., v., p. 67. An. 1830.

Squeteague. Narraganset Indians. Checouts. Mohegans.

'The Otolithi are distinguished from all $\uparrow$ the other Sciænoideæ by the presence of a tooth on each intermaxillary bone much longer and stronger than the others,

* Cuvier says Lake Ontario, but M. Le Sueur, in the paper above cited, says Lake Erie, which is material, as it cannot ascend thither from the sea, though it may into Lake Ontario.

+ Ancylodon jaculidens is considered, by Cuvier, as being really an Otolithus with a pointed tail, but differing from the others in the shortness of its snout, and the extreme length of some of its teetb. $A_{r}$ parvipinnis resembles the Otolithi also, but differs from them, and also from A.jaculidens, not only in the dorsals being very small, but also in their being perfectly separated from each other. 
and therefore termed a canine. They resemble the maigres in their structure, and especially in the smallness of the anal spine; and have, like that sub-genus, the exterior characters of the Scimnx in general, the bulging head, the cavernous cranial bones, and the long second dorsal. The pores on the lower jaw either do not exist, or they are so small as to be imperceptible. The air-bladders of those which have been examined possess two pointed horn-like arms, originating laterally and running forwards. The Otolithi inhabit the Indian Ocean and Atlantic const: of America, one species existing however in the sea of Goree, and another at the Cape of Good Hope. The Indian ones have canines on both jaws, the American species have only the upper canines, and it often happens that one of these is broken. or, from some cause, does not grow. The two African species have smaller-sized canines, and in one, $O$. aquidens, they are so little remarkable that the genus might readily be mistaken.

Dr. Mitchill informs us that the Squeteague " is a fish of a goorly appearance, wholesome and well-tasted, though rather soft. He is taken both by the line and seine, and is brought to the New York market in great numbers during the summer months. He is called weak-fish, as some say, because he does not pull very harel after he is hooked; or, as others allege, because labouring men, who are fed upon him, are weak by reason of the deficient nourishment in that kind of food. Certain peculiar noises under water, of a low rumbling or drumming kind, are ascribed, by the fishermen, to the Squeteague. Whether the sounds come from these fishes or not, it is certain, that during their season, only, they may be heard from the bottom of the water, in places frequented by the weak-fislr and not elsewhere. 'Tlie swimming-bladder is convertible into good glue. I have eaten as fine blancmange made from it as from the isinglass of the sturgeon." From the same author we learn, that this fish keeps within the limits of the salt water, never going into fiesh streams or ponds. It is lnown along the whole coast of the United States from Rhode Island to New Orleans, and Lieutenant-Colonel Hamilton Smith has taken it in the Baie des Chaleurs, near the mouth of the St. Lawrence.

"Its size is commonly from a foot to fifteen inches, but it often grows larger. One, twentyseven inehes in length by seven in depth, weighed hearier than six pounds. The head and baek are brown, with frequently a tinge of greenish; faintly silvery with dusky specks above the lateral line, which gradually disappear on the sides, until on descending to the belly, at clear white prevails from the chin to the tail. The eves are large and pale yellow." (Mitchill, l.c.) There are two strong canine teeth in the upper jaw, one of which is often broken, the rest of that mandible is armed with a single row of teeth, which are very small but distinct and pointed. The under jaw is also furnished with a row of small teeth which ix 
doubled anteriorly. The two dorsals are well separated, and the second, as well as the caudal and anal, is in a great part covered with small scales. The lateral line is straight, and is continued to the extremity of the caudal, which is slightly notched. There are four cacal appendages to the pylorus, which is very near the cardiac orifice of the stomach. The coats of the air-bladder are very thick, soft, and nacry.

$$
\text { Fins.-D. } 9 /-1 / 29 ; \text { A. } 1 / 13 ; \text { C. } 17 ; \text { P. } 16 ; \text { V. 1/5. (Hist. des Poiss. }{ }^{*} \text { ) }
$$

* Mr. Drummond sent me an Otolithus from New Orleans (O. Drummondii nob.), which appears to be quite distinct from regalis and Carolinensis, the only two species that are mentioned in the Histoire des Poissons as frequenting the coasts of the United States. It is more slender than regalis, and considerably more so than Carolinensis, the height of the body heing little more than a sixth of the total length, excluding the caudal. In the length of the head, which is exactly onefourth of the whole length, including the caudal, it resembles Carolinensis and surpasses regalis. It differs from the latter in having two distinct rows of small pointed teeth round the upper jaw, the outer row being more widely set. There is only one canine tooth in our specimen, moderately loug, slender, and very acute, but rendered very conspicuous by its whiteness. Two very acute flat points, divided by a deep angular notch, show through the integuments of the operculum. The caudal is rounded at the end, and the lateral line runs to the tip of the central rays. There are about sixty-six scales on the lateral line, exclusive of the minute ones, which extend pretty far over the caudal: there are scarcely any scales perceptible on the second dorsal and anal. The spine of the latter is small; being slender and not above one-third of the height of the soft ray which succeeds it. There are many small roundish blackish-brown spots on the back above the lateral line, and on the second dorsal and caudal fins. The back appears to have been dark and the sides and belly silvery. The labials and sub-orbitar bones have much nacry lustre. The total length of the specimen is eleven inches and a half, of which the caudal fin occupies one inch and a lialf. The last ray of the ventral is divided into four branches to the base.

Fivs.-D. $9 /-1 / 25 ; A .1 / 8 ; P .16 ; V .1 / 5 ; C .17 \frac{4}{4}$.

SPAROIDEA.

\begin{tabular}{|c|c|c|c|c|c|c|c|c|c|c|}
\hline GENERA, & 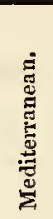 & 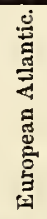 & 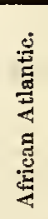 & 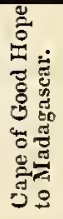 & 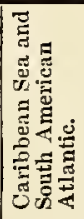 & 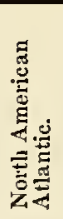 & 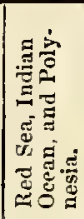 & 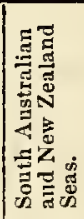 & 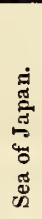 & $\begin{array}{c}\text { Totals } \\
\text { of } \\
\text { Species. }\end{array}$ \\
\hline 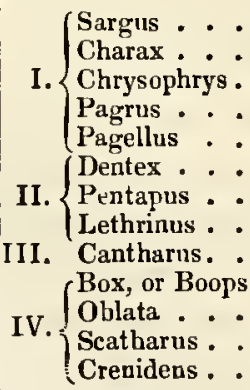 & $\begin{array}{l}4 \\
1 \\
2 \\
4 \\
6 \\
3 \\
- \\
\\
3 \\
2 \\
1 \\
1 \\
-\end{array}$ & $\begin{array}{l}\overline{1} \\
\overline{1} \\
\overline{3} \\
- \\
\overline{1} \\
2 \\
2 \\
- \\
- \\
-\end{array}$ & $\begin{array}{l}2 \\
\overline{1} \\
1 \\
1 \\
1 \\
\overline{1} \\
1 \\
3 \\
- \\
- \\
-\end{array}$ & $\begin{array}{l}- \\
\overline{4} \\
1 \\
1 \\
2 \\
- \\
\overline{2} \\
- \\
- \\
- \\
-\end{array}$ & $\begin{array}{l}6 \\
- \\
- \\
\overline{2} \\
1 \\
- \\
- \\
- \\
- \\
- \\
- \\
-\end{array}$ & $\begin{array}{l}2 \\
\overline{1} \\
1 \\
- \\
- \\
- \\
- \\
- \\
- \\
- \\
-\end{array}$ & $\begin{array}{r}- \\
11 \\
3 \\
\overline{16} \\
3 \\
40 \\
5 \\
1 \\
- \\
\overline{1}\end{array}$ & $\begin{array}{l}- \\
\bar{z} \\
3 \\
- \\
\overline{2} \\
- \\
- \\
\overline{1} \\
\overline{-} \\
-\end{array}$ & $\begin{array}{l}\overline{-} \\
\overline{2} \\
\overline{-} \\
\overline{2} \\
\overline{1} \\
- \\
- \\
\overline{-} \\
-\end{array}$ & $\begin{array}{r}14 \\
1 \\
20 \\
12 \\
12 \\
24 \\
5 \\
42 \\
12 \\
4 \\
2 \\
1 \\
1\end{array}$ \\
\hline & 27 & 10 & 11 & 10 & 9 & 4 & 80 & 6 & 5 & 150 \\
\hline
\end{tabular}


'THIs family is characterised by the oval form of the body, a spiny, undivided, scaleless dorsal, jaws not protractile, a toothless palite, unarmed opercular pieces, gill-rays not exceeding six, and few cæca. It is distinguished from the Scirenoidear by the unarmed gill-covers and the form of the cranium, which is not cavernous and does not bulge out: from the Chxtodontoidex by the vertical fins not being enveloped in scales; and from the Scomberoidex by the largeness of the scales on the borly. The dentition supplies characters for the division of the family into finu' tribes, or genera as they are reckoned in the Rigne Animal. 'The first (Sparus:) has the sides of the jaws armed with molars, or round teeth like paving stones. 'The anterior teeth may be either cutting, or conical, or like the pile of velvet, and the molars may be in many rows, or in two, or in a single row, and very smallthe sub-genera being characterised by the combination of these various kinds of dentition. The second tribe, or genus (Dentex), has conical teeth, even on the sides of the jaws, several (two, four, or more) of the anterior ones being longer and more or less hooked, resembling canines. There are also generally narrow strips of card-like, or velvet-like teeth, behind the others. The third tribe (Cantharus) has the teeth in form of velvet pile only, or in card-like plates. Lastly, the fourth (Boops and Oblata) has the edges of the jaws armed with cutting teeth in a single row, either with or without velvet-like plates behind, or small tubercular teeth, but never accompanied by rounded molars.

The Sparoidex belong more to the European and Indian or South seas, than to the American side of the Atlantic. Four species, viz., Sargus ovis, S. rhomboidalis, Chrysophrys aculeata, and Pagrus argyrops, frequent the coasts of the United States as high as New York; and some of these, it is probable, may range as far north as the British possessions, but we have no evideice of such being the fact. Some of the trivial names by which these fish are known in the Uniterl States, such as "Sheepshead," or "Tête de mouton," are used in the Canarlas to designate fish of other families. No one Sparoirl species is known to exist on both sides of the Atlantic. 


\section{M $E N O I D E A$.}

THIs snall family has many characters in common with the Sparoideæ, from which, however, it is at once distinguished by the very protractile mouth, and, in some instances, by the presence of teeth on the vomer, or denticulations on the preoperculum. The Mænoideæ have scaly bodies, thoracic ventrals, a single dorsal, clothed with very small scales, from four to seven cæca, and a large air-bladder, which is often forked at its posterior extremity. The mouth, when protuded, forms it tube, whose rounded orifice faces downwards in some genera, and directly forwards in others *. The teeth are en velours on the jaws with, in some cases, two or four small canines: the Mane have in addition small teeth on the vomer, but in the other genera the roof of the mouth is smooth.

Gerres aprion, a species belonging to the Caribbean Sen, ranges as far north as the Carolinas, but none of the family have been taken in a higher latitude. Mr. Couch states, in a memoir published in the Linnæan Transactions, that the Gerres rhombeus, a West-Indian species, follows drift-timber to the coast of Cornwall; but in Mr. Yarrell's beautiful and able illustrations of British Ichthyology, the fish that Mr. Couch speaks of is described as a new species of Serranus (S. Couchii).

\begin{tabular}{|c|c|c|c|c|c|c|c|c|c|}
\hline GENERA. & 苞 & 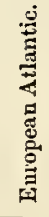 & 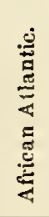 & 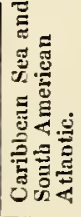 & 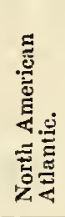 & 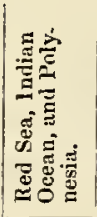 & 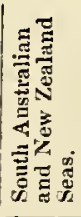 & 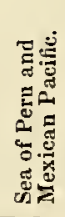 & $\begin{array}{c}\text { Totals s } \\
\text { of } \\
\text { opecies }\end{array}$ \\
\hline Mæna . . . . . & 4 & - & - & - & - & - & - & - & 4 \\
\hline Smaris. . . . & 5 & 2 & 1 & 1 & - & 1 & - & - & 10 \\
\hline Cæsio . . . . . & - & - & - & - & - & 10 & - & - & 10 \\
\hline \multirow[t]{2}{*}{ Gerres . . . . } & - & - & 1 & 5 & 1 & 8 & 1 & 3 & 18 \\
\hline & 9 & 2 & 2 & 6 & 1 & 19 & 1 & 3 & 42 \\
\hline Aphareus. . . . & - & - & - & - & - & 2 & - & - & 2 \\
\hline
\end{tabular}

\footnotetext{
* The genus zeus, and particularly its sub-genus equala, among the Scomberoideæ, and epilulus among the Labrolieæ, as well as some others, have similarly protractile mouths.
} 


\section{CHATODONTOIDEA.SQUAMMIPENNA.}

THe fish composing this fimily are recognisable, at first sight, ly the articulated, and often the spinous portions of their dorsal and anal fins being thickly enveloped in scales, and uniting so gradually with the compressed body that the line of junction becomes almost imperceptible*. 'Their intestines are pretty long and the ceca numerous. They are divided into three tribes. In the first, comprising the Chatodontes of Limneus, the long, slender, flexible teeth are disposed in several crowded rows on the jaws, like the hairs of a brush; the mouth is small; the palate and tongue are toothless; the gill-opening moderately cleft; and its menbrane supported by six rays only. This tribe forms a very natural group of fish, many of which exhibit the most varied and brilliant colours, being, in this respect, not in the least inferior to the most gay and shining of the feathered tribes. The presence or absence of a preopercular spine; the form of the dorsal, whether entire, notched, or double, the extent to which it is scaly, and the elongation of its spines by filaments; the number of anal spines; the form of the body; the size of its scales; the form of the muzzle; protuberances on the head, and some other varieties of structure, furnish characters by which the genera that enter into this tribe are distinguished from each other. The genus Platax has a row of cutting teeth exterior to the bristle-like ones, Psettus has teeth like the pile of shorn velvet, and both these genera have the toothless palate of the rest of the tribe. The second tribe contains two genera with cutting teeth in the jaws, viz., Pimilepterus, which has the incisors in a single row, with cutting edges rising vertically from horizontal bases that project backwards and fix them to the jaw : a stripe of velvet-like teeth behind, and also some asperities on the vomer and palate; and Dipterodon, of which the only one species that is known has teeth like those of the Sparoid genus Sargus: its vomer and palate are smooth. The third tribe is eharacterised by the presence of vomerine and palatine teeth, and by teeth in shorn velvet, or cardlike bands on the jaws. Scorpis, enumerated in this tribe by Cuvier, has a row of strong, cylindrical teeth exterior to those in a velvet-like stripe, and is, in many characters, similar to Platax, from which it is separated by the presence of palatine teeth.

* Sume of the Scionoulea, the Nebres, Lepipleri, and Equites, for iustance, have fins much like those of the Chatadontoidea, but they have not fine, flexible, bristle-like teeth, and in general they have a protuberant snout and cavernous cranium. The Iamulona have also scaly fins, but they are not so thick at the hase as to look like a part of the body, su that the general aspect of the fish is rery different. 
The Chætodontoidea belong chiefly to the Indian and South seas : the Bramus Raii, which abounds in the Mediterranean, and ranges on the Atlantic coast as far north as Demmark, is the only European fish of the family; comparatively few exist in the Caribbean Sea, and only four species range northward to the coasts of the United States; Ephippus faber and grigas are found as ligh as New York, and Holocanthus ciliaris and Pimilepterus Boscii have been taken on the Carolina shores. None are recorded as visiting British America.

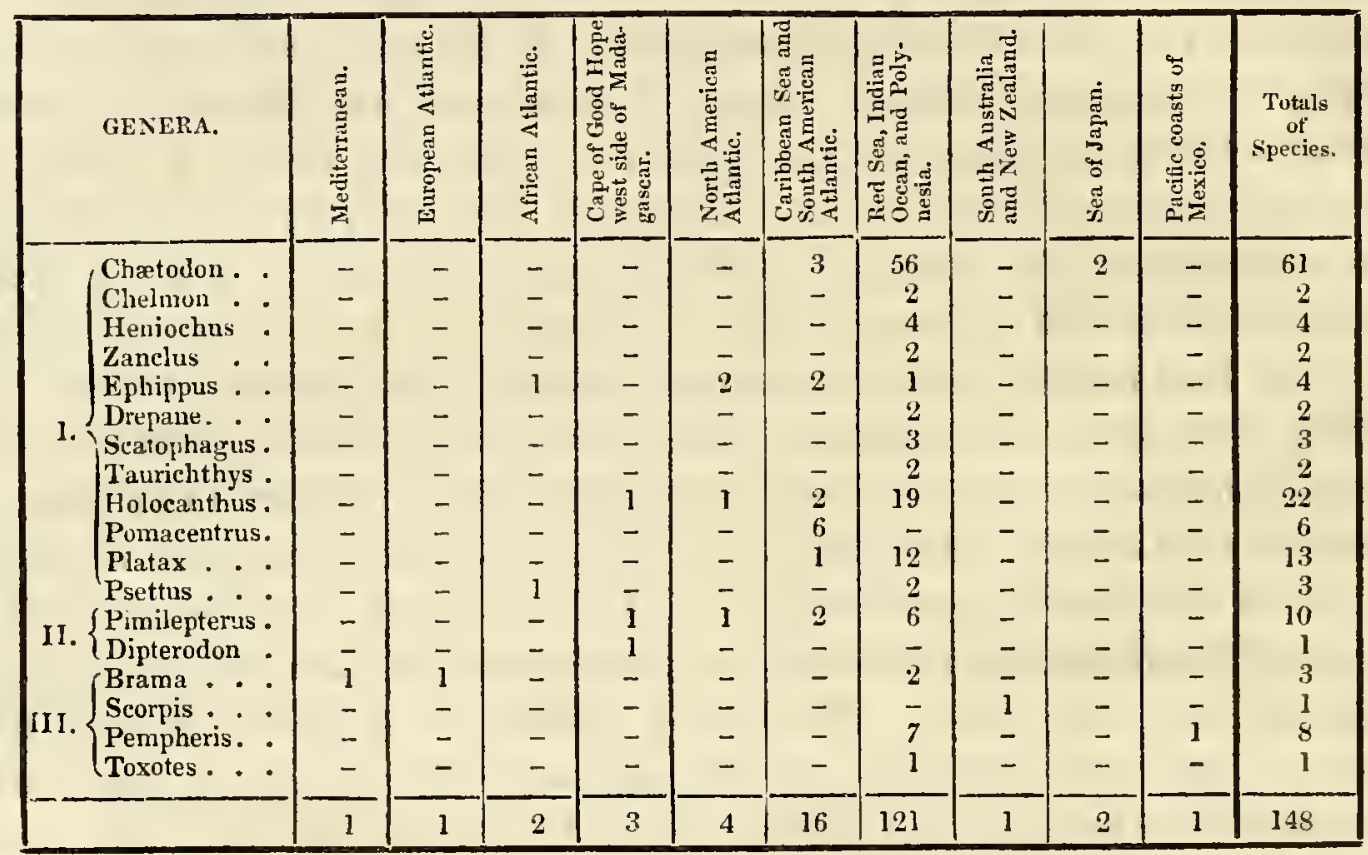


'Turs very remarkable, though small family, offers a curious peculiarity in the structure of the superior pharyngeal bones, which are partly dividerl into lamina that intercept cells of various forms, capable of containing a certain quantity of water. 'This apparatus, situated under the cranium, and sechuded from the external air by swelling gill-covers which press firmly against the body, furnishes the means of moistening the gills when the tish leaves the water. In fact, fish of this family have the singular habit of occasionally travelling some distance through the grass, and it is said, even of ascending palm-trees, for the purpose of entering the pools of water that collect in their cabbage-like tufts of leaves after a shower.

The genera are distinguished from each other by the form of the ventrals, or of some of the other fins; the presence or absence of denticulations on the sub-orbitar bones and opereular pieces; the form of the mouth; and insertion of the teeth. Almost all the species, forty in number, are found in fresh waters, and they are all Asiatic, with the exception of Spirobranchus, which exists in the rivers of the Cape of Good Hope, and differs from the rest in possessing palatine teeth. The genera are,

\begin{tabular}{|c|c|c|c|c|}
\hline Anabas & 1 & Colisa . & 9 & Trichopus \\
\hline Helostoma & 1 & Macropodus & 2 & Spirobranchus \\
\hline Polyacanthus & 3 & Osphromenus & 3 & Ophiocephalus \\
\hline
\end{tabular}




\section{SCOMBEROIDEÆ.}

There are few characters that are common to all the fish of this extensive family; but as even the most discordant of its members are connected by a continuous series of intermediate forms, it is impossible to separate them, and there is, indeed, a certain family likeness which extends to all, arising principally from the smallness and thinness of the scales, and the peculiarly soft, smooth aspect of the integuments; the vertical fins are not scaly; the opercular bones are destitute of spines or denticulations; and the pyloric cæca are numerous and often clustered. Most of the Scomberoideæ have the sides of the tail simply keeled, or with the keels covered by scale-like plates which are themselves keeled: many have the last rays of the second dorsal and anal fins detached, forming spurious finlets, as they are termed; others have the spinous rays of the first dorsal destitute of connecting membrane, aud capable of moving separately ; very generally the caudal is remarkably large and powerful, and the tail tapers greatly and is very muscular ; and in the greater part the spinous rays of the anal form a small fin distinct from the soft portion. These characters are not all to be found in any one fish or group, but their various combinations and modifications furnish the means of dividing the family into several tribes, which are capable of being more exactly defined than the family itself.

In the first tribe, of which the common mackerel is a typical species, the first dorsal is continuous; but both that fin and the anal are succeeded by spurious finlets, and the tail, though keeled, is unarmed : the body is fusiform, and the vigorous caudal fin gives great natatory power. Lepidopus and Tricliurus are considered as supplementary to this group*, though they want not only the spurious finlets, but even all the soft rays of the dorsal: in other respects they closely resemble Thyrsites and Gempylus, which are legitimate members of the tribe.

In the Histoire des Poissons, the small tribe of "Espadons" (Xiphida) follows next. It is characterised by the elongated form of the snout, resembling the flat blade of a sword, a javelin, or spit. The fish composing it are like the Tunnies in the minuteness of their seales, the keeled tail, the very powerful caudal fin, and in their interior organization. They have a continuous dorsal, the keels of the

* They are so placed in the Histoire cles Poissons, but in the Règne Animal they form the first tribe of the Tænioidex, or Puissons en ruban. 
tail destitute of scaly plates, teeth like the pile of shorn velvet, and a peculiar strueture of the gills.

The second grand tribe has the spinous rays of the dorsal standing solitarily without a connecting membrane, so that they can move separately. Chorinemus has, in addition to these, spurious finlets behind the dorsal and anal, as in the first tribe. Rynchobdella and Mastacembelus want the ventrals, and Notacanthuss has the anal united to the caudal, and all the rays of the dorsal detached from each other.

The third tribe has the lateral line armed in part, or for its whole length, but chiefly on the sides of the tail, by keeled or hooked shields, or strong scales. This character, in passing through a succession of genera, becomes gradually less marked, until the armour is reduced to scales so small, that they are remarkable merely when viewed in comparison with the more minute scales of the body. The extensive genus Caranx exhibits this kind of armour in the greatest perfection: while Vomer may be considered as the type of that section in which it becomes less and less conspicuous.

The fourth tribe is not so easily defined as the preceding ones, for though the genera composing it form, by easy transitions, a natural series, there are few positive characters common to them all; so that recourse must be had to negative ones for the limitation of the group, such as the want of spurious finlets, or free spines, on the back, and of keeled scales on the sides of the tail. The genera Seriola and Temnodon of this tribe have much affinity with Lichia of the second tribe; while Stromateus has the exterior form of many of the Chrotodontoider. Coryphana seems to differ widely from both in the compression and vertical height of the head; but Lampugus and Centrolophus are links which connect it on one side to Lichin, and on the other to Stromateus.

The habits of the Scomberoidex are quite in accordance with their great powers of natation: we find among them many fish that pass their lives remote from the land in the middle districts of the ocean, and the family may be termed pelagic, with as much propriety as some of the preceding ones have been named after the countries where they most abound. 'The Bonitos and Dolphins, or Coryphene especially, roam about within the Tropics, pursuing shoals of various linds of flying fisl. Several of the Scomberoider (Coryphana equisetis, C. dolfyn, C. azorica, Lampugus punctulatus, Centrolophus crussus) have been taken in the middle longitudes only of the Atlantic, so that they cannot be said to belong to one contiuent more than another; and there is a greater number of species that cross the Atlantic belonging to this family than to any preceding one. Among these 
are, Scomber grex, Pelamys sarda, Trichiurus lepturus, Elecate Atlantica, Lichia glaucus, Caranx carangus, and Nomeus Mauritii. Several not only traverse the Atlantic from side to side, but also range through other seas: thus Thynnus pelamys and Seriola cosmopolita are known on both sides of the Atlantic and in the Indian Ocean. Auxis vulgaris, which is common to the Mediterranean and Caribbean seas, also extends to the Indian Archipelago, if the Taso of New Guinea be the same species. Vomer Brownii visits both sides of the Atlantic, and also the sea of Peru. Many of the species mentioned above as traversing the Atlantic, exist also in the Mediterranean; and there are several others which have an extensive range in the latter sea, and through the whole eastern side of the Atlantic; though they do not cross to America, such as Scomber scombrus, Lepidopus argyreus, Xiphias gladius, and Naucrates ductor*. Trachurus saurel exists in the Mediterranean, and on the east side of the Atlantic, from the English Channel to the Cape of Good Hope: it is also found in the Indian Ocean, and in all parts of the Pacific, but not on the American side of the Atlantic. Pelamys Chilensis has been taken on both sides of the Pacific, namely, at Japan and Valparaiso. The genera peculiar to a single district of the ocean may be known by a reference to the subjoined table. They are fewer in proportion than in the preceding families, and mostly contain only a single species. There are very few fresh-water or riverfish in the family. Rhynchobdella and Mastacembelus inhahit the rivers and ponds of India, one species of the latter existing in a river near Aleppo. Notacanthus is supposed to inhabit the rivers of Greenland.

* Xiphias gladius is enumerated by Dr. Smith in his list of 'the fish of Massachusetts, but as he has included several other European species in his list, on very insufficient grounds, further evidence is required of its being an American fish. 


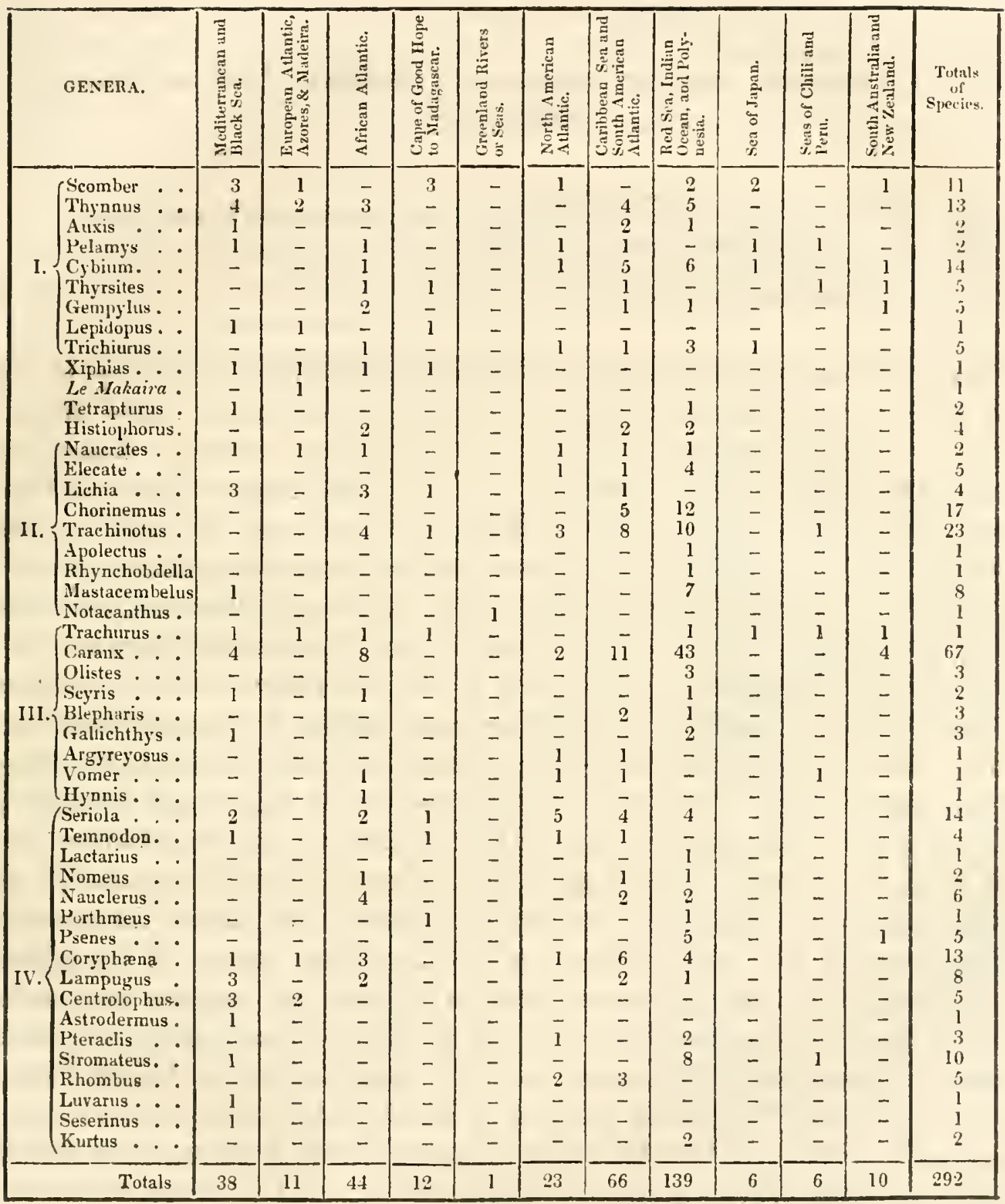




\title{
[36.] 1. Scomber grex et vernalis. (Mitchill.) Chub and Spring Mackerel.
}

\author{
Famix, Scomberoideæ. Genus, Scomber. Cuvier. \\ Thimble-eyed, Bull-eyed, or Chub Mackerel (Scomber grex), MircriLl, New Fork Tr., i.,p. 422. \\ Spring Mackerel (Scomber vernalis). IDEM, p. 423. \\ Le petit Maquereau de l'Atlantique (S. grex). Cuv. et VAL., viii., p. 45. \\ Le Maquereau printannier ( $S$. vernaiis). IDEM, p. 48.
}

The well-known Scomber scombrus, or Common Mackerel, is the type of the first tribe of Scomberoideæ, which is characterized by spurious finlets situated behind a continuous dorsal, a fusiform body, a compact, very taper, keeled but unarmed tail, and a large and powerful candal fin. The tribe comprises the bestknown fish of the family, and those which are most useful to man, viz., the Scombri, Thynni, and Orcyni, that traverse the seas in immense shoals, and form the object of vast and expensive fisheries. The Common Mackerel ranges on the European side of the Atlantic, from Iceland to the Canaries, and penetrates into the Baltic, Mediterranean, and Black seas, but not into the sea of Azof. It wants the air-bladder, but there are two Mediterranean species, S. pneumatophorus and colias, which possess that viscus, although they are extremely sinilar to the scombrus in external form. Two American mackerel, named S. grex and vernalis by Dr. Mitchill, also provided with an air-bladder, have precisely the exterior form and number of parts* of pneumatophorus, and even their skeletons exhibit no sensible variations, though there are some differences in the viscera, the stomach of the American fish being shorter, and the length and number of the pyloric cæca greater. The only differences between $S$. grex and vernalis seem to be in their size and colour, and they are very probably different ages of the same species. S. grex frequents the whole of the Atlantic coast of the United States, the Bermudas, the West Indies, the coast of Brazil, and the Cape of Good Hope. It is lighly probable that it also ranges to British North America, for mackerel exist on the coasts of Nova Scotia and Newfoundland, and La Hontan enumerates " maquereaux comme en Europe" among the fish taken in the estuary of the St. Lawrence. I have not been able to discover if there be mackerel on the Labrador coast, and have never heard of any having been seen in Hudson's Bay.

* In Preumatophorus, Fins.--Br. $7 ; D .10 /$ - $1 / 11-5$ finlets; $A .1 / 11-5$ finlets; C. $17 ; P .19 ; V .1 / 5$. 
Dr. Nitchill deseribes S. grex as about ten inehes long, having the back marked with meandering lines of pale and dark green, the green beconing lighter and less mottled towards the lateral line: the rest of the surfice exluibits changeable tints like a pigeon's neck, or variegated coppier ore. This species occasionally visits the coast of New York in the autumn, as was nemorably the ease in 1781 and 1813 , when the bays, creeks, and coves were literally alive with them, and the markets overloalded.

The same author says, the S. vernalis is a very elegant fish, sixteen or seventeen inches long and three deep. Its back is marked transrersely by deep-bhe curved parallel bands reaching below the lateral line. The intervening spaces are of a paler blue and recldish. brown. The head is bluish with dark spots and shades of green intermixed. The belly is silvery-white and iridescent, and all the hues are beautifully changeable. This fish is canght off the New Jersey capes with the hook, and is brought abundantly to the New York market.

Pelamys sarda and Cylium maculatum, also belonging to the first tribe of Scomberoideæ, frequent the coasts of the United States as high as Massachusetts *, but we have no account of their ranging northwards to the British possessions on that side of the Atlantic. Pennant gives Xiphias gladius a place among the American fish, in his Arctic Zoology, for no better reason than because it exists in most other seas; and Cuvier, though he has traced it from the Baltic through the North Sea, and the whole European and African Atlantic, and also in the Mediterranean, never saw an American specimen.

Of the second tribe of this family, Naucrates Noveboracensis, as the name implies, has been taken on the New York coast. It is most probably, according to the Histoire des Poissons, the same species with the $N$. ductor of the Mediterranean and the Tropical Atlantic. Gasterosteus Canadus of Limæus, which Cuvier refers to his Elecate Atlantica $\uparrow$ (a South American fish that is supposed to range to the Guinea coast), was sent to Linnæus from Carrolina, and not from Canada, as its appellation would lead us to suppose. It exists, however, as far north as New York, having been described and figured under the name of Centronotus spinosus, or Crab-eater, ly Dr. Mitchill, in the New York Transactions (i., p. 149, pl. 3, f. 9). Three species of 'T'rachinotus are also found on the coasts of the United States, viz., T'. fuscus, argenteus, and pamponus, which also range southwards to the Caribbean Sea and Sea of Brazil.

\footnotetext{
* Lientenant-Colonel Il. Smith informs me that Tunnies, most probalsly lelonging to the first of these species; are taken off Cape Cod, and the latter of the two is enumerated minong the fish of Massachusetts, by Dr. J. V. C. Simill. Cuvier received specimens of bo:h from New lork.

+ Elecate Americana. Règ. An., ii., p. 203.
} 


\title{
[38.] 1. Notacanthus nasus. (Cuvier.) Beaked Notacanth.
}

\author{
Faniry, Scomberoideæ, Cuvier. Genus, Notacanthus (Acanthonotus), Bцoch. \\ Acanthonotus nasus. Bloch, t. 431. Scinerder, Bloch, p. 390. \\ Le Notacanthe nez (Notacanthus nasus). Cuv. et Val., viii., p. 467.
}

The genera Rhynchobdella and Mastacembelus, are arranged in the Histoire des Poissons as an appendix to the second tribe of Scomberoidex, to which they bear nearly the same relation that the Xiphidæ do to the first tribe, by the want of ventrals; and they also, by a singular coincidence, show an analogy to the Xiphidæ, in possessing a somewhat prominent snout. Notacanthus resembles these genera in having a series of free spines, unconnected by membrane, in place of a dorsal fin, free spines before the anal, which is long and joins the caudal, small oval scales, and a prominent snout; but it differs from them in having ventrals, and from the rest of the Scomberoideæ in these fins being attached to the abdomen far behind the pectorals. It has also some other extraordinary characters.

Its form is riband-like, being greatly elongated and compressed. The anus is about oneseventh of the total length, nearer to the snout than to the tip of the caudal. There are about eighty rows of scales in a longitudinal line.

Fins.-Br. $8 ; D .10 / 0 ; A .13 / 116 ; C .8 ; P .17 ; V .1 / 8$. (Hist. des Poiss.)

$8 ; 10 / 10 ; A . \&$ C. $13 / 149 ; 16 ; 2 / 10 . \quad$ (Schneider.)

There are about thirty cylindrical, slightly-flattened teeth crowded into a single row on each side of the upper jaw, and more slender, pointed, and slightly curved ones in the lower jaw, disposed in three or four rows anteriorly, and in one on the sides.

(Hist. des Poiss.)

This fish was supposed by Bloch to be an inhabitant of the Indian Ocean; but it is, in fact, the native of a widely-distant country. Fabricius received a specimen from Greenland, and described it under the generic appellation of Campylodon. It was found in the winter time, lying dead near a hole in the ice, on one of the rivers of that country, but it was not known whether it had come out of the water by itself, or had been taken and abandoned there by a fisherman.

Four of the third tribe of Scomberoidex, or those which have the sides of the tail and part, or the whole, of the rest of the lateral line armed with scaly plates, are known to frequent the coasts of the United States; viz., Caranx punctatus, C. chrysos, Argyreyosus vomer, and Vomer Brownii, but the limit of their range northwards is not ascertained Zeus gallus, L., is mentioned by Fabricius in the 
Fauua of Greenland; but, in the first place, it cannot now be determined what the species was to which Linnæus gave that appellation, as in his list of Synonyma he has referred to fish of different genera ${ }^{*}$, and from various seas. In the second place, Fabricius did not see the fish himself, but merely learned from the Greenlanders, who called it "Kolliooseuternak," that it was extremely rare, and was furnished with four very long threads or tendrils, two of them placed forwards, and two behind. Cuvier thinks that it may have been the Lampris guttatus, which forms the subject of the next article.

The following fish of the fourth tribe of Scomberoidere frequent the Atlantic coasts of the United States:-Seriola Boscii, fasciata, lciarchus, zonatus, and cosmopolita, Temodon saltator, Coryphana Sueurii, Pteraclis Carolinus, and Rhombus longipinus and cryptosus.

[39.] 1. Zeus (Lampris) guttatus. (Retzius.) The Opah.

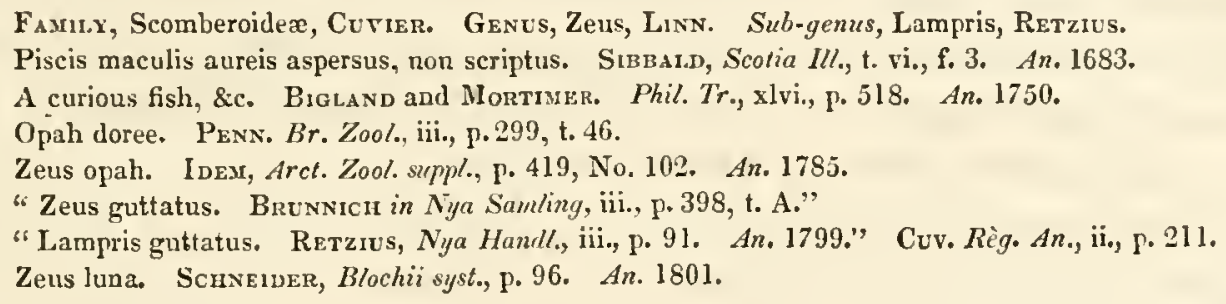

The Linnean genus Zeus, as restricted by Cuvier, comprehends fish which have a compressed body, a very protractile mouth, small scales, and few and feeble teeth. In the protrusive jaws it resembles the Mænoider, and differs from the Scomberoider, with which, indeed, it is not connected by many other external characters than the smalluess of the scales. It is divisible into several sub-genera, as Zeus (Cuv.), in which the spines of the notched dorsal are accompanied by long strips of membrane, and there is a row of forked spines along the base of that fin and of the aual. The type of this sub-genus is the well-known "John Dory" (jaune dorie), which has stood high in the estimation of English epicures, since the time that Quin made the discovery of its excellent flavour. A second subgenus, the Capros of Lacépède, contains only the Zeus aper of Linnæus, a Mediterranean fish. It has the notched dorsal of the dories, with still more protractile jaws, but wants the forked spines at the bases of the dorsal and anal: its whole body is covered with rough scales. 'The sub-genus Equula contains small fishes, 
many of them inlabitants of the Indian Ocean. They have a single dorsal with many basal spines, the anterior ones sometimes very tall, a compressed body, a very protractile muzzle, and the rims of the back and belly denticulated. The genus Lampris of Retzius, or Chrysotosus of Lacépède, has also only a single dorsal, with one small spine at the base of its very high anterior rays. The ventrals have ten very long rays, and the lobes of the caudal are also greatly elongated, but all these prolonged fins wear down with age. The sides of the tail are keeled. The opah, the only known species, is an inhabitant of the North Sea. Sir George Mackenzie informs us, that it frequents the Iceland seas; and if Cuvier's conjecture, alluded to in a preceding page, be correct, it is an occasional visiter of the Greenland coast. Pennant states that it has been taken at Newfoundland; and Dr. J. V. C. Smith enmmerates it among the fish of Massachusetts. It has been several times diven by storms upon the shores of Great Britain, and we have given several references to authors who have noticed it*. 'Their descriptions, however, differ in so many particulars, that it excites a doubt whether they had all the same species under examination. Sir Robert Sibbald's figure, which is the earliest, has the high commencement of the dorsal separated from the lower part of the fin by a small space; and Pennant's differs in several respects from that in Griffith's Cuvier. The colours also vary with the describer.

In the Règne Animal the body is said to be spotted with white, and the fins to be red. Sir Robert Sibbald calls the spots golden. Dr. Mortimer states the back to be dark blue or violet, and, as well as the bright green sides, to be dotted all orer with oblong white spots; the jaws pale red; the nose, gills, and belly silvery; and all the fins bright scarlet. One caught in Torbay is deseribed by Pennant's correspondent as being in general of a vivid transparent scarlet, varnished over with burnished gold, and bespangled with oval silver spots of various sizes. Mr. Harrison, of Newcastle, speaking of another which was cast upon the sands at Blytlı, says " all the fins are of a fine scarlet, but the eclours and beauty of the rest of the body, which is smooth and covered with almost imperceptible scales, beggars all description; the upper part being a bright green, variegated with whitish spots, and enriched with a shining golden hue, like the splendor of a peacock's feather; this by degrees vanishes in a bright silvery tint, and near the belly the gold again predominates in a lighter ground than on the back." ( $B r . Z o o l$.) This fish attains a great size; the one mentioned above, as being taken in Torbay, was four feet and a lialf long, two feet and a quarter high, but only four inches thick: it weighed one hundred and forty pounds.

Fins.-Br. $6 ; P .21 ; V .18 ; A .36 ; C .19 ; D .14 / 48$. (Schneider.) Br. $6 ;$ P. $16 ; V .16 ; A .36 ; C .26 ; D .56$. (Retzius.)

* The following may be added from the Rigne Animal. Zeus regius, Bonnat. Enc. Ichlhyol., f. 155 . Zens imperialis, Shaw. Nat. Nisc., Nu. 140. Z. luna, Guel. Scomber pelagocus, Gunner, Mem. de Dronth., iv., xii., 1. Le Crysotose lune, Lacep., iv., ix., 3. Le Poisson de lune, Duhamer, Sect. iv., pl, vi, f. 5. 


\section{TENIOIDE\&.}

'TuE publication of the Histoire des Poissons having as yet advanced no farther than the Scomberoidex, we are unable to continue the tables of the geographical distribution of the species; but taking the Règne Animal as our guide, we shall give brief notices of the characters of the ferv remaining families of Acanthopterygii. In the latter work the Poissons en vuban, or Tanioides, immediately succeed the Seomberoider, with which they are nearly connected; indeed, this aflinity is considered to be so strong, that Lepidopus and Trichiurus, which form the first tribe of the 'Tænioideæ in the Règne Animal, are transferred to the Scomberoidere in the Histoire des Poissons. Only four genera remain, and the species they contain have, as the family name denotes, a riband-like form, that is, a greatly elongated body with very flat sides: the scales are very small, the gill-rays are six in number, and the ventrals thoracic. Gymnetrus and Stylephorus form one tribe, characterised by a small and slightly-cleft mouth. They are distinguished from each other by the shape of the tail, which, in the former, terminates in a little hook, and in the latter is prolonged by a slender cord that exceeds the body in length. Gymnetrus is remarkable for the form of its fins, which are very long, and so fragile that they are perfect in young fish only. The anterior rays of the dorsal standing on the nape look like a tall plume; the caudal, which contains few but long rays, rises vertically from the extremity of the tail; the ventrals are also very long, but the anal is wanting: the mouth is very protractile, and is armed with a few small teeth; the lateral line gives origin to a series of small spines which are most prominent on the tail; the cæea are numerous, but there is no air-bladder. Four species of this very curious genus are indicated in the Règne Animal, one of them lueing common to the Mediterranean and North Sea, two proper to the latter, and two to the Indian Ocean. Stylephorus contains only one known species, which was taken in the Gulf of Mexico. It had no ventrals, and the caudal fin was shorter than in the preceding genus. Another tribe includes the two remaining genera, which have a short muzzle and an obliquely-cleft month. Cepola las but two or three non-articulated rays in the long dorsal, which are as Hexible as the others; but the ventral spines are pungent. The anal is long like the dorsal, and extends to the base of the caudal. there are six gill rays, conspicuous teeth, some cæca, and an air-bladder. One species is indicated as inhit- 
biting the Mediterranean, and another the sea of Japan. Lophotes contains only a single species, which inhabits the Mediterranean, but is very rarely caught. It has the top of the head elevated by a high bony crest, to which there is articulated a long and strong spine, having a membranous border; the dorsal, continued from this spine to the point of the tail, has short, simple rays, and there is a very small, distinct caudal: the ventrals are scarcely perceptible. The teeth are pointed and widely set.

\section{SIGANOIDEÆ._LES THEUTYES.}

ThIs family, which is peculiar to the warmer districts of the ocean, is as closely allied to the Scomberoideæ as the preceding one; but by other characters, such as the lateral armature of the tail in some genera, or the spine imbedded before the dorsal, in others. In all, the body is compressed, oblong, and surmounted by a single dorsal; the mouth is but slightly, or not at all, protractile; each jaw is armed with a single row of cutting teeth ; the palate and tongue are toothless; and the gill-rays are four or five in number. The Siganoideæ live on fuci and other sea-weeds, and their intestines are capacious, in conformity with their herbivorous habits. The genera are few in number. The first, Siganus, is distinguished from every other genus of fish by the ventrals having an exterior and interior spine which enclose the soft rays between them. It has an unarmed tail, as has also the genus Priodon. Acanthurus has a moveable spine on each side of the tail, which is capable of making a wound like a surgeon's lancet, and some of the species have also a brush of coarse hairs on the forepart of the lateral line. Prionurus and Naseus have fixed cutting laminæ on the sides of the tail, and Axinurus has but one of these laminæ on each side; it also differs from the others in its teeth being very slender. Acantlurus hepatus is enumerated by Schœpf among the New York fish. There are some other species in the warmer parts of the Atlantic, but the greater part of the family inhabit the Indian and Pacific oceans. The Acanthurus triostegus, and four others of that genus, were seen at Otaheite by the naturalists of Captain Beechey's expedition. 


\section{MUGILOIDEA.}

T'He Linnean genus Mugil exhibits so many peculiarities of organization, that Cuvier thinks it ought to be considered as a distinct family. The fish composing it have a nearly cylindrical form, large scales, two distinct dorsals, of which the foremost contains only five spinous rays, and ventrals situated a little posterior to the pectorals. The gill-rays are only six in number, the head is slightly depressed, and is protected by large scales or polygonal plates, the snout is very short, and the orifice of the mouth is transverse, with a re-entering angle formed by a keellike eminence of the lower jaw, fitted to a corresponding depression on the upper one. The teeth are extremely fine, and often nearly imperceptible, but the phinryngeal bones are much developed, and give to the entrance of the oesophagus the form of an angular slit, resembling the orifice of the mouth, through which liquids, or very attenuated food, alone can pass. The stomach is muscular like the gizzard of a fowl, the pyloric cæea are few in number, and the intestine is long and doublerl upon itself. 'The Mullets are esteemed to be fish of an excellent flavour. They enter bays and the mouths of rivers in large shoals, and have the habit of leaping high out of the water. Six species are noticed in the Règne Animal, as inhabitants of the European seas: viz., M. auratus, saltator, and labeo, proper to the Mediterranean ; M. capito and chelo, common to that sea and the North Atlantic; and $M$. cephalus, likewise found in the Mediterranean, but ranging through the African Atlantic to the Cape of Good Hope, and existing also in the Red Sea, if it be the same species with the $M$. our of Forskal, as is most probably the cuse. Five or six species belong to America, which have been confounded by author: under the name of $M$. albula. One of them, $M$. lineatus, frequents the coasts of the United States, where it attains the weight of two pounds and a half. Many species exist in the Indian Ocean, and one was observed in the harbour of Mazatlan, South California, by the naturalists of Captain Beechey's experlition.

The 'Tetragonurus Cuvierr (Rossi), a fish inhabiting the greatest deptlis of the Mediterranean, is an isolated species, which appenrs to be the only indication of a peculiar family. It derives its name from two salient ridges on each side of the tail, and in its structure it partly resembles the Mugiloidere, ind partly the Scomberoideæ. 
Atherina is also a genus which does not associate well with any other. It comprises small fish, whose young assemble in crowded shoals, and are greatly prized for their delicate flavour. They have an elongated body, two dorsals very widely separated, ventrals posterior to the pectorals, a very protractile mouth, which is armed with exceedingly slender teeth, six gill-rays and no cæca. All the known species have a broad silvery stripe on each flank. Four species, hitherto confounded under the name of $A$. hepsetus, exist in the European seas, and there are a considerable number in the Indian, Polynesian, Australian, and American seas. Dr. Mitchill enumerates three among the fish of New York, A. mordax, viridescens, and notata, the latter being the $A$. menidia of Linnæus. They are known by the names of "Silver sides," or "Silver fish."

GOBIOIDEE.

The Gobioide may be recognised by the slenderness and flexibility of their dorsal rays. They have an uniformly wide intestinal canal, no pyloric cæca, and no airbladder*. The family is divided into the following genera:-Blennius, Anarrhichas, Gobius, Callionymus, and Platyptera.

[40.]. 1. Blennius (Chinus) punctatus. (Fabr.) The Akooliakeetsok.

Familu, Gobivideæ. Genus, Blennius. Sub-genus, Clinus, Cuvier.

Blennius punctatus. Fasr. Fauna Grænl., p. 153, N. 110.

Centronotns punctatus. Schneider, Bloch, p. 166.

Akouliakeetsok. Greenlanders.

The genus Buennius has a well-marked character in its jugular ventrals, composed of two rays only. The body is elongated and compressed, the dorsal single, and its rays are almost all simple, though flexible. The skin is covered with mucus. Many of the species are viviparous, and both sexes are provided with a tubercle near the anus. The Blennies in general have the labit of swimming in

* Must of the Gobies have a simple air-bladder. 
small parties among rocks near the shore, and of leaping about on the strand, being capable of existing for some time ont of the watcr. They are in no repute as articles of food. Eight sub-grenera are indicated in the Règne Animal. 'The first (Les Blennies proprement dits) is characterised by the single row of long, equal, crowded teeth in each jaw, terminated posteriorly, in some species, by a long curverl tooth. The head is obtuse, the snout short, and the forehead vertical; the dorsal may be either two-lobed, or almost or altogether even. Most of the species liave a barbel over each eye, often in form of a tufted fringe, and many lave also a tuft on the temples. In others the superciliary tufts are scarcely perceptible, but the head is surnounted by a membranous crest which swells and reddens in the nuptial season. Others again (Pholis, Artedi) have neither crests nor superciliary tufts. Seven species belonging to this sub-genus are particularised in the Règne Animal as inhabitants of the European seas: one as belonging to the Indian Ocean, and another to the Sea of Brazil. There are doubtless many other foreign species, and sereral have been noticed by American naturalists, as inhabitants of the coasts of the United States*. None are mentioned by anthors as frequenting the coasts of British America.

Myxodes and Salarias, the second and third sub-genera, differ from the preceding chiefly in the form of the head. The former comprises some non-descript species, and the latter fish of the Indian Ocean. The fourth sub-genus, Clinus, las several rows of short pointed teeth, the first row being the longest. In some species, which have tufts over the eyes, the foremost rays of the dorsal are separated by a notch from the rest of the fin, or the anterior bit of the fin may be altogether detached, so as to appear like a crest on the back of the head. In others, the dorsal is continuous and even. The species indicated in the Règne Animal inhabit the North Sea, the South Atlantic in the vicinity of the Cape of Good Hope, and the Sea of New Zealand. The "akoolia-keetsol " of the Greenlanders belongs to this sub-genus. It inhabits deep waters, and is often found in the stomachs of the gadi, pleuronectes, and other large fish. The following description of it is abridged from Fabricius.

LENGTH six inches, depth one. BoDy thicker than the head, and nearly of equal girth throughout. Snout thin, the jaws cqual, the forehead flattish. The dorsal and anal are continued to the caudal fin, the former being joined to it by membranc, but the anal distinct. Skin lubricous with minute imbedded scales. The colour is tawny; the head is dotted with white, the throat, pectorals, and caudal are striped with the same, and there are about seven

- Blennius pholis, Mitcuill. New York Tr., i., p. 374. B. heniz, Le Steur. Journ. Ac. Sc. Phil, ir., p. 361. Blennius zeminatus, B. punctatus, Pholis novemlineatus, and Ph.quadrifasicalus, Wood. Journ. Ac. Sc. Phil., iv., 1'. 278. 
brown streaks on the cheeks. There are five black spots, joined to as many white ones, on the dorsal, and about twelve less conspicuous, and all black, on the anal.

Fins. $-B r .7 ; D .50 ; P .17 ; V .4^{*} ; A .38 ; C .18$.

\section{[41.] 2. Blennius (Clinus) lumpenus. (Fabr.) The Lumpen.}

Blennius cirris subgula pinniformibus quasi bifidis, areolis dorsi transversis. ARtedr. Syn., p. 45.

Blennius lumpenus. Fabr. Fauna Groenl., p. 151.

Teyarnak. GreenLanbers.

This is another Greenland species which is considered to be the same with one that exists on the Dutch coast. In calms it reposes on the clayey or sandy bottom of the places it frequents, with its body bent backwards and forwards; at other times it conceals itself among the sea-weed. It spawns among the fuci in the month of July.

\section{DESCRIPTION}

Abridged from the Fauna Groenlandica.

LENGTH eleven inches and a quarter, the thickness being scarcely one. Its body is round, nearly of equal diameter from the head to the anus, from whence it becomes more lanceolate. Head narrower than the body, mouth small, the upper jaw scarcely longer than the lower one. The ventral fins are so soft, white, and slender, that they may be readily taken for gular barbels; they contain, however, three rays, the lower of which is the longest, and is clivided from the next by a fissure : the upper ray is so small as to be scarceily perceptible. The even dorsal occupies the whole back, but is distinct from the obovate caudal: its spines curve backwards. The scales are small, round, and firmly imbedded in the smooth skin. The back and sides have a palish colour, and are marked irregularly with brown spotted circles: the head and pectorals are yellowish, and the belly white, with a yellowish tint behind the anus.

The fifth sub-genus of the Blennies is Cirrhibarba, which is founded on a single Indian species, having the form of Clinus, but teeth like velvet pile, a small barbel over each eye, another at the nostril, three large ones at the extremity of the snout, and eight on the tip of the jaw.

- Pinna ventrale's minuta qualuor quidem canstant radiis mollibus, \&ce. 


\title{
[42.] I. Buennius (Centronotus) gunneluus. (Linn.) Spotted Gunnelle.
}

\author{
Family, Gobioideæ, Cuvier. Genus, Blennius, Linn. Sub-genus, Centronotus, Scineidru. \\ B. gunnellus. LinN. Syst. Nat., ed, xiii., i. p. 442. Fabr. Faun. Groen., p. 149. \\ Spotted Blenny. PenN., Br. Zool., iii., p. 282. \\ Kurksuunak. GreEnLANDEizs.
}

Centronotus, the sixth sub-genus of the Blennies, has still smaller ventrals than the rest, these fins being scarcely perceptible, and often consisting of only a single ray. The head is small, the body elongated like the blade of a sword, and the dorsal, which extends the whole length of the back, is sustained throughout by simple rays. The dentition is similar to that of Clinus. The Spotted Gunnelle abounds in the European seas, is common in the gulfs and bays of Greenland, and probably frequents the whole American coast down to Newfoundland. Fabricius informs us, that in Greenland it dwells among the sea-weeds which grow near the shore, and that though it swims swiftly, after the manner of an eel, it often becomes a prey to the Bull-heads, Motellæ, and other littoral fish, as well as to various seabirds. It feeds upon marine insects and small crustaceæ. The only American specimen that we have seen was brought from the Labrador coast by Mr. Audulon, and is now in the possession of Mr. Yarrell. From long immersion in rum, in the same jar with some echini, it has become totally black, so that a comparison of its markings with those of the European fish cannot be made, and we are also ignorant of its internal structure. In external form, however, it bears a very close resemblance to a number of British specimens belonging to Mr. Yarrell, except that its head is proportionably somewhat longer, and its gill-cover rather more pointed. Fabricius mentions that large specimens taken on the Greenland coast are nine inches long, and that he saw one which measured a foot; but his description agrees so well with the English gunnelle, that there is no ground for believing it to be it distinct species, although the latter does not usually exceed six inches in length.

\section{DESCRIPTION}

Of a Labrador specimen preserved in rum.

Form-elongated, much compressed, particularly posteriorly : profile almost linear, the head rather obtuse, the tail slightly lanceolate, its tip, to which the caudal is attached, being rounded. The depth of the body, at any point between the nape and midway between the anus and caudal, is about one-eleventh of the total length, excluding the caudal. The anus is situated under the thirty-third or thirty-fourth dorsal spine. The head forms one-seventh 
of the length, is narrow, and tapers to a ridge before the eyes, the tip of the upper jaw being, however, rounded. When the mouth is closed, the under jaw ascends considerably, and the commissure of the lips is at the extremity of the head; but when the under jaw is depressed it is longer than the upper one. The lips fold back on the mandibles. The operculum is heart-shaped, its apex having a membranous margin which forms the acute tip of the gillcover. Gill-membranes united under the isthmus forming a transverse loose flap. A row of pores runs along each limb of the lower jaw, round the orbits, up the preoperculum, and across the nape.

ТЕЕтн-short, erect, and acute merely from their slenderness, disposed in a single row on the sides of the jaws, but aggregated anteriorly into two lows on the lower jaw, and into three in the upper one. There is also a transverse, two-rowed cluster of rather smaller teeth on the vomer, but the palate-bones are smooth.

Scales-minute, not tiled, and in most places scarcely touching, enveloped in the mucus which exudes from the skin. Lateral line straight and nearer to the belly than to the back.

Fins.-Br. 5-5;D.78/ ;. 2/43;P. 12; V. 1/1 , C. 20.

The dorsal fin commences opposite to the tip of the gill-cover, and extends to the caudal, to which it is united by membrane: it is about two lines high throughout; its rays are all spinous and scarcely flexible, with their acute points protruding beyond the membrane. $\mathrm{Mr}$. Yarrell reckons from seventy-six to eighty dorsal rays in the English Gunnelle; but Fabricius enumerates eighty-eight, which is almost the only discrepancy betwixt his description and our fish. The pectorals have an acutely lanceolate outline, and are attached opposite to the first dorsal spine. The ventrals are very small, and contain one conspicuous spine, with a minute branching ray imbedded in the membrane. They are situated a little before the pectorals. The anal commences close to the anus: its two anterior rays are spinous* and shorter than the others, which are forked and as long as the dorsal spines: the membrane of the anal unites with the cuneiform caudal, which is rounded at the end.

Colour.-Fabricius gives the following account of the Spotted Gunelle of Greenland. The body is greyish-yellow, with pale yellowish marks on the sides before the anus, and whitish ones behind : there are also twelve white marks with black centres upon the base of the dorsal fin, and as many totally white ones of a smaller size. The fins are yellowish, the anal and forepart of the dorsal being tawny; a black stripe crosses the gill-covers and crown of the head; there is another between the eyes; two white stripes alternate with these; and the throat is white. Mr. Yarrell says, "The uniform dark colour of my American specimen obscures every trace of spots. In the British fish, the black spots of the dorsal fin are partly encircled with a white line; but these markings do not occur on the anal fin, which rather partakes of the mottled alternate dark and light brown of the body."

\footnotetext{
* One of Mr. Yarrell's English specimens has two minute spines imbedded in the membrane behind the two ordinary ones at the commencement of the fin. Fabricius enumerates six gill-rays; the Labrador fish appears to me to contain five in each membrane; while Mr. Yarrell says there is " nothing deserving the name of branchiostegous rays beyond four, in either the American or British specimens."-Fabricius's words are:- "Membrana branchiostega, "ex quidem radios halet, duos inferiores minutissimos, tamen et facile pretereundos."
} 


\section{Disensions}

Of the Labrador specimen.

Inches. Lines.

Length from tip of upper jaw to end of caudal 7

tip of tail . . 7

anus . . 3

tip of gill-cover $\quad 0$

nape . . . 0

tip of labial $\begin{array}{llcc} & & \text { Inches, Lines. } \\ \text { Length of caudal fin } & 0 & 0 & 5 \\ \text { Depth of body } & 0 & 0 & 8\end{array}$

The Kamtschatka "Butrer-Fish," the Ophidium ocellatum, or Blennius ocellatus of Tilesius (Mem. de St. Petersb., iii., p. 237, t. 8, f. 2), which has six round spots on the dorsal, is considered by Cuvier to be akin to the Centronoti. It inhabits the harbour of St. Peter and St. Paul. Tilesius alludes to other species that frequent the sea of Kamtschatka and the vicinity of the Kurile Islands, as having been described by Pallas in his unpublished Fauna Rossica.

The Pustulated Blenny, noticed by Pennant in the Supplement to his Arctic Zoology, p. 115, as an inhabitant of the sea of Newfoundland, is said to have a pale, dull, yellow colour, with the whole body spotted in form of pustules; but no character is given by which we can infer that it belongs to any of the precerling sub-genera.

'The Zoarcès have no spinous rays whatever'; yet Cuvier thinks that they cannot be separated from the Blennies, which they resemble in having an anal tubercle, intestines without cæca, a smooth oblong body, and six gill-rays. Their ventrals are three-rayed, their teeth conical and arranged in one row on the sides of the jaws, but in several rows in front; the palate is toothless. Their vertical fins are united, the dorsal being, however, depressed at its junction with the caudal. The $Z$. viviparus, guffer, or eelpout of the European seas, is about a foot long. The Z. labrosus (Mitchill, pl. 1, f. T), which frequents the coast of New York, attains the length of three feet and a half. 


\title{
1. Blennius (Zoarces?) polaris. (Sabine.)
}

\author{
Family, Gobioideæ. Genus, Blennius. Sub-genus, Zoarees. Cuvier. \\ Blennius jolaris, Sabine. App. Parry's First Voy., p. cexii. \\ Ross. (Captain J. C.) Parry's Polar Foy., p. 200. \\ IDEM, App., liii. An. 1835.
}

On Captain Parry's memorable expedition, which first explored the way into the Polar Sea through Lancaster Sound, a blenny was found on the shore of North Georgia, where it had been left by the tide. We subjoin Captain Sabine's account of this individual, which is not sufficiently minute in the description of the teeth, and some other particulars, to enable us to refer the species positively either to Zoarces or to any of the sub-genera. In the want of scales it agrees with Zoarces.

"It bears a very near resemblance to the description and figure of $B$. viviparus in Muller's Zoologia Danica, but differs in the following particulars : the dorsal fin is united to the anal and caudal : the pectoral is not orbicular, as its length exceeds twice its breadth: the number of the rays fifteen. The teeth, though small, are sufficiently conspicuous to the naked eye: the colour a yellowish ground, lighter under the belly, having eleven large saddleshaped, brown markings across its back; the middle of these markings being much lighter than the edges; the whole back and sides have a marbled appearance; the yellowish ground, when viewed in a microscope, is thickly sprinkled with minute black specks. No scales were discovered, but they may have possibly been removed with the sand which had adhered to the mucous coating of the skin, and which was washed off. Length seven inches. The upper jaw projects rather more than the plate of the B. viviparus in the Zool. Dan. Ventral fins of two spines enclosed in a lax skin. This species is distinguished from the B. lumpenus, by the union of the dorsal and caudal fins, and by the upper jaw being considerably longer than the lower; and from B. ocellatus, Mem.de Petersb., t. 3, pl. 8, f. 2, by the ventral fins, which are wanting in the ocellatus, as well as by the absence of the spots on the dorsal fin of the latter.

\section{"B. imberbis, pinnis anali, caudali, dorsalique unitis."-SABINE, l. $c$.}

Captain James C. Ross, on his recent expedition, took a specimen of this fish from the stomach of a gadus callarias, which was caught on the west side of the peninsula of Boothia ; and he also discovered it in the Spitzbergen seas, when accompanying Sir Edward Parry on his most adventurous boat excursion over the ice. 


\section{[44.] 1. Anarrhichas lupus. (Limm.) Common Wolf-fish.}

Familu, Gabioidex, Cuvier. Genus, Anarthichas, Linn.

Anarrhichas lupus. Fabr. Faun. Granl., p. 138, No.97.

Keegooteeleek. Gresnlanders.

Cuvier considers the genus Anarrhichas to be so nearly allied to Blennius, that the principal difference is in the absence of the ventrals. The dorsal extends from the nape almost to the caudal, and is supported throughout by simple, but not stiff rays. The anal also nearly reaches the caudal, which is rounded as well as the pectorals. The whole body is smooth and slimy. The jaws, vomer, and palatebones are armed with large bony tubercles which support on their summits little enamelled teeth, but the anterior teeth are conical and longer. There are six gillrays, and neither cæca nor air-bladder. The fish of this genus being generally of a large size, and furnished with jaws so well armed, are dangerous.

The Common Wolf-fish inhabits the North Sea, being common enough as low as the French coast; and it is not rare in the southern bays of Greenland. Fabricius says that the largest one he saw was two feet long; but in the European seas, according to Gronovius, Cuvier, \&x., it reaches the length of seven feet. One, three feet long, weighs about twenty pounds. On the Greenland coast it associates itself with the Common Lump-fish, migrating along with it ; that is, retiring from the coast to the deep sea in autumn, and returning again in spring. Its great size and formidable teeth do not protect it from the assaults of the Lump-fish, for the latter, when alarmed for the safety of its offspring, pursues the WVolf-fish, and fustening upon its neck persecutes it to death, at least, such is the account given by Fabricius. It feeds upon crustaceæ and shell-fish, which it breaks in pieces with its teeth. Its motion is serpentine, like that of an eel, and when it is seen reposing in the cleft of a rock its body is undulated. It spawns in May, among the larger sea-weeds, a short way from the shore. It has a hoary colour with a whitish belly, dark head with white specks, and two rows of large blackish lateral spots; but there is considerable variety in the depth of the tints.

$$
\text { Fiss.-Br. } 7 ; D .73 / ; \text { P. } 20 ; V .0 ; A .45 ; C .18 \text {. (Fauna Gronl.) }
$$


[45.] 2. ANarrhichas minor. (Olafsen.) Lesser Wolf-fish.

" Hlyre (A. minor). Ot.Apsens og Bjarne, \&c. Ann. 1772, p. 592, to xlii."

Anarrhichas minor. Fabricius. Faun. Groenl., p. 139.

Kœrrak. Greenlanders.

'This species was seen in Greenland, and described by the Missionary Glahn in the year 1766, but it did not come under the notice of Fabricius. Its teeth are said to be different from those of the preceding species in form and arrangement, and to have a more cartilaginous texture. The fish was first described and figured by Olafsen, in the account of his voyage to Iceland.

Fins.-D. $70 ;$ P. 20;A. 44;C.21. (Fauna Grœnl.)

Goвıus. (Linn.) Fish belonging to this genus may be recognised at first sight by the union of their thoracic ventrals, either along their whole length, or merely at their bases, so as to form a single, hollow, and more or less funnel-shaped disk. Their gill-flaps, furnished with five rays only, are generally only slightly open, and, like the blennies, they can live for some time out of the water; they resemble these fish likewise in the structure of the intestines, the presence of the same little protuberance behind the anus, and in some of the species being viviparous. They are fish of a small or middle size, which live among rocks near the shore. Most of them have a simple air-bladder.

There are several sub-genera. Gobius (Lacép.) or the true Gobies, have the ventrals most completely united, the disk extending even before their bases, where it is margined by a transverse membrane. The species are numerous, many inhabiting the seas of Europe, and some even the fresh waters. Olivi, who studied the manners of one which inhabits the lagoons of Venice, observed that it preferred a clayey bottom, in which it excavated tunnels for its winter retreats. In the spring it selected a place abounding with fuci for its nest, and covering it with the roots of the Zostera maritima, he male shut himself up therein to wait for the females, who came in succession to deposit their roe which he fecundates, watches, and defends courageously. From these facts Cuvier judges this goby to be the phycis of the ancients, the only fish, says Aristotle, which constructs a nest. G. bosc (Lacépède) inhabits the bay of New York*.

The Gobioides of Lacépède differ from the true gobies in the union of the dorsals into a

*It is the Gobius alepidotus, ScHnk10er, Bl., and the G. viridi-pallidus, Mitcenr... New York Tr., p. 379, pl. 1, f. 8. 
siugle fun, and the more lengthened form of the body. The third sub-genus Tanioides (Lacépède) contains but one species, which has a vely extraordinary aspect. It has the single dorsal of the Gobioides with a still longer body. The lower jaw rises before the upper one, which is very short, and both are armed with long hooked teeth. The minute eyes are concealed beneath the skin, and the fish inhabits the muddy bottoms of ponds in the East Indies. A fourth sub-genus Periophtalmus (Schn.) contains fish of the Moluccas which harr the whole head scaly, and the pectorals also scaly for half their length, so that these fins appear to be supported upon arms. Their gill-openings being still narrower than in the other gobies, these fish can live longer in the air, and they often creep and jump upon the nud to escape from their enemies in the water, or to catch the small craw-fish, which form their principal nourishment. Some of them have a rentral disk like the gobies, others have the rentrals scparate almost to their bases. The firh sub-genus, Eleotris, differs from the others in haring distinct rentrals and six gill-rays. There are species in the East and West Indies*, Africa, and the Mediterranean, most of them inhabitants of fresh water, and often of mud.

Callionyus. (Limn.) The fish of this genus have two remarkable characters in their gill-openings, being restricted to a hole on each side of the nape, and in their ventrals being placed widely apart under the throat, and exceeding the pectorals in size. 'Their eyes are vertical, their intermaxillaries very protractile, and their preoperculum elongated posteriorly and terminating by spines. Their teeth are small and crowded, but there are none on the palate. They have the tubercle behind the anus, and want the cæca and air-bladder like the blennies. They are pretty fish with a smooth skin, and their first dorsal, which is supporter by a few setaceous rays, is often very elevated. There are several species in the European seas, and others in the Indian Ocean. Trichonotus setigerus (Schn.) appears to be merely a very elongated Callionymus, but the gill-openings are said to be fully cleft. Callionymus Baicalensis (Comephorus, Lacép.) has wide gillopenings, with seven rays in the membrane, very long pectorals, and, what is it peculiarity in this family, no ventrals. It is thrown up dead from the bottom of Lake Baikal after a storm.

Platrptera contiins two East-Indian fish, which have the lirge and distant ventrals of Callionymus, a slort depressed head, small mouth, wide gill-openings, large scales, and short dorsals placed far apart. 


\section{[46.] 1. Chirus monopterygius. (Cuvier.) Even-finned Chimu.}

Family, Gobioideæ? Cuvier. Genus, Chirus. Stelierr.

Labrax monopterygins. Parlas, Mêm. de Pétersb., ii., p. 391, pl. xxiii., f. 1.

T'he indefatigable Steller discovered two species of fish in the sea of Kamtschatka, and left descriptions of them in manuscript, under the names of Lebius, Chirus vel Labrax, and Hexagrammos. Tilesius also saw two in the same seas, one of which he described and figured as the Hexagrammos Stelleri, in the Mémoires de L'Academie des Sciences de St. Pétersburg for the year 1808 . In the mean time Pallas, receiving specimens of six different species from the same quarter, read an account of them in 1809 to the Society just mentioned, under the generic appellation of Labrax, which was published in the same volume with Tilesius's papers. Cuvier having appropriated the word Labrax to the Basses of the percoid family, distinguishes the present genus, in the Règne Animal, by the name of Chirus, and attaches it to the Gobioideæ, expressing an opinion, however, that it may prove to be the type of a distinct family. The characters of the genus are,-A pretty long body clothed with ciliated scales; a small unarmed head; a slightly-cleft mouth, furnished with small, conical, unequal teeth; and the spinous rays of the dorsal, which stretches along the whole back, almost always slender. Several rows of pores, resembling or forming so many lateral lines, give a peculiar character to the fish of this genus. Their intestines are destitute of cæcal appenrlages*, and some species have superciliary tufts, resembling, in that respect, certain blennies; but their ventrals contain five soft rays as usual.

Pallas says that all the known species live near the craggy shores of Kamtschatka, on the opposite American coast, and round the Kurile and Aleutian islands; but in his accounts of particular species he restricts some of them to certain parts of the Kamtschatka Sea.

Chirus monopterygius was taken off the island of Unalaschka.

It differs from the other species in its forked tail, and in its perfectly even, unnotched dorsal lin, supported by forty-six rays, which are all simple, setaceous, and flexible, the first twenty being, however, more slender than the rest. The rays of the pectoral and anal are also simple and setaceous. Those of the ventrals and caudal are forked. Gill-membranes conjoined and forming a loose flap under the isthmus. Teeth small, acute; and crowded on the jaws and 
vomer *. Scales small, closely tiled, very rough, and ciliated. Very small ones cover the top of the head and opercula. There is one porous row above the lateral line, and two some distance beneath it. In all the species the lateral line is prolonged between the rays of the caudal, and the membrane of that fin is minutely scaly. The scales do not extend to the other fins in this species, though they do in some of the rest.

FIss.-Br. $6 ; P .24 /$ V. $6 ; A .24 /$ C. $17 ; D .46 /$.

Dimensions.

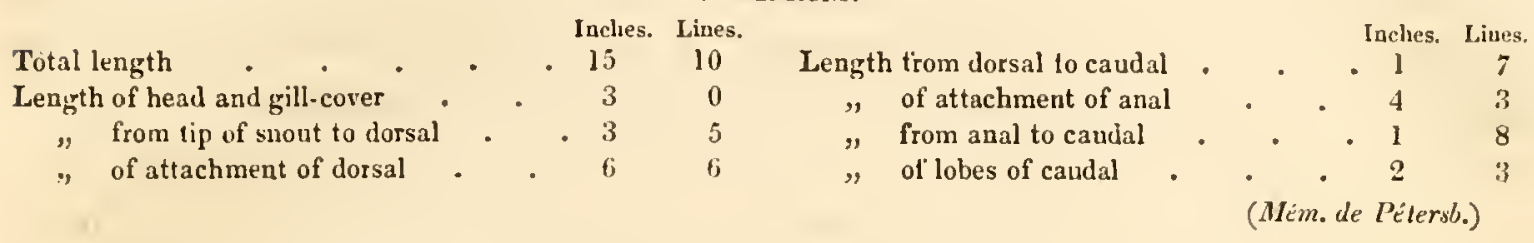

[4\%.] 2. Chirus decagramus. (Cuvier.) Ten-lined Chirus.

Labrax deragrammus. Palias, Mém. de Pétersb., ii., p. 386, t. xxii., f. 2.

\section{This species was taken by Billings off Cape St. Elias.}

It is covered with small roughish scales, which are least on the belly, top of the head, and gill-covers: there are also minute scales on the bases of all the fins betwixt the rays. The rows of pores are five on each side, including the lateral line, and one of them is interrupted between the ventrals and middle of the anal. The dorsal is deeply notched in the middle, the twenty rays of its anterior portion being simple, the twenty-four of its posterior one forked. The gill-cover ends in a membranous point. The body is bluish above, the back and sides being marked with pale and dusky blotches: the belly is whitish. The dorsal is spotted, the pectorals yellowish and clouded, and the anal and caudal blackish.

$$
\text { Fins.-Br. 5; P. 24; V.6;A.24;C. 16;D. 20/24=44. (Mém. de Pétersb.) }
$$

\section{DrMeNSIONS.}

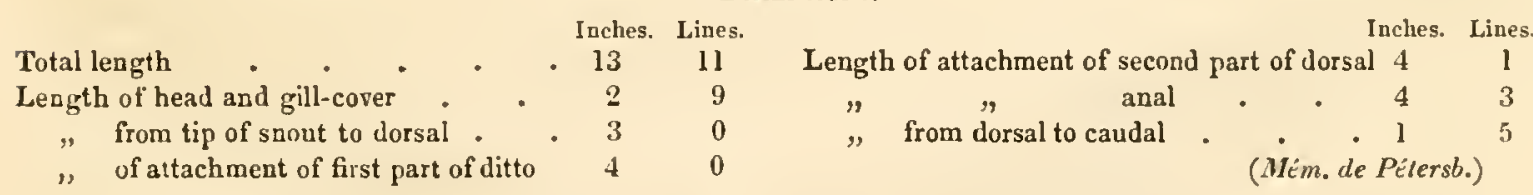

* Labrax lagocephalus and hexagrammus are also mentioned by Pallas as having teeth on the vomer, as we have rendered the expression areola palat; but in the accounts of the other sjecies maxillary teeth only are noticed. Tilesius's figure of Hexagramms S/elleri represents the vomer and palate smooth, and two crowded groups of teeth on the upper pharyngeal bones. Pallas speaking of C. hexagrammus says, "Areola palati ilidem asperata," which refers to the vomer, and not to the palate-boues, as is evident from Steller's more precise language: "paluto medio non procul a labiis pariter areola denticellis obsita est, ut et tuberculum imo ori denticulatum supra gulam ipsam." 
[48.] 3. Chinus octogramus. (Cuvier.) Eight-lined Chirus.

Labrax octogrammus. Pallas, Mém. de Pétersb., ii., p. 393, t. xxiii., f. 2.

This species abounds on the eastern coast of Kanitschatka, and also among the Aleutian Islands. It is named Terpugh, or " the file," by the Russians, on account of the roughness of its scales, and Idgajuk by the Aleutians.

Jaws rough with crowded teeth, the anterior ones of the lower jaw a little longer. Gillcovers ending in a membranous tip. Gill-membranes separate. Scales middle-sized, very finely ciliated, and exceedingly rough. The top of the head, gill-covers, and suborbitars, are covered with minute scales, as are also the membranes of the dorsal and caudal. There are two porous lines above the lateral line, and two below, the one next the dorsal fin short and inconspicuous. The dorsal is notched, the posterior part being higher than the anterior one, but both are supported by setaceous rays, as is also the anal fin. The rays of the pectorals and caudal are bifid. The colour of the back is olivaceous, and it is thickly dotted, as well as the sides, with brownish spots; the belly is yellowish.

Fins. $-B r .5 ; P .19 ; V .7 ; A .24 / ; C .15 ; D .19 / 24 /=43 /$.

\begin{tabular}{|c|c|c|c|c|c|c|}
\hline \multicolumn{7}{|c|}{ DiMENSIONS. } \\
\hline & lnches. & Lines. & & & Inches. & Lines \\
\hline Total length $\cdot$. & .15 & 8 & Length from dorsal to caudal & - & . 1 & $1 \frac{1}{2}$ \\
\hline Length of head and gill-cover . & 3 & 3 & $"$ of attachment of anal & & 4 & \\
\hline$"$ from tip of snout to dorsal & 3 & 5 & from anal to caudal & & . 1 & 7 \\
\hline of attachment of dorsal & 6 & 3 & & & de Péter & \\
\hline
\end{tabular}

[49.] t. Chirus superciliosus. (Cuvier.) Tufted Chirus.

"Lebius, Chirus vel Labrax. Steluer, Obs. Icthyol. Mscr."

Labrax superciliosus. Pallas, Mém. de Pétersb., ii., p. 388, t. xxii., f. 3.

This species was taken abundantly off Unalaschka by Billings, who sent many specimens to Pallas. That author has added to his description, Steller's account of the colours of the recent fish, and also some anatomical observations, which, if there be no mistake as to the identity of the species, are incompatible with the passage in the Règne Animal, which denies caca to this gemus. Steller describes sixteen long pyloric cæca, and two shorter ones. He also says that there is no airbladder, and that the fish feeds upon crabs and worms. 
The Tufted Chirus is distinguished by a sub-cartilaginous six-cleft superciliarly barbel. In this respect, in the thickness of its fins and skin, as well as in its general habit, Pallas thinks that this species is allied to the Blennies. The scales are small, thin, adhering firmly. and are finely streaked and ciliated. The top of the head and the gill-covers are scaly, but there are no scales on the fins, the caudal excepted. 'There are two thick porous lines above the lateral line and two below. The dorsal is notched, the rays of the anterior portion being simple, those of the posterior articulated. The rays of the anal are thick and scarcely forked. Colour of the body brownish-olive, with transverse irregular blotches of pale green. The under jaw, throat, and anterior part of the belly, are tawny-yellow. 'The dorsal is clouded; the pectorals have two broad brown stripes towards their bases, and the anal is marked with about five wavy bands of sea-green.

$$
\text { Fins. }-P .19 ; V .5 ; A .22 ; C .16 ; D .20 / 23=43 \text {. }
$$

Dimensions.

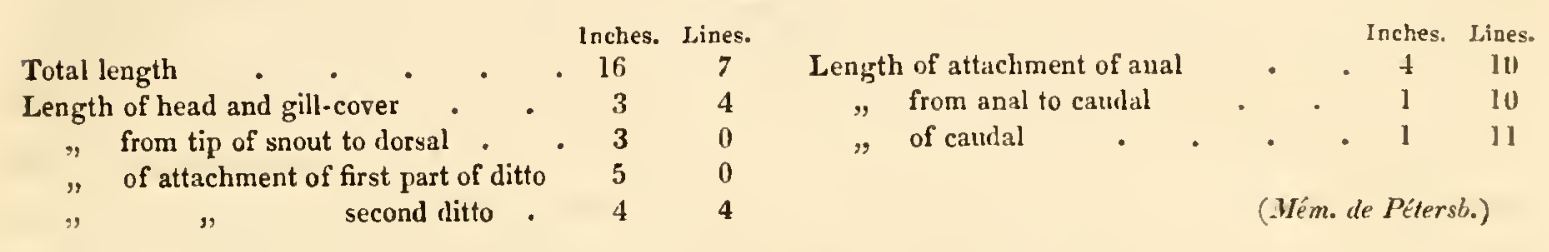

Chirus lagocephalus and hexagrammus are not mentioned as having been taken on the American coast. The latter is considered by Pallas to be the Hexagrammos asper of Steller, and is said to be very frequent during the autumn, in the harbour of St. Peter and St. Paul. Like the C. octogrammus, it is named Terpuck, on account of the rouglness of its scales; and in Pallas's opinion Steller confounded these two species together. In C. hexagrammus the dorsal is deeply notched, and the rays of both parts, and also of the anal, are simple and setaceous. Steller describes it as wanting an air-bladder, and having ten or twelve pyloric cæca. The stonach, which was a sac of the size of a pigeon's egg, with the pylorus on the right side, contained Nereides and roe of fishes.

The Hexagrammos Stelleri of Tilesius is also called Terpuck at Kamtschatka, and is considered by its describer to be the Hexagrammos asper of Steller; but it differs from Pallas': figure of that species in having a three or five-cleft superciliary tuft, and indeed from all the species of that naturalist, in the number of its rays and several other particulars. Tilesius: figure was drawn from a living fish, and ought to be more correct than Pallas's, whose specimens were dried, and who may therefore easily have overlooked the superciliary tuft.s. If deserves to be remarked, howerer, that the number of rays in Tilesius's figure do not correspond with his own description.

$$
\begin{array}{rrrrrrr}
\text { Fins.-Br. } 5 ; P .19 ; & V .5 ; A .22 ; & C .17 ; & \text { D. 20/24. } & \text { C. lagocephalus. } & \text { Pall. } \\
6 ; & 17 / ; & 6 ; & 22 / ; & 14 ; & 22 / 21 / . & \text { C. hexagrammus. Pall. } \\
6 ; & 18 ; & 6 ; & 23 ; & 20 ; & 30,12 . & \text { Hexagr. Stelleri. Tiles. } \\
& 17 / ; & 5 ; & 23 ; & 19 ; & 44 / . & \text { Hexagr. asper. Stell. } \\
& & & & & & \text { Mem. de Pétersb. }
\end{array}
$$




\section{BATRACHOIDEA.LLES PECTORALES PEDICULÉES.}

This family is composed of monstrous-looking acanthopterygious fish, whose pectoral fins are supported upon a kind of arm formed of the elongated carpal bones which in some genera perform the functions of hind feet, enabling the fish to creep over sand or mud like small quadrupeds. The ventrals are jugular, and the gillplates and rays (four, six, or seven) are enveloped in loose skin, which restricts the gill-opening to a small hole. Cutaneous appendages or barbels generally fringe the lips, or whole lower jaw to the pectorals, or even the entire body. The skin, except in some Batrachi, is destitute of scales, but is sometimes partially, or even generally, studded with bony tubercles. The skeleton is, for the most part, but imperfectly osseous. The pyloric eæca, when present, which is rarely, are short, and do not exceed two in number. Some genera have an air-bladder, others want it. In almost all there are two distinct dorsals; and in Lophius and Chironectes an interspinous bone, lying horizontally forwards on the head, supports several moveable free rays, whose summits are often swelled and fleshy, or even foliated or tufted. Batrachus has a spiny operculum and suboperculum, and a flat head broader than the body, but not very disproportionate in length: its gill-opening is situated before the ventrals, and it has two dorsals, the anterior one being supported by spinous rays. Lophius has a depressed form, and Chironectus a compressed one, and both have monstrously large heads, with a small hole behind the pectorals for an opening to the gills. In Malthe the head is flat, and greatly lengthened laterally by the projection of the large subopercula. Its gills open by a hole above and behind the arms which support the pectorals.

The Batrachoidex can live long out of the water, in consequence of the smallness of their gill-openings. The Chironectes, in particular, are able, even in warm countries, to pass two or three days in creeping over the land. All the Batrachoideæ conceal themselves in the mud or sand, and lie in wait to take their prey by surprise. Those species which have free rays on the head, with summits resembling worms, are said to move them backwards and forwards for the purpose of enticing small fish within their reach, and hence the name of "fishing-frogs" has been popularly applied to them. The Batrachoideæ exist in the Atlantic, Indian and Pacific oceans. Several inhabit the European seas. Lophius pisca- 
torius*, Chironectes lavigatus (or Lophius gibbus, Mitchill), Malthè vespertilio (Loph. vespert., Schœpf.), Batrachus tau (Loph. bufo, Mitch., or Batr. vernueil, Le Sueur), B. variegatus, Le Sueur, and Batrachus grmmiens (or Cottus grmniens, L. Schœpf.) frequent the sea of New York.

The Thutinameg, or Wind-fish of Hudson's Bay, which is said to come to the surface in windy weather only, belongs most probably to this family. It is, indeed, referred by Pennant to Lophius piscatorius, but on the authority merely of a short notice by Mr. Hutchins. It does not occur in the Fanna Gronlandica.

[50.] 1. Lophius (Malthe) cubifrons. (Richardson.) Square-browed Malthe.

Fasily, Batrachoideæ. Genus, Lophius. Lins. Sub-genus, Malthe. Cuv.

The sub-genus Malthe has the following characters assigned to it in the Rìgne Animal. The head much depressed and greatly widened by the jutting out of the elongated subopercula; the eyes far forward; the snout projecting like a small horn; the protractile mouth, of a moderate size under the snout; the gill-membranes sustained by six or seven rays, and opening on the dorsal aspect by a hole above each pectoral; a solitary, small, soft dorsal; the body studded with bony tubercles and furnished along the sides with barbels, but no free rays on the hearl; neither pyloric cæca nor air-bladder.

Mr. Audubon has very kindly presented to me a fish of this sub-genus, taken on the Labrador coast, which appears to belong to a species hitherto undescribed. I have compared it with the figures of Malthe vespertilio (Bl. 110 and Edwards 283), of $\boldsymbol{M}$. nasuta (Seba., i., 74, f. 2), and of M. stellata (Krusenstern's Voy., lxi., lower fig.), to all of which it is very dissimilar in the form of the cranium, and particularly of the snout. Three other species are indicated in the Reigne Animal, which are still unpublished; viz., M. notata, angusta, and truncata. 'The last of these names is the only one which is in any respect applicable to our new species, in which the forehead may be said to be truncated, instead of gradually narrowing into a projecting snout. I have received no account of the habits of the Square-browed Malthe. Its intestines were filled with small crabs and uni-

\footnotetext{
* The Lophius piscalor, or Bellows-fish, of Mitchill, as far as his description goes, does not appear to differ from the L. piscntorius of the European seas. His variety, folialus, is most probably a distinct species.
} 
valve shells, none of them crushed, the shells passing entire, per anum, after their inhabitants have been digested.

\section{DESCRIPTION}

Of a specimen taken on the Labrador coast and preservtd in rum.

Form-much depressed, the head very wide posteriorly from the spreading of the subopercular bones. The body tapers gradually from behind the pectorals to the caudal fin, becoming at the same time less and less depressed, the extremity of the tail at the insertion of the caudal fin being decidedly compressed. The gill-openings are about midway between the snout and end of the tail, and the anus is halfway between the pectorals and anal fin, or very little posterior to the gill-openings. The head (excluding the gill-plates), or rather the craniun, which is slightly moveable on the spinal column, is not at all disproportioned to the size of the fish; it has a cubical form, and the large eyes, having a perfectly lateral aspect, occupy the anterior halves of its sides. The upper surface of the cranium is flat, slightly hollowed between the orbits, where it is narrower, becomes again wider before them, and arching a little in a longitudinal direction, terminates abruptly and evenly, being supported on each side by a vertical pillar that forms the anterior margin of the orbit. On the edge of the forehead, between the tops of these pillars, there is a rounded knob about the size of a grain of duck-shot, coarsely granulated like the rest of the skin, and very unlike the tapering, acute snouts of $M$. vespertilio, nasuta, or even stellata. Beneath the knob-like snout, and between the shafts of the pillars above mentioned, there is a deep circular cavity, which is lined by a whitish membrane. A canal capable of receiving a crow-quill passes from the bottom of the carity between the orbits to the back part of the cranium. From under the orifice of the canal there proceeds a long barbel, composed of a bony ray with a thickened tip and a coating of soft skin : it is apparently capable of being protruded from the cavity, or retracted within it, at the pleasure of the fish. The nostrils open by two small orifices before the base of each of the orbital pillars. The mouth is situated directly under the anterior margin of the forehead when it is closed, and from the lower jaw inclining upwards the commissure of the lips has then a crescentic form; but when the mouth is open the descent of the lower jaw causes the intermaxillaries to advance on their pedicles, so that its orifice, which is then circular and about equal in diameter to one of the orbits, is protruded beyond the snout. The labials lie in the membrane behind the intermaxillaries.

TEETH-like very fine shorn velvet, cover the opposing surfaces of the intermaxillaries and lower jaw, the whole upper surface of the tongue, a broad rectangular plate on the vomer, a smaller contiguous plate on each palate bone, and four convex plates on the upper side of the gullet-the pharyngeal teeth being rather coarser than the others.

GıLL-Covers. - The very thick, nearly semicylindrical suboperculum extends from the cheek to the middle of the arm that supports the pectoral fin, rendering that part of the fish much wider than the borly. The thin, flat, nearly horizontal operculum, fills part of the space between the suboperculum and the spine. The gill-opening is a small round hole, situated between the arm of the pectoral and the spine, and opposite to the extremity of the suboperculum. 
The SkIN is every where closely covered with rough roundish grains, which are much smaller on the under surface of the fish. On the dorsal aspect of the head and body there are also many seattered, conical, granulated, bony tubercles, the largest being about the size of a split pea, occupying the middle of the back, and the roughest ones margining the sides of the tail. There are no restiges of any barbels on the sides of the head or body.

FiNs.-D. $5 ; C .9 ; A .4 ; V .5 ; P .11$.

The rays of the fins are with difficulty discernible through the thick and partially granulated skin which envelops them. They are all articulated. The pectorals have a fan-like form ; their rays, which are jointed but undivided, being about equal in length to their carpal elongation or arm. The ventrals, attached opposite to the middle of the preoperculum, are dilated and truncated at their ends. The anal fin is far back, and is about half the size of the ventrals: all its rays are articulated. The dorsal very small, and situated a little posterior to the anus, but a considerable distance before the anal fin contains five undivided rays, all articulated at the tips. The caudal is rounded at the end: its rays are forked and project a little beyond the membrane.

CoLovr.-The specimen has been so long immersed in rum, that its original colour cannot be determined. At present, its upper surface is greyish-white, with some brown blotches, as if of dirt, adhering to the grained skin. The caudal and pectorals are whitish, with small round brown spots. The under surface of the body is uniformly greyish-white.

InTEstines. - The stomach is a thin bag, an inch and a half long by an inch wide; the pylorus much contracted, being at one side of the fundus; the rest of the gut is delicate, having a diameter of about a quarter of an inch, and a length exceeding thrice that of the fish, being twice doubled upon itself. There are neither cæca nor air-bladder. The liver is large and oily.

\section{Dimensions.}

\begin{tabular}{|c|c|c|c|c|}
\hline \multirow{2}{*}{\multicolumn{3}{|c|}{ Length from frontal tubercle to tip of caudal }} & Inches. & Lines. \\
\hline & & & 7 & 8 \\
\hline ", & , & base of caudal & 6 & 5 \\
\hline :, & 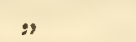 & dorsal & 4 & 0 \\
\hline , & 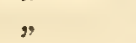 & gill-openings . & 3 & 2 \\
\hline$"$ & , & tip of suboperculum & 3 & $2 \frac{1}{2}$ \\
\hline$"$ & tip of unde & jaw to tip of caudal & 7 & 6 \\
\hline : & , & anal fin & 4 & 10 \\
\hline , & " & anus. & 3 & 4 \\
\hline$"$ & $"$ & ventrals . & 1 & 10 \\
\hline & , & base of rays of & & \\
\hline pectorals & - & . . . & 4 & 10 \\
\hline ", & ; & tips of ditto & 5 & 0 \\
\hline
\end{tabular}

\begin{tabular}{|c|c|c|c|c|c|c|}
\hline \multirow{3}{*}{\multicolumn{3}{|c|}{$\begin{array}{l}\text { Diameter of orbit } \\
\quad \| \quad \text { orifice of mouth }\end{array}$}} & & & \multirow{2}{*}{ Inches. } & \multirow{2}{*}{$\begin{array}{c}\text { Lines } \\
7\end{array}$} \\
\hline & & & . & & & \\
\hline & & & • & $\cdot$ & 0 & 6 \\
\hline Distar & e of ditto beneath sno & & • & & 0 & 3 \\
\hline Lengt & of intermaxillary & & $\cdot$ & . & 0 & 6 \\
\hline ," & labials . & & & & 0 & 7 \\
\hline " & limb of under jaw & & • & & 0 & 7 \\
\hline ” & suboperc & • & •• & & 2 & 3 \\
\hline ", & rays of pectorals & & & & 1 & 3 \\
\hline ,. & " caudal . & & & & 1 & 5 \\
\hline " & " ventrals & - & - & • & 1 & 3 \\
\hline$"$ & " anal . & - & P & & 0 & 10 \\
\hline ", & omach & & & & 1 & 6 \\
\hline & of small intestines & & & & .24 & \\
\hline
\end{tabular}




\section{LABROIDEÆE.}

The fish of this family are readily recognisable by their general aspect, their oblong scaly body, and single dorsal, whose anterior rays are spinous, with often a shred of membrane attached to them. Their pharyngeal bones are armed with teeth stronger than usual, but varying in form in the different genera. They have a strong air-bladder, and either no cæca or only two very small ones. The Linnæan genus Labrus forms a group which is distinguished by having one set of lips attached to the sub-orbitars, and another to the jaws, close gill-membranes supported by five rays, conical jaw teeth, the anterior and middle ones longest, and plaryngeal teeth in form of paving stones. The minor groups are characterised by combinations of several varieties of structure, such as the smoothness or scaliness of the head, the presence of denticulations on the preoperculum, the protractility of the mouth, which, in several sub-genera, can be projected in a tubular form, so as to seize small fish that are swimming within its reach, the straight or broken lateral line, the encroachment of the scales on the caudal, or even on the other vertical fins, as in the Chætodontoideæ, the prolongation of the first dorsal rays by long filaments, and some differences in the dentition. In the sub-genus Anampses the jaws are armed with only two flat teeth, which project from the mouth and curve outwards. The genus Xirichthys differs from Labrus chiefly in its very compressed form and the vertical profile of the head: it has large scales and an interrupted lateral line. Chromis resembles Labrus except in the jaw and pharyngeal teeth being in card-like plates, the vertical fins filamentous, and the lateral line interrupted. Cychla has all the teeth like velvet pile and in broad stripes. Plesiops differs from Chromis in having a compressed head and very long ventrals. Malacanthus, with the general characters and jaw teeth of Labrus, has the pharyngeal teeth of Chromis, the operculum ending in a small spine, and a long dorsal in which the spines are very few, slender, and flexible. Scarus is remarkable for convex jaws covered anteriorly and on their edges with teeth like scales. The pharyngeal teeth are in transverse plates, the sub-orbitar lips of the preceding genera are wanting, there being only those on the jaws, the scales are large and the lateral line interrupted. Calliodon and Odax, with some of the characters of Scarus, have others more closely resembling Labrus.

Many of the Labroideæ are remarkable for the intensity and purity, as well as 
brilliancy of their colours. They are very generally distributed, being found in all parts of the ocean, and also in lakes and rivers. Upwards of forty species exist in the European seas, chiefly in the Mediterranean, though there are several in the North Sea. The following occur on the coast of the United States: Labrus Americanus (L. tautoga, Mitch.), Cheilinus radiatus, Lachnolaimus suillus, Crenilabrus burgall (L. chogset, Mitch.), Xirichthys psittacus, X. lineatus, and some others.

Fabricius, while sailing along the Greenland coast, saw a fish of a shining blue colour swim past. The Greenlanders named it Keblernak, and Fabricius supposes that it may have been the Labvus exoletus of Linnæus, a North Sea fish, which is a Crenilabrus in Cuvier's system, and is remarkable for having five spines in its anal fiu. The sub-genus Crenilabrus is distinguished from the true labri solely by having a denticulated preoperculum. Its numerous species were included by Bloch in his genus Lutjanus.

\section{FISTULAROIDEA.-LES BOUCHES EN FLUTE.}

ThIs family is characterised by a long tubular muzzle, formed of the prolonged ethmoid, vomer, preopercular, interopercular, pterygoid, and tympanitic bones, at the extremity of which is the mouth, composed as usual of the palate bones, intermaxillaries, labials, and lower jaw. The intestinal canal is either straight and furnished with two cæcal appendages, or destitute of cæca, and twice or thrice doubled upon itself. The air-bladder is in some extremely small, in others of a moderate size, or even very large. The gill-rays are six or seven in number, or only two or three, and very slender. The scales are of a moderate size or small, or even so minute as to be invisible. 'The forepart of the back is more or less perfectly protected by osseous or scaly plates, which, in some instances, exist also on the flants. The dorsal is either single and supported, like the anal to which it is opposed, mostly by simple rays, or it is preceded by free spines, or there are two dorsals, the soft one being generally far back. There are two generic groups, $F i s-$ tularia, in which the body is cylindrical, and Centriscus, in which it is compressed and oval.

Fistularia tabaccaria frequents the const of the United States, $F$. serrata the West Indies and sea of Brazil, Centriscus scolopax inhabits the Mediterranean. Most of the others belong to the Indian Ocean. 
The preceding family is the last of that division of the Osseous Fishes which is named Acanthopterygian, or Spiny-finned, on account of the spinous rays which support the whole of the first dorsal, when there are two of these fins, or the forepart of the fin when there is only one: in some instances all the rays of a solitary dorsal are spinous, and occasionally the spines are free or unconnected by membrane. The anal has also one or more spinous rays, and there is generally one in each ventral. Several genera, however, are admitted into the division, although the spinous character of their fins is very imperfect, and also some which are absolutely destitute of spines*, because their habits and their anatomical structure, in general, ally them intimately with groups that are decidedly acanthopterygian.

The exposition of Cuvier's system of arrangement occupies more space in the preceding pages, than may appear to be necessary in a local Fauna; but we found it difficult to give, in any other way, correct characters of the various groups of spiny-finned fish which fall within the proper scope of the work, or to exhibit their true situation in the system, without a reference to the intermediate or connecting families. For it happens that this great division, though richer in genera and species than any other, does not admit of being split into orders, its only practicable subdivision being into natural families, which are so intimately linked to each other, that, as Cuvier says, the whole division might be considered as one great family. Owing to this close dependence of one group of acanthopterygii upon another, they are often more readily distinguishable by comparative characters than by positive ones, thus requiring the whole series to he noticed. These remarks are not so applicable to the remaining divisions of the class, and we shall, therefore, in treating of them, greatly restrict our quotations from Cuvier. 


\section{MALACOPTERYGII ABDOMINALES.}

The second division of osseous fishes is named Malacopterygian, or Soft-finued, because all the rays of the fins are articulated, excepting sometimes the first of the dorsal or pectorals. It can be conveniently divided into three orders, named Abdominal, Jugutar, and Apodal, from the position of the ventrals on the hinder part of the belly, their suspension to the humeral bones, or their total absence. 'The first order, or that in which the ventrals are attached to the belly behind the pectorals, but unconnected with the humeral bones, is the most numerous of the three, and includes most of the fresh-water fish. It contains five families, of which the first is the

\section{CYPRINOIDEF.}

Fish of this family are readily distinguishable by their slightly-cleft mouth, furnished with weak and frequently toothless jaws bordered by the intermaxillaries; by their strongly-toothed pharyngeal bones; and by the fewness of their gill-rays. They have a scaly body, no adipose fin, a stomach destitute of a cul de sac, and no pyloric cæca. They abound in the fresh waters of all quarters of the world, and are the least carnivorous of fishes. They exist in the aretic regions of the North American continent, as high as the 68th parallel, though it is remarkable that none occur in the Fanna Gronlandica, nor were any detected on the North Georgian islands, or Boothian peninsula, by the recent expeditions. The following North American species are indicated in the Règne Animal:-Barbuss species nova; Labeo cyprinus (Catastomus cyprinus, Le Sueur); Catastomus, 17 species; Lenciscus species nova; Pacilia multilineata, Le Sueur; Lebias ellipsö̈dea, Le Sueur; Fundulus canicolus, Valenciennes (Cobitis heteroclita, Linn., Mud-fish, Schœpf.); Fundulus fasciatus, Valen. (Esox pisciculuss et zonatus, Mitch.); Molinesia latipinna, Le Sueur; Cyprinodon flavulus, Viten. (Esox flavulus, Mitch., Pacilia majalis, Schn.); Cyprinodon ovinus (Eswx ovinus, Mitch.). In Dr. Mitchill's paper on the New York fish, we find the following, which are not in the above list: Cyprimus oblongus, very probably a Labeo; 
and C. chrysoleucas and atronasus, which are most likely Leucisci. Notwithstanding that Dr. J. V.C. Smith has mentioned as inhabitants of the waters of Massachusetts the Gold-fish of China, and the species so well known to European anglers by the names of Roach, Dace, Bleak, and Chub, we require more circumstantial evidence before we can venture to affirm that any of the Cyprinoideæ are common to the Old and New Worlds.

\section{[5l.] 1. Cyprinus (Abramis?) Smithil. (Nob.) La Quesche.}

\section{Family, Cyprinoideæ. Genus, Cyprinus. Sub-genus, Abramis, Cuvirr.}

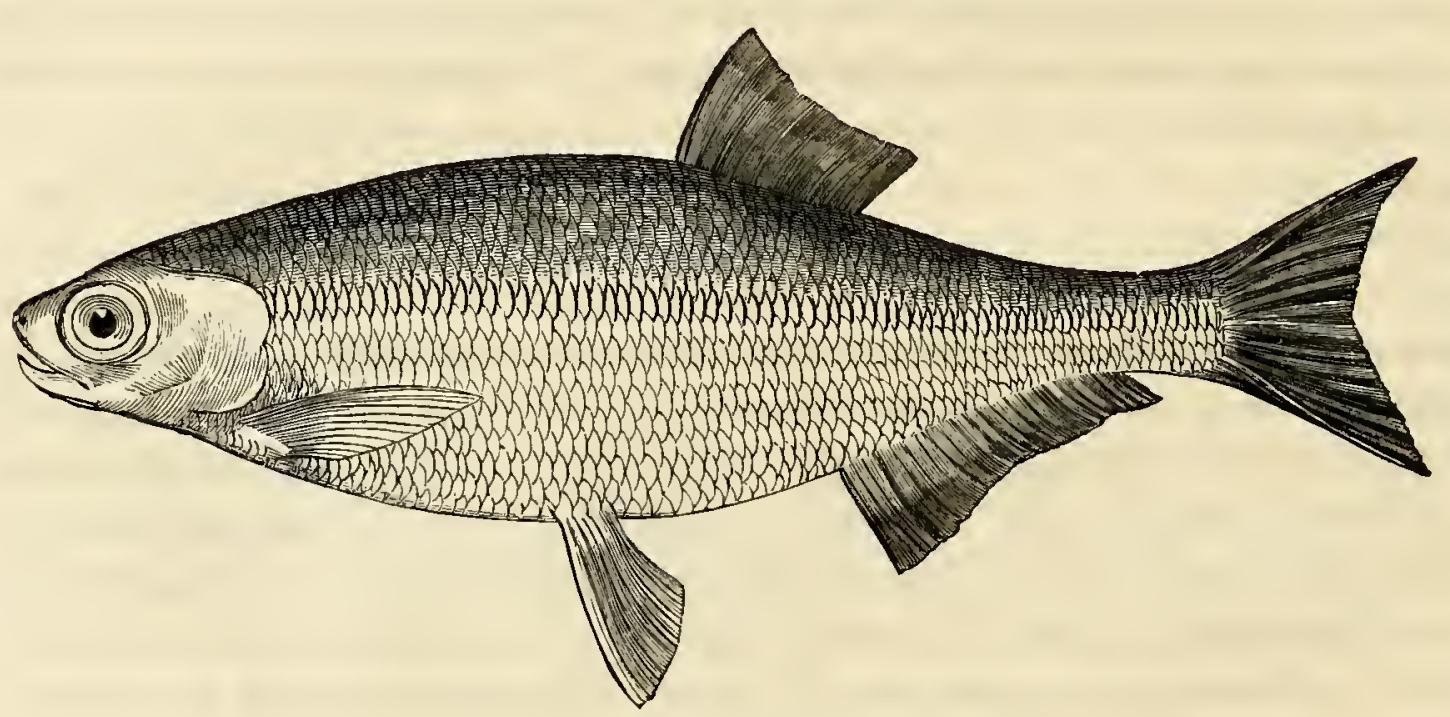

The Cyprini form a very numerous and extremely natural generic group, and may be easily recognised by the small mouth, toothless jaws, and three flat gillrays. The tongue is smooth; the palate is lined by a thick and highly-irritable substance, known vulgarly under the name of the carp's tongue; and the gullet exhibits a powerful masticatory apparatus: viz., large teeth attached to the lower pharyngeal bones, and fit for squeezing the aliments against a stony or enamelled disk, which is set in a process of the basilary bone. The dorsal is single, and the body covered by scales which are often of a great size. The Cyprini inhabit fresh waters, and are perhaps the least carnivorous of all fish, living in a great measure on seeds, herbs, or even mud. Their stomach is continuous with the intestine, 
which is destitute of crea, and the air-bladder is divided into two by a contraction. Cuvier distributes the fish of this genus into nine sub-genera, which are distinguished from one another by the extent of the dorsal and anal fins, the spinous or articulated structure of their second rays, the position of the dorsal, the smallness of the scales, the presence of barbels on the upper jaw or angles of the mouth, and the size and form of the lips. The sub-genus Abramis is characterised as having a short dorsal situated farther back than the ventrals, and a long anal, but neither spinous rays nor barbels. To this sub-genus I have, for the present, referrer the Quesche of the Canadians, a cyprinoid fish, of which Lieutenant-Colonel C. H. Smith has sent me a brief notice, accompanied by a drawing, which is copied in the annexed wood-cut*. In profile, and in the relative size and position of the fius, the Quesche bears a resemblance to the common Bream ; but one of the rays of its dorsal and anal being spinous, it does not correspond in that respect with the character assigned to Abramis by Cuvier; and the size of its anal fin excludes it from the sub-genus which contains the true Carps. The very forward position of the nostrils is unusual, and its toothed tongue is at variance with the definition of the genus Cyprinus. Its specific name is intended as a compliment to its highlytalented discoverer.

"The specimens were taken in the Richelieu, at its confluence with the St. Lawrence, and were all about nine or ten inches long; in form much compressed, the back arched, the dorsal nearer the tail than head, the anal long and oblique, extending to near the caudal fin. which is forked with pointed lobes, the eye very large and near the snout, the nostrils opening on the tip of the latter, the under jaw longest, the tongue toothed, gill-covers round and smooth, lateral line straight, containing sixty scales, scales commencing on the forehead above the eyes, rather large, shining, and pellucid, reflecting a brilliant green on the back, but having a silvery lustre on the sides and abdomen. I do not know in what division to place it, for though it has the form of an Abramis it has a spinous ray in the dorsal and anal, and teeth on the tongue.

"Fins.-Br. 3. P. 12;V.7;D. 1/12;A. 1/27;C. 18." (Ммітн in lit.)

- The wood-cut is a correct copy of Colonel Smith's sketch except in the scales, which are too small and crowded on the posterior part of the body. There ought to be only sixty scales on the lateral line, as mentioned in the text. 


\section{[52.] 1. Cyprinus (Catastomus) Hudsonius. (Le Sueur.) Grey Sucking-carp.}

Family, Cyprinoideæ. Genus, Cyprinus, Cuv. Sub-genus, Catastomue, Le Sueur.

Cyprinus catastomus. Fonster, Phil. Tr., 63, p.158, t. vi. An. 1779.

Namaypeeth and Sucker. PenN., Arct. Zool., Intr., p. cexcix., and ii., p. 402.

Catastomus Hudsonius. Le Suevr, Ac. Se. Phil., i., p. 107. Richardson, Fr. Journ. p. 717. An. 1823.

Grey Sucker. Fur Traders. Carpe blanche. Canadians. Namaypeeth. Crees.

In the Règne Animal the sub-genus Catastomus is characterised as having the same kind of thick, pendent, fringed or crimped lips with Labeo; and the short dorsal of Leuciscus opposed to the ventrals*. The species inhabit the fresh waters of North America. The first that we have to notice is the Grey Sucking-carp, or Namaypeeth of the Cree Indians. It is a common fish in all parts of the fur countries, abounding in the rivers, and even in land-locked marshes and ponds, but preferring shallow grassy lakes with muddy bottoms. In the beginning of summer it may be seen in numbers forcing its way up rocky streams, and even breasting strong rapids, to arrive at its proper spawning places in stony rivulets: soon afterwards it returns to the lakes. Its food, judging from the contents of the stomachs of those which I opened, is chiefly soft insects; but in one I found the fragments of a fresh-water shell. In the winter and autumn it is caught in nets, and in the spawning season (June) may be readily speared, or even taken by the

* Mr. Le Sueur's account of the genus is as follows:- "Back with a single fin. Gill-membrane three-rayed. Heal and opercula smooth. Jaus toothless and retractile. Mouth beneath the snout; lips plaited, lobed, or carunculated, suitable for sucking. Throat with pectinated teeth."-He adds some particulars applicalle to the sixteen species which he detected in the waters of the United States. "Scales in almost all marked with radiated lines, and fimbriated on their edges; their form more or less rhomboidal or roundish. Gill-covers large, and composed of three pieces; the anterior one small in some, as in macrolepidotus, large in others, as in communis : opening wide. Teeth none in the jaws, but those of the throat, on each side, are composed of a range of bones generally blunt and thick at their summits, placed in a pectinated form on an osseous arcuated bone, of which they are a component part, and sumetimes terminated in a hooked point as in maculosus. The teeth are enveloped in a thick mass of a whitish substance, which covers the throat and supplies the place of a tongue. Mouth generally lunated: to the palate is attached a membrane. Viscera.-The intestinal canul is very much developed, and it has its origin near the throat; the stomach is simple and without plaits or curvatures, being a continuation of this canal, and appearing to be confounded with it. The intestines make a numher of convolutions : in a macrolepidotus, sixteen inches long, they measured three feet five inches. The liver is deliquescent and soon passes into oil after exposure to the atmosphere. The air-bladder is sub-cylindric and is divided in most species into two parts:-in macrolepidotus it is divided into four. In the intestines river-shells (Lynnea, Bulimus, \&c.), which dwell on aquatic plants and on rocks or bottoms of rivers, are found. The Catastomi are enabled to take these shells by means of their lips, which are protruded forwards by their jaws. It is necessary to remark, that in all the species which I have examined, there is a line that runs from the nape beneath the eyes, and another along the head above the eyes, of small orifices for the passage of mucus; which lines are well defined after the fish is dried and desiccated, but not so conspicuons when recent. Some species also, in a dried state, have a tuberculated appearance on the head, not discernible in the living fish." Le Sueur, l. $c$. 
hand, in shallow streams. It is a very soft watery fish, but devoid of any unpleasant flavour, and is considered to be one of the best in the country for making soup. Like its congeners it is singularly tenacious of life, and may be frozen and thawed again without being lilled.

\section{DESCRIPTION}

Drawn up from recent specimens at Cumberland-House, lat. 54, March 10th, 1820.

Form.-The head is smooth, flattened laterally and on the vertex, convex before the eyes, with an obtuse snout : it increases in thickness, gradually, from the nose to the nape, which is broader than the shoulders. The greatest girth of the body is about half way to the dorsal fin, from thence it tapers till it passes the anal fin, and the tail is nearly linear: the depth of the body exceeds its thickness rather more than one half. The sides and back are somewhat flattened. The lateral line runs equidistant from the back and belly, straight till it comes opposite to the anal fin, when it inclines upwards at a very obtuse angle, and passes along the middle of the tail, giving that member a direction slightly different from that of the body. Scales for the most part broadly oval, or nearly obicular, and of a medium size, being one quarter of an inch in diameter. They are larger towards the tail, and smaller on the belly, particularly between the pectorals. The uncovered portion of each scale is vertically oval, and is marked with diverging lines corresponding to obscure crenatures on the edge.

HEAD constituting one-fifth of the total length. The eyes are situated about one diameter of their orbit distant from the upper part of the gill-opening, and twice as far from the tip of the snout. The nostrils are placed immediately before the eyes; the anterior larger opening has a soft skinny lid which shuts it when thrown forwards, and when turned backwards closes the posterior smaller opening. GiLL-covers.-The operculum is thrice the size of the suboperculum; their free edges unite into an even elliptical curve. The interoperculum has a narrow upright limb connected to the whole anterior edge of the operculum. The preoperculum, somewhat crescentic in form, is broader but shorter than the interoperculum, being included within its limbs. Various lines and tubercles, very evident on the head of the dried specimen, are not perceptible in the recent fish, the whole head being covered with a thick, smooth, mucous skin. The brain is protected by a piece of cartilage which, on maceration or boiling, drops out, leaving a rectangular opening before the nape one inch long and a quarter of an inch wide *.

Mouтн retractile, placed under the snout, and capable of being protruded a very little beyond it. Lips attached to the internaxillaries and lower jaw, studded with large soft papillæ, most conspicuous on the lower lip, which is much more dereloped than the upper one, and expands into two pendulous flaps. The commissure of the closed lips is shaped like a horse-shoe, but when the jaws are extended, the orifice of the mouth is nearly quadrangular, and wide enough to admit the point of the fore-finger. There are no barbels. The palate

* When the head is cooked the brain becomes visible through this opening, and is supposet, by the Indians, to be a small frog, which resides within the head of the fish. 
is lined by a thick, gelatinous, light-red membrane, which rises anteriorly into two uvula-like eminences. A furrow which commences between these is closed at the back of the palate by a large pulpy cushion, against which the branchial arches can be pressed. This cushion conceals a number of small bones and cartilages that lie between the extremities of the branchial arches. Attached to the posterior part of the cushion there is a white, firm, cordiform substance, which lines an irregular cribriform plate projecting from the basilary process of the occipital bonc. There are no teeth, but their place is supplied in the following manner. The two inferior pharyngeal bones have, when united, the form of a horse's hoof, and go nearly two-thirds round the pharynx. From the edge of each bone thirty-six processes spring in a pectinated manner; they are compressed laterally, somewhat chub-shaped, a little worn on their summits, and gradually diminish in size as they recede from the median line: two or three of the lowest and largest project through the very soft lining membrane, exhibiting narrow crowns of a very compact texture resembling enamel : the smaller pro cesses are tipt with soft pulpy rakers, having the form of those on the branchial arches. A strong muscular apparatus surrounding the pharynx, serves to press these parts against the cordiform cushion above mentioned with sufficient force to bruise the substances on which the fish preys. There are no superior pharyngeal bones, unless the irregular expansion of the basilar process may be so denominated. The rakers consist of a double row of thin and rather rigid crests, with scolloped edges springing from the inner margins of each branchial arch.

Fins.-Br. $3-3 ; P .17 ; D .12$ to $14 ; V .10 ; A .7$ or $8 ; C .18 \frac{3}{3}$.

The gill-membranes are united to each other by a plicated skin, destitute of scales and separated from the integuments of the abdomen by a transverse superficial furrow. They contain on each side three broad flat rays. The pectoral fins are elliptical, and contain seventeen crowded rays, of which the first is the strongest, its articulations being scarcely perceptible towards its base, and the fifth or sixth is the longest, the more posterior ones diminishing rapidly in length and strength. The ventrals, placed a little nearer to the gill-openings than to the caudal fin, have an obovate outline : their second ray is the strongest ; the first, which is half the length of the second and closely applied to it, appears upon a cursory examination to be spinous; but when it is divested of integument, some articulations may be perceived with a lens. The anal, extending to within its own length of the caudal, contains eight, or sometimes only seven, thick rays, the first short and scarcely perceptibly articulated; the others divided at the tips. When this fin is turned backwards its tip reaches the base of the caudal. The caudal has eighteen rays, with three short ones above and below : its margin is slightly crescentic. The dorsal is nearly quadrangular, and contains generally thirteen rays, though some specimens have one over or under that number: the second ray, about half as long as the succeeding one, appears to be spinous, or, at least, its articulations are not perceptible even through a lens: the first is so short as not to be readily discovered, and is closely applied to the second; the other rays are distinctly articulated, except at their bases, and divided twice or thrice at their summits, which spread slightly.

CoLour.-Back and sides bluish-grey with considerable lustre, the back being darkest, and 
the tint of the sides gradually passing into the pearl-white of the belly. Dorsal and candal fins bluish-grey : pectorals and ventrals ochre-yellow tinged with red: anal flesh-red. Irides saffron-yellow with pearly lustre.

Istestines.-The intestinal canal, in its eourse from the gullet to the anus, makes four conrolutions and a half, and bears a proportion to the length of the fish, excluding the caudal fin, of 50 to 18: the proportions, however, vary a hittle in clifferent individuals. At the commencement of the canal there is a very short, thick, glandular essophagus, succeeded by a stomach whose cliameter exceeds that of the rest of the intestine only so much as to leave a gibbosity at what may be termed the pylorus, or first turn of the intestine. From this turn the diameter of the gut, and the strength of its coats, dininish gradually: its inner membrane forms delicate and minute longitudinal wrinkles, waved and indented into each other in a very beautiful manner. There are no ccea. The lobes of the liver are unmerous and greatly involved in the folds of the intestine: the colour of the liver is pale. The gall-bladder lies between the intestines and air-bladder: its duct enters the stomach within an inch of the gullet: the bile is pale. 'The spleen is large and lies in a semicircular form round the exterior' conrolution of the intestine. The air-bladder extends the whole length of the cavity of the abdomen, and consists of two divisions, united by a very short tube which is bound to the spine by a strong fold of peritonæum : the upper division is the shortest, and is enveloped by a remarkably thick, shining, white capsule, which adheres strongly at its upper end to the spine and septum of the thorax: the bladder may be thrust from its capsule by a slight force. The proper eoats of the air-bladder are much thinner, but firmer and stronger than the eapsule. A small tube proceeds from the top of the lower division of the air-bladder, but its termination was not traced. The kidneys, as long as the cavity of the abdomen, are connected superiorly by a transverse lobe; and the urinary bladder is a long tube whose calibre scarcely exceeds the joint diameters of the ureters. The lining of the abdomen is white. Many small parasitic uorms were found attached by a kind of proboscis to the interior of the intestinal canal.

\section{Dimensions.}

\begin{tabular}{|c|c|c|c|c|c|c|c|c|c|c|}
\hline \multirow{2}{*}{\multicolumn{4}{|c|}{ Length from end of snout to tips of caudal }} & \multirow{2}{*}{$\begin{array}{c}\text { Inches. } \\
21\end{array}$} & \multirow{2}{*}{$\begin{array}{c}\text { Lines. } \\
\quad 9\end{array}$} & & & & \multirow{2}{*}{$\begin{array}{l}\text { Inches. } \\
\cdot 3\end{array}$} & \multirow{2}{*}{$\begin{array}{c}\text { Lines } \\
2\end{array}$} \\
\hline & & & & & & Length of pectorals & . & & & \\
\hline ", & ," & end of scales on ditt & tto . & .18 & 9 & Height of dorsal . & . & & 2 & 2 \\
\hline ", & , & beginning of anal & . & 15 & 6 & Length of its attachment. & . & & 3 & 0 \\
\hline , & , & first ray of ventrals & $\mathrm{s}$ & .10 & 7 & , ventrals . & . & & 2 & 2 \\
\hline , & , & ditto of dorsal & . & 9 & 0 & Depth of anal & & & 2 & 11 \\
\hline , & , & edge of gill-cover & - & 4 & 0 & Length of its attachment & 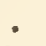 & & 1 & 4 \\
\hline , & , & nape $\cdot \quad \cdot$ & . & 3 & 6 & Space between it and base of caudal & al & & . 2 & 1 \\
\hline & ” & centre of orbit & - & . 2 & 3 & Depth of body before dorsal & - & & 3 & 7 \\
\hline Bread & of & pe . . . & . & 2 & 2 & Weight of recent fish & & & . 5lbs. & \\
\hline
\end{tabular}

Dr. Gairdner has forwarded to me from the Columbia and its tributaries several specimens of a catastomus, which agrees both externally and internally with the preceding, except in the belly being tinged with ochre-yellow. The stomach of one of them is filled with very young shells, apparently of an Unio. There are from 74 to 77 scales on the lateral-line, 46 vertebræ in the spine, and from 15 to 17 rays in the dorsal fin. 


\title{
[53.] 2. Cyprinus (Catastonus) Forsterianus. (Rich.) Red Sucking Carp.
}

\author{
Cyprinus catastomus, var. Forster, Phil. Tr., lxiii., p. 158. An. 1779. \\ Mithomapeth. Penn., Arct. Zool. Intr., p. ccxcix. \\ Catastomus Forsterianus. Richardoson, Fr. Journ., p. 720. An. 1823. \\ Red Sucker. Fur Traders. Meethqua-maypeth. Crees.
}

This fish is well known in every part of the country that lies north of Canada : we found it in Lake Huron and Great Slave Lake, and north of the latter it exists in greater abundance than the preceding species, which it entirely resembles in its labits. It makes a more gelatinous soup than any other of the northern fish, and is the best bait for trout or pike. It spawns in June. Though Forster has ranked it merely as a variety of the preceding, it is perfectly distinct, both in external appearance and in various internal characters.

\section{DESCRIPTION}

Drawn up from recent specimens and revised from prepared ones.

Form.-The back is broader and straighter than in the foregoing species, and the depth of the body is less, being about one-fifth of the length exclusive of the caudal, or scarcely exceeding the thickness: the back and sides are a little flattened, and the profile tapers gradually from the shoulders to the tail. Head contained five times and a half in the total length including the caudal fin: it is not so much compressed as in the foregoing and following species, and the snout is longer and more acute, as well as more moveable. The forehead is straight, not arched, and the anterior margin of the orbit is exactly mirlway between the tip of the snout and posterior edge of the gill-cover. Mouth larger than in C.Hudsonius and farther back, the upper lip, when protruded to the utmost, being scarcely even with the end of the snout. The pendulous flaps of the lower lip are also broader, and the papillæ larger. The interior of the mouth and gullet are similar to the same parts in C. Hudsonius.

Scales broadly oblong, their sides parallel, their ends segments of a circle; their surfaces impressed with lines radiating from the centre to all sides; their margins nearly even, instead of being crenated as in C.Hudsonius. They are considerably smaller than those of the latter fish, the difference being most apparent in the scales which cover the forepart of the back. Their size increases with their distance from the head, and those on the shoulder are but little larger than those between the pectorals. A scale taken from beneath the lateral line, midway between the pectorals and ventrals, is four lines long and three broad. A linear inch measured on the side near the gill-openings, contains nine scales, seren orer the ventrals, and five over the anal. There are from 98 to 107 scales on the lateral line, thirty in a vertical row 
behind the pectorals, and twenty-three just before the rentrals. The lateral line is straight, making no perceptible angle at the junction of the tail and body.

Fins. -Br. $3-3 ; P .18 ; D .12$ to $14 ; V .10 ; A .8$ or $9 ; C .18 \frac{3}{3}$.

The height of the dorsal execeds the length of its attachment; and its eighth or ninth ray is opposite to the first of the ventrals. The anal, when turned back, does not reach quite to the base of the caudal.

CoLour of the back intermediate between honey-yellow and oil-green (like old olive-oil); the sides are occupied by a series of patches of light lake-red, more or less continuous, forming a broad irregular stripe : the belly is white. The under fins are tinged with ochre-yellow, and at some seasons have a red hue; the dorsal and upper part of the caudal have nearly the tint of the back.

InTESTINES.-The lining of the abdomen is covered with a pigment similar to that which is attached to the choroid coat of the human eye : it is most abundant on the capsule of the airbladder, and soils the fingers, but is easily washed off. As it is not present in the foregoing or following species, it forms a convenient distinguishing character. The air-bladder is divided iuto two sacs, the lower of which sends a slender contorted tube to the œsophagus. The spleen lies in the centre of the convolutions of the gut. 'The length of the whole alimentary canal is to that of the fish, excluding the caudal fin, as 47 to 17 .

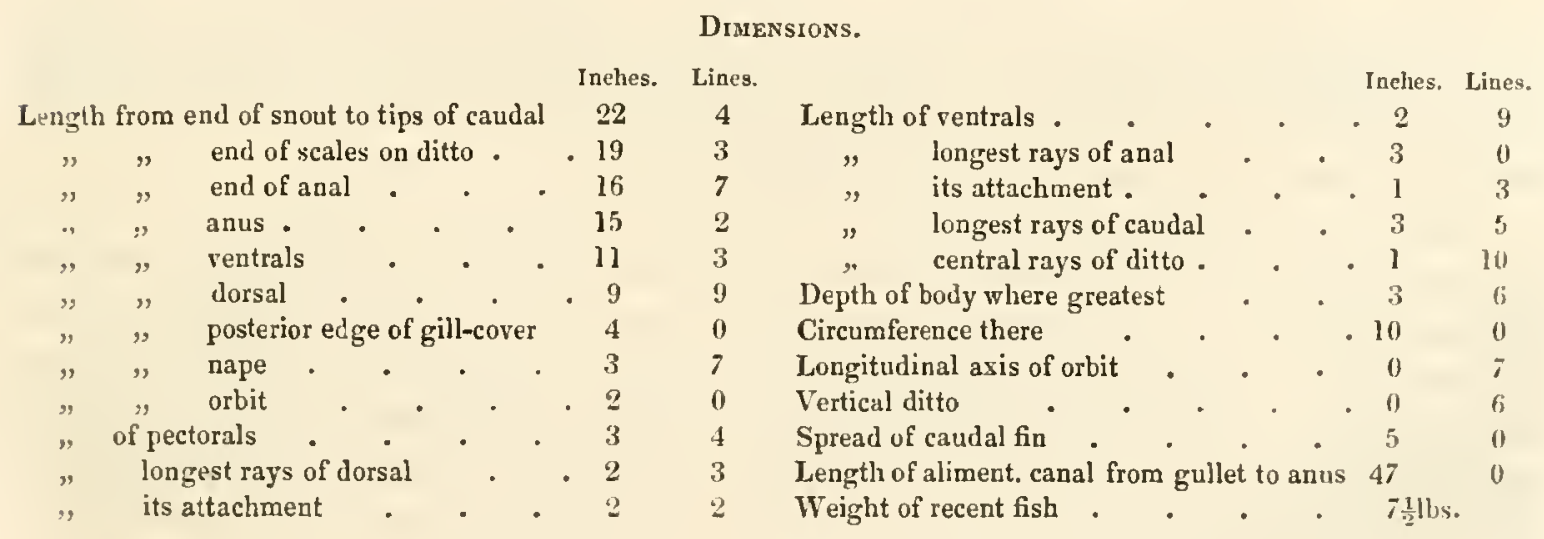




\section{[54.] 3. Cyprinus (Catastomus) Sueuril. (Rich.) The Picconou.}

Catastomus Le Sueurii *. Richardson, Fr. Journ., p. 772. An. 1823.

Picconou. Voyageurs. Wawpawhaw-Keeshew. Crees.

This handsome species was observed by us only in Pine-Island Lake, lat. 54 long. $110^{\circ}$; but it is not unknown in other parts of the fur-countries, though much more rare than the two preceding species. It may be at once distinguished from them by the size and lustre of its scales and the form of its lips, as well as by the anatomical peculiarity of having its air-bladder divided into three portions. There seems to be considerable variety in the form of the air-bladder in this sub-genus; in C. macrolepidotus of Le Sueur it has four divisions; but in the majority of the species only two. The habits of the Picconou are the same as those of the preceding species. It spawns in June.

\section{DESCRIPTION}

Of recent specimens at Cumberland House, April, 1820, revised from prepared ones.

CoLour-Back, sides, and gill-covers wood-brown, reflecting when opposed to the light many brilliant tints, in which emerald-green and gold-yellow predominate; bases of the scales bluish-grey, producing an appearance of reticulation; belly reddish-white. The dorsal has the hue of the back with a reddish margin, the other fins are almost entirely red.

SCALEs large, quadrangular with parallel sides and irregularly curved ends : their length and breadth nearly equal. Except in the pectoral region, where they are small, their size when in silu appears nearly the same over the whole body: the vertical height of their uncovered portion considerably exceeds its length. A linear inch measured longitudinally on the sides includes three scales, but vertically only two. There are 47 scales on the lateral-line, and about 10 in a vertical line under the dorsal. A scale detached from near the lateral-line above the ventrals measures eight lines and a half in length, and seven and a half in width. The lateral-line turns up decidedly at the anal as in C. Hudsonius.

FonM more compressed than in the preceding species. Profile oblong, having the greatest height, (which is about one-fourth of the total length, including the caudal,) at the begiming of the dorsal. The head is smaller than in either of the preceding species, forming scarcely the sixth of the total length. The very small mouth is farther back than in C. Hudsonius, being, when the jaws are retracted, an inch behind the tip of the rather narrow snout, and just even with it when they are protruded. The lips, instearl of being papillated, are furrowed vertically in a very regular' and beautiful manner. The palate and gullet resemble the same parts in C. Hudsonius, but are smaller, the comminuting apparatus being more delicate, and the osophagus remarkably contracted at its origin.

* The original specific name has been altered by dropping the prefixed article, as being more agreeable to the usual custom. 
Fins. $-B r .3-3 ; P .16 ; D .14 ; V .9$ or $10 ; A .9 ; C .18 \frac{3}{3}$.

The dorsal fin is larger than in the foregoing two species, and is nearly in the middle of the fish. The pectorals measure rather less than one-fifth of the distance between the gill-openings and caudal fin. The ventrals are under the middle of the dorsal. The tip of the anal, when turned back, rather overlaps the base of the caudal : its last ray is very small, and its first one short and applied to the base of the second. The caudal is more forked than in the preceding species. The rays of all the fins are thick, particularly those of the anal.

Intestines.-Lining of the abdomen white. There is no distinction between the stomach and rest of the gut. The alimentary canal makes four convolutions between the gullet and anus, and bears a proportion to the total length of the fish, excluding the caudal, of $4 \mathrm{l}$ to 16 . The lining of the intestine has the same minute longitudinal rugæe as that of the preceding two species. The air-bladder is divided into three portions, the central one being the largest, and conmunicating with the œsophagus. The upper one alone has a thick shining capsule.

Dimensions.

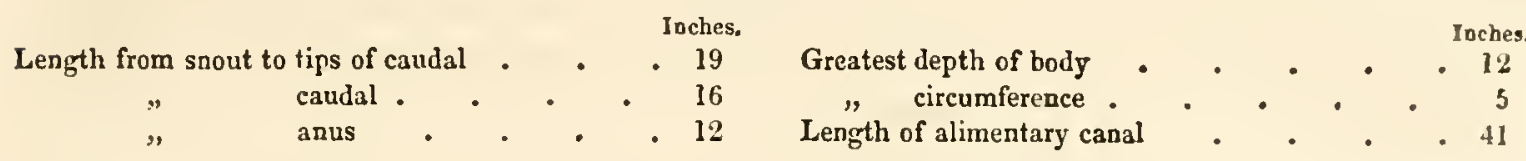

\section{[55.] 4. Cyprinus (Catastonus) aureolus. (Le Sueur.) Gilt Sucking-Carp.}

Catastomus aureolus. Le Sueur, Journ. Ac. Sc. Phil., i., p. 95. An. 1817.

M. Le Sueur, who discovered this fish in Lake Erie, gives the following account of it, which we quote because no specimen came under our notice.

"Anal fin long, pointed, and passing considerably beyond the base of the caudal, which is forked with pointed lobes, the inferior lobe being the largest : abdominal fin truncated."

"Body sub-cylindric, clevated at the nape; head quadrangular, gibbous above the eye, almost as high as long; the rays of the anal fin are very strong and large; scales rhomboidal, equal; body of a beautiful orange colour, which is deepest on the back, the base of the scales dark red; the sides are heightened witl golden reflections; pectoral, ventral, and anal fins of a fine red orange, cauclal fin of a deep carmine colour-the dorsal is paler than the rest of the fins; the lateral line is nearly straight, and commences on a level with the eye. Length of individual described sixteen inches: its depth three, and its thickness two inches and a half.

$$
\text { "Fins.-P. } 18 ; D .14 ; V .9 ; A .8 ; C .18 . " \text { (Le Sueur, l.c.) }
$$




\section{[56.] 5. Cyprinus (Catastomus) nigricans. (Le Sueur.) Black Sucking-Carp.}

Catastomus nigricans. Le Sueur, Journ. Ac. Sc. Phil., i., p. 103. An. 1817.

This species is, like the preceding one, an inhabitant of Lake Erie, where it is known to the fishermen by the names of "Shoemaker," and "Black Sucker." M. Le Sueur gives the following description of it.

"Head large, quadrangular; anal fin straight, its extremity reaching to the base of the caudal ; eyes oblong; the lateral line straight, below the level of the eye."_- "Body subquadrangular wear the head; tail straight, short; caudal fin forked with pointed lobes; dorsal quadrangular and small ; scales roundish ; colour of the back blackish, of the sides and abdomen reddish-yellow, with dusky blotches; pectoral, abdominal, and anal fins reddish; caudal and dorsal dashed with black. Length of specimen thirteen inches.

"Fins.-P. $18 ; D .11 ; V .9 ;$ A. 8; C. 18." Le Sueur, l. c.

\section{[57.] 1. Cyprinus (Leuciscus) gracilis. (Richardson.) Saskat- chewan Dace.}

Famul, Cyprinoideæ. Genus, Cyprinus. Sub-genus, Leuciscus. Cuvier. No-natcheegæs. Cree Indians.

Plate 78.

The Leucisci, or Daces, have a short dorsal and anal, are destitute of spinous rays or barbels, and exhibit nothing peculiar in the structure of their lips. The species which we have figured abounds in that part of the Saskatchewan which flows through the prairie district, and is taken at Carlton-house iu nets during the summer. It is but an indifferent article of food. Our specimen having been submitted to the inspection of Baron Cuvier, was returned with the following note attached to it: "Espèce particulière de Cyprin voisin de notre Cyprinus microcephalus."

\section{DESCRIPTION}

Of a specimen taken in the Saskatchewan, April, 1827.

Form.-Profile approaching to fusiform, most gibbous between the head and dorsal fin: belly flatter. Head small, crown broad and flat, muzzle rounded. The length of the head is contained five times in the total length from the snout to the tips of the central caudal rays. In the dried specimen lines or sutures can be observed on the top of the cranium, dividing it 
into nine rectangular pieces. Eyes large and lateral : the orbits are two lengths of their axis from the end of the snout, and three lengths from the tip of the gill-cover; the space between them is flat. Nostrils close to the orbits. Mouth small, toothless: its upper margin, formed by the intermaxillaries, has a slight motion, shutting within the labials. The labials form, as it were, an outer lip, which is continuous with the rounded extremity of the snout that projects about a line beyond the orifice of the mouth. Palate and vomer smooth.

Gill-covers, - Preoperculum a narrow crescent, exhibiting in the dried specimen five or six pores on its surfice, connected with an internal tube which pervades the whole bone. Operculum four-sided, larger than all the other bones of the gill-plates taken together: its anterior and under sides are the longest, and the latter orerlaps the margin of the sirapshaped suboperculum its whole length. A membranous border edges the gill-plate and forms a flap at its apex.

Scales large, thin, and, when dry, semitransparent. They vary little in size, and their length, which scarcely exceeds their breaclth, is about eight lines. Their exterior edges are semicircular and uneven, but not regularly crenated, and their bases are cut almost transversely, but with a slight point in the middle. The surface of their uncovered segment is marked with ten or twelre fine streaks radiating from the centre. The lateral line is straight and contains fifty-five scales: there are seventeen scales in a vertical row under the dorsal, of which seven are above the lateral line. In the dried specimen there is a clear longitudinal streak along the centre of each row of scales, occasioned by the narrow space which intervenes between the adjoining rows becoming apparent from the transparency of the covering scale.

Colour pale oil-green on the back, fading to white on the belly. Sides of the head nacry. Fins-Br. $3 ; D .9 ; P .17 ; V .8 ; A .10 ; C .19 \frac{4}{5}$.

The dorsal commences opposite to the attachment of the ventrals, and consists of nine rays, the first short and concealed by the skin; the second almost spinous, its articulations being only faintly visible at the tip; it is about half the length of the thircl, and is closely applied to it without the intervention of nembrane. 'The articulations of the other rays are also obsolete towards their bases, but their summits are more or less branched. The pectorals have seventeen rays, the first one being much stronger than the others, and its articulations visible only at its summit. The ventrals are attached exactly midway between the gills and the anal fin : their rays have strong bony bases, with their upper halves distinctly articulated. The anal has ten rays, the two first being very short; they are all articulated, and the posterior ones are much branched. The caudal fin is forked and has nineteen rays, with four short basal ones above and five below. The depth of the fork equals the length of the central rays.

Dimensions.
Length from tip of snout to the tips of the
caudal . $\quad$ Inehes. Lines.
$"$ " base of central caudal rays


[58.] 2. Cyprinus (Leuciscus) chrysoleucas. (Mitchill?) New York Shiner.

New York Shiner (Cyprinus chrysoleucas), Mrтchis, New Yorh Phil. Tr., P. 459?

Mr. Todd, of Penetanguishene, sent me a short notice of a small fish which he considered to be the same with the New York Shiner. It is caught in the month of May, while spawning, on the shallows of Lake Huron, and is said to associate with the Pomotis vulgaris*. It evidently belongs to the group of Leucisci which have the dorsal far back, but the descriptions given by Dr. Mitchill and Mr. Todd are not particular enough to enable us to infer, with any degree of certainty, that these gentlemen had the same species before them. They do not agree in their enumeration of the rays of the fins.

\section{DESCRIPTION}

By Mr. Todd of the largest individual which he saw.

"Head smooth, small, depressed on the upper aspect. Mouth small, even, toothless. Eyes large : irides yellow. Body deep, its depth being an inch and three-quarters in a fish six inches and a half long. Lateral line taking the curve of the belly. Dorsal fin far back. Tail forked. Colour of the back dark, of the sides golden-yellow.

"Fins._Br. $3 ;$ P. $10 ;$ V. $9 ; D .8 ; A .12 ; C .13$. (Mr. Todd.)

$3 ;$ P. $17 ;$ V. $9 ; D .9 ; A .14 ;$ C. 19." (Dr. Mitchill.)

Under the appellation of Exoglossum nigrescens, or Black Chub, M. Ratinesque describes a Cyprinoid fish which inhabits Lake Champlain. His account of it is exceedingly brief, and his genus Exoglossum, founded chiefly on the Cyprinus maxilingua of Le Sueur, is not adopted in the Règne Aninal.

"Head short, forehead smooth and convex; lower lip trilobated. Body oblong, blackish; lateral line nearly straight. Pectoral fins short, obovate; dorsal fin in the middle of the back ; tail slightly forked." (Rafinesque, Journ. Ac. Sc. Phil., i., p. 417.)

* Dr. Mitchill says that his C. chrysoleucas is found in the company of the Perca flavescens and Pomolis vulgaris. 


\section{ES O C I D E.}

Fisn of this family want the adipose fin, and the border of their upper jaw is either formed solely by the intermaxillaries, or if the labials enter at all into its composition, they are destitute of teeth. Their intestinal eanal is short, without caca, most of them have an air-bladder, and, with the exception of the Microstoma of the Mediterranean, all that are known have the dorsal and anal fins opposite to each other. The Esocida are voracious fish, many of them inhabitants of rivers. Most of the family is comprised in the Limnean genus Esox, which is subdivided in the Règne Animal into ten sub-genera, that differ from each other by many striking characters, such as the form of the body, which varies from a tolerably thick shape to a very slender one: the size of the scales, which may be moderately large, or quite imperceptible, or there may be a series of strong scales on the lateral line, or a row of keeled ones on each side of the belly: the mandibles also vary greatly in form, and somewhat in composition; thus both jaws may be moderately long and of equal length, or the upper one may be very short and the under one either simply projecting beyond it, or having its symphysis lengthened out into a half beak, or both jaws may be prolonged in the shape of a slender bill; the labials may form almost the half of the upper border of the mouth, or they may be altogether posterior to it, or even fixed to the cheek: there is an equal variety in the dentition, the teeth being, in some cases, small and confined to the margins of the jaws, in others long, card-like, and densely crowded on the mandibles, vomer, palate-bones, base of the tongue, branchial arches, and pharyngeal bones, or the pharyngeal teeth may be en pavì: the gill-covers have also very different forms in the different sub-genera, and in one case they are reduced to little membranous flaps : the gill-rays vary in number from three to eighteen or more. The stomias barbatus differs from the rest of the genus Esox in having a very long barbel on the lower jaw.

'The following species, among others, belong to the seas or fresh waters of the United States. Esox estor, reticulatus, niger, phaleratus, and hucius, Belone truncata, Scomber-esox scutellatus, and perhaps equirostrum, Exocatus exiliens, E. furcatus, Mitch. (or E. Nuttallii, Le Sueur, l.c., f. 1), and E. comatus, Miteh. (or E. appendiculatus, Wood, Journ. Ac. Se. Phil., iv., p. 278). Several species of Belone, Hemiramphus, and Exocetus frequent the Caribbenn Sea. The 
sub-genera Alocephalus, Microstoma, Stomias, Chauliodus, and Salanx, contain one, or, at most, two species each, and belong to the Mediterranean, with the exception, perhaps, of Salanx, whose habitat is not mentioned in the Règne Animal.

[53.] 1. Esox lucius. (Linn.) The Common Pike.

Family, Esocidæ. Genus, Esox. Sub-genus, Esox, Cuvier.

Esox lucius, Auctorum. Richardson, Fr. Journ., p. 716.

Eithinyoo-cannooshæoo. Cree Induans. Gedd, Scotis. Gedde, Danis.

The true Pikes form the first division of the Linnean genus Esox. Their slender intermaxillaries, armed with small pointed teeth, occupy two-thirds of the border of the upper jaw : the labials which lie on the sides of the jaw are toothless. The vomer, palate-bones, tongue, pharyngeals, and branchial arches, are stuck full of teeth in card-like plates, and the sides of the lower jaw are armed with a row of long pointed ones. The snout is oblong, obtuse, broad, and depressed : the solitary dorsal is opposite to the anal. The stomach, wide and plaited, is continuous with a slender intestine, which is twice folded upon itself and has no crea: the air-bladder is very large.

The Common Pike, a well-known inhabitant of the rivers and lakes of Europe and northern Asia, and even of the Caspian Sea, exists also in the United States of America, and in every piece of fresh water up to the arctic extremity of the continent; but it has not been found on the islands of the Polar Sea, nor is it mentioned by Fabricius as a native of Greenland. As it takes a bait set under the ice more readily than any other fish of the same districts, it forms an important resource to the Indian hunter in the depth of winter, when the chase fails him. In the summer it is occasionally shot while basking in shallow waters, but except in very urgent cases, powder and ball are of too high value in the fur countries to be thus expended. No quadruped, bird, or fish, that the pike can capture, seems to be secure from its voracity, and even the spiny perch is an acceptable prey to this water tyrant. The pike rarely weighs more than twelve pounds in the northern parts of America. Our specimen, taken in Lake Huron, was submitied to Cuvier's inspection, and it has also been carefully compared with English pilie, without any specific difierences having been detected. 


\section{DESCRIPTJON.}

CoLour.-Back tinged with blackish-green, which changes on the sides to light greenishgrey, and on the belly to pearl-white : on the tip of each scale there is a bright speck laving the form of the letter $\mathrm{v}$, and there are seven or eight longitudinal rows of oblong yellowishgrey spots on the sides of the head, body and tail. The checks yicld brilliant emerald-green reflections; the under jaw and gill-membranes are white: the irides greyish-purple with a gold-yellow circle round the pupil. The dorsal and caudal fins are blackish-green, the former marked with four patehy, longitudinal bands of oil-green, and the latter striped between the rays with the same: the anal is pale greenish-grey with two or three horizontal bands of yellowish-grey, or buff-orange: ventrals the same, with brownish-orange tips; and pectorals mostly brownish-orange shaded with grey.

Scales thin, broadly oval, their outer edge semicircular, their covered portion clceply divided by fissures into three or four lobes whose edges overlap *. The cheeks and upper half of the operculum are scaly, the rest of the head is corered with smooth skin. The scales on the sides, which are somewhat larger than those on the back, measure three lines and a half in length by two and a half in breadth. There are 124 on the lateral line, and 36 in a vertical row before the ventrals: a linear inch, measured on the sides, contains seven scales. The lateral line is straight and rather nearer to the back than to the belly; it is formed by a deep notch in every third or fourth scale, and a groove in the subjacent one: there are several rows of these emarginated scales on the back and sides, resembling lateral lines.

Form.-Profile oblong or lanceolate. Body four-sided, the back broader and flatter than the belly; the vertical diameter of the fore and middle parts of the body is about equal to oneseventh of its total length, caudal included : the transverse diameter is two-thirds of the vertical one, and the body carries its thickness to near the anal and dorsal fins, where it thins off into the compressed, tapering tail. Head forming one-fourth of the total length, caudal included. Orbits lateral, close to the crown and midway between the tip of the snout and the gill-openings. The space between the orbits is concave; the snout is broad, rounded, and depressed, and its tip is formed of a narrow cartilage covered by smooth membrane attached to the end of the vomer, and lying between the intermaxillaries. There are upwards of sisty pores on the head, disposed round the orbits, on the preopercula, occipital suture, and along the limbs of the lower jaw. The mouth is capacious. The intermaxillaries are very narrow, and are separated from each other by the somewhat dilated extremity of the vomer to which they are articulated: they are the only portion of the upper lip which is toothed. The labials have an oblong form, and are thrice the length of the intermaxillaries: their posterior piece is very moveable and projects a little beyond the anterior one. The under jaw is longer than the upper one by the thickness of the lip merely. The palate-bones are comnected to the

- In our English specimens there are nnly three lobes to the seales : in the Lake Huron one, most of the scales have four lobes, and their texture is more compact. These variations are, perhaps, to be atfributed to a difference in the age of the fish. The Lake IIuron specimen is larges, and may therefore be considered as older than the Finglish ones with which ve compared it. 
vomer by membrane which allows a free hinge-like motion. The tongue is broad and truncated at the tip.

TЕEтн.-The intermaxillaries and forepart of the lower jaw are furnished with a single crowded row of small slightly-hooked teeth: on the sides of the lower jaw there is a row of rather remote, long, straight, very sharp, awl-shaped teeth, implanted into the bone, with some pretty large ones merely adhering to the gums. The palate bones and vomer are armed with card-like bands of teeth, the interior rows on the former, and anterior one on the latter, being longest: the teeth on the vomer become finer, and the band narrower, pasteriorly, until it terminates in a point opposite to the angles of the mouth. The base of the tongue, the inferior and superior pharyngeal bones, and a series of small plates at the inferior union of the branchial arches, are rough like a file with minute teeth. The branchial arches are destitute of rakers, but a row of awl-shaped teeth, flanked on each side with nacry stripes of teeth, like velvet-pile, crowns their acute edges.

Gill-covers.-Preoperculum narrow, slightly curved, and carrying its breadth to its extremities. Operculum quadrangular, four times the height of the suboperculum, which exceeds it a little in length. Interoperculum almost concealed beneath the edge of the preoperculum. The gill-openings are very large: the left membrane overlaps the right one at their insertion into the isthmus : the rays are cylindrical, the upper one alone being flattened *

Fins.-Br. $15 ; D .20 ; P .16 ; V .10 ; A .18 ; C .18 \frac{9}{9}$. Lake Huron specimen.

$13 ; \quad 22 ; 14 ; \quad 10 ; 20 ; 18 \frac{7}{7}$. English specimen.

The dorsal contains twenty rays, of which the first four are short and closely applied to the fifth : the fin is considerably rounded, and the length of its attachment is equal to its height. The ventrals are situated midway between the tip of the snout and extremities of the caudal. The anal is shaped like the dorsal, and equals it in the length of its rays, but has a shorter attachment: it is opposed to the twelve posterior rays of the dorsal. The caudal is sharply forked.

INTESTINES.-On opening the belly the liver presents itself, having an oblong form without lobes. The duct of the gall-bladder enters the intestine about an inch below the pylorus. The stomach is a straight tube, plicated internally and capable of great distention: its muscular coat is strong, and several longitudinal bands of fat and blood-vessels are continued from its peritonæal coat along the rest of the intestine. Below the pylorus, which is much contracted, the intestine gradually diminishes in calibre and in the strength of its coats: but the rectum is a little wider. A cordiform spleen is attached to the stomach. A large air-bladder extends the whole length of the abdomen : it has a tendinous capsule to which it adheres but slightly. The kidneys, of a wax-yellow colour, speckled with black, extend along the spine from the gullet to an inch beyond the anus: the urinary bladder is separated from the kidney by the lower end of the air-bladder.

* One of our English specimens has 12 gill-rays, another has 13, and a third has 13 on one side and 14 on the other. 
Dimensions

Of Lake Huron specimen, dried.

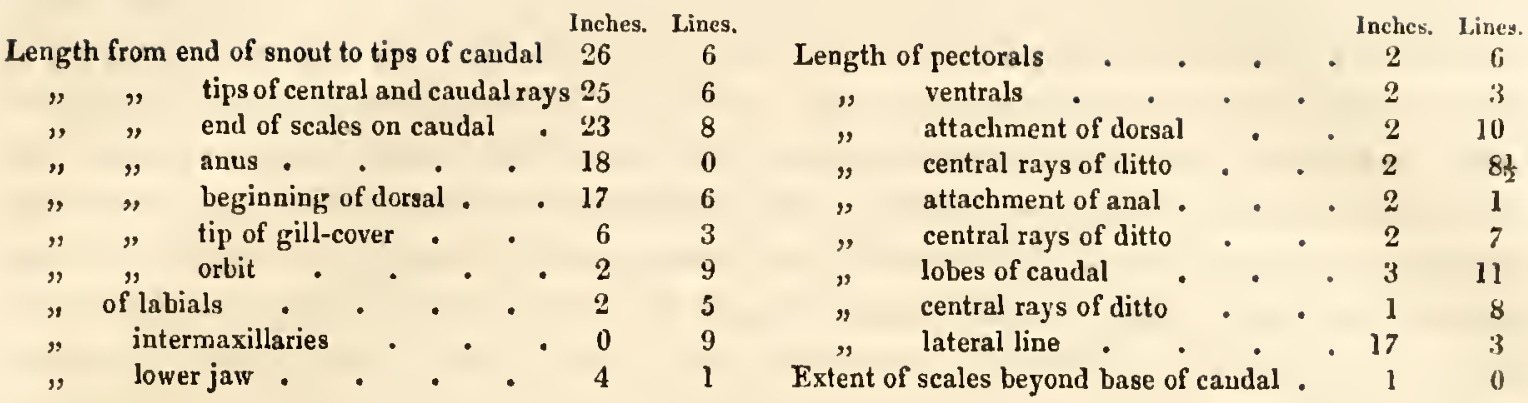

Of recent specimen taken in the Saskatchewan.

Length from end of snout to tips of caudal . 26

" " base of ditto . 22

" $"$ anus . . . 17

" of caudal fin .

$\begin{array}{rl}26 & 6 \\ 22 & 6 \\ 17 & 0 \\ 3 & 6\end{array}$

$\begin{array}{llrr}\text { from pylorus to rectum } & - & 15 & 0 \\ \text { of rectum - - } & & 2 & 6 \\ \text { whole alimentary canal } & \text { - } & 25 & 6\end{array}$

\section{Esox estor. (Le Sueur.) The Maskinongè.}

Esox estor. Cuvizr, Règ. An., ii., p. 282.

Our specimen of this pike was obtained at Penetanguishene, on Lake Huron, where it is rather scarce, being more common in Lake Erie and the southern Canadian waters. We did not meet with it in any of the rivers or lakes that discharge themselves into Hudson's Bay or the Polar Sea. Mr. Todd informed me that in the spring, which is its spawning season, it frequents the small rivers that fall into Lake Simcoe, and that it feeds on "small, gelatinous, green balls which grow on the sides of banks under water, and on small fishes." It attains the weight of twenty-eight pounds, and is considered as much preferable to the common pike for the table. It is a curious circumstance, that though the Maskinongè first received a distinct specific name from M. Le Sueur, his original description (Journ. Ac. Sc. Phil., i. p. 413), quoted in the Règne Animal, applies exactly to the $E$. lucius, and not at all to estor. Our specimen of the latter was identified by Cuvier.

\section{DESCRIPTION}

Of a Lake Huron specimen.

CoLour.-It differs from the Common Pike, in the general tint of the body being lighter than the markings: the back is rather dark, the sides light bluish-grey, interspersed with roundish distinct or confluent spots about the size of buck-shot. When exposed to a strong 
light, a quadrantal segment of each scale reflects bright colours, which change their place when the fish is moved, but there is no fixed pale angular mark on the tips of the scales, as in $E$. lncius. The scules are about half the size of those of the latter, and of a different form, their length and breadth being equal: and their middle lobe is the smallest; whereas in the Common Pike the middle lobe is rather the largest. The lateral line, measuring fifteen inches and a half, contains 162 scales, and there are about 45 in a vertical row before the ventrals: a linear inch on the sides contains a little more than ten scales. The structure of the gill-cover is, nearly that of E. lucius, but the suboperculum is slightly broader and more rounded pasteriorly, giving a curve to the edge of the plate, which is almost straight in $E$. lucius: there is also a distinctive mark in two rows of scales which descend on the anterior edge of the operculum in $E$. estor, until they reach the upper angular process of the suboperculum. The length of the head is contained four times and a half in the total length, including the caudal.

Fins.-Br. $18 ; D .21 ; P .12 ; A .21 ; C .199$.

The five anterior rays of the dorsal are short and applied closely to the base of the sixth. The four anterior rays of the anal are in like manner applied to the fifth.

.

DIMENSions

Of a dried specimen.

Inches. Lines.

Length from tip of snout to extrem. of caudal 23 central caudal rays $22 \quad 10$

anus . 15

beginning of dorsal 14

tip of gill-cover . 5

orbit - 2

of intermaxillaries .. .0

labials.$\quad \cdot \quad \cdot 2$

lower jaw

ventrals

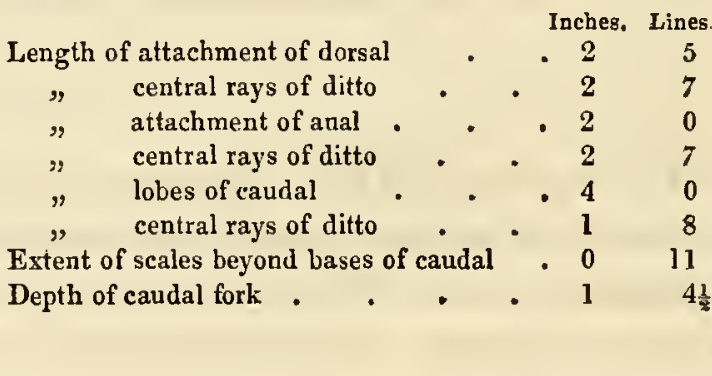

M. Le Sueur describes three other species of Esox which inhabit the fresh waters of the United States: viz., reticulatus, niger, and phaleratus; the first of which is known by its scaly opercula, and its flanks marked with brownish lines, which cross occasionally so as to form meshes.

\section{[55.] 1. Scomber-esox scu'tellatus. (Le Sueur.) Newfoundland Saury-Pike.}

Gunus, Esox. Linn. Sub-genus, Scomber-esox, Lacep., Cov. (Sä̈ris, Rafinesque.)

The scombrèsoces of Lacépède have a general resemblance to the Belones, garfish, or sea-needles, the same kind of long, slender bill, the upper border of which 
is entirely formed by the intermaxillaries; and also a row of keeled scales on each side of the belly, the seales which cover the rest of the body being scarcely apparent; but they are like the mackerels in the posterior rays of the dorsal and anal, being distributed in detached finlets.

The S. scutellatus, described by Le Sueur, was taken from the stomach of at cor! caught on the banks of Newfoundland; and the S. equirostrum of the same naturalist is known only by a specimen in the Boston Museum. Nothing is said of their habits, but they are probably similar to those of the European species-the Gowdnook, or Egypt-herring of the Scottish fishermen, which enters the Firth of Forth in considerable shoals almost every autumn. "It is," says Mr. Neill, " it stupid inactive fish, which is left on the shallows at the ebbing of the tide, with its long nose sticking in the mud, and is picked up in hundreds by the people from Kincardine, Alloa, and other places*."

[56.] 2. The Brazidian Pike of Pennant is most probably a Scomber-esou'. It resembles, it is true, a Hemiramplus in the great prolongation of the lower jaw ; but this sub-genus is characterised in the Règne Animal as having moderately large round scales, and no detached finlets behind the dorsal and anal: the known hemiramphi, moreover, inhabit the tropical seas, and it is, therefore, less likely that one should be found so far north on the Labrador coast as Croque Harbour, where Pennant's fish was taken. 'The following is that naturalist's account of it.

"Pike with the under jaw very slender, and twice as long as the upper: the head smooth: body covered with small scales: the dorsal and anal fins opposite: between them and the tail a row of small spurious fins like the mackerel. Taken off Croque Harbour, and communicated to me by Sir Joseph Banks." (Arctic Zoology, Suppl., p. 145.)

\section{[57.] 1. Exocetus exiliens. (Bloch.) North American Flying-fish.}

Fasily, Eyocidæ, Curier. Genus, Exocetus, Linn.

The Exoceti, or Flying-fish, are readily known from all the other groups of the same order by the very great size of their pectoral fins, which spread out so is to 
form a kind of wings capable of sustaining the fish during a short flight through the air. They have scales on the head and body, and a raised line of keeled scales along each flank, as in the gar-fish and saury-pikes; the head is flattened above and on the sides; the dorsal is over the anal; the upper lobe of the caudal is the shortest; the eyes are large; the intermaxillaries have no pedicles, and form the whole border of the upper jaw ; the teeth are small and pointed on both jaws, and "en pavés" on the pharyngeals; there are ten gill-rays; the air-bladder is large, and the intestines straight without cæca. Some species have barbels on the lower jaw.

The Flying-fish inhabit all the warm and temperate districts of the ocean. Cuvier remarks that their wing-like pectoral fins serve as parachutes merely, but after daily observation of their fight, during a voyage of several months within the tropics, I can give my testimony to the correctness of Mr. Collie's statement, marle in the Appendix to Captain Beechey's voyage, that these fish not only possess the power of descending and rising in the air without touching the water, but also of suddenly changing the direction of their flight, and going off even at a right angle previous to alighting in the sea. Their flight can extend to several hundred yards, and is very rapid, being apparently scarcely inferior to that of a swift bird : their descent into the water is sometimes sudden, as if they dropt down from exhaustion, at other times gradual like their ascent, and they occasionally bury themselves in the brow of a rising wave. They often rise from the water in a perfect calm, but they seem to take to the air more frequently during the prevalence of a moderate breeze, though this may be partly accounted for by our field of observation being increased when the ship was in motion. The approach of the vessel often occasioned the flight of a shoal of these fish, and we could then easily ascertain that the angle of the course with the wind varied, though I never saw them fly directly against a breeze, however slight. In the moonlight nights many flew into the ports of the small frigate in which $I$ was then serving, and furnished a very agreeable addition to our breakfast.

The exocetus exiliens, which Bloch obtained from Carolina, is distinguished by the position of its long ventrals behind the middle of the body. It is figured by Dr. Mitchill (pl. v., f. 3) under the name of the New York Flying-fish, although he makes no mention of it in his text. The young have black bands on their fins, and M. Le Sueur's E. fasciatus, taken in the Gulf-stream, is, in Cuvier's opinion, merely one of these. It is probably this species which, keeping in the warm waters of the Gulf-stream, ranges northwards to the banks of Newfoundland. Cuvier observes, that the E. exiliens and mesogaster of Bloch resemble each other so much that it is not easy to distinguish the species by the descriptions and figures of voyagers. 
Dr. Nitchill mentions the mesogaster as an inlabitant of the sea of New York; and Dr. Snith enumerates it among the fish of Massachusetts; but the notice of the former is too slight to prove that he has applied the name rightly, though sufficient to show that he is not speaking of the species which he has figured as the New York Flying-fish; and the latter writer gives no dlescriptions or figures in his work, whereby a naturalist may judge of the correctnes: of his determination of the species. The E. volilans, the most common species in the $\Lambda$ tlantic. has small ventrals situated before the middle of the borly. Both forms occur in the Pacific. Licntenant-Colonel Smith makes the following remark on an exocetus which he obserred oft the Isle of Sable, near Nova Scotia. "I wonld have taken it for mesogaster or exiliens, but the wings, instead of being rounded beneath, were very unequally and acutely two-lobed, by it notch extending obliquely to near their lower nargin; the eye was very large, the scalcs broad; the colour greenish-grey; and the length about ten inches. 


\section{SILUROIDE $Æ$.}

'THrs family is distinguished from the others of the same order by the skin being either naked, or protected by large bony plates, but always destitute of true scales. The intermaxillaries, suspended under the ethmoid bone, form the border of the upper jaw, while the labials are lengthened out into barbels, or are simply rudimentary. The intestinal canal is wide, without cæca, and doubles upon itself; the air-bladder is large, and adheres to a peculiar bony apparatus; the dorsal and pectorals have almost always a strong spine, with a joint for their first ray, and there is very often an adipose fin as in the Salmonoideæ. The family contains four genera, Silurus, Malapterurus, Aspredo, and Loricaria, the first of which, being by far the most extensive, is divided into twelve sub-genera. The species abound in the rivers of warm countries and are numerous in America. The following species have been detected in the United States. Bagrus marinus, Pimelodus catus, albidus, nebulosus, aneus, cauda-furcata, nigricans, natalis, and insigne (livrée, Le Sueur). Doras costatus, Callichthys (Silurus callichthys, Linm.) and Aspredo (S. aspredo, Linn.). The Mysti, Hypostomes, and Loricaria, are South American fish. The Schilbes, Synodontes, Heterobranchi, and Malapteruri, are inhabitants of the Nile, Senegal, and some Asiatic rivers. The Plotoses are Indian fish. The Silurus glanis is the largest fresh-water fish that exists in Europe, being sometimes upwards of six feet long, and weighing three hundred weight.

[58.] 1. Silurus (Pimelodus) conosus. (Richardson.) Huron Pimelode.

Famis, Siluroideæ. Genus, Silurus. L. Sub-genus, Pimelodus. Lacep., Cuv.

Fish belonging to the genus Silurus have the moutl at the extremity of the snout; and in most of the sub-genera the first ray of the pectoral fins is a strong spine, articulated in such a manner to the shoulder-bone, that the fish can at pleasure lay it along the body, or fix it perpendicularly, so as to render it capable of inflicting a very dangerous wound. The head is depressed, the intermaxillaries 
suspended to the ethmoid, and not protractile, the labials very small, but almost always prolonged into a fleshy barbel, besides which there are other barbels attached to the lower jaw, and even to the nostrils. The gill-covers want the subopercular bones; the strong, heart-shaped air-bladder adheres by its two upper lobes to it Lony apparatus belonging to the first vertebra. 'The stomach is a fleshy cul-de-sac ; and the gut is long and wide, without cæca.—Characters to distinguish the snbgenera from each other may be found in the number and extent of the dorsal, or the presence or the absence of the adipose fins, the spinous or soft structure of the first dorsal ray, the form of the head, the number of barbels or their absence, the nakeduess of the skin, or the presence of bony plates on the head, nape, lateral line, or whole of the sides, the dentition and the structure of the gills.

In the sub-genus Pimelodus, which is very rich in species, the body is destitute of lateral armature, being clothed merely with a smooth skin; the jaws, and frequently the palate-bones, are furnished with teeth like velvet pile, but there is no band of teeth on the vomer parallel to that on the upper jaw, as in the sub-genus bagrus. There is very great variety in the form of the head, and in the number of barbels appended to it. The Pimelodus conosus inhaljits Lake Huron, where it frequents muddy rivers and attains the weight of several pounds. It takes a bait readily and is excellent eating. A somerwat mutilated specimen, tilien at Penetanguishene, and presented to me by Mr. Todd, having been sent to Baron Cuvier, was returned with the following remark: "Pimelode très voisin du Silure noir de Lac Erie de La Sueur. Notre travail sur les Silures n'étant pas encore terminé nous n'avons pas fixé son nom." This pimelode belongs to the division or tribe of the sub-genus, in which there is only a single band of teeth on the upper jaw, and the head furnished with eight barbels, has an oval shape, without any bony plates appearing through the smooth skin.

\section{DESCRIFTION}

Of a specimen from Penetanguishene.

Fors.-Profile oval, tapering into the tail. Head broadly oval, forming two-ninths of the total length. Orbits small and nearer to the snout than to the gill-opening. Nostrils situated some distance before the eye; a slender barbel, half an inch long, springs from their posterior margin. Snout obtuse. Labials ending in a tapering barbel, which is an inch and a quarter long and reaches to the gill-opening; there are also two slender barbels on each side of the chin. Both jaws are armed with a brush-like band of short teeth, very conspicuous in the dried specimen. The palate and romer are smooth. The bones of the skull are firmly united together, and it is difficult to distinguish the pieces of the gill-covers through the skin. The upper gill-ray runs uncler the edge of the operculum, and is firmly joined to 
it at one corner, thus supplying the place of the suboperculum, which is wanting in this genus: the preoperculum, though firmly connected to the operculum by bone, is marked out by its slightly-elevated edge, but the interoperculum cannot be traced through the skin. There are nine gill-rays, all cylindrical except the two superior ones, which are flattened at their upper extremities. The gill-openings are rather confined. The humeral bones are strong and spreading, with a process which can be felt through the skin, extending backwards above the pectoral; the nape is smooth.

Fins.-Br. $9 ; D .1 / 7-0 ; P .1 / 8 ; V .8 ; A .24 ; C .17 \frac{9}{12}$.

The dorsal contains seven branched rays, the first of which is sheathed in the deep posterior groove of a strong acute pointed bone, that can be erected or depressed at the will of the fish. This bony spine is a little shorter than the first soft ray. The adipose fin corresponds to the hinder part of the anal. The pectoral is armed still more strongly than the dorsal, by a bone which is triangular at the base and compressed towards its acute tip : its posterior edge is serrated by ten or eleven acute teeth pointing downwards. The ventrals are posterior to the dorsal, and a little nearer to the caudal fin than to the end of the snout. The anal and caudal are large, and their outline, like that of the dorsal, is slightly rounded: the former has twenty-four rays, including three short anterior ones, and the caudal has many short basal ones, with seventeen long ones.

\section{Dinensions.}

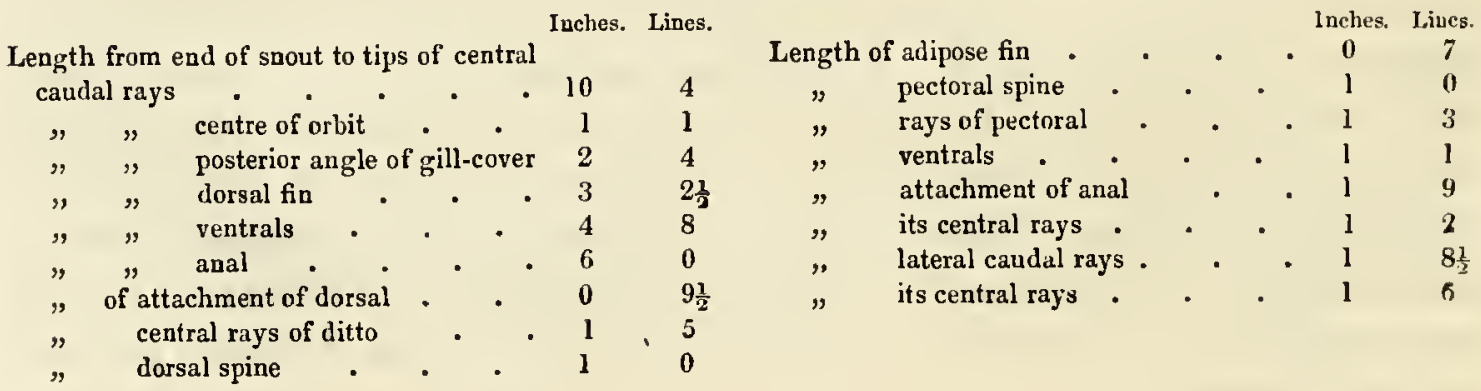

\section{[59.] 2. Silurus (Pimelonus) nigrescens. (Le Sueur.) Black Pimelode.}

Pimelode noirâtre (P. nigrescens). Le Sueur, Mém. Mus. d'Hist. Nat. Paris, v. p. 153, Pl. 16. Lowest figure.

The black pimelode described, together with six other species, by M. Le Sueur, in the work quoted above, inhabits Lakes Erie and Ontario and their tributary rivers, frequenting places where the bottom is muddy. It is said to attain a great size, and is a sluggish, inactive fish, generally lying still for a long time in one 
spot, so that it can be very readily captured by passing a noose over its head. It is also speared in the night time, by torch-light, which is a common mode of fishing in the lakes.

M. Le Sueur distinguishes this species by the orbicular slape of its head, the form of its body, which is broad anteriorly and compressed posteriorly, and by the black colour of it: iris. It has eight barbels in the ordinary situations: the two pairs on the lower jaw are of equal length; the eyes are small; the anterior nasal openings are tubular, and, as usual, it barbel springs from the hinder margin of each of the yosterior ones; the cheeks are rounded; the snout is broad and depressed; the upper jaw projects beyond the inferior one, and both are provided with fine, long, closely-crowded teeth, which are buried to their tips in the thick integuments : the gullet is also furnished with tubercles covered with teeth; the dorsal, broad and rounded, has its bony ray set posteriorly with teeth which point toward its base; the anal and ventrals are also rounded: the former is rery long, the latter and the adipose fin are of medium size; the caudal is slightly crescentic at the end; all the rays of the fins, except the bony ones of the pectorals and clorsal, are divided and concealed by the rery thick skin in which they are enveloped.

$$
\text { Fins.-Br. 8;D.7;P. 10; V. 8;A. 25;C. 16. (Le Sueur, l.c.) }
$$

[60.] 3. Silunus (Pinelodus) Borealis. (Richardson.) The
Mathemeg.

Cod mathemeg. Pexs., Arct. Zool. Suppl., p. 115 . No.94. Intr., cxid.

Silurus felis? Ricis., Frank. Journ., p. 723.

Le Chat. Canadan Vorageurs. Mathemeg. Crees.

'The mathemeg, or land cod of the residents in the fur countries, is taken sparingly, during the summer months, in the lakes through which the Saskitchewan fiows. It is the most northern American species of the family, but does not range higher than the 54th parallel. It is prized as a well-flavoured, rich fish, though its aspect is by no means prepossessing to one who is a stranger to its good qualities. Its Cree appellation signifies "ugly fish." A specimen which I brought home in 1821, is not now within my reach, but the species differs manifestly from the two preceding ones in the shape of its dorsal fin, and in its pectoral spine being void of serratures. The size of its head also requires it to be included in that tribe of the sub-genus which is indicated in the Règne Animal by the name of Les: Chats, or Cats, in which the head is very broad, covered with naked skin, ind fur- 
nished sometimes with six, sometimes with eight barbels : there are no palatine teeth.

\author{
DESCRIPTION
}

Of a specimen caught in Pine-Island Lake, lat. $54^{\circ} \mathrm{N}$.

CoLour dark greenish-brown on the back and sides : on the belly whitish.

Form.-Body oblong, tapering posteriorly; belly tumid before the ventrals. No scales: lateral line straight. Head flat and broad, its breadth equalling its length. There is a small lengthening of the cranium at the nape, which is concealed by the thick smooth skin. Snout obtuse, almost semicircular. Mouth at the extremity of the head, the upper lip slightly overlapping the lower one. There are eight barbels, two formed by the tapering labials and reaching to the gill-openings; two springing from the upper borders of the nostrils, about an inch long; and two pairs on the lower jaw, the outermost and longest measuring two inches and a half. Teeth small and erect in brush-like plates on both jaws: the palate and vomer smooth. Dorsal sub-quadrangular: its bony first ray smooth. The pectoral spine also free from denticulations. Adipose fin rather large and opposed to the posterior third of the anal. Anal large and long, terminating one-third of its own length from the base of the caudal. The latter has a wide shallow fork with obtusely-rounded lobes. The length of the specimen, excluding the caudal, was thirty inches.

Fins. $-D .1 / 6 ; P .1 / 6 ; V .9 ; A .25 ; C .17 \frac{3}{3}$. 


\section{SALMONOIDEA.}

THE fish of this family were collected by Linnæus into a single great genus, which is concisely characterised by a scaly body; a first dorsal having articulated rays; and a second small one, not sustained by rays, but formed merely of a fold of the skin enclosing fat, and hence named the adipose fin. 'The Salmonoidea have numerous cæca and an air-bladder; they almost all ascend rivers, their habits are voracious, and most of them are highly esteemed as articles of food. The surprising variety which exists in their dentition, and in the structure of their jaws, furnishes characters for the numerous sub-genera into which Cuvier has divided this extensive genus: but owing to the absence of obvious peculiarities by which we may distinguish one species from another of the same group in this family, and the difficulty of collecting specimens from various countries for comparison, inextricable confusion has crept into the synonymy. The loss which science has sustained in the death of Cuvier has deferred the rectification of this, which must be accomplished by some ichthyologist of adequate means and talents, before a precise statement can be made respecting the geographical distribution of the species.

In the Trouts, or 'True Salmon, constituting the first sub-genus (Salmo, Cuvier), the labials form a large portion of the border of the upper jaw, and there is a row of pointed teeth on these bones, the intermaxillaries, lower jaw, and palate-bones, and two rows on the vomer, tongue, and pharyngeals, so that the dentition is more complete than in any other tribe of fish. In the old males the point of the lower jaw is incurvated, and lodges in a cavity formed in the forepart of the roof of the mouth, anterior to a transverse membrane. The shape of the trouts is known to every one. Their ventrals are opposed to the middle of the dorsal, and the adipose is over the anal. They have about ten gill-rays. Their long, narrow stomach doubles upon itself, and the pyloric cren are very numerous; the air-bladder reaches from one end of the abdomen to the other, and communicates with the upper part of the œesophagus. The trouts have almost always spotted bodies, and they are generally excellent food. 'They ascend rivers to spawn and surmount cascades, thus attaining the rivulets and small lakes of the highest mountains. Such is the compendious character of the sub-genus contained in the Règne Animal, to which we may ard, that the group is an exceedingly natural one, so much so, 
that very minute observation and much practical skill are requisite for the due discrimination of the species. No attempt that has hitherto been made to frame proper specific characters for the trouts has succeeded, and a great number of names have consequently been introduced into science which it is almost impossible to appropriate correctly. In sonse instances, several nominal species have been created, by the description of different states of the same trout under separate names, and as frequently two or more species have been confounded together. Most of the American trouts, though perfectly distinct, have been described as identical with the common European ones. The rectification of this confusion is a matter that concerus the legislator as well as the naturalist, for nothing certain can be learnt of the habits of a trout until we have the means of recognising it in its various stages of growth; nor without such knowledge can the legislative enactments which abound in North America, as well as in Europe, be of much utility, or indeed fail of being actually injurious. Figures, unless perfectly correct in all the details, do not aid us much in distinguishing species which are so similar in external form ; and descriptions of colour, if unaccompanied by notices of peculiarities of structure, as is the case in many ichthyological works, are of still less 'service. The hues and markings of the trouts are modified by their age, food, and other circumstances. The younger individuals are generally more spotted than the older ones, which have a more uniform and often a deeper colour. When a trout has abundance of its proper aliment, as must be generally the case before it can attain a spawning condition, its scales acquire a splendour, and its marlings an intensity and distinctness very different from what the same fish exhibits when out of season-so that we might say with M. Agassiz, these fish bedeck themselves, like birds, in a nuptial garb. This gentleman also observes, that the tints of the trouts are most brilliant, and their colours most vivid in the autumn, and at the time of the greatest cold, or in the months of October, November, December, and January; which is the precise period of the development of the spawn in many of the species. He likewise states that the most beautiful Salmon-trout are found in waters which abound in small crustacea, direct experiments having shown to his satisfaction that the intensity of the red colour of their flesh depends upon the quantity of gammarina which they had devoured. Dr. Knox's researches give a nearly similar result, by proving the red substance which is generally to be found in the intestines of a salmon that has recently quitted the sea to consist of the eggs of echinodermata and crustacea. To this rich aliment he attributes the brilliancy of the scales of a salmon in prime condition, and the high flavour and deep colour of its flesh. 
Being convinced that much assistance in discriminating the different species of trout may be obtained by carefully observing the forms and relative sizes of the various parts of the head, particularly the opercular pieces, the heads of the American trouts, described in the following pages, are figured of the natural size, and two plates of the heads of British trouts are added for the purpose of comparison. The proportion of the head to the whole body, the dentition particularly of the vomer and tongue, and the form and size of the scales, have also been carefully noted in the descriptions. I have recently been led to conclude that the number of the pyloric crea ought to be taken into account as a specific distinction; but living as I do in a part of the country where there are no trouting streams, and far distant from waters affording a variety of species, I lave been unable to carry my anatomical researches to the extent that I could have wished; and I much regret that I did not turn my attention to this subject when I lad it in my power to examine recent American specimens. I have been indebted, it is true, to kind friends for numerous presents of trouts from the Orkneys, Sutherlandshire, Kinrosshire, Dumfriesshire, and Wales; but such distant land-carriage was productive, in many cases, of so much injury to the specimens, that I could not always satisfactorily determine how far differences in the number of the cæca were connected with variations of external form.

The following species of trout are mentioned in the Règne Animal as existing in Europe. Salmo salar, hamatus, Schiefermulleri, hucho, lemanus, trutta, fario, punctatus, marmoratus, salvelinus, alpinus, salmulus (sanlet or par), and umbla*. From the want of continental specimens for comparison, I am unable to say, with any pretension to correctness, how many of the British trouts can be arranged under

- Nilsson enumerates as inhabitants of the waters of Scandinavia,-1. TRutre:-Salmo salar, ocla, trutta, truttula, fario, punclafus. 1I. SALTELIN :-Salmo ventricosus, carbonarius, alpinus, pallidus, salvelinus, and rutilus. M. Agassiz, however, reduces the species on the continent of Europe to six, but admits that he has seen adlditiunal ones in Great Bri. tain. His species are:-

"1. Salao usubra, Linn., the Char of England, the Ombre Chevalier of the Lake of Geneva, the Rathch of Swiss Germany, and the Schurartz reutal of Saltzburg.-Synonyms: S. salvelinus, alpinus, Linn., salmarinus (but not the $S$. alpinus of Bluch). This fish is found in England, lreland, Sweden, Switzerland, and in all the southern parts of Germany.

"2. S. pario, Linn.-the Trout of brooks, Common trout, Gillaruo trout, and Par. Synonyms: Salmo silvaticus, Schrank, alpinus, Bloch, punctalus and marmoratus, Cuvier, and erythrinus, Linn. It is found as extensively as the first species.

"3. S. тrutta, Linn. Sea Trout-Salmon Trout. It is the same as the Salmo lemanus of Cuvier, and the S, albatus of Rondeletius. It is found as extensively as the tro preceding species.

"4. S. Lacustris, Linn. The same as the S. illanca and Schiefermulleri of Bloch. It is found in the lakes of Lower Austria, and in the Rhine above Constance.

“5. S. sajar, Linn. The true Sulmon. The Salmo hamatus of Cuvier is the old fish, and the S. Goctenii of Bloch is the young. Found in the northern seas, whence it ascends the rivers even as high as the Swiss lakes.

"6. S. иucro, Linn. Peculiar to the waters of the Daaube." (Agassiz. Paper read before the British Association at the Ediaburgh meetiog, reported in Lit. Gaz.) 
the preceding names: but to serve as an explanation of plates 91 and 92 , and also as an introduction to the descriptions of the American trout, I shall give a few notices of the British ones that $I$ have had an opportunity of examining. Of the correct designation of our most important trout,

1. Salmo salar there can be no doubt. The head of a "run fish," or of one taken on its way to the sea after spawning, is represented on Plate $91, \mathrm{f}$. 1 . The posterior edge of the gill-cover is the segment of a circle, into the formation of which the suboperculum enters largely, and there is but one tooth on the romer. The specimen was taken in the Water of Urr, a river of Galloway, in the month of December: some other particulars respecting it will be found in our account of the Quebec Salmon. Mr. Yarrell informs me that the Common Salmon has 60 vertebræ in the spine *. The number of pyloric cæca appears to vary. The gentleman just mentioned having sent me the viscera of two large female salmon, brought to the London market, in prime condition, in the month of April, I found 63 cæea in the one, and 68 in the other. The gut and larger cæca of the former were filled with botriocephali, the roe was about one-third grown: the latter, which was not quite so far advanced towards. the spawning state, was not infested with tape-worm: the alimentary canal of both was thickly lined with a tenacious mucus, mixed with some specks of a red matter resembling lobster spawn.

2. Salmon-trout. Under this name a fish is brought in large quantities to the London market in the beginning of summer. It has a very close resemblance to the Common salmon, of the same size, but has nevertheless an aspect so peculiar as to be readily recognised by the fishmongers. Its head is proportionably somewhat larger than that of the salar, but its vomerine teeth are nearly the same, that is, they vary in number from one or two to five or six, and are placed, in the latter case, two in front, the others in a single row, but turned alternately to opposite sides. The teeth generally are more slender and acute than those of the Common salmon. The gill-cover differs from that of the latter in the curve of its posterior edge being elliptical, in consequence of the suboperculum being much less rounded off. According to Mr. Yarrell, the Salmon-trout has only 59 vertebræ, or one fewer than the $S$. salar. One specimen from the Nith had 59 cæca, another 61 . The head of the latter is represented in Plate 92, f. 1, A, with a view of its open mouth (f. 1, B), to show the dentition. The scales of the Salmon-trout are thin and delicate, and the spots on the sides have sometimes a slender crescentic form; at other times they assume the shape of two crescents urned back to back, or that of the letter $x$. I have obtained specimens from Loch Stennis, in the Orkneys, from the rivers Nith and Medway, and from Wales. In the latter quarter it is coufounded with another species, under the name of Sewin. It feeds more upon fish than the Common salmon $\dagger$. I took a young coal-fish and a fragment of sand-stone from the

"Artedi says of the Common salmon of the Baltic (Lax Suecorum), "Vertebra in universum quinquaginta sex."

+ Lieuteuant-Colonel Lawrence, an ardent and experienced angler, infurms me that the salmon is more in the habit of springing out of the water than the Salmon-trout, and will do so either to take the artificial fly, or to disengage itself frum the hook when it feels the smart; but the Salmon.trout, as soon as it is struck by the angler, descends directly to the buttom of the pool, and can scarcely be dislodged. 
stomach of an Orkney specimen. Some British ichthyologists consider our Salmon-trout to be the Salmo trutta; but it is certainly not the species so designated on the continent, which has a prolonged double series of vomerine teeth. The brief remark in the Rène Animal, on the Truite de mer, or Salmo Schiefermulleri, applies in all points to our Salmon-trout.

3. The Hirung of the Nith, and Whiting of the Esk, Phinoc, or Salmo albus, of Fleming, Salmo Cumberland, or Le Saumon blanc, of Lacépède, resembles the two preceding so much as to be readily mistaken for either. The head bears the same proportion to the body as in the Common salmon, and its scales arc larger and still more delicate than those of the Salmontrout, but the colours and markings are nearly the same. It is most readily clistinguished by its romerine teeth extending farther back in two rows, and being clustered in front. In several specimens the creca were found to be 49 . The intestines were lined with the same kind of grey mucus, mixed with spots of the red substance which is found in the guts of the salmon. This species enters the rivers in July and August, its flesh has a deep salmon colour and a very excellent flavour. The usual size is from one to two pounds. Larger individuals are confounded with young salmon, and are sold indiscriminately with them in the Dumfries market, under the name of "grilses." Salmon-trout are also frequently sold by the name of Hirlings.

4. Plate 91, f. 2, represents the head of a trout which is in Mr. Yarrell's possession. It was taken from a Glamorganshire fish, said to be the SEwin (Salmo Cambriscus of Donovan), which is rery probably the same species with the Bull-trout of the T'weed, and the Salmo, hamatus of Cuvier. We have already remarked that the Salmon-trout is also called Sewin in Wales; indeed, the whole article in Pennant's British Zoology on the Grey evidently refers to the Salmon-trout*. As I have not seen an authentic specimen of the salmo humatus of the Règne Animal, I am unable decidedly to controvert M. Agassiz's opinion that it is merely a nominal species, founded upon a change of form which takes place in the old males of Salmo salar; but the evidence I have gleaned from authors induces me to follow Cuvier in consiclering it to be quite distinct. There can be no question that the two heads represented on our 91 st plate belong to different species : now the lower one is very like the head of the Tweed trout, which, in the whole shape, as well as in the markings of the body, closely resembles Bloch's figure, t. 98, quoted by Cuvier as his Salmo hamalus. Were the peculiarities of the latter merely the effect of age, we should not find it more thickly and generally spotted than even the younger individuals of the Common salmon, which is in fact the case. The following passage, quoted from the Lachesis Lapponica, tends to prove, not only the northern range of the Salmo hamatus, but also that the hook of the lower jaw is developed eren in young fish; but the old males of the Common salmon that we usually see in the Nith, and some other British rivers, have a consparatively slight hook. "Here," in Lulean Lapland, " the Common salmon is found with the under jaw occasionally hooked. I inquired whether this variety was esteemed a distinct species, or whether a difference arising from age: both of which questions $I$ was

* Pennant quutes doubtfully Sulmn erıx, Linn., as synonymous with his Grey. It is described by authors as having a deeper body than the Common salmon, grey spots, and an even tail, characters which all occur in an old Salmou-tront. The caudal fin becomes even in sereral species of trout as they advance in age. 
answered in the negative. I was shown a fish of the smallest size, which had in proportion as large a hook to the lower jaw as the largest. I inquired whether the hooked salmon were furnished with roe or milt. I was answered they had always milt. On opening seven of them I found this verified; whereas four salmon which were not hooked had roes. The hooked or male salmon is so called because the point of its lower jaw is bent inward and has a taper form resembling a finger, while, on the contrary, the upper one is formed with a cavity to receive the point, embracing it like a sheath for about half its length."

The Bull-trout of the Tweed is in little repute for the table; and Cuvier says that the flesh of the Salmo hamatus, though red, is not so rich as that of the Common salmon, and is held in less estimation. The Bull-trout of the Orkneys is also said to have the flesh hard and dry, and consequently to be little sought after by the country people; but as it had not entered Loch Stennis in the spring, at which time the other trouts of that lake were sent to me, I have not been able to procure a specimen, and am consequently ignorant how far it resembles the Tweed fish bearing the same name.

5. Nith Trout, \&c. Plate 92, f. 2, A and B, exhibits the head of a trout which was taken in the latter end of December in the river Nith. The entire specimen measured fourteen inches to the tips of the tail, or twelve inches and a half to the end of the scales on the base of the caudal fin. Figure $4, \mathrm{~A}$ and $\mathrm{B}$, represents a young fish from the Clouden, a tributary of the Nith: it measured seven inches to the end of the scales on the caudal, and three-quarters of an inch more to the tips of that fin. I have received fine specimens of precisely the same kind of trout from Loch Crosspiel, below the manse of Durness, Loch Kescaig, which discharges its waters into the Atlantic near Sandwood in Sutherlandshire, and from Loch Stennis in the Orkneys. It is a handsome fish, not so deep in the body as the Salmon-trout, and assuming a different general aspect, from its much darker colours and its smaller scales. The colour of the back is a dark mixture of oil-green and brocoli-brown, the sides are greatly paler, and the belly is whitish with dusky shades. In some localities, or at certain seasons, the sides have a reddish-brown tinge, and the belly is more or less deeply glazed witl orange. The forehead, snout, and gill-covers are crowded with rather large round or oval blackish-brown spots, and there are many roundish or stelliform marks on the back and sides, for some distance below the lateral line, some of which are surrounded by a paler circle, or tinged with aurora-red. The dorsal is variegated by several rows of smaller brown spots of different shades, and the adipose fin and upper lobe of the caudal are also spotted. The scales have an oval form, are considerably smaller, less flexible, and not so caducous as those of the Salmon-trout, and have a beautiful golden lustre. In the dried specimens an acute, prominent median ridge extends from the nape nearly to the tip of the snout, and the lateral ridges of the cranium are also conspicuous : in the fresh state, the head is smooth and rounded above, and the snout is very obtuse. The under jaw is exactly equal in length to the upper surface of the head. The vomerine teeth run back in a double row about half way to the gullet, and there are six teeth on each side of the tongue. The head in the females constitutes somewhat less than one-fourth of the total length excluding all the caudal beyond the scales : in the males the head is larger, four of its lengths extending from 
the tip of the snout to the centre of the middle caudal rays. The dorsal vertebræ are 58 in number, and the pyloric caca varied, in ten individuals, from 49 to 53. The young have paler colours, silvery scales, and about seven arterial blood-red spots on the lateral line, with pale areolx. They descend to the sea and return into the rivers to spawn in the winter time. Individuals varying from sixteen to twenty inches in length contained mature roe. This trout is not very choice in its selection of food, the stomachs of those which I opened containing liver shells, larve of insects, seeds of various vegetables, bits of straw and charcoal, much sand, small pebbles, the common coralline of our sea-shores broken down, and the roc apparently of its own species. The intestines of the young were filled with minute crustacese, flies, river-shells, and cod-bait, the last appearing to be a favourite food of the young of the salmon tribe.

Our Nith Trout possesses many of the characters ascribed to the Salmo trutta by continental ichthyologists*, but in the absence of the power of referring to authentic specimens for comparison, I am unable to give it that appellation with confidence, especially as the descriptions and figures of trutta, by many authors, apply nearly as well to our Salmon-trout. The liberality and kindness of Captain Barou have furnished me with a beautiful stuffed specimen of the Salmo Lemanus of Cuvier, which is said by M. Agassiz to be merely a particular state of Salmo trutta. It has at first sight a very different aspect from our Nith trout, owing to its much paler general colour, smaller and more numerous spots, and somewhat larger scales; but on examining the details of external structure, the relative proportion of parts, and the dentition, they are found to be very similar to those of the Nith trout. The posterior angles of the gill-cover are, however, more rounded, giving a convex curve to its edge approaching to that of the Salmon-trout, and the length of the under jaw rather exceeds that of the top of the head. I have had no opportunity of examining the viscera of the Swiss trout.

6. Loch Leven Trout. I am indebted to Mr. Arnott for very fine specimens of this celebrated trout, which, in external form, the proportional size of the various parts of the head and gill-cover, the size of the scales, and the dentition, agrees with the Salmo Lemanus; the only difference that I can perceive, between the specimens that I have compared, being in the almost white hue of the one, and the deep shades of colour in the other. The scales in both dry in the same manner, producing a small ridge in the centre of each, which I do not perceive in other trouts. Three individuals of the Loch Leven tront, that were dissected, had each 73 pyloric cæca, and in one of them 59 vertebræ were counted. The largest of the specimens measured twenty inches and a quarter including the caudal fin, and two inches less to the end of the scales. Its colours werc as follows. The back liver-brown, nape hair-brown, top of the head wood-brown, sides of the head and body silvery tinged with rose-red, under jaw, throat, and belly whitish, partially glazed, particularly near the ventrals, with Dutch. orange. The top and sides of the head are marked with round blackish-brown spots, which are largest on the gill-corers, where they equal swan-shot in size. The whole side of the fish, from the ridge of the back to half way between the ventrals and lateral line, is ornamented with

* Nilsson's character of the Laxloring of the Swedes, which is his Salmo trutla, applies exactly to our Nith Trout. 
many larger spots of venous blood-red margined with crimson. These spots are roundish, stelliform, or cruciform*. There are nine or ten rows of small brown spots on the dorsal, and some on the adipose fin and upper lobe of the caudal. The ridges on the top of the head, visible in the dried specimen, resemble those of the Nith trout in form, but they are more acutely prominent, particularly the lateral ones. The scales are broadly oval. The stomach contained the larvæ of insects, the remains of a fish, much sand, a bit of charcoal, and two or three fragments of sand-stone.

7. Salmo ferox. Sir William Jardine and Mr. Selby have recently given this name to a northern Scottish trout, of which a specimen has been kindly transmitted to me by $\mathrm{Mr}$. Selby, the well-known ornithologist. It resembles the Loch Leven trout in its dentition and the proportional size of the head; there is also a resemblance, though not a perfect one, in the form of the gill-cover; but the labials are much stronger and more curved, and the cranial ridges much less prominent and acute. The most decided difference is in the form of the scales, which in Salmo ferox are broadly oval, more nearly approaching to circular than in any of the preceding species; they are as thin and flexible as those of the Salmon or Salmontrout, though being more thickly covered with epidermis they are not so caducous. In colour, this fish is described as resembling the Loch Leven trout, but the spots in the specimens we have seen are fewer and larger. The caudal fin is even at the end, as in the old individuals of many other species of trout. The Salmo ferox inhabits Loch Awe, in Argyleshire, where it attains the weight of twenty-eight pounds. It spawns on the sides or near the gorge of the lake, rarely entering the feeding streams; and although it is occasionally taken in the river Awe, by which the lake discharges itself into the sea, it is said that it never attempts to reach the salt water. Its stomach is generally filled with fish. The colour of its flesh is orangeyellow, its flavour coarse and indifferent. There is a good account of this great trout in the last edition of the Encyclopædia Britannica, under the article Angling.

8. Salmo fario. The Common trout, the Burn trout of Scotland, is generally known throughout Great Britain. It varies very greatly in the hue of its body and the colour and brilliancy of its markings. Plate 92, f. $3, \mathrm{~A}$ and $\mathrm{B}$, represents the head of an individual nine inches and a half long to the end of the scales on the caudal, and ten inches and three quarters to the extremity of that fin. The under jaw is shorter than the top of the head, and the ridges of the palate bones and vomer, into which the teeth are implanted, are much more prominent than in any other species that has come under my observation. The vomerine teeth run far back in a double row. The specimen was taken in the Lake of Lochenbreck, in Galloway, and had the dusky yellowish hue of this trout when it inhabits dark waters. A much more glittering kind is taken in the Nith, Tweed, and other clear rivers, but I have not the means of ascertaining whether there be any structural difference or not. Mr. Yarrell informs me that the Salmo fario has 58 dorsal vertebræ.

9. Char. Torgoch, or Red-bellied trout. Plate 92, f. 5, A and B, exhibits the head of a female char taken in Llyn Cawellyn, near the foot of Snowdon, on the 17th of January,

* The spots of my specimen of the Salmo Lemanus are considerably smaller than those of Loch Leven trout, but the case might be different were a greater number of individuals compared. 
when ready to spawn. The scales of this trout are small, the colours peculiar, and there is merely a tuft of fine teeth on the forepart of the vomer, the rest of that bone being perfectly smooth. I owe the specimen to the kindness of J. L. Wynn, Esq., of Coëd Coch, in Denbighshire. The Tarrogan from Loch Borley, in Sutherlandshire, has a deeper body and larger scales than the Welsh Torgoch, but the want of good specimens has prevented me from instituting a fair comparison between the two. They agree in dentition, and differ from the preceding trouts in the scales being less crowded, and in many parts of the body not tiled but simply in contact.

The want of a sufficient number of specimens of the Par, and of some other Scottish trouts, causes me to pass them over without further notice*.

\section{[61.] 1. Salmo salar. (Auctorum.) The Common salmon.}

Family, Salmones (Salmonoideæ), Cuvier. (Salmonacei, NiLsson.)

Salmon abound in the rivers of Labrador, Canada, Newfoundiand $t$, Nova Scotia, the New England States, and in the waters of New York which fall into the St. Lawrence. Previous to the colonization of America, they appear to have ranged more to the south on the Atlantic coast than they do at present. The celebrated but unfortunate Hudson says, that on the 14th of September, 1609, while sailing up the magnificent river which bears his name, he saw "great store of salmons ;" but in recent times even a solitary salmon has rarely been known to stray thither, and the most southern stream on that coast which this fish now frequents, is Connecticut river, in latitude $41 \frac{1}{4}^{\circ} \mathrm{N} \ddagger$. Even there, however, it is becoming daily more scarce, the erection of weirs, milldams, and other obstacles to its ascent in the spawning season, having impeded its reproduction, and the New York market is now supplied with salmon from Kennebec river in the state of Maine. The salmon ascends the St. Lawrence and its tributaries as high as Lake

* Sir William Jardine has published an intersting paper on the Sutherlandshire trouts in the New Edinburgh Philosophical Journal. which I did not see until the preceding observations on the Salmonoidex had mostly gone to the press. He gives the following as the most convenient distinguishing marks of the Par, or Salmo salmulus, Ray :- "The great size of the pectoral fins, the shortness of the maxillary bone, and consequent diminutive gape, and the breadth between the rami of the lower jaw." In Pennant's British Zoology (8vo. ed., 1812), the figure in pl. 70, judging from the configurations of the markings and general habit, is that of a young salmon, while the lower figure, in pl. 87 , is the true Par.

+ The earliest account we have of Cabot's discovery of this island in 1497 (recorded on Adams's map) mentions salmon among its natural productions. Hakluyt, iii., p. 6.

\# "White salmons," noticed by Smith in his account of Virginia, and by subsequent writers, as abounding in the creeks of Pennsylvania, are evidently the Labre salmoïle of Lacépède, or Grystes salmoïdes of Cuvier, a percoid fish, which w have already alluded to in p. 31 . It is called "trout" by the inhabitants of Carolina and the neighbouring stales. 
Ontario, its progress farther up being effectually barred by the falls of Niagara: It has been noticed as a remarkable fact in the history of the fish, that it has never been known to enter the Niagara, or even to have been taken within thirty miles of its mouth, though there is nothing to hinder it from ascending to the foot of the falls, about fifteen miles from the lake. De Witt Clinton has, however, accounted for this fact in remarking the want of gravel beds in the Niagara, fitted to be depositaries of the salmon-spawn. Salmon are found in Lake Ontario at all seasons, and they have been caught in the Seneca, or Onondaga river, which falls into the south side of the lake in every month of the year, sometimes weighing thirtyseven pounds. "They pass," says De Witt Clinton, "Oswego at the entrance of this river in April, are then in five order, and spread over all the western waters in that direction, returning to Lake Ontario in October, much reduced in size and fatness." " Numerous conical erections of gravel, found in several of the western rivers, must have been raised by them." Another account states, that these fish make their appearance in Lake Oneida, which communicates with the Onondaga, in May, and that they eat nothing during their residence there, which continues till winter *. Mr. Todd informed me, that they enter the shallow, gravelly rivers in the vicinity of Toronto, on the north side of Lake Ontario, in August, are taken in great abundance in September, and continue to ascend until November. Their average weight is about eight pounds, and their length two feet and a half. They are taken in nets or speared by torch-light. Some years ago, a considerable fishery was established at the head of the lake, and great quantities of fish were cured for exportation, but the establishment was broken up by the war. No salmon have been seen in the Mississippi or its tributaries.

Salmon enter the rivers that fall into Hudson's Bay north of the 58th degree of latitude. According to Hearne, they are very numerous, in some seasons, in Knapp's Bay and Whale Cove, so that a vessel might speedily be loaded with them, but they are very scarce in other years. They are, he says, sometimes so plentiful in Churchill river, that upwards of two hundred fine fish have been taken in one tide, from four small gill-nets set within a mile of the fort; but at other times they are so rare that twenty nets have scarcely yielded the same number during the season, which begins in the latter end of June, and closes about the middle or end of August. The commencement of the season coincides with the breaking up of the ice $\uparrow$. The weight of the fish varies from eight to twenty pounds.

* Lit. and Phil. Trans, of New York, i., p. 147 and p. 500.

† The following dates were extracted from a Journal kept by Mr. Topping at Churchill factury, five or six miles above the mouth of the river :- 
Having seen only dried specimens of the Salmon of the Atlantic coasts of America, I cannot unequivocally refer it to the Salmo salar of European ichthyologists, though popular writers aftirm them to be the same. 'The identity of the Hudson's Bay salmon rests on more uncertain grounds, as I am not avare that it has been examined by any naturalist. I have for many years used every endeavour to procure a specimen in vain. An argument may even be adduced against the specific identity of the Hudson's Bay salmon with the salar, from the fact of its being unknown farther south in the bay than the Churchill river, in latitude $58^{\circ} 47^{\prime} \mathrm{N}$., though Nelson, Hayes, Albany, and Moose rivers, lying between the 50th and 57 th parallels, abound in the gravel-beds which salmon delight to spawn in. Dried salmon are among the articles of traffic brought to ships by the Esquimaux of Hudson's Straits, and the Salmo salar is mentioned in the Fuuna Gronlandica, though Fabricius states it to be so rare that he never saw it there, and had merely heard of its existence in two bays. It was not taken on any of the late expeditions to the arctic coasts of America or the Northern Georgian islands. It is said to frequent the Kamtschatdale rivers, and though in much smaller numbers than any of the many other anadromous trouts that are known there, it may, perhaps, range to the American side of the sea of Kamtschatka. Every voyager who has visited the north-west coast speaks of the great quantities of salmon taken by the natives; and Langsdorff mentions that "several sorts" of salmon resort to the bays and rivers of Oonalashka, Korliak, and Norfolk Sound. Eschscholtz, however, who stayed from March to the middle of August in one year, and during the latter part of August and beginning of September in another, on the island of Sitchka, in Norfolk Sound, observes that " there is no great variety in the kinds of fish, but the individuals are numerous, especially a well-flavoured sort of salmon." We shall have occasion hereafter to quote some of Lewis and Clark's notices of the trouts of the Columbia. The accounts given by authors of the habits of the American salmon are so very meagre, that it is necessary to borrow what we have to say of the natural history of the Salmo salar from the ichthyologists who have best described it as it exists in European waters.

Few fish have attracted more attention than the Common salmon of the Old

1809. June 17. River broke up.

1810. 19. River clear. July 3. Caught the first salmon.

1811. 23. River clear. July 31. Plenty of Sea-trout. August 12. Sea-trout gone.

1812. 10. River beginning lo open. July 5. River clear.

1813. 20. River clear. June 30. First salmon caught.

It is to be observed, that the ice accumulates at the mouth of the river for gome days after it has broken up opposite to the fort. 
World, its excellence as an article of diet, and the variety of interests involved in the fisheries established for its capture, rendering a correct knowledge of its natural history an object of much importance in an economical point of view. A wellauthenticated and connected account of its growth, from the newly-evolved fry to the full-sized fish, is, however, still a desideratum, for, although many facts have been established by competent observers, there are several gaps in the history of this trout, and in particular the form it assumes when half grown has not been fully discriminated from the young of other species. It is greatly to be regretted that our acquaintance with the Salmon of the American rivers is so very limited, for should it happen that the Salmo hamatus and trutta, or other closely-resembling species, are unknown in America, we might more readily ascertain how many of the forms known in Great Britain by the local names of smelts, smolts, or smouts, grawls, gilses, grilses, salmon-peel, kippers, liggers, \&c., actually belong to the salar. The natural history of the Salmon, prosecuted in a country where conflicting interests have not as yet sprung up to cause the perversion of facts, would furnish a rich field of research for ichthyologists, and afford the means of clearing up many mistakes which have crept into the works of naturalists, - great care being, of course, taken to ascertain the correct specific appellations of the subject under observation.

The Common salmon is an inhabitant of all the northern European and Asiatic seas, from the entrance of the Bay of Biscay round the North Cape, and along the coast of Asia to Kamitschatka and the sea of Ochotsk, including the Baltic, White Sea, Gulf of Kara, and other inlets. It is found in Iceland, and, according to Guldenstædt, it also inhabits the Caspian. At certain seasons the Salmon quits the sea, and ascends the rivers towards their sources for the purpose of spawning, preferring those streams which have stony or rocky bottoms, and convenient gravelly banks for the reception of the spawn. Nilsson, however, informs us, that in some instances the Salmon resides permanently in fresh water, for it is known, says he, to winter in the interior Swedish lakes, named Wenern and Siljan, from whence it ascends the rivers at the close of spring, without entering the salt water at all $*$.

As the Salmon is never taken on the British coast except in estuaries, rivers, or lakes, the depths of the sea to which it retires are unknown $\dagger$; but the microsco-

* In interioribus quibusdem lacubus, Wenern, Siljan hiemem degit, undè vere preterlapso fluvios adscendit. Lacubus igitur ut mari, pro hibernis utitur, aquam salsam nunquam attingens. Vernæ horum lacuum dicuutur pinguiores et carne saturatiores, quam marini, qui, itinere et impedimentos fatigati, dictos lacos inturdem attingunt. Nitsson, Pisces Scand.

$\dagger$ The following extract from Leems's Journey into Danish Lapland may throw some light on the matter. "At the 
pical researches of Dr. Knox have shown, as we have alrearly mentioned, that its food, previous to its quitting the salt water, consists of the eggs of various echinodermata and crustacea, this rich aliment giving the colour and flavour for which its thesh is so highly prized. On entering the fresh water for the purpose of spawning, it seems, like many other animals in the nuptial season, to lose its appetite for food, but will rise occasionally to the natural or artificial fly, and has been knowu to take both the minnow and worm* . Salmon in prime condition are taken in estuatries at every period of the year, but they do not quit the sea in considerable numbers until the summer is well advanced, and they continue in the tide-way, ascending with the flood and descending with the ebb, until the spawning season approaches. At first the fish has a bright silvery hue, with deep black spots on the back and sides, a head small when compared with the girth of the plump body loaded with juices and fat, the spawn occupies but little space, the salmon-lonse (Caligus piscinus) adheres to the gills, and tape-worms fill the intestines. As the reproductive organs advance to maturity, the salmon hastens up the river towards the gravelly deposits in the upland streams, which are its proper spawning places, surmounting the natural and artificial barriers that oppose themselves to its progress with surprising agility. Pennant mentions the perpendicular falls of Kennerth and Pont Aberglasslyn, in Wales, Leixlip, in Ireland, and East-eivel on the 'Tummil, in Scotland, as salmon-leaps, which evince the extraordinary nuscular efforts that the fish is capable of making; and travellers have recorded with admiration its perseverance in working its way up the cataracts of the Norwegian and Lapland rivers. Soon after its entrance into the fresh water, the dark spots on

close of the autumn, when the salmon taken in the rivers are lean and no longer saleable, the maritime Laplanders are accustomed to row unt a little from the shore into the deep, to take the salmon (who at this time of the year renuin im. moveable at the bottom of the sea), with an iron-headed spear, called in Lapland Harses. Lest the darkness of the night should obstruct them in this business, a fire is made on the prow of the vessel of pieces of fir-tree and the bark of the birch, which they call baral." (Yinkerton's Voy., i., p.427.) The salmon while feeding upun the ova uf echinodermata will, no doubt, remain almost stationary; but if they continue in a moderate depth of water, so as to be attracted by the light of a torch, or easily speared, one would expect them to be occasionally taken in the trawl-nets in such constant use in the British Channel.

* Mr. Niell relates that salmon kept along with other sea-fish in a salt-water pond in Galloway, were fecl with eels, shell-fish freed from the shell, and herrings cut into pieces. The habits of fish in captivity do not furnish correct indications of the food they would prefer when at liberty; but the following passage in Sir William Jardine's paper tends to prove, that salmon do not feed exclusively on crustacea, eniomostraca, or the ova of echinodermata, during their residence in the ocean, though it is certain that it is the remains of these substances which are chirfly distinguishable among the mucus which thickly lines the intestines of salmon when they ascend rivers in spawning cundition. "Iu the north of Sutherlınd a mode of fishing salmon is sometimes successfully practised in the firths, where sand-eels are used for bait: a line is attached to a buoy or bladder, and alluwed to float with the tide up the narrow estuaries. The salmon are alsu said to be occasionally taken at the lines set for haddocks, baited with sand-eels. At the mouths of rivers they rise freely at the artificial fly within fifty yards of the sea, and the common eartli-worm is a deadly bait for the clean salmon." The following additional remark occurs in a note: "Faber, in his Natural History of the Fishes of Iceland, remarks, that the Cummon salmon feeds on small fishes, and various small marine animals-Fleming says its favourite food in the sea is the sand.eel." (JArDine, /, c.) 
the back and sides are effaced, the salmon-louse shrivels and drops off, and the tapeworms die and are discharged. As the spawn augments in volume, the flesh of the salmon deteriorates, growing lean, flabby and insipid, and the bright silvery tints of the scales are replaced by brownish stains, giving rise to the epithet of "red-fish," in contradistinction to that of "clean," which the fish had on its first arrival from sea in high marketable condition. The gravelly shoals selected as spawning places are generally as high up the river as the fish can ascend. Furrows about eighteen inches deep being formed in the gravel by the male, according to some observers, or by both male and female as others report, the latter deposits in them her roe, and the former his milt, and carefully covers them up. The fish has been said to plough up the gravel with its fins, but it is more probable that it uses the nose for this purpose. Mr. Potts (quoted by Pennant) thinks that the tail is the instrument by which the gravel is filled in over the spawn, as he had observed the skin rubbed off that part; this abrasion, however, may be the result of friction against stones, in the efforts the fish makes to ascend the shallow streams. After securing the spawn, the salmon conmences its return to the sea, being now named, in the language of the fishermen, a "foul fish," ligger, kipper, or kelt; its gills are infested by the gisler, or brachiella salmonia, and it continues to have a dark colour, lank form, and to be unfit for food during the remainder of its stay in fresh water. The period of a salmon's stay in a river is determined by various causes. The ascent of most streams is facilitated by the land-floods of wet seasons, or rendered impracticable for a time by droughts; and Dr. Fleming thinks it probable that circumstances which favour the upward passage of the fish tend also to accelerate the ripening of the spawn*. In returning to the sea the fish keep the middle of the stream, and seek the deepest and saltest water of the estuary.

The following observations on the spawning of the salmon, and subsequent evolution of the young fry, in one of the tributary streams of the Tweed, are recorded by Dr. Knox in the paper we have already cited. "In November the river Whitadder, which has its source in a mountainous country nine bundred feet above the level of the sea, abounded in all the different kinds of salmon usually taken in the Tweed, with which this stream communicates at a short distance from Berwick. They were engaged every where in spawning, this being the usual time in which the act is carried on. A pair, seemingly $t$ of the ordinary Tweed

\footnotetext{
* El. Phil. Journ., x., p. 375, in a paper which gives a detailed account of the movements of the Salmon in the river Tay. The facts therein stated coincide generally with Mr. Potts's history of the Tweed salmon in Pennant's British Zoulogy.

† The Tweed Bull-trout, or Salmo hamatus, might be readily mistaken for the Salmo salar.
} 
silmon, from fourteen to sixteen pounds in weight, were watched. The ova were observed to be deposited near the sources of the stream on the 2nd of November, and covered up with gravel in the usual way. The spawning bed was placed at the foot of a pretty long and placid pool, and just at the top of a stream where the water first begins to feel the effects of the approaching descent. The water was about fifteen feet broad, with a depth of six inches. The breadth of the bed seemed to be about eight feet, and its length three or four, the whole having rather in oval form. It har the appearance of washed gravel, in consequence of the whole mass laving been turned over by the salmon during the process of depositing the ovi. On the 25th of February, or one hundred and sixteen days afterwards, hundreds of ova were turned up with the spade from the depth of from nine to twelve inches below the surface of the gravel. They were clear, transparent, and seemingly unchanged. On the 23rd of March the ova were found to be changing; the outer shell cast; the fry lying imbedded in the gravel as fishes, being twenty weeks from the period of their deposition. By the lst of April most of the fry had quitted the bed, by ascending through the gravel, and on the 19th of that month many were taken eight or even nine inches long, in excellent condition. Fry of the same size, but probably of a later deposit, were abundant in the same streams on the 5th of May. In a former year the roe was found unchanged on the 10th of April, but on the 1\%th the excluded fry were imbedded in the gravel, and on the 22 ud smoults were taken about the size of the little finger. The depth at which the ova are deposited raries, being sometimes about two feet below the surface of the bed. The food of the fry is exactly the same with that of the trout found in the rivers at the same period; viz., small insects, larvæ of flies, beetles, and codbait, with which the gravel of the stream abounds in an incredible degree. In the gravel-bed the ova of salmon and trout lie safe from every living enemy, and in the midst of profusion of food, whose habitat is the same as their own; and whose progress of incubation and subsequent rise through the gravel is quite similar. The great variety and quantity of these insects, together with the depth of their situittion (for the spade which took up the ova was also full of them), was truly surprising. It is probable that as these larve of insects, for such they mostly are, rise ahove the gravel to assume new forms, they offer ready food for the trout and salmon fry of all sizes which may be in the river ; but I do not suppose that these fishes dig under the gravel in search of food at any time *.

\footnotetext{
* No trout affords the young angler more certain amusement than the salmon fry. These unsuspicions smouts liave keen apjetites and rise with avidity at the artificial fly, however rudely made, provided it be small enough-but a cadıs worm, or a gentle impaled on a hackle, is a still more alluring bait. We have known a bare-legged truant kill thirty dozen in one day with the most inartificial tackle.
} 
"The growth of the fry is very rapid. On the 20th of April the rivers were full of salmon-smoults, varying from six to nine inches, having attained that length in about three weeks. They were in the finest possible condition, covered with small silvery scales, differing in shape from those of the trout or par. They are very tender, and constantly die a short time after being touched. During the months of March, April, and May, the rivers abound with kelts, or spawned salmon, descending towards the ocean, and smoults, or fry, pursuing the same course." Dr. Knox, in the appendix to the able paper from which the foregoing passages are abridged, remarks that there are two circumstances which persons of sound judgment and great experience with regard to the salmon question still think undecided, or at least demanding a more extended proof. The first is a series of experiments to determine the growth of salmon-fry from the state of the egg to its attaining the length of six, seven, eight, or nine inches, before which it is seldom seen by the angler, and after which it ceases to be found in fresh-water rivers; secondly, proof that the fish we call salmon-fry, taken in salmon-rivers by angling during the months of April and May, do really proceed to the ocean and return after a period to the rivers as grilse, Salmon-trout*, and salmon. The facts ascertained by Dr. Knox, in conjunction with the previous observations of others who have attended to the subject, go towards the answer of the first question; and the following extract from Sir William Jardine's paper may be considered as a reply to the second. "It has always been a subject of dispute whether the fry returned to the rivers as grilse in the same season in which they descended. I have had no doubt of this for several years, but it was very difficult to prove. In the Tweed I have killed grilse early in the season, so small as to weigh only two pounds, and seen them gradually increase in size as the season advanced; the intermediate size, however, between the fry and the two pound grilse was wanting. During the two years which the fisheries of Sutherland have been in the possession of the Duke, a set of experiments have been instituted by his factors, one of which leaves no doubt upon the subject. Last spring, several thousands of the fry were marked in the different rivers, among others by Mr. Baigrie, in the Laxford and Dinard, on the west coast. In the Laxford, the first grilse (marked in April as fry) returned on the 25th of June, and weighed three pounds and a half. Many others were got during the season, from this weight to six pounds and a half, returning to the rivers where the fry were marked, which was known by a particular mark being used in each, and showing that a return to their breeding ground was as frequent, or rather

* Dr. Knox considers our Salmon-trout to be merely a variety of the Salmo salar. 
as eonstant, as among the higher animals. These marlied grilse were unfortunately killed; but next year it is proposed to return them to the river with an additional mark, and endearour to take them again a second seison."

The spawning season conmences in most of the British streams in October, is at its height in November, and continues through December, comparatively few salmon spawning in January, February, or March. It is necessary that the different kinds or species of salmon should be more fully made out before we can refer to the history of the Common salmon the statements to be found in authors of the great differences in the spawning seasons in different rivers*.

The salmon has many enemies, of whom man is undoubtedly the chief, for its numbers diminish rapidly as civilization and the arts advance on the banks of the rivers it frequents. Notwithstanding the proverbial + activity of this fish, it is hard pushed in its own element by several of the mammalia. Captain Cartwright saw a bear taking salmon in the mouth of one of the Labrador rivers by diving in deep water $\neq$; the otter too, a well-known river poacher, makes great havock among the salmon of all ages; and the seal has been observed, on the const of Scotland, coursing a salmon like a greyhound in chase of a hare, turning it on every attempt it made to get to seaward, and finally securing it through the exertion of superior strength and sagacity. 'I'he following anecdote is told by the Rev. Mr. Hamilton, of a dog leaguing with man against this fish. "In riding from Port

* Dr. Arthur Young infurms us, that " in all the rivers which run into the Ban, the salmon spawn about the beginning of August, and as soo as they have done swim to the sea, where they stay till January, when they begin to return to fresh water, and continue doing so till August, in which voyage they are taked. The uets are set in the beginuing of January, but by Act of Purliament no nets or weirs can be kept down after the 12th of August. The young salmon are called grawls, and grow at a rate which I should suppose scarce any fish commonly known equals; for within the year some of them will come to sixteen and eighteen jounds, but in general ten or twelve pounds : such as escape the first year's fishery are salmon; and at two years old will generally weigh twenty to twenty-five pounds. This year's fishery (17j6) has proved the greatest that ever was known; yielding four hundred tons of firh; and tbey had the largest baul, laking one thousand four hundred and fifty-two salmon at one drag of a siagle net." - (Tour in Ireland.)

Linoxus states that the salmon-fishery of the Laxholms, or Salmon islands, in Lulean Lapland, commences " a fortnight before Midsummer (June 10th) and ends on St. Bartholomew's day, August 24, and that during that space of time the salmon keep ascending the rirer. After that day none of the fishermen remain. Few of the fish escape being taken, so as to return down the river. At Hichaelmas (29,h of September) the fishermen come here again, when they' catch a smaller sort of salmon." (Lachesis Lapponica, ii., p. I18.)

Leems relates that in the river Alten, which has its rise in the remotest mountains of Lapland, the fishery begins on the festival of St. John (June $24 t h$ ), at which time the salmon are very fat, and so large that a tun can scarcely hold sixteen, but those which enter the river as the autumn is approachin: are of a much smaller size and also lean. In the Thana, the principal river of Eastern Fiomark, the season lasts from the beginning of spring until two weeks after the festival of St. John the Baptist (July Sth). The fish in this river are peculiar for their breadth and fatness, aod are accounted the very best of their kind. (LeEss, Journey into Danish Laplancl. Aa.1767.) Sir William Jarcine, in speakiug of the sparning time, remarks that "The northern rivers, with little exception, are the earliest, a fact well known in the lonlon narkets." "It is a mistiken notion to suppose that the spawning season is only between Octoher and lebruary. In many rivers it would commence in the end of August, if the grounds and entrance to the rivers were luft oplen and unmolested." JakDISE, I. $c$.

+ "Dicilur namque salmo a sallu." OJ.Aus Magxes, Hisl. Sepl., p. 523.

† G. Cantwugut, Sirleen Ients' Residence in Labrador. 
Rush to the Giant's Causeway with some company, we had occasion to ford the river Bush, near the sea; and as the fishermen were going to haul their net, we stopped to see their success: as soon as their log perceived the men to move, he instantly ran down the river of his own accord, and took post in the middle of it, on some shallows where he could easily run or swim, and in this position he placed himself with all the eagerness and attention so strongly observable in a pointer dog who sets his game :-we were for some time at a loss to comprehend his scheme, but the event satisfied us, and amply justified the prudence of the animal; for the fish, when they feel the net, always endeavour to make directly out to sea. Accordingly, one of the salmon, escaping from the net, rushed down the stream with great velocity towards the ford, where the $\operatorname{dog}$ stood to receive them at an advantage. A very diverting chase now commenced, in which, from the shallowness of the water, we could discern the whole track of the fish, with all its rapid turnings and windings. After a smart pursuit, the dog found himself left considerably behind, in consequence of the water deepening, by which he had been reauced to the necessity of swimming. But instead of following this desperate game any longer, he gave it over, and ran with all his speed directly down the river till he was sure of being again seaward of the salmon, where he took post as before in his pointer's attitude. Here the fish a second time met him, and a fresh pursuit ensued, in which, after various attempts, the salmon at last made its way out to sea, notwithstanding all the ingenious and vigorous exertions of its pursuer. Though the dog did not succeed at this time, yet $I$ was informed that it was no unusual thing for him to run down his game; and the fishernen assured me that he was a very great advantage to them in turning the fish towards the net. During the whole of the chase, this sagacious animal seemed plainly to have two objects in view; one to seize his game, if possible, and the other to drive it towards the net when the former failed; each of which he managed with a degree of address and ingenuity extremely interesting and amazing*."

I have been able to procure only four specimens of the American salmon. The first one, described below, was taken from a tierce of salted fish, which a fishnonger assured me was inported from Quebec. The colours of the skin were remarkably well preserved by the salt, and the specimen, which had been split along the back with a sharp linife, was easily restored to its original form. It had then a very perfect resemblance to a British salmon of the same size. Three other specimens were prepared for me at the instance of James Keith, Esq., of La Chine,

* Rev. W. Hamilton, Hist, of the Basaltes on the Coast of Antrim, \&c. 1784. (Рinck. Coll., iii., p.877.) 
by a gentleman in charge of the fur-posts on the Mingan and Musquaw rivers, which fall into the St. Lawrence near its mouth. Were it not that the skins of these appear to have been overstretched in drying, so as to account, at least in some degree, for the differences of the relative positions of the fins, I should have considered them as distinct from the Salmo salar, and I still think that their identity with that species is somewhat doubtful.

\section{DESCRIPTION}

Of a specimen preserved in salt, imported from Quebec.

CoLovr.-Head bluish-grey above, very silvery on the sides; two round black spots about the size of a pea between the eye and the nape, and one upon the operculum. Back and upper parts of the sides pearl-grcy with a strong silvery lustre, reflecting a purplish tint when opposed to the light: the lower parts of the sides have an uniform pearly tint with much lustre. There are four rows of black spots above the lateral line, each spot surrounding one scale, and rumning into the interstices of the adjacent ones: some of the rows cease towards the hearl and tail ; they eontain about thirty spots on eacls side. The under jane, throat, and belly are unspotted white. The pectorals and candal are white at the base, their tips and the whole of the dorsal being bluish-grey : the anal and back of the ventrals are grey with whitish rays.

Scales thin, flexible, and nacry; the uncovered portion of each on the back and upper part of the sides is rhomboidal. Near the dorsal fin there are seven seales in a linear inch, but adjoining to the lateral line there are only six. On the lower parts of the sides the margins of the scales are segments of circles. A scale taken from the latcral line is oval, obtuse at both ends, and about one-third longer than it is wide. There are 124 seales on the lateral line, including the small ones on the base of the eaudal, and 47 in a rertical row below the dorsal, of which 20 are above the lateral line, and the same number between it and the ventrals.

Form.-Head small and neat, forming one-fifth of the total length exeluding the caudal : it is convexly conical when the jaws are closed, the profile of the forehead being a continuation of the moderate curre from the dorsal. Tip of the snout rounded but not broad. Orbits circular, placed one diameter from the upper end of the labials, two from the tip of the snout, and three and a half from the posterior edge of the gill-corer. The nostrils are as near again to the orbit as to the end of the snout. The intermaxillaries are cartilaginous and are one half the length of the labials. The labials are thin and flat with a slightly curved anterior edge: they are narrow at their junction with the intermaxillaries, but spread out into elliptical plates towards the angles of the mouth: the posterior piece, or apophysis, which is acutcly ellintical, forms more than half the breadth of the labial, but does not reach quite to the tip of the latter. The distance between the tip of the snout and extremity of the labial reaches a little beyond the base of the snout*, or a line drawn from the posterior edge of one orbit to that of the other. The under jaw is acute and projects slightly beyond the snout

\footnotetext{
* Linea rosiri basalis of Nilsson.
} 
when the mouth is open, but its tip is received within the intermaxillary teeth when the jaws are closed. The lower jaw is about two lines shorter than the distance between the tip of the snout and the nape.

TEETH conical, acute, mostly pointing backwards, and placed in a single row on the under jaw, edges of the palate-bones, and round the entire margin of the upper jaw, except about half an inch of the lower extremity of the labials : those on the sides of the snout and towards the tip of the lower jaw are a little longer than the others. There are two teeth on the anterior part of the vomer, one before the other, and five on the tongue, two on one side and three on the other. (In the head of the Scottish salmon, figured on plate 91, there is but one tooth on the vomer and four on the tongue.) Neither the vomer or palate-bones rise into ridges where the teeth are implanted, either in the American or European salmon, and there are no small teeth on the tip of the tongue.

GilL-covers.-The free edge of the gill-cover is semicircular, instead of being elliptical or angled as in many species of trout. Preoperculum broad, being but little narrower in its middle than the cheek, and more than half the width of the operculum : its posterior edge is even, but there are fise irregular, diverging, tubular prominences on the surface of its lower limb. Operculum about one-fourth higher than broad, and marked on its posterior and inferior borders with fine furrows. Suboperculum about one-third of the height of the operculum, but equalling it in width. Interoperculum irregularly triangular, with a long narrow limb passing forwards beneath the preoperculum to the articulation of the lower jaw.' Gill-rays twelie on the left side and eleven on the right.

Fins.-Dorsal containing thirteen rays, the first one being very short and with the second closely applied to the third, which nearly equals the fourth and longest. The ventrals are opposite to the ninth and three following rays of the dorsal. The anal contains ten rays, the first one being very short. The adipose fin is partly opposite and partly posterior to the termination of the anal. The caudal is forked.

A specinen of the Mingan River Salmon, prepared for me by Mr. Cumming, corresponds closely with the above description, except in the following particulars. Part of the snout before the orbit proportionally longer. Vomer perfectly toothless-Ventruls rather more posterior, being opposite to the three last rays of the dorsal. The adipose fin is also farther back, being wholly behind the anal. The caudal is almost even at the end when extended, being very slightly crescentic. The specimen has lost most of its colours in drying, so that its markings cannot be compared with the Quebec fish.

The kindness of the same gentleman has also furnished me with two specimens of the Musquaw River Salmon.- The largest has quite lost its colours and has been overstretched in stuffing, so that the dimensions of its body cannot be quoted with safety, but in the relative dimensions of the parts of its head it resembles the Quebec fish more closely than the preceding *. It has two teeth on the vomer, one before the other, and two on each side of the

\footnotetext{
* On comparing the dimensions of the larger Musquaw River salmon with that of a prime Scottish one of the same length in the subjuined table, the head of the former appears altogether smaller, but, as we have remarked above, the skin may have been overstretched, and the total length conseguently disproportionately increased. .
} 
tongue. The smaller specimen is in perfect preservation, exeept that its colours are fuded. The four rows of black spots are, howerer, clistinct enongh. There are four tecth on the vomer, the two anterior ones being abreast. It does not seem that in this specimen the relalive position of the fins could have been in any way altered, yet the rentrals correspond to the three last rays of the dorsal, and are even partly posterior to that fin. In other respects there is no material difference between it and the Quebec fish, and a close comparison with a small Scottish salmon, or grilse of nearly the same size, showed an almost perfect similarity in the seales and external form.

In the following table of dimensions I have given exact measurements not only of the American specimen but also of several British salmon with which I compared them.

$$
\begin{array}{lllllll}
\text { Fins.-Br. } 11-12 ; & P .13 ; & D .13-0 ; & V .9 ; A .10 ; & C .206 & \text { Quebec salmon. } \\
11-12 ; & 13 ; & 14-0 ; & 9 ; & 11 ; & 19 \frac{7}{5} \text {. Mingan R. ditto. } \\
11-11 ; & 14 ; & 15-0 ; & 9 ; & 12 ; & 19 \frac{5}{5} \text {. Musquaw R. ditto. } \\
10-12 ; & 14 ; & 14-0 ; & 9 ; & 12 ; & 194 . & \text { Ditto, ditto. }
\end{array}
$$

Dimessions.

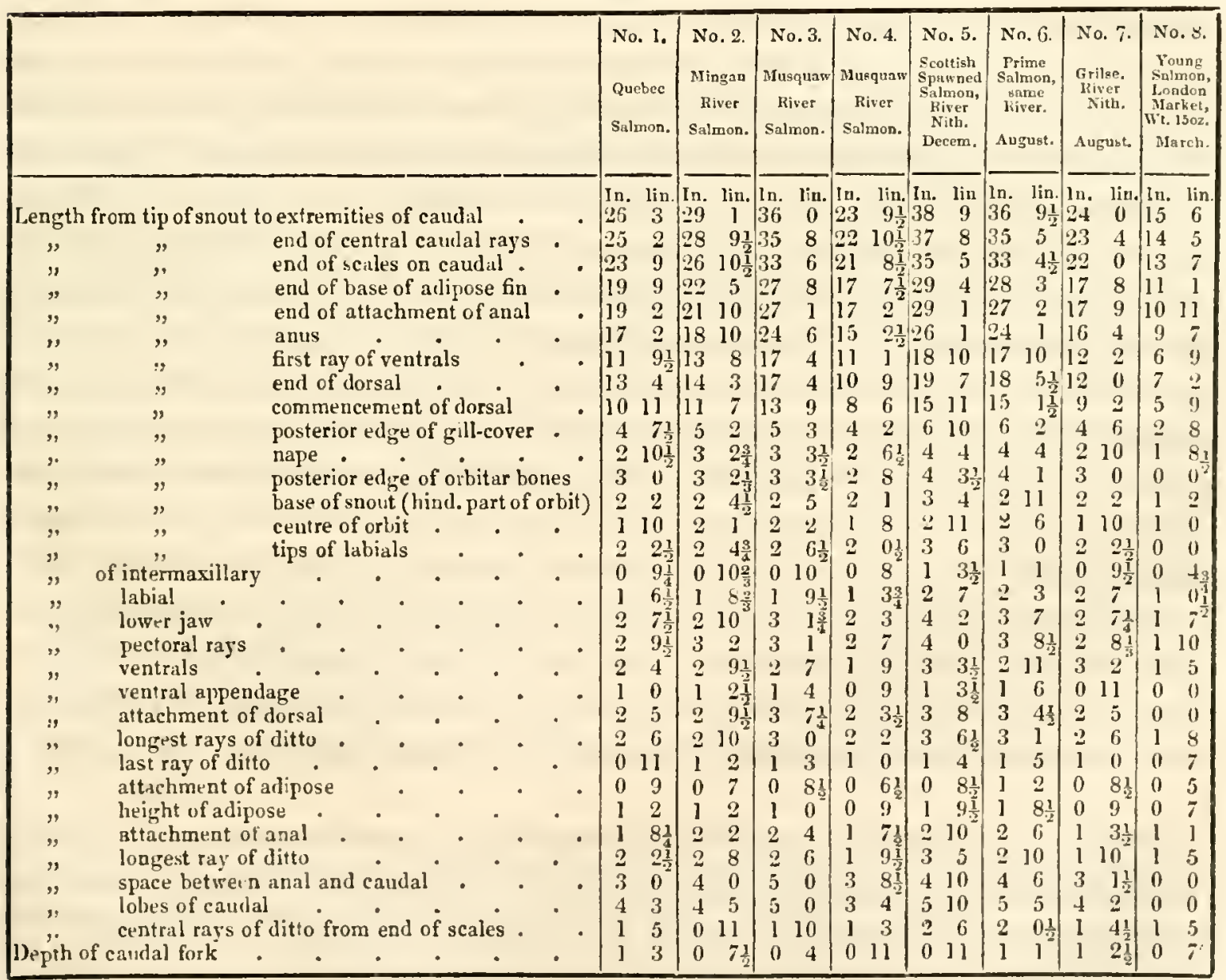

Ons. The dimensions of the intestines of two English salmun are given in a subsequent page, at the end of our account of the True trouts. 


\section{[62.] 2. Salmo Scouleri. (Richardson.) Olservatory Inlet Salmon.}

Fasruy, Salmonoidez. Genus, Salmo. Cuverr. Sub-genus, Salmo. Id.

\section{Plate 93.}

Fig. A, entire fish, one-third nat. size. $B$, head, and $C$, roof of the mouth, nat. size.

I am indebted to Dr. Scouler, of the Dublin Institution, for a specimen of this rery interesting salmon, which he obtained when on the north-west coast of America, in the service of the Hudson's Bay Company. It was taken in the month of August in Observatory Inlet, and Dr. Scouler remarks that " this arm of the sea was frequented at the time by such myriads of the salmon, that a stone could not have reached the bottom without touching several individuals, their abundance surpassing the efforts of imagination to conceive. The little brook that empties itself into the inlet was swarming with the fish ascending to spawn, and in the course of about two hours we killed sixty with boarding pikes. The hump before the dorsal fin consists of fat, and appears to be peculiar to the males, who acquire it after the spawning season, when their snouts become elongated and arched." Having directed Dr. Scouler's attention to Pennant's notices of the Kamtschatka salmon, he favoured me with the following second communication. "I will endeavour to answer your questions seriatim. I think the Observatory Inlet salmon comes nearest to the gorbuscha* of Kamtschatlia. According to the best of my remembrance, the colour of the belly is white, inclining to yellow, and the back is of a bluish leaden colour. Nothing can be more different than the appearance of the two sexes in the spawning season. The female is round and beautiful, with the jaws of equal length; while the male is compressed laterally and has a long arched snout with powerful teeth. The flesh of this salmon is red, and we thought it excellent, quite equal to that of the English salmon,- no one on board objected to it." "The natives of the Columbia use two modes of cooking salmon. One consists of steaming, which is accomplished as follows: A number of heated pebbles are thrown into a

* "The gorbuscha, or hunch-back, ascends the rivers in July. In form it resembles the Grayling: never exceeds a foot and a half in length: is of a silvery colour, and unspotted: the tail forked; the flesh white. After it has been some time in fresh water it changes its shape (the male especially) in a most surprising manner. The jaws and teeth grow prodigiousiy long, especially the upper, which is at first shortest, but soon shoots beyond the under, and grows crooked downwards: the body becomes emaciated and the meat bad: but what is most characteristic, an enormous bunch rises just before the first dorsal fin, to which it owes its name. Its flesh is bad, so that this fish falls to the share of the dogs. Rays. D.14-0; P. 15; V.11; A. 18." (PENN., Arct. Zool., Intr., p. cxxv.) 
wooden trough, and some bits of wood or small brauches placed over them; the pieces of fish are then put in, a little water added, and the whole covered with mats until the fish is cooked. The second mode is broiling the salmon. The intestines are taken out, and two or three bits of wood inserted into the body of the fish to keep it expanded transversely; a stronger stick is passed through the tail ind head, and its lower end stuck into the ground at a convenient distance from the fire. The salmon is to the north-west Indians what the cerealia are to us, the fishing season being their harvest. During the summer the natives reside near the coast, or on the banlis of rivers in which the salmon are abundant, and occupy themselves in curing the fish for winter use. They cut two long and broad slices from each side of the fish, dry it in the shade, and eat them like bread. Vast quantities are thus prepared, and thongh no salt is used it forms a palatable food, which I have often eaten. Sometimes the dried fish is broken down, kept in bags, and eaten by handfuls, when it may be called the pemmican of the north-west coast. After the salmon season the Indians retire inland with their abundant store.

"Pennant says the Kamtschatlia salmon die without returning to the sea, after" sparning. I never heard such an opinion mooted on the north-west coast, and saw nothing to confirm it; but as the streams which the American salmon ascend are often extremely shallow, and as they spawn in Observatory Inlet during the months of July and August, when the water is at the lowest, I should suppose that great numbers must perish from emaciation (for their flesh then becomes white, or at least a great deal less red and of bad quality), and from the extreme difficulty they must experience in returning to the sea from the want of water, and perhaps from its high temperature. Thousands must also be devoured by the osprey, the white-headed eagle, and the otter, in the fresh waters, and by the seals in the sea, so that I should think few survive. I am unable, however, to say whether any return to the sea or not; or whether the large teeth drop and the incurvated snout returns to its former diniensions. The females want the large teeth, and so do the males before spawning, at least I suw none with large teeth in the Columbia in April or May. We left that river in June, and did not return until September." (Scouler, in lit.)

The following extract from Sir Alexander Mackenzie's Journey to the Pacitic, describes the mode in which the salmon roe is preparcd for food by the natives of New Caledonia. "He took the roes out of a bag, and having bruised them between two stones, put them in water to soak. His wife then took a handful of dry grass in her hand, with which she squeezed them through her fingers; in the 
meantime her husband was employed in gathering wood to make a fire, for the purpose of heating stones. When she had finished her operation she filled a watape $^{*}$ kettle nearly full of water and poured the roes into it. When the stones were sufficiently heated, some of them were put into the kettle, and others were thrown in from time to time till the water was in a state of boiling. The woman also continued stirring the contents of the kettle till they were brought into a state of consistency; the stones were then taken out, and the whole seasoned with about a pint of rancid oil. The smell of this curious dish was sufficient to sicken me without tasting it, but the hunger of my people surmounted the nauseous meal. When unmixed with oil the roes are not unpalatable."

We have no means of ascertaining whether the Observatory Inlet salmon be one of the several kinds seen by Langsdorff at the island of Kodiak and on the adjacent coast, nor whether Dr. Scouler's conjecture, that it is the same species which abounds in the Columbia be correct; but Lewis and Clark's account of the salmon they observed in that river is subjoined to the following description of Salmo Scouleri.

\section{DESCRIPTION}

Of a specimen taken in Observatory Inlet by Dr. Scouler, 1825.

Form.-The profile is mueh arched between the nape and the dorsal fin, and the body there is thick but gradually tapers to the caudal. Head convex, transversely between the eyes, but in profile descending nearly in a straight line from the nape to the nostrils. Orbit ovate, situated more than thrice its length from the posterior edge of the gill-cover. The posterior orbitar bones reach backwards to the upper angle of the preoperculum. The nostrils open about half an inch anterior to the orbit. The jaws are very long, and, in our specimen, the intermaxillaries are greatly prolonged and ineurvated, projeeting beyond the lower jaw: they are about two-thirds of the length of the labials. This prolongation and ineurvature is said to be peculiar to the male after spawning $\dagger$, and is accompanied by great enlargement of the teeth which are implanted in the intermaxillaries and knobbed extremity of the lower jaw. The labials are linear-laneeolate and straight: their posterior tips pass a little beyond the upper angle of the preoperculum, or within half an ineh of the nape: the union between the two pieces of the labial is so complete that the suture cannot be distinguished. The under jaw is terminated by a dilated and slightly ineurved knob which is armed with very strong hooked teeth: its articulation is about an ineh posterior to the nape, and its length exceeds that of the upper surfaee of the head, including the snout, by about three quarters of an inch. The head, measured from the tip of the lower jaw to the edge of the suboperculum, forms one-fourth of the

* Watape is the root of the pine-tree, and the kettle is a basket made of the flexible twigs woven so compactly together as to be water-tight.

$\dagger$ A suecimen of a salmon, probably Salmo hamatus, once belonging to Donovan, and now in the British Museum, has a hooked nose very like that of Salmo Scouleri. 
total length including the eaudal, or if the measurement be made from the knob of the lower jaw to the tip of the central caudal rays, the head still constitutes one-fourth part.

TEEти.-There are nine very strong and considerably incurved tceth in a row on each intermaxillary, exclusive of four smaller ones which occupy the tip of the snout on both sicles of the prineipal row. The labials are elosely set with much smaller teeth in a single series, and the teeth on the limbs of the lower jaw are likewise close, numerous, and curved: those on the dilated knob of the jaw are very much curved and are the largest of all, being upwards of a quarter of an inch long. The palutine and vomerine teeth equal the posterior ones on the lower jaw in size, and are implanted in double rows: there are none on the anterior knob of the vomer. The tongue is long and narrow, and is armed with distant teeth on each side, about the size of those on the labials.

Gill-covers.- - The posterior edge of the gill-cover is formed by the union of three small segments of large circles. The operculum is strongly unarked with lines which radiate from its anterior upper angle: its lower edge slants downwards and forwards, so as to interpose itself between the preoperculum and suboperculum. The latter forms an acute spherical triangle, its convex side occupying nearly as much of the edge of the gill-cover as the operculum: the borders of both these bones are finely radiated. The interoperculum is shaped much as in other tronts, but its posterior angle reaches the edge of the gill-cover instead of being separated from it by the subopereulum as usual. The preoperculum is broad, being at its greatest width nearly equal to the operculum, and it is marked, as well as the adjoining part of the interoperculum, with elose raised lines and furrows, very different from the short diverging tubular ridges of this bone in other trouts. The bones of the head, in general, have an unusually fibrous texture. Gill-rays flat, but narrower and shorter than in most other species: the longest are the central ones under the articulation of the jaw, the more posterior ones being a little shorter: there are 12 on the right side and 13 on the left.

\section{Fins.-Br. 12-13;P. 16;D. 14-0;V.11;A.17;C. 199.}

The pectorals contain sixteen rays; the dorsal fourteen, the height of the fourth, fifth, or sixth, which are the longest, equalling the length of the attacliment of the fin. The adipose fin is opposite to the three last rays of the anal. The ventrals are under the ninth, tenth, and elerenth dorsal rays. The ventral appendages are long, reaching to within one-third of the tips of the fin. The anal contains seventeen rays, the first one short, and the second nearly equalling the third, which is the longest; the last one is half as long as the third. The caudal fin has an unusually tapering base, and is forked at the end, the depth of the fork being half the length of the central rays; it contains nineteen rays exclusive of nine short basal ones abore and below.

The Scales are small and vary in form, some being oval, others four-sided with the corners rounded. They are most regular and closest on the tail, being in contact but not tiled: on the anterior part of the back they are separated by spaces equal to their own breadth, but on the sides they are not so far apart. Under the dorsal fin, and near the lateral line, a linear inch includes eleven seales, the intervening spaces occupying about one-third of the inch. There are 170 scales on the lateral line, and 70 in a rertical row anterior to the ventrals, of 
which 30 are above the lateral line. The lateral line marked out by a small raised tube on the anterior part of each scale, is equidistant from the dorsal and ventral fins. The anus is situated at the commencement of the posterior third of the fish, caudal included.

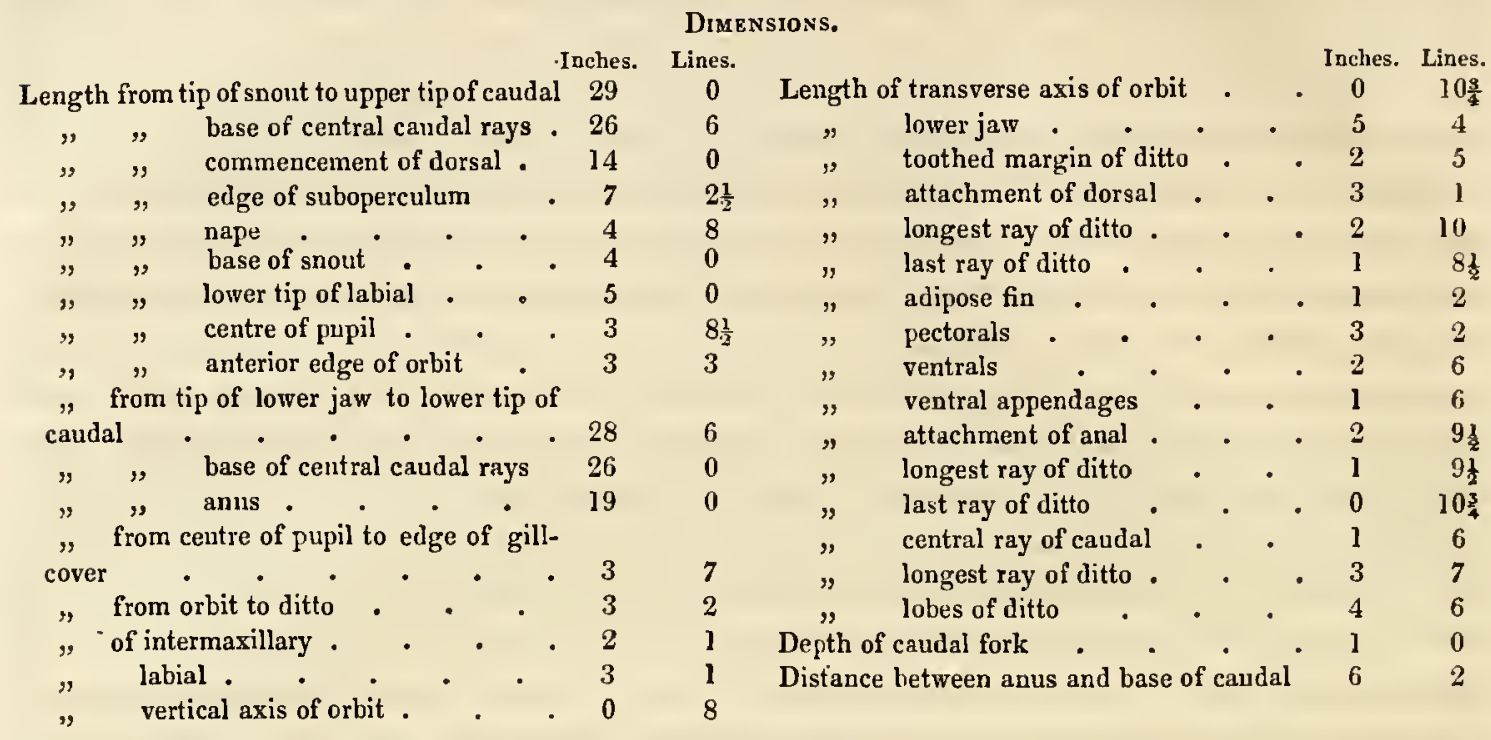

The anadromous trout of the Columbia river are described by Lewis and Clark under the names of the Common salmon, Red char, and Salmon-trout, which they state to be inhabitants of both the seas and rivers.

"The Common salmon are usually the largest, and weigh from five to fifteen pounds: they extend themselves into all the rivers and little creeks of this side of the continent (Pacific coast), and to them the natives are much indebted for their subsistence. They begin to run early in May. They are never caught with the hook, and we do not know on what they feed. The body of the fish is from two and a half to three feet long, and proportionably broad : it is covered with imbricated scales of a moderate size : the eye is large and the iris of a silvery colour : the pupil is black, the rostrum or nose extends beyond the under jaw, and both jaws are armed with a single row of long teeth, which are subulate and inflected near the extremities of the jaws, where they are also more closely arranged : there are some sharp teeth of smaller size, and the tongue, which is thick and fleshy, is armed with sharp points: the fins of the back are two; the first, placed nearer the head than the ventral fins, has several rays; the second, situated far back near the tail, has no rays. Both the fins and the belly are some times red, particularly in the male. The flesh of this fish, when in order, is of a deep fleshcoloured red, and every shade from that to orange-yellow; when very meagre it is almost white. The roes are in high estimation among the natives, who dry them in the sun, and preserve them for a great length of time: they are of the size of a small pea, nearly transparent, and of a reddish-yellow cast: they resemble very much, at a little distance, our common garden currants, but are more yellow.

"The RED CHAR are rather broader in proportion to their length than the Common 
salmon : the scales are also imbricated, but rather larger, the rostrum exceeds the under jaw more, and the teeth are neither so large nor so numerous as those of the salmon. Some of them are almost entirely red on the belly and sides; others are much more white than the salmon; and none of them are variegated with the dark spots which mark the body of the other: their flesh, roes, and every other particular with regard to form, are those of the salmon.

"Of the Salmon-trout we observe two species differing only in colour. They are seldom more than two feet in length, and much narrower in proportion than the salmon or red char. The jaws are nearly of the same length, and are furnished with a single series of small, subulate, straight teeth, not so long nor so large as those of the salmon. The mouth is wide, and the tongue is also furnished with small subulate teeth, in a single series on each side: the fins are placed much like those of the salmon. One of the kinds, of a silvery-white colour on the belly and sides, and a bluish light brown on the back and head, is found below the Great Falls, and associates with the red char in little rivulets and creeks. It is about two feet eight inches long, and weighs ten pounds. The eye is moderately large, the pupil black, with a small admixture of yellow, and the iris of a silvery-white, and a little turbid near its border with a yellowish-brown. The fins are small in proportion to the size of the fish. Fins.$D .10-0 ; P .13 ; V .10 ; A .12$. - The other kind is of a clark colour on the back, and its sides and belly are yellow, with transverse stripes of dark brown: sometimes a little red is internixed with these colours on the belly and sides towards the head. The eye, flesh, and roe are like those of the salmon. Neither this fish nor the salmon are caught with the hook, and we know not on what they feed. The white kind, found below the falls, is in excellent order when the salmon are out of season and unfit for use." (Lewis and Clark, iii., p. $66-68$.)

\section{[63.] 3. Salmo Rossin. (Richardson.) Ross's Arctic Salmon.}

Salmo Rossii. Richardson, in Nat. Hist. App. to Ross's Voyage, p. lvi.

Eekalook. Esqumaux of Boothia Felix.

Plate 80, one-quarter nat. size. Prate 85, f. 2, head of nat. size.

This species is named in honour of a highly-valued friend, Captain James Clark Ross, an officer who has had the singular fortune of being engaged in five successive expeditions of discovery in the Arctic seas: whose professional skill, exertions, and perseverance, are the subjects of Sir Edward Parry's eulogium, and whose scientific acquirements and contributions to Natural History are so generally known, that any attempt of mine to commend him would be want of taste, were it not allowable for one who has also spent the prime of his life in the same regions and 
in similar occupations, to add his meed of praise to retiring merit. To his friendship and liberality I owe the acquisition of this and three other trouts, taken in Regent's Inlet on his last expedition. The Salmo Rossii is so extremely abundant in the sen, near the mouths of the rivers of Boothia Felix, at certain seasons, that three thousand three hundred and seventy-eight individuals were obtained at one haul of a small-sized seine. They varied in weight from two to fourteen pounds, and rather exceeded, in the aggregate, six tons. In some the colour of the flesh was of a dark red, in others it was very pale, the dark ones being the firmest and best flavoured. As an article of food this salmon was much relished by the crew of the Victory. The malma, or golet of the Russians, which enters the rivers of Kamtschatka, agrees with the Salmo Rossii in its comparatively slender cylindrical form, scarlet spots on the sides, and the colours of some other parts; but we cannot, from the short notice of the malma by Pennant, offer an opinion respecting the identity or difference of the species. The habits of the two are evidently unlike, if it be true that the malna never congregates in shoals*. The Greenlanders give the same name to the Salno carpio of Fabricius, that S. Rossii receives from the Esquimaux of Boothia Felix ; viz., Eekalook.

\section{DESCRIPTION}

Of a dried specimen from Regent's Inlet.

Form, as compared with the Common salmon, more slender, with a straighter back, much less arched forehead and shoulders, and slightly larger head. The remarkable length of the under jaw, and the truncated snout, give a peculiar appearance to the fish, and in conjunction with the nature of the scales, and the colour of the skin, readily characterise the species. Head, when viewed from above, appearing broad and flat, there being very little convexity either longitudinally or transversely. The snout is very obtuse. The head, measured as usual from the tip of the snout, is one-fifth of the whole length to the end of the scales on the caudal, and if the measurement be made from the tip of the lower jaw, which is an inch longer than the upper one, five lengths of the head reach to the extremities of the caudal. In the dried specimen there is a smooth median ridge extending from between the eyes to the nape, and an even lateral ridge on each side, commencing at the nostrils and curving down behind the orbit. A series of pores runs along the lateral ridge, and down the scapular bones to the lateral line; a row crosses the nape, another runs down the preoperculum, and lastly, one, beginning at the nostrils, curves under the orbit, and upwards to the middle of the lateral

* " The malma, or golet of the Russians, grows to the weight of twenty pounds, and to the length of about twenty-eight inches. It is the most slender and cylindrical of all the genus. The head resembles that of a trout: the seales are very small: the back and sides bluish, with seattered spots of scarlet red: the belly white : ventral and anal fins red: tail slightly forked. It is sporadic, going dispcrsedly and not in shoals, ascends rivers to their very sources, feeds upon the spawn of uther sfecies, and gruws very fat. The natives salt those they take in autumn, and preserve frozen those which are caught when the frost commences." (Arct. Zool. Intr., i., p. cxxvi.) 
ridge, passing through the middle of the sub-orbitar bones. These pores exist in other trouts, but are rendered conspicuous in this species by the prominence of the ridges with which they are connected. Eye equidistant from the tip of the snout and nape. The orbit has an oval shape, and the nostrils are rather nearer to it than to the tip of the snout. Labials thin and of a narrow lanceolate form. The distance from the snout to the tip of the labial reaches from the former to the nape, and extends beyond the posterior sub-orbitar bones. The lower iaw is long, exceeding the length of the upper surface of the head by an inch and a quarter: its tip is a small incurvated knob. In the general form of the head the $S$. Rossii strongly resembles the British species figured in Plate 91, f. 2 : it cliffers in the greater length of the jaws, in the whole margin of the intermaxillaries being toothed, and in other particular: readily discoverable by comparing the plates, - the British fish has an edentate depression at the extremity of the snout for the reception of the knob of the lower jaw.

Tеeтн.- In the only specimen I have had an opportunity of examining, part of the teeth hare been injured and removed. They appear to have stood in a single series on the upper and lower jaws : the remaining ones are short, straight, and mostly obtuse, as if worn; there is also a single row of short, conical, but very acute teeth on each palate-bone; and though the romer has been broken in preparing the specimen, two similar teeth remain on its anterior extremity, and one farther back. The teeth on the tongue, amounting to about thirty, are smaller and more crowded than the palatine ones; they form two or more rows across the tip and one down each side.

Gill-covers.-Operculum rhomboidal with the corners rounded, its height being nearly twice its breadth. The suboperculum has the same form in a different position, its length corresponding with the breadth of the operculum. Both these bones are marked with circular indented lines crossed by straight ones radiating from the centre. The posterior edge of the interoperculum is indented and somewhat concave. Preoperculum rather wide, it: breadth being about half that of the operculum : on its middle there are raised direrging tubular ridges, and fine lines radiating from its centre to its posterior margin. The posterior edge of the gill-cover is inclined to the under one at an acute angle, the corner formed by the suboperculum being rounded. The gill-rays are flat, twelve on the right side and thirteen on the left.

Fins.-Br. 12-13;D. 13-0;P. 14;V. 10,A.11;C. 216.

The dorsal has thirteen rays, the first scarcely perceptible, the next also short, the third one quarter shorter than the fourth, which is the longest: the ninth ray is exactly opposite to the origin of the ventrals, and stands midway between the tips of the snout and of the central caudal rays : the last ray is divided to the base. The adipose fin is opposite to the penultimate anal ray. The pectorals are scimitar-shaped and contain fourteen rays. The ventrals have ten rays and the usual scaly appendages. The anal has eleven rays, of which the fourth and fifth are the longest. 'The caudal fin is forked, and contains twenty-one broad deeply-divided rays, with six short basal ones above and below.

Scales. - This species differs remarkably from all the American trouts that have come under my observation (except, perhaps, S. Hearnii) in the scales. They are small, particu- 
larly on the forepart of the back, where they are also most remote : and though rather larger and more crowded on the sides they are nowhere tiled, each scale being surrounded by a distinct space of smooth skin. Their general form is ovate or oval, and they are covered with a mucous skin, except a round or oval spot on the tip. The naked tips are larger on the sides, where they often assume a slightly crescentic form, and many of the scales there are truncated. As the skin dries the tips of the scales become elevated and rough to the touch. There are 134 scales on the lateral line, and 78 in a vertical row under the dorsal, 30 of them being above the lateral line. On the forepart of the body each scale on the lateral line corresponds to two rows above and below, so that there are in all between 240 and 250 rows on the sides. A linear inch includes about ten or eleven scales on most parts of the body. The lateral line is an inch nearer to the ridge of the back than to the upper ray of the ventral : it is formed by a series of ovate, dilated, acuminated scales, each having an elevated tube posteriorly, and a small pore on its tip. The distance between the anus and the base of the inferior caudal ray is contained two times and a half between the anus and gill-opening.

CoLour.-The back, top of the head, dorsal and caudal fins, have a hue intermediate between oil-green and hair-brown; the cheeks are nacry, and the sides pearl-grey, with a blush of lilac and a silvery lustre; there are a number of scattered dots of carmine in the vicinity of the lateral line; the colour of the belly varies in different individuals from faded orange to tile-red and arterial blood-red. These colours are described partly from the dried skin and partly from two drawings made by Sir John Ross.

\section{Dimensions}

Of the dried specimen.

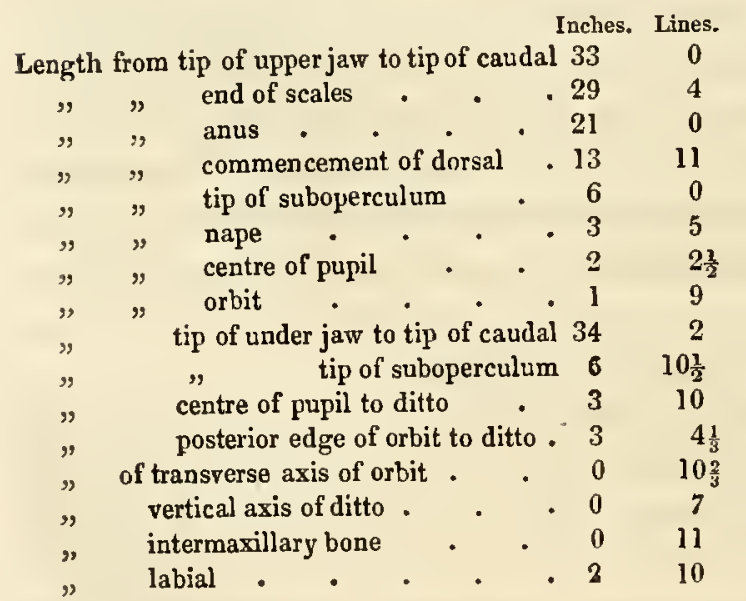

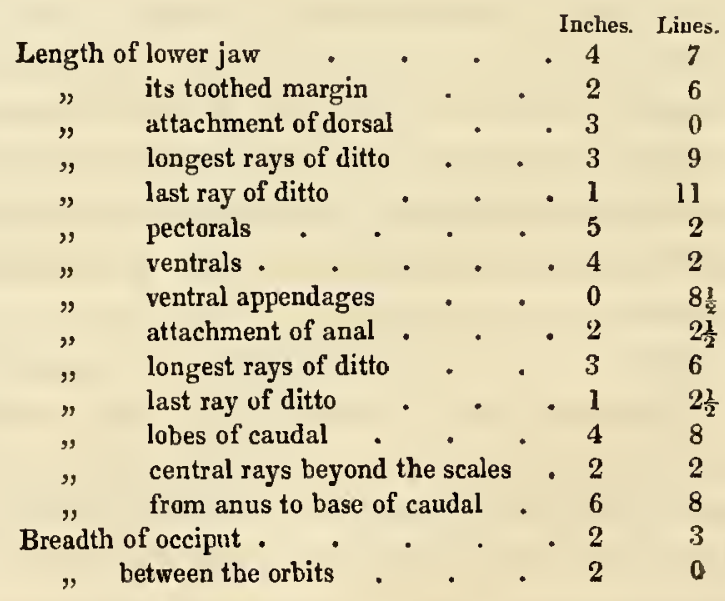




\section{[64.] 4. Salmo Hearnir. (Richardson.) Coppermine River Salmon.}

Salmo Hearnii. Ricuardson, Franklin's First Journ, p. 706.

This, which is another anadromous trout, was taken in the Coppermine River and adjacent sea, on Sir John Franlilin's First Expedition. Its flesh is red, and, though similar in flavour to that of the Common salmon, is, perhaps, less firm and more oily. Our party subsisted upon it for several days, but the Indians who then accompanied us, being unused to it, thought it unwholesome, and our Canadian voyagers were soon infected with the same apprehension. The well-known calimities that befell us on our return, prevented me from bringing home specimens of the fish, and I can introduce the speeies to maturalists, only through the medium of a description hastily drawn up on the spot, which does not altogether coincide with the account of any other salmon that I have seen or read of. The affecting story related by Hearne, of the slaughter of a poor old Esquimaux woman, by the Indians of his party, while she was engaged in taking this salmon at a cascarle near the mouth of the Coppermine, subsequently named, from the transaction, Bloody-fall, may be appropriately quoted here; as it contains the earliest notice of the fish, and, indeed, the only one previous to the publication of Sir John Franklin's narrative.

"It ought to have been mentioned in its proper place, that in making our retreat up the river, after killing the Esquimaux on the west side, we saw an old woman sitting by the side of the water taling salmon, which lay at the foot of the fall as thick as a shoal of herrings. Whether from the noise of the fall, or a natural defect in the old woman's hearing, it is hard to determine, but certain it is, she had no knowledge of the tragical scene which had been so lately transacted at the tents, though she was not more than two hundred yards from the place. When we first perceived her, she seemed perfectly at ease, and was entirely surrounder by the produce of her labour. From her manner of behaviour, and the appearance of her eyes, which were as red as blood, it is more than probable that her sight was not very good, for she scarcely discerned that the Indians were enemies till they were within twice the length of their spears of her. It was in vain that she attempted to fly, for the wretehes of my crew transfixed her to the ground in a few seconds, and butchered her in the most savage manner. There was scarcely a man among them who had not a thrust at her with his spear; and many in doing this 
aimed at torture rather than immediate death, as they not only poked out her eyes, but stabbed her in many parts remote from those which are vital. It may appear strange, that a person supposed to be almost blind should be employed in the business of fishing, and particularly with any degree of success; but when the multitude of fish is taken into account, the wonder will cease. Indeed, they were so numerous at the foot of the fall, that when a light pole, armed with a few spikes, which was the instrument the old woman used, was put under water and hauled up with a jerk, it was scarcely possible to miss them. Some of my Indians tried the method with the old woman's staff, and seldom got less than two or three at a jerk, sometimes three or four. 'These fish, though very fine and beautifully red, are but small, seldom weighing more, as near as I could judge, than six or seven pounds, and in general much less. Their numbers at this place were almost incredible, perhaps equal to anything that is related of the salmon in Kamtschatka, or any other part of the world."-After murdering the helpless old woman, together with upwards of twenty of her countrymen, and destroying all the property left at their tents, the party sat down to feast on the salmon, or, in the words of our author, "After the Indians had completed this piece of wantonness, we sat down and made a good meal of fresh salmon." (Hearne, Journ, \&c., p. 158.)

\section{DESCRIFTION}

Of a recent fish taken at Bloody-fall, Lat. $67^{\circ} 42 \frac{1^{\prime}}{2} \mathrm{~N}$., on July $16,1821$.

CoLour.-Back olive-green; sides pale ; belly bluish; several longitudinal rows of flesh-red spots on the back and sides, largest on the latter, where they are as big as a pea; cheeks and gill-covers nacry. SCALEs firmly imbedded in a mucous skin and very small, but possessing much pearly lustre.

FOR M like that of the Common salmon, with a proportionably larger head. Eyes small, situated opposite to the middles of the labials, and half an inch above their toothed edges. Nostrils midway between the eye and end of the snout. The intermaxillaries form a comparatively small portion of the margin of the mouth, and project somewhat from the rest of the jaw: the labials are strap-shaped. The lower jaw terminates in a small knob, which is received into a depression in the intermaxillaries. The gill-membrane contains ten oblique rays : the openings are wide.

ТеЕтн subulate, in a thin row on the labials and lower jaw : a solitary tooth of the same size stands on each side of the intermaxillary notch: there are likewise rows of teeth on the palate-bones, a few on the anterior part of the vomer, and some stronger ones on the tongue, all subulate.

Fins. $-B r .10 ; D . \quad ; V . \quad ; A .10^{*} ; C . \quad$.

* In the Appendix to Sir John Franklin's First Journey, the anal is stated to have 18 rays, from an error in the transcription of my original notes. 
'The space between the anal and caudal is greater than the length of the base of the forner. The caudal is large and very entire, being truneated with a slight rounding of the angles. The dorsal is opposite to the rentrals.

INTESTINEs similar to those of the trouts; stomach rather small : between thirty and thirtysix eylindrical exea from one to two inches long.

[6.j.] 5. Salmo alipes. (Richardson.) Long-finned Char.

Genus, Salmo. Cuv. Sub-gemus, Salvelinus. Nusson.

Salmo alipes. Richaroson, Nut. Hist. App. Ross's Ioy., p. lvii.

Prate 81, One-third nut. size, and $P_{\mathrm{LATE}}$ 86, f. 1, the head of the nat. size.

This trout evidently belongs to the Salvelini, or Chars, a sub-generic group characterised by the smallness of the scales and the arrangement of the vomerine teeth in a cluster on the anterior extremity of the bone, withont rumning backwards along a median ridge in a single or donble row. The European chars have at peculiarly neat aspect from their small bright seales; and in the spawning season their bellies generally assume a deep red or orange colour, agreeing in these respects with the majority of the American trouts that have come under our notice. The Salmo alipes, though it differs from $S$. Rossii in the smooth manner in which the scales are imbedded in the skin, in the relative proportion of the jaws, and in other particulars, resembles it closely in the general form, and especially in the sliape of the various bones of the face and gill-covers. It is remarkable for the great length of its fins, but in the opinion of M. Agassiz this cannot be regarded as a specific distinction, trouts inhabiting rapid, rocky streams, having their fins always much developed. Our specimen was taken with many other individuals in a small lake which discharges itself into Prince Regent's Inlet by a stream about half a mile long. It most probably visits the sea, though the fact of its doing so was not iscertained. Several brachiella adhered to the inside of its under jaw. The Esquimaux of Boothia Felix included it with several other kinds of trout, under the general appellation of eckalook-peedeook.

\section{DESCRIPTION}

Of a prepared specimen from a small lake in the peninsula of Boothia.

Form slender. The head forms more than a fifth of the total length, caudal included: it is convex above, both in profile and transrersely, the eranial ridges being similar to those of $S$. Rossii, but more prominent and acute. Snout very obtusely rounded, receiving the knobbed 
extremity of the lower jaw in a toothless space. Orbit ovate, situated twice its length from the end of the snout, and about three lengths and a half from the posterior edge of the gill-cover: its transverse axis is contained six times and a half in the total length of the head, but rather less than four times in the distance between the tip of the snout and nape of the neck: its upper margin is marked, in the dried specimen, by a few raised diverging lines. Nostrils twice as near to the orbit as to the end of the snout. Jaws nearly equal, the lower one appearing longer than the other when depressed. Intermaxillaries one-third of the length of the labials, each containing four teeth. Labials of medium length, thin and slightly curved, so as to approach the form of an italic $f$; their appophyses do not reach quite to their tips, and are as broad again as the limb of the bone to which they are attached. The distance from the tip of the snout to the posterior end of the labial nearly equals the length of the upper surface of the head. Lower jaw moderately strong, tipped by a small knob, and extending about half an inch beyond the snout, when depressed to the utmost.

TеEтH.-The labials, intermaxillaries, and lower jaw are armed with short, conical, acute, and very slightly-curved teeth in a single series: there is also a row of rather larger teeth intermised with smaller ones on the elevated outer edge of each palate-bone, and a projecting cluster of six or seven on the knob of the vomer, the posterior part of that bone being flat, smooth, and toothless. The tongue has six teeth in a row on each side, equal in size to those on the jaws, and three or four clustered rows of smaller ones on its tip : it is smooth in the centre.

GILL-Covers. - The forms of the opercular pieces, though similar to those of S. Rossii, differ in their relative dimensions, the breadth of the operculum being greater in proportion to its height, while that of the suboperculum is less : the preoperculum is also wider. There are twelve flat gill-rays on the left side, and eleven on the right.

Fins. $-B r .11-12 ; P .15 ; D .13-0 ; V .9 ; A .10$ or $11 ; C .19 \frac{6}{6}$.

The pectorals contain fifteen rays, and twice their length reaches from the gill-opening to the middle of the ventrals. The ventrals, when turned back, almost touch the anus. The fifth dorsal ray is the longest, the first one being minute: the attachment of the fin is two-thirds of its height. The adipose fin is opposite to the last rays of the anal. The anal is small in proportion to the dorsal, its rays being about one-fourth shorter than those of the latter. The caudal is forked : it contains nineteen broad deeply-divided rays, and six short basal ones above and below. The eighth dorsal ray is midway between the tip of the snout and extremities of the central rays of the caudal.

Scares small, thin, and roundish, firmly and smoothly imbedded in the skin: they are mostly in contact but not tiled, those on the back small and more remote; they are also small on the belly, but more crowded and of an oval form: on the sides they are somewhat truncated. The lateral line is formed of 126 scales similar to those of $S$. Rossii ; there are about 285 scales in a row close to the lateral line, and 70 in a vertical row anterior to the ventrals 29 of which are above the lateral line, and ten below the upper edge of the ventral. The anterior scales on the lateral line are so large and remote, that they correspond to two or three of the rows which descend from the back. 
Conour, as far as one can judge from the dried skin, hair-brown on the upper parts, the sides paler with yellowish marks, the belly white or ycllow, and the under fins orange with some darker streaks.

\section{Dimessions}

Of the dried specimen.

Length from tip of upper jaw to extremities

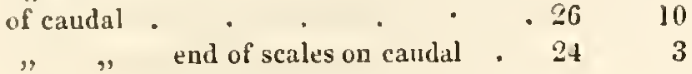

, " anus . . . . $17 \quad 6$

commencement of dorsial . 114

edge of suboperculum $\quad 5 \quad 6$

nape . . . $\quad 3 \quad 5$

centre of pupil . $\quad$ - $2 \quad 2 \quad 2$

edge of orbit . . . 118

under jaw to tips of caudal . $27 \quad 0$ , edgre of suboperculum 5

from centre of pupil to ditto $\quad 3$

from posterior angle of orbit to ditto 3

of transverse axis of orbit . . 0

vertical axis of ditlo. . . 0

intermaxillary bone . . 0

labial

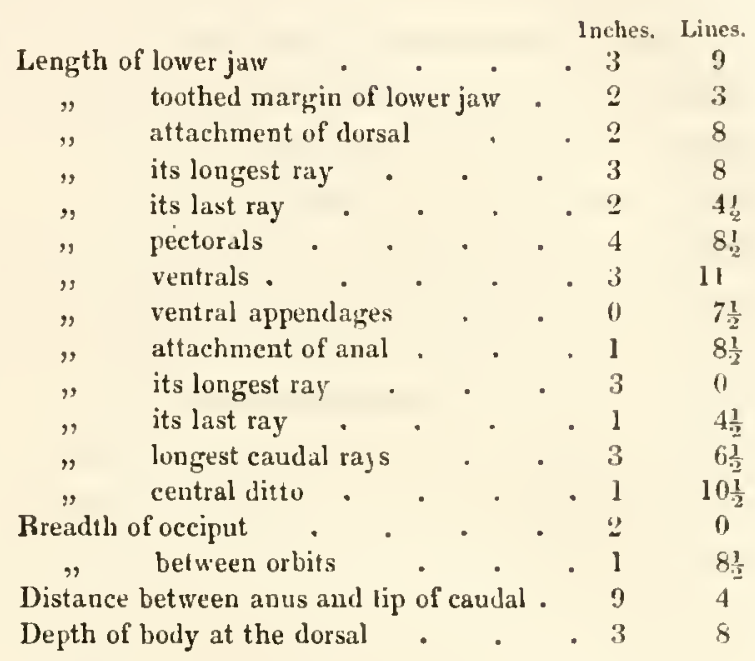

[66.] 6. Salmo nitidus. (Richardson.) The Angmalook.

Salmo nitidus. Ricilardson, Nat. Hist. App. Ross's Voy., p. Ivii.

Angmalook. Esquiraux.

Plate 82, f. 1, one-third nat. size. Plate 86, f. 2, head of nat. size.

This Char was found in the same lake with the preceding one, to which it is similar in the size and form of its head, and in the general appearance of its scales. If one may judge, however, from the inspection of a single prepared specimen of each, it has a thicker body, shorter upper jaw, and shorter fins. It is possible that these differences may be owing to age or individual variation, but the colours appear also to be dissimilar: hence it seems safer to describe the angmalook as a distinct species.

\section{DESCRIPTION.}

Fors. - Back nearly straight as in S. alipes, but the body is thicker, the belly more proninent, and the fins shorter. The middle of the tip of the snout and of the central caudal ray falls under the ninth dorsal ray, and a very little posterior to the origin of the ventrals. The 
adipose fin is placed at the commencement of the fourth quarter of the fish, inclucling the lobes of the caudal, and the anus is nearly twice as far distant from the snout as from the latter, being consequently farther back than in S.alipes. Head less arched above, both in profile and transversely, than in $S$. alipes: the mesial ridge and lateral porous curves are less prominent, and there are no radiating lines above the orbit: the head forms less than a fifth part of the entire length of the fish. The ovate orbit is the length of its axis and a half from the tip of the snout, and three lengths and a half from the posterior edge of the gillcover, being proportionally nearer the snout than in S. alipes : six diameters of the orbit are equal to the extreme length of the head. In this, as in S. alipes, the upper surface of the head measures just the same with the distance of the posterior edge of the suboperculum from the centre of the pupil, while in S. Rossii the top of the head is half a diameter of the orbit shorter. The nostrils are a little nearer to the eye than to the tip of the snout. The upper jaw is shorter than in S. alipes. The snout is rounded, and there is a small edentate space for the reception of the slightly-knobbed extremity of the lower jaw, which is a little shorter than the upper one when the mouth is shut, and scarcely surpasses it when the jaws are open. The intermaxillaries are less than one-third of the length of the labials; and the latter are shorter, stronger, and less curved than in S.alipes. The total length of the lower jaw exceeds the distance between the tip of the snout and nape by about two lines.

Тевтн as in $S$. alipes, the cluster on the knob of the vomer being, however, less prominent and not so crowded: the form of the cluster is triangular, three teeth wide anteriorly, and one tooth in the posterior angle.

GilL-Covers.-The opercular bones greatly resemble those of $\boldsymbol{S}$. Rossii and alipes, though the breadth of the operculum is less, being only half its height, and but just equal to the greatest width of the preoperculum. The height of the suboperculum is half its length. There are eleven gill-rays on the right side, and twelve on the left.

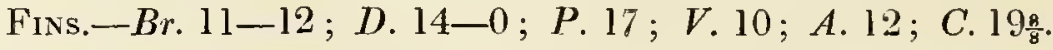

The fifth and sixth dorsal rays are the longest, the first being scarcely perceptible. The attachment of the anal is equal in length to the space between it and the base of the caudal. The adipose fin is opposite to the last rays of the anal.

SCaLes tiled, small, roundish: truncated on the sides: smaller and more pointed on the belly. There are 120 on the lateral line of a larger size, and about 270 in a row adjoining to that line, or 19 in a linear inch under the dorsal: a vertical row there contains 92 , of which 36 are above the lateral line, 42 betwixt it and the ventral, and 12 or 14 below the first ray of the latter.

Colour, according to Captain J. C. Ross, as follows: "Body above the lateral line deep green, softening towards the belly, which is of a beautiful yellowish-red tint posterior to the pectoral fin: throat and region of the pectorals white, slightly clouded by yellowisin-red. There are several rows of occellate red spots, confined principally to the space between the lateral line and yellowish-red of the belly: they vary in size, the largest being as big as a pea. Dorsal fin coloured like the back. Under fins dusky-red, the anal paler, and the first rays of the pectorals, rentrals, and anal white." 


\section{DimensLoNS}

Of the prepared specimen.

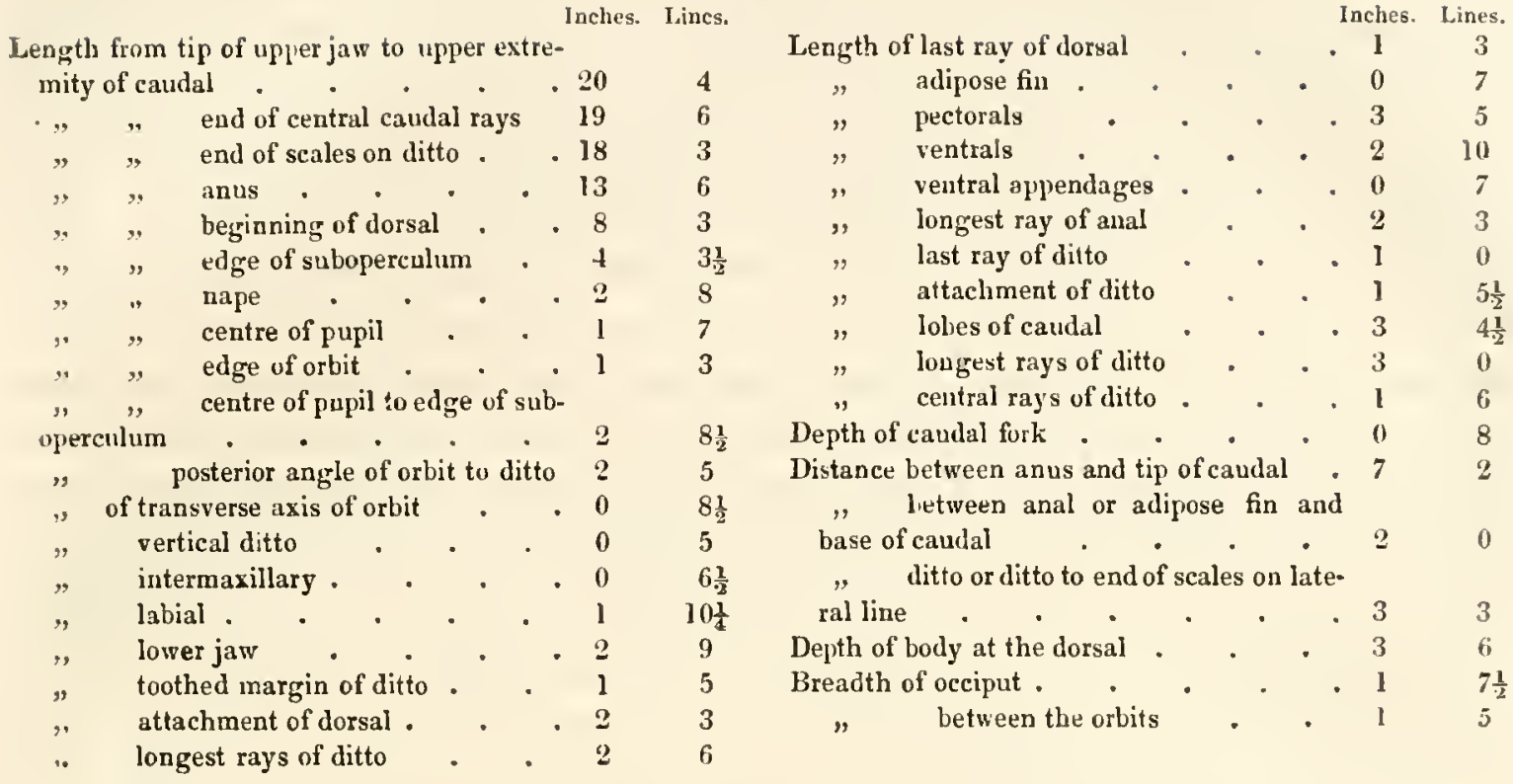

\section{[67.] 7. Saluo Hooni. (Richardson.) The Masamacush.}

The Masamacush. IHurcirns's Mss.

Salmo Huodii. Richaroson, Nat. Hist. App. Ross's Ioy., p. Iviii.

Plate 82, f. 2. Plate 83, f. 2, one-third nat. size. Plate 87, f. 1, heal nat. size.

'This Char, well known in the fur countries by its Cree appellation of Masāmècoos, is common in every river and lake from Canarla to the northern extremity of the continent. It is voracious, and readily takes a cod-hook baited with a piece of sucking-carp, pork, deer's heart, or the belly of one of its own species. We took many at Fort Enterprise in March, in gill-nets set under the ice, in the neighbourhood of an open rapid by which the waters of Winter Lake were discharged into a river that remained frozen up until June. At that time their stomachs were filled with the larve of insects. During the summer this fish is supposed to retire to the depths of the lakes, but it reappears in smaller numbers in the autumn, and is occasionally taken in the winter in nets, but seldom, by the hook, except in the spring. The spawning season is in April or May, judging from the great development that the spawn then acquires, though the spawning beds are unknown to us. The masamacush attains a weight of about eight pounds, but begins to spawn before it weighs more than two or three.

'Two representations are given of this species, the one (Plate 82, f. 2) being 
copied from a coloured drawing by Lientenant Hood, of a recent fish taken in Pine Island Lake, lat. $54^{\circ}$, the other is of a dried specimen, brought from Boothia Felix by Captain James Clark Ross, who took it in a small lake. The figure of the latter (Plate 83, f. 2), and particularly that of the head in Plate 8\%, f. 1, exhibit the correct forms of the opercular bones, and the relative size of the head and other parts which were not so rigidly attended to in Mr. Hood's spirited drawing. The arctic fish differs a little from the one common in the more southern parts of the fur countries, in having shorter labials, more crowded and brighter scales, with a different arrangement of colours, and longer fins; but the proportions of the other parts are so nearly the same, that I have not ventured to separate them in the alssence of a comparison of their internal structure. The shortness of the head distinguishes $S$. Hoodii from the two preceding species, to which its general resemblance is very close. For the purpose of comparison I have added the dimensions of a British Char in Mr. Yarrell's possession. That specimen, as well as the one from Llyn Cawellyn, the head of which is represented in Plate 92, f. 5, has shorter labials, and a larger eye than any of the American Chars which I have seen.

DESCRIPTION

Of a specimen from Boothia Felix.

Form.-The body is more slender than that of S. nitidus, and the head is a little more than a sixth of the total length, caudal included. The orbit is nearer the end of the snout than in S. nitidus, the intermaxillaries are shorter, and the labials shorter and somewhat wider. The lower jaw, when the mouth is elosed, projects beyond the upper one by the depth of the chin, and it appears still longer when the mouth is open: its length, applied to the upper surface of the head, passes about a quarter of an inch beyond the nape.

ТеЕтн smaller than in S.nitidus, but otherwise very similar, except on the tongue, that organ being armed with a single row on each side which meet in a curve at its tip : there are also two or three scattered teeth on the centre of the tongue, but no double or triple rows anteriorly.

Gill-covers.-The operculum is narrow, its transverse diameter being scarcely half its height. The height of the suboperculum exceeds half its length or transverse diameter.

SCales much like those of $S$. nitidus but somewhat brighter. There are 126 on the lateral line, 268 in a row immediately above it, 53 in a vertical row before the ventrals, of which 12 are below the first ray of that fin, and 28 above the lateral line.

Fins. $-B r .10-11 ; D .12-0 ; P .15 ; V .10 ; A .11 ; C .19 \frac{\mathrm{a}}{8}$. From Boothia Felix.

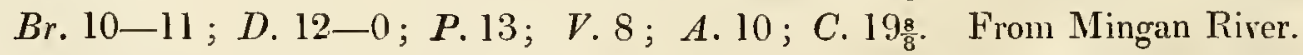

A larger individual from Mingan River, which falls into the estuary of the St. Lawrence, differs from the preceding in having more remote scales, there being only 120 on the lateral line: shorter labials: shorter fins; and caudal even at the end. In other respects the resemblance is complete. The Mingan River fish is the ordinary form of the masamacush, and the one from Boothia Felix ought, perhaps, to be considered as a variety with longer fins, arising 
from the nature of the rapid, rocky streams which it frequents : it is not, however, unlikely that an examination of recent specimens may reveal differences of internal structure sufficient to prove it to be a distinet species. A female specimen of the masamacush, taken in a small lake a little to the northward of the 64th parallel of latitude, on the 16th of August, exhibiterl the following tints of colour. Back and sides intermediate between olive-green and clovebrown, bestudded with yellowish-grey spots as big as a pea: a few of these spots on the gillcorers. Belly and under jaw white, the latter thinly dotted with bluish-grey. Dorsal and upper lobe of the caudal marked with smaller spots. Irides honey-yellow. Scales rather dull. This individual was twenty-one inches long, its flesh was red, and its roe but little developed. The intestines had the structure usual in the trouts, the caca were numerous, their insertions occupying about three inches of the length of the canal, the valuulce conniventes occupied two inches, and there was about an inch of smooth gut next the anus. The liver, small and triangular, had several small incisions on its inferior edge. The rakers and pharyngeal bones were armed with short tceth like relvet pile.

DrMensrons.

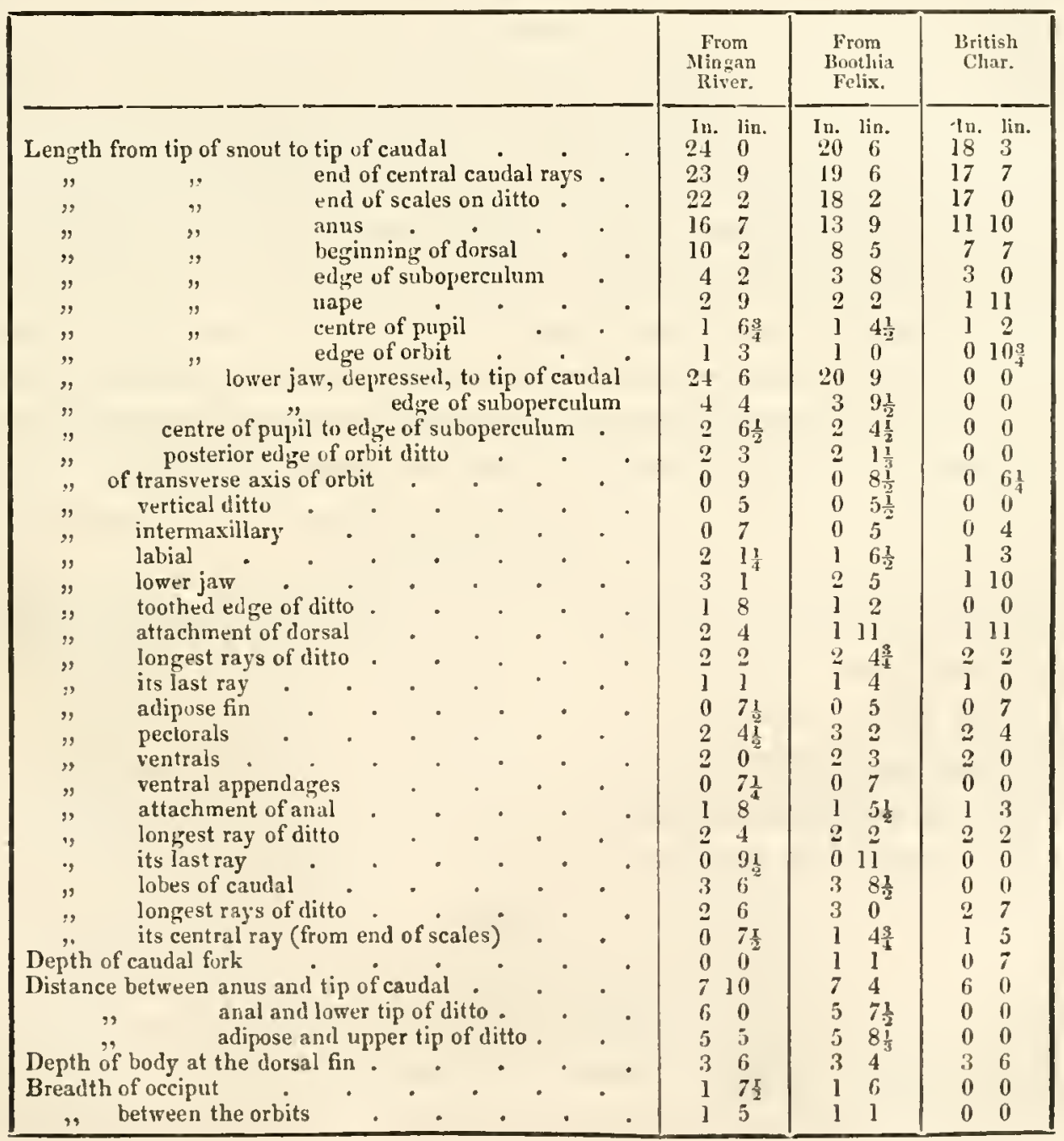


[68.] 8. Salmo fontinalis. (Mitchill.) New York Char.

Common Trout (Salmo fontinalis). MiтchiLs, New York Ph. Tr., i., p. 435.

Piate 83, f. 1, half nat. size. Plate 87, f. 2, head nat. size.

Dr. Mitchill describes this trout in the paper above referred to, making the following observations upon it. "He is reckoned a most dainty fish. They travel away to Hempstead and Islip for the pleasure of catching and eating him. He is bought at the extravagant price of a quarter of a dollar for a single fish, not more than ten or twelve inches long. He lives in rumning waters only, and not in stagnant ponds; and therefore the lively streams, descending north and south from their sources on Long Island, exactly suit the constitution of this fish. The heaviest Long Island trout that I have heard of weighed four pounds and a half." One caught near New York, measuring twenty-four inches in length, weighed four pounds eight ounces : the average weight of those usually caught is about threequarters of a pound. No opportunity occurred during the progress of the expedition of obtaining this trout in a recent state, but Mr. Todd kindly sent me a prepared specimen from Penetanguishene. He states that it ascends the rivers from Lake Huron in the month of May, and readily takes the hook during the summer; that the flesh is red, and that he never saw one exceeding the weight of a pound and at half. Mr. Todd's specimen was submitted to the inspection of Baron Cuvier, who returned it with the following remark: "Il nous parait bien nommé Salmo fontinalis de Mitchill. C'est probablement le Salmo Goedenii de Bloch." The latter synonym appears very strange, and must have originated in some mistake, for not to mention other differences, the $S$. Godenii has tolerably large scales, while the scales of $S$. fontinalis are so small, that in Dr. Mitchill's description the skin is said to be "scaleless." The S. Goedenii inhabits the Baltic, and is considered by M. Agassiz to be the young of the Common salmon. The Salmo fontinalis may be readily distinguished from the other species that we have already described, by the smallness of its scales, the shortness of its intermaxillaries, and the length and narrowness of the labials, exclusive of its colours, which are peculiar.

DESCRIPTION

Of a prepared specimen from Penetanguishene, on Lake Huron.

For u thickish. Head rather small, being contained five times and one-fifth in the total length. Mouth large. Jaws of equal length. Intermaxillaries very short, being scarcely a quarter as long as the labials. The latter are long, linear, and straight, with still narrower 
appophyses; their tips go beyond the posterior orbitar-bones and reach nearly to the articulation of the lower jaw. The distance betwcen the tip of the snout and the extremity of the labial equals the length of the upper surface of the head, and the lower jaw is about two lines longer.

TEEти rather long, slender, acute, and slightly curved, those on the labials smaller : the palatine tceth run far back on a slightly prominent ridge, and there is a triangular cluster of about ten teeth on the anterior part of the vomer. The tongue is armed with six teeth on each side.

Gili-covers.-Interoperculum short and triangular. Preoperculum narrow and mucli curved, with an even edge. The suboperculum is half as high as the operculum, and its angle touches the preoperculum. The right gill-membrane contains twelve rays.

Fins.-Br. $12 ; P .13 ; D .11-0 ; V .8$ or $9 ; A .10 ; C .19 \frac{8}{8}$.

The fifth dorsal ray is the longest, the first being almost imperceptible in a recent fish. The adipose fin is about its own breadth behind the anal. The latter equals, or rather exceeds the dorsal in the length of its rays, and is more remote from the caudal than usual, there being almost twice the length of its insertion between it and the base of the latter.

SCA LEs small, roundish, in contact, but not tiled, and firmly imbedded in a mucous epidermis which almost conceals them : they are smallest on the forepart of the belly. There are 244 rows of scales meeting at the lateral line, which contains only 116 : these are longer than the ordinary scales, and have each a mucous canal elevated above its surface. A vertical row under the dorsal contains 95 scales, viz., 41 above the lateral line, 42 between it and the upper edge of the rentral, and 12 below the level of the first ray of that fin.

Colour.- ("Back mottled, pale and brown : sides dark brown with yellow and red spots above and below the lateral line, the yellow surrounding the red, which appears like scarlet dots : sides of the belly orange-red: lowest part of the abdomen whitish with a smutty tinge. First rays of the pectoral, ventral, and anal fins white, the second black, the rest purplish-red: dorsal fin mottled with yellowish and black. Eyes large and pale." Dr. Mitchill.)

Dinensions

Of a prepared Lake Huron specimen.

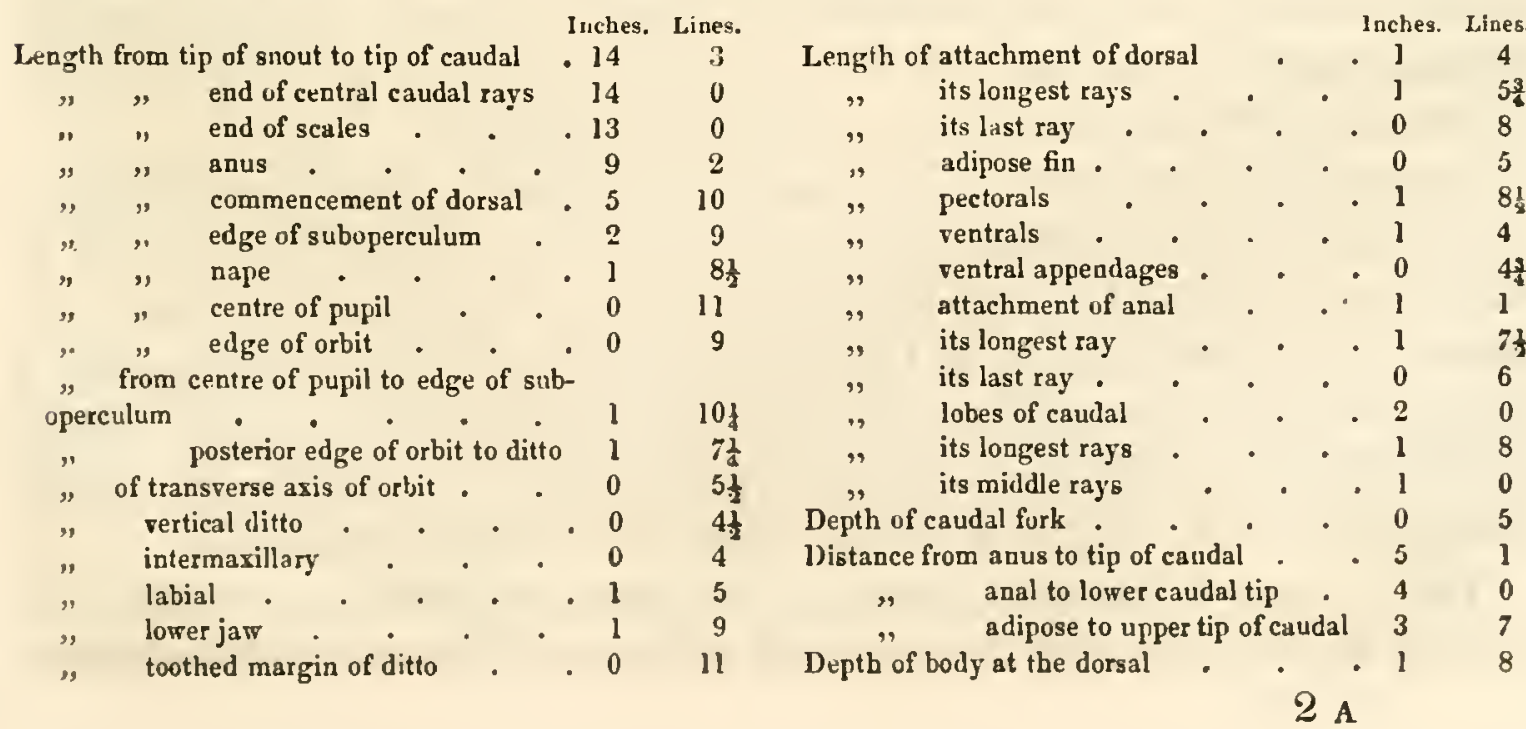


The Salmo fontinalis is probably what is called in the narrative of Lewis and Clark's Journey to the Pacific, the Mountain, or Speckled trout of the United States. Another species, which inhabits the upper waters of the Missouri and Columbia, is thus described in the same work. "We caught in the Falls half a dozen trout resembling in form and the position of the fins, the mountain, or speckled trout of the United States, except that the specks of the former are of a deep black colour, while those of the latter are of a red or gold colour: they have long sharp teeth on the palate and tongue, and generally a small speck of red on each side, behind the front ventral fins; the flesh is of a pale yellowish red, or, when in good order, of a rose-coloured red. We never saw this fish below the mountains, but from the transparency and coldness of the Kooskooskee, we should not doubt of its existence in that stream, as low as its junction with the south-east branch of the Columbia. It is not so abundant in the Columbia as in the Missouri." (i., p. 358, and iii., 601.)

I am unable to decide from Fabricius's account of the Greenland trouts, whether they are identical with any of those described above, or whether they ought to be reckoned as distinct species. His S. CARPIo, named Eekallook, Kebleriksoak, Satooack, and Sardlooak, by the natives, is probably $S$. Hoodii. It is an inhabitant of the rivers, lakes, estuaries and bays of Greenland, and feeds upon caplin, herrings, sticklebacks, small crabs, worms, and spawn of fishes. It is named Lax, or the Salmon, in the histories of Greenland, and is supposed by Fabricius to be the same with the Kundsha of Pallas, a trout which abounds in the gulfs of the Icy Sea and of Kamtschatka, but is said not to ascend rivers.

Another Greenland trout with an orange belly, named by the natives Eekallook and Iviksarok, was considered by Fabricius to be the same species with his $S$. carpio, but he changed his opinion, in some degree, after leaving the country, and referred it to the S. A L.PInUs of Linnæus, when he had no longer an opportunity of comparing it with carpio. It congregates with the preceding, and may possibly be the trout I have described under the specific name of $S$. nitidus, the tawnyorange colour of the belly in both being confined to the spawning season.

The S. stagnalis (Fauna Gronl., p. 175) agrees best with our S. alipes. It inhabits alpine waters, and never descends to the sea. It is named Eekallookak. 
The Salmo Rivalis (Fauna Granl., p. 176), named by the Greenlanders Aunardlek and Eekalloogak, if it be not the young of some of the preceding, is most probably distinct from any that we have described. In the minuteness of its scales it resembles $S$. fontinalis. It inhabits rivulets and ponds, feeds upon insects, and buries itself in the mud in the winter, where it is frozen up, never visiting the sea. It is only six inches long. The word Eekallook seems to be the general Freenland and Esquimaux name for the trouts of the middle or smaller size.

[69.] 9. Salmo namaycush. (Pennant.) The Namaycush.

\author{
Namaycush, Hutchins's Mss., p. 115. \\ Salmon namaycush. Penn., Arct. Zool., ii., Suppl., p. 139, No. 165 ; and Intr., p. cxli. \\ Salmo amethystus. Mitcrill, Journ. Ac. Sc. Phil,, i.,p. 410. An. 1818. \\ Nammècoos. Crge Indiass. Thlooesinnel. Cuepewyans: Keyteeleek. \\ Esquimatx. Salmon-trout. Canadians.
}

\title{
Plate 79, one-third nat. size. Plate 85, f. 1, head nat. size.
}

'This magnificent trout, which equals or surpasses the Common salmon in size, is a denizen of all the great lakes that lie between the United States and the Arctic Sea, but it does not exist, as far as $I$ have been able to ascertain, in any tidal waters. According to the report of fishermen on Lake Huron, seventeen pounds is its average weight, but they occasionally capture individuals weighing sixty pounds; and Dr. Mitchill states, that at Michilimackinac it has been known to attain the enormous size of one hundred and twenty pounds. Such a weight must, however, be very rare, for Carver, who passed a winter at Michilimackinac, does not appear to have met with any at all approaching to that magnitude. "One of my chief amusements," says he, "was that of fishing for trouts. 'Though the straits were covered with ice, we found means to make holes in it, and letting down strong lines, of fifteen yards in length, to which were fixed three or four hooks baited with small fish, we frequently caught two at a time, of forty pounds weight each, but the common size is from ten to twenty pounds." Particular lakes in the fur countries were mentioned to us as yielding trout of sixty or even ninety pounds, but none exceeding forty pounds came under our own observation*. The namaycush is the tyrant of the lakes; no fish inhabiting the same waters can

- According to La Hontan, "Les plus grosses Truites des lacs onf cinq pieds et demi de longueur et un pied de diamelre; elles ont la chair rouge." (Mém. de C Amérique, ii., p 58.) 
resist its voracity. The grey sucking-carp is most frequently found in its stomach; in the month of March, in lat. $64^{\circ}$, we saw that capacious receptacle crammed with the young of the lota maculosa, and Mr. Todd says that the Herring salmon forms its principal food in Lake Huron.

The habitual residence of the naniaycush is in the deepest parts of the lakes, but at certain seasons it resorts to the shallows to spawn. This movement occurs in Lake Huron about the 10th of October, and in the course of three weeks it retires again to the centre of the lake. During its stay in the narrow channels which separate the innumerable islands that skirt the northern borders of the lake, the Indians spear it in the night, by torch-light. In the fur countries it is taken occasionally in the autumn, in nets, and from March till May more abundantly by cod-hooks baited with sucking-carp, and set through holes in the ice in eight or nine fathoms water, but it is rarely seen in the summer or winter months, except when fished for at great depths. It resorts to the shallows in the spring, most probably in quest of food, as at that period many fish, upon which it preys, seek the borders of the lakes where the ice first breaks up, to feed upon the larvæ of insects which then swarm near the shore. The flesh of the namaycush is reddish or orangecoloured, being paler when out of season. When in good condition it yields much oil, and is very palling to the appetite if simply boiled, but roasting renders it a very pleasant article of diet. 'The Canadian voyageurs are fond of eating it raw, in a frozen state, after scorching it for a second or two over a quick fire, until the scales can be easily detached, but not continuing the application of the heat long enough to thaw the interior. The stomach when boiled is a favourite morsel with the same people.

The American trouts described in the preceding pages are, with the exception of $S$. Scouleri, similar to European species in the forms of the different bones of the face and gill-covers, but the namaycush exhibits much peculiarity in these respects, and its cranium is composed of much stronger and firmer bones than is usual in the genus. The coats of its stomach are remarkably thick, though they do not equal those of the Coregonus albus.

\section{DESCRIPTION}

Of specimen (Plate 79) taken in Lake Huron, October, 1824.

CoLour.-The head, back, and sides have a dark greenish-grey colour, which, when examined closely, is resolved into small roundish yellowish-grey spots on a bluish-grey ground, which covers less space than the spots : the latter are most evident on the sides, where they are as big as duck-shot, each of them including three or four scales. The uncovered portion 
of each scale is roundish, and its convex centre, having a greyish hue and silvery lustre, is surrounded by a dark border of minute dats which are deficient or less numcrous on the yellowish-grey spots, and also on the bluish-white belly. The dorsal and caudal fins have the greenish-grey tint of the back, and the ventrals and anal are muddy-orange, this colour also partially tinging the pectorals. The irides are bright honey-yellow with blue clouds. The teeth, gums, and roof of the mouth have a tinge of purple, whence Dr. Mitchill gare the name of amethystus to the species.

Scales moderately small, thin, flexible, obtusely oval, tiled, and firmly imbedded in the skin; the uncorered roundish part of each scale measures less than a line. The scales on the under surface of the tail, and adjoining part of the belly, are rather larger, and those on the lateral line, 133 in number, are mostly elliptical, being narrower and somewhat longer than the others. About 221 rows of scales meet at the lateral line, and a vertical row beneath the commencement of the dorsal contains 82 , of which 32 are above the lateral line. There are thirteen scales in a linear inch measured on the sides, and a single detached scale measures about one line and three-quarters. The lateral line is about an inch nearer to the dorsal than to the upper ventral ray.

Form much like that of the Common salmon : the profile of the head and body bulges a little, and the sides are somewhat flattened. The head forms one-fourth of the total length from the snout to the tips of the caudal: it is flattish above and slightly convex in profile. Radiating lines on the frontal bone appear through the dried skin, but the elevated central ridge and curved lateral uneren ones, conspicuous in several of the trouts already describerl, are nearly obsolete in this species. The skull is more bony than that of the Common salmon, and the snout, instead of being cartilaginous, is formed of firm bone. Eye midway between the tip of the snout and nape, and twice as near the former as to the hinder edge of the gillcover, the measurement being made from the centre of the pupil. There are seven diameters and a half of the circular orbit in the total length of the head, and five and a half in that of its upper surface. The nostrils, consisting of two small contiguous orifices on each side, are situated before and a little above the angle of the orbit: the foremost orifices have a soft elevated edge, and are the largest.

The jaws are very strong. In the male the upper one overlaps the conical knob of the lower one by about half an inch : in the specimen now under consideration, which is supposed to be a female, the jaws are nearly equal, but the soft parts have been partly eaten by insects. The labials, not quite thrice the length of the intermaxillaries, are strong and nearly cylindrical (not a thin plate as in other trouts), and the appophysis, attached above like a crest, projects beyond the limb of the bone, in which respect also this trout differ's from its congeners. The distance between the tip of the snout and lower extremity of the labial reaches from the snout to about an inch beyond the orbit, falling fully three-quarters of an inch short of the nape. The under jaw, thick and rounded, is articulated to the lower end of the preoperculum, and also by a hinge-like joint to the jugal-bone. The length of the lower jaw is equal to that of the upper surface of the head. The porous lines on the heads of other trouts exist likewise in this, being mostly connected with foramina in the bones. 
TeEth.-The borders of the intermaxillaries, labials, lower jaws, and palate-bones are armed with very acute, slightly-curved, strong conical teeth: there is a circular cluster on the knob of the vomer, a double row extending at least half an inch backwards on that bone, and a row on each side of the tongue equally strong and more curved than the others: a deep furrow runs down the centre of the tongue between the rows of the teeth, and the soft parts form a smooth median ridge in the roof of the mouth, without any corresponding elevation of the bone. All the teeth are surrounded by soft gums, in which some small moveable teeth are implanted. The following is a scheme of the dentition in the individual under examination.

TeETu.-Intermax. 7-7; Labials 19-19; Lower Jaw 19-19; Tongue 8-8; Vomer 7-7*; exclusive of the smaller teeth, which fall off with the soft parts.

Gill-covers.-Preoperculum moderately curved, nearly rertical. Suboperculum deeper than in the other trouts, articulated at its inner angle to the operculum and preoperculum by a slencler process which is concealed by these bones : its edge forms fully one-half of the free border of the gill-corer and is finely grooved. The gill-rays, 12 in number, are flat, those nearest the gill-cover being the broadest : seven of them are inserted into the long appophysis of the hyoid bone, one or two into the intermediate cartilage, and the remainder into the posterior appophysis.

Fins.-Br. 11-12†;D. 14-0;P. 14;V. 9;A.11;C. 196.

The dorsal fin is situated in the middle of the fish, the exact middle between the end of the snout and tip of the central caudal ray, being opposite to the eighth dorsal ray and a little anterior to the ventrals: the height of the dorsal exceeds the length of its attachment: its fourth ray is the longest, the third is half as high, and is, together with the two very short anterior ones, closely applied to its base. The adipose fin is small and has a club-shaped profile. The ventrals contain nine rays each, the first being about twice as stout as the others. The anal contains eleven rays, the first of which is one-third shorter than the second and is closely applied to it: the last ray is two-thirds shorter than the second and is opposite to the adipose : the space between the anal and caulal measures more than the attachment of the former.

INTEstines.-(Of a male killed in Winter Lake.) Stomach a large sac continuous with the œsophagus and not to be distinguished from it, bent upwards and bulging a little at the bend : its imner membrane is longitudinally plaited. Caca numerous, their insertions occupying three inches and a half of the intestine. The internal coat of two inches of the lower part of the gut is disposed in circular valvula conniventes. The air-bladder communicates with the cesophagus by a tube as big as a crow-quill. In a female specimen I found a number of long, slender, opake worms in the air-bladder, of a whitish colour, with a slightly-

\footnotetext{
* The vomer is injured, so that the exact number of its teeth cannot be ascertained, but the above number still exists upon it.

† The specimen from which the figure was taken consists of the left side of the fish only, and shows twelve gill-rays; but as that side of the membrane grenerally has a ray more than the right side, I have marked it as above. I noted an individual which I examined at Winter Lake, lat. $64 \frac{1}{2}^{\circ} \mathrm{N}$., as having only eleven rays, not adverting to any difference between the two sides. Dr. Mitchill's scheme of the raỵs of his Lake Huron specimen is as follows:-

Fins:-Br. $13 ; D .13-0 ;$ I. $9 ; A .13 ;$ C. $19 \frac{5}{5}$ or $\frac{\dot{s}}{6}$.
} 
curved stripe running along one side : they were pointed at both ends, the least acute being the end that moved most, and having apparently an orifice in its apex. The male namaycush measured thirty five inches, including the caudal, and sixteen from the tip of the snout to the dorsal. The colours mentioned in the preceding description are those of this individual at the time of capture; the spots become more evident as the skin dries. The trout described by Dr. Mitchill was brought from Michillimackinac, and weighed thirty-two pounds and a half after the intestines were removed. It was fifty-four inches long, nine deep, and twentyfour in circumference.

Dimenstons

Of the Lake Huron specimen described above.

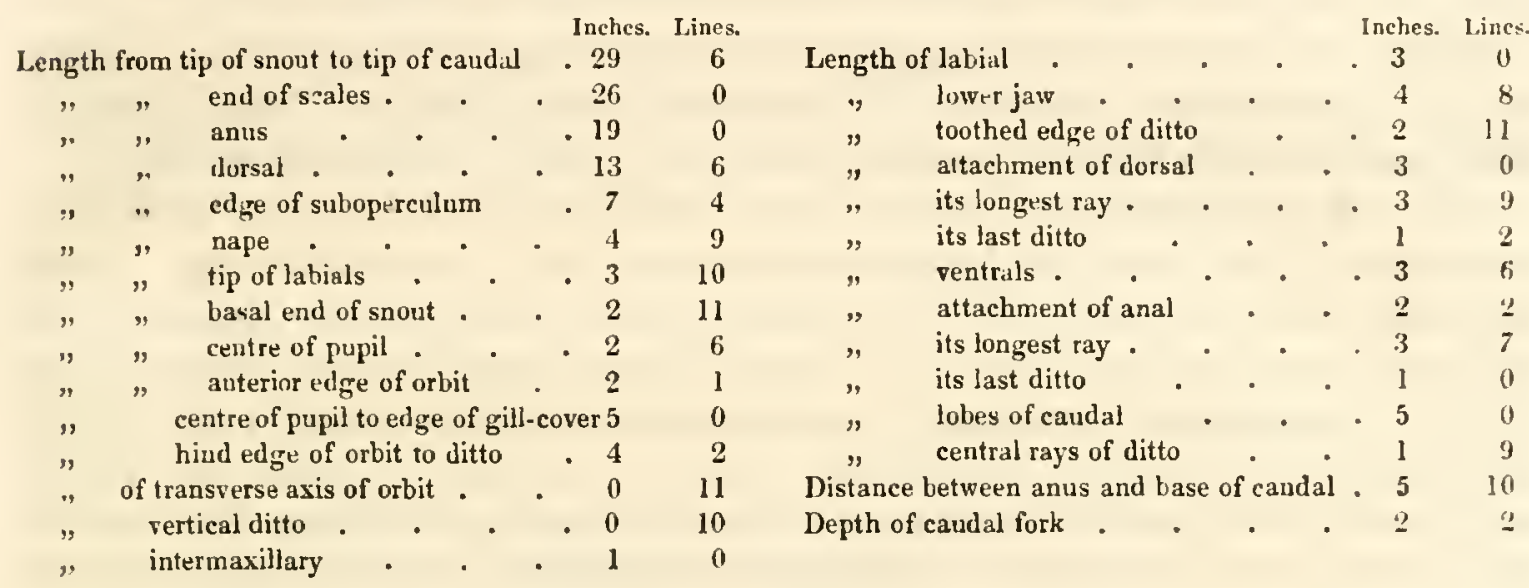

[0.] 10. Salmo Mackenzil. (Richardson.) The Inconnu.

Inconnu. Mackenzie, Foy. in N. Amer., p. 9, and elsewhere.

Salmo Mackenzii. Ricuardson, Frank. Journ., p. 707, plate.

Plate 84, one-third nat. size. f. a., nat. size.

'This, according to Indian information, is an anadromous species, and is only known to exist in the Mackenzie and its tributaries, to which it can have access from the sea. It is never taken above the cascades of Slave River, in latitude $60^{\circ} \mathrm{N}$.; but it forms an important article of food, at certain seasons, on Great Slave Lake and the Mackenzie. Its flesh is white, and when in good condition tolerably palatable, though rather soft and oily, and soon becoming disagreeable when used as daily food : it is firmest and best near the mouth of the Mackenzie, and when out of season is considered by the natives to be very unwholesome. The Incon- 
nues usually taken in the nets vary in weight from five to fifteen pounds, but individuals are reported to have been caught of thirty or forty pounds.

The Inconnu differs from the typical trouts in its general aspect, and in the smallness of its teeth, which are crowded like velvet pile, and are altogether wanting on the labials: it seems to stand on the confines of the sub-genus, and to connect the trutta with the coregoni. It disagrees with the latter in the number of its gill-rays, in having palatine and vomerine teeth, and in the form of the body.

\section{DESCRIPTION}

Of a specimen taken in Great Slave Lake in the spring of 1822.

CoLour of the back and sides changing from bluish-grey to greenish-grey when moved in the light: of the belly bluish-white; the sides have a strong silvery hue. Scales sub-orbicular, four lines in diameter, and possessing much pearly lustre. Lateral line straight.

Form.-Body roundish; in profile lanceolate. Head long and compressed with a flattened vertex. The sagittal line rises between the orbits into a smooth acute ridge. Orbits large, oval, situated as near again to the tip of the snout as to the edge of the gill-corer. The sub-orbitar bones, apparently about six in number, form a circular plate mostly posterior to the eye; a narrow process runs under the eye to the anterior orbitar, which is sub-orbicular and radiated on the surface. Nostrils close to the orbit: the anterior opening has a raised margin, and is contiguous to the posterior one. The intermaxillaries, forming about one-third of the border of the upper jaw, lie transversely, overlapping the curved articular ends of the labials, and giving a truncated form to the snout. The labials, thick and strong, have a lanreolate sbape; they are articulated with the cartilaginous ends of the palate-bones through the medium of a small curved process. The under jaw is strong, and has broad, flat sides with an obtuse and slightly-knobbed extremity, which projects four or five lines beyond the upper jaw : its articulation being as far back as the posterior edge of the orbit, adnits of considerable depression, but the opening of the inouth is not of corresponding magnitude, for it is contracted by a fold of integument which extends from the middle of the labial to the side of the lower jaw.

TеEтH.-The intermaxillaries, extremity of the lower jaw, vomer, palate-bones, and tongue, are armed with narrow bands of teeth "en velours," as are also the root of the tongue and the superior and inferior pharyngeal bones.

GiLL-COvErs. - The operculum and suboperculum form a very regular semicircle by the union of their posterior edges. The preoperculum is much curved, and includes a naked cheek, not wider than itself, between it and the sub-orbitars. The gill-openings are large : the membranes contain ten flat rays. The branchial rakers are rigid, awl-shaped, and rough interiorly, with minute teeth: those on the upper arch exceed half an inch in length, the others are smaller.

Fins.-Br. $10 ; D .15-0 ; P .17 ; V .12 ; A .18 ; C .226$.

The dorsal, opposed to the rentrals, is about its length nearer to the caudal fin than to the 
snout : it is obliquely quadrangular and higher than long: its three first rays are short and lie closely against the base of the fourth. 'The anal has a slightly-crescentic margin, and occupics more than half the space between its last ray and the caudal fin : its three anterior rays are minute. The caudal is large and forked.

INTEstines.- The asophagus and stomach three inches long, have nine internal longitudinal folds, and make a sliort turn upwards before terminating in the pylorus. A space of two inches between the pylorus and the insertion of the gall-duct is surrounded by crowded ceca; beneath the gall-duct the insertious of the crea are confined to one side of the intestinal tube : the caca are very numerous, slender, conical, and about a quarter of an inch long. The remainder of the intestine descends in a straight line to the anus: the valvula corniventes occupy an inch and a half of its lower end, a small piece next the anus being smooth*. The air-bladder is large and communicates by a wide tube with the osophagus. There is a large spleen attached to the curvature of the stomach.

Dimessions. - The length from the tip of the snout to the end of the caudal is twenty inches and a half, or to the end of the scales on that fin, eighteen inches.

\section{[7l.] 1. Salmo (Osmerus) eperlanus. (Artedi.) The Smelt.}

Family, Salmonoidex. Genus, Salmo. Linn. Sub-genue, Osmerus, Artedi.

Osmerus radiis pinaæ ani septemdecem. ArtEd, Spec., p. $45 . S_{y n} .$, p. 21.

Salmo eperlanus, Linn, Auctorum. Spirling. Scotis.

According to Cuvier there is only one known species of this sub-genus, the highly-prized Smelt of the European seas and estuaries of the larger rivers. It exists as far north as Sweden, and is enumerated by Lawson and Catesby among the fish of America, but it does not occur in the Fauna Gronlandica. M. Le Sueur has described a smelt taken between Newport and Boston, under the name of Osmerus viridescens; but as Cuvier, though well acquainted with that gentleman's ichthyological papers, has not noticed this smelt in the Règne Animal, we

* The following dimensions of the intestines of two English female salmon, omitted to be inserted in a preceding page, may be contrasted with the above.

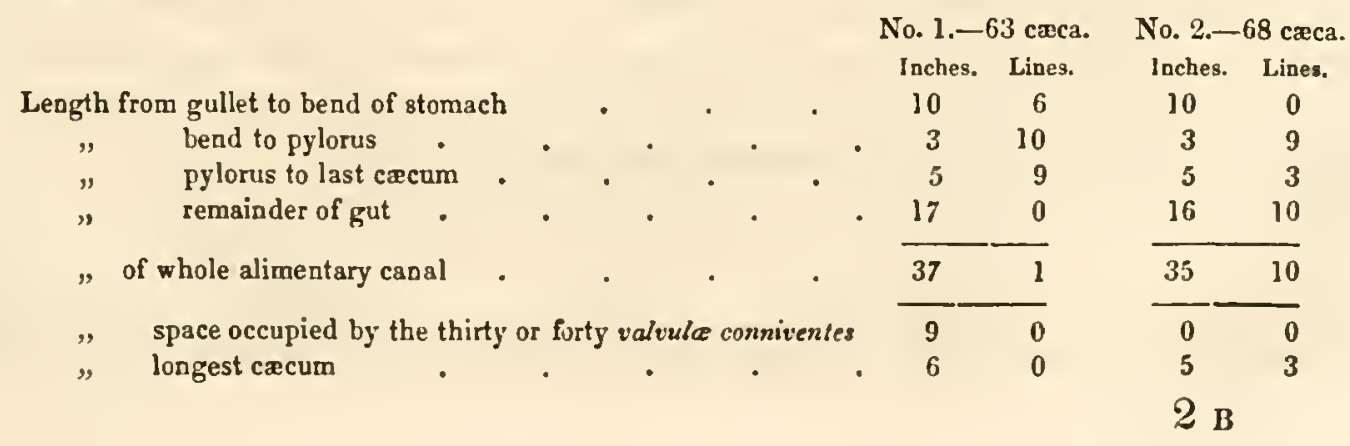


may infer that he did not consider its title to rank as a species sufficiently established. Lieutenant-Colonel Hamilton Smith has sent me a drawing of a smelt, which having been taken at Halifax, in Nova Scotia, is therefore likely to be the same with the New England one: this bears an almost exact resemblance to the European fish, except that the ventrals are farther back, commencing under the sixth ray of the dorsal. Steller and Mr. Collie mention the common smelt as frequenting Awatscha Bay.

The European Smelt has a row of small, short, closely-set teeth on the intermaxillaries and labials; somewhat longer and more remote ones on the lower jaw; and a row on both edges of the palate-bones, the teeth of the outer row being long and distant; there are four long teeth on the anterior end of the vomer, viz., two on each side continuous with the outer row of the palatine-tectl. The triangular tongue is armed with about ten strong teeth, two large ones being implanted in the apex, one before the other. The branchial arches are attached below to a narrow isthmus proceeding from the root of the tongue, and having two rows of minute teeth on its surface, but the upper pharyngeal bones are smooth. The slender rakers are rough with teeth internally, as in the trouts. The roof of the mouth and the head generally have some resemblance to the same parts of a pike, and the palate-bones have a similar menubranous attachment to the vomer, admitting of lateral movement as in that fish. The under jaw is longer than the upper one, even when the mouth is closed. The gill-covers are those of a trout, the rays being however fewer. The first rays of the dorsal and ventrals are opposite to each other, and stand midway between the tip of the snout and termination of the scales on the caudal. The adipose fin is attached a little posterior to the middle of the anal, which is long. The tail is slender and the caudal fin forked with acute, widely-spreading lobes and a tapering base. The scales are large, thin, very deciduous, and brilliant, reflecting beautiful green tints on the upper part of the body; the sides and belly are silvery. The body is unspotted. "The smell of the fisl, when recently taken from the water, is like that of a cucumber.

$$
\text { Fins.-Br. 7-8;P. 14;D. 10——0; V. 8;A. 16*;C. } 19 \frac{10}{10}
$$

* Artedi reckons seventeen anal rays, and Lieutenant-Colonel Smith counted the same number in his Halifax smelt. In our specimen of the European fish, the last ray is divided to the base, so that there appear to be seventeen on a cursory examination. 
[T2.] 1. Salmo (Maldotus) viluosus. (Cuvier.) The Capelin.

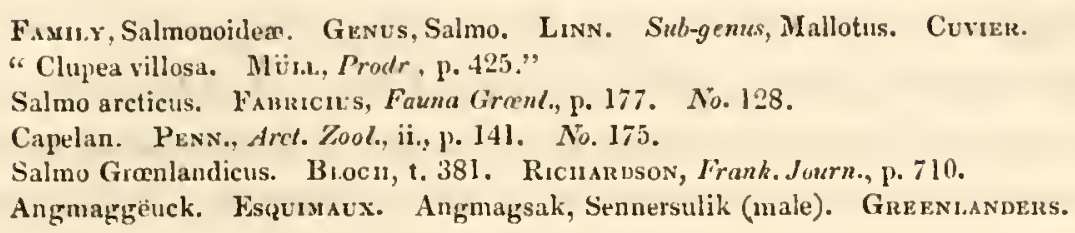

'This sub-genus, like the preceding one, contains only a single ascertained species, which frequents the northern seas. It swarms on the coasts of Norway, Lapland, Icelind, Greenland, Newfoundland, the Welcome, Coronation Gulf, and, if the Ouiki, or Salmo catervarius of Steller be the same, it inhabits the Sea of Kimtschatka. It has not been mentioned by travellers as existing in the Icy Sea of Siberia, but is very probably an inhabitant of that sea also, thus completing the circuit of the arctic coasts. It approaches the shore in dense shoals in the spawning season, the females preceding the males. 'The latter, it this period, acquire elevated bands on the sides, composed of soft, tumid, elongated scales, by which it is said they adhere together, sometimes to the number of ten or more, and in this state they are occasionally driven on shore by the wind in immense quantities. Some males, named sennersuitsut by the Greenlanders, want the ridges of enlarged scales. April, May, June, and July are the months in which the Capelin approaches the Greenland coast. In the beginning of August we observed multitudes of the males congregated on some sandy shoals near the mouth of Back's River, which falls into Bathurst's Inlet. Many of them leaped into the canoes and furnished a very acceptable dish of fish for our table, much relished by the whole party. Mr. Anthony Parkhurst, who is said by Pennant to be the first author who has noticed this fish, in a letter to Hakluyt written in 1578, after indulging in some facetious remarks respecting his skill in charming it and the squid or cuttlefish to come ashore, observes, that the nature of the squid is to come by night as well as by day; but the other, which is like a smelt, and is called by the Spaniards Anchovas, and by the Portuguese Capelinas, "commeth also in the night, but chiefly in the day, heing forced by the cod that would devoure him, and therefore for feare comming so neare the shore, is driven drie by the surge of the sea on the pibble and sands. Of these being as goorl as a smelt you may take up with a shove-net as plentifully as you do wheate in a shovell, sufficient in three or four houres for a whole citie."

The Malloti are very nearly allied to the Osmeri, the principal difference being 
in the smallness of their teeth. Their resemblance to each other in the form and structure of the heild is very close : both have, when fresh, a strong smell of cucumbers, and both are said to emit, occasionally, a very noisome stench. Nilsson states that the stinking smelt, named Nors by the Swedes, is a smaller kind, but differing only in size from the larger, which is named Slom. The Capelin is much used in the Newfoundland fishery as a bait for cod, and it is also dried in large quantities and exported to London, where it is sold principally in the oyster shops. Dried capelin forms so important an article of food in Greenland, that it has been termed the daily bread of the natives.

Although authors have taken it for granted that there is but one species of Capelin, we do not know that the fact has been fully established by a comparison of specimens from different seas. The description quoted below from my notes, of the appearance of a recent individual taken in the American polar sea, differs from the Newfoundland fish (of which through the kindness of M. Audubon, I possess a number of specimens preserved in spirits) in the appearance of the scales on the back, and in the top of the head being granulated ; but when I recollect the disadvantages under which that description was originally drawn up, I cannot venture to consider it as sufficient to warrant me in concluding that it relates to a new species.

\section{DESCRIPTION}

Of a male specimen taken in Bathurst Inlet, lat. $67^{\circ} \mathrm{N}$, August 4, 1821.

Form.-Profile of the body linear, the head forming a lanceolate termination on the one side, and the attachment of the anal fin sloping suddenly up towards the tail on the other. The back is broad. Head. The eye is large, and the centre of the pupil is eight lines distant from the obtuse extremity of the upper jaw. The under jaw, acute and longer than the upper one, is capable of considerable depression. When the mouth opens its sides are formed by the labials, whose posterior piece is very moveable, as in the Coregoni. The jaws, tongue, palate, and vomer, are furnished with minute teeth, which are more readily felt than seen. The branchial arches are set with a single row of bristle-like rakers, which appear to be smooth under the lens. The gill-openings are very large: the membranes contain nine rays.

SCales. - Instead of scales of the ordinary form, the back is covered with small smooth grains like shagreen, but soft to the touch, which are continued along the upper surface of the head to the snout. A prominent obtuse ridge, of nearly equal breadth throughout, extends along the lateral line from the gill-opening to the caudal fin : it is composed of soft, tumid, semi-lanceolate, acute, diaphanous processes, or altered scales, minutely spotted with black and densely tiled, with the points turned towards the tail. There is a similar but less prominent ridge between the pectorals and ventrals, which re-commences behind the latter fins, and is continued, though less conspicuously, to the anal. These ridges cause the sides to appear 
hollow as if pressed in. They are said by Cuvier to be peculiar to the male in the spawning season, and to be produced by a modification of the scales. The sides and belly are covered with delicate and very bright silvery scales, which are dotted on the margins with black specks: they are tiled and adhere firmly.

Fiss.-Br. $9 ; P .17 ; D .14-0 ; V .8 ; A .22 ; C$.

The pectorals are large, sub-orbicular, and placed near to each other. The first dorsal commences about midway between the occiput and caudal: it measures three-quarters of an inch in height, and contains fourteen rays, of which the two anterior ones are short, and the remainder forked at the tips: the connecting membrane is very thin and transparent. The ventrals, situated opposite to the dorsal, resemble the pectorals in size and form: they contain eight bifurcated rays, and measure, when expanded, an inch in diameter. The anal is supported throughout by rays of nearly equal length, but owing to the form of the part to which it is attached, its margin forms a convex curve : it contains twenty-two rays, the anterior being the strongest, and haring the membrane scolloped between them, the posterior ones are delicate: its attachment exceeds an inch in length, being thrice as long as the space between it and the caudal. The adipose fin is five lines long and one line and a half high : it is situated a little anterior to the termination of the anal, and is composed of a thin membrane attached to a small ridge of the smooth tubercles that cover the back. The caudal is deeply forked.

Cocour of the back and top of the head dull leek-green, with bright green and yellow reflexions when moved in the light. The sides and belly are silvery, minutely dotted with black. The gill-covers and jaws are mostly bluish-black with some bright silvery spots; the irides are silvery.

Intestines.-The osophagus opens into a forked stomach, both parts of which point downwards; one is a blind sac, the other, of equal size, terminates in a delicate gut, which is contimued in a straight line to the anus. Six caca of unequal length surround the pylorus. The faces are of a honey-yellow colour. The melt of the specimen was large and mature.

Dimensions.

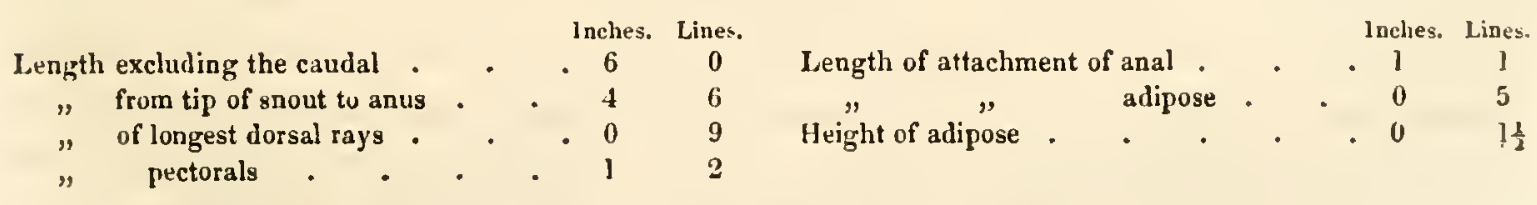

In my Newfoundland specimens, which are all males, the teeth are small and acute, set in a single series on the intermaxillaries, labials, lower jaw, across the front of the vomer, and on the anterior part of the outer edge of the palate-bones and posterior part of their inner edge. The tongue has a flat oval surface, which is surrounded by about twenty teeth, there are two or three minute ones scattered orer the central space, and two rows exist on the isthmus which supports the branchial arches, as in the smelts. A small median ridge extends the whole length of the upper part of the head; the lateral ridges, more prominent, rise into even, acute-edged, bony crests orer the orbits. The back is covered with small, round, thin, flat scales, of a different colour from those on the lower part of the body, and having 
no lustre. Were these scales to become tumid they would assume the granulated appearance noticed in the account of the Bathurst Inlet fish. The top of the head is covered with smooth skin on which there are many black specks. The pectorals almost touch below, and include an acutely elliptical space between their origins and the gill-openings. The anal is attached to a compressed, acute, and somewhat projecting portion of the tail. In other respects the description of the Bathurst Inlet fish applies exactly to those from Newfoundland. The rays vary in different specimens, as may be observed in the following table.

$\begin{array}{rrrrrrr}\text { Fins.-Br. } 9-10 ; & D .14-0 ; & P .20 ; & V .8 ; & A .23 ; & C .19 \frac{14}{14} . & \text { No. } 1 . \\ 9-9 ; & 14-0 ; & 20 ; & 8 ; & 21 ; & 19 \frac{14}{14} . & 2 . \\ 9-9 ; & 13-0 ; & 19 ; & 8 ; & 21 ; & 19 \frac{1}{4} . & 3 . \\ 9-9 ; & 14-0 ; & 18 ; & 8 ; & 23 ; & 19 \frac{14}{4} . & 4 . \\ 9-9 ; & 13-0 ; & 20 ; & 9 ; & 21 ; & 19 \frac{14}{14} . & 5 . \\ 9-8 ; & 13-0 ; & 19 ; & 8 ; & 22 ; & 19 \frac{14}{14} . & 6 . \\ 8-8 ; & 13-0 ; & 18 ; & 8 ; & 23 ; & 19 \frac{14}{14} . & 7 .\end{array}$

In all, the last ray of the dorsal is divided to the base, and that of the anal nearly so. The caudal is much forked.

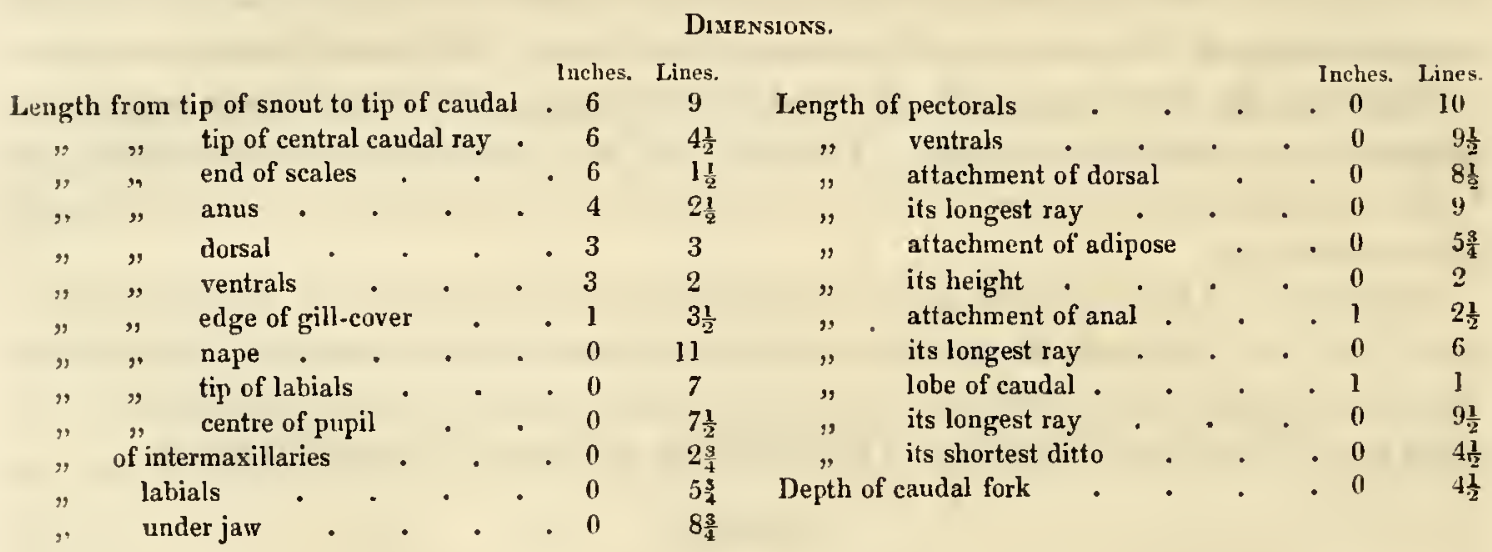

\section{[73.] 1. Salmo (Thymallus) signifer. (Richardson.) Back's Grayling.}

Family, Salmonoidex. Genus, Salmo. Linn. Sub-genus, Thymallus. Cuvier. Coregonus signifer. Rıсн., Fr. Journ., pl. 26, p. 711. Cuvızr, Règ. An. (sub. Thymallo.)

Hewlook-powak. Esquimaux. Poisson bleu. Canadian Voyagers.

\section{Plate 88.}

'This very beautiful fish abounds in the rocky streams that flow through the primitive country lying north of the 62nd parallel of latitude, between Mackenzie's 
River and the Welcome. Its highly-appropriate Esquimaux name, denoting "wing-like fin," alludes to its magnificent dorsal, and it was in reference to the same feature that I bestowed upon it the specific appellation of Signifer, or the "standard-bearer," intending also to advert to the rank of my companion, Captain Back, then a midshipman, who took the first specimen that we saw with the artiticial fly. It is found only in clear waters, and seems to delight in the most rapid parts of the momntain streams. In the autumn of 1820 we obtained many by angling in a rapid of Winter River, opposite to Fort Enterprise. 'The sport was excellent, for this grayling generally springs entirely out of the water when first struck with the hook, and tugs strongly at the line, requiring as much dexterity $t o$ land it safely as would secure a trout of six times the size. 'The stomachs of the individuals that we then took were filled with a black earthy-looking mitter, mixerl with what appeared, on a cursory examination, to be gravel, but which was perhaps, in reality, fragments of the shells that abound in the waters it inhabits. The roes of individuals caught towards the end of August were considerably developed, but neither the spawning places, nor the preeise period of spawning, were ascertained by us. The Indians say that it spawns in the spring, and that its winter residence is in the lakes.

The characters by which the Graylings are distinguished from the trouts in the Rigne Animal, are the smallness of the mouth, the fineness of the teeth, the great size of the dorsal fin, and the largeness of the scales. 'The stomach is a very thick sac, the gill-rays are seven or eight in number.

'The plate which is given of Back's Grayling in the narrative of Sir John Franklin's First Journey, was executed from an individual taken in Winter Lake, and carefully skinned and dried. I much regret that that specimen having gone to decay, I cannot compare it with the one brought by the last expedition from Great Bear Lake, of which the figure in the present work is an exact representation, drawn on a scale of half the natural size. The two figures differ in the relative size of the head, depth of the body, and some other particulars. The dorsal fin in the first plate is incorrect, not from any finult of the skilful artist who drew it, but owing to a part of the fin, which was broken off in the carriage, having been supplied by guess. The individuals taken in Great Bear Lake were much duller in their tints of colour than those we obtained in Winter River, probably because the latter being nearly in a spawning condition, were more brilliant than at other seasons. 


\section{DESCRIPTION}

Of a specimen from Great Bear Lake, latitude $65^{\circ} \mathrm{N}$.

Colour.-Back dark; sides of a hue intermediate between lavender-purple and bluishgrey; belly blackish-grey with several irregular whitish blotches. There are five or six quackrangular spots of Prussian-blue on the anterior part of the body, each tingeing the margin of four adjoining scales. The head is hair-brown above, the cheeks and gill-covers the same, combined with purplish tints, and there is a blue mark on each side of the lower jaw. The dorsal fin has a blackish-grey colour, with some lighter blotches, and is crossed by rows of beautiful Berlin-blue spots; it is edged with light lake-red. The ventrals are streaked with reddish and whitish lines in the direction of their rays.

Scales covered with a thickish epidermis and consequently haring little lustre; they are scmi-oral, their exterior edges being a segment of a circle, and appearing under a lens finely but irregularly toothed or serrated : their bases are truncated, and show three lobes or teeth corresponding with four deep groores that converge in the middle of the scale: the fine concentric lines of structure are waved. The scales are smaller on the forepart of the back and belly: on the sides they measure four lines transversely, and rather less from their exterior edge to the base. There are 87 on the lateral line, including three or four small ones on the base of the caudal, and 27 in a vertical row anterior to the ventrals, of which nine are above the lateral line. The scales do not end on the caudal as in the trouts, lararets, \&c., but extend farthest on the lobes, having the same forked termination with the fin itself. In this respect, and in the roughness of the scales, the Graylings have an analogy with the Percoidece and other rough-scaled fishes. The lateral line is straight, and the scales contposing it, though of equal size with the others, show only half as much surface when in their place.

Fonm.-Body compressed with an elliptical profile, the head, when the mouth is shut, ending acutely, but when viewed from above, or in front, the snout is obtuse. The greatest depth of the body is scarcely one-fifth of the total length, caudal included. Head small, bcing one-sixth of the total length, excluding the caudal, or one-seventh including it. In the dried specimen there is a slightly-elevated sagittal ridge, the occiput is radiated, and the tubular lateral ridges extend conspicuously fron the nostrils to the upper angle of the gillcorer. A line of tubes also passes along the middle of the infra-orbitar bones, another down the upper limb of the preoperculum, and there are three diverging tubes on the lower limb of that bone. Orbit large, distant half its own diameter from the tip of the snout, and two diameiers from the edge of the gill-cover. Nostrils midway between the orbit and tip of the snout. The infra-orbitar bones consist of four distinct radiated ones behind the eye, a narrow tubular ridge beneath the orbit, and a small thick plate with diverging tubular lines before the eye. Mouth not cloven as far back as the edge of the orbit. Intermaxillaries narrower and longer than in the coregoni, but orerlapping the articular ends of the labials less than in the truttce. Labials thin elliptical plates, the posterior piece lanceolate and as broad as the anterior one. Under jaw tolerably strong and rounded at the tip, which, when depressed, projects about four lines beyond the snout. 
TEETI small, subulate, pointed, and slightly curred, standing in a single crowded series on the intermaxillaries, labials, and under jaw ; in two rows on the acutely projecting edge of the palate-bones; and in a cluster of six or seren on the anterior extremity of the vomer; the latter bone is lat and smooth posteriorly. The tongue is also smooth, but the pharyngeal bones and the cartilaginous rakers of the upper branchial arch are rough: the rakers of the other arches are smaller and softer.

GilL-covers.-Preoperculum having the form of a moderately-curved and rather wide crescent. Subopercnlum more than half the height of the operculum, and not exceeding it in length. Interoperculum small and acute-angled. Eight gill-rays on the left side and nine on the right.

Fins. $-B r .9-8 ; D .23-0 ; P .15 ; V .9 ; A .13 ; C .19 \frac{\mathrm{g}}{8}$.

The dorsal contains 23 rays, which increase in succession from the first minute one: the three last and longest ones exceed in height the greatest depth of the body: the commencement of the dorsal is far forwards, or about half way between the gill-openings and ventrals, and its attachment is equal to the distance between its first ray and the centre of the eye, or between its last ray and the adipose fin. The adipose fin is partly behind the anal. The ventrals originate a little anterior to the middle between the snout and the base of the caudal, or under the eighteenth dorsal ray. Their scale-like appendages are long, thin, and pointed. Anal rather small and rounded anteriorly. Caudal deeply forked.

Intestines.-The alimentary canal, having its lining disposed in five large longitudinal folds, descends from the gullet for two inches and a half, when it dilates considerably, bends upwards upon itself, and terminates in a narrow pylorus: the dilated part resembles the stomach of the coregonus albus, or attihawmeg, in its structure, but its coats are thinner. The intestine, having rery thin coats, runs in a straight line from the pylorus to the anus, being exactly equal to the abdominal carity in length. It gives origin, within three-quarters of an inch of the pylorus, to eighteen cæca, and between two and three inches of its inferior part are furnished with internal circular folds, or valvulce conniventes. The liver is small, without lobes, and there is a large spleen attached to the curvature of the stomach. The air-bladder is large and communicates with the esophagus. The faeces were black.

On comparing the American specimen with a fine English grayling, for which I am indebted to Mr. Yarrell, the following were the most obrious differences. The English fish is much lighter in colour, with more lustre, and exhibits about sixtcen faint longitudinal bands passing through the centres of the same number of rows of scales. Its body is thicker, its head larger, and the distance between the orbit and end of the snout measures double to what it dloes in Back's grayling. The tubular ridges on its head are less conspicuous, and its mouth is wider; but its under jaw does not not project so far as in the latter. It also presents a remarkable difference in the want of palatine-teeth, these bones being quite smooth and rounded on the edge. The tecth on the mandibles are smaller than in the American grayling, and those on the vomer are perceptible only by the aid of a lens. Both hare tecth on the pharyngeal bones and rakers. There are 81 scales on the lateral line of the English 
grayling, the scales are more nearly smooth on the edge tahn in the American fish, and the teeth of their bases are smaller and more numerous, being four or more.

Dimensions.

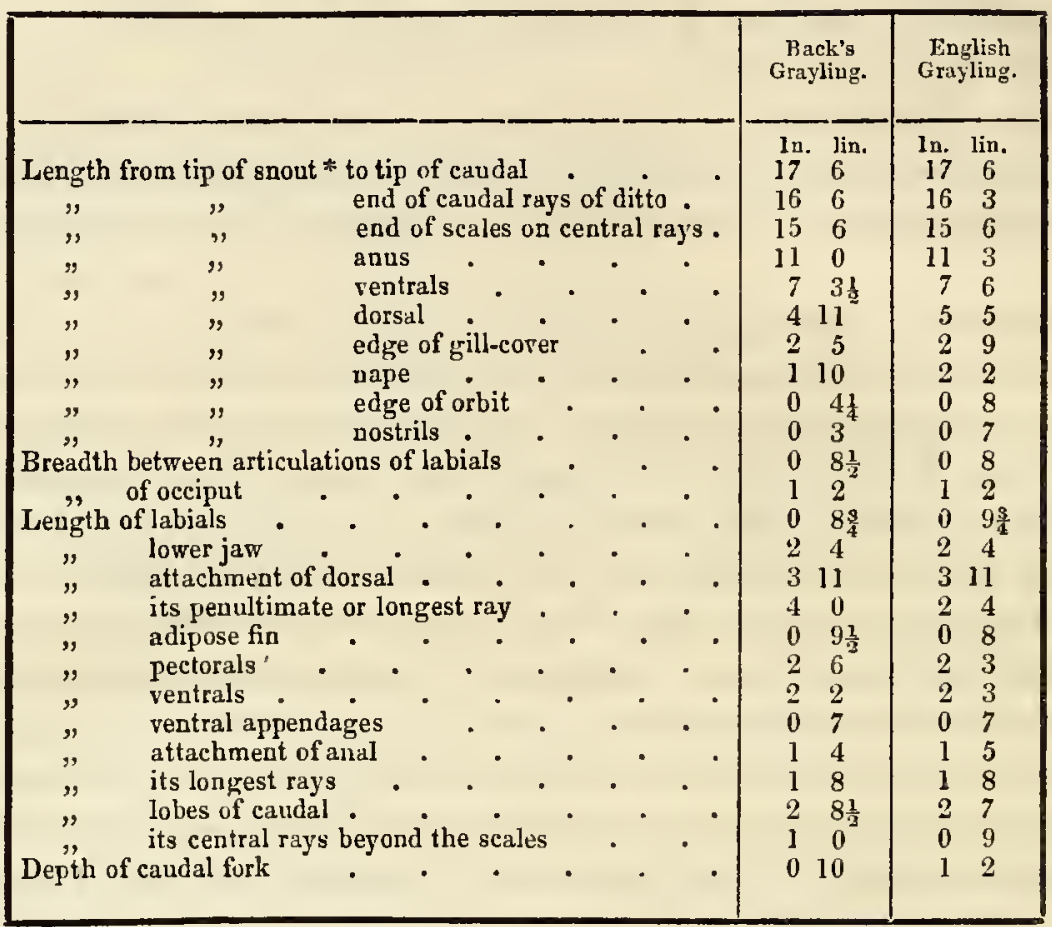

\section{[74.] 2. Salmo (Thymallus) thymalloides. (Richardson.) Lesser Grayling.}

Coregonus thymalloides $f$. Richardson, Frankl. Journ., p. 714.

A much smaller grayling was taken in Winter River along with Back's grayling, from which it differed in its tints of colour, brighter scales, and in the shape and size of its dorsal fin. At the time, I thought these variations sufficient to characterise it as a distinct species, but having since ascertained that the dorsal fin vitries greatly in size, and even in shape, in the European graylings of different

* Or articulation of labials, and not including the intermaxilaries, which project beyond the snout when the mouth opens.

† Thymalloides is objectionable as a specific name in the sub-genus Thymallus, but I did not consider necessary to alter it, as the species is a doubtful one. 
ages, I think it probable that it may lave been the young of the Thymallus signifer. The subjoined imperfect description is all that $I$ have to guide me in forming a judgment on this matter now, as I neglected to prepare a specimen in the autumn, when this small fish was plentiful, and none were seen in the spring. The Lesser grayling rises eagerly at the artificial fly. The stomachs of those which we opened were filled with sand and black earth.

\section{DESCRIPTION}

Of a recent specimen taken iu Winter River, August, 1820.

FORM.-Body compressed with a lanceolate profile, belly rather broader than the back. The dorsal fin has, like Back's grayling, from twenty to twenty-four rays, but the posterior ones do not branch out so much, and scarcely exceed the others in height; the three first rays only being shorter : the lieight of the fin is one inch. Ventrals situated under the middle of the dorsal.

CoLovr._Sides bluish-grey with purplish reflections, belly white. The scales have a bright pearly lustre. The head is hair-brown, and the gill-covers exhibit some purplish tints. Dorsal fin dark bluish grey, with several rows of purplish spots bordered by lighter red. Ventrals streaked with opake white.

Fins.-Br. 8; D. 23-0; P. 17; V. 9;A. 10;C. $19 \frac{8}{8}$.

Lengtu, excluding the caudal, eight inches and a half. Distance between the tip of the snout and anus six inches.

[75.] 1. Salmo (Coregonus) albus. The Attihawmeg.

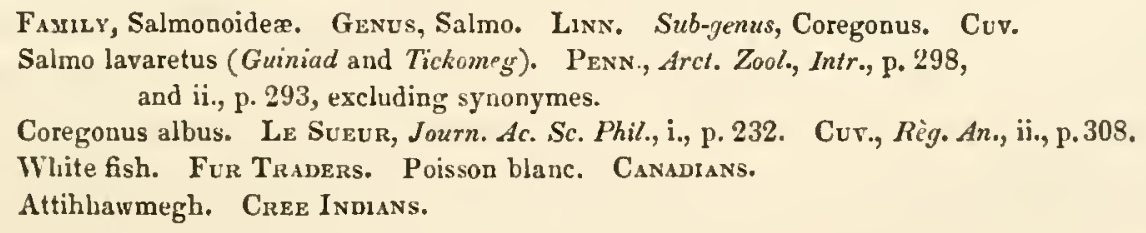

Plate 89, f. 2, A and B, half nat. size.

Several species of this sub-genus have been celebrated for the delicacy of their flavour, but none have been more justly so than the Attihawmeg, which is an inhabitant of all the interior lakes of Anerica, from Erie to the Arctic Sea. Several Indian hordes mainly subsist upon it, and it forms the principal food at many of the fur posts, for eight or nine months of the year,-the supply of other articles of diet being scanty and casual. Though it is a rich, fat fish, instead of producing satiety it becomes daily more agreeable to the palate; and I know, from experience, 
that though deprived of bread and vegetables, one may live wholly upon this fish for months, or even years, without tiring. Its good qualities were known as early as the time of La Hontan, who says, "Les poissons des Lacs sont meilleures que ceux de la mer et des riviéres, surtout les Poissons blancs; qui surpassent toutes les autres espèces en bonté et en délicatesse." The colour of its flesh is bhishwhite at all seasons, changing to a pure opaque white when boiled, whence its appellation of " white-fish," for though there are many other white-fleshed fish in the northern waters of America, this is by far the most important one.

In certain lakes, and in some seasons, the Attihawmeg is loaded with fat, particularly about the shoulders, where it produces a hump. After the spawning season its flesh becomes lean and rather watery, but not unwholesome, and it may be improved by suspension in the open air for a month or six weeks. Though the coolness of the weather, at that time of the year, prevents putrefaction from proceeding far, the fish acquires a strong taint, while it becomes richer, firmer, and altogether more agreeable to the palates of the icthyophagists of the fur countries than when fresh. The mode of cooking the Attihawmeg is generally by boiling. After the fish is cleaned, and the scales scraped off, it is cut into several pieces, which are put into a thin copper kettle, with water enough to cover them, and placed over a slow fire. As soon as the water is on the point of boiling, the kettle is taken off, shook by a semicircular motion of the hand backwards and forwards, and replaced on the fire for a short time. If the shaking be not attended to exactly at the proper moment, or be unskilfully performed, the fish coagulating too suddenly liecomes comparatively dry to the taste, and the soup is poor. The stomach, when cleaned and boiled with the rest of the fish, is a favourite morsel with the voyageurs.

The Attihawmeg does not exist in the St. Lawrence below the falls of Niagara, and, according to Mr. Hutchins, it is never seen in the tidal waters of Hudson's Bay*; but it is common enough, and of fine quality, in the mouths of the Mackenzie, Coppermine, and other rivers that fall into the Arctic Sea. We did not actually take any in the salt water, but it most probably can live indifferently in fresh or salt water, like several species of trutta, and coregoni that occasionally wander to the sea, though they are not strictly anadromous. Many lakes, either absolutely land-locked, or cut off from the sea by lofty cascades which tish cannot surmount, contain fine Attiharmeg, together with the Round-fish, an allied species to be afterwards described, which we also found in the Arctic Sea. In

* The "Titymeg as big as a Herring," mentioned in the narrative of the Voyage of the Dobbs and California as abounding in Hayes and Nelson rivers, within reach of the tidal waters of Hudson's Bay, is, I believe, of a different species, named by Mr. Hutchins Winepeg-attihaumeg, and by Pennaut Sea-guinitd. 
October the Attihawmeg quits the lakes and enters the rivers, for the purpose of depositing its spawn. It ascends the stream in the night-time, and returns to the lake as soon as it has spawned. Dr. 'Todd informed me that it enters Severn River from Lake Huron about the 25th of October, and retires to the depths of the lake again by the 10th of November; but that in some rapid rocky rivers of that lake individuals are taken throughout the year. A few spawn in the summer. It is a gregarions fish, and resorts to different parts of a lake according to the season of the year, its movements being in all probability regulated by its supply of food. In winter the fisheries are generally established in deep water, remote from the shore; towards the breaking up of the ice they are moved near to the outlets of the lake, and in the summer comparatively few Attihawmeg are canght, except what are speared in the rivers. After the spawning period the fall-fishery, as it is terned, is more productive in shallow bays and on banks near the shore. I was informed, in the fur countries, that this fish preys on insects, and that it occasionally, though rarely, takes a hook baited with a small piece of meat. The stomachs of some taken in Pine Island Lake, under the ice, contained i dark-coloured earth mixed with the slender fibrils of vegetable roots, and a few soft insects or larvæ like white worms. Dr. Todd found fresh-water shells and small fishes in the stomachs of the Lake Huron Attihawmeg; indeed, shelly mollusca (Helix, Planorbis, Lymneus, Pahudina, \&c.) appear to be a favourite food of several trout and coregoni, both in Europe and America. The Attihawmeg has some resemblance to the herring in the structure of its jaws and gill-covers, and, like that fish, it dies speedily when taken out of the water. The usual weight of the Attihawmeg is from two to three pounds, and, when very fat, it attains to seven or eight pounds; but these linge fish are confined to particular localities. In certain lakes it reaches a much greater size, having been taken in Lake Huron of the weight of thirteen pounds, and in Manito Lake, it is said, of twenty pounds. 'The largest seen by Mr. Hutchins, in the vicinity of Hudson's Bay, weighed between four and five pounds, measured twenty inches in length, and four in depth. One of seven pounds weight, cilught in Lake Huron, was trientyseven inches long.

The Attihawmeg is taken in the winter time in gill-nets set under the ice. Each net is fifty or sixty fathoms long, and of a depth proportionate to that of the water, and in setting it for the first time a series of holes are made through the ice, at such a distance apart, that a long stick can be readily passed in the water from one to the other: a line, rather longer than the net to which it is fistened, being attacherl to the stick, is carried along and brought out at the extreme hole. 'The net being 
buoyed up above by thin oblong pieces of fir, and loaded below with stones, is drawn beneath the ice by means of the line, and firmly fixed at each end to stakes thrust through the holes. After the first time the intermediate holes in the ice, being useless, are allowed to freeze up, but the extreme ones are opened daily, and the net examined by the fisherman, who draws it out at one hole, while his assistant veers away the line at the other. A careful fisherman changes the net every second or third day, for the purpose of drying and repairing it. Occasionally two or more nets are attached to each other, and set in the same way as a single one. As the ice in the fur countries varies from three to six feet in thickness, the labour of setting a net is considerable, and when the cold is severe, even the re-opening of the holes occupies much time. Most of the fish enter the net by night. They freeze as they are taken from the water, and are thus preserved in a perfectly sound state until spring; but the newly-taken fish are superior in flavour to European palates. 'The Copper Indians strike the fish through holes cut in the ice, using a very ingenious fish-gig, constructed of rein-deer horns, on the same principle, but superior in its effect, to the "stong" with which eels are commonly taken in Lincolnshire.

The Attihawmeg differs from the other known coregoni in the extraordinary thickness of its stomach, which resembles the gizzard of a fowl. Baron Cuvier having examined my Lake Huron specimens, returned them ticketed, "Coregone voisin de le Palée de Lac de Geneve." The sub-genus Coregonus is characterised in the Règne Animal as having a mouth like the Graylings, but less perfectly armed, being often entirely destitute of teeth. The scales are large and the dorsal is not so long as it is high anteriorly. The $C$. oxyrhinchus is distinguished from other European species by a soft prominence on the tip of its snout, and the C. maranula by the lower jaw projecting beyoud the upper one, agreeing in that character with the Salmo clupeoides of Pallas: the rest have the snout blunt as if truncated, like that of the Attihawmeg and most of the American coregoni.

\section{DESCRIFTION}

Of a specimen taken in Lake Huron.

Form.-Profile ovate, more or less gibbous before the dorsal fin, with a slightly-tapering tail inclining a little upwards. The greatest depth of a well-grown Attiharweg is between a third and a fourth of its length, excluding the caudal, but when very fat the depth is greater *. The body is compressed, the transverse diameter being considerably less than the vertical one.

\footnotetext{
* In an Attihawmeg of the ordinary size, taken in Pine Island Lake, the depth of the body was to the length of the fish, exclusive of the caudal, as five to seventeen.
} 
Head narrow below, with a moderately wicle frontal bone, and forming one-fifth of the length, excluding the caudal. The upper surface of the head is smooth and eren, in the recent fish, but in drying, the straight, lateral, tubular ridges become visible, traversing a depression over each orbit: the saggital crest is searcely perceptible, even in the naked skull, and it is cut short anteriorly by a groove which is widest at its termination between the nostrils. The ryes are large, and situated a little more than a diameter of the orbit from the tip of the snout, and near thrice as far from the edge of the gill-plate. The infra-orbitar bones cover more than two-thirds of the cheek: they are traversed by a tubular ridge with short lateral branches. 'The nostrils are placed midway between the tip of the snout and the orbit. The snout is blunt when seen in front, but its profile is more acute: it projects a little beyond the shut mouth, but when the jaws are separated the intermaxillaries descend from it perpendicularly, the tip of the lower jaw being then in the same line also. The mouth has a small orifice, and when shut its angles are depressed. The intermaxillaries are higher than they are long, $\mathrm{or}^{\mathrm{N}}$ they measure more vertically than they do transversely, so that the orifice of the mouth is farther beneath the snout than in the succeeding species. The labials thin, luroad and pyriform, are articulated by their narrow end to the palatine-bones, in contact with the ball and socket joint of the intermaxillaries: the posterior piece, or appophysis, is as broad as the anterior one and about two-thirds as long. The limb of the under jaw expands into a thin plate, which glides under the anterior sub-orbital when the mouth closes.

TEeth.-The jars and tongue are furnished with a few teeth, which are too minute to be readily seen by the naked eye, and too slender to be very perceptible to the finger. 'The palate and romer are quite smooth.

GiLl-covers,-The preoperculum is sharply curred and rather broad, its width in the middle equalling the height of the suboperculum. A tubular ridge runs along the anterior edge of its upper limb, and separates on the lower one into four diverging branches. The other bones of the gill-cover are thin and smooth. The operculum measures one-third more rertically than it does horizontally; while, on the contrary, the suboperculum is twice as long as it is high. The interopercnlum is triangular. The gill-membrane is rendered thick by the quantity of muscle and a shining membrane which line its eight thin, flat, curred rays. The branchial arches have each a single row of erect, subulate rakers, a quarter of an inch long, and rough on their inner surfaces. The pharyngeal bones are inconspicuous and toothless.

Scales rather smaller on the fore part of the belly and back than elsewhere: they are irregularly orbicular on the sides, and about half an inch in diameter. They have a bright pearly lustre, and are thin and very deciduous. The lateral line contains 80 scales, including those on the base of the caudal, and there are 24 in a vertical line before the dorsal, of which 10 are above the lateral line, and as many between it and the upper ray of the rentrals. The scales on the lateral line are somewhat smaller, and differ a little in form from the arljoining rows. Lateral line slightly arched in its course along the body, but after passing the anus running horizontally through the tail.

Colour, in the shade, bluish-grey on the back, lighter on the sides, and white on the belly, 
giving place to a nacry and iridescent pearly lustre in a full light. Cheeks, opercula, and irides thickly covered with nacre.

\section{Fins.-Br. $8 ; D .15-0 ; P .16 ; V .11 ; A .15 ; C .19 \frac{7}{7}$.}

The fifth and sixth rays of the dorsal are the longest, and the three first are closely applied to the base of the fourth. The middle between the tip of the snout and base of the caudal fiu, is opposite to the ninth or tenth dorsal rays, and posterior to the attachment of the ventrals. The adipose $f i n$ is rather large, and is situated opposite to the termination of the anal: it contains no rays whatever, and is not supported by interspinous bones: its base is clothed with small scales. The ventrals contain eleven rather stout rays. The anal, shaped like the dorsal, contains fifteen rays, of which the three first are applied to the base of the fourth, and the last one is divided to its origin. The anal occupies a little more than half the space between the anus and caudal. The caudal is forked and spreads widely. The scales terminate upon it by the same outline as in the trouts, being three sides of a rectangle *.

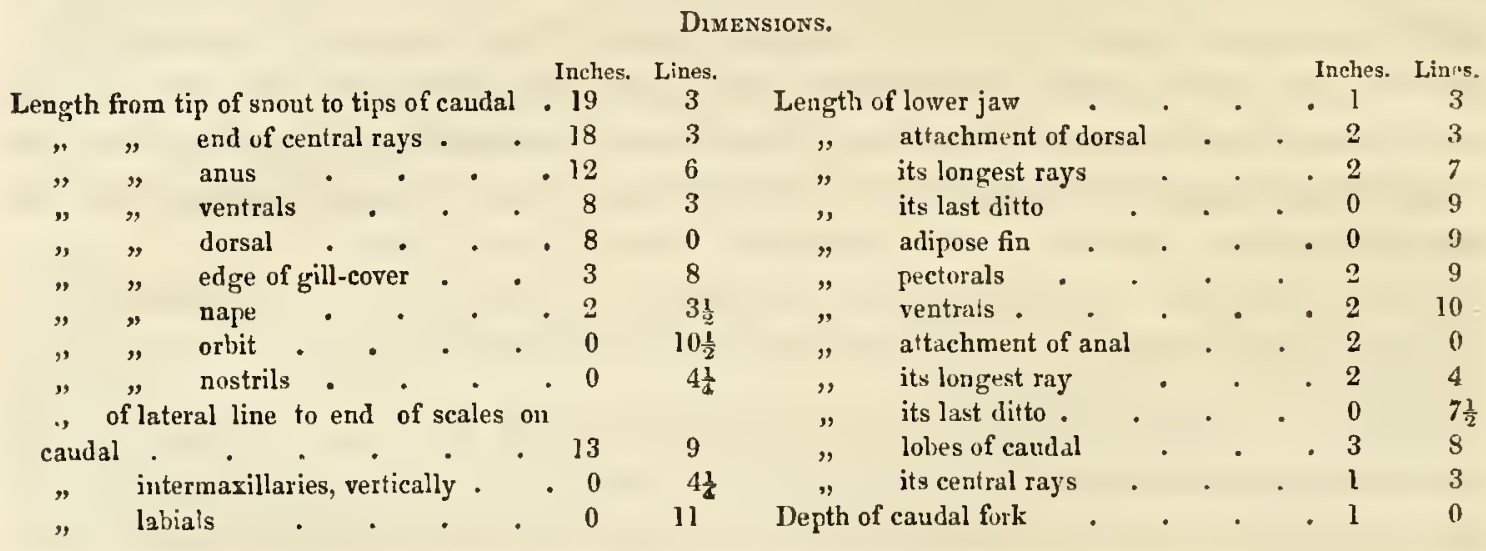

\section{INTESTINES}

Described from a specimen taken in Pine Island Lake, in lat. $54^{\circ}$ N., in the winter of $1819-20$.

On opening the abdomen a multitude of caca present themselves, involved in the folds of a membrane which is a production of the peritonæum, bearing a strong resemblance to the omentum of quadrupeds, and, like it, most commonly loaded with fat: it descends about half way down the belly, concealing the stomach and liver, and is closely connected with the former viscus by numerous vessels. A narrow spleen is attached to its right border. The alimentary canal descends from the gullet in form of a wide tube fire inches long, having its lining disposed in six longitudinal folds. An inch of the upper part of the lining has a red colour and glandular structure, and may be considered as belonging to the cesophagus. The remainder of the tube may be termed the upper stomach: it crosses the liver by a sudden turn, and bending upwards terminates in an oviform bag two inches and a half long, which may be denominated the proper stomach. It has, from the thickness of its substance, a strong resemblance to

\footnotetext{
* The engraver has not represented this happily in any of our plates of coregoni ; but the form that is meant may be seen by turning to plate 84 , or any of the other trouts.
} 
the gizzard of a fowl, and consists of a thin peritonæal coat; a thick firm semi-transparent one, which, when boiled, separates into layers; a thinner, but firmer and almost cartilaginous one; and, lastly, an inner membrane of a grey colour and spongy substance, differmg materially, in appearance, from the lining of the upper stomach: its folds are nearly obsolete. The pylorus is in the fundus of the stomach, which touches the upper extremity of the abdomen. From this a slender intestine, with thin coats and a few internal longitudinal folds, descends to the anus. I $t^{\circ}$ is encircled, at its commencement, by elustered caca, which continue to be inserted, on one side, for two-thirds of its length. There are in all about one hundred and fifty of them, an inch long, of a conical form, and filled with a yellowish mueus. The lower part of the intestine is furnished internally with circular folds, or valvula conniventes, but a small portion next the anus is smooth. The liver is small, obtusely triangular, and without lobes; it lies anterior to the œsophagus, and posterior to the cæca and intestine. The gall-duct, which has remarkably thick coats, terminates in the intestine about half an inch below the pylorus. The air-bladder extends the whole length of the abdomen, and is connected with the upper part of the stomach by a pretty wide tube.

\section{DiMENSIONS.}

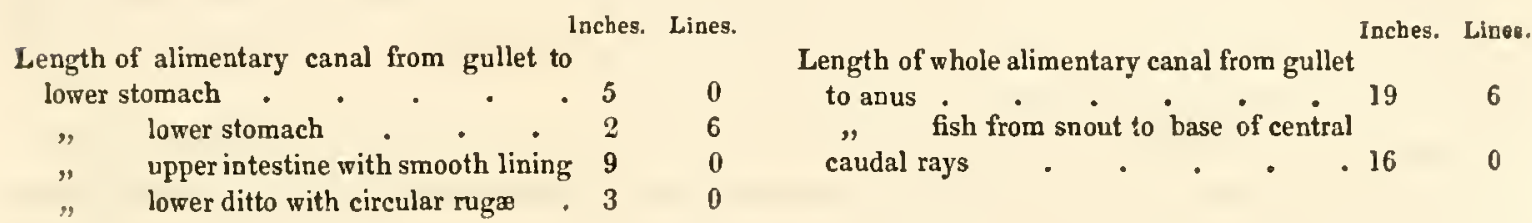

\section{[76.] 2. Salmo (Coregonus) tullibee. (Richardson.) The Tullibee.}

Ottonneebees. Cree Indins. Tullibee. Fur Traders.

This fish is very generally diffused through the waters of the fur countries, but nowhere is it taken in such numbers as the Attihawmeg. The fishermen know it at once, but as I was a novice in ichthyological pursuits when the recent fish were before me, I failed in detecting discriminating external characters, and my prepared specimens having gone to decay, the deficiency cannot now be supplied. In the appendix to the narrative of Sir John Franklin's First Journey, I referred the Tullibee doubtfully to the Coreganus Artedi of Le Sueur; but on re-considering the description of that fish, it appears to be decidedly unlike the former in its pointed snout and round scales. The Tullibee differs from the Attihawmeg in having a much thinner stomach and a smaller number of cæca, yet its food and general habits are the same with those of that fish. It is much inferior as an 
article of food, being generally lean and watery, though it is wholesome and destitute of any disagreeable flavour.

\section{DESCRIPTION *}

Drawn up from an examination of recent male specimens in the winter of 1819-20 at Cumberland-House, Pine Island Lake, lat. $54^{\circ} \mathrm{N}$.

CoLour.-In the shade, the back is greenish-grey, the belly white, and the sides of an intermediate hue; but when opposed to the light, the whole body is silvery, with much lustre. The top of the head is covered with smooth bluish-grey skin. Scales oblong, half an inch long, and of nearly uniform size.

Form much compressed, the belly rounded, the back rather more acute. The profile is broadly oblong, tapering suddenly at the anal; the head conical. Eyes large, and rather more than their own diameter from the end of the snout. The orifice of the mouth is transverse and rather small, and when the jaws are open the snout appears truncated. The intermaxillaries are small and cartilaginous; the labials oblong, and when thrown forward by the opening of the mouth their under ends project beyond the snout. The lower jaw is a little longer than the upper one: its knobbed tip fits into a depression between the intermaxillaries. The gill-membranes are plaited at their insertion into the isthmus. The cheeks are nearly covered by the sub-orbitar bones.

TEETH not perceptible on the jaws, but there is a small plate of minute ones on the centre of the tongue: there are also two rows of minute teeth on the inner sides of the cartilaginous rakers. Each branchial arch is furnished with a single row of rakers, the central ones of the upper arch, which are the longest, measuring half an inch.

Fins.-Br. $8 ; D .14-0 ; P .16 ; \boldsymbol{V} .12 ; A .8 ; C$. .

The first two rays of the dorsal are short. The caudal has a shallow fork.

INTESTINES.-The alimentary canal descends from the gullet for an inch and a half, it is then bent upwards for another inch and is more dilated, but there is no extraordinary thickening of the coats as in the Attihawmeg: its thick lining is disposed in six longitudinal folds, and forms a prominent ring at the pylorus, where it evidently terminates. Between the pylorus and the upper end of the abdominal cavity there is a thin bag, having the same width with the fundus of the stomach; it is lined by a firm, somewhat glandular, membrane, perforated by the mouths of numerous creca. The slender intestine runs straight downwards to the anus from this dilated commencement: its under half, furnished with regular valvulce conniventes, has a greater caliber than its upper half. There are in all about one hundred and twenty cæca, inserted into the dilated sac, and a short way down the slender tube of the intestine. The gall-duct opens near the pylorus. The spleen is long and large. The melt has a wood-browil colour.

* I have omitted such parts of my original notes as agree with the preceding account of the Attihawmeg and are more generic than specific. 
Dimensions.

\begin{tabular}{c} 
Length from tip of snout to base of central caudal \\
rays - \\
Greatest depth of body \\
\hline
\end{tabular}

\section{[7\%.] 3. Salmo (Coregonus) Artedr. (Le Sueur.) Le Sueur's Herring Salmon.}

Coregonus Artedi. Le Sueur, Journ. Ac. Sc. Phil., i., p. 231.

This species having been taken in Lake Erie and the Niagara River, requires to be noticed in this work. M. Le Sueur says that it is locally known by the name of Herring-salmon, and is considered to be very delicate food. As it did not fall under our notice, we shall transcribe the description given of it by its discoverer.

\section{DESCRIPTION}

Quoted from M. Le Sueur.

"Body sub-fusiform, a little elevated at the back; head small, having an osseous radiated plate which is covered by the skin ; snout pointed."- "In form this species approaches the scombri, a section of it is oval. Head small and narrow; snout short, terminated by small intermaxillaries; maxillaries wide, sharp-edged as in the herring. edges entire; mandibles carinate, producing inwardly a triangular pedunculate expansion; very small conical teeth inserted in the skin of the lips at the extremity of the jaws: these teeth were sufficiently manifest in a small individual, but not visible in a larger one, a female, which came under my observation. Rays in the osseous plate of the head tubular, and open at the exterior, some tending backwards, and others towards the end of the snout. A faint carinate line divides the top of the head in the dried specimen. Lateral line straight and near the middle; nostrils double, close to the end of the snout and articulation of the maxillaries; scales round, approximated, easily falling off; the base of the tail is covered with them. Colour ash-blue at the back, paler and silvery on the rest of the body, with yellow tints on the tail, head and dorsal ; iris whitish, pupil black. Length ten to twelve inches.

"Fins.-Br. $9 ;$ P. 16;D. 12-0; V. $12 ; A .13 ; C .-\frac{6}{6}$ ".

M. Le Sueur, in comparing our Attihawneg, or his Coregonus albus, with C. Artedi, says that it has a less fusiform body, and the back elevated from the nape to the dorsal. "The C. albus," he further states, "has morc depth of body, a greater elevation of back, and much stronger proportions in its body, fins, and scales. The adipose fin, which is broad, appears to consist of delicate rays, much pressed and in pairs." A careful examination of the dried specimens of our $C$. albus from Lake Huron, exhibited no rays whaterer, nor any interspinous bones to support them, but the fin in drying splits in a fibrous manner. 


\title{
[78.] 4. Salmo (Coregonus) quadrilateralis. (Richardson.) The Round-fish.
}

\author{
Coregonus quadrilateralis. Richardson, Franklin's Journ., p. 714. \\ Kathèh. Copper Indians. Okeugnak. Esquimaux.
}

Prate 89, f. 1, A and B, one-half nat. size.

This Coregonus exists in the Polar Sea, off the mouths of the Coppermine and Mackenzie, and in all the clear rivers and lakes north of the 62nd parallel of latitude, being thus an inhabitant of both salt and fiesh water, though we have no information as to its quitting the one for the other at any stated period*. Our Esquimaux interpreter, Augustus, informed us that his countrymen who frequent the shores of the Welcome are well acquainted with it. Though a general inhabitant of the northern waters, it is not so plentiful as the Attihawmeg, nor so gregarious, neither is it equally prized as an article of food. When in the fresh waters it preys on larvæ and soft insects. I have to regret that the stomachs of those we took at sea were not examined, but it seems to obtain food there well suited to its wants, as the individuals we caught in Bathurst's Inlet, on the 6th of August, were larger, fatter, and brighter in colour, than those we obtained inland. It spawns in September.

From the body of this species being less compressed than that of the Attihawmeg, our voyagers named it the Round-fish, and I have given it the specific appellation of quadrilateralis, on account of a flattening of the back, belly, and sides being superadded to its general sub-fusiform shape. Baron Cuvier made the following observation on the specimen which I submitted to his inspection:"Coregone voisine du Salmo maræna. Nous en avons une très semblable du Lac Ontario; elles différent du poisson des Lacs de Suisse parce qu'elles ont le museau un peu plus pointu."

\section{DESCRIPTION}

\section{Of a specimen taken in Great Bear Lake, lat. $641_{2}^{\circ} \mathrm{N}$.}

SCALEs smaller than those of the Attihawmeg and very regularly disposed, the uncovered portion of each having a rhomboidal form. A scale taken from the side measures four lines transversely, and half a line less in the other direction : its outline presents five or six very slight

\footnotetext{
* A Scottish species of Coregonus which inhabits the Castle Loch of Lochmaben, and is locally known hy the name. of Vendise, has been taken in the Solway Firth, but as the fisherman in whose net it was caught was totally unacquainted with it, it had perhaps merely strayed accidentally to the sea.
} 
angular projections, and its surface is destitute of any radiating furrows, having only the usual fine concentric strix. The scales on the anterior part of the back have short marginal ridges, causing them to appear as if finely toothed. The lateral line is straight, equidistant from the dorsal and ventrals; the scales composing it are smaller than the adjoining ones and truncated, the uncovered portion being nearly triangular; they are ninety-six in number, including six very small ones on the caudal. A vertical line before the dorsal contains twenty-three or twenty-four scales, of which nine are above the lateral line and eight between it and the rentrals. A linear inch on the sides contains six scales or six and a half.

CoLour of the back and sides intermediate between honey-yellow and wood-brown, with a narrow blackish-grey border to each scale: the tints are paler on the sides, and the belly is pearly-whitc. The scales are bright. The cheeks, gill-covers, and irides have a yellow colour with metallic lustre, and the fins are also mostly yellowish.

Form elegant. Profile lanceolate tapering evenly into the tail: the belly rather less curved than the back, which is moderately arched. The bady is four-sided with the angles rounded off: the depth one-fifth of the total length, excluding the caudal, and the thickness two-thirds of the depth. Head small, being only one-sixth of the length from the tip of the snout to the end of the scales on the caudal : it is of considerable breadth at the nape, and becomes one-fourth narrower between the anterior edges of the orbits, where it rounds off suddenly into a thin snout, which droops in profile. In the dried specimen there is a short sagittal erest between the orbits, and also lateral tubular ridges as in the Attihawmeg, but the former does not end in a furrow. The orbit is exactly its own diameter from the end of the snout, and two diameters and a half from the edge of the gill-cover. The nostrils are nearer to the orbit than to the tip of the snout. The mouth is remarkably small, and its orifice is quadrangular, the end of the lower jaw being truncated to the same wilth with the horizontal edge of the small intermaxillaries. The labials are very small, particularly their appophysis; their tips fall short of the orbit. The under jaw, even when depressed to the utmost, does not reach so far forward as the tip of the snout. The suboperculum is wiclest anteriorly, and the operculum is heart-shaped. No TEEтH whatever can be perceived, even with a lens, in the dried specimen: the branchial rakers are small and soft.

Fins.-Br. $7^{*} ; D .15-0 ; P .15 ; V .11 ; A .13 ; C .19 \frac{7}{7}$.

The dorsal is farther forward than in the Attihawmeg, the distance from the end of the snout to its first ray, when carried backwards, scarcely reaching the adipose fill, while in the latter species it passes it. The centre betrreen the tip of the snout and end of the scales on the candal is under the penultimate dorsal ray. The adipose is partly posterior to the anal. The caudal is forked.

Istestines.-Stomach like that of the Tullibee, the pylorus very narrow. Caca eightyseven, crowded under the pylorus where they surround the gut, and also occupying one-third of its length in three or four rows. The lower third of the intestine is furnished with valvulce conniventes, half an inch of it at the anus being smooth. Faces black.

\footnotetext{
* This seems to be the prevalent number of gill-rays, but some of the individuals taken in the Arctic Sea had eight.
} 


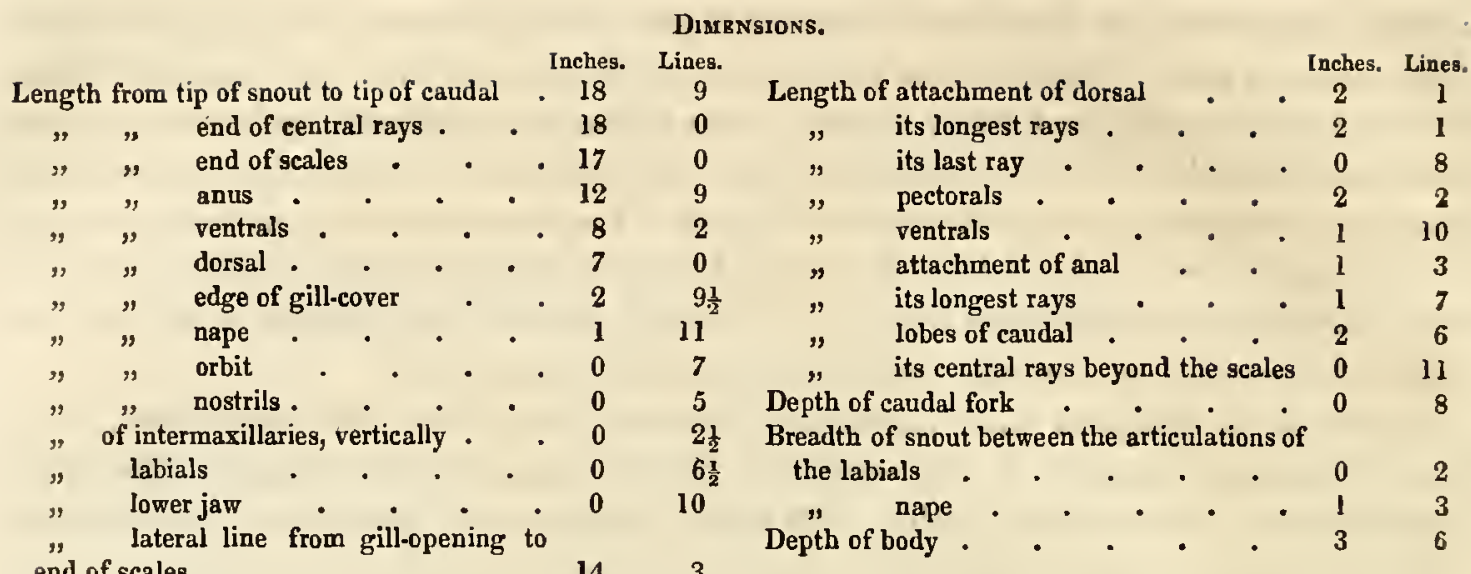

\section{[79.] 5. Salmo (Coregonus) Labradoricus. (Richardson.) Musquaw River Coregonus.}

Mr. Cumming did me the favour of preparing a specimen of this Coregonus, which inhabits Musquaw River, that falls into the Gulf of St. Lawrence, near the Mingan Islands. The colours and exact form of the body cannot be determined from the dried specimen, but in the shape of the scales and opercular pieces it resembles the Attihawmeg, though its labials, and consequently the orifice of its mouth, are much smaller.

\section{DESCRIPTION.}

Form.-Body apparently much like that of the Round-fish: its depth is one-fifth of the length, excluding the caudal. Head small, constituting only a sixth part of the distance between the tip of the snout and end of the scales on the caudal. The orbit is exactly twice as far from the edge of the gill-cover as from the tip of the snout. Cranial ridges nearly as in the Round-fish. The labials are a little longer than in that fish, and their posterior pieces are of a different shape, being ovate, whereas they are acutely elliptical in the other. The under jaw measures a very little more than one-half the length of the upper surface of the head, and when the mouth is distended its tip is exactly even with the end of the snout. Jaws and palate toothless: four longitudinal rows of teeth on the tongue.

Scales orbicular, thin, flexible, and deciduous, seventy-eight on the lateral line, corresponding with an equal number of rows on the back and belly. The middle, between the tip of the snout and end of the scales, is at the thirty-second scale of the lateral line, and opposite to the third ventral ray, or tenth dorsal one. A linear inch, measured on the sides, includes seven scales. There are eight scales between the dorsal and lateral line, and as many between the latter and the ventrals. 
Fins. $-B r .8-9 ; D .15-0 ; P .15 ; V .12-11 ; A .15 ; C .19 \frac{9}{9}$.

The three anterior rays of the dorsal are short, as are also the two first anal ones. The first ray of the ventral is opposite to the space between the eighth and ninth dorsal ray. The adipose corresponds with the end of the anal, and the attachment of the latter equals the space between its last ray and the outermost of the nineteen longer caudal rays.

Dixensions.

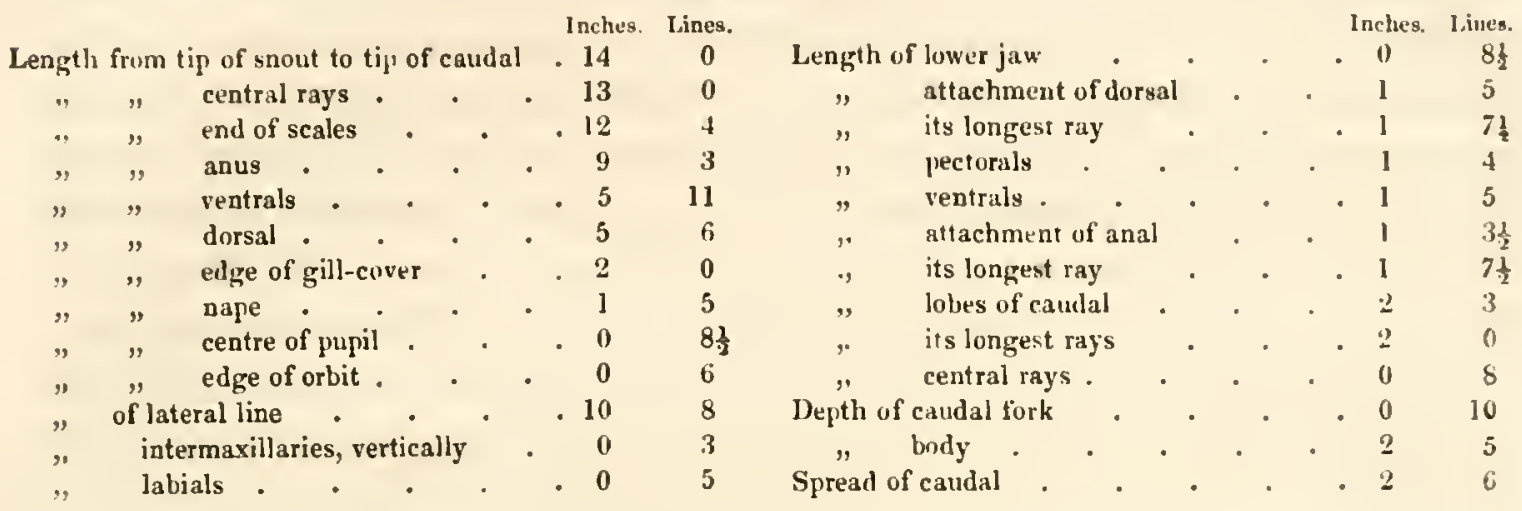

\section{[80.] 6. Salmo (Coregonus) lucidus. (Richardson.) Bear Lake} Herring-Salmon.

Pi.ate 90, f, 1, A and B, one-half nat. size.

Baron Cuvier's remark on our specimen of this fish was, "Coregone, encore phus semblable au Salmo maræna que le Round-fish: Mais les ecailles du Salmo marana somt plus grandes que celles de le Herring-Salmon." We have not had an opportunity of comparing the American species with the marana, but the lucidus and quadrilateralis differ much from each other in the form of the body, as well as in other particulars, such as the size and shape of the scales, the breadth and comparative length of the snout, and the size of the labials and aperture of the mouth. The $C$. lucidus has a compressed body, like a species which we have received from Lake Leman under the name of La fera, and also like the Vendace, or Vendise*, from Lochmaben in Scothand, but the scales of these two are smaller; the Fera has larger intermaxillaries like the Atthowmeg, and the Vendace has an acute under jaw, which forms the extreme point of the head when the mouth is closed. None

* Piscis in lacu Mabano, Vandesius. Srbast., Scot. llustr., lib. 3, p. 26. Tradition says that King Robert Bruce introduced this fish into the Castle Loch from France. 
of the American coregoni, described in this work, have the snout so decidedly posterior to the tip of the under jaw as the Lochmaben fish, the nearest approach to it being the Lake Huron Herring-Salmon, to be afterwards described.

The Bear Lake Herring-Salmon was seen by us nowhere but in the great sheet of water whence it derives its trivial name. That lake extends from the 65 th to the 67th parallel of latitude, and is remarkably clear and deep. Its surplus waters are carried off by a large stream which falls into the muddy current of the Mackenzie, and there are no rapids, between it and the sea, that fish cannot surmount, yet none of the anadromous salmon of the Aretic Sea have been known to enter the lake ; the Salmo Mackenzii confining its migrations in fresh water to the Great Slave Lake, and the turbid branches of the Mackenzie River. The Namaycush, Masamècoos, Attihawmeg of large size and very fine quality, Round-fish, and Back's grayling, are taken in Great Bear Lake, but none of them so abundantly as the C. lucidus, of which the nets yielded us fifty thousand in the year 1825-6*. The lake begins to freeze in October, and in the course of November most of its narrower arms are covered with ice, but, according to Indian report, its centre is not closed for the season before the beginning of January, and during the whole winter a small piece of water continues open at the point from whence the Bear Lake River issues. The ice begins to break up in shallow bays towards the end of May, and is entirely gone by the end of June. In September the nets were set near Fort Franklin, at the influx of a river about four miles from the outlet of the lake, and their daily produce was between three and four hundred Herring-Salmon. 'Though the fish continued to be equally plentiful at that spot during October, the fishery was discontinued on account of the floating ice, which did not become firm enough for the nets to be set with safety under it before the middle of November; and in the beginning of December the Herring-Salmon, resorting in numerous shoals to the outlet of the lake, were of course followed thither by the fishermen. At this spot, the water was three or four fathoms deep, but the fish could be easily seen through the clear ice, which enabled the Indians to spear a few, though more fell a prey to the otters. In January the fishery was not only unproductive, but several of our party suffered severely from the bad quality of the fish, whose intestines contained at this time a matter so caustic as to blister the hands of those whose duty it was to clean them. From the end of February the fish daily improved in quantity and quality, until the rivers opened in May, when the fisheries were again removed to the mouths of several small streams which fall into the lake.

* In eighteen months we obtained about three thousand five hundred trout, none weighing less than two pounds, and some exceeding thirty. 
Attihawmeg and Namaycush differ from the Herring-Salmon in resorting to the greatest depths of the lake in the winter, and it may be here observed, that fish can receive a free supply of fresh air during that season, even in the centre of the most extended lake, through the wide rents caused by contraction of the ice at low temperatures. Warmer weather causes the ice to expand again, and great blocks of it are then forced up through the crevices, so as to form walls sometimes twenty feet in height. The memoranda of various particulars respecting the habits and anatomical structure of the Herring-Salmon, that I made during our residence on Great Bear Lake, were lost in the struggle that we had subsequently with the Esquimaux, and at this distance of time I cannot supply the loss from memory.

\section{DESCRIPTION}

Of a specimen taken in Great Bear Lake.

Form in profile closely resembling the Round-fish, but the body is much more compressed, and the head larger, being one-fifth of the length between the tip of the snout and end of the scales on the caudal, and nearly equal to the greatest depth of the body. In the dried specimen, the breadth of the nape equals the distance between the supra-orbital plate of the frontal bone and the articulation of the lower jaw, and the width between the upper ends of the labials is twice as great as in the Round-fish. The sagittal ridge rises into an acute crest from the nape to the nostrils, and the tubular ridges on the frontal bone and anterior suborbitars, are more conspicuous than in any of the preceding species. The orbit is situated the length of its diameter from the end of the snout, and thrice as far from the edge of the gillcover. The orifice of the mouth is large in comparison with that of the other coregoni, equalling the orbit in diameter: when the jaws are extended, the intermaxillaries are brought into a line with the forehead, instead of dropping vertically as in the Round-fish. The labials are large, and have a widely oblong form, carrying their breadth close to both extremities; their tips, when the mouth is shut, reach as far back as the centre of the orbit; the anterior piece is traversed by an obtuse keel, and the posterior one is only half as long, and less than half as wide as the anterior one. There are no teeth. Gill-covers. The preoperculum is broader than usual, particularly its upper limb: there are four conspicuous tubular rays on its lower limb. The interoperculum is large, being bigger than that of the Attihawmeg. The posterior margin of the gill-cover is uneven or slightly lobed.

Fins.-Br. 8-8;D. 14-0;P.19;V.11;A. 14;C. 199.

The eighth ray of the dorsal, the first of the ventrals, and the thirty-third scale of the lateral line, are situated midway between the tip of the snout and end of the scales on the caudal. The ventral appendages are slender and unusually long. The adipose is about its own breadth posterior to the anal, which is smaller than in the Attihawmeg. The caudal is deeply forked.

Scales transversely oval, considerably larger than those of the Round-fish, but smaller than those of the Attihawmeg; one from the side measures five lines vertically, and four 
longitudinally, the uncovered edge is a segment of a large circle, the base is rather angled, or widely three-lobed. There are eighty-eight scales on the lateral line; ten rows above that line at the dorsal, eight between it and the ventral, and three or four from thence to the mesial line of the belly. The scales on the sides are larger than those of the back; a linear inch includes six of them. The lateral line is straight and equidistant from the dorsal and ventrals.

CoLour. - The scales have much pearly and iridescent lustre. In the dried specimen the back is lighter than that of the other coregoni, and the sides of the head yield strong greenish and golden reflections*.

\section{Dimensions.}

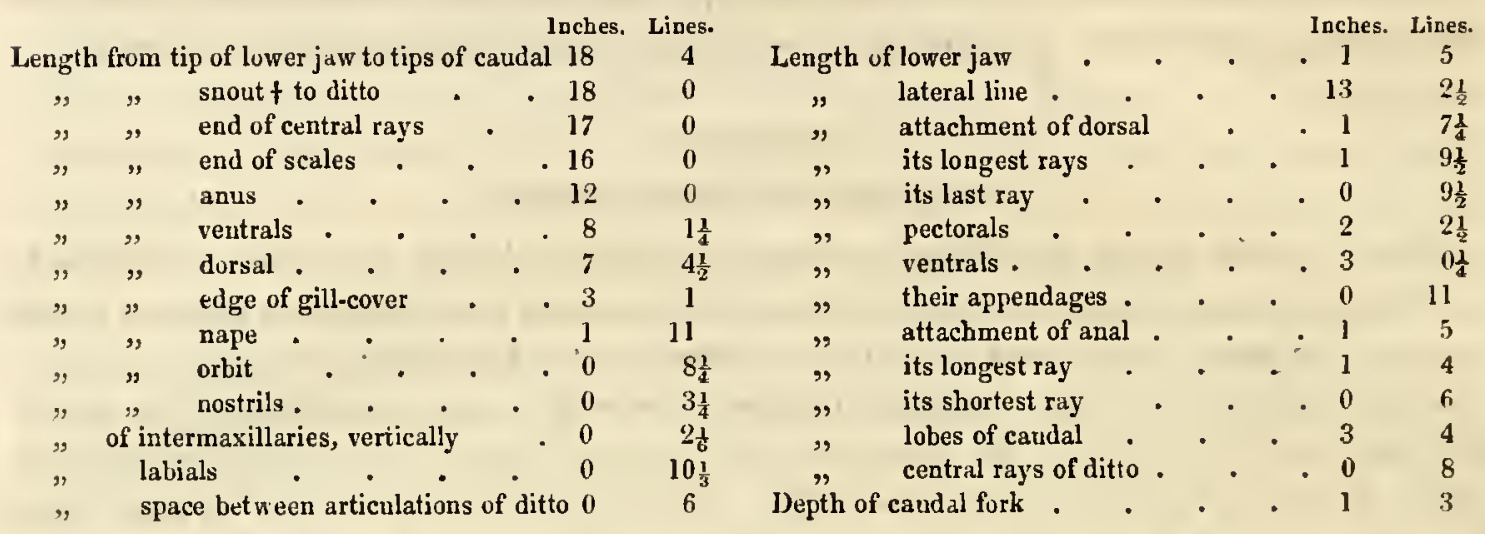

\section{[81.] 7. Salmo (Coregonus) harengus. (Richardson.), Lake Huron Herring-Salmon.}

Plate 90, f. 2, $A$ and $B$, one-half nat. size.

This fish is plentiful at Penetanguishene on Lake Huron, but I am unable to determine whether it be the same with the $C$. Artedi of Le Sueur, which we have already noticed as an inhabitant of Lake Erie. Baron Cuvier's remark upon our specinen was, "Espèce nouvelle voisine des Coregones." It resembles C. lucidus very nearly, its larger head, smaller scales, and a slight difference in the position of its ventrals being the principal distinctive characters I have been able to detect in the dried specimens. Having lost my notes of the dissections which I made of $C$. lucidus, and having examined the recent specimens of $C$.harengus only cur-

* My notes of the appearance of the recent fish were lost, as I have stated above.

$f$ The articulations of the labials and intermaxillaries are considered as the end of the snout, not the edges of the latter, which, when the mouth is open, are extended on a line with the upper surface of the snout. 
sorily, I can say nothing respecting any differences that may exist in their viscera. An argument against the identity of the species may be adduced from their habitats being upwards of twenty degrees of latitude apart.

The Lake Huron Herring-Salmon is gregarious like the Bear Lake one, and frequents sandy bays during the summer months. It spawns in $A_{\text {pril }}$ and May, and at that time is ocensionally seen in rivers. According to Mr. Todd's observations it is " a timid fish, appears to be in constant rapid motion, and associates in shoals in pursuit of the fry of the small fishes on which it feeds." As an article of diet it is well tasted and wholesome, though much less rich and agreeable than the Attihawmeg.

\section{DESCRIPTION}

Drawn up from notes made at Penetanguishene, aided by a re-examination of the dried specimens.

Colour, in the recent fish, olire-green on the back, silvery on the sides and belly, and blackish-green on the top of the head: the gill-covers, cheeks, and irides are whitish and nacry.

SCales of the same form with those C. lucidus, but only of two-thirds the size: on the sides their transverse diameter is four lines, their longitudinal one rather more than three, and when in situ, eight are included within a linear inch. There are eighty-four on the lateral line *, and twenty-two in a vertical row under the dorsal, of which nine are above the lateral line, and eight between it and the ventrals. The lateral line is straight.

Form.-Body compressed, back rounded, belly slightly flattened, the greatest thickness, howerer, being at the lateral line, which is rather nearer to the back than to the belly: the height of the body, at the dorsal, is double its thickness. Profile like that of $C$. lucidus, the head being, however, more acute $f$. The snout is obtuse, when seen in front or from above, and the vertex is smooth and rounded in the recent fish: in the dried specimen the radiated tubular lines near the nape, the sagittal ridge and other eminences, appear as in C. lucidus, but not so prominently. The length of the head is more than onc-fourth of the distance between the tip of the snout and end of the scales on the caudal, and somewhat less than one-fifth of the total length, including the lobes of the caudal. In the position of the eye, and the forms of the jaws and opercular bones, this species scarcely differs from C. lucidus. When the mouth is fully open its orifice measures seren lines vertically, and fire and a half transrersely: the under jaw, which is narrow but not acute, then projects about four lines beyond the articulations of the labials.

TEETH, none on the jaws, romer, or palate, but three rows of very slender ones on the tongue may be perceived by the aid of a lens. Rakers stiff, subulate, and rough on the margins, the middle ones of the first arch, which are the largest, measuring five lines.

* One specimen had only seventy-seren scales on the lateral line, but the same as the ahove in a vertical row.

+ The figure, which was taken from a dried specimen, presents a less elegant profile than that of the recent fish.

2 F 2 
Fins.-Br. 9-9;D. 12 or $13-0 ; P .16 ; V .12 ; A .13 ; C .19$ 웡.

The ventrals originate under the sixth or seventh dorsal ray, but the structure and form of all the fins are nearly as in C. lucidus. The adipose is not supported by interspinous bones, but it exhibits in the dried specimen a very fine, apparently, fibrous structure, which entirely disappears when the fin is moistened. In one specimen the centre between the tip of the snout and end of scales on the caudal, corresponds with the first ray of the ventrals and thirtieth scale of the lateral line, in another it is a little posterior to the first ventral ray, being at the thirty-third scale of the lateral line: in the last specimen the lateral line has seven scales more than the other.

\section{Dinensions}

Of two dried specimens.

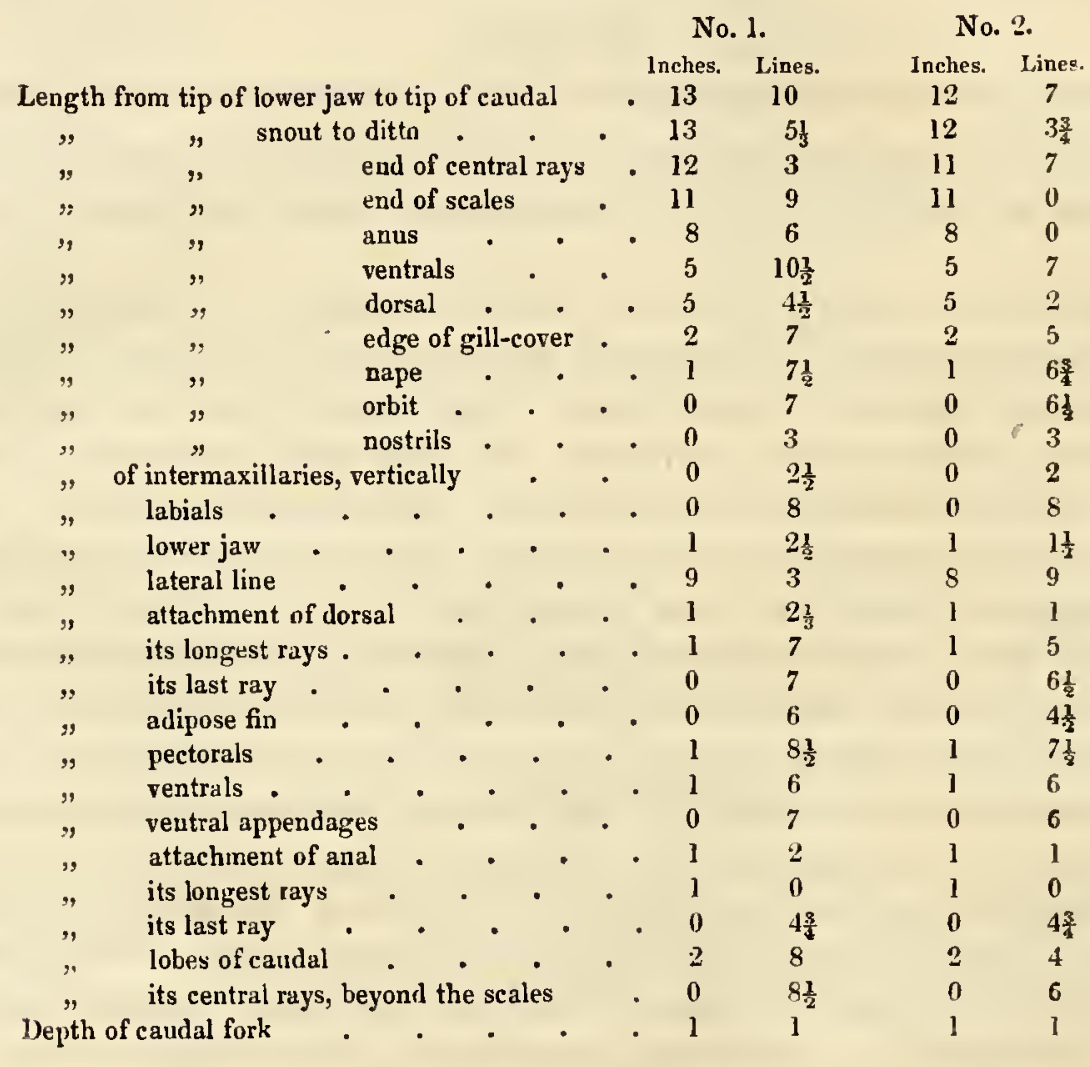

I subjoin the dimensions of two European Coregoni alluded to in the preceding pages, that they may be compared with the American species. 


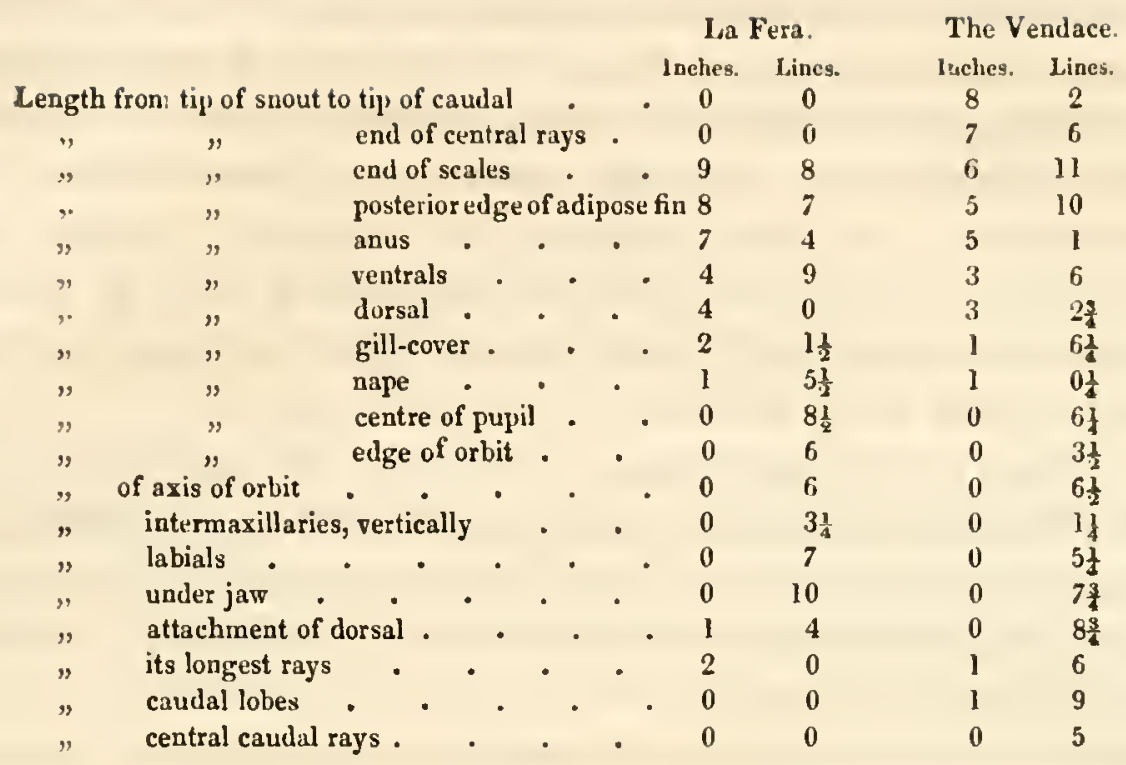

The Coregonus fera (Jurine) resembles our Attihawmeg, or C. albus, in the shape of the head, cranial ridges and depressions, and opercular bones, but its body is much more compressed, having more nearly the form of our Herring-Salmon. The under jaw, when depressed, reaches beyond the snout. There are no visible teeth on the labials or roof of the mouth, some minute ones exist on the intermaxillaries, and the conical tongue is covered with teeth, which, though very slender, can be readily seen. There are about seventy scales on the lateral line. The ventrals are under the eighth or ninth dorsal rays, and their appendages are short and three-edged. The stomach of my specimen contained a quantity of sand and the remains of two fish, one a percoid fish, the other apparently a coregonus, with scales as large as those of the fera itself. The following are the lengths of the parts of the alimentary canal.

\begin{tabular}{|c|c|c|c|c|c|c|c|c|c|}
\hline & Inches. & Lines. & & & & & & lies. & Lines \\
\hline Distance between gullet and bend of stomac & ch 3 & 0 & Distance between last cæcum & and & val & vula & & & \\
\hline of thick part of stumach & 1 & 2 & conniventes . . & . & - & & - & 2 & \\
\hline Oistance between pylorus and last cæcum . & 2 & 3 & Length of gut occupied by ditto & & & - & & 2 & \\
\hline " last cæcum and anus & 4 & 7 & , smooth gat at anus & . & - & & & 0 & \\
\hline eugth of whole canal & 11 & 0 & Length of gut below сæса & & & . & & 4 & \\
\hline
\end{tabular}

'The Vendace of Lochmaben (Coregonus vandesius) has a much larger eye than the Fera. Its lower jaw projects beyond the upper one, even when the mouth is shut. There are seventy-three scales on the lateral line. A male taken in the Solway Firth, with the melt about one-third of the full size, had some small pieces of the stems of grass and a few grains of quartzose sand in its stomach, apparently fragments of the case of the cod-bait. Mr. Yarrell has found shells in the stomachs of individuals taken in the Castle Loch, while Dr. Knox ascertained that those he examined had been feeding upon minute malacostraca. 
In the paucity of our information respecting the fish of New Caledonia, the following notices, collected from the Journal of Mr. D. W. Harmon, a partner of the North West Company, are valuable. 'This gentleman resided for several years at a fur-post on Stuart's Lake, which lies in the 55th parallel of latitude, and 125th degree of longitude, and which discharges its waters by a stream, named also Stuart, into Frazer's River, that falls into the Strait of Juan da Fuca. As his remarks upon fish relate chiefly to the Salmon tribe, this appears to be the most appropriate place for their insertion.

" 1811. May 11. Stuart's Lake. The ice in the lake broke up this afternool1. 22. We now take trout in the lake, with set lines and hooks, in considerable numbers, but they are not of a good kind. It is perhaps a little remarkable, that pike or pickarel have never been found in any of the lakes and rivers on the west side of the Rocky Mountains.

"August 2. It is impossible at this season to take fish out of this lake or river. Unless the salmon from the sea soon make their appearance our condition will be deplorable. 10. Sent all our people to a small lake about twelve miles off, out of which the natives take small fish, much resembling salmon in shape and flavour, but not more than six inches long. They are said to be very palatable. 22. One of the natives has caught a salmon, which is joyful intelligence to us all, for we hope and expect in a few days to have abundance. These fish visit, to a greater or less extent, all the rivers in this region, and form the principal dependence of the inhabitants as the means of subsistence. The natives always make a feast to express their joy at the arrival of the salmon. The person who sees the first one

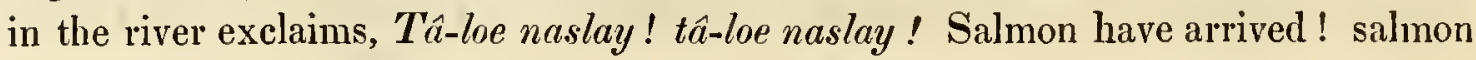
have arrived!-The exclamation is caught up with joy, and repeated with animation by every body in the village.

"Septemler 2. We bave now the Common salmon in abundance. They weigh from five to seven pounds. There are also a few of a larger kind, which will weigh sixty or seventy pounds. Both of them are very good when just taken out of the water. But when dried, as they are by the Indians here by the heat of the sun, or in the smoke of a fire, they are not very palatable. When salted they are excellent. As soon as the salmon come into Stuart's Lake they go in search of the rivers and brooks that fall into it, and these streams they ascend so far as there is water to enable them to swim; and when they can proceed no farther up, they remain there and die. None were ever seen to descend these streams. They are found dead in such numbers, in some places, as to infect the atmosphere with a terrible stench, for a considerable distance round. But even when they are in a 
putrid state the natives frequently gather them up and eat them, apparently with the sime relish as if they were fresh.

"October 21. We have now in our store twenty-five thousand salmon. Four in a day are allowed to each man. I have sent some of our people to take white fist (Attihawmeg).

"November 16. Our fishermen lave returned to the fort, and inform me that they have taken seven thousand white tish. 'They weigh from three to four pounds, and were taken in nine nets of sixty fathoms each. 17. 'The lake froze over in the night.

"1812. January 30. I have returned from visiting tive villages of the Nateotains, built on a lake of that name, which gives origin to a river that falls into Gardner's Inlet. 'They contain about two thousand inhalitants, who subsist principally on salmon and other small fish, and are all well made and robust. 'The salinon of Lake Nateotain have small scales, while those of Stuart's Lake have none.

"May 23. Stuart's Lake. This moming the natives caught a sturgeon that would weigh about two hundred and fifty pounds. We frequently see much larger ones, which we cannot take for want of nets sufficiently strong to hold them.

"August 15. Salmon begin to come up the river. Few salmon came up Stuart's River this fall, but we procured a sufficient quantity at Frazer's Iake and Stillas. These lakes discharge their waters into Frazer's River, which is about fifty rods wide, and has a pretty strong current. The natives pass the greater part of the summer on a chain of small lakes, where they procure excellent white fish, trout, and carp ; but towards the latter part of August they return to the banks of the river, in order to take and dry salmon for their subsistence during the suceeeding winter.

"1813. August 12. Salmon have arrived.

"1814. August 5. Salmon begin to come up the river. 'They are generally taken in considerable numbers until the latter part of September. For a month they come up in multitudes, and we can take any number we please.

"September 20. We have had but few salmon this year. It is only every" second season that they are numerous, the reason of which I am unable to assign.

" 1815. August 13. Frazer's Lake. Salmon begin to come up the river, which lights up joy in the countenances both of ourselves and of the natives, for we had all become nearly destitute of provisions of any kind.

" 1816. September 9. Salmon begin to come up this river.

"1817. August 6. Stuart's Lake. Salmon arrived. In the month of Junte 
we took out of this lake twenty-one sturgeon, that were from eight to twelve feet in length. One of them measured twelve feet two inches from its extreme points, four feet eleven inches round the middle, and would weigh from five hundred and fifty to six hundred pounds. All the sturgeon that we have caught, on this side of the mountain, are far superior in flavour to any $I$ ever saw in any other part of the world.

"The Carrier Indians reside a part of the year in villages, built at convenient places for taking and drying salmon, as they come up the rivers. These fish they take in abundance with little labour; and they constitute their principal food during the whole year. They are not very unpalatable when eaten alone, and with vegetables they are very pleasant food. Towards the middle of April, and sometimes sooner, the natives leave their villages, to go and pass about two months at the small lakes, from which, at that season, they take white fish, trout, carp, \&c., in considerable numbers. But when these begin to fail, they return to their villages and subsist on the small fish which they dried at the lakes, or on salmon, should they have been so provident as to have kept any until that late season; or they eat herbs, the inner bark or sap of the cypress tree (pinus Banksiana), berries, \&c. At this season few fish of any kind are to be taken out of the lakes or rivers of New Caledonia. In this manner the natives barely subsist, until about the middle of August, when salmon again begin to make their appearance in all the rivers of any considerable magnitude; and they have them at most of their villages in plenty until the latter end of September, or the beginning of October. For about a month they come up in crowds, and the noses of some of them are either worn or rotted off, and the eyes of others have perished in their heads; yet in this maimed condition they are surprisingly alert in coming up rapids. These maimed fishes are generally at the head of large bands, on account of which the natives call them mee-oo-tees, or chiefs. The Indians say that they have suffered these disasters by falling back among the stones when coming up difficult places in the rapids which they pass. The Carriers take salınon in the following manner. All the Indians of the village assist in making a dam across the river, in which they occasionally leave places to insert their baskets or nets of wicker-work. These baskets are generally from fifteen to eighteen feet in length, and from twelve to fifteen feet in circumference. The end at which the salmon enter is made with twigs in the form of the entrance of a wire mouse-trap. When four or fire hundred salmon have entered this basket, they either take it to the shore to empty out the fish, or they take them out at a door in the top, and transport them to the shore in their large wooden canoes, which are convenient for this purpose. When the 
salmon are thrown upon the beach, the women take out their entrails and hang them by the tails on poles in the open air. After they have remained in this situation a day or two, they take them down and cut them thimner, and then leave them to hang for about a month in the open air, when they will have become entirely dry. They are then put into store-houses, which are built on four posts, about ten feet from the ground, to prevent animals from destroying them, and, provided they are preserved dry, they will remain good for several years."-Hanmon's Travels in North America. 1820.

Captain Dixon, who visited the North-west coast of America in the years 1786 and 1787, on a trading expedition, in company with Captain Portlock, mentions that they took great numbers of tine salmon with the seine in Cook's River, or Inlet (lat. $60^{\circ}$ ), in the month of July, and that in the end of June, in the following season, they saw large quantities hung up to dry by the natives of Norfolk Sound, a harbour formed by the Island of Sitka, where the Russian Fur Company's establishment of New Archangel has been since erected. Eschscholtz speaks of only one sort of salmon as frequenting that Sound, and remarks that it is well-flavoured, but Captain Dixon thought it inferior to the kind which he obtained in Cook's River.

After the preceding pages had gone to the press, I received a letter from Dr. Gairdner, of Fort Vancouver, on the Columbia River, of which the following is an extract. "My duties at Vancouver prevent me from collecting many Columbia tish, as I have no leisure for journeys through the country. Such, however, as I happen to have by me, I now send you with great pleasure, for your work on North American Zoology; they are entirely fresh-water species, my travels not having as yet extended to the coast. I suljoin a short description of each. which I marle from the recent specimens, the characters, particularly those dependent on colour and dimensions, being liable to alteration by the spirits. 'The early dispatch of the vessel leaves me no time for transcribing the anatomical details." Dr. Gairrner had used the precaution of wrapping the specimens in tow previous to putting them in spirits, and of soldering them up in a tin case, which was protected by at cask, yet all this care, I regret to say, dicl not insure them against the accilents of a long royage. The tin case received some injury, and became so leaky as to suffer 
much of the spirit to run out, and the consequence was, that six specimens of salmon were incorporated into one mass by the continued motion of the vessel. The other fish, being of a smaller size, less oily, and perhaps more indurated by longer immersion in spirits, arrived in better condition. By picking the bones of the salmon out of the putrid mass, I have been able to make a few additions to Dr. Gairdner's descriptions quoted below. In all the specimens the vertebræ are more numerous than in the European species. It is to be observed, that the two or three last vertebræ of the tail diminish rapidly in size and turn up, the square form of the termination of the vertebral column in the Salmonoidea being produced by the dilatation of the interspinous bones attached to the under side of the curved point of the spine; while the corresponding upper interspinous bones are slender, awl-shaped, crowded, and irregular. The reader will find notices of the salmon of the North-ivest coast by referring back to pages 158 and 162, as well as in the passages quoted above from Harmon's Travels; and to complete the history of the fish of the Columbia, as far as known, I will add the mode of stacking the salmon, described in Lewis and Clarke's Journal. "Near our camp are five large huts of Indians engaged in drying fish, and preparing it for the market. 'The manner of doing this is by first opening the fish and exposing it to the sun on their scaffolds. When sufficiently dried, it is pounded fine between two stones, and is then placed in a basket about two feet long and one in diameter, neatly made of grass and rushes, and lined with the skin of a salmon stretched and dried for the purpose. Here they are pressed down as hard as possible, and the top covered with skins of fish, which are secured by cords through the holes of the basket. The baskets are then placed in some dry situation, the corded part upwards, seven being usually placed as close as they can be put together, and five on the top of them. The whole is then wrapped up in mats, and made fast by cords, over which mats are again thrown. Twelve of these baskets, each of which contains from ninety to a hundred pounds, form a stack, which is left exposed till it is sent to market; the fish thus preserved is kept sound and sweet for several years, and great quantities of it, they inform us, are sent to the Indians who live below the falls, whence it finds its way to the whites who visit the mouth of the Columbia. We observe, both near the lodges and on the rocks of the river, great numbers of stacks of these pounded fish." (Lewis and Clarke, ii., p. 275.) "The salmon (S. quinnat) is almost the only fish caught in great abundance above the falls; but below that place we observe the salmon-trout, and the heads of a species of trout smaller than the salmontrout, which is in great quantities, and which they are now burying to be used as their winter food. A hole of any size being dug, the sides and bottom are lined 
with straw, over which slins are placed; on these the fish, after being well dried, are laid, covered with other slins, and the hole closed with a layer of earth twelve or fifteen inches deep." (Idem, p. 278.) It is very probible that the same species of salmon may frequent the North-west coast and Kantschatka, but Steller's descriptions, as quoted by Pennant, are not sufficiently detailed to enible us to identify them.

[82.]

11. Salmo QuinNat.

The Quinnat.

Sub-genus, Salmo. Cuvier.

"This is the species which ascends the Columbia earliest in the season, commencing its run in the month of May in enormous shoals, clearing the greater Dalles, cascades and rapids innumerable, and making its way to the sources of the river, where, at the close of the season, it is found dead on the beach in great numbers. The muscular power of this fish is truly astonishing, even in a cliss of the animal kingdom remarkable for vigorous movements, for it may be seen ascending channels at the Kettle Falls so rapid, that when a stone as big as a man's head is dropped into them, it is shot downwards with the swiftness of an arrow*. Individuals of this species have often been seen with their noses fiirly worn down to the bone, and in the last stage of emaciation, yet still striving, to the last gasp, to ascend the stream. The selection of particular streams for spawning is a remarkable feature in the history of the fish. It ascends the Walamet, Snake, and Kootanie rivers, \&c., and passes by the Kawalitch, Okanagan, Dease's river and others, seeming to prefer a rapid stream interrupted by falls, to one of a quieter character, though other circumstances must regulate its choice, as some of the rivers which it refuses to enter have an extremely rapid current. It is this salmon which forms the main subsistence of the numerous hordes of Indians who live upon the banks of the Columbia, and it is known by the name of quinnat, for one hundred and fifty miles from the mouth of the river. It attains a large size, weighing often from thirty to forty pounds."-G. [The quinnat is evidently the "Common salmon" of Lewis and Clarke, whose description of it we have quoted in page 162. These travellers mention the first arrival of the salmon at the Skilloot village, below the site of Fort Vancouver, as having occurred on the 18th of April, in the year 1806. -R.]

* In the map published by the Society fur the Diffusion of Useful Knowledge, the descent at the Kettle Falls is staterl at twenty-one feet; but Lewis and Clarke were of opinion that in high floods the water below the falls rises nearly tu a level with that above them.-R. 
" Colour.-General tint of the back bluish-grey, changing, after a few hours removal from the water, into mountain-green : sides ash-grey with silvery lustre : belly white : back above the lateral line studded with irregular rhomboidal or star-like black spots, some of them occellated. Dorsal fin and gill-covers slightly reddish : tips of the anal and pectorals blackishgrey : the dorsal and caudal thickly studded witl round and rhomboidal spots, back of the head sparingly marked with the same. Whole body below the lateral line, with the under fins, destitute of spots. Lower jaw and tongue blackish-grey; roof of the mouth tinged here and there with the same. Scales large. TEETH disappearing on the mesial line of the upper jaw, one row on each palate bone, a few small teeth on the forepart of the vomer, and two rows on the tongue. Form.-Greatest convexity of the back at the origin of the dorsal; end of the caudal semilunar; adipose opposite to the posterior end of the anal; dorsal of greater height than length. Fins. $-B r .17 ; P .16 ; V .10 ; A .16 ; D .14-0 ; C .196$.

“ Dimensions.

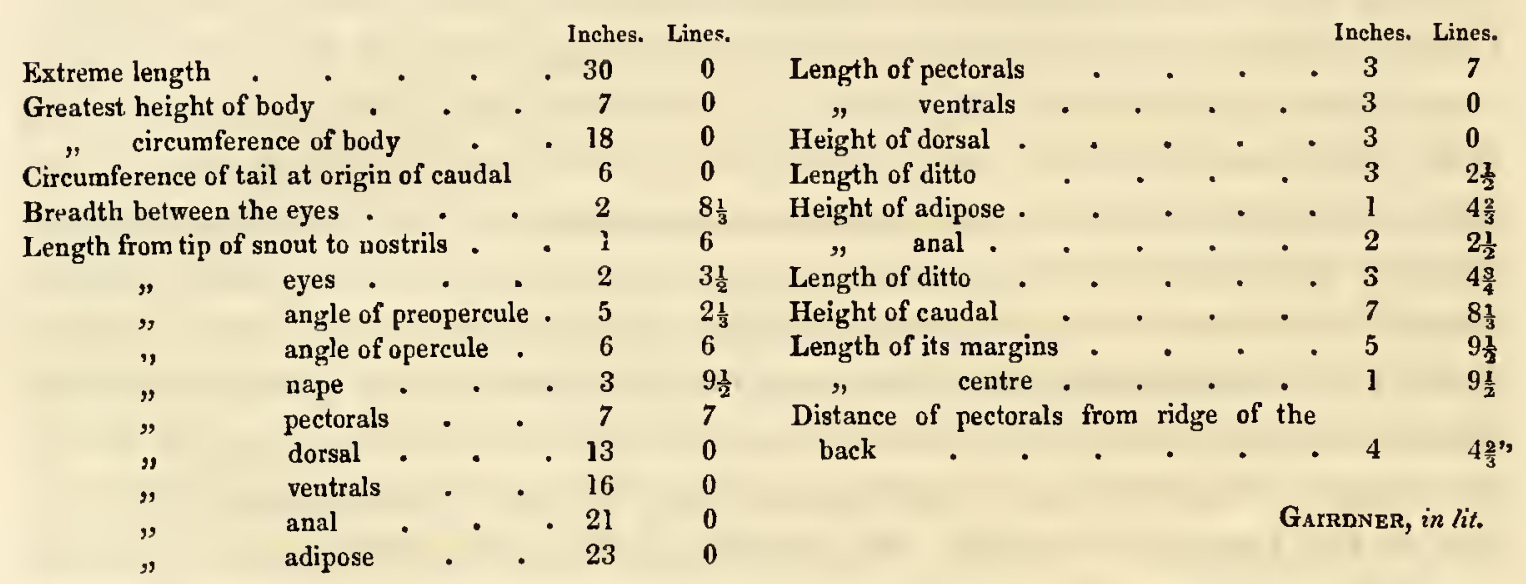

[The specimen of this salmon, though it is very soft and has lost its scales, still retains its form, so that I am able to add the following particulars to Dr. Gairdner's description.- General form much like that of a Salmon-trout (p. 140, No. 2). The head is exactly onefourth of the length, from the tip of the snout to the end of the scales on the caudal. The snout is cartilaginous as in $S$. salar, and the length of the lower jaw rather exceeds that of the upper surface of the head. The edge of the gill-plate is an arc of a circle as in that species, but the suboperculum is still more sloped off, having much the form of that of $S$. Scouleri (pl. 93). There are sixteen gill-rays on the right side, and seventeen on the left. The largest teeth are those of the under jaw, of which there are eleven in each limb, placed at regular distances, with some small ones in the intervals attached to the soft parts only. The labial and intermaxillary teeth are similar to these, and but little inferior in size. The lingual-teeth, considerably smaller than those in the jaw, are placed in two parallel rows, five in each. The palatine-teeth are a little shorter than the lingual ones, and those on the vomer are the smallest of all, scarcely protruding through the soft parts in the recent specimen: there are nine of them-two in front, the others in a single series, running upwards of half an inch 
backwards, or about two-thirds as far back as the palatine-teeth. The gullet is armed with small teeth above and below. The jaw-teeth are as big as those of the Salmon-trout, pl. 92, f. 1. There are sixty-six vertebra in the spine. The pyloric caca are very numerous, there being about one hundred and fifty-five of them, and their insertions surround the intestine from the pylorus until it makes a bend downwards, below which they continue to be inserted for a short way on one side of the gut only.

\begin{tabular}{|c|c|c|c|c|c|c|c|c|}
\hline & Inches. & Lines. & & & Inches. & Lines. \\
\hline & & Length from end of snout to tip of caudal & 15 & 6 & Lengt & of alimentary canal . & .13 & 10 \\
\hline & " end of its & central rays & 14 & 5 & $"$ & from gullet to bend of stomacl & 4 & 0 \\
\hline , & end of sea & & 13 & 5 & , & bend to pyloris & 1 & \\
\hline ", & of lateral line . & . & 10 & 10 & $n$ & pylorus to last cæcum & 3 & \\
\hline " & intermaxillaries & $\bullet$ & 0 & 8 & , & of remainder of gut & 5 & 3 \\
\hline ", & labials & . & 1 & $3 \frac{1}{2}$ & & & & \\
\hline , & lower jaw & & 2 & $1 \frac{1}{2}$ & & & & R.] \\
\hline
\end{tabular}

\section{[83.] 12. Salmo Gairdnerit. (Richardson.) Gairdner's Salmon.}

Queachts. Natres of the Banks of the Columbia*.

[The specific name which I have given to this salmon is intended as a tribute to the merits of a young though able naturalist, from whom science may expect many important acquisitions, and especially in the history of the Zoology of the Northwest coast of America, should his engagements with the Hudson's Bay Company permit him to cultivate that hitherto neglected field of observation.-R.]

" This species ascends the river in the month of June, in much smaller numbers than the quinnat, in whose company it is taken. Its average weight is between six and seven pounds.

" Colour.-Back of head and body bluish-grey; sides ash-grey. Belly white. The only traces of rariegated marking are a few faint spots at the root of the caudal. Form.-Profile of dorsal line nearly straight, tail terminating in a slightly semilunar outline. Ventrals correspond to commencement of dorsal and adipose to end of anal. Tевтн._Jaws fully armed with strong hooked teeth, except a small space in centre of upper jaw. Vomer armed with a double row for two-thirds of its anterior portion. Palate-bones also armed with strong teeth. Fins. $-B r .11-12 ; P .13 ; V .11 ; A .12$.

* From an accidental transposition of the labels, the right application of the Indian names to this fish and Salmo parcidens is somew hat doubtful. 


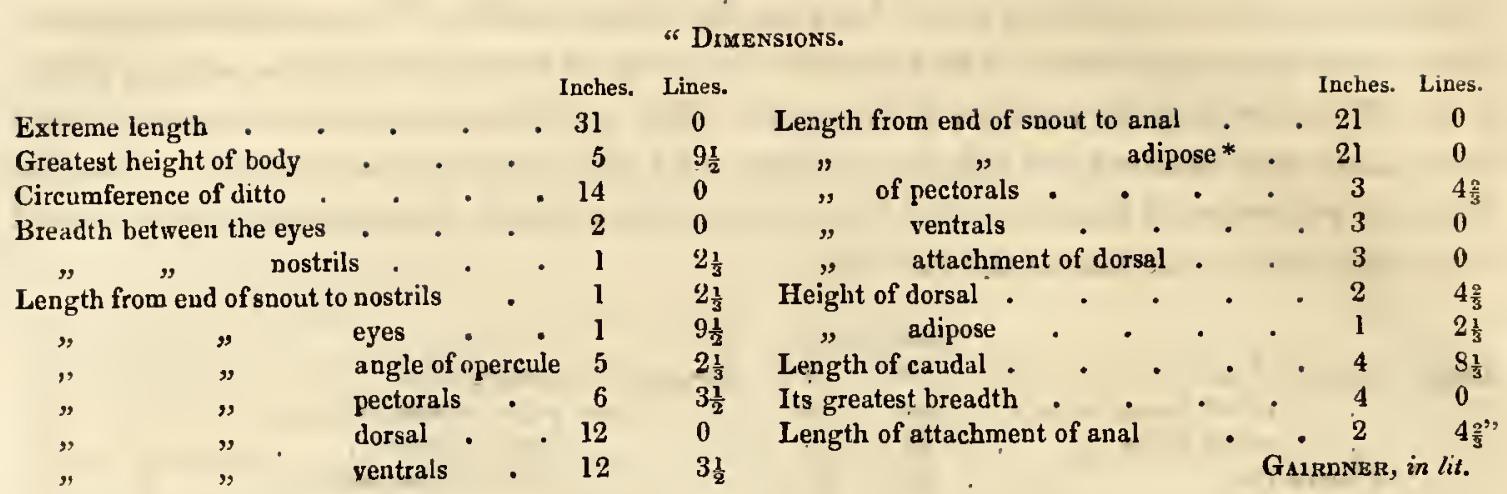

[In this species the gill-cover resembles that of $S$. salar still more strongly than that of the quinnat does, the shape of the suboperculum in particular being precisely the same with that of salur. The teeth stand in bony sockets like those of the quinnat, but are scarcely so long. Thase of the lower jaw and intermaxillaries are a little smaller than the lingual ones, and somewhat larger than the palatine or labial ones. The tongue contains six teeth on each side, the rows not parallel as in the quiunat, but diverging a little posteriorly. The pharyngeals are armed with small sharp teeth. The numbers of the teeth, excluding the small ones which fall off with the gums, are as follow : Intermax. 4-4; labials 21-21; lower jaw 11-11; palate-bones $12-12$; vomer lost ; tongue $6-6$. When the soft parts are entirely removed, the projecting under edge of the articular piece of the lower jaw is acutely serrated, in which respect this species differs from all the others received from Dr. Gairdner. There are sixtyfour vertebre in the spine. $-\mathrm{R}$.]

\section{[84.] 13. Salmo paucidens. (Richardson.) Weak-toothed Salmon.}

Quannich. Natives of the Banks of the Columbia.

"This salmon ascends the Columbia at the same time with the $S$. Gairdnerii, and in equal numbers. It is taken in company with that species and the quinnat, and has an average weight of three or four pounds.

" Colour.-Back of head and body bluish-grey; sides ash-grey with a reddish tinge; belly white. No trace of spots on the body or fins. Form.-Commissure of the mouth very oblique approaching to vertical, dorsal profile quite straight, tail forked. Ventrals corresponding to middle of the dorsal and adipose to posterior extremity of the anal. TEETH sparingly scattered and feeble on the jaws, only a few short weak ones on the anterior extremity of the vomer, and on the palate-bones. Fins.-Br. $13 ; P .17 ; V .12 ; A .17 ; D .12-0$.

\footnotetext{
* Dr. Gairdner must have accidentally put down wrong figures here in transcribing his notes, as the adipose is not oppo-
} site to the commencement of the anal, but to its end.-R. 
" Dimensions.

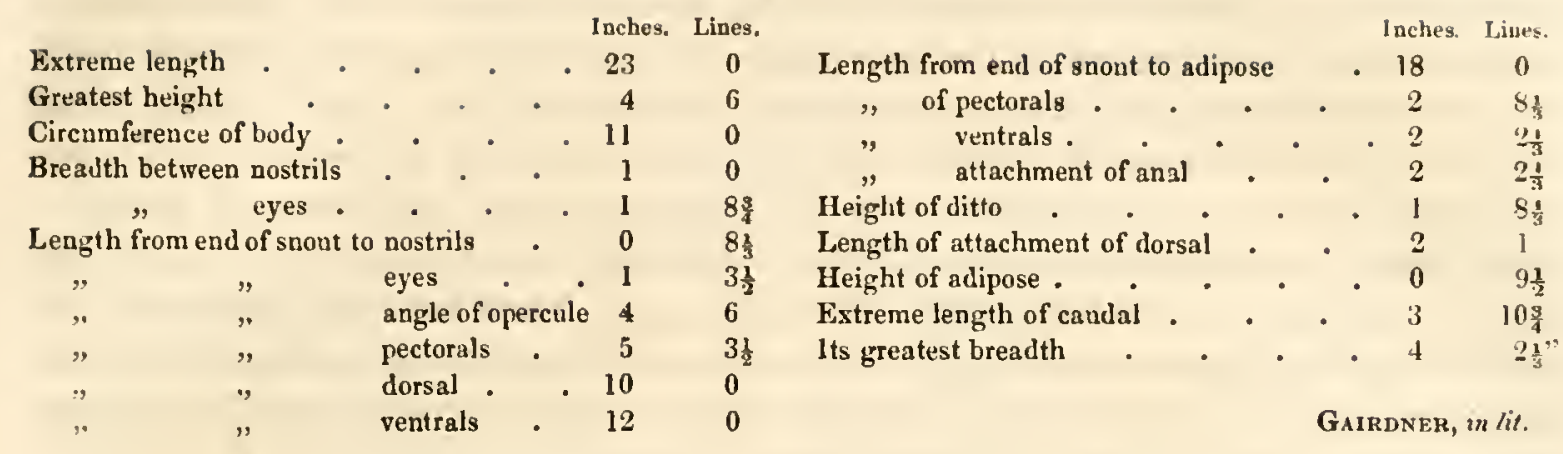

[Fron the labels having dropped off, I cannot refer the fragments of any of the specimens to this species with certainty, but, I am inclined to think that a spine, containing sixty-six vertebre, belongs to it, and if so, the gill-cover is extremely like that of S. Scouleri (pl. 93), and the bones of the head have the same fibrous structure which we have noticed in the description of that species. None of the teeth have been preserved, but those of the lower jaw appear to have been fixed in cartilaginous sockets, which have separated from the bone, learing a rough surface. The palate and upper jaw-bones are lost. The union of the branchial arches at the root of the tongue is longer and narrower than in the preceding two species, and the gill-openings consequently are more ample. Either this species or the S. Scouleri, or perhaps both, are named "Red-char" by Lewis and Clarke. See p. 162.-R.]

\section{[62.] 2. Salmo Scouleri. (Richardson.) The Ekewan.}

Salmo Scouleri, p. 158. Plate 93.

"The Ekewan, which averages thirty pounds in weight, ascends the Columbia towards the end of August and in the month of September. Its flesh is paler and of inferior quality to the four preceding kinds." [From Dr. Gairdner's description of this species I have little doubt of its being the same with the S. Scouleri of Observatory Inlet (p. 158), and I should without hesitation have referred to it the spinal column and opercular bones noticed at the close of the account of the preceding species, had not Dr. Gairdner mentioned that no specimen of the Ekewan was sent, as he had not obtained one small enough to be put in spirits.-R.]

"Colour.-Body abore mesial line smoke-grey, passing on head and tail into bluish-grey: a slight reddish tinge at the root of the dorsal and between it and the adipose. Fins bluishgrey, and all tinged with red except the caudal, which, with the back, is studded with irregular semilunar and stellated blackish-brown spots. A large vermilion-red patch in the concavity 
of the vertex, and another on the preopercule. Body below the mesial line greyish-white with a reddish tinge. Fonm.-A remarkable flattening over extremity of snout, behind which a slight concavity to occiput, where the body rises suddenly into a hump, and continues rising as far as the first dorsal, this elevated portion being accuminated into a ridge: A notch behind the point of the snout gives an arched outline to the commissure of the mouth. Lower jaw also arched upwards, so that the two jaws do not approach each other when the mouth is closed, except at the two extremities. TeEтh.-Jaws fully armed with strong hooked teeth, except a small space in the mesial line of the upper jaw. Teeth moveable, from being imbedded in soft cartilaginous sockets. Two rows of strong lingual teeth, a single row on each palate-bone, and a few rudimentary ones can be felt in a single row on the anterior extrenity of the vomer. Teeth on the pharyngeal bones. Rays. $-B r .16 ; P .16 ; V .9 ; A .16$; D. 12-0.

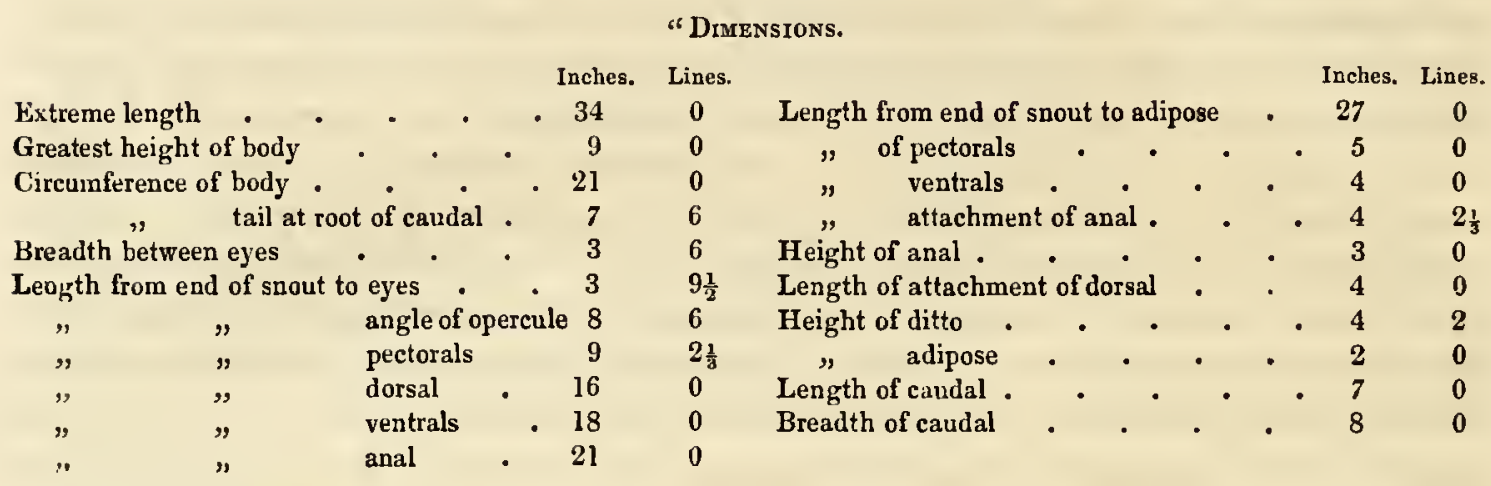

"This description applies to a female-the male differs in the upper jaw being elongated into a proboscis, which projects beyond the lower jaw when the mouth is closed : it is formed of a moveable cartilaginous mass articulated to the extrenity of the nasal bones, and is furnished with teeth as well as the rest of the jaw. The lower jaw is narrower and entirely received within the concavity of the upper one when the mouth is shut."-GAIRDNER, in lit.

\section{[85.] 14. Salmo tsuppirch. - The Tsuppitch.}

Tsuppitch. Natives of the Banks of the Columbia.

"The Tsuppitch ascends the Columbia at the same time with the Ekewan. I counted 1644 ova in the ovary of a female.

"CoLour.-Back of body and head studded with oval and circular spots: sides and fins, including the caudal, destitute of spots : back mesially bluish-grey passing on the back of the head into blackish-grey, and on the sides into yellowish-grey, with a greenish tinge and silverywhite. General colour of the fins ash-grey. TEEтн.-Jaws fully armed with minute sharp teeth, a single row on each palate-bone, a very few on the anterior end of the vomer in a single 
series, and a double row on the tongue. Form.-Hearl small, exactly conical, terminating in a pointed snout. Commissure of mouth very slightly oblique. Convexity of dorsal profile rising gradually to origin of first dorsal, and declining from thence to the tail. Caudal forked. RAYs.-Br. $13 ;$ P. $13 ; V .10 ; A .13 ; D .12-0$.

"Dimensions.

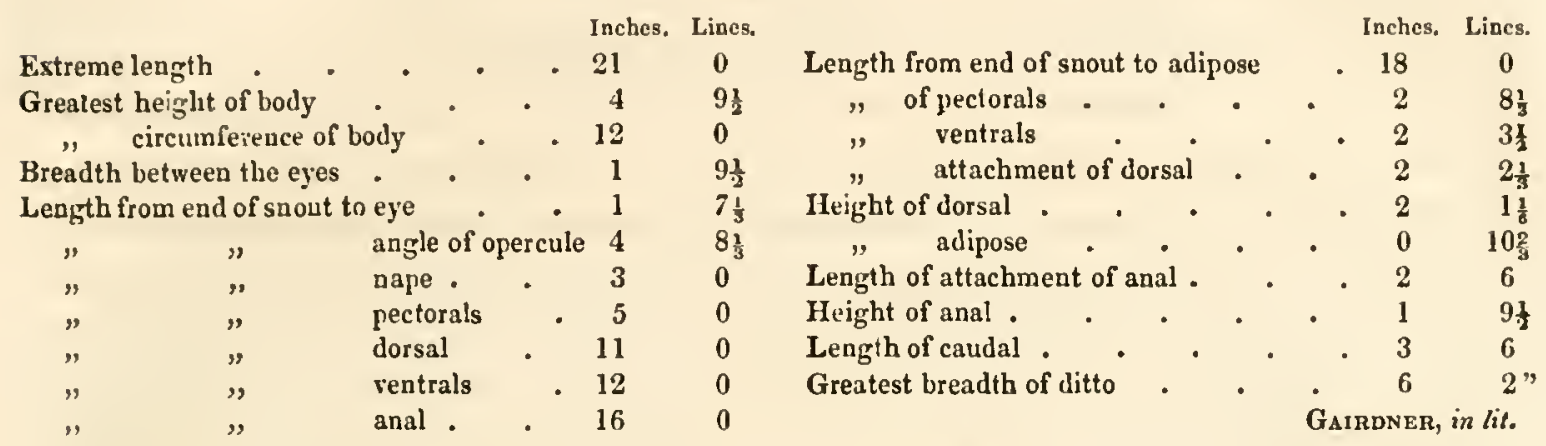

[A spine containing sixty-four vertebra, and an under jaw with ten curved teeth in each limb, are all the bones that I can with any appearance of correctness refer to this species. The teeth are of equal size with those of $S$. Gairdneri, or perhaps rather larger, and are attached to the jaw-bone through the medium of cartilage.-R.]

\section{[86.] 15. Salmo Clarkit. (Richardson.) Clarke's Salmon.}

[Dr. Gairdner does not mention the Indian name of this trout, which was caught in the Katpootl, a small tributary of the Columbia, on its right bank. I have thelefore named it as a tribute to the memory of Captain Clarke, who notices it in the narrative prepared by him of the proceedings of the Expedition to the Pacific, of which he and Captain Lewis had a joint command, as a dark variety of Salmontrout (see p. 163). In colour this species resembles the Mykiss of Kamtschatka, and there is no very material discrepancy in the number of rays in the fins. Vide Arct. Zool., Intr., p. cxxvi.-R.]

"Colour.-Back generally brownish purple-red, passing on the sides into ash-grey, and into reddish-white on the belly. Large patches of dark purplish-red on the back. Dorsals and base of the caudal ash-grey, end of caudal pansy-purple. Back, dorsal, and caudal studded with small semilunar spots. A large patch of arterial-red on the opercule and margin of the preopercule. Pectorals, ventrals, and anal greyish-white, tinged with rose-red. TеEтн.-Both jars armed with strong hooked teeth, a single row on each palate-bone, a double row on the anterior half of the romer and on the tongue. Dorsal profile nearly straight. Ventrals opposite to the middle of the first dorsal. Fissure of mouth oblique. Extremity of caudal nearly even. Fins.-Br. $11 ;$ P. $12 ;$ V. $8 ; A .13 ; D .11-0$. 


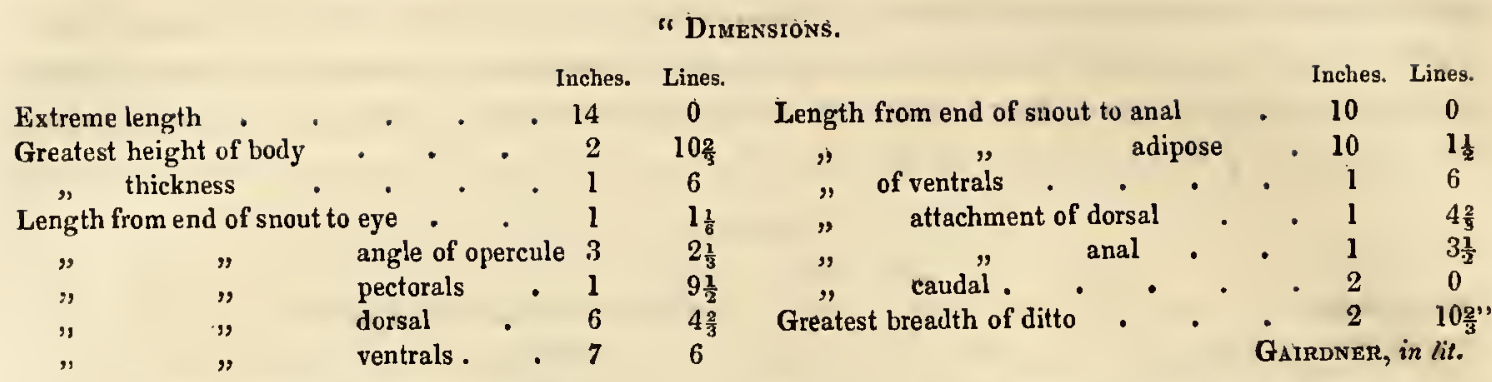

[There appear to have been two specimens of this species sent to me by Dr. Gairdner. In both the spinal column contains sixty-two vertebræ. The teeth, which are closely set, rather long, slender and acute, and, in the older specimen, considerably curved, are in number as follows: Intermax. lost; labials $28-30$; palate-bones $15-17$; vomer 13 , two in front and the others in a single flexuose series, as long as the dental surface of the palate-bones; lower jaw $13-13$; tongue $6-6$, in two almost parallel rows. The lingual teeth are the largest and most. curved, those of the lower jaw are next in size, then follow the vomerine, palatine, and labial teeth, which are equal to each other. The pharyngeal teeth are also proportionally long, and there is an oblong plate, rough with very minute ones, on the isthmus which unites the lower ends of the branchial arches. This space is quite smooth in $S$. salar, in several, if not in all the English trouts, and in S. quinnat, Gairdneri, and in the imperfect specimen which I have referred to $S$. Scouleri. In the latter the surface of the arches is also quite smooth, but in the quinnat and Gairdneri minute rough points become visible with a good eye-glass. In all the trouts the compressed rakers have their thin inner edges more or less strongly toothed. In one of the specimens of S. Clarkii the spinal column is nine inches long, in the other six.-R.]

\section{[87.] 2. Salmo (Mallotus ?) Pacificus. (Richardson.) North-west Capelin.}

Sub-Genus, Mallotus. Cuvier?

"The Indian name of this fish is Oulachan. It comes annually in inmense shoals into the Columbia about the 23rd of February, but ascends no higher than the Katpootl, a tributary which joins it about sixty miles from its mouth. It keeps close to the bottom of the stream in the day, and is caught only in the night. The instrument used in its capture by the natives is a long stick armed with sharp points, which is plunged into the midst of the shoal, and several are generally transfixed by each stroke. It is the favourite food of the sturgeon, which enters the river at the same time, and never has a better flavour than when it preys on this fish. The Oulachan spawns in the different small streams which fall into the 
lower part of the Columbia. It is much prized as an article of food by the natives, and arrives opportunely in the interval between the expenditure of their winter stock of dry salmon and the first appearance of the quinnat in May." ['This fish is noticed by Lewis and Clarke in the following terms. "The anchovy, which the natives call olthen, is so delicate a fish that it soon becomes tainted, unless pickled or smoked: the natives run a small stick through the gills, and hang it to dry in the smoke of their lodges, or kindle small fires under it: it needs no previous preparation of gutting, and will be cured in twenty-four hours: the natives do not appear to be very scrupulous about eating it when a little foetid."'-R.]

"CoLour generally silvery-white, passing on the back into a blackish tinge. Large irregular, but generally oval spots of yellowish-white and blackish-grey on the back. A bluishblack spot over each orbit. Margins of lips black. Back of head greyish-white. Minute black dots on the silvery basis of the cheeks. Form.-Head small and pointed. Large suborbital covering the greater part of the cheek. Opercule terminating in a thin rounded angle. Mouth opening obliquely upwards, its fissure extending as far back as the anterior margin of the orbit. Lower jaw projecting beyond the upper one, and terminating in a rounded knob turned slightly upwards. Margins of upper jaw entirely formed by the intermaxillaries, on which there are a few minute setæ in place of teeth. Lower jaw, vomer and palatines devoid of teeth. Tongue rough, and pharyngeals armed with teeth. Fins. $-B r .8 ; P .11 ; V .8 ; D .11-0$; A. 20. Adipose fin thin and containing little fat. Lateral line straight and continuous.

"Dimenstons.

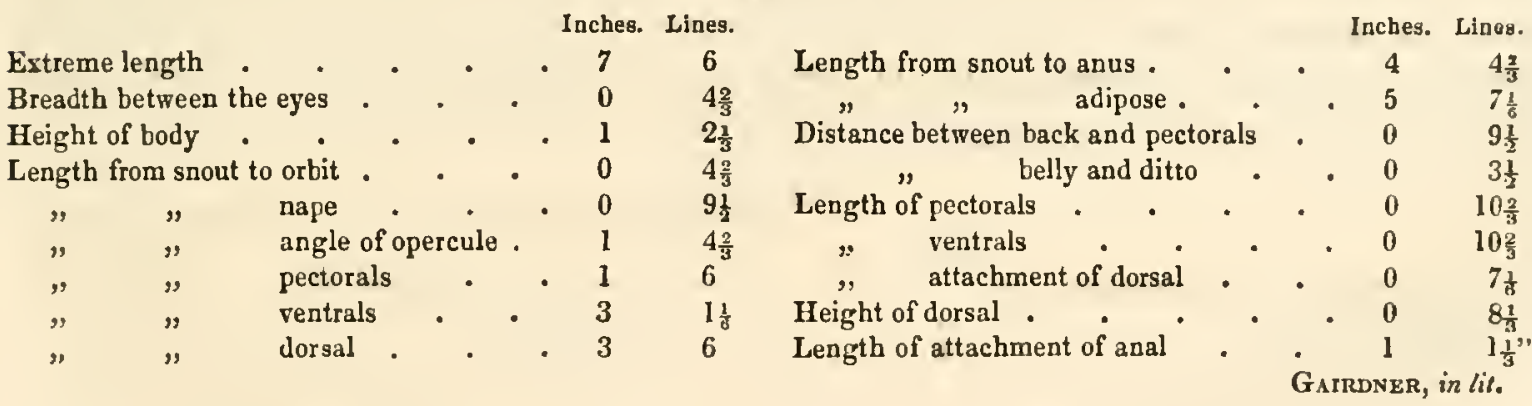

[Five specimens were sent to me by Dr. Gairdner, but they were unfortunately all so much injured that I can add very few particulars to that gentlenan's brief description. In the general form, the appearance of the scales, the black specks on the head and body, the form of the anal and its attachment to a compressed projecting edge of the tail, the structure of the lower jaw and gill-covers, and in the shape of the head as far as it could be ascertained, this fish closely resembles the capelin (p. 187). On the other hand the ascent of the species into fresh water to spawn, and perhaps its dentition, ally it to the smelt (p. 185). Head as in the capelin, forming one-fifth of the length between the tip of the snout and end of the central caudal rays. Caudal forked. Dorsal commencing a very little anterior to the middle between the tip of the snout and end of scales on the caudal, agreeing, in this respect, more nearly with the 
smelt than with the capelin, in which the dorsal is farther back, its first ray being equidistant from the end of the snout and the extremity of the central caudal ray. Anal of one specimen containing twenty-one rays. Gill-covers thin, papery, and flexible, lined with nacre. In drying, the surfaces of the opercular-bones are marked with wrinkles parallel to their sides, as may be observed in the smelt and capelin, but not so conspicuously. These wrinkles are most evident on the square operculum. As the thin lining of the mouth and lips is mostly abraded, from the putrescency of the specimens, the dentition can be only imperfectly ascertained from them. In four specimens no teeth whatever can be discovered; but in a fifth, a female full of mature roe, the lower jaw is armed with a single series of very slender, curved teeth, rather more distant, and a little longer than those of the capelin. There is also a solitary tooth remaining on the vomer of the same specimen, occupying the place of the exterior vomerine tooth in the smelt, and nearly as large. Tongue conical as in the smelt, and not presenting an oval flat surface surrounded with teeth like the capelin. In all the specimens the upper jaw was so much injured that its structure could not be ascertained, but it is probable that the intermaxillaries, being small as in the capelin, were not distinguished from the labials by Dr. Gairdner, in his examination of the recent fish. The rakers of the branchix are long and slender as in the smelts and capelin. The stomach resembles that of the capelin: the descending portion ends in a pointed sac, and a short branch which it gives off in the middle terminates in the pylorus. The intestine makes a bend, or rather twist, downwards at the pylorus, and runs straight to the anus, its calibre gradually becoming less as it approaches the latter. There are nine cæca, three of them rather shorter than the others close to the pylorus, the other six, inserted in a single series down one side of the intestine, are each half an inch long. In three specimens there are sixty-eight vertebræ in the spine, and in two sixty-nine. A male specimen, with the melt half grown, showed no traces of villi, or altered scales, on the lateral-line, though the skin was apparently entire in that place. Male capelins, destitute of the ridges of elongated scales, are occasionally taken in Greenland. (See p. 187.)

\section{Dimensrons.}

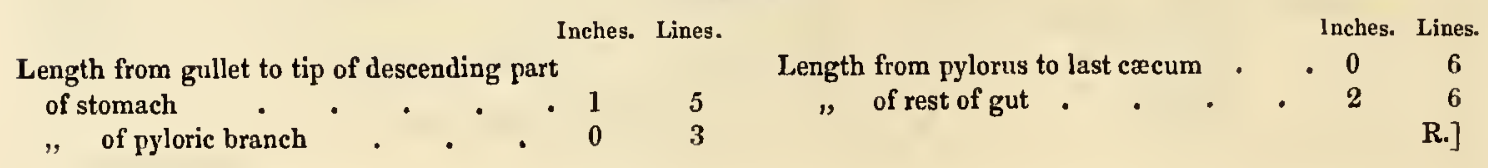




\section{CLUPEOIDEA.}

THE members of this family may be at once recognised by their having jaws similar in structure to those of the trouts, but no adipose fin. Their bodies are always very scaly. The greater number possess an air-bladder and numerous cæca. Only some species ascend rivers. The following are indicated in the Règne Animal as frequenting the shores of the United States. Alosa vernalis (Spring-herring, or Alewife, Mıтсн.), A. astivalis (Summer-herring, Мгтсн.), A. menhaden (Bony-fish, Hard-heads, or Marsh-bankers, Miтch.), A. matowaka (Long Island-herring, Mrтch.), Chatöessus oglina (Megalops oglina, Le Sueur), Ch. Cepediana (Megalops Cepediana, Le Sueur), Elops Carolina, Butirinus vulpes (Catesby, t. 1, f. 2), Hyodon clodalis, H. tergisus (Le Sueur), Amia calva, Lepisosteus rostratus (Esox osseus, Linv.), and L. spatula. Dr. Mitchill mentions in addition to these Clupea halec, pusilla, parvula, indigena, vittata, ccerulea, alosa, mediocris, and sadina, the last being an Engraulis, and the two which precede it Shads. Dr. Smith gives Clupea minima in his list of Massachusetts fish, and M. Rafinesque's uncertain genera of Pomolobus, Dorosoma, and Notemigonus, are founded on Ohio fish, which Cuvier thinks are more or less nearly allied to the Alosa. The Engraulis encrasicholus has a place in the Fauna Gronlandica of Fabricius, from having been found in the stomachs of seals killed in Davis' Straits far from the shore. All the specimens he saw were much mutilated, and the species therefore must be doubtful.

[88.] 1. Cuupea harengus. (Linn.) The Common herring.

Fasury, Clupeoidex. Gevos, Clupea. Lins. Sub-genus, Clupea. Cuvier. Clupea harengus. Fabricius, Faun. Granl., p. 182. Rich., Fr. Journ., p. 716. Kapiselik. Greenlanders.

In the herrings a small portion only of the upper jaw consists of the short, narrow intermaxillaries, its sides, which are alone protractile, being formed by the comparatively long labials; the acute rim of the belly has the scales arranged like the teeth of a saw. The labials are moreover divisible into three pieces, the gill- 
openings wide, the branchial rakers long, slender, and closely set, the stomach forms an elongated sac, the cæca are numerous, the air-bladder is long and pointed, and the ribs are more numerous and slender than in other fish. The True herrings, constituting the sub-genus clupea of Cuvier, have their labials curved anteriorly, and divisible longitudinally, into several pieces, the orifice of the mouth of a middle size, and no notch in the upper lip.

Peunant describes the Common herring as so abundant on the coast of Carolina, that the inhabitants fling it ashore by shovels-full, but he at the same time expresses a doubt whether it be of the same species with the European fish of the same name; and it is indeed evident that this is not the case, for he says that it leaves the salt water in March, and runs up the rivers and shallow streams in such numbers that the passengers trample many under foot in crossing the fords. It is not the habit of the Common herring to enter fresh waters, but several species of shad are known to ascend the American rivers. The clupea harengus is, however, included by Schöepf and Dr. J. V. C. Smith in their respective lists of the fish of New York and Massaclusetts; and popular writers on the British American colonies have mentioned, without hesitation, its existence in the seas of Newfoundland and Nova Scotia; yet it is not noticed by Dr. Mitchill. Fabricius says it is rare on the Greenland coast and in Davis' Straits, and that it is but of a small size in those seas, its length not exceeding five inches and a half. The herring of the Kamtschatka seas, mentioned in the description of that country, is, if we may judge from its habitually entering rivers, most probably a shad*; but $\mathrm{Mr}$. Collie observed a clupea, which he referred to harengus, pretty abundant in Awatska Bay; it was of a small size, and had a ventricose belly.

'The migrations of the Common herring have been greatly celebrated by ichthyological writers, and the reader will find in Pennant's British Zoology a very circumstantial and highly interesting detail of its hybernation within the arctic circle, and of its issuing thence in the spring in a mighty army $\dagger$, composed of countless multitudes, the vanguard appearing off the Shetland Islands in April and May, and the main body following in June, when it separates into two wings; one proceeding

\footnotetext{
* " The herring, both the common and the variety, found in the Gulf of Bothnia, called membras, and by tlie Swedes ströeming, visit these coasts in shoals, perhaps equal to those of Europe. There are two seasons, the first about the end of $\mathrm{Mlay}$, the second in October. The first species are remarkably fine and large; they ascend rivers, and enter the lakes : the autumnal migrants are clused up in them by the shifting of the sand at the mouths of the entrance, and remain confined the whole winter. The natives catch them in summer in nets ; and in winter in most amazing numbers, by breaking holes in the ice, into which they drop their nets, then cover the opening with mats, and leave a small hole for one of their companions to peep through and observe the coming of the fish, when they draw up their booty, and string part on packthread for drying; and from the remainder they press an oil white as the butter of Finland."-PENN., Arct. Zoor. Intr., p. cxxvi.

$\dagger$ From Pennant we learn the name of the herring is derived from the German word heer, signifying an army.
} 
to the westward, supplies the Hebrides, and moving onwards to the north of Ireland divides into two columns, which take different sides of the island; the other wing, seeking the eastern coasts of Britain, and filling every bay and creek in its progress, passes through the English channel, and, like the western phalanx, disappears in the expanse of the Atlantic. The whole of this account is now supposed to be imaginary by naturalists, who assert that the herring fattens in the depths of the ocean, and approaches the shore in shoals merely for the purpose of depositing its spawn. Cuvier, however, says " this celebrated fish quits the northern seas every year in summer, and descends upon the western shores of France in the autumn in numberless legions, or rather in dense shoals of incalculable extent, which spawn by the way, and arrive, greatly attenuated, at the mouth of the channel in the middle of winter. The fattest are those which are taken farthest to the north; when they reach the coast of Lower Normandy they are empty, and their flesh is dry and disagreeable." 'The herring is unknown in the Mediterranean.

On Sir Joln Franklin's first expedition we took several individuals of a clupea in Bathurst's Inlet, on the 5th of August, 1821, which I supposed to be the Common herring. In the absence of specimens I can only subjoin the description which was drawn up on the spot, although it is too general to serve the purpose of identifying the species. In the European herring the teeth on the intermaxillaries and lower jaw are sufficiently conspicuous, but none were perceptible on these bones in the Bathurst Inlet fish, whose characters, as far as noted, agree in all other respects with those of clupea harengus.

\section{DESCRIPTION}

Of a recent herring taken in Bathurst's Inlet, August 5, 1821.

Form.-Head conical in profile, its not very acute apex being formed by the tip of the under jaw, which extends about two lines beyond the upper one. Eyes large, and situated laterally at an equal distance from the nape and tip of the snout. Nostrils a snall elliptical opening on each side, lying transversely on the upper surface of the nose, and not risible when the fish is viewed in profile. Gill-covers and sub-orbitar bones covered with nacre. The intermaxillaries form about one-fourth of the margin of the upper jaw : the labials are broad, and their anterior edge is elliptically curved and minutely serrated or toothed; a process runs behind the narrow limb of the intermaxillary to be articulated to the snout, and there are two other pieces or processes imbedded in the fine membrane that forms the anterior portion of the parietes of the mouth: when the mouth is shut, the labials lie upon the broad limbs of the lower jaw, which are composed of plates having the thinness and nacry appearance of the sub-orbitar bones. The narrow, membranous lower lip, which folds over the edge of the lower jaw, is stretched out by the opening of the mouth. The edge of the labials is 
finely toothed, and a cluster of minute teeth exists on the vomer, but none can be perceived on the intermaxillaries or lower jaw. The gill-membrane, thick and nacry, contains eight rays, of which the posterior ones are flat, and the penultimate one ends in a transparent obtuse point.

Fins.-Br. $8 ; P .16 ; D .19 ; V .8 ; A .16$.

The dorsal commences rather posterior to the middle of the fish, excluding the caudal: its two anterior rays are short, and closely applied to the base of the third, the others are forked. 'The ventrals are small and opposite to the middle of the dorsal. The anal is half an inch high anteriorly, and gradually lowers to half that height: its attachment is almost twice as long as the space betwixt it and the caudal. The latter fin is large, cuneiform, and deeply forked.

CoLour.-The back, when moved in the light, yields various beautiful reflections of green and gold; the belly and sides are white, with pearly lustre and violet reflections, and the sides of the head are deeply tinged with gold-yellow. Scales readily deciduous, large, thin, and orbicular, possessing much nacry lustre*.

InTEstines (but cursorily examined).-Stomach forked, the blind side rather longer than the other. A considerable number (between fourteen and twenty?) of long, slender caca surround the pylorus + . Air-bladder thickly covered with nacre. Roe slightly developed.

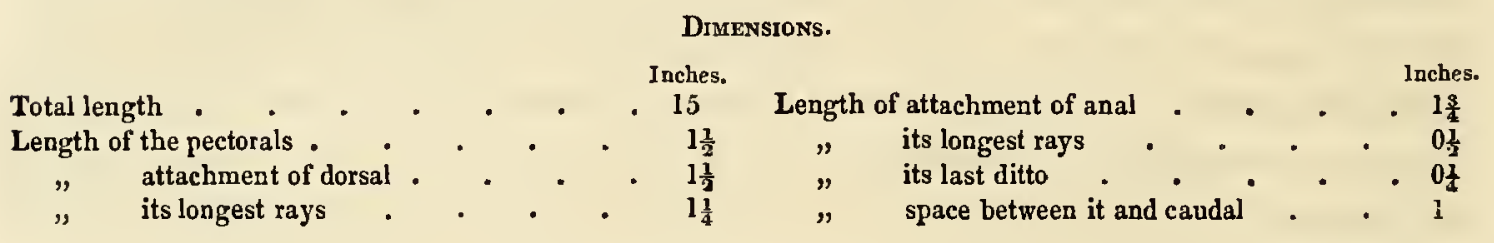

\section{[89.] 1. Hiodon chrysopsis. (Richardson.) The Naccaysh.}

Family, Clupeoidex. Cuvier. Genus, Hiodon. Le Sueur.

Hiodon clodalis. Richardson, Frank. Journ., p. 710, excl. syn.

Oweepeetcheesees. Crees. Gold-eye, Fur Traders. Naccaysh. Voyageurs.

This singular and beautiful little fish inhabits the lakes which communicate with the Saskatchewan, in the 53rd and 54th parallels of latitude, but does not approach nearer to Hudson's Bay than Lake Winipeg. In my account of the fish obtained on Sir John Franklin's first expedition, I considered this species to be the same

\footnotetext{
* Few of the distinctive characters of the Common herring, enumerated in the Règne Animal, are comprehended in the above description :-They are "La carène du ventre peu marquee, le subopercule coupt en rond; des veines sur le sous-orbitaire, le prépercule et le haut de Copercule. Ses ventrales naissent sous le milieu de la dorsale, la longueur de sa tête est cinq fois dans sa longeur totale, et en portant en arrière le distance de son museau à sa première dorsale, on atteint le milieu de la caudale. Son anale a seize rayons." P. 318.

+ Artedi says the cæca are sixteen or seventeen in number.
} 
with the Hiodon clodalis of the Ohio, described by M. Le Sueur; but a more careful consideration of his figure and description has induced me to give a distinct specific name to the northern fish *.

The Naccaysh is taken during the summer months only, and in small numbers, in the gill-nets set for other fish. It bites eagerly at an artificial fly or worn, but angling is seldom practised in the fur countries. Its flesh is white, resembling that of the perch in flavour, and excelling it in richness. 'The want of an adipose fin separates the Naccaysh from the Salmonoider, with which it seems, in some respects, to have a greater affinity than with the Clupeoilex: it differs from both in having only one cæcum.

\section{DESCRIPTION}

Of the recent fish taken at Cumberland House, lat. $54^{\circ}$ N., May, 1820.

Form.-Profile sub-oval, the belly more curved than the back; tail much narrower than the body, its under margin joining the curve of the belly by a considerable slope which is occupied by the anal fin. Body greatly compressed; thickest above the lateral line, and thinning gradually into the very acute even edge of the belly: the back thins off more suddenly, but its ridge is less sharp than the rim of the belly. The head likewise is mitch compressed and has a conical profile, the snout forming an obtuse apex. The vertex is covered with smooth skin, and there is a large scale on each side of the nape. The large eye approaches very close to the margin of the mouth. The nostrils are placed above the level of the eye in the triangular space between the orbit and tip of the snout: the membranous border of the anterior opening forms a lid to the posterior one. The whole cheek is covered by the nearly circular plate of the infra-orbitar bones. Gill-openings large; gill-plate edged by a narrow, somewhat cartilaginous border. The mouth has a wide orifice which clescends obliquely as it

* The following is M. Le Sueur's character of the genus:-

"CHar. Body as in the genus Clupea, but without the carinated abdomen. Tongue supplied by the os hyoides, which is furnished with strong teeth. One dorsal fin. Eyes very large."- "Body compressed as in the herrings, but without abdominal serratures. Head narrow; snout very slort, obtuse, without scales; posterior sulmorbits covering the cheeks, anterior ones concealing the maxillaries; preoperculum large, triangular, curving under the throat, its posteriur angle rusuded, corering almost the whole of the suboperculum; the interopercuhm very small, squamiform; operculum large. rounded, having a nutch in its upper part. Eyes very large, siruated near the end of the snuut, and nearly occupying the space between the summit of the head and the angle of the month; they are furaished with a gelatinuus, nictitating inembrane, which extends on a part of the operculum. Nostrils double, placed at the end of the snout, above and near the intermaxillaries. Mouth of a mildling size, jaws sub-equal; intermaxillaries short, articulated with the maxillaries, both very narrow. Teeth cunic, equal, close set, in a single row on the maxillaries and intermaxillaries; strunger and in several rows on the lower jaw ; very fine on the palate; the vomer equally furnisbed with several ranges of very strong ones on its whule length. Tongue supplied by the os hyoides, which is armed with two principal raws of very strung, bent, conic teeth, betweeu which there are several rows of very sinall teeth. Branchiostegous rays sliort, superior ones enlarged at their exiremities, of the number of eight or nine; branchial arch furnished on each sile, anteriorly with denticulations (rakers) which interlack one with the other. Air-bladder long, compressed; twa small globular air-vessels placed each in al cavily under and on each side ot the cavity of the cranium: these appear to enable the fish to rise with facility to the surface of the water to lake its prey. It was not ascertained whether they communicated with the bladder or not. Fins: a single dorsal, placed opposite to the commencement of the anal; pectural placed low, near the opercula : ventrals midway between the peclorals and anal. Scales large, pellucid at the edges, easily deciduous." LE Surur, $l$. $c$. 
runs backwards. The intermaxillaries and labials form nearly equal portions of the upper jaw : the former are almost immoveable, but the ends of the latter are thrust forward a little as the mouth opens. Lower jaw strong.

TeEth conical, in a single row on the intermaxillaries and labials, those on the former being considerably the largest : there are two rows having their points inclined backwards on the lower jaw, with an intervening narrow bony surface covered with minute teeth. The vomer projects from the roof of the mouth and is armed like the lower jaw. The palate-bones are rough with minute teeth. The tongue is furnished on its margins with hooked teeth which are the largest of all, and its centre is occupied by a crowd of small curved ones ("dents en carde"). Club-shaped cartilaginous rakers, rough with teeth, stand in double rows on the anterior edges of the branchial arches; and at the union of the arches, both above and below, there are thin plates covered with small teeth. The thick gill-membranes contain nine small cylindrical rays : the left membrane overlaps the right one at their insertion into the isthmus.

Fins.-Br. $9 ; P .12 ; V .7 ; A .34 ; D .11 ; C$.

The first ray of the pectorals is considerably stronger than the others. The ventrals, situated half way between the pectorals and anus, are small and contain seven rays, which support a delicate membrane. The anal, occupying the whole of the upper slope behind the anus, contains thirty-four rays, which become successively shorter as they are more posterior: the edge of the fin is slightly waved. The small dorsal, opposed to the anal, contains eleven rays. The caudal is crescentic, its lower lobe being rather the largest.

Scales irregularly orbicular and large, being about half an inch in diameter; when in situ they have a bluish-grey colour at the base with bright silvery tips. The irides and sides of the head are tinged with honey-yellow. The lateral line is straight till it passes the dorsal fin, when it is slightly deflected.

INTESTINES.-The æesophagus is distinguished by its more delicate and whiter internal folds from the stomach, which is a long tube that makes a curve at its fundus, and has its lining disposed in nine or ten longitudinal folds of a reddish colour: its pyloric orifice is much contracted. Immediately below the pylorus the intestinal canal dilates considerably, after which it forms a tube of equal diameter throughout, and nine inches long, without any distinct rectum : its lining is villous and destitute of valvula conniventes. An obtuse cacum, threequarters of an inch long, opens into one side of the dilated intestine next the pylorus, and the gall-duct into the other side. The thin fæces of the lower intestine have a honey-yellow colour. The alimentary canal makes one convolution in its course from the œsophagus to the anus. The oblong liver lies mostly on the right side, there being merely a small lobe on the left: it has a reddish-orange colour. There are two small spleens. The air-bladder is capacious and communicates with the cesophagus. The kidneys are bluish-grey, thickly studded with dark brown specks. The lining of the abdomen is of a pearly hue, and the roe pure white. 


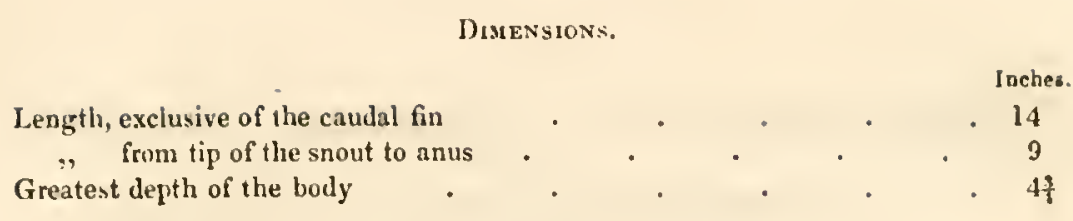

Observation:- The hiodon clodalis, obtained by M. Le Sueur at Pittsburgh, on the Ohio, differs from the preceding, according to his description and figure, in the snout being manifestly shorter than the lower jaw, in the smaller depth of the body and less-arched betly, in the lateral line being slightly curved before the dorsal, and not deflected posteriorly, and in the number of the rays of the fins, which are as follow: $P .13 ; V .7 ; A .30 ; D .15$. M. Le Sueur thinks it possible that the hiodon clodalis may be the same species with the tergisus described below, the notched fin being merely a sexual difference. My description of the naccaysh was drawn up at Cumberland House before I had seen M. Le Sueur's account of the genus, and I have had no opportunity since of examining specimens from the United States, otherwise I might have been able to point out the distinctive characters more clearly.

\section{[90.] 2. Hiodon tergisus. (Le Sueur.) Notch-finned Hiodon.}

Hiodon tergisus. Le Sueur, Juurn. Ac. Sc. Phil., i., p. 366. An. 1817.

Fresh-water herring. UNited States, apud vulgos.

This species was found by M. Le Sueur at Buffalo, on Lake Erie, and by Mr. 'I. Say at Pittsburgh, on the Ohio. M. Le Sueur gives the following description of it :-

"Spec. Char. Anal fin large and rounded on its anterior part, very narrow on its posterior part, notched in the middle."- " CoLour of the gill-covers golden, eyes brown and golden, back bluish, sides silvery, and fins yellow with metallic reflections on the rays.

"Form.-Body lengthened, elevated; back almost straight and parallel to the abdomen; tail narrow. Lateral line slight, arched towards the back. Dorsal subquadrangular, elevated on its anterior part, the three first rays simple, the last double, the intermediate ones divided. Pectorals falciform, pointed, placed horizontally in a longitudinal depression. Ventrals large, somewhat rounded at their points, and furnished with a squamiform appendage at their base. Anal long, with pretty strong divided rays, the last one double, the three first simple. Caudal forked, lobes pointed, equal. RAxs. $-B r .9 ; P .13 ; V .7 ; A .32 ; D .15 ; C .187$. Length thirteen inches." --LE SuEur, $l$. $c$. 
[85.] 1. Amia ocellicauda. (Richardson.) Marsh-fish.

Poisson de marais. Canadians.

The genus Amia stands next in the Règne Animal to Erythrinus, which it is said to resemble in the jaws and teeth, the hard osseous plates that cover the head, the large scales, and flat gill-rays*, which are, however, twelve in number. Between the limbs of the lower jaw there is a kind of osseous shield, which exists also, though but in a rudimentary form, in megalops and elops. Behind the conical teeth there are others like small paving stones, and the dorsal, which commences between the pectorals and ventrals, extends nearly to the caudal: the anal, on the contrary, is short. The nostrils have each a little tubular appendage. The stomach is capacious and fleshy, the gut wide and strong, without cæca, and, what is remarkable, the air-bladder is cellular like the lung of a reptile. Only one species, the amia calva, has been hitherto described; it feeds upon craw-fish, and inhabits the rivers of Carolina, probably not ranging far north, as it does not occur in the published lists of the New York or Massachusetts fish.

Mr. Todd sent me a notice of a Lake Huron fish, named locally Poisson de marais. It is speared by the Indians in the rushy shallows which it frequents, but is seldom eaten by the settlers. A specimen which Mr. Todd prepared, being unfortunately destroyed by vermin, never reached me, but his short description corresponds with the characters of the genus Amia, though the gill-rays are fewer than in the Carolina species.

"Poisson de marais-Order, Авdominales." — "Back and sides dark, belly and fins dark green. Head short, flattened at top and on the sides; eyes small ; jaws even ; mouth capacious; tongue obtuse. Two short cirrhi on the upper lip, the lower lip notched. One row of sharp longer teeth on the margin of the jaws, more interiorly shorter clustered ones; two patches of teeth on the upper part of the gullet. Pectorals near the throat. Ventrals about the middle of the fish. One anal. One dorsal extending from four inches behind the neck to the tail, which is oblong and round, with an irregular round spot of the size of a shilling, bordered with scarlet at the base of the seven upper caudal rays. Scales large, semicircular, and membranaceous exteriorly; square where inserted into the skin. The intestines make three longitudinal turns in the abdomen. Rays. $-B r .8 ; P .17 ; V .7 ; A .9 ; D .48 ; C .22 .{ }^{.}$ Todp, in lit.

* "The Erythrini, like the rest of the Clupeoidea, have small intermaxillaries, the greater part of the sides of the upper jaw being formed by the labials; a row of conical teeth occupies the margin of the jaws, and anteriorly there are some large ones mixed with the others. Each palate-bone is furnished with two plates of teeth like velvet-pile; and there are five broad gill-rays."-Règne Animal. 


\title{
[86.] 1. Lepisosteus Huronensis. Northern Mailed-fish.
}

\author{
Fasilu, Clupeoideæ. Genus, Lepisosteus. Lacḱpede, Cuvier
}

In this genus the intermaxillaries, labials, and palate-bones, united to the vomer and ethmoid, form a long snout, the under jaw is equally long, and the whole interior surfaces of both are rough like a file with minute teeth, their margins being armed with long pointed ones. The gill-covers are joined on the throat by a common membrane, which is supported on each side by three rays. The body is invested with scales of a stony hardness; the dorsal and anal are opposite to each other and far back. The two exterior rays of the caudal, and the anterior ones of the other fins, are furnished with scales whose projecting edges produce serratures. The stomach is continuous with a slender intestine which makes two folds and has many pyloric cæca. The air-bladder, which is cellular as in Amia, extends the whole length of the abdomen. The Lepisostei acquire a large size, and their flesh forms an agreeable article of diet. They abound in the rivers and lakes of the warmer parts of America.-Règne Animal.

The Northern Mailed-fish inhabits Lake Huron, where it is speared by the natives in the marshy inlets during the summer season. It also exists in Lake Ontario, from whence a specimen, now in the York Museum, was brought by Captain C. Dalton. La Hontan mentions it in the following terms: "Le Poisson armé est de trois pieds et demi de longueur ou environ; il a des écailles si fortes to si dures qu'il est imopossible qu'aucun autre poisson puisse l'offenser; ses ennemis. sont les Truites et les Brochets, mais il sait très-bien se défendre contre leur attaque par le moyen de son bec pointu qui a un pied de longueur*, et qui est anssi dur que sa peau. Il est delicat, et sa chair est aussi ferme que blanche." The safety of this fish depends more on its defensive than on its offensive armour, for, notwithstanding the power ascribed to its beak by La Hontan, its jaws are too feeble to enable it to assail a large trout or pike with advantage. The general resemblance of its bill to the muzzle of a gavial is very striking, and it is probable that, like that animal, it retains its prey in its jaws till life is extinguished. The under jaw being, however, articulated before the orbit, where there is no space for a strong muscular apparatus, it cannot, like the crocodiles, whose under jaw is pro-

* An individual three feet and a half long would have the head and bill together a foot long, if proportional to our specimen. 
longed behind the cranium, master animals capable of making strong efforts to escape. A specimen of the Northern Mailed-fish, which was prepared for me by $\mathrm{Mr}$. Todd, at Penetanguishene, having been sent to Cuvier, was returned with the following remark, "Esox osseus, LiNn. Lepisosteus rostratus, Nов. ;" but M. Agassiz, who has studied this genus of fishes with great diligence, in connexion with the closely-allied fossil tribes, is of opinion that the Lake Huron Lepisosteus is a distinct species from the more southern one described by Linnæus, and Mr. Gray has kindly supplied me with a note of the specific peculiarities which he drew up at M. Agassiz's request.

\section{DESCRIPTION}

Of a dried specimen from Penetanguishene, on Lake Huron.

Form.-Body elongated, roundish, fusiform, slightly flattened on the back, belly, and sides; deepest at the ventrals, where its vertical diameter exceeds its thickness by about a ninth part. In profile the back is slightly arched. Head four-sided, its breadth greater by onethird than the height of the gill-covers : it is even and flat above and on the sides, which taper gradually into a narrow beak, more than twice the length of the rest of the head. The whole surface of the head and bill is bony, finely furrowed and granulated, except the gillmembrane, and its prolongation forwards between the limbs of the lower jaw: the sutures of the bones are very evident. Orbits circular, situated close to the articulation of the lower jaw, and thrice their own diameter from the edge of the gill-plates. Nostrils close to the end of the bill, the posterior orifices on the dorsal aspect, the anterior ones lateral. Cheeks altogether behind the orbit, covered by about twenty polygonal plates, resembling the rest of the surface of the head, and concealing the preoperculum and infra-orbitar bones. Edge of the gill-cover semi-oval: suboperculum and operculum nearly of equal size: interoperculum larger than either and nearly as broad. Bill flat, or very slightly rounded on its upper surface, which is formed by the ethmoid bone bordered on each side by the long narrow labials, the blunt tip being composed of the small intermaxillaries that are attached to the end of these bones. The under jaw equals the labials in length, and its rounded tip shuts in behind the intermaxillaries, so that eren the nostrils project beyond the mouth : the posterior limbs of the lower jaw expand vertically, rising nearly as high as the upper margin of the orbit. Tongue long and narrow, regularly wrinkled transversely with a median line in the dried specimen.

TеEтн.-There are two contiguous rows of straight, subulate, very acute teeth on the labials, intermaxillaries, and under jaw : those composing the outer row being unequal in size, though small and densely crowded; the interior ones are distant and all about two lines long. The vomer, palate-bones, and inner surface of the lower jaw are covered by multitudes of very minute teeth, which are bounded on each side by an even row a little taller than the others.

Scales.-The body is covered with strong thick scales, which look as if composed of enamel, but are not quite so hard, as they yield slightly to the knife. They are thickened in the 
middle, and have a nearly rhomboidal outline, with two processes at the base which are concealed by the overlying scale. The median line of the back is marked by a row of rather broader scales, having a semicircular or heart-shaped edge. From this line the rows of scales descend obliquely down the sides in curves, resembling a reversed italic $>$. A very narrow depression of the upper edge of each seale, including the two processes mentioned above, is the whole of its surface that is covered by the supcrior scale when in situ; near the tail the uncovered portion of a scale is a very acute rhomboid, but towards the head its outline is more nearly rectangular, with one slightly convex edge. The surfaces of the scales covering the forepart of the back are coarsely grooved in a radiated manner. The scales on the sides are five lines long by three and a half wide, and a linear inch measured along the oblique rows includes four of them; but when measured along the lateral line, or in the axis of the back, it extends to three and a quarter : there are sixty-five on the lateral line. The ternination of the scales on the caudal forms an oblique curved line like the letter $f$, whicls crosses the direction of the rows at a right angle, the scales extending farthest back on the uppermost part of the fin. The exterior rays of the caudal, and the first rays of the other fins, are armed with a double row of tiled, tapering scales, ending in short spinous points which, being very acute and brittle, are capable of producing dangerous wounds. All the rays of the fins are likewise studded with minute bristles. Lateral line nearly straight, marked by a clear line traversing the axis of each scale with a pore in the centre.

Fins. - Br. $3-3 ; D .7 ; P .15 ; V .6 ; A .8 ; C .13$.

The dorsal commences opposite to the two last rays of the anal, and is rather smaller than that fin. The ventrals are attached exactly in the middle between the extremities of the bill and caudal. The latter is rounded at the end, and its rays are twice or thrice divided down to their middles.

CoLour of the head a light green; of the fins yellowish with roundish black spots half an inch in diameter. There are also some black spots on the posterior part of the body and tail. The scales have the light, bluish, semitransparent hue of enamel. The mucus or epidermis, which has dried on their margins, gives many of them the appearance of being scrrated.

\section{Dimensions.}

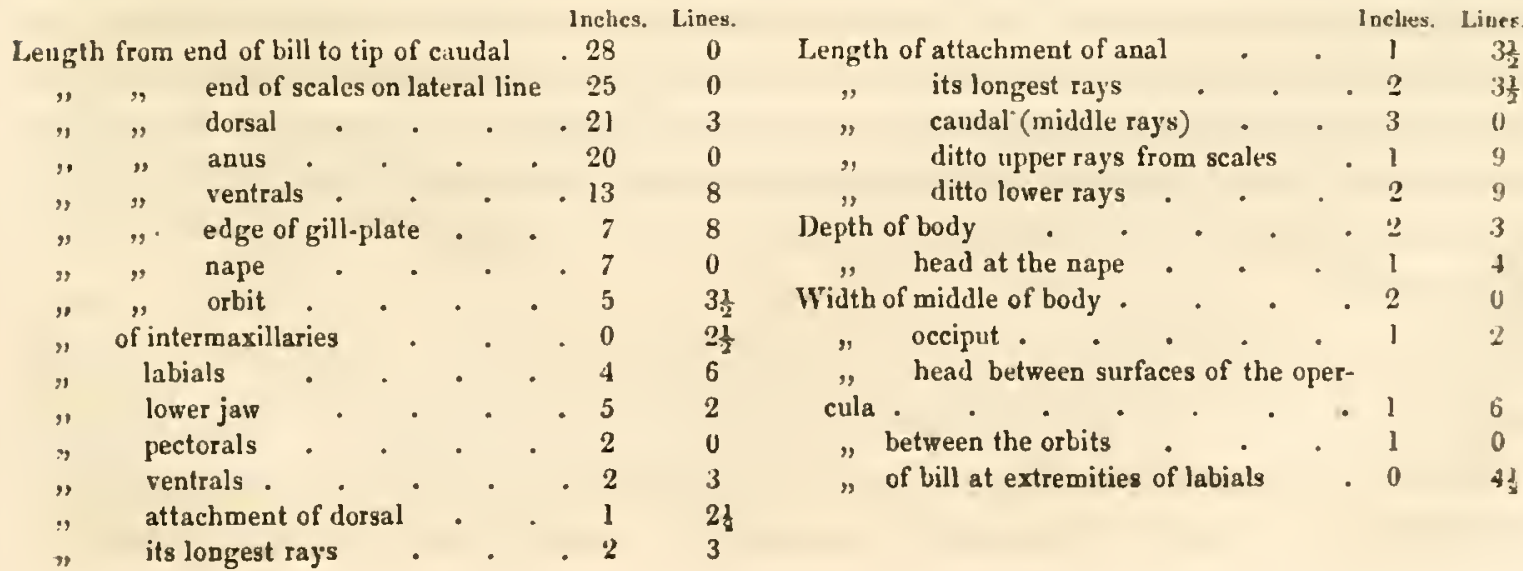


The following is Mr. Gray's notice of the species :-

"Lepisosteus Huronensis. Jaws elongate, slender, with a series of close, small, acute teeth on the outer edge, and a row of rather distant, larger, elongated, conical, acute teeth, just within their edge, and within them there is a narrow band of very short, small, velvet-like teeth, which is contracted to a single series in front. Middle of the palate minutely granular behind, with smaller velvet-like teeth in front. Head and operculum granular. Body pale yellowish (under the epidermis white), with some large black spots on the tail and caudal fin. Scales rhombic, smooth, with a sub-central, longitudinal convexity, which is sometimes produced into a very slight descending process at the hinder part of the lower edge, the margins entire, the lower edge arched. The vertebral series rather larger, generally sub-cordate, with a slight central groove and a posterior nolch. Lateral line rather indistinct. The first ray of all the fins and sides of the tail furnished with a series of elongated, sub-cylindrical scales, their acute, spine-like tips rather recurved."- "This species is allied to Lepisosteus osseus, BLoch, t. 390, and to a new species which M. Agassiz has lately described from two specimens in the collection of the British Museum, under the name of Lepisosteus gracilis (Proc. Zool. Soc., 1834), in the form of the beak, and is intermediate between them in the slenderness and comparative length of that part, as the following measurements will show.

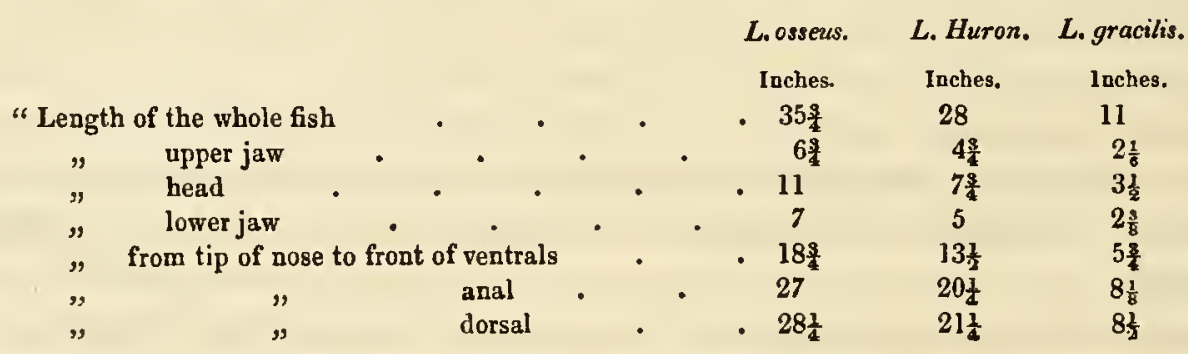

"Lepisosteus Huronensis differs from the other two in the scales being quite smooth; while in $L$. osseus the scales of the front of the body are slightly radiately grooved, and their edges are crenulated; and in L. gracilis the disk of the scales is rather granulated, their margin smooth and entire. It also differs from both these, and from all the other known species of the genus, in being spotted. The three long-nosed species are easily distinguished from each other by their dentition, for $L$. gracilis has a series of long, rather distant teeth on the roof of the mouth, on each side, within the two thin velvet-like bands. L. osseus, on the contrary, has no such rows in that place, but the whole hinder part of the roof of the mouth is covered with rather large, short, conical teeth behind the two marginal velvet-like bands." J. E. Gray, in lit. 


\section{MALACOPTERYGII SUB-BRACHIATI.}

\section{GADOIDE $A$.}

THE third order of fish in Cuvier's arrangement is named Jugular, from the forward position of the ventrals under the pectorals, and comprehends all the softfinned fish which have the pelvis attached directly to the humeral bones. It includes the Linnean genera gadus, pleuronectes, cyclopterus, and echeneis, which are raised to the rank of families in the Règne Animal.-The Gadoidea are most abundant in the northern seas, some species being plentiful in the highest latitudes to which navigators have penetrated, but few, comparatively, are known to exist within or near the tropics. Most of the family are agreeable articles of food, and their capture finds employment for myriarls of fishermen, and investment for a very large capital. A large portion of the Gadoidea are mentioned by authors as common to both sides of the North Atlantic, and even to the Icy Sea and sea of Kamtschatka ; but there is much reason to believe that the specitic identity of fish of this family, inhabiting distant localities, has been very often inferred from a recollection of the general resemblance of the type, rather than from an actual comparison of the specimens. The lists furnished by Fabricius and the ichthyologists of the United States seem particularly to require revision. The following have been mentioned as frequenting the coast of the latter country, but $I$ think it probable that several of them are different from the European species whose names they now bear. Morrhuæ.-Gadus morrhua, Bank cod, Penn., Mitchill; G. callarias, Dorse, common cod of New York, Mitchill; G. rupestris, Rockcod, Sмiтн (G. callarias, var. Мıтсн.); G. arenosus, Shoal-cod, Sмiтн; (G. callarias, var. Miтcн.); G.tomcod, Schoepf (G.tomeodus, Mitchill); G.aglefinus, Penn., Mıтch.; G. fasciatus, Frost-fish, Penn. (G. fiescus, Sirth, G. tomcodus, pruinosus, Mitchill) ; G. blennoides, Blennoid cod, Mitch. MerLANGI.-Merlangus vulgaris, Whiting, Sirth; Gadus albidus, New York Whiting, Mitchild; Gadus purpureus, New York Pollack, Mitchill ; Merlangus pollachius, Pollock, Snith. Merluccir._Gadus merluccius, Hake, Mitch., Snith. Lote.-Gadus maculosus vel maculosa, LE Suevr; G. compressus vel Molva Huntia, Le Suevr. Brosmir.-Brosmius vulgaris, Cusk, Smith. 
Phycides._Gadus tenuis, Slender cod, Мгтсн.; G. punctatus, Spotted cod, Mıтсн.; Blennius chuss, Schoеpf, Encheliopus Americanus, Schn., Gadus longipes, Мгтсн.; Raniceps blennoides, Garter fish, Вмгтн.

Tilesius mentions gadus macrocephahus, gracilis, morrhua, and liscus, as inhabitants of the seas of Kamtschatka, but the members of this family that frequent the north-west coast of America are almost totally unknown. Dixon informs us that he took hake in Norfolk Sound, which proves nothing more than that the fish which he so calls resembles a merhuccius.

\title{
[93.] 1. Gadus morrhua. (Auct.) Common Cod-fish.
}

\author{
Famiry, Gadoideæ. Cuv. Genus, Gadus. Linn. Sub-genus, Morrhua. Cuv \\ Morrhua vulgaris (maxima asellorum species). Beton, p. 121. An. 1551. \\ Gadus dorso tripterygio, ore cirrato, cauda æquali fere cum radio prino spinoso. Artedr. \\ Gadus morrhua., Fabric., Fauna Groenl., p. 146, No. 102. Nitch., Fish of New York, \\ i., p. 367, No. 1. Sмrтt, An. of Massach., p. 16. An. 1835. Ross, Captain J. C., \\ App., p. xlviii. An. 1835. \\ Common Cod. Penv., Arct. Zoolo, ii., p.114, Suppl., No. 87. \\ Saraudlirksoak, or Ekalluarksoak. Greentanders. Keeling. Scots.
}

'The sub-genus Morrllua is characterised by the presence of three dorsals, two anals, and a barbel at the extremity of the lower jaw. It contains many species. The Common cod-fish is probably an inhabitant of all the northern seas, down to the 41 st parallel. It abounds in the North Atlantic, where it frequents sandbanks lying from twenty to eighty fathoms under water. Pennant is of opinion that its proper range is between the 66th and 50th parallels of latitude, those caught north and south of these degrees being either few in quantity or bad in quality. "The great rendezvous," says he, "of the cod-fish is on the banks which lie off the coasts of Newfoundland, Cape Breton, Nova Scotia, and New England; few are taken north of Iceland, but on the south and west coast they abound, and they again swarm off Norway, in the Baltic, and off the Orkneys and Hebrides." It does not exist in the Mediterranean. Dr. Mitchill states the callarias to be the Common cod of New York, while the morrtua, or "Bank cod" as he calls it, is brought to the market of that city from Nantucket, and the coast beyond, between November and April only, the summer temperature of the United States' waters being, in his opinion, sufficient to kill it. Cod-fish, of excellent quality, are found in the estuary of the St. Lawrence, pretty high up. Fabricius says that the morrhua is less conmon on the Greenland coast than the callarias ; but Captain James 
C. Ross informs us, that on the west coast of Greenland, in latitude $66 \frac{1}{2}^{\circ} \mathrm{N}$., a number of very fine cod-fish were caught by the crew of the Vietory, on a bank consisting of small stones, coarse sand, and broken shells, with from eighteen to thirty fathoms of water orer it. He alds that there are several other banks of considerable extent on that const, some of them in the vicinity of the Danish colonies, where the cod-fish assemble in astonishing numbers. 'This fish is also found on the American side of the Greenland seas, for Davis observed many in possession of the Esquimaux who inhalsit the land between Cape Raleigh and Cumberland Strait, and the following passage oceurs in the narrative of his third voyage, when embarling in the Moonshine of thirty-five tons, he ran to the southward from latitude $67^{\circ}$, across the entrance of Hudson's Strait, to $57^{\circ}$ on the Labrador coast. "Coasting the shore towards the south, we saw an incredible number of birds: having divers fishermen aboord our barke, they all concluded that there was a great skull of fish: we being umprovided of fishing furniture, with a long spike nayle made a looke and fastened the same to one of our sounding lines: before the baite was changed we took more than fortie great cods, the fish swimming so abundantly thicke about our barke as is incredible to bee reported, of which, with a small portion of salt that we had, we preserverl some thirtie couple, or thereaboutes, and so returned for England." (Halihyt, iii., p. 120.)

Small cod-fish, resembling the rock-cod of the British coast, were purchased by Captain James C. Ross from a party of Esquimanx, who were fishing for them throngh holes in the ice on the west side of the peninsula of Boothia, and he was told that in the antumn full-sized ones were taken farther to the westward ${ }^{*}$. The Common cod, or a variety of it, is mentioned by Tilesius as inhabiting the sea of Ochotsk, but I have met with no account of its having been retected on the American side of the Pacific. The food of the cod-fish is very various, consisting of all kinds of fish that inhabit the banks it resorts to, molluscæ, both soft and shelly, crustacee, and marine insects. 'The baits most generally used on the banks of Newfoundland are capelin and cuttle-fish. At certain seasons the stomachs of the cod brought to the London market are filled with young muscles. For an account of the important fisheries which have been established for the capture of the cod, the reader may consult Du Hamel, Pennant, or the several Encyclopedias which are daily issuing from the press. The cod-fish evidently derives its English name from its softness, flaccidity, and shape, the word cod (Saxon corse) still being in common use in Scotland to signify a bag or pillow.

* This fish was termed by the Esquimaux owuk. 
Not having access to any variety of specimens of American cod-fish, I shall not attempt to give a detailed description of the species. A specimen brought from Newfoundland by Mr. Audubon, to whom it was given by the fishermen as an uncommon kind or variety, does not appear to differ from the small brown cod which is taken on rocky parts of the British coast.

Its length is sixteen inches, the head forming one-third part, and the central rays of the square caudal fin measuring an inch and a quarter. The lateral line is arched anteriorly, descending at the second dorsal, and then running straight to the tail, keeping rather nearer to the anal than to the dorsal in its course. The teeth of the upper jaw and vomer are acute, of various lengths, and crowded into bands : on the lower jaw they stand almost in a single series.

Fins.-Br. 7-7; P. 18; V. 6; D. 15-19-17;A. 19-17; C. - . Newf. sp. $7-7 ; \quad 18 ; \quad 6 ; \quad 14-20-17 ; \quad 19-20 ; \quad 38$ to 40. Dav. St. sp.

The number of rays of the Davis' Straits' fish are quoted from Captain James C. Ross, who says that the average weight of fifteen individuals was sixteen pounds, and their length thirtysix inches and a half, of which the head formed one-fourth part, and the caudal fin oneseventh. Though the number of rays was various in different specimens, the second dorsal always contained more than either the first or third. The alimentary canal rather exceeded the body in length, and the pyloric crea amounted to two hundred and fifty.

[94.]

2. Gadus callarias. (Linn.) The Dorse.

Gadus callarias. Fabricrus, Fauna Groenl., p. 144.

Cadus callarias. Ross. App., p. 1.

Saraudleek. Greentanwers, Feleetok. Esquimaux of Boothia.

The Dorse is mentioned by Fabricius as common on the Greenland coast, and Captain James C. Ross observed it in the inlet to the west of the peninsula of Boothia, where it is taken abundantly, though in very poor condition, by the Esquimaux, who fish for it from the middle of May till near the end of June, through holes cut in the ice. It is plentiful in the White Sea and along the whole northern coast of Europe, particularly in the Baltic. Fabricius states that on the Greenland coast it feeds upon small fishes, crustaceæ, and molluscæ, and that it is most frequently observed at some distance from the bottom, with its tail directed obliquely downwards. A smaller variety, differing from the larger one in the number of rays of the fins, is taken in some places only, in the winter time, under the ice. The callarias of Dr. Mitchill is probably a distinct species. 
Those that Captain James Ross saw on the coast of Boothia seldom exceeded fourteen inches in length, though a few were obtained of greater size. They were provided with fortytwo pyloric cæca, and the average number of rays in their fins were as follows.

Fins.-Br. $7 ; P .19 ;$ V. $6 ; D .12-19-23 ; A .22-22 ; C .40$ to 44. Ross.

$\begin{array}{llllll}7 ; & 20 ; & 6 ; & 14-19-19 ; & 21-19 ; & \text { 40. Faun.Gron., lar.var. } \\ 7 ; & 19 ; & 6 ; & 13-24-18 ; & 22-18 ; & \text { 44. Ditto, small ditto. }\end{array}$

Dimensions

Of a specimen taken on the coast of Boothia.

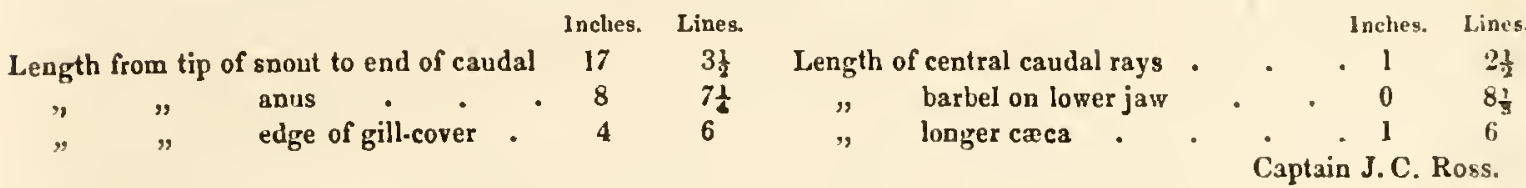

[95.]

Gadus Fabricil. The Meesarkornak.

Gadus æglefinus. FABricius, Faun. Grænl., p. 142. No. 100.

Meesarkornak, eekallooäk. Greenlanders.

Fabricius considers this fish to be the Gadus aglefinus of authors, the haddock or haddy so abundant in the Scottish firtlss. The haddock is vulgarly supposed to have been the fish out of whose mouth St. Peter took the tribute-money, the black marks at the pectorals being considered to be the impressions left by the saint's finger and thumb, which the species has retained ever since. The same honourable origin is commonly ascribed to the black lateral spot on the body of the Dory, but superstition has entirely overlooked the fact, that neither that fish nor the haddock exist in the sea of Gennesaret, whose waters are perfectly fresh. As Fabricius seems to have identified the Meesarkornak with the haddock, solely from its agreement with Artedi's very brief notice of the latter, and as it does not possess the distinguishing marks at the pectorals, I have ventured to name it as a distinct species, considering the addition of another synonym, even should it prove to be unnecessary, as less injurious to the interests of science, than the error of ascribing to a fish too wide a geographical range, or habits which do not belong to it. 'The Meesarkornak frequents the northern bays of Greenland pretty abundantly in the winter season, spawns on the littoral sea-weeds in February, and of course under the ice, and is of so curious a disposition that it is readily attracted to the surface by agitating the water, especially in the evening. Sometimes it leaps upon the ice, when it becomes the prey of the Arctic fox, which lies in wait for such a chance, 
and is even said to know how to bring about this desired event, by stirring the water with his foot through a crevice. The Greenlanders take it in a similar way with their hands, having learnt the art, according to Fabricius, from the fox.

The species attains the length of fourteen inches. The colour of the back is soiled or livid white, the sides are mimutely spotted with black, and the under parts are pure white. There is a short barbel under the chin.

Fins.-Br. $6 ;$ D. 13-15-23; P. 19; V. 6;A.17-20;C. 32. Fauna Grænl.

[96.]

4. Gadus ogac. The Ogak.

Gadus barbatus. Fabricius, Fam. Gronl., p. 146.

Ogak, or Owak. (The young ogarak, or owarak, pl. ogarkæt, or owarkæt.) GreEnLANDERs.

This is a larger species than the Whiting-pout of the English seas, to which Fabricius refers it, and it wants the black spot at the base of the pectorals: a new specific appellation is therefore as much required as in the case of the preceding species. As the Esquimaux of the peninsula of Boothia call the rock-codling (p. 324), which they take near Cape Isabella, by the same name which the Greenlanders apply to this, viz., owak, or owuk, it is probable that they nearly resemble each other, if they are not specifically the same.

The ogak is described by Fabricius as rarely exceeding eighteen inches in length and five in depth, and as corresponding with the description given by Artedi (sp. 65), except in wanting the dark spots at the base of the pectorals. It lives among sea-weeds in deep, shady places, in conpany with the Cottus Grrenlandicus, where it feeds upon capelin, blennies, launces, and other small fish, as well as upon crustacex. It spawns among the sea-weeds in February or March, while the ice is as yet entire, and in June multitudes of its young, no bigger than sticklebacks, nay be seen along the shore. In its habits this fish resembles the gadus callarias, but it keeps nearer the bottom, and the male and female are said to consort with each other under the same stone.

Fins.-Br. 7; D. 15-19-16; P. 18; V.6;A. 22-17; C. 32*. Faun. Gr., p. 147.

* The following rays are attributed to the gadus barbutus by Artedi. Fins. $-B r .7$ or $8 ; D .13-24-20$ or 21;P.19; V. $6 ; A .31-21$. 


\section{Gadus (Mfirangus) carbonarius. Coal-fish.}

Fasur.x, Gadoidex. Cuv. Genus, Gadus. Linn. Sub-gemus, Merlangus. Cuv. Merlangus carbonarius (Coal-fish). Sasine, App. Parry's First Foy., p. ccxi.

The merlangi, or coal-fish, differ from the true cod in having no barbels; they derive their English name from the dusky pigment which tinges their skin, and which, when they are handled, soils the fingers like moist coal. Specimens of the Common coal-fish, from four to five inches long, were taken in a trawl-net on the west coast of Davis' Strait, on Sir Edward Parry's first voyage. 'This fish, when lull grown, bears a considerable resemblance to the salmon in the size of its scales and elegant form, notwithstanding its dark hue. It swims near the surfice, and occasionally takes a mackerel-hook towed along in a smart breeze. The young resort to the rocky bays of the Orkneys and Hebrides in immense numbers, where, according to the perior of their growth, they are known by the names of cuddy, sithe, seth, and sillock. They rise eagerly at an artificial fly of the rudest construction, and are secured with so much facility, and in such numbers, that an amateur angler would think lightly of the sport, even were he to overcome his disgust at the dirty colour and disagreeable smell his hands acquire in taking the fish from the hook. They yield, however, a plentiful harvest to the northern fisherman, who thus obtains both food, and oil for his lamp, with little exertion. On the Yorkshire coast the young are called parrs, and when a year old billets. They are said not to attain their full size until they are four years of age. The species is reported to exist sparingly in the Mediterranean.

The merlangus vulgaris, or Whiting, is enmmerated in the list of the Massachusetts fish by Dr. J. V. C. Smith, and the same, or a very similar one, of the New York seas, is named gaclus ulbidus; by Dr. Mitchill. La Hontan also says that whitings, like those of Europe, exist in the estuary of the St. Lawrence.

[98.] 2. Gadus (Merlangus) polaris. (Sabine.) Polar Cocl-fish.

Merlangus polaris. SABrxe, Parry's First loy.; Ross, App. Parry's Third Foy., p. 110.

Ides, Parry's Polar V'oy., p. 199. Ines, Sir Jolin Ross's Second Voy., App. p. li.

This small species was taken on Sir Edward Parry's first voyage of discovery whilst swinming among the surface ice of Baffin's Bay; nultitudes were gathered 
on his second voyage, from the rocky pools of the Duke of York's Bay, in Southampton Island, where they had been left by the falling tide; it was again found equally plentiful, on his third expedition, in Prince Regent's Inlet; and on Sir John Ross's recent voyage great numbers were collected from crevices in the ice that covered Batty Bay, in July, 1833, and several were obtained, even in the winter time, in Felix Harbour. The merlangus polaris is also an inhabitant of the Spitzbergen Sea, having been found on Sir Edward Parry's polar voyage, as far north as latitude $82 \frac{3}{4}^{\circ} \mathrm{N}$., in plenty, in small bays where streams of fresh water run into the sea. It is "highly probable that this is the same fish with the gadus virens of Fabricius, or the ordleet, as he supposes, of the Greenlanders, which is said to swim near the surface, and to be an agreeable article of food. The Polar coal-fish forms the principal nourishment of the numerous sea-forvl which migrate to the Arctic regions in summer, its habit of frequenting the top of the water rendering it an easy prey. The beluga drives it upon the ice in shoals. In the summer it is muclı infested by a lernaa, which attaches itself to the gills.

Captain Sabine describes it as being between five and six inches in length, and as being very nearly allied to the gadus virens, from which it may be distinguished by the third dorsal being larger than the two anterior ones, whereas, in virens, the middle one is the largest: the lower jaw rather exceeds the upper one; the tail is slightly forked. Captain James Ross says that there is a considerable variation in the number of rays in the fins, the average of a great many differing slightly from Captain Sabine's enumeration. Its length, he says, seldom exceeds ten inches.

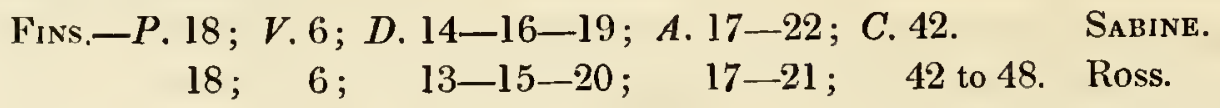

[99.] 1. Gadus (Lota) maculosus. (Cuvier.) The Methy.

Family, Gadoideæ. Cuv. Genus, Gadus. Linn. Sub-genus, Lota. Cuv.

Gadus lota. Pennv., Arcl. Zool., Intr., p. cxci. Rich., Fr. Journ., p. 724.

Gadus maculosus. Lue Sueur, Journ. Ac. Sc. Phil., i., p. 83. An. 1817.

Lota maculosa. Cuv., Règ. An., ii., p. 334. 1829.

Molva maculosa. Cuv., in lit. An. 1828.

Methy. Crees. La loche. Voyageurs. Dog-fish. Eel-pout. United States.

The lota, or lings, have two dorsals, one anal, and more or less numerous barbels. Some species are inhabitants of fresh water. The Common ling, or gadus molva of Linnæus, is supposed by Fabricius to be a Greenland fish, named by the natives eevirksoak, but he had not an opportunity of examining a specimen. The 
Methy exists in every river and lake from Canada to the northern extremity of the continent. It is extremely voracious, and preys on all kinds of fish, which it takes chiefly or solely in the night. I opened several taken in Pine Island Lake, in the month of March, which were filled with cray-fish to such a degree, that the form of their bodies was quite distorted, the soft integuments of their bellies admitting of great dilatation. It spawns in February, and, consequently, at a period when the water is thickly covered with ice everywhere north of the great lakes of the St. Lawrence. Its roe consists of very small eggs, which are so numerous that Mr. Hutchins is reported, by Pennant, to have counted 6r1,248 in a single fish. When well bruised and mixed with a little flour, the roe can be haked into very good biscuits, which are used in the fur countries as tea-bread. The liver is also considered to be a delieacy, but the flesh is eaten only in times of great scarcity, being watery and tasteless, thongh in the few trials we were obliged to make of its qualities, it dirl not appear to be unwholesome. Dogs, accustomed to feed on the offal of every other kind of fish which exists in those countries, will not eat any part of this, even when pressed by hunger. Its European representative, on the contrary, the Burbot, is considered to be a delicate-flavoured fish.

At Fort Good Hope, on the lower part of the Mackenzie, I observerl a fish of this genus, which differed from the ordinary state of the Methy in having much brighter and more varied colours, forming reticulations; but we were on the eve of embarkation, the pressure of other avocations prevented me from recording its characters, or even preparing a specimen,--and, returning by another route, I had no opportunity of seeing it again.

\section{DESCRIPTION}

Of a recent specimen killed in Pine Isknd Lake, March 31, 1820.

Form.-Profile oblong, tapering gradually into the lanceolate, acute extremity of the tail, which reaches nearly to the centre of the obovate caudal fin. The body, unless when distended with roe, or with its prey, is compressed, its greatest circumference being just behind the pectorals, and nearly equalling one-half its length: the depth of the body there is about one-sixth of the length. HEAD broad, depressed, the jaws of equal length and rery obtuse: its length is contained rather less than six times in the total length, or rather more than five times when the caudal fin is excluded. Eyes small, with a lateral aspeet, but from the flatness of the forehead appearing partly on the upper surface. The centre of the oval orbit is two lengths of its axis from the tip of the snout, and somewhat short of four lengths from the posterior edge of the gill-cover-there being five lengths and a half in the total length of the head. Nostrils anterior to the orbit, the apertures small, and the foremost furnished with a long, loose, skinny lid. The upper lip, attached to the intermaxillaries, fits into a fold of the integuments of the snout. The intermaxillaries are attached to the snout by cartilages which admit of a 
rotatory motion but no protrusion: their lower ends are with the labials which lie in the angle of the mouth, thrust out a little by the extension of the jaws. The labials are about half as long as the intermaxillaries, their posterior extremities pass a little beyond the centre of the orbit. The lower jaw is strong, and there is a small cirrhus attached to the tip of the chin. TEETH.-The intermaxillaries and lower jaw are armed with slender, hooked teeth, in even, card-like, rather broad belts. A still broader belt covers the knob of the vomer and anterior ends of the palate-bones. There are teeth of the same kind on the pharyngeal bones, and on a double row of tuberculous rakers on each branchial arch. The tongue is obtuse, fleshy, and smooth. GiLt-covers rounded and edged with soft membrane; the branchial aperture is large, and its membrane, containing seven curved rays, is continuous with its fellow, forming a flap which is loose behind : the rays are semi-cylindrical, being flat exteriorly.

Scales small, roundish, and so deeply imbedded in a gelatinous epidermis as to be scarcely perceptible in the recent fish. When examined with a lens, the concentric circles indicating their growth are perceived to be very regular, but no radiating furrows can be seen. The epidermis is covered with minute dark specks, most conspicuous though less crowded on the lighter-coloured sides and belly. In the dried specimen scales are perceptible, either scattered or crowded, on every part of the liead, body, and fins, except the muzzle, lips, edges of the orbits, and labials: on the forepart of the body the scales are nearly their own breadth apart, but posteriorly they are more close, and on the tail they are in contact or even tiled: they are also crowded on the cheeks, gill-covers, and caudal fin; but very small and widely scattered on the dorsal and anal fins, and scarcely perceptible on the gill-membrane. As the scales dry they become depressed in the centre, or saucer-shaped. Lateral line marked by a continuous, slender furrow, lined or bordered with minute scales: it is nearer to the back than to the belly, and is slightly arcbed till it passes the first third of the anal fin, after which it takes a straight course and is no longer discernible, when it comes within three inches of the extremity of the tail. The anus is exactly midway between the snout and tip of the tail (excluding the fin).

Fins.-Br. $7^{*} ; P .16 ; V .6 ; D .12-74 ; A .71 ; C .50$.

The pectorals are unequally obovate and contain sixteen rays. The ventrals or jugulars, situated anteriorly to the pectorals, are soft, slender, and tapering to a point: the first of their six rays is the strongest. The first dorsal contains six rays, the first of which is short, and the last one very slender. The distance from the snout to the anus being divided into four parts, the first dorsal occupies rather more than the anterior half of the fourth part. The second dorsal, commencing about a quarter of an inch from the first, contains seventy-four rays, the three or four first ones gradually increase in length, the margin of the rest of the fin is even, and it is rounded off at its termination. The fin in general is nearly half an inch lower than the first dorsal. The anal fin, commencing opposite to the ninth ray of the second dorsal, and close to the anus, is of equal height throughout, except the two or three first rays, which are short: it is rounded off at its termination like the second dorsal. The rays of the

* Foster could find only six gill-rays in his specimen from Hudsun's Bay. 
dorsals and anal are, as in all fish, double, but they are most visibly so at their bases, their summits spreading very slightly. The caudal fin is oborate, its extremity being nearly semicircular. It takes its origin in contact with the second dorsal and anal, but its form renders it sufficiently distinet: it contains fifty rays, the four central ones attached to the end of the vertebral column, the others to slender distinct interspinous bones, nine of the rays of the base above and below gradually increase in length, the other thirty-two are nearly equal to each other, but originating on the lanceolate tail give the peeuliar form to the fin.

CoLouk.-Head and back dull cliestnut brown tending to yellowish-brown, the back marbled with lighter spots : belly orange-white, becoming grey towards the sides by the aspersion of dark brown specks. Ventrals white.

\section{INTESTINES.}

The wide esophagus is lined by a white membrane having longitudinal folds : the stomach is distinguished from it by still greater width, a stronger muscular coat, and by the reddish colour of its lining, which also presents more numerous and somewhat convoluted folds. The very small pylorus is so situated as to leave one half of the stomach in form of a cul de sac. An inch from the stomach the caca, about sixty in number, encirele the intestine, uniting into ten large trunks whose orifices are close to each other: they are filled with thin feculent matter. The intestine gradually diminishes in calibre, and its coats become weaker towards the anus; next which, however, there is a more muscular portion with an approach to a valvular apparatus at its origin, formed by a contraction of the muscular coat, and a corresponding projection of the lining of the canal. The whole alimentary canal makes two convolutions, and its length to that of the fish, excluding the caudal fin, is as thirty-eight to twenty-two. The liver has a cream-yellow colour tinged with flesh-red: its ransverse diameter is the greatest, and it has a small central triangular flap or lobe; it was observed, howerer, that the size and form of the liver varied considerably in different individuals. The gall-duet terminates in the intestine below the openings of the cæca; there is a dilatation in it equal in size to the gall-bladder itself. The spleen is situated near the rectum. The airbladder has tro short horns at its upper end, and its lining is encrusted by a number of stelliform fatty substances. The firm cordiform kidneys are lodged in a sac between the spine and lower end of the air-bladder. The urinary bladder is strong and muscular.

Disignsions.

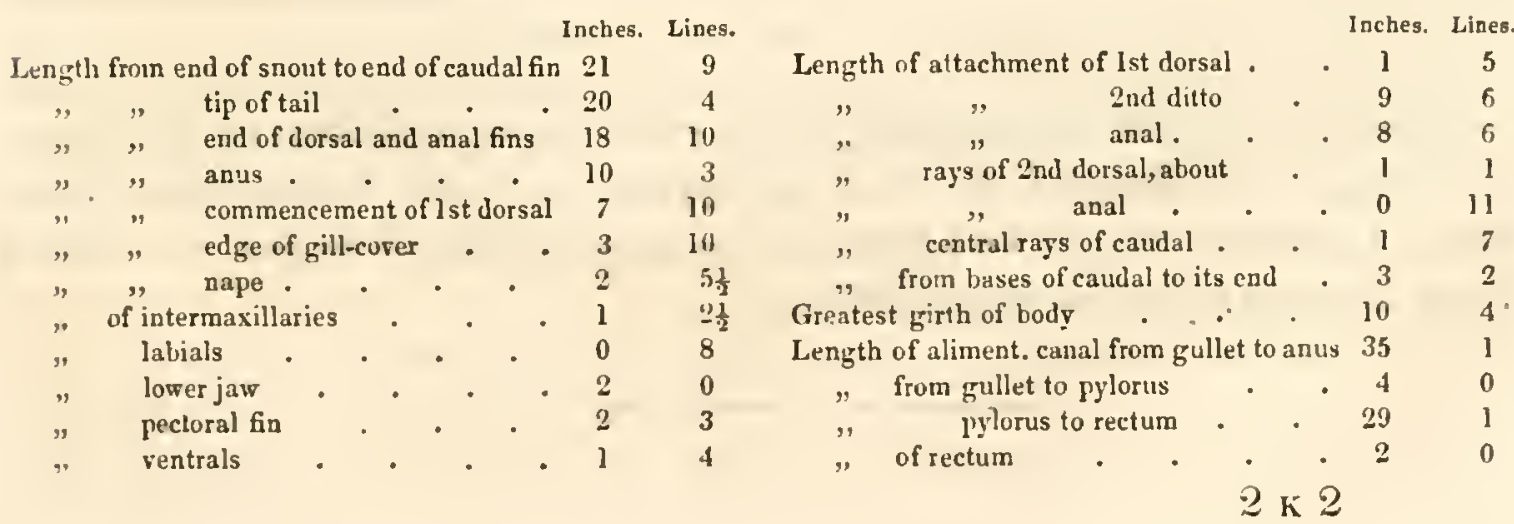




\title{
[100.] 1. Gadus (Brosmius) flavescens. (Le Sueur.) Yellow tusk.
}

\author{
Family, Gadoidex. Cuv. Genus, Gadus. Linn. Sub-genus, Brosmius. Cuv. \\ Le Brosme jaune (Brosmerus flavescens). Lis Suevr, Mém. du Mus., v. p. 158. \\ An. 1817. Pl, 16, f. 2. \\ Tusk, or Cusk. Newhoundiand Fishermen.
}

The brosmii, or tusks, have only a single long dorsal.-Fabricius refers the neyorpalloogak of the Greenlanders to this sub-genus, but as he did not see the fish himself, and gives no description of it, we have no means of judging how far it agrees with the Yellow tusk, which inhabits the banks of Newfoundland sparingly. M. Le Sueur, who is our sole authority for the latter as a distinct species, does not say whether or not it is the same with the cusk of the Massachusetts coast, which Dr. J. V. C. Smith refers to the brosmius vulgaris. In the Yellow tusk the lower jaw is longer than the upper one, but in the Common tusk the upper jaw is the longest. 'The following is M. Le Sueur's description of the Newfoundland species.

CoLour, generally, an agreeable yellow, the dorsal, pectoral, and anal, edged with black and white. The very thick skin is furnished with small, round, crowded scales, very irregularly placed. The lateral line is arched above the pectorals. Form.-The body is long, broadest next the head, and compressed towards the tail. The head broad and flat, the snout obtuse and rounded. The eye large and oblique, the lower jaw has two barbels. The orifice of the mouth is wide. The teeth on the jaws and palate are sharp, with the points turned backwards, and are crowded into many rows. The pharyngeal bones, above and below, are toothed, and the branchial arches are armed on the sides with little tubercles studded with strong conical curved teeth. Fins.-Br. $; ; P .25 ; V^{\gamma} .6$. The dorsal and anal are very long, and their rays consequently numerous, as is the case also with the caudal, which is of a large size. The length of the specimen was two feet. Le Sueur, l. c.

Fabricius mentions one other species of gadus as an inhabitant of the Greenland seas, the akooleeäkeetsok, which he supposes to be the merluccius, or hake, but this reference must be very uncertain, as his knowledge of the fish was derived solely from the reports of the natives. 


\section{[101.] 1. Gadus (Phycis) punctatus (Mitch.) Spotted Phycis.}

Familix, Gadoiler, Cuv. Giknts, Gatus. Linn. Sul-genus, Phycis. Aktedo.

Spotted coll (Gades punctatus). MircuiL.., i., I. 372.

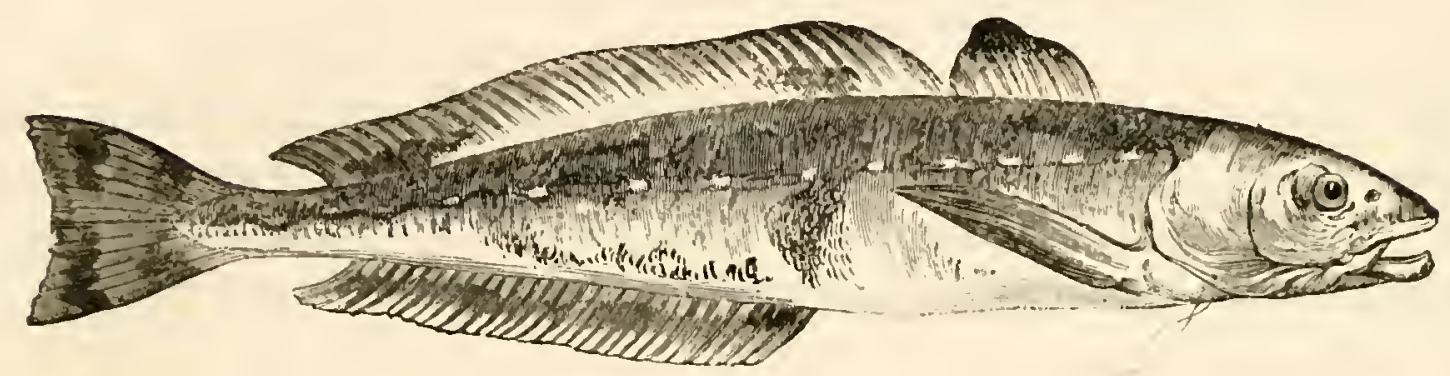

The sub-genus phycis is characterised by the ventrals containing only a single ray, which is often forked. The head is large, there is a barbel attached to the chin, and there are two dorsals, the second of which is long. The Spotted phycis is figured and described by Dr. Mitchill as one of the New York fish, though he says it is the rarest of this family in that quarter. Our wood-cut is from a sketch made by Lieutenant-Colonel Hamilton Smith, of a specimen which was captured off Halifax, Nova Scotia.

"Length ten inches. Colour of the back and sides pale brown or whitish, with lines between the scales; of the neck and belly dull white with suffusions of cream colour. First dorsal marked above with a black spot surmounted by the white tips of the rays. Anal brownish edged with black. Lateral line distinct and peculiar, consisting of a narrow black mark, alternating at spaces of half an inch apart, with white dashes about one-eighth of an inch long. In some individuals there is an imperfect whitish straight fillet under the lateral line. The chin has one small cirrhus. Ventrals two cleft, the second ray two inches long. Rays.-P. $13 ; V .1 ; D .9-47 ; A .47 ; C .23 . "$ Mitchill, $l . c$. 


\title{
[102.] 1. MACrourus RUPESTRIS. (Bloch.) Rock Grenadier.
}

\author{
Family, Gadoideis affinis. Cuv. Genus, Macrourus. Bloch. \\ Coryphæua rupestris. Fabricius, Fauna Groenl., p. 154 . No.111. \\ Macrourus rupestris. SchN., Bloch, p. 103, t. 26. \\ "Lepidoleprus cœlorhynchus. Risso, pl. vii., f. 22." \\ lngmingoak. Greenlanders.
}

This fish exists in the bays of south Greenland, the European Atlantic, and Mediterranein. It inhabits great depths of water, and is fished for with a long line. When drawn to the surface its body is distended with air, and it emits a grunting sound like the gurnard. Its flesh is prized by the Greenlanders.

\section{DESCRIPTION}

Compiled from Fabricius, Schneider, and Cuvier.

FonM.-Body oblong, thick anteriorly, slender posteriorly. Head large, depressed with a flat immoveable snout, formed by the union of the sub-orbitar and nasal bones, projecting over the mouth. Eyes large and prominent. Gill-openings wide. Mouth ample. Jaws moveable as usual, and armed with very fine short teeth in five rows. Tongue and palate smooth. Scales silvery, hard, and armed on the head and forepart of the body with several longitudinal serrated ridges, on the posterior parts with only one ridge: the gill-membranes and fins are alone free of scales. Lateral line straight and near the back. Anus in the anterior third part of the fish. Fins pointed. 'The second dorsal and anal, both very long, unite to form the accuminated caudal: first dorsal short and high. A difference in the number of the second dorsal and anal rays, as given by Fabricius and Schneider, has evidently originated in the latter enumerating among the rays of these two fins those of the caudal.

$$
\begin{array}{rrrr}
\text { Fins.-Br. } 6 ; P & 18 ; V .8 ; D .11-112 ; A .112 ; C . & \text {-. Fabricius. } \\
7 ; & 19 ; \quad 7 ; 1 / 11-124 ; 148 ; & 27.2 \text {. Schneider. }
\end{array}
$$




\section{PLATESSOIDEÆ.FLAT FISH.}

THE fish of this family were included by Linnæus in a single large genus, which was named plenronectes by Artedi, to denote their peculiar habit of swimming on one side. They have, in fact, a character of which there is no example in any other family of vertebrated animals, that of both eyes being on the same side of the head, which is the uppermost when the fish swims, and is more or less deeply coloured, while the other side is always whitish. The orifice of the mouth is oblique, with unequal sides, and the greatly compressed body partakes more or less of the want of symmetry observable in the head; the pectorals are seldom uniform, the dorsal occupies the whole length of the back, the anal fringes the under edge of the body, and the ventrals, which are often joined to one another, appear like an anterior continuation of it. There are six gill-rays. The abdominal cavity, which is small, is prolonged into the substance of the tail to give room for the lodgment of the viscera, the anus being far forward. The cranium is composed of the ordinary number of bones, though their forms are curious, owing to both the orbits being on one side. There is no air-bladder, and these fish seldom leave the bottom. 'The latter circumstance may account for the fish of this family being found in all climates, the temperature of the bottom of the ocean being comparatively equable. The Flat fish yield a wholesome and agreeable article of diet to the inhabitants of every coast. 'The following are reported to inhabit the seas of the United States; but as many of them have been very imperfectly described, it is not certain whether they are all proper species, or even rightly referred to the subgenera. Platesse.-Pleuronectes dentatus, Summer flounder. Linn., Schoepf, Mitchill; Pleur. Americanus, Schn. (Rhode Island flounder, Schoepf); Pleur. melanogaster, Black-bellied flounder, Mitchill; Pleur.oblongus, Spotted flounder, Mitchill. Hippoglossi.-Pleur. hippoglossus, Halibut, Schoepf, Penn., Mitch., Smith. Rhombi.-Pleur.argus vel lineatus, Bloch, Catesby; Rhombus maximus, Turbot, Snith. Solez.-Sole, Pleur. solen, Penn. (Soleu vulgaris, Smith). Achiri.-Pleur. lineatus, Linn. (Pleur. mollis, New York sole, Miтch.) ; Pleur. plagiusa, Garden, Linn.

It is highly probable that many of the above extend their range to the British American coasts. La Hontan mentions "plies et turbots comme en Europe," as frequenting the embouchure of the St. Lawrence, and Pennant enumerates the 
Common flounder, halibut, plaice, and sole, as inhabitants of the American seas generally. The halibut and two others exist on the Greenland coast, and two species have been observed on the arctic coast of America. Four were noticed by Mr. Collie in the bay of A watska, " one, allied to the pleuronectes platessa of Linnæus, having a spinous line extending from the posterior part of the eyes to the hinder and upper part of the operculum, the remainder of the head being smooth; another, noted as a variety of the last, but having the head covered with roughly projecting tubercles; the third, the pleuronectes stellatus of Pallas, and the fourth, supposed to be the pleuronectes hippoglossus.(?) Eschscholtz, speaking of the natural productions of Norfolk Sound, on the north-west coast of America, says that there is no great variety of fish, but the individuals are numerous. In his short list he includes a pleuronectes several feet long, probably the halibut, which is found abundantly in the same neighbourhood. "While we lay here," says the author of that voyage, " the natives supplied us very plentifully with laalibut, which we bought of them for beads and small toys. The place where these halibut were caught is in the offing round the point of land. Our whale-boat was one day sent to this place with seven hands on a fishing party, but their success was greatly inferior to that of two Indians, who were fishing at the same time, which is rather extraordinary, if we consider the apparent inferiority of their tackle to ours. Their hook is a large simple piece of wood, the shank at least half an inch in diameter; that part which turns up, and which forms an acute angle, is considerably smaller, and brought gradually to a point: a flat piece of wood, about six inches long, and near two inches wide, is neatly lashed to the shank, on the back of which is rudely carved the representation of a human face. They bait their hook with a kind of fish called by the sailors squid (cuttle-fish), and having sunk it to the bottom, they fix a bladder to the end of the line as a buoy, and should that not watch sufficiently, they add another. Their lines are very strong, being made of the sinews or intestines of animals. One man is sufficient to look after five or six of these buoys; when he perceives a fish bite, he is in no great hurry to haul up his line, but gives him time to be well hooked; and when he has hauled the fish up to the surface of the water, he knocls him on the head with a short club, provided for the purpose, and afterwards stows away his prize at his leisure: this is done to prevent the halibut, which sometimes are very large, from damaging, or perhaps upsetting, his canoe in their dying struggles. Thus were we fairly beat at our own weapons; and the natives constantly bringing us plenty of fish, our boat was never sent on this business afterwards." Dixon also observed another flat-fish which is frequently mentioned in the account of the voyage under the name of 
sand-dab. "Our hooks and lines were generally overboard, but the only kind of fish we canght was a sort greatly resembling a flounder, and called by the sailors sand-dabs." Lewis and Clirk say that a flounder, the same with the Atlantic species, is well known at the mouth of the Columbia River, where it is often left on the beach by the recess of the tide. The Indians eat it and think it very fine. Mr. Collic saw a rhombus on the coast of California.

\section{[103.] 1. Pleuronectes (Platessa) stellatus. (Pallas.)} Stellated flounder.

Fasur, Platessoidex (Poissons plats). Cuv. Genus, Pleuronectes. Linn. Sub-genus, Platessa. Cuv.

Pleuronectes stellatus. P'aldas, Nov. Act. Petrop., i. p. 347. An. 1783. Tilesius, lib. cit., i., t. ix., f. l, p. 387. An. 1787 .

Cambala. Ressians. Tanticu. Kurisass.

In the sub-genus platessa, or the flounders, there is a row of obtuse cutting teeth on each jaw, and most frequently some teeth en pavés on the pharyngeal bones; the dorsal does not extend farther forward than the upper eye, and, like the anal, it leaves a naked space between its termination and the caudal. The flounders have a rhomboidal form, and in most the eyes are on the right side. 'They have two or three small ceca. On Sir John Franklin's first expedition we caught a flounder at the mouth of the Coppermine, and of several other rivers that fall into the Aretic Sea. As the subjoined brief description, which was the only memorial I could preserve of it, agrees pretty well with the published accounts and figures of the pleuronectes stellatus of Pallas, I have considered it to be that species. If this opinion be correct, the stellated fiounder is most probably an inlabitant of the Kamtschatdale seas, and of the whole north coast of America. It is plentiful on the Kamtschatdale coast, near the mouths of rivers, and in sheltered bays, where it is most readily taken in May and June. In winter it is said to bury itself in the sand. It varies in size from ten to fourteen inches. Tilesius says that it is distinguished from all other species by the black stripes on the fins, and the forms of its tubercles or scales.

\section{DESCRIPTION}

Of a recent specimen, taken July 16, 1821, off the Coppermine River, lat. $673^{\circ} \mathrm{N}$.

Fonm.-Profile of the body broadly elliptical, terminated by a strap-shaped tail and a candal fin scolloped between the rays. Eyes on the left side, moderately large. Nostrils 
close to the upper lip, so as to be closed by the retraction of the jaws. The upper margin of the mouth is formed entirely by the intermaxillaries, the labials lying in a membrane behind them, and acting as a lever in aid of their protrusion. Under jaw longer than the upper one. Teeth small, chisel-shaped, forming an even row on the intermaxillaries and lower jaw. Tongue conical, blunt, and smooth. Palate also smooth. Five gill-rays, the interior one, which is the smallest, being united to its fellow in the opposite membrane. The dorsal commences above the centre of the orbit, and ends at the strap-shaped tail : it is highest in the middle, thus having the form of an obtuse-angled triangle. The anal begins half an inch behind the anus, and is similar in shape to the dorsal, with which its termination corresponds: the two fins conjointly give a rhomboidal outline to the fish : their rays are simple but articulated, and the membrane is scolloped between them: the central rays of both fins are two inches long. There is a small spine at the beginning of the anal pointing forwards. The ventrals, situated under the pectorals, contain six rays. Scales.-Skin of both sides of the body studded with stellated, bony tubercles*. Colour of the upper side liver-brown without spots, of the under surface white tinged with red towards the tail: the fins are reddish with broad vertical black stripes. Length one foot.

\section{[104.] 2. Pleuronectes (Rhombus) glacialis. (Pallas?) Aretic Turbot.}

Genus, Pleuronectes. Lins. Sub-gente, Rhombus. Cuv.

Pleuronectes glacialis. Pallas, Reise durch versch. Prov. des Rusch, 1772-73, p. 706†?

'This fish was taken in Bathurst's Inlet, under similar circumstances with the preceding. No specimens were brought home, and the description is too brief and general to serve to identify the species completely. Unless Pallas has overlooked the nearly hidden anal spine, ours is a different species from his.

* Pallas describes these tubercles as follows:-_ Tubercula omnia centro glabrata, hive radiatim muricata, extimo spinulis longioribus subradiantia." Tilesius calls them "tubercula stellata," "aculeato-stellata," or " stellula aculeatce ;" and Mr. Collie, who observed the species in Awatska Bay, says that they are subpentagonal, set round with small blunt teeth. The stomachs of the individuals he upened contained small fishes. The rays of the fins are cuunted as follows by the two former authors.

$$
\begin{aligned}
& \text { RAYs.-Br. } 3 ; D .56 ; A .37 ; P .12 ; V .6 ; C .18 \text {. Pallas. } \\
& 6 ; 52 ; 40 ; \quad 8 ; 6 ; \quad 16 \text {. Tilesius. }
\end{aligned}
$$

+ Pallas's short description of his 1 . glacialis is as fullows :- "Dodrantalis, facie Flesi. Oculi a latere dextro fusco, subaspero; Latus album læve. Spinæ nullæ, nec ad pinnas, neque in lineâ laterali. Tractus capitis, pone oculos prominulus, scaber, sed non in tubercula divisus. Radii medii pinnæ dorsi anique a latere fusco quasi spinulis minutissimis hispidati. Radii p. dorsi 56, ani 39. Frequens in oris arenosis Oceani glacialis." 


\section{DESCRIPTION}

Of a recent specinien, taken in Bathurst Inlet, lat. $67^{\circ} 40^{\prime}$ N., 5th August, 1821.

Form.-Profile somerrhat orate, the snout rather acute, and the tail linear or strap-shaped for half an inch. HEAD.-Eyes moderately large, on the right side, near the snout. Nostrils between the eyes. Month small, its margin formed by obtuse lips; when closed the small, callous, obtuse tip of the lower jaw projects upwards. Teeth fine, brush-like, in an cven band on both mandibles. Fiss. - Dorsal and anal bordering the body to the height or depth of an inch, becoming narrower before and behind. There is a spine almost concealed by the skin at the commencement of the anal. The ventrals are under the pectorals; both are small. Caudal cuneiform, entirc. Scales small, those on the back rough-edged, those on the white sides smooth. Lateral line straight. CoLour.-A mixture of yellowish-grey and dull, greenish-grey, somewhat clonded but without defined spots. Belly bluish-white. Caudal fin irregularly spotted with red. Irides wood-brown. 


\title{
DISCOBOLI.
}

'Tue union of the ventrals into a disk with which the fish can adhere, as by it sucker, to stones and other substances, is a distinguishing character of this family. The species, few in number, are arranged in two genera-Lepadogaster, mostly European, and not hitherto detected in America; and Cyclopterus, distributed throughout the northern parts of the Atlantic and Pacific. The following have been enumerated among the fish of the United States. Cyclopterus lumpus, Penn., Smith (C. covuleus, Mitchill); C. minutus, Smith.-C. ventricosus, Pall., and $C$.gelatinosus, Inem, inhabit the sea between Kamtschatka and America.

\section{[105.] 1. Cyclopterus lumpus. (Linn.) The Lump.}

\author{
Famtly, Discoboli. Cuv. Genus, Cyclopterus. Linn. Sub-genus, Lumpus. Cuv. \\ Cyclopterus lumpus. FaBr., Faun. Groenl., p. 131. \\ Common lump. Penn., Arct. Zool, Suppl., p. 110. No. 13. \\ Blue lump fish (Cyclopterus coeruleus). Miтchild, i., p. 480, pl. II., f. 7. \\ Nepeesa, Angusedlok, male, Arnardlok, female, Grennlanders.
}

The genus Cyclopterus possesses a well-marked character in the form of the ventrals, whose rays surround the pelvis, and are united by a membrane into a single concave oval disk, or sucker. The mouth is wide, and the jaws and pharyngeals are armed with bands of small pointed teeth; the gill-covers are small, and the gill-openings are closed below by their membrane, in which there are six rays. The very large pectorals unite with each other almost under the throat so as to embrace the disk of the ventrals. The skeleton acquires little bony hardness, but the viscous skin, destitute of scales, is sprinkled with small hard tubercles. The stomach is pretty large, the cæca numerous, the intestine long, and the air-bladder of a moderate size. There are two sub-genera, Lumpus and Liparis, which are distinguished from each other by the form of the body and the presence of one or two dorsals. In the lumps there is a very low first dorsal supported by simple rays, and a second one with branched rays opposed to the anal; the body is thick. 'The Common lump appears to be an inhabitant of both sides of the North Atlantic, in all the temperate latitudes, and up to the Arctic circle; but it seems to be most 
abundant about the 60th parallel, being very plentiful among the Orkney islands, and on the Greenland coast. Dr. Mitchill describes the lump of the New York coast as a distinct species, under the name of Cyclopterus coruleus, but his figure is a tolerable representation of the Common lump, and no part of his description disagrees with this species,-the colours of his specimen being very similar to those of the "pavonian sucker" of Betumaris Bay, described by the Reverend Hugh Davies, which differs from the common state of the lump merely in the brillianey of its tints. Indeed this fish varies greatly in liue according to its age and sex, the male being generally more coloured. Lieutenant-Colonel Hamilton Smith obtained a lump resembling Mitchill's, in the Baie des Chaleurs of the Gulf of St. Lawrence. Fabricius describes the lump as approaching the rocky bays on the Greenland coast, in the months of April and May, for the purpose of spawning. The female precedes and deposits her roe among the larger algæ, and in fissures of the rocks; the male shortly follows and fructifies the eggs, adhering so closely to the mass of roe, that the impression is left upon the hollow surface of the shield formed by the ventrals; after which he keeps watch over the sacred deposit, and guards it from every foe with the utmost courage. If driven from the spot by man, lie does not go far, but is continually looking back, and in a short time returns. Even the well-armed wolf-fish hazards his life if he approaches the lump's nest: for this creature, notwithstanding the smallness of its teeth, is (as we have already mentioned, p. 95, on the authority of Fabricius) capable of attaching itself to its adversary's neck, and inflicting thereon a mortal wound. Lacépède denies the truth of the whole of this story, attributing its origin to the vivid imagination of some one who having occasionally seen two of these fish sticking to the same stone in the vicinity of a deposit of spawn, inferred that the eold and sluggish lump is animated by ardent feelings of constant love, conjugal tenderness and fidelity, and a devoted attachment to its offspring. But, notwithstanding the eloquence which this writer has employed to discredit the vulgar opinion of the lump's care for its progeny, it is not perhaps altogether devoid of truth, and it can be supported, if not by direct testimony, at least by analogous facts. The gouramy (osphromenus: olfax), one of the anabasidea, which attains the size of a turbot, is said to dig a pit in the sand wherein it deposits its roe: we have quoted, in page 96, Olivi's account of the male Venetian goby building a nuptial cliamber for the reception of the spawn which he impregnates, as it is deposited there by various females that come in succession into his harem: the hassars of Essequibo, belonging to the genera Doras and Callichthys of the siluroid fanily, not only construct a nest of leaves or grass to contain their roe, but the male and female (for they pair) watch and de- 
fend it till the young come forth * : the protection which some of the cartilaginous fishes are reported to afford to their young, by receiving them into their mouths, is not less remarkable: in short, when we consider the instinct with which various reptiles and insects are endowed for the preservation of their eggs, there does not appear to be anything surprising in the fact, that some tribes of fish have been formed with similar desires and powers.

The food of the lump consists chiefly of soft mollusca, particularly small pteropodes and acalepha, as clio, medusa, and berije, which abound in the northern seas. The Greenlanders eat its flesh, either cooked or dried, and its skin raw, throwing away only the tubercles, being in this respect less nice than the seals of the Pentland firth, which devour a great many lumps but reject the skins. If the authority of Sir Walter Scott is to pass current in gastronomy, the lump, or cock-paidle as it is named in Scotland, is a fish of good quality, for he makes Mr. Oldbuck give the same price for one that he does for the bannock-fluke, or turbot. The epithet of cock-paidle seems to have originated in the resemblance of the first rorsal, which is enveloped, like the rest of the fish, in a thick, tuberculated skin, to the comb of a domestic cock. Sibbald mentions another "gibbosus piscis," as known in Scotland by the name of " hush-paidle," or " bagaty." Not having access to an American specimen of the lump, I shall omit the description.

$$
\begin{aligned}
& \text { Fins.-Br. } 4 ; D .0-11 ; P .20 ; V .6 ; A .11 ; C .12 \text {. Fabricius, l. c. } \\
& 6 ; \quad-11 ; 17 ; 6 ; 11 ; \quad 9 \frac{3}{3} \text {. Scottish specimen. }
\end{aligned}
$$

\section{[106.] 2. Cyclopterus minutus. (Pallas.) Diminutive lump.}

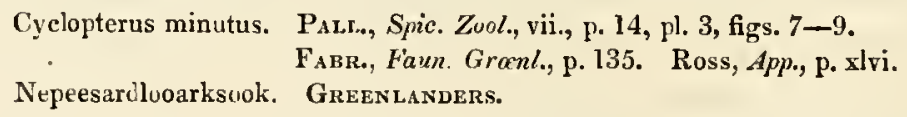

Captain J. C. Ross says "Pallas's description of this extraordinary and beautiful little fish is most perfect. It is found in many parts of the Atlantic Ocean; Fabricius observed it in the southern parts of Greenland, and great numbers were taken by us from among the extensive floating patches of sea-weed that are met with off that coast; but it has never been seen at any great distance to the north-

\footnotetext{
* This is not the only analogy that these fishes present to the anabasidea. Like the latter they travel over land in quest of water when the pools which they inhabit dry up, and, according to Indian information, they also possess the power of carrying an internal supply of water, but we are not informed whether the reservoir be situated over the gills, as in the anabasidea, or elsewhere.
} 
ward of the Arctic circle. It rarely much exceeds an inch in length, and is therefore not used by the natives of Greenland as food, but constitutes the chief means of subsistence to the several species of gulls which are seen hovering over those banks of sea-weel in astonishing numbers." Ross, $l$. $c$.

\section{[10\%.] 3. Cyclopterus spinosus. (Fabricius.) Spiny lump.}

Cyclopterus spinosus. Fabr., Fam. Groenl., p. 134.

Nepersardlook. Greenlanuers.

Fabricius saw but a single individual of this species, which he obtained in the southern part of Greenland. It is not eaten by the natives.

The tubercles of the skin are not ranged in rows as in the lump, their bases are rough, and they rise into a longish spine in the centre, the largest being upon the upper parts, while the belly is smooth. The first dorsal is not so high, nor so thick, as in the lump, and its edge is not armed with tubercles, but its soft rays are evident enough. The hue of the fish is blackish, the belly whitish, and the twelve first rays of the pectorals quite white. Fins.-Br. $6 ; D .6-11 ;$ P. 23; V. $6 ;$ A. 10;C. 10.-Fauna Gronl.

\section{[108.] 4. Cyclopterus ventricosus. (Pallas.) Bellying lump.}

Cyclopterus ventricosus. Pali., Spicileg., II., 1, 2, 3.

Lepadogaster ventricosus. SchNerd., Bloch, p. 3.

This species being an inhabitant of the straits which separate Kamtschatka from America, and therefore belonging equally to both continents, ought to be enumerated in a list of American fish.

[109.] 1. Cyclopterus (Liparis) comunis. (Artedi.) Unctuous sucker.

Famiu, Discoboli. Cuv. Genus, Cyclopterus. Linn. Sub-gemus, Liparis, Artedi.

Cyclopterus liparis. F F 1 Br., Faun. Gronl., p. 135. Ross, App. Parry's Polar Voyage, p. 199.

Liparis communis. SABine, App. Purry's First Voyage, p. ccxii. ; Ross, App., p. xlvii.

Abapokeetsok. Greesinders. Sea-snail. Yorismire Fisuermen.

The Unctuous sucker is said to inhabit all the northern seas. It abounds on 
the Greenland coast, and was taken on the west side of Davis' Strait, in the 70th parallel of latitude, on Sir Edward Parry's first expedition, and more recently near Felix Harbour, in Regent's Inlet, by Captain James C. Ross. The same officer observed it on the north side of Spitzbergen in $80 \frac{1}{2}^{\circ}$ of latitude. Fabricius says it feeds upon young fish, small crustaceæ, and marine confervæ. It is not eaten by the Greenlanders. The fish of this sub-genus have only one dorsal, which is, like the anal, pretty long: the body is smooth, elongated, and compressed towards the tail. I have had no opportunity of comparing American specimens of the unctnous sucker with the European fish, but Captain Sabine says that those taken in Davis' Strait differ in no respect from the unctuous suckers of the English coast. Captain James C. Ross states that the average length of those that came under his observation, in his various voyages, was about three inches.

Fabricius notices a liparis of a larger size, which is known to the Greenlanders by the name of amersulak. Though this kind attains the length of a foot, and agrees, he informs us, in many particulars with the cyclopterus gelatinosus of Pallas, he does not think that it is a distinct species from the preceding one.

The following notice of a fish of this family, which inhabits Behring's Strait, is from the Appendix to Captain Beechey's Voyage. “Off St. Lawrence Island was caught in a dredge, a fish apparently allied to the genus Liparis. It had the ventral fins placed before the pectorals, but united and continuous with them; a flat, raised, and rough tubercle, of nearly the diameter of an English sixpence, was seated forwards between the pectorals, its anterior part reaching as far as the ventrals: its cceca were pretty numerous (Collie). The roughness of this tubercle renders it difficult to refer the fish to any known species, but it is probably nearly related to the cyclopterus gelatinosus, Pallas, a liparis which is known to inhabit the seas in which this was obtained. The existence of caca removes it from Lepadogaster of Gouan." Bennetw, App., p. 50. 


\section{ECHENEIDEAS.}

THE members of this family, which contains only one genus, may be at once recognised by a flat disk on the top of the head with which they attach themselves to sharks, ships' bottoms, \&c.: it is composed of transverse moveable cartilaginous plates, toothed or spinous on their posterior edges, and divided into two series by a mesial longitudinal line. The echeneidea have an elongated body clothed with small scales; a single, soft dorsal opposite the anal; the head altogether flat above; the eyes lateral; the mouth horizontal and rounded; the lower jaw projecting beyond the upper one, and armed, like the intermaxillaries, with small teeth in card-like plates; a very uniform row of slender teeth, resembling eye-lashes, on the edge of the labials, which form the border of the upper jaw ; the romer furnished anteriorly with a cardiform stripe of teeth, and its whole dilated surface as well as the tongue rough. They have eight gill-rays, the stomach forms a wide, blind sac, the eæca are six or eight, the gut is wide and short, and they want the air-bladder. The echeneidea are very disagreeable-looking fish, the flatness of the top of the head giving them the appearance of swimming belly upwards: they fasten themselves upon the shark apparently for the purpose of being conveyed at ease through the ocean, and of being ready to consume any small fragments that drop from the monster's jaws when he takes his prey. Great numbers attach themselves to ships' bottoms in the tropical seas, particularly on the coast of Africa, and when the cook throws the washings of his coppers overboard, they dart off to feed upon the grease and boiled pease with which the water is soiled, returning again in a short time to the ship, swimming with a wriggling motion like an eel, and with considerable velocity, so as to overtake with ease a vessel going before a brisk gale. They are wary in taling a bait, but may be occasionally allured by a pellet of fat, or a little piece of rreasy dough, covering a very small hook. 'The echeneidea inhabit both the Atlantic and Pacific, being numerous only within the tropics; their northern limit, in the former sea, appears to be about the 48th parallel. A well-known Mediterranean species, which exists also in the ocean, was fabled by the ancients to possess the power of arresting a ship in its course, whence its name of $\varepsilon \chi^{\circ}$ vy is, and echeneis among the Greek and Roman authors, and of remora by more modern writers. The same species, and another of a larger size named naucrates, are included by Drs. Mitchill and Snith in their respective lists of the fish of New 
York and Massachusetts, but their identity with those known to European naturalists by the same names is questionable. Dr. Mitchill enumerates twenty-four plates in the disk of his Big oceanic sucker (echeneis naucrates), while the naucrates of Cuvier has only twenty-two; and Dr. Smith's figure of the echeneis of Boston, which he refers to remora, represents a much more slender fish than the Mediterranean one of that name, the number of the plates of the disk being, however, eighteen in both. Echeneis lineata of Schneider has only ten plates in the disk, and $\boldsymbol{E}$. osteocheir of Cuvier has the pectoral rays compressed, bony, and terminated by a slightly crenated little plate.

[110.] 1. Echeneis naucrates. (Auct.) Ship-master echeneis.

Fadily, Echeneideæ. Genus, Echeneis. Artedi.

A specimen of an echeneis in the Zoological Museum, obtained by Mr. Audubon on the banks of Newfoundland, has twenty-two pairs of nearly transverse plates in its disk, agreeing in this and other respects with the accounts of the echeneis naucrates, to be found in ichthyological works, but I have had no opportunity of procuring an authenticated example of the latter wherewith to compare it. The naucrates, or ship-master, inhabits all the warmer districts of the Atlantic, and was taken by Mr. Collie among the Soutl-Sea Islands. 
ANGUILLIFORMES.

\section{MALACOP'TERYGII APODES.}

ANGUILLIFORMES.

[111.] 1. Angulla rostrata. (Le Sueur.) Beaked-eel.

Familx, Anguilliformes. Cut. Genus, Anguilla. Thuxberg. Sul-genus, Murana. Lacép.

Murana rostrata. Le Suev r, Journ. Ac. Sc. Phil., i., p. 81. An. 1817.

THrs order contains only one natural family of which the members have serpentiform bodies, clothed with thick, soft skin in which the scales are scarcely perceptible, their ribs are few, and they have no crea; almost all of them possess airbladders, often of very curious shapes.-The $\mathbf{E}_{\mathrm{L}} \mathrm{L}$ fanily may be recognised by their small opercula, surrounded concentrically by the gill-rays, and enveloped in the skin, so that the gill-opening is reduced to a small tube whose orifice is far back. 'Tlueir bodies are long and slender', and their scales, embedded in a fat thick skin, become visible only when this dries up: they all want the ventral fins and pyloric cæca, and their anus is far back. All these fish were included by Linnæus in his great genus Murena, which has been divided and subdivided by subsequent writers, who have introduced many new designations for their groups, and applied the generic name murcena, each after his orn fancy, to divisions of very different extent and value.-The eels, anguilla of Thuberg, or murana of Bloch, are known by the double character of the existence of pectoral fins and of the gill-openings being placed beneath them. Their stomach is a long blind sac, their gut almost straight, and their elongated air-bladder has a peculiar gland in its middle. 'The extent and form of the vertical fins serve to characterise the minor divisions of anguilla, such as the true eels, or murana of Lacépède, the congers or congri of Cuvier, and the ophisuri of Lacépède.-The murays, murana of Thunbergs (gymnothorax, Bloch, muranoplis, Lacépède), want the pectorals altogether, their gill-openings are merely a little hole on each side, and their gill-covers and their small feeble rays are so concealed by the skin, that their existence has been altogether denied by able naturalists : their stomach is a short bag, their air-bladder small, oval, and high up in the belly. 
The Common eel of Europe belongs to the True eELs, or that division of Thunberg's genus anguilla, in which the commencement of the dorsal is pretty far behind the pectorals, and to a minor group in which the upper jaw is shorter than the under one. The French fishermen recognise in the Common eel of ichthyological writers (murcena anguilla, Linn.) four different kinds or, as they say, species, viz., l'anguille verniaux, which is the most common; the long-beaked eel, which has a more compressed and pointed snout; the flat-beaked eel, or grig of the English, in which the snout is flatter and more obtuse and the eye smaller; and l'anguille pimperneaux, or glut-eel, which has a shorter snout and larger eyes than the others (Règne Animal).-.-The Common eel is mentioned by Pennant, Schoepf, Mitchill, Smith, and many other writers and travellers, as existing in America, and abounding especially in the St. Lawrence, but like many other North American fishes, supposed to be irlentical with the European ones of the same name, the species does not appear to have been determined by an actual comparison of specimens, nor have I discovered in the accounts of American fish, any notice of the four kinds or species we have just alluded to. M. Le Sueur describes five species which inlabit the waters of Massachusetts and New York, under the names of murana rostrata, Bostoniensis, serpentina, argentea, and macrocephala, all of them, he believes, previously unknown to naturalists*. His murana rostrata was found in lakes Cayuga and Seneka, whose waters fall into the St. Lawrence; but whether it be the species which forms the object of the extensive eel-fisheries on this river, of which we shall shortly give an account, we have no means of determining. As he mentions that its eyes are large, it is not likely to be the longheaked eel of the Règne Animal. De Witt Clinton states that the Common eel has often been observed endeavouring in vain to surmount the falls of Niagara, by winding its way upwards among the moist and slippery rocks, and that it is altogether unknown in the superior waters of the St. Lawrence $\uparrow$. Mr. Todd was, however, informed that an Indian speared an eel, three feet long and five or six inches in circumference, at the mouth of the Nattawasaga, which flows into Lake Huron. He had an opportunity, shortly after it was lilled, of conversing with several Canadians who saw it, and who assured him that it was actually an eel. 'The lamprey being well known, both to the Indians and Canadians, could not have been mistaken by either of them for an eel. The surprise which the capture of

* Dr. Mitchill mentions anguilla vulgaris, conyer and oceanica, as New York fish, the latter being, he supposes, lescribed only by himself.

+ He also informs ns that eels nere unknown in the Passaic above the great falls until a canal was cut at Paterson, since which time they have become plentiful in the upper branches of that river. Phil. Tr., New Fork, i., p. 148. 
this fish excited, proves that it is very rare in those parts. I never saw any lind of eel in the rivers of the Fur countries, nor heard of one existing there. Althongh the gill-nets used by the natives and fur traders in fishing have the meshes too large to retain an eel, that fish eould scarcely have escaped their notice did it exist in any numbers in the northern waters. The non-existence of the eel in the waters of the Fur countries is the more remarkable from its being an inhabitant of the lakes and rivers of the southern part of Greenland, though in small numbers. Fabricius says it is called neemereeak by the natives, and that the largest which he saw was thirty inches long and six in circumference. It is an object of abhorrence to the Greenlanders, who will not eat it. According to Vaneouver, " a small sort of eel" of a yellowish-green colour and extrenrely good flavomr, inhalits Port Diseovery, in the straits of Juan da Fuca.

The following account of the mode of fishing for eels, which prevails aluove Quebec for fifteen leagues along the St. Lawrence, is from La Hontan. "At low water they stretch out hurdles to the lowest water-mark, and that space of ground being then dry by the retreat of the water, is covered over and shut up hy hurdes. Between the hurdles they place, at certain distances, instruments called ruckes, from the resemblance they bear to a bee-hive, besides baskets and little nets belayed to a pole, which they call bouteux and bouts de quièves. Then they let all stand in this fashion for three months in the spring, and two in the autumn. Now as often as the tide comes in, the eels looking out for shallow places, and making towards the shore, crowd in among the hurdles, which hinder them afterwards to retire with the ebb water; upon that they are forced to bury themselves in the above-mentioned engines, which are sometimes so over crammed that they break. When it is low water, the inhabitants take out the eels, which are certainly the biggest and largest in the world. They salt them in barrels, where they will keep a whole year without spoiling, and indeed they give an admirable relish in all sauces, nay, there is nothing that the council of Quebec desires more than that this fishery should be plentiful in all years." (La Hontan, An. 1684. Pink. Coll.) Kalm, travelling through Canada nearly ninety years afterwards, drew up a description of the same fishery, which we shall also quote, as it differs from the preceding in the details, and gives us some further insight into the habits of the eel. "They place hedges along the shore made of twisted osiers, so close that no fish can get through them, and from one foot to a yard high, according to the different depth of the water. For this purpose they choose such places where the water runs off during the ebb, and leaves the hedges quite dry. Within this enclosure they place several weels, or fish traps, in form of eylinders, but broader below. They 
are placed upright, and are about a yard high and two feet and a half wide: on one side, near the bottom, is an entrance for the fishes, made of twigs, and sometimes of yarn, made into a net. Opposite to this entrance, on the other side of the weel, looking towards the lower part of the river, is another entrance like the first, and leading to a box of boards about four feet long, two deep, and two broad. Near each of the weels is a hedge leading obliquely to the long hedge, and making an acute angle with it. This latter hedge is made in order to lead the fish into the trap, and it is placed on that end of the long hedge which looks towards the upper part of the river; now when the tide comes up the river, the fish, and chiefly the eels, go up with it along the river-side; when the water begins to ebb, the fish likewise go down the river, and meeting with the hedges they swim along them, till they come through the weels into the boxes of boards, at the top of which there is a hole with a cover, through which the fish can be taken out. This apparatus is made chiefly for the eels. In some places hereabouts they place nets instead of the hedges of twigs." The following passage occurs also in the same work. "They catch eels and porpesses at Quebec at the end of September and during the whole month of October. 'The eels come up the river at that time, and are followed by the porpesses which feed upon them." (Pink. Coll., xiii., pp. 632-672.)

As the Common eel thrives and multiplies in ponds from whence it cannot migrate to the sea, it becomes a matter of interest to ascertain whether there be any specific distinction between the resident and migratory kinds, and the fact that the eel exists in North America, in those parts only to which it has access from tidal waters, is important in such an inquiry.

\section{DESCRIPTION}

Of the Beaked eel of Lake Cayuga, quoted from M. Le Sueur.

"Snout elongated, pointed, and straight; eyes large and situated very near the angle of the mouth; body tumid in the centre, narrowed to a point at both extremities: upper parts varied with grey and olive, sometimes of a slate-blue: lower parts white: dorsal and anal fins reddish, which colour deepens as it approaches the tail ; pectoral fins small, acute, and bluish. Length from eighteen to twenty-four inches."

There is little doubt of the North American coasts being frequented by some of the numerous species of murana (Thunb.). Murana moringa of Cuvier is figured in Catesby, pl. 21, from a Bahama specimen, and Dr. Mitchill mentions murana meleagris among the New York fish. The black and green muray of Catesby, pl. 20, is considered by Pennant to be the common murana helena of Linnæus. 
[112.] The Ophidium viride of the Fauna Gronlandica is unknown to Cuvier, though he believes it to be allied to the Eels. 'The species is said to attain the size of a cod, but the only specimen seen by Fabricius measured no more than two inches. It is taken with a hook and bait in deep water, on the southern coast of Greenland, and is eaten, when of sufficient size, by the natives, who call it oonernak.

It resembles a blenny in form, the head being broader than the body and grooved betwixt the eyes. The mouth is wide, beardless, and toothless; the gill-rays are seven in number, the membrane ventricose; there are eleven rays in the peetorals; the dorsal, beginning behind the head, is, together with the anal, united to the eaudal, whose longer rays are produced to a point; there are no ventrals; the anus is situated nearer to the head than to the end of the tail. The whole fish has a green colour except the belly, before the anus, and the fins, which are white. Fauna Gronl., p. 142.

A fish taken from the stomach of a kittiwake gull, in Prince Regent's Inlet, was considered by Captain James C. Ross, as identical with Fabricius's ophidium viride, from its accordance with the description of that author. App. Parry's Third Voyage, p. 110.

\section{[113.] 1. Saccopharynx ampullaceus. The Bottle-fish.}

FAmir, Anguilliformes. Cuv. Genus, Saccopharynx. MitchiL..

Ophiognathus ampullaceus. Harwood, Ph. Tr., An. 1827, p. 49, pl. 7.

In this singular genus the body, capable of being inflated like a sack or leathern bottle, is terminated by a very long and slender whip-like tail, edged above and below by the narrow dorsal and anal which unite at its tip. The mouth, armed with long sharp teeth, is cleft far past the eyes, which are close to the very short pointed snout. The gill-openings, having the form of irregular slits, and large enough to permit the three branchiae to be seen, are under the very small pectorals. The slin is soft, slimy, loose, and slightly granular in appearance. The extensibility of the jaws and throat. is extraordinary, being even greater than that exhibited by the serpent tribe. Only two examples of the genus are known to have been taken, and, with the exception of dimensions, they realise many of the popular accounts of the great American sea-serpent. They are voriteious fish, with a eapacious stomach and short straight gut. One of the specimens had recently before its capture swallowed a fish longer than its own body, and the 
other had apparently exhausted itself in vain attempts to gorge a sea-perch thicker than itself. The individual described by Dr. Harwood, measuring four feet and a half in length, was captured in the entrance of Davis' Strait, by Captain Sawyer, of the ship Harmony, and the other was taken by Captain Hector Coffin, about midway between the Labrador coast and Ireland, in the 52ud parallel of latitude. A description of the latter, by Dr. Mitchill, is contained in the first volume of the Annals of the Lyceum of New York, but it is unaccompanied by a figure, and the detiils which are given do not clearly point out the differences between it and Dr. Harwood's ampullaceus. Dr. Mitchill, believing his fish to be the stylephorus chordatus of Shaw, appears to have intended to retain the specific appellation, and merely to change the generic name to saccopharynx, which having the priority of opliognathus must be adopted.

In Dr. Harwood's fish the anal terminates insensibly fourteen inches, and the dorsal twenty and a half, short of the tip of the tail, and there are a few slender filaments springing from near the termination of the latter; but in the saccopharynx chordatus the dorsal and anal extend in form of fillets, or narrow ribands, quite to the tip of the tail, where they unite with a very indistinct caudal, of which Dr. Mitchill could perceive only a few hair-like rays. This author also mentions a whitish longitudinal stripe on each side of the dorsal fill, and another less erident and disappearing sooner, on each side of the anal. About fifty pairs of slender barbels or threads an inch long depended from the dorsal stripes, all the way from the head down the back, and along the tail. As soft barbels go to decay generally sooner than other parts of a fish, the specimen of ampullaceus may have been imperfect in these appendages, and also in the extent of the vertical fins. In chordatus the tail was sufficiently flexible to allow several knots to be tied on its tip as upon a piece of whip-cord. It had no teeth on the lower jaw, while ampullaceus had a single series of long teeth on the intermaxillaries and lower jaw. Dr. Mitchill's specimen was a female, with large ovaries full of eggs, but the sex of Dr. Harwood's is not mentioned.

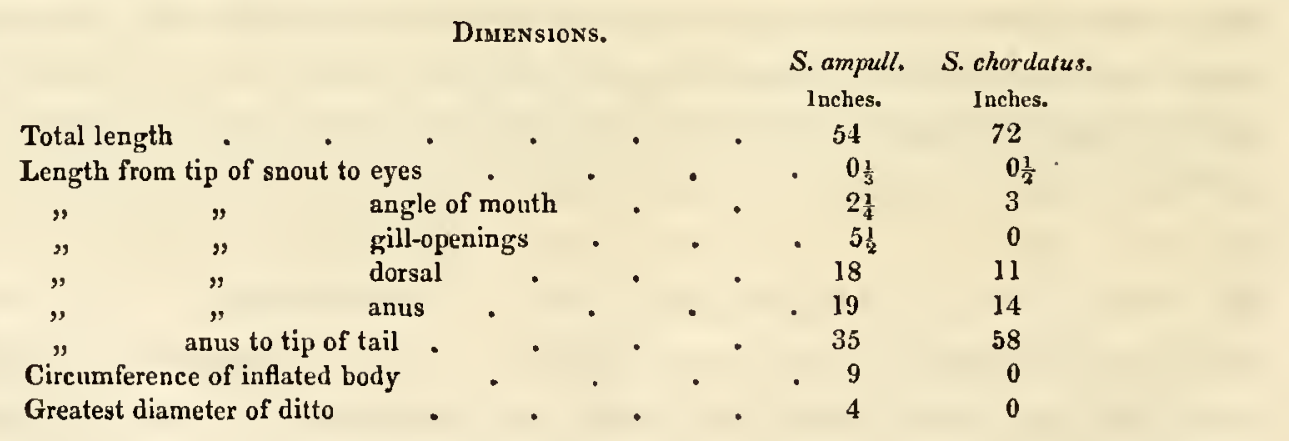




\section{[114.] 1. Opindum stigma. (Bennett.) Branded ophidium.}

Famu, Anguillifurmes, Cuv. Genus, Ophilinm. Lisn.

Ophidium stigma. Bennetr, App. Beechey's I'oy. ined.

The ophidia resemble the anguilla in the backward position of the vent and the union of the dorsal and anal to the caudal, which forms a pointed extremity to the fish; the body is long and compressed like the blade of a sword, and covered, as in the eels, with small scales planted irregularly in the substance of the skin. 'These fish differ, however, from the eels in the wideness of their gill-openings, which are furnished with a conspicuous operculum, and a membrane supported by short rays: their dorsal rays are jointed but not branched.-The genus is subdivided in the Règne Animal into the true ophidia, which have two pairs of small barbels attached to the tip of the hyoid bone and depending from the throat; and the fierasfers, which want these appendages, and have a dorsal so slender that it looks like a mere fold of the skin. 'The Cirrhous ophidium of Dr. Mitchill, which is an inhabitant of the New York seas, belongs to the first division; but the Spinous ophidium of the same author is evidently a centronotus, and of the same species, or at least very nearly allied to the Labrador fish which we have described at page 91 .

The Branded ophidium of Mr. Bennett was discovered in Kotzebue Sound, on Captain Beechey's recent voyage to Behring's Strait, but the only specimen that was obiained was not preserved.

"The caudal, dorsal, and anal fins were united inio a transparent ridge; the scales were very small, and the rays of the branchial corcring distinct."-Collie. "Its colour dilutebrown with roid swathes or spots, and a purplish spot near the beginning of the dorsal fin. Its snout obtuse, chin with a large gibbosity, and teeth small. Its length five inches."-Lay. Its peculiar characters, gathered from the notices presersed of it, are thus summed up by Mr. Bennett.- Ophidium (imberbe?) pallidè brunneum, fasciis maculisque plurimis; macula magna purpurea ad ortum pinna dorsalis." - BENNET, l. c. 


\section{[115.] 2. Ophidium Parrit. (Ross.) Parry's Ophidium.}

Ophidium Parrii. Ross (Captain J. C.), App. Parry's Third Voy., p. 109, and Polar Voy., p. 199. IDEM, App. Ross's Second Voy., p. xlvii.

This species, discovered and describer by Captain James C. Ross, has not come under the notice of any other naturalist. It was first seen on Sir Edward Parry's third voyage in Baffin's Bay and Prince Regent's Inlet, swimming among ice, in the cavities of which it finds refuge from the sea-fowl, who, from its keeping near the surface, would find it an easy prey if deprived of such retreats : a glaucous gull, shot near Felix Harbour, on Sir Joln Ross's recent voyage, ejected one, measuring four inches in length, from its stomach. Captain J.C. Ross informs us that this ophidium belongs to Cuvier's sub-genus Fierasfers, and in its general appearance approaches nearly to the Ophidium viride of Fabricius (p. 2\%1), but has very much larger pectoral fins, the number of their rays being between three and four times greater than in Fabricius's fish. His description of it is as follows :-

" HEAD very obtuse, being of equal length, depth, and transverse diameter, broader than the body, flattened and grooved between the eyes, which are lateral and rather large; irides pearl-white. Mouth rather large, placed at the extremity of the head, and armed with numerous minute teeth on the palate and either jaw: lower jaw rather longer and without cirrhi. Bony three times the length of the head, ensiform, much compressed, and gradually tapering towards the tail, which is pointed. Neck much arched, giving a greater depth to the body than to any other part. Back of a dark greenish-brown colour, which is lighter on the sides; belly before the vent white; vent nearer the head; fins partake of the colour of that part of the body on which they are inserted. Fins. - The dorsal, which rises just behind the head, and anal, which commences close to the vent, unite witl the caudal, and together consist of ninetyfive rays, of which there are fifty in the dorsal and superior half of the caudal, and forty-five in the inferior half of this fin and the anal. The pectoral fins, which are very large, contain thirty-seren rays, and when stretched backwards along the body, extend rather beyond the rent, completely covering the whole of the belly and throat. The individuals raried fron four to eight inches in length. The following measurements are of an ordinary-sized fish :-

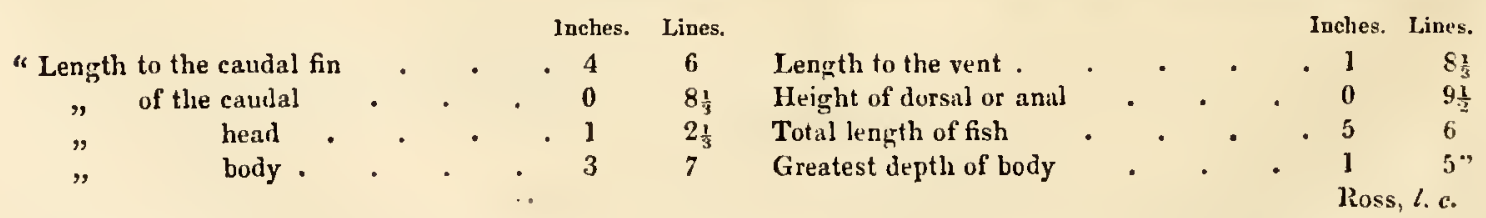

On Sir Edward Parry's Polar expedition a putrid ophidium was found among 
some sea-weed on WValden Island, to the north of Spitzbergen, which was considered to belong to this species, but the pectoral fin, though of large size, contained only twenty-eight rays.-Ross, Pary's Polar Voy., p. 199.

\title{
[116.] 1. Amodytes lancea. (Cuv.?) Sand launce.
}

\author{
Famux, Anguilliformes. Cuv. Gaves, Ammodytes. Lres. \\ Ammodytes tobianus. Fabricies, Fuuna Groenl., p. 140. \\ Lance (Ammodyles tobianus). PENn., Arct. Zwol., ii., Suppl., p. 113.
}

'The launces have, as their name imports, an elongated body like the preceding genera, a dorsal fin supported by unbranched jointed rays occupying a great part of the back, an anal of a similar appearance, and a forked caudal separated from the other two by small spaces. The snout is pointed, the upper jaw extensile, but shorter when the mouth is shut than the lower one. The stomach is fleshy and pointed, and they have neither air-bladder nor pyloric cæca. They feed on worms, and bury themselves in the sand, from whence the fishermen dig them when the tide retires. Pennant states the Ammodytes tobianus of Linnæus to be plentiful at Newfoundland, and Dr. Mitchill enumerates it among his New York fish; but as naturalists have until lately confounded two species under the Linnæan name, and the one Pennant has figured as tobianus in British Zoology is the lancea of Cuvier, it remains to be ascertained to which of the species the American fish is to be referred, if indeed it belongs to either.-Neither Pennant nor Mitchill have favoured us with a description of the transatlantic launce.

Fabricius considers the putsrotok of the Greenlanders to be the Ammodytes tobianus, and from the number of rays in its dorsal and anal being greater than in the lancea of Cuvier, it is probably the species represented by Bloch, pl. 72, f. 2 . It frequents parts of the sea having sandy or clayey bottoms, in which it hides its head, and remains quiet with its tail pointing upwards and body spirally twisted. It rarely visits the surface, though it is occasionally observed swimming near pieces of ice, and in the month of May it approaches the beach in company with the capelins. It searches among the sand with its pointed snout for the worms upon which it feeds.

$$
\text { Fins.-Br. } 7 ; D .67 ; P .14 ; V .0 ; A .34 ; C .16 . \text { Fabricius. }
$$




\section{LOPHOBRANCHII.}

In this, the fifth order of fish according to Cuvier's arrangement, the jaws, as in the preceding orders, are complete and free; but the branchix, unlike those of other fish, are divided into little round tufts disposed by pairs along the arches: they are shut in by a large gill-cover bound down by a membrane, in which there is merely a small hole for the exit of the water, and only vestiges of rays. The Lophobranchii may also be known by their bodies being encased from one end to the other by shields which give them, in almost every instance, an angular form. They are generally of small size, and almost destitute of flesh. Their alimentary canal is even, without cæca, and their air-bladder slender, but large enough in proportion to the size of the fish. The order is divided into two genera, Syngnathus and Pegasus, the species of the latter being inhabitants of the Indian Ocean. Syngnathus is subdivided into three sub-genera, viz., the Sea-pipes, or True syngnathi, the Sea-horses, or Hippocampi, and Solenostomus, of which the only known species is an inlabitant of the Indian seas. Pennant mentions the Lesser pipe-fish, or Syngnathus acus of Linnæus, as belonging to North America, and Drs. Mitchill and Smith include Syngnathus typhle in their lists of the New York and Massachusetts fish. The peculiarity of the syngnathi carrying their roe after impregnation in little pouches under the belly or tail, which are cleft to give. exit to the young when they are hatched, has been long known to naturalists, but Mr. Yarrell has recently shown that it is the male fish alone which is provided with these receptacles for the roe. 


\section{PJECTOGNA'THI.}

Tне sixth order of osseous fish makes a near approach to the Chondropterygii in the imperfection of the jaws and the tardy ossification of the slieleton, which is nevertleless fibrous, and in its general structure the same as in ordinary fishes. Their principal distinctive character consists in the labials being joined inmoveably to the intermaxillaries which form the upper jaw, and in the arch of the palate being united by suture to the cranium, and consequently destitute of all notion. The gill-covers and rays are noreover concealed under a thick skin which leaves only a small branchial slit; there are no ribs; the true ventrals are wanting, the alimentary canal is wide, without cæca, and an air-bladder of considerable size is almost always present. The order comprises two very natural families, the Gy NoDontes, which, instead of teeth, have their jaws armed with a substance like ivory, divided internally into plates, and having a general resemblance to the beak of a parrot; and Sclerodermata, which are readily known by a conical or pyramidal swout projecting from before the eyes, and terminated by a small mouth armed with a few distinct teeth in each jaw. Their skin is generally rough, or clothed with hard scales*. The following species have been stated to frequent the cunsts of the United States :-Diodon menctatus, Cuvier (D. attinga, Schoepf, $D$. hystrix, BL.) ; D. rivulatıs, Cuvier (D. maculato-striatus, Mitchill) ; $D$. pilosus, Mitchilı; Tetraodun geometricus, Schneider Bl.; T. lineatus, BL., Schoepf; T. hispidus, Schoepf; T. turgidus, Mitchill ; T. lavigatus, Willovgh., Schn. Bl.; T. curvus, Mitchild; Orthagoriscus mola, Schn. (Tetraodon mola, Jinn., Scroepr); Balistes tomentosus, Linn.; B. vetula, Bu.; B. hispidus, Linn., Schn, Bl.; B. monuceros, Linn., Penn. (Aleuteres monoceros, SnitiI); B. aurantiacus, Shith ; B broccus, Shith; B. sufflamen, Surti ; Ostracion triqueter, Sniтn; O. bicaudalis, Sniтn; O. quadricornis, Schn., $B l$. There is considerable confusion in the application of these names, some of them, at least, being preoccupied by fish belonging to other quarters of the ocean. 


\section{CHONDROPTERYGII ELEUTHEROPOMI.}

\section{STURIONIDEA.}

'The Cartilaginous fishes (those whose skeleton contains no bony fibres, but only small calcareous grains) are considered by Cuvier as forming a series parallel to the osseous fishes, in the same way that the marsupial animals represent the unguiculated mammalia. They are not, in his opinion, either inferior or superior in their organization to the osseous fishes, for many of the genera approach the reptiles in the structure of the ear and genital organs, while others show so much simplicity of form, and such imperfect vestiges of a skeleton, that one might even hesitate in ranking them among the vertebrated animals. The two orders into which the series is divided are characterised by the condition of the gills. The eleutheropomi ${ }^{*}$ resemble ordinary fishes in their gill-openings, which are furnished with a cover edged by a greatly-restricted membrane destitute of rays. This order comprehends only two genera or families, one of which, acipenser of Linnæus, or the Sturionidea, is included by M. Agassiz along with the plectognathi, syngnathi, and fifty extinct genera in his order of Ganoidians; his Placoidians embracing the rest of the cartilaginous fishes. The following Sturionidea have been mentioned by authors as existing in the waters of the United States. Acipenser brevirostris, LE SUEur; A. rubicundus, ID. ; $A$. oxyrhynchus, ID. ; $A$. maculosus, ID.; Platirostra edentula, ID.; Polyodon spatula, Règne Animal.

\section{[117.] 1. Acipenser transmontanus. (Richardson.) Columbia River Sturgeon.}

Family, Sturionideæ. Genus, Acipenser. Auct. Sub-genus, Sterleta. Brandt.

The sturgeons resemble the sharks in general form, but their bodies are defended by bony shields disposed in five, or in a few instances in three, longitudinal rows; their head is also well cuirassed externally; their toothless mouth, situated

\footnotetext{
* Donati operculis branchialibus liberis. Lovetsky. Eleuthéropomes. Dumeril.
} 
under the snout, is supported upon pedicles, which give it more protractility than the month of the sharks; the upper jaw, formed by the mion of the palate-bones and labials, contains merely vestiges of the intermaxillaries; the eyes and nostrils are lateral ; the snout is furnished beneath with barbels; there is no vestige of an auditory opening, the little hole behind the temples, which has been so considered, being, in fact, only a spiracle leading to the gills; the anal is under the dorsal, which is posterior to the ventrals; the caudal embraces the turned-up end of the spine, and has a broad lobe mnderneath anterior to the principal point. In this genus, as in the selacians, there is a conglomerated pancreas, and the lower part of the intestine is furnished with a spiral valve which serves to delay the passage of its contents. The sturgeons are anadromous fish, ascending rivers in shoals for the purpose of spawning. The migrations of some are confined entirely to fresh waters, others pass a part of the year in the sea. They are particularly abundant in the seas and rivers of northern Asia, and are of great importance, in an economical point of view, to the various nations moler the Russian sway. Caviar is made from the roe, isinglass from the air-bladder, the flesh is eaten fresh, salted, or preserved by aromatic substances, and even the ligamento-cartilaginous cord which pervades the spine constitutes a Russian delicacy named vesiga.

The sturgeons of North Ameriea, though almost equally numerous with those of Asia, are of comparatively little benefit to the natives. A few speared in the summer time suffice for the temporary support of some Indian hordes, but none are preserved for winter use, and the roe and sounds are utterly wasted. 'The ingenious methods practised in Asia of capturing the sturgeon by weirs and moveible chambers are not resorted to in America, though west of the Rocky Mountains salmon are taken by analogous means, which we have already described. The northern limit of the sturgeon in America is probably between the 55th and 56th parallels of latitude. I have met with no account of its existence to the northward of Stuart's Lake, on the west side of the Rocky Mountains, and on the east side it does not go higher than the Saskatchewan and its tributaries. It is not found in Churchill River, nor in any of the branches of the Mackenzie or other streams that fall into the Arctic Sea, a remarkable circumstance, when we consider that some species swarm in the Asiatic rivers which flow into the Icy Sea. Sturgeon occur in all the great lakes communicating with the St. Lawrence, and also along the whole Atlantic const of the United States down to Florida. Peculiar species inhabit the Mississippi, and it is therefore probable that the range of the genus extends to the Gulf of Mexico.

The sturgeon-fishery of Pine Island Lake, whose waters fill into the Saskatche- 
wan, is most productive in the summer, a stray individual being very rarely taken at other seasons. The sturgeons make their first appearance when the river breaks up in the spring, and the lake is flooded with muddy water. The great rapid which forms the discharge of the Saskatchewan into Lake Winipeg, appears quite alive with these fish in the month of $\mathbf{J}$ une, and some families of the matives resort thither at that time to spear them with a harpoon, or grapple them with a strong liook tied to a pole. Notwithstanding the great muscular power of the sturgeon it is timid, and we have seen one so frightened by the paddling of a canoe, that it lan its nose into the muddy bank, and was taken by a voyageur, who leaped upon its back. The Saskatchewan sturgeon weighs from ten to twenty pounds, and rarely attaius the weight of sixty. June is the principal spawning time, but individuals filled with roe have been killed in every season of the year. As this fish is not taken near Hudson's Bay, it is probable that it winters in Lake Winipeg without visiting the sea, though we are not aware that there are any cascades in Nelson's* River which it cannot surmount. On comparing a number of these sturgeons with one another, considerable variety was perceived in the length and acuteness of their snouts, and in the intensity of the colour of their bodies: the older fish had smoother and flatter shields. I brought home specimens of the two most distinct kinds in 1821, and on drawing up a few hasty motices of the fish for the Aplendix to the Narrative of Sir John Franklin's First Expedition, followed the opinion of Forster in considering them to be specifically the same with the acipenser Ruthenus, or sterlet of the Russian rivers. The specimens having gone to decay, I have no means of correcting this reference, which is doubtless erroncous. As far as I can recollect, the Saskatchewan sturgeon, known to the Crees by the name of nameyoo, is very similar to one which exists on the west side of the Rocky Mountains, which I shall now allude to more particularly.

Two specimens of a sturgeon, which I have named acipenser transmontanus, were sent to me from Fort Vancouver by Dr. Gairdiner, accompanied by the following notice:- "The species attains eleven feet in length, and a weight of six hundred pounds $\uparrow$; the small specimens sent home were chosen for their portability. It enters the Columbia early in March every year, and is caught as ligh up as Fort Colville, notwithstaniling the umerous intervening cataracts and rapids, which seem to be insuperable barriers to a fish so sluggish in its movements.

\footnotetext{
* The Saskatchewan loses its name when it falls into Lake IVinipeg, whose superfluous waters are carried to Iludsou's Bay by Neison's River.

T The huro is reported by Pallas to attain a weight of nearly three thousand pounds, and a length exceeding thirfy fect.
} 
It disippears about the month of September. It is termed by the Cheenooks katlook, and in the linguage of the Cascarle Indians nakhun."-The Columbia River sturgeon belongs either to the sturiones or sterleta, two of the four groups into which Brandt has divided the genus, the approximation or remoteness of the shields by which these two forms are characterised not being very precise as a practical mark of distinction*. Its snout is broad as in the Common sturgeon $A$. sturio, lut much more depressed, and its mouth is comparatively large. In its general form and proportion of parts it strongly resembles $A$. Ruthenus, but whether it be the same with the sturgeon of Stewart's Lake and Frazer's River, noticed in page 215 , we lave no means of ascertaining.

\section{DESCRIPTION}

Of No. 1, specimen of $A$. Iransmonlanus from the Columbia River.

Form elongated, tapering from head to tail, the borly keeled by five rows of shields, the dorsal row being the most prominent, and the lateral one least so ; the belly and under surface of the head are flattish; the cheeks are also flat, and the snout rounds off laterally from the nostrils, terminating in a moderately-acute point; the top of the head is slightly convex, both longitudinally and transversely, with a shallow depression extending from between the orbits backwards on the mesial line; the profile shelves off suddenly before the nostrils into the greatly-depressed snout, which, when seen from above, is semilanceolate, its breadth at the nostrils being equal to its length anterior to these openings; in profile the snout appears thin and horizontal, but its flexible point is readily tumed up a little. Two pairs of slender, tapering barbels, quite simple at their tips $\dagger$, hang from beneath the snout about midway between its point and the orbit; the exterior pair, which are a little posterior to the others and rather longer, measure an inch and a half. A bone, forming a narrow, even, flat ridge, is perceptible through the skin covering the under surface of the snout, and terminates abruptly opposite to the anterior margin of the orbit, on the verge of the large cavity in which the mouth is lodged. The snout, if measured from the orbits, forms one-twelfth of the total length of the fish, but less than one-fifteenth if measured only from the nostrils. The mouth is posterior to the eye, and when protruded has an oval orifice, whose axis lying transversely mea-

* Professor Lovetsky, adopting Brandt's subdivision, has given the following arrangement of the species known to him :-

1. Husoves.-Snout acute or obtuse, wholly or parlly cartilaginous, more or less pellucid; shields which arm the body distant from ane another. A. huso, Linv.; A. husoniformis, Lovet.; A. dauricus, Georo.; A. oblusirostris, Lus Sueur; A. rubicumdus, Le Sueur.

2. Sturtones.-Snout obluse or awl-shaped, covered with bony shields not pellucid; slields distant. $A$. Guldensiädlii, Brandt ; sturio (A. Lichlensteinii, Schn., Bl.) ; A. schipa, Guldenst.; A. Geckelii, Fux.

3. Steriets.-Snout awl-shaped, curered with bony shields, not pellucid; shields imbricated. A. Ruthenus, Lisis. ; A. aculealus, Fiscurer.

4. Hecopes.-Snout long (one-sixth or one-seventh of the length of the body), covered witls strung bony shields; shields distant. A. stellutus, Pars.. ; A.oxyrhynchus, Mitcis.; A. maculosus, Le Suevu. (Lovetskx, Nouv. Mim. ile Iforcou, iii., ए. 257. An. 1834.)

t The barbels of $A$. Rwihenus have fringed tips. 
sures an inch and a half, or nearly as much as the distance between the anterior nostrils and the tip of the snout: when the jaws are retracted the commissure of the mouth is transverse, and is drawn considerably within the under surface of the head. The lips, thin and pendulous at the junetion of the jaws, are separated by a fissure on the medial line of the upper jaw, and are altogether wanting on the middle half of the lower jaw. The tongue is fixed, prominent, and smooth, and there are no teeth whatever. The orbits are small and circular and the nostrils large, particularly the posterior openings. Four lengths and a half of the head are equal to the entire length of the fish.

The GilL-Cover eonsists of a pretty large operculum, which has a form more like that of A. schipa than any of the other figures in Lovetsky's monograph*: a chain of three smaller bony plates proceeding from the lower corner of the operculum gives firmuess to the gillmembrane, which is not to be distinguished from the softer parts of the gill-cover.

Skin.-The whole upper surface of the head is encased in bony plates of various forms, which are rough, with radiating, granulated ribs: the plates on the snout actmit of a little motion, the others are fixed; a few small ones exist on the tip of the bone beneath the snout, and farther back rises into two tubereles. The suborbitar bones, humerals, and scapulars, have surfaces still more rough than the upper plates, in conjunetion with which they form a firm helmet that compensates for the too great flexibility of a eartilaginous cranium. The shields on the body have rough saddle-shaped bases, with very acute central ridges terminating in a hook or spine which points backwards, and is longest and most acute on the posterior dorsal shields; there are also some serratures on the ridge of the shields beneath the point of the spine. The dorsal row contains fourteen shields, exclusive of one without a spine, which is incumbent on the first ray of the dorsal fin : the anterior of these shields is fixed among the plates of the head, the others more with the skin, and are near each other, though not in actual contact. The shields on the lateral lines have lozenge-shaped bases, placed obliquely, and are smaller and farther apart than the dorsal ones anteriorly, but the posterior ones successively diminish and approximate until they reach the curvature of the tail, beyond which they cannot be easily reekoned, though they can be traced in form of a cartilaginous line extending along the under margin of the tail to its tip: excluding the extreme caudal ones, then, there are in this specimen forty-two lateral shields on the left side, and forty-seven on the right. The ventral shields, of which there are eleven on the left side, and nine on the right before the ventrals, are wider apart than the lateral ones, and of an intermediate size between them and the dorsal ones. There are also five or six suborbicular, spineless plates in two rows, between the vent and anal fin, one on the commencement of the latter, and another on the upper ray of the caudal. The compressed, turned up part of the tail is covered above the lateral line by ten or eleven crowded rows of small, rough, lozenge-shaped plates, which give it a reticulated appearance. The rest of the skin is studded with small, scattered, stellated tubercles of rarious forms and sizes; some exist even on the

\footnotetext{
* In Professor Lovetsky's monograph on Russian sturgenn, no statement is given of the parts that are included under
} the name of snout, so that we cannot compare the length of this member in our fish with that of his. 
lining of the gill-openings, the shin surrounding the eyc and nostrils being the smoothest. There is a short, smooth groove on the under edge of the tail, between the caudal and anal fins, the use of which is not apparent.

Fiss. $-B r .0 ; P .43 ; V .34 ; D .52 ; A .33 ; C .27 / 86$.

The pectorals have a greater spread than any of the other fins; their first ray is very strong and bony, its slender tip, howerer, being articulated. The ventrals are far back, being nearer to the tip of the tail than to the end of the snout: they have a horizontal position, which, in conjunction with the size of the pectorals, and the position of the mouth, shows that the fish is constructed for taking its prey on or near the bottom of the water. The anal begins as far from the rent as its termination is from the caudal: its middle rays are the longest. The dorsal commences a little posterior to the vent, and terminates a very little anterior to the end of the anal. The portion of the caudal above the tail gradually narrows and disappears short of the point; its rays are rigid and bony, or spinous with very acute points. The under part of the fin is considerably broader, particularly its anterior lobe; its margin is sickle-shaped, and its rays are articulated like those of the other fins. The rays of all the fins are very rough. There are seventecn interspinous bones connected with the dorsal, and eleven with the anal.

CoLour._- Bory and top of the head of a hue intermediate between yellowish and bluishgrey, partially iridescent; shields ash-grey, giving a spotted appearance to the back. Sides silvery-white, with faint vertical bluish-grey bands. Belly white." (Gairdner.)

INTESTINES. - The esophagus, or upper part of the stomach, is furnished with seven longitudinal rows of crenated papille; the rest of the stomach is smooth, with thin coats forming longitudinal folds, except close to the pylorus, where the parietes of the stomach are thick and fleshy, like the gizzard of a fowl. The upper half of the gut, below the pylorus, has its lining finely reticulated, and the remainder is traversed by a spiral membranous valre. A little below the pylorus there is a glandular-looking pancreas which communicates with the gut; when laid open it appears to consist of honey-combed cells, much resembling the second stomach of a ruminating quadruped. The air-bladder communicates with the upper part of the stomach by a pretty large hole. The stomach was filled with the remains of some nearlydigested malloti pacifici, mixed with the light wrack that collccts in the eddies of rivers, such as decayed leaves, water-worn pieces of wood, and the exuvia of the larra of ncuropteræ.

The second specimen has a longer and rather more acuminated snout, twelve dorsal shields, forty-two and forty-three lateral ones, and twelve rentral ones on each side. There are also a few roundish plates ranged near the bases of the dorsal shields. In other respects it resembles the preceding ones perfectly. 
Dimensions.

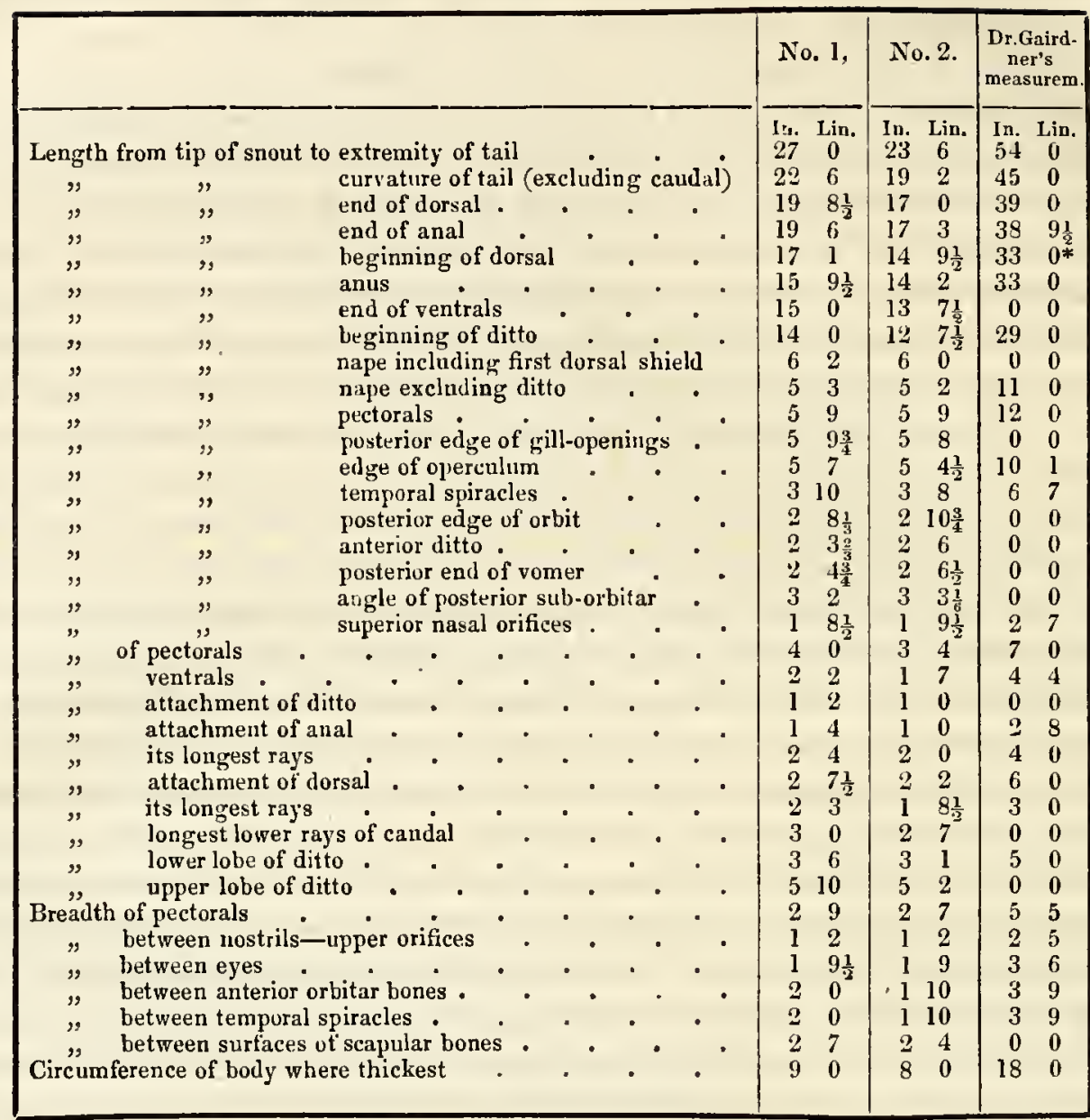

\section{[118.] 2. Acipenser rubicundus. (Le Sueur.) Ruddy sturgeon.}

Acipenser rubicundus. Le Sueur, Ph. Tr., Philad., New Series, i., p. 388, pl. 12.

This sturgeon, which was very imperfectly known to Pennant and other writers who have mentioned Canadian animals, was first established as a distinet species by M. Le Sueur, who found it in lakes Ontario, Erie, Huron, and Michigan. The individuals inhabiting the three latter sheets of water are of course cut off

* This measurement was probably made by Dr. Gairdner to the anterior edge of a shield incumbent on the dor al which is nearly opposite to the posterior verge of the vent. 
from all communication with the sea by the falls of Niagara, and even the sturgeon of Lake Ontario do not perhaps descend the St. Lawrence, as I have no notices of their having been taken in the lower parts of that river. La Hontan says " the lake sturgeons are commonly five or six feet long, but I once saw one of ten feet, and another of twelve. They are caught by the savages with nets in the winter and grapples in the summer." August is termed the sturgeon month by the Canitdian Indians, on account of the productiveness of the fishery at that period. Carver states that sturgeon of excellent quality may be taken in Lake Superior at almost all seasons of the year, but whether they are of the same species with the ruddy sturgeon we have no means of judging. The latter is remarkable for wanting the "tbdominal shields, agreeing in this respect with the A. nudiventris of Lake Aral, which Professor Lovetsky considers to be a variety of $A$. schipa. 'This author refers $A$. mbicundus to the sub-genus sturio, in which the shields are remote and the opake snout is protected by strong bony plates. It is described by M. Le Sueur as having

A yellowish-red colour on the back, and olivaceous-red on the sides. Its head, which forms one-eighth of the total length, is flat above with a roundish snout, haring its four barbels nearer to its tip than to the mouth. The breadth at the eyes is equal to the distance from thence to the end of the snout, which in a fish four feet long is only three inches. The dorsal ridge is much elevated at its junction with the nape. There are nine dorsal shields and thirtyfive lozenge-shaped lateral ones. Fins. $P .50 ; V .28 ; A .22 ; D .42$. (Le Sueur, l.c.)

[118.] Chumera. — Elephantfish.

Elephant fish. Vancouver.

The chimara, though placed by Cuvier at the end of the sturionidea, seem to belong more properly to his second order of chondropterygii, in which the gills are fixed, for though there is only one apparent gill-opening on each side, the gills in reality adhere by a large part of their borders, and there are consequently five holes communicating with the external gill-opening. 'They have, moreover, a great resemblance to the sharks in their general form and the position of their tins. They have a rudimentary operculum concealed by the skin, and their jars, still more reduced than those of the sharks, are furnished with hard plates, four above and two below, in place of teeth. The projecting snout is marlied with rows of pores. The males are distinguished by trifid bony appendages to the ventrals, and they 
have also two spinous laminæ in front of these fins, and a fleshy barbel between the eyes, terminated by a cluster of prickles. The gut is short and straight, with a spiral valve as in the sharks. These fish produce very large leathery eggs, having flat velvety edges*. The only two species known to Cuvier were placed by him in separate sub-genera. The Chimera monstrosa, or king of the herrings, inhabits the European seas, where it preys on fish that migrate in shoals. The Callorhynchus antarcticus frequents the southern seas. The researches of Mr. Collie, during Captain Beechey's recent voyage, render it probable that several undescribed species exist in the Pacific. One was seen at Coquimbo, on the coast of Chili, and another at Monterey, in California, possessing characters intermediate between Chimæra and Callorhynchus. Another, inhabiting the northern parts of the Pacific, is described in the Appendix to the Narrative of the Voyage alluded to by Mr. Bennet, under the name of chimara Colliei. An elephant fish, taken by Vancouver in Port Discovery, lat. $48^{\circ}$, in the Straits of Juan da Fuca, may possibly belong to this species.

* Captain King says that the spawn of Callorhynchus bears a strong resemblance to a broad leaf of sea-weed, within the coats of which the fish, already perfect in form, is discovered suspended in fluid. Griffith's Cuvier, x., p. 97. 


\section{CHONDROPTERYGII TREMATOPNEONTES.}

'The cartilaginous fishes with fixed gills, forming the eighth order of their class in Cuvier's arrangement, are the trematopnès of Dumeril, or the placoidians: of M. Agassiz. Their gills adhere by their outward edges in such a way that the water either escapes by as many holes in the shin as there are intervals betwixt them, or by a common conduit in which all these holes end. Another peculiarity in the structure of these fishes consists in the frequent suspension of small cartilaginous bows in the flesh opposite to the gills, and which may be called branchial ribs. The order is divided into two families.

\section{SELACHII.}

The sélaciens of Cuvier, or plagiostomes of Dumeril, comprise the sharks and rays, which have many common characters. They have the ordinary jaw bones merely in a rudimentary state, their place being supplied by the palatine and postmandibular bones, which are alone armed with teeth, and are suspended to the cranium by a single bone, that represents at once the petrous, jugal, and temporal bones and the preoperculum. 'The gill-rays are attached to the os hyoides, as in osseous fishes, although they are not so perceptible externally, but there is no vestige of any of the three opercular pieces. The ventrals are situated on the hinder part of the abdomen on each side of the vent. The pancreas is in form of a conglomerated gland, and not divided into distinct cæca, and the short gut is provided in its lower part with a spiral valve. These fish are either oviparous or viviparous, and possess well-organised oviducts. The males have curious appendages on the inside of their ventral fins, whose use is not known. The following species have been mentioned as inhabitants of the seas of the United States.

Scrubir.-Seyllium Eduardsii, Cuv. (Squalus canis, Mrtchild; S. coniculu et catulus, Suith). Carcharie.-Squahus carcharias, Penn., Mitchild, Snith; Carcharias vulpes, Sintri (Squalus vulpes, Mitchild); Squalus glaucus, Mitchild, Sintri ; Squalus punctatus, Ideni ; Squalus obscurus, Le Suedr; Squalus littoralis, Inen. Seraches.-Selaclee maximus, Siriti (Squalus 
maximus, Mrtchint; Squalus elephas, Le Suevr). Scrmni.-Squalus Americanus $*$ M Mtchile; Somniosus brevipimis, Le Sueur. Zygene.-Zygana malleus, Valenc. (Zygana vulgaris, Smith; Squalus zygana, Mitchild); Zygana tiburo, Snitin (Squalus tiluro, Penn.). Squatina.-Squatina Dumerilii, Le Sueur. Pristes.-Squalus pristis, Penn. Raiz.-Raia torpedo, ocellata, diaphana, centroura, and bonasus, Mitchill, Raia batis and clavata, Sнrtu; Raia Suyii, Desmarestii, eglanteria, Chantenay, Le Suevr ; Trygon Sabinum, Cuv. (Raia Sabina, Le Suevr); Trygon micrura, Cuv. (Raia Maclura, Le Sueur); Myliobatis Fremenvillii, Le Sueur; Myliobatis quadriloba, Cuv. (Raia quadriloba, Le Sueur). Cepin loptera.-Cephaloptera mobular, Cuv. (Ceph. giorna, Le Sueur; Cephaloptera vampyrus, Mitchill. Devil ray, Penn.). From the imperfect descriptions of many of the above fish, and the want of figures, we cannot be certain of the right application of the names.

\section{[119.] 1. Squalus (Carcharias) vulgaris. (Cuvier.) The White shark.}

White shark. Penn., Arct. Zool., Suppl., p. 105.

The sharks constitute an extensive genus, which is known by the elongated body, thick fieshy tail, and pectorals of mediun size, so that in their general form they are not widely different from ordinary fishes. Their gill-openings and eyes are lateral, their snout is sustained by three cartilaginous branches proceeding from the forepart of the cranium, and their rudimentary intermaxillaries, labials, and premandibular bones are readily discernible. Many of them are viviparous, others oviparous. The spine is divided throughout into rertebræ, and the small ordinary ribs, as well as the branchial ribs, are apparent. The sub-genera are characterised principally by the form of the snout and nostrils, the presence or absence of spiracles on the top of the head, the extent of the gill-openings, the number and position of the dorsil fins, the existence of spines before these fins, the presence or absence of the anal, and the form of the teeth, which are either cutting or en pavès. The carcharia, a most celebrated and numerous group, have sharp

* It is probable that this is not the Squalus Americanus of Gmelin, which is a European species wrong named, from his mistaking Cape Breton, near Bayonne, for the island of Cape Breton, in the entrance of the Gulf of St. Lawrence.Règne Animal. 
cutting teeth, most generally serrated on the edges, their first dorsal is considerably before the ventrals, and the second one opposite to the anal. They are destitute of spiracles, the nostrils are under the middle of the depressed snout, and the posterior gill-openings are over the pectorals. The Common or White shark, the terror of all seas, attains the length of thirty feet, and may be recognised by its teeth, which, in the upper jaw, are in form of an isosceles triangle with reetilinear sides and jagged or serrated edges; in the lower jaw they have a narrow point upon a broader base. The rows of teeth are said to increase with the age of the fish, which, when adult, has six distinet ranges, the outer teeth being then two inches and a half long. 'This shark has a flat head, and a round depressed snout projecting beyond the mouth, which is underneath the head. The pectoral fin is large, as it very frequently is in fishes which have large heads and mouths so situated.

\section{[120.] 2. Squalus (Carcharias) Terrenova. (Richardson.) Newfoundland Shark.}

Green-backed shark (Squalus punctatus). MIтchiLI, i., p. 483 ?

I am indebted to Mr. Audubon for a small and apparently young specimen of this shark. It is closely allied to the carcharias glaucus by the form of its teeth, which are not however serrated, at least in the young state, and its pectorals cannot be said to be very long and much pointed like those of the Blue shark. The Green-backed shark of Mitchill agrees with ours in the teeth not being serrated, but his description is not particular enough to enable us to say that they are the same species.

\section{DESCRIPTION}

Of a specimen taken at Newfoundland.

FonM-Head, and particularly the snout, broad and depressed, the latter rounded at the tip : the breadth of the head betreen the eyes is about half its length, and at the nape about two-thirds. The body tapers considerably, is much compressed posteriorly, and the tail, exclusire of the fin, is thin and narrowly lanceolate. There is a narrow, oblong, flattened space between the second dorsal and caudal, which, in the squalus glaucus, is said to be triangular; a sinilar flat space extends from the anal to the under lobe of the caudal, and there is a broader and somewhat triangular one between the rentrals and anal. The pectorals, rather larger than the first dorsal, have, like it, nearly the form of a latteen sail, but the latter fin has 
a little slip at its posterior end higher than the portion immediately preceding it. The ventrals, second dorsal, and anal are small, and the two latter have each a posterior slip, taller in proportion than that of the first dorsal. The origin of the second dorsal corresponds with the end of the anal. The ventral appendages are semicylindrical, covered with the common integuments exteriorly, and terminated by a minute, hard, callous tip. The tail at the origin of the caudal inclines a very little upwards. The anterior under lobe of the caudal is as high, but not so wide, as the first dorsal : it is connected by an even fillet of fin about twice as long as itself, to the second lobe, which uniting with the upper portion of the caudal forms an oblong lanceolate tip to the tail; the upper half of the caudal is widest at the extrenity, and gradually becomes lower as it runs forwards, being no longer perceptible a little posterior to the commencement of the under part of the fin.

Sxin.-The whole exterior of the fish, including the fins, feels rough when rubbed towards the snout. On examining a portion of the skin with a powerful microscope, it is observed to be completely encrusted by a congerics of small, hard, transparent, lancet-shaped, tricuspid spines or scales imbedded in a fibrous matter. The roughness exfends to the anterior half of the tongue and palate, and to portions of the branchial arches. There are several rows of minute pores on the head, particularly on the cheeks and at the angles of the mouth. Two pores larger than the others, but not capable of admitting the point of an ordinary-sized pin, exist on the hind part of the head, one on each side of the mesial line. There are no traces of spiracles near the eyes.

ТЕЕтн.-There are four rows of teeth in each jaw, having the form of very oblique spherical triangles, the posterior side much the shortest, and the acute point directed towards the corners of the mouth, and overhanging a small rounded lobe of the base. The edges of the teeth are rery acute, but even under a good lens do not appear dentated or serrated, though a slight inequality, approaching to crenature, may be perceived with a high magnifying power. There is scarcely any difference in the form of the teeth of the two jaws.

\section{Dimensions}

Of a specimen kept in spirits.

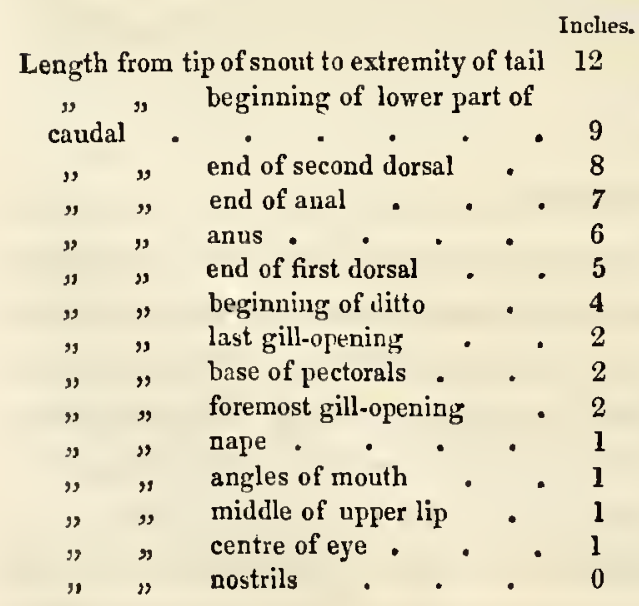

Lines
$9 \frac{1}{2}$
0
0
8
0
0
0
$9 \frac{1}{3}$
$8 \frac{1}{2}$
$2 \frac{1}{3}$
$9 \frac{1}{2}$
$9 \frac{1}{2}$
1
3
8

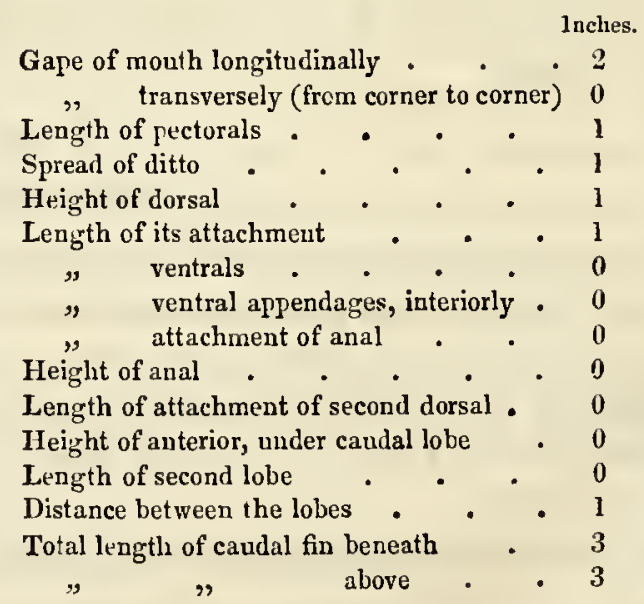

Lines. 2 


\section{[121.] 1. Squalus (Selache) maxmus. (Cuvier.) The Basking Shark.}

Squalus maximus. Farr., Faun. Groenl., p. 130.

This sluggish shark acquires the name of "basking" from its habit of lying motionless on the surface of the water. Notwithstanding its great size it is not ferocious like the White shark, and is little drealed by man. Fabricius says that it feeds on the smaller whales and dolphins, which it swallows entire. It is named Kaksib kannioa by the Greenlanders, and is a very rare fish on the Greenland coast. It has, in addition to the general form of the carcharia, spiracles, long gillopenings almost encircling the neck, and small conical teeth not serrated.

\section{[122.] 1. Squalus (Spinax) acanthias. (Cuvier.) Piked Shark, or Doge fish.}

Squalus acanthias. Fabr., Faun. Groenl., p. 126.

This species, so conmon on the coast of Scotland, where it is named the "Picked or Piked Dog," from the strong spine at the beginning of each dorsal, is said by Fabricius to be an inhabitant of the Greenland coast also. It is named kookeeleek by the natives, who fish for it in the winter time through holes in the ice. The fish of this sub-genus want the anal, but possess spiracles, and their jaws are armed with many rows of small cutting teeth. Lieutenant-Colonel Hamilton Smith informs me that he has taken the Common dog-fish of the English Channel on the coast of Nova Scotia.

\section{[123.] 1. Raia fullonica. (Iinn.) The Fuller. \\ Fannux, Selachii. Cuv. Gevus, Raia. Linv. Sub-genus, Raia. Cuv. Raia fullonica. Farr., Fuma Grenl., p. 125. \\ Taraleekeesak, Aglernak. Greenlanders.}

The Common skate furnishes a characteristic example of the peculiar form of the rays, in which the greatly-depressed body is extended laterally by the addition 
of wide fleshy pectorals that unite anteriorly with one another, or with the snout, and stretch backwards along the sides of the belly as far as the ventrals. 'The eyes and spiracles are on the dorsal aspect, the mouth, nostrils, and gill-openings on the ventral one. The dorsal fins are most generally situated on the tail. Their brown leathery eggs have a square form with projecting points at the angles.

The fuller ray receives its name from the resemblance of its spiny back to the instrument used in dressing cloth. It is called on the Yorkshire coast white hause, from the colour of its throat. Fabricius mentions it as an inhabitant of the deeper southern bays of Greenland, but he is not quite certain whether the fish he describes be the same with that of all the various authors whom he quotes. Indeed, Cuvier remarks that the references of Artedi, Linnæus, and Bloch, in respect to the rays, inust be altogether disregarded, as they are in inextricable confusion, arising from the number of rows of caudal spines being considered a principal character, though they vary with age and sex, and cannot therefore distinguish species. Characters founded upon the roundness or sharpness of the teeth are equally vague and uncertain in their application. There are doubtless many fish of this genus on the Newfoundland coast; but from the circumstances just mentioned the species cannot be quoted with any approach to correctness.

\section{CYCLOSTOMATA.}

THE suckers of Cuvier, or cyclostomes (round mouths) of Dumeril, forming the second family of the cartilaginous fish with fixed gills, have the most imperfect skeletons, not only of their own class, but of all vertebrated animals. Indeed, they approach the annelida, both in external appearances as well as in many details of structure, some of them closely resembling leeches, and others being inore like the red-blooded worms, so that some naturalists have doubted their right to be classerl with fish *. Their fleshy circular, or semicircular lip, placed at their anterior extremity, is supported by a cartilaginous ring, formed by the union of the palatine and mandibular bones. The vertebræ are merely incomplete cartilaginous rings, scarcely distinct from each other, and pervaded by a tendinous chord which con-

\footnotetext{
* Sir Everard Home considers the Lamprey and Myxine as intermediate between the fishes and vermes, and remarks that they are hermaphrodites, and have much analogy in their mode of respiration with the leeches and the aphrodita aculeata. (Phil. Trans., June, 1815, p. 256.) The Ammocales inhabit the mud of streams, and resemble worms still more than the fish Sir Everard Home mentions. They may be said to have no skeleton whatever.
} 
tains a mucilaginous mattex. There are no ordinary ribs, but the branchial rilss are much developed, forming a sort of chest for containing the gills, which, in plate of having the usual appearince of leaves, or combs, are united each to the adjoining one so as to form oval bags. The nostrils open by a single orifice, in front of which there is the entrance to a blind cavity, that has been erroneously considered as an air-hole or spiracle. The gut, slender and straight, is furmished with a spiral valve.

\section{[124.] 1. Petronyzon tridentatus. (Gairduer.) Tridentate}

\section{Lamprey.}

Faniry, Cyclostomata (Les suceurs). Cuv. Genus, Petromyzon. Cuvi, Lins.

Petromyzon tridentatus. Gardoner, in lit.

Squaqual. Indians of the banks of the Warasier.

The lampreys have seven gill-openings on each sile; their maxillary ring is armed with strong teeth, and the inner surface of the circular lip is likervise provided with tubereles enerusted by a hard shell and resembling teeth. The tongue, furnished with two longitudinal rows of little teeth, works backwards and forwards like the sucker of a pump. 'The water passes from the mouth to the gills by a membranous tuhe situated under the cesophagus and pierced by lateral holes. There is one dorsal fin anterior to the anus, and another behind it which unites with the caudal; the latter looks like a mere fold of the skin, its rays being fint: fibres that are scarcely pereeptible. These fishes adhere strongly to stones and other bodies by their mouth, and also to fishes, the largest of which they ean destroy by draining them of their fluids. 'Three species are described as European, viz., the P. marinus, fluvialis, and planeri, the two former of which are mentioned by Mitchill and Smith as inhabitants of the United States waters.

The triclentate lamprey abounds at the falls of the Walamet, which we have already had occasion to say is one of the tributaries of the Columbia. Dr. Gairdner gave it the name of tridentatus, from the upper side of its maxillary ring being arned with three conspicuous and contiguous teeth, of which the middle one is the smallest. It resembles $P$. marinus and fuvialis in the dorsals being distinet.

\section{DESCRIPTION.}

Mouth broadly oval, its axis parallel to that of the body. The thick obtuse lips are furnished with a circular row of small nipple-like papillx, about fifty-siz in number, each standing in the 
middle of little circular depressions having a raised margin, which are partly concealed by a rugose, tessellated plate, investing the inner surface of the lips, and of the same horny nature with that which forms the outside of the teeth,-both are softened and peel off when the specimen is kept immersed in spirits. Four small, acute, conical teeth stand in a row across the upper part of this plate, and four larger ones occupy each of its sides, the upper and lower pairs being bicuspid, and the middle ones tricuspid: these stand on the sides of the maxillary ring, or inner orifice, and have their ends turned towards it; the inferior margin of this orifice is armed with a slightly-curved dental piece, having five acute points or teeth; and opposite to it, on the upper side of the orifice, is another piece, having two large, acutely-conical lateral teeth, with a smaller central one. The tongue is also clothed with a horny-looking substance, which is edged anteriorly by a row of about twenty fine teeth.

The dorsal fins rise in even curves which are lighest in the middle; the first one is about one-third of its owu length distant from the second one, which unites with the caudal, the point of junction being marked by a depression. A fold of skin becomes perceptible on the under edge of the tail, a short way behind the anus, and gradually expands into the lower caudal lobe towards the tip of the tail, where its height, in conjunction with that of the upper lobe, equals the greatest height of the second dorsal.

CoLour. - "Back and sides bluish-grey with irregularly-scattered yellowish patches. Belly yellowish-whitc." (Gairdner.)

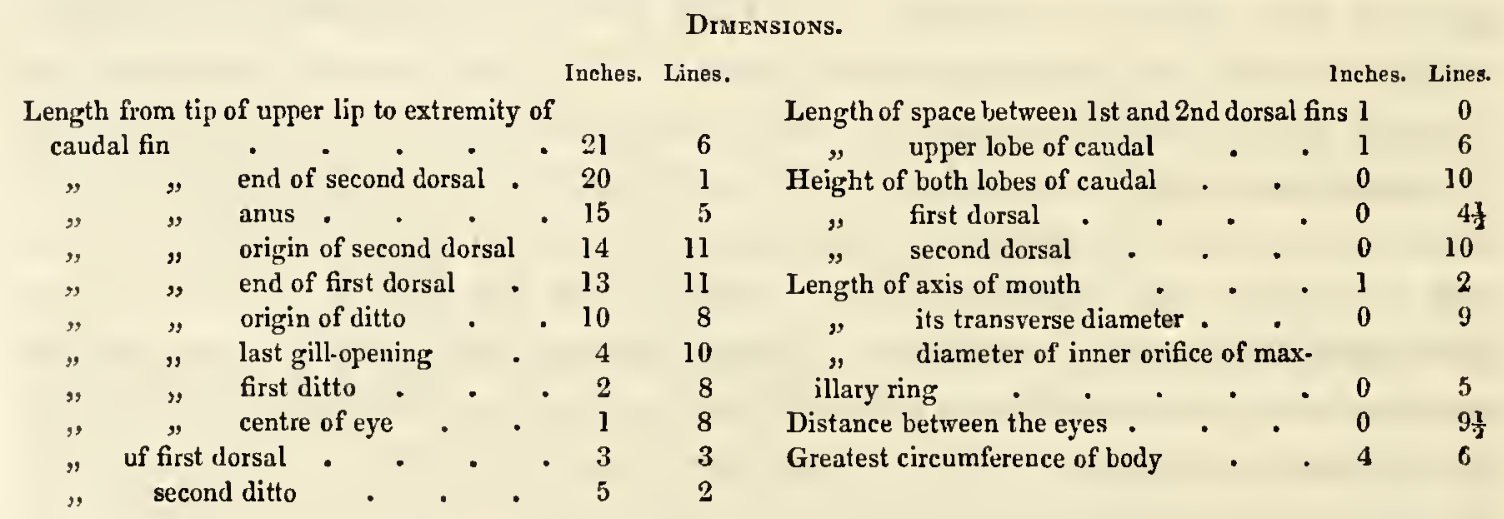

\section{[125.] 2. Petromyzon fluvialis. (Linn.) River Lamprey.}

Petromyzon argenteus. Bцосн, t. cccexv., f. 2.

Petromyzou fluvialis. Richardson, Frank. First Journ., p. 705.

A lamprey having teeth like fuvialis was found in Great Slave Lake adhering to an Inconnu (Salmo Mackenzii). It was very like Bloch's figure above referred to, which Cuvier thinks is not different from fluvialis. 


\section{A D D E N D A.}

Page 43, before Cottus polaris.

[126.] 2(bis.) Cottus asper. (Richardson.) Prickly Bull-head.

I AM indebted to Dr. Gairdner for this interesting and very distinct species of fresh-water Bull-head, which is common in the Columbia River. It resembles golio in its general form, but is distinguished from it, at first sight, by the roughtness of the skin, exclusive of other characters. It is a larger fish.

\section{DESCRIPTION}

of a male specimen.

Form.-Head not so much depressed as in gobio, its height being proportionably greater and its breadth less; it forms a third part of the length of the fish, excluding the caudal. The top of the head is flat, or rather widely concave, the margins of the orbits being smoothly and roundly elevated; there are no other indications of lateral ridges, nor any tubercles or spines: on the top of the skull. On close examination a small spinous point may be detected on the nasal bones; the operculum ends in a thin flat point, which is masked by a narrow, flexible, cartilaginous process of the suboperculum, imbedded in membrane, and forming the tip of the gill-corer; the suboperculum ends anteriorly in an acute point, but its edge is even : the spine at the angle of the preoperculum is more evident, and when divested of the skin which envelops it, shows a very acute, clear point, curved slightly upwards; the under edge of the preoperculum forms two distinet angular points : the scapular bone ends in an acute point, whieh ean scarcely be felt through the skin, but none of the bones margining the gill-openings, nor any of the opercular pieces, are serrated. In the recent specimen the spines are perceptible only to the touch, being concealed from the eye by the integuments. The posterior tips of the intermaxillary pedicles may be mistaken for spines. The under lip projects a little beyond the upper one when the mouth is elosed. The eyes are more than one of their diameters apart. The ShIN of the head is quite smooth to the touch, but it is dotted, particularly on the crown, with minute soft warts. The belly, a stripe adjoining the anal on each side, a small space round the base of the caudal, and the interscapular space anterior to the first dorsal, are also smooth; but the rest of the skin of the body is thickly studded with very small, subulate, acute spines 
directed backwards. These spines are too minute to be seen distinctly by the naked eye, but a little fold of skin, raised by each of them, produces a roughness which is very visible; they resist the finger only when it is drawn against their points. The lateral line, formed by a furrow, interrupted by about forty-four contractions, is very conspicuous.

$$
\text { Fiss.-Br. 6-6; P. } 16 ; V .1 / 4 ; D .9 /-21 ; A .18 ; C .96 .
$$

The ventrals are situated posterior to the three under rays of the pectorals and anterior to the upper ones. The pectorals are obliquely obovate. The first dorsal, commencing opposite the upper pectoral ray and supra-scapular point, is lower than the second one and not half its length; its spines are slender, but scarcely flexible, and its membrane is attached to the lower third of the first ray of the second dorsal; the sixth and seventh spines are the longest. The second dorsal commences opposite the anus, and extends a little farther back than the anal.

" Colours, generally, greyish-white; top of the head, back, and sides studded with small elove-brown spots, in some places confluent and forming patches. Pectorals, dorsals, and caudal marked with transverse rows of clove-brown spots. Under parts whitish with minute specks." (Gairdner.)

INTESTINES.-The stomach is a roundish muscular bag, having one-third of its cavity beneath the pylorus. There are five cæca, four of them slender, cylindrical, and of unequal lengths, the fifth a short oval bag.

\section{Dimensions.}

Inches. Lines.

Length from tip of snout to extremity of cau.

\begin{tabular}{|c|c|c|c|c|c|}
\hline dal & - & • & - & 9 & 6 \\
\hline$"$ & bas & ase of caudal & & 8 & 3 \\
\hline 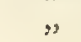 & en & nd of second dorsal. & - & 7 & 4 \\
\hline$"$ & enc & nd of anal & & 7 & 2 \\
\hline " & bes & eginning of ditto & • & 4 & 6 \\
\hline , & beg & eginning of second dorsa & & 4 & 2 \\
\hline$"$ & an & nus $\quad \cdot \quad \cdot \quad \cdot$ & • & 4 & 2 \\
\hline$"$ & beg & eginning of first dorsal & & 2 & 7 \\
\hline " & up & pper ray of pectorals & - & 2 & $8 \frac{1}{3}$ \\
\hline$"$ & tip & p of gill-cover & - & 2 & 8 \\
\hline$"$ & firs & rst ray of ventrals & & 2 & 3 \\
\hline 2 & ans & ngle or spine of preopercu & ulum & 2 & 2 \\
\hline$"$ & na) & ape $\quad \cdot \quad \cdot$ & • & 2 & 1 \\
\hline$"$ & pos & osterior edge of orbit & & 1 & 3 \\
\hline " & en & nd of labial & • & 1 & 3 \\
\hline " & ant & nterior edge of orbit & & 0 & 9 \\
\hline$"$ & , tip & i)s of intermaxillary pedi & icles & 0 & $6 \frac{1}{2}$ \\
\hline$"$ & of labials & . & - & $\mathbf{l}$ & 3 \\
\hline & lower ja & jaw . . . & - & 1 & 4 \\
\hline readt & h between o & orbits & • & 0 & $7 \frac{1}{2}$ \\
\hline$"$ & , & tip of preopercular spine & & 1 & 9 \\
\hline$n$ & $\eta$ & pectorals . & & 1 & 6 \\
\hline
\end{tabular}

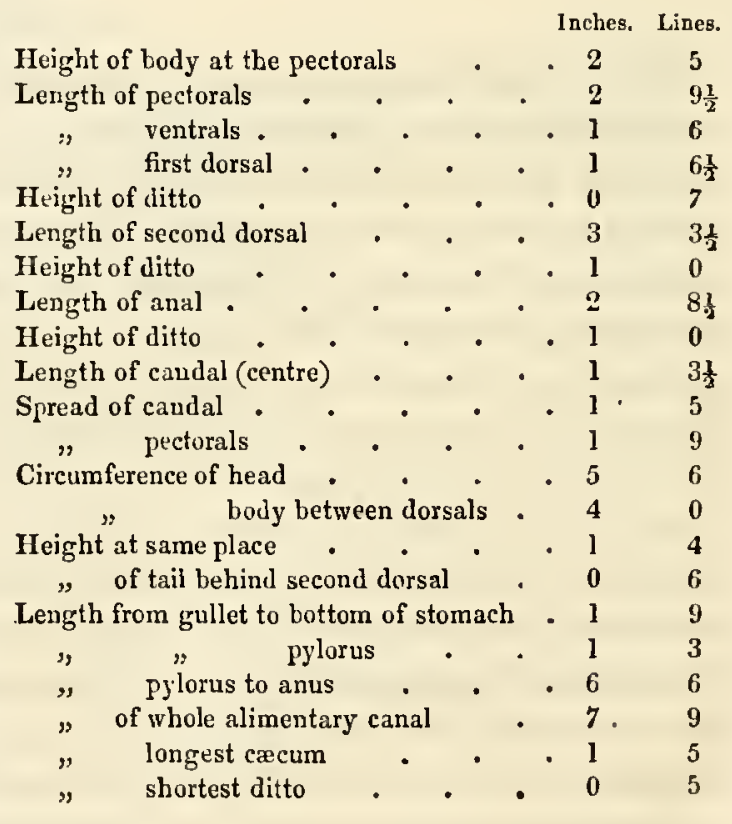


Page 46.

\section{[15.] 5. Cottus Grannandicus. (Cuvier.) Greenland Bull-head.}

I am obliged to Mr. Audubon for three specimens of a cottus taken at Newfoundland, which are almost without at doubt examples of the species described by Fabricins under the appellation of scorpius, called Gronlandicus by Cuvier, and known to the Greenlanders by the names of kaneeok. and kaneoonak. They have the four tubercles bounding a square area on the top of the head, and the sixteen spines enumerated by Fabricius; viz., a nasal, opercular, subopercular, scapular, and humeral one, with three preopercular ones on each sile; the colours of the body also, and rays of the fins, agree sufficiently well with the description in the Fauna Gronlandica. As Captain J. C. Ross informs us that the cottus quadricomis of the appendices to Sir Edwarl Parry's first and third voyages, and of Sir John Ross's recent one, is nitmed Kan-ny-yoke by the Esquimaux of Boothia, it is rendered probable that it also ought to be referred to Gronlandicus. The scorpioides of Fibricius, quoted by the authors of these appendices as synonymous with their quadricomis *, is named pokudlek and eegarsok by the natives, and differs from the true quadricornis of Linnæus and Bloch by many characters; it wants the nasal, scapular, and humeral spines which exist in Gronlandicus. Dr. Mitchill gives so slight a notice of his cottus scorpins (the cottus Mitchilli of Cuvier), that it is impossible to come to any certain conclusion respecting it, but the little that he does say of its colours, and the comparative length of its spines, applies also to Grenlandicus. Cottus octodecim-spinosus may be realdily distinguished from Gronlandicus by the length of its preopercular spine, which in the latter falls more than its own length (or nearly three-quarters of an inch in our largest specimen) short of the tip of the opercular spine. The two species differ likewise remarkably in the size of the pyloric creca, ind in other respects. Their tints of colour are, howerer, at times much alike, for the markings in Mr. Audubon's specimens are very similar to those exhibited by specimens of octodecim-spinosus, brought from Nerfoundland by MI. Pilaye. (Hist. des Poiss., viii., p. 459.)

Cuvier remarks that the account of the koneeok and other Greenland species given by Fabricins, forms the ground-work of almost all that has been said by

* In page 45 I hazarded a conjecture that this fish might be identical with my hexacornis, under the supposition that the two anterior horns might have been overlwoked, but the acquisition of the Newfoundland specimens having dispelled the obscurity which hung over the scorpiues of Fabricius, has rendered a reference of the quadricornis of the recent Arclic Vuyages to the Groenlandicus more likely to be correct. 
naturalists of the sea-scorpion and father-lasher (scorpius and bubalis) of European seas. The kaneeok is described as a most voracious fish, and this character is fully maintained by the individuals from Newfoundland, whose stomachs contained the vertebral columns of several small fish, some entire crabs, the peelings of potatoes, and other substances.

\section{DESCRIPTION.}

Fonm.-Head large, forming more than a third of the length of the fish, caudal included; its height at the nape is about a fourtl of the length, exclusive of the caudal, and its breadth there, when the gill-covers are closely slut, scarcely exceeds its height. Eyes lateral with a slight inclination upwards, and placed their own diameter apart. The upper border of the orbit is much elevated and terminates posteriorly in a rounded, obtuse, somewhat uneven knob, about the size of a grain of duck-shot. At the foot of this, and so covered by skin as not always to appear distinct, there is a smaller tubercle which forms the commencement of a low even ridge, that separates the temples from the crown of the head, and terminates on the nape by a tubercle sinilar to the orbitar one. The space bounded by the orbitar and nuchal tubercles of each side is flat, and in the female nearly square, but in the males it is narrower, the posterior tubercles being nearer to each other than the anterior ones. The space between the orbits is much depressed and is bounded anteriorly by the nasal spines and the prominent ends of the intermaxillary pedicles which play between them. In cottus octodecim-spinosus the place of the four tubercles on the top of the head is occupied by compressed, curred spines. There are velvet-like plates of teeth as usual on the intermaxillaries, lower jaw, and vomer, but none on the palate bones in Gronlandicus.

Spines. - None of the spines project distinctly through the skin in the ordinary state of the fish, though all are subulate and acute. The nasal ones are small. The principal one at the angle of the preoperculum is stout, straight, awl-shaped, and only about one-sixth of the total length of the head, or rather shorter than the diameter of the orbit; it is inclined a little upwards; an equally stout spine, only half as long, springs from its base beneath and inclines slightly downwards; while the lower limb of the preoperculum ends just behind the articulation of the lower jaw in a spinous point directed forwards-the number of preopercular spines being the same as in cottus scorpius. The anterior under spinous angle of the suboperculum points dowiwards, but there are no serratures nor spines on the edge of this bone, which is continued backwards by a thin, strap-shaped, flexible, cartilaginous process forming, with the integuments in which it is imbedded, a triangular, but not very acute tip to the gill-cover. The opercular spine is much concealed by the skin, and falls nearly half an inch short of this tip. The scapular spine, though shorter than the opercular one, to which it is parallel, is fully as stout. The tip of the short humeral spine coincides exactly with the tip of the gill: cover. There are no serratures on any of the spines, or bones of the head or shoulder, in which respect this species differs from bubalis; while by there being only two, and not three, strong spines at the angle of the preoperculum, it is distinguished from the quadricornis of tinnæus and my hexacornis.

$$
\begin{aligned}
& \text { Fins -Br. 6-6;P. } 17 ; V .1 / 3 ; D .10 /-17 ; A .13 ; C .11 \frac{5}{5} \text {. In two specimens } \\
& 6-6 ; \quad 17 ; \quad 1 / 3 ; \quad 10 /-18 ; 12 ; 11 \frac{5}{5} \text {. In one ditto. }
\end{aligned}
$$


The pectorals are large and wide, reaching backwards to the anus and second dorsal. The first dorsul, commencing opposite to the tip of the gill-corer, is high anteriorly and rounds off gradually posteriorly, its membrane terminating exactly at the base of the second dorsal. The spinous ray of the ventral is short and not easily distinguishable from the first soft ray to which it is applied.

Skin.-The top of the head is sprinkled with little soft conical pimples, and on the body and posterior surfaces of the pectoral rays there are a number of small circular scales, whose surfaces, and particularly their posterior margins, are studded with very short minute spines. The general tint of the upper parts of the fish is dark-brown, which is mixed on the top of the head with large clay-coloured patches, anch on the gill-covers, nape, and pectorals, with crinsson-red blotches; there are also some smaller spots of the latter on the back. The sides, belly, and pectoral and ventral fins are ornamented by perfeetly circular spots as big as the point of the finger, of dead-white, gencrally bounded by a ring darker than the neighbouring skin. Some of the white spots on the pectorals are placed excentrically on a larger orange-coloured mark, and there is a row of large orange spots on the under surface of the tail. The dorsal fins are blackish with oblique dull, yellowish, irregular spots or bars. On the anal the yellowish bars alternate more distinctly with the purplish-black ones, there being three of each; and on the caudal there are three transverse rows of contiguous, large, black spots on a yellowish ground, with indications of a fourth row on the tips of the rays. The colours of the female specimen are much less brilliant.

Ixtestines. - The stomach is a bag with folds towards its fundus, and minute reticulated wrinkles romul the pylorus, where its parietes are thickened. The linings of the osophagus and stomach have a very different appearance, and are separated by a distinct line. There are seren long cylindrical pyloric cæec. The liver is very large, and after long immersion in spirits retains a bright scarlet colour.

\section{Dimensions}

Of a female specimen.

Inches, Lines.

Length from tip of upper lip to end of caudal 13 base of central rays of ditto 11 end of second dorsal . .10 end of anal . . 10 beginning of ditto - . 8 anus . $\quad . \quad 6$ begrinning of second dorsal . 6 beginning of first dorsat . 4 tip of gill-cover . . 4 tip of opercular spine . . 4 tip of preopercular spine . 3 nape . . . . 3 tıp of labial . . . 2 posterior edge of orbit $\quad 2$ anterior edge of ditio . 1 of axis of orbit . . . . 0 vertical diameter of ditto $\quad 0$

Distance betreen upper margins of orbits - 0

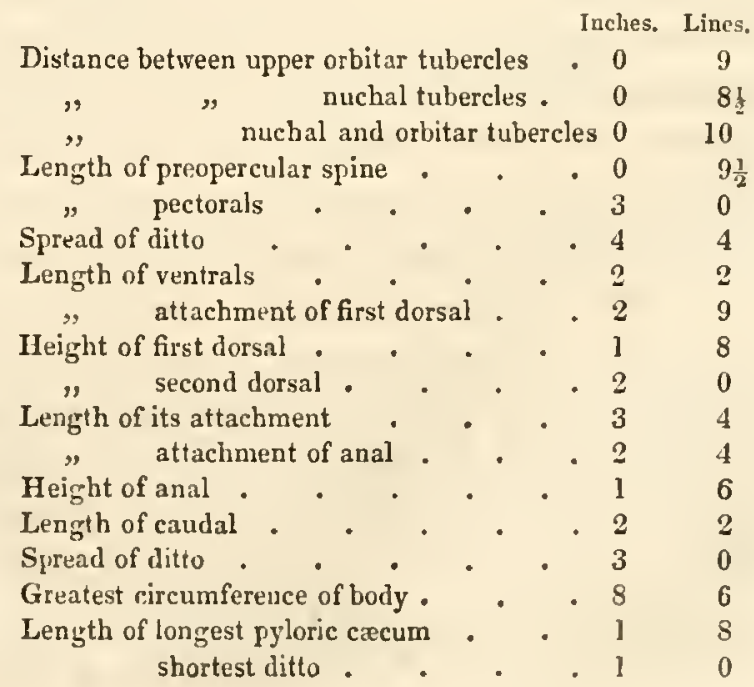




\section{Page 52, before Sebastes Norvegica.}

\section{Scorpena bufo. (Cuvier.) Sea Toad.}

La scorpène crapaud de mer (Scorpana bufo). Cuv. et VaL., iv., p. 306.

Mr. Audubon brought a specimen from Nervfoundland of this fish, which is an inhabitant of the Caribbean Sea and coast of Brazil, and will, no doubt, be hereafter detected in the intervening sea of the United States. I have received no account of its habits, nor is anything said on that subject in the Histoire des Poissons.

Cuvier observes that the most obvious distinctive mark of the sea-toad consists in the axilla of its black pectoral being dotted with round milk-white spots, a character which is not destroyed by immersion in spirits, and is very conspicuous in our specimen, though it is injured elsewhere. The barbels, and the soft integuments of the head in particular, are decayed, so that the spines and ridges of the cranium are much exposed, and a greater number may be reckoned than Cuvier enumerates in his description of scorpana scrofa, but the principal ones occupy the same situations as in that species, though they are more prominent and robust. The nasal spines are not denticulated, which is the only circumstance in which the Nenfoundland fish does not correspond with the description of bufo in the Histoire des Poissons. Thirtytwo or thirty-three spines may be reckoned on each side of the head and shoulder, viz., one on the nasal bone; five on the elevated bony margin of the upper half of the orbit, the lowest one before and behind being the sharp terminations of the bone; three in a row extending backwards from the orbital ridge to the nape, occupying the position of the cranial ridges in the cotti, and flanking a deep circular depression on the top of the skull; five in a row parallel to the abore, commencing close to the orbit, passing over the temples and ending on the shoulder; the posterior part of this row is doubled, adding two spines more; four divergent ones on the anterior sub-orbitar; three on the ridge of the second sub-orbitar which traverses the cheek obliquely; six on the preoperculum, as in scorpana porcus, the principal one being at the angle, and the two next in size standing at equal distances a little way below it; two on the operculum, tipping its divergent, obtuse keels which are slightly furrowed longitudinally; the acute points of the suboperculum and interoperculum, pointing downwards and in contact with each other, are not spinous; the thirty-second spine tips the humeral bone immediately above the pectoral, and the edge of the bone is widely notched abore the spine, so that the upper corner of the notch, which is acute and prominent, may be taken for another spine. The bands of teeth on the jaws, vomer, and palate-bones are narrow. 'The upper and lower pharyngeals are also toothed en velours.

Fins. $-B r .7-7 ; P .20 ; D .12 / 9 ; A .3 / 5 ; V .1 / 5 ; C .14 \frac{5}{5}$. 
The fifth dorsal spine is the tallest, but the third, fourth, sixth, and seventh are scarcely perceptibly shorter, the eleventh is as high as the second, and the twelfth is taller, being equal to the tenth, but shorter than the third. The anal spines are very robust, they are deeply grooved behind, and also furrowed in front, seeming as if they were formed by the consolidation of two or three spines, particularly the second one, which is highest and stoutest, and is enlarged clownwards by the thin expansion of one of the edges.

The scales are obtusely oval, with crenatures on their basal margin corresponding with from fourteen to twenty furrows that converge towards the exposed edge of the scale, which, with a portion of the adjoining surface, appears rough under the mieroscope, but is not groored or toothed. A scale on the anterior part of the body is rather more than a quarter of an inch long, and thirteen of them, when in situ, are included within a linear inch. There are fortyseven on the lateral line, and thirty-four in a vertical row where the body is highest. The colours have been mostly destroyed by the spirit in which the specimen is kept, but, exclusive of the spots on the pectoral already noticed, various large marks on the flanks are discernible, and there are traces of a large spot on the tips of the soft rays of the dorsal.

\section{Dimensions.}

Inches, Lines.

Length from tip of upper lip to end of caudal 7 beginning of ditto . . 5 end of dorsal . $\quad$. $4 \quad 11$ end of anal . . . 4 beginning of ditto . . 4 anus . . . 3 tip of humeral spine $\quad 2$ gill-cover . . . 2 tip of opercular spine . 2

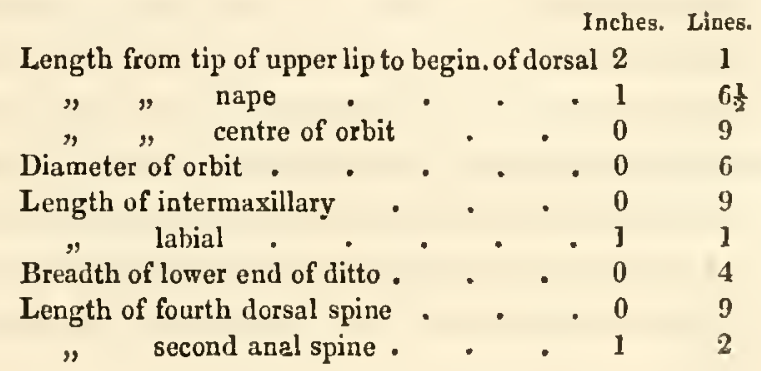

\section{Page 111, after Abramis Smithii.}

\section{[128.] 2. Crprinus (Abramis) balteatus. (Rich.) Red-sided Bream.}

'This pretty little bream, which is an inhabitant of the Columbia, was sent to me by Dr. Gairdner.

\section{DESCRIPTION.}

Colour. - "Back of head and body mountain-green, with iridescent tints of yellow and blue. Belly silvery-white. A bright gold-yellow band behind the eye on the margin of the preoperculum, and a broad scarlet-red stripe beneath the lateral line, extending from the gill-opening to the anal. Fins of an uniform greenish-grey colour without brilliancy." (Gairdner.)

Form much compressed, the depth of the body being equal to one-fourth of the distance between the tip of the snout and the caudal fork, while its thickness is only equal to a tenth 
of the same distance. The profile curves moderately from the snout to the dorsal, just before which the depth of the body is greatest, but it continues to be considerable at the insertion of the anal, the belly running as it were into an acute edge at that place : the short piece of the tail behind the anal is narrow. The head, forming exactly one-fourth of the length of fish, excluding the caudal, has a conical profile when the mouth is shut, the apex being formed by the tip of the lower jaw, which projects a very little beyond the commissure of the mouth. The top of the head is comparatively broad and rounded, its thickness at the nape being equal to that of any part of the body, and the snout, when viewed from above, appearing obtuse. Eyes large, much nearer to the snout than to the gill-opening. Nostrils near the eyes. Mouth toothless, small, its commissure descending obliquely and not reaching farther back than the nostrils: the lower jaw, when depressed, projects considerably beyond the upper one. GiLL-Covers.-Bony operculum quadrangular, its slightly-convex under edge being equal to the anterior one, and fully one-third longer than the upper or posterior one: the latter is widely emarginated, or cut with a concave curve. The suboperculum, one-third of the height of the operculum, is rounded off posteriorly in the segment of a circle, forming an obtuse tip to the gill-cover: both these bones are edged with membrane. Preoperculum narrow.

SCALES thin and sub-orbicular, their transverse diameter being rather greater than their longitudinal one. A few crenatures may be obscurely seen on their basal edges with a lens, and very faint lines proceeding from them towards the centre. There are about fifty-seven scales on the lateral line, and the greatest diameter of one taken from the anterior part of the sides measures a line and a half. A linear inch includes sisteen or seventeen of them in situ. The lateral line is curved convexly downwards, just before the rentrals, rising so as to run straight through the tail. It is formed by a short tube on each scale.

F1Ns.-Br. 3-3;P. 17;D. 11;V.9;A. 19 to $22 ; C .197$.

The ventrals are attached a little anterior to the middle, between the tip of the snout and base of the caudal, or opposite to the eighth ray of the clorsal; their tips reach to the anal. The anal and dorsal are high anteriorly, and become considerably lower posteriorly, with a slight concave sweep; the articulations of the first ray of each are obsolete.

The air-bladder is divided by a contraction into two portions, of which the lower one is the largest. There are forty vertebræ in the spine.

\section{Dumensions.}

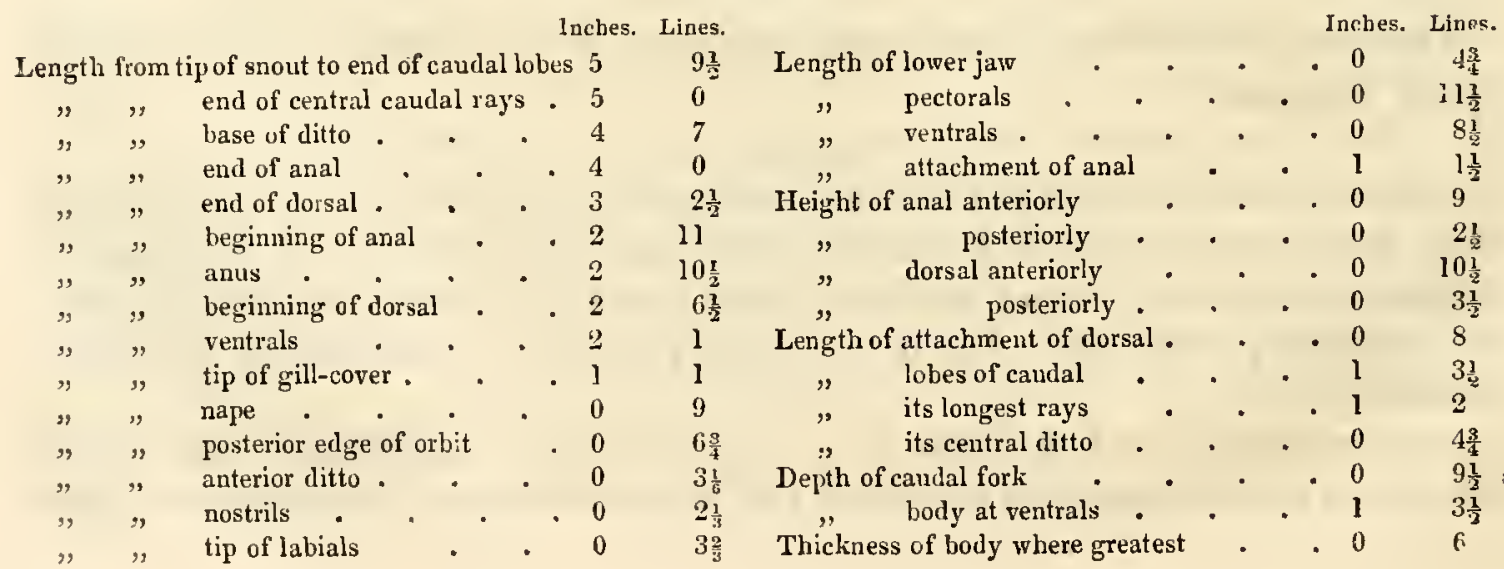


Page 115, after Catastomus Hudsonius.

[129.] 6. Cyprinus (Catastomus) reticulatus. (Cuvier.) Lattice-scaled Catastomus.

Catastomus reticulatus. Cuvier, in lit.

I had referred an imperfect specimen of this fish, obtained in Lake Huron, to C. Hudsonius, but after examining several very well-prepared examples from Albany River, I think it probable that it may prove to be a distinct species. If, on a comparison of the recent fish, this question be decided in the negative, Cuvier's specific name must give place to Le Sueur's prior one of Hudsonius.

The head is less convex at the eyes, the eyes themselves are farther back, the mouth is a little smaller, and the depth of the body somewhat greater than in C. Hudsonius; but the length of the head, which does not form a fifth part of the whole length of the fish, and the other external proportions, are the same as in that species. The scales, however, which are more distinctly radiated and crenated, exhibit in the prepared specimens of the younger individuals a nearly uniform hyacinth-red tint; and in the older ones reddish-orange tips with dark grey bases, forming a coloured mesh-work, whence the specific name. The belly is pale. The scales of the lateral-line vary in number from 70 to 77 , and there are 18 or 20 in a vertical row under the dorsal.

Fins.-Br. 3;P. 17 to $19 ; D .14$ to $15 ; V .10$ to $11 ; A .8 ; C .20 \frac{1}{4}$.

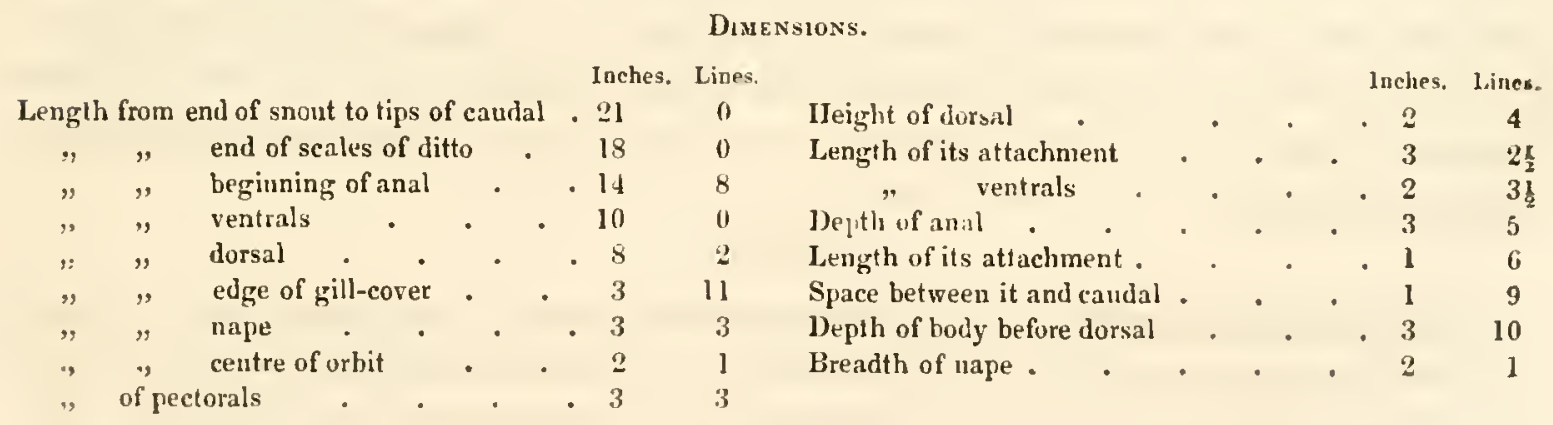

\section{Page 119. Catastomus Sueurii.}

By the acquisition of three well-prepared specimens from the Albany River district, Iudson's Bay, I an cnabled to give the dimensions of this fish more fully. 


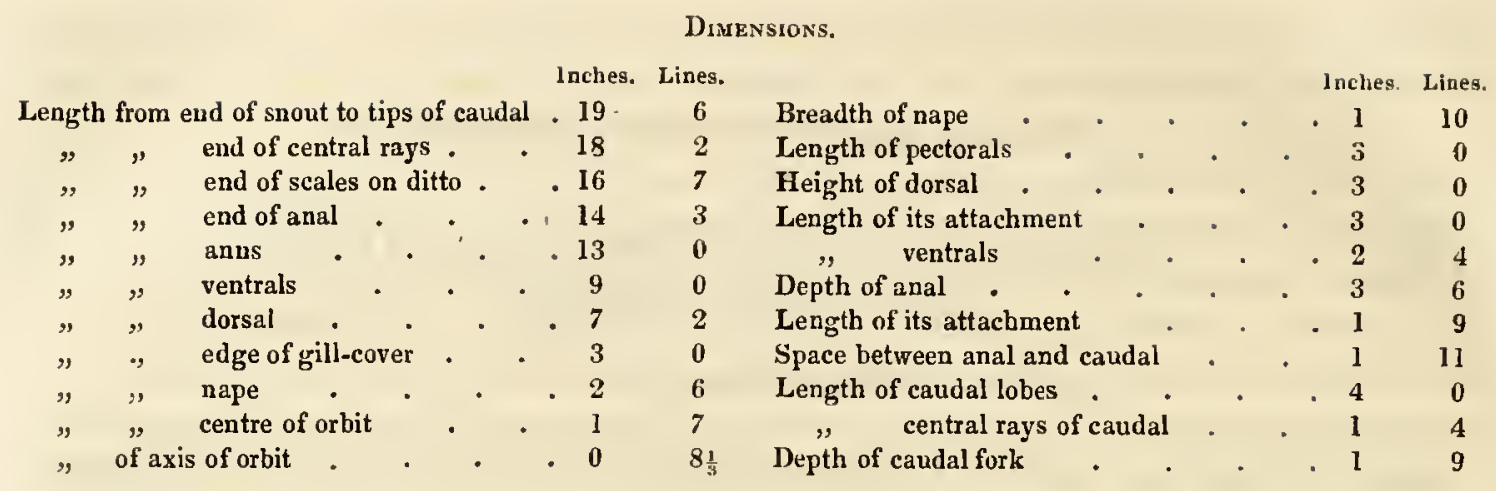

\section{Page 122, to follow Cyprinus (Leuciscus) chrysoleucas.}

\section{[130.] 3. Cyprinus (Leuciscus) caurinus. (Rich.) North- west Dace.}

Famnx, Cyprinoideæ. Genus, Cyprinus. Sub-genus, Leuciscus. Cuv.

This dace inhabits the Columbia River, and is abundant at Fort Vancouver, from whence I have obtained two dried specimens through Dr. Scouler, and more recently two preserved in spirits from Dr. Gairdner. The latter gentleman makes no mention of it in his notes, and does not seem to have distinguished it from the following species, of which examples were inclosed in the same vessel; hence the tints of colour in both, when fresh, may be supposed to be nearly the same. It is very different from leuciscus gracilis in the size of its head, the form and size of its scales, and other characters, being much more closely allied to the Common European dace, from which, however, it may be readily distinguished by the following characters.

\section{DESCRIPTION.}

Form handsome, moderately compressed, circumference of the body greatest just before the dorsal, where the height is equal to one-fifth of the distance between the tip of the snout and end of the central caudal rays : the thickness there rather exceeds half the height. The shoulders are thick and arched in profile. The head forms one-fourth of the length of the fish, caudal excluded : the snout is rather obtuse, and projects a little beyond the shut mouth; the orbit is nearly two of its diameters from the tip of the snout, and almost three diameters from the most posterior part of the gill-flap. The under jaw shuts within the upper one, and its tip is then more than the thickness of the upper lip, or above two lines posterior to the end of the snout. Gill-cover rather broadly edged with membrane, rounded at the apex; posterior edge of operculum straight. 
SCALES sub-orbicular, crenated exteriorly, and impressed with from fourteen to twenty fine but conspicuous lines, radiating from near the base, which is neither furrowed nor crenated. There are seventy-five on the lateral line, twenty-four in a vertical line before the dorsal, and ten in a linear inch measured on the forepart of the sides.

$$
\text { Fins.-Br. } 3-3 ; P .18 ; D .10 ; V .10 ; A .9 ; C .196 .
$$

The dorsal commences exactly midway between the tip of the snout and base of the central caudal rays: its first ray is so short as to be scarcely perceptible through the skin, and with the second one is closely applied to the base of the third: the latter and the fourth are the longest. The ventrals are attached under the fifth dorsal ray, or considerably before the middle of the fin, and midway between the gill-opening and end of the anal, which is similar in shape to the dorsal, being highest anteriorly. The caudal is deeply forked.

\section{Dimensions.}

\begin{tabular}{|c|c|c|c|c|}
\hline \multirow{2}{*}{\multicolumn{3}{|c|}{ Length from tip of snont to extremity of }} & \multirow[t]{2}{*}{ Inches. } & \multirow[t]{2}{*}{ Lines. } \\
\hline & & & & \\
\hline & & & .12 & 6 \\
\hline ” & " & end of central caudal rays & 11 & 2 \\
\hline$\eta$ & $\eta$ & base of ditto. & 10 & 6 \\
\hline$"$ & ", & end of anal & . 8 & 5 \\
\hline " & ", & beginning of ditto & . 7 & 6 \\
\hline ", & $"$ & anus . . & 7 & 5 \\
\hline ", & ” & end of dorsal & 6 & 5 \\
\hline$"$ & " & ventrals . . & & 7 \\
\hline " & $"$ & beginning of dorsal & & 4 \\
\hline , & ", & pectorals . . & . 2 & 9 \\
\hline , & ” & tip of gill-cover & & 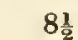 \\
\hline ", & " & tip of bony operculum & . 2 & $7 \frac{7}{6}$ \\
\hline " & $"$ & nape . . . & 2 & $2 \frac{1}{2}$ \\
\hline$"$ & $"$ & posterior edge of orbit & . 1 & 4 \\
\hline$"$ & ” & anterior ditto & 0 & $10 \frac{1}{3}$ \\
\hline & , & anterior nostril . & . & $6 \frac{3}{2}$ \\
\hline " & & tip of labial . & 0 & 9 \\
\hline ", & & argin of upper jaw, one side & 0 & 8 \\
\hline & & to under jaw . & . 0 & $6 \frac{3}{4}$ \\
\hline
\end{tabular}

\begin{tabular}{|c|c|c|c|c|c|}
\hline \multirow{3}{*}{\multicolumn{2}{|c|}{ Length of under jaw to articulation }} & & & Inches. & ine \\
\hline & & & & 0 & \\
\hline & outh. & & & 0 & \\
\hline$" \quad$ transverse ditto & $\cdot$ & . & & 0 & $8 \frac{1}{4}$ \\
\hline pectorals . & - & - & - & 2 & \\
\hline$\Rightarrow \quad$ ventrals . . & & & & 1 & \\
\hline Height of dorsal anteriorly & . & & & 1 & \\
\hline , ditto posteriorly & & & & $\mathbf{0}$ & \\
\hline Length of attachment of dors & sal & & & 1 & \\
\hline & & & & 1 . & \\
\hline Height of anal anteriorly & & & & 1 & \\
\hline osteriorly & & & & 0 & \\
\hline Length of caudal lobes & & & & 2 & \\
\hline Idle rays & & & & $\mathbf{0}$ & \\
\hline Depth of caudal fork & & • & & l & \\
\hline Height of body before dorsal & & & & 2 & \\
\hline Greatest thickness & & 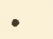 & & 1 & \\
\hline " circumference . & & & & 6 & \\
\hline Thickness at nostrils & & - & & 0 & g \\
\hline " between orbits & - & & & 0 & 10 \\
\hline of nape & & & & 1 & \\
\hline
\end{tabular}

\section{[131.] 4. Cyprinus (Leuciscus) Oregonensis. . (Richardson.) Columbia River Dace.}

This species is also an inhabitant of the Oregon, or Columbia River, and is so similar in general appearance to the last, that it may be readily confounded with it, though it is certainly specifically distinct, as may be seen by the following differences.

FORM more tapering forwards, the shoulders not being so high : head longer, forming onefourth part of the length of the fish, including the middle caudal rays: snout obtuse and even 
with the margins of the upper and lower jaw when the mouth is closed : mouth considerably larger, being cleft as far back as the edge of the orbit: anterior sub-orbital more oblong and perforated by a greater number of foramina: the gill-cover less widely rounded, and the edge of the operculum concave, though not so much so as in leuciscus gracilis, pl. 78. The dorsal also stands farther back, being nearer to the tip of the tail than to the point of the snout, while the ventrals stand under the first dorsal ray, and midway between the orbit and base of the central caudal rays. The distance from the gill-openings to the ventrals reaches from the latter to half way between the anal and caudal. The size of the scales, generally, and their number on the lateral line, is the same as in leuciscus caurinus, but their form is more perfectly orbicular, and those on the belly are proportionably smaller.

Fins.-Br. $3-3 ;$ P. $15 ;$ D. $10 ;$ V. $9 ; A .9 ;$ C. $19 \frac{9}{9}$.

"CoLour of the back and top of the head intermediate between yellowish grey and brocolibrown, passing gradually on the sides, below the lateral line, into sulphur-yellow, the latter colour prevailing also on the cheeks, gill-covers, and bases of the fins. The belly is silvery white." (Dr. Gairdner.)

Dimensions.

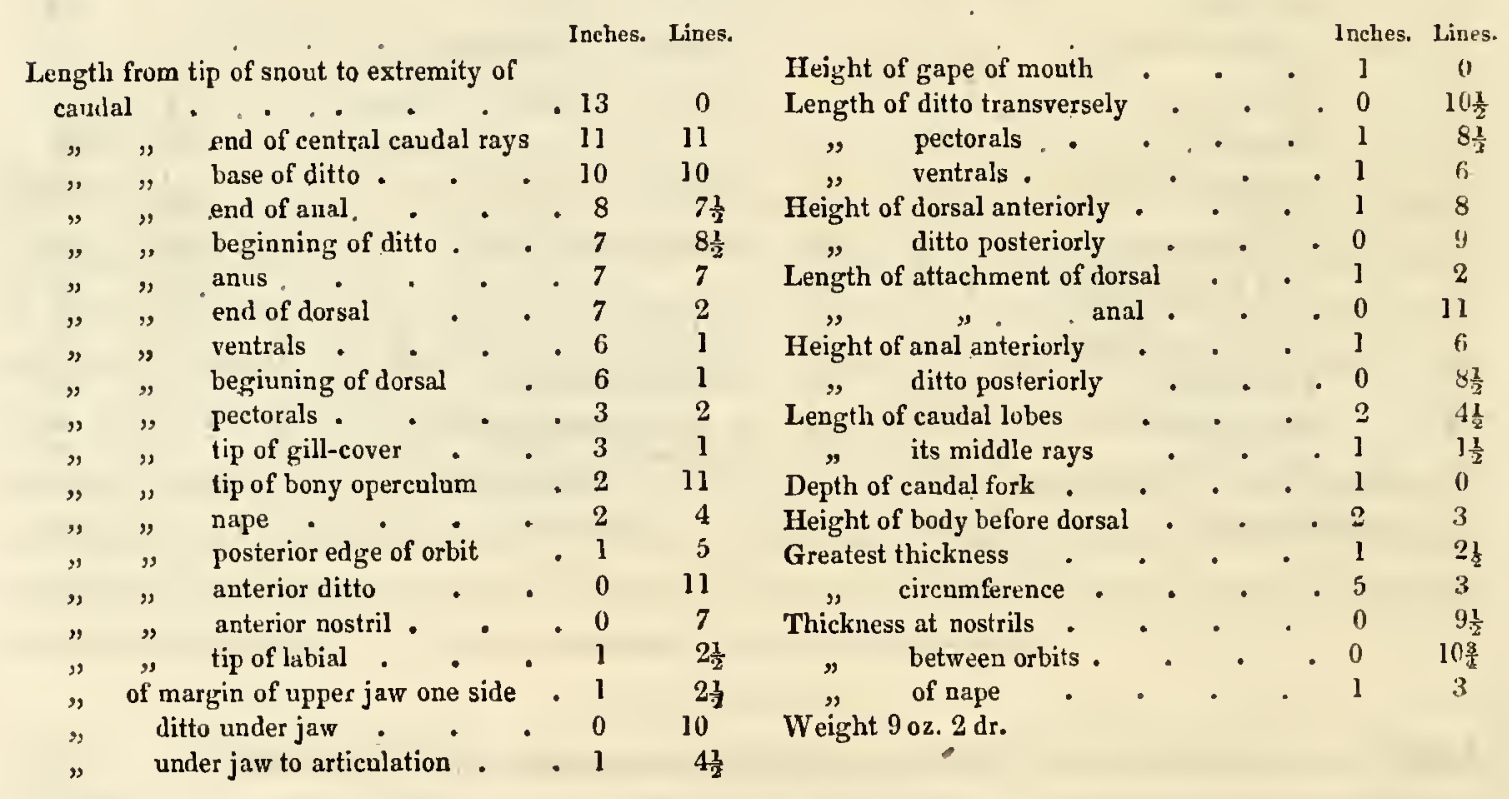

\section{Page 141. Sewin, Salmo Cambriscus.}

Mr. Yarrell, in the tenth number of his History of British Fishes, which has just reached me, states this fish to be the same with the Salmo eriox of Linnæus, Salmo griseus seu cinereus of Ray and Willughby, and the Whitling and Bull 
trout of the Tweed. Its young are named Warkworth and Coquet trout, in the north of England, and it is also supposed to be the species which the Scottish fishermen call Norway trout and Norway salmon. I have recently ascertained that the note at the bottom of parge 140 respecting the habits of the Salmon-trout refers properly to the salmo Cambriscus, which is termed salmon-trout in many' parts of Cormwall and Wales, while the appellation of Sewin is given indiscriminately to our Salmon-trout (p. 140), and to the salmo trutta, or Nith trout (p. 142). Colonel Lawrence informs me that the hook of the under jaw is very decided, even in the young salmo Cambriscus. This fact, together with a consideration of the synonyms quoted by Mr. Yarrell, tends to strengthen the opinion I have expressed of the Lapland salmon noticed by Linnæus, the S. hamatus of Cuvier, the Bull trout of the Tweed, and the S. Cambriscus of Donovan, being one and the same species. According to Mr. Yarrell the normal number of the dorsal vertebra in the Bull-trout is 59 .

\section{Page 144. Salmo fario.}

In Mr. Yarrell's work, part x., 13. 53, the normal number of the dorsal vertebræ in this species is stated to be 56 , instead of 58 as I have mentioned in the text.

\section{Page 226, to follow Salmo Clarkii.}

By the friendly attentions of P. W. Dease, Esq., I have received small specimens of three different linds of trout from New Caledonia. One species, named by the natives* Duggang, agrees exactly. in external characters with the Salmo nitidus of the peninsula of Boothia (page 171, pl. 82, f. I), the only discrepancy being some traces of a different distribution of spots and tints of colour, which may be owing to the different seasons in which the fish were captured, or to the mode of preparing the skins.

Another, named Suppar, of which there are three specimens, resembles the young of an anadromous salmon. 'The sciles are thin, flexible, and bright, the hody is marked chietly above the lateral line with seattered crucial or crescentic black spots, and the dorsal and caudal are thickly dotted with oval blackish marks

\footnotetext{
* The envelopes of the specimens on which the names rere written having been disturbed at the Curtum-house. dle appropriation of the natire names is not quite certain.
} 
in rows*. The fins generally, but the under ones especially, are small, and the latter appear to have been of a pale hue. In form and proportion of parts, as well as in dentition, this fish strongly resembles the Hirling, noticed in p. 141, and might easily be confounded with the Salmon trout, p. 140, pl. 92, f. 1; though on examination some slight differences in the forms of the opercular pieces may be detected. The characters ascribed by Dr. Gairdner to the Tsuppitch of the Columbia (p. 224) agreeing well with this fish, and the names being so similar, we may conclude that they are the same, and also that they belong to the species named Silvery-white Salmon trout, by Lewis and Clarke. (Vide F. B. A., iii. p. 163.)

The ULta of the New Caledonia tribes differs from the last in the scales being firmer, duller, and rather smaller, and the body more thickly and generally covered with black spots, which extend well down the sides. The spots on the dorsal and tail are also more regular and conspicuous, and the teeth are stronger, especially those on the palate bones; a flexuose row on the vomer does not extend quite so far back as the palatine teeth. The Ultai is most probably the Salmo Clarkii, p. 225, and also the Dark salmon trout of Lewis and Clarke, noticed in p. 163.

It is interesting to receive two fish so like European species as the Suppai and Ultai from rivers falling into the Northern Pacific. They are very closely allied indeed, by excernal form, to the Salmon trout, No. 2, p. 140, Hirling, No. 3, p. 141, and Nith trout, No. 5, p. 142, which are considered by many Ichthyologists to be only varieties of salmo trutta, produced by local causes.

\section{Drmensions.}

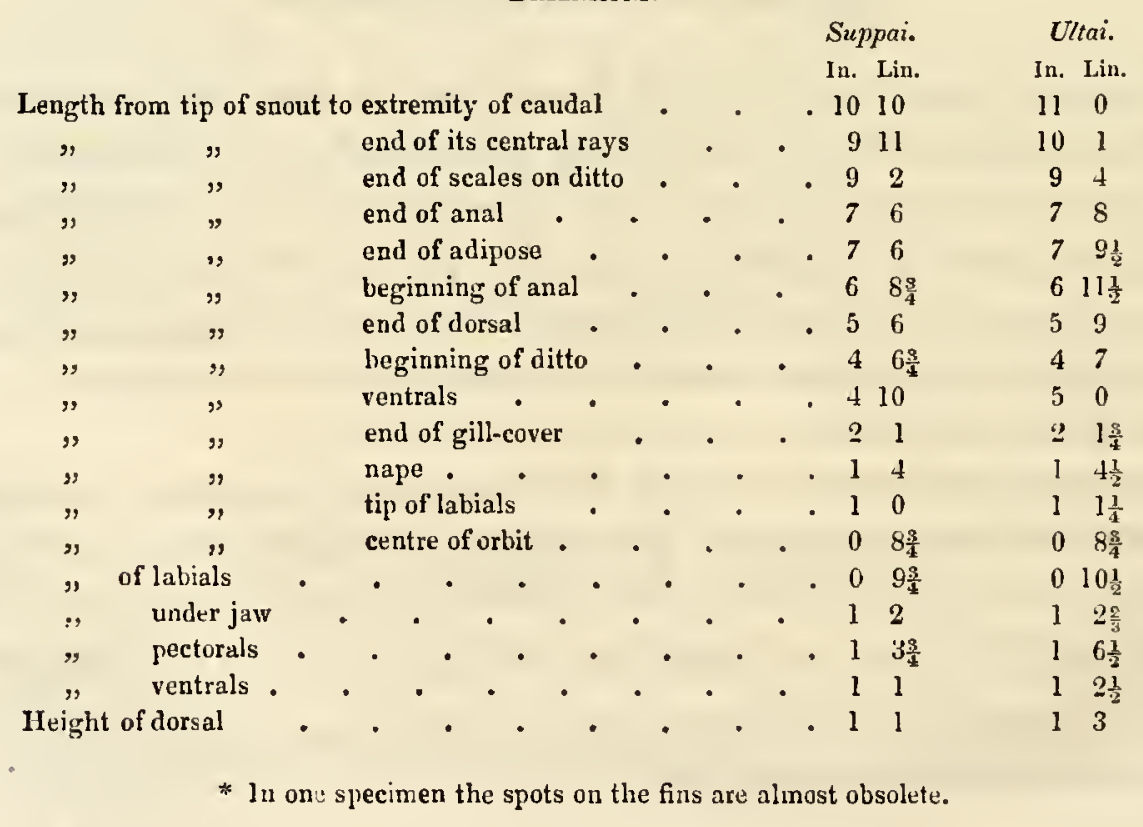




\section{Page 183. Salmo Mackenzir.}

Having received several heads of this fish through the kind attentions of $\mathrm{Mr}$. King, who accompanied Captain Back on his recent expedition, I have been enabled to give a view of the teeth in plate $94, \mathrm{f}$. 1 .

All the teeth are en velours, the band on the intermaxillaries and end of the lower jaw is very narrow, that on each palate bone is broader and unites before with a pretty large circular patch on the anterior extremity of the romer. The greater part of the surface of the tongue is corered with teeth, though its tip is smooth. The labials and sides of the lower jaw are perfectly toothless. The posterior piece of the labial is widest abore, tapcring gradually to an acute point, which is even with the extremity of the anterior piece, and its length is about two-thirds of that of the latter. The under jaw is shorter than the upper surface of the head. The rays of the gill-membrane vary from nine to ten on the right side, and from ten to eleven on the left, there being generally, though not always, one more of the latter.

\section{Page 201. Salio (Coregonus) tullibee.}

The acquisition of a specimen of the Tullibee from Albany District, Hudson's Bay, enables me to make some essential additions to the description of thigt fish.

In external appearance, and especially in the size and lustre of the scales, the Tullibee corresponds with the group of Coregoni, named Salmon-herrings, and bears the strongest resemblance to C. lucidus, p. 207, pl. 90, f. 1. The depth of the body is, howerer, greater than in that species, and the scales are so tiled, that the uncovered portion measures considerably more vertically than longitudinally. The posterior piece of the labial is likewise wider, and the suboperculum has a fuller, though rounded exterior cdge, giving the gill-plate more the form of that of $C$. albus, pl. 89, f. 2. The greatest depth of the considerably-compressed body is equal to one-fourth of the total length, caudal included; while the head forms a fifth part of that length. The under jaw protrudes rather more beyond the upper one than in C. lucidus. The lateral line contains eighty-one scalcs, whose tubular ridges are curved downwards more conspicuously than in other species. There are twenty-three scales in a vertical row under the first ray of the dorsal, a linear inch measured in that direction containing four scales in silu, or rather more than seven in a longitudinal direction. The first ray of the rentrals and fifth of the dorsal is opposite to the thirty-first scale of the lateral line, which is exactly midway between the tip of the snout and end of the scales on the cauderl.

Fins. $-B r .8-9 ; P .16 ; D .15-0 ; V .12 ; A .14$ or $15 ; C .19 \frac{7}{7}$. 


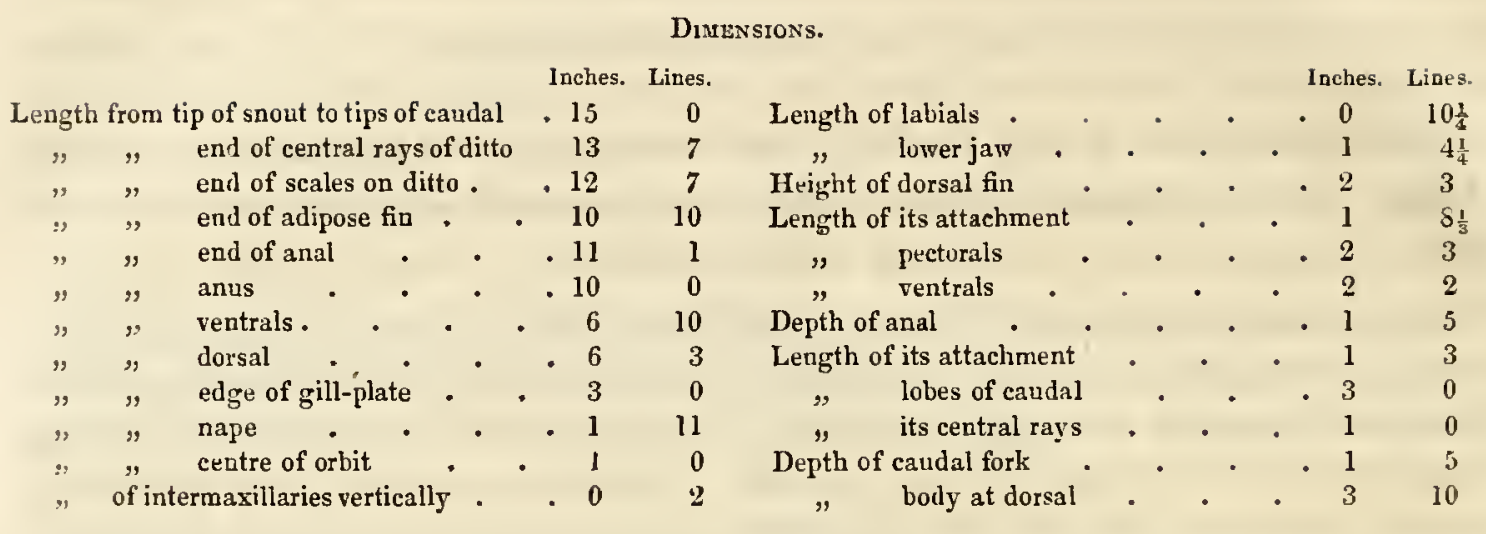

Obs. Though the species of Coregoni described in this work may be readily distinguished when compared either in a recent or prepared state with each other, yet there may be a difficulty in recognising any single species merely from the descriptions, as the form, colours, and peculiar appearances of the scales are apt to change in spirits, or when dried, and distinctions depending on magnitude are strictly comparative; it may therefore be useful to recapitulate some of the characteristic marks which are less likely to vary. In C. albus and Labradoricus the lower jaw is equal to the upper one; in C.tullibee, lucidus, and harengus, it is longer; and in C. quadrilateralis it is shorter. In C. allus the labials are equal in length to the long axis of the orbit (the eye being removed), and their posterior piece has a broad pyriform shape with the obtuse end down. In C. Labradoricus the labials have a similar form, but they are decidedly smaller, being shorter than the axis of the orbit. In this species also the suboperculum is more cut away posteriorly, and the head is proportionally smaller in all its dimensions. In C. tullibee, lucidus, and harengus of the herring-salmon group, the labials have a more oblong shape, being as wide close to their articulation as at their lower end; and the intermaxillaries are very narrow vertically, so that the edge of the upper lip is but a very little way beyond or beneath the tip of the snout, according as the mouth is shut or open. The depth of body of the tullibee is greater than in the other two species, and its gill-plate, as mentioned above, has a different form. C. lucidus: and harengus can scarcely be distinguished from each other except in a recent state. C. quadrilateralis may be known by its very small mouth, small labials, short under jaw, and its peculiar shape of body, which, though flat on the sides, is 
less compressed than any of the other North American Coregoni that we have seen.

In Plate 94, f. 2, the head of a Coregonus allus is represented the size of life, to show the correct forms of its different parts: in $f .2, b$, the mouth is seen in front, and in c, on the stretch sideways, exhibiting the depth of the intermaxillaries, which is much greater than in the herring-salmons, of which reduced figures are given in plate 90 .

Page 232. Hiodon chrysopsis. Plate 94, f. 3. Three views of the head, full size.

The dental surface of the vomer widens gradually towards the gullet, and the palate bones have, in addition to the row of conical teeth on their edges, a small oval plate of minute teeth near their middles.

Page 285, to follow Acipenser rubicundus.

\section{[132.] 2. Acipenser Rupertianus. (Richardson.) Rupert Land Sturgeon.}

Acipenser ruthenus major. Forster, Phil. Trans., lxiii., p. 149. An. 1773.

Plate 97, f. 1, one-third natural size. Shields full size: a. dorsal : b. lateral : c. ventral.

'T'wo specimens of this sturgeon have reached me from Albany River District. It is a species quite distinct from the $A$. transmontanus (p. 278, pl. 97, f. 2), but is probably the same with the sturgeon which abounds. in the Saskatchewan, and has been noticed in p. 279. It ranks decidedly among the Sterlete of Brandt, approaching $A$. Ruthenus closely in its general character.

\section{DESCRIPTION.}

Form more slender and the dorsal profile less elevated anteriorly than in $A$. transmontanus; the top of the head and snout are also more nearly in the same line than in that species, there being no sudden convexity anterior to the orbits. The snout is slender and tapers gradually to its extremity, which though narrow is not acute: its breaclth at the nostrils equals half the length from thence to its tip, and its sides, instead of sloping off' into a thin edge as in the Columbia Rirer sturgeon, are flattened and have a rertical height equal to half the transverse breadth. The upper surface of the snout is finely gramulated and 
radiated like the top of the head, but its under surface is quite smooth, without any plates on the end of the subrostral bone or cartilage, which is slender and little prominent even in the dried specimen. There are four barbels situated rather nearer to the orbits or mouth than to the tip of the snout. They are quite simple, tapering and smooth, except that their inner surfaces are studded with papillæ like beads, in a erowded double series. The anterior margin of the orbit is exactly midway between the tip of the snout and first dorsal shield. The shape of the operculum is somewhat different from that of $A$. transmontanus, and its surface, instead of being reticulated, is marked with fine granulated lines radiating from its middle. Mouth smaller than that of the Columbia River sturgeon.

Shields in general not so much compressed as those of $A$.transmontanus. There are thirteen or fourteen dorsal ones, including a spineless one incumbent on the dorsal; the spines of the others resemble those of the sturgeon just mentioned: there are also two flat shields between the dorsal and caudal. The lateral shields, thirty-five in number, have less acutely spinous ridges than those of $A$. transmontanus, but with more oblique, longer, and more approximated lozenge-shaped bases. The abdominal shields, nine or ten on each side, are smooth or even pitted on the apex, instead of being crowned by an acute spine-tipped ridge : there are two large flat shields between the anus and anal, and two smaller ones fill the space between that fin and the caudal. There are also in one speeimen two small shields between the ventrals, -one before the other. Integuments of the tail nearly as in $A$. transmontanus.

Fins.-Br. $0 ; P .40 ; V .30 ; D .40 ; A .25 ; C .28 / 84$. The fins in general, but the vertical ones especially, are smaller than those of $A$. transmontanus.

\section{Dimensions.}

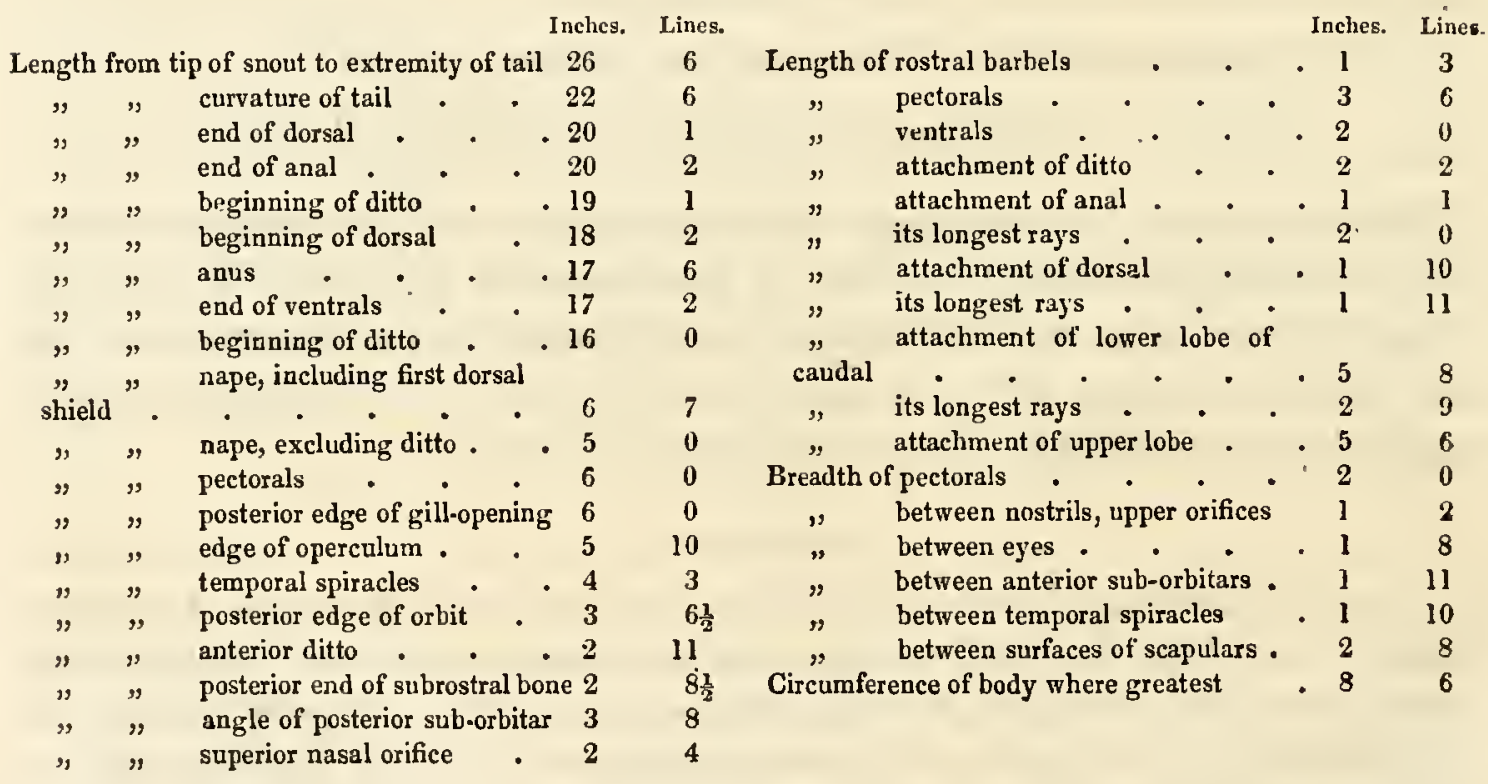


OBs. Acipenser maculosus and A. oxyrhynchus of Le Sueur, Am. Phil. Trans., An. 1818, differ from $A$. Rupertianus in their abdominal shields being acutely keeled and spinous. A. maculosus has a broader snout than the latter. Acipenser transmontanus is represented one-third of the natural size in Plate 97, f. 2. The shields full size, a. dorsal, b. lateral, c. ventral.

Page 291, to follow Spinax acanthias.

[133.] 1. Squalus (Scymnus) Gunneri. The Northern Scymnus.

Family, Selachii. Genus, Squalus. Sub-genus, Scymnus. Cuvier.

Squalus Carcharias. Fabricius, Faun. Groull, p. 127.

Eekalloorksoak. Greentanders.

This species, which we omitted to quote from Fabricius in its proper place, rivals the White Shark in size, and is greatly dreaded in the Greenland seas. It is reported to have occasionally destroyed the native fisherman by biting off his lower extremities, together with the bottom of the skin-covered kayack in which he was seated.-The scymni have spiracles, but are destitute of the anal fin and dorsal spines. The second dorsal is over the ventrals.

\section{Page 295. Cottus Asper.}

Plate 95, f. 1, two-thirds natural size.

I neglected to mention in the description of this species, that it differs from its congeners in having teeth on the palate-bones, being in that respect like Hemilepidotus, to which genus it will probably be hereafter referred. It wants the scales however of the latter, and its dermal spines are peculiar. A side view of the fish, a front of the head, and the roof of the mouth, are represented on the plate. 


\section{Page 297. Cottus Grenlandicus.}

Piate 95, f. 2, two-thirds natural size.

A reference to this plate could not be made before, as it was executed after the description of the species had gone to press. The same parts are represented as in the figures of Cottus asper. 


\section{OLLU S C A.}

The few fresh-water Shells collected on the Expedition having been placed in the hands of Mr. James De Carle Sowerby, he kindly furnished me with the following list, in the year 1828.

Names.

1. Helix attenuata.

2. , gularis .

3. , rudis

4. " paludosus (minuta, Say)

5. „ albolabris

6. Succinea putris .

7. , ovalis

8. Bulimus lubricus

9. Melampus bidentatus, SAY (au-) ricula, Lam., Conovulus, Montf.)

10. Valvata tricarinata

Ditto

Ditto

Ditto.

Localities.

Lakes Superior, Winipeg, and Saskatch. R.

ditto

ditto.

Ditto ditto ditto.

Ditto ditto ditto.

Ditto ditto ditto.

Ditto to Methy Lake (lat. $57^{\circ}$ ).

Ditto to the Saskatchewan River.

Ditto to the Saskatchewan River. to Methy Lake.

11. " syncera . . Methy Lake to Great Bear Lake (lat. 65 ).

12. Planorbis campanulatus (Helix
angulata, SHEPH., Lin. Tr.) Lake Superior to Saskatchervan.

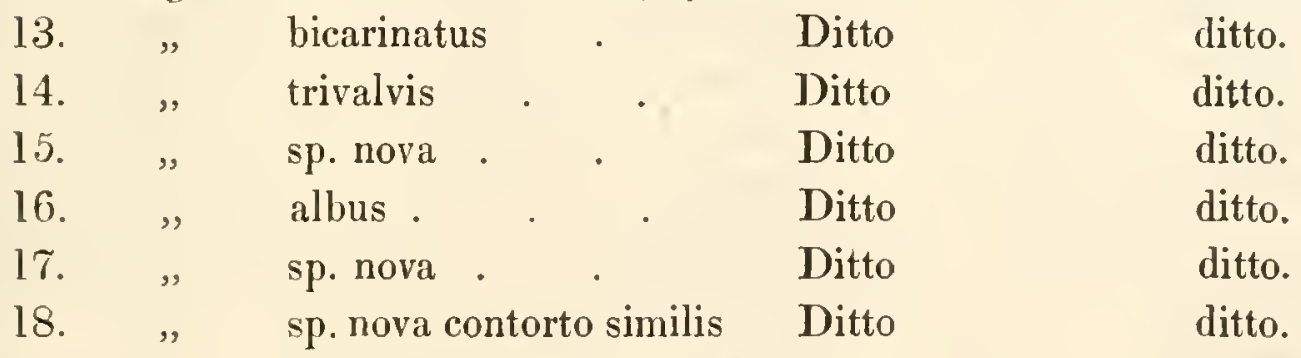

19. " parvus . . Methy Lake.

20. " sp. nova . . Ditto to Great Bear Lake.

21. " sp. nova. . Saskatchewan.

22. Ancillus rivularis, $\mathrm{SAY}$

23. Physa rivalis

24. " $\left.\begin{array}{c}\text { turrita (elongata) SAY } \\ \text { Bulla hypnorum, LINN.) }\end{array}\right\}$

25. " sp. nova

26. " foutinalis . . Methy Lake to Bear Lake. 
Names.

Localities.

27. Physa heterostropha .

Canada to Saskatchewan.

28. " ancillaria, SAY

Ditto ditto.

29. ", sp. nova

Ditto to Methy Lake.

30. Limnea n. sp. similis stagnali

Lake Superior to Lake Winipeg.

31. „ columella

Ditto

ditto.

32. " palustris . . . Canada to Great Bear Lake.

33. „ fossaria . . Ditto to Saskatchewan.

34. „ n. . . . . Ditto ditto.

35., catascopium . Ditto ditto.

36. " sp. dubia . . Ditto ditto.

37. " sp. n. leucostomæ similis Ditto ditto.

38. " sp. nova . . Ditto ditto.

39. Melania conica, SAY . Lake Superior ditto.

40. „ sp. nova . . Ditto ditto.

41. " sp. nova . . Ditto ditto.

42. Paludina decisa, var. . . Ditto ditto.

43. " limosa . . Ditto to Methy Lake.

44. Cyclas rhomboidea . . Ditto to Lake Winipeg.

45. $"$ similis . . Ditto ditto.

46. „̋lata (Pera, Leach) appendi- $\}$ Ditto ditto.

47. ", calyculata . . Methy Lake.

48. „ stagnicola . . Ditto.

49. „ media . . . Ditto.

50. „ pulchella. . . Ditto.

51. Unio plicatus . . . Saskatchewan.

52. „ radiatus . . . Ditto.

53. „ radiatus, var. . . Ditto.

54. „, purpureus . . . Ditto.

55. „, purpureus, var. . Ditto.

56. Anodon undulatus . . Ditto.

57. , anatinus . . Ditto. 


\section{N D E X.}

[The Latin names of groups or species, whose characters or descriptions are contained in the text, are in siral. caprtals. and those accidentally referred to, or synonymes, in llalics.]

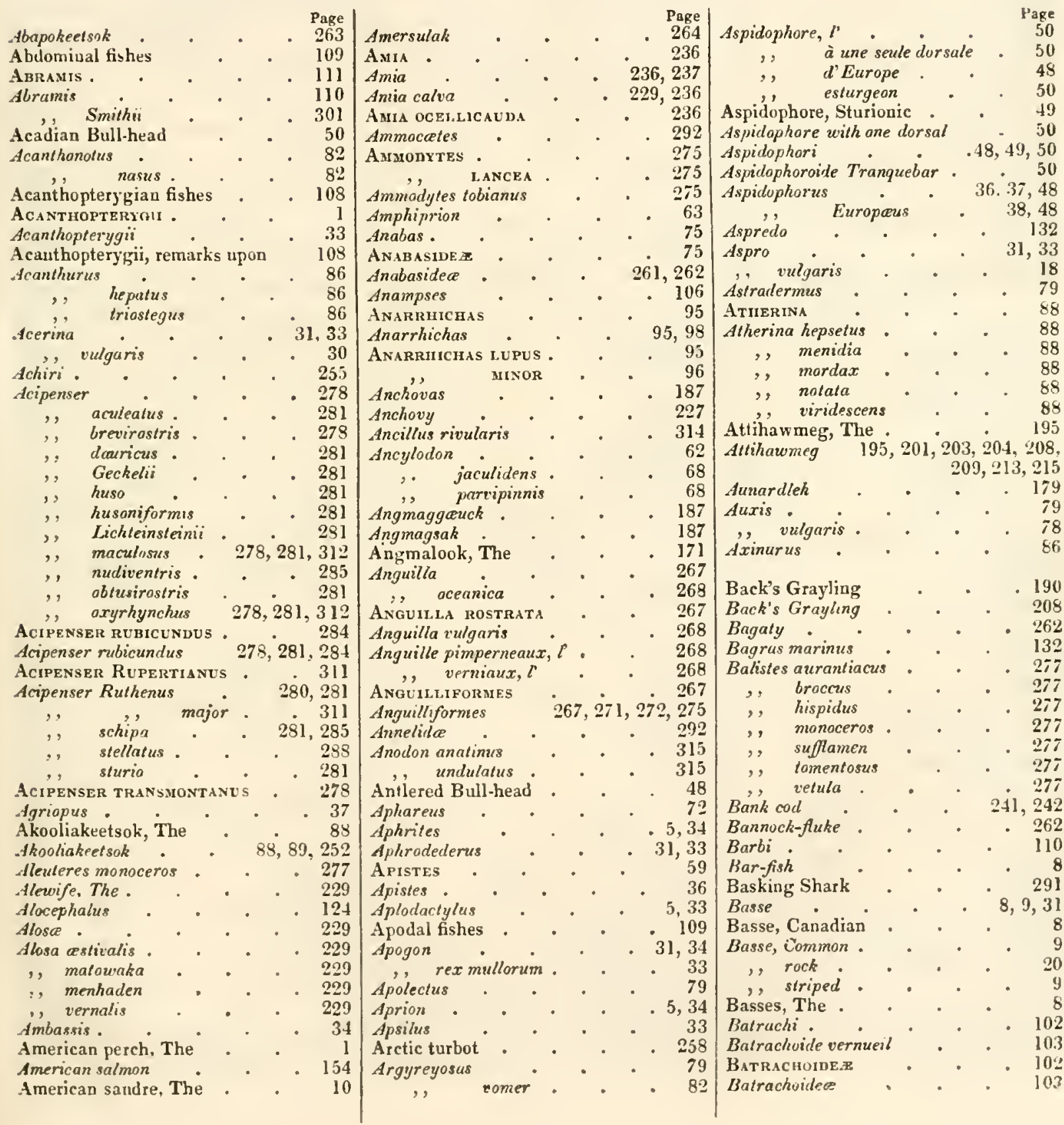




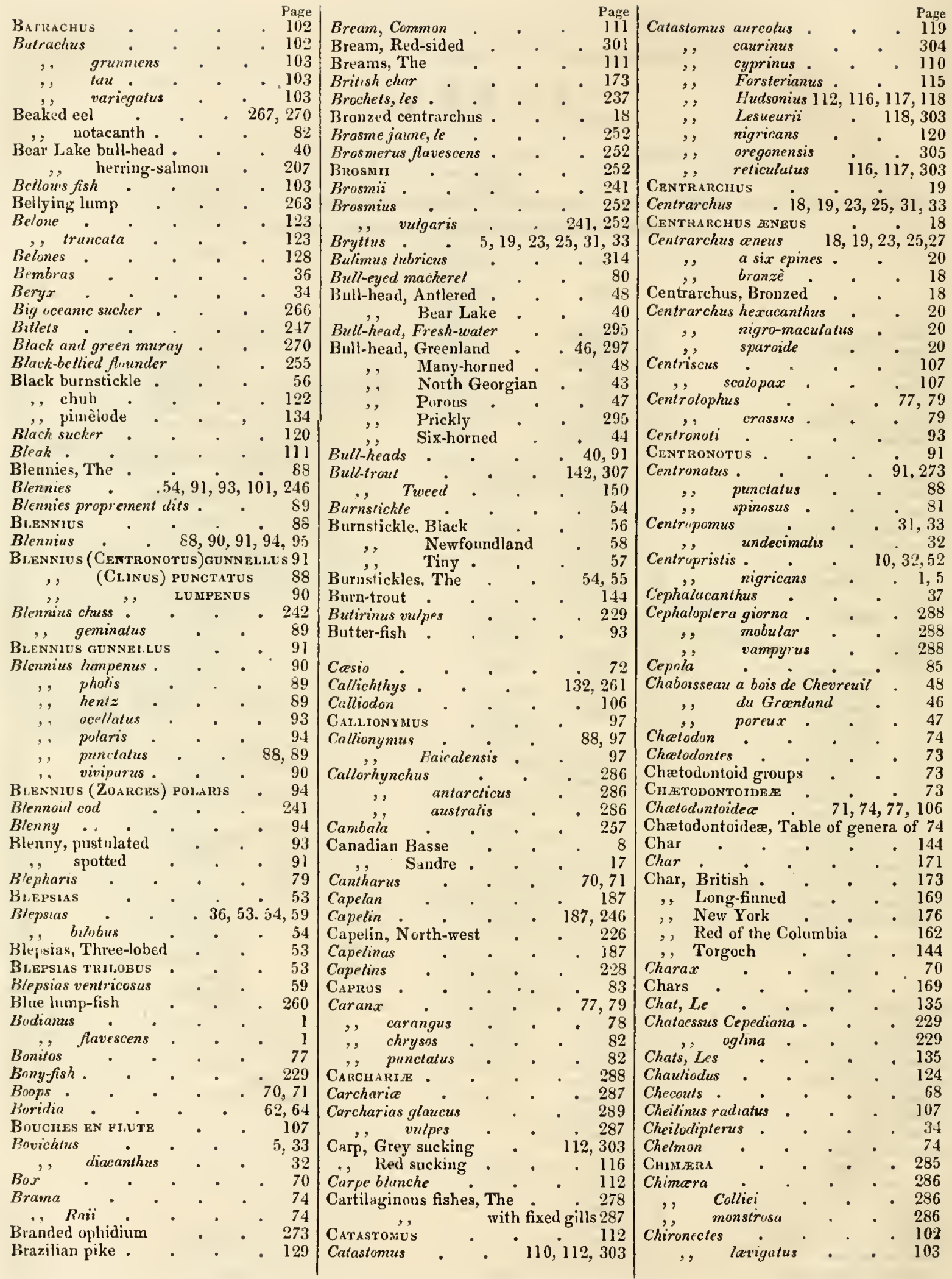




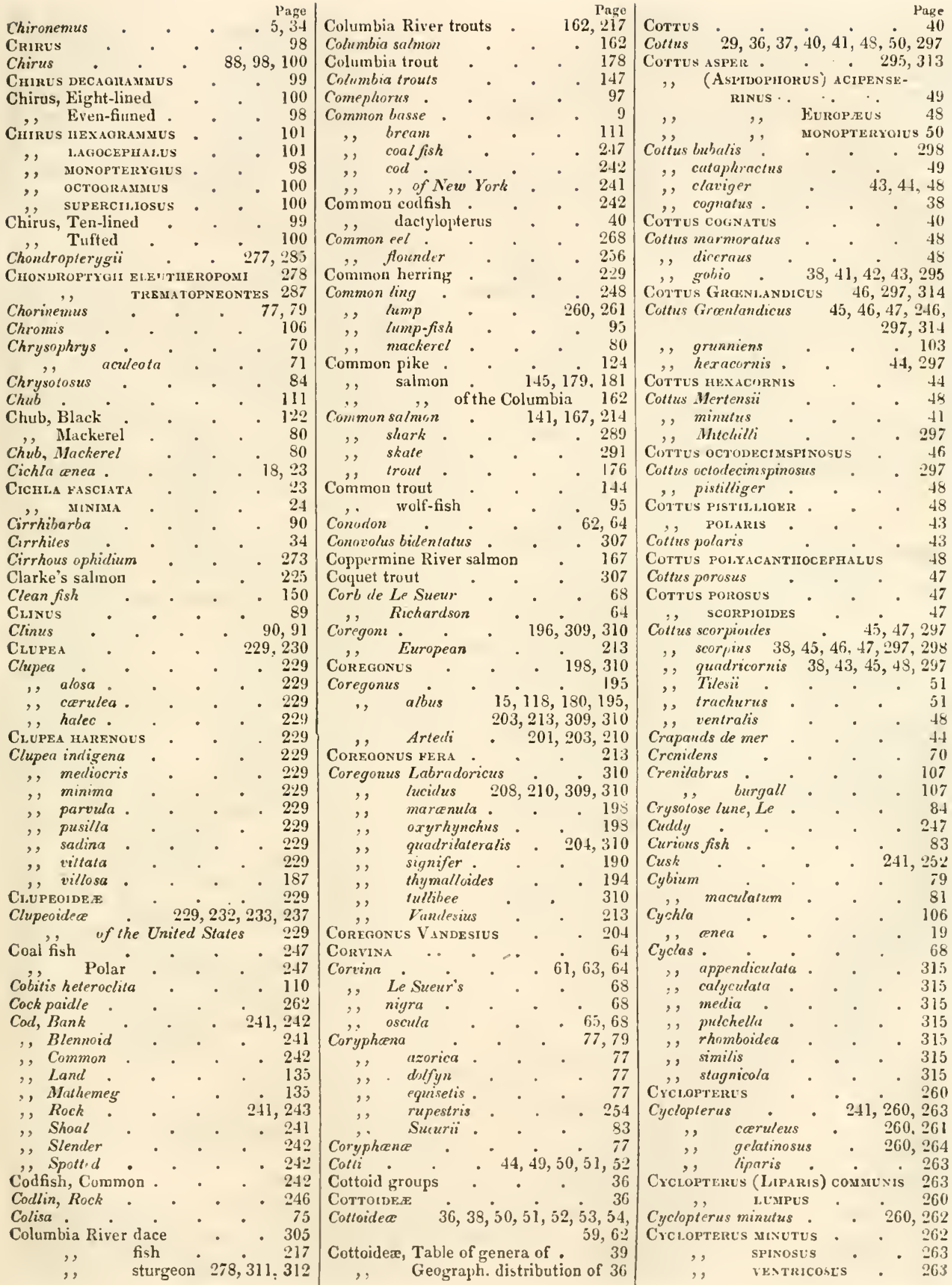




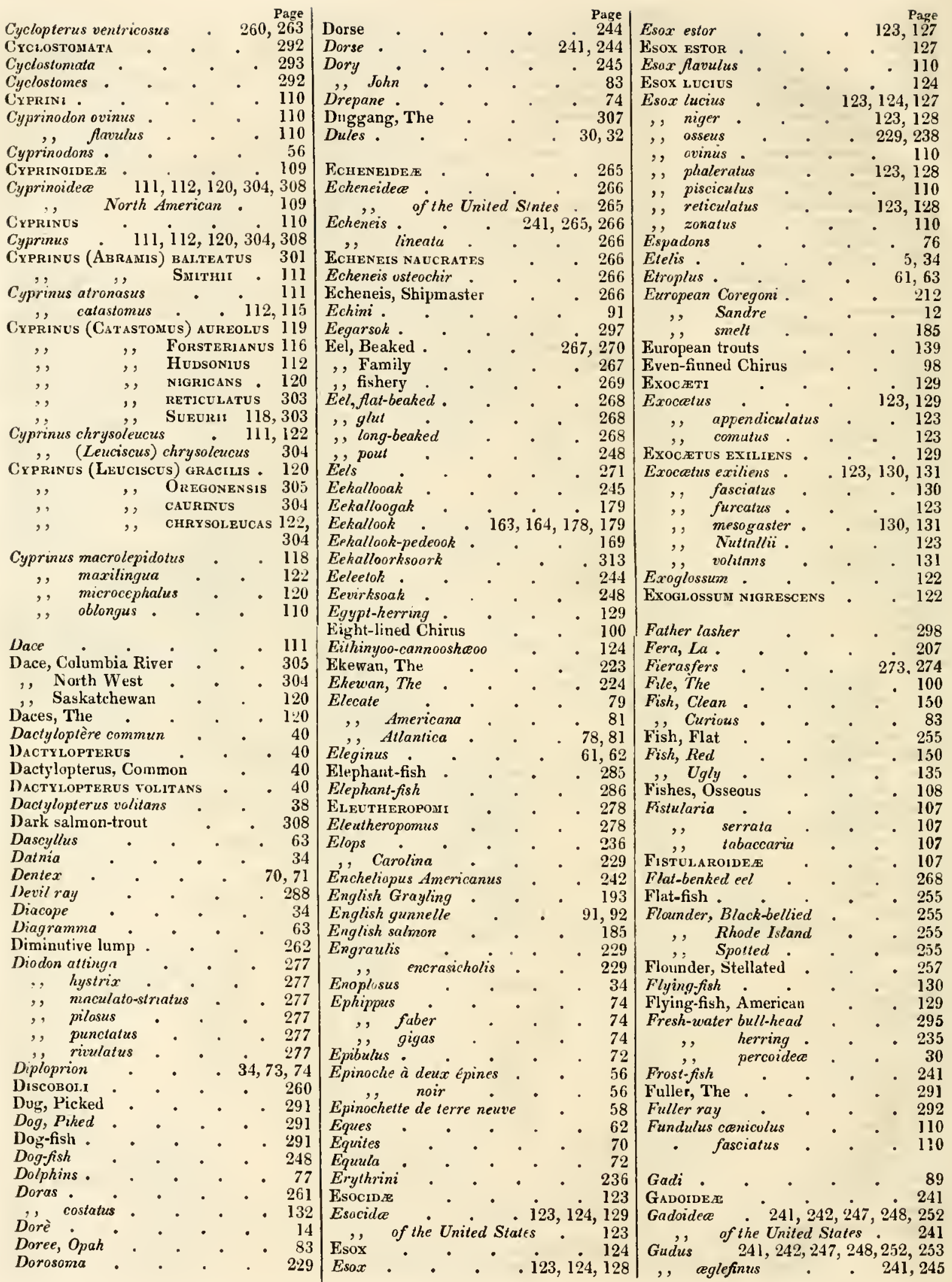


INDEX.

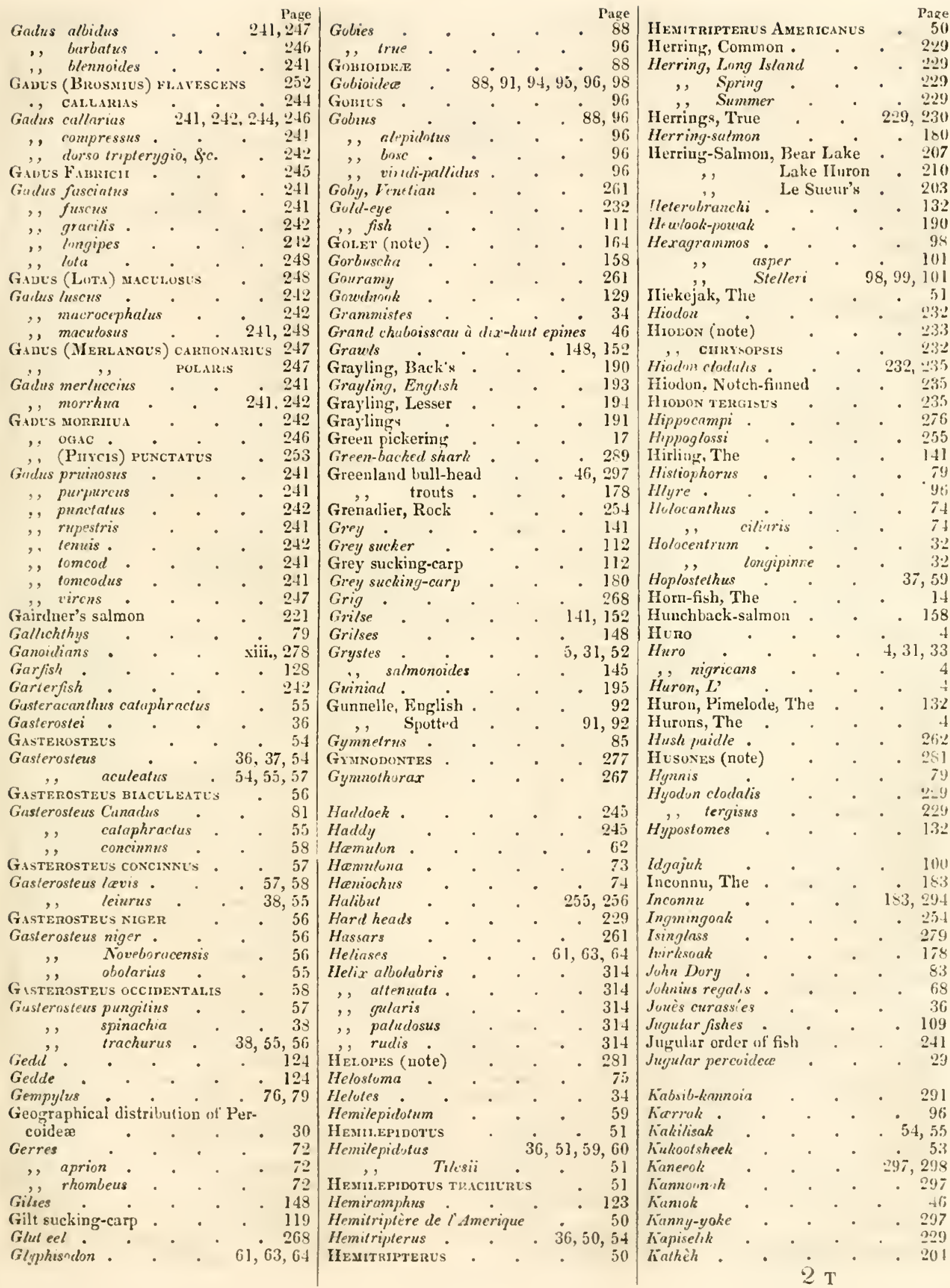




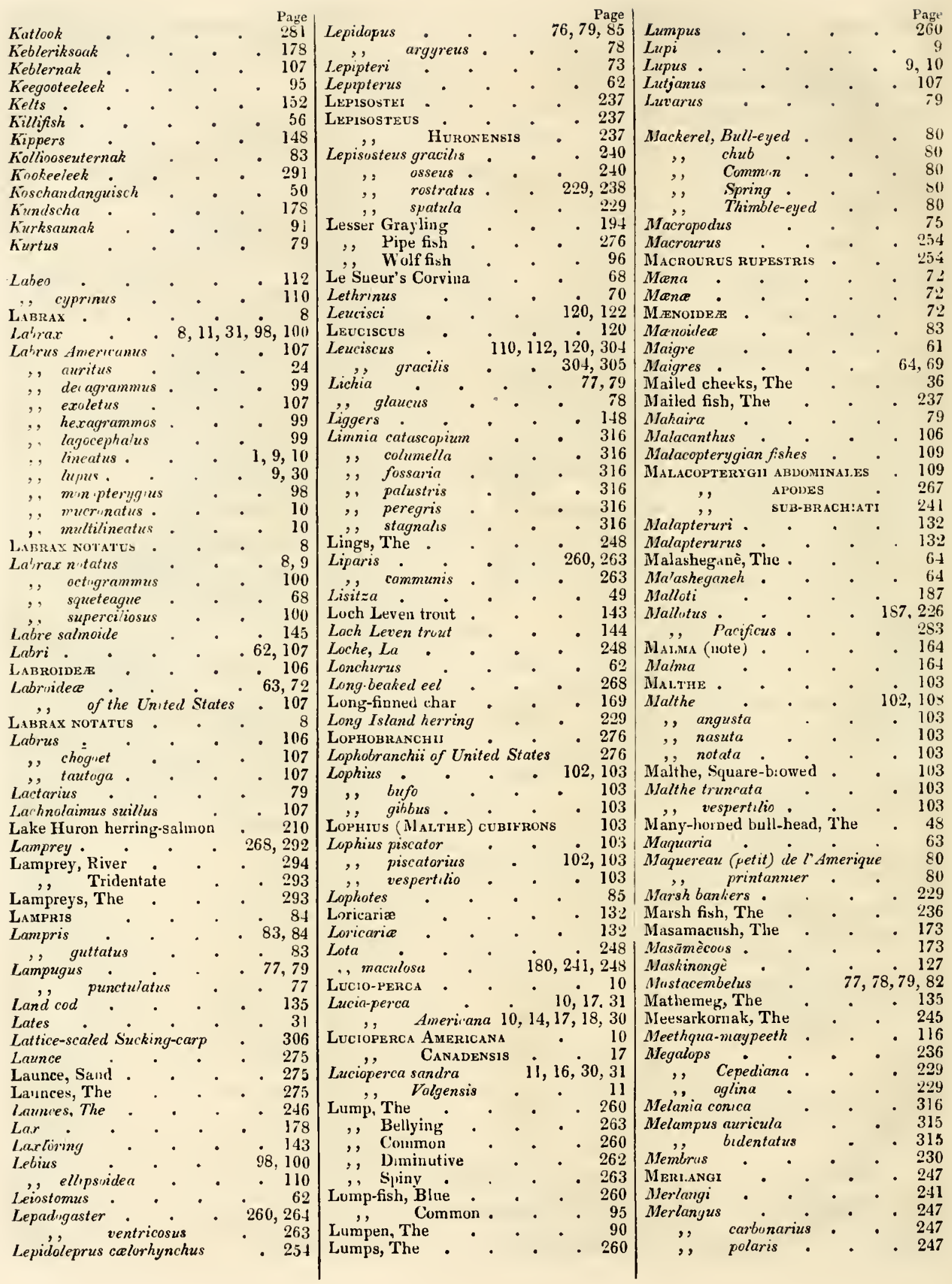




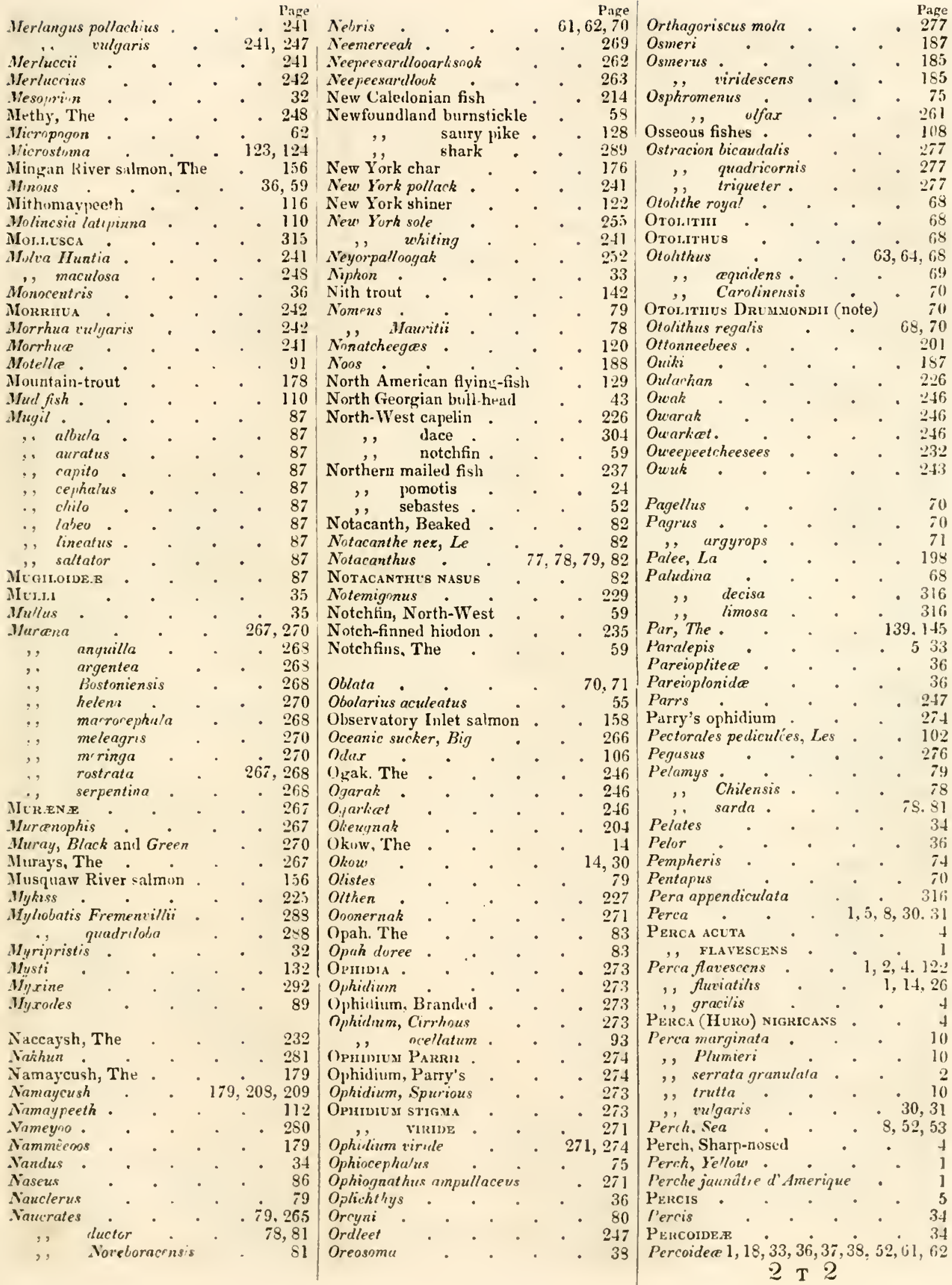




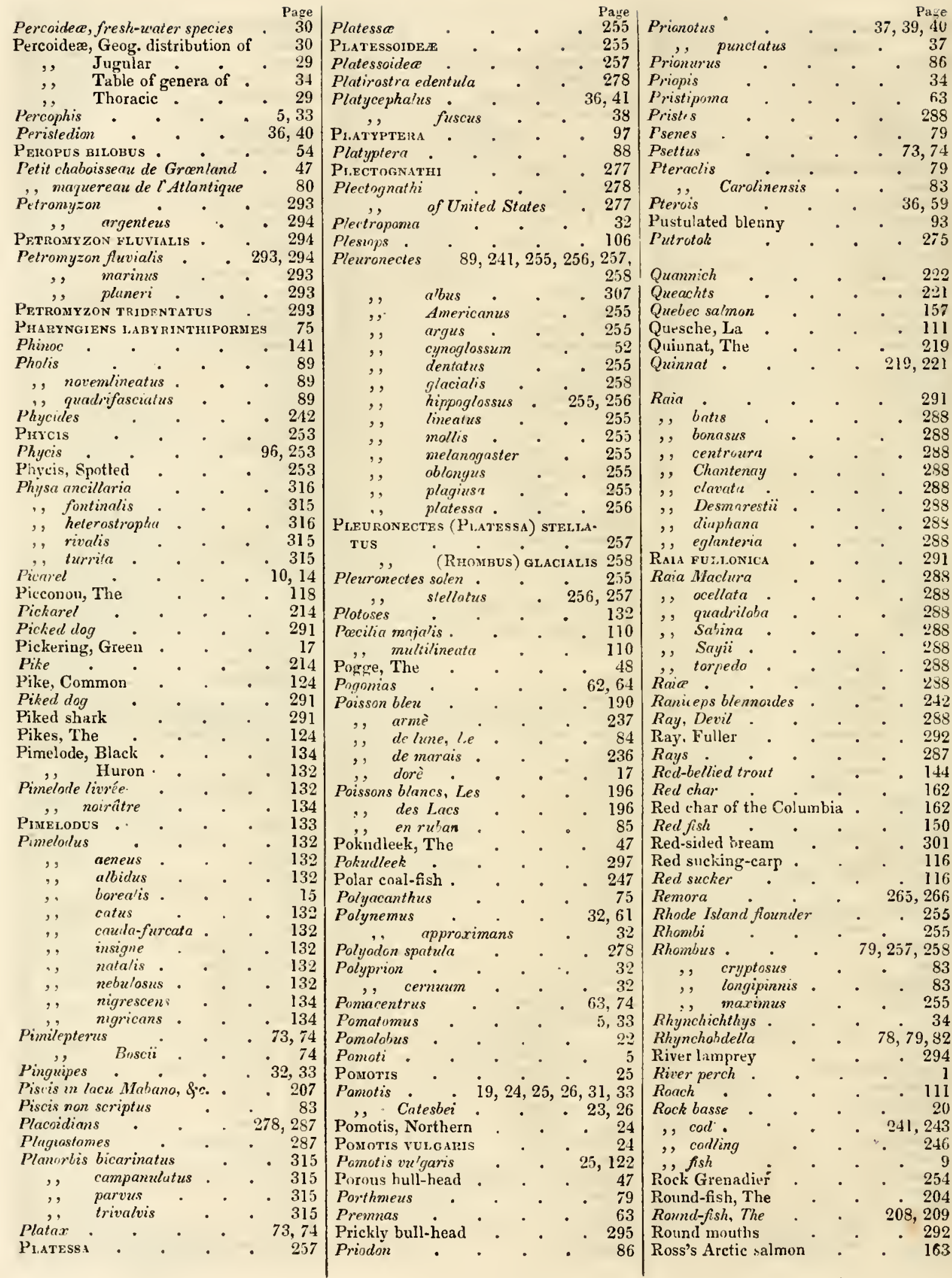




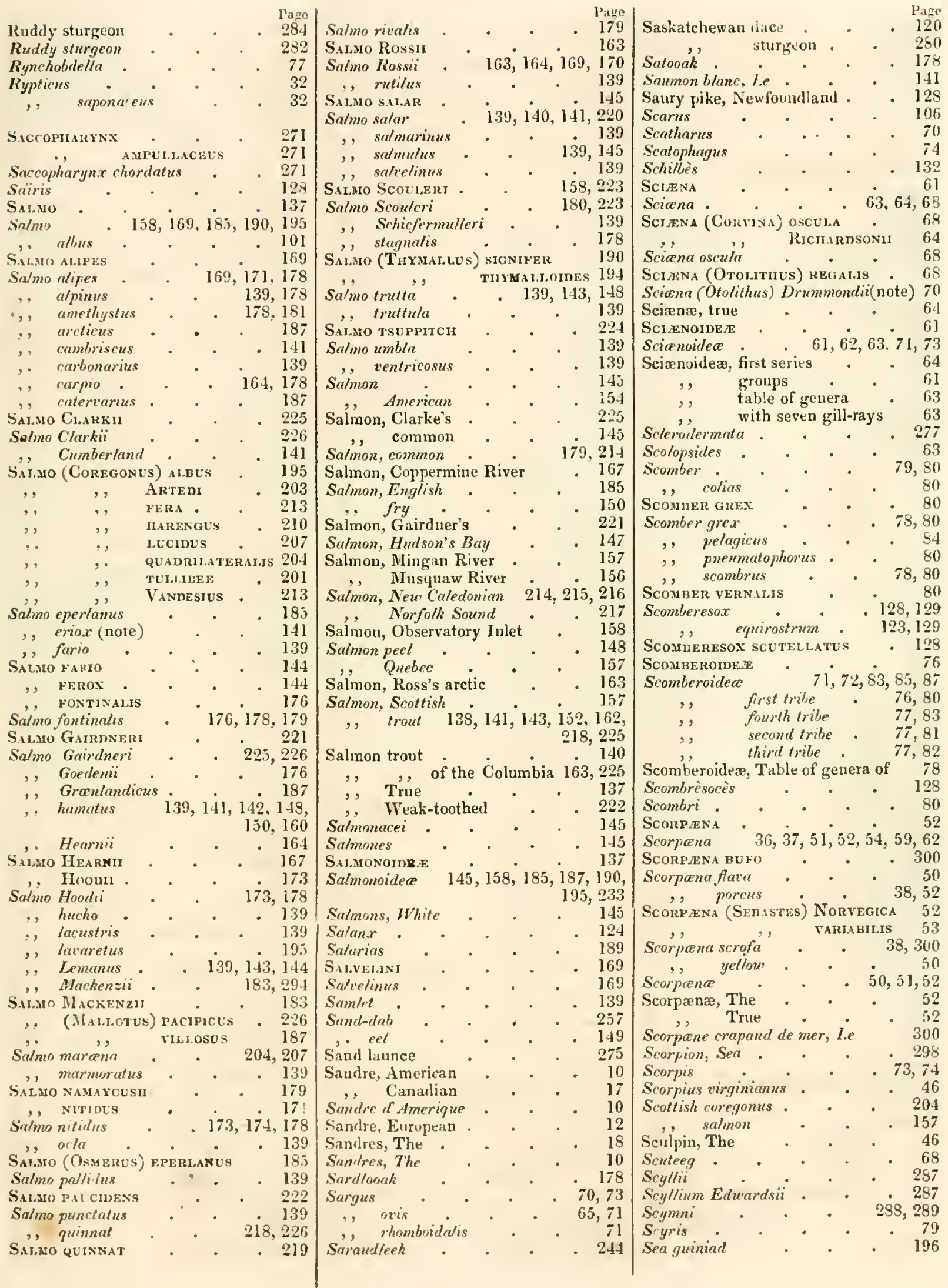




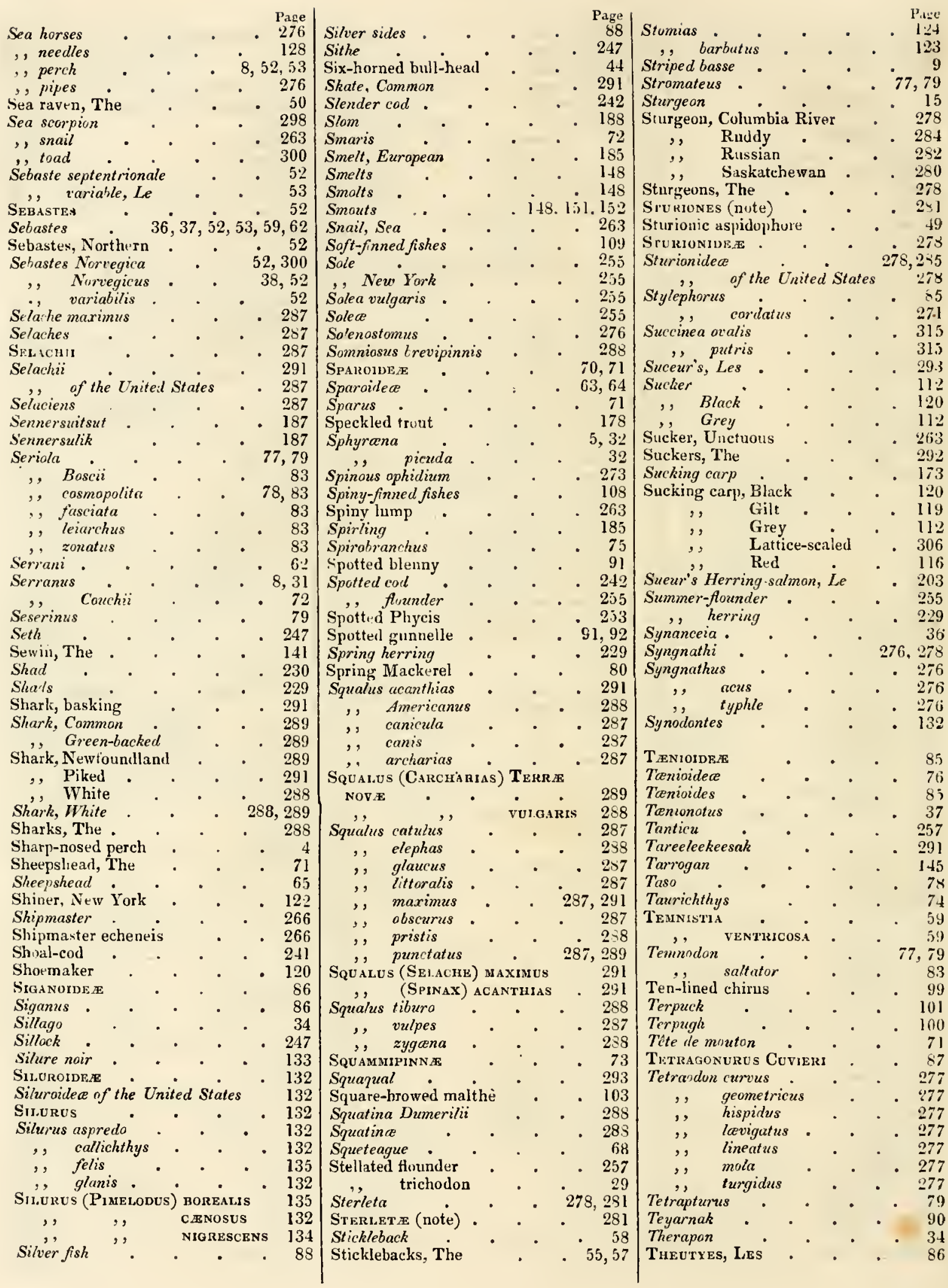




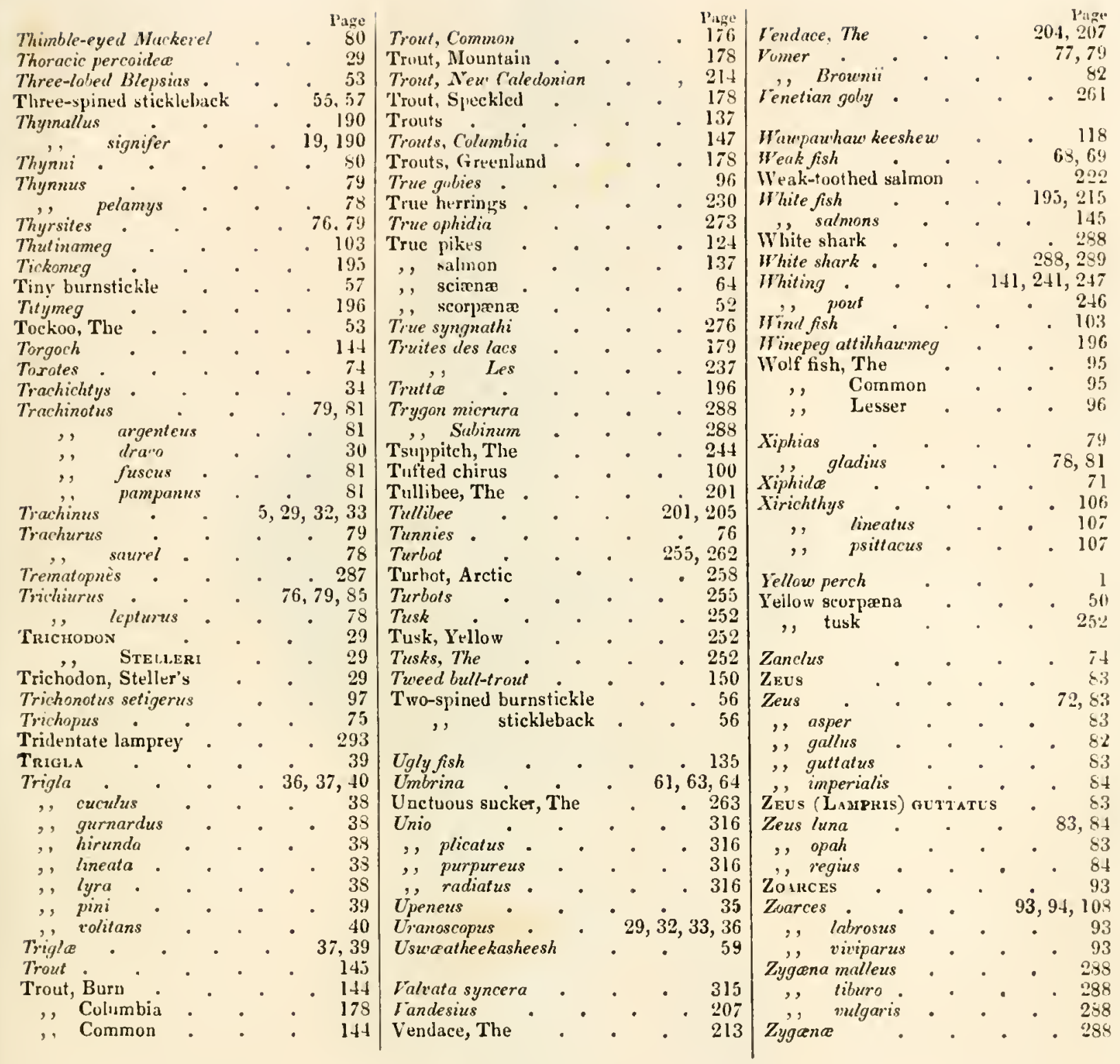



$\frac{\sqrt{2}}{3}$

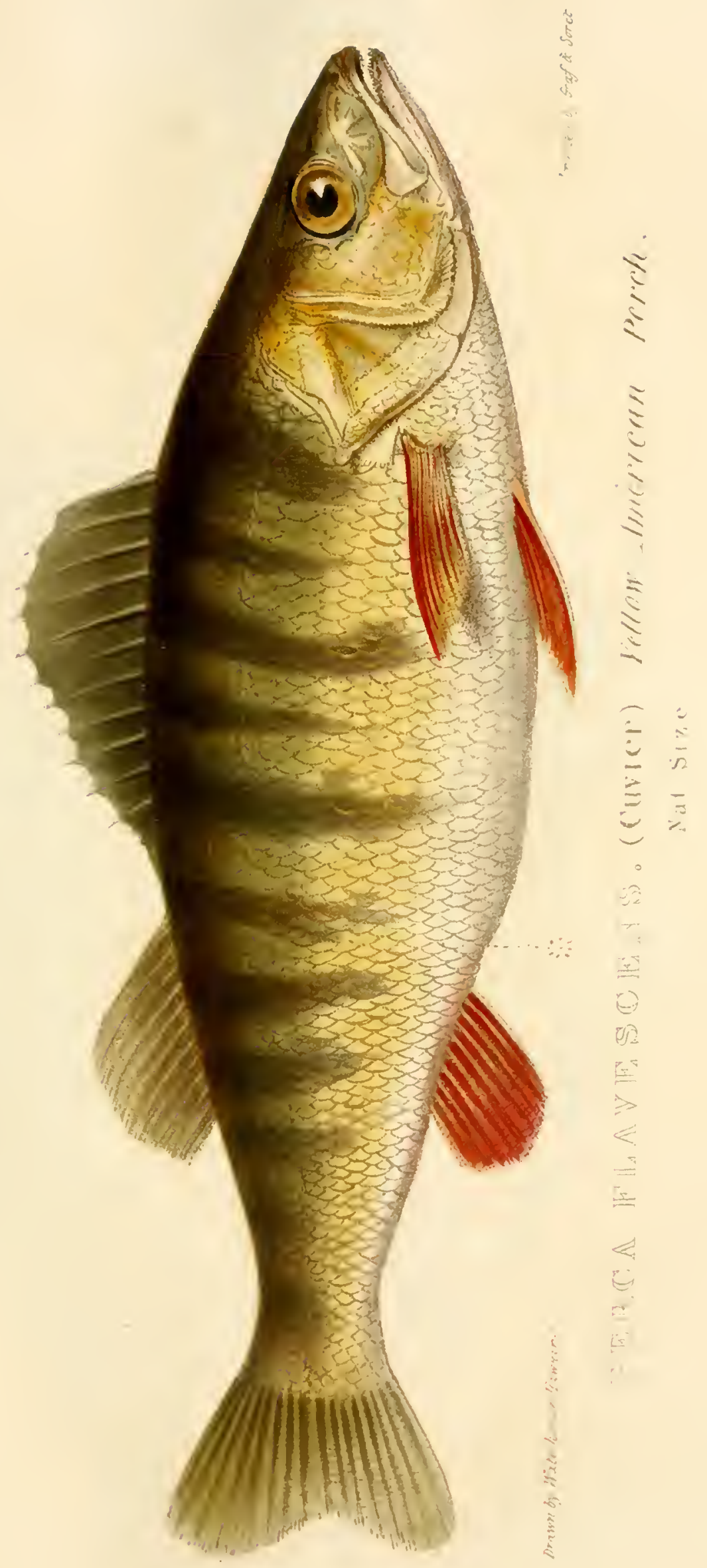




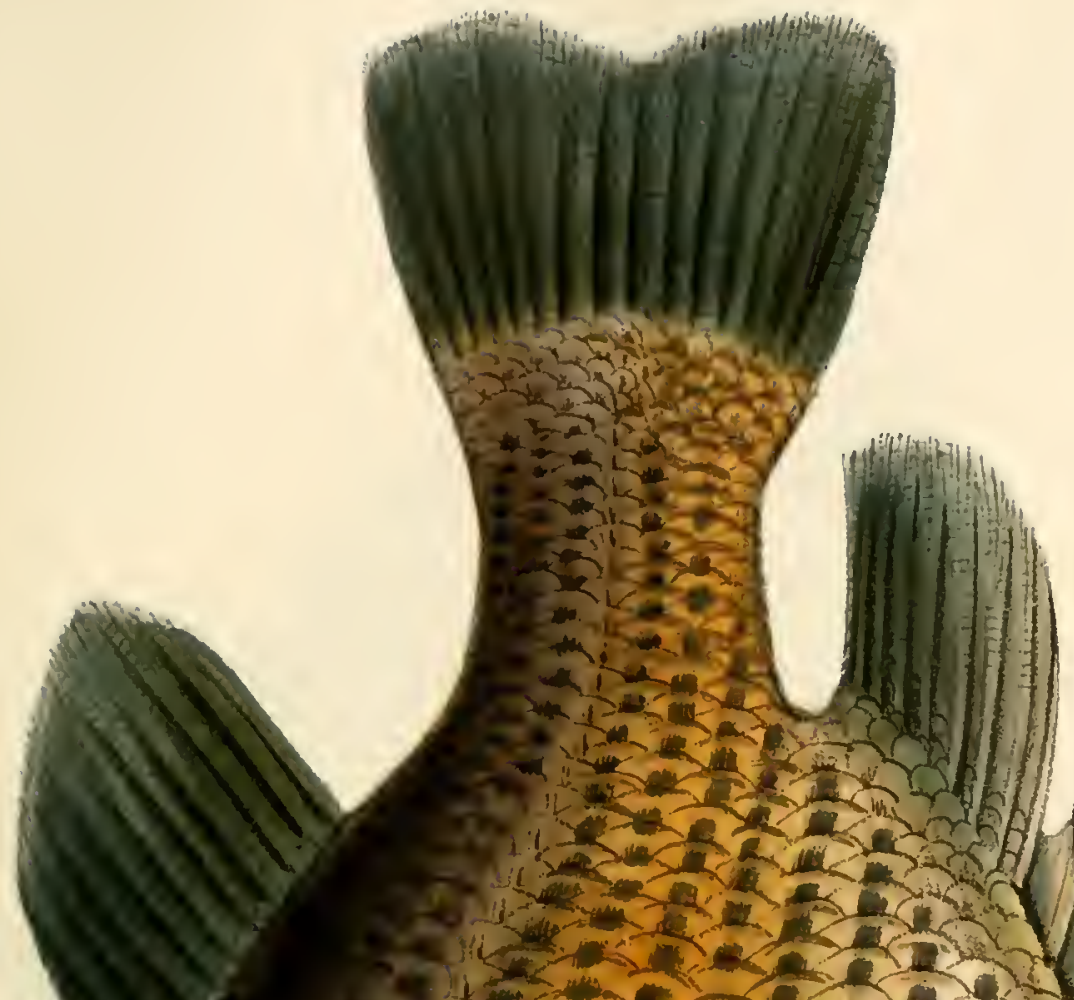

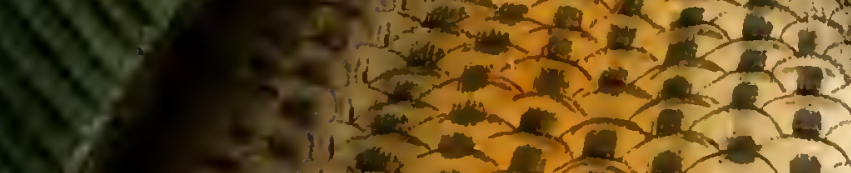

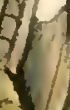

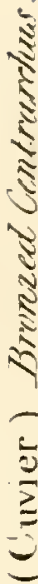

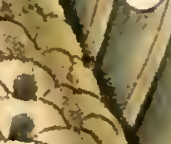





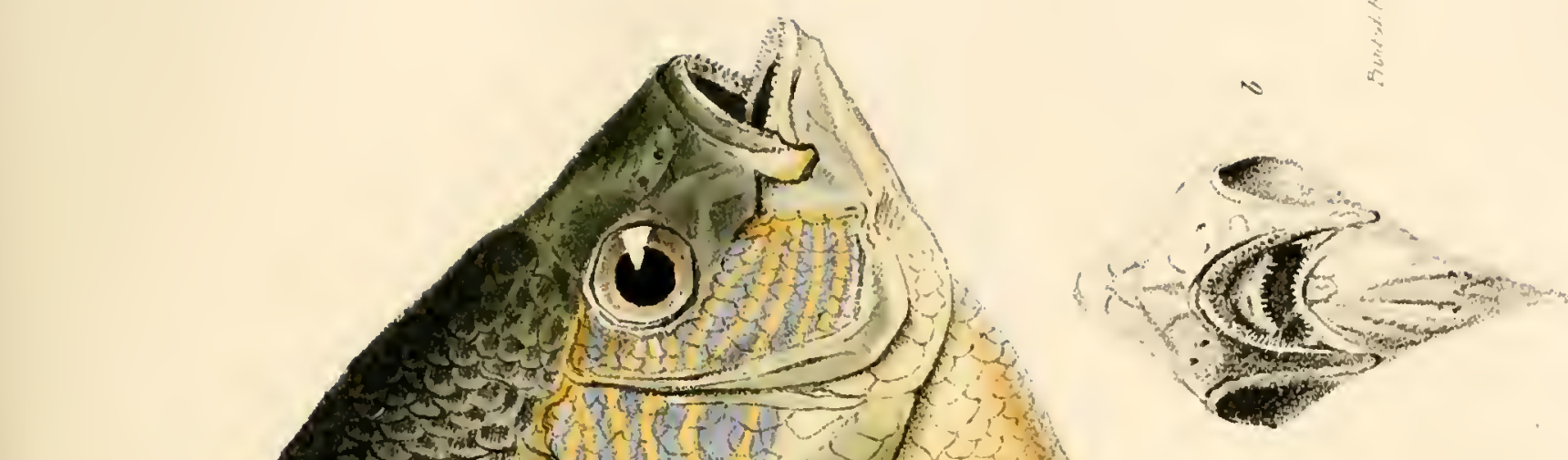





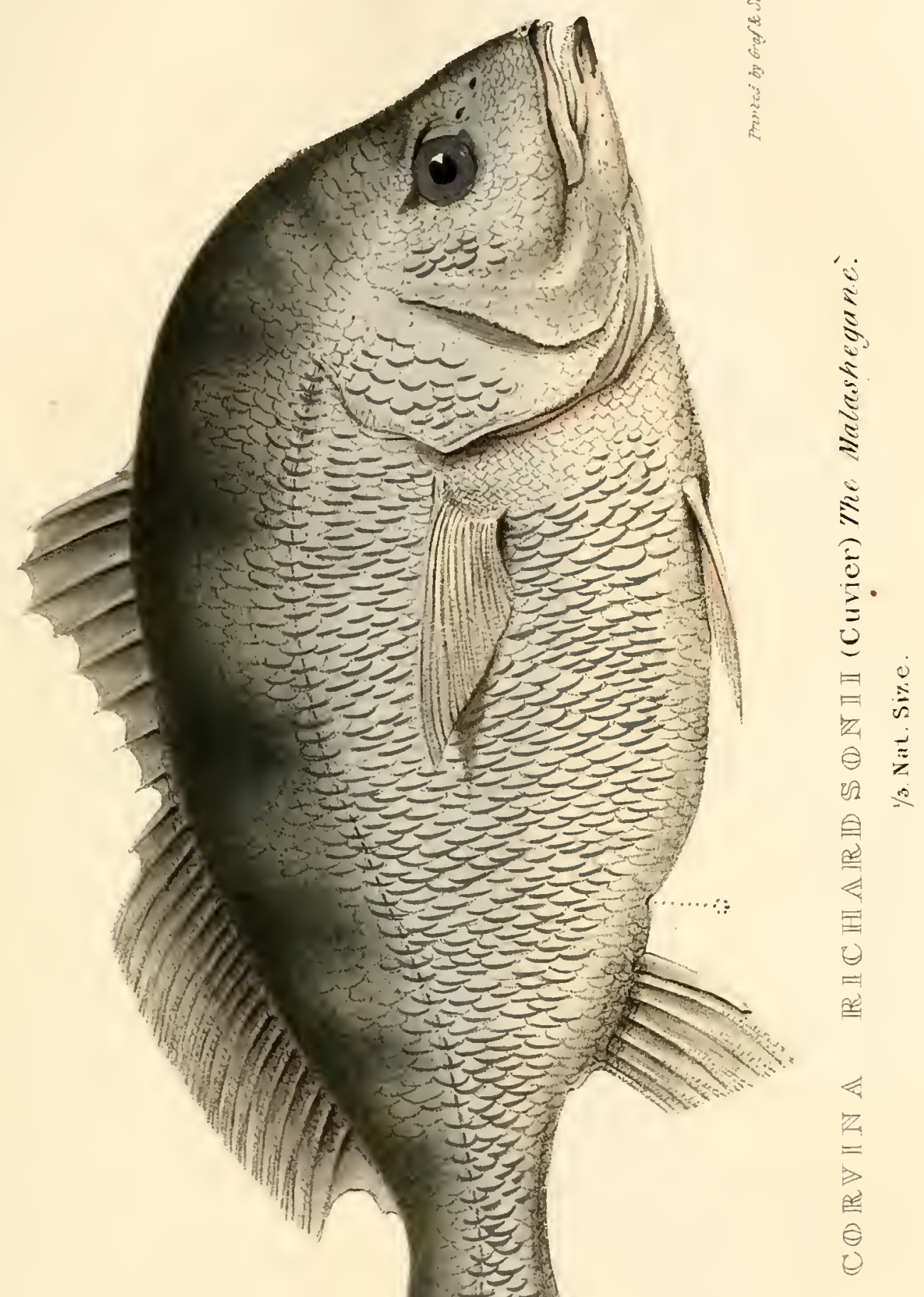





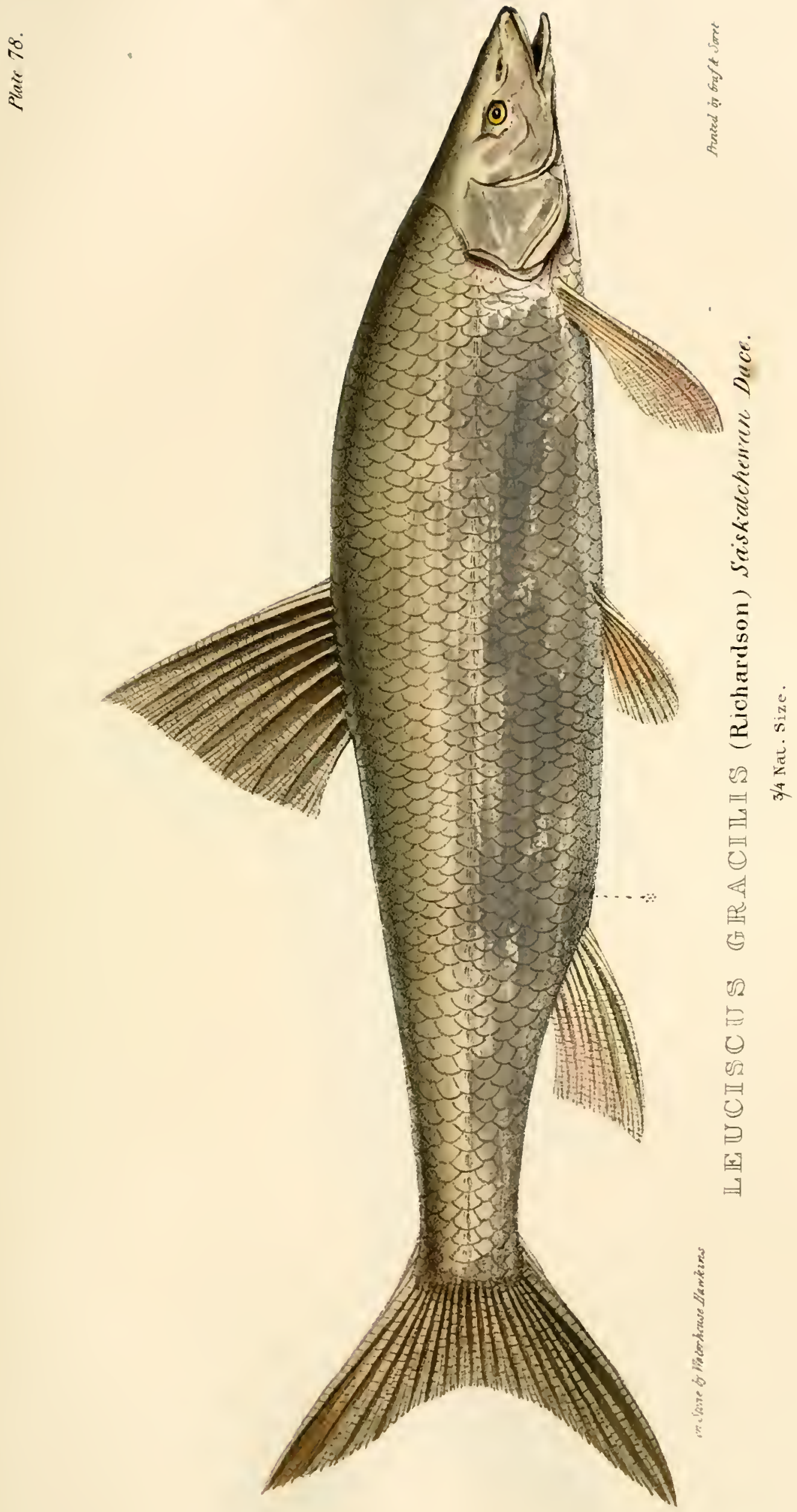






$$
d
$$


.

, 


$$
1
$$





$$
11
$$



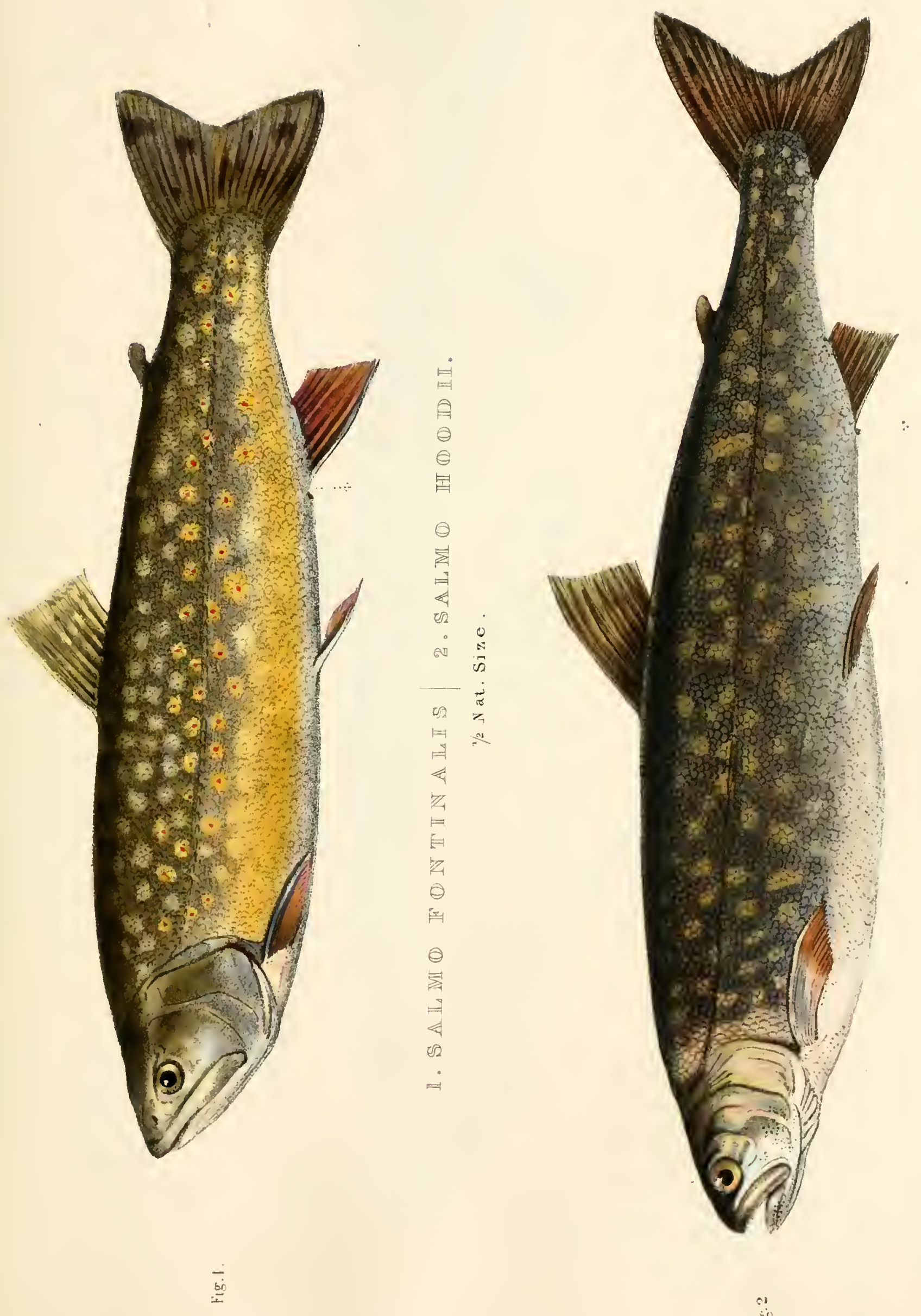



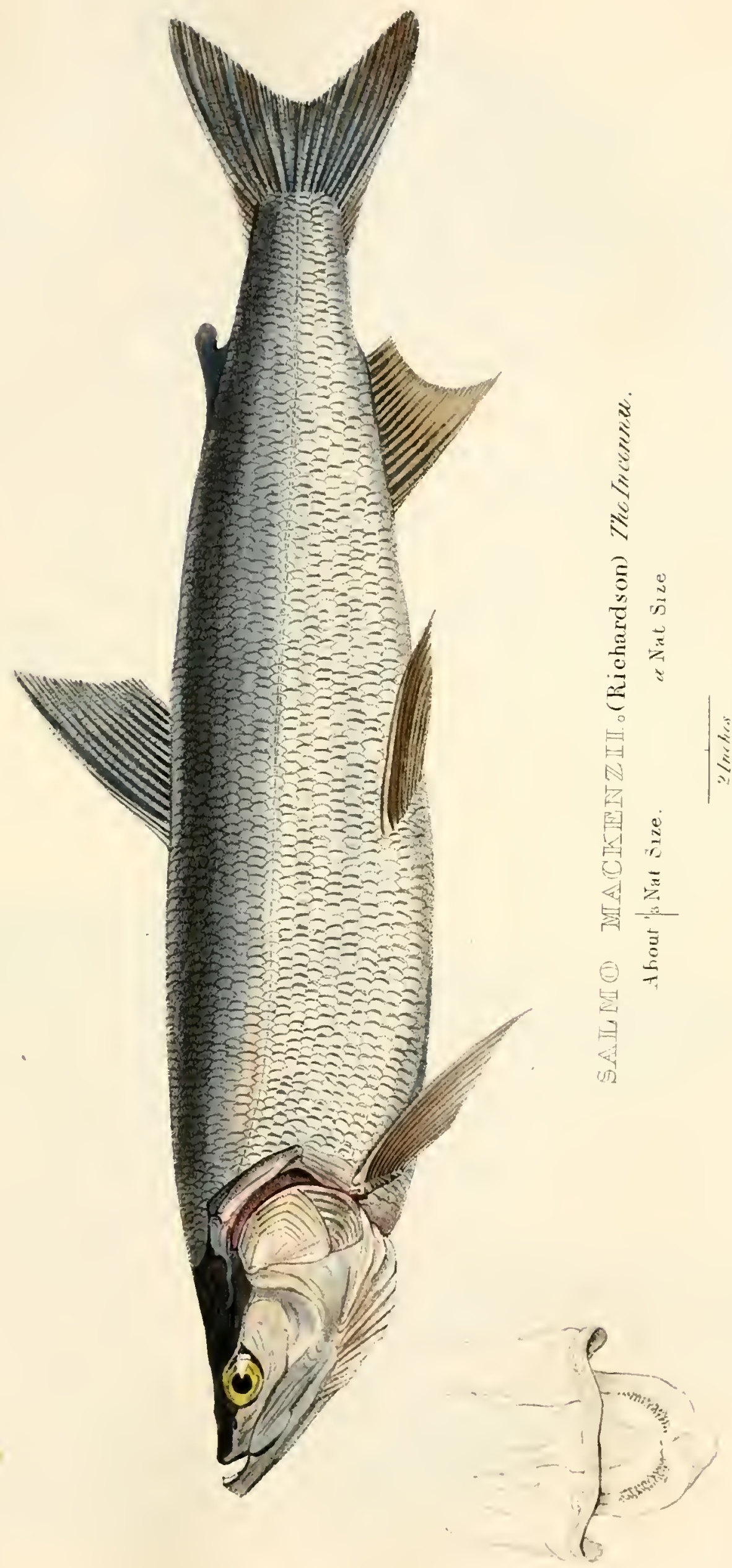





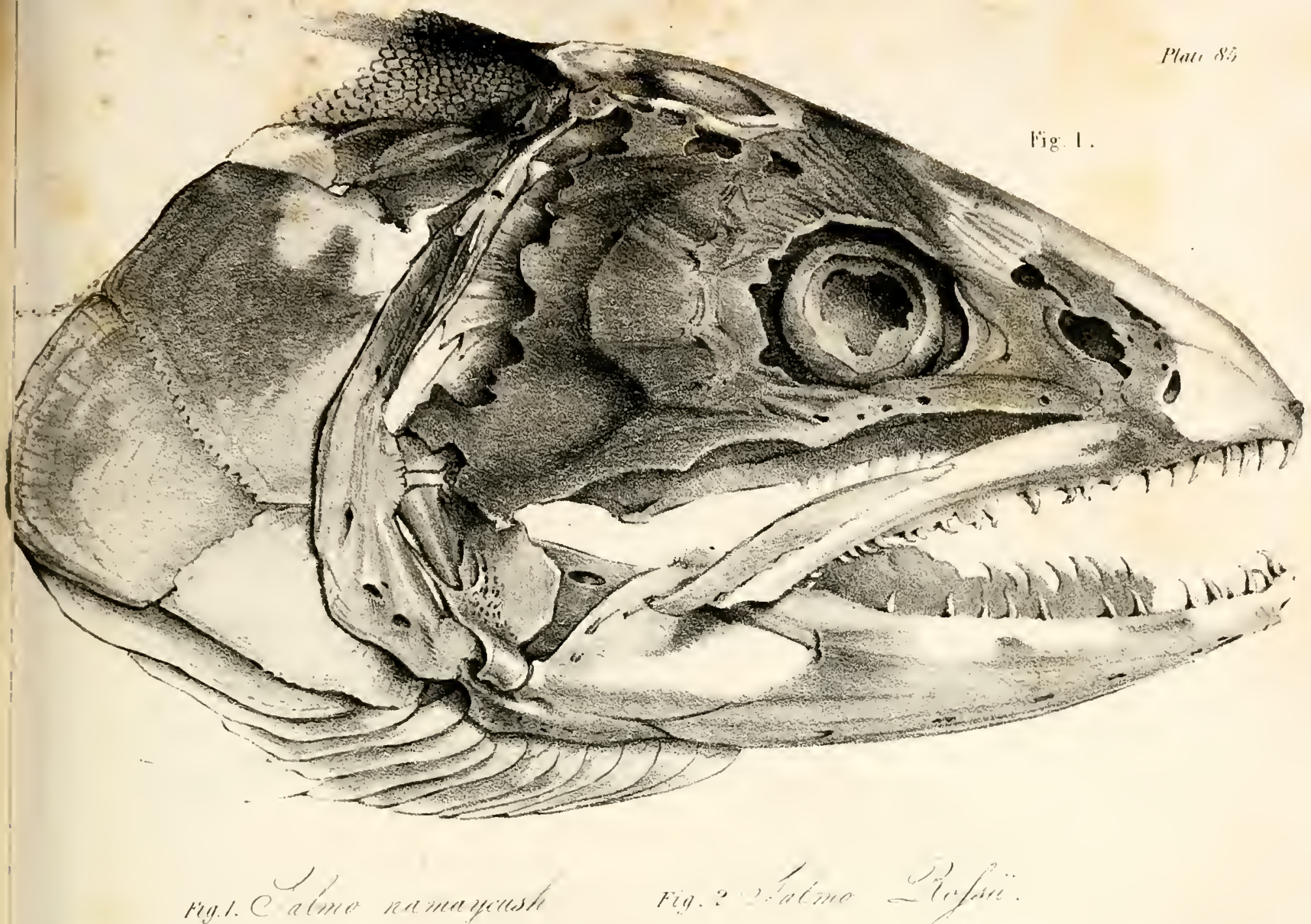

lig. 2

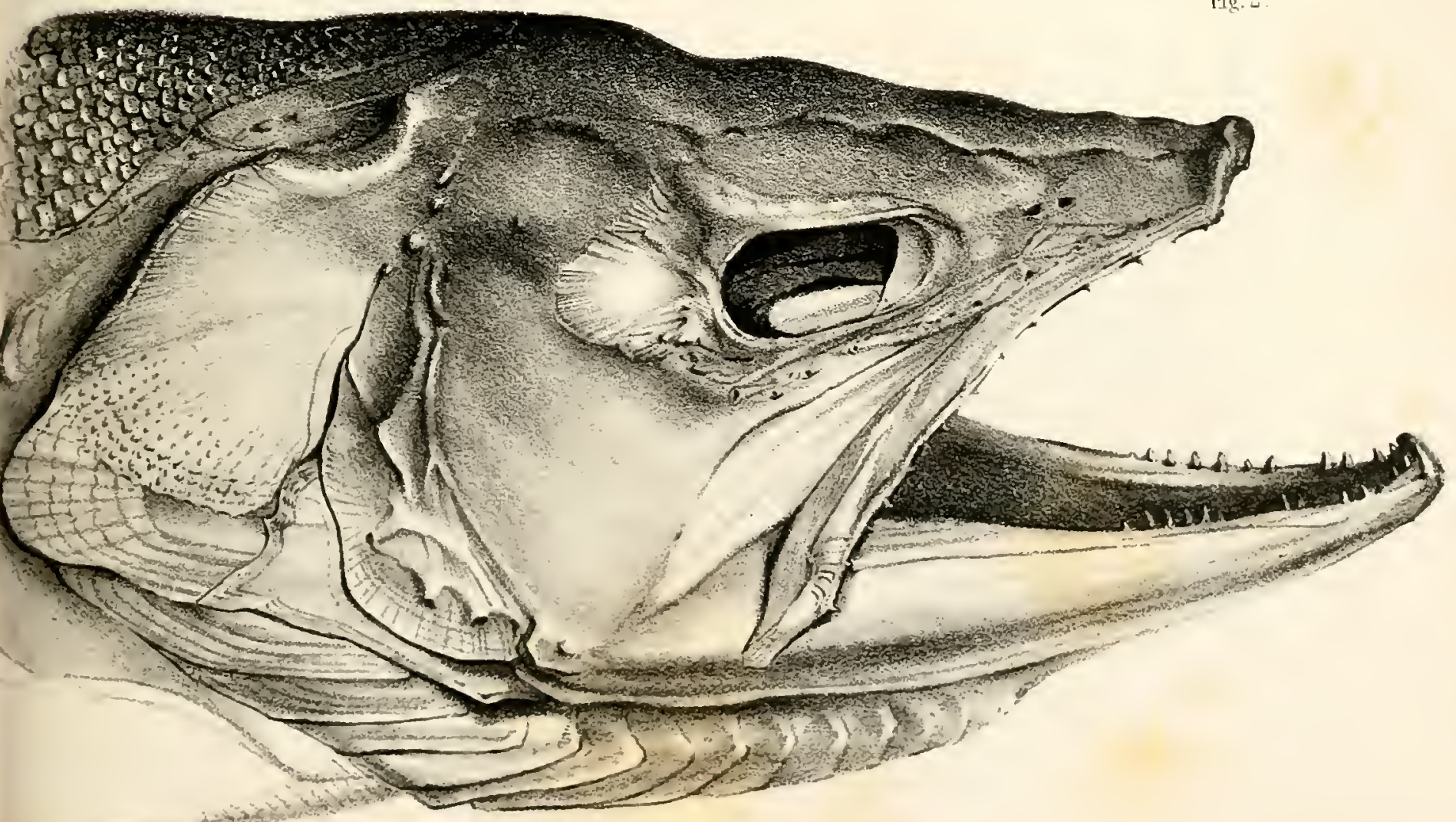





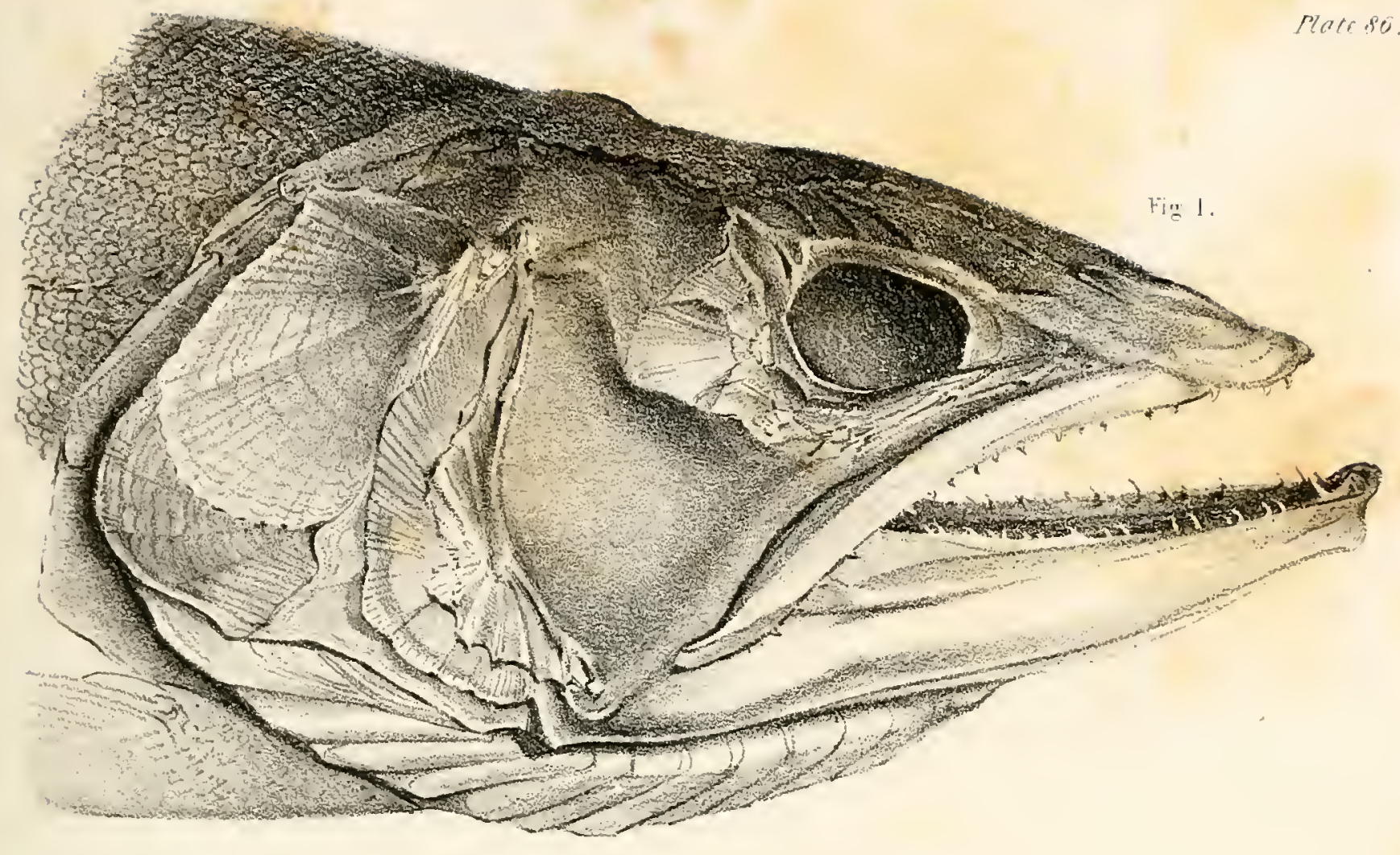

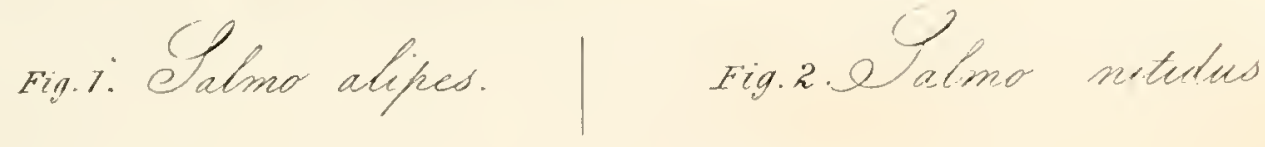

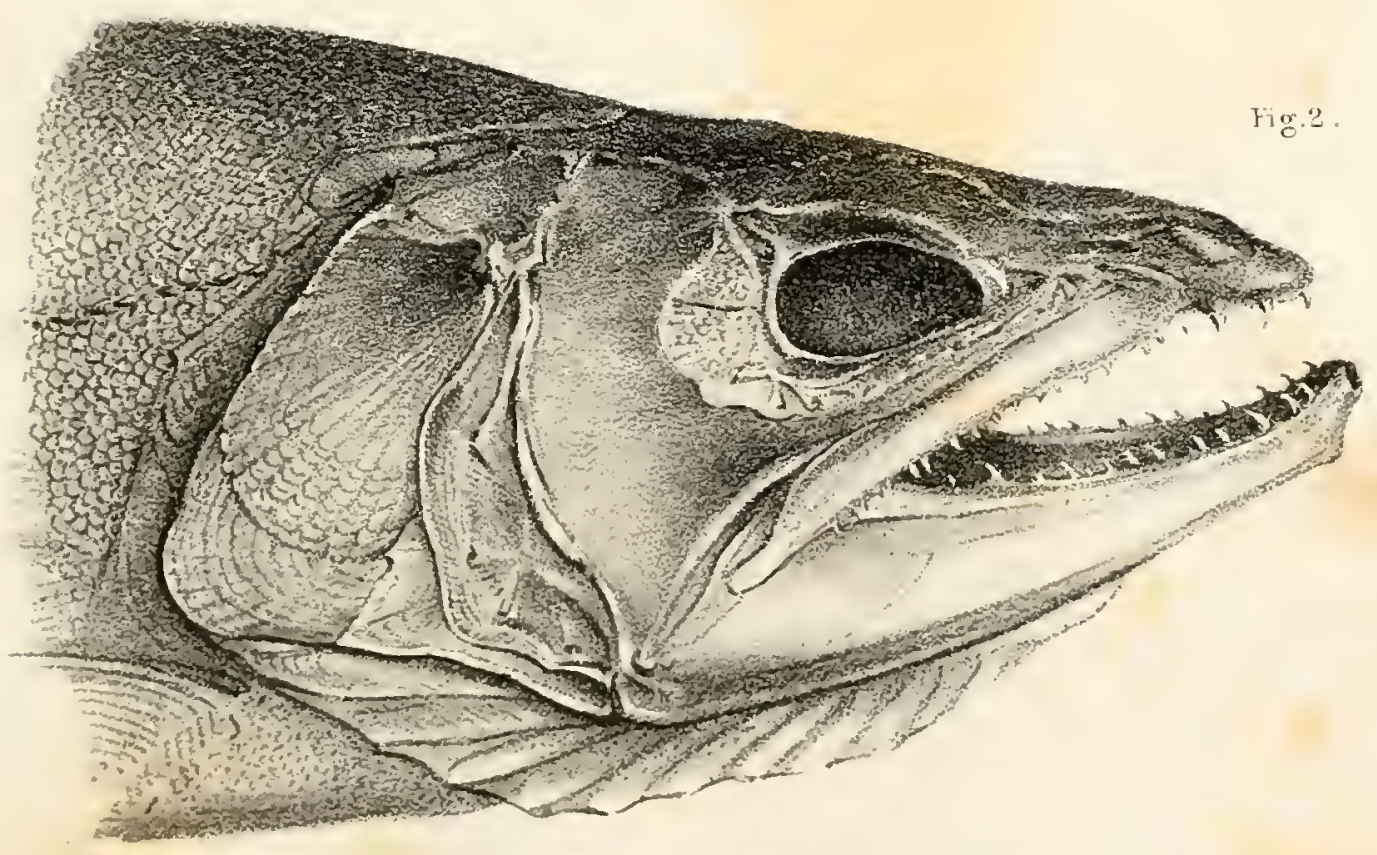





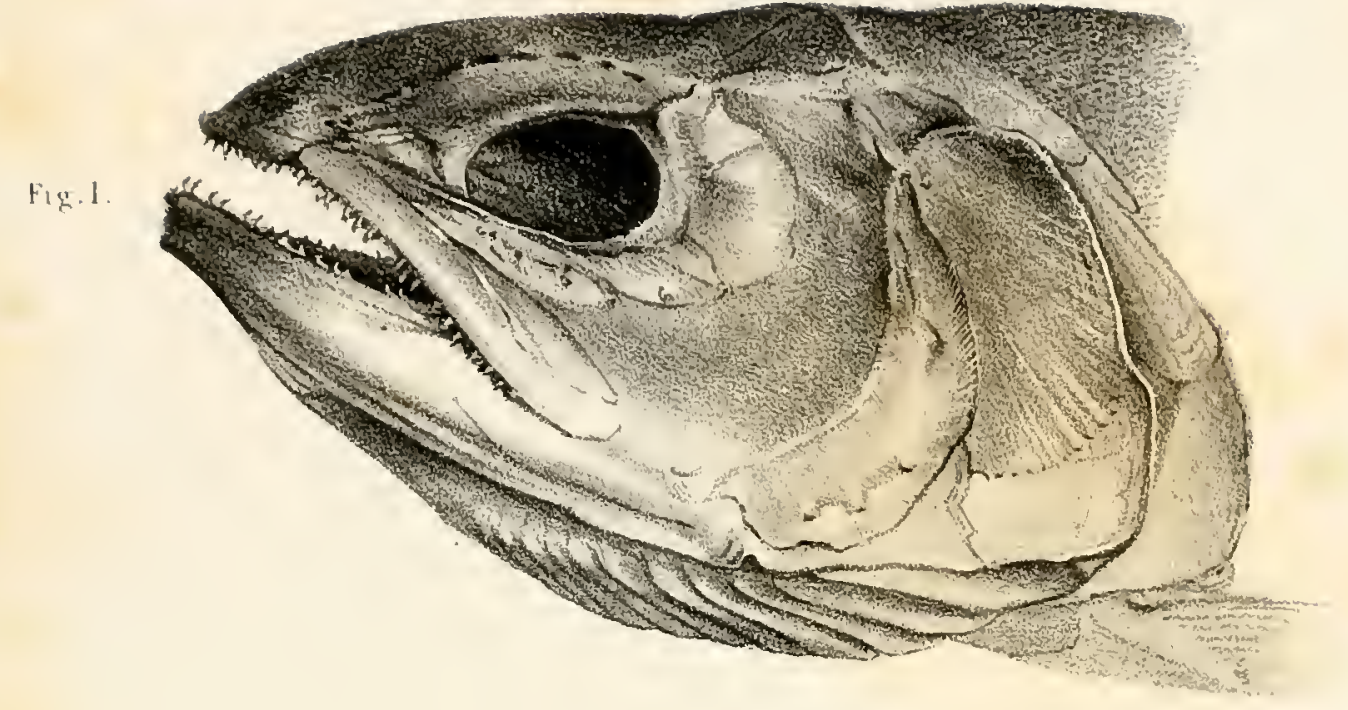

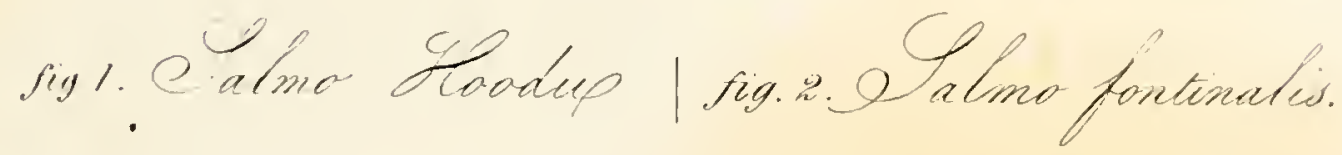
Nat. Size.

Fig. 2

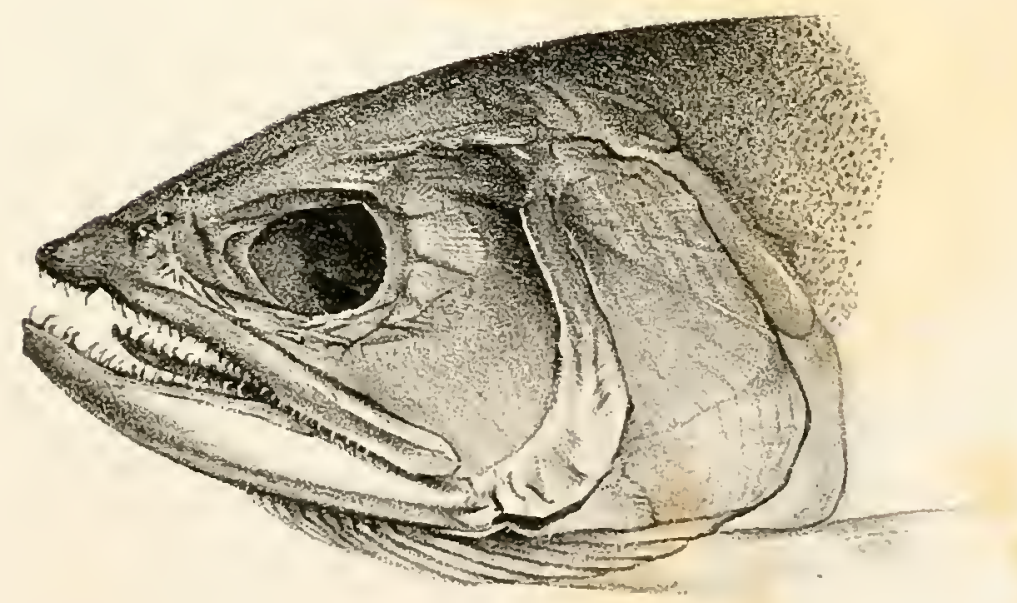





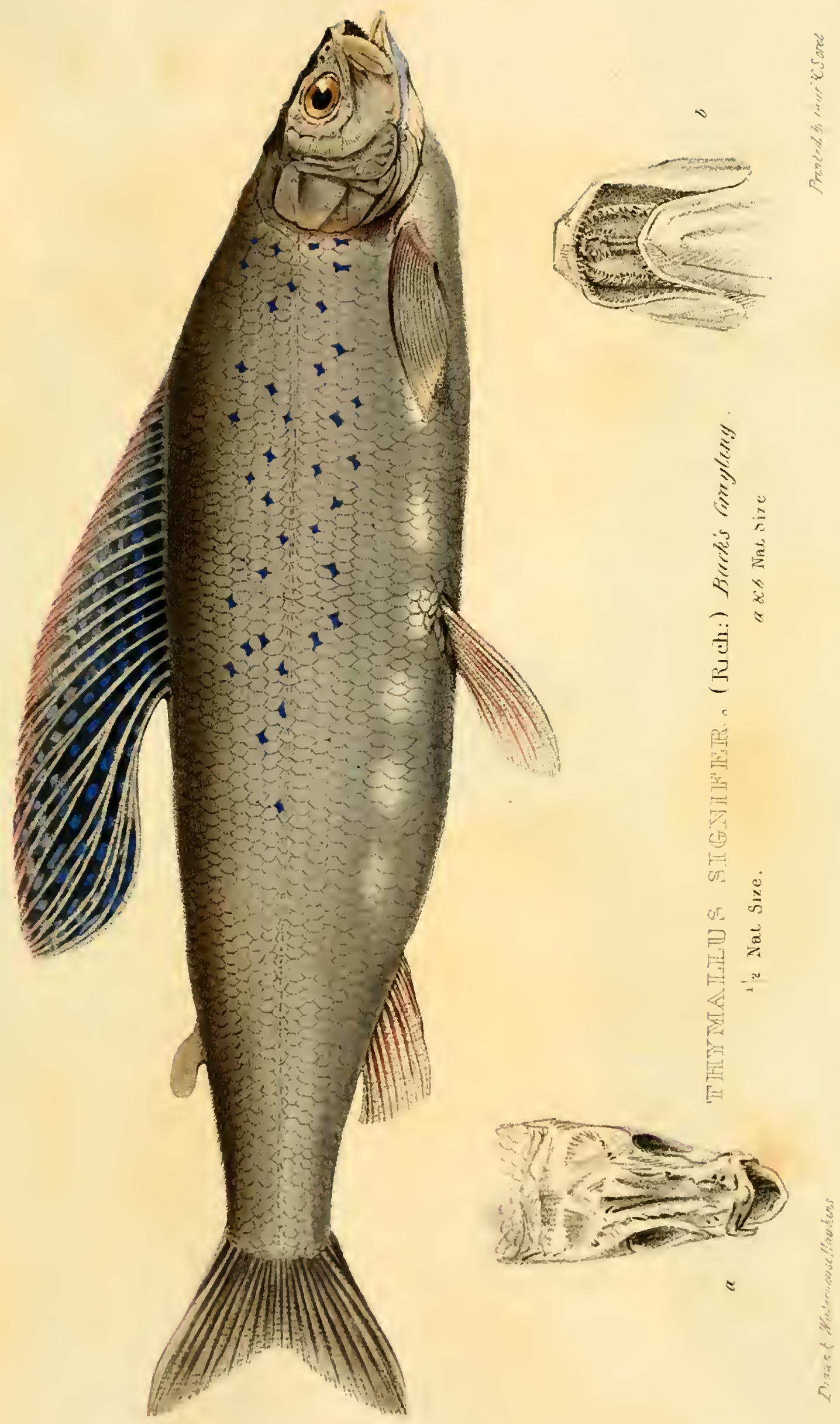




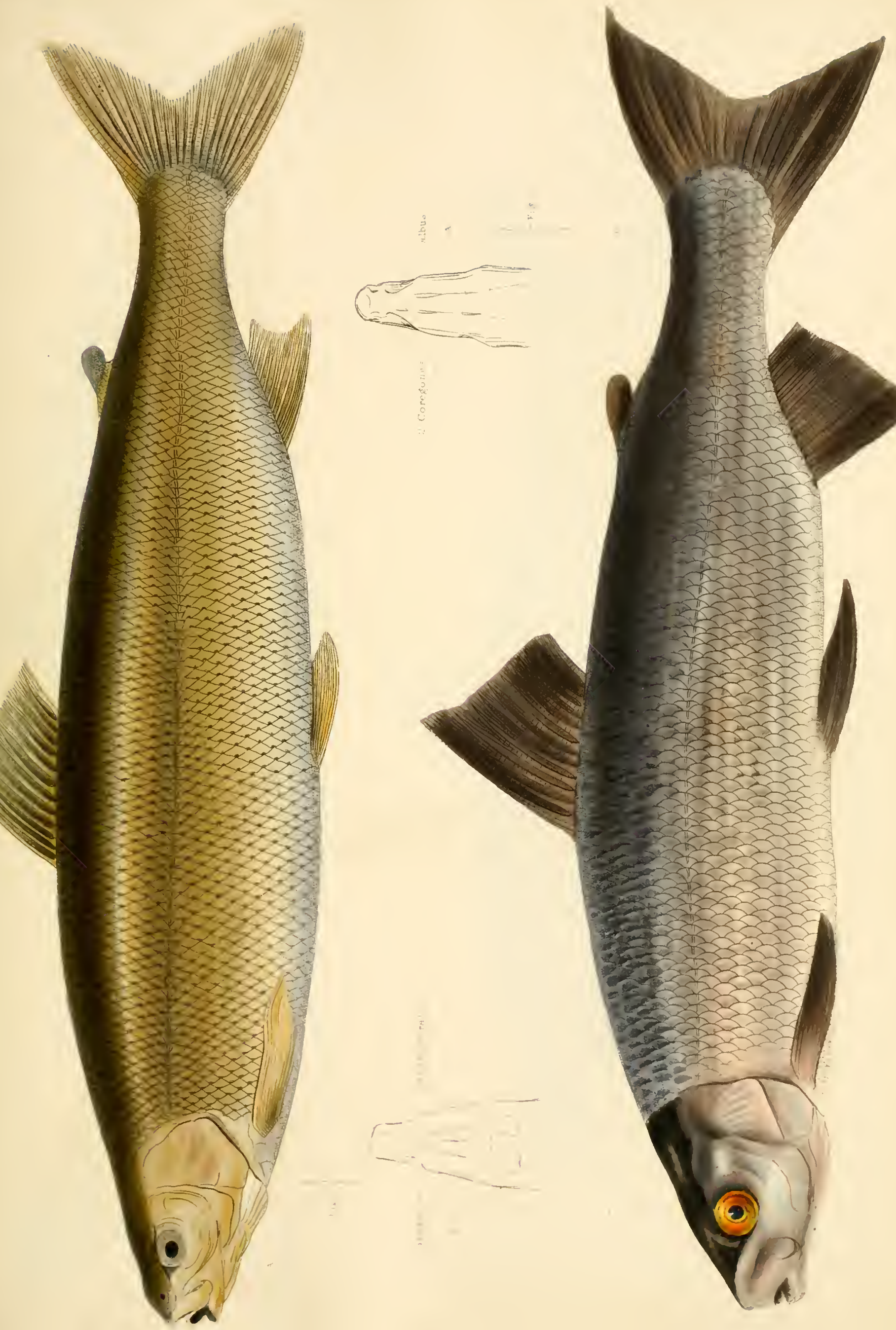


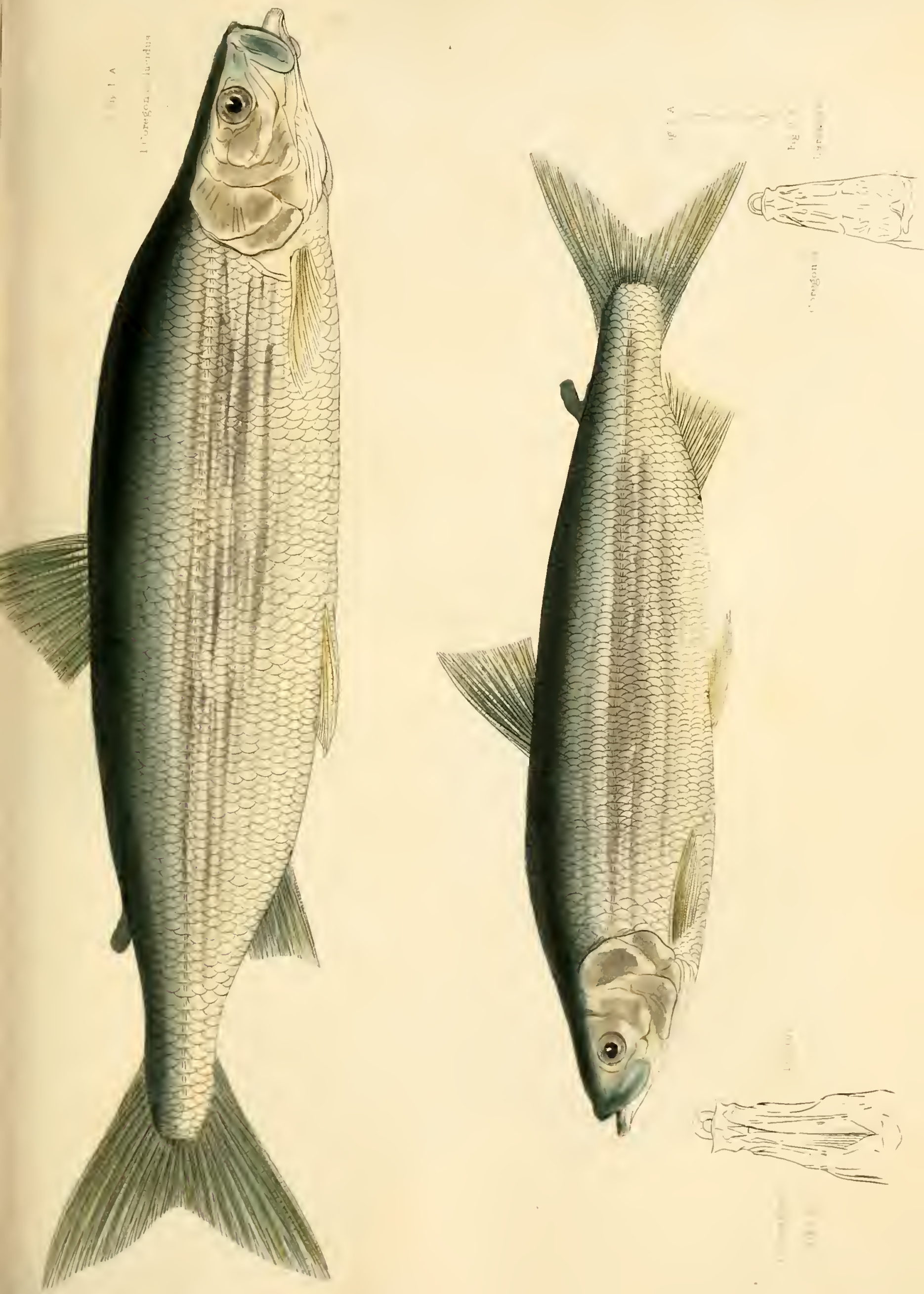



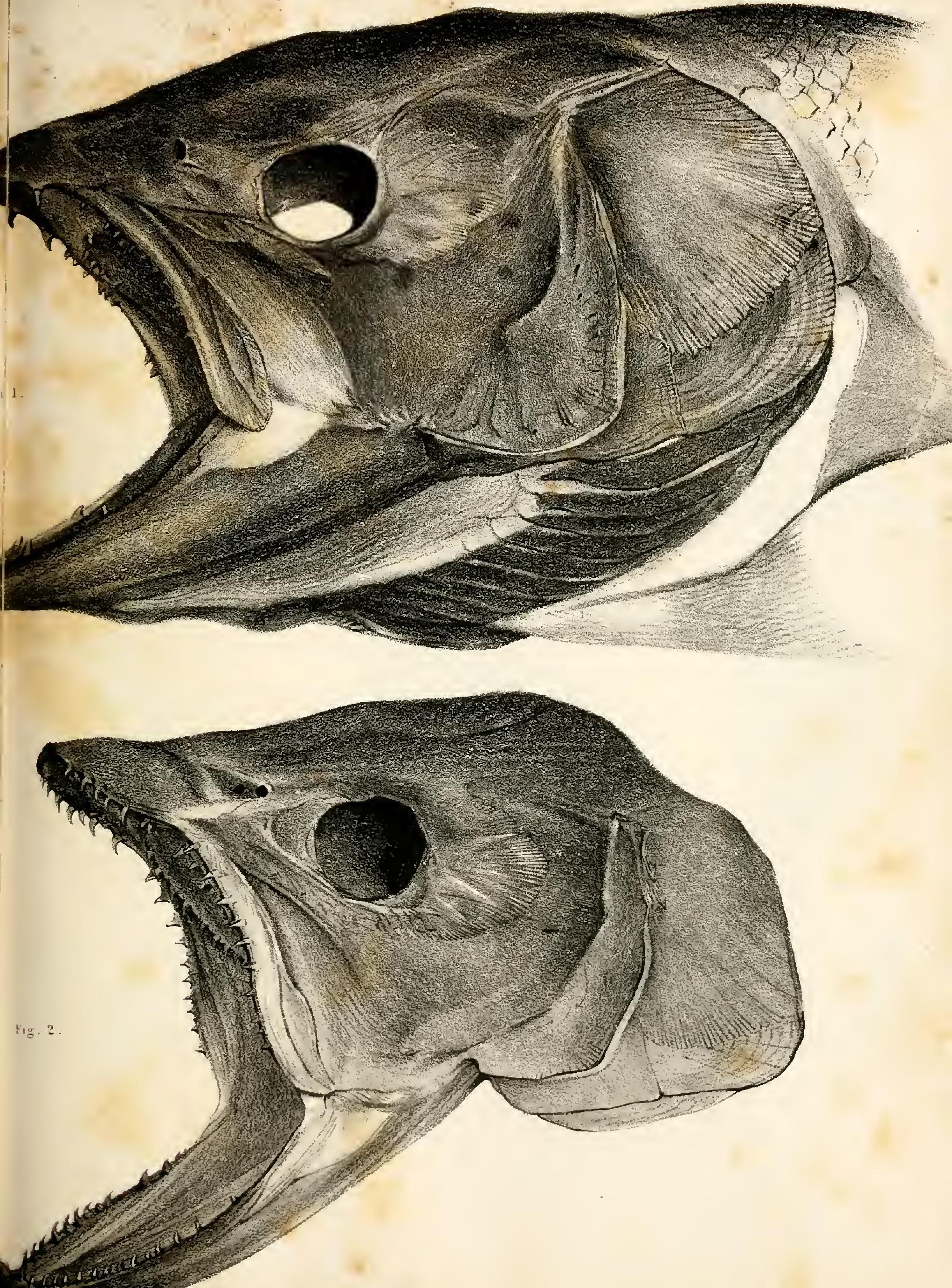




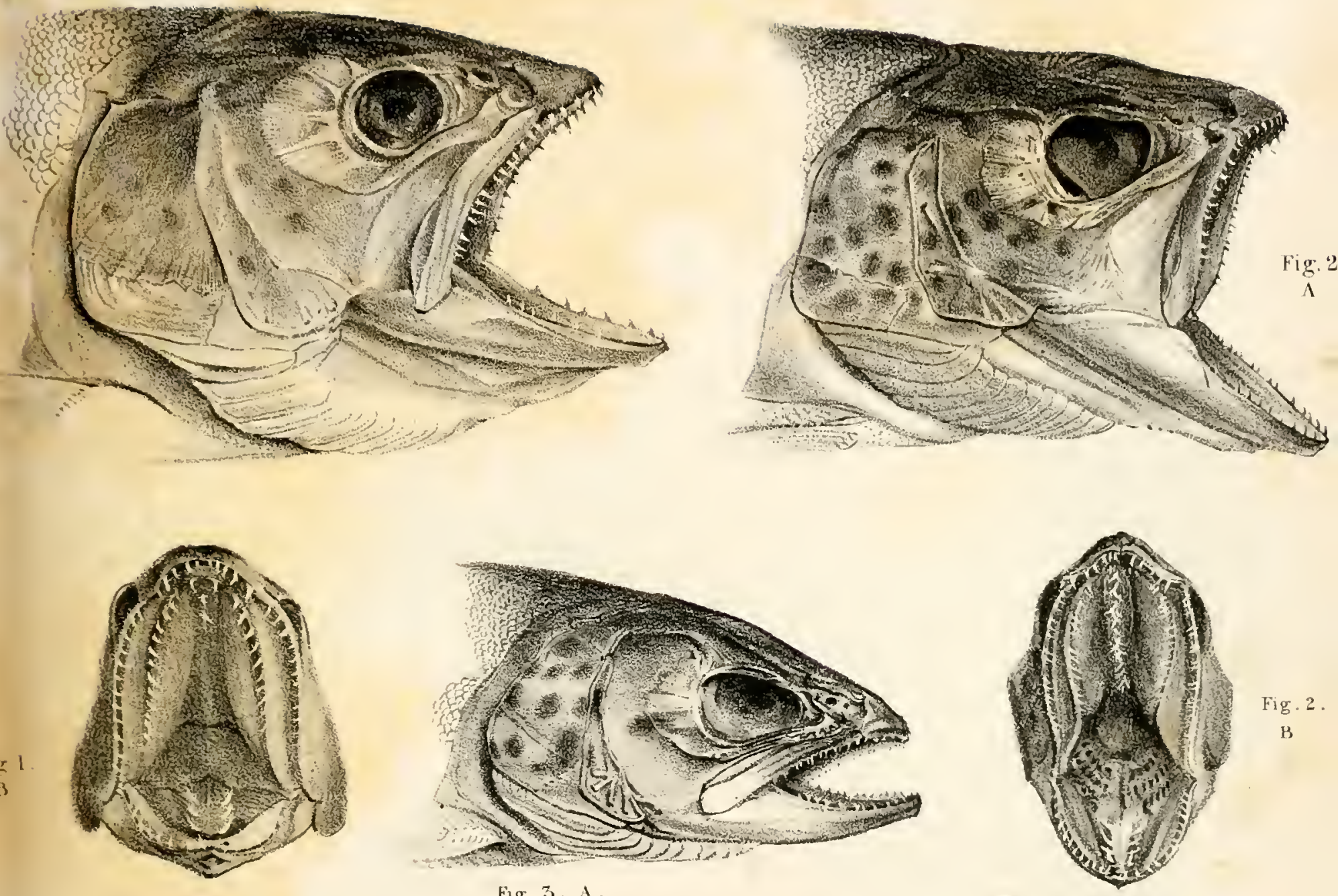

Fig. 2 .

$B$

Fig. 3. A
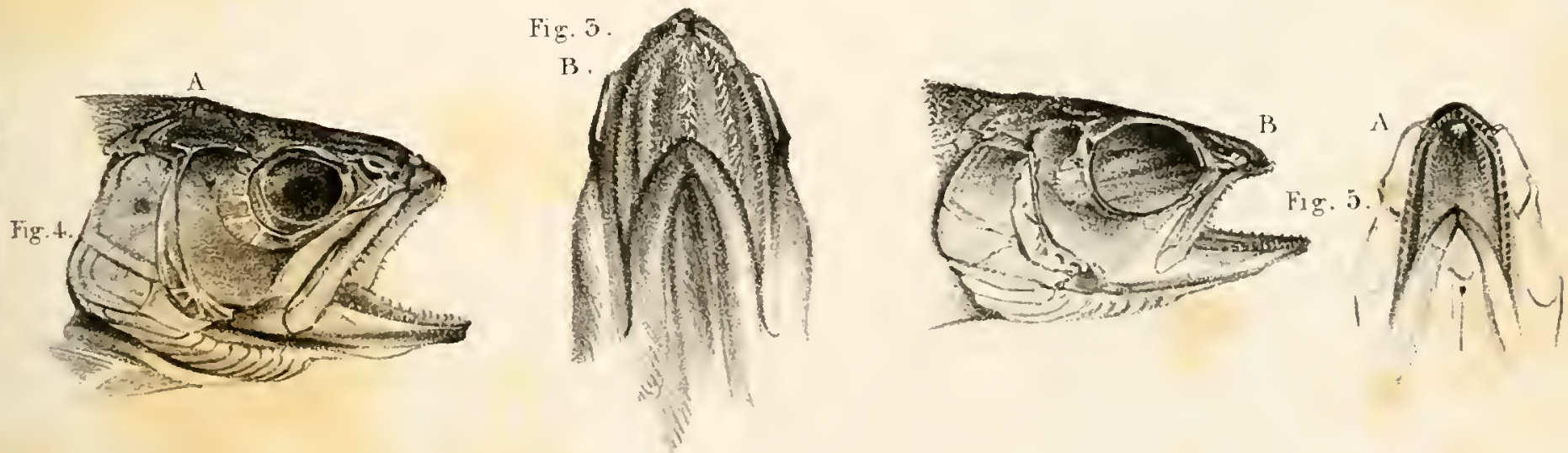



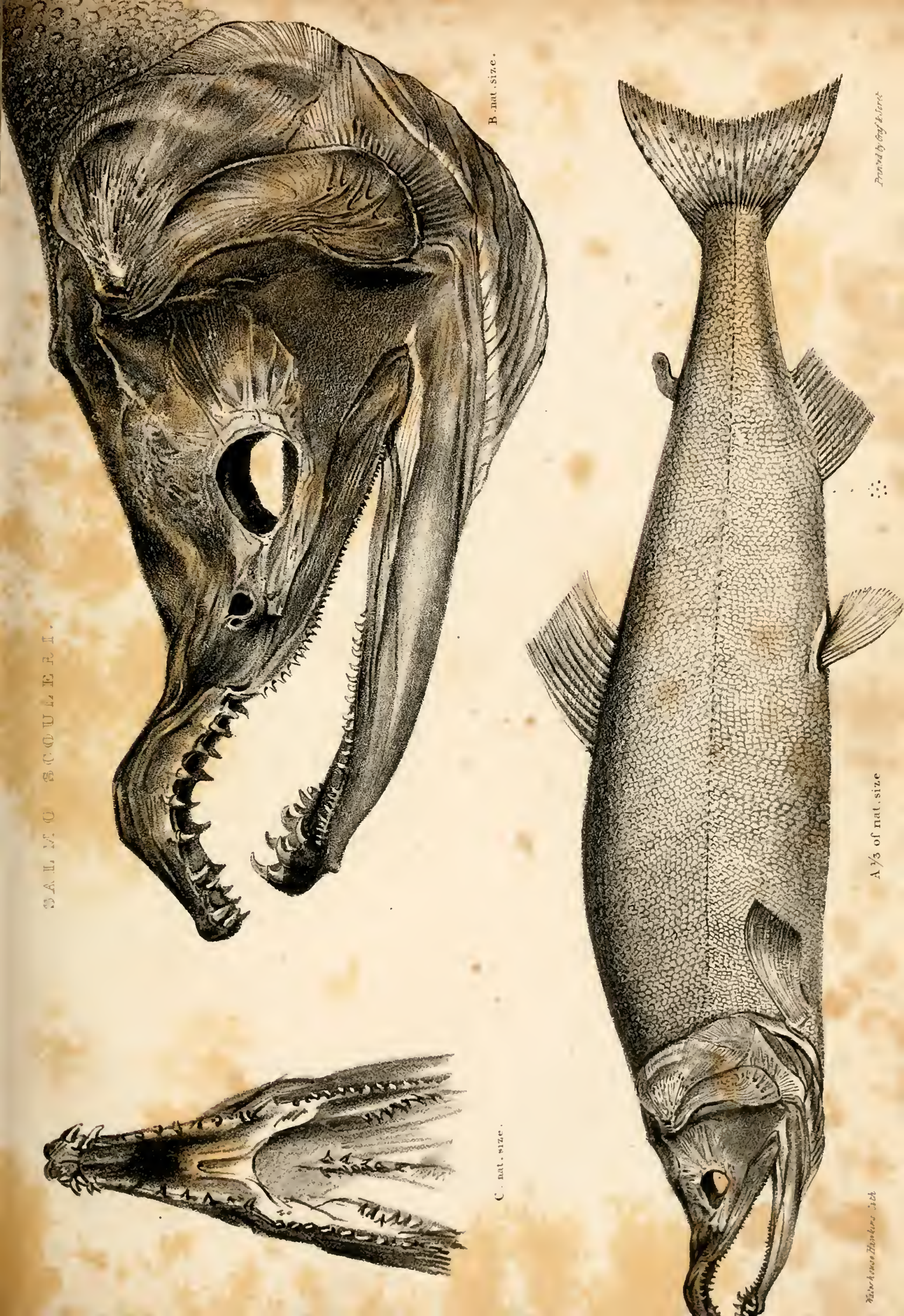



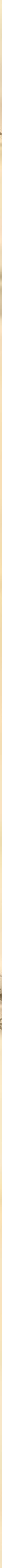
$x^{2}$

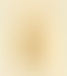




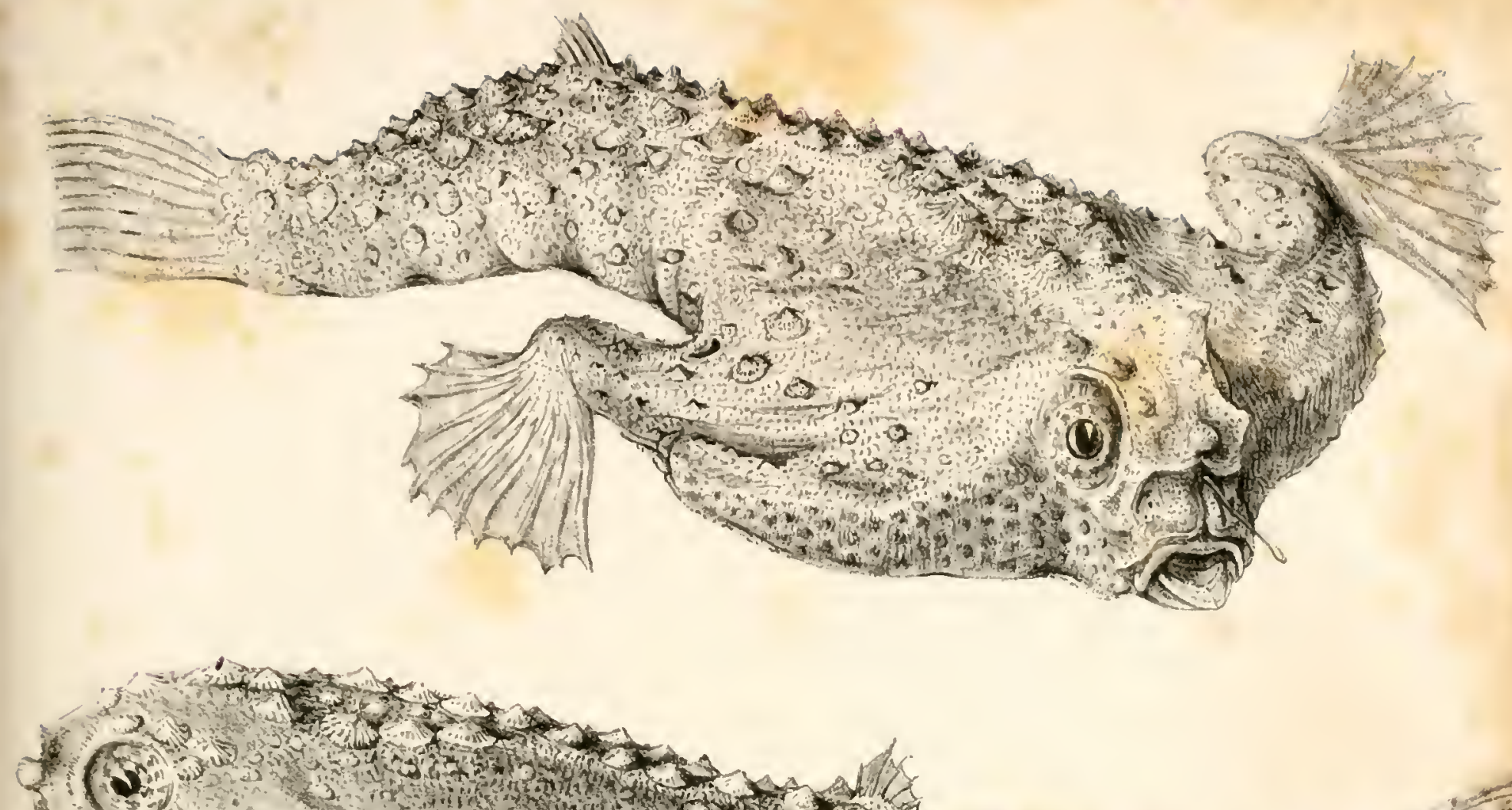

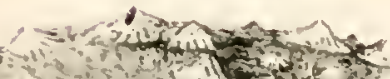

(c)

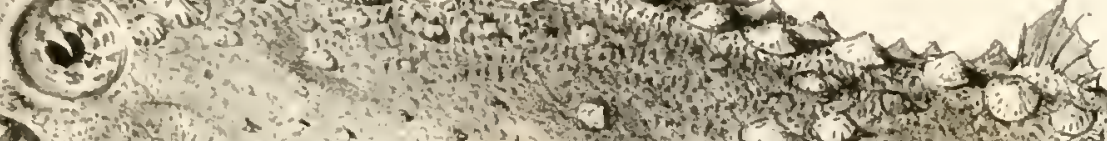

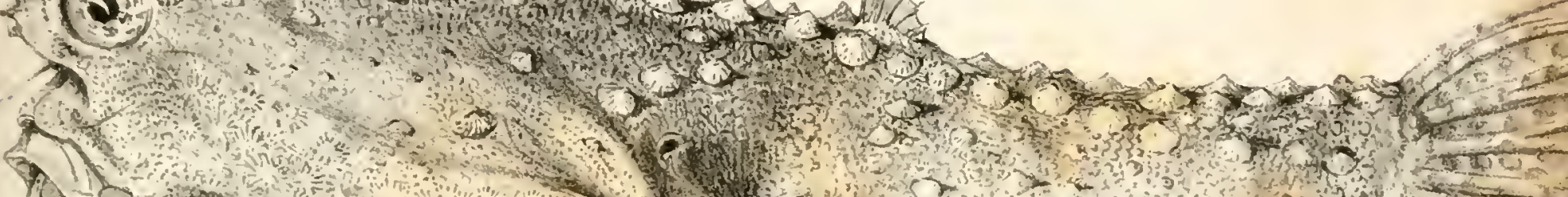

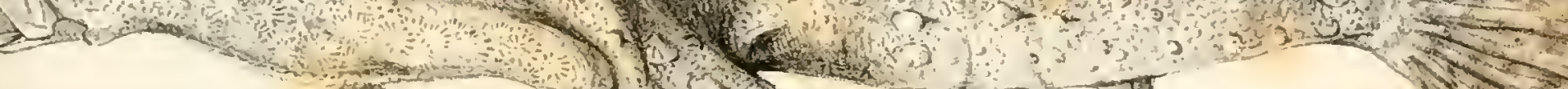
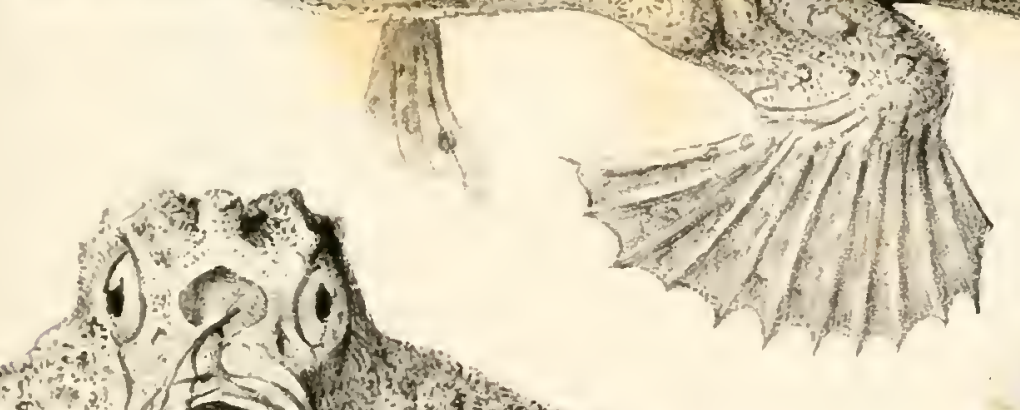

if Hon
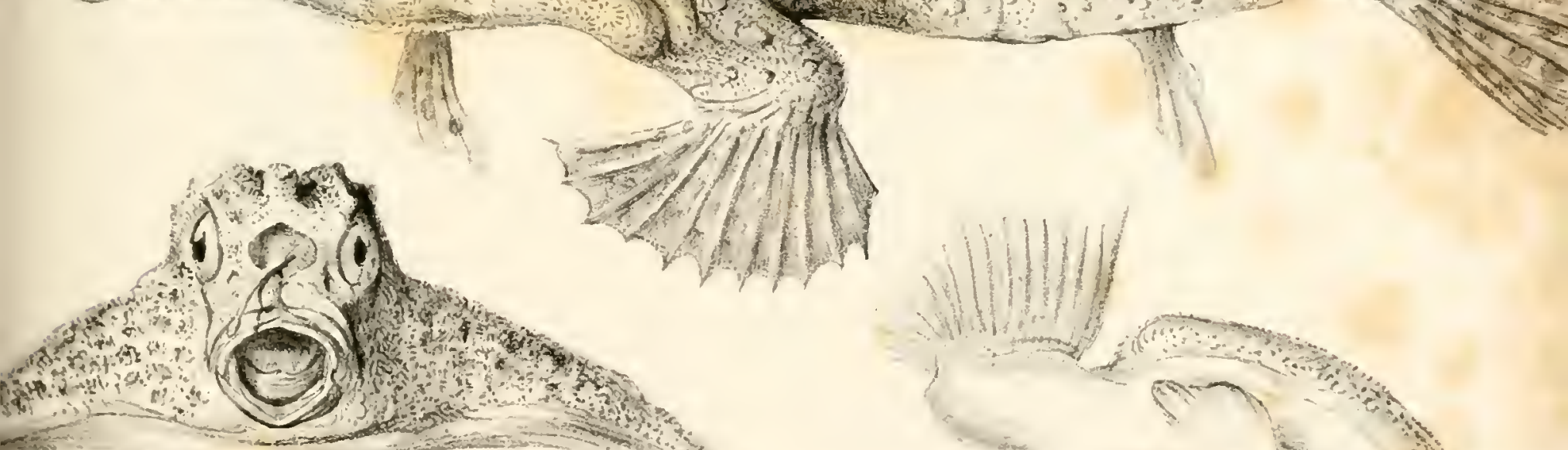


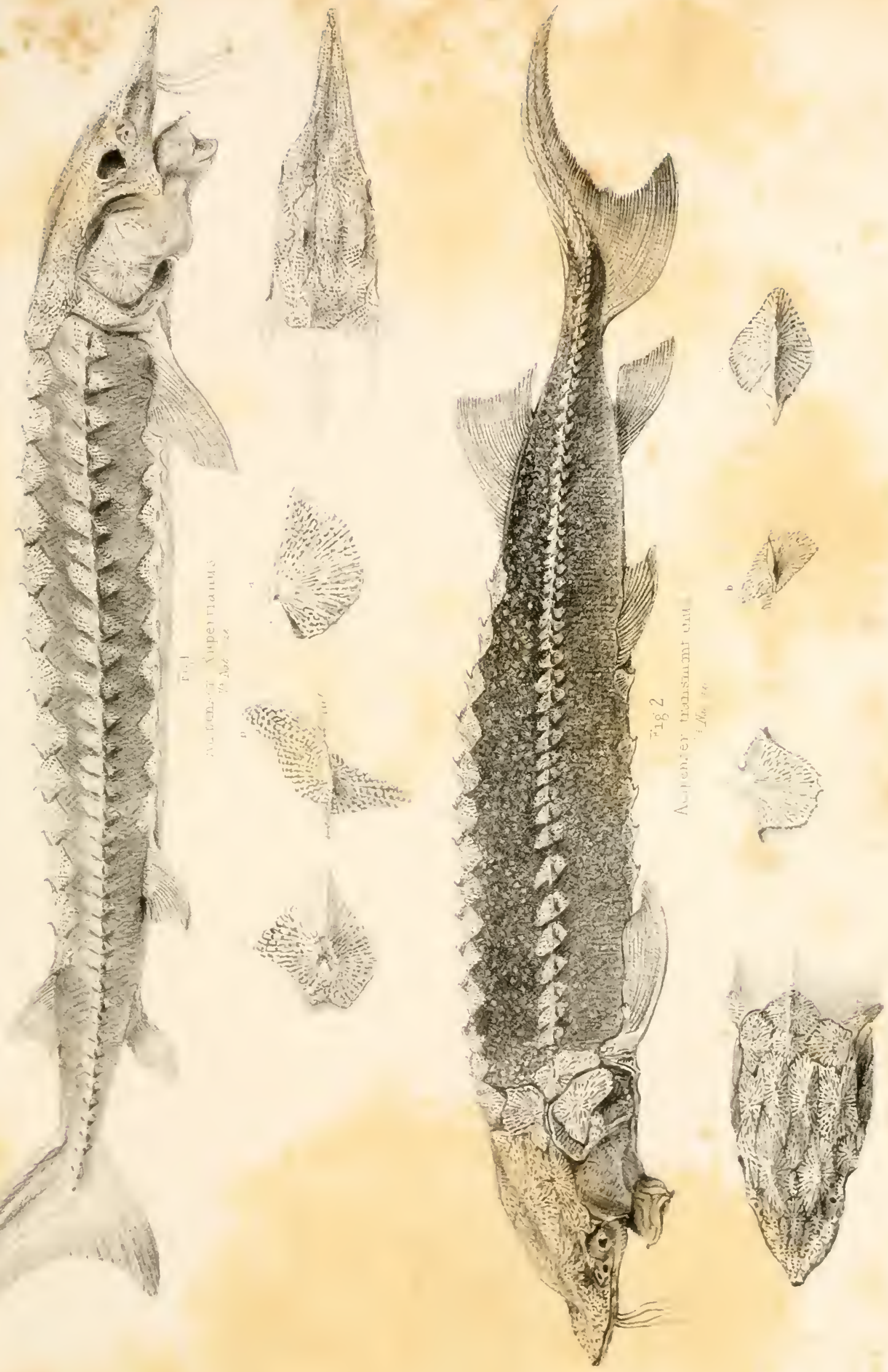

FAUNA BOREALI-AMERICANA.

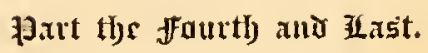

\section{T H E I N S E C T S. \\ BY}

THE REV. WILLIAM KIRBY,

M.A. F.R.S. F.L.S. F.G.S. ETC. 



\section{F A U N A \\ BOR E A L I - A M ER I C A N A; \\ OR THF \\ Z \\ OF TIE \\ NORTHERN PARTS}

or

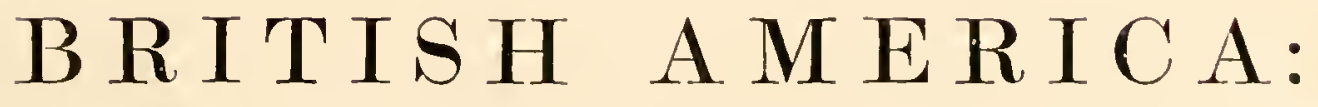

CONTAINING

DESCRIPTIONS OF THE OBJECTS OF NATURAL HISTORY COLIECTED ON THE LATE NORTHERN LAND EXPEDITIONS, UNDER CONMAND OF CAPTAIN SIR JOHN FRANKLIN, R.N.

Iis

JOHN RICHARDSON, M.D. F.R.S. F.L.S. \&c.

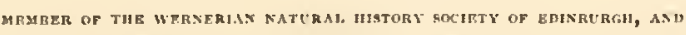

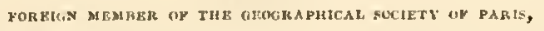

SURGEON AND NATURALIST TO THE EXPEDITION,

ASSISTED BY

WILLIA II SWAINSON, EsQ. F.R.S. F.L.S. \&c.

AND

THE REVER END WILIIAM KIRBY, M.A. F.R.S. F.L.S. \&c.

ILLUSTRATED BY SEVERAL COLOURED ENGRAVINGS.

PUBLISHED UXDER THE AUTHORITY OF THE RIGHT HOXOUR-IBLE THE SECHETARY OF STATE FOR CULONIAL AFTALS.

\section{NORWICH :}

PRINTED AND PUBLISHED BI JOSIAH FLETCHER;

AND SOLD IN LONIOXY BY

LONGMAN, ORME, BROWN, GREEN, \& LONGHANS.

Muccexxin. 
Sortwity:

PRINTED BX JOSHAH FLETCHER, UPPER HAYMARKET. 


\section{TABLE OF CONTENTS.}

PAGE

Ixtronuctios . . . . . . . . . . . . . . . . xix

Tabular view of the groups of the Orders Coleoptera and Hymenoptera . . . xxvii

\section{N S E C T S.}

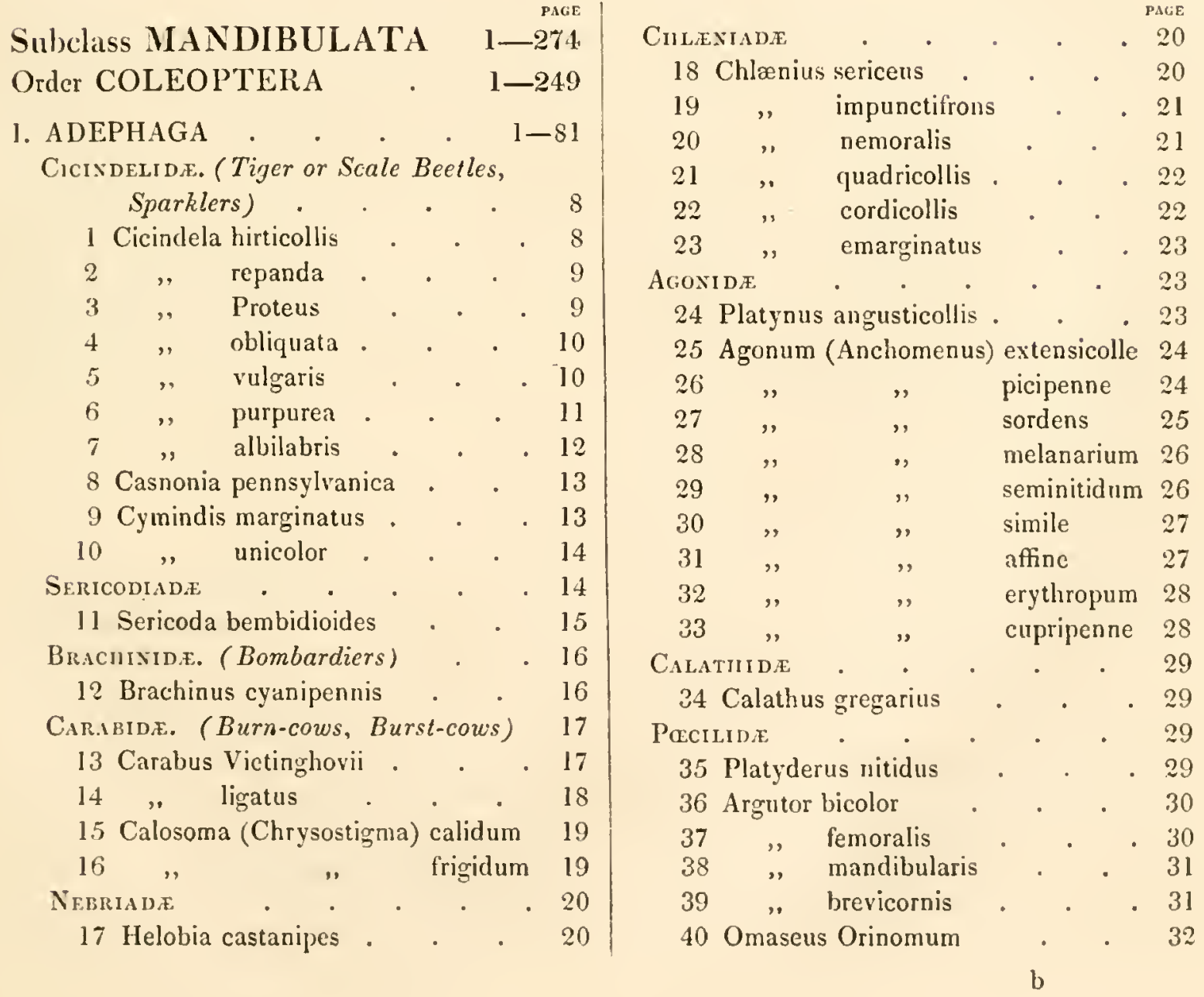


41 Omaseus Nigrita • • . 32

42 " picicornis . . . 33

43 Stereocerus similis . . . 34

44 Curtonotus convexiusculus . . 35

45 , rufimanus . . 35

46 " brevilabris . . . 35

47 " latior . . . 36

48 Pœcilus lucublandus . . $\quad 36$

49 " castanipes . . . 37

50 " chalcites . . 37

Amarid E $\quad . \quad . \quad . \quad .38$

51 Amara vulgaris . . . . 38

52 ", inæqualis . . . 39

53 . impuncticollis . . 39

54 „ pallipes . . $\quad$. 39

55 " lævipennis . . . 40

56 " discors . . . 40

HARPALIDA . . . . . 41

57 Harpalus pleuriticus . . 41

58 " basilaris . . . 41

59 " Ochropus . . 42

60 " interpunctatus . . 42

61 , longior . . . 43

62 , laticollis . . . 43

63 " carbonarius . . 44

$64 \%$ rotundicollis . . 44

65 " Stephensii . . 45

Stenolophide . • • • • 46

66 Stenolophus versicolor . . 46

Trecinde . . . . . 46

67 Trechus tibialis . . . 46

68 " ruficrus . . 47

69 , flavipes . . . 47

$70 \quad "$ communis . . . 48

71 , similis . . . 48

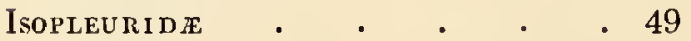

72 Isopleurus nitidus . . . 50

Mac Leayi (in a note) $\quad 50$

Patrobide . . . . . 50

73 Patrobus americanus . . 51

PeryPhide . . . . 52

74 Peryphus bimaculatıs . $\quad$. 52

$75 \quad, \quad$ sordidus $. \quad . \quad .52$

76 " scopulinus . . 53

77 , Rupicola . . . 53
78 Peryphus picipes . . $\quad 54$

79 , concolor . . . 54

80 " (Lopha) quadrimaculatus 54

81 " (Eudromus) nitidus . 55

82 Tachyta picipes . . 56

Bembidiade . . . . . 57

83 Notaphus nigripes . . . 57

$84 \quad "$ intermedius . . 58

85 " variegatus . . 58

86 Bembidium impressum $\quad$. $\quad 59$

Elaphride . . . . . 60

87 Opisthius Richardsoni . . 61

88 Elaphrus Clairvillii . . 61

89 " intermedius . . 62

90 " obscurior . . 63

91 Notiophilus aquaticus _ . 63

OMOPHRONIDA $\quad$. $\quad . \quad$. $\quad .64$

92 Omophron Saii . . . 65

HALIPLIDE $\quad$ • $\quad$ • $\quad$. 65

93 Haliplus impressus • • 65

94 Hydroporus nigre-lineatus . 66

95 , parallelus . . 67

$96 \quad, \quad$ lævis • . . 67

$97 \quad$ " picatus . . . 68

98 , similis . . . 68

99 Laccophilus biguttatus • 69

Dytiscina. (Water-beetles, Toe-biters) 69

100 Colymbetes semipunctatus $\quad 69$

101 , bicolor . . 70

102 ", phæopterus . . 70

103 " 03 bifarius . . 71

104 , reticulatus . . 71

105 " picipes . . 71

106 " assimilis . . 72

$107 \quad " \quad$ triseriatus . . 73

108 " (Hydaticus) rugicollis 73

$109 \quad, \quad$, MacCullochii 74

110 Dytiscus Ooligbukii . . 74

111 " Harrisii . . . 76

112 (Leionotus) Franklinii 77

Gyrinide. (Whirlwigs) . $\quad 78$

113 Cyclinus assimilis . . . 78

114 Gyrinus impressicollis . . 79

I15 " æneus . • • 80

116 ," ventralis . . . 80 


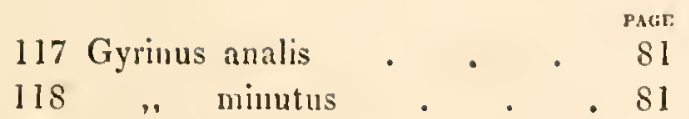

II. BRACHELYTRA. (Rove Beetles,

$$
\text { Cock-tails) . . . 81-95 }
$$

PrDERIDE . . . . . 86

119 Pxderus riparius . . 86

Laturobiade. . . . . 86

120 Lathrobium puncticolle . 86

121 , Gravenhorstii . 87

122 , bicolor . . 87

123 Gyrohypnus assimilis . . 88

Onaliadæ. . . . . $\quad . \quad 89$

124 Omaliun marginatum . $\quad 89$

Aleocharide $\quad$ • . . 90

I25 Aleochara pallitarsis . 90

TACuÝ⿴囗十⺝

126 Tachyporus acuductus . . 90

127 , affinis . . 91

Philontilidi: $\quad$. $\quad$. 9 I

12S Philonthus politus . . 91

129 , mandibularis . . 92

130 " picatus . . 93

131 " fulvipes . . . 93

StapHyinide. (Cock-tail R. B.) 94

132 Staphylinus chrysurus . . 94

Creophllide

133 Creophilus villosus . . 95

11I. ENTAPHIA. (Burying Beetles) 95-99

Necrophoride . . . . 95

134 Necrophorus velutinus . . 96

135 , hebes . 96

136 .

137 ". Melsheimeri • . 97

138 , Hallii . . 98

139 ," pygmæus . . 98

IV. NECROPHAGA. (Carrion Beetles) 99-118

SILPHid: . . . . . . 99

140 Necrodes surinamensis . . 99

I4I Oiceoptoma (Thanat.) marginale 100

142 ," , lapponicum 100

143 ,. , trituberculatum 101

I 44 ",,$\quad$ inæquale 102

145 , (Necrop.) americanum 102

146 " " terminatum 103

$147, \quad, \quad$ affine . 103
PAGE 148 Oiceoptoma (Necrop.) canadense 104 Peltide . . . . . 104

149 Peltis ferruginca . . 104

Nitidulide $\quad$ • . . 105

150 Nitidula obscura . . 105

151 , Ossium . . 106

152 , discoidea . . 106

Exg10 . . . . 107

153 Ips De Jcanii . . . 107

Cirolevidi . . , . 108

154 Choleva (Catops) Spenciana 108

Scaphidade . . . . 108

155 Scaphium castanipes . 109

Anisotomide . . . . 110

156 Leiodes punctostriatus . . 110

Sylvanide . . . . 110

157 Corticaria denticulata . . 110

Cryptopilagide . . . 111

158 Atomaria atra $\quad . \quad 112$

159 Cryptophagus humeralis $\quad 112$

160 , concolor . . 112

Dernestide. (Leather Eaters, or Fur

Beetles) . . . . 113

16 I Attagenus cylindricus . . 113

162 ," Pellio . . 114

163 Dermestes lardarius . . 115

164 " Dissector . . 115

Brrrilne. (Pill Beetles) • . 116

165 Byrrhus picipes . . . 116

166 " concolor . . . I17

167 ". cyclophorus . . 117

168 , varius . . . 118

V. PHILHYDRIDA • . 119-121

HYDROPIJLIDE $\quad$. . . . 119

169 Hydrobius fuscipes . . 119

170 " marginalis . . 120

171 " melanocephalus . 120

Histeride. (Mimic Beetles) . 121

172 Hister Paykullii . . . 123

173 , Harrisii . . . 124

VI. LAMELLICORNIA. (Chafers) 125-143

Copride. (Dung Chafers) • 125

174 Onthophagus latebrosus . . 125

175 , scabricollis . 126

Trog1D王 . . . . . 127

b 2 


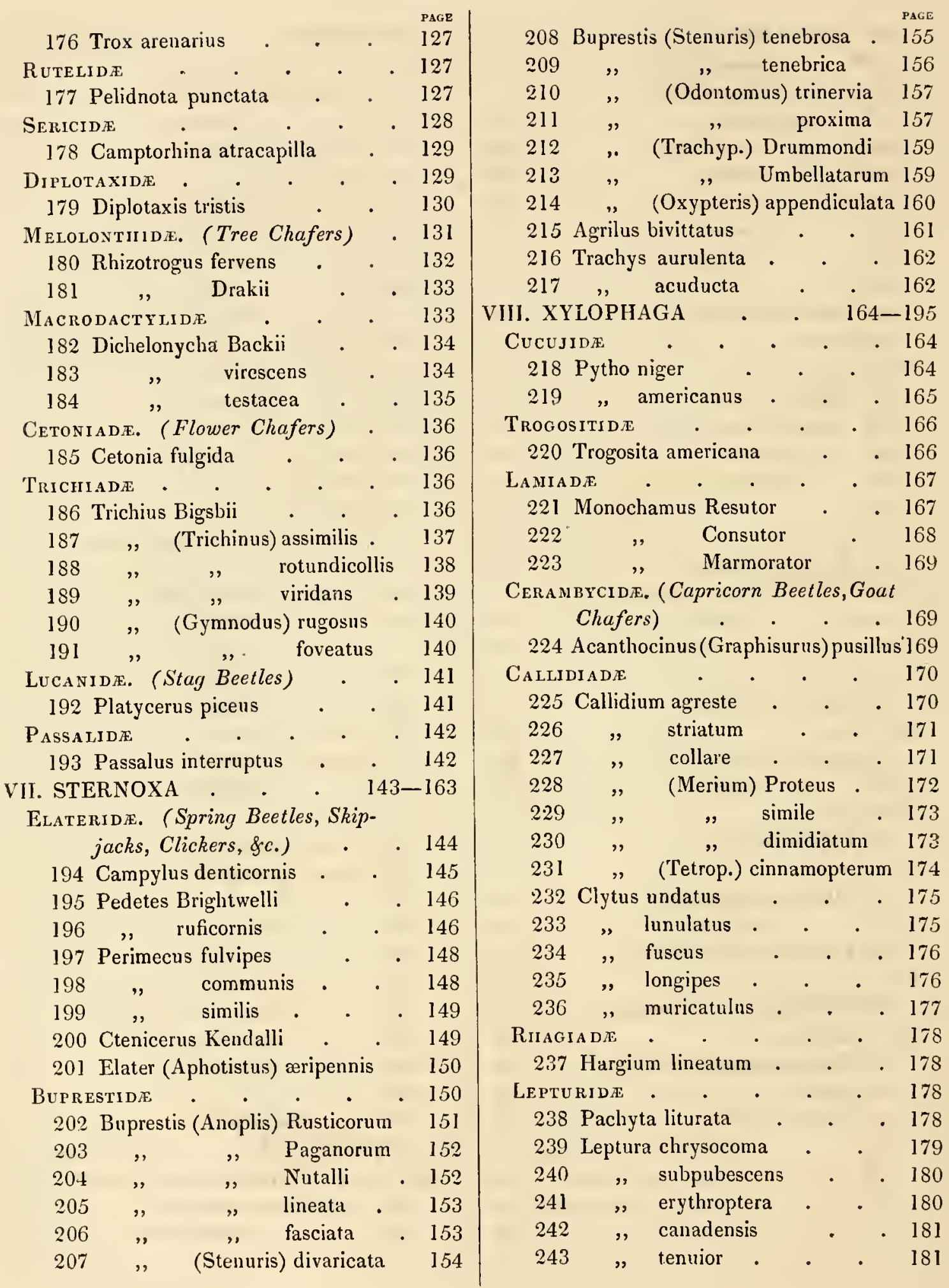




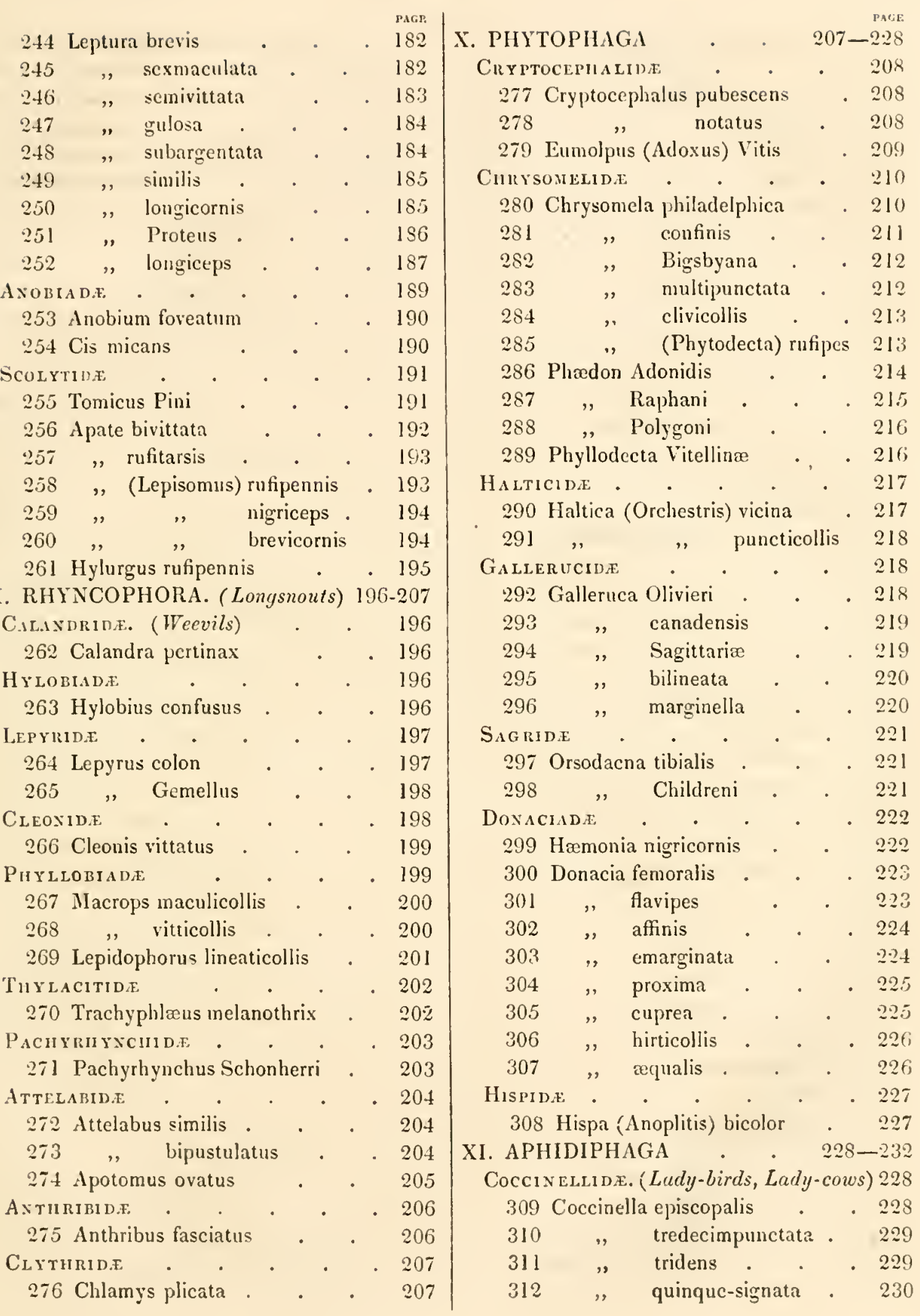




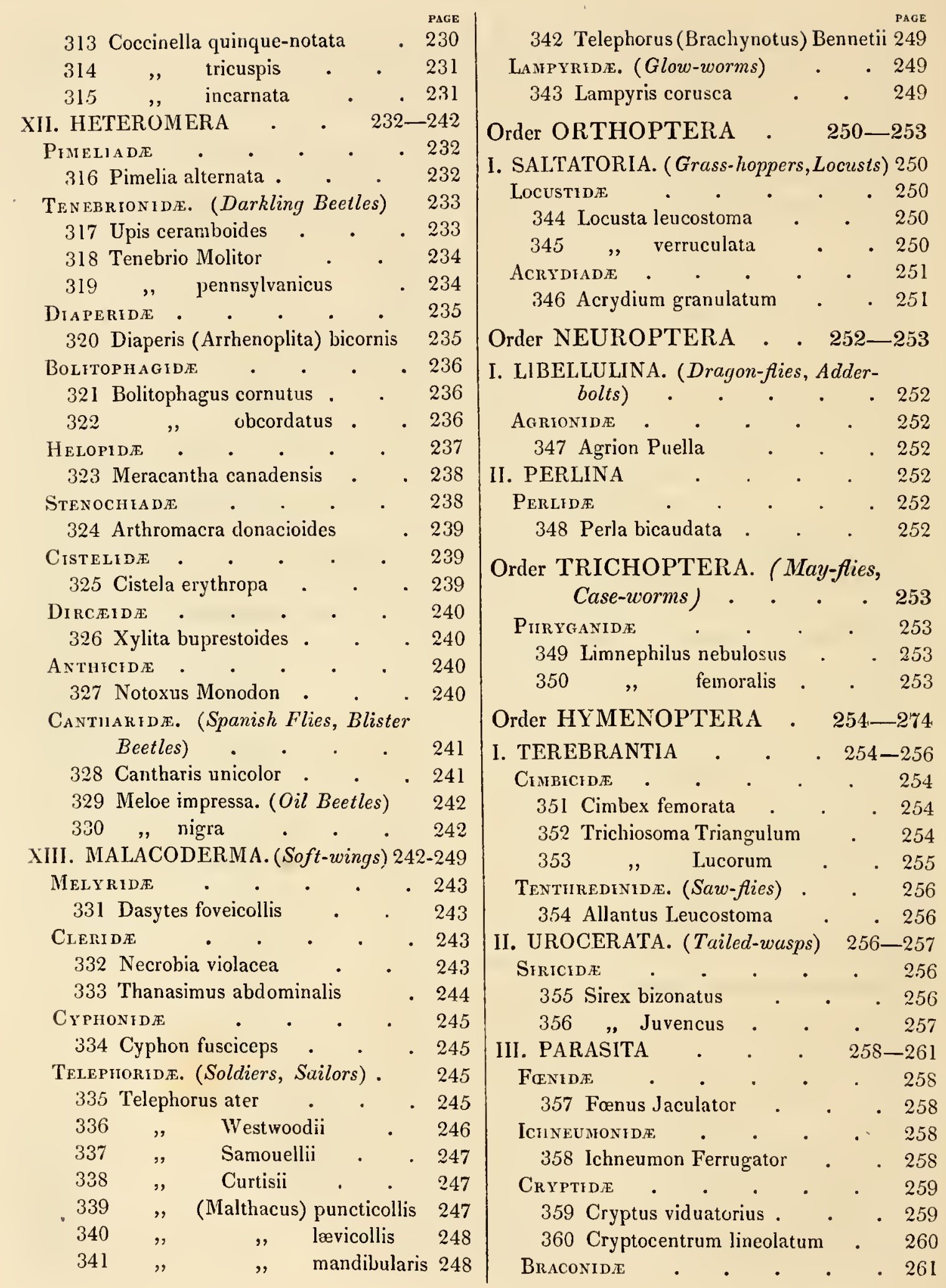




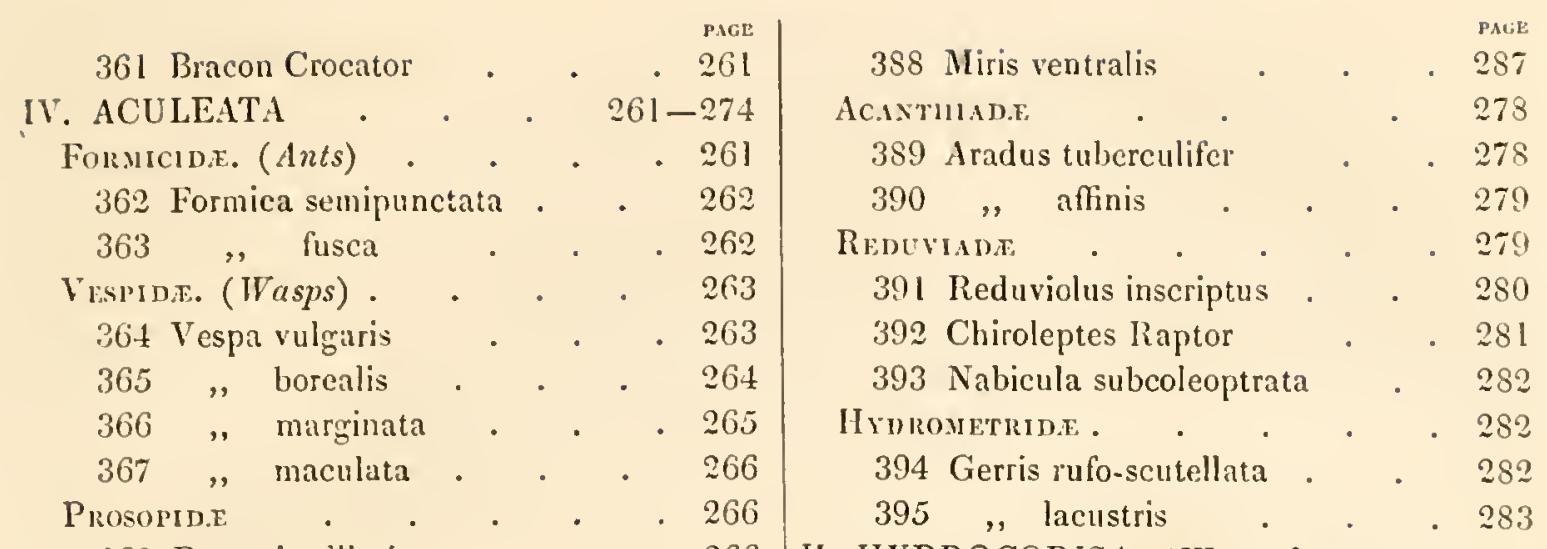

368 Prosopis elliptica . 266

Axprexidez . • • • . 267

369 Halictus rubicundus . . 267

370 , crassicornis . . 267

371 Andrena impuncta . . 268

$3 \pi 2$, varians . . . 268

Novadid.. (Cuckoo-bees) • . 269

373 Nomada americana . . 269

Cinelostonide . . . . 270

374 Chelostoma albifrons . . 270

Meg.Achilide . . . . 270

375 Megachile maritima • . 270

Axtrophoride. . . . . 271

II. HYDROCORISA. (Water-bugs) 283-285

Corixide • . . . . 283

396 Corixa striata $\quad$. $\quad 283$

397 " carinata . . . 284

398 ," planifrons . . . 284

Notonectidie - . . . 285

399 Notonecta insulata . 285

Order HOMOPTERA . . . 285

Cercopide . . . . 285

400 Cercopis marginella . . 285

Order LEPIDOPTERA • 286-309

376 Anthophora bomboides . . 271

Boмвгд. (Humble, or Bumble-bees, or

Dores) . . . . 272

377 Bombus Sylvicola . . . 272

378 " borealis . . . 272

379 , Terricola . . . 273

380 ., Derhamellus . . 273

$38 \mathbf{i}$, Praticola . . . 274

382 " virginicus . . 274

Subclass HAUSTELLATA 275-318 Order HEMIPTERA • • 275-285

I. GEOCORISA. (Land Buys) . 275-283 Pextatonide . . . . 275

383 Pentatoma Camifex . . 275

384 " variegata . . 276

385 , trilineata . . 276

Edesside . . . . 277

386 Edessa nebulosa . . . 277

Capside . . . . . . 277

387 Miris punctulatus . . . 277

I. DIURNA. (Butterfies) • 286-300

Papilionida. (Swallow-tails) • . 256

401 Papilio Turnus . . . 286

Coliade. (Whites, Yellows) • . 287

402 Colias Edusa . . 287

403 Pontia casta . . . . 288

Nympinalde . • . . 289

404 Melitæa Selenis . . 289

405 Argynnis Cybele . . 289

406 " Myrina . . . 290

407 " Aphrodite . . 290

408 " Freya . . . 291

VANESSIDE $\quad . \quad . \quad . \quad . \quad 292$

409 Vanessa (Grapta) C. argenteum 292

410 , furcillata . . . 292

411 , Antiopa (Willow Butterfly) 293

412 "Atalanta(Grand Admiral) 294

413 Cynthia Cardui (Painted Lady) 295

414 ," Huntera (Belle Dame de

l'Amerique) . . . 296

Hipparchia de. (Ringlets, Heaths) 297

415 Hipparchia Nephele . . 297 
416 Hipparchia discoidalis . . 298

LrCÆNID E. (Hair-streaks, Coppers, Blues) 298

417 Thecla Augustus . . . 298

418 Lycæna Dorcas . . . 299

419 Polyommatus Lucia . . 299

Hesperiade (Skippers) • 300

$420^{\circ}$ Hesperia Peckius . . . 300

1I. CREPUSCULARIA. (Hawk Moths)

$30 \mathrm{I}-303$

ZYGENIDE . . . . 301

421 Alypia Mac Cullochii . . 301

SPIINGIDE . . . . . 301

422 Smerinthus Cerisyi . . 301

423 Deilephila intermedia . . 302

SESIADE . . . . . 303

424 Sesia ruficaudis . . . 303

1II. NOCTURNA. (Moths) • . 303

Lithosia DE . . . . 303

425 Callimorpha Parthenice . 303

426 " Virguncula . . 304

427 Lithosia miniata . . . 305

Ctenucnime . . . . . 305

428 Ctenucha Latreillana . . 305

NocturDe $\quad$. . . . 306

429 Plusia rectangula . . 306

430 " Gamma . . 307

431 " falcifera . . . 308

432 " Iota (Gold Spangle) . 308

Order DIPTERA • • • 309-316

I. NEMOCERA . • . 309-31l
Culcide (Gnats, Mosquitos) $\quad 309$

433 Culex Punctor . . . 309

Tipulide. (Crane-fies, Long-legs, sc.) 310 434 Tipula Pratorum . . . 310

BIBIONIDE . . . . . 310

435 Aspistes (Arthria) analis . . 311

II. TANYSTOMA.$\quad \cdot \quad$. $\quad 311$

EMPIDE . . . . . . 311

436 Empis luctuosa . . . 311

437 " geniculata . . . 312

Bonвilade. (Humble-bee Flies) . 312

438 Bombylius major . . . 312

439 " pygmæus . . 313

TABANide. (Horse-fies, Breeze) . 313

440 Tabanus affinis . . . 313

441 ". zonalis . . . 314

442 Chrysops sepulchralis . . 314

III. ATHERICERA . . . . 315

SỸRIIDE . . . . . 315

443 Scæva Ribesii . . . 315

Muscide. (Flies) . . . . 316

444 Musca Cadaverum . . . 316

445 , mortisequa . . 316

Order HOMALOPTERA . . 317

Hippoboscrnæ. (Forest-fies) . . 317

446 Hippobosca equina . . 317

Order APHANIPTERA. (Fleas) • 318

447 Pulex Gigas . . . . 318

In the vertebrated animals almost every genus has an English as well as a Latin name: but this is not the case with insects, of which, comparatively speaking, very few are so distinguished. To invent appropriate English names for nearly 200 genera, would be no easy task; and as they are generally known by their scientific appellations, the author thought it would be better to use the Latin name, without translating it. For the convenience of those readers who wish to know by what English name any old genus or species has been usually distinguished, the author has added such name to it in the above Table. 


\section{A RCTIC I NSEC'TS.}

To make the above List of the Insects of the Northern Provinces of America, chiefly under the dominion of Great Britain, as complete as possible, I shall add an enumeration of those described by Otho Fabricius in his Fanna Groenlandira, and those taken in the several Expeditions to the Aretie Regions of America, conducted by Captains Parry, Sir John Ross, and Back, described in the Appendix to their several Narratives by Mr. Curtis, Mr. Children, and myself, distinguished by the letters F. C. Ch. and K. affixed to each species.

Order THYSANURA. Iat.

\section{Podura plumbea $F$.}

, aquatica $F$.

, ambulans $F$.

" pusilla $F$.

, maritima $F$.

, lummicola $F$.

Order PARASITA. Lat.

- Pediculus. Lat.

7 Pediculus hurnamus $F$.

" Canis $F$.

, Lagopi $F$.

-* Ricinus De G. Nirmus Herm.

Pediculus Strigis $F$.

,$\quad$ Corvi $F$.

" Clangulie $F$

" Grylle $F$.

" Bassani $F$.

, Lari $F$.

" Tringæ $F$.

$" \quad$ Hiaticule $F$.

Philopterus (Docophorus) communis $\mathrm{Ch}$.

$\begin{array}{lll}" & , & \text { platyrhynchus } C h . \\ , & \quad, & \text { auritus } C h . \\ , & \text { ocellatus } C h .^{\prime}\end{array}$

(Nirmus) affinis $\mathrm{Ch}$.

" testudinarius $\mathrm{Ch}$.

" biseriatus $\mathrm{Ch}$.

(Lipeurus) jejunus $C h$.

(Goniodes) Chelicornis $C h$.

Liotbeum (Colpocepbalum) subsequale $C h$.

" (Physostomum) sulphureum $\mathrm{Ch}$.

" " Inarginatum $\mathrm{Cl}$.

Order COLEOPTERA. L.

Colymbetes mostus $C$.

Dytiscus marginalis $F$.

Stapbylinus balteatus $F$.

fuscipes $F$.

lignorum $F$.

Silpha pedicularia $F$.

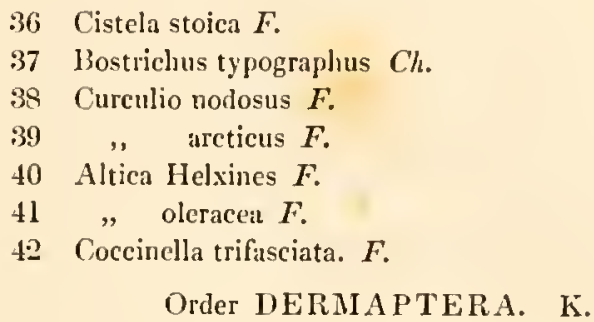

36 Cistela stoica $F$.

37 Bostrichus typographus $\mathrm{Ch}$.

38 Curculio nodosus $F$.

$39 \quad, \quad$ arcticus $F$.

40 Altica Helxines $F$.

41 " olcracea $F$.

42 Coccinella trifasciata. $F$.

Order DERMAPTERA. F.

43 Forficula $C$.

Order ORTHOPTERA.

44 Acrydium sulphureum $\mathrm{Ch}$.

Order NEUROPTERA.

45 Libellula Virgo $F$.

Order TRICHOPTERA.

46 Pbryganea rhombica $F$.

47 Tinodes hirtipes $C$.

Order HYMENOPTERA.

48 Ichneumon Moderator $F$. (Pimpla?)

49 " Larixe $C$

50 Ephialtes $C$.

51 Campoplex arcticus $C$.

52 Microgaster unicolor $C$.

53 Myrmica rubra $C$.

5t Apis alpina $F$. (Bombus)

55 Bombus Kirbiellus $C$.

Order HEMIPTERA.

56 Acanthia stellata $C$.

57 Pedeticus variegatus $C$.

Order LEPIDOP'TERA.

$$
\text { Diurna. }
$$

58 Papilio Tullia $F$.

59 Colias Boothii $C$.

60 Hipparchia Rossii C.

6l Melitiea Tarquinius $C$.

62 Polyommatus Franklinii $C$.

$$
\text { Nocturna. }
$$

63 Laria Rossii $C$.

64 Euprepia Hyperborea $C$. 
Argyrotosa Parryana $C$.

Order DIPTERA.
Culex caspius $C . \quad$ (C. pipiens L.)

Phalæna B. Graminis (Episema. Chareas) $F$. " N. Lucernea (Agrotis) $\mathrm{F}$.

, Brassicæ (Mamestra) $F$.

" Myrtilli (Anarta) $\boldsymbol{F}$.

" depuncta (Orthosia) $F$.

Hadena Richardsoni $C$.

Psychophora Sabini $K$. $C$.

Oporaria punctipes $C$.

Phalæna G. tristata $F$.

" hastata $F$.

, Tort. uncana (Erastria) $F$.

Orthotænia Bentleyana $C$.

, reptans $F$. (Simulium Lat.)

"pulicans $F . \quad$ (C. pulicaris L.)

Chironomus polaris $K$. C.

Ctenophora Parrii $K$.

Tipula rivosa $F$. (Pedicia Lat.)
84 Tipula regelationis $F$. (Trichocera Meig.)

85 " monoptera $F$. (Doubtful)

86 " pennicornis $F$. (Cecidomyia Lat.)

87 ", atra $F$. (Doubtful)

88 " aretica $C$.

89 Musca stercoraria $F$. Scatophaga

90

91

92

93

94

95

96

97

98

99

100

101

102

103 Empis
" scybalaria $F$

" cloacaris $F$.

" roralis $F$. (Doubtful)

" vivax $F$. (Doubtful)

Helophilus bilineatus $C$

Tachina hirta $C$.

Anthomyia dubia $C$.

Scatophaga apicalis $C$.

Volucella mortuorum $F$. (Surcophaga Meig.)

" vomitoria $F$. (Musca L.)

" Cæsar F. (Musca L.)

" Lappona $F$. (Sericomyia Lat.)

Tabanus Groenlandicus $F$.

empis borealis $F$. 


\section{LIS'T OF PLATES.}

PLATE I.

HG.

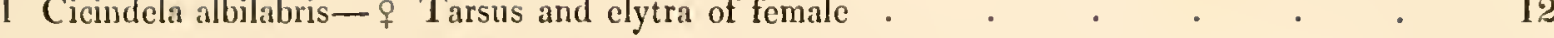

2 Sericoda bembidioides-a Maxillary palpus. $b$ Labial ditto . . . . . . . 1.5

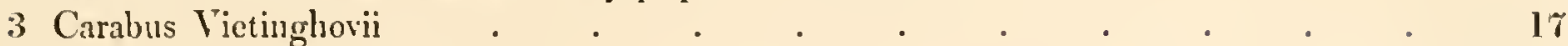

4. Agonum cupripeme-a Elytrum . . . . . . . . . . . . . . . 28

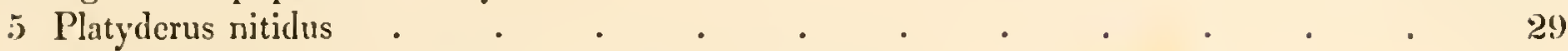

6 Isopleurus nitidus- $a$ Maxillary palpus. $b$ Labial ditto _ . . . . . 50

7 Peryphus (Eudromus) nitidus-a Maxillary palpus. b Labial ditto . . . $\quad 55$

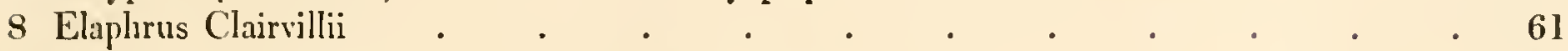

9 Opisthius Richardsonj-a Maxillary palpus. $b$ Labial ditto _ . . . . 61

\section{PLATE 11 .}

1 Dytiscus (Lcionotus) Franklinii- $\delta$ Hand of the male . . . . . 77

2 Latlırobium Gravenhorstii . . . . . . . . . . . 87

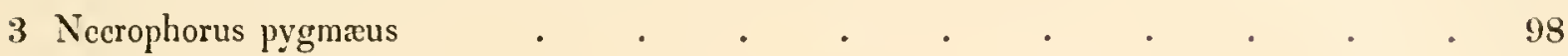

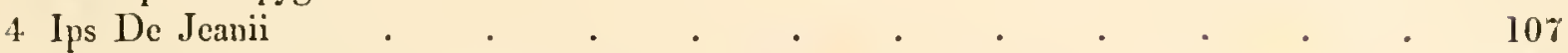

5 Thanasimus abdomiualis . . . . . . . . . . . . . 244

6 Dichclonycha Backii . . . . . . . . . . . . . . . . . . . 134

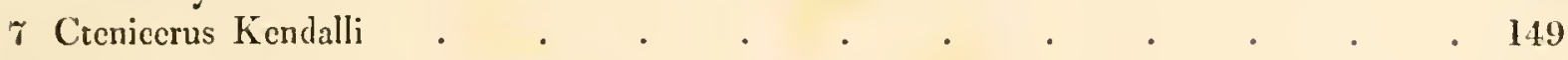

8 Buprestis (Trachypteris) Drummondi . . . . . . . . . . . . $\quad$. 159

9 Buprestis (Odontomus) trinervia . . . . . . . . . . . . . . 157

PLATE III.

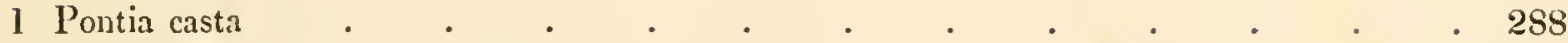

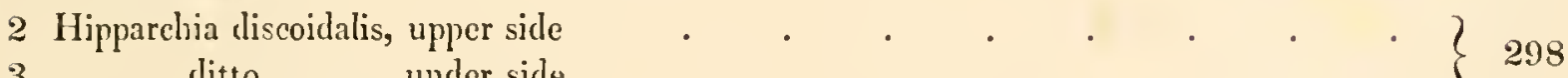

3 ditto under side . . . . . . .

4 Thecla Augustus, upjer side . . . . . . . . . . . . .

5 ditto under side . . . . . . . . . . $\}$

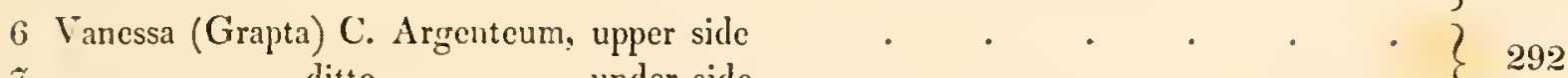

7 ditto under side . . . . . . $\}$

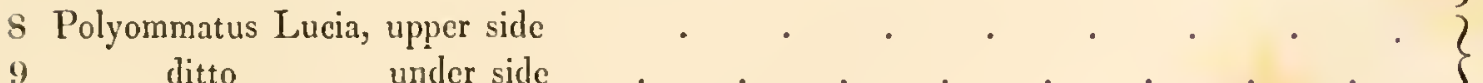

PLA'TE IV.

I Lyeæua Dorcas, upper side

2 Hesperia Peckius, upper side

3 ditto under side

4 Smerinthus Cerisyi

6 Callimorpha virguncula 


\section{PLATE V.}

Fig.

1 Scaphium castanipes- $a$ Antenna

2 Leptura chrysocoma-a Eyc

3 Diplotaxis tristis

4 Coccinella episcopalis

5 Callidium (Merium) Proteus

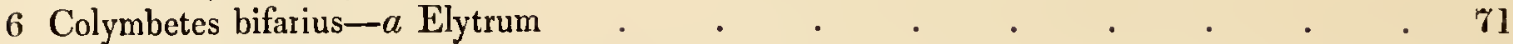

7 Lepyrus Gemellus . . . . . . . . . . . . . . . 198

8 Callidium (Tetropium) cinnamopterum - $a$ Eye _. . . . . . . $\quad 174$

9 Pimelia alterunta

PLATE VI.

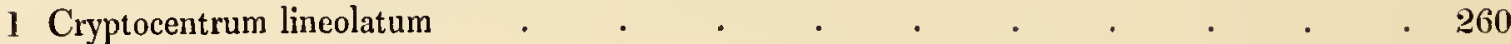

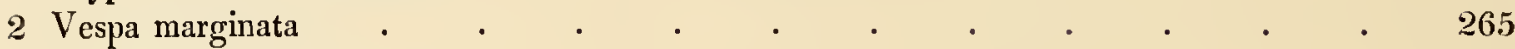

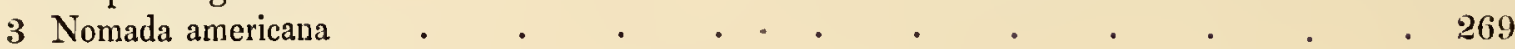

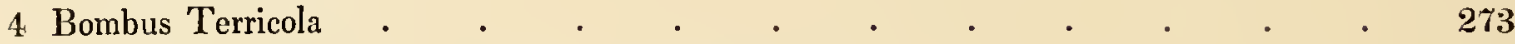

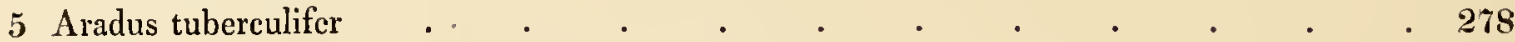

6 Pentatoma (Neottiglossa) trilineata-a Under side of the trunk _ . . $\quad 276$

7 Reduviolus inscriptus . . . . . . . . . . . . . . . $\quad 280$

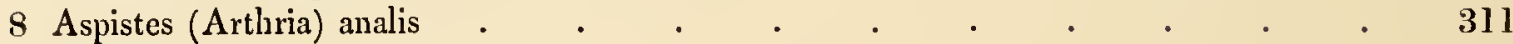

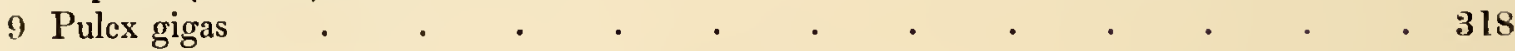

PLATE VII.

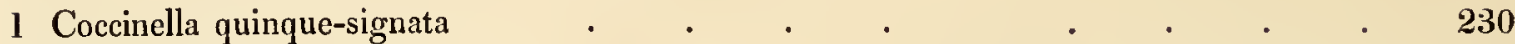

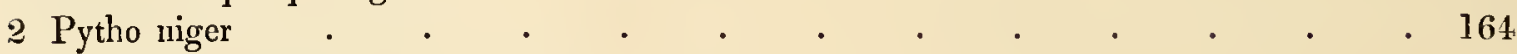

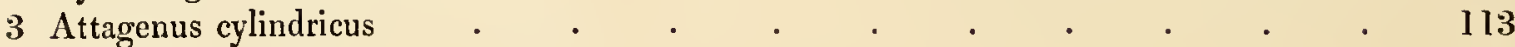

4 Telephorus (Malthacus) puncticollis _ . . . . . . . . . . . 217

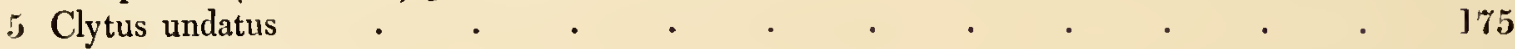

6 Orsodacna Childreni . . . . . . . . . . . . . . . . 221

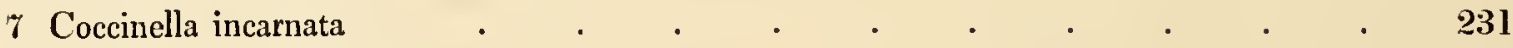

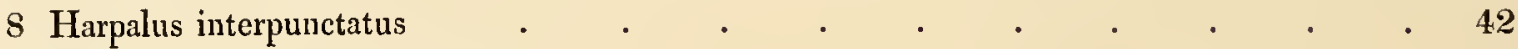

9 Haltica (Orchestris) puncticollis . . . . . . . . . . . . . . $\quad$. 218

PLATE VIII.

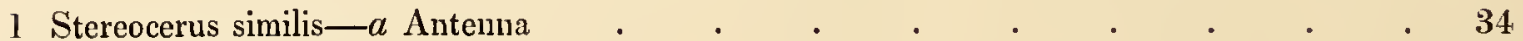

2 Apatc (Lepisomus) rufipennis-a Antenna. b Eye . . . . . . 193

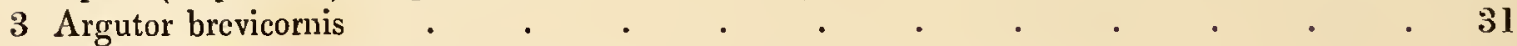

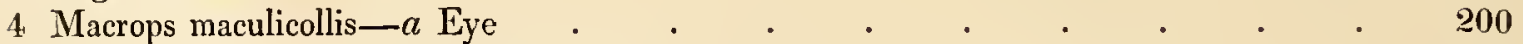

5 Apate bivittata- + Prothorax of female . . . . . . . . . . 192

6 Tachyta picipes-a Maxillary palpus . . . . . . . . . . . 56 


\section{EXPLANATION OF SOME TERMS, USED IN THE FOLLOWING WORK, NOT IN GENERAL USE.}

TERMS RELATING TO THE HEAD.

Iols. Molary plate or space. (Sec p. 82, 129, \&c.) A broad flat space on the inner side of the base of some mandibles, laving no molary teeth at their apex, of Coleopterous insects (many Lamellicorns and Hydrophilus) usually transverscly grooved, but sometimes smooth, and used in mastication.

Pronuscrs. The Haustellnm, or instrument of suction, of the Hemiptera and Homoptera.

Lisge... The Tongue. (p. 49,78, \&c.) Often connate witb the Labium and called by that name. It is, however, sumetimes a separate organ. (Sec Introd. to Ent. iii. 3j7, E.)

Scarts. Scape. (p. 31, \&c.) The first, and often most conspicuous joint of the Antenna, terminating below in the bulb, which inosculates in the head and acts the part of a rotula.

Pedicellus. The Pedicel. (p. 109, Sc.) The second joint of the Antenne, inosculating in the Scapus.

Nists. The Nose. (p. 67, 276) The terminal piece of the face witls which the Labrum, or upper lip, articulates, often called the Clypeus.

Postrisuss. The Afternose. (p. 128) 'The part of the facc, lying behind the Nasus, immediately contiguous to the Antennce, when distinctly marked out as in Camptorhina. (p. 43,94.)

Russanus. The Nostril-piece. (p. 43, 94) The space between the anterior margin of the Nasus and the Labrum, which in most of the Lamellicorn bectles is vertical; in Necrophorus it consists of membrane.

TERMS RELATING TO THE TRUNK.

Truxces istumatus. 1sthmiate-trunk. (p. 188) When an isthmus is formed letween the Trunk and the Elytra, as in Passalus.

Masitruscus. The Manitrunk. (p. 69) The anterior portion of the Trunk to which the arms or fore legs are attached. P'rothorax. The Fore-thorax. (p. 8, 35, \&c.) 'The upper side or Shield of the Manitrunk.

Ors. The Ora. (p. 106, 142) The inflexed or inferior lateral margin of the Fore-thorox, in many genera separated from the Fore-breast by a suture.

Asterectus. The Fore-breast. (p. 17, 126) The under side of the Manitrunk.

Prostersivi. The Fore-breastbone. (p. 74, 87) An elevation of the Fore-breast between the Arms.

Brachis. The Arms. (p. 72:) Or first pair of legs.

Cravicula. (p. 39) Or first joint of the arms answering to the Coxce of the two last pair of legs.

Scaptus. The Shoulderlade, or sccond joint of the arms, answering to the Trochanter in the other legs.

Huserus. The Shoulder. (p. 87, 132) The third joint of the arms, answering to the thigh.

CíвrTus. The Cubit or Fore-arm. (p. 7, 74) The fourth joint of the arms answcring to the Tilia or shank.

Mavus. The Hand. (p. 2, 47) The fith portion of the arms, usually consisting of more than a single joint, and answering to the Tarsus or fout.

Alitruxcus. The Alitrunk. (p. 60) The posterior portion of the Trunk, which bears the organs of tlight and the legs. This part is resolvable into two segments.

MEDitruscus. The Mid-trunk, to which the upper organs of flight and the mid-legs are attached.

Mesotionax. The Mid-thorax. The upper side of the mid-trunk, bearing the upper organs of flight.

Elytra. Wing-cases. Horny or leathery organs peculiar to Colcoptera. 
Hypoderma. (p. 16) The membranous lining of the Elytra.

Epipleura. Side-cover. (p. 21, 27) The inflexed margin of many Elytra, covering the sides of the Alitrunk and Abdomen.

Tegmins. (p. 250) Organs of a less firm consistence peculiar to Orthoptera.

Hemelytra. (p. 275) Organs peculiar to the Heniptera, consisting of two portions, a hard or leathery base called the Corium, and a terminal Membrane. (p. 275.)

ALA. Wings. Membranous organs of flight common to the remaining Orders.

TEGULA. Base-covers. (p. 256, 264) Concavo-convex pieces that defend the base of the wings in Hymenoptera.

Medipectus. Mid-breast. (p. 135, 165) The under side of the Mid-trunk, bearing the intermediate pair of legs.

Peristetinum. The anterior part of the Mid-breast.

Scapularia. The Scapulars. (p. 75) The lateral pieces outside the mid-legs.

Mesosternum. Mid-breastbone. The middle piece, between the above legs.

Potruncus. After-trunk. The last segment of the Trunk, bearing the under wings and posterior pair of legs.

Mетатновax. The After-thorax. (p. 259) Tbe upper side of the After-trunk, which bears the above wings, and terminates posteriorly in the Postscutellum. (p. 266.)

Postrectus. The After-breast. $(94,165$, \&c.) The under side of the Potrunk.

Mesostethium. (p. 75) Anterior part of the above, situate between the intermediate and postcrior legs.

Parapleure. (p. 77) Two pieces, one on each side the postpectus, outside the posterior legs.

Metasternum. The After-breastbone. A central and often elevated part between these legs.

TERMS RELATING TO THE ABDONEN.

Hrpopyguer. (p. 130, 15.5) The last ventral segment of the Abdomen, with the Podex, or last dorsal segment, forming the Anus.

Ovipositor. Egg-placer. (p. 257) The instrument with which the Orthoptera, and many Hymenoptera, convey their egg̣s to their proper station.

Caunur.t. (p. 253) Two or more jointed, flexile, anal organs. 


\section{N T ROD U C T ION.}

TuE state of society in which the works of Creation are duly investigated, is not its state of infancy or boyhood, but that of its maturity and confirmed manhood; for, in its earlier and ruder stages, the sciences in general are looked upon with indifference, and not scldom with contempt; but, in proportion as civilization advances, they aequire daily more and more importance. 'The last, probably, that is raised to its proper rank in the public estimation, is the study which is distinguished by the name of Natural History: hence it happens that the patronage and fostering care of princes and statesmen have been usually extended later to this branch of science than to any other ; and a just sense of the value of it, in public men, seems an indication of a very advanced state of society, and a proof that the public mind is wholly liberated from all the trammels of prejudice. When the inspired wisdom of the most powerful and magnificent of the Hebrew monarchs was directed to this object, and he composed treatises, for the instruction of his people, both upon plants and animals, then the Israclitish nation had attained the acmé of its civilization and glory; and that celebrated Græco-Macelonian prince and conqueror, whose highest privilege it was to have been the pupil of Aristotle, at the period when science in Greece had attained its zenith, is related to have given it in charge to his tutor to pay particular attention to the study of animals, and, in order to furnish him with materials, employed several thousand men, both in Europe and Asia, ${ }^{1}$ in collecting them.

But it is scldom that sovereigns, or their ministers, have extended their fostering patronage to the science in question, till their attention has been excited by the 
celebrity, studies, and labours of some eminent individual amongst their subjects; and they have thus been induced to cast an eye of favour upon them; their own thoughts and time are necessarily too much absorbed by politics, and the higher dnties of their station, or office, to allow them much leisure to direct and employ them elsewhere, unless some such stimulus awakens their attention to the subject, its merits, and claims to notice.

It was by his ardent zeal in the cause he had embraced; and the mighty power of his intellect; and his indefatigable labours and studies; and his profound knowledge of his sulject for the time; and the wide celebrity of his name, that the Aristotle of the North, the illustrious Linné, attracted to himself, and the science that he loved, the favourable regards, and the effectual aid of the higher powers; in consequence of which, under their auspices, eminent naturalists were sent ont to explore various and distant regions, for the purpose of discovering, studying in their native soil, and collecting, their natural productions. Thus it was that Kalm went out to North America; Tornstroen and Osbeck to China; Forskahl to Arabia; Thunberg to Japan; Sparrman to China and the Cape; Hasselquist to the Levant, Palcstinc, and Egypt; and others to various other regions of the globe.

In our own country, till within a few years, the collection of natural productions made no part of the official duty of those employed by government in exploring unknown, or little known, countries; and if such collection was made in any expedition undertaken by authority, it was solely owing to the taste and inclination of some individual connected with it. It was thus that the late Rt. Hon. Sir Joseph Banks, led by the love of science alone, and his own native ardour in her cause, at first distinguished himself; a circumstance that became the stepping-stone which originally placed him upon the eminence in the scientific world which from that time he held, and which caused him, in the event, to be looked np to by those in power, and enrolled him in the list of his Majesty's Most Honorable Privy Councillors. Accompanying Capt. Cook, the most illustrious of our circumnavigators, in his first voyage, with the aid of his zealous and learned friend the late 
Dr. Solander, he made such collections, both in Zoology and Botany, as had never before rewarded the zeal and efforts of any single individual; and from regions which till then had remained unexplored, and of some of which the very existence was till then unknown, poured vast sums of her peculiar wealtl into the general treasury of Natural Science.

Sir Joseph employed the influence he had accuired with the Government in promoting the interests of that science, and sccuring to it a portion of the same encouragement which had been bestowed upon other branches of art and literature; so that to examine and collect the natural productions of a country, began, at length, to be regarded as an important object, and to form part of the official duty contained in the instructions delivered to commanders of voyages and expeditions of discovery.

And, certainly, merely to ascertain the geographical position and limits of any country, considered as the sole object of such expeditions, although to the Geographer and Navigator confessedly of the first importance, yet considered per se, and independently of any knowledge of the inhabitants and productions of such country, it loses the largest portion of its interest. The advantages that may be derived from an intercourse with it, furnish one of the principal motives for exploring it, and these may be ranged under two heads, accessions to science, and accessions to commerce: the former as useful in the enlargement of the human mind, in the improvement of the human intellect, and in adding to our stores of knowledge; as the latter is in the enlargement of our property, and in adding to our stores of individual and national wealth. And the studies, labours, and observations of the man of science often lead to knowledge highly useful in ascertaining how far the latter object may be promoted by intereourse with any given country. The Zoologist, the Botanist, and the Geologist, each in his peculiar department, may direct the attention of the man of commerce to those districts where such productions of the animal, vegetable, or mineral kingdoms abound, as may be made articles of profitable speculation. 
Anongst the other objects of Natural History collected in Captain, now Sir John, Franklin's last Expedition to the Polar Seas, the Insects form a very principal and interesting feature, not only on account of the number of individual species, which is considerable, but also on account of several new forms which they present to the scientific Entomologist; some of them connecting tribes before placed far asunder, ${ }^{2}$ and filling up many vacant places in a scientific arrangement of these minute but not unimportant animals; others exhibiting an Asiatic aspect ; and the majority representing, as it were, known European types; and though varying from them in characters of more or less importance, known European species; so that the American Entomologists, for want of comparing one with the other, appear often to have confounded them.

Dr. Richardson, who was associated with Sir John Franklin in his first, as well as in his second, Journey, and to whom was intrusted the Natural History Department of the Expedition, the duties of which office he fulfilled with the same indefatigable zeal and singular skill, that his excellent commander evinced in the general conduct of it, having, at the recommendation of my worthy and learned friend, the Regius Professor of Botany at Glasgow, Sir W. J. Hooker, placed in my hands the above collection for arrangement and description, I must here premise a few observations on the plan I intend to pursue for the accomplishment of those objects.

I must first observe that the majority of the insects in question were necessarily collected during the brief summers of the Arctic regions, when it was requisite to use all possible dispatch in proceeding northwards while the season permitted : it was to be expected, therefore, that they must be hastily put together in boxes, or bottles of spirits, as they were collected, but it is wonderful, considering their number, that so little damage was sustained from this mode of packing them, none having received such injury as to render it difficult to describe them, except some of the Diptera, and the Libellulina, of which there seem to have been many, and which were so mutilated, most having lost their abdomen, that they could not be ascertained or described. 
Having in my cabinet a number of insects, including some new and singular forms, which were chiefly collected in Canada by Dr. Bigsby, and in Nova Scotia by Dr. Mac Culloch, I thought it would add considerably to the interest of the present Fauma, if, as far as relates to the insects, it were made coextensive witl the British Territories in North America; I have, therefore, with the consent of Dr. Richardson, included them in my catalogue, which may thus be regarded at the first attempt at an ontline, meager indeed and imperfect, of British American Entomology.

I must also here observe, that several of the insects collected in the Expedition, were taken in the journey from New York to Cumberland-house, without its being noted on which side of the $49 \mathrm{th}$ parallel of Latitude, the southern limit of the Zoology of the British American Fur Countries, as fixed in Dr. Richardson's Introduction, ${ }^{4}$ they were taken; so that it was not in my power to distinguish the species taken in the British from those taken in the American territory. I thought it therefore best to include the whole.

So many different methods of arrangenent have been traced out, or adopted, by different Entomologists, no two having altogether pursued the same path, that when I first set to work upon these insects, after I had ascertained the genus to which each species belonged, and which of them appeared to be non-descript, it was a source to me of no little thought, doubt, and perplexity to determine upon whose footsteps I should tread in the arrangement of them in a series, especially with regard to the Coleoptera Order, or Beetles. Two eminent Entomologists, my lamented friend M. Latreille, and Mr. W. S. Mac Leay, amongst others of less note, have taken great pains to form natural groups, but upon different principles, and both have rendered important services to the science; but both also, in some degree, by the adoption of an hypothesis, have tied their hands and impeded their own progress. M. Latreille by following Gcoffroy's method, in which the number of the joints of the tarsi is assumed to indicate the primary sections of the Order 
before alluded to, though in general he has discriminated, limited, and located his groups with a felicity peculiar to himself, yet in consequence of his assumption of the above system as an invariable guide, has, in many instances, been induced to separate groups that are evidently nearly related, and to scatter them far and wide through his various sections. Mr. Mac Leay, likewise, by assuming the number five for the universal regulator of every group-whether primary, intermediate, or ultimate- of the whole animal kingdom, though in many cases it may prevail, has by no means made it clear that it is the keystone of the mighty arch of nature, or the clue by which her mazy labyrinth may be traced through all its windings and recesses.

Whoever considers the infinite ramifications of the Animal and Vegetable Kingdoms, the vast number of groups differing in rank and value, and rolling wheel within wheel, almost ad infinitum, of which each consists; may readily conceive that the formation of a numerical system, whether the number assumed as the regulator be two, three, four, five, or seven, is a labour of no very difficult accollplishment; but to construct it so that the groups of each section, from the primary to the ultimate, shall be equal or nearly equal in value, which alone can prove that it is the system of the Creator,-hic labor, hoc opus est.

Mr. Stephens, in his Systematical Catalogue of British Insects, containing, I believe, the last that has been published, has given a still different, and, upon the whole, an improved arrangement, in which he implicitly follows neither of his predecessors, and has taken great pains, as far as his means and limited subject permitted, though in some things he also appears to me mistaken, and who is not: to follow the light afforded him by nature. Sir J. F. W. Herschel's observations on this subject merit particular attention. "The classifications by which science is advanced, however, are widely different from those which serve as bases for artificial systems of nomenclature. They cross and intersect one another, as it were, in every possible way, and have for their very aim to interweave all the objects of nature in a close and compact web of mutual relations and dependence."5

${ }^{5}$ Disc. on the Study of Nat. Philosophy, Cab. Cycl. xiv, n. 134: 
When so many eminent men form different conclusions from the same premises, we may rest assured that there is something in the subject of their lucubrations that admits of hesitation, and justifies variety of opinions; and this is clearly the case with respect to the arramgement of natural objects; for whether we consider the productions of our globe, in all their affinitics, as best represented by a branching tree, a net, or a sphere formed of an infinity of larger and smaller orbits, connected on every side, and placed ad infinitum wheel within wheel; if we set ourselves to arrange and describe upon paper the individuals composing any department of the three kingdoms, we shall find that it is above us either to conceive or delineate it so as to maintain all its connections undisturbed and unbroken. We must do it in a series, which can only be a series of mutilations and dislocitions. It will be like cutting off every branch and twig of the tree to place them end to end; like tearing up the net to place all the meshes one after the other; like blowing up the whole sphere, and unravelling, as it were, all its orbits great and small, to make a continuous thread of them. So that it is a hopeless case to) attempt an arrangement according with nature in all its parts; vain man, with all his boasted powers of intellect, cannot conceive, much less utter and embody it. All that he can accomplish is to give some general idea of it, and to describe some fractions of it. He can also attend to the composition of his groups, and keep those together that are really related; but as to conterminous groups, he will often be at a loss which is nearest to the one in question, for from different parts of the same group, a variety of others will often branch off in different directions.

In the following pages, therefore, profiting by the labours of my predecessors, I have sometimes followed one and sometimes another, according as they appeared to une best to have interpreted nature, and sometimes, where it scemed expedient, I have entered new paths in my arrangement; it has been my endeavour principally to make my groups as near to nature as possible, but with regard to the series and concatenations of them, for the reasons above assigned, it was not possible to place them on paper as they are inscribed, by the Great AUTror of nature in her pages. 
The author cannot conclude this Introduction without returning his acknowledgments to those gentlemen, to whom it will appear from a perusal of the following pages he is under great obligations for very considerable additions to his catalogue of the insects of the British Provinces in North America, namely to Dr. Bigsby, of Newark, and Capt. Sheppard, of her Majesty's Royal Regiment of Artillery, for those of Canada; and to Dr. Mac Culloch, and Capt. Hall, late of her Majesty's 81st Regiment, for those of Nova Scotia. From Dr. Thaddeus Harris, and Mr. Drake, he has received several specimens from the Province of Massachusets, which are likewise found in the British Provinces. 
The following Table exhibits the gronps adopted in this work in the Orders Coleoptera and IIymenoptera only, the author, on account of the small number of specimens collected, having made no additions to those already established in the other Orders.

\section{Class Insecta.}

Subclass Mandibuiata.

\section{Order Coleop'tera.}
I. Adephaga $\left\{\begin{array}{l}\text { Geadephaga } \\ \text { Hygradephaga } \\ \text { Hydradephaga }\end{array}\right.$
II. Brachelytra
Homogenea
Heterogenea
Mierocephala
Fisslabra

III. Entaphia

IV. Neerophaga

V. Philbydrida

VII. Sternoxa

VI. Lamellicornia $\left\{\begin{array}{l}\text { Petalocera } \\ \text { Rectocera }\end{array}\right.$

VIII. Xylophaga S Brevieornia Longieornia

IX. Rbynchophora $\{$ Gonatoeera Orthocera

x. Phytophaga Creliea

XI. Aphidiphaga (Melasoma

XII. Heteromera $\left\{\begin{array}{l}\text { Stenelytra } \\ \text { Stracorni }\end{array}\right.$ XIII. Malacoderma $\quad \begin{aligned} & \text { Serripalpia } \\ & \text { Trachelida } \\ & \text { Vesieantia }\end{aligned}$
Sruneipennia

$\{$ Sarrotbropoda

Cystopoda

S Quadrimana

$\{$ Dimanı
Sobilia

i Plebeja

f Diman:

¿ Quadrimana

\section{$\left\{\begin{array}{l}\text { Aeutipal pia } \\ \text { Subulipalpia }\end{array}\right.$ \\ Filipalpia \\ f Eunecha \\ $\{$ Gyroneeba}

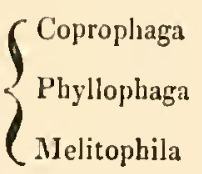

S Isocera

$\{$ Anisoeera

$$
\left\{\begin{array}{l}
\text { Longirostria } \\
\text { Brevirostria }
\end{array}\right.
$$

\section{\} Hierentoma \\ $\{$ Sternucha \\ $\{$ Aposterna}

\section{Order Hymenoptera. .}
I. Terebrantia $\{$ Securifera
II. Urocerata
S Pupivora
III. Parasita
\{ Larviviora
IV. Aculcata
Heterogyna
Lestica
$\left\{\begin{array}{l}\text { Diplopteryga } \\ \text { Anthophila }\end{array}\right.$ 



\section{LIST OF AUTHORS REFERRED TO IN THIS VOLUME IN ADDITION TO THOSE REFERRED TO IN THE PRECEDING VOLUMES.}

N.B. The Italic lctters indicate the abbreviations of the tilles of the worls quoted in the following volume.

Acta. Nidr. . . . . Det Trondhjemske og Norske videnskabers selskabs skrivter. Kiobenhavn, 1761. 8 vo.

,. Ups. . . . . Acta literaria Scientiarum Sueciæ, vol. 4. Upsala, 1735-39.

, . . . . . Nova acta Regiæ Societatis Scientiarum Upsaliensis, 1773. 4to.

Adays. Ad. . . . Memoires de la Societé imperiale des naturalistes de Moscou.

Albix. Alb. . . . Historia naturalis Insectorum Anglicanorum. Londini, 1710. 4 to.

Aldrovandus. Ald. - De animalibus Insectis. Libri septem. Bononiæ, 1602. fol.

Adural or Amm ral. Adm. Jacob l'Admiral veranderingen von veel Insecten. Amsterdam, 1774. fol.

AMoreux. Am.

Notice des Insectes de la France reputés venimeux tirée des ecrits des Naturalistes, des Médecins, et de l'observation. Paris, 1799. 8 vo.

Axyales. Ann. Museum d'Histoire Naturelle de Paris, tom. 20. Paris, 1802-13. 4to.

Barbet, Barb.

The Genera Insectorum of Linnæus exemplified by various specimens of English insects drawn from nature. London, 1781, 4 to.

Barowsкy. Bar. . . Gemeinützige Naturgeschichte des Thierreichs.

Bsunix. Bau. . . . Historia admirabilis fontis Bollensis. Montisbeligardi, 1598. 4 to.

Bechsteix. Bech. . . Naturgeschichte des In-und Auslandes. Nurnberg, 1793. 8vo.

Bercstrïser. Berg. . Nomenclatur und beschreibung der Insecten in der grafschaft HanauMünzenberg. Hanau, 1770-80. 4to.

Berkexhout. Berk. . - Synopsis of the Natural History of Great Britain and Ireland. London, 1795. $12 \mathrm{mo}$.

Buxglex. Bing. - . Animal Biography, or anecdotes of the lives and manners of the Animal Creation. 3 vols. London, 1803. 8vo.

Blaқкалlт, Blank. . . Belg. Shouberg der rupsen, wormen, maden, en vliegende dierkens daar mit voortcommende. Amsterdam, 1688. Leipzig, 1690. Svo.

Blumexвacn. Blum. - Hand-buch der naturgeschichte. Gottingen, 1803. 8vo.

Воск . . . . . Naturgeschichte von Preusen, tom. 5.

Bolkuausex. Bork. . . Naturgeschichte der Europaischen Schmetterlinge, \&c. Frankfurt, 1788 -89. 8vo.

Rheinisches Magazin zur erweiterung der Naturkund. Giessen, 1793. 8 ro. 
Bradley. Brad. . . A philosophical account of the works of Nature. London, 1732 . 4to. 1739. 8vo.

Bratm _. . . Insecten-Kulender. Mainz, 1790. 8 vo.

Butterfiles. . . . . British Butterflies, their distinction, generic and specific. Birmingham, 1828. $24 \mathrm{mo}$.

Cederhieln. Ced. . . Faunæ Ingricæ Prodromus, exhibens methodicam descriptionem agri Petropolensis. Leipzig, 1798. 8vo.

Chrldren. Child. . . Narrative of the Arctic Land Expedition, 1833-35, by Capt. Back, R. N. Appendix No. iii, Insecta. London, 1836. 8vo.

Cin ristrus. Christ. . . Naturgeschichte, classification, und nomenclator, der insecten bienen, vespen, und ameisengeschlect (Hymenoptera L.) Frankfurt, 1791.4to.

Clatrville. Clair. . Entomologie Helvetique, ou catalogue des insectes de la Suisse, rangés dans une nouvelle methode. Tom. 2. Zuric, 1798-1806. 8vo.

Coquebert. Coq. . . . Illustratio iconographica Insectorum, quæ in Musæis Parisinis observavit et in lucem edidit J. C. Fabricius. Parisiis, 1797-1804. 4to.

Cramer. Cram. . . Papillons exotiques des trois parties du monde, l'Asie, l'Afrique, et l'Amerique. Utrecht, 1779. 4to.

Curtis. . . . . . British Entomology. London, 1824-36. 8 vo.

" . . . . . Appendix to Capt. Sir John Ross's Second Voyage in search of a North West passage, in 1829-33. London, 1836. 4to.

DE GeER. . . . . Memoires pour servir a l'Histoire des Insectes: 7 tom. Stockholm, $1752-78$. 4to.

Dejean. Dej. . . . Catalogue de la collection des Coléoptères de M. le Baron Dejean. Paris, 1821. 8vo.

, . . . . Species général des Coléoptères. 5 tom. Paris, 1825-31. 8vo.

Dictionnaire. D. . . Noveau $D^{\prime} H$ istoire Naturelle appliqué aux arts. 36 tom. Paris, 1825 -31. 8 vo.

Des Sciences Naturelles. 8 tom. Paris, 1804. 8vo.

Dillwy . Dill. . . Memoranda of Coleopterous insects found in the neighbourhood of Swansea. 8vo. Distributed by the author

Doxovan. Don. . . . Natural History of British Insects, explaining them in their several states. London. 1792-. 8vo.

Drury. Dru. . . . Illustrations of Natural History. 3 vol. London, 1770.4 to.

Duftschuidt. Duft. . . Fauna Austriæ, oder beschreibang der Ostereichsen insecten fur angeliende freunde der Entomologie. Lingund Leipzig, 1805

Duncan. Dun. . . The Naturalist's library conducted by Sir William Jardine, Bart. F. R.s. \&c. vuls. 2 \& 3, Beetles and Butterflies. London, 1835. 12 mo.

Escusckoltz. • . . Zoologischer Atlas.

Ernst. . . . . Papillons d'Europe peints d'après nature. Paris, 1779. 4to.

Esper. Esp. . . . Die Schmetterlinge in abbildungen nac der natur, mit beschreibungen. Erlangen, 1777. 4to. 
Fabricius. Fab. . - Systema Entomologiæ. Flensburgi, et Lipsiæ. 1175. 8vo.

Genera Insectorum, eorumque characteres naturales, secundum numerum, figuram, et proportionem omnium partium oris, adjecta Mantissa specierum nuper detectarum. Chilonii, 1776. $12 \mathrm{mo}$.

". . . . Entomologia Systematica emendata et aucta, tom. 4. IIafniæ, 1798. 8vo.

" . . . . Systema Eleutheratorum, tom. 2. Kiliæ, 1801. 8 vo.

" . . . . Rhyngotorum. Brunsvigæ, 1803. Svo.

,. . . . . - Piezatorum. Brunsvigæ, 1804. 8vo.

, . . . . Antliatorum. Brunsvigæ, 1805, 8vo.

, . . . . . Glossatarum Welchen D. Illiger im sechsten Bande seines magazins uns lieferte, die Gattungsnamen. Ochs. Schmett. v, vorrede. vii.

Fallex. Fall. . . . Monographia Cantharidum et Malachiorum Sueciæ. Lundæ, 1807. 4to. , . . . . Diptera Sueciæ. Lundæ, 1814. 4to.

Fiscuer (J. L.) Fisch. . Versuch einer Naturgeschichte vom Livland entworfen. Leipzig, 1778. 8 vo.

Fiscrer (Gotth.) Fisch. Entomographie de la Russie publiée au nom de la Société Imperiale. 3 tom. Moscou, 1820-28. 4to.

Forster. Forst. . . . Novæ species insectorum centuria prima. Londini, 1771. 8vo.

Folikcror. Fourc. . Entomologia Parisiensis, sive catalogus insectorum, qux in agro Parisiensi reperiuntur, tom. 2. Parisiis, 1785. $12 \mathrm{mo.}$

Fiśsı . . . . . Beschreibung von allerley Insecten in Deutschland. Berlin, 1766. 4 to. , . . . . . . Naturgeschicht.

Fuessly. Fuess. - . Verzeichniss der ihm bekann bekannten Schweitzenschen Insecten. Zurich und Winterthur. 1775. 4to.

Archiv der insecten-geschichte herausgege. Zurich und Winterthur, 1781-94. 4to.

Georfroy. Geoff. . . Histoire abregée des Insectes, dans laquelle ces animaux sont rangés suivant un ordre méthodique. 2 tom. Paris, 1764. 4 to.

Germar. Germ. . . . Magazin der Entomologie. Halle. 3 tom. 1813. 8vo.

Insectorum species novæ aut minus cognitæ, descriptionibus illustratæ. Halæ, 1824. $12 \mathrm{mo}$.

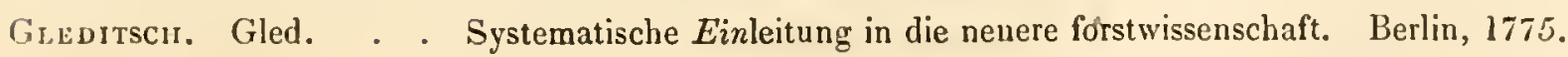
8vo.

Godart \& Dupoxciez. God. Histoire Naturelle des Lepidoptères de France. Paris, 1818. 8vo.

GOEDART. Goed. . . De Insectis in methodum redactis cum notularum additione opera M. Listeri, \&c. Londini, 1685. 8vo.

Goeze Entumologische beitrage zu Linnés 12, Ausgabe des Natur System, 3 tom.

Leipzig, 1777. 8vo. 
GuezE . . . . . Europaische Fauna de naturgeschichte der Europaischen thiere. Leipzig 1799. 8 vo.

Gould . . . . . An account of the English Ants. London, 1747. 18 mo.

Graveshorst. Grav. - Coleoptera Microptera Brunsvicensia. Brunsvicæ, 1802. 8vo.

" . . . Monographia Coleopterorum micropterorum. Gottingæ, 1806. 8vo.

" . . . Ichneumonologia Europea, tom. 3. Uratislaviæ, 1829. 8 vo.

Grovorius. Gron. . . Zoophylacium Gronovianum. Leyden, 1765-87. fol.

Gyldenilal. Gyll. . . Insecta Suecica, tom. 4. Scaris, 1808-13. Lipsiæ, 1827. 8vo.

Harrer. H-r. . . Beschreibung derjeniken Insecten welche Herr. D. Jacob. Christoph. Schæffer in 280 ausgemahlten kupper-tafeln herausgegeben hat. Regensburg, 1784. 8vo.

Harris. H-s. . . The English Lepidoptera or Aurelian's pocket companion. London, 1775. 8 vo.

, . . . . . The Aurelian, or Natural History of English Insects, namely Moths and Butterflies, London, 1778. fol.

An Exposition of English Insects. London, 178\%. 4to.

Hawоrтн. Haw. . Lepidoptera Britannica, sistens digestionem novam insectorum Lepidopterorum quæ in Magna Britannia reperiuntur, part 4. Londini, 1803-28. 8ro.

HedLexius. Hell. . . Kongl. Svenska vetenskaps Academiens handlingar. Stockholm, 1786. Act. Holm.

HeLlwig. Hellw. . . Fauna Etrusca, iterum edita, et annotatis perpetuis ancta. Helmstadii, 1795. 8vo.

Herbst. . . . . Archiv der insectengeschichte. Zurich und Winterthur, 1781. 4to.

" . . . . . Natursystem aller insekten von Jablonsky per Herbst. Coleoptera, vol. x. Berolini, 1785-1801. 8vo.

, . . . . . Gemeinnuzzige Naturgeschichte des Thierreichs. 1787.

, . . . . . Natursystem aller bekannten in und ausländischen Insecten, \&c. Von Carl. Gust. Jablonsky. Berlin, 1789-1801. 8vo.

Hersched (Sir J. F. W.) J On the study of natural philosophy, Cabinet Cyclopæelia, xiv. London, Hersch. . . 1831 . $12 \mathrm{mo}$.

Hörnagel. Höff. . . . Icones insectorum volatilium, tom. 4. Frankfurt, 1630-1694. 4to.

Hïrnagel. Hüf. . . Tabellen von den tagvögelnder Berliner gegend im sweiten bande des Berlineschen Magazin. 1766. 8vo.

Hoppe. . . . . . Entomologisches Taschenbuch. Regensburg, 1796-97. 8vo.

, . . . . . . Enumeratio Insectorum elytratorum circa Erlangam indigenarum. Erlangæ, 1795, 8vo.

Huber. Hub. . . . . Recherches sur les mœurs des Fourmis indigènes. Paris et Geneve, 1800. $12 \mathrm{mo}$.

Hubner. Hubn. . . Beitrage zur geschichte der Schmetterlinge. 2 tom. Augsburg, 178689. 8vo. 
Hurier. Hubn. . . Der Sammlung Europaischer Schmetterlinge, Augsburg, 1796

". . . . . . Larvæ Lepidopterorum. 4to.

, . . . . . Verzeichniss bekannter Schmetterlinge. Augsburg, 1816. $12 \mathrm{mo.}$

lLr.ıGek. lllig. . . . Verzeichniss der Käfer Preussens cntworfen von Johann Goltlieb Kugellan. Halle, 1798. 8vo.

Magazin fur insectenkunde herausgegeben. Brawnschweig, 1801

JERuYx. Jerm. . . . The Butterfly Collector's Vade-mecum, with a synoptical table of Butterflies. Ipswich, 1827. $12 \mathrm{mo.}$

Jов Lот. Job. . . . . Descriptions et usages de plusicurs noveaux Microscopes, avec de nouvelles observations sur des insectes, et autres animaux qui naissent dans les liqueurs. Paris, 1718. 4to.

Josston. Jons. - . - Historiæ Naturalis de insectis libri tres. Amstelodami, 1657. fol.

Jouknal. Journ. . . Zoological. 5 vol. London, 1824-30. 8vo.

Juruxe. Jur. . . . Nouvelle methode de classer les Hymenoptères et les Diptères. Geneva, 1807. 4to.

Клких. Kirb. - . . Monographia $A p u m$ Angliæ, or an attempt to divide into their natural genera and families such species of the Linnean genus $A$ pis as have been discovered in England, tom. 2. Ipswich, 1802. 8vo.

Kirry \& Spexce Kirb.\&Sp. Introduction to Entomology, 5th edit. 4 vols. London, 1828. 8vo. Kı.t. . . . . . Monographia Siricum Germaniæ atque generum illis adnumeratorum. Berolini, 1803. 4to.

" . . . . . Entomologiæ Brazilianæ specimen.

". . . . . . Entomologische Monographien. Berlin, 1824. 8vo.

Kxocı. . . . . . Beytrage zur Insecten gesehichte. Leipzig, 1781-83. 4to.

" . . . . Neve Beitrage zur insecten kunde. Leipzig, 1801, 8ro.

Krüxrz. Krün. . . . Oekonom technolog. Encyclopedie, oder allgen system der Staats stadthaus. Haus und Landwirthschaft. Berlin, 1787-1804. 8vo.

LAXG. . . . . . Verzeichniss seiner Schmetterlinge. Augs. 1789. 8vo.

Lanarck. Lam. . . . Histoire naturelle des Animaux sans Vertèbres. 7 tom. Paris, $1815-$ 22. 8 vo.

LATREıLL. Lat. - . Histoire naturelle des Fourmis, et recueil de memoires et d'observations sur les abeilles, les araignées, les faucheurs et autres insectes, avec figures. A Paris, 1802. Svo.

Histoire Naturelles des Crustacés et des Insectes. 14 ton.. A Paris, 1802-6. Svo.

Genera Crustaceorum et Insectorum, tom. 4. Paris and Strasburg, 1806-9. 8vo.

Considerations Générales sur l'Ordre naturel des animaux, composant lit Classe des Crustacés, les Arachnides et les Insectes: avec un tableau méthodique de leur genres disposés en Familles. A Paris, 1810. $8 \mathrm{ro}$. 
Latreille. Lat. - . . Les Crustacés, les Arachnides et les Insectes, distribués en Familles naturelles. Ouvrage formant les tomes 4 et 5 , de celui de M. le Baron Cuvier sur le Règne Animal. Ed. 2. Paris, 1829. 8vo.

, . . . . Cours d'Entomologie, tom. 1. Paris, 1831. 8vo.

Laicirarting. Lai. . . Verzeichniss der Tyroler Insecten, tom. 2. Zurich, 1781-84. 8vo. LEACH. . . . . . Zoological Miscellany, being descriptions of new or interesting animals. 3 vols. London, 1814-17. 8 vo.

On the genera and species of Eproboscidean Insects, in the Memoirs of the Wernerian Natural History Society. Edinburgh, 1817. 8vo.

Edinburgh Encyclopædia by Brewster-articles Entomology and Insecta. 18 vols. Edinburgh, 1810-30.

Transactions of the Linnean Society of London-several communications. 17 vols. $1791-1835$.

LePECIIn, Lep. . . . Tagebuch der reise durch verschiedenne provinzen des Russischen Reichs. 3 tom. Altenburg, 1774-83.

LESKE . . . . . Museum Leskeanum. Regnum animale, quod ordine systematico disposuit atque descripsit. D. L. Gust. Karsten. Lipsiæ, 1789. 8 vo.

l.eтtson. Lett. . . . The Naturalist's and Traveller's Companion. London, 1772. 8vo.

Lewiv. Lew. - . . Papilio's of Great Britain. London, 1795. 4to.

Lichtenberg and Voigt. ? Magazin fur das neueste aus der Physik und Naturgeschichte. Gotha. Liclit. V. . . $\} 8$ vo.

Linné. Linn. . . . Iter Oelandicum et Gotlandicum. Holmiæ, 1745. 8vo.

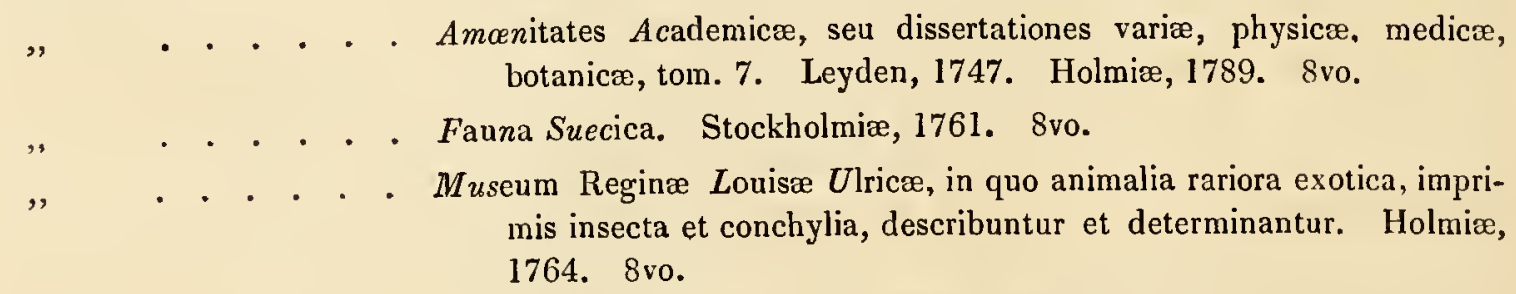
1764. 8 vo.

, . . . . . Systema Naturæ. Ed. 13, tom. 3. Vindobonæ, 1767-70. 8vo.

" . . . . . Iclem cura J. Frid. Gmelin, tom. 6. Lipsiæ, 1788. 8vo.

List e R. List. . . . Appendix ad historiam animalium Angliæ, una cum Scarabæorum Anglicanorum quibusdam tabulis $\boldsymbol{M}$ utis.

Mac LeAy. Mac L. - . Horæ Entomologicæ. 2 vols. London, 1819. 8vo.
Mid. Goedart.

,

Annulosa Javanica, or an attempt to illustrate the natural affinities and analogies of the insects collected in Java by Thomas Horsfield, M.D. \&c. and deposited in the Museum of the Hon. East India Company. London, 1825. 4to.

Marshair. Marsh. . Entomologia Britannica. Coleoptera. Londini, 1802.8 vo.

Martyn. Mart. . . The English Entomologist exhibiting all the Coleopterous insects found in England. London, 1792. fol. 
Megerla. Meg. . . . Catalogus insectorum qua Vienna Austrix dic 14 et sequente Decembris 1801 , auctionis lege distrahuntur.

Meıgkx. Mcig. . . . Klassification und Beschreibung der Europaischen Zweiflügeligen insecten. 2 vol. Brawnschweig, 1804. 4to.

Systematische Beschreibung der bekannten Europaischen Zweifligeligen insccten (Diptera.) 5 tom. Hachen, 1818-26. 8 vo.

Systematische Beschrcibung der Europaischen Schmetterlinge, mit abbildungen, auf steintafeln, 4 Band. Aachen et Leipzig, 1827-29. 4 to.

Mrisuermer. Melsh. . Catalogue.

Menis. Mer. . . Erucarum ortus, alimentum, et paradoxa metamorphosis. Amstclodami, 1717. 4to.

" . . . . . Histoire des Insectes d'Europe. Amsterdam, 1736. fol.

Mеквет. Merr. . . - Pinax rerum naturalium Britannicarum. Londini, 1667. 12 mo.

Mıкам. Mik. . . . Monographia Bombyliorum Bohemia. Pragæ, 1796. 8vo.

MüLLER, (O. F.) Müll. . Fauna insectorum Fridrichsdalina, sive methodica descriptio insectorum agri Fridrichsdalensis. Hafniæ et Lipsia, 1764. Svo.

" . . . . Zoologiæ Danicæ Prodromus. Hafniæ, 1786. 8vo.
" . . . . Linnaisches Natursystem nach der houttuynischen ausgabe, 1804.

" (C. L.?) . . . Der Naturforscher. 30 vols. Halle, 1774. 4 to.

Mouffer. Mouff. . . Insectorum, sive minimorum animalium theatrum. Londini, 1634. fol.

Ochsexuesizr. Ochs. . Die Schmetterlinge von Europa. 4 vols. in 5. Leipzig, 1807-16. 8vo.

, Ochs. Tr. Fortsetzung der Ochsenheimerschen werks, von Friederich Treitsche. 2 vols. in 4. Leipzig, 1825-27. 8 vo.

Olvier. Oliv. - . Encyclopédie Methodique. Histoire naturelle des animaux. Paris, 1782. 4 to.

Entomologie, on histoire naturelle des insectes avec leur charactères génériques et specifiques, leur synonymie, et leur figure enluminée. 8 tom. A Paris, 1789-1808. 4to.

Osomatomologia. Onom. Medica completa, Oder volstandiges Lexicon aller kuntstartur de Naturgeschichte. 7 vols. Frankfurt, Leipzig, 1758-75. 8 vo.

Pallas. Pall. . . . Reise durch verschiedene provinzen des Russischen reichs. 3 tom. St Petersburgh, 1773-76. 4to.

Paxzer. Panz. . . Fạuna insectorum Americæ Borealis Prodromus. Norimbergæ, 1774. 4 to.

Beitrage zur geschichte der Insecten Erlanyæ. 1793. 12 mo.

Entomologia Gcrmanica, exhibens insecta per Germaniam indigena. Norimbergæe, 1795.

Faunx insectorum Germanica initia. Norimbergx, 1796-1805. 
Panzer. Panz. . . . Kritische Revision der insecten Faune Deutschlands, nach dem system bearbitet. Nürnberg, 1805. $12 \mathrm{mo}$.

Paykull. Payk. . . . Monographia Caraborum Sueciæ. Upsaliæ, 1790. 8 vo. Fauna Suecica Insecta, tom. 3. Upsalix, 1798-1800. Svo.

Petagna. Petagn. . . Institutiones Entomologicæe, tom. 2. Neapoli, 1792. 8vo.

" . . . . Specimen Insectorum Ulterioris Calabriæ. Moguntiæ. 1797. 4to.

Petrver. Pet. - . . Musæi Petiveriani rariora naturæ continens, animalia, fossilia, plantas, ex variis mundi plagas advecta, ordine digesta, et nominibus propriis signata. Londini, 1695. 8 vo.

" . . . Gazophylacium naturæ et artis. 10 Decades, Londini, 1702. fol.

Poda. Pod. . . . . Insecta Musæi Gracensis. Græcii, 1761. 8vo.

Pontoppidan. Pont. - Kurzgefasste nachrichten die Naturhistorie in Daunemark betreffend. Aus dem Danischen ubersetzt. Kopenhagen und Hamburg, 1795, 4 to.

Posselt. Poss. - . - Beytrage zur anatomie der Insecten Tubingen, 1804. 4to.

Preysler. Preys. . . Verzeichniss Böhmischer Insecten. Pragæ, 1790. 4to.

Ram Donr. Ramd. . . Abhandlung über die Verdaungswerkzeuge der Insecten. Halle, 1811. 4 to.

RaY. Rai. . . . . Historia Insectorum. Londini, 1740. 4to.

Reaunur. Reaum. . . Memoires pour servir a l'Histoire des Insectes. 6 tom. Paris, 173442. 4to.

Röse L. Rös. . . . . Insecten belustigung. 4 tom. Nurnberg, 1746. 4 to.

Rossi. Ross. . . . Fauna Etrusca, sistens insecta, quæ in provinciis Florentina et Pisana, See Hellwig. prasertim collegit P. R. Liburni, 1790. 8vo.

Sabine. (Capt. Edward) An account of the animals seen by the late Northern Expedition whilst Sab. E. . . . $\}$ within the Arctic Circle, being No. 10 of the Appendix to Capt. Parry's Voyage of Discovery. London, 1821. 4to.

Salnt FargeaU. St. Farg. Monographia Tenthredinetarum Synonymia Extricata. Parisiis, 1823. 8 vo.

Samovelle. Sam. . . Entomologist's useful Compendium. London, 1819. 8vo.

" . . . . Nomenclature of British Entomology alphabetically arranged. London, 1819. 8vo.

$\mathrm{S}_{\mathrm{AY}}$. . . . . . American Entomology, or a description of the Insects of North America, illustrated by coloured figures. 2 vols. Pliladelphia, 1824-28. 8 vo.

" . . . . . Transactions of the American Philosophical Society. New Series. 8vo.
" . . . . Journal of the Academy of Natural Sciences, Philadelphia.

SchæfFer. Schæff. - . Elementa Entomologica. Regensberg, 1766. 4to.

Schaller. Schall. . Abhandlungen der Halleschen naturfurshenden gesellschaft. Dessau und Leipzig, 1782. 8 vo. 
Scueldenberg. Schell. Cimicum in Helvetia aquis et terris degentium genus in Familias redactum. Turici, 1800. 8vo.

" . . . Genres de Mouches Diptères. Zurich, 1803. 8 vo.

Scumedens. Schmiedl. Enleitung in die Insectenlehr. Leipzig, 1786. 8vo.

Scrixerner. Schneid. - Systematische Beschreibung der Europaischen Schmetterlinge Halle. 1787. 8ro.

Neuestes Magazin für die Leibhaberder der Entomologic. 5 heftes. Stralsund, 1791-94. 8vo.

Scuösiterk. Schön. . . Synonymia insectorum, oder versuch ciner synonymie aller bisher bekannten insecten. 3 tom. Stockholm, 1806-17. 8vo.

Curculionidum Dispositio methodica, cum generum characteribus, descriptionibus, atque observationibus variis, \&c. Lipsia, 1826. 8 vo.

Scuraxk. . . . . . Enumeratio insectorum Austria indigenarum. Augusta Vindelicorum, 1781. 8vo.

Fauna Boica. Durchegedachte, geschichte der in Bajern einheimisclıen und zamen thiere. Nurnberg, 1798. 8vo.

Scineber. Schreb. . . Novæ Species insectorum. Halæ Magdeburgix, 1759. 410.

Sciwartz. Schw. . . Neuer Raupenkalender. Nurnberg, 1791. Sro.

Nomenclator uber in den Röselschen insecten belustigungen und kleemanschen beitragen zur insecten-geschichte, \&c. Kafer. Nurnberg, 1793. 4to.

Scuwenck feed. Schwenck. Theriotrophium Silesia, in quo animalium, h. e. quadrupedum, reptilium, avium, piscium, insectorum natura, vis, usus, sex libris perstringuntur. Lignicii, 1603. 4to.

Scopolr. Scop. . . . Entomologia Carniolica, exhibens insecta Carniolia indigena, et distributa in Ordines, Genera, Species, Varietates, methodo Linneano. Vindobanx, 1763. 8vo.

" . . . . . Annus Historico-Naturalis quartus. Lipsia, 1770. $12 \mathrm{mo.}$

Scriba. Scrib. . . . . Journal fur die lieb-haber der Entomologie. Frankfurt, 1790. 8vo.

" . . . . . Beytrage zu der Insecten geschichicte herausgegeben. Frankfurt, 1790 -93. 4to.

SEBA. Seb. . . . Thesaurus locupletissimus rerum naturalium, tom. 4. Anstelodami, 1734. fol.

Seliguanx. Selig. . . Aves. Norimbergæ, 1749-50. fol.

SEPP. . . . . . Beschouwing der wonderen Gods in de minstgeachtte scheprelen of $N e$ derlandsche Insecten. 3 tom. Amsterdam, 1742. 4 to.

Sudw. . . . . . General Zoology. 6 vols. nsects. London, 1806.

Syiтn Sir. J. E. . . . Natural History of the rarer Lepidopterous insects of Georgia including their systematic characters, the particulars of their several metamorphoses, and the plants on which they feed, collected from the observations of Mr. John Abbott, many years resident in that country. 2 vols. London, 1797. fol. 
xxxviii

Spinola. Spin.

Stepuens. Steph.

,

Stewart. Stew.

Stoll.

Stroem. Stro.

Sturm.

,

"

Sulzer. Sulz.

Swammerdam. Swamm.

Thunberg. Thunb.

,

,

Transactions. Trans.

Uddman. Udd. . .

VIEWEg. View. .

VILLERS. Vill. . . .

Voet.

\section{LIST OF AUTHORS QUOTED.}

Insectorum Liguria species novæ aut rariores, tom. 2. Francofurti ad Mœnum, 1809. 4to.

Illustrations of British Entomology. Mandibulata Haustellata. 10 vols. 1827-1837. 8vo.

A systematic Catalogue of British insects, being an attempt to arrange all the hitherto discovered indigenous insects, in accordance with their natural affinities, \&c. London, 1829. 8vo.

Elements of the Natural History of the Animal Kingdom, being an introduction to the Systema Naturæ of Linnæus. London and Edinburgh, 1802. 8 vo.

Cigales et Panaises qui se trouvent dans les quatre parties du monde, l'Europe, l'Asie, l'Afrique, l'Amerique. Amsterdam, 1788. 4to.

Physik og œconomisk beskrivelse over fogderiet söndmor beliggende i Bergens stift i Norge. 2 tom. Soroë, 1762-66. 4 to.

Insecten Cabinet nach dur natur geseichnet und gastochen. Nürnburg, 1791-92. $12 \mathrm{mo}$.

Deutschlands $F$ auna in abbildungen nach der natur mit beschreibungen. 5 tom. Nürnberg, 1805-15. $12 \mathrm{mo}$.

Catalog meiner insecten sammlung Kafer. Nürnberg, 1826. 8 vo.

Die Kennzeichen der Insecten, nach anleitung des königl. Schwed Ritters Carl. Linnæus. Zurich, 1761. 4to.

Abgekürtze Geschichte der insecten. 2 vols. Wintershur, 1776. 4 to. Biblia Naturæe, seu historia insectorum. Leyden, 1738. fol. Translated into English by Sir John Hill. London, 1758. fol.

Dissertatio entomologica sistens Insecta Suecicæ. Upsaliæ, 1784-95. 8 vo.

Musæum naturalium Academiæ Upsaliensis. Upsaliæ, 1787-1800. 4to.

Insecta Hymenoptera illustrata, pars 1, Ichneumonides, Memoires de l'Academie imperiale des sciences de St. Petersbourg, 1822. 4 to.

Of the Entomological Society of London. London, 1807-10. 8vo.

Novæ Insectorum Species. Diss. Præs. Joh. Leche. Resp. Is. Uddman. Aboæ, 1753. 4 to.

Tabellarisches Verzeichniss in der Churmark Brandenburg einheimischen Schmetterlinge. 2 heft. Berlin, 1789-90. 4to.

Caroli Linnæi Entomologia Faunæ Suecicæ descriptionibus aucta D.D. Scopoli, Geoffroy, De Geer, Fabricii, Schrank, \&c. speciebus vel in systemate non enumeratis, vel nuperrime detectis, vel speciebus Gallia australis locupletata, generum specierumque rariorum iconibus illustrata. tom 4. Lugduni, 1789. 8 vo.

Descriptiones et icones Coleopterorum. 4 to.

lcones insectorum Coleopterorum synonymis commentarioque perpetuo illustravit D. G. W. F. Panzer. Erlangæ, 1794. 4to. 
WaGNer. Wagn. . . Historia naturalis Helvetia curiosa. 'Tiguri, 1680. 12 mo.

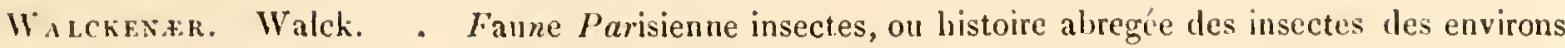
de Paris. 2 tom. Paris, 1802. 8vo.

WuBR. Web. . . . Observationes Entomologicœ continentes novorum qua condidit generum characteres, et nuper detectarum specierum discriptiones. Kiel, 1801. 8vo.

Wienfmax. Wied. . Zoologisches Magazin herausgegeben, vol. 2. Altona, 1818-23. 8vo. " . . . Diptera Exotica. Pars. 1. Kilia, 1821. 12 mo.

Wifnn. Wienn. . . Systematische verseichniss der Schmetterlinge der W"ienergegend. Wien. 1776. 4to.

Elitio altera cura Illigeri. Brunsvici, 1801. 8vo.

Wrikes. . . . . . Twelve new designs of English Butterflies. London, 1742. 4 to.

One hundred and twenty plates of English Moths and Butterfies. London, 1773. 4to. 



\section{NORTHERN ZOOLOGY.}

PART IV.

I N S E C T A.

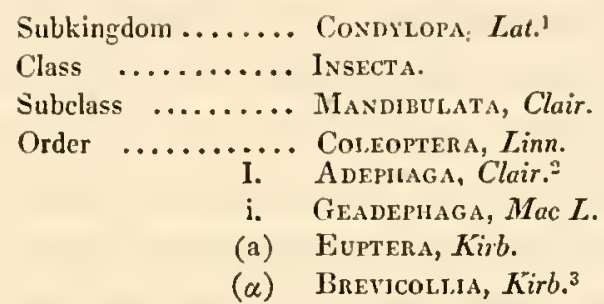

THERE is one circumstance which I may mention in this place, distinguishing the majority of the tribes of this section-Adephaga ${ }^{4}$ and found also in some conterminous ones, as the Staphylinida and Silphide-which demands particular attention, since it has been used as a distinctive character of sereral of its groups : I allude to the dilatation of the anterior, and in several cases also of the intermediate, tarsus, in the males. But though Entomologists have paid some attention to this circumstance, they appear to have gone little further, and have not made all the use that they might have done, with advantage to the science, of the sexual distinctions observable in this part of these animals; for they have taken little or no notice of the rariations in the clothing of the sole or underside of these dilated joints; speaking of it generally, except in the case of male Dytiscide, mercly as a brush. Latreille, indeed, in his last work, ${ }^{5}$ mentions papillae as well as brushes,

1 I.at. Cours D'Ent. i, 18. These are the Annulosa of modern Zoologists. For my reasons for adopting Latreille's term in preference, sce my Bridgewater Treatise, ii, 17.

= I have not adopted, on the present occasion, the plrascology proposed in the Introduction to Entomology, (rol iv, p. 393) to distinguish the different subdivisions into which each section of an Order is resolvable, in descending to the families and genera, because $J$ have not the mcans of applying it universally, or of making such a valuation of each as will indicate at once the denomination to which it is entitled.

3 I consider the Euptera as forming three subtribes-riz. Longicollia (Colliuris,) Brevicollia (Cicindela) and Fissicollia (Manticora.) 
but seems not to have examined them very closely, and to have acquired no very precise idea of their nature. I shall, therefore, under the present head, enlarge a little upon this subject.

The Predaceous Beetles, considered with respect to this circumstance, are of three descriptions. 1. Those that exhibit no such distinction. 2. Those that have only the anterior tarsi or hands dilated. " 3 . Those that have the two anterior pair so circumstanced.

1. This sexual character, though very general, is not universal in the Adephaga. In the Cicindelidans the dilatation, though existing, is less conspicuous; in the Colliuridans the tarsi in botl sexes are dilated, so that in them it is no sexual distinction; and the same circumstance occurs in the Longicollia-Agra, Casnonia, \&c. amongst Latreille's Truncatipennes (Brachinidce Mac Leay); in the Manticoridans, and the Bipartiti Latr. (Scaritida Mac Leay) and likewise in some of the Truncatipennes, as Lebia, Dromia, and in some Carabidans, as Procerus, there is no dilatation in either sex; and amongst the Hydradephaga Mac Leay, the sexes of Haliplus seem very slightly distinguished in this respect.

2. The majority of the Geadephaga have only the anterior tarsus or hand of the male dilated, and may be distinguished, with regard to this circumstance, by the name of Dimani; some of the Truncatipennes have only the posterior side of the joints dilated, this is the case with Anthia, Galerita, \&c. but, more generally, both sides of the three or four first joints are so circumstanced; in the Hydradephaga, only in Hydaticus and Acilius, this character is restricted to the hand.

3. Amongst the Geadephaga, Latreille's Quadrimani-Harpalus, Ophonus, Stenolophus, \&c.- - have the joints of the four anterior tarsi dilated, but amongst the Hydradephaga this character is to be found in the majority.

The next circumstance, that calls for our attention, is the number of these dilated joints, for they vary in different tribes and genera. Thus the Peryphide have the first joint only of the hand dilated; the Bembidiade the first and the posterior side of the second; Patrobus, Pogonus, \&c. the two first; but the most common, or what may be called the typical structure in this respect, is that in which the three first joints are dilated; this obtains in the Cicindelidae, Calosoma, and the great majority of the Eutrecha, even in those that have the four anterior tarsi dilated; in the Hydradephaga the same number prevails; in the Carabidans and Trechus, \&c. four joints are dilated.

The most important circumstance, however, connected with the present subject 
is the lining that covers the sole of these dilated tarsi, or the kind of foot-cushions with which they are furnished. These are of three descriptions.

1. A dense brush of stiff hairs. This is to be found in the Cicindelidans, the Carabidans, and the Chlaniadans; insects so furnished may be denominated Sarrothropoda. I have noticed no particular variations of this kind of footcushion; in the last mentioned tribe, however, the Chlceniadans, the brushes are broader, the consequence of the greater dilatation of the joints, than in the other Sarrothropodous Geadephaga.

2. The next kind of foot-cushions are formed of little membranous vesicles or cysts, which are arranged in various ways in different tribes. In some, as Helluo costatus, the hand is furnished with a compound cushion, there bcing a brush on each side, and in the middle a line formed of short transverse rows of vesicles; in Anthia the dilated side of the joint only has a line of vesicles included between lateral brushes; in Brachinus and many others is a double oblique series of vesicles on each joint; in Agonum these vesicles are imbricated lying one upon another; in sone, as in Harpalus interpunctatus of this catalogue, these little organs are arranged without order, and cover the whole joint. In this respect this species differs from the other Harpali, in which the vesicles are arranged nearly as in Brachinus. The insects that have this kind of foot-cushion may from it be named Cystopoda.

3. The third description of foot-cushions is when they are formed of pedunculated cups or suckers, as in several of the Hydradephaga, particularly Dytiscus, in whose hands may be seen two larger umbilicated cups with an infinity of minute ones, which I have elsewhere described. ${ }^{6}$ These may be named Pyxidiopoda. The great object of all these formations is to enable the male to fix himself firmly in coitu, which is probably done by producing a vacuum, for which at least the cysts and cups seem particularly fitted, ${ }^{7}$ and they may be rendered useful in tracing the affinities of the different groups of the Section, as will appear under another head.

Geadephaga. Numerous, and seemingly inextricable, difficulties stand in the way of a perfectly natural arrangement of this vast group, which includes the whole of the Terrestrial Predaceous Beetles, for the Systematic Entomologist feels quite at a loss, when he asks himself by which path shall I next proceed: 'Though 
its typical Tribe, the Euptera offer no very material obstacle to the accomplishment of his purpose, a number of rival forms next present themselves, each preferring seemingly well founded claims to guide him towards a natural arrangement. Under the present head, perhaps, it may be useful to discuss this subject, a clear iusight into which will prove, that it is not at all wonderful that Entomologists have adopted different methods of arrangement, and that each, is in some degree right. It may first be asked-what is that Typical Form, from which, led by nature, in an attempt to arrange the insects of the present Order, we must set off, as from a common centre or summit, round which all, as it were, revolve, and towards which all tend? This is a question, even in the present advanced state of the science, difficult to answer; for we have beetles before us of vast bulk and strength, elephants in the class of insects, but which are distinguished neither by the swiftness of their motion nor by the elegance and beauty of their forms; others we have, less clumsy indeed and gigantic, but remarkable for the perfection and symmetry of their general structure; the lightness and velocity of their motions both on the earth and in the air; and for the splendour and brilliance of their colours. Such, with only one or two exceptions, are the Euptera or Tiger Beetles. Amongst the higher animals, the Lion, chief of the Predaceous Quadrupeds, is usually accounted as the king of beasts; a similar reason will justify modern Entomologists for regarding the above tribe of beetles as the typical and most perfect form amongst insects, especially Coleoptera, instead of the Lamellicorn beetles, which Linné had elevated to that rank.

Having selected a typical or central tribe, let us next consider its composition. As far as at present known, it is composed of three principal groups. One remarkable for its long cylindrical neck and slender body, and for having all the tarsi of both sexes dilated and furnished with a brush, the penultimate joint terminating in a single lobe, the type of which is Colliuris longicollis; another with a short depressed neck, a stouter body, slender tarsi, with only the three first joints of the hand of the males slightly dilated, and covered underneath with a brush, and the penultimate joint not lobed, the type of which is Cicindela campestris; a third, removed to a vast distance from the preceding ones both in its aspect and many of its characters: in the former and its colour, which is a dismal black, resembling Latreilles Melasomes; as to the latter, though the claw of its maxillæ articulates with the lobe, and the mandibles are armed by long and threatening teeth as in Cicindela, yet having a neck or prothorax, like that which distinguishes the males in Anthia, bilobed behind; having the surface of the elytra plane with it 
very large Epiplenra; having no wings, and the hand of the male not heing dilated nor furnished with a brnsh. The type of this sombre tribe is Manticora Gigas. From this statement it appears that in this Tribe, as at present known, there is no circular arrangement, it may be rather said to form a semicircle, beginning with the Colliuridans, passing from them by the narrow Cicindelidans to the type, and thence proceeding by Megacephala and the dark-coloured Cicindelidans towards Manticora with which the semicircle terminates at its lower extremity. 'To complete the circle it will be necessary to cast an eye over the other branch of the Geadephaga, the Eutrecha, and endeavour to discover which, anongst its different tribes, will best supply us with the means of doing it. Our eye probably night first be canght by the gigantic Anthice, and immediately we should be strnck by a considerable resemblance between these, especially the males, and Manticora, and by a closer examination be convinced that they approached each other in the line of affinities; having found a link that connects with one end of our semicircle, we shonld next look round for some slender long-necked form to place next the other, and we should soon discover a group, consisting of several gencra, in the same tribe with Anthia, that exhibited a most remarkable resemblance to the $\mathrm{Col}$ liuridans; upon inspecting these more nearly we should select Agra as almost the counterpart of Colliuris, comparing the head, the neck, the elytra, and especially the tarsi, we should find them all formed upon the same plan, except that in Colliuris the penultimate joint of the latter has only one lobe, which in Agra is bilobed, and feel a strong conviction, that this agrecment in structure was not merely an analogical resemblance, ${ }^{8}$ but an indication of close affinity. If we next look for some middle form, which, like Cicindela campestris, may be regarded as ncarly equidistant from the two extremes, perhaps no better known genus could be selected than Calleida of De Jean, which, in colonr, is almost as brilliant as a Cicindela; and, in form, may be regarded as nearly the mean of the semicircle of Truncipennia to which it belongs. This is the present aspect of the central group and of the tribe which appears most nearly connected with it; but to what alterations future discoveries may open a door I will not presume to conjecture. It would be rash to affirm that insects may not be found to complete a separate circle both of Euptera and Truncipennia, but the above arrangement scens to follow from our present knowledge of them.

S Mr. W. S. Mae Leay (Annulos. Javan. 8) seems to regard these as only analogical characters, but the points of agreement are too numerous for any thing but affinity. The agreement of these two genera in having all the tarsi of both sexes dilated, and furnisbed witb a brush, with the penultimate joints lobed, is alone a suflicient proof. 
I shall next proceed to state the result of my investigation with regard to affinities observable between other tribes of the Euptera and the Eutrecha. Mr. W.S.Mac Leay, in his arrangement, places Elaphrus next to the Cicindelidans, ${ }^{9}$ and its claims to affinity with them can scarcely be doubted; but when we turn onr attention to one of the Elaphridans described in this catalogue, Opisthius Richardsoni, we find that the tribe is also connected by aftinity with the Subulipalpi of Latreille, as Bembilium, \&c. a further confirmation of this may be derived from an inspection of Ocydromus flavipes (Bembidium Steph.) which though clearly one of the tribe last mentioned, is as clearly related to Elaphrus. It is evident therefore that, by the Elaphridans, the Cicindelidans are connected with the Subulipalpi, which I cannot agree with Mr. Mac Leay in regarding as belonging to the Harpalide; the Acutipalpi (Trechus and affinities) Subulipalpi and Elaphridae appear to me to form a distinct tribe, consisting of Eutrecha delighting in humid places and constituting an intermediate or transition group (or perhaps a minor section which might be named Hygradephaga) usually consisting of small insects between the Greadephaga, or terrestrial, and the Hydradephaga, or aquatic, Predaceons Beetles. Here then we have a second series connected with Cicindela.

Mr. Mac Leay considers the Carabidans as near in affinity to the Cicindelidans, nor am I disposed to deny that they make an approach towards them; for the males of both are Sarrothropodous, the nearest approximation to Cicindela that these make, as far as I have had an opportunity of examining the family, is by Carabus splendens Oliv. ${ }^{1}$ but this is still at a great distance and many forms are wanted to fill up the interval. The Carabidans go off one way towards the Cystipodous Dimani by the Chloeniadans and so proceed to the Quadrimani, from which we may enter the osculant group of Elapliridans, \&c. by Stenolophus which connects my Harpalidans with Trechus, \&c.

Thus we have three distinct tribes that branch from the typical group, but we seem to find nothing amongst the Bipartiti of Latreille to tend towards them, unless we may suppose Oxygnathus De Jean, and some of the other Scaritidans, to be connected with it by their mandibles. A circumstance however has been related of the larva of Aristus bucephalus which indicates some affinity between it and that of Cicindela; we are told it has the same habits and form, ${ }^{2}$ but to look at the perfect insects, we see little resemblance, except an approach in the form of the thorax

3 Annulos. Javan. 8.

I This insect is synonymous with that mentioned in the Introd. to Ent. (iv, 506, note) under the name of C. lavigatus.

N. D'H. N. ix, 510. Article Ditomus. 
to that of Manticora. Intervening forms may hereafter be fonnd, which may connect it with that genus, which itself, in some respects, has the aspect of one of the Bipartiti, or Scaritide Mac Leay.

From the above statement I trust it will appear evident that almost all the different tribes of Geadephaga immediately connect with the Typical Gronp, or branch from it, and that it is impossible to describe them in the order in which they are arranged by nature, and that, therefore, the different authors who have written upon them are all correct in their views, thongh they have taken different routes in departing from the central station. 'Thus Latreille, De Jean, and Stephens, are right when they assume the 'Truncipennia as an evident aftinity; and Mr. Mac Leay'also in going off by Elaphrus and Carabus and returning by the Brachinidae and Anthia.

Under the present head I may further observe with regard to the sculpture of the elytra of the present sub-section, that, with the exception of Manticora and Omophron, at least as far as an extensive examination cnables me to decide, they all, if viewed under a very porrerful magnifier, appear to consist of a most minutely and beautifully reticulated substance, chagrined, as it were, with innumerable granules. In some, as Harpalus carbonarius, the Bembidiadans, \&c. this circumstance is more conspicuous than in others, and it gives these animals a silky appearance; though most visible in the elytra, it may commonly be discovered in the head and prothorax. In the Hydradephaga it is most visible in the Gyrinidans. It is not however confined to the Predaceous Beetles, since it may be discorered in the Buprestidans and many other Coleopterous insects.

I shall here also observe once for all, that in all the Eutrecha, or Ground Beetles, that have a notch in their Cubit, with the exception of those whose elytra are distinguished by elevated ridges, as Anthia, Brachinus, and some others, near the margin of the elytra, where they are striated or furrowed, on the eighth furrow from the suture, or in the interval between it and the ninth, is usually a series of from twelve to thirty or more ocellated impressions, or impressions with an eleration in their centre, placed at various intervals, and sometimes only at the base and apex of the elytrum; those that have no notch in the cubit have usually no appearance of this kind, but in Cicindela these impressions, but without the central clevation, may be traced. The typical number of furrows, in the Ground Beetles is nine, but in Omophron, Calosoma Sycophanta and some others there are fifteen. 


\section{Family CICINDELIDE. Cicindelidans.}

I. Genus CICINDELA. Linn. ${ }^{1}$

* Labrum unidentate.

\section{Cicindela hirticollis. (Say.) Hairy-necked Cicindela.}

Cicindela birticollis. Say. Amer. Trans. N. S. i, 411, 2, t. xiii, f. 2.

Length of the hody $6 \frac{3}{4}$ lines.

\section{Locality not stated.}

DESCRIPTION.

This species not a little resembles C. hybrida, but the labrum is prominent in the middle, and more conspicuously unidendate; the colour of its upper surface is browner with less of a purple tint; the prothorax is rather more hairy; the lateral margin of the elytra is white, from which proceed five white branches; the two first forming a humeral crescent with the lower limb bending obliquely towards the base of the elytrum, the third becoming a broken or S-shaped band, the extremity of which nearly reaches the suture; and the two last, forming a crescent at the apex of the elytrum, to produce which the whiteness of the margin is subinterrupted: the suture terminates in a minute point, and the apex of the elytra is serrulate. Underneath the body is green or goldengrecn, with the sides rather more thickly covered with snowy hairs than in the other species of the genus.

N. B. In the male the S-shaped band is interrupted.

1 The larva of this genus, as well as that of Aristus, lies in wait for its prey, suspended by its dorsal hooks, in a little burrow it has formed. Its body is depressed. Its head corneous with eight eyes, the two external or lower ones being very minute. The plates that corcr the trunk are coriaceous. The abdomen is fleshy, armed on its back with a pair of suspension-hooks. It has no anal processes. In many respects it exbibits an analogy both with spiders and the larva of the ant-lion.

Our present acquaintance with the species of this splendid genus is not so intimate as might be expected, since we bare not yet attained to such a knowledge of them as will enable the Entomologist to distinguish with certainty the species from the mere variety. Count De Jean (Species Général des Coléoptères, i, and Supplement to ii) has described 144 species of the genus as now restricted; but whoever looks at his specific characters will perceive that, in general, they are taken from the white spots or bands of the elytra. These by no means, however, afford a certain and constant diagnostic. For instance, one individual confessedly of the same species, will have a white humeral crescent, an angular or broken discoidal band, with a terminal crescent, all extremely well defined. Another will exhibit the same characters, but become less distinct, and morc faintly traced; in a third the humeral and terminal crescents of the elytra will have each become two distinct spots; which in a fourth will altogether disappear ; lastly in a fifth, to name no more variations, the discoidal band will be almost, as it were, unbent. So that, in some spccies, without the aid of other characters, these markings of the elytra will often be insufficient. 


\section{Cicindela repanda. (De Jean.) Wam Cicindela.}

Cieindelu repanda. De .J. Coléopt. i. 74?

Length of the boly $5 \frac{1}{1}-6$ lines.

Lociality not stated.

\section{DESCMIPTON.}

Very like the preceding species, but the labrum is shorter and less prominent in the middle; the lateral margin of the elytra is not continuously white; the lower limb of the bumeral erescent slopes towards the apex of the elytrum; the broken or S-shaped band terminates in a streak at the margin: all the markings also of the elytra are buff-coloured rather than white; and the minute mucro or point that terminates the suture, and the serrulations of the apex of the elytra, are less conspicuous.

De Jean regards this species as synonymous with $C$. hirticollis, but, if I am correct in my reference to him, of which I have little doubt, they are elearly distinet.

\section{Cicindela Proteus. Proteus Cicindela.}

C. (Proleus) labro unidentato medio subprominulo, supra fusco-cuprea, elytris punctis quatuor, fasciaque media fracta, albis. Proteus Cieindela, with the labrum unidentate, rather prominent in the middle; above brown-eopper, elytra with four white dots and a mesul broken white band.

Length of the body $5 \frac{3}{4}$ lines.

This species, of which several specimens were taken in the Expedition, appears to abound in North America. Dr. Bigsby met with it in Canada, and there was a specimen in the late Mr. Marshan's collection probably from the United States.

DESCRIPTION.

Similar to C. repanda, but instead of the humeral and terminal erescents, in all the varieties, are four white dots, two at the base and two at the apex of the elytra; the middle broken or tortuous hand resembles the figure 7 reversed, and does not terminate in a marginal streak. The body underneath, as usual, is golden-green, or green with clouds of blue, above it is dark brown with a tint of copper.

VARIETY. B. With the apical dots not larger than the humeral.

C. Witl an interrupted creseent at the apex.

D. With three apieal and two humeral dots; intermediate band intemally abbreviated.

E. Like the last but with only one humeral dot. 
** Labrum tridentate.

\section{Cicindela obliquata. (De Jean.) Oblique-marked Cicindela.}

Cieindela obliquata. De J. Coléopt. i, 72.

Length of the body $6 \frac{1}{4}-7 \frac{1}{4}$ lines.

Many taken in the Expedition, and apparently abundant in N. America. I received it many years since, but without a name, from my lamented friend Professor Peck.

DESCRIPTION.

Body above greenish-copper, underneath golden-green clouded with hlue. Labrum white, tridendate slightly prominent in the middle; mandibles white at the base, black at the tip; palpi black; labial with the intermediate joint rufous, darker at the tip. Elytra with a large white humeral creseent, extended at the lower end obliquely beyond their middle ; mesal band bent downwards, recurved at the end, and connected by a marginal line with a crescent at the apex.

In the male the intermediate joint of the labial palpi is white, and the mesal band is not connected with the terminal crescent.

5. Cicindela vulgaris. (Say.) Commou Cicindelu.

Cicindela vulgaris. Say. Amer. Trans. $N$. S. i, 409, 1, t. i, f. 1 . obliquata. De J. Coléopt. i, 72, 56; ii, Suppl. 414, 56.

Length of the body $6 \frac{3}{4}-7 \frac{1}{2}$ lines.

A common species in all N. America.

DESCRIPTION.

Very nearly related to $C$. obliquata and regarded by Count De Jean as synonymous with it. They differ however in the following particulars. In C. vulgaris the upper surface of the body is nearly black, without any tint of bronzed-green. The bumeral erescent of the elytra is slenderer, and its lower extremity does not approach so near the mesal band. In the females the intermediate joint of the labial palpi is black. In the males the underside of the body, with the exeeption of the anus, is of a fine blue instead of a golden-green. 
Cieindela purpurea. Oliv. Ent. ii, n. 33, 11 ; . iii, f. 34. Schön. Synn. i, 240, 14. De J. Cat. 1. Say. Amer. Trans. N. S. i, 449,8 ; t. xiii, f. 8 .

Cicindela marginalis. Fub. Syst. Eleuth. i, 240, 43. De J. Coliopt. i, 55, 39.

Length of the body $7-7 \frac{1}{2}$ lincs.

Several varieties of this beautiful species were collected in the Expedition, but the finest specimen I have seen was taken in Canada by Capt. Sheppard, F.L.s. of his Majesty's Royal Regiment of Artillery. I have also received it from various other parts of. North America. The green varieties of this species scem to be the American representatives of $C$. campestris so common in England and all Europe. As this species varies greatly, I shall take my deseription from Capt. Sheppard's specimen, which may be regarded as the most perfect type of the species.

\section{DESCRIPTION.}

운

Body underneath with the trunk resplendent with green, gold, and copper,--abdomen, with the exception of the green anal segment, blue; above purple with the base and apex of the prothorax green; the suture of the elytra is also green, and adjoining to the lateral margin is a blue and green longitudinal stripe; at the base of the elytra is a humeral dot, a little before the middle near the margin a round spot, in the middle a bent band, below this another round spot, and at the apex a triangular one, all pale buff-coloured and distinctly marked.

VARIET: B. 3 . In this the spots and band of the elytra are the same in number and situation, but not so broadly traced as in $\Lambda$. The liumeral dot is also larger than the marginal one between it and the band. Taken in Canada by Dr. Bigsby.

C. F. Latcral stripe of the elytra all green; spotted as in B, but the humeral spot is of the same size as the succeeding one. In Mr. Marsham's collections.

D. + . Elytra without the humeral and first marginal spots; the other spots as in variety $\mathrm{B}$, except that the band does not approach the lateral margin.

E. $\delta$. + . Elytra with a discoidal oblique and apical transverse streak. Taken in the expedition, and in New England, by Professor Peck.

F. ․ Elytra purple tinted with green, lateral stripe blue and green; discoidal band siunated; no bumeral or marginal spots: apical as in the type. Taken in Canada by Dr. Bigsby.

G. \&. Elytra entirely green, spotted like variety D.

H. ठ̊. + . Elytra green with a blue marginal stripe, spotted like variety E. Taken in the Expedition, and in New Jersey by Mr. Drake.

The transition from the fully characterized type of the present species to those varieties with only two spots, and from them, by means of variety F, to those with green elytra, is so gradual as to convince any careful inspector of them, that all belong to one species: yet a person who had never examined the intermediate varieties would seemingly have good reason for considering them as forming, at least, tliree distinct ones. 
C. (albilabris) labro albo obsolete tridentato, medio prominulo; supra purpurascenti-nigra: elytris excavato-punctatis : guttis tribus marginalibus fasciaque fracta discoidali, albis.

White-lipped Cicindela, with the labrum white, obsoletely tridendate, rather prominent in the middle; elytra broadly punctured with three marginal dots and a broken discoidal band, all white.

PLATE I. FIG. 1 .

Length of the body $6-6 \frac{1}{2}$ lines.

Taken in Lat. $64^{\circ}$, and also in Canada by Dr. Bigsby.

DESCRIPTION.

$\delta$

Body underneath green or golden-green clouded with blue; above black with a purplish tint: labrum white, prominent, armed in the middle with three short tecth, the lateral ones obtuse; above with an intermediate obtuse longitudinal ridge: elytra, under a powerful magnifier, covered with innumerable minute granules, and also with numerous shallow impressions, a series of larger ones is parallel with the suture; the angular white discoidal band reaches neither the suture nor the lateral margin; there are also three marginal white dots, one humeral, another between it and the band, and one between the latter and the apex.

VARIETy. B. ס. Body underneath blue, anus green; above black with the spots of the elytra buff-coloured.

C. ठ. Body underneath as in B: elytra with only two marginal dots, the band and apical dot almost obliterated, the humeral dot distinct.

D. + . Body underneath blue with a black anus: elytra with no marginal white dots; band replaced by a faint streak and dot. Plate I. Fig. 1. + .

This species, though apparently common in North America, is not noticed by Say, who perhaps mistook it for $C$. sylvatica Linn. of which it may be regarded as the American representative, and with which it agrees in its prominent upper lip, and the shallow impressions and markings of its elytra, as well as nearly in its general colour. But besides its smaller size, it differs from it materially in having a white instead of a black upper lip with an obtuse longitudinal ridge and not an acute one, terminating in three almost obsolete short teeth instead of a single longer one; and likewise by the want of the silky lustre produced by granulations much more visible, which distinguishes the elytra of C. sylvatica. 
(b) Eutracus. Kirb.

(a) Truscupennis. Trirb.

Family AGRIDE. Agridans.

II. Genus CASNONIA. lat.

\section{Cassonia pesserbvanica. (De Jean.) Pemmyluamin Casmomia.}

Casnonia pennsylranica. De J. Coléopt. i, 171.

Attclabus pensylvanicus. Linn. Syst. Nat. i, 620, 5. Fab. Syst. Eleuth. ii, 418, 7.

Ophionea pensylvanica. Klug. Ent. Bras. 24, 1.

Odacanthri pensylvanica. Herbst. Ins. x, 2:21, 2 t. clxxiii, f. 12.

Agra pensylvanica. Lat. Gen. i, 196, 3, t. vii, $f .1$.

Length of the body 3 lines.

'Two speciunens taken.

\section{DESCRIPIION.}

Body black. Head lozenge-shaped, elongated posteriorly, as in irapleidia, which gives the animal somewhat of a serpentine aspect, and commected with the prothorax by a rather long neek: antenne rufous at the base: prothorax fusiform, widest posteriorly, having on each side an oblique basilar furrow: clytra testaeeous with two black bands, one in the middle and the other near the apex, which unite at the lateral margin; their anterior half is striated with punetures: the legs are testaceous, penultimate joint of the tarsi bipartite with very slender lobes. ${ }^{2}$

\section{Family LEBIAD王. Lebiadams.}

Genus CYMINDIS. Lat.

$$
\text { 1. * Crmindis marginatus. Margined Cymindis. }
$$

C. (marginatus) piceus, junctatissimus; antennis, ore, prothoracis lateribus explanatis, clytrorum striatorum margine laterali maculaque humerali, pedibusrque, rufis.

Margined Cymindis, piccous, thickly punctured; antenne, mouth, dilated sides of the protborax, hateral margin and shoulders of the striated elytra, and leys, rufous.

Length of the body $1 \frac{11}{2}$ lines.

One specimen of this insect was taken in the ronte from New York to Cumberland-house, and the other in Lat. $65^{\circ}$. It is nearly related to C. pubescens of De Jean, ${ }^{3}$ but it appears distinct.

- De Jeun (Ubi. Supr. i, 170) says that the penultimate joints of the tarsus is filiform, but it is really bipartite, though the lobes into which it is divided are very slender.

3 Spec. Génér. des Coléopt. i, 215, 16. 


\section{DESCRIPTION.}

Boly depressed and flat, as in its congeners, piceous; above densely punctured: mouth rufous : antennæ longer than the prothorax, piceo-rufous: front between the eyes transversely wrinkled: prothorax convex, with a longitudinal channel; lateral margin dilated, reflexed, and rufous: clytra striated or slightly furrowed, with the furrows and their interstices punctured; viewed on one side they appear hairy with upright ferruginous hairs; their shoulders and lateral margin are obscurely rufous; their apex oblıquely truncated, and subemarginate: the legs are rufous.

Variety. B. Piceo-rufous; elytra concolorate.

\section{2. * Cymindis unicolor. Unicolorate Cymindis.}

C.' (unicolar) punctatissimus fernugineus: pedibus dilutioribus; prothoracis margine haud explanato.

Unicolorate Cymindis, thickly punctured, ferruginous; legs paler; lareral margin of the thorax not dilated.

Length of the body $3 \frac{1}{2}$ lines.

One specimen only taken.

DESCRIPTION.

This species greatly resembles variety $\mathbf{B}$ of the preceding. It is however smaller and paler; the prothorax has no longitudinal chamel, and its lateral margin is not dilated.

\section{Family SERICODIADAE. Sericodiadans.}

IV. * Genus SERICODA. Kirb.

Labrum transverse, subquadrangular: with the anterior angles rounded.

Mandibles acute, incurved at the apex, not toothed?

Labium ${ }^{4}$ emarginate with a minute tooth in the sinus.

Maxilla

Palpi

Maxillary five-jointed: first joint very minute, second longer than the rest, subcylindrical, attenuated at the base; third obconical; fourth as long as the third, fusiform, truncate; fifth very minnte, retractile within the fourth. 5

Labial three-jointed: joints nearly equal in length; the two first conical; the last fusiform, truncated. 6

Antenne rather incrassated toward the apex; scape incrassated; second joint the shortest, and the third rather longer than the others.

4. The labium here is synonymous with the mentum of most modern Eutomologists for reasons assigned in the Introd. to Ent. (iii, 420. 5th Ed.) 
Body depressed, narrow. Head triangular. Eycs large and prominent. Neck very little constricted. Prothorax short, chamnelled, widest anteriorly: with the angles rounded. Elytre obliquely truncated at the apex, and emarginate, so that internally they terminate in an acumen. Cubit emarginate. Tarsi with the penultimate joint entire. Clews single, not pectinatecl.

The maxillary palpi of the genus here defined present an anomaly observed in no other known colcoptcrous genus, they appear to be furnished with a minute fifth joint retractile within the fourth. In one of these palpi, in the only specimen taken, this little aceessory joint is not apparent, but in the other it is distinctly secn emerging from the fourth joint, or rather, as this last appears broken at the apex, it is uncovered. There is only one supposition that can reconcile this case to the general rule, that no coleopterous maxillary palpus shall exceed four joints, namely-that this is an effort of nature, by a reproduction, to restore the mutilated organ so as to fulfil its functions. Did the insect belong to the Crustacca or Arachnida this would be a satisfactory explanation of the anomaly, but I do not recollect any instance upon record of a genuine insect having reproduced a lost organ. I thought it possible that the palpi of other Predaceous beettes might contain a retractile joint, and this truncated apex seemed in some degree to favour the idea, but I did not succeed in my endeavours to discover one.

The above structure of the palpi, if not accidental, seems to give our little insect some affinity with the Sutulipalpi of Latreille, but its general characters and aspect appear to demand a place for it somewhere between those Truncipennia whose claws are not pectinated, and those who have those organs so armed. 1. Sericoda bembidiondes. Bembidian Sericoda.

S. (bembidioides) sublus nigra, supra nigro-renea, subsericea; prothorace sublrapezoideo, posterius bifovealo : elytris subsiriatis brevibus subinebulosis, apud suturam fovearum serie.

Bembidiun Sericoda, black underneath, above black-bronzed rather silky; prothorax subtrapezoidea], with a pair of impressions behind; elytra substriated, impunctured, somewhat elouded, with a series of impressions adjoining the suture.

PLATE I, FIG. 2.

Length of the body $3 \frac{1}{4}$ lines.

Only a single specimen taken.

Mr. Drummond, in answer to my queries with respect to this, and some others of the more remarkable insects taken in the Expedition, observes, upon reading ny description of this insect, that it agrees with one taken on the sandy shores of Lake Winnipeg in the spring of 1825, that it runs on the sands with great agility, and frequently flies when attempted to be taken. But this statement agrees so precisely with the motions of Bembidium impressum as described by Linné and Gyllenhal (see under that insect) that I suspect Mr. Drummond had his eye to it, rather than Sericoda. 


\section{DESCRIPTION.}

Body underneatl black, glossy; above the black has a brassy tint, with somewhat of the lustre of silk: head, between the eyes, marked with a short, anteriorly forked furrow : prothorax subtrapezoidal, anteriorly subemarginate, sides oblique with the margin reflexed, transversely very minutely wrinkled, with a pair of anterior excavations in the disk, posteriorly also somewhat impressed on each side : elytra longer than the head and prothorax together, slightly furrowed with impunctured furrows, obsoletely clouded; there is a series of about five shallow impressions near the suture.

\section{Family BRACHINIDE. Brachimidans.}

V. Gemus BRACHINUS. Web.

\section{Brachinus cyanipennis. ${ }^{7}$ (Say.) Blue-winged Bombardies.}

Brachinus cyanipennis. Say. Journ. III, i, 443.

Length of the body 5 lines.

Several specimens of this insect were taken in the Journey from New York to Cumberland-house, and in Lat. 54 ${ }^{\circ}$; Mr. Nuttall took it near the Missouri; and Mr. Say in great numbers near Engineer Cantonment, where they were found hybernating in the fissures of a stone-quarry; it was taken also in Canada by Dr. Bigsby.

\section{DESCRIPTION.}

This species is very closely allied to B. crepitans, common in England and all Europe, but the second and third, as well as the other joints of the antennæ are red : the principal distinction, however, is in the shape of the prothorax, which is shorter, anteriorly more dilated, and the posterior angles are more prominent: it is scarcely half the size of its compatriot B. fumans, and differs from that, and all other Brachini that I have examined, in having the thin white membrane that terminates the elytra, especially at their internal angle, much longer and more conspicuous; this membrane, which is a continuation of the hypoderma or lining of the elytra, is but just discoverable in B. crepitans; the extreme base of these organs is testaceous: the underside of the abdomen is rufo-piceous. In other characters this insect agrees with the species last named.

7 As many speeies have blue elytra this name is not sufficiently distinetive. 
Having arrived at this point, I must now retrace my steps, and starting again from another branch of the Cicindelidans (Cicindela) proceed by the Carabide.

(b) Ontusipennia. Kirb.

(a) Nobilia. Kirb.

\title{
Family CARABIDE.
}

\author{
Genus CARABUS. Limn.
}

\section{Carabus vietinghovir. (Adams.) Vietinghoff's Carabus.}

Carabus Victinghovii Ad. Mem. iii, 170, t. xii, f. 3. Fisch. Ent. Russ. i, 98, t. ix, f. 19. De J. Coléopt. ii, 61, 21.

PLATE I, FIG. 3.

Length of the body 10 lines.

\section{DESCRIPTION.}

\section{우}

Body very black and glossy. Head punctured between the cyes with confluent but not minute punctures; anterior part of the front wrinkled on each side, but the nose and upper-lip are quite smooth; the seven terminal joints of the antenna are brown: the prothorax is nearly square with the sides rounded anteriorly and the posterior angles a little prominent; it is decply channelled, transversely wrinkled in the disk, confluently but not minutely punctured on the sides; the disk also is black, but the sides exhibit shades of dark blue and green, at the margin they are of a most brilliant ruddy copper, some of the anterior punctures also appear as if gilded: the clytra are rough and as it were reticulated with longitudinal and transverse clevations, the former nearly arranged in lines which produce decp cavities; the disk is of a func decp blue, the sides grcen and the lateral margin of the same ruddy colpper as that of the prothorax. The body underncath is quite smooth in the disk, with some irregular elevations and depressions on the sides: the sides of the antepectus, or forebreast, are of a finc green; the intermediate segments have cach a pair of iupressions from which a hair emerges. This is most visible in the male.

I at first regarded this splendid insect as a new species. I thought it, indeed, very near Carabus Vietinghovii, but as it did not altogether agree either with Dr. Fisclser's figure or description, and was found in another quarter of the globe, I regarded it as distinct; but having received from my friend Mr. Hope, a Russian specimen of that insect, I find no difference sufficient to constitute a species. In that specimen the marginal gilding of the prothorax and elytra is greener with scarcely any of the ruddy hue of copper which gives such brilliance to the American specimen. It has been observel that the plants on the other side of the rocky mountains are of an Asiatic type, and the present animal, and some others I shall hereafter notice, furnish a proof that several of the insects are similarly circumstanced. 'The sculpture of the elytra of this specics is preciscly that of a Procerus, to which genus I at first referred it, but the tarsi of the male are dilated which is the character assigned to Carabus. The only specimen taken was brought over in spirits, and affords a striking proof of the excellence as well as conrenicuce of that mode of destroying and preserving bectles for 
transportation. ${ }^{8}$ It has been in my custody more than tweive months since it was taken out of the spirits, and it has never been at all mouldy, nor has it ever suffered from the attack of Acari, \&c. from which other insects preserved with it have not escaped, which leads me to conjecture that immersion in spirits, if for a sufficiently long period, renders an insect distasteful to the little devastators of our cabinets.

\section{Carabus ligatus. (Knoch.) Ligatured Carabus.}

Carabus ligatus. Germ. Ins. i, 6, 10.

carinatus. De J. Coléopt. ii, 80, 35 ?

Length of the body $7 \frac{1}{2}$ lines.

Taken in Canarla by Dr. Bigsby.

DESCRIPTION.

Body black and glossy. Head oblong, impunctured, separated from the neck by a transverse slender curving ridge forming anteriorly a deep sinus; ridge, defending the base of the antenna, conspicuous; frontal impressions long, not deep; antennæ not much longer than the prothorax: prothorax nearly square, black slightly bronzed; sides lightly punctured, lateral margin reflexed; it is faintly channelled, depressed transversely at the base, with a punctured impression on each side: elytra bronzed, subdepressed with scarcely any sinus at the apex, lateral margin reflexed and carinated : each elytrum with thirteen or fourteen rows of impressed punetures; a triple series of oblong discoidal elevations; interstices with numerous transverse linear impressions: abdomen underneath smooth with a few minute punctures on the sides.

The insect here deseribed agrees with Germar's description of Knoch's C: ligatus, but it is doubtful whether it be synonymous with C. carinatus of De Jean. In most respects, indeed, it aeeords precisely with his description, but the head is not slightly punctured, as he states his specimens to be.

\section{Genus Cílosona. Fal. \\ i. * Subgenus. Ciirysostigxa.}

Calosoma. Maxillary Palpi with the last joint of the length of the last but one. Elytra gilded.

Chrysostigma. Maxillary Palpi with the last joint shorter than the last but one. Elytra obscure with gilded punctiform impressions.

The Genus Calosoma clearly admits of being divided into two families. The first, which I regard as the typical family, including $C$. Sycophanta and $C$. Scrutator, distinguished by the golden splendor of its whole upper surfaee, and by having the last joint of the maxillary palpi of the same length with the preceding one; and the other, including the rest of the known species, not remarkable for the lustre of their upper surface, but for several rows of gilded punctiform impressions or stigmata upon their elytra, and distinguished by having the last joint of the above palpi shorter than the last but one. 
Calosoma calidum. Fab. Syst. Eleuth. i, 211, 1. De J. Colíopt. ij, 197, 5.

Carabus calitus. Frub. Syst. Ent. i, 37, 8. Oliv. Ins. iii, 35, 30, 26, t. iv, f. 45 .

length of the body 9 lines.

\section{This species is very common in all parts of North America; several specimens were taken in the Expedition.}

\section{DESCRIPTION.}

Body short, underneath rery black, glossy. Head thickly and confluently punetured and wrinkled; frontal impressions short and large; mandibles obliquely wrinkled : prothorax transverse, very slort, thickly and confluently punctured; dorsal chamel slight and abbreviated; lateral margin reflexed particularly at the posterior angles: elytra with fifteen elevated obtuse ridges interseeted by innumerable transverse impressed lines; on the fourtl, eighth, and twelfth ridges, which are wider than the others, are from nine to eleven punctiform impressions conted, as it were, with brilliant gold leaf, often of the ruddy hue of copper; one or two also are usually to be seen at the base of the sutural ridge; in some specimens one on one side, and two on the other, in others two and three: the body underneath is thickly and confluently punetured on each side.

$$
\text { 2. * Calosoma (Chrysostigma) frigidum. Frigid C. Chrysostigma. }
$$

C. (frigidum) nigrum, subtus latcribus obscure virescentibus; ctytris striatis: striis punctatis, interstitiis clevatis transvcrse lineatis, foveolisque bilobis triplici serie; marginc vircscenti; prothoracis angulis posticis deflexis.

Frigid Calosoma, black underneath with greenish sides; elytra furrowed with the furrows punetured; interstices of the furrows elevated with transverse lines impressed, and a triple series of bilobed obscurely gilded punctiform impressions ; margin greenish ; posterior angles of the prothorax depressed.

Length of the body $9 \frac{1}{3}$ lines.

\section{'Taken in Drummond's Island, Canada, by Dr. Bigsby.}

\section{DESCRIPTION.}

Not unlike C. calidum, but longer in proportion and more depressed. Body black, not glossy above. Head confluently punctured and wrinkled: mandibles obliquely but less densely wrinkleá, and frontal impressions longer than in $C$. calidum: prothorax searcely wider than the head, posterior angles bent downwards: elytra scarcely at all bronzed, lateral margin, obscurcly green, with the same number of elevated lines as in $C$. calidtm, but in the furrows formed by them is a series of punctures, and the transverse lines are less conspicuous; there is a triple series of punctiform impressions, but they are bilobed, smaller, and the gilding is greenish and less conspicuous; they are also less numerous, there being only seren or eight in the series next the suture, eight or nine in the intermediate one, and three only towards the apex in the external one: at the base there is also a pair on each side: the sides of the body underneath are greenish, punctured and wrinkled. 
(ß) Plebeia. Kirb.

\section{Family NEBRIAD王. Nebriadans.}

VIII. Genus HELOBIA. Leach.

\section{1. * Helobia castanipes. Chestmut-foot Helobia.}

H. (castanipes) atra, nitida ; elytris piceis, striatis : striis subpunctatis, foveolis quibusdam impressis; antennis pedibusque, castaneis.

Chestnut-foot Helobia, black, glossy; elytra piceous, furrowed : furrows indistinctly punctured with some punctiform impressions; antennæ and legs pale chestnut.

Length of the body 5 lines.

Two specimens were taken in Lat. $65^{\circ}$.

DESCRIPTION.

Body black, glossy. Antennæ, mouth, mandibles, and palpi pale chestnut or mahogany colour; the former more dilute at the apex ; front with three or four slight furrows between the eyes; upperlip very short : prothorax heart-shaped, constricted posteriorly, convex in the disk; sides and base depressed and lightly punctured : elytra dark piceous, striated or slightly furrowed: furrows very obsoletely punctured; interstices very flat; between the second and third furrows, adjoining the latter, are from three to five shallow but rather large impressions: the legs are slender, of a pale chestnut or mahogany colour, in one of the specimens the thighs are darker than the rest of the leg.

N. B. In one specimen there are three and in the other five impressions.

(c.) Sarrothropoda. Kirb.

\section{Family CHLÆNIAD无.}

IX. Genus CHLANIUS. Bonell.

\section{Chlenius sericeus. (Say.) Silly Chlcenizes.}

Chlænius sericeus. Say. Amer. Trans. N. S. 61, 1. De J. Coléopt. ii, 347, 47. laticollis. De J. Cat. 8.

Carabus sericeus. Forst. Cent. 58. Oliv. Encycl. v, 341, 89.

Length of the body $6-7$ lines.

Several taken in the Journey from New York to Cumberland-house. In Canada, by Dr. Bigsby. 


\section{DESCHITHON.}

Body black underneath, above of a rich silky green, bronzed on the head and prothorax. Head punctured with scattered punctures; the middle space betwees the eyes has a central punctiform impression; upper-lip and mandibles ferruginous; palpi and antenna paler; the latter, lualf the length of the body, the third joint being twice the length of the following one: prothorax subquadrangular with curving sides, channelled with the channel abbreviated at both extremities; hasilar impressions oblong: scutellum acuminate, black: elytra not shining, very slightly furrowed with punctures in the furrows; the interstices also being most numerously and minutely punctured; thickly set with yellowish hairs: legs deep yellow with black coxx.

$$
\text { 2. * Chlenius implinctifross. Impunctifiont Chlomim. }
$$

C. (impunctifrons) niger; capite levi prothoracequc viridibus; elytris obscuris virescente-nigris; cpipleura apice, antcnnis basi, pedibusque testaceis.

Impunctifront Chlenius, hlack with its smooth head and prothorax green; elytra not shining, greenish-black ; apex of the side-covers and legs testaceous.

Length of the body $5-5_{-1}^{3}$ lines.

DESCRIPTION.

Smaller than C. sericeus, though like it. Head without punctures; antennæ black with the three first joints testaceous: scutellum not acuminate: elytra black with a shade of green; apex of the epipleure or side-covers and legs testaceous; coxx chestnut. In other respects this agrees with the preceding species.

\section{Chlenius nemoralis. (Say.) Nemoral Chlemins.}

Chlænius nemoralis. Say. Amer. Trans. N. S. 6.5, 8. De J. Coléopt. ii, 332, 34.

- amethystinus. De J. Cat. 8.

Carabus amethystinus. Melsh. Cat.

Length of the body 6 lines.

A pair taken in the Journey from New York to Cumberland-house. I have excluded the synonyms of Fabricius and Olivier, to which De Jean has arlded at mark of interrogation, because they both describe the species they call $C$. amethystims, as blne moderncath, of which colour our insect has not the slightest shade, and Olivier's figure ${ }^{9}$ evidently belongs to a much smaller insect.

9 Ins. t. xi, f. 126. 


\section{DESCRIPTION.}

Body black underneath. Head and prothorax bronzed-copper; front wrinkled; mouth and oral organs ferruginous; antennæ rufous, the three first joints clearer than the rest: prothorax rather narrow anteriorly, densely punctured, somewhat hairy ; channelled, with a posterior linear impression on each side: scutellum black, triangular : elytra deep blue, with a shade of violet, furrowed like the other species, with the interstices of the furrows indistinctly and most minutely granulated : legs rufous.

\section{4. * Chlenius quadricollis. Square-necked Chlcmius.}

C. (quadricollis) niger, capite thoraceque subquadrato aneo-viridibus; palpis, antennis basi, pedibusque testaceis ; elytris caruleomigris.

Square-necked Chlænins, black; head and subquadrate thorax bronzed-green ; palpi, legs, and base of the antennæ testuceous; elytra blue-black.

Length of the hody 6 lines.

Taken by Dr. Bigsby in Canada.

DESCRIPTION.

Body hairy like the others, black underneath. Head and prothorax bronzed-green; mandibles piceous; palpi and three first joints of the antennæ testaceous; the latter are longer than the thorax, with the fourth joint as long as the third : prothorax rather square, a little narrower before, with the sides curving, sculptured like the preceding species: scutellum subacuminate: elytra blue-black, furrowed with deeper furrows very visibly punctured, interstices minutely punctured.

\section{5. * Chl}

C. (cordicollis) niger; prothorace obcordato ; palpis, pedibus, antennisque basi, rufis ; elytris nigro-virescentibus.

Heart-necked Chlænius, black ; prothorax obcordate; palpi, legs, and antennæ at the base rufous; elytra black with a sliade of green.

Length of the body 8 lines.

\section{Taken in Canada by Dr. Bigsby.}

\section{DESCRIPTION.}

Body black. Head impunctured; palpi rufous; antennæ dusky, with the three first joints rufous, the third much longer than the fourth : prothorax obcordate, constricted behind, deeply channelled, disk gibbous on each side of the channel, centre of each gibbosity smooth, remainder of the prothorax punctured; posterior lateral impression longitudinal: elytra black with a shade of green, sculptured as in the preceding species, but the interstices of the furrows are more visibly punctured: legs testaceous, thighs darker. 


\title{
6. Chlanius emarginatus. Emurginate Chlouins.
}

Chlienius emarginatus. Say. Amer. Trans. N. S. 64, 7. De J. Colíopt. ii, 366, 6.5?

Jength of the body $6 \frac{3}{3}$ lines.

\section{'Taken in the Journey from New York to Cumberland-house.}

DESCRIPTION.

Bosly hairy, punctured; black underneath. Head glossy green, with a tint of copper between the eyes, and a network of very minute, confluent, transverse wrimkles; maxilla and palpi rufous, maxillary palpi very long; upper-lip transverse, rufo-piceous, anteriorly subemarginatc; mandibles piecous; antenna rufous, louger than the prothorax with the third joint rather longer than the fourth: prothorax dusky-grcen, transverse, rather narrowest at the apex, very thick and minutely punetured; basilar impressions double, the inner one the longest: clytra black with a very faint tint of bluc: legs rufous.

This is most probably the Chlcnius emarginatus of Say, but it does not exaetly aecord with De Jcan's description.

(d.) Crstopods. Kirb.

(y) Dimana. Kirb.

\section{Family AGONID正. Agomidans.}

\author{
X. Genus PLATYNUS. ${ }^{1}$ Bonell.
}

\section{(24) 1. Platyvus angusticollis. (De Jcan.) Narrow-necled Platymus}

Platynus angusticollis. De J. Cat. 10. Steph. Illustr. Mandib. i, 83, 1.

Carabus angusticollis. Fab. Syst. Eleuth. i, 182, 64.

— Duft. Fn. Austr. ii, 173, 2:31. assimilis. Payk. Fn. Surec. i, 119, 30. collaris. NJarsh. Ent. Brit. i, $443,39$.

Harpalus angustieollis. Gyll. Ins. Suec. ii, 81, 2.

Anchomenus angusticollis. Sturm. Deutsch. Fr. v, 168, 2, t.xxx? De J. Coléopt. iii, 104, :

Length of the body $j$ lines.

Taken in Lat. 54 $4^{\circ}$ and $65^{\circ}$. Not uncommon in Britain.

1 Latreille places tbis gesus, Anchomenus, and Agonum, in the same tribe witl Chlenius, Licinus, Panayaus, \&e. which be distinguishes by the appellation of Patellimani, (Crust. Archn. ct Ins. i, 401, ") but it seems to have eseaped this learued and acute Entomologist, that in these genera, though the form of the dilated joints of the hand of the males differs from that of his Simplicimani, yet tbat underneath, like them they are furmisbed, not with a brush like the last named genera, hut with little membrasıus bags or eysts.

- I hare quoted this work under the tille which M. Latreille himself affixed to those copies that were presented to his friends or sold separately-viz. Les Crustacés, Les Arachnides et Les Insestes, forming two volumes per se, and the th and 5 th of Baron Cuvier's 2nd edition of the Regne Animal. 
DESCRIPTION.

Body very black, glossy, somewhat narrowed. Head smootln, narrower than the prothorax, including the neck subrhomboidal, without it triangular; palpi and antennæ piceous; frontal impressions large: prothorax narrower than the elytra, obcordate, longer than wide; dorsal channel deep terminating anteriorly in a transverse obtuse angular impression; lateral margin dilated, especially at the base, reflexed, somewhat piceous in a strong light, basilar impressions single, large, round, with a few scattered indistinct punctures: elytra rather deeply furrowed; furrows very slightly punctured, between the second and third are two punctiform impressions, the anterior one being adjacent to the former furrow, and the posterior to the latter.

\section{Genus AGONUM. Bonell.}

ii. Subgenus Anchomenus. ${ }^{2}$

(25) 1. Agonum (Anchomenus) extensicolle. Ertended-neclied A. Anchomemus.

Anchomenus extensicollis. De J. Coléopt. iii, 113, 11.

—— viridanus. De J. Cat. 10.

Carabus extensicollis. Melsh. Cat.

Feronia extensicollis. Say. Amer. Trans. N. S. ii, 54, 34 .

Length of the body $4 \frac{1}{2}$ lines.

A pair taken in Lat. $54^{\circ}$.

\section{DESCRIPTION.}

Body black underneath, above dark green sometimes brouzed; palpi, legs, and three first joints of the antennæ reddish-yellow : prothorax quadrangular, elongate, somewhat constricted posteriorly, lateral margin very slender; basilar impressions oblong: elytra furrowed, furrows obsoletely punctured; five punctiform impressions in the third furrow from the suture.

\section{2. * Agonum picipenne. Pitch-winged Agomum.}

A. (picipenne) nigrum, nitidum; ore pedibusque rufis; prothorace oblongo-orato; elytris piceis, foveolis quutuor vel quinque impressis.

Pitcl-winged Agonum, black, glossy; month and legs rufous; prothorax oblong-ovate; elytra piceous with four or five punctiform impressions.

Length of the body $3 \frac{1}{4}-4$ lines.

Several specimens taken in Lat. $54^{\circ}$.

${ }^{2}$ Anchomenus differs from Agonum in scarcely any respect, except in having the posterior angles of the prothorax less rounded, and as it is closely connected with it by those species, which like Agonum picipes luare a longer prothorix, I consider it merely as a subgenus. 
DESCRIPTION.

Body black, glossy. Mouth and its organs rufous, except the upper-lip which is edged with that colour; antenne longer than the prothorax, piceous with the scape paler than the other joints: prothorax longer than in the following species, oblong-ovate, with the lateral margin piccous, and not dilated posteriorly as in the majority; basilar impressions rather shallow, oblong: elytra oblong, rufo-piccous, slightly furrowed, furrows impunctured; five punctiform impressions between the second and third; the three anterior ones adjacent to the latter, and the two posterior to the former: legs dusky rufous.

VARIETY B. With only four punctiform impressions, legs paler.

C. With the second, third, and fourth joints of the antennæ piccous, the rest ferruginous: impressions of the clytra as in $\mathrm{B}$.

D. Larger, elytra with five impressions, in other respects like C.

This specics appears very like $A$. lenum De $\mathrm{J}_{\mathrm{c}},{ }^{3}$ which is also North American, but the colour of the underside of the body and of the head and prothorax is different.

\section{3. * Agonum sordens. Dingy Agomm.}

A. (sordens) nigrum nitidum; prothorace postice angustiori, antennis basi, pedibusque testaceis ; elytris sordide testaceis foveolis quinque impressis.

Dingy Agonum, black, glossy ; prothorax narrower behind; base of the antennæ; and legs testaceous; elytra dingy-testaceous, with five punctiform impressions.

Length of the body 3 lines.

Two specimens taken in Lat. $54^{\circ}$.

\section{DESCRIPTION.}

Body black, glossy. Head rhomboidal ; mouth, mandibles at the tip, palpi at the basc, and scape of the antennæ, rufous; frontal impressions very slight : prothorax scarcely longer than wide, narrowest behind; dorsal channel rather deep; lateral margin underneath testaceous; basilar impressions oblong, deepish : clytra dusky-testaceous, in one specimen a little bronzed, slightly furrowed, furrows impunctured; betwecn the second and third are five punctiform impressions placed as in the last specics: epiplcura and legs testaceous.

3 Coléopt. iii, 166, 39. 


\section{Agonum melanarium. (De Jean.) Black Agomum.}

Taken in Lat. $54^{\circ}$.

Agonum melanarium. De J. Coléopt. iii, 152, 19.

Carabus pullatus. Melsh. Cat. 89.

Length of the body $4 \frac{3}{4}$ lines.

\section{DESCRIPTION.}

Body black, glossy. Mandibles at the tip, mouth and scape of the antennæ, piceous : prothorax nearly as long as wide ; disk transversely wrinkled; lateral margin at the base much dilated, rather incrassated, and subangular; posterior impressions large and distinctly punctured : elytra wider than the prothorax, subemarginate at the base; distinctly furrowed with very minute aud inconspicuous punctures in the furrows; three punctiform impressions in the third furrow from the suture : legs piceous.

This species is the Ameriean representative of $A$. versutum, which it much resembles." It is however larger, the transverse wrinkles of the disk of the prothorax, and the punctures in its posterior impressions, are more distinct; the furrows of the elytra are rather deeper with more convex interstices, and the three punctiform impressions are all adjacent to the third furrow, whereas in $A$. versutum the anterior one alone is adjacent to that furrow, the two other adjoining the second.

\section{5. * Agonum seminitidum. Half-glossy Agomum.}

A. (seminitidum) nitidum, subtus nigrum, capite prothoraceque viridi-aneis, elytris obscurioribus, nigro-ceneis, quinque-foveolatis. Half-glossy Agonum, glossy, black underneath, head and prothorax greenish-bronzed; elytra more obscure, black-bronzed, with five punctiform impressions.

Taken in Lat. $54^{\circ}$.

Length of the body $4 \frac{1}{2}$ lincs.

\section{DESCRIPTION.}

Body smooth, glossy, black underneath. Head greenish-bronzed, very glossy, with frontal impressions lunular; antennæ longer than the prothorax: prothorax greenish-bronzed with a copper tint, very glossy, channelled, disk transversely and minutely wrinkled; basilar impressions longitudinal, lateral margin, particularly at the base, reflexed: elytra black-bronzed, less glossy than the head and prothorax, lightly furrowed; furrows punctured; in the insterstice between the second and third furrows are five punctiform impressions, two nearer the base and three nearer the apex of the elytrum, so tliat the interval between the second and third is greater than that between the others.

VARIETy B. Second and third punctiform impressions not more distant than the others. In this specimen, on the left hand elytrum, there are only four impressions, and on the other five, but in neither are the second and third situated as in A. It may be a distinct species, but I can discover no other difference. 
A. (simile) nitidun, sublus aterrimum, supra ceneo-nigrum; elytris stria suturali reliquis profundiori, quinque-foveolatis.

Similar Agonum, glossy, underneath very black, above a little bronzed; elytra with the sutural furrow dceper than the rest, marked with five punctiform impressions.

Length of the body $8 \frac{1}{1}$ lines.

\section{Locality not stated.}

\section{DESCRIPTION.}

Body glossy, underneath very black, above black slightly brouzed. Autenna scarcely longer than the prothorax: prothorax rather longer than broad; basilar impressions roundish, impunetured: elytra more bronzed than the head and prothorax, lightly furrowed; furrow adjoining the suture more depressed and decper than the rest; in the space between the second and third furrows are five equidistant punctiform impressions, the two anterior adjoining the latter furrow, and the three posterior the former.

This little specics greatly rescmbles $A$. seminitidum. It is however much smaller, less bronzed, the prothorax is longer in proportion, the sutural furrow is deeper, and the impressions are differently arranged.

\section{Agonum afrine. Kinlred Agonum.}

4. (afine) atrum, nitidum; prothorace subquadrato, margine laterali postice vix reflexo; elytris aneo-nigris, trifuveolatis; trochanterilus quatuor anterioribus rubris.

Kindred Agonum, black, glossy; prothorax rather square, with the lateral margin scarcely reflexed at the base; clytra slightly bronzed with three punetiform impressions; four anterior trochanters red.

Length of the body 4 lines.

\section{Locality not stated. A single specimen taken.}

\section{DESCRIPTION.}

Body very black, glossy. Antennx longer than the prothorax: prothorax of the same width before and behind so as to appear more square than in the preceding species; its lateral margin at the base is likewise not reflexed, the dorsal channel is slight, and the disk is minutely and transversely wrinkled; the basilar impressions are deep, large, and circular : elytra very slightly brouzed; three punctiform impressions, the anterior one adjoining the third furrow, and the two posterior the sccond, are visible in the usual situation: the four anterior trochanters are of a deep red. 


\section{8. * Agonum erythropum. Red-legged Agomum.}

A. (erythropum) nigrum, nitidum, supra nigro-eneum; prothorace postice angustiori; elytris trifoveolatis ; pedilus rufescentibus. Red-legged Agonum, black, glossy, above bronzed; prothorax narrower behind; elytra with three punctiform impressions ; legs dusky rufous.

Length of the body $4 \frac{1}{4}$ lines.

\section{Taken in Canada by Dr. Bigsby.}

\section{DESCRIPTION.}

Body glossy, black underncath, above bronzed. Antennæ black with the scape dusky rufous: prothorax tinted with copper, obcordate with rounded angles; basilar impressions round and deep: elytra tinted with copper, with three nearly obsolete punctiform impressions in the usual situation: legs dusky rufous; in other respects it resembles $A$. seminitidum.

This species appears to be the American representative of $A$. parumpunctatum. It is, however, larger, more bronzed, the impressions are less distinct and more distant, and the thighs as well as the tibiæ and tarsi are rufous.

\section{Agonum cupripenne. (De Jean.) Copper-winged Agomm.}

A. cupripenne. De J. Coléopt. iii, 139, 6.

- formosum. Sturm. Cat. 89.

Feronia cupripennis. Say. Amer. Trans. N. S. ii, 50, 26.

Carabus metallicus. Melsh. Cat.

PLATE I, FIG. 4.

Length of the body $4-4 \frac{1}{2}$ lines.

Many specimens of this lovely Agomm were taken in Lat. 54 ${ }^{\circ}$. It appears to be very common in North America, where it represents $A$. sexpunctatum, the most brilliant of our European species, but which $A$. cupripeme far exceeds in beauty.

\section{DESCRIPTION.}

Body glossy, underneath black with a slight shade of green, especially on the head and breast. Head above of a fine green, glossy, smooth with the usual frontal impressions; mouth, excluding the upper-lip and palpi, rufous; antennæ longer than the prothorax, black, scape tinted with green : prothorax green, channelled, basilar impressions rather deep : scutellum green : elytra ${ }^{4}$ lightly furrowed, furrows impunctured, three (four?) minute equidistant punctiform impressions, in the usual situation, the anterior one adjacent to the third furrow, and the two posterior ones to the second; as to colour these organs are of a fine cupreous purple, with the base and sides of a lovely green : legs black with the four anterior trochanters and the base of the posterior, rufous.

In the male the posterior trochanters are entirely black. 


\section{Family CALATHIDE. Calathidans.}

xII. Genus CALATHUS. Bonell.

1. Calathus gregarius. (De Jean.) Gregarions Calathus.

Calatbus gregarius. De J. Coliopt. iii, $76,13$.

Carabus gregarius. Melsh. Cat.

Feronia gregaria. Say. Amer. Trans. N. S. ii, 47, 21.

Length of the body $4 \frac{1}{2}$ lines.

'Taken frequently in Lat. $54^{\circ}$.

DESCRIPTION.

Body glossy, rufo-piceous underneath, above nigro-piceous. Palpi and antemne pale testaceous: prothorax quadrangular with the angles rounded; anteriorly emarginate; channelled; basilar impressions slight; lateral margin rufous dilated posteriorly: elytra furrowed, furrows impunetured; four punctiform impressions between the second and third furrows, the three anterior ones adjacent to the latter, and the posterior one to the former: legs pale testaceous. This genus is distinguished from the following one by laving its claws pectinated.

\section{Family PCECILIDE. Preilidans.}

$$
\text { 1. * Platyderus nitidus. Glossy Platyderus. }
$$

$P$. (nitidus) ater, nitidus; antennis piccis : scapo rufo; pedibus testaceis; elytris sulcatis foveolis duabus impressis.

Glossy Platyderus, black, glossy ; antennæ piceous with a rufous scape; legs testaceous : clytra deeply furrowed with two punctiform impressions.

PLATE I, FIG, 5.

Length of the body 4 lines.

Three specimens, all females, taken in Lat. 54\%

DESCRIPTION.

Body black, glossy. Head triangular ; mouth piceous; antennæ rather longer than the prothorax, piceous with the terminating joints paler, scape rufous : prothorax subquadrangular with the posterior angles rounded, emarginate at the base, as well as at the apex, slightly channelled, with a pair of linear basilar impressions on each side, the external one being oblique and the other longitudinal: elytra rather deply furrowed with two punctiform impressions, in the usual situation; viewed in the sun, the elytra exhibit cliangeable shades of blue and bronze: forebreast piceous: legs clear testaceons. 
XIV. Genus ARGUTOR. ${ }^{5}$ Meg.

\section{Argutor bicolor. Two-coloured Argutor.}

A. (bicolor) nitidus, supru niger, subtus, untennis, pedibusque brunneis; prothorace toto lavi utrinque sulculo impresso; elytris trifoveolatis.

Two-coloured Argutor, glossy, above black; underneath, antennæ and legs, mahogany-coloured; prothorax inpunctured with a little furrow impressed on each side; elytra with three punctiform impressions.

Length of the body 3 lines.

Taken twice in Lat. $54^{\circ}$.

\section{DESCRIPTION.}

Body glossy, above black, beneath mahogany-coloured. Antenna, and palpi at the base, dark mahogany-colour: prothorax longer than wide, rather narrowest at the base where it is slightly sinuated, anterior angles rounded, without punctures, dorsal channel slight, a deep short basilar furrow on each side: elytra slightly furrowed with impunctured furrows, the seventh from the suture obsolete; in the interstice between the second and third are three punctiform impressions, the anterior one adjoining the latter, and the two posterior ones the former.

This species approaches very near to $A$. erythropus De Jean, ${ }^{6}$ but it is smaller, and the posterior angles of the prothorax are not rounded. The underside of the body, the legs, and antennæ are all of the same colour, sometimes a little darker, at others a little paler.

2. * Argutor femoralis, Black-thighed Argutor.

A. (femoralis) nitidissimus, ater; antennis scapo, tibiis tarsisque piceis; prothorace toto lavi, utrinque basi sulculo inpresso; elytris trifoveolatis, striatis : striis antice subpunctatis.

Black-thighed Argutor, very black and glossy; scape of the antennæe, tibix and tarsi, piceous; prothorax impunctured, on each side at the base with a little furrow; elytra with three punctiform impressions, furrowed, furrows anteriorly slightly punctured.

Taken in Lat. $54^{\circ}$.

Length of the body $3 \frac{1}{2}$ lines.

DESCRIPTION.

This species approaches very near to the preceding one, and its place is between that and $A$. vernalis, of which last it is the American representative. It differs from $A$. bicolor chiefly in having only the scape of the antennæ and the tibix and tarsi of a different colour from the rest of the body and in having the anterior half of the furrows of the elytra slightly punctured; and from the latter in baving the prothorax narrower at the base, with only a single impunctured impression on each side.

5 This genus, or subgenus, the specics of which are usually minute and inhabit moist places, differs chiefly from $P$ acilus in having the third joint of the antenna longer than the fourth, without any ridge, and in the basilar impressions of the prothorax bcing mostly single.

${ }^{6}$ Coléent. iii, 243, 33. 
A. (mandibularis) mitidus, sublus niger, supra nigro-ceneus; mandibulis, palpis, pedilus, antennisque scapo, rufis ; prothorace. obeordato, postice utrinque sulculo impresso ; elytris biforeolatis, striatis: striis punetatis.

Mandibular Argutor, glossy, underneath black, above black-bronzed; mandibles, palpi, legs, anl scape of the antenne, rufous; prothorax obcordate, with a hasilar furrow on ench side; clytra with two punctiform impressions, furrowed, furrow's punctured.

Jength of the body $: 3$ lines.

'Taken in Lat. j4 $4^{\circ}$.

DESCRIPTION.

Body glossy, underneath black, above black-bronzed. Mandibles, palpi, scape of the antennx, and legs rufous, or rather pale-chestnut; frontal impressions rather wide: prothorax truncato-obcordate, with a basilar furrow on each side and a few punctures at the posterior angles: elytra lighluly furrowed with punctures in the furrows; two punctiform impressions in the usual situation, one a little beyond the middle of tle elytrum adjacent to the second furrow, and the posterior one near the apex adjacent to the third.

VARIETY B. Black above with the whole antennæ rufous, elytra piccous. Perhaps an immature specimen.

\section{4. * Argutor brevicornis. Short-homed Argutor.}

A. (brevicornis) ater nitidus, antennis masculis prothorace brevioribus pedibusque mifis; prothorace obcordato basi utrinque sulculo inspresso; rlytris trifoveolatis straitis: striis punctatis.

Short-loorned Argutor, glossy, very black, male antennie shorter than the prothorax, and the legs rufous; prothorax obcordate, with a little basilar furrow on each side; elytra with three punctiform impressions; furrowed, furrows punctused.

\section{PLATE VIII, FIG. 3.}

Taken in Lat. $65^{\circ}$.

Length of the body 3 lines.

\section{DESCRIPTION.}

This with the preceding species, in the shape of the prothorax, which is obcordate, departs a little from the others. A. brevicornis resembles $A$. mandibularis in many respects, but the body is black, as are also the mandibles and palpi; the antemnx of the male are shorter, and those of the female not longer, than the prothorax; one of these organs in the latter sex, in the only female specimen taken, appears to have been affected by some discase, for the two last joints are larger than the preceding ones, so as to form a kind of knob; it is the right-hand antemua that is so circumstanced: the little furrows at the base of the prothorax are wider than in A. mandibutaris; the elytra of the male have three, and those of the female four, punctiform impressions all adjacent to the third furrow. The eight last joints of the antennx in this specics lave less down and shine more than is usual with the ground-bectles in general. 
XV. Genus OMASEUS. Zieg.

\section{Omaseus orinomum. (Leach.) Mountain Omaseus.}

Omaseus orinomum. Leach. MS. Curtis. Brit. Ent. i, 15. Steph. Illustr. Mandib. i, 114, 3, t. vii, f. 3. Length of the body 51 lines.

Taken frequently in Lat. $54^{\circ}$. and $65^{\circ}$.

DESCRIPTION.

Body oblong, glossy, black. Head rather ovate, undemeath in some specimens chestnut, in others black; palpi piceous; prothorax subcordate rather longer than wide; a deep, punctured, basilar impression on each side; posterior margin slightly sinuate; elytra subacuminate, lightly furrowed with from four to six largish impressions in the second and third furrows, the first usually heing in the third and the second on the second furrow, but the others occasionally varying; the natural number of these impressions seems to be five; legs black with piceous tarsi.

VARIETy B. Legs chestnut.

C. Tibiæ and tarsi chestnut.

From the number of specimens collected in the Expedition I should conjecture this to be one of the most common of North American insects. It appears, however, not to have been noticed by Say, nor was it amongst those collected by Dr. Bigsby in Canada, or by Dr. Mac Culloch and Captain Hall in Nova Scotia.

\section{Omaseus nigrita. (Curtis.) Negro Omaseus.}

Omaseus Nigrita. Curtis Brit. Ent. i, 15. Steph. Illust. Mandib. i, 114, 5.

Carabus Nigrita. Payk. Mon. Car. 79. Fn. Suec. i, 157, 77. Panz. Fn. Germ. xi, 11. aterrimus. Marsh. Ent. Brit. i, 444, 30.

Harpalus Nigrita. Gyllenh. Ins. Suec. ii, 88,8 .

Platysmus Nigrita. Sturm. Deutsch. Fn. v, 64, 16.

Length of the body $5 \frac{1}{4}$ lines.

DESCRIPTION.

Body very black and glossy. Frontal impressions nearly straight; palpi, scape, and summit of the antennæ, piceous: prothorax subcordate; rather deeply channelled; basilar impressions large, punctured, in each are two little abbreviated furrows and a ridge adjoining the margin; the base itself has a slight sinus: elytra very deeply furrowed, furrows very indistinctly punctured; three minute punctiform impressions in the usual situation, the anterior one adjoining the third and the two posterior ones the second furrow : legs dark piceous : ventral segments of the abdomen minutely wrinkled on each side: on the sides of the breast are some scattered punctures. 
In the European specimens the legs are black; the ridge between the basilar impression and the margin is less prominent; amongst the wrinkles on each side the ventral segments there are punctures; the sides of the breast also are more thickly and grossly punctured. There is, however, an apterous specimen of an American female, which agrees with the British ones in these respects.

'The Carabus Nigrita of Paykull, is clearly synonymous with the species known by that name in Britain, and of which I have received Swedish specimens by the kindness of Major Gyllenhal. Mr. Marsham appears to have mistaken it for a very different and larger species (O. aterrimusi) concerning whicls Paykull observes ${ }^{8}$ that it differs from $O$. Nigrita in having the impressions on the elytra visible to the naked eye, while in the latter they are not to be discerned but under a lens. It is clear that Carabus Nigrita of Fabricius ${ }^{9}$ is a distinct species, synonymous according to him with C. nigro-striatns of De Geer, and C. striatus of Paykull, mistaken by several authors for $C$. leucophthalmus of Linné; Fabricins also refers to Paykull's $C$. striatts under C. niger (Platysma niger Steph.)

I have likewise excluded the synonym of De Jean, for he describes his Feronia (Omasens) Nigrita, as having the two longitudinal impressions on each side of the base of the prothorax almost entirely efficed, and the posterior angles as not discernible except under a powerful magnifier; and the male as having on the last ventral segment of the abdomen an elevated point $;^{1}$ none of which characters are to be found in $O$. Nigrita.

\section{Osiaseus picicornis. Pitch-hormed Omaseus.}

O. (piciccrnis) ater, nitidus; palpis antennisque nigro-piceis, prothoracis forcis posticis unisulcis punctatis carinula nulla; enlepectore lavi; elyeris trifoveolatis.

Pitch-horned Omaseus, very black, glossy; palpi and antennæe nigro-piceous; basilar impressions of the prothorax punctured, once furrowed and without any little ridge; forebreast impunctured; elytra witb three punctiform impressions.

Length of the body $5 \frac{1}{2}$ lines.

\section{Taken with the preceding species?}

\section{DESCRIPTION.}

This species differs from $O$. Nigrita, which it greatly resembles, in having the first three joints of the antennæ nearly black, the rest being paler: the prothorax is rather longer in proportion and less constrieted at the base; the basilar impressions have only one well-defined furrow, and no little ridge intervenes between them and the margin; the antepectus is without any punctures: the legs are piccous with black thighs.

- Curtis Brit. Ent. i, t. xץ. Stepb. Illustr. i, 113, I.

9 Ent. Syst. i, 200, 164.
${ }^{8}$ Fr. Succ. i, $157,76$.

1 Coléopt. iii, $284,78$. 
XVI. * Genus STEREOCERUS.

Labrum transverse, scarcely emarginate.

Palpi, maxillary with the second joint subcylindrical, the third obconical, in the male as long as the last, in the female longer, the last subcylindrical truncated at the apex.

labial with the last joint subcylindrical truncated at the apex.

Labium emarginate with a short entire tooth in the notch.

Antennce robust, with the third joint a little longer than the rest, suddenly incrassated at the summit; the fourth clavate; the following ones compressed and subcampanulate; the last ovate. ${ }^{2}$

Body rather narrow. Head somewhat orbicular; frontal impressions oblique : prothorax nearly as long as wide, rather narrowest at the base, truncated before and behind; dorsal channel not abbreviated; lateral margin reflexed, depressed postcriorly; basilar impressions with a double furrow, anterior angles rounded, posterior rather acute: scutellum acutangular: elytra parallel, subsinuated at the apex: hand of the male with the three first joints dilated and triangular.

This genus, or subgenus, appears to connect those that have robust antenne, as Omaseus, \&c. with those that have those organs more slender, as Pacilus, \&c. Its general aspect is that of Curtonotus, but the intermediate tooth of the labium (Mentum Latr.) is entire as in Bradytus: the penultimate joint of the palpi in the male is as long as the last, which in the first of these genera is longer and in the second shorter; the last joint is more cylindrical and consequently more widely truncated at the sunmit than in either.

\section{1. * Stereocerus similis. Similar Stereocerus.}

S. (similis) piceo-niger, nitidus; antennis pedibusque castaneis; elytris œneo-piceis; occipile punctulato.

Similar Stereocerus, piceous-black, glossy; antennæ and legs chestnut; elytra piceous tinted with bronze; occiput minutely punctured.

\section{PLATE VIII, FIG. 1.}

Length of the body $5 \frac{1}{4}$ lines.

A pair were taken in Lat. $54^{\circ}$.

\section{DESCRIPTION}

Body of a piceous-black, glossy. Palpi piceous; antennæ chestnut: frontal impressions deep, rather curving; occiput punctured with scattered punctures: prothorax nearly square with curved sides; basilar impressions wide, punctured, deeply bisulcate, with an elevated little ridge betwcen them and the margin : clytra bronzed, furrowed, furrows starcely punctured : legs pale chestnut.

In the female the elytra are not bronzed, the legs are darker, and the terminal joint of the palpi is longer. 
XVII. Genus? CURTONOTUS. ${ }^{3}$ Steph.

\section{Cuntoxotus convexiusculus. (Stephens.) Comer Cutonotus.}

Curtonotus eonvexiusenlus. Steph. Illustr. Mandib. i, 138, 1, ı. viii, $f$. 1.

Carabus convexiusculus. Marsh. Ent. Brit. i, 462, 82.

'Taken in Lat. 650:

Length of the borly $5 \frac{1}{1}$ lines.

\section{DESCRITTON.}

Body dark piceous, sometimes a little bronzel. Antenna and palpi rufous; frontal impressions short connected by a rather deep furrow : prothorax constricted and punctured at the base, depressed on each side; basilar impressions bisulcate; posterior angles acute, recurved : elytra furrowed, furrows punctured: sides of the ventral segments of the abdomen somewhat punetured and wrinklecl, those of the mid-breast grossly punctured : legs chestruut.

\section{2. * Curtonotus rufimanus. Reel-handed Curtomotus.}

C. (rufimanus) nigro-piceus, nitidus; antennis, palpis, manibusque rufis.

Red-landed Curtonotus, dark-piceous, glossy; antennce, palpi, and hands rufous.

Length of the body 5 lines.

Several taken in Lat. $54^{\circ}$.

\section{DESCRIPTION.}

This is extremely similar to the species last described, from which it principally differs in having the legs of the colour of dark pitch, with the exception of the hands or anterior tarsi, which are rufous: the sides of the ventral segments of the abdomen also appear less conspicuously puncturerl.

C. (brevilabris) nigro-piceus; labro brevi transierso; antennis palpisque rufis; elytris pcdibusque castaneis.

Short-lipped Curtonotus, dark-piceous; upper-lip short, transverse; antenne and palpi rufons; elytra and legs chestnut.

Length of the body $+\frac{1}{3}$ lines.

A single specimen taken in Lat. $65^{\circ}$.

${ }^{3}$ At first sight Curtonotus appears merely a subgenus of Bradytus Stepl., but the notch in the intermediate tooth of the labium, and the dentated intermediate tibix of tlo male seem to afford good ground for considering them as distinct genera. 
DESCRIPTION.

Like the preceding species but smaller: the upper lip is blacker, not half so long and slightly emarginate: the elytra are dark and the legs pale chestmut; the furrows of the former are less conspicuously punctured: the frontal impressions likewise are longer and connected by a slighter furrow.

\section{4. * Curtonotus hatior. Broad Curtonotus.}

C. (latior) brevis, piceus; supra œneo-tinctus ; labro, antennis, palpis, epipleuris, pedibusque rufis; naso sinu obtusangulo ; prothorace transverso.

Broad Curtonotus, short, piceous, above bronzed; upper-lip, antennæ, palpi, side-covers, and legs rufous ; nose with an obtusangular sinus; prothorax transverse.

Length of the body 5 lines.

One specimen only taken.

\section{DESCRIPTION.}

This species has a good deal the aspect of Bradytus apricarius, but it is a larger insect and rather wider in proportion; and the bifid intermediate tooth of the lower lip proves that it is a true Curtonotus. Body piceous, above bronzed. Upper-lip, palpi, antennæ, side-covers, and legs all rufous, nose at the anterior margin has an obtusangular sinus; frontal impressions punctiform connected by a slighltly-drawn line or furrow : prothorax wider than long, the lateral margins forming a segment of a circle without any posterior constriction; at the base the prothorax is depressed, the basilar impressions are bisulcate, the inner furrow being the longest: furrows of the elytra punctured.

XVIII. Genus PECILUS. Bonell.

\section{Pecilus lucublandus. (De Jean.) Lucubland Pacilus. ${ }^{4}$}

Feronia lucublanda. Say. Amer. Trans. N. S. ii, 55, 36.

- (Pocilus) lucublanda. De J. Coléopt. iii, $212,6$.

Carabus lucublandus. Melsh. Cat.

Pœcilus similis De J. Cat. 11.

Length of the body 5 lines.

Many specimens taken in Lat. $54^{\circ}$.

${ }^{4}$ I suppose the trivial name of this species, lucublandus, is derived from lucus and blandus, an untranslatable epitliet, I have therefore given it an English termination. 


\section{DESCRIPTION.}

'This species is nearly related to $P$. cupreus, and is its $\Lambda$ merican representative; but it differs from it in several important characters. Body glossy, undemeath black, above bronzed. Head not punctured; frontal impressions nearly round; three first joints of the antenne rufous, with the longitudinal ridge on the third, which distinguishes the species of this genus, black, the rest of the antennx is black: prothorax witl, a slight shade of green, channelled, somewhat depressed at the base; disk transversely wrinkled; lateral margin dilated posteriorly; basilar impressions clouble, the exterior one punctiform, the interior longitudinal: elytra with a shade of eopper, deeply furrowed; furrows scarcely punctured with convex interstices, and four punctiform impressions between the second and the third, all adjacent to the latter: siles of the ventral segments of the abdomen wrinkled and punetured, those of the breast grossly punctured : legs dark chestnut.

VARIETY. B. With the legs and palpi ferruginous, furrows indistinetly punctured.

C. With the furrows of the elytra distinctly punctured.

D. Entirely black with the sides of the prothorax impunctured, elytra violet.

\section{2. * Pecilus castanipes. Chestmut-footed Procilus.}

P. (castanipes) atcr, nitidus; prothorace postice leviter foveato vix punctulato; elytris striatis: striis lavibus, trifoveolatis. Chestnut-footed Pœcilus, biack, glossy; prothorax with slight basilar scarcely punctured impressions; elytra lightly furrowed; furrows impunctured, with three punctiform impressions.

Length of the body $5 \frac{1}{2}$ lines.

One specimen only taken.

DESCRIPTION.

This species differs from variety $\mathrm{D}$ of $P$. lucublandus, which it much resembles, in being entirely black; in having slighter basilar impressions less distinctly punctured: it has likewise only three punctiform impressions on the elytra, the granular reticulations of the substance of which are also more easily discovered.

\section{Pecilus chalcites. (De Jean.) Bronzed Pocilus.}

Feronia (Pocilus) chalcites. De J. Coléopt. iii, 211, 5.

_ chalcites. Say. Amer. Trans. N. S. ii, $56,37$.

Carabus chalcites. Melsl. Cat.

Length of the body 5 lincs.

Only a single specimen taken. 


\section{DESCRIPTION,}

This species appears to be related to $P$. lucublandus, but it is narrower in proportion, the upper surface of the body is of a changeable colour, green or copper, "as the site varies in the gazer's hand." The basilar impressions of the prothorax are green and blue and more grossly and distinctly punctured; the lateral margin is not dilated posteriorly or depressed, as in the other Pecili: the sides of the elytra are green, their furrows are more distinetly punctured than even those of $P$. cupreus, and they exhibit only two punetiform impressions, both beyond the middle of the elytrum: the legs are black.

Family AMARIDÆ. Amaridans.

XIX. Genus AMARA. Bonell.

\section{Amara vulgaris. (Latreille.) Common Amara.}

Amara vulgaris. Latr. Crustac. Arachn. and Ins. i, 192. De J. Cat. 9; Coléopt. iii, 463, 5. Sturm Dentsch. Fn. i, 48, 26. Steph. Illustr. Mandib. i, 128, 5.

Carabus vulgaris. Linn. Fn. Suec. 799 ; Syst. Nat. i, 672, 27. Fab. Syst. Eleuth. i, 195, 37. Illig. Kaf. Preuss. 167, 33. Marsh. Ent. Brit. i, $438,16$.

- dispar. Payk. Fn. Suec. i, 167, 88.

ovatus. Ross. Fn. Etrusc. i, 89, 200.

- Var. $\delta$, Payk. Mon. Car. 132, 81.

Harpalus vulgaris. Gyllen. Ins. Suec. ii, 138, 48 ; iv, 444, 48.

Length of the body $4-4 \frac{1}{4}$ lines.

Many specimens taken in Lat. $65^{\circ}$. and in the Rocky Mountains.

\section{DESCRIPTION.}

Body black, glossy; above black-bronzed. Scape of the antennæ pieeous; imner lobe of the maxillæ, and first joint of the outer palpi, testaceous; basilar impressions of the prothorax double, deepisl, impunctured, the external one oblique; channel abbreviated anteriorly, with a punctiform impression beyond the middle: furrows of the elytra lightly drawn, indistinctly punctured; apex subaeuminate or suddenly narrowed: legs black with the hairs, spurs, and claws, testaceous.

VARIETY B. Bright, bronzed with a eupreous tint.

C. Wholly black. 
1. (incqualis) nigra, nitida, supra nigro-anea; antcnis articulis duobus prinis rufis ; prothorace postice utrinque bisulco; elytris striarum intcrstitiis incqualibus.

Unequal Amara, black, glossy; above black-bronzed; two first joints of the antenne rufous; prothorax at the base with two furrows on eacb side; interstices of the furrows of the elytra uneven.

Length of the body $f$ lines.

Sereral taken in Lat. $54^{\circ}$.

DESCRIPTION.

Very like A. vulgaris, but the two first joints of the antemia are rufous; the basilar impressions of the prothorax are not so deep; and the interstices of the furrows of the elytra are convex and uneven, in other respects there is little difference between them.

\section{Amara mipuncticollis. (K.) Smooth-mecked Amara.}

Feronia impuncticollis. Say. Amer. Trans. N. S. ̈̈, 36, 3.

Taken in Lat. $54^{\circ}$.

Length of the body 4 lines.

DESCRIPTION.

This differs from its two predecessors principally in having the three first joints of the antennæ nearly yellow: the tibiæ and tarsi also are dark piceous, as are likewise the clavicles or anterior coxæ, and the trochanters: the interstices of the furrows of the clytra are plane.

\section{4. * Amara pallipes. Pale-legged Amara.}

A. (pallipes) nitida; subtus picea, supra nigro-anca; antennis basi rufis; prothorace postice bifovcolato: fovcolis punctatis pedibus flavescentibus.

Palc-legged Amara, glossy; underneath piceous, above black-bronzed; antennæ rufous at the base ; basilar impressions of tbe prothorax punctiform, double, punctured; legs yellowish.

\section{()nly one specimen taken.}

Length of the body 3 lines.

\section{DESCRIITION.}

Body glossy; underside, mandibles, coxæ, and tarsi piceous; upperside bronzed. 'Three first joints of the antennæ rufous; frontal impressions very slight, connecting line very distinct: dorsal channel of the prothorax nearly entire; basilar impressions rather punctiform, punctured: elytra not subacuminate: legs yellowish. 


\section{5. * Amara levipennis. Smooth-winged Amara.}

A. (lavipennis) nitida, supra nigro-anea; prothorace foveolis basilaribus subobsoletis; elytris substriatis : striis minutissime et vix conspicue punctulatis.

Smooth-winged Amara, slossy; above black bronzed; basilar impressions of the prothorax almost obliterated; elytra very slightly furrowed: furrows very minutely and scarcely conspicuously punctured.

Length of the body $3 \frac{1}{3}$ lines.

Three or four specimens taken in Lat. $54^{\circ}$.

DESCRIPTION.

Body glossy; the underside, legs, and antennæ black; upperside black-bronzed : frontal impressions very slight : prothorax smooth with the basilar impressions very faint: furrows of the elytra very lightly drawn, and sometimes subinterrupted: intermediate trochanters piceous.

\section{6. * Amara discors. Discordant Amara.}

A. (discors) picea, nitida; ore, antennis, thoracis margine laterali, pedibusque ferrugineis ; elytris obscurioribus striatis : striis obsolete crenulatis.

Discordant Amara, piceous, glossy; moutb, antennæ, lateral margin of the prothorax, and legs ferruginous; elytra rather obcure, furrowed; furrows very obsoletely crenulated.

Length of the body 4 lines.

One specimen only taken.

\section{DESCRIPTION.}

This species has somewhat the aspect of a Harpalts, but it exhibits the true charactcrs of Amara: it appears to be related to A.discrepans of Mr. Stephens. ${ }^{5}$ Body dark piccous, glossy. Upper-lip, palpi, mouth, and antennæ ferruginous : prothorax a little narrowed behind; bead of the lateral margin rufous; basilar impressions rather slight : elytra less glossy than the rest of the body, the infinitely minute and numernus granular reticulations of their substance being more conspicuous than usual; the furrows of the elytra from minute punctures exhibit a slight appearance of crenulations: legs pale chestnut. 


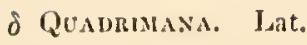

\section{Family HARPALIDA. Harpalialuns.}

XX. Genus HARPALUS. Lait.

1. *hirpaus pleuriticus. Pleuritic Harpulus.

H. (pleuriticus) riger, nitidus; polpis, antcnnis, pedibus, prothoracis marginc laterali, epipleuraque clytrorum, fulvcsccntibus. Pleuritic Ilarpalus, black, glossy; palpi, antenine, legs, lateral masgin of the prothorax, and side-covers of the elytra, tawny-yellow.

Length of the body $4 \frac{1}{4}$ lines.

Taken frequently in Lat. $54^{\circ}$.

DESCRIPTION.

Body black, glossy. Frontal impressions punetiform; upper-lip piceous, with the lateral and anterior margin palcr; palpi and antemne tawny-yellow; the latter shorter than the prothorax, with all the joints, the scape excepted, which is the longest and thickest, nearly of equal length: prothorax mearly square with all the angles rounded, wider than long; basilar impressions oblong, punctured, each intermediate between the dorsal channel and the margin, which last is tawny-yellow: elytra rather less glossy than the head and thorax, somewhat piceous; furrows of the elytra impunctured; a single rather obsolete punctiform impression is observable in the second furrow near the apex of the elytrum, which is slightly siuuated; sidc-covers and legs tawny-yellow.

This species is related to $H$. tardus and its affinities, but quite distinct.

$$
\text { 2. * Harpalus basilaris. Busilar Harpalus. }
$$

II. (bosilaris) niger, depressus; antennis fuscis basi flavis; clytris custaneo-nigris.

Basilar Harpalus, black, depressed; antennse dusky-yellow at the base; elytra chestnut-black.

Lengtb of the body 4 lines.

Taken with the preceding and in equal numbers.

DESCRIPTION.

This species differs from the preceling, which it nearly resembles, in having the two first joints of anteunx yellow, and the remainder dusky; in having the prothorax still wider in proportion to its length, with its posterior angles more acute and impunctured, and with narrower basilar impressions also without punctures; its lateral margin is also black and less prominent: the side-covers of the clytrin are likewise black: the lems are dark-piceous, with yellowish-red trochanters. In other respects it resembles $H$. pleuritictts. 


\section{3. *Harpalus ochropus. Ochre-legged Harpalus.}

A. (ochropus) niger, nitidus; prothorace lavi profundius canaliculato; margine laterali, antennis prothoracis longitudine, pedibusque, fulvis.

Ocbre-legged Harpalus, black, glossy; prothorax impunctured, rather deeply channelled; with the lateral margin, antennæe, which are as long as the prothorax, and legs, tawny.

Length of the body $3 \frac{1}{3}$ lines.

DESCRIPTION.

This comes very near to $H$. pleuritictts, but is considerably smaller; the antennæ are longer; the prothorax is impunctured at the base, its basilar impressions are linear; the side-covers of the elytra are chestnut; and its thighs are more robust in proportion.

\section{4. * Harpalus interpunctatus. Interpunctured Harpalus.}

H. (interpunctatus) ater, nitidus : antennis scapo, palpisque apice, rufescentibus : prothorace punctulato disco lavi, postice leviter at late foveato; elytris subsulcatis, interstitiis minutissime punctulatis.

Interpunctured Harpalus, black, glossy ; antennæ with the scape and last joint of the palpi rufescent ; prothorax punctured with the disk smooth; basilar impressions shallow but wide; elytra rather deeply furrowed, with the inter'stices of the furrows very minutely punctured.

PLATE VII. FIG. 8

Length of the body $5 \frac{1}{2}$ lines.

Many taken in Lat. 54\%

\section{DESCRIPTION.}

Body proportionally longer than in the antecedent species, black, glossy, not depressed. Head triangular with a pair of confluent red dots, visible only in the sun, between the eyes; antennæ shorter than the prothorax, with the scape and last joint of the palpi rufous: prothorax subquadrangular; anterior angles rounded; dorsal channel drawn from the apex to the base; punctured especially posteriorly, disk impunctured transversely wrinkled; basilar impressions shallow; lateral margin dilated posteriorly: elytra rather deeply furrowed, furrows impunctured, interstices convex, very minutely but not thickly punctured : the four anterior tarsi of the male, as was observed before, ${ }^{6}$ are furnished with a thick brush of vesicles, not arranged in a double series, as in other species of the genus, but resembling, in this respect, the sarrothropodous Geadephaga, ${ }^{7}$ except that the brush is not formed of hairs. 


\section{5. * Harpalus lovglor. Lomger Harpulus.}

11. (longiar) oblongus, niger, antennis, palpis, pedibusque, rufo-fulvis; naso apice membranacco; prothorace postice punctulato ; nlytris langinsculis striarum lateralium interstitiis obsalcte punctulatis.

Longer Harpalus, oblong, black; antenux, palpi, and legs rufo-fulvous; apex of the nose membranous; prothorax punetured bebind; elytra raber long with the interstices of the lateral furrows obsoletely punctured.

Length of the body $5 \frac{1}{4}-7 \frac{1}{3}$ lines.

'Two specimens taken, the largest in Lat. $54^{\circ}$.

DESCRIPTION.

Body black. Upper-lip piceous; antennx, palpi, and legs reddish-tawny, the first longer than the prothorax; the nose terminates anteriorly in a reddish membrane or rhinarium: prothorax quadrangular with all the angles rotnded, rather longer than wide; dorsal chamel anteriorly abbreviated ; lateral margin minutely punctured, much depressed, especially at the posterior angles; basilar impressions double, shallow, and minutely punctured : elytra very little glossed, more than twice the length of the prothorax, furrows impunctured with convex interstices, the lateral ones with some scattered very minute punctures; the vesicles on the sole of the four anterior tarsi of the male are arranged as in the other Harpali.

Both the specimens taken in the Expedition are males, or I should lave supposed the unusual differenec in their size was sexual, probably the small one was taken in a higher latitude.

\section{6. * Harpalus laticollis. Widle-mecled Hurpalus.}

H. (laticollis) ater, nitidus; palpis apice antennisque basi rufis; prothorace lato, postice obsolete punctulato et foveato ; clytris subsulcatis interstitiis canvex is lavilus, foreola unica.

Wide-necked Harpalus, very black, glossy; apex of the palpi and base of the antennæ rufous; prothorax wide, at the base obsoletely punctured and impressed ; elytra furrowed with convex impunctured interstices, and a single punctiform impression.

Length of the body $5 \frac{1}{2}$ lines.

A single specimen taken.

DESCRIPTION.

This insect very closely resembles $H$. interptenctatus; it differs principally in having a rather wider prothorax with all the angles rounded, with the dorsal channel abbreviated anteriorly, and with only the base very indistinctly punetured: the interstices of the furrows of the elytra are also without punctures, and there is a single punctiform impression in the usual situation adjacent to the second furrow. 


\section{Harpalus carbonarius. (Say.) Coal-black Harpalus.}

Harpalus carbonarius. Say. Amer. Trans. N. S. ii, 82, 13.

Carabus carbonarius. Melsh. Cat.

Length of the body 6 lines.

Two specimens taken in Lat. $54^{\circ}$.

\section{DESCRIPTION.}

Body depressed, black, rather glossy. Last joint of the palpi and margin of the upper-lip rufous; antennæ as long as the prothorax, scape rufous with a black spot above: prothorax like that of the preceding species, but more widely depressed, at the posterior angles: elytra without any gloss, slightly furrowed; furrows impunctured; two very minute punctiform impressions in the usual situation beyond the middle of the elytrum adjoin the second furrow. The opacity of the elytra is produced by the innumerable granules of their surface, common in this tribe, being more than usually conspicuous. 8

\section{Harpalus rotundicollis. Round-necked Harpalus.}

H. (rotundicollis) nigricans, nitidus; palpis apice, antennisque, rufis; prothorace angulis rotundatis postice sulfoveato; elytris subsericeis.

Round-necked Harpalus, brownish-black, glossy; antennæ and apex of the palpi rufous; prothorax with all the angles rounded, basilar impressions slight; elytra with somewhat of a silky lustre.

Length of the body $5 \frac{1}{2}$ lines.

Two specimens taken.

\section{DESCRIPTION.}

Body brownish, black, glossy, Antennæ length of the prothorax, and as well as the tip of the palpi, rufous: prothorax wider than long with rounded angles; basilar impressions shallow, round, and punctured: the elytra exhibit a silky lustre from the granulations mentioned in the description of the last species; there is a single punctiform impression in the usual situation nearer the apex; in this and the following species these organs are transversely truncated with a slight sinuosity: legs rufous or rufo-piccous with black thighs; coxæ and trochanters rufous. 
11. (Strphensii) ater, nitidissimus; anlcnnis ferrugineis; prothorace nigro-aneo : angulis rotandatis; elyfris ancis subsulcatix apice transversis integris: petibus piccis.

Stepheris' Harpalus, very blaek, very glossy; antenne ferruginous; prothorax black-bronzed witl rounded angles; elytra bronzed, rather deeply furrowed, transverse and entire at the apex; leurs piceous.

Lengtl of the body 41 lines.

A single specinen taken in Lat. 50 $4^{0}$.

DESCRIPTION.

Body black and very glossy. Head very smooth with the usual frontal impressions; antemna rufous with the basilar joints darker; palpi rufous: prothorax black-bronzed, shaped like that of the antecedent species, obsoletely chamelled, at the base punetured on each side, but without any impressions: elytra bronzed, brilliant, furrowed with impunctured furrows; punctiform impressions as in $H$. rotundicollis ; apex transverse, entire, with the external apical angle rounded: legs piceons, hands rufous, posterior trochanters very large.

ii Hrgraderiaga.

a Acutipalpia.

a Quamimana.

This Section consists of the littoral or subaquatic Adephaga. It may be divided, with oue anomaly, into three minor sections distinguished by their palpi, which may be denominated-I, Acutipalpia, 2, Subulipalpia, and 3, Filipalpiu. Anongst these we seem to have a representative, in miniature, of many of the Geadephagous tribes and genera.-Thus, e.g. Elaphrus represents Cicindela; Opisthius or Bembidium, Calosoma; Notiophilus, in some sort, Carabus; Catascopus and Pseudomorpha ${ }^{9}$ the Truncipennia; Stenolophus the Harpalide; Isopleurus the Cystopodous Dimana; and Lopha perhaps the Bipartita. P'robably further investigation may make it evident, that Argutor also belongs to this subtribe.

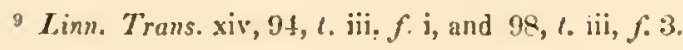




\section{Family S'TENOLOPHIDE. Stenolophidans.}

XXI. Genus STENOLOPHUS. Zieg.

\section{1. * Stenolophus versicolor. Changeable Stenolophus.}

Si. (versicolor) piceo-niger; antennis basi, prothoracis margine laterali, pedibusque, rufis ; elytris rufo-fuscis, sub luce violaceo micantibus.

Changeable Stenolophus, piceous-black; base of the antennæ, lateral margin of the prothorax, and legs, rufous; elytra reddish-brown, in the light shining with a tint of violet.

Length of the body $2 \frac{1}{2}-2 \frac{3}{4}$ lines.

Three specimens were taken in Lat. $54^{\circ}$.

DESCRIPTION.

Body dusky-black, glossy. Palpi, mouth, and scape of the antennæ rufous : prothorax scarcely longer than wide, rounded behind, with the basilar impressions punctured: elytra reddish-brown, viewed in the sun or in the light, they exhibit a changeable tint of violet; a punctiform impression adjoins the second furrow; apex slightly sinuated; epipleura yellow : thighs dusky, especially the posterior pair, which are larger than the others; tibia and tarsi rufous.

The female has less of the violet tint, and the elytra are of a pale mahogany colour.

VARIE'T B. With the two first joints of the antennæ rufous; legs yellow.

$\beta$ Dimana. ${ }^{2}$

Family TRECHIDE. Trechidans.

XXII. Genus TRECHUS.3 Clair.

\section{1. * Trechus tibialis. Red-shanked Trechus.}

T. (trbialis) niger, subnitidus; palpis apice, antennis basi, tibiisque, rufis; prothorace sulquadrato, postice utrinque sulculo impresso ; eljtris unifoveolatis, marginibus apicis rufescentibus.

Red-shanked Trechus, black, rather glossy; palpi at the apex, antennæ at the base, and tibiæ, rufous; prothorax rather square, with a basilar furrow on each side; elytra with a single punctiform impression; margins of the apex rufous.

Length of the body $2 \frac{3}{4}$ lines.

Only a single specimen taken.

1 II. Latreille (Crust. Arachn et Ins. i, 391) has placed this genus at a considerable distance from Trechus, though he appcars awarc of their affinity; but Mr. Stephens has properly inserted it between Ophonus and the latter genus. He has, however, in his characters of Stenolophus omitted to notice its most striking distinction, that in the male insect the penultimate joint of the four anterior tarsi is cleft to the base into two narrow lobes. In Harpalus and Ophonus this joint is heart-shaped. The last joint of the palpi in the present genus, is conical though subtruncated and belongs to this tribe.

2 Mr. Stephens (Illustr. Mandib. i, 167) says that the four anterior tarsi in Trechus are dilated in the males, which would make them belong to the preccding stirps, but this is an oversight, for only the anterior pair or hands are dilated. See Sturm. Deutsch. Fn. v, t. cxlix-cli.

${ }^{3}$ The four first joints are dilated in the hands of the males in this genus. 


\section{DESCRIPTION.}

'This species upon a slight inspection might be mistaken for an Argutor, ${ }^{4}$ but it exhibits all the most important characters of the genus under which I have placed it. 'The body is black, somewhat glossy. The tip of the palpi and scape of the antennæ are rufous: the prothorax is rather wider than long, but nearly square; the short basilar furrows obscrvable in Argutor distinguish this species from the succeding ones: clytra lightly furrowed, furrows impunctured; in the usual situittion adjacent to the second furrow a little beyond the mildle of the elytrum a very minute punctiform impression is just discernible; the lateral margin and suture at the apex of the elytra are reddish: the tibia are rufous but the cubit is black at the tip; the tarsi are darker, the hand has four dilated joints as in the other species of the genus.

\section{2. * Trechus ruficrus. Red-legged Trechus.}

T. (ruficrus) niger; antennis scapo, pedibus, prothoracisque nargine, rufis: elytris luridis: litura pone medium nigricant.

Red-legged Trechus, black; seape of the antennæ, legs, and margin of the prothorax, rufous; elytra lurid with a blackisl bloteh beyond the middle.

\section{Length of the body $2 \frac{1}{3}$ lines.}

\section{One specimen only taken.}

\section{DESCRIPTION.}

Body black, glossy. Palpi piccous; scape of the antennæ and mouth rufous : prothorax subobcordate; channelled, channel not abbreviated, margin rufous especially the basilar; angles rounded; basilar impressions single, round, and punctured: clytra lurid or dirty yellow with a large blackish cloud or blotch beyond the middle: legs dull rufous, thighs darker.

$$
\text { 3. * Trechus flavipes. Yellow-legged Trechus. }
$$

T. (fuvipes) piceus, nitidus; capite subtus, ore, antennis, prothorace, elytrisque limbo, rufescentibus; palpis pedibusque flutis. Yellow-legged Trechus, piceous, glossy; head underneath, moutb, antennæ, prothorax, limb of the elytra, more or les: rufous; palpi and legs yellow.

\section{Length of the body $2 \frac{1}{3}$ lines.}

\section{Many taken in Lat. $54^{\circ}$.}

4 I suspect that the genus bere quoted, consisting also of minute species, and inbabiting moist places, (sce alove p. 30 , note 5) belongs rather to the present subsection than to the Geadcphaga; Trcchus tibialis secms to lead from Argutor to Trechus. 


\section{DESCRIPTION.}

Body piceous, glossy. Head underneath, nose, mouth, and oral organs-except the palpi which are pale yello:v - and antennæ rufous; three first joints of the latter paler than the others: prothorax rufous, rather longer than wide, between square and obcordate; basilar impressions single, very slight, punctured, and black: elytra rufous, with a broad black stripe adjoining the suture and parallel with it; furrows rather deep, impunetured: legs pale yellow.

N.B. In the majority of specimens the black stripe of the elytra is very faint, and in some evanescent, and the impressions as well as the rest of the prothorax rufous.

\section{4. * Trechus immunis. Impunctured Trechus.}

T. (immunis) piceus, nitidus; ore, antennis, pedibusque, rufis; prothorace obscure rufo; foveis posticis impressis, lavibus. Impunctured Trechus, piceous, glossy; mouth, aritennæ, and legs, rufous; prothorax obscurely rufous, with the basilar impressions ratber deep, impunctured.

Length of the body $1 \frac{3}{4}$ lines.

Two specimens taken with the preceding species.

DESCRIPTION.

Similar to $T$. flavipes but smaller, the nose is piceous, the thorax is more dusky; dorsal channel indistinet; basilar impressions decper and impunctured: elytra dark piceous with merely the bead of the lateral margin rufous; the furrows also are more lightly drawn: legs darker.

T. (similis) niger, nitidus; ore, antennis, prothoracis elytrorumque limbo, pedibusque, flavo-rufis ; prothorace postice punctulato. Similar Trechus, black, glossy; mouth, antennæ, limb of the prothorax and elytra, and legs, reddisb-yellow; prothorax punctured at the base.

Length of the body $3 \frac{2}{4}$ lines.

Two specinens taken in Lat. $54^{\circ}$.

\section{DESCRI PTION.}

Body black, glossy. Mouth reddish yellow; palpi yellow; upper-lip and mandibles rufous, the latter black at the tip; antenna dusky-rufous, three first joints more yellow: prothorax between obcordate and square, with the whole of the base distinctly and grossly punctured; basilar impressions shallow; limb of the prothorax is reddish-yellow, the disk is occupied by a large square black spot: the suture, lateral margin, and apex widely, and the inner base of the elytra, are reddish-yellow; 
acljoining to the suture is a broad black stripe not reaching the apex; the furrows are rather dleep and impunctured; and in the usual situation, a little beyond the middle, a punctiform impression is adjacent to the second furrow: the sides of the fore-breast, the anus, and the legs, are reddishyellow.

VARIETY B. Thorax without a black spot in the disk, body underneath piceous.

'Tlis species, though very like ' $T$. favipes, is quite distinct from it; it is nearly related also to T. Alavicollis of Sturm, ${ }^{5}$ but it is much larger, the three first joints of the antennx, and not the scape only, are paler than the others; and the prothorax is transversely punctured at the base, which in that species is impunctured.

\section{Family ISOPLEURIDE. ${ }^{6}$ Isopleuridans.}

\section{XXIII. "Genus ISOPLEURUS.}

Labrum rather square, emarginate at the tip.

Palpi maxillary, antepenultimate joint longer than the rest, subcylindrical; penultimate shorter than the last joint, obconical; last semi-ovate, subtruncate. ${ }^{7}$

labial, penultimate joint longer than the rest, subclavate; the last semilanceolate, subacute. ${ }^{8}$ Labium decply emarginate sometimes with a short intermediate denticle, or prominence.

Tongue shorter than the paraglossx.

Antenne three first joints glossy, the third very little longer than the subsequent ones.

Bdoy linear-oblong. Head subtriangular; frontal impressions punctiform. Prothorax subquadrate, rather narrowest anteriorly; sides curving: base as wide as the elytra. Scutellum wider than long. Elytra with the sides parallel, very slightly sinuated at the apex. Hand of the males with three dilated joints.

I know two species belonging to this genus, one taken by Mr. Drummond, in the late Expectition, amongst the Rocky Mountains, and the other, which is in my own cabinet, I judge from the pin with which it is transfixed, to have been taken in the East Indies by Major General Hardwicke, and probably given by him to the late Mr. Marsham, at the sale of whose cabinet, though $I$ have no memorandum of the fact, I suspect I purchased it. If this conjecture turns out correct, this is an instance of another Oriental form from the above mountains, and confirms a remark Mr. Sabine once made to me, that the natural productions, he spoke of the plants, on their western side appeared of an Asiatic type.

It should be observed however that the Asiatic species differs from the American in having no prominence in the sinus of the labium, its maxillary palpi also are less acute, and the prothorax not so narrow before, or more approaching to a square, so that perhaps it may form a subgenus in the Isopleuridans. This genus seens to have some relationship to Amara.

5 Deutseh. Fn. v, 87, 11, t. cli,f.c.

6 The Trechidans and Isopleuridans eamot be included in one family because the former has four dilated joints in the band of the male insect and the latter only three. I placed Stenolophins next to Harpalus, beeause the males of both agree in being quadrimanous, or having four dilated tarsi; yet $I$ am rather inclined to think that Isopleurus and Trechus, as representing the Dimanous Geadephaga, ought to be placed first. 


\section{1. * Isopleurus nitidus. Glossy Isopleurus.}

I. (nitidus) piceus, nitidissimus, supra piceo-aneus; antennis, epipleura, pedibusque, rufo-flavis ; elytris striis subpunctatis, apice lavibus.

Glossy Isopleurus, piceous, very glossy, above bronzed with a tint of piceous; antennæ, side-rover, and legs, reddishyellow; furcows of the elytra slightly punctured, but not at the apex.

PLATE I, FIG. 6.

Length of the body $3_{4}^{1}$ lines.

A single specimen taken in the Rocky Mountains.

DESCRIPTION.

Body very glossy, underneath rufo-piceous, above bronzed with a light tint of piceous. Upperlip rufous; palpi, antennæ which are slender, side-cover of the elytra and legs reddish-yellow: prothorax rather wider than long, punctured posteriorly, basilar impressions double: furrows of the elytra slightly punctured, at the apex impunctured. ${ }^{9}$

\section{Family PATROBIDE. Patrobidans.}

XXIV. Genus PATROBUS. Meg.

I consider the Patrobidans as forming a family distinct from the Pogonidans, though both agree in having only two dilated joints in the hand of the males, because the former have the last joint of the palpi more or less conical and acute ; and in the other they are filiform and truncate. De Jean has formed his first division of his Feronians of these two families, the last of which, the Pogonidans, consists of the modern genera Pogonus, Cardiaderus, Blemus, Epaphius, and Aepus;

9 The following is a description of the Oriental species :-

\footnotetext{
* Isopleurus Mac Leayi. Mac Leay's Isopleurus.
}

I. (Mac Leayi) niger, nitidus, supra aneus; ore, palpis, antennis scapo, pedibusque, rufo-flavis; clytris apice pallidis, latere externo brevissime pilosis, striatis: striis secundo, tertio, et septino foveolis octo impressis.

Mac Leay's Isopleurus, black, glossy, above bronzed ; mouth, palpi, scape of the antennæ and legs reddish-yellow ; elytra pale at the tip; at the lateral margin hairy witb very short hairs ; lightly furrowed; second, third, and seventh furrows with eight punctiform impressions. 
and the first, the Patrobidans, of Baripus and Patrobus. ${ }^{1}$ Pogomus, \&c. are not very distant from Trechus and Isopleurus; they belong as clearly to the Hygradephaga, and as clearly lead to the Patrobide, which though of greater size than most of the constituents of that subsection, maintain, as far as they are known, the same love of humid and littoral stations, and, though differing in their palpi and size, are nearly related to the Subulipalpia: the discovery of a very few intermediate links would connect Patrolus and Peryphus; and even now, if closely inspected and compared, they will be found to possess many characters in common. In the first place, in thic tribe to which Peryphus belongs, in the males, the two first joints of the hand are dilated, the second indeed only on one side, and cystophorous, as in Patolues: in the next, the head and eyes in both are very similar as to form and likewise sculpture, and the same may be said of the prothorax and elytra.

\section{DESCRIPTION.}

Antenna, the scape excepted, dusky-rufous, rather longer than the prothorax; joints that succeed the third thicker than the basal ones: prothorax wider than long, impunctured; basilar impressions singlc, slight : elytra furrowed; furrows lightly drawn, impunctured; on each of the following furrows, viz. the 2 nd, 5 th, and 7 th, are eight punctiform impressions; epipleura pale yellow.

\section{Patrobus Anericanus. (De Jean.) American Patrobus.}

Patrobus Americanus. De J. Cat. 10; Coléopt. iij, 34, S.

Feronia longicornis. Say. Amer. Trans. N. S. ii, $40,9$.

Carabus longicornis. Melsh. Cat.

Length of the body $5 \frac{3}{4}$ lines.

Three specimens taken in Lat. $54^{\circ}$.

DESCRIPTION.

Body black, glossy. Head triangular, smooth; frontal impressions long and deep; upper-lip and mandibles piceous; mouth and palpi rufous; antennæ longer than the thorax, dark mahoganycolour, third joint twice the length of the fourth: prothorax obcordate, constricted behind; dorsal channel rather deep terminating anteriorly in a transverse segment of a circle, so as to form a cross with curvilincar arms; lateral margin rather incrassated; basilar impressions single, large, wrinkled, and thinly punctured: elytra furrowed, four furrows next the suture deeper than the others, and more visibly punctured, with more convex interstices, last but one nearly obliterated: legs paleyellow with mahogany-coloured coxa and trochanters; foot-cushions of the male with a double series of minute vesicles. 
(b) Subulipalpia.

\section{Family PERYPHIDÆ. ${ }^{2}$ Peryphidans.}

XXV. Genus PERYPHUS. Meg.

\section{1. * Peryphus bimaculatus. Tivo-spotted Peryphus.}

1. (bimaculatus) niger, nitidus; supra viridi-aneus; pedibus rufis; elytris macula obliqua apicis lurida.

Two-spotted Peryphus, black, glossy; above green-bronzed; legs rufous; elytra with an oblique lurid spot at the apex.

Taken in Lat. $65^{\circ}$.

Length of the body $3 \frac{1}{4}$ lines.

DESCRIPTION.

Body glossy, underneath black, above blaek-bronzed with a slight greenish tint. Head triangular, with a thick convex neek; frontal impressions long and deep; antennx longer than the prothorax, third joint of the length of the suceeding ones; seape and palpi rufous: prothorax obcordate convex, at the base depressed, constricted, and grossly punctured; dorsal ehannel as in Patrobus; basilar impressions single, round, and deepish : elytra slightly furrowed with the furrows punctured; the seventh from the suture nearly obliterated; apex nearly smooth, near which is an oblique pale spot: legs rufous with darker thighs, espeeially in the middle.

N.B. When the elytra are raised from the body they are dusky-bronzed.

\section{2. * Peryphus sordidus. Sordid Peryphus.}

$P$. (sordidus) nitidus; subtus sordide rufus: ano infuscato ; capite prothoraceque nigro-ceneis; antennis articulis tribus primis, palpis, pedibusque, pallide r fis; elytris luridis: macula magna obliqua apicis pallida.

Sordid Peryphus, glossy, underneath dirty rufous with the anus embrowned; head and prothorax black-bronzed; three first joints of the antennex, palpi, and legs, rufous; elytra lurid with a large, oblique, pale spot near the apex.

Length of the body 3 lines.

A single specimen in Lat. $54^{\circ}$.

DESCRIPTION.

This so nearly resembles $P$. bimaculatus, that I first put it aside as an immature specimen, but further consideration induees me to consider it as distinet. It is wholly pale rufous, exeept the head the prothorax and the anus : the three first joints of the antennæ and the base of the fourth are also rufous : the prothorax appears rather narrower in proportion, and less distinetiy punetured at the base; the spot at the apex of the elytra is larger; and the thighs are rather slenderer.

2 The Peryphide are distinguished from the Bembidiade, not only by the shape of the thorax, but by having the apex and sides of the elytra smooth, or with obliterated furrows. 
$P$. (scopulinus) niger, nitidus; capite prothoraccque subviridi-ancis; antennis articulis tribus primis, palpis, pedibusque, rufis; clytris fusco-ancis, bifoveolatis, macula obliqua apicis lurida.

Scopuline Peryplus, black, glossy: head and prothorax bronzed with a slight tint of green; three first joints of the antenne, palpi, and legs rufous; elytra brown-bronzed with two punctiform impressions, and an olslique lurid spot near the ajex.

Length of the body $2 \frac{1}{2}$ lines.

Two specimens taken in Lat. $54^{\circ}$.

DESCRIPTION.

This species, though related to them, is distinct from the two preceding ones; it approaches very near $P$. littoralis, probably synonymous with Carabus rupestris Fab., but the elytra have no spot at the base, and in the usual situation, but adjaeent to the third furrow, are two punetiform impressions, not to be discovered in that species.

The body, head, and prothorax do not differ either in colour or sculpture from $P$. bimaculatus, but the palpi are considerably shorter, the three first joints of the antennex are rufous, the thighs are not darker than the rest of the leg: the elytra are of a dark mahogany-brown a little bronzed, with rather deeper furrows and punctures.

$P$. (rupicola) nitidus, piceus; capite prothoraceque aneo-piceis; antennis pedibusque rufis; elytris bifoveolatis maculis duabus, posteriori obliqua, pallidis.

Rock Peryphus, glossy, piceous; head and prothorax bronzed, piceous; antennæ and legs rufous ; elytra with two punctiform impressions and two pale spots, the posterior one oblique.

Length of the body 21 lines.

Taken abundantly in Lat. $54^{\circ}$. and $65^{\circ}$.

DESCRIPTION.

This little species appears to be the Amcrican representative of $P$. littoralis, which in many respects it closely resembles. It is however a smaller insect, the body is invariably piccous or rufopiceous, and the head and prothorax are of the same colour bronzed; the antenna are ferruginous with the scape paler: the prothorax is rather shorter. 
$P$. (picipes) niger, nitidus; elytris immaculatis, bifoveolatis; antennis scapo, pedibusque, piceis.

Pitch-footed Peryphus, black, glossy; elytra unspotted with two punctiform impressions; scape of the antennæ, and legs, piceous.

Length of the body $2 \frac{1}{4}$ lines.

Two specimens taken in Lat. $65^{\circ}$.

DESCRIPTION.

Body black, glossy, above scarcely at all bronzed. First joint of the antennæ rufo-piceous; sculpture of the head, prothorax, and elytra precisely that of the preceding species of the genus: elytra unspotted with two punctiform impressions situated as in $P$. scopulinus, \&c.: legs rufo-piceous. This comes very close to $P$. nitidulus, but that species has no punctiform impressions, and the legs are of a different colour.

\section{6. * Peryphus concolor. Concolorate Peryphus.}

$P$. (concolor) niger, nitidus, elytris apice levibus, striis lateralibus haud obliteratis.

Concolorate Peryphus, black, glossy; elytra smooth at the tip with the lateral furrows not obliterated.

Length of the body $2 \frac{1}{2}$ lines.

DESCRIPTION.

Body and members black, glossy, above bronzed. Scape of the antenux piceous : prothorax less constricted behind than in $P$. picipes; space between the basilar impressions impunctured; elytra more deeply furrowed with larger punctures in the furrows; the lateral furrows are not obliterated, hut the apex of the elytrum is impunctured.

iii. Subgenus Lopha. Meg.

8. Peryhhus (Lopha) quadrimaculatus. Four-spotted P. Lopha.

Lopha quadrimaculata. De J. Cat. 17. Steph. Illust. Mandib. ii, 22, 3.

Cicindela quadrimaculata. Linn. Fn. Suec. 751 ; Syst. Nat. i, 658, 13.

Elaphrus quadrimaculatus. Illig. Kaf. Preuss. i, 232, 17.

Carabus pulchellus. Panz. Fn. Germ. xxxviii, t. 3.

- subglobosus. Payk. Fn. Suec. i, 142, 58.

- quadrimaculatus. Berk. Syn. i, 108.

Bembidium quadrimaculatum. Gyll. Ins. Suec. ii, 22, 9. Sturm. Deutsch. Fn. v, 178, 40.

- oppositum. Say. Amer. Trans. N. S. ii, 86, 7?

Length of the body $1 \frac{3}{4}$ lines.

Two specimens taken in Lat. $54^{\circ}$. 


\section{DESCRIPTION.}

Body black, glossy. Heal and prothorax bronzed-green; four first joints of the antennæ rufous, the succeeding ones dusky; palpi rufous dusky at the tip; frontal impressions rather oblique: prothorax very much constricted behind, so as to appear almost triangular, depressed at the base with a transverse series of punctures; basilar impressions small: elytra piccous faintly bronzed, with a large roundish pale spot at the base, and another smaller, rather transverse one, beyond the middle; they are not furrowed, but have the usual number of rows of punctures which do not extend to the apex, and the lateral one is nearly obliterated: the legs are rufous.

$$
\text { iv. * Subgenus Eudrouus. }
$$

Prothorax nearly square, with double basilar impressions. Elytra with only the disk punctured in rows.

This subgenus differs from the other Peryphide in having a prothorax precisely resembling that of a Precilus, of which genus it may be regarded as the analogue amongst the Subulipalpia.

\section{9. * Peryphus (Eudromus) nitidus. Glossy P. Eudromus.}

P. E. (nitidus) niger, nitidissimus; supra nigro-aneus; elytris lavissimis, apud suturam puncto-striatis.

Glossy P. Eudromus, black, very glossy, ahove bronzed; elytra very smooth, punctured in tows next the suture.

$$
\text { PLATE I, FIG. } 7 .
$$

Length of the body $3 \frac{1}{5}$ lines.

Two specimens taken in Lat. $54^{\circ}$.

\section{DESCRIPTION.}

Body linear-oblong, subdepressed, very glossy, underneatlı black, above black-bronzed. Head triangular; frontal impressions long and rather curvilinear; scape of the antennæ rufous underneath: prothorax nearly square and level with curving sides; dorsal chamsel nearly obsolete; basilar impressions double, the inner one round and rather deep, the other very slight with a little ridge between it and the margin: anterior and posterior margin nearly straight: elytra with sides nearly parallel as well as the apex impunctured; a quintuple series of punctures adjoins the suture, which extends very little beyond the half of the elytrum, with traces of slight furrows beyond it. 


\section{XXVI. * Genus TACHYTA.}

Palpi with the last joint most minute, and with difficulty discoverable. ${ }^{3}$ Antenna subfiliform, submoniliform, with all the joints nearly equal in length.

Body oblong, subdepressed. Prothorax narrower than the elytra, rather obcordate. Elytra obsoletely furrowed.

This appears entitled to rank as a genus in a modern system, not only from having the last joint of the palpi much shorter and more minute than the other Peryphidans, but likewise from its moniliform antennæ. It seems to approach to Tachys, but the prothorax is of a different shape coming near that of Bradytus and Curtonotus. It seems to be the analogue of Dromiustruncatellus and affinities.

$$
\text { 1. * Tachyta picipes. Pitch-foot Tachyta. }
$$

T. (picipes) nigra, nitida ; prothorace obcordato utrinque unifoveato ; elytris levibus, apud suturam substriatis: striis lavibus; pedibus piceis.

Pitch-foot Tacbyta, black, glossy ; prothorax obcordate; basilar impressions single; elytra smooth, obsoletely furrowed at the suture, furrows impunctured; legs piceous.

PLATE VIII, FIG, 6.

Length of the body $1 \frac{1}{3}$ lines.

Four specimens taken in Lat. $54^{\circ}$.

DESCRIPTION.

Body black, glossy. Frontal impressions rather oblique; eyes less prominent than usual in the tribe: prothorax broader than long, subobcordate; basilar impressions, which are single, and dorsal channel, rather deep: elytra with three obsolete impunctured furrows next the suture which do not reach the apex. Apex rounded: legs piceous. 


\section{Family BEMBIDIADE.4 Bembidiadms.}

\section{(8.3) 1. * Notaphus Nigripes. Black-foot Notaphus.}

N. (niyripes) niger, nitidus; supra virrscenti-ancus; clytris lincola basilari, fusciis duabus postica undulata, apiceque, luridis. Black-foot Notaphus, black, glossy; above bronzed with a greenish tint; elytra with a basilar streak, two bands, the posterior undulated, and the tips, lurid.

Length of the body 2 lines.

Three specimens taken in Lat. $54^{\circ}$.

\section{DESCRIPTION.}

Body black, glossy; above bronzed with a greenish tint ; the whole upper-surface under a powerful magnificr appears covered with innumerable granules, which are much more distinctly seen in this family than in the Peryplide. Scape of the antenna, which are longer than the prothorax, rufo-piceous; frontal impressions parallel; the punetiform impression adjoining the eyes on their inner side has a central elevation: prothorax short with a deep dorsal channel; basilar impressions double with a little ridge between the external one and the margin : elytra furrowed, furrows punctured for about two-thirds of their length, the first and second reach the apex where they are confluent; the thirl and fourth stop a little short of the apex and are also confluent, as are the fifth and sixth, which are still shorter, and terminate in a little furrow common to both; the seventh and eighth reach the apex where they likewise unite; two punctiform impressions, in the usual situation, adjoin the third furrow; at the base of the elytrum, in the interstice between the fifth and sixth furrows, is a longitudinal lurid streak, then follows an abbreviated and articulate ${ }^{5}$ band of the same colour, consisting of four streaks, those near the lateral margin being much the longest; in the interstices between the second and third furrows are two such little streaks; near the apex is likewise another band both articulated and undulated, consisting of seven spots, the marginal one being rather the longest; the tips of the elytra are likewise lurid.

$N$. nigripes is related to $N$. ustulatus, and appears to be its American representative; it differs from it in laving black legs, and the lurid markings of the elytra are different: it comes nearest to Gyllenhal's Varicty C. 6

4 The Bembidiadce are distinguished from the Peryphide by the elytra having the typical number of furrows, none being obliterated. 


\section{2.* Notaphus intermedius. Intermediate Notaphus.}

N.(intermedius) niger, nitidus; capite prothoraceque viridi-@neis; elytris luridis aneo-nitidis; maculis dualus, fasciaque intermedia, nigris; antennis scapo, palpis, pedibusque, rufis.

Intermediate Notaphus, black, glossy ; head and prothorax green-bronzed; elytra lurid glossed with bronze, with two black spots, and a black intermediate band; scape of the antennæ, palpi, and legs, rufous.

Length of the body $I_{5}^{4}$ lines.

A single specimen taken in Lat. $54^{\circ}$.

DESCRIPTION.

Very nearly related to $N$. nigripes, but the head and prothorax are greener; antennæ as long as the prothorax; the palpi are rufous with the penultimate joint rather dusky: clytra bronzed-luricl with a round black spot near the basc, a larger near the apex, and an angular band of the same colour between them: the legs are dull rufous. The sculpture of the elytra is nearly the same as in that species, but the fifth furrow by a turn outward almost intercepts the sixth and seventh, and then runs to the apex of the elytrum; the furrows themselves are black.

\section{3. * Notaphus variegatus. Variegated Notaphus.}

N. (variegatus) niger, nitidus; supra nigro-aneus; antennis scapo, pedilusque rufo-piceis; elytris luridis nigro variegatis, striatis : striis abbreviatis; trifoveolatis.

Variegated Notaphus, black, glossy; above black-bronzed; scape of the antennæ and legs rufo-piceous ; elytra lurid, variegated with black; furrowed, furrows abbreviated, trifoveolate.

Length of the body $1 \frac{3}{4}$ lines.

DESCRIPTION.

This also is related to $N$. nigripes, but is quite distinct. The head and prothorax are without any green tint; the antennæ are not longer than the prothorax, the prothorax is proportionally not so wide before and narrower behind: elytra scarcely at all bronzed; lurid with a large blackish clond or spot near the base, another near the apex, and an intermediate black angular band; the furrows of the elytra, especially the external ones, do not reach the apex, or at least are obliterated; they are punctured the whole of their apparent length; instead of two, there are three punctiform impressions: the legs are rufo-piccous. 
XXVIII. Genus BEMBIDIUM. Lat.

(86) 1. Benbidun mpressun. (Gyllenhal.) Impressed Bembidium.

Bembidium impressum. Gyll. Ins. Succ. ii, 13, 2. De J. Cat. 16. Sturm. Deutsch. Fn. v, 177, 45. Stepb. Illustr. Mandib. ii, 32 .

Carabus velox. Linn. Fr. Suec. 803. Iter. Oeland. 207. Syst. Nat. ii, 672, 31 ?

Elaphrus impressus. Fab. Syst. Eleuth. i, 246, 4. Illig. Kaf. Preuss. i, 277, 6. Panz. Fn. Germ. x], t. 8.

- striatus. Payk. $F_{n}$. Suee. i, 175, 3.

Jittoralis. Oliv. Ent. ii, $6,34,4 ; t$. i, $f .7$.

Cicindela striata. Marsb. Ent. Brit. i, 393, 7.

Length of the body $2 \frac{1}{3}$ lines.

Taken frequently in Lat. $54^{\circ}$. and $65^{\circ}$. and in the Journey from New York to Cumberland-house. On the sandy shores of Lake Winnipeg in the spring of 1825: Mr. Drummond. In Canada. Dr. Bigsby.

This little insect appears pretty generally dispersed. In England it has been rarely met with; the only known British specimen was in the late Mr. Marsham's collection, and is now in Mr. Stephens'. The former gentleman, in his description, refers to Mr. Donovan's eabinet. I have seen specimens taken by Mr. Wilkin in Flanders; and Oliver infurms us, for there can be no doubt with respect to his synonym, though hitherto overlooked by Entomologists, that it is found on the banks of the Seine near Paris. It is found in Sweden, Major Gyllenhal informs us, on the sandy shores of lakes, where it is remarkable, in warm weather, for the promptitude and celerity of its motions both on the earth and in the air: and Mr. Drummond observes, I have no cloubt with respect to this insect rather than Sericoda bembidioides, "that it runs in the sand with great agility, and frequently flies when attempted to be taken." Linné also observes of his Carabus velox, which the Entomologists of Sweden hold to be a variety of it, that it runs and flies with the most velocity of any coleopterous insect: a circumstance, which as well as its large eyes, proves its title, in common with Elaphrus, to claim some affinity with the Eupteru, (Cicindela L.) 
DESCRIPTION.

Body underneath green, bronzed, very glossy; above bronzed, gloss much obscured, occasioned by an infinity of most minute reticulations visible only under a good magnifier, which give it a granulated appearance; frontal impressions and ocellated punctures as in Notaphus; eyes very large and prominent; palpi bronzed with the second joint obscurely rufous; antennx longer than the prothorax, with the scape, and the base of the second and third joints, rufous : prothorax short, depressed both at the base and apex, the depressed part being wrinkled longitudinally; dorsal channel and basilar impressions rather deep, in the latter are two little furrows: in the elytra, a little beyond the middle, in the interstice between the second and third furrows, are two quadrangular, oblong, slightly depressed spaces of a somewhat golden lustre, and marked at the anterior end with a punctiform impression; immediately before, betwcell, and after the depressed spaces, is a levigated and rather elevated one of the same shape; the furrows of the elytra are arranged nearly in the same way as those of Notaphus intermedius above described: the legs are rufous with the thighs bronzed at the apex.

(c) Filipalpia.

\section{Family ELAPHRIDE. Elaphridans.}

XXIX. * Genus OPIS'THIUS.

\section{Oral organs scarcely different from those of Elaphrus.}

Body depressed and flat. Head triangular, antennæ much more slender and longer than those of Elaphrus, third joint rather longer than the fourth. Prothorax very short, transverse, scarcely wider than the head; anteriorly obsoletely obtusangular, posteriorly subrepand, depressed a little at base and apex; channelled, but without basilar impressions ; sides gibbous ; angles all obtuse. Scutellum rather obtusangular. Elytra, alitrunk, ${ }^{8}$ and abdomen very much dilated, nearly twice the width of the prothorax, without furrows, with several rows of obsolete mammillated impressions. Legs rather longer and more slender than those of Elaphrus; the hands of the male have the four first joints a little dilated and furnished underneath with a brush.

This appears to be one of those transition genera which Mr. W. S. Mac Leay has denominated osculant, and to unite the Hygradephaga filipalpia with the subulipalpia, and more particularly Elaplerus with Bembidium. From the latter it borrows its general aspect, its short prothorax, its dilated elytra, alitrunk and abdomen; its oral organs, its head, and in some respects its elytra, and its legs are those of the former; its antennæ resemble those of Cicindela; and the hand of the male has four dilated joints furnished with a brush as in the Carabida.

The alitrunk is that part of the trunk which bears the wings and the four posterior legs. 


\section{1. * Opisthius Richardsoni. Richardson's Opisthius.}

O. (Richardsoni) subobscurus; subtus niger; subpilosus, supra nigro-ancus; clytris dilutatis planis, fovcolarum lcvium seriebus quatuor ; tibiis obscure rufis.

Richardson's Opisthius, gloss rather obseured; black underneath and somewhat hairy; above black-bronzed; elytra flit, dilated, with four rows of slight impressions; tibia obscurely rufous.

PLATE I, FIG. 9.

Length of the body

Breadth of the prothorax $4 \frac{1}{4}$
1 lines elytra taken together $2 \frac{3}{4}$

Mr. Drummond, from my description of this curious insect, thinks it was taken in May, 1825, on an island of Lake Winnipeg, frequenting moist muddy places from which the water had shrunk.

\section{DESCRIPTION.}

Body with the gloss obscured; underneath black, somewhat hairy, above a little bronzed. Antennx nearly half the length of the body, four first joints greenish-bronzed, the rest deep blue; front with a slight impression between the antennæ and a few scattered short whitish hairs: prothorax very short, more bronzed, transversely very minutely wrinkled: elytra with three rows of oblong greenish very slight impressions, each with a central oblong elevation, with another levigated one between each; adjoining the lateral margin is a fourth scries of greenish-bronzed more numerous impressions without any central or intermediate elevations: thighs green-bronzed, tibix obscurely rufous, tarsi black, legs hairy.

XXX. Genus ELAPHRUS. Fab. 1. Elaphrus Clairvillia. Clairville’s Elaphrus.

E. (Clairvillii) viridi-aneus, supra punctulis induratis irroratus: elytris faveis annulatis caruleis punctatis quadruplici scrie; fronte inter oculos fovcola impressa; fcmoribus virdibus.

Clairville's Elaphrus, green-bronzed, above sprinkled with minute gilded punctures; elytra with annulated, blue, punctured impressions in a quadruple series: thighs green.

Elaphrus riparius. Say. Amer. Trans. ii, 80 ?

PLATE I, FIG. 8.

Length of the body 4 lines.

A single specimen taken in the journcy from New York to Cumberland-house. 


\section{DESCRIPTION.}

Body glossy; underncath green-bronzed; above black slightly bronzed, covered with minute scattered, gilded punctures. Mandibles and palpi piceous; antenmæ black, with the three first joints dark blue; front with an elevation between the eyes, rather deeply impressed in the centre : prothorax longer than wide, uneven, with two large discoidal elevations separated by a dorsal channel, each with a central impression; a single basilar impression at the posterior angles tinted with blue: elytra with four irregular rows containing in all twenty-one slight circular impressions punctured, and tinted with blue, each, except the marginal ones surrounded by an elevated ring, and placed in a wider impression; between each of these impressions in the two first rows is an elevated and levigated space: thighs glossy-green, the posterior pair rufous at the base; tibiæ and tarsi piceous.

I am doubtful whether this species may not be Mr. Say's E. riparius, but it is not the real one, from which, and E. uliginosus, it is distinguished by being much less thickly dusted with greengold glittering punctures, which gives it a blacker hue. The impression also in the elevated space between the eyes is much deeper. The blue-tinctured impressions of the elytra are also more distinct, and surrounded by a more elevated ring.

It may be here observed that the peculiar sculpture which is so conspicuous in the elytra of Elaphrus may be first traced in those of Bembidium impressum which exhibits two gilded impressions; in Opisthius these impressions become more numerous, and assume a seriatim arrangement; and in the genus first named they become more perfect and prominent-this affords a further proof of the affinity of the Bembidiadans and Elaphridans.

\section{2. * Elaphrus intermedius. Intermediate Elaphrus.}

E. (intermedius) punctulatissimus, subtus viridi-aneus, supra nigro-aneus; tibiis rufis; elytris foveis subimpressis centro eminentibus quadruplici serie; plaga elevata, lavigata, discoidali, communi.

Intermediate Elapbrus, very minutely and thickly punctured; undemeath green-lرonzed, above black-bronzed; tibix rufous; elytra with four rows of slight impressions with an eminence in the ceutre, and an elevated levigated discoidal space common to both elytra.

Length of the body $\&$ lines.

\section{Taken by Dr. Bigsby in Canada.}

\section{DESCRIPTION.}

This species resembles E. cupreus, but it is quite distinct. The body is more thickly and minutely punctured on the whole upper surface; underneath it is of a fine bronzed-green; above it is blacker and less brilliant: the head is greenish; the middlc space between the eyes is less elevated than in that species, and wrinkled longitudinally without any impression: the impressions on the discoidal elevations of the prothorax are fainter: the elytra like the other spccies have a quadruple scries of impressions, but they are broader, more slight, without any elevated ring, are more minutely punctured, have a slight elevation in the centre, and are of the same colour with the rest of the elytrum; the marginal series is nearly obsolete; just before the middle, adjoining the suture is a quadrangular elevation which unites with that of the other elytrum: the thighs are green, rufous at the base, tibia rufous, tarsi piceous. 


\section{3. * Elaphirus obscurior. Obscurer Elaphius.}

E. (obcurior) supra obscuro-cupreus, capite prothoraceque punctulatissimis; elytris obsolcte fovcatis, spatiis elevatis lerigatisque quatuor.

Obscurer Elaphrus, above obscurely cupreous, head and prothorax thickly and minutely punctured; elytru rery slightly impressed, with four polisbed clerations.

Length of the body $3 \frac{1}{1}$ lines.

\section{A single specimen taken in Lat. $65^{\circ}$.}

\section{DESCRIPTION.}

This species is more strongly marked than the majority of the Elaphri. On the underside the head and trunk are copper with a slight tint of green; the abdomen of a dusky purplish copper: above it is copper-coloured; the head, with the exception of the upper-lip, is very thickly and confluently punctured, with a levigated but scarcely elcvated space between the cyes; the four first joints of the antennæ are cupreous: prothorax not wider than the head, confluently and thickly punctured; discoidal elevations not conspicuous nor impressed; elytra not glossy, punctured with seattered punctures, marked by a quadruple series of very slight impressions, some nearly obsolete, most of them marked out by a very slight elevated ring and a circle of punctures, three levigated quadrangular spaces near the suture and arranged in a line parallel with it, and a fourth triangular one removed from it, near the apex; the disk of the elytra is faintly purple: legs bronzed.

XXXI. Genus NOTIOPHILUS. Dum.

\section{Notiophilus aquaticus. Aquatic Notiophilus.}

Notiophilus aquaticus. De J. Cat. 18; Coléopt. ii, 227, 1. Latr. Crust. Arachn. et Ins. i, 418. Steph. Illustr. Mandib. ii, 32, 1. Sam. Compend. 148, 1. Leach. Ed. Encycl. ix, 79.

Cicindela aquaticà. Linn. Fn. Suec. 752; Syst. Nat. ii, 658, 14. Goeze. Eur. Fn. viii, 686, 3. Miill. Linn. Nat. Syst. V. i, 331, 14. Schrank. Enum. 193, 361. Vill. Ent. i, 325, 10. Berk. Syn. i, 105. Don. Ins. viii, t. 351, f. 2. Mlarsh. Ent. Brit. i, 393, 6.

_- striata. De G. Ins. iv, 118, j.

- pusilla. Schreb. Nov. Spec. 10,6.

- semipunctata. Marsh. Ent. Brit. i, 394, 8. Vill. Ent. i, 326, 12.

Elaphrus aqquaticus. Fab. Syst. Eleuth. i, 246, 7. Oliv. Ent. ii, 34, 6,5, t. i, f. 6. Ced. Fn. Ingr. 28, 85. Panz. Ent. Germ. i, 69, 6; Fin. Germ. xx, t. 3. Illig. Kof. Preuss. i, 224, 1. Payk, Fn. Succ. i, 177, 5. Ross. Fn. Etrusc. i, 193, 478. Hoppe. Taschenb. 1796, 182, 37. Gyll. Ins. Suec. ii, 10, 4 ; iv, 399, 4. Duft. Frn. Austr. ii, 191, 2. Walck. Fn. Paris i, 61, 5. Lat. Gen. i, 182, 5.

Elaphrus semipunctatus. Fab. Syst. Fleuth. i, 246, 8. Oliw. Ent. ii, 34, 6, 7, t. i, f. 3. Panz. Ent. Germ. i, 69, 7. Ross. Fn. Etrusc. i, 194, 479. Herbst. Arch. 116, 3. Clair. Ent. Helvet. ii, 166, t. xxw, f. в. 6. Walck. Frn. Paris. i, $61,6$. Buprestis. Geoff. Ins. i, 157, 31 . 


\section{DESCRIPTION.}

Body very glossy, black underneath, above bronzed. Head with seven furrows between the eyes, the two lateral ones the deepest; nose anteriorly wrinkled longitudinally, behind with a pair of transverse punctiform impressions with a minute rather sharp elevation between them; antennæ short, obscurately rufous at the base: prothorax punctured with the disk transversely smooth; dorsal channel abbreviated; basilar impressions single, large: elytra punctured in rows, the interstice between the sutural and the second rows thrice the width of the other interstices: there are nine rows of punctures, thie fourth, fifth, and six are also furrowed; the seventh, eighth, and ninth terminate in furrows, which run to the end of the elytrum, the two exterior ones becoming confluent : between the third and fourth rows in the anterior half of the elytrum is a deep punctiform impression, and another very minute one with a central elevation is discoverable between the apex and the little furrow in which the fifth and sixth rows after they become confluent terminate: thighs a little bronzed.

\section{Family OMOPHRONID艮. Omophronidans.}

This family, as far as at present known, consists only of a single genus, which appears separated by a very wide interval from the other insects of the present section, and makes a near approach to those Hydradephaga, or aquatic predaceous beetles that have no scutellum, as Haliphs and Hydroporus, with which, indeed, Clairville has associated it; and it agrees with them not only in having no apparent scutellum, a character scarcely to be found, that I am aware, in any true Geadephagous genus ; ${ }^{9}$ but its larva also, as appears from $\mathbf{M}$. Desmaret's description of it, though it wants the suctorious mandibles, exhibits a striking resemblance to that of Dytiscus. In fact, as far as our present knowledge leads us, its cognate forms are all in that tribe, none at present discovered among the terrestrial predaceous beetles coming near it. Future discoveries will probably help to fill up the hiatus between them; at present, however, it must be regarded as nearer to the Hydradephaga than the Geadephaga. I shall therefore consider it as occulant between them.

9 Mr. W. S. Mac Leay (Annulos. Javan. i, 23, 4l, t. i, f. 4) has described an insect, which he places amongst his Harpalide, under the name of Anaulacus sericipennis, and which he regards as an anomaly, that has no apparent scutellum. which in this circumstance and in its shape seems to resemble Omophron, but as yct I bave not had an opportunity of examining the insect. 
X゙xil. Genus OMOPHRON. Lat.

\section{1. *mophrox Sair. Suyj's Omophrim.}

O. (Suii) nigra: fronte antennis, pedibus, elytrisque fasciis duabus angulato-undulatis apiceque, testaccis; labro, prothoracis lateribus, clytrisque margine laterali, aryenteis.

Say's Omopliron, blick; front, antenne, legs, two angulato-undulated bands and apex of the elytra, testaceous; upper-lip, sides of the prothorax, and lateral margin of the elytra, silvery.

Length of the body 31 lines.

\section{Taken by Dr. Bigssby in Canada.}

DESCRIP'TION.

'This species seems intermediate between O. limbatum and O. labiatum. From the former it differs in having a much fainter tint of green on the darker parts of the body; in its black prothorax with silvery sides as well as margin. From the latter in having the lateral furrows as deep and distinctly punetured as those of the disk; and, instead of two reddish spots near the base of the elytra, having two angulato-undulated bands, one near the base and the other beyond the middle, and the tips, testaccous; all connected by the margin of the same colour. It seems to have escaped the describers of $O$. limbatum that the upper-lip and lateral margin of the prothorax and elytra are likewise silvery, though not so conspicuously as in O. labiattm and Saii.

'The sculpture of the clytra in this genus, as well as in Calosoma, differs from that of the other terrestrial predaccous bectles in hasing more than nine furrows, which appears to be the typical number in the section.

iii. Hyoradepuaga. Mac L.

a. Eunecha. Kirb.

\section{Fanily HALIPLID压. Haliplidans.}

XXXIII. Genus HALIPLUS. Lat.

\section{Haliplus impressus. Impressed Haliplus.}

Haliplus impressus. Lat. Gen. i, 234, 2, t. vi, f.6? N. D. D'H. N. xiv, 156. Gyll. Ins. Suec. i, 547, 3. Steph. Illustr. Mandib. ii, 39, 2?

Dỵtiscus impressus. Fab. Syst. Eleuth. i, 27I, 7I. Payk. Fn. Suec. i, 235, 49. Oliv. Ent. iii, 40, 32, 42, t. iv, f. 40. Illig. Kaf. Preuss. i, 260, 30. Panz. Fn. Germ. xiv, t. 7. Thunb. Ins. Suec. vi, 77. Selıneid. Mag. 367. Goeze Eur. Fn. viii, 745, 7. Brabm. Ins. Kál. i, 23, 82.

laminatus. Schall. Hall. i, 314 .

Alavicollis. Marsh. Enı. Bril. i, $430,47$.

Lengtli of the body $1 \frac{1}{2}$ lines, nearly.

One specimen taken in Lat. $65^{\circ}$. 
I have added a query to the synonym of Latreille, because, though his description agrees with our insect, his figure does not, for it represents the elytra with eight black spots, which are not to be found in $H$. impressus. Mr. Stephens, in his description, does not mention that the punctures forming the rows on the elytra are black, which in a describer usually so accurate, renders his synonym somewhat doubtful.

\section{DESCRIPTION.}

Body reddish-yellow. Head punctured, dusky behind : prothorax yellow, depressed in the middle posteriorly, with a transverse curved series of punctures in the depression; anteriorly there are five or six black dots arranged transversely; at the base, between the central point and the margin on each side, an oblique little furrow but not easily discoverable, is impressed : elytra pale-yellow with a cinereous tint, nine rows of black punctures on each, those near the lateral margin being the faintest; anteriorly, in the interstices of the rows, there are also a few black punctures; the apex of the elytra is oblique terminating in an acute point: the laminæ that cover the posterior legs are punctured.

XXXIV. Genus HYDROPORUS. Clair.

\section{Hydroporus nigro-lineatus. Black-lined Hydroports.}

Hydroporus nigro-lineatus. Steph. Illustr. Mandib. ii, 52. 6.

Hyphydrus nigro-lineatus. Schon. Syn. ii, 33, 16, t. iv, f. 2. Gyll. Ins. Suec. iii, 688, 13, 14.

Length of the body $2 \frac{1}{2}-2 \frac{3}{4}$ lines.

A pair taken in Lat. $65^{\circ}$.

DESCRIPTION.

Body lurid-yellow, somewhat glossy, minutely and thickly punetured. Antennæ dusky at the tip : prothorax with a minute black rhomboidal spot in the disk, which is marked with a punetiform impression; anteriorly it has a transverse series of punctures larger than those of the rest of its surface: elytra most numerously and minutely punctured; the suture, and four longitudinal stripes not reaching the apex, nor the first and third the base, all black; the fourth or outermost is distant from the margin and interrupted: the alitrunk and abdomen are black.

In the female, which is less glossy, the external stripe is continuous, and only the second reaches the base; and in the male the prothorax is more conspicuously punetured, and the anterior series of punctures is wanting. 
II ALIPLADA.

\section{Hydroporus parallelus. (Say.) Parallel Hydroporus.}

17ydroporus parallelus. Say. Journ. Acad. Phil. III, i, 153, I.

Length of the body 21 lines.

\section{One specimen only taken. Mr. Say took it in the Upper Missonri.}

\section{DESCRIPTION.}

Body most thickly and minutely punctured, underneath mostly black. Head black with a pair of vertical dots, a line between the eyes, a triangular spot on the nose and the mouth, reddish-yellow; antenna dusky at the tip : prothorax reddish-yellow with a large discoidal irregular black spot, which does not reach the anterior margin, and is divided longitudinally by an articulated reddish-yellow stripe; there is likewise a black dot on each side, and the posterior margin is lblack: the elytra are black with seven very narrow lurid-yellow stripes, which are confluent at the base and apex by pairs; the third from the suture is twice interrupted; a series of punctures adjoins the fourth stripe on the side next the suture: the epipleura and lower margin of the prothorax are lurid-yellow: the legs are testaceous with the four anterior tarsi black.

\section{3. * Hydroporus terts. Smooth Hydroporus.}

H. (lavis) lavissimus, sublus niger, supra luridus; prothorace postice transverse impresso: maculis duabus, elytrisque lineis sex, maculisque tribus lateralibus, nigris.

Smooth Hydroporus, very smooth, black underneath, above lurid; prothorax transversely impressed behind: with two spots, elytra with six lines and three lateral spots, all black.

Lengtls of the body 2 lines.

One specimen only taken.

DESCRIPTION.

Very like the preceding species but smaller; it differs principally in being perfectly smooth and without punctures, even when examined under a powerful magnifier. The head has two larger vertical lurid-yellow spots, and there is a triangle of the same colour between the eyes, which at its base is dilated and occupies the nose and mouth: the prothorax is lurid-yellow, with two oblong oblique dusky spots beyond the middle; towards the base is an obtusangular transverse impression, and on each side, at a little distance from the margin, is an oblong punctiform impression; in the clytra are six distinct narrow black stripes, none of which are confluent except at the apex; at the side, but at some distance from the lateral margin, are three black spots placed in a line, or a stripe wider than the others twice interrupted: the legs are testaceous with the posterior tibix black at the tip. 


\section{4. * Hydroporus picatus. Pitch-coloured Hydroporus.}

H. (picatus) obscums, punctatissimus, supra piceus; capite, antennis, pedibus, prothoraceque antice, ferrugincis, elytris obsolete quadristriatis : striis postice abbreviatis.

Pitch-coloured Hydroporus, not glossed, very thickly punctured, above piceous ; head, antennæ, legs, and prothorax anteriorly, ferruginous : elytra with four obsolete posteriorly abbreviated furrows.

Length of the body $2 \frac{1}{3}$ lines.

A single specimen taken in Lat. $54^{\circ}$.

\section{DESCRIPTION,}

Body dark piceous, without gloss; covered, especially abovc, with an infinity of punctures. Head obscurely ferruginous, dusky behind, with a palcr quadrangular spot extending to the mouth between the eyes; antennæ ferruginous: prothorax with its anterior half dark ferruginous, marked with a discoidal punctiform impression or little furrow: clytra with four posteriorly abbreviated punctured furrows, very difficult to be discerned, and only by looking on one side from behind : forebreast and legs ferruginous; alitrunk and abdomen black.

\section{5. *Hydroporus similis. Similar Hydroportes.}

H. (similis) subnitidus, punctatus, supra dilute piceus; capite prothoraceque, antice, pedibus antepectoreque, testaceis; elytris, dimidio basilari grosse punctato et distinete quadristriato.

Similar Hydroporus, rather glossy, punctured; above piceous with a paler tint; head and protborax anteriorly, legs and fore-breast, testaceous : basilar half of the elytra coarsely punctured, and with four distinct furrows.

Length of the body $2 \frac{2}{8}$ lines.

\section{Taken with the preceding species?}

\section{DESCRIPTION.}

I at first regarded this as the other sex of $H$. picatus, but upon inspecting their tarsi I found they were both males. This species is smaller, more glossy, the parts that in that are dark ferruginous, in this are much paler; the punctures on the upper surface are less numerous and larger, especially those of the basilar half of the elytra, and the four furrows, particularly the three dorsal ones, are deeper and more distinct; the disk of the prothorax also is transversely levigated and impunctured.

Both these insects come very near to $H$. picipes, but that species has not the discoidal impression in the prothorax; and its elytra are dark testaccous, striped with black.

N. B. All the above species belong to Mr. Stephen's second division of the family with the sides of the prothorax rounded. 
XXXY. Genus LACCOPIIHUS, Leaeh.

\section{Laccophulus bigutratus. Ti(t)-sputted Laccophilus.}

I. (biguttatus) niger; eapite, prothorace, pedibusque, pallide flaris; clytris fusco-cincreis gutta marginali obscura flara.

Two-spotted Laccophilus, black; head, prothorax, and legs, pale yellow; elytra einereous-embrowned, with an obscure yellow marginal spot.

Lengtt of the body 2 lines.

One specimen only taken.

DESCRIPTION.

Body very smooth, glossy. Head dirty yellow; palpi and antennx dusky at the tip ; manitrunk 1 dirty yellow; elytra embrowned-cinereous, with a line of punctures, as in the other species, adjacent to the suture, and a pale yellow, indistinct, oblong, anterior, marginal spot: legs dirty yellow, posterior tarsi dusky; alitrunk and abdomen nigro-piceous; apex of the segments of the latter reddishyellow.

This species is smaller than L. minutus, which it resembles, and the colour of the clytra and underside of the body differs.

\section{Family DYTISCID无. Dytiscidans.}

XXXVi. Genus COLYMBETES. Clair.

(100) 1. * Colmubetes semipunctatus. Semipunctured Colymbetes.

C. (scmipunetatus) ater, nitidus; ore, antennis, tarsisque quatuor antcrioribus, ferrugincis; elytris disco seriatim, latere sparse, punctatis.

Semipunctured Colymbetes, very black, glossy; mouth, antennæ, and four anterior tarsi, fcrruginous; elytra punctured in lines on the disk, on the sides without order.

One specimen only taken.

Length of the body $3 \frac{l}{4}$ lines.

DESCRIPTION.

Body oblong, glossy, very black; above very slightly bronzed; under a powerful magnifier the whole upper surface is most minutely reticulated, and the under covered, with longitudinal scratches. Head with a pair of vertical red crescents placed transversely, and scarcely visible except when the sun shines; upper-lip, palpi, and antennæ ferruginous; mandibles black; prothorax anteriorly witls a continuous transverse marginal series of punctures, posteriorly with one widely interrupted in the middle; and in the disk witl a misute furrow: elytra with a triple dorsal series of punsetures not regularly or singly arranged, with other seattered punctures interjacent especially towards the apex, on the side the punctures, which are not numerous, are seattered without order; in the sutural series the punctures are distant and single; beyond the middle of each elytrum not far from the lateral margin is a red streak, not distinctly visible except in a strong light: the arms are piceous, and the four anterior tarsi ferruginous.

1 The manitrunk is that part of the trmk that bears the arms or fore-legs. It includes the prothorax and antepectus. 


\section{2. *olymbetes bicolor. Two-colonred Colymbetes.}

C. (bicolor) ater, ellipticus, convexus, nitidus, ore, antennisque testaceis; pedibus, elytrisque latere externo, brunneis; prothoracis strie postico continuo.

Two-coloured Colymbetes, very black, elliptical, eonvex, glossy; moutb, and antennæ, testaceous; legs, and elytra externally, mahogany-colour; posterior series of the prothorax continuous.

Length of the body $3 \frac{1}{2}$ lines.

A single specimen taken in Lat. $54^{\circ}$.

\section{DESCIIPTION.}

Body nearly elliptical, convex, smooth, glossy, and very black. Reticulations more visible in the head than in the rest of the surface; a pair of round obscure red spots in the vertex; mouth, palpi, and antenne, testaceous: anterior transverse series of the prothorax with single punctures at the sides but seattered ones in the middle, posterior series continuous with single and rather distant punctures: elytra externally of a pale mahogany colour; with a double dorsal series of punetures, not numerous nor regularly arranged, which do not reach the apex; there are a very few scattered punctures besides in the side : legs malrogany-colour.

3. * Colymbetes pheopterus. Brown-winged Colymbetes.

C. (pheopterus) ellipticus, subdepressus, ater, nitidus; elytris fuscis, nargine laterali dilutioribus ; ore, antennis, pedibusyue, ferrugineis : prothorace seric postico interrupto.

Brown-winged Colymbetes, elliptical, subdepressed, very black, glossy: elytra brown, externally paler, mouth, antennæ, and legs, ferruginous : prothorax with the posterior series interrupted.

Length of the body $3 \frac{1}{4}-3 \frac{1}{2}$ lines.

Two specimens taken in Lat. $54^{\circ}$.

\section{DESCRIPTION.}

Body nearly elliptieal, rather depressed, smooth, very black, glossy. Head with a pair of transverse obscure red spots in the vertex; mouth and antennæ testaceous : posterior series of the prothorax thickly punctured, and discontinuous in the middle: elytra brown, a little paler at the base and side; epipleura yellow; sculpture of the elytra like that of $C$. semipunctatus, but fewer punctures in the side: legs ferruginous; body undernenth longitudinaliy seratehed.

This species appears to be the American representative of C. paludosus (Dytiscus politus Marsh.) which it nearly resembles, but the anterior part of the front is black, and not yellow as in that species; and the prothorax is wholly black, without a broad rufous margin. 


\section{4. *olymbetes bifarius. Bifurian Colyubetes.}

C. (bifurius) ovalis, niger, obscuriusculus; antcnnis, ore, pedibus, thoracisque margine luterali, rufis; clytris bifuriam acuductis.

Bifariun Colymbetes, black, not glossy ; antenna, moutl, legs, and lateral unargin of the prothorax, rufous; elytra acudueted two ways.

PIJATE V, FIG. 6.

Length of the body $3 \frac{1}{1}$ lines.

\section{A single specimen taken in Lat. $54^{\circ}$.}

\section{DESCRIPTION.}

Bodly oval, smooth, black, less glossy. Head with a pair of vertical red crescents; mouth, antemux, and palpi ferruginous; maxillary palpi with the last joint black; prothorax longitudinally acuducted, with the bead of the lateral margin rufous : elytra at the base longitudinally, at the apex transversely, acuducted $:^{2}$ forebreast and legs picco-rufous.

\section{Colymbetes reticulatus. Reticulated Colymbetes.}

C. (rcticulatus) oblongus, niger, supra reticulatim acuductus; elytris nigricantibus; latere, prothoracisque fascia mcdia, flavescentibus; pcdibus ferrugineis.

Reticulated Colymbetes, oblong, black, aeudueted like network; elytra dusky-einereous, with the side and the mesal band of the prothorax yellowish; legs ferruginous.

Length of the body $3 \frac{1}{1}$ lines.

Three specimens taken in Lat. $65^{\circ}$.

DESCRIPTION.

Body oblong, black, gloss obscured from its being covered as it were with a web of the finest network, sculptured as if with the point of a needle. Head with a pair of round red vertical spots: prothorax with a yellow mesal band and lateral margin : elytra dusky-cinercous with the side yellowish: legs ferruginous.

$(105)$

6. * Colrubetes picipes. Pitch-legged Colymbetes.

C. (picipes) ovalis, supra anco niger, obscurus, reticulatim confertissime aeuductus; ore antennisquc ferrugincis; pedibus quatuor anterioribus piccis.

Piteh-legged Colymbetes, oval, above bronzed-ulack ; very thickly acuducted like network ; mouth and antennx ferruginous ; four anterior legs piccous.

Length of the body $4 \frac{1}{4}$ lines.

Two specimens taken, one in Litt. 54 $4^{\circ}$, the other in Lat. $65^{\circ}$. 


\section{DESCRIPTION.}

Body oval, black, above slightly bronzed, not glossy, covered above and below like the preceding species, as it wcre, with a web of nct-work; but the reticulations are more minute. Upper-lip, palpi, and antennæ ferruginous; a pair of oval, minute, obscure, red spots mark the vertex : prothorax with the anterior transverse serres of punctures double in the middle, the postcrior one not easily discernible, discontinuous in the middle : there appear no rows of punctures on the elytra, but a few scattered ones may be discovered: the four anterior legs are piceous.

This species approaches $C$. chalconatus, but it is longer, less glossy, the reticulations of the surface are more distinct, no rows of punctures are discoverable, as in that, on the elytra, which as well as the prothorax are all of one colour; and the posterior legs are black. It seems still nearer C. ater, but it is much smaller, less convex, and has no fenestrated spot on the elytra.

\section{Colymbetes assimuls. Similar Colymbetes.}

C. (assimilis) obovatus, depressus, lavis, niger; prothorace flavcscenti, immaculato; elytris flaveseentibus, nigro ereberrime irroratis; pedibus flavis; brachiiis brevissimis piceis.

Similar Colymbetes, obovate, depressed, smooth ; prothorax dirty-yellow without spots ; elytra dirty-yellow, sprinkled with innumerable black dots; legs yellow : arms very short, piceous.

Length of the body $5 \frac{3}{4}$ lines.

\section{Taken in Nova Scotia by Dr. Mac Culloch.}

\section{DESCRIPTION.}

Body rather depressed, between oblong and obovate, smooth, rather glossy, black, covered above with an infinity of very minute reticulations. Head dirty-yellow; vertex black, with a pair of confluent transverse reddish spots: prothorax dirty-yellow, rather dusky in the disk, transverse, punctures nearly obliterated: elytra of the same colour as the prothorax, but sprinkled with innumerable black dots, which however do not extend to the base and sides; a row of more distant and larger dots adjoins the suture: the fore-breast, the base and apex of the other ventral segments of the abdomen, are dirty-yellow; the legs are of the same colour, but the arms are shorter than usual and piceous; the dilated posterior coxæ are sculptured with branching rugosities.

This species represents $C$. notatus, which it is very like, but the elytra are wider towards the apex which gives the insect an obovate shape; the black dots of the elytra are more numerous, and minute; the prothorax is without spots: and the arms or fore-legs are shorter and of a different colour. 
(107) S. * Colmubetes tri-seriatus. Three-rowed Colymbetes.

C. (tri-seriatus) niger; antennis, pedibusque testaceis; prothorace testaceo fuscia discoidali nigra; elytris nigricantibus latere externo flavis, transversim confertissime acuductis, punctis longitudinaliter triseriatis.

Three-rowed Colymbetes, black; antennæa and legs testaceous; prothorax testaceous with a discoidal black band; elytrib dusky, externally yellow, transversely very thiekly acudueted, with a triple longitudinal scries of punctures.

Length of the body $7 \frac{3}{4}$ lines.

A single specimen taken. I have a specimen also from New England, taken by Professor Peck.

DESCRIPTION.

Body elliptical, rather depressed, underneath black, and covered with an infinity of branching or confluent wrinkles, as if seratched by a pin or needle. Head black, anteriorly testaceous, between the eyes is a pair of transverse red spots; antemm and palpi testaceous, dusky at the tips: prothorax testaecous with an abbreviated, subbilobed, discoidai band; variously acuducted so as somewhat to resemble net-work: seutellum ferruginous, black at the base, very minutely and confluently punetured: elytra dusky, which colour, for they are really lurid or dirty-yellow, is produced by an infinity of transverse black lines or furrows, but whieh at the lateral margin lose their blackness; besides these there are three rows of punctures arranged longitudinally but not regularly, the first adjoining the suture, and the two others being diseoidal; between the outer one and the margin, especially near the apex, are some scattered punetures; the epipleura, and sides of the fore-breast, are yellow: legs testaceous; thighs and tibiæ punctured.

This species is intermediate betwen $C$. striatus and $C$. dolabratus, with the former it agrees in the majority of its characters, particularly in the longitudinal rows of punetures, except that its sutural one is more perfect; and with the latter in the prothoracie band, and the colour of the legs. 'The transverse furrows of the elytra are rather deeper than those of the first-mentioned species, and not so deep as those of the last.

These inseets, adding $C$. fuscus, may perhaps be regarded as forming a subgenus, whose common charaeter is the peculiar sculpture of the elytra.

v. Subgenus Hxdaticus. Leach.

(108) 1. * Colymbetes (Hydaticus) rugrcolbis. Wrinkle-necked C. Hydaticus.

C. H. (rugicollis) obotatus, subrufus, nigricanti-nebulosus; prothorace longiludinaliter acuductus; elytris flavescentibus, nigro reticulatis.

Wrinkle-necked C. Hydaticus, obovate, subrufous, clouded with dusky; prothorax longitudinally acuducted; clytra yellowisb, reticulated with black.

Length of the body 6 lines.

Taken in Nova Scotia by Dr. Mac Culloch. 
DESCRIPTION.

Bolly rather obovate and depressed; underneath rufous clouded with dusky. Head subrufous, dusky behind; antennæ and palpi yellowish, dusky at the tip: prothorax with the posterior angle acuminate, subrufous, dusky in the disk, posteriorly scratched longitudinally as if by a pin : elytra pale-yellow, thickly and minutely reticulated or vermiculated with black; lateral margin yellow, unspotted; epipleura yellow; prosternum depressed.

This species appears to represent $C$. $H$. irroratus. 2. * Colymbetes (Hydaticus) Mac Cullochir. Mac Culloch's C. Hyduticus.

C. H. (Mac Cullochii) obovatus, depressus, niger, nitidus; ore, antennis, pedibusque quatuor anterioribus, prothoracis limbo fasciaque, elytrisque fascia undulata, punctoque apicis, pallidis.

Mac Culloch's C. Hydaticus, obovate, depressed, black, glossy; mouth, antennæ, four anterior legs, limb and band of the prothorax, aud undulated apical band and dot of the elytra, all pallid.

Length of the body $5 \frac{3}{4}$ lines.

\section{Several taken in Nova Scotia by Dr. Mac Culloch.}

\section{DESCRIPTION.}

Body obovate, depressed, glossy; underneath black, confluently punctured and wrinkled. Head posteriorly minutely punctured, black; nose, mouth, and its organs, and a band between the eyes, pale yellow; antennx pale with the joints above dusky at the tip: prothorax punctured, pale-yellow, with a discoidal band, dilated at each extremity and surrounded by a black margin, of the same colour : elytra black, sprinkled with innumerable pale-yellow dots; near the apex is a pale, angular, undulated band, and beyond it a round white spot; the margin of the elytrum is paler than the rest: the three intermediate ventral segments of the abdomen have each a pair of roundish pale spots, one on each side; the four anterior legs are pale-yellow.

XXXVII. Genus DYTISCUS. Linn.

\section{Dytiscus Ooligbuki. Ooligbuk's Dytiscus.}

D. (Ooligbukii) oblongo-ovatus, olivaceo-niger; subtus flavo-testaceus, suturis ct segmentorum marginibus, nigris; prothoracis linbo, elytrorumque latere, Aavis; his apice punctatis foveolatisque; metasterni lobis acuminatis.

Ooligbuk's Dytiscus, oblong-ovate, olive-black; underneath yellowish-red with the sutures, and the margins of the segments, black; limb of the prothorax and side of the elytra yellow; the latter punctured and foreolated at the apex; lobes of the metasternum acuminate.

Length of the body $\left\{\begin{array}{l}\text { Male } I \text { inch and } 4 \text { lines. } \\ \text { Female } 1 \text { inch and } 5 \text { lines. }\end{array}\right.$

A pair were taken by the Esquimaux Ooligbuk in the Great Bear Lake River. 


\section{MESCRII'LION.}

d

Body reddish-yellow underneath, above olive-black. Heal minutely but thinly punctured; montl, nose, and antennx yellow; there is a red angular spot on the vertex: prothorax obsoletely chamelled, minutely and thinly punctured, with the limb widely yellow, but less so behind where the yellow sends two teeth into the black disk; an anterior and posterior transverse line of larger punctures are also visible: scutellmm wholly black: elytra with two discoidal longitudinal rows of punctures; three others, in which the punctures are more distant and less conspicuous, are interposed, one between the suture and the first row, the next between the first and the second, and the third between the second and the lateral margin; there are besiles a few scattered and very minute punctures; at the apex these rows are all lost in a number of scattered punctures intermixed with punctiform impressions; the side of the elytra, the external half of their base, and an oblique gleam at the apex are all yellow, which colour though occupying a considerable breadth of the side, at the base and apex is a narrow strip: $: 3$ the sutures of the breast and margins of the ventral segments of the abdomen are black or dusky; scapulars rather thickly, decply, and confluently punctured; lateral angles of the mesostethium wrinkled; posterior dilated; coxæ thinly punctured, legs yellow; the lobes of the metasternum are acuminated as in D. circumflexts. ${ }^{4}$

The female differs from the male, in having the yellow parts redder, especially on the under-side of the body; the head and the prothorax are more thickly and distinctly punctured; the angular red signature of the vertex reaches the red spot between the eyes and the nose; the elytra are ploughed out into ten deep furrows, the external ones being the widest, there is also a very short onc between the sixth and seventh at the base; these furrows approach the end of the elytrum, and most of them terminate in a series of punctiform impressions which nearly reach the tip; the eighth and ninth furrows are shorter than the rest, and included between the confluent ends of the seventh and tenth; the whole elytrum is thickly and visibly punctured; the scutellum is piceous: the mesostethium is black with a large anterior yellow spot; the sutures and the margin of the segments are more widely and distinctly black than in the male.

I at first regarded this as a variety of $D$. marginalis, and it is probably the species to which Linné refers as found in North America: but upon a close examination I am convinced that $D$. Ooligbukii, though the representative of that species, is not synonymous with it. The lobes of the metasternum which terminate in a long acumen like those of D. circumflexus sufficiently prove this; the prothorax of the male is shorter and more distinctly punctured, and the elytra less so. 'The female has a little furrow betwcen the sixth and seventh, not in $D$. marginalis; the furrows are all parallel, and fall short of the apex one thirl of the length of the elytrum-otler more minute differences are also observable.

As this species was taken by the useful, worthy, and honest Esquimaux Ooligbuk, I trust I may be excused for giving to it his name.

3 If the elytra are rubbed bard, the black colour eomes off and leaves the yellow.

4 Curtis, Brit. Ent. iii, t. xcix, f. c. 


\section{2. * Dytiscus Harrisir. Harris's Dytiscus.}

D. (Harrisii) niger, prothoracis limbo, elytris latere et fascia obliqua integra apicis, lutcis ; brachiis, femoribusque badiis ; metas terni lobis apice rotundatis.

Harris's Dytiscus, black; limb of the prothorax, side and oblique entire apical band of the elytra, reddish-yellow ; arms and thighs, pale chestnut; lobes of the metasternum rounded at the apex.

Length of the body 1 inch and 8 lines.

One specimen taken in the Journey from New York to Cumberland-house.

\section{DESCRIPTION.}

Body black, underneath banded and clouded with pale chestnut. Head smooth; nose, upperlip, and palpi, reddish-yellow; the latter with the last joint dusky; between the eyes is an obscure, roundish, red spot: prothorax smooth except an anterior transverse series of punctures which does not reach the sides; as in the preceding species it is surrounded by a broad reddish-yellow margin: sculpture of the elytra like that of D. Ooligbukii, \&c. but not so grossly punctured at the apex; side reddish-yellow, the yellow stripe terminating in a fork or two branches, the upper one not consisting of dots as in D. marginalis, \&c. but entire and toothed: a reddish-yellow arch marks the dilated posterior coxa, and the base of the abdomen is of the same colour; arms and thighs, pale chestnut, tibix and tarsi of the four posterior legs black: the lobes of the metasternum are remarkably obtuse.

I have named this insect after a very eminent American Entomologist, Dr. T. W. Harris, who well merits such distinction.

v:. * Subgenus Leionotus.

Elytra fominea haud sulcata.

Several species of Dytiscus being already known, distinguished from the typical group by the females having elytra without furrows, and as smooth as those of the male, as, for instance, $D$. conformis, circumcinctus, \&c. ${ }^{5}$ it is evident that they form a distinct group, and of that kind now denominated a subgenus.

5 See Gyll. Ins. Succ. iv, 370, 1, 371, 2. 


\section{(112) 1. * DYtiscus (Leionotus) Fraxhinil. Franklin's D. Leionotus.}

1). L. (Franklinii) oblongo-ovatus, nitidissimus; subtus nigricans, supra nigro-olivaceus; ore, thoracis limbo, elyerisque latere, flavicantibus: liw juxta suluram seriatim obsoletissine granulatis; metasterno lobis aculis divergentibus.

Franklin's D. Leionotus, oblong-ovate, very glossy; dusky underneath, above dark-olive; mouth, margin of the prothorax, and side of the elytra, yellowish; elytrit near the suture with some very obsolete rows of granules; lobes of the metasternu m sharp, diverging.

\section{PLATE II, FIG. I.}

Length of the body 1 inch and 4 lines.

A pair taken in Lat. $65^{\circ}$.

\section{DESCRIPTION.}

ठ

Body oblong-ovate, glossy as if covered with varnish; underneath black spotted and banded with pale chestnut; above dark olive, in certain lights of a beautiful olive-green. Head with a very few minute, scarcely discernible, punctures; antemnx chestnut; mandibles and palpi black; nose, upperlip, margins of the prothorax, and side of the elytra, dusky yellow : prothorax distinctly channelled, surrounded within the margin with an irregular series of punctures, interrupted at all the angles, and in the middle anteriorly and posteriorly: elytra sculptured as in the two preceding species, except that there are several very obsolete rows of flat granules scarcely discernible between the suture and the first row of punctures; and there is no yellow oblique band or gleam near the apex: legs black, with the arms and intermediate thighs dusky or dusky lurid; the lobes of the metasternum very acute, more than usually diverging, incurved a little at the apex.

Head more visibly, though still very minutely, punctured: prothorax minutely punctured : elytra more coarsely punctured at the apex: legs dusky lurid, posterior tibiæ darker, tarsi black; scapulars, and parapleuræ grossly punctured; angle of the mesostethium wrinkled; posterior coxæ lightly, but not thickly, punctured; lobes of the metasternum very acute, not incurved at the apex.

This species a good deal resembles $L$. L. conformis, but it is larger, the legs are darker, the elytra do not exhibit traces of three or four obsolete flat ridges, but in the interstices between the suture, and the first and second rows of punctures, are several rows of obsolete, very minute, flat granules or tubercles not easily discernible except under a strong magnifier: the lobes also of the metasternum diverge more than in the species alluded to. 
b. Gyronecha. Kirb.

\section{Family GYRINIDE. Gyrinidans.}

XXXVIII. * Genus CYCLINUS.

Labrum transverse, anteriorly circumscribed by the segment of a circle, at the apex ciliated.

Labium with the intermediate lobe very short, truncated; the lateral ones large, longer than the tongue, externally rounded.

Mandibule very short, concealed by the labrum.

Maxille with the upper lobe obsolete, the lower one unguiform.

Palpi very short, clavate with the last joint subsecuriform, obliquely truncated.

Lingua subquadrangular.

Antennee obliquely subtruncated at tle apex.

Body depressed, obovate; scutellum covered; elytra with nine obliterated furrows; arms shorter than the body.

The genus whose characters are here given, and the type of which is Gyrinus Americanus, occupies an intermediate station between Dineutus Mac Leay ${ }^{6}$ and Gyrimus. From the former it differs in having a ciliated upper-lip, truncated antennæ, and arms shorter than the body; and probably in other characters not woticed in Mr. Mac Leay's brief description and definition of the genus. It is distinguished from Gyrinus by its broad, depressed body; by the different shape of the last joint of its palpi, and by liaving no apparent upper lobe to its maxillæ: ${ }^{7}$ it has likewise no visible scutellum, and the elytra have only nine obliterated furrows, whereas in most Gyrini there are eleven. The tongue (or labium of most modern authors ${ }^{8}$ ) is much shorter in Gyrinus with a pair of deep impressions. The genus here laid down appears to be widely dispersed as I have specimens belonging to it from India as well as from America.

\section{1. *yclinus assiminas. Similar. Cyclimus.}

C. (assimilis) niger, elyeris subsulcatis : sulcorum interstitïs punctulatis, apice undulatis.

Similar Cyclinus, black; elytra slightly furrowed, with the interstices of the furrows minutely ptinctured; apex of the elytra undulated.

Length of the body $5 \frac{1}{2}$ lines.

'Two specimens taken in Lat. 54'.

6 Annulos. Javan. i, 30, 57.

7 Mr. Curtis, in his British Entomology, (ii, t. 79, ) bas figured the maxillæ of Gyrinus bicolor, which liave evidently a spinform npper-lobe, $(f .3$,) but in a very good preparation of the Trophi of $G$. natator, in my cabinet I can discover no trace of it, in either maxilla. Can it be a sexual distinction?

s Introd. to Ent. iii, $419,450$. 
DESCRIPTYN.

Body depressed, obovate; underneatls glossy, black, slightly bronzed; upper-lip minutely punctured; front wrinkled between the eyes; nose impressed on each side: prothorax anteriorly on each side with a transverse series of punctures parallel with the margin, and with a slight discoidal transverse impression; at the base obtusangular and somewhat wavy: elytra with nine very slightly impressed furrows, the interstices of which are minutely punctured; at the apex the clytra are wavy; epipleura black-bronzed : legs and anus testaceous.

This species approaches very near to Gyrinus Americanus belonging to the same genus, of which I at first regarded it as merely a variety, but upon comparing it with the specimen preserved in the Linnean cabinet, it appears clearly distinct. That species is smaller, bronzed above, and the interstices of the furrows are without punetures.

XXXIX. Genus GYRINUS. Linn.

(114) 1. * Gyrinus impressicolnis. Chamnel-necked Gyjimus.

G. (impressicollis) cceruleo-niger, nitidus; prothorace anterius transverse profunde impresso ; clytris nargine, et striarum punctulis, aneo-nitentibus; apice sparse punctatis obtusissimis.

Channel-necked Gyrinus, blue-black, glossy; prothorax anteriorly with a deep transverse impression ; margin of the elytra and punctures of their furrows glittering and bronzed; apex very obtuse and irregularly punctured.

Length of the body 4 lines.

Taken in Canada by Dr. Bigsby.

DESCRIPTION.

Body glossy, black underneath, above blue-black. Head a little bronzed; nose transversely impressed, wrinkled; frontal impressions large and deep: prothorax with a deep anterior transverse impression, reaching nearly from side to side, in the centre of which is also a deep punctiform impression, and bchind it on each side two others, but wrinkled and more shallow; on each side also is a large gibbosity or boss: elytra nearly oblong, with eleven rows of shining bronzed punetures; at their apex the punctures are scattered, the margins also are bronzed; epipleura black; the tip of the elytra is very obtuse and almost truncated: legs rufous.

This species is very near G. marinus, but it is much larger, and is sufficiently distinguished from it by the deep furrow or channel that runs quite across the prothorax, its more prominent bosses, and its impressions. In G. marinus, also the punctures at the tip of the elytra are not scattered, but mark out a cresecnt-shaped arca, and the apex itself is not so obtuse. 


\section{Gyrinus aneus. (Leach.) Bronzed Gyrimus.}

Gyrinus æneus. Sam. Nom. i, 20. Curt. Brit. Ent. ii, 79. Steph. Illustr. Mandil. ii, 95, 1.

Length of the body $2_{5}^{4}$ lines.

Taken in Canada by Dr. Bigsby.

DESCRIPTION.

Very like the preceding species, but much smaller, the transverse impression of the nose and the frontal impressions are not so deep; that of the prothorax is not so couspicuous, and there are no lateral bosses; the elytra are much narrower at the apex, where, as in G. marinus, a crescent is marked out by punctures.

G. (ventralis) nitidus, subtus ferrugineus, supra caruleo-niger; elylris margine onni, et striarum punctalis, (Eneo-nitentỉuss. Ventral Gyrinus, glossy, underneath ferruginous, above blue-blaek; both margins of the elytra, and the punctures in the rows, brilliantly bronzed.

length of the body 2 웅 lines.

Two specimens taken in Lat. $54^{\circ}$.

DESCRIPTION.

Nearly related to $G$. ceneus, but the whole prone surface of the body, the epipleura of the elytra, and the legs, are ferruginous; in which particulars it resembles $G$. lineatus; it is however much smaller than that species, the punctures in the rows are more conspicuous, and the elytra have no bronzed stripes. 
G. (unalis) nitulus, inferne piecus; ano, antepcetoris latcribus, labio, pedibusquc, rufis ; superne caruleo-niger ; elytris margine omni, strurumque punctulis, anco-nitentibus; epiplcura pieco-renea.

Anal Gyrinus, glossy, underneath piceous; anus, sides of the forebreast, under-lip, and legs rufous; above blue-black; elytra with both margins, and the punctures in the rows, brilliantly bronzed; epipleura piceous-bronzed.

Length of the body 3 lines.

One specimen taken in Lat. $54^{\circ}$.

\section{DESCRIPTION:}

Near the preceding, but larger, punctures of the rows larger: breast-bones ${ }^{9}$ black; mouth, sides of the forebreast, anus, and legs, rufous; the remainder of the underside of the body, piceous: side-cóvers bronzed with a piceous tint.

\section{(118) 5. Gromus minutus. (Fabricins.) Mimete Gyrimus.}

Gỵrinus minutus. Fab. Suppl. 65, 8. Syst. Eleuth. i, 276, 10. Latr. Gen. ii, 61, 2. Hist. Nat. viii, 153. Gyll. Ins. Succ. i, 143, 5. Steph. Illustr. Mandib. ii, 96, 3.

Natator. Var. ß. Payk. Fn. Suę. i, 239, 1.

bicolor. Oliv. Ent. iii, $41,14,8$; t. i, f. 8 .

Kirbii. Narsh. Ent. Brit. i, 100, 2.

Length of the body 2 lines.

A single specimen taken in Lat. $65^{\circ}$.

DESCRIPTION.

TAnifis 13. Body above blue-black, with the sides, particularly of the prothorax and elytra, bronzed; underneath piceous, with the lobes of the metasternum, anus, and legs, rufous: epipleura rufo-piceons. In other respects it precisely resembles the European specimens.

9y this term are meant the pieces of which the breast is composed. See Introd. to Ent. iij, $541,560,573$. 


\section{BRACHELYTRA. Cuv.}

Having described the insects included in my plan belonging to the first great Coleopterous group, or section, both terrestrial, intermediate, and aquatic, I must now turn my attention to the next, but which ought to be regarded as such, is a question not yet fully decided; since different Entomologists, and those of the first eminence, having quitted the Adephaga, or predaceous beetles, distinguished by the upper-lobe of their maxillæ being palpiform, have pursued different routes. M. Latreille places next to the aquatic Adephaga the Brachelytra of Cuvier, consisting of the great Linnean genus Staphylimus; while Mr. W. S. Mac Leay takes next the remainder of the aquatic beetles, as forming one great group, which he denominates Philhydrida. ${ }^{1}$

This gentleman seems to wonder that so acute an Entomologist as M. Latreille should not perceive an affinity which almost all other investigators of insects have acknowledged: ${ }^{2}$ the last mentioned author, however, in his most recent work, perhaps with a view to this objection, has assigned his reasons for this opinion, and they seen not devoid of weight. "The anatomy," he observes, "of these insects, differs essentially. The alimentary canal of the Hydrophili, has considerable analogy by its length, surpassing four or five times that of the body, and by its texture, with that of the Lamellicorns (Scarabous L.) and approaches that of the Adephaga only with regard to its biliary vessels. They have neither the natatory vesicle, nor the excrementitial apparatus which characterizes the Dytiscidce. In the females that apparatus is replaced by organs secreting the matter that forms her egg-cocoon. Finally, the male genital organs have the closest affinity with those of the preceding family:"3-viz. the Clavicornes including the Silphidce, \&c. M. L. Dufour also observes, that this structure of the male genital organs, justifies M. Latreille in placing his Palpicornes (Hydrophilus, \&c.) where he does. ${ }^{4}$

If we further compare the oral organs of Hydrophilus with those of Dytiscus, we shall find a striking difference. The mandibles are not precisely like those of any other genus, but in one respect they resemble those of many Lamellicorns; at the base, on the inner side, they are furnished with a large molary space or plate, ${ }^{5}$ but not striated. They are evidently fitted for strong work; at the apex is a stout

1 Annulos. Javan. 6. ${ }^{4}$ Ibid. note 1.
2 Ibid. 32.

5 Linn. Trans. xiv, 105. Introd. to Ent. iii, 435. 
somewhat conical tooth, rather obtuse with a lateral prominence; then follow three flat rather distant teeth emarginate at the apex, which appear to act as incisives, intermixing somewhat of a molary structure; and next succeeds the molary plate: now this is as dissimilar as possible to the toothless mandible of a Dytiscus. ${ }^{6}$ The maxillæ are equally dissimilar, ${ }^{7}$ those of Hydrophihs approaching those of a Silpha, except that the spine on the lower lobe is truncated, and terminates in two unguiform bristles. The lower-lip and the tongue also exhibit no resemblance. ${ }^{8}$

The affinity, therefore, of Dytiscus and Hydrophilus, cannot be proved by those characters, which are usually and properly regarded as the most essential indications of it; and recourse must be had to characters that have been judged less important, such as their being cohabitants of the same element, exhibiting a striking resemblance in their general aspect and form, and in their external parts and organs: and here I must candidly own, that, with the exception of the antennæ, and the hands of the male, the resemblance is most striking, and can scarcely be the effect of any thing, for analogy seldom extends to so many points of agreement, but a near approach to each other.

It may be further argued, that some insects of the tribe make a nearer approach in their more essential characters than Hydrophilus itself-this appears to be the case with Sperchens, with respect to the palpiform or upper lobe of its maxillæ, ${ }^{9}$ $P$ a $m$ 'nus in its mandibles, ${ }^{1} \& c$. and future observers may make further discoveries.

The above observations, however, prove that $M$. Latreille was not led by mere system to doubt the connection of the two groups in question. His greatest error, as it seems to me, was that of placing his Serricornes (Buprestis, Elater, \&c.) before his Clavicornes and Palpicornes, which clearly have no business there, since they separate tribes that ought not to be disunited. To me the last-named tribe, or Philhydridie of Mr. Mac Leay, appears to bear the same relation to the Hydredephaga, that the former, or Necrophaga of the same author, do to the Geadephaga, but there seems to be an osculant group necessary to connect the latter, which appears not wanted in the former. The group to which I allude is the Brachelytra, or Staphylimus of Linné: and these M. Latreille, though they connect at least in two points with the Geadephaga, and scarcely in any with the Hydradephaga, has placed after the latter: nor could he do otherwise in a linear arrangement, without breaking up the great and natural group of the Adephaga; unless indeed he had 
followed Mr. Mae Leay's arrangement, which places the Brachelytra at the end of his circle of Chilopodimorpha: hut as he does not connect it with the point from which he at first sets out, nor indeed with any of his Cicindelida, it seems to fall short of his system. Conneeted as it is, as I shall presently shew, with the Geadephaga and Necrophaga of Mac Leay, on each side by more than one link, even this would not lead to a natural arrangement.

We see then, as in the former instance, that both these gentlemen, according to their different views, were correct, and followed nature; Mr. Mac Leay, in placing the Philhydrida next to the Hydradephaga, and M. Latreille, in placing the Brochelytra next to the Adephaga in general. I shall now assign the reasons which induce me to prefer M. Latreille's arrangement.

Scarcely any tribe of insects seems to be found in such various sitnations and in such different substances as the one in question. Some are found in dry and sandy spots; others in humid ones; some under stones; others in chalk; some under bark; others in the wounds of trees where the sap exudes; some on the shore of the sea, or of æestuaries under the sea-weed; others under or in decaying vegetable substances; some again in flowers; many in the various kinds of fungi; the majority perhaps in cow-dung; and several, lastly, in dead flesh and the carcases of animals. But though their range is thus nearly universal, and the substances they frequent are so various, are we from hence to conclude that these substances are their appropriate food, or may we not rather infer that their principal object in frequenting most of them is to devour the larvæ of other insects that are bred there? Olivier and Latreille appear both to have been of this opinion $;^{2}$ and if we examine the insects themselves we shall find eharacters, in the majority of them, that indicate a predaceons character. Their very aspect, at least that of many, exeites the idea of a ferocions animal; especially when they move with their threatening jaws expanded, and their abdomen turned over their back, like the scorpion when preparing to strike. These jaws also, or mandibles, much resemble those of the Adephaga, and are of a laniary description, which conld only be useful to predatory animals, to enable them to seize and lacerate their prey; they usually also cross each other at the tip like the tribe just named, especially the Cicindelidce. The maxillæ too of the generality have, the npper lobe palpiform and biarticulate, ${ }^{3}$ though not so slender as in the Adephaga. Their alimentary eanal, as appears both from Ramdhor and L. Dnfour, ${ }^{4}$ does not essentially differ from that of the

2 Oliv. Ins. iii, No. 42, 3. Latr. N. D. D'H. N. xxxii, 116.

3 Grav. Micr. Prolegom. xxxix, note, says they are triarticulate, but they are not so in Goerius olens.

4 Ramdh. Verd. Ins. t. iii, f. 6. Latr. Crust. Arachn. et Ins. i, 433, note 2. 
tribe just named. It must not, however, be forgotten, that predaceous animals will sometimes content themselves with vegetable diet, and vice versa herbivorous ones will sometimes attack animal matter. Cats will eat bread; I have seen, more than once, Harpalide devouring the seeds of umbelliferous plants; Silpha 4-punctoto, Mr. Mac Leay informs us, ascends the oak for the purpose of devouring caterpillars: the same learned Entomologist remarks, with respect to carnivorous Coleoptere, "that as the aberrant insects of any group leave the living animal food, which forms the entire subsistence of the normal part of the same gronp; they prey on dead animal matter, or, in preference to other vegetable matter, on fungi,"5 to which it may be further added, in preference to fresh vegetable matter, on putrid or putrescent-thus Creophilus, an aberrant Brachelytrous genus approaching Silpha, lives on dead flesh, and others, as Oxyporus, on fungi.

From all the circumstances and characters above detailed, it scems evident, that, with the exceptions just stated, the Brachelytra may generally be looked upon as predaccous, therefore I regard their affinity to the Geadephaga as more intinate than that of the Plithydrida to the Hydradephaga.

There are two points by which the group in question may enter that of the terrestrial Adephaga: one is that which Mr. Mac Leay has indicated, and which has been adopted in Mr. Stephens' Systematic Catalogne, by Lesteva Lat. (Anthophagus Gravenh.) which appears connected with those that have truncated elytra, as Lebia, \&c.; and the other is by the Stenide, which exhibit as much of a Cicindelidan port and aspect as the other does of a Curabidan. These appear to approach towards Colliuris, not only by their narrow bodies and clavated antennæ, but likewise in having truncated elytra.

Led by these considerations, I shall now proceed in the first place to the description of the Brachelytra upon my list, as coming next the terrestrial Adephagu, from which I shall procecd to the Necrophaga, or Clavicornes of M. Latreille's last work, and from them to the Phillydidida, or Palpicornes of the latter author, as the group that connects with the aquatic ones, which will still maintain Mr. Mac Leay's circular distribution though inverted.

I must here observe, that, after Linné and Fabricius, Mr. Stephens, in the work lately quoted, has made the Brachelytra his last colcopterous group, thinking perhaps that their abbreviated elytra connects them with Forficula, and their anal sț̣les, which sometimes, as in Diunous Leach, become setæ, with Blatta: at the 
samc time regarding them as the last group in the great circle of Coleoptera connected with the first by Anthophagus.

Not having so clear a view of the divisions and subdivisions of this section of Coleoptera, I have contented myself mostly with indicating the families to which the North American species here described belong.

i. HoMogeNeA. Kirb.

\section{Family P EDERIDE. Pcederidans.}

XI. Genus P瓜DERUS. Fab.

\section{Peaderus riparius. (Fabricins.) Bank Paderus.}

Prderus riparius. Fab. Syst. Eleuth. ii, 608, 1. Oliv. Ent. iii, 44, 4, 2, $t$, i, f. 2. Payk. Fn. Suec. iii, f27, :. Panz. Fn. Germ. ix, t. xi. Grav. Micr. 62, 5, 2. Gyll. Ins. Suec. I, ii, 372, 1. Ced. Fn. Ingr. 373. Ross. Fu. Etrusc. 626. Hellw. Fu. Etrusc. 626. Leach. E. E. ix, 9l. Sam. Compend. 173, t. iv, f. 12. Steph. Illustr. Mandib. v, 280. Lat. Hist. Nat. ix, 345, 2, t. lxxix, $f .8$.

Stapbylinus riparius. Linn. Fn. Suec. 846. Syst. Nat. ii, 684, 8. De Geer. Ins. iv, 28, 14, t. i, f. 18. Marsh. Ent. Brit. i, 503, 17. Donov. Brit. Ins. v, t. 167. Vill. Ent. i, 4]4, 8. Schrank Enum. 441. H-r. Ins. $407 . \quad$ Martin Eng. Ent. t. xli, f. 23. Schæff. Ic. t. Jxxi, f. 3. Berk. Syn. i, 110. Stew. Elem. ii, 89.

Length of the body 3 lines.

Several taken in Lat. $54^{\circ}$.

DESCRIPTION.

Head, breast, two last joints of the abdomen, base of the tibix and apex of the thighs, black: prothorax, legs, and four first segments of the abdomen testaceous : elytra dark blue; antennæ dusky.

\section{Family LATHROBIDÆ. Lathrobidans.}

XLI. Genus LATHROBIUM. Grav.

\section{2. * Lathrobium puncticolle. Puncture-necked Lathobium.}

L. (puncticolle) nigrum; prothorace fere toto punctato ; elytris thorace longioribus, antennis? pedibusque, castaneis.

Puncture-necked Lathrobium, black; prothorax nearly all punctured, elytra which are longer than the prothorax, antennie? and legs, dark chestnut.

Length of the body 5 lines.

A single specimen taken in Lat. $54^{\circ}$. 


\section{DESCRIPTION.}

Budy black, rather glossy, hairy except the prothorax. Head obovate, minutcly and thickly punctured; mandibles, palpi, and what remains of its mutilated antennx, dark ehestnut: prothorax an oblong square witl all the angles rounded; punctured, but not very thickly, with searcely any smooth longitudinal space: elytra longer than the prothorax, thickly punctured, of a dark chestnut: legs mahogany, cubit armed with a short wide tooth or prominence on the inner side at the base, the four first joints of the hand are dilated, indicating probably that the specimen is a male. This appears to be the representative of $L$. dentatum $F$, which it nearly resembles, but the elytra are considerably longer, the colour of the legs is darker, and the humerus, or anterior thigh, is proportionally smaller and has no tooth.

\section{(121) 3. * Lathrobium Gravenhorsti. Gravenhorst's Lathrobium.}

I.. (Gravenhorstii) nigrum; antennis pedibusque testaceis; elytris castaneis; prothorace punetato spatio distincto longitudinuli levi. Gravenhorst's Larhrobium, black; antenn and legs testaceous; elytra dark chestnut; prothorax punctured with a distinct longitudinal smooth space.

\section{PLATE II. FIG. 2.}

Length of the body $1-1 \frac{1}{2}$ lines.

Two specimens taken in Lat. $54^{\circ}$.

DESCIRPTION.

This species a good deal resembles the preceding, but the palpi, mouth, scape of the antennæ, and legs, are testaceous, the remainder of the antennæ is darker; mandibles chestnut. Head oblong: anterior angles of the prothorax scarcely rounded; a distinct intermediate longitudinal smooth space adjoining which is a series of punctures strikingly distinguishes this species from L. puncticolle, the sides of the prothorax are covered with scattered punctures: the tip of the segments of the abdomen, ventral as well as dorsal, is testaceous.

\section{(122) 4. Lathrobium bicolor. (Gravenhorst.) Bicolorate Lathrobium.}

Lathrobium bicolor. Grav. Micr. 179, 1.

Length of the body $4_{3}^{\circ}$ lines.

Taken in Canada by Dr. Bigsby. 


\section{DESCRIPTION.}

Body testaceous, hairy. Head oblong, wider than the prothorax, black, thickly punctured; mandibles and other oral organs dusky-rufous; antennæ nearly as long as the prothorax, of the same culour but paler at the base and apex: prothorax punctured with a smooth longitudinal intermediate space: elytra thickly punctured: abdomen black, anus testaceous.

Gravenhorst describes Knoch's specimen, which also came from North America, as having dark chestnut thorax, elytra and anus; in the specimen here described they are of the same colour witl the legs. The differenee, as they agree in other respects, is probably aecidental.

\section{Family GYROHYPNIDE. ${ }^{6}$ Gyrohypnidans.}

XliI. * Genus GYROHYPNUS. Kirb. Steph.

\section{1. * Grrohypnus assimilis. Similar Gyrohypmus.}

G. (assimilis) niger; prothorace seriebus dorsalibus multipunctis, antennis rufis; elytris pedibusque flavo-testaceis: illis apuce nigricantibus.

Similar Gyrohypnus, black; prothorax with its dorsal series many-punctured; antennæ rufous; elytra and legs yellowshtestaceous, the former blackish at the tip.

Length of the body 9 lines.

Two specimens taken in Lat. $54^{\circ}$.

DESCRIPTION.

This species approaches very near to $G$. ochraceus, but it is more slender in proportion to its length. Body black and glossy. Head rather larger than the thorax, behind the eyes are some rather large scattered punctures; antennæ and palpi rufous; neck rufo-piceous: prothorax piceous, with a triple scries of punctures on each side leaving a discoidal smooth space; the dorsal ones consist of seven or eight punctures, and the intermediate ones are really a continuation of the dorsal, since by the intervention of a puncture or two both are united so as to form a figure resembling a bishop's crosicr; the lateral scries consists of a very few points, not casily seen; near the anterior angle the elytra are scarccly longer than the prothorax, punctured, with some of the punctures arranged in rows and others scattered; from the humeral to the inner apical angle, they are internally yellowish-red, and cxternally blackish: legs yellowish-red.

6 The species of this family when they sleep, or are in a torpid state, roll themselves up like a serpent. See Stephens' Illustr. Mandib. v, 258. 
ii. Heterogenes. Kïb.

\section{Family OMALID 2 . Omalidans.}

It appears to me that the pentamerous genera Micropeplus, Proteinus, Omalium, Lesteva, \&c. belong to a distinct tribe from the trimerous oncs, Oxytelus, \&c. $\Lambda \mathrm{s}$ this tribe includes genera that lead towards Nitidula, Catheretes, \&c. on one side, as Micropeplus and Proteinus; and towards Lebia, \&c. as Lesteva, on the other, I have given it a name indicative of that circumstance.

The reader will here recollect that having described those Brachelytra that lead to Stenus, of which last there were none taken in the Expedition, and so connecting with one branch of the Geadephaga, I now go to the insects nearest to Lesteva, of which likewise there were no specimens, which lead to another.

XLIII. Genus OMALIUM. Grav.

1. * Omalium marginatum. Margined Omalium.

O. (marginatum) piceum, nitidum, punctatum; prothorace utrinque latius marginato, trifoveolato; pedibus, antennisque rufis. Iargined Omalium, piceous, glossy, punctured; lateral margins of the prothorax ratber wide, with three punctiform impressions; legs and antennie rufous.

Length of the body $3 \frac{3}{4}$ lines.

One specimen taken in Lat. $65^{\circ}$.

DESCRIPTION.

Body piceous, glossy, naked, rather grossly punctured. Head narrower than the prothorax; eyes prominent; antennæ rather longer than the head and thorax, dusky-rufous: prothorax rather wider than long, lateral margin somewhat dilated; near it, and partly in it, is a deep punctiform impression, and above the scutellum another obsolete one: elytra something wider than the prothorax, and nearly as long as the abdomen, paler at their apex: legs dusky-rufous.

This species is related to $O$. tectum, but it is more grossly punctured, the lateral margin of the prothorax is much more dilated, and the punctiform impressions more distinct. 
iii. Subuldpalpia. Kirb.

\title{
Fanily ALEOCHARIDÆ. Aleocharidans.
}

XLIV. Genus ALEOCHARA. Grav.

\author{
1. * Aleochara pallitarsis. Pale-footed Aleochara.
}

A. (pallitarsis) nigra, vix nitida; thorace orbiculato, subcanaliculato, postice foveolato: elytris prothorace longioribus, piceis, apice summo rufis : pedibus piceis tarsis rufis.

Pale-footed Aleochara, hlack, scarcely glossy; prothorax orbicular, slightly channelled, posteriorly foveolate : elytra longer than the prothorax, piceous, at the extreme tip rufous: legs piceous, with rufous tarsi.

\section{Locality unknown.}

Length of the body 2 lines.

This minute insect belongs to Gravenhorst's second family of Aleochara. ${ }^{7}$.The species of this genus of minute Brachelytra are so extremely numerous, nearly 200 baving been discovered in Britain alone, and so difficult to discriminate, that it is not with great confidence that I give this as nondescript. I have many undescribed species in my cabinet that come very near it, but I cannot find one that altogether agrees with it.

\section{DESCRIPTION.}

Body black, gloss deadened by short inconspicuous hairs. Head rather spherical, narrower than the prothorax, very minutely punctured; antennæ shorter than the prothorax, rather robust, intermediate joints turbinate, last joint ovate, acute: prothorax suborbicular with the sides deflexed, very minutely and thickly punctured; dorsal channel nearly obsolete; a large punctiform impression just above the scutellum: elytra longer and rather wider than the thorax, piccous-black, extreme tips rufous, very minutely and thickly punctured : legs piceous-black with rufous tarsi.

iv. Microcephala. Lat.

\section{Family TACHYPORIDE. Tachyporidans.}

XLV. Genus TACHYPORUS. Grav. 1. * Tachyporus acuductus. Acuducted Tachyporus.

T. (acuductus) nigro-piceus; prothoracis angulis posticis, antennis, pedibusque, testaceis ; elytris minutissime acuducti... Acuducted Tachyporus, dark-piceous, posterior angles of the prothorax, antennæand legs, testaceous ; elytra most minutcly acuducted.

Length of the body 1 line.

Taken near Cumberland-house, Lat. 54․ 


\section{DESCRIPTION.}

Body dark-piccous, naked, smooth, glossy. Antenna and mouth testaceous: prothorax very smooth, wider than the elytra, posterior angles testaceous : elytra longer than the head and prothorax together, piceous with the external apical angle testaceous; if viewed under a good magnifier, they appear covered, especially next the suture, with minute branching seratehes, as if made by a pin or needle, intermixed with very small punctures : abdomen very short and conical, scarcely margined, piceous with the segments paler at their tip.

\section{2. * Tachyporus affinis. Contiguous Tachyporus.}

T. (affinis) nigro-piceus, nitidus; antennis pedibusque testaceis; elytris castaneis, punctulatissimis.

Contiguous Tachyporus, dark-piceous, glossy; antennæ and legs testaceous; elytra chestnut, very much and minutely punctured.

Length of the body 1 line.

Taken with the preceding species.

DESCRIPTION,

This species is extremely similar to $T$. acuductus, but the posterior angles of the prothorax are not testaccous: the elytra are palish-chestnut and thickly covered with very minute punetures, without any seratches.

v. Fissilabra. Lat.

\section{Family PHILONTHIDE. Philonthidans.}

XLVI. Genus PHILONTHUS. Leach.

\section{Philonthus politus. Polished Philonthus.}

Philontbus politus. Kirb.

- puncticollis. Steph. Cat. 279, 6. Illustr. Mandib. v, $228,6$.

Staphylinus politus. Linn. Fn. Suec. 843. Syst. Nat. ii, 683, 5. Fab. Syst. Eleuth. ii, 534, 22. Scop. Carn. 304.

Schrank. Enum. 437. Payk. Fn. Succ. ii, 391, 31. Ross Fn. Etrusc. 606. Vill. Ent. i, 412, 5. Geoff. Ins. i, 367, 17? similis. Marsh. Ent. Brit. i, 497, 3 ?

æueus. Fourc. Ent. Par. 17. Grav. Micr. 17, 18?

Length of the body 5 lines.

Taken in Nova Scotia by Capt. Hall. 
This species is, I apprehend, Staphylinus politus of the Linnean Cabinet, since Mr. Stephens has marked it as such in his Catalogue above quoted, either from his own inspection of the Linnean specimens, or on the authority of a manuscript of mine, now in his hands, written long ago when I examined that collection with a view only to the British species of insects. ${ }^{8}$ It must, however, be observed, that it appears from Linné's description, in his Fauna Succica, that he regarded several distinct species as merely varieties of it. I have on the above account considered it as the genuine St. politus, under which name it stands in my last MS. Catalogue; which, though made many years ago, is more recent than that from which Mr. Stephens appears to have borrowed his name.

Mr. Marsham's synonym is rather dubious, since his description of his St. similis does not accord with the insect here given as St. politus, which has a black head and prothorax somewhat bronzed, and elytra more bronzed. I have not placed Gyllenhal's synonym under St. ceneus, since he describes his insect as having a subquadrangular head, and the side of the prothorax rather sinuated towards the base, which does not at all correspond with our insect.

The species generally regarded as $\boldsymbol{P}$. politus is distinguished by an ovate head, and may probably have been considered by Linné merely as a variety of his insect.

\section{DESCRIPTION.}

Body very black, hairy. Head orbicular, scarcely narrower than the prothorax, naked with the exception of a few long lateral bristle-like hairs, slightlly bronzed, very glossy, smooth with a few punctures on each side in the occiput; antennæ shorter than the prothorax, last joint emarginate at the tip : prothorax rather narrowest before and transverse, rounded behind, slightly bronzed, very glossy and smooth, with a few long hairs on each side, on the disk is a double series, each consisting of four punctures, there are three or four others in the sides : elytra bronzed, thickly punctured with a long hair issuing from each puncture: claws of the tarsi fcrruginous.

\section{2. * Philonthus mandibularis. Mandibular Philonthus.}

P. (mandibularis) ater, pilosus, capite ovato prothoraceque, glaberrimis nitidissimis aneo-nigris; nandibulis capile brevioribus eastaneis, elytris ancis.

Mandibular Plilonthus, very black, hairy : head ovate with the prothorax quite naked and very glossy, bronzed-black; nandibles shortcr than the head, chestnut; elytra bronzed.

Locality unknown.

Length of the body 5 lines.

${ }^{8}$ In his Illustrations he does not give the reference to $P$. politus. 


\section{DESCRIPTION.}

This species differs from the preeding chiefly in the shape of the head, and the colour of the mandibles, agreeing in the former particular with $P$. politus of modern Entomologists, from which it differs, besides their colour, in having the mandibles shorter than the head: the intermediate joints of the tarsi also are rufo-piceous.

\section{3. * Philonthus picatus. Pitched Philonthus.}

P. (picalus) piccus, antennis basi, pedibusque testaceis ; prothorace punctis scriatis $6,3,2$.

Pitched Philonthus, piccous; base of the antennæ and legs testaceous; prothorax with punctures in rows $6,3,2$.

Length of the body 3 lines.

Two specimens taken in Lat. $54^{\circ}$.

DESCRIPTION.

Body piceous, as usual in the genus somewhat hairy. Head ovate, naked, and very glossy, with a few scattered punetures on each side behind the eyes and four between them; antennæ as long as the head and thorax, scape testaceous : prothorax naked and very glossy; dorsal rows consisting of six punctures, there are five more punctures near the anterior margin arranged in two oblique rows between them and the lateral margin, and three or four other punetures are discoverable nearer the base: clytra chestnut, hairy; tips of the abdominal segment and anus rufous: legs testaceous.

\section{Philonthus fulvipes? Tawny-legged Philouthus.}

Philonthus fulvipes. Kirb.

Staphylinus fulvipes. Grav. Micr. 24, 33. Mon. 75, 66. Panz. Fn. Germ. xxvii, t. 9. Gyll. Ins. Suec. ii, 313, 59?

Length of the body about 3 lines.

A single specimen taken in Lat. $54^{\circ}$.

DESCRIPTION.

Body black, hairy except the head and prothorax which are naked, and very glossy. Hearl seulptured like that of $P$. picatus; antennæ with the two first joints testaceous: prothorax sculptured with regard to the dorsal series as in that speeies, then follow about five punetures in an irregular wavy series extending from near the base towards the apex, between which and the anterior angle are two plaeed obliquely, and several besides are discoverable in the lateral and posterior margins: 
the scutellum is black: the elytra punctured, testaceous, and lairy: the abdomen is entirely black; the legs arc testaceous with the posterior coxæ black; the hands are not dilated.

I cannot affirm with any confidence that this is the true Staphylinus fulvipes of Gravenhorst, but it answers so well, in almost every particular, to his description, that I do not feel myself justified in giving it as a distinct species. He makes the intermediate dorsal series to consist only of three punctures, whereas in the Amcrican species there are five placed in an irregular line and at unequal distances. Some doubt rests upon Gyllenhal's synonym, since he describes the three first joints of the antennæ as testaceous, the sculpture also of the prothorax is different, and he says that the anterior tarsus in both sexes is dilated.

\section{Family STAPHYLINIDE. Staphylinidans.}

XLVII. Genus STAPHYLINUS. Linn.

\section{1. * Staphylinus chrysurus. Golden-tail Staphylinus.}

St. (chrysurus) supra cinereo-eneus nigro nebulosus; postpectore ${ }^{9}$ anoque villoso-aureis, antennis caule pedibusque, rufis. Golden-tail Staphylijus, above cinereous-bronzed clouded with blick; after-breast and anus brilliant with golden hairs; stalk of the antenna and legs rufous.

Length of the body $5 \frac{1}{2}$ lines.

Taken in Nova Scotia by Dr. Mac Culloch.

DESCRIPTION.

Body underneath black, somewhat glossy, sprinkled with yellow hairs. Head suborbicular, scarcely wider than the prothorax, confluently punctured, bronzed, and covered not thickly with short pale-yellow hairs, which give it a cinereous tint, with several indistinct blackish spots; rhinarium ${ }^{1}$ and upper-lip palc yellow; mandibles rufous at the base; stalk of the antennæ testaceous, the six last joints are brown and larger than the rest, so as to form a clava: prothorax sculptured, cloathed, and coloured like the head, but more distinetly spotted and clouded with black, widest behind with a slight lateral sinus near the base: scutellum almost covered by a heart-shaped velvetty black spot: elytra, as to sculpture, cloathing, and general colour, rescmbling the head and prothorax, but they are differently spotted with black; in the centre of the base is-an oblique oblong spot, then follows an angular interrupted band, and lastly, is a sickle-shaped band with the handle towards the lateral margin, the blade is very broad and includes an insulated cinereous spot; neither of these bands reach the suture or the lateral margin, which is tawny-yellow: the two last segments of the abdomen, especially the penultimate, are thickly covered with short decumbent hairs, which in certain lights reflect a brilliant golden lustre; the after-breast is covered with hairs if possible still more brilliant : the legs are testaceous, but the thighs except their tip, and a dorsal line, are blaek.

This species resembles St. hybridus and maculosus, but is sufficiently distinguished by its golden tail and breast: it is one of the smallest of the genus.

\footnotetext{
9 See Introd. to Ent. iii, 381. 4. 573.

${ }^{3}$ Ibid. iii, 363. A. 480.
} 


\section{Family CREOPHILIDE. Creophilidans.}

XlVIII. * Genus CREOPHILUS. Kirb.

\section{Creophilus viluosus. (Kirby.) Villose Creophilus.}

Staphylinus villosus. Grav. Micr. 160, 2.

Length of the body 7 lines.

Taken in Lat. 54 $4^{\circ}$ in Canada, also by Dr. Bigshy, and in Nova Scotia by Capt. Hall. I have specimens likewise taken in Britain.

\section{DESCRIPTION.}

This species is extremely similar to C. maxillosus, and its American representative. 'The following circumstances prineipally distinguish them. The anterior angles of the prothorax in $C$. maxillosus are thinly cloathed with shortish black hairs; in C. villosus these hairs are cinereous, longer, more numerous, and cover a larger portion of the angle: in the former, the band of the elytra is whiter and wider than in the latter : in the former also the back of the abdomen, especially the third and fourth segments, is mottled with cinereous hairs; in the latter the second and third have each a cinereous band interrupted in the middle : again the four first ventral segments in C:. maxillosus are thickly covered with decumbent cinereous hairs, with each a lateral black spot on both sides, while in C. villosus only the three first segments are so distinguished; and finally, in the former the sides of the postpectus are covered witl black hairs, and in the latter with cinereous.

\section{ENTAPHIA. Kirb. \\ Family NECROPHORIDE. Necrophoridans.}

XLIX. Genus NECROPHORUS. Fab.

Mr. Mac Leay (Anmulos. Javan. i, 39) seems to regard Necrophorus, in the circle of Necrophaga, as the analogue of Creophilus in the circle of Brachelytra, from which it should seem that he had not compared the oral organs of these two genera, if he had he would have immediately have perceived that Necrophorus forms rather an osculant group by which a transit is made from one to the other. For besides that the labrum, labium (lingua) and palpi of both nearly agree, the maxillæ of Necrophorus are formed upon the same plan as those of the Staphylinidee, particu- 
larly Creophilus, the upper-lobe in both being obliquely divided into two articulations, and the lower being large, short, and very hirsute; whereas in Necrodes and the other Silphidce, though the upper-lobe is the same, the lower terminates in a sharp incurved spine- the mandibles of Creophilus and Necrophorus differ a little, the latter not terminating in a long laniary acumen, and its teeth being less pronounced. As to external form Necrophorus is evidently intermediate between Creophilus and Necrodes. It has the disengaged head and neck, and truncated elytra and wings of the former, and the thorax and general aspect of the latter tribe. When we add to this that both live upon dead flesh-no doubt can remain of their affinity. Indeed a general agreement in their trophi, especially the maxille, is as strong a proof of affinity as can well be furnished.

* Prothorax dilated anteriorly.

1. Necrophorus velutinus. (Fabricius.) Velvet Necrophorus.

Necrophorus velutinus. Fab. Syst. Eleuth. i, 334, 5 .

tomentosus. Web. Obs. Ent. i, 47,1 .

Length of the body 8 lines.

Taken in Nova Scotia by Dr. Mac Culloch.

DESCRIPTION.

Body black; nose separated posteriorly from the front by a straight line, anteriorly furnished with a submembranous rhinarium, above which is a round flattencd tubercle; knob of the antennæ black: prothorax dilated anteriorly, thickly covered with golden pile: elytra with two orange-coloured bands, toothed as it were on both sides, the anterior being the widest; epipleura pale ycllow: postpectus covered with golden pile: posterior trochanters truncated at the apex and emarginate.

$$
\text { 2. * Necrophorus hebes. Unsensed Necrophorus. }
$$

$N$. (hebes) ater; rhinario nullo distincto; elytris fascia maculaque aurantiis, epipleura apice maculaque bascos nigris.

Unsensed Necrophorus, black, with no distinct rhinarium; elytra with an orange-coloured band and spot; apex and basilar spot of the epipleura, black.

Length of the body 7 lines.

Taken in Nova Scotia by Captain Hall. 


\section{DESCRIITION.}

Like the last, but the nose is separated from the front by a curved line, it is also marked on each side by a deep longitudinal furrow, and is depressed longitudinally in the centre; but what more strongly elaracterizes it, is the want of the rhinarium or nostril-piece discoverable in most of the other species: the anterior part of the prothorax is less conspicuously dilited and naked: the elytra anteriorly have a strongly toothed orange band including a black dot at the suture; posteriorly they lrave a lirge toothed spot of the sane colour; the epipleura is orange in the middle, black at the tip with a black spot at the basc connected with the black disk: postpectus not brilliant with golden pile.

(136)

3. * Necrophorus obscurus. Oliscure Necrophorus.

N. (obscurus) ater; rhinario vix distincto; clytris fasciis duabus obscuris, epipleuraque, rubris : antonnis clav'a ferruginea.

Obscure Necrophorus, black; rhinarium scarcely distinct, elytra with two obscure bands, and the epipleura, red: knob of the antennæ ferruginous.

Length of the body $9-10$ lines.

\section{A pair taken in the journey from New York to Cumberland-house.}

\section{DESCRIPTION}

Body black. Nose separated from the front by a straight abbreviated line, with a deep oblique furrow on each side and no distinct rhinarium; three last joints of the knob of the antennæ ferruginous: prothorax anteriorly dilated: clytra with two rather obscure deep red bands, the anterior one broad, dentated and reaching from the epipleura to the suture: the posterior one extcrnally broad, internally narrow, and reaching neither epipleura nor suture; epipleura deep red, narrower than usual: posterior trochanter emarginate.

(137) 4. * Necrophorus Melshemeri. Melsheimer's Necrophorus.

N. (Mclsheimeri) antcnnis capitulo rhinarioque ferrugineis ; elytris fasciis duabus epiplcuraquc, aurantiiis ; trochanteribus posticis apice truneatis extus recurvis.

Melsheimer's Necrophorus, knob of the antennæe and rhinarium ferruginous; two bands of the elytra and the epipleura orange-coloured; posterior trochanters truncated at the apex and externally recurved.

Length of the body 9 lines.

A single specimen taken in the Journey from New York to Cumberland-house. 


\section{DESCRIPTION.}

Body black. Nose separated from the front by an obtusangular line; rhinarium orangecoloured, subtrapezoidal; three last joints of the knob of the antennæ ferruginous: prothorax dilated anteriorly: elytra with two orange-coloured subundulated toothed bands reaching from the epipleura to the suture; epipleura broad, orange-coloured: posterior trochanters truncated at the apex with the external angle reeurved; tibiæ dilated, especially the anterior pair, or cubits: post-. pectus on each side covered with tawny hairs.

** Prothorax not dilated anteriorly.

\section{5. * Necrophorus Hallit. Hall's Necrophorus.}

N. (Hallii) ater; prothorace subrotundo; antennis capitulo, elytris fascia antica, lunulaque postica, aurantiis ; rhinario angulis anticis elongatis.

Hall's Necrophorus, black, prothorax nearly round; knob of the antennæ, anterior band and posterior crescent of the elytra, orange-coloured; anterior angles of the rhinarium elongated.

Length of the body $8-9$ lines.

Taken in Nova Scotia by Capt. Hall, and in Massachusets by Mr. Drake. DESCRIPTION.

Body, as usual, black. Nose separated from the front by a straight line, channelled; rhinarium distinct, membranous, tawny, anterior angles elongated; knob of the antennæ with the three last joints dull-orange: prothorax nearly circular, anteriorly emarginate : elytra with an anterior angular band which does not reach the suture, and a posterior crescent or kidney-shaped spot, both of a deep orange; epipleura black; wings dusky: trochanters emarginate at the tip.

\section{6. * Necrophorus pygmeus. Pigmy Necrophorus.}

N. (pygmaus) ater, prothorace subrotundo; antennis capitulo nigro; elytris fascia antica, maculaque postica, obscure rubris ; rhinario transverso.

Pygmy Necrophorus, black, prothorax subrotund; knob of the antennæ black; anterior band and posterior spot of the elytra, of a dark obscure red; rhinarium transverse.

\section{PLATE II, FIG. 3.}

Length of the body 6 lines.

A single specimen taken in the Rocky Mountains. 
DESCRIPTION.

This is the smallest known species of the genus. Nose scparated by a nearly straight line from the front; rhinarium transverse, not membranous; knob of the antennx black: prothorax nearly circular, there is a slight sinus on each side, and a deeper anterior one : elytra with an anterior angular band dilated at the epipleura, and a nearly semicircular spot at the apex of a dull decp recl; cpipleura of the same colour but black at the apex, and with a black spot at the base: posterior trochanters emarginate at the tip.

\section{NECROPHAGA. Lat.}

\section{Family SILPHID无. Silphidans.}

L. Genus NECRODES. Wilkin.

\section{(140) 1. Necrodes surinamensis. (Latreille.) Surinam Necrodes.}

Necrodes surinamensis. Latr. Crust. Arachn. et Ins. i, 498, note 2.

Silpha surinamensis. Fab. Syst. Eleuth. i, 336, 1. Linn. Syst. Nat. Gmel. iv, 1620, 48. Oliv. Ent. ii, 11, 6, 1, t. ii, f. 1 I. Herbst. Ins. v, 173, 2.

Boucler de Surinam. Dict. des D. Sc. Nat. v. 256, 3.

Length of the body $9-11$ lines.

\section{Taken in Nova Scotia by Dr. Mac Culloch.}

DESCRIPTION.

Body oblong, depressed, black, rather glossy. Head lightly, neck confluently, punctured; nose not distinct from the front; knob of the antennæ cinercous: prothorax nearly circular, anteriorly emarginate, slightly punctured in the disk, more thickly at the base and sides; a long basilar impression, or furrow on each side: elytra thickly punctured, with three longitudinal ridges; towards the apex, between the second and third, is a tumour, and after that an abbreviated orange band formed of threc spots, that nearest the suture not touching the others.

The postcrior thighs of the male of this species are not much more incrassated than those of the female, but on each side of the knee-pan, or eavity that receives the head of the tibia, is a minute tooth. 
LI. Genus OICEOPTOMA. Leach.

vii. Subgenus Thanatophilus. Leach.

O. Thanatophilus marginale. Kirb.

Silpha marginalis. Fab. Gen. Ins. Mant. 215, 7, 8; Syst. Eleuth. i, 338, 9. Oliv. Ins. ii, 11, 10, 6, t. i, f. 5. Herbst. Ins. v, 180, 8. Linn. Syst. Nat. Gmel. iv, 1621, 52.

noveboracensis. Forst. Cent. 17.

Length of the body 6 lines.

Several specimens taken in Lat. $54^{\circ}$., taken also by Dr. Mac Culloch in Nova Scotia.

I have retained Fabricius' trivial name for this species, although Dr. Forster's was first published by five years, for two reasons, first because it has been generally adopted, and next because it is a much better name. The name of a district given to an animal being improper, unless it is really peculiar to such district, or more abundant there than elsewhere. Generally speaking the name imposed by the first discoverer and describer, ought to be studiously retained : but where another name has been long in possession, and the one imposed originally is manifestly absurd or improper; to prevent confusion in the first case it should be retained, and in the second rejected or altered. The rights of individuals should be always maintained, except where they interfere with the general benefit and perfection of the science.

DESCRIPTION.

Body oblong, black, very thickly punetured. Head with an oblong punetiform impression in the space between the eyes: the margins of the prothorax, the lateral more widely, are of a pale-red : the whole disk is covered by a large three-lobed black spot, with the lateral lobes the smallest and shortest: the elytra are reddish-brown with three longitudinal ridges, the external one, as usual, stopping short of the apex. In the female the elytra at the apex are subsinuated and subacuminated.

2. Oiceoptoms (Thanatophilus) iapPonicum. Lapland O. Thanatophilus.

Oiceoptoma ('Thanatophilus) lapponicum. Kirb.

Silpha lapponica. Herbst. Ins. v, 209, 35, t. lii, f. 4. Thunb. Ins. Suec. 5, 72. Fab. Syst. Eleuth. i, 338, 11. Gyll. Ins. Suec. i, 278. 12.

- rugosa. Variety. Iinn. Fn. Suec. 455. Payk. Fn. Suec. i, 339, 9.

— candata. Say. Journ. Acad. Phil. I1I, i, 192, 1. 
Taken abundantly both in the Journey from New York to Cumberland-house, in Lat. $65^{\circ}$. and in Canada by Dr. Bigsby. This species abounds in the huts of the Laplanders, devouring every thing-skins, flesh, and dried fish.

This insect was sent me by Dr. Harris, as the Silphat candata of Say, and it agrees very well with his description, but it is evidently the Silpha lapponica of modern Entomologists, which Linné regarded as a varicty only of $S$. rugususa. Gyllenhal describes the ridges of the elytra as ruming straight-they certainly run straighter than those of the last named species, with which he compares it, but the inner ones are flexuose at the end.

N.B. The elytra of the male have a very slight sinus at the tip, and no acumen.

DESCRI PTION.

Body oblong, black. Three last joints of the antenux brown; head and prothorax covered with rather long decumbent hairs, of a yellowish cinereous colour with somewhat of silvery lustre: in the prothorax, in some specimens, there are six rows of black spots, viz. two discoidal ones, each containing five spots, next, on each side, is an intermediate one of five, and lastly, a lateral one of only two; in other specimens there are only the discoidal rows, each consisting of five spots; and one that I received from Canada has no spots at all: scutellum subacuminate, subcinereous from hairs with a hlack spot on each side; elytra black, punctured, with some very short scattered cinereous hairs, scarcely visible except under a lens; on each elytrum are three longitudinal ridges, the outermost one more elevated, but shorter, than the others, and nearly reaching the base, bent inwards a little at the apex; the intermediate one reaching neither base nor tip of the elytra, and more bent and flexuose at the apex, and that nearest the suture taking its origin a little nearer the base than the last and approaching nearer to the tip where it is flexuose; on each side of the two inner ridges is a row of punetures very close to each other, and in the intervals between the ridges are four rows, one in each, of hemispheric tubercles; the elytra are acuminated at the apex and sinuated.

\section{3. * Oiceoptona (Thamatophilus) trituberculatum.} Tritulierculate $O$. Thanatophilus.

O. T. (tri/uberculatum) pubesccnte-fuscum; proflhorace subcanaliculato, clytris tricarinatis postice trifuberculatis.

Trituberenlate $O$. Thanatophilus, brown from pubesecnce; prothorax a little channelled, elytra with three ridges, and three tubereles near the apex.

Lengtls of the body $4 \frac{1}{4}$ lines.

Several specimens taken in the Journey from New York to Cumberland-house, and in Lat. $54^{\circ}$. 


\section{DESCRIPTION.}

This species appears to be the American representative of Silpha opaca, from which it differs in being smaller, and proportionally narrower; the prothorax is longer in proportion to its width, and has an obsolete channel : the elytra are more distinctly punctured, and besides the ordinary elevation at the termination of the external ridge, have two smaller ones at that of the other two ridges; the ridge next the suture also is more elevated at its termination than in $S$. opaca, of which in every other respect it is the exact counterpart. The elytra of the female are slightly sinuated at the apex, and obtusely acuminate.

VARIETy B. Quite black.

\section{(144) Oiceoptoma (Thanatophilus) ineQuale. Unequal O. Thanatophilus.}

Oiceoptoma ( Tbanatophilus) inæquale. Kirb.

Silpha inæqualis. Fub. Syst. Eleuth. i, 340, 14. Oliv. Ent. ii, 11, 14, 12, t. ii, f. 20. Herbst. Ins. v, 185, 12, t. 41, f. 2. Linn. Syst. Nat. Gmel. I, iv, 1620, 49.

Length of the body $5 \frac{1}{4}-6$ lines.

Several taken in the Journey from New York to Cumberland-house, and in Lat. $54^{\circ}$.

\section{DESCRIPTION.}

Body black, not at all glossy, minutely punctured; punctures not visible except under a good leus. Three last joints of the antennæ cinereous: prothorax anteriorly emarginate with four discoidal obtuse ridges, the lateral ones undulated and oblique and the intermediate ones straight and parallel : elytra with the three customary longitudinal rilges, the outermost the shortest and most elevated, and the intermediate one towards the apex curving inwards; in the female the apex of the elytra is subacuminate and very acute, but with scarcely any sinus; in the male it is rounded.

\section{viii. * Subgenus Necrophila. \\ Body very much dilated. \\ Epipleura very large.}

\section{Oiceoptoma (Necrophila) Americanum. American O. Necrophila.}

O. Necrophila Americanun. Kirb.

Silpha Americana. Linn. Syst. Nat. ii, 570, 7. Fab. Syst. Eleuth. i, 337, 6. Oliv. Ent. ii, 11, 8, 4, t. i, f. 9. Herbst. Ins. $\mathbf{v}, 176,5$.

Bouclier Americain. Dict. Des. Sc. Nat. v, 256, 2.

Blatta Americana. Catesb. Carol. iii, $t . \mathrm{x}, f .5$. Seligm. Av. iv, $t$. cviii, $f .7$.

$\left.\begin{array}{l}\text { Length of the body } 8 \frac{1}{2} \\ \text { Breadth of ditto... } 7\end{array}\right\}$ lines.

Taken in Nova Scotia by Capt. Hall. 


\section{DESCRIPTION.}

Body very much depressed, thiekly punetured with a hair issuing from each puncture; on the under-side black. Head with a round impression between the eyes: prothorax pale-yellow with a subquadrangular sublobate black spot in the disk; punctures of the prothorax very thick, those of the discoidal spot resembling seratches: elytra brown-black, rather silky, with two longitudinal, undulated, obsolete ridges that do not reach the apex ; their surface is covered with irregular elevations, and near the suture is a series of punctiform impressions; epipleura very wide with its horizontal portion resplendent with a lustre between bronze and gokl, vertical part, or inner margin, yellow ; the suture of the elytra terminates in a minute point.

Olivier says there are three ridges on the elytra, but only two are discernible in the specimen here deseribed. It is singular that no author has noticed the brilliant side-covers of the elytra.

\section{(146) 2. * Oiceoptoma (Necrophila) terminatum. Terminated O. Necrophill.}

O. N. (terminatum) nigrum, prothorace pallide flavo, macula discoidali lobata nigra; elytris apice flavis, acuminatis; epipleura subaurata, intus flava.

Terminated O. Necrophila, black, prothorax pale-yellow, with a black lobed discoidal spot; elytra at the apex yellow, acuminate; epipleura somewhat gilded, with the inner margin yellow.

Length of the body $9 \frac{1}{4}$ lines.

Taken in Nova Scotia by Capt. Hall.

DESCRIPTION.

This species seems nearly related to $O . N$. Americanum, but it is narrower in proportion to its length, the front has a distinet oblong impression; the clytra are yellow at the apex and acuminate, which last is probably a sexual character; the epipleura is less brilliant than in the preceding specics, and the elytra are not silky. In other respects it resembles it and may possibly be the female.

\section{(147) 3. * Oiceoptoma (Necrophila) affine. Kindred O. Necrophilu.}

O. N. (affine) nigrum, prothorace pallide flavo, macula lobata discoidali nigra; elytris apice flavis acuminatis; epipleura nigrocarulescanti, intus flava.

Kindred O. Necrophila, black; protborax pale-yellow with a black, lobed, discoidal spot: apex of the elytra yellow and acuminated; epipleura black-blue, inner margin yellow.

\section{Length of the body 9 lines.}

'Taken in Nova Scotia by Dr. Mac Culloch.

\section{DESCRIPTION.}

Very like the preceding species, but the frontal impression is smaller and round: the discoidal black spot of the prothorax is smaller, with the lateral lobes rounded, and with round confluent punctures: the horizontal part of the epipleura is black with a slight tint of bluc, and not at all bronzed. 


$$
\text { 4. * Oiceoptoma (Necrophila) Canadense. Camada O. Necrophila. }
$$

O. N. (Canadense) nigrum, prothorace flavo, macula magna discoidali nigra; elytris apice flavis; epipleura subaurata intus flara.

Canada O. Necrophila, black, prothorax yellow with a large black discoidal spot; elytra yellow at the tip; epiplenra goldenbronzed, internally yellow.

Length of the body 7 lines.

Taken in dead fish on the shores of Lake Huron in Canada, by Dr. Bigsby.

DESCRIPTION.

This species approaches near to $O . N$. Americanum, but it is smaller, the frontal impression is decper and oblong; the discoidal spot of the prothorax is much larger, extending from the anterior to the postcrior margin, it is scarcely at all lobed, and only the punctures of its posterior part exhibit the appearance of angular scratches: the elytra are dirty-yellow at the apex, and the yellow occupies a much greater portion of the extremity than in the two preceding species, they are not acuminate at the tip, but have a very slight tendency to a sinus; the epipleura in colour resembles that of O. N. Americanum, but is less brilliant.

\section{Family PELTIDE. Peltidans.}

LII. Genus PELTIS. Kugell.

\section{Peltis ferruginea. (Fabricius.) Fermginous Peltis.}

Peltis ferruginca. Fab. Syst. Eleuth. i, 344, 2. Gyll. Ins. Suec. i, 253, 2. Illeg. Kaf. Preuss. i, 376, 2. Kugel]. Schneid. Mag. 509, 2. Steph. Illustr. Mandib. iii, 29.

Silpha terruginea. Linn. Fn. Suec. 458. Fab. Ent. Syst. i, 253, 21. Payk. Fn. Suec. i, 339, 15. Oliv. Fint. ii, 11, 20, 20, t. ii, f. 13. Herbst. Ins. v. 195, 21, t. li, f. 10. Panz. Fn. Germ. Ixxv, t. 17. Ced. Fn. Ingr. 145. Goezé. Eur. $F_{n}$. viii, 289,10 . Vill. Ent. i, 81, 16. cimicoides. De Geer. Ins. iv, 183, 9. cassidoidea. Lep. Tag. i, 312, $t$. xix, f. 3.

Thymalus ferrugineus. Latr. Gen. ii, 9, l. N. D. D'H. N. xxxiv, 71.

Nitidula rubicunda. Scrib. Journ. 173, 120.

Ostoma rubicunda. Lai. Tyr. Ins. ii, 102, 1. Scbrank Fn. Boic. i, 518, 601. Scbæff. Icon. t. xl, f. 7. H-r. Ins. 146. Müll. Linn. Nat. Syst. V, i, 130, 19.

Length of the body 5 lines.

A single specimen taken in the Journey from New York to Cumberland-house. The insects of this genus are usually to be met with under the bark of trees, and in fungi. 


\section{DESCRIPTION.}

Body oblong, flat, ferruginous, resembling greatly, as De Geer has observed, the common bedbug. Head thickly punctured: prothorax depply emarginate for the reception of the head, thickly punctured; lateral margin sloping, reflexed: disk of the clytra with six elevated ridges gradually diminishing in length from the suture outwards; between the ridges is a double row of punctures, each pair of punctures being comected by a transverse furrow; outside the discoidal ridges are several irregular rows of punctures; lateral margin reflexed; epipleura linear at the apex, gradually dilated at the base.

\section{Family NITIDULID瓜. Nitidulidans.}

LIII. Genus NITIDULA. Fab.

\section{(150) 1. Nitidula obscura. (Fabricius.) Obscure Nitilula.}

Nitidula obscura. Fab. Gen. Ins. Mant. 215, 1-2. Syst. Elcuth. i, 3Ł8, Gyll. Ins. Suee. j, 221, 9. Illig. Kaf. Preuss. i, 383, 7. Payk. Fn. Stec. i, 349, 3. Oliv. Ent. ii, 12, 5, 3, t. i, f. 3. Herhst. Ins. v, 230, 2, t. liii, f. 2. Thunb. Ins. Suec. 70. Ross. Fn. Etrusc. i, 58, 141. Panz. Ent. Germ.124, 3. Schneid. Mag.510,5. Goeze Eur. Fr. viii, 295, 3. Marsh. Ent. Brit. i, 130, 3. Walck. Fn. Paris. i, 107, 2. Latr. N. D. D'H. N. xxiii, 9. Steph. Cat. 78, 832. Silpha rufipes. Linn. Syst. Nat. ii, 573, 24.

Nitidula rufipes. Steph. Illustr. Mandib. jii, $35,8$.

Dermestes fuscipes. Fourc. Ent. Par. i, 22, 21.

Length of the body $2 \frac{1}{4}-2 \frac{1}{3}$ lines.

\section{Several specimens taken in Lat. $65^{\circ}$.}

\section{DESCRIPTION.}

Body subdepressed, black, with its lustre obscured by inconspicuous decumbent subcinereous hairs. Head minutely punctured, transversely impressed between the eyes; occiput clevated; mouth and stalk of the antennæ piceous: prothorax minutely punctured, most visibly at the sides, which are depressed; lateral margin reflexed; elytra very obtuse at the apex, they have the appearance of being aculucted which seems to be produced by the pubescence : legs piceous or rufo-piccous.

The legs in the American specimens, as to colour, appear to agree better with Olivier's term piceis, than with Paykull's and Gyllenhal's ferrugineis, and rufo-ferrugineis; but the difference is so slight that $I$ have little or no liesitation in giving it as their $N$. obscura. 
N. (ossium) nigra, subpubescens, pedibus ferrugineis, prothoracis lateribus elytrisque piceis.

Bone-frequenting Nitidula, black, somewhat downy; legs ferruginous, elytra and sides of the prothorax piceons.

Nitidula obscura. $\beta$. Steph. Cat. i, 79, 832, 8 ?

Length of the body $1 \frac{1}{2}-1 \frac{3}{11}$ line.

Several specimens taken in Lat. $65^{\circ}$.

DESCRIPTION.

Mr. Stephens regards this as a variety only of the preceding species, but it is smaller, narrower in proportion, the legs and stalk of the antennæ are paler, and the elytra and sides of the prothorax, in the British as well as American specimens, are piceous. In other respects they agree.

3. Nitidula discoidea. (Fabricius.) Discoidal Nitidula.

Nitidula discoidea. Fab. Syst. Ent. 78, 5. Syst. Eleuth. i, 252, 23. Gyll. Ins. Suec. i, 219,6. Illig. Kaf. Preuss. i, 381, 4. Oliv. Ent. ii, 12, 15, 21, t. ii, f. 8. Herbst. Ins. v, 237, 8. t. 53, f. 7. Panz. Fn. Germ. Ixxxiii, t. 5. Ross. Mant. i. 24, 56. Schneid. Mag. 519, 15. Linn. Syst. Nat. Gnel. iv, 1630, 16. Goeze. Eur. Fn. viii, 297, 5. Marsh. Ent. Brit. i, 133, 12. Walck Fn. Paris, i, 110, 15. Lat. N. D. D'H. N. xxiii, 9. Stew. Elem. ii, 40. Sam. Compend. 5l, $t$. ii, $f .5$. Steph. Illustr. Mandib. iii, 34, 6.

Nitidula hæmorrhoidalis. Payk. Fn. Suec. i, 352, 7. Var. $\beta$.

Ostoma discoidea. Lai. Tyr. Ins. ii, 108, 5. Brahm. Ins. Kal. i, 48, 160.

Silpha discoidea. Vill. Ent. i, 87, 41.

Length of the body $1 \frac{1}{3}$ line.

Many specimens taken in Lat. $65^{\circ}$.

DESCRIPTION.

Considerably smaller than the British specimens. Body subdepressed, black, above minutely punctured, subpubescent. Stalk of the antennx; sides of the prothorax, which has posteriorly a pair of discoidal obsolete impressions, legs and anus, rufous : elytra with a large anterior discoidal suborbicular pale-rufous spot common to both, in which, in some specimens, is a black dot; apex of the elytra obscurely variegated with rufous.

Fabricius, and after him Mr. Marsham, describes the legs of this species as black; but others have properly denominated them by the term ferruginous and piceous. In the American specimens they vary in colour from piceous to pale-rufous. The author first mentioned, both in his Systema Entomologia and Systema Eleutheratorum, has printed the trivial name discoides, but this has generally been regarded as a typographical error. 


\section{Family ENGIDZ. Engidans.}

LIV. Genus IPS. Fab.

$$
\text { 1. * Ips De Jeanit. De Jean's Ips. }
$$

I. (De Jeanii) nigro-picea, nitida, punctulatissima; elytris subdilutioribus lineolis quatuor pallidis.

De Jean's Ips, dark-piceous, glossy, thickly and minutely punctured : elytra rather more dilute, with four white linear spots.

$$
\text { PLATE II, FIG. } 4 .
$$

Length of the body $2 \frac{1}{4}$ lines.

Three specimens taken in Lat. $65^{\circ}$.

DESCRIPTTON.

Body linear, depressed, thickly and minutely punetured, glossy, black or dark piceous. Head with a punctiform impression in the vertex, and a larger impression on each side between the eyes: prothorax quadrangular, rather narrowest behind: elytra piceons or rufo-piceous, with two oblong white spots at the base, forming an interrupted line, and two oblique nearly parallel ones below the middle: legs piceous. In the other sex the elytra are subacuminate.

Variety B. With five white spots: viz. 1, 2, 2.

Though the transition from the Brachelytra by Necrophorus to the Necrophaga, especially the Silphidce, is so evident, ${ }^{2}$ yet the road to be taken when we depart from the latter tribe is not equally clear: the Nitidulidae indeed manifest a close affinity to the Silphide, but the Engide seem separated from both by a rather wide interval, and from them varions routes present themselves, some would go next to the Catheretidce, others to the Cryptophagida, and others to Choleva and the Scaphidiadce. The former of these tribes seems to me nearer to the Nitidulida than the Engide, and may be regarded as opening a road from then towards the Brachelytra; the Cryptophagida appear much further removed, and are leading towards the Dermestidce; I shall therefore next proceed by the last tribes, whose affinity to the preceding Necrophaga is generally admitted. ${ }^{3}$

$$
\text { 2 See abore, p. } 95 \text {. }
$$




\section{Family CHOLEVIDÆ. Cholevidans.}

LV. Genus CHOLEVA. Lat. Sp.

ix. * Subgenus Catops. Steph.

1. *holeva (Catops) Spenciana. Spencian C. Catops.

C. C. (Spenciana) nigra, pallido pubescens; prothorace angulis rotundatis, postice subrepando; antennis basi, pedibusque ferrugineis; elytris ferrugineis apice nigris.

Spencian C. Catops, black with pallid pubescence; prothorax with rounded angles, posteriorly rather wavy; legs, and base of the antennæ, ferruginous; elytra ferruginous, black at the tip.

Length of the body 2 lines.

A single specimen taken. Locality not stated.

\section{DESCRIPTION.}

Body black, covered with decumbent pale hairs. Head minutely punctured; antennex shorter than the prothorax, the two first joints ferruginous, the eighth shorter and smaller than the rest; mouth and palpi ferruginous; prothorax not visibly punctured with all the angles rounded; base with a slight sinus on each side: elytra acute, very minutely punctured with a hair emerging from each puncture, witlout furrows except a single one parallel with the suture, ferruginous, black at the tip: abdomen piceous, rufous at the base: legs ferruginous.

This species appears to present the type of a new family of Choleva, not noticed in Mr. Spenccr's Synopsis Sectionum, in his admirable Monograph of that genus. ${ }^{4}$ From his first section (Choleva Steph.) it borrows the rounded postcrior angles of the prothorax; from his second (Catops Stcph.) its clavated antennæ; and from his third (Ptomaphagus Steph.) its unfurrowed elytra: it seems properly included in the second, with which it most agrees in habit.

\section{Family SCAPHIDIADE. Scaphidiadans.}

LVI. * Genus SCAPHIUM. Kirb.

Labrum transverse, submembranous, subemarginate.

Labizm subquadrangular, corneous.

Tongue membranous?

Maxillary Palpi four-jointed: first joint very short; second rather longer than the rest, nearly cylindrical; third obconical; last conical, acute.

Laỏial Palpi threc-jointed: joints nearly cylindrical?

4 Linn. Trans. xi, 138. 
Antemer situate below the eyes under the elevation of the nose, eleven-jointed :5 scape suljincrassated, scarcely longer than the following joint; pedicel subcylindrical; four subsequent joints much more slender than the rest of the antenux, obconical, gradually decreasing in length: the five last joints incrassated so as to form a long knob, all turbinate exeept the terminal one which is obturbinate; the second joint of the knob is smaller than the others and more spherical.

Body oblong, somewhat depressed. Head triangular, eyes lateral, hemispherical; nose with a triangular elevation : prothorax longer than wide, subquadrangular; sides antcriorly rounded, towards the base constricted; base and apex straight: scutellum at the apex somewhat truncated: elytre linear, very obtuse and nearly truncated at the apex but not abbreviated, sides curved; epipleura ensate: legs rather short; thighs subcompressed, rather clavate ; tibia cylindrical, somewhat curved, bicalcarate at the apex with minute spurs; tersi all five-jointed, joints not casily discerned; claws siugle: first ventral segment of the abdomen very large.

This genus possesses many characters in common with Scaphidium, but it differs in the situation and knob of its antennx, in its palpi, and in the shape of its eyes and prothorax. It scems intermediate betwcen the Cholevidans and Scaphidiadans: agrecing with the former in all the circumstances just mentioned except the last; and with the latter in its locomotive organs, and certain peculiaritics in the sculpture of its prothorax and elytra. It is probably a fungivorous genus.

\section{1. * Scaphium castaxipes. Chestmut-foot Scaphium.}

S. (caslanipes) nigrum, glabrum, nilidum, supra punctatum, nigro-aneum; elytris disco puncto-striatis; antennis pedibusque castaneis.

Cbestnut-foot Scaphium, body black, naked, glossy, punctured; above black-bronzed; elytra in the disk with rows of punctures; antenna and legs chestnut.

\section{PLATE V, FIG. 1.}

Length of the body 3 lines.

A single specimen taken in the Journey from New York to Cumberland-honse.

\section{DESCRIPTION.}

Body naked, glossy; underneath smooth, black, with a very light sliade of bronze; above more evidently bronzed, punctured. Moutl, palpi, and antenne pale chestnut : prothorax behind, on each side, marked witl a pair of punctiform impressions, between these impressions are several large punctures, but not in a regular transwerse series as in Scaphidium: clytra with six discoidal rows of punctures; the fonr rows nearest the suture reach the base, but not the apex, and the two exterual ones neither base nor apex; the first row also terminates towards the base in three large distinet punctures, and from the base of the third runs a transverse row, as in Scaphidium, to the sutural furrow, which is impunctured: the legs are pale chestnut.

5 Plate V, Fig. 1, $a$. 


\section{Family ANISOTOMIDÆ. Anisotomidans.}

LVII. Genus LEIODES. Lat.

\section{1. * Leiodes puncto-striatus. Puncture-striated Leiodes.}

L. (puncto-striatus) castaneus, nitidus; antennis pedibusque nufis ; elytris puncto-striatis : punctis impressis, interstitiis lavibus. Puncture-striated Leiodes, chestnut, glossy; antennæ and legs rufous; elytra with impressed punctures in rows, interstices impunctured.

Length of the body 1 line.

A single specimen taken in Lat. $65^{\circ}$.

\section{DESCRIPTION.}

Body hemispherico-ovate, naked, glossy, chestnut. Head very lightly punctured; mandibles rather prominent; palpi and antennæ rufous, clava of the latter much incrassated consisting of five joints, the second of which is extremcly minute : prothorax very large, wider than long, very lightly punctured, with the sides paler than the disk: elytra deeply and grossly punctured in rows, interstices impunctured: legs and under-side of the prothorax rufous: anus paler than the rest of the abdomen.

This species closely resembles the Anisotoma badia of Sturm, ${ }^{6}$ but the elytra are not finely punctured, as Mr. Stephens describes them in that species.

\section{Family SYLVANID压. Sylvanidams.}

LVIII. Genus CORTICARIA. Marsh.

\section{1. *orticaria denticulata. Denticulate Corticaria.}

C. (denticulata) picca, subnitida : prothorace postice impresso, lateribus denticulatis; elytris puncto-striatis.

Denticulate Corticaria, piceous, rather glossy; prothorax with a posterior impression, and denticulated sides; elytra with rows of punctures.

Length of the body I line.

A single specimen taken in Lat. $65^{\circ}$.

6 Deutsch. Fn. ii, t. xxiv, f. E; comp. Steph. Illustr. Mandib. ii, 171, 5. 


\title{
DESCRIPTION.
}

Body dark piceous, rather glossy, naked, minutely punctured. Prothorax rather orbicular, with a circular deepish impression just above the scutellum; sides distinetly denticulated : elytra with several rows of punctures.

The insect here described approaches very near to Corticaria impressa of Mr. Marsham (Ips impressa Oliv. $)^{7}$ but it is sufficiently distinguished not only by its colour but eliefly by the very visibly denticulated sides of its prothorax.

I may here observe that most authors, probably on the authority of Latreille, have rejected the synonym of Olivier; his figure, however, appears to me clearly to denote Mr. Marsham's insect, which was I believe first described by Herbst, ${ }^{8}$ under the name of Latridius gibbosus, and has no relation to Cryptophagus serratus, of which the first mentioned learned author seems to regard it as a varicty.

\section{Family CRYPTOPHAGIDE. Cryptophagidans.}

\author{
LIX. * Genus ATOMARIA. Kirb. Steph.
}

\section{DESCRIPTION.}

Body elliptical. Antennæ anteocular with the intermediate joints rather slender; scape much incrassated, the three terminal joints often gradually increasing in size, subturbinate, except the last which is obturbinate and very acute ; these three joints form a short club or knob; head subtriangular; eyes small, round, and convex : prothorax transverse, convex, subquadrangular with curved unarmed sides: scutellum transverse: elytra taken together ovate, very convex: legs short, rather slender; tibiæ curved; tarsi five-jointed? claw-joint long; claws simple.

This genus, consisting of very minute insects, differs from Cryptophagus, in having the legs and the stalk of the antennæ much more slender; the prothorax and elytra viewed separately are more convex, and the former has a transverse basilar impression not observable in the latter, and its sides are always unarmed. The extreme minuteness of all the species has prevented me from obtaining any clear idea of the parts of the mouth, so that I can only give the above as the distinctive characters of the genus.

Both Latreille and Gyllenhal consider Cryptophagus as a pentamerous genus, but it appears from Mr. Curtis's figure and description of C. Populi that one sex is heteromerous. ${ }^{9}$ Whether this is the case with Atomaria I have not been able to ascertain; all those individuals, however, that I have examined appear to have pentamerous posterior tarsi.

7 Marsh. Ent. Brit. i, 110, 11. Oliv. Ent, ii, 18, 14, 21, t. iii, f. 24.

\footnotetext{
$s$ Herbst. Ins. v, 5, t. xliv. f. 2 .

${ }^{9}$ Brit. Ent iv, t. 160, f. 51 .
} 


\section{Atomaria atra. Black Atomaria.}

Atomaria atra. Stepl. Illustr. Mandib. iii, 67, 13.

Cateretes ater. Herbst. Ins. v, 15, 5, t. xlv, f. 5, e, E.

Dermestes ater. Panz. Fn. Germ. xxiii, t.9.

-__ fimetarii. Payk. Fn. Suec. i, 293, 21.

Latridius ater. Selneid. Mag. v, 577, 10.

Silpha nitidula. Marsh. Ent. Brit. i, 123, 24.

Length of the body $\frac{2}{3}$ line.

One specimen only taken.

\section{DESCRIPTION.}

Body black, punctured, glossy. Mouth reddish ; antennæ rufous : elytra pubescent, piceous, rufous at the tip : anus and legs rufous.

\section{Genus CRYPTOPHAGUS. Herbst.}

\section{1. * Cryptophagus humeralis. Humeral Cryptophagus.}

C. (humeralis) niger, supra punctatus, pubescens; prothorace inermi; scutello obtusangulo; elytris humeris rufescentibus; pedibus castaneis.

Humcral Cryptophagus, black, above punctured and pubescent; prothorax unarmed; scutellum obtusangular; shoulders of the elytra reddish; legs chestnut.

Length of the body $1 \frac{3}{4}$ line.

Several specimens taken in Lat. $54^{\circ}$.

DESCRIPTION.

Body subcylindrical, black; above punctured and pubescent, rather glossy. Prothorax rather widest behind, with the basilar angles somewhat depressed: scutellum transverse, obtusangular: shoulders of the elytra obscurely rufous: legs, especially the tibix and tarsi, pale chestnut.

\section{2. * Cryptophagus concolor. Concolorate Cryptophagus.}

C. (concolor) ferrugineus totus, supra punctatus, pubescens : prothorace inermi; scutello obtusangulo.

Concolorate Cryptophagus, wholly ferruginous; above punctured, pubescent ; prothorax unarmed; scutellum obtusangular.

Length of the body $1 \frac{1}{2}$ line.

A single specimen taken in Lat. $54^{\circ}$. 
DESCRIPTION.

In shape, sculpture, and pubescence this species resembles the preceding, but it is smaller, and the whole insect is entirely of one colour-dark ferruginous.

N. 13. The two species last described differ from the other Cryptophagi in having the thorax without serratures or denticles, and the scutellum obtusangular, and may perhaps form a subgenus.

It should seem to result from a comparison of Necrobia with Cryptophagus that there is an affinity between them ; the former, as restricted by Mr. Stephens, ${ }^{1}$ is at necrophagous genus: $N$. Quadra, of which I was the first discoverer and sent to the late Mr. Marsham with that Trivial name, I found apon the bones of dead animals very busily engaged in devouring what remained upon them. If this idea prove correct, it will furnish another instance of a collateral departure from the main stem of the system in a different direction from that to which its more evident affinities conduct us.

\section{Family DERMESTID王. Dermestidans.}

LXI. Genus ATTAGENUS. Lat.

\section{Attagenus cylindricus. Cylindrical Attagemus.}

A. (cylindricus) nigra-piceus, subcylindricus, cinereo-subpubescens; antennis medio tarsisque rufis.

Cyliudrical attagenus, subcylindrical, dark-piceous with cinereous down : antennæ, in the middle, and tarsi, rufous.

PLATE VII, FIG, 3.

Length of the body 2 lines.

Two specimens taken in the Rocky Mountains.

DESCRIPTION.

This little species has much the air of a Cryptophagus, but belongs to the present genus. The body is subcylindrical, dark-piceous, very minutely punctured, and covered, but not thickly, with decumbent einereous hairs. The two first joints of the antennæ are large, globular, and of the same colour with the rest of the body; the intermediate oncs very minute and pale rufous; the three last are inerassated and form an oblong piccous knob, of which the terminal joint is as long as the two preeding ones, ovate and acute: the prothorax behind is very obsolctely trilobed with the intermediate lobe rounded: the tarsi are rufous. 
Attagenus pellio. Lat. N. D. D'H. N. iii, 64. Leach, E. E. ix, 94. Sam. Compend. 182. Steph. Mllustr. Mandib. iii, 126, 1. Kirb. and Sp. Introd. to Ent. i, 234; iii, 324.

Dermestes pellio. Linn. Fn. Suec. 411 ; Syst. Nat. ii, 562, 4. Fab. Syst. Eleuth. i, 313,6. Gyll. Ins. Suec. i, 151, 7. Payk. Fn. Suec. i, 279, 4. Illig. Kaf. Preuss. i, 316, 6, $a$. Latr. Gen. ii, 32, 2. Oliv. Ent. ii, 9, 11, 10, $t$. ii, $f .11$. Herbst. Ins. iv, 128, 11, t. xl, f. 8, F. Ross. Fn. Etrusc. i, 32, 75. Ced. Fn. Ingr. 126. Walck. Fn. Paris. i, 90, 2. Panz. Ent.Germ. i, 95, 5. Hoppe. Tasch. 1797, 146. Blum. Handb. ed. 7, 321, 2. Marsh. Ent. Brit. i, 63, 6. Berk. Syn. i, 89. Don. Brit. Ins. vii, t. ccxxxi, f. 3. Stew. Elem. ii, 31. Sharv. Gen. Zool. vi, 32, t. vii. Scrib. Journ. 152, 78. Scop. Carn. 37. Müll. Zool. Dan. 56, 486. Lai. Tyr. Ins. ii, 62, 4. Schrank. Enum. 28, 48. Goeze. Eur. Fn. viii, 183, 2. Brabm. Ins. Kal. i, 9, 32, 238, 816. Pod. Mus. Grac. 22, 3. Fourc. Ent. Par. i, 18, 4. Müll. Naturf. iii, 63. Vill. Ent. i, 45, 4.

bipunctatus. De Geer. Ins. iv, 197, 3.

Geoffr. Ins. i, 100, 4. Act. Ups. 1736, 117, 11. Schæff. Ic. t. xlii, f. 4. H-r. Ins. 45, 46. Müll. Linn. Nat. i, 101, 4. t. iii, f. 2. Bar. Nat. vi, 60, 2, t. iii, f. в. Bechst. Nat. ii, 822, 2. Frisch. Ins. v, 22, t. viii. Bock. Nat. v, 25, 14. Müll. Fn. Frid. 2, 16. Rai. Hist. Ins. 85, 35.

Dermestes pellio. $\beta . \gamma . \delta$. Illig. Kaf. Preuss. i, $316,6, \gamma$.

—_ ater. Panz. Ent. Germ. i, 96, 7.

- cylindricornis. Schrank. Naturf. xxiv, $65,8$.

Megatoma Schrankii. Schneid, Mag. i, 480.

atra. Herbst. Ins. iv, 95, 2, t. xxxix, f. 2. Sulz. Inf. t. ii, f. 5-7.

Length of the body $2 \frac{3}{4}$ lines.

\section{Taken in Nova Scotia by Captain Hall.}

This species, though particularly destructive to furs, is to be met with in other animal matters, and is very common in houses. De Geer describes its larva as having a very long body covered with a hard shining skin of a reddish-brown colour and hairy; as having six legs, and the posterior extremity terminated by a long remarkable tail, formed of rufous hairs as long as the body, and placed horizontally in the same line: He says their motion is gliding, but by snatches.

\section{DESCRIPTION.}

The American specimen, which is a male, is considerably larger than my British ones and blacker; but in other respects it precisely resembles them. The species may generally be known by its black or dark-piceous colour, covered, especially underneath, with decumbent whitish or cincreous hairs. The stalk of the antennx, and the tarsi, are testaceous, and the last joint of the former, in the male, is longer than the two first and cylindrical : the prothorax at the three posterior angles has threc white spots formed of hairs, and the elytra one in the middle near the suture. 
1،XII. Genus DERMESTES. Linn.

Dermestes lardarius. Limn. Fn. Succ. 408; Syst. Nat. ii, 561, 1. Fab. Syst. Eleuth. i, 312, 1. Payk. Fn. Succ. i, 276, 1. Gyll. Ins. Succ. i, 146, 1. Illig. Kaf. Pruess. i, 31], 1. Lat. Gen. ii, 31, 1. 'Ilist. Nat. ix, 2-10. N. D. D'H. N.

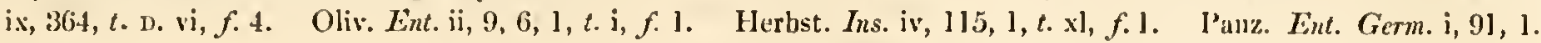
Preysl. Bühm. Ins. i, 13, 10. Ross. Fr. Etrnsc. i, 31, 73. Blum. Handb. ed. 7, 321, i. Scop. Cam. 34. Ced. Fit. Ingr. 124. Fisch. Naturg. v. Livl. 132, 251. De Geer, Ins. iv, 192, 1, t. vii, f. 15. Marsh. Ent. Brit. i, 60, 1. Brahm. Ins. Kal. i, 17, 155 and 238,817 . Schneid. Mag. 478, 1. Barb. Ins. 18, t. iii, f. 1. Goezc Eur. Fr. viii, 176, 1. Muill. Zool. Dan. Pr. 56, 485. Lai. Tyr. Ins. ii, 59, 1. Schrank, Enum. 24, 40. Pont. Nat. 199, 1. Mïll. Naturf. ii, 61. Pod. Mus. Grac. 22. Geoffr. Ins. j, 101, 5. Fourc. Ent. Par. i, 18, 5. Walck. Fu. Paris i, $90,1$. Vill. Ent. i, 44, 1. Miill. Linn. Nat. i, 100, 1, t. iii, f. 1. Bar. Nat. vi, 59, 1,t. iii, f. A. 1, 2. Bechst. Nat. ii, 822, 1. licht. Mlag. vii, 4, 34. Bock. Nat. v, 24, 11. Frisch. Ins. v, 25, t. ix. Scbaef. Icon. t. xlii, f. 3. H-r. Ins. 41, \&c. (iocd. List. 276, f. 114. Rai. Itist. Ins. 107, 4. Blank. Belg. 95, t. xi, f. k. Schmied. Ins. 203. Kriin. Encycl. vii, 345. Voet. Cul. $t$. xxxi, $f$. 1. Berk. Syn. i, 89. Stew. Elem. ii, 31. Shaw. Gen. Zool. vi, 31, $t$. vii. Leach E. E. ix, 94. Sam. Compend. 181, l. Kirb. and Sp. Introd, i, 228. Steph. Illustr. Mandib. iji, 121, 1.

Length of the body $4 \frac{3}{4}$ lines.

'Taken in Nova Scotia by Capt. Hall; in Massachusets by Mr. Drake.

Latreille observes that this insect is found in every quarter of the old world, and the specimeus from which the following description is taken, furnish a proof that it is also a devourer of hams and bacon in the new. These, however, could not have been its original food, since it must have existed before hams and bacon were invented: in fact, though often found in them, it feeds indiscriminately on all animal substances, whether putrescent or dried.

\section{DESCRIP'ION.}

The American specimens differ in no respect from our English ones. The body is black, covered more or less with decumbent cinereous hairs. It may always be known by the fusco-cinereous base of the elytra with three black dots placed in a triangle.

D. (disscctor) niger, pubescens; antennis brunneis, pedibus piceis, capite prothoraceque fusco cincrcoque, elytris cinerco, nebulosis. Dissector Dermestes, black, pubescent; antennx mahogany-colour, legs piceous, bead and prothorax clouded with brown and cinereous, elytra with cinereous only.

Length of the body $3 \frac{1}{3}$ lines.

'Taken by Dr. Bigsby in Canada. 


\section{DESCRIPTION.}

This species appears to be the American representative of $D$. murinus, from which it differs principally in having the upper-side of the body less conspicuously mottled with whitish hairs, and with having brown ones intermixed witl those of the head and prothorax: the antenne also and palpi are of a dull mahogany colour, which in the last species are black, and the knob of the former is considerably narrower; underneath also the hairs on $D$. Dissector are not so densely planted as in D. murinus, and are finer, and of a purer white.

\section{Family BYRRHIDÆ. Byrrhidans.}

LXIII. Genus BYRRHUS. Linn.

\section{1. * Brrrhus picipes. Pitch-legged Byrrhus.}

B. (picipes) niger, pube obscurus, elytris vittis tribus obsoletis interruptis, fasciaque postica abbreviata, holosericeis atris; pedibus piceis.

Pitch-legged Byrrhus, black, gloss obscured by hairs, elytra with three obsolete interrupted stripes, and a posterior abbreviated band, of a deep velvet-black; legs piceous.

Length of the body $3 \frac{4}{5}$ lines.

A single specimen taken in Lat. $54^{\circ}$.

DESCRIPTION.

Body black, covered with short decumbent hairs. Scutellum velvetty-black: elytra with a pair of deep black interrupted stripes terminating in a transverse abbreviated posterior band of the same colour: legs piceous.

The insects of this genus are, most of them, so extremely alike in shape and sculpture, differing principally, like the Humble-bees, ${ }^{2}$ in size and the colour of the pubescence that covers them, that it is difficult to say whether any individual is entitled to rank as a species, or ought only to be considered as a variety. That here described seems to claim a distinct name as well as most, since it not only differs from the subsequent one in the colour of its pubescence, but likewise in that of its legs. I at first considered it as $B$. ater, but it does not agree with the general descriptions of that insert.

¿ Kirb. Mon. Ap. Angl. i, 207. 


\section{Byrrius concolor. Concolorate Byrrhus.}

B. (concolor) niger, pube abscurus, prothoracc distinctc canaliculato; elytris vittis tribus interruptis obsolctis holosericeis atris. Concolorite Byrrhus, black, gloss obscured by pubcsence; prothorax distinctly cbannclled: elytra witlı three obsolete interrupted velvetty deep black stripes.

Length of the body 3 lines.

Two specimens taken in Lat. $54^{\circ}$.

DESCRIPTION.

This nearly resembles $B$. picipes, but it is much smaller, the prothorax is more distinctly clannelled, the elytra have no black band, and the legs arc black.

We have a variety? of this species in Britain, rather larger and not quite so black, with the prothoracic channel less distinct, which Mr. Stephens scems to regard as a variety of B. pilula, ${ }^{3}$ but it is only three-fourths of the size of that species, rather wider in proportion to its length, and its pubescence is of a different colour. The only thing in which they agree is in having thrce interrupted velvetty stripes on the clytra, but in $B$. pilula the first is more distant from the suture than in $B$. concolor.

B. (cyclophorus) ferrugineus, supra niger, pube obscurus, coleoptris circulo pallido subinterrupto inscriptis.

Circle-bearing Byrrbus, ferruginous, above black, gloss obscured by pubescence; coleoptra inscribed with a pale subinterrupted circle.

Length of the body $3 \frac{1}{4}$ lines.

One specimen only taken.

\section{DESCRIPTION.}

Body underneath and limbs dull ferruginous, above black with some cinereous hairs intermixed. Antenuæ piceous: elytra with two deep black subinterrupted stripes, and inscribed in the middle with traces of a circle formed of palc, or cinereous hairs, common to both. The circle is probably more distinct in recent specimens. 
Byrrhus varius. Fab. Syst. Ent. 60, 2; Syst. Eleuth. i, 105, 10. Oliv. Ent. ii, 13, 7, 5, t. i, f. 6. Illig. Kaf. Preuss. i, 93, 7. Lat. Gen. ii, 42, 2. Sturm. Deutsch. ii, 104, 11. Gyll. Ins. Suec. i, 197, 4. Payk. Fn. Suec. i, 76, 2. Panz.

Fn. Germ. xxxii, t. 3. Thunb. Ins. Suec. 67. Linn. Syst. Nat. Gmel. iv, 1613,5. Stew. Elem. ii, 36.

___ maculatus, Herbst. Archiv. 25, 2.

- sericeus. Steph. Mllustr. Mandib. iii, 138, 6.

Cistela varia. Lai. Tyr. Ins. $\mathrm{i}, 71,2$.

- sericea. Forst. Cent. i, 15. Marsh Ent. Brit. i, I04. Steph. Cat. 98, 1034, 6.

Voet. Col. t. xxxii, f. 4 ? Schæf. Icon. $t$. cexxvii, f. 4. H-r. Ins. i, 64, 53 .

Length of the body $2 \frac{3}{4}$ lines.

Several specimens taken in the Journey from New York to Cumberland-house.

DESCRIPTION.

Body underneath black. Head and prothorax bronzed, the gloss obscured by glittering hairs, above the scutellum is a patch of golden ones: scutellum channelled, covered with paler hairs: elytra slightly furrowed, bronzed with the alternate interstices of the discoidal furrows green-bronzed, spotted with little velvetty patches of black hairs.

The European specimens have not the patch of golden hairs above the scutcllum: in other respects they are precisely the same.

Taking our departure from the Geadephaga, or terrestrial braneh of the Predaceous, we have at length arrived at the contines of the Lamellicorn, Beetles; but before we proceed to the consideration of them, we must revert to the aquatic branch, and the tribes, connected with it, that tend also to the same point: and here, as our former route, if I may so speak, was by land; so now we must ehiefly travel by water, since the Philhydrida of Mr. Mac Leay, which we are next to describe, are mostly inhabitants of that element : or at least abound in very humid situations : but our voyage will not be long, since only three specimens belonging to one genus of these tribes were collected in the Expedition. 


\section{PHILHYDRIDA. Mac L.}

Family HYDROPHILIDAE. Hydrophilidans.

LXIV. Gchus HYDROBIUS. Leach.

A. Elytris multistriatis.

$(169)$

1. Hydrobius fuscipes. Brown-legged Hydrobius.

Hydrobius fuscipes. Sam. Compend. 187, 1. Steph. Illustr. Mandib. ii, 128, 2.

Hydrophilus fuscipes. De Geer Ins. iv, 377, 3. Illig. Kaf. Preuss. i, 247, 8. Oliv. Ins. iii, 39, 12, 6, t. ii, f. 9. Foure. Ent. Par. i, 66, 4. Stew. Elem, ii, 77. Marsh. Ent. Brit. i, 403, 3. Gyll. Ins. Suec, i, 114, 3. Müll. Zool. Dan. $69,655$.

scarabroides. Fab. Syst. Ent. 228, 4; Syst. Eleuth. i, 251,9. Payk. Fn. Suec. i, 180, $3 . \quad$ Herbst. Ins. vii, 301, 7, t. cxiii, f. 11. Panz. Fn. Germ. lxvii, f. 12. Ross. Fn. Etrusc. i, 196, 482. Ced. Fn. Ingr. 88. Goeze. Eur. Fn. viii, 714,3. Linn. Syst. Nat. Gmel. iv, 1942, 3. niger. Lesk. MTus, i, 35, 769.

Dytiscus fuscipes. Linn. Fn. Suec. 766; Syst. Nat. ii, 664, 4. Vill. Ent. i, 342, 4. Berk. Syn. i, ]06. Mart. Eng. Ent. t. xxiii, f. 15. gyrinoides. Schrank. Enum. 199, 372.

- scarabrooides. Brahm. Ins. Kal. 115, 397.

Scarabreus aquaticus. Limn. $F n$. Suec. 404.

Hydrophilus. Geoffr. Ins. i, ]84, 4.

Length of the body 3 lines.

\section{A single specimen taken in Lat. $65^{\circ}$.}

\section{DESCRIPTION.}

Body oblong, convex and rather vaulted; underneath black, very minutely and thickly punctured, with a pale short decumbent hair planted in each puncture; above slightly bronzed, more conspicuously punctured, naked and rather glossy. Head slightly impressed on each side between the eyes; palpi pale rufous, last joint dusky at the tip; antennæ rufous with a black knob: sides of the prothorax with two or three groups of larger punctures: elytra furrowed with thickly punctured furrows, dusky rufous at the sides: legs dark rufous, base of the thighs black.

This is smaller than my British specimens, the furrows of the elytra are rather deep, and their sides more conspicuously rufous. 
B. Elytris unistriatis.

Hydrobius marginellus. Steph. Illustr. Mandib. ii, 131, 11 ?

Hydrophilus marginellus. Fab. Ent. Syst. i, 185, 17; Syst. Eleuth. i, 252, 19. Illig. Kaf. Preuss. i, 246, 5. Herbst. Ins. vii, 303, 10, Ł. cxiv, f. 2, B. Panz. Ent. Germ. i, 71, 7. Haw. Ent. Trans. i, 85. affinis b. Gyll. Ins. Suec. iv, 277, 12.

margipallens. Marsh. Ent. Brit. i, 408, 21.

Length of the body $1 \frac{2}{3}$ line.

Two specimens taken in Lat. $54^{\circ}$.

\section{DESCRIPTION.}

Body subelliptical, convex, minutely punctured, black; above glossy. Palpi and antennæ dusky rufous; knob of the latter black: sides of the prothorax, and the anterior margin dusky rufous: elytra with a single furrow adjoining the suture; sides dusky rufous : tibiæ dusky rufous; tarsi rufous.

I have subjoined a mark of interrogation to the synonym of Mr. Stephens, because he describes his specimens as having an impression above cach eye, and two larger ones in the disk of the prothorax, which are not discoverable in the American specimens, nor in the British specimen described from my cabinet by the late Mr. Marsham, under the name of $H$. margipallens. ${ }^{4}$

Hydrobius melanocephalus. Steph. Illustr. Mandib. ii, 129, 5.

Hydrophilus melanocepbalus. Oliv. Ins. iii, n. 39, 14, 10, t. ii, f. 12, a. b. Fab. Syst. Eleuth. i, 253, 23. Gyll. Lns. Suec. i, 119, 9. Illig. Kaf. Preuss. i, 246, 6; Mag. i, 66, 6; Ent. Trans. i, 86. minutus. Payk. Fn. Suec. i, 182, 6. 4 punctatus. Herbst. Ins. vii, $305,12, t$, exiv, $f .4$, D.

Length of the body $2 \frac{1}{4}-2 \frac{1}{2}$ lines.

Two specimens taken in Lat. $54^{\circ}$.

4 There appears to be an error of the press in the statement of the length of this species in Mr. Marsham's work; instead of $\frac{3}{4}$ it should bave been $1 \frac{3}{4}$ line, which is the length of the specimen from which his description was taken. 
DESCRIPTION.

Body subelliptical, minutely punctured; underıcath black somewhat hairy with very short inconspicuous lairs, above lurid or dirty-yellow, glossy, more conspicnously purectured. Head black with a quadrangular yellow spot before each eye; nose gibbous, separated from the front by a transverse angular line; palpi and antenne dirty-yellow, the latter with a black knob: prothorax with a dark, discoidal, subquadrangular spot, which does not reach the anterior margin: clytra witl a furrow adjoining the suture; shoulders with a dusky line: tibia and tarsi dusky rufous.

Vaniety B. Larger, dusky rufous above, spots before the eyes larger and subtriangular: black spot on the prothorax wider but not so near the anterior margin; shoulders of the elytra without a dusky line.

The American specimens have no black spots contiguous to the discoidal one on the prothorax, noticed by Major Gyllenhal and Mr. Stephens. Variety B. is very like Variety \%. of Stephens (Var. c. Gyllenh.) Hydrophilus dermestoides of Forster and Marsham, but the front is spotted.

Most modern Entomologists seem agreed in placing the Sphceridiadae next to the Philhydridn, and the genera that connect them are clearly Hydrolius and Cercyon. The insects of this last genus indeed are generally terrestrial, but one species is strictly aquatic-I allude to Cercyon aquaticum, ${ }^{5}$ which Fabricius has deseribed under the name of Hydrophilus hemorrhoidalis, ${ }^{6}$ and which was sent me as sueh by Gyllenhal so long ago as 1802. Afterwards in his Insecta Suecica, he denominates it Sphieridium hemorrhoum. ${ }^{7}$ This family, as well as the Byrrhide, has considerable affinity with the Histeride, to which it approaches by Abreus; so that the aquatic branch which leads from the predaccous beetles here again seems to meet the terrestrial, and which by means of the Histeritle proceed, as it were, together to the Lamcllicorn tribes: Hister of Linneus, therefore, seems rather an osculant group, than a part and portion of the great section last mentioned.

5 Step. Illustr. Mandib. ii, 138, 6. 6 Ent. Syst. i, $185,16$.

; i, 107, 9. Mr. Stepbens' Cercyon homorrhoum (Illustr. Mandib. ii, 143, 23) must therefore be a different speeies. Mr Stephens, both in his Catalogue $(64,658,32)$ and in the work just quoted $(145,32$, ) bas referred to my MIS. Catalogue, for a name he has adopted; but the name is ineorrectly written. Instead of Sphoridium contexium, in my Catalogue it stands, as it should, as the neuter of converior, S. convexius. 


\section{Family HISTERIDÆ. Histeridans.}

This family, though not numerous, presents to the scrutinizing Entomologist many different forms, which appear to lead many different ways. M. Latreille has observed with respect to it, that though, in many respects, the Histers seem to approach the coprophagous Lamellicorns, yet that other considerations founded upon their anatomy indicate a station near the Silphida, ${ }^{8}$ which he says is likewise the opinion of M. L. Dufour: accordingly there are several forms in the family that appear to tend that way: thus Onthophilus exhibits some of the peculiar characters of Micropeplus, one of the Nitidulida; Spharites, one of the lastnamed family, ${ }^{9}$ but of a different general aspect, was long regarded as a Hister ; and in the typical form, or true Histers may be traced many characters which are also to be found in Necrophorus. But still I am of opinion that the Histerida are the steppingstone, as I have before observed, on the one side from the Necrophaga and on the other from the Philhydrida to the Lamellicorn tribes, but that they diverge into two branches, one leading to the coprophagous Lamellicorns, and the other to the lignivorous ones, or stag-beetles.

Mr. Mac Leay, as I lately hinted, has associated the tribe we are considering, with the latter portion of the Lamellicorn beetles, forming a separate secondary group of them under the denomination of Rectocera, which he has further subdivided into two circles or columns, which, from the supposed nature of their food, he distinguishes by the appellations Saprophagous and Thalerophagous, or devourers of putrescent and nonprutescent substances: the former consisting of the Histerida, and the latter of the Lucanidce. But is there really this distinction between them? The former group, besides dung, which is their more general pabulum, feed also upon animal matter, upon fungi, and upon decaying timber, and many upon the sap exuding from the wounds of trees ; the latter, in their feeding state, are generally found in putrescent wood, and therefore are saprophagous; what they feed upon in their perfect state appears not to have been clearly ascertained, and their oral organs scarcely afford a certain indication of the nature of their food. If they are found to feed upon the exuding sap of trees, this is hardly sufficient to distinguish them from the Histers, which very often do the same. It seems to me, therefore, that I best follow the guidancc of nature, when I consider the Histeridae 
as forming an oscnlant group between the Lamellicornia, and the Necrophaga and Philhydrida, rather than as belonging to the former, and likewise when I regard the coprophagous IIisters as connected with the coprophagous, and the lignivorous ones with the lignivorous, Lamellicorns: so that they appear to diverge towards the two extremities of that vast primary group; for that the Lucanidee are most intimately connected not only with Trogosita and its cognate genera, but by means of Priomus and some new genera, with the great Capricorn group, I hope to make evident hereafter.

I must observe here, however, that there is a certain group of the Histeride which appears to make a near approach to the Scolytides: the group I allude to has been formed into a genus, under the name of Tryponceus by Esehscholtz, ${ }^{1}$ formed of three Bostrichi of Fabricius, viz. B. thoracicus, B. proboscideus, and B. pustulatus; which indicates that a road may be formed from the lignivorous Histeride towards Scolytus, \&c.

LXY. Genus HISTER. Linn. 1. * Hister Paykulit. Paykull's Hister.

H. (Paykullii) ater, nitidus, cubitis tridentatis : dente exteriori fisso; prothorace utringue bistriato: stria exterioriabbrevinta : elytris striis sex discoidalibus, nempe tribus externis distinctis integris, tribusque internis cx punctis conflatis, abbreviatis.

Paykull's Hister, black, glossy, cubits armer with tliree teeth, the outermost clcft: prothorax with a double furrow un each side, the exterior one abbreviated : elytra with six discoidal furrows, the three external ones entire and distinctly drawn, the three internal ones abbreviated and composed of punctures.

Length of the body $3 \frac{1}{5}$ lines.

One specimen taken in the Journey from New York to Cumberland-house.

DESCRIPTION.

Body black, glossy. Head circumscribed by a rather decply ploughed furrow; antennæ piceous with a pale knob; mandibles longer than the head: prothorax rather wider behind, seemingly quite smooth, but under a strong magnifier it appears thickly covered with very minute lightly impressed punctures; it is circumscribed on all sides, by a decpish furrow, between this furrow and the lateral margin is another abbreviated one less impressed; elytra besides a distinct marginal furrow 
have three discoidal subpunctured ones running from the base to nearly the apex; between the external discoidal furrow and the margin is a series of punctures near the apex, representing what is called the marginal furrow, and between the internal one and the suture are the traces of three others, the first just discernible, drawn, but interruptedly, from the base to the apex; the second consisting of three or four punctures near the apex, and the third parallel with the suture, consisting also of punctures, sometimes confluent, and extending from the apex not quite half the length of the elytrum; the surface of the elytra is covered with minute punctures very lightly impressed, so as not to be discoverable except under a good magnifier: the cubit or anterior tibia is armed with three teeth, the last of which appears cleft from its being furnished at the apex with two short truncated transparent bristles, the two other teeth have only one such bristle.

This species, which belongs to Mr. Stephens' family, A. a. 2,2 differs in its sculpture, from any Hister at present known. Its aspect is that of $\boldsymbol{H}$. unicolor, with which it likewise agrees in size, and many other characters, but it belongs to the section with the sides of the prothorax twofurrowed; whereas, in $\mathrm{H}$. unicolor, they have only one furrow; the elytra likewise of $\mathrm{H}$. Paykullii are punctured, which in the species just mentioned are perfectly smooth, even when viewed under a powerful magnifier.

\section{2. * Hister Harrisil. Harris's Hister.}

H. (Harrisii) ater, nitidus, punctatus; prothorace utrinque bistriato, postice foveola impresso; clytris septem-striatis : striis interioribus duabus untice abbreviatis; cubitis multidentatis.

Harris's Hister, black, glossy, punctured; prothorax with two furrows on eacls side, and a posterior punctiform impression; elytra with seven furrows, the two interior ones anteriorly abbreviated; cubit multidentate.

Length of the body $3 \frac{1}{4}$ lines.

\section{One specimen taken in the Journey from New York to Cumberland-house.}

\section{DESCRIPTION.}

Body black, glossy, thickly punctured, the punctures on the upper-surface, being most conspicuous. Head circumscribed; antennæ and palpi nearly of a mahogany colour; mandibles longer than the head; nose slightly impressed: prothorax with two furrows at the lateral margin, both nearly reaching the base, the inner one, as usual, when arrived at the anterior margin, with the corresponding one on the other side forming one furrow surrounding the prothorax on three sides; just above the scutellum is a punctiform impression : the elytra, including the submarginal one, have seven distinct furrows, the two next the suture being anteriorly abbreviated and very short, espccially the first; from the base of the first, or external discoidal one, an obsolete furrow runs obliqucly towards the submarginal one; the four discoidal entire furrows when arrived near the apex of the elytra are bent towards the suture: cubit piceous, armed with five teeth, the three outer oncs obtuse. 


\section{LAMELLICORNIA.}

i. Petalochira. Ilum.

a. Copropliacia. Kirb.

a Herentona. Kirb.

\section{Family COPRIDAE. Copridans.}

LXVI, Genus ONTHOPHAGUS. Iat.

Ontbophagus latebrosus. Sturm. Cat. i, 178.

Copris latebrosus. Fabr. Syst. Eleuth. i, 34, 20.

Length of the body $\left\{\begin{array}{l}0,3-33^{3} \\ \delta^{3} \frac{1}{2}\end{array}\right\}$ lines.

A single specimen of the female taken in the Jonrney from New York to Cumberland-honse. I have also a specimen of the male taken in New England, by the late Professor Peck. The larger female was taken, 1 believe, in the province of Massachusets, by Mr. Drake.

The species of this little interesting genus, remarkable for the great variety of processes resembling horns, that arm the head of the males, are as widely dispersed as those of any genus of beetles; they are to be found in every climate from the frigid to the torrid zone, nor do they increase in size as they recede from the former and enter the latter, for the most minute species are to be found in Southern India, where they abound, while the largest seem to inhabit temperate climates.

\section{DESCRIPTION.}

$\delta$

Body entirely black, except the hands or anterior tarsi, which are rufous : gloss obscured by hairs. Nose at the apex bent upirards, forming a vertical, triangular, acute tooth; on the vertex are two obsolete transrerse ridges: the prothorax is rough with little granules, and anteriorly sends forth a longish wide horn trincated at the end and overhanging the head: the two angles of the apex are elevated, and the space between them is deflexed, and bidentate: the cubits are armed with four sharpish teeth.

\section{}

The female differs from the male merely in having the shield of the head more distinctly notched on each side, and the apex of the nose rounded and reflexed, but without any triangular horn or tooth; in having two distinet ridges on the vertex, and in having no prothoracic horn, which is replaced by a transwerse emarginate ridge in the middle. 
O. (scabricollis) ater, obscurus, capitis clypeo femineo utrinque integro, vertice bicarinato; prothorace scaberrimo, antice subprominente, cubito obtuse quadridentato.

Rough-necked Onthophagus, black, not glossy; shield of the head of the female not notched on each side, vertex tworidged; prothorax very rough, anteriorly rather prominent; cubit obtusely quadridentate.

Length of the body 4 lines.

A single female specimen taken in Canada by Dr. Bigsby.

DESCRIPTION.

This is so like the last insect that I felt at first disposed to consider it as merely a variety. The following differences in their characters induce me however to consider them as distinct. Not to mention the difference of size, the female of $O$. latebrous has a distinct notch on each side of the head, of which there is no trace in $O$. scabricollis, the ridges of the vertex of the latter are more elevated, the prothorax is larger in proportion and much rougher, with larger and more numerous granules, and the four teeth of the cubit, which in the former are long and acute, in the latter are shorter and obtuse.

B. Arenicole. Kirb.

\section{Family TROGIDE. Trogidans.}

LXVII. Genus TROX. Fab. 1. * Trox arenarius. (Fabricius.) Sand Trox.

'T. arenarius. Fab. Ent. Syst. i, 87, 3; Syst. Eleuth. i, 111, 5. Oliv. Ent. i, 4, 10, 9, t. i, f. 7. Herbst. Ins. iii, 17, 2, t. xxi, f. 2. Gyll. Ins. Suec. i, 11, 3. Panz. Fn. Germ. xcvii, $t$. 1. Sturm. Deutsch. Ins. ii, 149, 5. Scbueid. Mag. 279, 2. Lat. Gen. Crust. et Ins. ii, 99, 3.

Scarabæus arenarius. Marsh. Ent. Brit. i, 25, 41.

- arenosus. Linn. Syst. Nat. Gmel. iv, 1586, 398.

Silpha scabra. Linn. Syst. Nat. ii, 573, 23.

Trox scaber. Illig. Kaf. Preuss. i, 99, 2. Steph. Illustr. Mandib. iii, 215, 3.

—_ barbosus. Lai. Ins. Tyr. i, 31, 3. Scrib. Ins. i, 45, 10, t. v, f. 3. Journ. i, $58,45$.

- hispidus. Payk. Fn. Suec. i, 81, 3.

Length of the body 3 lines.

Taken by Capt. Hall in Nova Scotia. 


\section{DESCRIPTION.}

Body oblong, black, without any gloss. Head covered with cinereous varioles; nose a little reflexed, rounded with a slight tendency to be obtusangular; antennæ ferruginous: prothorax with a wide rather obsolete dorsal chamnel; sides with two impressions, one near the anterior angle, and the other basilar in the disk; base lobed; lateral margin fringed with ferruginous bristles: elytra slightly furrowed, interstices with each a series of elevations crowned with brown bristles, the elevations of the alternate series are minute; anterior tibia with three acute teeth, they are also serrated at the base.

b. Pinglopisaga. Kirb.

a. Sternucha. Kirb.

\section{Family RUTELID无. Rutelidans. ${ }^{3}$}

LXVIII. Genus PELIDNOTA. Mac L.

\section{$(177)$}

\section{Pelidnota punctata. Dotted Pelidnota.}

Pelidnota punctata. Mac L. Hor. Ent. i, 158.

Ratela punctata. Lat. Gen. ii, 106.

Melolontha punctata. Fab. Syst. Ent. 33,8; Syst. Eleuth. ii, 166, 28. Oliv. Ent. i, 5, 22, 18, t. i, f. 6. Herbst. Ins. iii, $69,16, t$. xxiii, $f .6$. Illig. Mag. iv, 78,28 .

Scarabæus punctatus. Linn. Mus. L. U. 23, 21; Syst. Nat. ii, 557, 76. Drury. Ins. i, 75, t. xxxiv, f. 5. Voet. Col. i, $45,65, t$. viii, $f .65$. Mü̈ll. Linn. Nat. v. 87, 76 .

Onom. Nat. vi, 937. Gronov. Zooph. 146, 438.

Length of the body $12 \frac{3}{4}$ lines.

Taken by Dr. Bigsby in Canada, near Lake St. Clair. Found also in Virginia, Carolina, Maryland, and New York.

\section{DESCRIPTION.}

Body very minutely punctured, glossy, black, underneath a little bronzed, above luteous. Head black at the base, with the blackness bilobed; punetures of the nose confluent; antenna luteous; palpi black: prothorax, as well as the head, darker than the clytra; sides confluently punctured, a round blackish spot on each side near the lateral margin: scutellum black, a little bronzed, with a basilar luteous spot : clytra with threc distant black-brown spots or dots, the first and last oblong, the middle one round; breast, and base of the abdomen, hairy with long hairs: legs black, a little bronzed; cubit tridentate.

3 The Rutelida exhibit the vertical prostcrnum of the Dynastide, which is wanting in the Anoplognathida, I therefore consider them, with Latreille, as more immediately connected with the former family, and have placed them accordingly. 


\title{
B. Aposterna. ${ }^{4}$ Kirb.
}

\section{Family SERICIDÆE. Sericidans.}

\author{
LXIX. * Genus CAMPTORHINA. Kirb.
}

Labrum transverse, emarginate.

Mandibles very short, subtrigonal, curving, without teeth; molary space subtriangular, surface furrowed, the outer margin appearing denticulated from the ridges of the furrows being more elevated there, on the opposite side there appears to be a kind of channel.

Maxille linear, incurved at the tip and terminating in four stout teeth.

Labium oblong, forming one piece with the mentum; narrowed, subemarginate, and sloping inwards at the apex.

Palpi maxillary, four-jointed, gradually incrassated: first joint very minute, second obconical; third of the length of the second, thicker; fourth as long as the second and third together, rather oblong.

labial, three-jointed, filiform: last joint as long as the two first together.

Antenne nine-jointed: scape much incrassated at the apex; the pedicel less incrassated, sphericaloblong; the two following joints rather filiform; the fifth and sixth shorter and inclining to pateriform; and the three last elongated and forming a rather slender knob.

Body oblong, subcylindrical. Head inserted, subtriangular, with the vertex of the triangle anterior, truncated; nose short, transverse, distinct, reflexed, separated from the postnasus on each side by a cleft; nostril-piece inflexed, transverse, and nearly vcrtical; postnasus distinct, depressed, curved; front convex; eyes subhemispherical; cantlus septiform: prothorax transverse, with an anterior sinus taken from its whole width to receive the head, posteriorly subrepand: scutellum an isosceles triangle: elytra linear: breast-bones not prominent: medipectus or midbreast elevated: legs thus located::; tarsi subsetaceous; claws two, very short, incurved, each bifid or bipartite, with the lobes acute: podex only partly covered.

This genus is very nearly related to Serica of Mr. W. S. Mac Leay. It differs, however, in the number of tceth that terminate the maxilla, having only four instead of six; in having both the lobes of the claws that arm the tarsi acute, whereas in that genus the inner one is truncated, and in having none of the silky bloom which the species of Serica usually exhibit. Mr. Mac Leay speaks of its antennæ being ten-jointed, this, if correct, would furnish another striking distinction, but in $S$. brunnea, the type of the genus, under a very strong magnifier I can perceive only nine joints, and M. Latreille in this agrees with me. ${ }^{5}$

4 This tribe is distinguished by having no prominent prosternum or mesosternum.

5 Crust. Arachn. et Ins. i, 562. Not. 2. 
C. (atracapilla) glubra, subnitida, punctata, sordide brmnea; prothoracis disco capileque postice, nigris; ; clytris late sulcatis : sulcis inordinate punctatis.

13lack-cap Camptorhina, naled, rather glossy, punctured, of a dirty mahogany eolour; with the disk of the prothorax, and posterior fart of the head, black; elytra widely furrowed, furrows irregularly punctured.

Length of the body $5 \frac{1}{4}$ lines.

\title{
Taken in Canada by Dr. Bigsby, and in Nova Scotia by Capt. Hall.
}

\section{DESCRIPTION.}

Body rather glossy, with very few hairs, grossly punetured, of a dull mahogany colour. Antennæ and palpi rufous; nose smooth, piceous; afternose piceous, thickly punctured; the rest of the head black, less densely punctured with the vertex impunctured: limb of the prothorax mahoganycoloured; disk of the scutellum smooth: clytra with eight wide shallow furrows, irregularly punctured; the rilges between them impunctured, and obtuse : legs hairy or bristly, tarsi chestnut.

VAriety B. Elytra chestnut, paler at the sides.

\section{Family DIPLOTAXIDÆ. Diplotaxidans.}

\author{
LXX. Genus DIPLOTAXIS. Kirb.
}

Labrum transwerse, lanceolate, anteriorly emarginate.

Mandibles very short, trigonal, incurved, truncated and concavo-convex at the apex; molary space small, irregular, channelled?

Maxilla very short, incurved, incrassated at the base; apex armed with three short, stout, conical teeth.

Labium very short, transverse, entire, separated by a faint line from the mentum.

Mentum quadrangular, rather wider than long.

Palpi maxillary four-jointed, very minute, cylindrical; second and third joints thicker, equal in length, obconical ; last thickest and longest, lanceolate-ovatc, acute.

labial three-jointed; first joint obconical; second subcylindrical; third nearly as long as the other two, but scarcely thicker, conical.

Antenna ten-jointed; scape elongato-obconical; pedicel nearly spherical; third and fourth joints conical; fifth and sixth nearly top-shaped; seventh pateriform ${ }^{6}$ the three last forming a short ovate knob. 
Body between oblong and obovate, not hairy. Head inserted, subtriangular with the vertex of the triangle truncated; rhinarium transverse, vertical, widely emarginate; nose transverse, distinct, anterior margin reflexed and subemarginate; no distinct postnasus or afternose; canthus septiform, cleaving: $:^{7}$ prothor ax transverse with an interior sinus of its whole width to receive the head: scutellum short, triangular, somewhat rounded at the vertex : podex and part of the penultimate dorsal segment of the abdomen uncovered: legs thus located :: ; cubit tridentate ; tarsi filiform, slender : claws bipartite, the interior lobe the shortest and widest, and very obtuse; the exterior very slender and acute.

This genus, at the first blush, seems to exhibit some affinity both with Chalepus and Apogonia; with regard to the latter, this arises merely from its having few or no hairs, and from its rows or punctures in pairs observable in the elytra; but with the former it agrees in more particulars, for its mandibles are truneated at the apex and concavo-concave, as those of Chalepus are represented, and correctly, in Mr. Mac Leay's figure $;^{8}$ the antennæ likewise are not very different, except that the scape in the latter insect is more dilated at the apex: but this exhibits a character which at once separates it, and widely, from Diplotaxis, the prosternum sends up a vertical process behind the base of the arms, hairy at its summit, a character which is to be detected, but more or less conspicuously, in all the various genera and subgenera that form Mr. Mac Leay's large family of Dynastida though it is less prominent in Megasoma, the most gigantic genus of them all. The maxillæ, often so constant, in this family or rather tribe, vary without end, the mandibles are more constant, as is also the labium, but the vertical prosternum, ${ }^{9}$ varying as to elevation and shape, is their constant diagnostic: so that it is evident that Chalepus is one of those intermediate forms which connect two tribes or circles; allowing this, and that the Rutelidee also and Anoplognathida are intimately connected with the Dynastide, ${ }^{1}$ we have another instance of unconnected ramifications, which lead by different routes to different tribes. It may be here not out of place to observe, that in the true Rutelida, there is the vertical prosternum of the Dynastida, and the horizontal projecting mesosternum ${ }^{2}$ of the Anoplognatlide, which last have no elevation of the prosternum.

\section{1. * Diplotaxis tristis. Sad Diplotaxis.}

D. (tristis) castanea punctatissima; scutello levi; elytris puncto-striatis: striis discoidalibus didymis ; tarsis intermediis tibia longioribus; antennis palpisque rufis.

Sad Diplotax:s, chestnut, thickly punctured, scutellum without punctures; elytra with punctures in rows, the discoidal rows paired; intermediate tarsi longer than the tibia ; antennæ and palpi rufous.

PLATE V, FIG. 3.

Length of the hody $5-5 \frac{1}{2}$ lines.

Several specimens taken in Lat. 54․ 'Taken also in Novia Scotia by Capt. Hall.

7 I call the canthus cleaving, when it appears to ellter the eye.

8 Hor. Entomolog. t. ii, $f .15, \mathrm{D}$. Mr. Mac Leay describes the maudibles as acutc, but this appears a slip of thic pen, for they are obliquely truncated at the apex and concavo-concave, as Mr. Curtis bas represented them.
9 Introd. to Ent. iii, 368, B.
1 Hor. Ent. 67.
- Introd. to Ent. iii, 378, C. 
I at first regarded this species as a variety of Melolontha mesta of Knoch, but upon comparing it with Germar's description, ${ }^{3}$ it appears quite distinet; for it is not at all bronzed, the nose is not rounded, and the four posterior tarsi, especially the intermediate pair, are longer than the tibia. It comes very near to Say's M. mosta, (which is quite distinct from Knoch's,) from which it is principally distinguished by its impunctured scutellum.

\section{DESCRIPTION.}

Body dark chestnut, more or less grossly punctured above and below. Head thickly punctured with a pair of impressions between the eyes; nose subemarginate ; antennx and palpi rufous: prothorax thickly punctured, slightly impressed at the four angles: scutellum impunctured: clytra rather paler than the head and prothorax, with nine rows of punctures, viz. a single one at the suture, four arranged in pairs in the disk, and four in the sides; the interstices between the rows are also irregularly punctured; the four posterior tarsi, especially the intermediate pair, are longer than the tibix.

Obs. In more recently diselosed specimens the body is often entirely pale-chestnut and sometimes rufous.

\section{Family MELOLON'THIDE. Melolonthidans.}

\section{Genus RHIZOTROGUS. Lat.}

Palpi maxillary four-jointed; first joint minute; second rather long, obconical; third shorter triangular; last thicker and longer than the others, subovate, rather obtuse.

_ labial three-jointed; first slender, obconical; second thick obconical; last not thicker than the second, obconical.

Antennce ten-jointed; scape incrassated; elongato-obconical; pedicel spherical; three following joints subcylindrical projecting internally towards the apex into an obtuse angle; sixth and seventh rather platter-shaped; three last elongated into a linear knob of almost the length of the rest of the antemnx.

Body oblong, subcylindrical. Head short, inserted, subtrapezoidal; nose distinet, separated by a wavy line, trausverse, anteriorly rounded, emarginate with a reflexed margin : prothorax transverse, curved, behind and at the sides obtusangular with angles rounded: scutellum subtriangular, vertex rounded: elytra with two obsolete abbreviated ridges: anus uncovered; pordex large: breast very hairy : location of legs ::: spurs 1,2,2, tarsi long, filiform : claws bifid, inner division divaricated and dentiform. 
M. Latreille, in his last work, 5 has united to this genus Amphimalla solstitialis, which on account of its having only nine joints in its antennæ, lee had, and I think with reason, considered as distinct ; for besides this character, the mandibles are of a very different shape, being shorter and smaller in proportion to the size of the animal, with the truncated portion narrower and concavoconvex; the maxillæ are armed with only four teeth, and are more incrassated at the base; the claws have only a minute tooth at the base, and the elytra are many-ridged, besides other minor differences; I think, therefore, I am justified in still considering them as belonging to different genera. Rhizotrogus should be placed between Amphimalla and Melolontha, from which last it may always be distinguished by having only three leaves in the knob of its antennæ.

As Latreille's character of the genus is insufficient, I have drawn up a new one.

\title{
1. Rhizotrogus fervens. Fervid Rhizotrogus.
}

\author{
Melolontha fervens. Gyll. Schön. Syn. iii, App. 74, 106 \\ ferivida. Oliv. Ins. i, $5,24,21, \ell$. ix, f. 109 ? \\ quercina. Knoch. Ins. i, 74, 2 ? \\ Length of the body $9 \frac{1}{2}-10$ lines.
}

Two specimens taken in Lat. 54\%. B, in Canada by Dr. Bigsby.

\section{DESCRIPTION}

Body either pale or dark chestnut, rather glossy, naked. Head short, black, thickly and grossly punctured, vertex transversely impunctured; nose separated by a bisinuated line from the front, anteriorly reflexed and subemarginate; antennx testaceous with the knob in the males paler and elongated: prothorax transverse, usually darker in the disk, punctured with scattered punctures; sides subobtusangular with the margin very obsoletely notched; behind subrepand or bisinuate : scutellum with a few scattered punctures towards the sides: elytra four times the length of the prothorax, with three obsolete ridges, very slightly punctured and wrinkled: disk of the abdomen impunctured: breast covered with long hairs: legs testaceous; cubit obtusely trideutate ; tarsi longer than the tibiæ.

VARIETY B. Rather wider in proportion, entirely dark chestnut, the legs excepted. In cvery other respect precisely the same.

5 Crust. Arachn. et Irs. i, 56I, note I. 


\section{2. * Rhizotrogus Drakir. Diake's Rhizotrogus.}

R. (Dralii) castaneus, nitidus, punctatus; antennis testaccis; podice mayno.

Drake's Ruizotrogus, chestnut, glossy, punctured; antemie testaeeous ; podex large.

Length of the body $9+11 \frac{1}{4}$ lines.

A single specimen taken in the Journey from New York to Cumberland-house. B and C, by Mr. Drake in Massachusets.

\section{DESCRIPTION.}

This species is extremely similar to the last, it differs principally in having the sides of the scutelluin more thickly punctured, the ridges of the elytra, except the sutural one, are scareely discoverable, and the podex larger and rounder at the apex: the tarsi also are longer in proportion: the knob of the antennx in all the specimens is longcr.

B. Much larger, and the elytra appear somewhat more thickly punctured, but it is scarcely distinct.

C. Like $A$, but the ridges of the elytra are all discernible.

\section{Family MACRODACTYLIDÆ. Macrodactylidans.}

\section{Genus DICHELONYCHA. Harr. ${ }^{6}$}

Labrum transverse, lanceolate, scarcely emarginate.

Mandibles short, trigonal, incurved, toothless, acute : molary space transvcrse, furrowed.

Maxille minute, linear, bidentate with short teeth.

Labium subquadrangular, not distinct from the mentum.

Palpi maxillary four-jointed; first joint very minute; second longer than the third, obconical; third triangular; last joint as long as the three others together, very large, subsecuriform. labial three-jointed; joints short, subfiliform; last truncated.

Antennee ninc-jointed; scape obconical, incrassated; pedicel subspherical; third and fourth joints subfiliform; fifth obconical; sixth subturbinate; the three last forming a short suborate knob.

Body narrow, subcylindrical. Head subquadrangular; nose transverse, separated by an indistinct obtusangular line, anteriorly reflexed; rhinarium transverse marked with a transverse series of ratler large punctures; eyes prominent; canthus entering: prothorax hexagonal, the sides being obtusangular: scutellum rounded at the vertex, dilated at the base: clytra linear, rounded at the apex, obsoletely ridged, wrinkled; epipleura vertical, narrow : legs rather slender; hind legs long; cubit tridentate; tarsi filiform; claws equal, all bifid at the apex: podex subtriangular.

- I receired a species of this genus under this name from Dr. Harris, which therefore I adopt. I had called it Stcnia. 
This genus evidently belongs to the same family with Macrodactylus, from which it is distinguished by having its maxillæ armed only with two teeth, the last joint of its palpi of a different shape, and its labium approaching to a square form: whereas in the latter genus the maxillæ are more conspicnous and armed with three teeth, the last joint of the palpi is subovate, and the labium is oblong and channelled.

The species of this genus, as far as at present known, appear to be confined to the more northern parts of the new world; I have seen none south of the province of Massachusets, from whence I have received specimens both from Dr. Harris and Mr. Drake. Type of the genus Melolontha linearis Herbst. ${ }^{7}$

\section{1. * Dichelonycha Backit. Back's Dichelomycha.}

D. (Backii) nigra albido-pilosa ; elytris aneo-viridibus sericeis; antennis castaneis, clava nigra; naso valde, reflexo.

Back’s Dichelonycha, black : hairy, bairs white; elytra bronzed-green, silky; antennæ chestnut with black knob; nose much reflexed.

PLATE II. FIG. 6.

Length of the body $4 \frac{1}{2}$ lines.

Several specimens taken in Lat. 54\%

DESCRIPTION.

Body black, glossy, hairy, especially underneath, with white deeumbent hairs; above thickly and coarsely punctured. Nose much reflexed, margin entire; stalk of the antennæ chestnut: elytra silky, green, more or less bronzed.

VARIETY B. Antennæ rufous. Tarsi pale chestnut.

2. * Dichelonycha virescens. Virescent Dichelomycha.

D. (virescens) picea, subtus piloso-nivea; antennis pedibusque flavo-testaceis; clytris flavis sub luce virentibus; prothorace dorso subcanaliculato, utrinque impresso.

Virescent Dichelonycha, piceous, underneath covered with snowy hairs; antennæ and legs yellow-testaceous; elytra yellow with a grecn lustre : prothorax with a slight dorsal channel, and an impression on each side.

Length of the body $4 \frac{3}{4}-5$ lines.

Taken in Canada by Dr. Bigsby, in Nova Scotia by Dr. Mac Culloch, in Massachusets by Dr. Harris, and in Pennsylvania by Dr. Horsfield. Dr. Bigsby found it common on the different species of Salix. 
DESCRIP'TION.

Body piccous, thickly covered underneath, exeept the disk of the breast and abdomen, with decumbent snowy lairs, minutely punctured, punctures most numerous in the upper side. Head uearly black, covered with glittering decumbent hairs; nose very obtuse and almost truncate, less reflesed than in $D$. Backii, reflexed part obscurely rufous; rhinarium, underside of the head, and mouth with its organs, rufous; antenna reddish-ycllow: prothorax nearly black with the sides a little paler, with a longitudinal discoidal rather obsolete channel and an impression on each side; sprinkled with short glittering decumbent hairs : scutellum rufous, thickly covered at the base with whitish decumbent lairs: elytra reddish-yellow tinted with green, sprinkled with short decumbent whitish hairs, the lateral punctures are almost arranged in dense rows: abdomen rufous; podex thickly covered with snowy hairs: legs reddish-yellow; tarsi darker; posterior tibix black, reddish at the base; posterior tarsi piceous.

Vanivity B. Head and prothorax rufo-piceous; legs rufous.

C. Head and prothorax rufous mottled with dusky; clytra with a green spot at the shoulders and tips; posterior legs entirely rufous: trunk rufous.

N.B. This may be distinct, but the prothorax has the channel and impressions observable in A. \&c.

Dr. Harris sent me a specimen of $D$. virescens as the Melolontha linearis of Herbst and Schönherr, but it is not likcly that so accurate and minute a describer as Major Gyllenhal, who usually lets no character escape him, should have overlooked the dorsal channel and lateral impressions of the prothorax of this species. Besides the colour and other characters do not agree. ${ }^{8}$

3. Dichelonycha testacea. Testaceous Dichelomycha.

D. (testacea) tota rufo-tcstacea; elytris subvirescentibus, capite prothoraceque ninutissime punctulatissimis.

Testaceous Dicbelonycha, entirely rufo-testaceous; elytra with a sligbt tint of green; bead and prothorax very minutely and thickly punctured.

Length of the body $4 \frac{1}{3}$ lines.

Taken by Dr. Bigsby in Canada.

DESCRIPTION.

Very similar to Variety C of the preceding species; but the body, with the exception of the eyes which are black, is entirely of one colour, rufo-testaccous, the head, prothorax, and tarsi being rather darker than the rest; the eyes are larger and more prominent; the head and prothorax, especially the latter, are more thickly and minutely punctured; and in this there is no dorsal channel ; its margins, especially the lateral, are more hairy, the clytra cxhibit no humeral or apical green spot; and they are very slightly tinted with that colour. 
c. Melitophila, Lat.

\section{Family CETONIADZ. Cetoniadans.}

LXXIII. Genus CETONIA. Fab.

\section{Cetonia fulgida. (Fabricius.) Fulgid Cetonia.}

Cetonia fulgida. Fab. Syst. Ent. 48, 27; Syst. Eleuth. ii, 150, 77. Oliv. Ent. i, 6, 33, 35, t. viii, f. 75. Linn. Syst. Nat. Ed. Gmel. iv, 1574, 336. Voet. Col. i, 17, 24, t. iii, f. 24 ?

Length of the body $7 \frac{1}{2}$ lines.

Taken in Canada, at Lake St. Clair, by Dr. Bigsby.

DESCRIPTION.

Body dcpressed, of a beautiful glossy green. Head black underneath, above grossly punctured ; eyes reddish-brown; antennæ brown-black; nose anteriorly subemarginate and a little reflexed; prothorax with a triple posterior sinus, grossly but not thickly punctured, sides luteous : scutcllum an isosceles triangle, impunctured: elytra, in some lights, luteous, in others with a shade of green; at the base grossly but not thickly punctured, the remainder of the elytrum is acuducted like net work; disk longitudinally depressed : podex dusky, luteous at the apex, with four triangular, white, basilar spots; abdomen underneath with a double series of triangular white spots on each side, the outer ones elongated: sides of the breast lairy; mesosternum suborbicular, hairy; legs luteous; tarsi and base of the cubits, brown-black.

Family TRICHIAD正. Trichiadans.

LXXIV. Genus TRICHJUS. Fab.

1. Trichius Bigsbir. (Kirby.) Bigsby's Trichius.

Trichius Bigsbii. Kirb. Zool. Journ. iii, 155, t. v. f. 7

Length of the body 7 lines.

Taken in Canada, near Lake St. Clair, by Dr. Bigsby. 


\section{DESCRIPTION.}

This speeics exhibits the habit and general aspect of $T$. fasciatus, but it is larger and less hairy. Body obovate, black, covered more or less with tawny longish hairs. Head quadrangular; nose reflexed, emarginate ; antennx and palpi luteous, black at the tip : prothorax trapezoidal, narrowest anteriorly, sides rounded or subotusangular, posteriorly with an obsolete sinus near each angle: seutellum short, rounded at the apex : elytra without hairs, covered as it were with a bloom; luteous with a black margin and nine black spots-viz. one large one at the shoulders, seven in the disk arranged transversely $2,3,2$, and one larger than the rest on the apical tumour; the humeral and apieal spots are glossy : three tawny-yellow mealy spots, the intermediate one straight and longitudinal, and the lateral ones sinuated and oblique, mark the podex : the tibia and tarsi of the four anterior legs are deep ferruginous; cubit bidentate.

x. Subgenus Trichnus. Kirb.

Trichini. Kirb. Zool. Journ. iii, 156, **.

The insects that compose this little group, as far as at present known, are all North American; and are distiuguished from the legitimate Trichii (Legitimi K.) by having the last joint of the palpi more slender, and the elytra hairy without any of the bloom observable in those of T. fasciatus, Bigsbii, \&c. The type of the sulggenus is $T$. piger Fab.

T. T. (assimilis) niger, subhirsutus, nitidus; elytris disco macula basilari communi pallida; singnlis fasciis duabus, lineolaque suturali pollinoso-niveis.

Similar T. 'Trichinus, black, bairy; glossy ; tlytra taken together with a discoidal basilar pale spot, eachl marked with a pair of bands, and $\mathrm{a}$ line parallel to the suture, mealy-white.

Length of the body $4 \frac{1}{2}-5$ lines.

Taken in Lat. $65^{\circ}$; in Nova Scotia by Capt. Hall; and in Massacliuscts by Dr. Harris. 


\section{DESCRIPTION.}

Body obovate, black, covered more or less with long yellowish hairs. Head punctured; nose reflexed, emarginate; stalk of the antennæ testaceous, scape and knob black; palpi dusky: prothorax punctured, less laiiry in the disk, not channelled : elytra black, very short, depressed next the suture with an intermediate ridge; at the base is a large pale-yellow spot common to both elytra, from which run a pair of narrow, white, mealy bands, which nearly reach the external margin, and a white mealy stripe adjoining the suture also runs from the same spot to the apex of the elytrum: the podex is covered with long yellowish hairs, so thick on the sides as almost to conceal the oblong white mealy spot common to the subgenus : legs black.

N. B. In the specimen taken in the Expedition, the white mealy stripe next the suture appears to have been rubbed off and is replaced by a continuation of the pale spot.

There appear to he many species of this subgenus. That now described Dr. Harris thought might be a variety of $T$. piger $\mathrm{F}$, but it differs from that species not only in painting, but also in sculpture and cloathing; for it has no channel on the prothorax, which is very conspicuous in the former insect; the podex is covered with very long and dense hairs so as to conceal the lateral mealy spots, while in T. piger the hairs are very short and the mealy spots very conspicuous. The head and thorax of the latter are bronzed, the whole of the antennæ testaceous, the elytra, podex, and legs 9 also, are testaceous, the former with a pair of abbreviated lateral bands, but no sutural stripe. So that $T$. assimilis is clearly distinct.

\section{3. * Trichius (Trichinus) rotundicollis. Round-necked Trichinus.}

$T . T$. (rotundicollis) niger, pallido villosus; prothorace suborbiculato, canaliculato; elytris fasciis duabus intus testaceis, extus, lineolaque ante scutellum, pollinoso-albidis.

Round-necked T. Tricbinus, black with pale bair: prothorax suborbicular, channelled; elytra with two bands internally testaceous, externally, as well as a line before the scutellum, mealy-white.

Length of the body $5 \frac{1}{2}$ lines.

'Taken in Nova Scotia by Capt. Hall.

${ }_{9}$ Olivier's Cetonia pigra (Ent. i, $6,64,78, t$. vii, $f .54$ ) is described as baving the legs black-bronzed. If this is not an error it must be a distinct species. 


\title{
DESCRIPTION.
}

Body obovate, black; covered, partieularly underneath, with longish pale hairs. Head very thickly punetured; nose reflexed, emarginate; stalk of the antenne, excluding the seape, testaceous: prothorax suborbieular, with the segment of a circle taken out next the head; very thickly punctured, channelled, sprinkled with short yellowish hairs; at the side of each of the four angles is a mealywhite spot: the elytra next the lateral margin have two transverse mealy-white streaks or bands, which are continued towards the suture by a broader, naked, ferruginous, obseure band; just below the scutellum, on each elytrum, is another mealy stripe, and parallel with the suture is an obscure, naked, ferruginous one: podex hairy with the ordinary mealy pale spots very conspicuous; it is sculptured with transverse undulated lines: cubits robust with two stout teeth: a mealy spot marks the base of the posterior legs.

\section{4. * Trichius (Trichimus) viridans. Verdant Trichimus.}

T. T. (viridans) supra viridans, subtus pallido-villosus; prothorace subtrapezoideo, canaliculato; elyiris fasciis duabus intus testaceis, extus, lineolaque ante scutellum, pollinoso-albidis.

Verdant T. Trichinus, above green, underneath with pale hair: prothorax subtrapezoidal, ehannelled; elytra with two bands internally testaeeous, externally, as well as a line before the scutellum, mealy-white.

\section{Length of the body $4 \frac{4}{5}$ lines.}

\section{A single specimen taken in Canada by Dr. Bigsby.}

\section{DESCRIPTION.}

In the markings of its elytra this species agrees precisely with that last described, but the upper side of the body, especially the head and prothorax, is green; the latter is of a different shape and less thickly punctured; and the eubit and its teeth are less robust: the podex also is more hairy. These can scarcely, all of them, be mere sexual distinctions.

It seems intermediate between $T$. rotundicollis and $T$. viridulus.

\author{
xi. * Subgenus Granodus. Kirb.

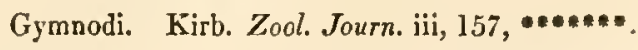

This is a very natural group of the genus Trichius, the species of which are common to Europe and North America. The type of it, T. Eremita, has long been known as a European insect. It was first noticed and figured by Rösel, and received its present name from Scopoli. ${ }^{1}$ The species that compose it are nearly naked, and without any mealy spots : the nose is truncated, and the cubit is tridentate. It appears to make a near approach to the South American Goliathi. 
T. G. (rugasus) nigro-piceus, subnitidus; prothorace canaliculato, utrinque obtusangula, cum capite confluenter punctato ; elytris confluenter rugosis.

Wrinkled T. Gymnodus, nigro-piceous, rather glossy : prothorax channelled, obtusangular on each side, with the head confluently punctured : elytra confluently wrinkled.

Length of the body $10 \frac{1}{2}-13$ lines.

Taken in Nova Scotia by Dr. Mac Culloch and Capt. Hall.

\section{DESCRIPTION.}

Body rather glossy, dark pitch-colour, naked above with a few scattered hairs on the underside and on the legs. Head above plane, thickly covered with impressions and punctures that anastomose and run into each other, in some specimens leaving here and there some elevated, levigated, narrow spaces : nose anteriorly transverse, reflexed: prothorax with a longitudinal posteriorly abbreviated channel; sides obtusangular; surface covered, less thickly in the disk, with large, and often confluent, punctures: scutellum an isosceles triangle, channelled, with a few scattered large punctures on each side: elytra indistinctly furrowed, confluently and irregularly wrinkled, wrinkles marked with shallow indistinct punctures, interstices elevated : cubit aeutely tridentate : podex transversely irregularly acuducted.

\section{Trichius (Gymnodus) foveatus. Impressed Gymnodus.}

T. G. (faveatus) piceus, subnitidus; elytris dilutioribus, aneo-tinctis; verniculatim canfluenter rugosis; prothorace canflucnter punctato, canaliculato, utrinque subfoveato : capite inter aculos profunde foveata.

Impressed T. Gymnodus, piceous, somewhat glossy; elytra pale, a little bronzed, wrinkled, wrinkles contorted like worms and confluent; prothorax confluently punctured, channelled, somewhat impressed on each side; head with a large deep impression between the eyes.

Length of the body $11 \frac{1}{2}$ lines.

\section{Taken in Nova Scotia by Capt. Hall.}

\section{DESCRIPTION.}

Near the preceding species, but perfectly distinct. Body nearly naked, somewhat glossy, of a dark pitch-colour. Nose and front between the eyes with a very deep and large impression, the bed of which is acuducted in circles with a minute puncture in the centre of each; the rest of the head is confluently punctured; above the bed of the antennæ the front rises into a rather lofty levigated prominence: the prothorax is shaped like that of G. rugosus, but is rather less obtusangular, the channel is deeper, with its sides more elevated, and there are one or two slight impressions between it and the margin; the punctures on the disk are rather more numerous: the elytra are paler than the rest of the body and a little bronzed, the wrinkles of the surface are more vermiform than in the species just named, without any punetures, and the appearance of furrows is less distinct: the podex is distinctly punctured and scarcely acuducted ; and the cubit is sinuated rather than dentated, the three prominences being extremely obtuse. 


\section{ii. RECTOCERA.}

Having finished the petalocerous or rather orthocerous Lamellicorn beetles, we must next proceed to those the stalk of whose antennie nostly forms an angle with the scape, so that these organs appear as if they were broken, which, as was before observed, ${ }^{2}$ form one branch of Mr. Mac Leay's Rectocerons beetles. These are not to be regarded, though they exhibit an analogical relation, respect being had to their food," as following the Trichicule in the line of affinity, but in order to link them to their apparently nearest relatives, we must retrace our steps to the Histeride, where we shall find a tribe that are lignivorous, of a depressed form, and with more than usually protended mandibles, of which Hololepta maxillosı may be regarded as the type $:^{4}$ it is towards these that the Lucaridce appear to tend, at one extremity, though still many forms are wanted to fill the interval.

Although I have not altered Mr. W. S. Mac Leay's denomination of the tribe before us, it must be observed that, in some families belonging to it, as the Lamprimide, Passalide, \&c. the antennæ are not broken. 'The family last mentioned, the Passalide, is not only distinguished by the stalk of the antennæ not forming an angle with the scape, as in the Lucanidae; but the form of the insects that compose it, is narrower, more cylindrical, and less depressed. From this family, as we shall see hercafter, a branch appears to diverge, by the Bostrichidans to the great Rhynchophorous tribe.

\section{Family LUCANIDÆ. Lucanidans.}

LXXV. Genus PLATYCERUS. Lat.

(192) 1. Platycerus piceus. Piceous Platycerus.

Lucanus piceus. Web. Obs. Ent. i, 84, 2. Fab. Syst. Eleuth. ii, 252, 20. Illig. Mag. i, 249. Thunb. Mem. Nat. de Mosc. i, 202, 30. Schön. Syn. iii, 327, 31. frontosus. Knoch.

Length of the body 6 lines.

A single specimen taken in the Journey from New York to Cumberland-house.

2 See abore, p. 122.

3 The Trickiadce as well as the Rectocera feed on putrescent timber.

- Oliv. Ent. i, 8, 1, 1, t. ii, iii, f. 8. 
DESCRIPTION.

Body dark piceous, rather glossy, thickly punctured. Nose very retuse, or rather with a large sinus; mandibles shorter than the head, acute, armed on their inner side with a stout tooth with the segment of a circle taken out of it; antennæ pale chestnut: prothorax with the lateral margin obtusangular, subcrenate, and reflexed; disk longitudinally impunctured, and obsoletely channelled: scutcllum channelled, impunctured : elytra furrowed : cubit serrulate and denticulate, two sharp teeth longer than the rest at the apex; tarsi chestnut.

This is the smallest species of the stag-beetle tribe. As Schönherr has not placed it under Platycerus, but under Lucanus, and as the insect here described is a true Platycerus, it should seem that he either did not know L. piceus, or that I am mistaken in my reference. My specimen agrecs exactly with the short description in the Systema Eleutheratorum, but I have no opportunity of consulting Weber.

\section{Family PASSALIDÆ. Passalidans.}

LXXVI. Genus PASSALUS.

\section{Passalus internuptus. Interrupted Passalus.}

Passalus interruptus. Fab. Ent. Syst. ii, 240, 1.

Lucanus interruptus. Linn. Syst. Nat. ii, 560, 4. Oliv. Ent. i, 1, 25, t. iii, f. 5 ?

Passalus cornutus. Fab. Syst. Eleuth. ii, 256, 3?

Length of the body $1 \frac{1}{4}-1 \frac{8}{12}$ inch.

\section{Many taken in the Journey from New York to Cumberland-house.}

\section{DESCRIPTION.}

Body black or piceous, underneath sometimes rufo-piceous, impunctured, glossy. Hcad with a crooked horn between the eyes pointing towards the mouth, and a triangular elevation adjoining each eye on the inner side; labrum with a deep sinus; mandibles with threc teeth at the extremity, and one in the middle of the upper side; knob of the antennæ consisting of three hairy joints, the outer one thicker than the others and curved: prothorax channelled, impressed on each side near the base; under a powerful lens several scattered very minute punctures may be discovered on its surface; the ora, or undersides of the prothorax, ${ }^{5}$ are likewise punctured, and soft with tawny hairs: clytra furrowed; furrows punctured: cubit many-toothed; intermediate tibiæ densely bearded, on the outside, with tawny hairs.

The bent or nodding horn on the head of the species here described has generally been taken for a sexual character; but I am inclined to regard this as a mistaken notion. Specimens thus circum- 
stancel, as far as I have been able to ascertain, have hitherto been found only in North America; while those with a tuberculated heal are found in various parts of South America, in the East and West Indies: and I lave one in my cabinet from New Holland. Eleven specimens of the former were collected in the Expedition, varying in size, and not a single one of the latter.

As Linné describes his Lucanus interruptus, "Vertice spina recumbente," a character peculiar to the species here described, I have restored to it its proper name, which Fabricius in lis last work, had assigned to the South American species with a tuberculated vertex: calling the North American one or true Passalus interruptus by the trivial name of $P$. cornutus. These two species, which have been regarded as sexes, differ not only in the processes that arm the head, but also in the labrum, the sinus being deeper in one than in the other: the cubit in the Linnean $P$. interruptus has more teeth than in the Fabrician, and the intermediate tibia is much more thickly bearded.

At the first blush, the most direct course next to pursue would be from the Rectocera by one route towards the Capricorn bectles, and perhaps by another in the direction of some of the Heteromera: but a different and numerous tribe of beetles dernand our attention before we leave the Lamellicorns. Latreille has placed his Sternoxi, forming the tribe alluded to, and including the great Linnean genera Buprestis and Elater, at the head of his family of Serricornes, which with him succeeds that of the Brachelytra or Staphylinus L. and is followed by his Clavicornes, including most of the beetles that prey upon carrion $:^{6}$ but this, as has been observed above, ${ }^{7}$ separates tribes that ought not to be disunited; and I cannot help thinking, with Mr. W. S. Mac Leay, that their place ought to be much nearer the Lamellicorns. This learned Entomologist includes both in the same great section, under the title of Chilognathiformes or rather Chilognathimorpha, ${ }^{8}$ but what precise place he assigns them, he has nowherc clearly stated. Many intermediate forms, however, as yet undiscovered, are wanted to connect the Sternoxa evidently with the Lamellicorns. As many of the Elateridce, and I believe all the Buprestidae are timber-devourers, I shall venturc at present to regard them as entitled to a station somewhere between the lignivorous Lamellicorns and the Capricorns, with which last in their tarsi, the Buprestidee particularly, exhibit considerable affinity.

Regarding the groups from which they diverge, and those to which they direct their course, as not yet indicated I shall now describe the species of Sternoxa taken in the Expedition.

Crusl. Arachn. el Ins. i, 442.
s IIor. Enlomolog. 423; comp. Annulos. Javan. i, 5. 


\section{STERNOXA. Lat.}

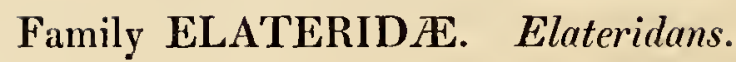

Latreille appears to consider the Fire-flies (Elater noctilucus and affinities) as the type of the genus Elater ; ${ }^{9}$ Linné and Fabricius those with flabellated antennæ, as $\boldsymbol{E}$. gigas and fabellicornis: but as the latter, though large insects, have a very short pectoral mucro, it is probable that their power of leaping ${ }^{1}$ is less than that of the others; therefore the name Elater does not equally well apply to them, and it will be better to distinguish them by M. Latreille's name Hemirhipus, considering E. noctilucus, \&c. as the true Elaters.

There are several types of antennæ in this family, all of which appear to run into each other-viz. flabellate, pectinate, serrate, submoniliform, filiform, and subsetaceous; as there are likewise of tarsi, which perhaps afford a more certain character, combined with others, for the distinction of genera and subgencra. Thus the majority perhaps of the Elateridans have neither suckers, nor cushions of hairs, e.g. E. fascicularis, pectinicornis, Sputator, fasciatus, mesomelus, \&c.: others again have a single sucker on the fourth joint, this is the case with three American undescribed species in my cabinet: a third description, have a cushion cdged with hairs on the second and third joints, E. obscurus, \&c. Linn? Payk. E. ruficaudis Gyll.: another species, brought, I believe, from the West Indies by Admiral Plampin, has three transverse reniform suckers on the second, third, and fourth joints: in $E$. niger again the apex of the first, sccond, and third joints is furnished with a brush; in E. ligneus, suturalis, and affinities, there are three large suckers on these joints : in $\boldsymbol{E}$. flabellicornis there is a naked cushion or sucker on the four first joints, that on the fourth being the largest : and lastly, in E. noctilucus, fuscipes, fulgens, \&c. the same joints are furnished with a brush. 
LXXVII. Genus CAMPYLUS. Fïsel. 1. Campylus dexticonsis. Denticorn Campylus.

C. (denticornis) niger, villosus, naso, prothoracis margine onni, clytrisque latere externo, favis; antennis articulis intermedius apice intus in dentem prominentibus.

Denticorn Campylus, black, hairy; nose, margins of the prothorax, and external margin ol the elytra, yellow; intermediate joints of the antenno terminting in it tooth on their inner-side.

I Length of the body 6 lines.

\section{'Taken in Canada by Dr. Bigsby.}

\section{DESCRIPTION.}

This is the Ameriean representative of $C$. mesomelas, from which it is sufficiently distinguished by its toothed antenne and longer prothorax. Body linear, black, hairy with pale decumbent liairs. Head punctured; antenna longer than the prothorax, filiform, with all the joints, except the seape, pedicel, and terminal one, terminating at their internal extremity in a prominent tooth, less conspicuous in the two lower ones; upper-lip, and nose which is reflexed and overhangs the mouth, yellow: prothorax channelled, punctured, quadrangular, with the anterior angles rounded, and the posterior diverging and terminating in a sharp tooth or prominenee; sides rather wavy; limb yellow: scutellum subeordate: elytra minutely and thickly punctured, slightly furrowed, furrows thiekly punctured; marked with a narrow yellow stripe which does not reach the apex; there is also a short yellow streak on the shoulders: base of the tibia, elaw-joint of the tarsi, and claws, yellow.

\section{LXXVIII. * Genus PEDETES. Kirb.}

Laỏrum transverse.

Mandibles bidentate at the apex.

Palpi maxillary, with the last joint seeuriform.

Antenne filiform, not retractile within the prothorax.

Tarsi with the second and third joints furnished with a sucker.

Body narrow, linear, elongate. Head inserted to the eyes; eyes large and hemispherical; nose anteriorly rounded or subtruncated, and reflexed, overhanging the mouth and base of the antennx; rhinarium transverse, inflexed, concavc: prothorax elongate, subquadrangular; anterior angles prominent, rounded; posterior scarcely diverging, prominent, dentiform: scutellum somewhat obcordate: elytra rounded at the apex; side-covers at first coulter-shaped, then linear : prosternal mucro long and rather slender.

This genus, the type of which is E. obscurus L. and Payk. E. ruficandis Gyll.2 approaches very near to Campylus, from which it is principally distinguished by a more convex and longer prothorax, the posterior angles of which are scarcely divergent; but more partieularly by the suckers at the apex of the second and third joints of the tarsi: the last of which are lobed.

? That the Jinnean $E$. obsenrus is a long narrow inscct, and therefore not the $E$. obscurus of Gyllenhal, is evident from his comparing it with $E$. lineuris. 


\section{1. * Pedetes Brightwelli. Brightwell's Pedetes.}

P. (Brightwelli) testaceus, capite prothoraceque obscurioribus; elytris striatis; striis excavato-punctatis ; interstitiis punctulatis : antennis subattenuatis.

Brightwell's Pedetes, testaceous; head and prothorax dusky; elytra slightly furrowed, furrows deeply punctured; interstices minutely punctured; antennæ rdther slender.

Jength of the body 6 lines.

\section{Taken in Nova Scotia by Capt. Hall.}

DESCRIPTION.

Body elongate, more slender than that of the type, testaceous; hairy, with decumbent pale hairs; thickly punctured. Head dusky-red; antennæ longer than the prothorax, slenderer than usual in the tribe, scarcely serrated, with the four last joints rather slenderer than the rest; eyes large and hemispherical; nose a good deal reflexed: prothorax convex, channelled, dusky red, darker in the disk; elytra pale testaceous; furrowed, furrows deeply punctured; interstices minutely punctured with seattered punctures: legs paler than the rest of the body, and nearly yellow.

xii. * Suhgenus Asapues. Kirb.

Body wider.

Nose not overhanging the mouth.

Rhinariun attenuated in the middle.

Prothorax short, posterior angles eariuated.

I am doubtful whether this should not be considered as forming a distinct genus. The general form is very different. But as the tarsi have suckers on the second and third joints, till more species are discovered, I have given it as only a subgenus of Pedetes.

\section{Pedetes (Asaphes) ruficonnis. Red-horned P. Asaphes.}

P. (Asaphes) niger, punctulutus, pubescens ; antennis obscure rufis, elytris piceis, substriatis.

Red-horned P. Asaphes, Blaek, minutely punctured, downy; antennx dusky-rufous; elytra piceous, very slightly furrowed. Length of the body $7 \frac{1}{4}$ lines.

'Taken in Nova Scotia by Capt. Hall. 
DESCRIPTION.

Body blaek, rather glossy, minutely punetured, downy with pale down. Antennæ, mouth, and palpi rufous or dusky-rufous; labrum and mandibles piceous; nose rounded, not reflexed, not overshadowing the mouth; antenne serrated on the inner side in the mildle, last joint acuminated: prothorax short, widest behind, very obsoletely channelled, sides submargined; posterior angles dentiform, strongly earinated: elytra piccous, or rufo-piceous, very slightly firrowed with oblong punctures in the furrows, interstices minutely punctured: margin of the abdomen and of the penultimate segment, rufous.

\section{LXXIX. * Genus PERIMECUS. Dillw?}

\section{Parts of the mouth nearly as in Elater.}

Antennce not retractile within a furrow of the prothorax; scrrated on their inner side in the middle; seape incrassated: pedicel short, obeonical; terminal joint lineari-lanceolate.

Tarsi filiform, without sucker or cushion.

Claws pectinated.

Body linear, attenuated towards the anus. Nose rounded, overhanging the mouth; rhinarium deep; eyes large, hemispherical: prothorax short, eonvex, narrowest before; anterior angles not prominent, posterior elongated, dentiform, above with a sharp ridge: scutellum subquadrangular: elytra linear, attenuated at the apex : prosternal process long, suddenly attenuated at the apex : tarsi filiform, hairy, without suckers, euslion, or brush; claws distinctly pectinated.

This genus, of which Elater fulvipes is the type, is distinguished from all the other Elateridans by having its elaws finely peetinated, a charaeter in which it agrees with Lebia and many others of the Truncipennia amongst the Geadephaga, This striking distinction has been overlooked by Gyllenhal and all the other Entomologists who have described this insect.

I had originally named this genus Ctenonyx, but Mr. Stephens having distinguished another by the name of Ctenonychus, prebably related to Elater unguli-serris of Gyllenbal, ${ }^{3}$ under the idea that the type of the genus is $E$. fulvipes Linn. I have adopted the name given by Mr. Dillwyn, to distinguish that inseet, as forming a new genus : still some doubt rests upon the identity of their specimens with the American: as Mr. Stephens deseribes the eyes as small, whereas in my speeimen they are large, but this may be a sexual charaeter.

\section{? Schün. St/n. iii, 136, 186.}




\section{Perimecus fulvipes. Tawmy-foot Perimecus.}

Perimecus fulvipes. Dillw. Mem. Col. 32. Steph. Illustr. Mandib. iii, 263, 1 ?

Elater fulvipes. Herbst. Ins. x, 46, 52, $t$. clxii, $f$. 2. Gyll. Ins. Suec. i, 407, 37 .

castanipes. Payk. Fn. Suec. iii, 23, 27. Marsh. Ent. Brit. i, 38I, 15.

- fuscus major. De Geer, Ins. iv, 146, 3.

- major. Gmel. L. Syst. Nat. iv, 1915, 104.

- rugosus. Marsh. Ent. Brit. i, 381, 16?

Length of the body 7 lines.

\section{Taken in Canada by Dr. Bigsby.}

\section{DESCRIPTION.}

Body black, punctured, glossy; gloss and colour obscured by numerous decumbent pale hairs. Antennæ pale chestnut, with the third joint double the length of the second: posterior angles of the prothorax carinated: elytra with nine rows of large and deep punctures, interstices minutely punctured: legs pale chestnut.

The only difference that I can discover between the American and European specimens, is in the length of the third joint of the antenne, which in the latter is scarcely longer than the second; and this may probably be a sexual distinction.

Elater communis. Gyll. in Schön. Syn. iii, Append. 138, 189. cinereus. Web. Obs. Ent. i, 77, 2? Illig. Mag. i, 248?

Length of the body $6 \frac{1}{3}$ lines.

\section{Several specimens taken at Cumberland-house Lat. 54\%.}

\section{DESCRIPTION.}

Very similar to the preceding species, but much smaller. Body chestnut-coloured, darker or lighter in different specimens, punctured, glossy, hairy: third joint of the antennæ twice the length of the second: prothorax thickly punctured, obsoletely chamelled, chiefly behind: elytra, antcnnæ, and legs rather paler than the rest of the body, the former sculptured as in the last species. 


\section{3. * Perinecus simisis. Similar Perimecus.}

$P$. (similis) niger, pubescens; antennis pcdibusque fulvis : prothorace parcius punctatn, hand canaliculato: elytris puncto-striutis. Sinilar l'erimecus, blark, downy : antenne and legs tawny: jrothorax less thickly punctured and not channelled: elytla with larger punctures in rows.

'Taken in Lat. $54^{\circ}$. Length of the boly $6 \frac{1}{3}$ lines.

DESCRIPTION.

I should have given this as merely a variety of the last; but besides its blacker body, the punctures of the prothorax are not nearly so numerous, and there is no appearance of its being channelled: the brcast is chestnut.

\section{Genus CTENICERUS. Lat.}

$(200)$

\section{CTenicerus Kendalli. Kendall's Ctenicerns.}

C. (Kendalli) niger; fronte impressa; prothorace canaliculato: elytris testaceis apice litura intermedia nigra; pedibus piceis. Kendall's Ctenicerus, black, front impressed: prothorax channelled; elytra testaceons, at the apex with an intermediate black blotch; legs piceous.

PLATE II, FIG. 7.

Length of the body 7 lines.

A single specimen taken in Lat. $65^{\circ}$.

\section{DESCRIPTION.}

Body black, thickly punctured; gloss obscured by inconspicuous hairs. Head with two impressions between the eyes; nose subemarginate; antennæ shorter than the prothorax, serrated: prothorax longer than wide, channelled, posterior angles diverging, very acute, carinated: scutcllum suboval, covered with white hairs : elytra rather wider than the prothorax, testaceous with a black discoidal blotch at the tip; slightly furrowed with punctures in the furrows; intcrstices punctured : legs piceous.

This species, which is a female, is related to Ct. cupreus, but is much wider in proportion to its length.

LXXXI. Genus ELATER. Linn.

xiii. Subgenus Aphotistus. Kirb.

'This subgenus differs from the type, ( $E$. noctilucus, \&c.) principally in the absence of the phosphoric spot in the prothorax, \&c. The antennæ are not so compressed and less distinctly serrated. Eluter ceneus Linn. may be regarded as the type of this subgenus of which Mr. Marsham's $E$. impressus is regarded as a varicty; but I think it distinct, and the true $E$. impressus of Fabricius. There are types of several other subgenera that may be regarded as belonging to Elater, as E. murimus, sainguineus, \&c. 


\section{(201)} 1. * Elater (Aphotistus) enripennis. Bronze-winged E. Aphotistus.

F. A. (aripennis) ater; clytris reneis nitidis; antennis pedibusque piceis; prothorace obscuro, obsolete canaliculato, confertissine punctrito.

Bronze-winged E. Aphotistus, very black; elytra bronzed shining; antenuæ and legs piceous: prothorax sot glossed, obsoletely channelled and very thickly punctured.

Length of the body 6 lines.

Several taken in Lat. 54\%. C'umberland-house.

DESCRIPTION.

Body very black, without hairs, underneath very minutely punctured. Head thickly and confluently punctured; nose with two slight impressions : antennæ shorter than the prothorax, third joint longer than the fourth: prothorax very thickly punctured, obsoletely channelled, longer than wide, rather narrowest before, sides curving, posterior angles acute, diverging, carinated: scutellum heartshaped: elytra bronzed, or green-bronzed ; furrowed, furrows punctured; interstices convex, minutely punctured; tips acute : a discoidal rufous spot or band, and sometimes two, marks the underside of the abdomen: legs piceous.

This species is the American representative of $E$. impressus, from which it differs principally in being smaller, narrower in proportion, with the head and prothorax not at all bronzed, and the latter more thickly punctured and without any gloss.

\section{Family BUPRESTIDÆE. Buprestidans.}

This splendid family, as well as the preceding, has been very little studied. Mr. Curtis has proved from the examination of two species, ${ }^{4}$ that their oral organs differ, and probably many of the groups are similarly circumstanced. Latreille has divided the family into two sections, those that have not and those that have a scutellum.5 Buprestis Gigas, one belonging to the latter family, may be regarded as the original type of the genus. 
LXXXII. Genus BUPRESTIS. Linn.

xiv. "Subgenus ANorlss. Kirl.

Labrum submembranaceous, small, rounded at the apex.

Palpi with the last joint subcylindrical.

Rhinarizm transverse, appearing like a part of the labrum.

Nose witl a sinus taken out.

Antennee serrated internally, but with the joints less prominent and longer.

Elytra subtruncated at the apex, without serratures or terminal conspicuous points.

Tarsi with a sucker on all but the claw-joint, first joint covered by it.

The type of this subgenus is Buprestis rustica L.

(202) 1. * Buprestis (Anoplis) rusticorum. B. Anoplis of the Rustics.

B. A. (rusticorum) nigro-enca, nitida; fronte, genis, ventrisque lateribus, luteo-maculatis; elytris strialis, apice rotundatis.

I) Anoplis of the Rusties, black-bronzed, glossy: front, cheeks, and sides of the belly spotted with luteous ; elytra slightly furrowed, rounded at the tip.

Length of the body $9 \frac{1}{2}$ lines.

A single specimen taken in Lat. $54^{\circ}$.

\section{DESCRIPTION.}

Body black-bronzed, punctured, glossy. Head with a levigated elevation in the centre between the eyes, channellad behind; marked with two yellow spots underneath on the cheeks, a triangular one adjoining the eyes on their inner side, and two dots of the same colour between them: prothorax grossly punctured with levigated spaces, the discoidal one longitudinal; above the scutellum is an impression; sides converging at the base of the prothorax; anterior angles with a yellow stripe: elytra slightly furrowed with numerous very minute punctures in the furrows; rounded at the apex: interstices with scattered punctures; those of the second, third, fourth, fifth, eighth and ninth furrows elevated so as to form an obtuse ridge: the four last ventral segments of the abdomen have on each side a reddish-yellow spot, those on the last segment being the largest and most irregular; anus with two distinct lateral tecth.

This species is so similar to B. rustica, that at first I regarded it as merely a variety, that insect however is smaller; the head has a distinct longitudinal channel : the prothorax is less thickly punctured, and the sides, at the base, converge less but more suddenly: the clytra are truncated, or rather premorse, at the apex with a few minute denticles: the mandibles have a yellow spot, and there are none on the ventral segments of the abdomen, except the anal one: the anal tecth also are obsolete. 
B. A. (Paganorum) nigro-aneu, nitidn, fronte ad oculas, genis, ventrisque lateribus luteo-maculatis: pratharace antice subcanstricta; elytris striatis, apice subattemuatis truncatis.

B. Anoplis of the villagers, black-bronzed, glossy; front, eheeks and sides of the belly spotted with luteous; elytra slighlly furrowed, sulattenuated and truncated at the tip.

Length of the body $7 \frac{3}{4}$ lines.

\section{A single specimen taken at Cumberland-house, Lat. 54\%.}

\section{DESCRIPTION.}

Very like the species last described. Body of the same colour, head, anterior angles of the prothorax, and underside of the abdomen similarly spotted, except that in the former there are no frontal dots. The prothorax however is differently sluaped, being somewhat constricted anteriorly, with the sides towards the base rounded, it is also channelled; the scuipture of the elytra is similar, but they are more attenuated and truncated at the end, like $B$. A. rustica, and armed with three minute denticles.

B. A. (Nutalli) nigra-anea, nitida; flava supra et infra maculata: elytris striatis : striarum interstitiis alternis canvexis; apics truncatis.

Nutall's B. Anoplis, black-bronzed, glossy ; spotted above and below with yellyw : elytua slightly furrowed, with the alternate inter'stices of the furrows convex; truncated at the tip.

Length of the body $7 \frac{1}{2}-8$ lines.

\section{Several specimens taken in Lat. $65^{\circ}$. and on the Rocky Mountains.}

\section{DESCRIPTION.}

This species appears to be related to $B$. octoguttata. Body black-bronzed, glossy, punctured; underneath with a few pale decumbent hairs. Head confluently punctured with several irregular conuected levigated spaces; labial palpi, spot on the mandibles, labrum, lower margin of the eyes, and frontal spots, yellow: prothorax bisinuate both at the apex and base, grossly punctured will several levigated spaces; lateral margin, except the base, and part of the anterior, yellow; elytra slightly furrowed, furrows punctured: interstices alternately convex and plane; the sutural one is convex and forked at the base; the flat ones are most punctured, but the convex ones more grossly; in the disk of the elytra are three equidistant irregular yellow spots arranged longitudinally, and nearer the base, on the second ridge, a line of confluent yellow dots; the apex of the elytra is trun- 
cated : on each of the ventral segments of the abdomen the sides are marked with a triangular orange-coloured spot, those on the anal segment being larger and irregular : the coxæ also and underside of the thighs are partly of the same colour.

Vanetr 13. Without the yellow line of confluent dots at the base of the elytra, and with the spots arranged longitudinally indistinct.

C. With all the ventral orange spots large and irregular.

D. Front with a large central spot. Base of the belly bluish.

E. Elytra with only yellow spots. Front as in D.

F. With only one distinct yellow spot.

The most certain distinction of this varying species is the alternately convex and plane interstice of the furrows of the elytra.

\section{(205) 4. Buprestis (Anoplis) lineata. (Fabricius.) Streaked B. Anoplis.}

Buprestis lineata. Fab. Syst. Ent. 217, 10; Syst. Eleuth. ii, 192, 37. Oliv. Ent. ii, 32, 28, 33, t. viii, f. 80. Linn. Syst. Nat. Gmel. iv, 1928, 46. Herbst. Ins. ix, 284, 209.

Length of the body 9 lines.

\section{Taken in Nova Scotia by Captain Hall.}

\section{DESCRIPTION.}

Body above black-bronzed, underneath bronzed, punctured. Head below and mouth orange: mandibles black with a basilar orange spot; front obscurely banded and dotted with the same colour; vertex channelled: prothorax dilated posteriorly; anterior angles deep orange: elytra slightly furrowed: furrows scarcely punctured; interstices flat, grossly punctured; truneated at the apex and armed with three minute tecth, one nearly obsolete; on each elytrum arc two obscure deep orange stripes, the outer one diverging towards the base so as to pass below the shoulders, the inner one subinterrupted, widest towards the base, and not reaching the apex: fore-breast anteriorly orange. 5. Buprestis (Anoplis) fasciata. (Fabricius.) Banded B. Anoplis.

Buprestis fasciata. Fab. Ent. Syst. ii, 191, 23; Syst. Eleuth. ii, 191, 31. Oliv. Ent. ii, 32, 21, 22, t. ix, f. 92. Herust. Ins. ix, 162, 90, t. cxlv. f. 12. Say. Amer. Ent. ii, t. xxvi, f. 2. Linn. Syst. Nat. Gmel. iv, 1927, 42.

Length of the body $7-8$ lines.

Taken in Canada by Dr. Bigsby ; B and C, in Nova Scotia by Capt. Hall. 
DESCRIPTION.

Body of a lovely brilliant green, punctured underneath with a few pale hairs. Hearl confluently punctured; antennæ bronzed; vertex channelled: prothorax transverse marked before the middle with two transverse impressions, and another just above the scutellum; grossly punctured: elytra furrowed; furrows thickly punctured; interstices convex with fewer punctures; apex truncated with the angles terminating in a short point; beyond the middle of the elytrum is a rather broad, especially next the suture, wavy orange band surrounded by a dusky blotel1; beyond this and near the apex is another oblique abbreviated little band of the same colour.

VARIETY B. Smaller with the bands paler and narrower.

C. With only a single band narrowest next the suture: prothorax without the anterior impressions.

xv. * Subgenus Stenuris. Kirb.

Labrum minute, comeous, subemarginate.

Palpi with the last joint subsecuriform.

Rhinarium indistinct.

Nose with a sinus taken out.

Antenne serrated internally with the joints shorter and more prominent: third joint not longer than the fourth.

Elytra attenuated at the apex.

Tarsi with a sucker on all but the claw joint, first joint not wholly covered by it.

Buprestis Iurida may be regarded as the type of this subgenus, which may be known by the shortness of the joints of its distinctly serrated antennx, and attenuated apex of its elytra. $B$. anlenuata, though near it, belongs to a different subgenus, with nearly filiform antenne, and with the first joint of the tarsi nearly covered by the sucker.
6. * Buprestis (Stemuris) divaricata.
(Say.) Divaricated B. Stemmis.

Muprestis divaricata. Say. Journ. Acad. Phil. III, i, 163, 9.

Length of the body 10 lines.

Taken in Canada by Dr. Bigsby; I received both sexes also from Massachusets by the kindness of Dr. Harris. 
DESCRIPTION.

Body below copper-bronzed, above dusky-bronzed; glossy; conflucntly punctured and wrinkled. Head with numerous branching, levigated, narrow spaces; eyes yellow surrounded with a black orbit; mandibles blick at the tip; front longitudinally impressed in the centre: prothorax with numerous levigatcd spaces, obsoletely chimmelled; sides anteriorly rounded with a slight sinus near the base; basilar angles diverging: elytra very obsoletely furrowed, reticulated with numerous elevated lines, many' scattered levigated spaces; hicarinated at the apex, the inner ridge being very short; suture terminating in a point; at their truncated extremity the elytra are divaricated and suddenly attenuated: the first segment of the abdomen, and the breast bones are hollowed ont into a longitudinal channel : prosternum linear.

N. B. The specimens sent by Dr. Harris are as brilliant above as below.

\section{(208) 7. * Buprestis (Stenuris) tenebrosa. Tenelrous B. Stenuris.}

13. St. (tencbrosa) confluenter punctata; supra nigra, obscura; subtus cuprea nitida: prothorace lactmoso, latius canaliculuto; clytris spatiis elevatis pluribus concalenatis; apice subito attenuatis rotundatis.

Tenebrous B. Stenuris, confluently punctured, above black, obscure; below cupreous, glossy: prothorax uneven, channelled with a wide channel: elytra with many concatenated elevated spaces; suddenly attenuated at the apex and rounded.

Length of the body $7 \frac{3}{6}$ lines.

Several taken in Lat. $65^{\circ}$. and in the Rocky Mountains.

DESCRIPTION.

Very like the species just described but much smaller. Body confluently punctured, upper surface black, with only the elevated parts glossy, lower bronzed-copper and glossy. Mouth and antenne bronzed; eyes black; front sculptured as in St. divaricata : prothorax uneven with shallow impressions and a broad dorsal chamnel; distinctly bisinuate at the base; surface with levigated elevations: scutellum very minute, impressed: elytra divaricated and suddenly attenuated at the apex, which is rounded and has a single ridge ; surface rough with many concatenated and levigated irregular elevations, side of the tip bronzed : breast channelled underneath, but the first segment of the abdomen less conspicuously, prosternum nearly an isosceles triangle: hypopygium ${ }^{6}$ with thrce short teeth.

6 See Introd. to Ent. iii. $389,11.2$ 
B. St. (tenebrica) conflucnter punctata, supra nigra obscura, subtus cuprea nitida; prothorace sublacunoso, latius canaliculato ; elytris striatis, apice subito et valde attenuatis, subtruncatis.

Dark B. Stenuris, confluently punctured; above black, obscure ; below copper, glossy; prothorax with shallow impressions, widely channelled; elytra furrowed, suddenly and much attenuated at the apex, subtruncated.

Length of the body $7 \frac{3}{4}-9$ lines.

\section{Several taken in Lat. $54^{\circ}$. and at Cumberland-house.}

\section{DESCRIPTION.}

This species differs principally from St. tenebrosa, which in other respects it greatly resembles, in having the prothorax without any levigated elevations, and with the impressions, except the channel which is better defined, more obsolete. The elytra are distinctly furrowed, especially next the suture, with punctured furrows, and there is only a series of levigated elevations near the lateral margin; the attenuated apex of the elytra is longer, rather truncated, and underneath of a dark blue: the prosternum is linear, and the base of the abdomen scarcely channelled: the teeth of the hypopygium are longer and of a brilliant ruddy-copper.

VARıETy B. Smaller, upper surface black-bronzed.

$$
\text { xvi. * Subgenus Odontomus. Kirb. }
$$

Labrum minute, corneous, subcmarginate.

Palpi with the last joint cylindrical.

Rhinariutm indistinct.

Nose witl an angular sinus.

Antenne as in Stenuris, but the third joint is twice the lengtl of the fourth.

Elytra at the base circumscribed by the segment of a circle, scrrulated at the apex.

Humeri incrassated and armed with a tooth.

Tarsi as in Stenuris.

Prosternum flat, constricted in the middle.

This subgenus, or perhaps genus, of which Buprestis chrysostigma Linn. may be regarded as the type, and to which also $B$. femorata Fabr. and many others belong, is strikingly distinguished by its incrassated anterior thighs, or humeri, ${ }^{7}$ armed with a stout tooth; the back of the abdomen, in all the known species, is of a beautiful blue or green. 

9. * Buprestis (Odontomus) trinervia.
Triple-veined
B. Odontomes.
B. O. (trincrvia) punctata, supra nigro-anca, witida, subtus pilosa; naso sinu obtusangnla, fronte plana; prothorace lacunoso, canaliculato, utrinque subemarginato, elytris trinerviis, spatiis pluribus punctatis subauratis: tibiis quatuor anticis arcuatis.

Triple-reined 13. Odontomus, punctured; above black-brouzed, glossy; hairy underneatl ; siuus of the nose obtusangular, front flat: protborax with broad slallow impressions, clsannelled, sides subemarginate; elytra with tbree clerated lincs, and many spaces punctured, and obscurely gilded; four anterior tibia arcuate.

PLATE II, FIG. 9.

Length of the body $5 \frac{1}{3}-5 \frac{3}{4}$ lines.

Several specimens taken in Lat. $54^{\circ}$. and $65^{\circ}$. and in the Rocky Mountains.

\section{DESCRIPTION.}

Body punctured, above black-bronzed, below copper-coloured and glossy. Head obscurely copper, confluently punctured and wrinkled, with a pair of levigated irregular elevations between the eyes; nose bilobed with divarieated lobes forming an obtusangular sinus; antennæ copper witl a testaceous pedicel: prothorax transverse, confluently punctured with several levigated spaces; lightly and widely impressed, impressions faintly gilded; disk channelled; sides very slightly emarginate; base with a double sinus: scutellum triangular, acuminated: elytra with the depressed parts confluently punctured and very faintly gilded; with three subinterrupted longitudinal ridges connected by transverse levigated elevations; the two external ridges become confluent and proceed as a single ridge to the apex; lateral margin towards the apex minutely serrulate: back of the abdomen of a fine silky green: underside of the body thinly planted with hoary hairs; prosternum constricted in the middle and terminating towards the anus in a dilated trilobed point: shoulders much inerassated, armed below with a stout tooth; cubits clubbed at the apex; four anterior tibiæ bent or bowed: hypopygium bidentate.

This species is the American representative of B. chrysoslogma, to which it approaches very near, but it is considerably smaller; the elytra have only three ridges, and want the two golden impressions that distinguish that insect, and the back of the abdomen is of a different colour. It is also very like B. femorata, but the sinus of the nose is obtusangular, and not at all acuminated; the frontal tubercles are less elevated, the prothorax is rougher, the ridges and elevations of the elytra are bolder, and the hypopygium is distinetly bidentate.

$$
\text { 10. * Buprestis (Odontomus) proxima. Neurest B. Odontomus. }
$$

B. O. (proxima) punctala; supra nigro-cnea, subtus cuprea; prothorace elytrisque calatis spatiis depressis pluribus punctatis subauratis : tibiis amnibus arcuatis.

Nearest B. Odontomus, punctured, above black-bronzed; prothorax and elytra embosscd, with several depressed punc tured faintly gilded spaces: all the tibire arcuate.

Length of the body $5 !$ lines.

A single specimen taken in the Expedition. 


\section{DESCRIPTION.}

Body minutely and thickly punctured; above black-bronzed obscure; underneath cupreous with the gloss obscured; except near the anus, cloathed with numerous rather long decumbent hoary hairs. Head somewhat cupreous, hoary from decumbent hairs; nose green, bilobed with divaricated lobes, including a somewhat obtusangular sinus; antennæ green; vertex channelled: prothorax embossed in the disk, impressed and wrinkled at the sides; depressed parts punetured and reflecting a faint lustre of copper: scutellum an isosceles triangle, depressed and green at the base, elevated part black: elytra embossed, with a ridge extending from the apex where it is broader, by the side of the suture towards the base where it is abbreviated; the depressed spaces have a faint lustre of copper and bronze, and are thickly punctured; apex rounded and obsoletely serrulated: shoulders incrassated with a short robust tooth : all the tibia are bent or bowed; cubit not dilated at the extremity: hypopygium with a deep sinus.

This nearly resembles $B$. O.trinervia, but is sufficiently distinguished by having only a single ridge on the elytra, and the posterior tibix as well as the other pairs, bowed: the prothorax also is not chamnelled and its sides are rounded.

xvii. "Subgenus Trachypters. Kirb.

Labrum transverse, nearly oval.

Palpi with the last joint cylindrical.

Rhinarium indistinet.

Nose with a rounded sinus.

Antenne filiform, shorter than the thorax, subserrated, with the joints from the third to the end gradually decreasing in length.

Body above rough from numerous reticulations and granules.

Elytra diverging at the apex, and rounded.

Tarsi with minute suckers at the apex of the four first joints; first joint of the posterior pair elongated.

Prosternum linear.

This sulgenus differs from the preceding not only in the sinus of the nose forming a segment of a circle, and the length of the first joint of the posterior tarsi, but also in having nearly filiform antennæ very slightly serrated on their inner side, and with their joints, beginning with the third, gradually decreasing in length. The type is Buprestis decastigma Fab. It may be subdivided into two sections, one with the apex of the elytra serrulated, to which the type belongs, and the other with it entire. 
- Apex of the clytra entire.

\section{(212) 11. * Buprests (Trachypteris) Drumnond. Drummomel's B. Tiachypteris.}

13. T. (Drummondi) supra niy,ro.ecnea, subus anca, nitida; prothorace varie acuducto desco fere concentrice; elytris puncludutissimis integerrimis, guttis tribus luteis triongulo ordinatis.

Drummond's 13. Trachypteris, alove black-bronzed, underneath bronzed, glossy : prothorax variously acuducted, in tle disk nearly coneentrically; clytra very numerously and minutely punctured, very entire; with three yellow dots arranged in a triangle.

PLATE II, FIG. 8. Var. B.

Length of the body $4 \frac{3}{4}$ lines.

Several specimens taken in Lat. $54^{\circ}$. and $65^{\circ}$. and in the Rocky Mountains.

\section{DESCRIPTION.}

This elegant little species at first sight might be taken for a small variety of $B . T$. decastigma, but upon a nearer inspection it will be found to belong to a different division of the subgenus, and other very peculiar characters will be discovered which distinguish it from that and every other described species.

Body as it were reticulatcd with numerous punctures, bronzed, more obscurely on the upper snrfire, more glossy on the lower. Head very thickly punctured, obsoletely and slenderly channelled; apex of the nose levigated: prothorax transverse, with a double sinus in the basilar margin; obsoletely channelled, impressed on each side nearer the base, covered with innumerable scratehes variously drawn, those of the disk being somewhat concentric; sides punctured: scutellum very minute, transverse: elytra very thickly punctured, and also exhibiting an appearanee of granulations, slanting at the apex; the disk of the elytra, nearer the apex than the base, is marked with three yellow roundish dots arranged in an obtuse-angled triangle with the vertex towards the side: underside of the abdomen towards the anus less thickly punctured.

VARIETY B. Elytra with four yellow dots, a minute one, but varying in size, being placed outside the anterior one.

\section{Buprestis (Trachypteris) umbellatarum. (Olivicr.) Umbel-freupenting B. Trachypteris.}

Buprestis umbellaratum. Fabr. Mant. i, 183, 74; Syst. Eleuth. ii, 210, 131? Oliv. Ent. ii, 32, 81, 112, t. iii, f. 2:3 2 Hcrbst. Ins. ix, 257, 174, t. cliii, f. 6. Illig. Mag. ii, 250, 18, iv, 94, 131. I Linn. Syst. Nat. Gmel. iv, 1936, 90 ?

Length of the body 23 lines.

Several specimens taken near Cumberland-house, Lat. $54^{\circ}$. 
The description that Fabricius and Olivier have given of B. umbellatarum is so extremely brief, that I am by no means certain that the insect $I$ here give under that name is really synonymous with it. As far as their description goes it corresponds, and also with Olivier's figure, but that is very indistinct. It has been found in Barbary, Portugal, and Provence. Fabricius says it affords no characters except its colour and smooth elytra; but it will be found upon a close inspection, I speak with regard to the American specimens, to exhibit several.

DESCRIPTION.

Body black-bronzed, covered all over as it were with a fine net-work, produced by minute lines as if scratched by a pin or needle; above dull, below glossy. Antennæ much shorter than the prothorax : prothorax transverse with rounded sides, and longitudinal basilar impressions near each posterior angle: scutellum triangular: elytra with three very slight impressions arranged longitudinally; an obsolete series of punctures runs parallel with the lateral margin; apex obtuse and very minutely serrated : prosternum acuminate.

\section{xviii. * Subgenus Oxypterrs. Kirb.}

Labrum minute, subemarginate.

Palpi last joint subcylindrical.

Rhinarium indistinct.

Nose with a sinus taken out forming the segment of a circle.

Antenne as long as the prothorax, subsetaceous, subserrated internally.

Body rough from numerous granules.

Elytra diverging, very acute at the apex.

Tarsi as in Trachypteris.

The type of this subgenus is Buprestis appendiculata, it is principally distinguished from the preceding by its longer antennæ, more slender towards the extremity, and by its very sharp elytra.

\section{Buprestis (Oxypteris) appendiculata. (Fabricius.) Appendicled B. Oxypteris.}

Buprestis appendiculata. Fab. Ent. Syst. Em. ii, 210, 102. Herbst. Ins. 234, 154, t. cxlvii, f. 2. Gyll. Ins. Suec. i, 451, 11. Panz. Fr. Germ. lxviii, 22.

$\longrightarrow$ Morio. Payk. Fn. Suec. ii, $230,17$.

-_ acuminata. De Geer Ins. iv, 133, 7. Thunb. Mus. Ups. iv, 52, 2.

-_ acuta. Linn. Syst. Nat. Gmel.iv, 1939, 105.

longipes. Say Journ. Phil. III, i, 164, 10.

Length of the body $4 \frac{1}{1}-5 \frac{1}{4}$ lines.

Several specimens in the Rocky Mountains, and near Cumberland-honse. 


\section{DESCRIPTION.}

Body black, not glossy. Head minutely and thickly punctured, chamnelled, on each side of the channel between the eyes is an impression; antenne nearly as long as the prothorax: prothorax scarcely wider than long, channelled, with a large but shallow impression on each side; sides thickly punctured so as to rescmble net-work; rounded with the basilar angles depressed and a little diverging: scutellum ncarly heart-shaped, acute: clytra rough with very minute and numerous granules, and several very slight shallow impressions, between which runs an obsolete obtuse ridge from the shoulder towards the apex, serrulated at the apex, and terminating in a very sharp point: breast minutely and thickly punctured; prosternum a little constricted in the middle, point triangular.

LXXXIII. Genus AGRILUS. Meg.

\section{Agrilus bivittatus. Two-striped Agrilus.}

A. (bivittatus) granulatus, supra niger, subtus aneus; prothorace elytrisque vitta communi postice abbreviata, sulaurata. Two-striped Agrilus, granulated, above black; underneath bronzed; prothorax and elytra, with a pale golden stripe posteriorly abbreviated common to both.

Lengtll of the body 4 lines.

Taken in Canada by Dr. Bigsby; I also purchased a specimen, probably taken in Georgia, at Mr. Francillon's sale.

DESCRIPTION.

Body subcylindrical, elongated and slender; covered, especially above, with innumerable minute granules; upper surface black, lower bronzed-copper, glossy, hairy, especially anteriorly, with very minute decumbent white hairs. Nose narrow, truncated anteriorly; antennx bronzed: prothorax nearly square, rather narrowest at the base; sides slightly curving; a double basilar sinus; a rather broad stripe formed of minute decumbent pale golden hairs covers cach side of the prothorax, and then forming a bend, runs along the disk of the clytra, tending towards the suture, becoming gradually evanescent as it approaches the end of the elytra, which it docs not reach: scutellum divided into two portions by a transverse ridge, the basilar one transverse, and the apical triangular and acuminated: elytra linear, constricted below the base, subacute and serrulated at the apex; at the base is a rather deep circular impression: exposed sides of the dorsal segments of the abdomen thickly covered with white decumbent hairs: lyypopygium entire. 
LXXXIV. Genus TRACHYS. Fab.

$$
\text { 1. * Trachys aurulenta. Aurulent Trachys. }
$$

T. (aurulenta) nigro-caruleus, nitidus; capite bilobo; elytris subtrinerviis, maculis cupreo-auratis, fasciisque argenteis. Aurulent Trachys, black-blue, glossy; head bilobed; elytra obsoletely three-ridged, spotted with golden-copper, and banded with silver, hairs.

Length of the body 3 lines.

Taken in Canada by Dr. Bigsby. There were also specimens in the late Mr. Francillon's cabinet, probably taken in Georgia by Mr. Abbot.

This may possibly be $\boldsymbol{F}$. tesselata of Fabricius, but his description of that species is so short, omitting many of the characters of the insect before us, that it appears best to consider it as distinct.

DESCRIPTION.

Body obovate, hlack-blue, glossy. Sinus of the head deeper than in the other species; face nearly covered with glittering copper-coloured decumbent hairs; antennæ shorter than the prothorax: prothorax transverse, repand on each side at the base with a central lobe, concave at the apex; anteriorly in the middle very convex; sides and base depressed; surface impunctured and tesselated with ruddy-copper hairs like those of the head: scutellum at the base transverse, with the vertex terminating in a long and sharp acumen: clytra with three ridges, the two inner ones less distinct, parallel, obtuse and abbreviated at each extremity, the external one distinct, acute running from the shoulder in an undulated line nearly to the apex of the elytrum; several rows of larger punctures are discernible, and several spaces thickly punctured with minute ones; the elytra are also spotted with several hairy ruddy-copper spots, and ornamented with four or five undulated lairy indistinct silver bands : underneath the tint of blue is very faint and the disk of the breast is bronzed : the mesosternum is hollowed out into a deep chamel.

\section{2. * Trachys acuducta. Acuducted Trachys.}

T. (acuducta) oblonga, cuprea, nitida, fronte retuso; setulis squamuliformibus incana; prothorace transverse acuducto. Acuducted Trachys, oblong, copper-coloured; front retuse; hoary with scale-like little bristles; prothorax transversely acuducted.

$$
\text { Length of the body } 4 \text { lines. }
$$

Taken by Capt. Hall in Nova Scotia. 
DESCRIPTION.

Body oblong, punctured, hairy with scattered minute decumbent bristles resembling little scales, of a bronzed and glossy copper colour. Front with a slight sinus: prothorax transverse, trilobed at the base; disk longitudinally convex and naked; sides hairy; surface in the disk covered with minute transverse undulated lines curving upwards, and sides reticulated with them: scutellum transverse acuminated: elytra uneven, constricted before the middle, clouded and obsoletely banded towards the apex with minute whitish bristles; tips rounded, serrulate: prosternum broad, a little constricted in the middle, rounded at the apex.

Having gone through the Chilognathimorphous beetles of Mr. Mac Leay, the connection of which with the Lamellicorn and other tribes, probably owing to the non-discovery of existing intermediate forms, it is at present difficult to trace,though the Elateridans appear clearly to go off at one extremity by the Cebrionidans to the soft-bodied Coleoptera, or Malacoderma, \&c. of Latreille, and so perhaps by other tribes, as I shall endeavour to shew hereafter, to the confines of the Orthoptera-having accomplished this task we must again retrace our steps, and returning to the lignivorous Lamellicorns, pursue our course towards the Capricorns and other wood-devourers amongst the beetles. There are two main roads by which we may proceed, one from the Lucanidans, or genuine Rectocerous beetles, which lead to the Capricorns; and the other from the Passalidans, that do not properly answer that denomination, the last ten joints of their antennæ not forming an angle with the first, leading to an osculant tribe of timber-borers, which from that circumstance, I would call Xylotrypa, distinguished by their cylindrical form, including the modern genera Scolytus, Hylessinus, Bostrichus, \&c. I shall begin with the first, and, after Gyllenhal and Mac Leay, shall consider Trogositu as nearly connected with the Lucanide, particularly Platycerus. 


\title{
VIII. XYLOPHAGA. ${ }^{8}$ Kirb.
}

\author{
i. Isocera. ${ }^{9}$ Kirb. \\ Family CUCUJIDE. Cucujidans.
}

LXXXV. Genus PYTHO. Lat.

Latreille, on account of the Heteromerous structure of its tarsi, has placed this genus amongst his Helopians, with which it possesses few other characters in contmon. Fabricius, with better reason, has placed it next to Cucujus, to which genus he originally regarded it as belonging. With his C.rufus (Catogenus Westwood) ${ }^{1}$ it agrees, not only in its depressed body, and impressed prothorax, but in its labrum, internally toothed mandibles, bilobed maxillæ, with the lower lobe much shorter than the upper, and in its mentum : the palpi are more like those of Cucujus flavipes, as figured by Olivier : the labium, in the specimen I dissected, is a minute, round, corneous piece between the labial palpi; the tongue is shrunk up, but is evidently membranaceous : the mandibles are incurved at the apex and armed with two sharp teeth, on its inner side are four minute ones, thus approaching the structure of these organs in the Lucanidae.

\section{1. * Pytho niger. Black Pytho.}

$P$. (niger) niger nitidus, punctulatus; antennis tarsique rufis : prothorace canaliculato, utrinque longitudinaliter fovcato, medio latiore, postice constricto : elytris striatis basi punctulatis.

Black Pytho, black, glossy, minutely punctured : antennæ and tarsi rufous : prothorax channelled, longitudinally impressed on each side, widest in the middle, constricted behind; elytra furrowed, ininutely punctured at the base.

\section{PLATE VII, FIG, 2.}

Length of the body $5 \frac{1}{1}-5 \frac{1}{2}$ lines.

Several taken in Lat. $54^{\circ}$. and in the Journey from New York at Cumberlandhouse.

s I would restrict this name to those which bave eleven joints in their antennz; thus excluding the Xylotrypa, which have only ten.

9 By this term I would characterize these Xylophaga, the terminal joint or joints of whose antennæ do not form a club ; those in which it does I denominate Anisocera.

1 Zool. Journ. xviii, 221. 


\section{DESCRIP'TION.}

Body linear, depressed, black, shining, punctured. Head with a longitudinal impression on each side between the eyes; nose smootl, flat, with the intermediate space less punctured; antennæ and palpi dusky-rufous: prothorax conspicuously channelled, with the usual deep longitudinal impression on each side, lateral contour very convex, constricted posteriorly : elytra furrowed with elevated smooth interstices; furrows punetured and abbreviated at each end; base of the elytra, where the furrows cease, punctured: body underneath minutely punctured; abdomen piccous; tarsi rufous.

Varietr B. Tibix also rufous: thighs piceous.

C. Body entirely ferruginous. It agrees with $\mathrm{A}$ in sculpture and every other respect except colour.

Nany indiviluals of the present species were taken in the Expedition, all of them agrecing in having no tint of blue in the elytra; in having the levigated part of the base punctured, and the sides of the prothorax more prominent, than in $P$. depressus, from which it seems clearly distinct.

\section{2. * Pytho Americanus. American Pytho.}

P. (Amcricanus) rufus; capile prothoraceque nigris, hoc antice latiori, obsoletius canaliculato, utrinque longitudinalitcr forcato: elytris atro-caruleis, striatis, basi vix punctulatis.

American Pytho, rufous : head and prothorax black; the latter widest anteriorly, less conspicuously channelled, longitudinally impressed on both sides : elytra deep blue, furrowed, scarcely punctured at the base.

Length of the body $5-7$ lines.

Several taken in Lat. $54^{\circ}$. and in the Journey fronı New York to Cumberlandhouse.

\section{DESCRIPTION.}

This species differs from the preceding chiefly in having the abdomen, medipectus, postpeetus, legs and mouth rufous; in a slight punctured elcvation on each side of the nose; the space between the eyes also is more distinctly punctured, and there are two deep impressions under the head betwcen the cyes; the prothorax is widest anteriorly, and not constricted behind; and the elytra are deep blue, and scarcely punctured at the base.

It differs from $P$. depressus, in being wider in proportion to its length, and in having the abdomen, and two posterior sections of the breast, invariably rufous.

VARIETY B. Elytra rufous at the sides and tip.

C. Elytra entirely rufous.

D. Elytra entirely rufous; head and prothorax piceous.

E. Body cntirely rufous. 
ii. Anisocera.

\section{Family TROGOSITIDE. Trogositidans.}

LXXXVI. * Genus TROGOSITA. Oliv.

$$
\text { 1. * Trogosita Americana. American Trogosita. }
$$

T. (Americana) ylabra. picea, fronte foveata, elytris substriatis; striis punctatis; antennis clava incrassata : prothorace subquadrato.

American Trogosita, naked, piceous; front impressed; elytra slightly furrowed : furrows punctured : antennæ with a thick knob : prothorax rather square.

Length of the body 5 lines.

Two specimens taken in the Journey between New York and Cumberland-house:

DESCRIPTION.

This species is the American representative of $T$. caraboides from which it principally differs in being larger, with the frontal impressions more distinct; the stalk of the antennæ much slenderer, and the knob thicker: the prothorax not so narrow and constricted at the base, and the elytra slightly furrowed.

The tribe to which Trogosita belongs, though evidently connected with that after which I have placed it, appears to bring us very little nearer to the Capricorns; their prothorax indeed and depressed body indicate some approach towards them, but their antenna and general habit shew them to require many intermediate forms to fill up the interval between them. M. Latreille's third family of his Tetramera, whicl he denominates Platysoma, will however now carry us on towards the confines of the last mentioned tribes: for in this family, the antennæ lose their knob, and become nearly setaceous, and in several species the prothorax is armed with little teeth like the Prionidans: there is an insect belonging to the family I am speaking of, which De Geer has deseribed and figured under the name of Altelabus glaber, ${ }^{2}$ but which in a modern system would stand as a distinct genus, ${ }^{3}$ approaching very near to Prionus, except that its prothorax has no teeth, and the antenna are proportioually shorter; owing to its protended mandibles, it has the aspect of a miniature Prionus exsertus. ${ }^{4}$

But a near approach, in another instance, is made by the Prionidans to the Lucanidans, Amongst the insects collected by the late lamented Sir Stamford Raffles in Sumatra, is an anomalous species, or rather genus, apparently belonging to the first of these families, which exhibits also the antennæ and tibia of the last, and itself, as to its tarsi, is heteromerous; thus interchanging characters, and proving its right to affinity, with the Lucanidans.

From what has been above stated, it appears clear I think that the Xylophaga by means of Trogosita, as Messrs. Gyllenhall and Mac Leay have observed, touch upon the Iucanida, and it is equally evident, that M. Latreille is also correct in connecting, by means of his Platysoma, the Xylophaga with the Capricorns: ${ }^{5}$ we may observe here that the genus Spondylis, though placed by Latreille amongst the Prionidans seems to furnish a link connecting the Platysoma, to which it surely belongs, with another family of Capricorns the Lamiadans; and particularly with a genus, or subgenus, belonging to it, the type of which is Lamia vermicularis of Donovan. ${ }^{6}$

: De Geer iv, 35l, 2, t. xix, $f .14$.

+ Oliv. Ins. $66, t$. viii, $f .31$.

3 I call it Gnathophorus.

6 This genus stands in my calinet under the name of Sthenera. 
Having thus won our way to the Capricorn bectles, I shall now describe the species belonging to it taken in the Expedition.

\author{
iii. Longicornis. Latr.
}

\title{
Family LAMIADE. Lamialans.
}

LXXXVII. Genus MONOCHAMUS. De J.7

Labrum rounded at the apex and subemarginate.

Labium membranaceous, bipartite, with hairy lobes.

Mandibles subcompressed, trigonal, toothless, acute and incurved at the apex.

Maxille bilobed, lobes hairy at the apex and rounded, the upper lobe the longest.

Palpi maxillary four-jointed: first joint short subcylindrical; second longer than the third, gradually thicker towards the obliquely truneated apex; third shaped like the seeond but shorter and somewhat bent; fourth fusiform, subtruncated at the apex.

labial three-jointed, first joint minute; second incrassated at the apex; third fusiform, subtruncated.

Antenne subsetaceous, elongated, eleven-jointed; seape subcylindrical, rather thicker towards the apex, constricted at the base; pedicel very short, subturbinate; third joint longer than the rest, which are nearly equal in length and filiform.

* Elytra rough from wrinkles and punctures.

$(2 \cdot 21)$

1. Movochamus resutor. Resutor Monochamus.

11. (resutor) niger; prothorace spinoso; elytris confucnter punctatis ct rugosis, femineis cincreo maculatis; scutello palliclo; antenris pedibusque rufescentibus, illis in masculis longioribus, in feminis medincribus.

Resutor Monochamus, black; protborax spinose; elytra confluently punctured and wrinkled, those of the female spotted with cinereous; scutellum pale; antennx and legs reddish; the former, in the males, longer than the body; in the femalcs not exceeding it in length.

Length of the body $10 \frac{3}{8}$ lines.

Frequently taken in Lat. $65^{\circ}$.

7 As neither De Jean nor Latreille bave given characters of this genus I subjoin them. 


\section{DESCRIPTION.}

This insect resembles $M$. sutor in so many particulars, that it is not without considerable hesitation I describe it as distinct. It exhibits however some characters that seem to indicate more than a casual variety, produced by difference of climate, \&c. The antennæ of the male of $M$. resutor are considerably shorter than those of the same sex of $M$. sttor; the lubrum and rhinarium are shorter; the former is rufo-piceous; the first joint of the antennæ, the five or six of the last joints are rufescent, as are the legs more or less, and the tooth that arms the intermediate tibia is more prominent. The antennæ of the female are but little longer than the body, and not annulated with cinercous.

This species is intermediate between $M$. sutor and $M$. sartor.

** Elytra without wrinkles.

\section{2.* Monochamus confusor. Confused Monochamus.}

M. (confusor) nigro cinereoque nebulosus et variegatus: prothorace spinoso; elytris testaceis punctatis piloso cinereis, nigro maculosis : scutello pallido: antennis rufescentibus basi nigris.

Confused Monochamus, clouded and variegated with black and cinereons : prothorax armed with spines : elytra testaceous, punctured, cinereous from bairs, spotted and dotted with black : scutellum pale; antennæ reddish, black at the base.

Length of the body 1 inch and $1 \frac{3}{4}$ line.

Taken in Nova Scotia by Dr. Mac Culloch, in Canada by Dr. Bigsby, in Massachusets by Mr. Drake.

\section{DESCRIPTION.}

Body linear, elongate, black, covered with white or cinereous decumbent hairs, but so as to let the black appear in confused spots and reticulations. Labrum rather long, fringed anteriorly with ferruginous hairs; maxillary palpi long; rhinarium broad, rufous; antennæ testaceous with the redness obscured by decumbent cinereous hairs, but the scape and pedicel are black; the antennæ of the female are something longer than the body; those of the male are twice its length: the spines of the prothorax are stout, covered thickly with white hairs, and dotted posteriorly with black; in the disk is a central oblong impression: scutellum thickly covered with white decumbent hairs, with a black longitudinal line: the ground colour of the elytra is testaceous which is more or less obscured and clouded by white decumbent hairs, besides there are several black dots and oblong spots produced by erect hairs; at the base of the elytra, especially on the projecting shoulders, are numerous round elevated smooth little spaces, and their whole surface is eovered with scattered minute punctures.

N.B. In the male the black spots and dots of the elytra are fainter, and sometimes nearly obliterated. 
M. (marmorator) niger, fulvo nebulosus; prothorace spinoso; elytris nigro, cinereo, fulvoque marmoratis.

Marbled Monochamus, black, clouded with tawny; prothorax spinose; elytra marbled with black, cinereous, and tawny.

Length of the body 11 lines.

A single specimen taken in Lat. $54^{\circ}$.

DESCRIPTION.

Body black, covered underneath, but so that the black appears in various places, with subcincreous, or somewhat tawny deeumbent hairs. Head and prothorax covered in the same way but with redder hairs: spines of the prothorax very robust, rather long, sharpish: scutellum covered with a coat of cinereous hairs, divided by a black longitudinal line: elytra black, marbled variously with cinereous and reddish tawny hairs; the cinereous spots are dotted with black; the surface of the clytra when laid barc appears punctured, and at the base are several confluent smooth elevated spaces; suture and lateral margin testaceous; apex acute.

N. B. The antennæ in the specimen are broken off.

\title{
Family CERAMBYCIDE. Cerambycidans.
}

\author{
LXXXVIII. Genus ACANTHOCINUS. Meg. \\ xix. Subgenus Graphisurus. Kirb. \\ Anus of the female with a long exserted ovipositor.
}

The type of this subgenus is Cerambyx fasciatus of De Geer. ${ }^{8}$ It comes near to Acanthocinus cedilis, the female of which has an exserted ovipositor, but not so long, and the scape of the antennæ is of a different shape; so that they would, if considered as belonging to the same subgenus, form two divisions.

\section{(224) 1. * Acanthocinus (Graphisumes) pusiluus. Duarf A. Graphisurus.}

A. G. (pusillus) prothorace postice acute spinoso; cinerco-pilosus nigro punctatus; elytris fascia obliqua maculisque plurilus fuscis.

Dwarf A. Graphisurus, prothorax towards the base armed with an acute spine; body with a coat of cinereous hairs dotted with black; elytra with an oblique brown band, and several spots of the same colour.

Lèngth of the body $4 \frac{1}{1}$ lines.

A single specimen taken in the Journey from New York to Cumberland-house.

$$
\text { s De Geer } v, 114, t \text { xir, f. } 7 .
$$




\section{DESCRIPTION.}

This species is one of the most minute of the Capricorn tribes. Body linear, black but covered with a coat of whitish decumbent hairs, which appears more or less sprinkled with black dots. Head longitudinally channelled; antennæ mutilated in the specimen, but those joints that remain are white at the base: prothorax short, armed on each side, towards the base with a short sharp spine, punctured with scattered punctures; elytra punctured especially towards the base, mottled and speckled with brown, with an oblique brown band a little beyond the middle, apex of the elytra rounded: podex and hypopygium, or last dorsal and ventral segments of the abdomen elongated, so as to defend the base of the ovipositor which is exserted, causing the insect to appear as if it had a tail ; the hypopygium is emarginate: thighs much incrassatad at the apex.

\section{Family CALLIDIAD死.}

LXXXIX. Genus CALLIDIUM. Fab.

\section{1. * Callidium agreste. Country Callidium.}

C. (agreste) fuscum, subobscurum, punctulatissimum; protharace, trifoveato ; elytris lineis tribus elevatis apice confluentibus: corpore subtus albido villoso; pectore longius.

Country Callidium, brown, less ohscure, very minutely and thickly punctured; prothorax with three impressions; elytra with three elevated lines confluent near the apex; body underneath coated with white hairs, those on the breast being longer than the rest.

Length of the body 11 lines.

Several specimens taken in the Expedition, and likewise in Nova Scotia by Dr. Mac Culloch and Capt. Hall.

\section{DESCRIPTION.}

I at first took this for a variety of C. rusticum, but on a closer inspection I found it differed in the sculpture as well as colour; and having received a specimen of that insect from Dr. Harris, in which its characters were all preserved, I am induced to describe $C$. agreste as a distinct species.

It differs from C. rusticum in being smaller, of a darker brown, without a tint of red; and in having more gloss. The prothorax has three deep round impressions, while in the insect last named, the impressions are slight, and the two anterior ones oblong: the elevated lines of the elytra are more prominent and become visibly confluent towards the apex, where they form several reticulations: the underside of the body is much more thickly covered with hairs, which are hoary instead of yellowish, those on the breast being longer than those on the abdomen. In other respects these two insects resemble each other. 
Callidium striatum. Fab. Ent. Syst. I, ii, 329, 48; Syst. Eleuth. ii, 343, 57. Oliv. Ins. 70, t. ii, f. 24. Herbst. Arch. 2. xxvi, f. 13. Panz. Fr. Germ. lxx, I3. De Geer Ins. v, 90, 26. Payk. Fn. Suec. iii, 83, 4. Lai. Tyr. Ins. 74, 8. Cerambyx striatus. Linn. Fn. Suec. 668; Syst. Nat. ii, 635, 73.

Length of the body $5 \frac{1}{4}$ lines.

A single specimen taken in Lat. $65^{\circ}$.

DESCRIPTION.

Body linear, black, thiekly punctured, underneath with a few hairs, glossy; above without any hairs or gloss. Antennæ a little longer than the prothorax: prothorax suborbicular, covered thiekly with minute granules, with an elevated tuberele in its disk: elytra most minutely and thickly granulated, with four longitudinal slight furrows oceupying the half adjoining the suture, the alternate interstices being most elevated: tarsi rufo-piceous.

3. *allidium collake. Red-collared Callidium.

C. (collare) nigrum, supra obscurum, punctatissimum; prothorace laviusculo, nitido, rufo, lateribus subspinosis.

Red-collared Callidium, black, above obscure, very thickly punctured; prothorax smoother, glossy, rufous, with the sides subspinose.

Length of the body 5 lines.

A single specimen taken in Lat. $54^{\circ}$.

DESCRIPTION.

Body linear, black, hairy with whitish scattered hairs. Head thickly punetured; antennæ shorter than the body, rather hairy, piceous, scape black: prothorax rufous, with a few scattered punetures, glossy, projecting on each side into an angle or short spine: elytra very thickly and confluently punctured : body underneath glossy, slightly punetured: anterior part of antepectus rufous: tarsi piceous, first joint of nearly equal length in all the legs.

This species seems to be nearly related to $C$. sanguinicolle of Germar, ${ }^{9}$ but it differs in having the thorax less punctured than the rest of the upper surface of the body, and armed with rudiments of spines, and the first joint of the posterior tarsus is not more elongated than the rest.

9 Coleopt. Spec. Nor. i, s15, 687. 
xx. * Subgenus Merum. Kirb.

Thighs clubbed.

This subgenus differs from the genuine Callidia, in having all the thighs incrassated at the apex. Cerambyx variabilis Linn. may be considered as its type.

\section{Callidium (Merium) Proteus. Proteus C. Merium.}

C. $M$. (Proteus) nigrum, punctulatum, pilosum; prothorace utrinque punctis confluentibus scabro; elytris violascentibus lineis longitudinalibus callosis pallidis; femoribus rufis.

Proteus C. Merium, black, minutely punctured, hairy : protborax on each side rough with confluent punctures; elytra tinted with violet, with longitudinal, callous, pale lines: thighs rufous.

PLATE V, FIG. 5.

Length of the body $5-8 \frac{1}{2}$ lines.

Taken abundantly especially in Lat. $65^{\circ}$.

\section{DESCRIPTION.}

Body black, minutely punctured, hairy with longish hoary hairs, especially underneath. Nose with a deeply ploughed transverse furrow; front behind the antennæ violet, confluently punctured; palpi black, maxillary rather long, last joint an obtusangular triangle; antennæ longer than the prothorax: sides of the prothorax very rough with deep confluent punctures: elytra wrinkled, violet, with three lougitudinal, subinterrupted, callous, pale lines, of which the intermediate one is the longest, and the external one the shortest: legs piceous, with the incrassated part of the thighs testaceous.

This species varies extremely both in size and colour. The following are the principal varieties.

VARIETY B. Head and prothorax violet; elytra lurid with only two callous lines. Length $6 \frac{1}{4}$ lines.

C. Head, except at the base of the antenna, black; sides of the prothorax violet, disk bronzed: elytra as in the last. Length 5 lines.

D. Head and prothorax black: elytra lurid; lines faintly marked. Length $5 \frac{1}{3}-7$ lines.

E. Head and prothorax bronzed : elytra lurid bronzed, with two distinct lines. Length 6 -7 lines.

F. Head violet; prothorax bronzed: elytra as in the last. Length 6 lines.

G. Like the last, but the callous lines of the elytra are obsolete. Length $5 \frac{1}{2}-6 \frac{1}{2}$ lines.

H. Head and prothorax black : elytra lurid with three lines. Length $7 \frac{1}{2}$ lines.

I. Head and prothorax black-bronzed: elytra bronzed-lurid with two lines. 


\section{Callidium (Merium) simile. Similar C. Merium.}

C. M. (simile) nigrum, punctulatum, pilosum; prothorace utrinque pulvinatum, minutissime et confertissime confluenter punetulatum; elytris anco-luridis, lineis duabus elevatis callosis pallidis confluentibus, antennis apice femoribusque rufis.

Similar C. Merium, black, minutely punetured, hairy, prothorax pillowed out on each side, and most minutely and thickly punctured with confluent punetures: elytra bronzed, lurid, with two clevated callous coalescing pale lines; antennæe at the apex, and thighs, rufous.

Lengtls of the body 7 lines.

\section{A single specimen taken with the preceding species.}

\section{DESCRIPTION.}

This species in most respects is so like $C$. M. Proteus, that I had set it by as another variety; but upon further consideration I am induced to give it as distinet, sinee it differs not only in colour but in the form and seulpture of the prothorax and other parts.

The apex of the palpi is more dilated, so that it is strictly securiform; the front behind the antennæ is elevated and gibbous, with few seattered punctures: the sides of the prothorax are more puffed out, and much more minutely and thinkly punctured, and there is a pair of impressions in the disk: the antennæ also at the base are rufous: in other respects it does not differ from $M$. Proteus.

\section{Callidium (Merium) dimidiatum. Halved C. Merium.}

C. M. (dimidiatum) obscure rufum, supra nigrum; elytris antice rufis; prothorace granulato, posticc canaliculato.

Halved C. Merium, obseurely rufous; black above; elytra rufous at the base; prothorax granulated, channelled posteriorly.

Length of the body 4 lines.

\section{Two specimens taken in Lat. $54^{\circ}$.}

\section{DESCRIPTION.}

Body not glossy; impunctured; hairy underneath; and except the forebreast, which is black, of a dull rufous. Head channelled between the eyes, behind them convex; antennx rufous, shorter than the body: prothorax somewhat coaretate at the base; minutely granulated; obsoletely channelled, more conspicuously behind: elytra rufous anteriorly.

This species comes very near to C. (Merium) Alni, but it is larger and has no white bands. 
xxi. * Subgenus Tetropium. Kirb.

Eyes four, connected by an elevated line. ${ }^{1}$

Antenne robust, short: scape much inerassated, subcylindrical, remaining joints subclavated.

Prothorax constricted anteriorly and posteriorly.

Thighs much inerassated, sometimes clubbed.

The type of this subgenus is Callidium triste Fabr. for those with clavated thighs, and $C$. aulicum, for those in which they are incrassated nearly their whole length. These insects will be found to have four distinct eyes, separated by the substance of the head elevated into a ridge, which at first sight appears a continuation of the eye, but which evidently has no lenses implanted in it-they are also distinguished by their robust and short antennæ.

(231)

7. Callidium (Tetropium) cinnamopterum. Cinnamon-winged

C. Tetropium.

C. $T$. (cinnamopterum) atrum, pilosum; antennis, pedibus, pectoris lateribus, elytrisque rufis; femoribus incrassatis; haud clavatis. Cinnamon-ivinged C. Tetropium, very black, hairy; antennæ, legs, sides of the breast, and elytra rufous : thighs incrassated but not clubbed.

PLATE V, FIG. 8.

Length of the body $3 \frac{1}{4}-6$ lines.

Several specimens taken in Lat. $65^{\circ}$.

\section{DESCRIPTION.}

At first sight this species seems the exact counterpart of Calliditm triste, which it resembles in almost every respect; but upon examination it will be found that the thighs of these two insects are of a very different shape, those of $C$. T. triste being much attenuated at the base, while those of $C$. $T$. cinnamopterum are not at all. In the latter also the sides of the fore-breast are red, and the elytra are considerably darker, very near the colour of cinnamon.

The American specimens vary much in size, but all agree in the shape of the thighs. 
XC. Genus CLYTUS. Fab.

- Prothorax subglobose unarmed.

a. Yellow-banded.

$(232)$

1. Clutus undatus. Wavy Clytus.

C. (undatus) niger, holosericcus; prothorace basi et apice intcrrupte; clytris lineala transversa, fusciis duabus undutis, upiceque, pallide flavis; antennis, pcdibusque rufis.

Wavy Clytus, black velvetty; base and apex of the prothorax intercuptedly; transverse linelet, two wavy bands, and apex of the elytra, pale-yellow; antennx and legs rufous.

PLATE VII, FIG. 5.

Clytus undulatus. Say. Am. Ent. iii, 53. Long. Second Exp. ii, 29], var. $\beta$, mihi.

Length of the body 8 lines.

Two specimens taken in Lat. $54^{\circ} .65^{\circ}$.

\section{DESCRIPTION.}

Body black, underneatl hoary from decumbent hairs, above velvetty. Head anteriorly hairy with whitish hairs, behind the antennæ very thiekly punetured; palpi, labrum, tip of the nose and eheeks, eyes, antennx, and subface rufous; prothorax rough with very minute and numerous granules, the base and apex have an interrupted band of yellow hairs, and a hoary spot on each side produced by hairs : seutellum dark brown: elytra with an oblique linelet adjoining the scutellum, another in the disk near the base, two wavy bands, the extremities of the anterior one pointing towards the base, and of the posterior one towards the apex; the apex and suture, all pale yellow, produced by deeumbent hairs : underneath on each side of the breast are three spots of the same colour, as likewise is the tip of the ventral segments of tne abdomen; the legs are rufous, sprinkled with hoary hairs.

This species is intermediate between $C$. arietis and $C$. arcuatus, but perfectly distinet from both.

b. White-banded.

(233)

2. Chytus lunulatus. Lumulated Clytus.

C. (lunulatus) niger, capite lavi, occipite punctato: prothoracis margine antico; elytris lunula antica, fasciis duabus, intermcdia juxta suturam reflexa, pastica interrupta, abdomine segmentis ventralibus apice, albis: antennis pedibusque obscure rufis.

Lunulated Clytus, black : head smooth, oceiput punctured : anterior margin of the prothorax, anterior lunulet, two bands, the intermediate one running back along the suture, the posterior one interrupted, and apex of the ventral segments of the abdomen, all white: antennæ and Jegs obscurely rufous.

Length of the body $7 \frac{1}{4}$ lines.

One specimen taken in Lat. 54 $4^{\circ}$. 'Taken also in Canada by Dr. Bigsby, and in Nova Scotia by Capt. Hall. 


\section{DESCRIPTION.}

This species is extremely similar to the preceding, but its bands and spots are quite white without any tint of yellow : the prothorax has no posterior interrupted band, the anterior spot of the elytra is crescent or kidney-shaped, the thighs are dusky; and the eyes are black; but the most striking distinction is exhibited by the head, which is perfectly smooth and without punctures, but when the occiput is disengaged from the prothorax, as it is when the head is inclined forwards, the front will be found to be separated from it by a bilobed line, belind which the head is thickly and confluently punctured.

\section{Clytus fuscus. Brown Clytus.}

C. (fuscus) nigro-fuscus, prothoracis basi et apice interrupte, elytris sutura, puncto baseos, fasciis duabus interruptis, abdominisque segmentis ventralibus apice, albis: antennis, oculis, pedibusque, rufis.

Brown Clytus, black-brown, base and apex of the prothorax interruptedly, suture, dot near the base, and two interrupted bands of the elytra, and the apex of the ventral segments of the abdomen, all white : antennie, eyes, and legs rufous.

Length of the body $5 \frac{1}{3}$ lines.

A single specimen taken in Lat. 54\% .

DESCRIPTION.

This species resembles the last in having the occiput similarly punctured, and the markings of the elytra are similar, except that instead of the white streak at the base there is only a dot: but it is of a brown colour, with the head and prothorax nearly black: the former is distinctly granulated; the palpi, labrum, eyes, and antennæ are rufous, as in C. undatus, and like that the prothorax has both an anterior and posterior interrupted band of white hairs; the elytra and underside of the body are reddish-brown: the legs rufous, posterior ones very long.

* Prothorace magis oblongo, muricato.

\section{Clytus longipes. Long-legged Clytus.}

C. (longipes) subtus, elytrisque, fuscus : prothorace oblongo disco carinato et muricato; elytris puncto, fasciisque tribus sublunatis piloso allis; pedibus rufis: posticis longissimis.

Long-legged Clytus, body underneath and elytra brown; prothorax oblong with the disk carinated and muricated; dot and three sublunar bands of the elytra, white from bairs: legs rufous: the posterior pair very long.

Length of the body $5 \frac{1}{4}$ lines.

A single specimen taken in Lat. $54^{\circ}$. 


\section{DESCRIPTION.}

Body reddish brown, underneath hairy, with white decumbent hairs. Head black, minutely and thickly punctured, with a longitudinal slight channel, transversely elevated between the antennæ; vertex elevated; palpi, labrum, antenux and extremity of the nose, rufous: prothorax black, rather oblong, elevated longitudinally in the disk with an anterior bowed transverse ridge, followed by several minute acute tubercles, next in the middle is another shorter ridge, which is also suceected hy similar tubercles: the sides of the prothorax are granulated; between the granulated portion and elevated disk, it is minutely reticulated, with a pore in the centre of each reticulation : elytra brown, subacute, with three bands formed of decumbent white hairs; the first forming a creseent at the seutellum, which runs along the base and down the suture; the second in the middle first running transverscly, then turning upwards towards the base and again turning down so as to form a hook next the suture; the third near the apex, runuing transversely from the external margin to the suture and then turning upwards so as to form another crescent; there is also a dot between the two first bands near the lateral margin; there is a large hairy white spot on the sides of the breast, and the anterior ventral segments have a white hairy band at the apex: the legs are rufous, the hinder pair remarkably long.

C. (muricatulus) subtus elytrisque fuscus; prothorace oblongo muricato; elytris puncto, lunula, fasciisque duabus obliquis, piloso-allis ; pedibus rufis.

Muricated Clytus, body underneath, and elytra, brown; prothorax oblong, muricated : dot, crescent, and two oblique bands of the elytra hairy-white: legs rufous.

Length of the body 5 lines.

Many specimens taken in Lat. $54^{\circ}$.

DESCRIPTION.

This comes extremely near to the preceding species, but is smaller, the discoidal ridges of the prothorax are nearly obsolete, that part has four white hairy spots, the bands of the clytra are differently shaped, and the posterior legs are considerably shorter: the breast and base of the abdomen underneath are hoary with white hairs, but not always spotted and banded. 


\section{Family RHAGIADE. Rhagiadans.}

XC1. Genus HARGIUM. Leach.

\section{Hargium lineatum. Stripe-necked Hargium.}

Stenochorus lineatus. Oliv. Ent. iv, 69, I3, 6, $t$. iii, $f .22$.

Rhagium lineatum. Schön. Syn. iii, 414, 5 .

Length of the body $5 \frac{1}{4}$ lines.

Taken more than once in Lat. $54^{\circ}$. and also by Mr. Drake in the province of Massachusets.

\section{DESCRIPTION.}

Body black, ratlier glossy, hoary from longish cinereous hairs. Head constricted behind into a neck, punctured with large scattered punctures; antennæ shorter than the prothorax, robust, last joint ovate, pedicel testaceous: prothorax constricted anteriorly and posteriorly, armed on each side by a stout rather sharp spine, punctured like the head, and hairy, but there are three longitudinal stripes without hairs, and the intermediate one without punctures, the lateral ones pass over the spines: elytra mottled with whitish or cinereous hairs, with three longitudinal ridges, the two external ones confluent near the apex, and a little higher up including between them a short abbreviated ridge; the interstices are punctured like the head and prothorax; at the base and lateral margin the elytra are reddish, and on the ridge next the suture there are two yellowish spots: coxæ, trochanters, and base of the thighs reddish : abdomen carinated underneath.

\section{Family LEPTURIDÆ. Lepturidans.}

XCII. Genus PACHYTA. Meg.

\section{Pachyta liturata. Blotched Pachyta.}

P. (liturata) atra, villoso-incana; elytris nudis, luridis, lituris tribus nigris, anticis duabus subparallelis.

Blotehed Pachyta, very black, hairy with hoary hairs; elytra naked, lurid, with three black blotches, the two anterior ones nearly parallel.

Length of the body $7-9$ lines.

Several specimens taken in Lat. $54^{\circ}$. and $65^{\circ}$. 


\section{DESCIRIPTION.}

This is the American representative of $P$. quadrimaculata, from which it differs principally in being not so hairy, with hoary instead of yellow-tinted hairs: the punctures of the prothorax and elytra are more minute; the antenna are rather shorter, and the clytra, instead of two subquadransgular black spots, have three less black linear ones, the two anterior ones being partly parallel, and in some specimens confluent.

\section{Genus LEPTURA. Linn.}

This genus may be thus subdivided with respect to the species about to be described.

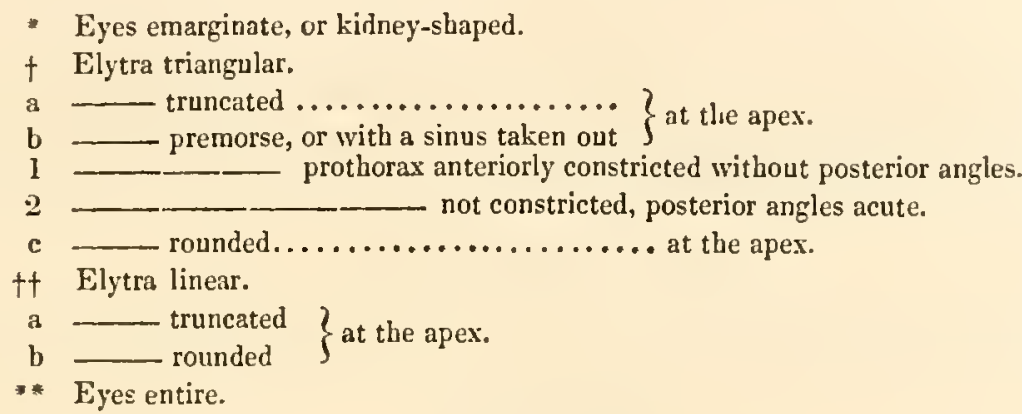

$$
\text { * }+ \text { a. }
$$

$$
\text { 1. * Leptura chrysocoma. Goldy-locks Leptura. }
$$

L. (chrysocoma) holosericea, lanugine aurea; elylris testaceis, apice extus obscurioribus; antcnnis pedibusque nigris.

Goldy-locks Leptura, velvetty with golden pile : elytra testaceous, at the apex externally dusky; antenna and legs black.

$$
\text { PLATE V, FIG. } 1 .
$$

Length of the body $5 \frac{1}{2}-6 \frac{1}{4}$ lines.

Several specimens taken; the largest, in the Journey from New York; the smaller, near Cumberland-house. Taken likewise by Dr. Mac Culloch and Capt. Hall, in Nova Scotia. 
DESCRIPTION.

This beautiful insect, is related to $L$. virens, but perfectly distinct. The body appears to be black, but that colour is, in most parts, nearly concealed by a thick and mostly long coat of brilliant golden hairs with a very slight tint of green, where the coat is thin the body appears minutely punctured. Head subelongated, the neck exserted, subtriangular; nose with only a few scattered whitish hairs; antennæ black, third, fourth, and fifth joints rather slenderer and longer than the succeeding ones: prothorax between globose and bell-shaped, constricted anteriorly, channelled, grossly punctured: substance of the elytra pale testaceous, towards the apex externally they are dusky; the golden down on them is shorter and decumbent; apex diverging and obliquely truncated: underside of the abdomen particularly brilliant from decumbent hairs: legs less hairy than the rest of the body.

\section{2. * Leptura subpubescens. Subpulescent Leptura.}

L. (subpubescens) nigra, fiavo-subpubescens : prothorace punctis confluentibus scabro; elytris pallide testaceis, apice divergentibus, fastigiatis, nigris.

Subpubescent Leptura, black, red with thin yellow down : prothorax rough with confluent punctures; elytra pale testaceous, diverging, fastigiated and black at the apex.

\section{Length of the body not noticed.}

\section{Taken in Canada by Dr. Bigsby.}

\section{DESCRIPTION.}

Body black, thinly coated with yellow hairs. Head and neck grossly punctured; antennæ longer than the prothorax, black, downy, intermediate joints rather slenderer than the others, fourth shorter than the fifth: prothorax shaped as in C. chrysocoma, widely but obsoletely channelled; rough and reticulated, as it were, with numerous confluent punctures, sides more hairy than the disk: elytra thickly punctured, pale testaceous, black at the apex, where the suture curves outwards so that they diverge from each other, extremity nearly transversely truncated: abdomen underneath minutely, breast rather grossly, punctured: podex subemarginate.

\section{$*$ b 1 .}

\section{3. * Leptura erythroptera. Red-winged Leptura.}

L. (erythroptera) atra, subpubescens, punctata ; prothorace punctis rugoso, antennis pallido annulatis ; elytris grosse punctatis, rubris, apice summo nigro, pramorso.

Red-winged Leptura, very black, subpubescent, punctured ; prothorax wrinkled with punctures; antennæ annulated with pale : elytra grossly punctured, deep red, extremity black, premorse.

Length of the body 8 lines.

Taken in Nova Scotia by Capt. Hall. 


\section{DESCIRPTION.}

Body very black, slightly downy, underneath minutely punetured. Head shorter than in the last section, as well as the neck obsoletely chamnelled; thickly lut not minutely punctured; antennx rather longer than the prothorax; third and fourth joints a little slenderer than the others, and pale red at the base; the sixth is pale with a black spot on eech side at the apex; and the whole of the eighth is of the same colour; the last joint is acuminated: the prothorax is constricted anteriorly, and the constricted part is perfectly smooth, the rest is thickly and confluently punctured and wrinkled; at the base the prothorax is depressed and obsoletely trilobed: scutellum black, representing an isosceles triangle: elytra of a dull red, grossly and decply punctured; cxtremity scooped out with the external angle longer than the internal and acuminate: mesosternum emarginate posteriorly.

\section{Leptura canadensis. (Olivier.) Canada Leptura.}

Leptura canadensis. Fab. Syst. Eleuth. ii, 357, 15. Oliv. Ent. iv, 73, 8, 6, t. iii, f. 27. Illig. Mag. iv, 122, 1j.

Length of the body $6 \frac{3}{4}-8$ lines.

\section{Taken in Nova Scotia by Dr. Mac Culloch.}

DESCRIPTION.

Body very black, slightly downy, minutely punctured. Head as in the last species, but the neck is not channelled; antennæ with base of the fifth joint, the whole of the sixth and eighth, except the black apex of the former, pale or pale rufous: prothorax as in L. erythroptera, only decply and confluently puncturcd but not wrinkled: clytra black, sanguineous at the base. In other respects this species resembles that insect; the external angle of the apex of the elytra is however shorter.

$$
+\mathrm{t} \mathbf{2}
$$

\section{5. * Leptura tenuior. Slenderer Leptura.}

L. (tenuior) nigra, pube flava; elytris flavo quadrifasciatis; pedibus abdomineque testaceis.

Slenderer Leptura, black, with yellow down; elytra with four yellow bands; legs, and abdomen testaceous.

Length of the body $5 \frac{3}{6}$ lines.

Taken in Canada by Dr. Bigsby. 


\section{DESCRIPTION.}

Body black, rather slender, slightly punctured, thinly coated with decumbent yellow hairs. Antennæ shorter than the body, fifth joint scarcely longer than the fourth: prothorax between bellshaped and a truncated cone, a little constricted in the middle, fringed with yellow hairs anteriorly and posteriorly: scutcllum triangular: elytra testaceous, yellow at the base, and with three yellow bands, the first interrupted; oblique sinus at the apex not so deep as in the two preceding species: legs testaceous; abdomen of a deeper colour; and segments scarcely emarginate.

This species differs in habit from the two preceding ones, it is narrower in proportion, and comes nearer to $\boldsymbol{L}$. quadrifasciata, but the posterior angles of the prothorax, though acute, are not so prominent, it helongs however to the same subdivision, with the last mentioned insect.

$$
\text { 6. * Leptura brevis. Short Leptura. }
$$

L. (brevis) nigra, brevis, pubescens; antennis articulis ultimis sex basi pallidis; elytris grosse punctatis vitta laterali lutea. Short Leptura, black, short, pubescent; six last joints of the antennæ pale at the base; elytra grossly punctured with a luteous lateral band.

Length of the body 5 lines.

Taken in Canada by Dr. Bigsby.

\section{DESCRIPTION.}

Body shorter than usual in proportion to its widith; black, underneath minutely punctured and thinly covered with rather silvery decumbent hairs. Head thickly and confluently punctured, rather downy with erect hoary hairs; antennæ shorter than the body; fourth, fifth, and sixth joints long and slenderer than the rest; six last short and pale at the base: prothorax between bell-shaped and globose, deeply and confluently punctured; downy with some erect hoary hairs; anteriorly constricted, posteriorly depressed: scutellum linear covered with pale decumbent hairs: elytra very grossly and deeply punctured, shorter than the abdomen and rounded at the apex, with a lateral hand bent a little inwards towards the base, which it does not reach, of the colour of the yolk of an egg; anus entire: down on the legs yellow.

\section{Leptura sexmaculata. (Linné.) Six-spotted Leptura.}

Leptura sexmaculata. Linn. Fn. Suec. 686; Syst. Nat. ii, 638, 11. Fab. Syst. Ent. 197, 11 ; Ent. Syst. I, ii, 346, 37. Syst. Eleuth. ii, 362, 47. Oliv. Ent. iv, 73, 26, 35, t. 4, f. 43. Payk. Fn. Suec. iii, 123, 25. Gyll. Ins. Suec. iv, 14, 13. Panz. Fn. Germ. lxix, 21 ? Miull. Zool. Dan. Pr. 94, 1058.

- testaceo-fasciata. De Geer Ins. v, 133, 9.

Pachyta sexmaculata. Steph. Illustr. Mandib. iv, 265, $5 \nmid$ ?

Length of the body $5 \frac{1}{2}$ lines.

Two specimens taken in Lat. $65^{\circ}$. 


\section{DESCRIPTION.}

Body rather short, black, downy, minutely punctured. Head very thickly and minutely punctured, obsoletely chanuelled; antennæ slender, shorter than the body, fifth joint considerably longer than the fourth: prothorax shaped as in the preceding species but less depressed posteriorly; very thickly as well as minutely punctured: scutellum triangular : elytra palc-yellow, with an archeel black spot at the base, then follows an interrupted band consisting of threc acute black spots placed in it triangle, beyond the middle is a dentated black band which reaches neither the suture nor the lateral margin; the apex also, the suture, and the lateral margin towarls the apex, are all black.

VARIETY B. Head not chamnelled: spot at the base of the elytra coalescing with the interncdiate and lateral ones of the anterior band, and reaching the lateral margin; interior spot reaching the suture so as to form the half of a spot common to both elytra; the intermediate band is broader and reaches both the suture and lateral margin.

* t十 a. 8. * Leptura semivittata. Hulf-striped Lepturu.

I. (semivittata) linearis, nigra, supra nitida, subtus argenteo-sericea : elytris vitta dimidiata, flexuosa, lutea, apice truncatis. Half-striped Leptura, linear, black, above glossy, underneath silvery from silky hairs; elytra with a luteous flexuose stripe reaching half their length; truncated at the tip.

Length of the body 6 lines.

\section{Taken in Canada by Dr. Bigsby.}

\section{DESCRIPTION.}

Body long and narrow, black, underneath slightly and minutely punctured, with the sides of the breast and abdomen brilliant with a silvery lustre from decumbent silky hairs, above glossy and almost naked. Head thickly punctured, but belind each eye there is a levigated space; antennæ longer than the prothorax, intermediate joints not slenderer than the others, the fourth as long as the fifth; neck short and levigated: prothorax bell-shaped, not constricted anteriorly, depressed posteriorly; thinly punctured, especially in the disk: scutcllum triangular: elytra punctured but not thickly, punctures almost arranged in rows, towards the apex they are very slight; a reddish-yellow subflexuose stripe runs from the middle of the base of the elytra a little more than half way towards the apex, which is diverging and truneated: the ventral segments of the abdomen terminate in a reddish membrane. 


\section{9. * Leptura gulosa. Red-throated Leptura.}

L. (gulosa) linearis, nigra, supra nitida, subtus sericeo-argentea; gula rufescenti; elytris vitta postice abbreviata lutea; apice truncatis.

Red-throated Leptura, linear, black above glossy, underneath silvery from silky hairs ; throat reddish ; elytra with a luteous stripe abbreviated posteriorly; truncated at the apex.

Length of the body 5 lines.

\section{Taken in Nova Scotia by Dr. Mac Culloch.}

DESCRIPTION.

Very nearly related to the preceding species, from which it differs chiefly in being much smaller, in having the underside of the body more thickly covered with hairs glittering like silver; in having the throat pale-red; the fifth joint of the antennæ longer than the fourth; the punctures of the elytra more numerous and scattered; the yellow stripe running nearer to the apex of the elytra, dilated at the base and not flexuose: the fore-breast also in the disk, the after-breast on each side, and the base of the thighs are obscurely red : the tibiæ are piceous.

$$
\text { * }+ \text { b. }
$$

\section{0. *eptura subargentata. Subargent Leptura.}

L. (subargentata) linearis, nigra, punctulatissima; corpore subtus, prothoracisque angulis posticis ex pube subargenteis : elytris apice rotundatis.

Subargent Leptura, linear, black, very minutely and thickly punctured, with the hody underneath, and the posterior angles of the prothorax rather silvery from down; elytra rounded at the apex.

Length of the body 4 lines.

Taken in Lat. $65^{\circ}$.

DESCRIPTION.

Body narrow, entirely black, very minutely and thickly punctured, underneath glittering, but less conspicuously with silver pile: antennæ shorter than the body, nearly filiform, fourth and fifth joints of equal length: prothorax perfectly bell-shaped, anteriorly not constricted, posterior angles acute, diverging and covered with silver pile: elytra rounded at the apex. 
L. (similis) linearis, nigra, punctulatissima, corpore subtus ex pube subargenteo; elytris apice rotundatis; antennis scapo fenori. busque rufis.

Similar Leptura, linear, black, very minutely and thickly punetured, body underneath, rather silvery from down; elytra rounded at the apex; seape of the antennse and thighs rufous.

Length of the body $3 \frac{1}{3}$ lines.

A single specimen taken in Lat. $65^{\circ}$.

DESCRIPTION.

This may possibly be the other sex of the preceding species which it resembles in every respect, except that the antenix are rather longer, the scape or first joint, all but the base on the upper side, is rufous, as are likerise the thighs and four anterior tibix; the posterior thighs are however black at the apex.

12. * Leptura loxgicorsis. Lomg-horned Leptura.

I. (longicornis) nigra, clongata; elytris grosse punetatis, vitta pedibusque basi, testoceis; antennis mediocribus.

Long-borned Leptura, black, elongated, stripe of the grossly punetured elytra, and base of the legs, testaceous; antennxe as long as the body.

Length of the body 5 lines.

A single specimen taken in Lat. $6.5^{\circ}$.

\section{DESCRIPTION.}

At first sight this species a good deal resembles $L$. semivittata and gulosa of the former section, but its eyes are entire, and its antenne much slenderer and of a different type, more nearly resembling those of $L$. argentata and similis. Body black, minutely punctured, downy, especially underneath, with silvery hairs. Head minutely, thickly, and confluently punctured; labrum and base of the mandibles rufous; last joint of the palpi securiform; antenna very slender nearly as long as the body; scape incrassated, rufous, black at the base: prothorax a little constricted anteriorly, very thickly punctured with a longitudinal dorsal impunetured line or channel: scutellum longitudinally concave, rounded at the apex; elytra nearly linear, grossly punctured, glossy, nearly black, with a pale stripe extending from the middle of the base to near the apex, and gradually approaching the suture; apex subtruncated: legs rufous at the base. 


\section{3. * Leptura Proteus. Proteus Leptura.}

L. (Proteus) nigra, subpubescens, nitidiuscula; oculis integris subauratis; antennis elytris pedibusque colore variantibus ; prothorace canaliculato postice bigibbere.

Protens Leptura, black, subpubescent, rather glossy; eyes entire, inclining to a golden lustre ; antennæ, elytra, and legs varying in colour; prothorax channelled, posteriorly with a gibbosity on each side.

Length of the body $3 \frac{1}{4}-5 \frac{1}{2}$ lines.

Taken abundantly in Lat. $54^{\circ}$. and $65^{\circ}$.

DESCRIPTION.

Body narrow, black, punctured, somewhat glossy, rather hairy, especially underneath, with decumbent hairs, those on the elytra have somewhat of a golden lustre, the rest are silvery. Nose more grossly punctured than the rest of the head; vertex convex; eyes subovate, pale with a slight golden lustre; antennæ filiform, longer than the prothorax, obscurely rufous, with the four first joints black, fifth joint longer than the fourth : prothorax eampanulate, anteriorly eonstricted, posterior angles a little diverging; thinly punctured; channelled, the channel running between two dorsal gibbosities: scutellum triangular : elytra rather widest at the base, and punctured there more grossly next the suture; diverging and truncated at the apex: tibiæ piceous or rufo-piceous; four posterior thighs rufous at the base.

VARIETY B. In this variety only the base of the six last joints of the antenna is rufous; all the thighs are rufous at the base, and the tibix of a clearer red, but they are dusky at the apex; tarsi rufous at the base. Length of the body $3 \frac{3}{4}$ lines.

C. Elytra with a stripe at the base, tips and lateral margin rufous : antenmæ entirely black: legs as in variety $B$. Length of the body $4, \frac{3}{4}$ lines.

D. Elytra with a longitudinal rufous stripe dilated at the base and apex; bead of the lateral margin also rufous: antenna and legs nearly as in $B$, but the whole of the tarsi is obscurely rufous. Length of the body 3-4 lines.

E. Elytra rufous with the suture and a stripe near the margin abbreviated at both ends, dusky: antennæ as in $\mathrm{A}$; legs as in $\mathrm{B}$. Length of the body $4-5$ lines.

F. Elytra rufous, with a dusky suture; antennæ as in A; legs as in D.

G. Like F, but elytra luteous; antennæ all black. Length of the body 4 lines.

H. Like $\mathrm{F}$ and $\mathrm{G}$, but legs and antennæ black. Length of the body $3 \frac{3}{4}$ lines.

This speeies is the Ameriean representative of $L$. femorata of Paykull and Gyllenhal, which is not clearly synonymous with that of Fabricius and Olivier, it differs, without mentioning colour, in having much sloorter antennæ, and in being glossy. Mr. Marsham's L. femorala has reniform eyes, and therefore belongs to another section, it may be that of Olivier.

$L$. Proteus seems to vary ad infinitum in the colour of the elytra, antennæ, and legs, but as all the varieties agree in every respect except colour and size, and the elytra advanee so gradually from pale rufous to black, or viee versa, there ean be little doubt of the identity of the different varieties. 


\section{4. * Leptura roxgiceps. Long-headed Leptura.}

L. (longiccps) nigra, punctulata, ex pube alba subincana; capite elongato; prothorace canaliculato; elylris luridis litura antica, sutura, apiccque, nigris.

Long-headed Leptura, hack, minutely punctured, somewhat hoary from white down; head elongated; prothorax elannelled; elytra lurid with an anterior bloteh, the suture, and apex black.

Length of the body 4 lines.

Several specimens taken in Lat. $54^{\circ}$. and $65^{\circ}$.

\section{DESCRIPTION.}

Like the preceding species but shorter in proportion with a longer bead. Body black, punctured, hoary with rather silvery down: head as long or longer than the prothorax; eyes pale, subtriangular; antennæ with the second, third, and fourth joints slenderer than the rest: prothorax shaped as in L. Proteus, constricted before, depressed behind, but without diverging angles, channelled but with no gibbosity on each side the channel: elytra nearly linear, very thickly punctured, dirty-yellow, with a dusky lateral blotch extending from the base beyond the middle of the elytrum, suture and subtruneated apex black; down yellowish.

Having now described all the Capricorn beetles and other Longicomia of Latreille taken in the Expedition, and being arrived at a spot whence there is a direet path to his Eupoda, I shall again retrace my steps, and call back the reader's attention to the last family of Mr. W. S. Mae Leay's Rectocera, the Passalida, from which, as was before observed, ${ }^{2}$ we may get an approach, by the Scolytida, \&c. to the great tribe of Rhynchophorous beetles, or those the anterior part of whose head terminates in a rostrum or snout.

A most remarkable insect, taken by Edward Bennett, Esq. in Choco, in Colombia, and a specimen of which may also be seen in the collection of the British Museum, may be here noticed, as supplying the first stage in the route now indicated. Its general figure is that of a Passalus, only more convex and cylindrical; it has the same deseription of mandibles but rather straighter; a similar upper-lip; the vertex is crowned with an incurved horn as in Passalus cormutus, \&c.; the 
furrows of the elytra are similar and crenated; and between the claws, as in the thalerophagous Lamellicom Beetles, and some of the saprophagous is a plantula or little spurious joint, but instead of a single pseudonychium or bristle, it is furnished with two on each side. ${ }^{3}$ All these circumstances prove something more than an analogical relation between this genus and Passalus, and that they may be placed near to each other in the scale of affinities, with no very wide interval between them. Phrenapates differs from the last-mentioned genus, chiefly in its tongue, the lobe of its maxilla, in its antennæ without a lamellated or pectinated knob; in having all the tibiæ armed with teeth, and in its heteromerous tarsi.

Having thus, as it should seem, discovered a link that may be connected with the Passalide, by the intervention probably of some intermediate genus, ${ }^{4}$ we are next to look for some group, leading towards the Rhynchophorous beetles, that will approach it on the other side. Fabricius placed Sinodendrum amongst the Bostri-

${ }^{3}$ Introd. to Ent. iii, 385, 691. In the genuine Dynastide the Plantula is very conspicnous, but instead of Pseudonyclia it terminates in a pencil of stiffish hairs.

I shall here give the characters of the genus alluded to in the text.

* Genus Phrenapates. Kirb.

Labrum transverse, submembranous, subemarginate, bairy, especially at the apex.

Labium nearly square, above longitudinally lacunose; at the apex emarginate in the middle with a sinus on each side.

Tongue horny, linear; dilated at the base, rounded at the apex, above convex.

Mandibles protended, robust, three-sided, widest at the base and excavated, toothed at the apex, and internally.

Maxilla one-lobed; lobe narrow, acnte, fringed with hair on the inner side.

Maxillary palpi four-jointed, filiform, the three first joints subclavated, the third shorter than the rest, last joint cylindrical.

Labial palpi three-jointed, filiform, two first joints subclavated, the third straight internally; curving externally, the first joint longer than the rest.

Mentum three-lobed, intermediate lobe much shorter than the lateral ones, truncated.

Antennce robust, eleven-jointed, joints somewhat spherical, the three last larger than the rest, so as to form an oblong knob.

Body subcylindrical, naked. Head transverse, scarcely narrower than the prothorax: eyes small, prominent, subhemispherical: trunk isthmiated: prothorax very slightly channelled, anteriorly and posteriorly subsinuated on each side; prosternum dilated at the base; at the apex recurved between the arms ; mesosternum an obtuse mucro ; metasternum a rounded lobe: legs, posterior pairs distant; thighs subcompressed linear; tibie armed with spiny teeth, with a pair of moveable spurs and a pair of fixed teeth at the apex; four anterior tarsi five-jointed, with the four first joints very short, the last elongated and clavate; posterior four-jointed with the first joint rather long, the two next short, the claw-joint as in the other legs; claws single incurved; between the claws is a spurious joint furnished at the end with two pairs of bristles: scutellum triangular; elytra slightly furrowed, furrows crenate.

There is a Sierra Leone insect taken by Afzelius, and described by Gyllenlal,** under the name of Passandra sexstriata, which comes near Plrenapates, but the labium, tongue, and antennæ differ.

P. BENNETTIr, nigra, glabra, nitida : capite tricorni, cornu intermedio incurvo, apice subemarginato, lateralibus obliquis truncatis. Length of the body, mandibles included, 1 inch 2 lines. 'Two or three specimens taken by Edward Bennett, Esq. in Choco in Colombia.

The mandihles in this species are incurved at the apex, and armed with three sharpish teeth, the intermediate one being the longest; on the innerside are two short obtuse ones, of which the posterior one is the smallest.

4 Sinodendrum cylindricum appears an intermcdiate insect agreeing in many characters with Phrenapates. Its antennæ exhibit the knob of those of the Lucanide.

* Sclı̈n. Syn. iii, append. 146, 200, t. vi, f. 3. 
chide, to which Mr. W. S. Mac Leay acknowledges it exhibits an affinity worthy of further investigation, ${ }^{5}$ it exhibits likewise characters that connect it with the Lamellicorns, and Phrenapotes is similarly circumstanced. There are several such characters that appear occasionally in all these tribes, thus lamellated antenne anc fonnd in Phloiotribus and Sinodendrum, as well as in the Lamellicorns; the spurions joint between the claws of the tarsi is found in Bostrichus, as well as in Phrenupates and the tribe just naned; all the tibia are armed with spiny tecth in Sinodendrem, Phrenapates, and some Bostrichi; the head also is armed with a horn not only in the two first, but in some species, of the last of these genera.

Giving dne weight to all these circumstances, I think it may be fairly deduced from them, that the Passalide by Phrenapates and Sinodendrum lead oft to the Bostrichide, which are generally acknowledged to lead in their turn to the Rhynchophorous beetles. Having cleared, as I hope, this point, I shall now proceel to the description of the insects of the two latter tribes, taken in the Expedition.

iv. XYlotrypa. Kirb.

\section{Family ANOBIDE.}

Latreille has placed his Ptiniores, including the present funily, at a great distance from the other Lignivorous beetles, to which I agree with Mr. Stephens in thinking they properly belong; but I regard them as forming two funilies at least, Ptimide and Anobida. I hesitate, however, as to their place, for they seem to occasion a disruption of affinities, if placed between the Bostrichidere and Scolytider; I am therefore disposed to consider them as out of the direct line, and forming a branch from the former of these families. As there are only two species in the collection belonging to this family, I shall describe them in this place. 
XCIV. Genus ANOBIUM. Fab.

* Elytris striatis.

\section{1. * Anobium foventum. Excavated Anobium.}

A. (fovcatum) rufo-fuscum subtus dilutius, pubescens, subcylindricum; prothorace dorso elevato in medio foveato, utrinque unidentato.

Excavated Anobium, reddish brown, paler underneath, pubescent, subcylindrical; back of the prothorax elevated with an excavation in the middle; armed on each side with a tooth.

Length of the body 2 lines.

A pair taken in Lat. $65^{\circ}$.

DESCRIPTION.

This species very closely resembles $A$. striatum, of which it may be regarded as the American representative. It differs principally in having a rather large exeavation in the middle of the elevated back of the prothorax, the sides of which are armed with a triangular tooth or prominence.

The male is obscurely rufous, both above and below, the female is browner above.

$\mathrm{XCV}$. Genus CIS. Lat.

\section{Cis micans. (Fabricius.) Glittering Cis.}

Cis micans. Gyll. Ins. Suec. iii, 379, 2? De Jean Cal. 102. Steph. Illustr. Mandib. iii, 345, 4.

Anobium micans. Fab. Ent. Syst. i, 238, 13; Syst. Eleuth. i, 324, 14. Illig. Kaf. Preuss. i, 331, 7. Payk. Fr. Suec. $\mathrm{i}, 309$, 3. Herbst. Ins. v, 64, 10, $t$. xlvii, $f .11, \mathrm{k}$.

Ptinus villosulus. Marsh. Ent. Brit. i, 86, 14.

Length of the body 1 line.

Two specimens taken in the Expedition.

DESCRIPTION.

Body subeylindrical, black-brown, glossy, with numerous short upright pale rather glittering hairs; minutely but not very visibly punetured. Head rather flat and lacunose; antemne and legs testaceous. Prothorax anteriorly sinuated on each side with the middle lobe rounded and projecting a little over the head; sides slenderly margined; posterior angles rounded. Punetures of the elytra seem almost, but very indistinetly, arranged in rows.

I am not quite elear that this is Major Gyllenhal's $C$. micans. The clava of the antemne is of the same colour with the stalk, and the punctures of the elytra appear almost but not evidently arranged in rows, which leads to some suspicion that it may be the C. Kispidus of that author. It is however the Ptinus villosulus of Mr. Marsham: and I think the Anobium micans of Fabricius and Paykull. 


\section{Family SCOLYTID瓜 ${ }^{6}$}

XCVI. Genus TOMICUS. Lat.

\section{Tomicus PIxi. (Say.) Fir Tomicus.}

Bostriehus pini. Say. Journ. Acad. Phil. V. ii, $\mathbf{9 5 7}$, is.

- ${ }_{-}$typographus $\ldots . . .$. Melsh. Cat.

Length of the body $1 \frac{3}{4}-2$ lines.

Frequently taken in the Journey from New York to Cumberland-house, and also in Lat. $65^{\circ}$. Mr. Say says it is very destructive to many species of the genus Pimus.

\section{DESCRIPTION.}

Body cylindrical, deep chestnut, glossy, hairy underneath. Head above with scattered granules; nose fringed with yellowish hairs; antennæ testaceous: prothorax rather oblong, angles rounded, anteriorly granulated with minute elevations, posteriorly punctured with seattered punctures, hairy next the head and on the sides: elytra hairy on the side, with five rows of transverse punctures next the suture, which reach only to the truncated part; punctures of the side and apex scattered; apex truncated obliquely and excavated, with the external edge of the excavation armed with four denticles, of which the second and third are the largest: legs pale chestnut; tarsi testaceous.

In the other sex? the elytra are entire and unarmed, and the dorsal rows of punctures on the disk of the elytra are more numerous.

VARIETy B. Eintirely rufous, or pale-chestnut.

XCVII. * Genus APATE. Fab.

Antenna with a large rather ovate, hairy, solid compressed knob; with an elongate, clubbed scape; subglobose-pedicel; stalk with four or five indistinct joints. ${ }^{7}$

Eyes bipartite, immersed, with the lobes connected by a series of lenses. ${ }^{8}$

Front in one sex excavated into a concavity, in the other plane.

- I consider those Xylotrypa as forming this family which have capitate antennæ; those in which they terminate in an elongated knob of three joints, as Bostrichus, \&c. I denominate Bostrichida. 
Prothorax short, sulglobose, anteriorly elevated and rough with points.

Elytra substriated, unarmed at the tip in both sexes.

Geoffroy having long since separated two Xylophagous genera from Dermestes Linn. under the names of Bostrichus and Scolytus, ${ }^{9}$ I follow Latreille in adopting his nomenclature in preference to that of Fabrieius and Herbst; the first naming the Bostrichus of Geoffroy Apate, and his Scolyttes, Hylesinus ; and the last distinguishing the latter genus by the uneouth appellation of Ekkoptogaster.

I have here restricted the name of Apate to those Xylotrypa which agree in their charaeters with Apate limbata Fab. (Dermestes domesticus Linn.) which I regard as the type of the genus.

It appears intermediate between Bostrichus Geoff. and Tomicus Latr. From the former it borrows its subglobose prothorax, rough anteriorly with sharp points or dentieles, and from the latter its antenne terminating in a solid compressed knob. ${ }^{1}$ It differs from both in its bipartite eyes connected only by a few lenses, and by the eoneave forehead of one sex.

\section{Apate bivittata. Two-striped Apate.}

A. (bivittrta) picea; prothorace rufescenti, postice rugulis transversis, antice denticulis, scabro; elytris vittis duabus apice conniventibus pedibusque luteis.

Two-striped Apate, piceous; prothorax reddish, posteriorly rough with transverse wrinklets, anteriorly with denticles; elytra with two luteous stripes united at the tip; legs luteous.

$$
\text { PLATE VIII, FIG, } 5 .
$$

Length of the body $1 \frac{3}{1}$ line.

\section{A pair taken in the Expedition.}

\section{DESCRIPTION.}

Very near $A$. domestica (A. limbata $\mathrm{F}$.) but distinet. Body piceous or nigro-piceous, cylindrieal; underneath with some seattered pale hairs. Head rough with minute elevations or granules; nose terminating in a transverse ridge; antennæ testaceous with a very large knob: prothorax subglobose, reddish, rough behind with numerous transverse rugosities; before with sharp points or denticles: elytra with several rows of punetures, and two luteous stripes which unite at the apex of the elytrum; or perbaps it might be better to say, luteous, with two piceous stripes, one of the disk and the other of the side, but not reacbing the apex: anus and legs testaceous.

In the other sex the front, or rather face, is hollowed out into a concavity; the prothorax is black anteriorly, and less rough from rugosities and points. ${ }^{2}$

9 Geoff. Ins. i, 301, 309, comp. Linn. Fn. Suec. 416-421.

1 In Tomicus typographus, under a powerful lens, the knob appears annulated, but in the smaller species this character is scarcely to be detected.

2 Plate VIII, Fig. 5, a. 
A. (rufitarsis) nigra cyllindrica; prothoracis scabri basi, antennis, tarsis, elyerisque rufis : his humcris nigris.

Red-footed Apate, black, cylindrical ; base of the rough prothorax, antennæ, tarsi, and elytra, rufous; the latter with black shoulders.

Length of the body $1 \frac{3}{3}$ line.

\section{'Two specinens taken in the Expedition.}

\section{DESCRIPTION.}

Body cylindrical, black, hairy underneath. Head hairy; face concave; antennæ pale testaceous: prothorax rufous posteriorly, granulated especially anteriorly; elytra punctured in rows, rufous, with a black lutumeral blotch: tarsi rufous.

The face of the other sex is probably plane; and the prothorax with more prominent points and asperities.

xxii. * Subgenus Lrprsosus. Kirb.

Prothorax anteriorly narrower, subconstricted, not armed with elevated points or denticles.

Elytra inflexed at the base, covered with minute depressed hairs, resembling little scales.

This subgenus agrees with a genuine Apate in its eyes, antennæ, legs, \&c. but the prothorax is of a different shape, never asperated with rugosities, points, or denticles, and like Cis, the body, particularly the elytra, is covered witlı scale-like hairs. This little group, if placed between Tomicus and Apate, scems rather to interrupt the scries of Xyloptrypa with an elevated and asperated prothorax; it may perhaps be best regarled as branching off from the latter in another direction? 1. * Apate (Lepisomus) rufipexsis. Red-winged A. Lepisomus.

A. I. (rufipennis) nigra, punclulata, fronte bituberculata, antice transverse depressa, prothorace carinato; orc, anlennis, elytris, pedilusque, rufescentibus.

Red-winged A. Lepisomus, black, minutely punctured; front bituberculatc, anteriorly with a transierse depression; prothorax ridged; mouth, antennx, elytra, and legs, rufescent.

PLATE VIII, FIG. ?.

Length of the body $1 \frac{1}{4}$ line.

'l'wo specimens taken in Lat. $65^{\circ}$. 


\section{DESCRIPTION.}

Body black, minutely punctured, hairs white, decumbent; those of the prothorax and elytra looking like minute scales. Head with a pair of minutc tubercles, not easily discovered, in the space between the eyes, anteriorly transversely impressed; mouth and antennæ pale rufous : prothorax very thickly and minutely punctured, with a rather obsolete longitudinal dorsal ridge: elytra dull-red, with several rows of larger punctures, the interstices of which are very minutely and thickly punctured, at the base rough with minute elevations: legs rufous.

\section{2. * Apate (Lepisomus) nigriceps. Black-headed A. Lepisomus.}

A. L. (nigriceps) rufus, punctulatissimus ; capite nigro, unituberculalo, naso impresso.

Black-headed A. Lepisomus, rufous, minutely and thickly punctured; head black, with a frontal tubercle; nose imprcssed.

Length of the body 1 line.

A single specimen taken in Lat. $65^{\circ}$.

DESCRIPTION.

Smaller than the preceding. Body rufous, minutely and thickly punctured. Head black, with a very minute tubercle between the eyes; nose impressed; antennx and underside of the head pale rufous : elytra sculptured as in the preceding species, but the rows of punctures are less conspicuous.

\section{3. * Apate (Lepisomus) breviconnis. Short-horned A. Lepisomus.}

A. L. (brevicornis) nigra punctulatissima, piloso-incana; antennis brevissimis pedibusque rufis.

Short-horned A. Lepisomus, black, very minutely and thickly punctured, hoary from hairs; antennæ very short, with the legs rufous.

Length of the body 1 line.

A single specimen taken in Lat. $65^{\circ}$.

DESCRIPTION.

Body black, covered with hoary hairs, above resembling scales. Antennæ very short with a small knob, rufous: front without a tuberclc, nosc not impressed; elytra not striated. This species secms to indicate another section of the genus. 
XeVIII. Genus HYLURGUS. Lat.

$(261)$

1. Hylurgus rufipensis. Red-winged Hylurgus.

H. (mfipennis) niger, pilosus, subnitidus; prothorace subcarinato; elytris rufis, sulcatis, sulcis punetatis, interstitiis dorsalibus scabris.

Red-winged Hylurgus, black, lairy, rather glossy; prothorax with an obsolete ridge; elytra rufous, furrowed, furrows punctured, with the dorsal interstiees rough.

Length of the body 3 lines.

Many specinens taken in the Journey from New York to Cumberland-house, and in Lat. $65^{\circ}$.

DESCRIPTION.

Body dusky, hairy, rather glossy, punctured. Head black, confluently punctured; vertex obsoletely channelled; antennx rufous : prothorax constricted anteriorly, and dusky-rufous; base with a double slight sinus, and dorsal ridge terminating in an impression at the angle between the sinuses: elytra rufous, furrowed; furrows punctured; interstices of the furrows rough with minute elevations, especially at the base, which is inflexed: tibix and tarsi dull-rufous; the former denticulated on one side.

N. B. In some specimens the elytra and anterior part of the prothorax are piceous or nearly black; in others the elytra are testaceous, and the prothorax piceous and paler anteriorly.

From Hylurgus the transit to the Rhynchophorous beetles by the lignivorous genera Cossomus, \&c. is very obvious, and has been admitted by Latreille and several modern Entomologists. In the present arrangement, indeed, I have reversed that of Latreille, because, for the reasons above stated, the passage is from one branch of the Rectocer' of Mac Leay by the Xylophaga to the Rhynchophora, which keeps together the great body of lignivorous Coleoptera. 


\title{
IX. RHYNCHOPHORA. Lat.
}

i. Gonatocera. Schün.

I. Longirostres. Linu.

\section{Family CALANDRID王. Calandridans.}

XCIX. Genus CALANDRA. Clair.

\section{Calandra pertinax. (Olivier.) Pertinaceous Calandra.}

\author{
Calandra pertinax. Oliv. Ent. v, No. $83,90,24, t$. xxviii, $f .417$.
}

Length of the body 7 lines.

Taken in Canada by Dr. Bigsby.

DESCRIPTION.

Body obversely pear-shaped, black, naked. Head immersed in the prothorax, smootlı; rostrum rather shorter than the prothorax, compressed, impunctured, channelled above at the base and tumid; antennæ a little longer than the rostrum, scape as long as the rest of the antennx, knob pear-shaped: eyes immersed, lateral, subovate, not meeting below: prothorax oblong, rather narrowest anteriorly, tricostate, the two lateral costæ sending a branch towards the base; four depressed broad punctured dull-red stripes occupy the intervals between the elevated parts; sides a little elevated and punctured; the punctures of the stripes and sides are whitish; scutellum an isosceles triangle, excavated at the base: elytra oblong, very slightly furrowed with whitish punctures in the furrows; suture, and alternate interstices, elevated; the others or depressed ones dull-red : body underneath with scattered whitish punctures varying in size: postpectus and tarsi chestnut.

\section{Family HYLOBID无. Hylobidans.}

C. Genus HYLOBIUS. Germ.

\section{Hylobius confusus. Confused Mylobius.}

H. (confusus) nigro-piceus, piloso-incanus, rostro crassiasculo sub.breviori; prothorace confluenter punctato; dorso rugoso; elytris puncto-striatis, pilis albidis confuse maculatis.

Confused Hylobius, nigro-piceous, boary from bairs; rostrum rather thick and short: prothorax confluently punctured, wrinkled in the back : elytla with punctures in rows, confusedly mottled with whitish hairs.

Lengtb of the body $4 \frac{1}{4}$ lines.

Taken in Canada by Dr. Bigsby, also in Massachusets by Mr. Drake. 


\section{DESCRIPTION.}

Body oblong, of a dark pitch-colour, hoary from decumbent hairs, confluently more or less punctured. Rostrum thickish and rather shorter than the prothorax; thickly and confluently punctured: prothorax with a dorsal levigated line not reaching the base; disk witl numerous confluent irregular excavations or wrinkles; sides confluently punctured : elytra with ten rows of olslong deep punctures, the interstices of which are confluently punctured, mottled confusedly, except at the base, with whitish hairs: thighs armed with a short tooth; tibix, as in the other species of the genus, armed at the apex with an inflexed stout spine or claw: tarsal claws recldish.

N. 13. In a natural arrangement Pissodes aught to be near Hylobites.

\section{Family LEPYRIDÆ. Lepyridans.}

Cl. Genus LEPYRUS. Germ.

\section{Leprrus Colox. (Limné, Germar.) Colon Lepyrus.}

Lepyrus Colon. Germ. Mag. ii, 340, 29. Schün. Curc. 168.

Curculio Colon. Linn. Mant. ii, 531. Hcrbst. Ins. vi, 89, 50, t. lxw, f. 6. Payk. Fn. Suec. iii, 223, 42. Panz. Fu。 Germ. xlii, 2; Encycl. Ins. v, 478, 28. Fuess. Arch. 68, t. xxiv, f. 1.

Fibynebrenus Colon. Fab. Syst. Eleuth. ii, 441, 15. Gyll. Ins. Succ. iii, 164, 84.

Liparus Colon. Oliv. Ins. v: $83,291,317, t$. vii, f. 76.

Curculio oblongus, fuscus, \&c. Geoff. Ins. i, $280,6$.

Length of the body 6 lines.

Several specimens taken in Lat. $65^{\circ}$. Taken also by Dr. Bigsby in Canada.

This species approaches very near to L. arcticus. which it is singular that Entomologists have placed in a different genus, some considering it as a Cleonis, ${ }^{3}$ others as a Iylobius, ${ }^{4}$ it exhibits however precisely the same characters as $L$. Colon, even to the markings of the prothorax, elytra, and abdomen.

\section{DESCRIPTION.}

Body black covered with decumbent gray hairs. Rostrum arched, thickish, a little longer than the prothorax, confluently punctured, having also a dorsal longitudinal ridge, tenminating between the eyes in a little narrow excavation: prothorax narrowest anteriorly, covered with minute elevations prodncing wrinkles, and having also a dorsal longitudinal ridge and two oblique, rather curved stripes formed of dense white hairs: the elytra have several rows of punctures, with the interstices minutely granulated; each clytrum has a discoidal white dot a little below the middle, and, in several specimens, there is also an indistinct one between it and the apex: on each side of the abdomen underneath, as in L. arcticus, are four yellowish ronnd spots formed of hairs. In some specimens the pubescence has a tawny huc, in others the indistinct spot is obliterated.

3 De Jean and Sturm.

1 Schünherr. The characters in which it differs from Hylobius are principally the carinated rostrum, the unarmed thighs, and the straight tibix, so that it is scarcely more than a subgenus! 


$$
\text { 2. * Lepyrus gemellus. Twin-streaked Lepyrus. }
$$

L. (gemellus) ater albido-pilosts, rostro, prothoraceque albido bivittato, carinatis; elytris striis gemellis pluribus piloso-albis. Twin-streaked L. gemellus, very black, covered with white hairs, rostrum, and prothorax two-striped with white, ridged: elytra with several pairs of laairy white longitudinal streaks.

PLATE V, FIG. 7 .

Length of the body $7 \frac{1}{4}$ lines.

A single specimen taken in Lat. $65^{\circ}$.

DESCRIPTION.

Body very black, covered more or less witls decumbent white hairs, and also with minute tubercles. Rostrum as in L. Colon : prothorax ridged, confluently tuberculated, minutely punctured between the tubercles, marked on each side with an oblique stripe composed of white hairs: elytra confluently tuberculated, with five pairs of longitudinal streaks, composed of white hairs, converging towards the apex: the first and fifth including the rest.

2. Brevirostres. Linn.

\section{Family CLEONID_E. Cleonidans.}

CII. Genus CLEONIS. Meg.

In the Introduction to Entomology, willing to retain the ancient name Curculio, to indicate one of the modern genera into whieh the immense tribe of Rlyynchophora is divisible, we had considered Linné's Curculio nebulosus, belonging to the present genus, as the type of it, but viewing the matter more attentively, it strikes me that the only group entitled to be distinguished by that ancient name, is the Curculio of Pliny and the Romans, called by us the weevil, and by the French Calendre, which Clairville, latinizing the word, has made Calendra. ${ }^{5}$ The species above described as a Calandra belongs to a different group from Curculio granurius, Ory $\approx$ e, Zew, \&c. distinguished by its superior size and its triangular and very distinct scntellum. I wonld therefore propose calling this and its congeners, Calandira, and the granivorous ones, above noticed, Curculio.

${ }_{5}^{5}$ In his plate it is written Calundra, which Fabricius has adopted. Clair. Ent. Helvet. i, 62, $t$. ii. 


\section{1. * Cleosis vitratus. Striped Cleomis.}

C. (viltatus) linearis, piloso-intanus; rostro subcarinato; prothorace elytrisque vittis tribus nigricantibus.

Striped Cleonis, linear, hoary from pile; rostrum obsoletely ridged; prothorax and elytrib with three blackish stripes.

Length of the body $3 \frac{1}{2}-5$ lines.

\section{Several specinens taken in the Expedition.}

\section{DESCRIPTION.}

Body narrow, black, elothed with decumbent hoary pile. Head thickly eovered with hairs, but on each sicle from the eye to the insertion of the antemn, the hairs are less dense, which gives the appearance of a blackish stripe; rostrum thick, shorter than the prothorax, obsoletely ridged, punctured : prothorax obsoletely ridged, punctured with rather large scattered punctures, often concealed by the hairs, with three blackish stripes, produced as in the liead by the hairs being thinner: the elytra also have three similar stripes, and are punctured in rows: the abdomen underneath appears as if dotted with black from the same cause.

\section{Family PHYLLOBIDAE. Phyllobidans.}

\section{Genus IIACROPS. Kirb.}

Body oblong, winged. Rostrum shorter than the prothorax, subcylindrical, somewhat arched, having a dorsal longitudinal ridge; bed of the scape of the antennæ oblique reaching from near the apex of the nostrum to the middle of the eye; antemne apical, longer than the head, eleven-jointed; scape as long as the remainder of the antennæ, incrassated at the apex, reaching the eye; two next joints longer than the subsequent ones, obeonieal; the following four very short, top-shaped; the four last forming a subovate knob; cyes lateral, subimmersed, long, forming, in some measure, an isosceles triangle with the base rounded, and the vertex downwards: prothorax subglobose: antcpectus emarginate, sides obsoletely lobed: scutellum very minute, triangular; coleoptera oblong: thighs unarmed; tibix armed with a very minute incurved spine or spur; tarsi not dilated, penultimate joint bipartite.

At first sight the species of this little group would be set aside as belonging to Sitona Germer, with which they possess many characters in common; a eloser inspection, however, will satisfactorily prove that they belong to different genera. In the genus just named, the rostrum is shorter, thieker, and clannelled; the knob of the antennx eonsists only of three joints, the bed of the seape turns below the eye; the eye inself is round: the antepectus is not emarginate, or lobed: the tibix have no incurved spine.

I cannot find this genus in Schönherr. 


\section{Macrops maculicollis. Spotted-necked Macrops.}

M. (maculicollis) niger piloso-subincanus; prothorace obsolete carinato postice utrinque macula baseos alba; antennis caule, femoribus basi, tibiis tarsisque obscure rufis.

Spotted-necked Macrops, black, rather hoary from pile; prothorax obsoletely ridged, having on each side posteriorly a white spot; stalk of the antennæ, base of the thighs, and the tibiæ and tarsi obscurely rufous.

PLATE VIII, FIG. 4.

Length of the body 2 lines.

Two specimens taken in Lat. $65^{\circ}$.

DESCRIPTION.

Body black, rather hoary from decumbent hairs and scales. Rostrum very minutely punctured; ridge reaching from the base to the apex; stalk of the antennæ a dull-red : prothorax minutely and thickly punctured, obsoletely ridged, having the sides, especially at the base, covered with little white scales : elytra furrowed, furrows punctured: tibix, tarsi, and base of the thighs of a dull obscure red, posterior thighs on the inside more distinctly rufous.

\section{2. * Macrops vitticollis. Stripe-necked Macrops.}

M. (vitticollis) nigricans, squomulosus; rostro apice carinato; prothorace vittis tribus cinertis, laterallbus subundulatis; elytris cinereo-marmoratis : antennis caule, tibiis tarsisque, rufescentibus.

Stripe-necked Macrops, blackish, covered with minute scales; rostrum ridged at the apex; prothorax with three cinereous stripes, the lateral ones rather wavy; elytra mottled with cinereous: stalk of the antennx, and the tibix and tarsi rufescent.

Length of the body $2 \frac{1}{4}$ lines.

\section{A single specimen taken.}

\section{DESCRIPTION.}

Body covered with brownish-black scales. Rostrum ridged at the tip, the rest covered with scales, which perhaps conceal the remainder of the ridge; stalk of the antennæ rufous : prothorax with three narrow pale stripes, the lateral ones a little waved: scutellum pale; elytra slightly furrowed; furrows minutely punctured; mottled with pale : tibiæ and tarsi, the former obscurely, rufous. 
CIV. "Genus LEPIDOPHORUS. Kirb.

Body corered with scales. Antemne longer than the head, eleven-jointed; scape as long as the remainder of the antennx, reaching to the eye, growing gradually thicker towards the apex; pedicel as long as the two following joints, obconical; the remaining joints of the stalk rather top-shaped; knob three-jointed, ovate, acute; rostrum shorter than the prothorax, thick, subcylindrical, straight; bed of the scape of the antennæ very short, not reaching the eye; eyes subobtusangular, with the vertex downwards: prothorax rather longer than wide, barrel-shaped : elytra taken together oblongoval: scutellum punctiform: thighs clubbed, unarmed; tibix armed at the apex with a short incurved spine; penultimate joint of the tarsi bilobed.

This genus is extremely near to Barytomes Germar; in that, however, the third joint of the antennz is nearly as long as the second, the bed of the scape is less strongly marked, the eyes are nearly round, and the elytra at the apex form a ridge with each other. These genera appcar leading towards the Orthocerous Rhynchophora, the bed of the scape in them becoming shorter and almost evanescent.

(269) 1. * Lepidophorus liseaticoldis. Streali-neclied Lepidophorus.

L. (lineato-collis) niger albido squamulosus et pilosus: prathorace vittis tribus angustis albis; antennis pedibusque rufescentibus; elytris apice seriatim setulosis.

Streak-necked Lepidophorus, black with whitish scales and pile: prothorax with three narrow white stripes; antennæe and legs reddish-brown: elytra at the apex with little bristles in rows.

Length of the body $2 \frac{1}{2}$ lines.

\section{Several specimens taken in Lat. $65^{\circ}$.}

\section{DESCIITPION.}

Body black, underneath hairy with little whitish round scales and hairs of the same colour intermixed. Head and rostrum behind the antennæ covered with similar scales; antennæ dusky-red: prothorax dusky, confluently punctured with three whitish longitudinal narrow indistinet stripes formed of minute scales: elytra mottled with whitish and dusky round scales; slightly furrowed with punctures in the furrows; at the apex, in the deflexed part, there is a series of white rigid minute bristles between each furrow: legs hairy, reddish brown; thighs darker. 


\title{
Family THYLACITIDE. Thylacitidans.
}

\author{
CV. Genus TRACHYPHLEUS. Germ.
}

1. * Trachyphleus melanothrix. Black-haired Trachyphlous.

T. (melanothrix) lutosus, ${ }^{7}$ fuscus, supra atra-setosus; prothorace subcanaliculata ; elytris subsulcatis, sulcis punctatis ; antennis tarsisque rufis.

Black-baired Tracbyphlœus, lutose, brown, above bristled with black bristles : protborax slightly channelled; elytra with sballow punctured furrows; antennæ and tarsi rufous.

Length of the body $2 \frac{3}{4}$ lines.

A single specimen taken in Lat. $65^{\circ}$.

DESCRIPTION.

Body really black, but quite covered with a brown powdery substance, resembling mud or dirt. Head impressed between the eyes; rostrum longer than the head, and nearly as wide, emarginate and hairy at the end; antennæ rufous, scape covered with brown powder: prothorax transverse, obsoletely channelled, with several short rigid black bristles on each side of the channel arranged nearly in rows: elytra obsoletely furrowed with slight punctures in the furrows, and between each furrow is a row of longer rigid black truncated bristles; a few whitc ones are discernible at the apex: legs bristly, with white bristles, rufous, but the thighs are covered with powdery scales.

We may leave the Gonatocerous group, or circle, by an insect which exhibiting all the other characters of Schönherr's legion of Brachyrhynchi, belongs to the Orthocerous division of that author, or Rhynchophora with straight unbroken antennæ, but there seem to be several links wanting between it and the Brachyceride. Rhinaria ${ }^{8}$ in which the antennæ, though the scape is very short, may be termed subfracte, since that joint forms a very obtuse angle with the rest of the antennæ, would intervene between the other Gonatocera, and the insect here alluded to. 


\section{Family PACHYRHINCHIDE.}

CVI. "Genus PACHYRHYNCHUS. Kirb.

Jabrum subemarginate, subdistinct.

Mandibles armed with two teeth at the apex.

Labittm nearly square.

Palpi conical.

Antenna short, inserted in a roundish lateral eavity near the apex of the rostrum, eleven-jointed: scape short, as long as the third joint, somewhat incrassated at the apex; pedicel obconical, as long as the fourth joint; third joint obconical elongated; the following five joints growing gradually shorter and wider; knob ovate acute.

Body oblong pear-shaped. Rostrum almost as wide as the head, subcylindrical, a little wider at the tip, ridged between the eyes and antennæ, an angular impression between the former; eyes round, prominent: prothoras subcylindrical, rather narrowest anteriorly : antepectus not emarginate nor lobed: eoleoptera oblong, depressed at the apex: thighs clubbed, unarmed; tibiæ unarmed; penultimate joint of the tarsi bipartite.

\section{1. * Pachrohychus Schönherri. Schönherr's Pachyrhyuchus.}

$P$. (Schönherri) piloso-incanus : prothorace obsolete albido trivittato, scutello albo: elytris seriebus quatuor purctorum nigrorum. Schönherr's Pachyrhynchus, hoary from pile : prothorax with three faint whitish stripes; scutellum white: elytra with four rows of black dots.

Length of the body 5-7 lines.

Taken in Canadla by Dr. Bigsby. Also in Georgia? by Mr. Abbott.

DESCRIPTION.

Body thickly covered, especially underneath, with hoary pile. Antennæ shorter than the head; eyes brown: prothorax with three faint whiter stripes: scutellum white: elytra with nine rows of punctures, and at the base of the lateral margin is a portion of a tenth row, between the second and third; in the sixth, seventh, eighth, and ninth rows the pile is thicker thain in other parts of the elytrum, so as to form three white stripes, on these stripes there are also four rows of distant black dots on each elytrum. 
ii. Orthocera. Schün.

\title{
Family ATTELABIDÆ. Attelabidans.
}

CVII. Genus ATtELABUS. Linn.

\author{
1. * Attelabus similis. Similar Attelabus.
}

A. (similis) ater, nitidus; occipite, prothorace, scutello, elytrisque rubris; his puncto-striatis; striarum interstitiis lavibus; capite postice transversim, et inter oculos longitudinaliter, impressum.

Similar Attelabus, very black, glossy: occiput, prothorax, scutellum, and elytra red : the latter punctured in rows with impunctured interstices; bead behind transversely, and between the eyes longitudinally, impressed.

Length of the body $2 \frac{1}{2}$ lines.

Taken in Canada by Dr. Bigsby.

\section{DESCRIPTION.}

This species is nearly the transcript of $A$. curculionoides, for which $I$ at first mistook it, but a closer inspection convinced me it was distinct. They agree in being black, glossy, and naked; in having a red prothorax and elytra, the latter with several rows of punctures; in having the head and rostrum more or less punctured, with curved impressed lines on each side just above the eyes, in the disk of the front; the prothorax also in both is minutely punctured, and the cubit arched and internally serrulated. They differ, however, in several respects. In A. curculionoides the head is wider in proportion, the occiput black, levigated, with a central impression; the curved lines of the front not distinctly punctured; the stalk of the antennæ rufous; the prothorax at the base is streaked with transverse linear impressions; the scutellum is nearly black, and the interstices of the rows of punctures of the elytra are irregularly punctured. In $A$. similis the hinder part of the head which is punctured and wrinkled, and scutellum are rufous, a transverse impression divides the occiput from the front; the curved lines are distinctly punctured; in the front between the eyes is a wide channel; the antenna are piceous; the prothorax is not streaked at the base: and the elytra between the rows of punctures are levigated.

\section{Attelabus bipustulatus. (Fabricius.) Two-pustled Attelabus.}

Attelabus bipustulatus. Fab. Ent. Syst. ii, 385, 3; Syst. Elenth, ii, 418, 5. Herbst. Ins. vii, t. 105, f. 7. Oliv. Ent. $\mathrm{v}, 81,10,11, t . \mathrm{i}, f .11$.

ater, elytris macula baseos rufa. Encycl. Ins. iv, 278, 3.

Length of the body 2 lines.

Taken in Canada, near Lake St. Clair, by Dr. Bigsby. 


\section{DESCRIPTION.}

In sculpture this species for the most part agrees with $A$. curculionoides, exeept that there is an impression between the eyes, and a pair on the disk of the prothorax. 'The whole of the body is very black, except the shoulders of the elytra, which are covered by a large oblong red spot, the anterior thighs are armed with a minute tooth: the disk of the coleoptera, or elytra taken together, towards the base is depressed; and the scutellum is olversely triangular, the vertex of the triangle pointing towarls the liead.

CVIII. * Genus APOTOMUS. Kirb.

Antennce inserted in the side of the rostrum near its base, eleven-jointed; short scape and pedicel nearly equal in leugth, incrassated; six following joints rery minute, increasing gradually in width; the three last joints large, distinct, forming an oblong knob: rostrum about the length of the head: prothorax obsoletcly lobed behind : scutellum punctiform : elytra furrowed, abbreviated : podex uncovered: four posterior legs distant; anterior tibiæ straight not scrrulated.

This genus, the type of which is Attelabus ovatus Fabr. and Oliv. scems intermediate between Attelabus and Rhynchites. It differs from the former principally in the articulation of the stalk of the antennx, the joints of which, in Apotomus, are comparatively much more minute and shorter; in the anterior tibix which are shorter, straighter, and not serrulated; in its shorter head, and less dilated tarsi. From Rhynchites it differs in the shortness of its rostrum with the antenna inserted at the base instead of the middle, and having the breast of the male unarmed : from both it differs in the lobed prothorax; in the elytra being obliquely abbreviated internally both at the base and apex; in their furrowed surface; in its naked podex; and, which is a strong character, in having the four posterior legs distant from each other.

In its lobed prothorax, it agrees with Rhinobatus, Rhynocyllus, Eurhinus, Illiger, \&c.: it is worthy of observation, that in this latter genus and Centrinus, the four posterior legs are likewise distant; and that the males in Centrinus have an armed prothorax like Attelabus.

\section{Aротоmis ovatus. (Fabricius.) Ovate Apotomus.}

Attelabus ovatus. Fabr. Syst. Eleuth. ii, 426, 35. Oliv. Ent. v, 81, 11, 13, t. i, f. 13.

Lenglh of the body $1 \frac{1}{4}$ line.

Variety B taken by Dr. Bigshy near Lake St. Clair. 
DESCRIPTION.

Body very short, between pear-shaped and ovate, deep violet, naked, minutely punctured. 'Head black, rostrum levigated: prothorax somewhat lozenge-shaped, emarginate anteriorly, very thickly and confluently punctured, with a levigated discoidal longitudinal line: elytra furrowed, furrows punctured.

VARIETy B. Blue-green.

\title{
Family ANTHRIBIDE. Anthribidans.
}

\author{
CIX. Genus ANThribUS. Fab.
}

\section{Anthribus fasciatus. Banded Anthribus.}

\author{
Macrocephalus fasciatus. Öliv. Ent. iv, 80, 9, 9, t. i, f. 9 .
}

Length of the body 4 lines.

\section{Taken in Canada by Dr. Bigsby.}

\section{DESCRIPTION.}

Body black, covered more or less with brown decumbent short lairs. Rostrum angular, thickish, dilated at the tip, below the antennx covered thickly with snow-white decumbent pile; antennæ almost as long as the thorax, rufous, knob dusky-brown; front marked with two whitish dots, one adjoining each eye on their upper side : prothorax wrinkled with a transverse discoidal impression, and near the base with an elevated transverse ridge: elytra wrinkled with a discoidal tubercle near the base, near the apex adorned with an irregular angular band composed of snow-white decnmbent pile: abdomen whitish with a double indistinct series of black dots: tibix with a white ring.

VARIETY B. With the tubercles of the elytra less eonspicuous; the abdomen snowy-white; thighs variegated with white.

I have no memorandum whence I received this variety. It is smaller, and probably Ameriean.

There seems some approach in this genus to the Capricorn tribe, see Macrocephalus cinereus Oliv. Ent. t. i, $f .2$.

This species does not appear well to arrange under any of Schönherr's subgenera of Anthribus. 


\section{Fanily CLYTHRIDÆE. Clythridans.}

CX. Genus CHLAMYS. Knoch.

\section{Chlamys plicata. Plicute Chlamys.}

Chlamys plicata. Oliv. Ent. vi, 96, 876, 3, t. i, f. 3. Klug. Monogr. 114, 2.2.

tuberosa. Knocl. Nene. Beytr. i, 128, 1, t. iv, f. 42 ?

Clythra plicata. Fab. Suppl. iii, 10; Syst. Eleuth. ii, 33, 20. Coq. Illustr. Ic. iii, 129, t. xxix, f. 8.

Bruchus gibbosus. Fab. Ent. Syst. ii, 370, 8; Syst. Eleuth. ii, 397, 10. Linn. Syst. Nat. Gmel. iv, $1735,10$.

Length of the body 2 lines.

Taken in Canada by Dr. Bigsby. I have also received a specimen probably taken in New England by Professor Peck, from my friend the Rev. T. Brown, rector of Hemingston, Suffolk; and another from Massachusets from Dr. T. Harris, Jun.

DESCRIP'TION.

Body obscure, bronzed. Head impressed posteriorly between the eyes; rhinarium, antenna, and an elevated space adjoining the eyes anteriorly, rufous; nose indistinctly punctured: protliorax very finely and concentrically scored, with some scattered indistinct punctures; posteriorly considerably elevated: elevation bifid; belind this elevation the prothorax is producted and emarginate : scutellum obtriangular: elytra tuberculated with several acute, compressed tubercles, the anterior ones carinated; interstices with some scattered deep punctures: space between the four posterior legs punctured with large shallow punctures.

\section{PHYLlOPHAGa. Kirb.}

\section{i. Crelica. Latr.}

It appears to me tliat no very wide interval separates the Anthribide from the Cyclica of Latreille, the former tribe have lost the conical palpi, thus receding from one great character of the Rhynchophorous beetles; their maxilla is also different and distinctly bilobed, approaching more nearly to that of the Cyclica-many forms however still intervene between them. On the above account, I have transposed Latreille's two sections of Eupoda and Cyclica. 


\section{Family CRYPTOCEPHALIDA. Cryptocephalidans.}

CXI. Genus CRYPTOCEPHALUS. Fab.

(277) I Cryptocephalus pubescens. (Fabricius.) Pubescent Cryptocephalus.

Cryptocephalus pubescens. Fab. Gen. Ins. 220, 11, 12; Syst. Eleuth. ii, 43, 15. Oliv. Ent. vi, 96, 61, t. vi, f. 91. hirsutus. Linn. Syst. Nat. Gmel. iv, 1703, 22.

Length of the body $2 \frac{1}{4}$ lines.

Taken in Canada by Dr. Bigsby.

DESCRIPTION.

Body black with a very slight brassy tint, a little glossy, grossly and thickly punctured; downy more or less with cinerascent down: prothorax with a longitudinal levigated line, posteriorly with a double sinus: seutellum elevated towards the apex, perfectly smooth: elytra with a lateral lobe towards the base, shoulders with a tubercle.

\section{Cryptocephalus notatus. (Fabricius.) Marked Cryptocephalus.}

Cryptocephalus notatus. Fab. Mant. i, 83, 56 ; Syst. Eleuth. ii, 33, 76? Lin. Syst. Nat. Gmel. iv, 1708, 56 ?

Length of the body $2 \frac{3}{4}$ lines.

Taken in Canada by Dr. Bigsby.

DESCRIPTION.

Body black, naked, glossy. Nose with a bilobed reddish-yellow spot at the apex; front with a yellow curvilinear spot adjoining the eyes on their inner side; between the eyes behind is a pair of round impressions, and a longitudinal intermediate abbreviated channel; antenna mutilated in the specimen, but what remains of them is reddish-yellow: prothorax levigated, but sprinkled with very minute and slight punctures, visible only under a powerful magnifier; behind with a slight sinus on each side: scutellum levigated and elevated posteriorly: elytra deeply punctured with the punctures arranged in rows, the sixth row from the suture is interrupted, and in the interstices on each side of it are some irregular punctures, the intermediate rows do not reach the apex; a luteous band, abbreviated next the suture and growing gradually wider till it reaches the lateral margin, and an irregular spot at the apex of the same colour, distinguish the elytra.

Fabricius describes his $C$. notatus in so few words that it admits of some doubt. whether his insect is synonymous with Dr. Bigsby's here characterized. The spots at the apex can scarcely be denominated puncta, but as he occasionally designates a large spot by this term, and both insects are from North America, for the present it may be allowed to stand under the above name. 
CXII. Genus EUMOLPUS. Kilug.

This genus may be further resolved into two subgenera distinguished by the absence or presence of a lateral prothoracic margin. The former hairy, without much gloss, and approaching nearest to Ciyptocephalus, and the latter naked, extremely brilliant, and receling from that genus towards the Chrysomelide.

The first I shall denominate Adoms (Inglorious), the last Endorus (Glorious). $E$. Vitis may be regarded as the type of the former, and $E$. ignitus of the latter subgenus.

xxiii. * Subgenus Adoxus. Kirb.

Labritm subtransverse, entire.

Palpi (maxillary) with the two last joints much inerassated, the penultimate obeonical, and last conical or subovate.

Antennce with the pedicel as long as the third joint, the last joint apparently consisting of two joints.

Body not glossy, hairy. Nose with a sinus taken out: prothorax very convex and almost hemispherical, with the sides producted and emarginate.

In Endoxus the labrum is emarginate, the prothorax transverse, not so convex, sides margined and not producted; and the antenne have the pedicel, or second joint much shorter than the third, and the last joint wears less the appearance of articulation.

Eumolpus Vitis. Fab. Syst. Eleuth. i, 422, 20. Panz. Fu. Germ. Ixxxix, 12. Latr, Crust. Arach. et Ins. ii, 147. Oliv. Ent. vi, $96,911,28, \iota$, i, f. 9.

Cryptocepbalus Vitis. Fab. Syst. Ent. 108, 15; Ent. Syst. ii, 60, 36. Linn. Syst. Nat. Gmel, iv, 1704, 27. Oliv.

Enryel. Method. vi, 612. Ross. Fn. Etruse. i, 105, 252. Panz. Ent. Germ. i, 195, 13. Gocze. Eur. Fr. viii, 403, 3. Le Gribouri de la Vigne. Geoff. Ins. i, ㄴ3, … villosus. Sebneid. Mag. $219,33$.

Chrusomela villosula. Schrank. Enum. 95, 181.

Length of the body $2 \cdot-\frac{3}{1}$ lines.

Several taken in the Journey from New York, in Lat. $54^{\circ}$. and $65^{\circ}$. 


\section{DESCRIPTION.}

Body black, a little glossy, hairy with cinerascent hairs, minutely punctured. Palpi rufous, last joint black ; five first joints of the antennæ rufous, the rest black : elytra and tibiæ rufous.

Both Geoffroy and Fabricius complain of the ravages committed by this little species upon the vine in Europe, and probably it is equally destructive to those of America.

\section{Family CHRYSOMELID E. Chrysomelidans.}

'This family, even as it stands in Latreille's last work, (Crustace's, Arachnides, et Insectes) will admit of further subdivision, assuming for characters, the antennæ, palpi, eyes, and prosternum. If we take Chrysomela goettingensis for the type of the genuine Chrysomela, we may arrange under it all those of Latreille in which the punctures of the elytra are scattered or not arranged in rows.

CXIII. Genus CHRYSOMELA. Linn.

\section{Chrysonela Philadelphica. (Linné.) Philadelphian Chrysomela.}

Chrysomela Philadelphica. Linn. Syst. Nat. ii, 592, 44. De Geer Ins. v, 353, 6, t. xvi, f. 13. Fab. Syst. Ent. 103, 49 ; Syst. Eleuth. i, 444, 135 . Oliv. Ent. v, 91, 525, 33, t. ii, f. 22. Petiv. Gazoph. t. xxvi, $f .11$. decipiens. Web. Obs. Ent. i, 52, 1 ?

Length of the body $3 \frac{1}{2}-4-4 \frac{3}{4}$ lines.

The type and variety $\mathbf{C}$ taken in Canada by Dr. Bigsby. Variety B in Nova Scotia by Dr. Mac Culloch.

DESCRIPTION.

Body ablong, black-green, naked, glossy, convex, punctured witl scattered punctures. Palpi, antennæ, rhinarium, and legs rufous; labrum hairy: prothorax with the punctures at the sides morc numerous than those on the disk: elytra pallid, witl a longitudinal stripe at the suture with three diverging obsolete branches, and several irregular spots; one at the shoulders larger than the rest and as it were broken, or obtusangular, all of a dark green: the elytra are grossly punctured with scattered punctures, but next. the suture the punctures are disposed in two rows, the sutural one 
extending fiom the base to near the apex, where it becomes confluent with the second, both diverging towards the base and surrounding the upper branch of the sutural stripe; there is a fourth series of punctures at a little distance from the lateral margin, and the interstice between them is impunctured; cpipleura dark-grecn.

N.B. The two lower branches of the above stripe are surrounded by a common series of punctures.

VAriery 13. Smaller, green-bronzed, green spots of the elytra more numerous, epipleura pallid.

C. Sutural stripe with only ouse branch, the two lower ones forming separate spots;

epipleura pallid.

'This varying species may be known from the succeeding oncs by the green colour of its body; all the varieties are distinguished by the obtusangular spot at the shoulders of the elytra: the varying number of green spots on these organs is produced by the separation of some of the irregular ones into distinct ones, and the lower branches of the sutural stripe doing the same. Variety $\mathrm{C}$ comes nearest to that figured by De Geer and Olivier.

$(281)$

2. Chrysomela confinis. Neighbouring Chrysomela.

C. (confinis) anto-viridis, punctata; antennis, palpis, pedibusque ferrugineis ; elytris rufescentibus, murgine laterali, viltayue flexuosa discoidali pallidis, lineis insuper flexuosis, maculisque irregularibus, aneo-vividilus, elevatisque.

Feighbouring Chrysomela, bronzed-green, punctured; antennæ, palpi, and legs ferruginous; elytra rufescent with the lateral margin and a flexuose stripe of the disk pallid; sides with flexuose lines and irregular spots of bronzed.green and clevated.

Length of the body $4 \frac{1}{2}$ lines.

A single specimen taken in Nova Scotia by Capt. Hall.

- DESCRIPTION.

Nearly related to the preceding species. Body oblong, obscurely bronzed-green, grossly punctured. Palpi, antennæ, legs, and rhinarium ferruginous: punctures of the protlorax scattered in masses, with the interstices very minutely punctured: scutellum bronzed: elytra reddish with a discoidal flexuose irregular pale stripe dilated at the base and towards the apex; there are also two flexuose dark-grcen discoidal stripes in the disk, the exterior one ncarly reaching the base and the interior approaching nearer to the apex, between thesc towards the base is a single oblong green spot, and outside them are many irregular ones of the same colour; all these spots and stripes are convex and mostly circumscribed by punctures; there is a double series of punctures diverging towards the base; and an oblique abbreviated one between these and the scutellum, as in many Harpalide, \&c.; the interstice between the double series is green at the base. There is a lateral series of punctures also as in C. Philadelphica. 
C. (Bigsbyana) viridis, palpis, pedibus, antennisque rufis; prothorace antice et lateribus rufescentibus; elytris pallide rufescentibus, vitta suturali, macula magna fracta bilaba humerali, punctisque pluribus, nigris aut nigro-viridibus.

Bigsby's Chrysomela, green, palpi, antennæ, and legs rufous; anterior margin and sides of the prothorax, reddish ; elytra pale-red, with a sutural stripe, a humeral broken bilobed spot, and several dots hlack or dark-green.

Length of the body 4 lines.

A single female specimen taken in Canada by Dr. Bigsby.

\section{DESCRIPTION.}

Colour and sculpture of the body like those of the preceding species, from which $C$. Bigsbyana differs principally in having the sides and anterior margin of the prothorax reddish-yellow: the elytra are of the same colour, but the suture itself, especially at the base, a stripe parallel to it, a large humeral bilobed spot, the interior lobe of which is obtusangular or broken, and several irregular dots and spots on the elytra are black-green.

\section{Taken frequently in the Journey from New York to Cumberland-house.}

\section{DESCRIPTION.}

Body, head, antenma, and legs ferruginous. Prothorax pale-yellow, with two posterior triangular ferruginous spots with a dot of the same colour between them; the punctures of the prothorax are more numerous and smaller than in C. Philadelphica, \&c.; elytra yellowish-white; suture and a confluent stripe circumscribed with the double series of punctures, diverging towards the base of the elytra, ferruginous; surface covered with irregular greenish dots and short lines, as in the preceding species, a row of punctures marks the exterior side of the elytra, the interstice between it and the margin is immaculate and impunctured, the rest of the elytrum being thickly covered with scattered minute punctures. 


\section{5. *hrisomela clivicoldas. Hill-nected Chrysomela.}

C. (clivicollis) violacea; clytris rufis maculis tribus dipjormibus suturaque violaccis; femoribus anticis bidentutis ; prothoracis disco volle elevato.

Hill-neeked Chrysomela, violaceous; elytra red with three differently shaped spots, and lse suture violaceous; anteriol thighs bidentate; disk of the prothorax very mucl elevated.

Length of the body $4 \frac{2}{3}$ lines.

\section{A single specimen taken in Canada by Dr. Bigsby.}

\section{DESCRIPTION.}

Body between oblong and hemispherical, violet. Head punctured; labrum without punctures: prothorax elevated in the centre to an obtuse peak, from the summit of which descend several concentric channels which run nearly to the margin, the interstices of which are punctured: scutellum violet with a green tint: elytra reddish, punctured, punctures scattered with some tendency to arrange into rows; three large dark violet spots distinguish the elytra, the first upon the shoulders subtriangular with the vertex truncated, the second near the apex bilobed, the third at the base forming with that on the other elytrum a large cruciform spot; suture violet: anterior thighs armed with two stout teeth.

This singular species in its form and the markings of its elytra seems to make some approach to the Coccinellidre, but it exhibits all the characters of a genuine Chrysomela; should more species be found agreeing with it in the remarkable peak of the prothorax and tectin of the fore thighs, it might be regarded as forming a subgenus.

$$
\text { xxir. "Subgenus Puytodecta. Kirb. }
$$

Tibice armed near the apex with an external tooth.

Elytra punctured with the punctures arranged in rows.

(285) 6. Chrysonela (Phytolectu) rufipes. Red-legged C. Phytodectu.

Chrysomela rufipes. De Geer Ins. v, 295, 4, t. viii, f. 25. Payk. Fn. Surc. ii, 69, 2.2. Gyll. Ins. Suec. iii, 4S6, 629. 10-notata. Marsh. Ent. Brit. i, 175, 13.

iv, $3: 38,3$

10-punetata. Serib. Journ. 289, 182. Mart. Col. t. xvi, f. 40. Secph. Cat. 2222, 2276, 17; 1llustr. 1/undit.

La Curysomele rouge à points noirs. Geofir. Ins. i, 2.j8.

Lengtb of the body $2 \frac{3}{4}$ lines.

A single specimen taken in the Expedition. 
Chrysomela 10-punctata $\beta$. (Linn. Syst. Nat. ii, 590, 32) is by many authors referred to as synonymous with $C$. ruffipes De Geer, but it appears from the description of that variety in the first edition of the Fauna Suecica (p. 1354) that it had black legs, and therefore belongs to $C$. nigripes De Geer. By Linné's considering the black-legged species as his variety $\beta$, it seems not improbable that $\alpha$ had red legs.

\section{DESCRIPTION.}

The American differs a little from the British specimens. In the first place it is scarcely half the size, not only the mouth but the space before and between the eyes is rufous, only the vertex and occiput being black: the black spot of the prothorax, instead of consisting of two distinct spots connected only at their base, is only divided at its apex into two lobes, and the spots of the elytra, though similarly arranged, are less distinct: they agree in having the body underneath, except the rufous anus, black; and the legs rufous.

\section{CXIV. * Genus PHEDON. Meg.}

Labrum transverse, scarcely notched.

Palpi (maxillary) four-jointed; first joint minute; second longer than the rest incrassated at the apex; third as large, or larger than the fourth, triangular; fourth rather conical, truncated. Antennce scape incrassated; pedicel shorter than the following joints; third, fourth, and fifth longer and obconical; five next triangular, larger than the antecedent ones and terminated by an ovate acute joint.

Body oblong; eyes transverse, oblong; prothorax transverse; scutellum rounded at the apex; elytra rather soft, oblong, with punctures not arranged in rows.

N. B. This genus is principally distinguished from Chrysomela by the last joint of the palpi being smaller than the preceding one and of a different shapc. ${ }^{9}$

\section{Phemon Adonidis. Adonis-eating Phcedon.}

Chrysomela Adonidis. Pall. It. 463, 29. Fab. Spec. Ins. i, 117, 10; Syst. Eleuth. i, 431, 52. Herist. Arch. 56, 29, t. xxiii, f. 17. Panz. Ent. Germ. i, 158, 10; Fn. Germ. c, t. iv. Oliv. Ent. v, 91, 560, 90. Hoppe. Taschen. 1796, 175, 24. Scrib. Journ. 22, 2, and 27, 12. Schrank. Naturf. xxiv, 65, 12. Hübn. Naturf. xxiv, 38, 2. Linu. Syst. Nat. Gmel. iv, 1683, 140. Cartis. Brit. Ins. iii, t. exi. Steph. Illustr. Mandib. iv, 338, I. trilineata. Fab. Gen. Ins. Mant. 219, 6-7.

—_ dorsalis. Fab. Gen. Ins. Mant. 220,6-7. Shrank. Naturf. xxiv, 66, 13. Hübn. Nuturf. xxiv, 39, 3, t. ii, f. 2. Linn. Syst. Nat. Gmel. iv, 1683. 141 .

Length of the body $3-4$ lines.

Several speeimens taken in Lat. 54\%

${ }^{9}$ In Mr. Curtis's figure the palpi and maxille are those of the genuine Chrysomela, which, as he could not dissect the specimen in the British Muscum, he has evidently given instead of those of $P$. Adonidis. 


\section{DESCRITTION.}

Body black, punctured, sprinkled underneath with einereous hairs. Vertex rufous with an wecipital black spot: prothorax reddish-yellow, with a large discoidal black spot reaching from base to apex and constricted anteriorly; on each side also there is a round black dot: scutellum black, impunctured : elytra reddish-yellow, thickly punctured with scattered punctures; suture black except at the base; a black discoidal stripe or bloteh reaching neither to the base nor the apex, anteriorly obliquely truncated and postcriorly acute, also distinguishes these organs.

VARIETY B. With the discoidal stripe acute at each extremity and smaller.

C. With the discoidal stripe evanescent.

Mr. Stephens, in his Catalogue of British Insects, has placed this insect in his section of Chrysomela with securiform palpi, and elytra with punctures in rows. He was probably led to this by Mr. Curtis's figure, in which the palpi, for the reasons lately assigned, are securiform, and the punctures dispersed in rows, though Mr. Curtis describes the elytra as "somewhat irregularly punctured." In the American specimens, and Panzer's figure, there is not the least appearance of rorss.

Phædon Raphani. Steph. Illustr. Mandib. iv, 336, 33.

Chrysomela Raphani. Fab. Syst. Eleuth. i, 430, 47. Payk. Fn. Suec. ii, 62, 15. Herbst. Arch. 59, 42, t. xiii, f. 42. Linn. Syst. Nat. Gmel. iv, 1690, 201. Brahm. Ins. Kal. i, 68, 221. Gyll. Ins. Suec. iii, 472, 19. Steph. Cat. 221, 22971, 12.

rea. Fab. Want. i, 75, 106.

- viridula. De Geer Ins. v, 311, 19. Limn. Syst. Nat. Gmel. iv, 1688, 179.

- Polygoni, variety $\beta$. Linn. Fn. Suec. 5:0.

- Hypochæridis. Marsh. Ent. Brit. i, 184, 35.

Galleruca Raphani. Fab. Ent. Syst. ii, 19, 26. Panz. Ent. Germ. i, 172, 11.

Length of the body $2 \frac{1}{6}-2 \frac{3}{4}$ lines.

\section{Several taken in Lat. $54^{\circ}$.}

\section{DESCRIITION.}

Body oblong, punctured, glossy; underneath black with the disk a little bronzed, above green or green-gold. Head and prothorax minutely punctured ; five first joints of the antennx bronzed and glossy; the remainder cinereous and obscure : scutellnm impunctured, violet: elytra very thickly punctured, punctures not arranged in rows : parapleura confluently punctured : disk of the postpectus bronzed and transversely striated with very slightly impressed striolx.

In the female the abdomen, as in Ph. Polygoni, is often so distended with eggs as to make the elytra appear abbreviated.

VARIETY B. With the whole of the upper surface green, without any golden lustre. 


\section{3. Рhædon Polygoni. Knot-grass-eating Phodon.}

Phredon Polygoni. Steph. Illustr. Mandib. iv, 336, 12.

Chrysomela Polygoni. Linn. Fn. Succ. 520; Syst. Nat. ii, 589, 24. Fab. Syst. Ent. 100, 32; Syst. Eleuth. i, $439,102$. Marsl. Ent. Brit. i, 178, 19. Payk. Fn. Suec. ii, 61, 14. Gyll. Ins. Suer. iii, 474, 20. De Geer Ins. v, 322, 26. 'Thunb. Mus. Ups. v, 108, 38. Ross. Fn. Etrusc. Hellw. i, 87,209. Ced. Fn. Ingr. 188. Goeze Eur. Fn. viii, 372, 11. Müll Zool. Dan. Pr. 82, 894. Panz. Ent. Germ. i, 161, 29. Oliv. Ent. v, 91, 576, 114, $t$ iii, $f$. 36. Lai. Tyr. Ins. ii, 154, 13. Schrank. Erum. 77, 142. Vill. Ent. i, 125, 20; Fn. Frid. 8, $69 . \quad$ Schæff. Ic. t. 161, f. $4 . \quad$ H-r. Ins. 241, 118. Mart. Col.t. xiv, f: 2 . Don. Brit. Ins. t. xcvi, f. 1. Moll. Ent. Mag. ii, 41, 92. Steph. Cat. 221, 2270,11 .

Buprestis salicina. Scop. Carn. 199 ?

Le Criocere bleu a corcelet rouge. Geoffr. Ins. i, $242,4$.

Length of the body 2 lines.

\section{Taken in Nova Scotia by Dr. Mac Culloch and Capt. Hall.}

DESCRIPTION.

Body oblong-ovate, punctured, glossy, underneath black. Head deep blue, with an abbreviated clianuel in the vertex between the eyes; antennæ piceous, witl the five first joints rufous : prothorax convex, rufous : elytra deep blue, thickly punctured : legs rufous with piceous tarsi; anus rufous.

N. B. Pl. Raphani and Polygoni may perhaps form a subgenus.

\section{CXV. * Genus PHYLLODECTA. Kirb.}

Labrum transverse.

Palpi (maxillary) like those of Chrysomela.

Antenne growing gradually thicker to the apex, with the second and third joints equal in length and longer than all the others except the last, which is ovate.

Body oblong; eyes nearly round; elytra with rows of punctures.

This genus is distinguished from the other Clrysomelida by having the second and third joints of the antennæ of equal length.

\section{(289) 1. Phyllodecta Vitelline. (Linné.) Willow-eating Phyllodecta.}

Chrysomela Vitellinæ. Linn. Fn. Suec. 519; Syst. Nat. ii, 589, 23. Fab. Syst. Ent. 104,55. Gyll. Ins. Suec. iii, 497. 35. De Geer Ins. v, 323, 27. Ross. Fn. Etrusc. Hellw. i, 83, 200. Marsh. Ent. Brit. i, 180, 23. Steph. Cat. i, 221, 2.268, 9. Bechst. and Scarf. Nat. Ius. i, 133,8. Goeze Eur. Fn. viii, 367, 10. Müll. Zool. Dan. Pr. 888. Brabm. Ins. Kal. i, 49, 163. Lai. Tyr. Ins. i, 164, 20. Schrank. Enum. 73, 135. Gled. Einl. i, 452, 9, ii, 61, 86. Müll. Linn. Nat. v, i, 171, 23. Bar. Nat. vi, 93, 6. Mart. Col. t. xiv, f. 1. Vill. Ent. i, 124, 19. Muill. Fn. Frid. 9, 84. Rüs. Ins. ii, 3, t. i, f. i, 5. Stew. Elem. ii, 47. Sam. Nom. i, 10.

La Chrysomele briquetée. Geuffr. Ins. i, 263, 15.

Galleruca Vitellinæ. Fab. Syst. Eleuth. i, 487, 49. Payk. Fn. Suec. ii, 94, 12. Ced. Fn. Ingr. 198. Panz. Fn. Germ. xliv, t. xvi ; Ent. G. i, 171, 7. Illig. Mag. i, 424, 49.

Salicis. Scb. Nomen. i, 55, 23.

Coccinella Vitellinæ. Scop. Carn. 224.

Phædon Vitellinæ. Steph. Illustr. Mandib. iv, 335, 10.

Length of the body $2 \frac{1}{3}$ lines. 


\section{DESCIIPTION.}

Body oblong, a little inclining to ovate, glossy; underncatlı black-bronzed, scarcely punctured; above bronzed with a copper tint, minutely punctured. First and second joints of the antemin rufous: scutellum impunctured: elytra punctured in rows, with the interstices indistinctly punctured : tarsi piceous with the first joint rufous.

\section{Family HALTICIDÆ. Hulticidans.}

CXVI. Genus HALTICA. Gcoff. xxr. "Subgenus Orchestris. Kirb.

Antenuce simple.

Body oblong.

Prothorax with no transwerse impression.

Elytra punctured but not in rows.

Posterior tarsi short, inserted in the apex of the tibia.

'This subgenus corresponds with Stephens's family-b. 1, *†, of which H. Nemornm is the type. 1. *Haltica (Orchestris) vicisa. Neighbouring H. Orchestris.

H. O. (vicina) pallida, pectore, capile menctis tribus; prothorace quatuor lincolaque, coleoptris vittis quinque, tarsisque, niyris. Neighbouring H. Orchestris, pale, with the breast, tliree dots of the head, four and a streak of the prothorax, five stripes common to both elytra, and tarsi blact.

Length of the body $3 \frac{1}{3}$ lines.

A single specimen taken.

UESCRIPTION.

Body underneath pale rufous with the disk of the postpectus black. Head punctured in the vertex, dirty-white, with a pair of contiguous black dots between the eyes and a subtriangular one on the nose; antennæ black with the underside of the scape and the two next joints dusky-rufous: prothorax very minutely and lightitly punctured, white with two irregular black spots placed obliquely on each side, and a black longitudinal streak between them: scutellum black: elytra very minutely and thickly punctured, with a sutural stripe common to both, a discoidal one rather nearer the lateral margin, and another just above it all black; the intermediate stripe falls short of the apex of the elytra: the upper side of the tibix is dusky, and the tarsi are black.

This species is nearly related to Gallerneca caroliniana of Fabricius and to Haltica alternata of Illiger, but the markings of the head and thorax are different. 


$$
\text { 2. * Haltica (Orchestris) puncticollis. Dotted-neck H. Orchestris. }
$$

H. O. (puncticollis) aterrima, prothorace cum antepectore pallide favis; illo punctis duobus lineolaque impressa atris. Dotted-neck H. Orchestris, very black, with the prothorax and antepectus pale-yellow, the former with two dots and an impressed linelet also black.

$$
\text { PLATE VII, FIG, } 9 .
$$

Length of the body $2 \frac{3}{4}-3$ lines.

\section{A single specimen taken in Lat. 65 ${ }^{\circ}$. Taken also by Professor Peck in New England :}

\section{DESCRIPTION.}

Body subovate, very black, underneath glossy. Head irregularly punctured behind: antennæ underneath piceous at the base: prothorax very minutely and lightly punctured, pale-yellow with two black round dots in the disk between which above the scutellum is a less black triangular impression: elytra very minutely and lightly punctured : forebreast pale-yellow.

VARIETY B. Elytra with a blue tint.

\section{Family GALLERUCID无. Gallerucidans.}

CXVII. Genus GALLERUCA. Geoff.

* Elongatæe.

\section{Galleruca Olivieri. Olivier's Galleruca.}

Altica quadrimaculata. Oliv. Ent. v, 93, 673, 6, t. i, f. 6 .

Length of the body $3 \frac{1}{4}$ lines.

Taken in Canada by Dr. Bigsby.

\section{DESCRIPTION.}

Very near related to Galleruca quadrimaculata F. Body long, glossy, reddish-yellow : posterior part of the head black, a cross impressed between the eyes; antennæ dusky with the four first joints rufescent: prothorax impuncturcd, transversely subimpressed behind, sides margined: elytra very minutely and lightly punctured with punctures just visible under a good lens; at the base of each elytrum nearest the suture is a roundish black spot, and another large oblong one extends from above the middle towards the apex : postcrior thighs a little incrassated; tarsi dusky especially at the apex; medipectus and postpectus black.

This species forms a link between the Halticida and Gallerucida: it is clearly the Altica quadrimaculata of Olivier, and may be regarded as the American representative of Galleruca quadrimaculata F. from which it differs principally in the colour of its antennæ and its incrassated postcrior thighs. 


\section{Galleruca Canadessis. Camalian Galleruca.}

F. (Canadensis) sordide rufa, pubescens ; antennis nigris basi nufescentibus ; capite puncto postico, prothorace tribus transverse positis, elytris vilta laterali suturaque, niyris.

Cauadian Galleruca, dirty-rufous, downy; antentne blaek, rufescent at the base, heal with a dot behind, prothorax with three placed transversely, elytra with a lateral stripe and the suture, all black.

Length of the body 4 lines.

\section{Taken in Canada by Dr. Bigsby.}

\section{DESCRIPTION.}

Body elongate, hairy with short decumbent cinereous hairs or down, dirty-rufous, underneatl black. Head with a black vertical spot; six last joints of the antennæ black, the others, except the seape, rufous black at the tip; scape rufous, black above: prothorax transversely impressed, sides posteriorly oblique with a slight sinus; three equidistant irregular black spots or dots placed transversely on the disk: the two elytra taken together have three black stripes, the intermediate or sutural one being common to both, and converging with the lateral ones at the tip: anus obscurely rnfous.

** Breviores.

(294) 3. Galleruca Sagittaria. (Gyllenhal.) Arrou-heal Gallerucu.

Galleruca Sagittariæ. Gyll. Ins. Succ. iii, 511,8 .

Length of the body $2 \frac{3}{4}$ lines.

Several specimens taken in Lat. 54 . Taken also by Dr. Bigsby in Canada.

\section{DESCRIPTION.}

Body brown, a little downy, not glossy. Mouth dirty-yellow: prothorax transverse, impressed, reddish-yellow, with three black nearly confluent spots: scutellum subquadrangular, truncated at the apex: elytra grossly but not thickly punctured; suture and lateral margin paler than the rest of the elytrum: anus and legs reldish-yellow; tarsi darker.

VAnietx B. With the base of the antennæ yellowish underneath, the black spots on the prothorax distinet, and the elytra entirely of a brownish-yellow. 
G. (bilineata) subpubescens, subtus nigra, supra cum pedibus fusco-rufa : prothorace nigro indistincte maculuso : elytris linei. duabus subelevatis approximatis nigricantibus.

Bilineate Galleruca, suhpubescent, black underneath, above, with the legs, brownish-red: prothorax indistinctly spotted with black : elytra with two somewhat elevated approximated blackish lines.

Length of the body 2 lines.

A single specimen taken in Lat. $54^{\circ}$.

DESCRIPTION.

Nearly related to the preceding species, but smaller, the whole of the head is rufous, the joints of the antennæ are shorter: the prothorax is longer in proportion to its width: and the elytra, nearer the suture than the lateral margin, have two somewhat elevated approximated blackish ridges, the interior one being the shortest and extending from near the middle to the base, and the other reaching neither base nor apex. 5. * Galleruca marginella. Bordered Galleruca.

G. (marginella) atra, prothorace canaliculato, subtestaceo, nigro maculato; elytris margine laterali pallide testaceo.

Bordered Galleruca, very black, prothorax channelled, subtestaceous spotted with black; elytra with the lateral margin pale testaceous.

Length of the body 3 lines.

A single specimen taken in Lat. $65^{\circ}$.

DESCRIPTION.

Body very black, a little downy. Mouth and basc of the first joint of the antennæ subtestaceous or reddish-yellow: prothorax wider than long, impressed and confluently punctured on each side, with a longitudinal dorsal channel; behind the margin has a slight sinus; reddish-yellow with three black spots, the intermediate one being the smallest; elytra grossly and thickly punctured; lateral margin and apex reddish-yellow: legs dusky-yellow; last ventral segment of the abdomen yellow and deeply emarginate. 
Having described the British American insects, as far as collected by Dr. Richardson, Dr. Bigsby, \&c. belonging to the second tribe of Latreille's Cyclicu, to which we gained an approach from the Rhynchophora, we must now retrace our steps, and going back to the Lepturide, enter from then to his Eupoda, and so proced to his first tribe of Cyclica.

ii. Eupod.. Lat.

Family SAGRIDÆ. Sagridans.

CXVIII. Genus ORSODACNA. Lat.

1. * Orsodacna tibialis. Iellow-shanked Orsodacua.

O. (tibialis) picea, subtus piloso-incana, supra punctatissima, femoribus basi tibiisque flavis.

Yellow-shanked Orsodacna, piceous, underneath covered with hoary pile, thighs at the base and tibiæ yellow.

Length of the body $2 \frac{3}{4}$ lines.

A single specimen taken in the Journey from New York to Cumberland-house. DESCRIPTION.

Body piceous; underneath hoary with decumbent hairs; above naked, glossy, thiekly punctured. Palpi and two last joints of the antennx obscurely rufous; front between the eyes with a transverse levigated elevation: prothorax longer than wide, constricted at the base: lateral margin and epiplcuræ or side-covers of the elytra, except at the base, yellowish-red : thighs, at the base, and tibix reddislsyellow, the four posterior tibia darker at the apes.

\section{2. * Orsodacna Chuldreni. Children's Orsodaciul.}

O. (Childreni) flavesccns, occipite postpectore abdomincque, nigris; elytris pallidis sutura, vitta laterali, fascia anyulata basiyue nigris.

Children's Orsodacna, yellowish, occiput, postpectus, and abdomen black; elytra pallid witl the suture, a marginal stripe, an angular band, and the base black.

$$
\text { PLATE VII, FIG. } 6 .
$$

Length of the body $2 \frac{3}{4}$ lines.

A single specimen taken in Lat. $54^{\circ}$. 


\section{DESCRIPTION.}

Body above punctured, naked. Head and its organs yellow, with the eyes, occiput, and apex of the mandibles black; a levigated transverse elevation of the front, as in the preceding species: prothorax longer than wide, constricted at the base, with an impression in the middle, pale-yellow, disk embrowned: scutellum rufous: elytra rather paler than the prothorax, with a stripe adjoining the lateral margin, an angular band beyond the middle and the base, black: antepectus, anus, and legs, yellow, rest of the underside of the body is black, and hoary with decumbent white hairs.

\section{Family DONACIADE. Donaciadans.}

CXIX. Genus HæMONIA. Meg.

\section{1. * Hemonia nigriconnis. Black-horned Hamonia.}

H. (nigricornis) lutea; antennis, pectore, abdominisque basi, nigris; prothorace canaliculato, subquadrato, medio constricto; elytris puncto-striatis, apice bispinosis, interiori brevi.

Black-horned Hæmonia, luteous : antennæ, breast, and base of the abdomen black ; prothorax channelled, subquadrangular, constricted in the midole; elytra punctured in rows, armed at the extremity with two spines, the innermost one short.

Length of the body 3 ? lines.

\section{Taken in Canada by Dr. Bigsby.}

\section{DESCRIPTION.}

This species is considerably larger than H. Equiseti and Zosterce, from which it is perfectly distinct. Body luteous above and glossy; underneath it is covered with a thick coat of pale, decumbent, rather silky, hairs with somewhat of a golden splendor, if these are rubbed off, the colour of the breast and basal abdominal segment is black. Head hairy, dusky, with a levigated naked testaceous longitudinal elevation between the eyes; antennæ black, robust, very little longer than the prothorax; prothorax subquadrangular with prominent anterior and posterior angles making it appear constricted in the middle, it is channelled with an irregular discoidal impression on each side; a few large dusky punctures are observable where the channel terminates: elytra with ten equidistant rows of large punctures which converge at the apex; besides these there is an abbreviated row at the base next the suture, as in many Harpalide, \&c. the apex of the elytra terminates in two teeth or spines; the inner one short and dentiform, the outer one long and spiniform: legs and anal portion of the abdomen yellow, the former with all their articulations dusky at the extremity.

The sculpture of the elytra in this species much resembles that of another aquatic genus Haliplus, Lat. 
CXX. Genus DONACIA. Fub. Hoppe.

- Elytra ronnded at the apex.

a Posterior thighs unarmed.

$\mathrm{b} \longrightarrow$ armed with one tooth.

c —— two tectl.

* Elytra truncated at the apex.

* a.

(300) 1. * Donacia femoralis. Femoral Donacir.

D. (femoralis) viridi-cnea, aurato; antennis, tibiis, tarsis, femoribusque basi, tcstaceis; prothorace punctulatissimo, postice impresso, antice prominentius tuberculato.

Femoral Donaeia, green-bronzed, gilded; antennæ, tibia, tarsi, and base of the thigbs testaceous, very minutely and thiekly punetured, impressed posteriorly, anteriorly more prominently tuberculated.

Length of the body $3 \frac{1}{4}$ lines.

\section{'Taken in Nova Scotia by Dr. Mac Culloch.}

\section{DESCRIPTION.}

Body bronzed, gilded, with a greenish tint, very minutely and thickly punctured, not conspieuously liairy underneath. Frontal channel slight; antennx, except the scape which is bronzed, and mouth rufous: prothorax with an impression above the scutellum; anterior tubercles more than usually prominent : scutellum rather large : elytra with single slight anterior impression adjoining the suture: legs rufous, but the thighs, which are much inerassated, except the base and summit, are green-bronzed; posterior thigh without any tooth: abdomen as in the preceding species.

This species seems nearly related to Donacia pusilla Say. ${ }^{1}$

b.

\section{2. * Donacia flavipes. Yellow-legged Donacia.}

D. (flavipes) cupreo-aurata; antennis pedibusque testaceis; prothorace subelongato, subtuberculato, latius canaliculato, varic et confertim ruguloso.

Yellow-legged Donacia, copper-gilded: antenna and legs testaceous; prothorax subelongated, subtuberculated, rather widely channelled; vuriously, thickly, and minutely wrinkled.

Length of the hody 4 lines.

A single specimen taken in Lat. 65.

'Journ. Acad. Nat. Sc. Philed. v, 293, 4. 
DESCRIPTION.

Body bronzed-copper with a golden lustre; clothed below with very short, somewhat silvery, decumbent hairs, the metallic splendor of the hody being visible through them. Head thickly, minutely, and confluently punctured or wrinkled, channelled between the eyes: antennæ testaceous, longer than the prothorax: prothorax subquadrangular, longer than usual in the genus, widely channelled, very minutely, thickly, and confluently punctured and wrinkled; anterior tubercles large and not prominent: elytra with two impressions adjoining the suture, elevated at the base: legs testaceous.

Very nearly related to $D$. discolor Hoppe, Marsh, \&c. but quite distinct.

\section{3. * Donacia affinis. Kindred Donacia.}

D. (affinis) cuprea, valde aurata : antennis, ore, pedibus, abdomine segmentis apice, anoque, testaceis: prothoracc punctato; elytris apud suturam semel leviter impressis.

Kindred Donacia, copper, much gilded : antennæ, moutb, legs, segments of the abdomen at the apex, and anus, testaceous ; elytra with a single light impression at the suture.

Length of the body $3 \frac{3}{4}$ lines.

\section{Taken by Dr. Mac Culloch in Nova Scotia.}

\section{DESCFIPTION.}

Body minutely punctured, copper-coloured brilliant with the splendor of gold; underncath very slightly hairy. Head channelled between the eyes; antennæ and mouth testaceous: prothorax widest anteriorly, channelled, punctured but not thickly, lateral anterior tubercles levigated: scutellum small: elytra with a single impression, not far from the base, adjoining the suture; base elevated: margin of the ventral segments of the abdomen of a fine bright, the anus of a deeper, orange: legs testaceous.

Very near D. flavipes, but the sculpture of the prothorax, the impressions of the elytra, and the colour of the underside of the abdomen are different. It differs from $D$. discolor in having the prothorax much more thinly punctured, the anterior tubercles, which in that species are near obsolete, more prominent, and the scutellum much smaller.

\section{Donacia emarginata. Emarginate Donacia.}

D. (emarginata) atro-carulea, subtus argenteo-sericea: elytris impressis; podice emarginato. Emarginate Donacia, black.blue, underneath with silver pile : elytra impressed : podex notched.

Length of the body $3 \frac{2}{3}$ lines.

Taken with the preceding. 


\section{MESCRIPION.}

Body black-blue, cloathed underneath with pile, in certain lights, glittering like silver. Antcnna black: tubercles of the prothorax prominent: elytra with an impression near the suture: last dorsal segment of the abdomen emarginate: thighs very thick, bronzed, posterior one with a stout tooth.

This species comes very near $D$. serieea, but it is sufficiently distinguished by its deeply notehed podex, and the silver pile that cloaths its body underneath, which in that species hass a golden lustre.

D. (proxima) femoribus bidentatis, dente altero minuto; supra atro-violacea nitida, capite subanto; elytris punctis viridi-inauratis; subtus holosericeo-argentea.

Proximate Donacia, thighs bidentate with one tooth minute, above dark violet, glossy; head ratber bronzed: punetures of the elytra green-gilt: body underneath covered with a satin silver pile.

Length of the body 5 lines.

\section{Taken in Canada by Dr. Bigsby.}

\section{DESCRIPTION.}

Body a little flattened, covered undemeath with a dense cont of glittering silver pilc resembling satin. Head a little bronzed, chamnelled betwecn the cyes, minutely punctured; palpi testaceous; antennæentirely black: prothorax in the disk dark violet and channelled, sides bronzed and impressed; anterior tubercles not prominent: scutellum bronzed: elytra nearly black with a slight tint of violet, punctures green-gilt, interstices of the rows not wrinkled; an anterior impression near the suture; rounded at the apex: posterior legs long, with thighs somewhat curved, attenuated at the base, armed at the apex with two teeth placed consecutively, the first long, slender, and acute; the last wide, short, and denticulated posteriorly.

This species is nearly related to D. erassipes Fab. but the antemn and the legs are entircly black, the teeth on the posterior thighs are not equal.

$$
\text { 6. * Donacia cuprea. Copper-colomed Domucio. }
$$

D. (cuprca) supra cuprca, nitida; subtus ex pube densa cincrea; antennis nigris; pclibus obscure rufis, femoribus posticis unidentatis : prothorace subtransuerso.

Copper-eoloured Donacia, above copper-colourcd, glossy; underneath with a thiek coat of cinereous pile; antennæ blaek ; legs obseurely rufous, posterior thighs unidentate; prothorax subtransverse.

Length of the body $4 \frac{1}{2}$ lines.

Taken in Canada by Dr. Biggsby. 
DESCRIPTION.

Body above copper-coloured, glossy ; underncath covered with a thick coat of decumbent pile of a cinerous colour, glittering in certain lights. Head downy, channelled; mouth and palpi rufous; mandibles and antennæ black: prothorax rather wider than long, very minutely, thickly and confluently punctured and wrinkled; channelled, with a pair of impressions on each side, anterior tubercles not prominent : scutellum downy : elytra very grossly punctured in rows; a single anterior impression near the suture; truncated at the apex: three intermediate ventral segments of the abdomen have a yellow margin: legs obscurely rufous; thighs bronzed in the middle; posterior thighs with a minute tooth near the apex.

7. Donacia hirticollis. Hairy-necked Donacia.

D. (hirticollis) pubcscens, subtus holosericeo-argentea; elytris glabris, atris; striarum punctis viridi-inauratis ; femoribus posticis unidentatis.

Hairy-necked Donacia, downy, satiny, underneath and silvery; elytra naked, black, with the punctures of the rows green gilt ; posterior thighs unidentate.

Length of the body $3 \frac{1}{2}$ lines.

A single specimen taken in Lat. $65^{\circ}$.

DESCRIPTION.

Body underneath covered with a thick coat of decumbent pile resembling satin and shining like silver. Head hoary from inconspicuous hairs, most minutcly and confluently punctured with a slight interocular channel with an obtuse ridge on each side; antennæ with the second and third joints equal in length; labrum glittering with silver pile: prothorax longer than wide, hoary from inconspicuous down, most minutely and confluently punctured, channelled, sides subimpressed, anterior tubercles flat: scutellum large, levigated: elytra black, punctured in rows, whose interstices are wrinkled; posterior thighs with a single short obtusangular tootl.

This pretty species comes near D. bidens Oliv. which I always find on Potamogeton natans, but it is sufficiently distinguished by its black thorax hoary from down, and legs without any red.

8. Donacia equalis. Equal Domacia.

Donacia æqualis. Say. Joum. Nat. Sc. Philad. vi, 428?

Length of the body $4-4 \frac{1}{2}$ lines.

Many taken in the Journey from New York to Cumberland-house. 
DESCRIPTION.

Body underneath covered with a thick coat of silver pile as in the preceding species. Hearl bronzed, hoary from cinereous down, minutely and confluently punctured, cliannelled between the eyes with a longitudinal obtuse ridge on each side the channel; antennx black, bronzed at the base, second and third joints equal in length ; mouth piccous: prothorax bronzed and gilded, rather longer than wide, thickly and confluently punctured and wrinkled; channelled; sides longitudinally suhimpressed; anterior tubercles obsoletc: scutellum hoary from down: clytra bronzed, gilded, punctured in rows except at the apex where the punctures are confluent, two impressions adjoining the suture, and one in the middle of the base; apex truncated: ventral segments of the abdomen, the last excepted, with a bright orange margin : posterior thighs with a stout short tooth.

N. B. In the male the ventral segments are without the orange margin.

Varietr B. Prothorax bright copper, elytra black-brónzed.

\section{Family HISPIDE. Hispidans.}

CXXI. Genus HISPA. Linn.

xxri. * Sulgenus Axoplitis. Kirb.

Body without spines; third joint of the antenne not much longer than the second: scape unarmed.

In the genuine Hispa, of which $H$. atra may be regarded as the type, the structure of the intenne is very different from that both of the other spinose ones, and of those that are without spines; the four first joints terminating externally in a spine, that of the scape being longer than the rest and not being a prolongation of the external angle. In H. erinacea, and several other American species, the third joint is very long, in Anoplitis it is scarcely longer than the second, as in Hispa atra, but the four first joints are without the spine. We have therefore here types of three subdivisions, viz. Hispa proper, Anoplitis, and Lobacantha, as I would denominate H. erinacea and affinities, from the lobes crowned with spines which project from the elytra.

\section{(308) 1. Hispa (Anoplitis) bicolor. (Olivier.) Tero-coloured H. Anoplitis.}

Hispa bicolor. Oliv. Ent. vi, 95, 774, 27, t. ii, f. 27; Encyclop. In.s. vii, 96, 5. Length of the body $3_{-1}^{3}$ lines.

Taken in Canada by Dr. Bigsbỵ. Mr. Francillon had specimens from Georgia. Olir. 


\section{DESCRIPTION.}

Body linear, naked. Head black, smooth, channelled between the eyes; antennæ robust, scarcely longer than the prothorax, black; eyes large, dark-brown : prothorax transverse, narrowest anteriorly, red, with four dusky spots placed transversely, grossly punctured, posterior angles producted, behind with a slight sinus on each side; space above the scutellum truncate: scutellum dull-red: elytra linear, black, three-ridged, with an abbreviated ridge towards the apex between the second and third; ridges elevated; interstices with a double series of large and very close punctures; between the sccond and third at the base and apex the series is quadruple, in the middle triple ; lateral margin and apex serrulate: underside of the body blood-red: legs black, base of the thighs red.

We now come to a tribe of beetles which though generally regarded as nearly related to the Cassidiadce, Chrysomelidee, and other phytiphagons tribes are of predaceous baljits, subsisting aliogether upon Aphides. In some respects they appear related to the Anisotomidee and some Nitidulidee, ${ }^{2}$ and their natural place is not yet satisfactorily ascertained.

\section{APHIDIPHAGA. Lat.}

\section{Family COCCINELLIDE. Coccinellidans.}

CXXII. Genus COCCINELLA. Linn.

* Body oblong, subdepressed.

I Spotted with black.

C. (episcopalis) atra, angusta; pedibus testaceis : fronte lineolis tribus pallidis signata ; prothorace coleoptrisque pallide luteis; vittis duabus communibus atris hamatis, pedum episcopale referentibus.

Episcopal Coccinella, black, narrow; legs testaccous : forebead marked with three pale lines: prothorax and elytra, taken together, pale-yellow, with two black, hooked stripes, common to both, resembling a bishop's crosier.

PLATE V, FIG. 4.

Length of the body 2 lines.

Taken in the Journey from New York to Cnmberland-house.

2 Nitidula hemipharica Lin. Trans. xii, 395. 28, Hemitoma K. IIS. 


\section{DESCRIPTION.}

Body narrow, nearly linear, having at first sight the aspeet of a IIaltice, undemeath black. Head black with three oblong pale yellow spots, two adjoining the eyes on their inner side, and one placed backwards in the vertex; moutl, antemax, and palpi rufous: prothorax and both elytra taken together, pale yellow with two black stripes, common to both, resembling a bishop's crosicr, the crook being on the thorax and the stalk on the elytra; suture of the latter black except at the tip: legs pale testaccous: anus, sides of the abdomen, and tips of the ventral segment, except the basal one, pale.

\section{(310) 2. Coccinela tredecin-junctata. Thirteen-dotted Coccinellu.}

Coccinclla tredecim-punctata. Linn. Fn. Succ. 481; Syst. Nat. ii, 582, 20. Fah. Syst. Ent. 83, 25; Syst. Eleuth. i, :369, 76. Payk. Fn. Succ. ii, 42, 44. Gyll. Ent. Succ. iv, 207, 26. Marsh. Ent. Brit. i, 156, 19. Illig. Kaf. Preuss. i, 425, 14, \%. Herbst. Ins. v, 323, 79, t. 57, 11 ; Arch.43, 8. Panz. Ent. Germ. i, 139, 27. Scop. Ent. Car. 76, 238. Ross. Fn. Etrusc. i, 63, 157. De Geer Ins. v, 375, 9. Ced. Fn. Ingr. 160. Thunb. Nov. Act. Ups. v, 104, 29. Miill. Zool. Dan. Pr. 66, 629. Schrank. Enum. 55, 102. Vill. Ent. i, 101, 18. Oliv. Ins. vi, 98, 1023, 53, t. vi, f. 79. Brahm. Ins. Kal. 78, 251. Geoff. Ins. i, 324, 7. Schæff. Icon. t. xlviii, f. 6. H-r. Ins. 161, 80. Reaum. Ins. iii, t. xxxi, f. 19; Acta. Nidr. iv, 7. Mïll. Fr. Frid. 6, 53. Stew. Elem. ii, 43. Dou. Brit. Ins, xi, Ł. 362, f. 2. Haw.

Ent. Trans. i, 276 . Step. Illustr. Mandib. iv, 388, 28.

Length of the body 3 lines.

Several specinens taken in Lat. $54^{\circ}$.

DESCRIPIION.

Body oblong, black, lightly and minutcly punctured; underneath slightly downy. Mouth and its organs pale rufous; nose white, whiteness with a posterior central lobe; antennæ rufous: prothorax white with a large discoidal spot falling short of the anterior margin, where it is truncated; sides lobed, besides which there is a black dot on each side connected with the above spot: elytrin reddish-yellow with six largish black dots, namely $1,2,2,1$, and one at the scutellum common to hoth clytra; the first marginal dot is ovate, the rest approaching to round: the tibiæ and tarsi are testaccous: there are two transverse white spots on each side the breast, between the four posterior legs; and four triangular pale ones on each side the abdomen.

VARIETY B. Nose rufous, with a parallegramiseal white spot between the antenna.

(311)

3. Coccinelat triness. Trident Coccinella.

C. (tridens) atra, fronte antice tridente, prothorace margine antica et laterali, maculaque quadrata postica, albis ; coleoptri.s luteis, maculis scptem difformibus atris.

Trident Coecinella, very black, anterior trident of the front; anterior and lateral margin and square posterior spot of the prothorax, white; elytra taken together lutcous, with seven divcrsely shaped black spots.

Length of the body $2 \frac{1}{4}$ lines.

Two specinens titken in the Expedition. 


\section{DESCRIPTION.}

Body rather oblong, very minutely punctured; black underneath, with two distant white spots on the breast, and three contiguous ones on each side of the abdomen. Head black with a transverse white band or trident between the eyes, trieuspidate both anteriorly and posteriorly; the intermediate posterior lobe the longest : prothorax white with a large bipartite black spot, each lobe being trilobed with rounded lobes resembling a trefoil leaf and connected with the other by a transverse band: elytra pale reddish-yellow; with three black spots and one at the scutellum common to both elytra, placed $2,1,1$; the scutellar spot somewhat bell-shaped, the humeral one roundish, the intermediate one nearly kidney-shaped, and that nearest the apex rather crescent-shaped.

VAniety B. Frontal band replaced by three white spots, the intermediate the longest and linear.

This species scems to come near C. Parenthesis Say, but still appears distinet.

** Body bemispherical.

\section{4. *occinella quingue-signata. Five-signed Coccinella.}

C. (quinque signata) atra, oblongo-hemispharica : coleoptris fulvis : fascia communi boseos, duabus abbreviatis disci, punctisque duobus opicis, nigris; frontis macula, angulisque thoracinis anticis, albis.

Five-signed Coccinella, black, between oblong and hemispherical ; elytra taken together tawny, with a basilar band common to both, two abbreviated ones and two dots near the apex, black; spot of the front and anterior angles of the prothorax white.

PLATE VII, FIG. I.

Length of the body 3 lines.

A single specimen taken in Lat. $65^{\circ}$.

DESCRIPTION.

Body oblong-hemispherical, very minutely and thickly punctured; underneath black and a little downy. Head black with an acute white spot in the forehead between the eyes; antenna obscurely rufous, dusky at the base and tip: prothorax black, anterior angles and intermediate streak, white: elytra tawny-yellow with an abbreviated band common to both at the base, an oblique discoidal abbreviated band and apical dot, black; four distant lateral triangular white spots mark the breast. 5. * Coccinella quingue-notata. Five-marlied Coccinella.

C. (quinque-notatu) atra hemispharica, coleoptris rufo-fulvis, fascin communi buseos, et quatuor discoidalibus, abbreviatis, nigris; fronte maculis duabus, prothoraceque angulis anticis pallide luteis.

Five-marked Coccinella, black, hemispherical ; elytra tawny-rufous, with a basilar band common to both, and four discoidal ones, abbreviated, black; front with two spots, and prothorax with the anterior angles, pale-yellow.

Length of the body $3 \frac{1}{3}$ lines.

A single specimen taken in Lat. 54\%. Taken also by Dr. Bigsby in Canada. 


\section{DESCRIPTION.}

Very like the last, but shorter and more hemispherical. 'Two subtriangular transverse spots between the eyes, apex of the nose, dot at the sinus of the eyes, and anterior angles of the prothorax whitish-yellow; basal band of the elytra broadest at the suture, the two other black spots are of equal size and placed transversely, and each forms an abbreviated band, falling far short of the suture and the lateral margin, so as to be scarcely more than two transverse spots; scutellar angle of the elytra paler than the rest: the breast lias no white spots. In other respects it is exactly like C. 5-signata.

C. (tricuspis) atra, coleoptris fulvis, fascia communi bascos antice tricuspidi, el duabus apicis abireviatis, atris; capite punctis duolus, prothoraceque margine antico, angulisque, favis.

Tricuspidate Coccinella, black; elytra taken together tawny, with a basilar trieuspidate band common to both, and two abbreviated ones at their apex : prothorax with the anterior margin and angles yellow.

Length of the body $2 \frac{1}{4}$ lines.

\section{Several specimens taken in the Journey from New York to Cumberland-honse.}

DESCRIPTION.

Body black, punctured. Head with two irregular transverse yellow spots between the eyes; antennæ pale rutous, black at the tip : prothorax with the anterior angles and a slender portion of the anterior margin yellow, the black part forming a large three-lobed spot; the middle lobe being the longest and truncated, the lateral ones shorter and rounded; elytra tawny-rufous, paler and almost yellow at the base and sides, where there is a black band common to both elytra not reaching the lateral margin, which anteriorly has a double sinus so as to form three triangular lobes or points in the band; towards the apex of each elytrum is another irregular black band, which reaches neither the suture nor the margin.

C. (incarnala) supra incarnata ; prothorace maculis duabus magnis transversis nigris; coleoptris maculis undecim, tribus communibus, nigris : tarsis abdominisque margine nufesccutibus.

Flesh-coloured Coccinella, above flesh-coloured; prothorax with two large transverse blacl: spots: elytra taken together with eleven black spots, tbree of which are common to botb.

PLATE VII, FIG. 7.

Length of the body 2 lines.

A single specimen taken in Lat. $65^{\circ}$. 
DESCRIPTION.

Body black. Mouth and its organs and antenna reddish: prothorax flesh-coloured with two large subquadrangular black spots, separated by a narrow flesh-coloured stripe, which occupy almost all the disk : elytra flesh-coloured, taken together with eleven roundish rather large black spots, three of which are common to both elytra, viz. $3,4,3,1$, the common spot at the apex is transverse: legs black with the base of the thighs and tibix, tarsi, sides of the abdomen, and anus testaceous.

This species seems to come near $C$. borealis of Thunberg, but it differs in colour and the number and disposition of the spots.

\section{HETEROMERA. Geoft. Lat.}

I have deferred the description of the Heteromera till now, because one of that subdivision, Meloe, appears evidently to be one of the links that connect the Coleoptera with the Orthoptera; yet, as was long since observed, ${ }^{3}$ the predaceons genus Manticora scems to present some signs of a leading off towards, to the first tribe of the Heteromera the Melasoma of Latreille.

j. Melasoma. Lat.

Family PIMELIADA. Pimeliadans.

CXXIII. Genus PIMELIA. Fab.

1. Pimelia alternata. Alternating Pimelia.

P. (alternata) atra, obscura; prothorace punctato lacunoso; elytris tricostatis: costis subtuberculatis : interstitïs serie punctorum elevatorum.

Alternating Pimelia, black, obscure; prothorax punctured, with some shallow impressions : elytra three-ribbed, ribs sultuberculate; interstices with a series of granular elevations.

PLATE V, FIG. 9.

Length of the body $6 \frac{1}{2}$ lines.

A single specimen taken at Carlton-house, Lat. 53 $3^{\circ}$ in April.

\footnotetext{
3 See above, p. 4.
} 


\title{
DESCRIPTION.
}

Body dull-black, oblong, naked. Head minutely punctured; antenne shorter than the prothorax : prothorax widest in the middle, subquadrangular with the sides rounded, minutely but not very thickly punctured, with some slight impressions in the disk: scutellum short, wide, rounded at the apex: elytra with six elevated granulated lines alternatcly more pronounced, besidcs the suture and marginal one separating the epipleura, which mect just above the apex : cpipleura granulated : posterior legs much longer than the four anterior.

Mr. Say says of his $P$. rotunda, that it was the first of that genus found on the New Continent; that above described furnishes therefore a valuable addition to the American insect Fauna. Afrie: appears to be the metropolis of the genus, though several species have been found in Russian Tartary.

\section{Fanily TENEBRIONIDE. Tenebriomiduns.}

\author{
CXXIV. Genus UPIS. Fab.
}

1. Upis ceramboides. Ceramboid Upis.

Upis ceramboides. Fab. Ent. Syst. ii, 515, 1; Syst. Eleuth. ii, 584, 1. Payk. Fn. Suec. iii, 350, 1. Gyll. Ins. Suec. ii, 594, 1. Herbst. Ins. vii, 237,5, l. cx, f. 5. Lat. Hist. Nat. x, 296, t. viii, f. 7.

Attelabus ceramboides. Linn. Fn. Suec. 643; Syst. Nat. ii, 621, 12. Oliv. Ent. i, 220, 9.

Tenebrio ceramboides. Oliv. Ent. iii, 57, 9, 8, t. i, f. 7. Lat. Gen. ii, 171, 3.

—_ variolosus. De Geer. Ins. v, $32,2, t .2, f .1-3$.

Spondylis ceramboides. Fub. Manl. i, 127, 2.

Curcutio maximus. Udd. $N$. Ins. Sp. $26, t . \mathrm{i}, f .1$.

Length of the body $8-8 \frac{1}{2}$ lines.

A pair taken, in the month of April, in Lat. 65\% ${ }^{\circ}$ Taken also in Canada by Dr. Bigsby.

\section{DESCRIPTION.}

Body dull-black, narrow, naked, minutely punctured. Head nearly round, depressed, porrected; cyes lateral, kidney-shaped; nose circumscribed by the segment of a circle; antenne a little shorter than the prothorax, joints obconical, four last lentile-shaped: prothorax a little wider than the head, oblong with rounded sides: scutellum rounded at the apex: elytra taken together wider than the prothorax, a little dilated beyond the middle, and then sloping to the apex, which is acute; very unequal with numerous irregular deep impressions and rugosities, variously separated by a number of clevated lines or obtuse ridges rumning confuscdly in various directions : legs long; thighs incrassated; tibiæ and tarsi slender.

This insect is stated by Fabricius to inhabit a particular kind of Boletus (B. fomentarius L.): Gyllenhal says that it inhabits perennial fungi growing upon trees, particularly of the genus Betula. It has not yet been discovered in Britain; but if attention be directed to these fungi it may very likely at length make its appearence in the list of British insects. 
CXXV. Genus TENEBRIO. Linn.

\title{
1. 'Tenebrio Molitor. Meal-worm Tenebrio.
}

Tenebrio Molitor. Linn. Fn. Suec. 815; Syst. Nat. ii, 672, 2. Fab. Syst. Ent. 255, 2; Syst. Eleuth. i, 145, 8. Payk. Fn. Suec. i, 89, 3. Gyll. Ins. Suec. ii, 590, 1. Marsh. Ent. Brit. i, 474, ]. Vill. Ent. i, 385, 1. Miill. Fn. Frid. 21, 213; Zool. Dan. 74, 794. Mart. Col. t. xxxix, f. 2. Berk. Syn. i, 108. Stew. Elem. ii, 83. Shaw. Gen. Zool. vi, 102, t. xxx. Leach. Ed. Enc. ix, 102. Sam. Comp. 59, t. iv, $f .1$. Illig. Kaf. Preuss. i, 113, 1. Oliv. Ent. iii, 57, 12, 13, t. i, f. 12. Herbst. Ins. vii, 240, 1, t. cxi, f. 1. Panz. Fn. Germ. xlii, t. 12; Ent. Germ. i, 40, 3. Ross. Fn. Etrusc. i, 231, 577. Petagn. Ins. Cal. 26, 128. Scop. Carn. 259. De Geer Ins. v, 34, 3, t. ii. f. 4. Ced. Fn. Ingr. 36. Poss. Ins. Beytr. i, 25, t. iii, f. 1-14. Blum. Hand. Ed. 7, 335, l. Fisch. Nat. v, i, 138, 290; Act. Ups. iv, 1736, 19, 1. Roem. Ins. t. xxxiv, f. 31. Frisch. Ins. viii, $t$. 1. Sulz. Gesch. t. vii, f. 52. Geoff. Ins, i, 342, 6. Schæff. Icon. t. lxvi, f. ]. H-r. Schmett 187. Lat. Gcn. ii, 179, 2; N. Dict. D'H. N. xxxiii, 44, t. R. 1, f. 10; Crust. Arachn. et Ins, ii, 25. Stepb. Illustr. Mandib. v, 8, 1.

Length of the body $7 \frac{1}{2}$ lines.

\section{Taken in Nova Scotia by Captain Hall.}

DESCRIPTION,

Body oblong-linear, minutely and numerously punctured, a little glossy, naked, above piceous, underneath rufo-piceous. Head uneven, nearly orbicular; anteriorly rufo-piceous; antennæ and palpi rufo-piceous: prothorax transverse, sides rounded with a reflexed margin; posterior margin wavy, just above which, on each side, is a roundish impression; posterior angles acuminate : scutellum transverse, subacuminate: elytra scarcely wider than the prothorax, slightly furrowed, furrows punctured with the interstices transversely somewhat wrinkled, and most numerously and minutely punctured : shoulders short, compressed and incrassated; cubit curved.

The grub of this common beetle may very possibly have been originally imported into North America from Europe in flour.

\section{Tenebrio pennsyluanjcus. Penmsylvanian Tenebrio.}

\author{
Tenebrio pennsylvanicus. Knoch. Ncue. Beytr. 167, ‥
}

Length of the body $8-9$ lines.

Several specimens taken in the Expedition in Lat. $54^{\circ}$.; it was also sent me by Dr. Harris.

Knoch says that it is found under bark. 


\section{DESCRIPTION.}

Body long, rather widest towards the anus, black, minutely punctured, naked, not glossy. Hear somewhat quadrangular, longer than in the preceding species, uneven : prothorax nearly square with a minute impression above the scutcllum; posterior margin wavy; lateral very slender and a little rounded: scutellum subtriangular: elytra with nine rows, including the marginal one, of punctures, and an abbreviated oue at the base next the suture; under a powerful lens the interstices are minutely but not thickly punctured: the shoulders are scarcely thicker than the thighs.

ii. Taxicorsis. Lat.

\section{Family DIAPERIDEE. Diaperidans.}

CXXVI. Genus DIAPERIS. Geoff.

xxvii. "Subgemus Anrunopirta. Kïb.

Hear of the male armed with horns.

Diaperis hemorrhoidalis Payk. may be considered as the type of this subgenus, which differs from the legitimate Diaperides in being less convex and having the head of the male armed with two or more horns.

(320) 1. * Diaperis (Arhenoplita) bicornis. Two-horned D. Arrhenoplita.

Diaperis hicornis. Oliv. Ent. iii, $5 \dot{5}, 6,4, t$. i, f. 4.

Hispa bicornis. Fab. Gen. Ins. Mant. 215, 3, 4; Mant. Ins. i, 47, 4. Linn. Syst. Nat. Gmel. 1734, 18.

Length of the body $\left\{\begin{array}{l}\text { Male } 1 \frac{1}{2} \\ \text { Female } 2\end{array}\right\}$ lines.

\section{Several taken in the Ronte from New York to Cumberland-house.}

DESCRIPTION.

Body punctured, glossy; underneath black, above black-bronzed or green-bronzect. Head of the female transwersely impressed between the eyes, unarmed; in the male just behind the cyes is a pair of long cylindrical vertical piceous horns rather paler at the apex, between which is a deep excavation; the nose also at the apex is armed with a pair of minute triangular tecth; mouth, in both scxes, rufous; antennæ black with the three first joints attenuated and rufous: prothorax transverse with the sides rounded, posteriorly obtusangular but not lobed: scutellum triangular : elytra slightly furrowed with the furrows punctured; interstices minutely punctured: anus underneath with two transverse obtuse ridges: legs rufous. 


\section{Family BOLITOPHAGIDÆ. Bolitophagidans.}

CXXVII. Genus BOLITOPHAGUS. Hlig.

\section{1. * Bolitophagus connutus. Horned Bolitophagus.}

Bolitophagus cornutus. Fab. Syst. Eleuth. i, I12, I.

Opatrum bifurcum. Fab. Ent. Syst. Suppl. 40, 1.

- cornutum. Panz. Fn. Am. Boreal. Prad.t. i, f. 5, 6. Say, Am. Ent. iii, t. li.

Eledona cornuta. Lat. Hist. Nat. x, 312.

Length of the body 5 lines.

Taken in Canada by Dr. Bigsby, in a Boletns of the birch, near Lake Huron.

DESCHIPTION.

\section{우}

Body oblong, black without the least gloss. Head transverse, nutant, flat, uneven ; cheeks angular; antennæ with the three last joints thicker than the rest, the last being the largest : prothorax crescent-shaped; sides anteriorly expanded, toothed; posteriorly constricted with acute lateral angles; disk anteriorly elevated into a crest terminating in two rounded subtuberculated lobes; behind the crest are four obsolete subtuberculated ridges: scutellum rounded : elytra tuberculated with the tubercles arranged in rows; those next the suture and towards the apex being the largest : some irregular rows of punctures are also discernible in the interstices; upper margin of the epipleura obtusely dentated.

\section{2. * Bolitophagus obcordatus. Obcordate Bolitophagus.}

B. (obcordatus) nigricans, prothorace obcordato, plano, incequali: elytris fuscescentibus; antice obtuse tricarinatis, postice bituberculatis; seriatim foveatis.

Obcordate Bolitophagus, prothorax obcordate, flat, unequal : elytra embrowned, anteriorly obtusely tricarinate, posteriorly bituberculate; deeply impressed in rows.

Length of the body $6 \frac{1}{4}$ lines.

Taken in Nova Scotia by Capt. Hall.

DESCRIPTION.

Body linear-oblong, pollinose. Head brown-black, subtriangular; labrum ciliated with yellow hairs; antennæ black-piceous, last joint smaller than the two antecedent ones, which are bigger than the rest: prothorax brown-black, obcordate with a larger anterior sinus for the head; surface flat, uncven behind from five obtuse ridges, the lateral ones abbreviated, and before from several rounded tubercles: scutellum minute: elytra embrowned with a yellowish tint from lutose scales, anteriorly 
with three obtuse ridges; the interior one very short; the intermediate one discoidal, abbreviated at eacl end; and the exterior one reaching from the base to the apical tubercles, of which there are two much elevated, the interior one being the largest and highest; in the interstices there are four rows of deep impressions: the sides of the antepectus are verrucose: the abdomen is black-brown with lutose sides; the disk is longitudinally, densely, and thickly wrinkled, and the sides are verrucose: legs black-brown.

'This species differs from the preceding one in the form of the thorax and the clava of the antenux, and ought perhaps to form a subgenus.

iii. Stenelytra.

\section{Family HELOPIDE. Helopidans.}

CXXvill. Genus MERACANTHA. Kirb.

Labrum transverse, scarccly cmarginate.

Labium subtriangular, longitudinally and obtusely ridged in the middle with a decp impression on each side.

Mandibles bidentate? at the apex.

Maxille mutilated.

Maxillary palpi first joint minute; second longer than the rest, clavate; third obconical; fourth very large, securiform.

Labial palpi broken off.

Mentum trapazoidal.

Antenne filiform, scape incrassated; pedicel obconical; third joint longer than the rest, subcylindrical, a little incrassated at the apex; fourth shorter than the fifth, subobconical; fifth longer than the subsequent ones, clongate, obconical; 6 - 10 obconical, gradually decreasing in length, and the 9 th and 10 th in thickness; 11 th ovate acute.

Body ovate, convex, apterous. Head triangular; front elevated on each side at the eyes protecting the base of the antennx; eyes large, lateral, internally cmarginate. Prothorax ratlier wider than long, narrowest antcriorly, subquadrangular; margined on the sides and anteriorly, margin very slender. Scutellum an obtusangled triangle. Elytra with the epipleura narrow, falciform; shoulders incrassated armed with a tooth; calcaria very short and scarcely visible.

This genus appears related to Acanthopus Megerle, ${ }^{3}$ but differs in its gencral form and several of its characters. 
M. (canadensis) nigro-anea, glabra, nitida, punctata : elytris striatis : strïs punctatis; interstitiis punctulatis.

Canada Meracantha, black-bronzed, raked, glossy, punctured; elytra furrowed, furrows punctured ; interstices minutejy punctured.

\section{Length of the body 6 lines.}

Taken in Canada by Dr. Bigsby.

DESCRIPTION.

Body black-bronzed, naked, glossy, punctured: on the upper side of the body the colour is more metallic. Head and prothorax confluently punctured, two last joints of the antennæ pale from hairs : elytra slightly furrowed, the sutural and the marginal furrows meeting at the apex and including the rest; furrows punctured; interstices very minutely and thinly punctured: sides of the abdomen longitudinally wrinkled: tooth of the shoulder short and wide, placed a little above the middle.

\section{Family S'TENOCHIAD五. Stenochiadans.}

CXXIX. * Genus ARTHROMACRA.

Labrum transverse.

Labium dilated above the insertion of the palpi, subemarginate.

Mandibles bidentate at the apex.

Maxilla bilobed; lobes thick, obtuse.

Maxillary palpi incurved, four-jointed; first joint minute; second longer than the rest, clavate; third shorter than the fourth, triangular; fourth very large, securiform, with the truncature oblique.

Labial palpi three-jointed, last joint securiform.

Mentum obtriangular.

Antennce filiform, eleven-jointed: scape short, incrassated; peclicel short, incrassated at the apex; joints $3-8$ obconical, nearly twice the length of the pedicel ; last joint cylindrical, downy, as long as the five antecedent ones taken together.

Body long and slender. Head triangular; eyes kidney-shaped. Prothorax cylindrical not wicler than the head. Scutellum rounded. Elytra wider than the thorax, linear. Legs slender; tarsi very long.

'This genus is sufficiently distinguished from Stenochia, which it a good deal resembles, by the remarkable length of the last joint of the antennæ, which occupies more than a fourtl part of the whole length. 


\section{Artironacra donaciondes. Domacia-litie Arthromacra.}

4. (donacioides) nigro-renea, nitida, supra punctatissina : antennis tursisque fulvis, illis basi et apice, his apice, nigricantibas. Donacia-like Arthromacra, bluck-bronzed, glossy; above thickly punctured : antenne and tarsi tawny; the former dusky at the base and apex, and the latter at the apex.

Length of the body 5 lines.

Taken in Camada, near lake St. Clair, by Dr. Bigsby. I received specimens also from Massachusets from Mr. Drake.

DESCRIT'TION.

Body black-bronzed with a greenish tint, glossy, with the whole upper surface thickly and irregularly punctured; underneath, except the sides of the trunk, impunctured. Antenna much longer than the head and prothorax, scape and pedicel dusky, $3-8$ joints tawny-yellow; last joint black, downy: prothorax nearly cylindrical; elytra wider than the prothorax, obtuse at the apex: thighs a little incrassated; apex of the cubit and tarsi tawny-yellow; two last joints of the latter dusky.

'This singular insect, at first sight, looks very like a Donacia, a resemblince merely given by its colour.

\section{Family CISTELIDEE. Cistelidans.}

Cxxy. Genus CISTELA. Fab.

1. Cistela eryturopa. Reel-legged Cistela.

C. (erythropa) elliptica, nigra, antennis infuscatis basi, pedibusque, rufis : prothoracc postice subtrilobo: clytris striatis.

Red-legged Cistcla, elliptical, black, base of the embrowned anteunæ and legs, rufous: prothorax posteriorly olssoletely tbree-lobed: elytra slightly furrowed.

Length of the body 5 lines.

Taken in Canada by Dr. Bigsby.

DESCRIPTION.

Body elliptical, gloss obscured, especially on the elytra, by very short decumbent hairs. Head longitudinally and slightly impressed between the eyes; antenux longer than the prothorax, reddish brown, with the three first joints rufous: prothorax transverse, anteriorly not wider than the head, posteriorly obsoletely trilobed, and nearly as wide as the elytra; lateral angles acute: elytra slightly furrowed; furrows searcely punctured : legs pale rufous; posterior tarsi long, embrowned. 


\section{Family DIRCÆID无. Dircceidans.}

CXXXI. Genus XYLITA. Payk.

\section{Xylita buprestoides. Buprestidam Xílita.}

Xylita buprestoides. Payk. Fn. Suec. i, 249, 1. Mc L. Hor. Entomolog. 1, 464, Note *. Steph. Illustr. Mandib. v, 36, I. Dircza discolor. Fab. Suppl. 121, 2; Syst. Eleuth. ii, 89,2. Panz. Fn. Germ. xcvii, t. 6; Crit. Revis. i, 96. Dufts. Fn. Austr. ii, 264, 3. Illig. Mag. v, 234, 2. Lat. Crust. Arachn. et Ins. ii, 44. lævigata. Gyll. Ins. Suec. ii, 517, 1.

Serropalpus lævigatus. Hell. Act. Holm. 1786, 318, 2. Illig. Kaf. Preuss. i, 131, 8. Lymexylon levigatum. Panz. Ent. Germ. 206, 8; Fn. Germ. xxiv, t. 16.

Length of the body 3 lines.

'Taken in Canada by Dr. Bigsby.

DESCRIPTION.

Body narrow, black-brown, very minutely and thickly punctured, sprinkled with short decumbent pale hairs, not glossy. Head inserted; eyes hemispherical; palpi rufous; antennæ nearly as long as the prothorax, ferruginous, a little embrowned at the apex : prothorax not wider than long, anteriorly narrowest, posteriorly obsoletely trilobed; sides rounded: scutellum transverse: elytra very little wider than the prothorax: tarsi ferruginous.

As Paykull was the original describer of this insect, with Mr. Mac Leay and Mr. Stephens, I have retained his name in lieu of that of Fabricius, adopted by most continental Entomologists.

v. Trachelida. Lat.

Family ANTHICIDE. Anthicidans.

CXXXII. Genus NOTOXUS. Geof.

\section{Notoxus Monodon. Unicorn Notoxu.}

Notoxus Monodon. Say, Amer. Ent. i, $t$. iv, $f$. inf.

Anthicus Monodon. Fab. Syst. Eleuth. i, 289, 4.

Length of the body $1 \frac{2}{3}$ line.

A single specimen taken in Lat. $65^{\circ}$. 
DESCRIPTION.

Body liairy with pale hairs. Head blackish; moutl, palpi, and antemne testaceous: prothorax testaceous; horn convex above, margin denticulated: elytra testaceous witl a blackish band near the apex which rises upwards at the suture, and three blackish spots; two at the base, and one between the band and the apex, the last very faint: legs testaceous: postpectus and base of the abdomen embrowned : the remainder of the prone part of the body is testaceous.

vi. Vestcantia, Lat.

\section{Family CANTHARIDE. Cantharidans.}

CXXXII. Genus CANTHARIS. Geoff.

\section{Cavtharis unicolor. One-coloured Cantharis.}

C. (unicolor) tota nigra, piloso-incana; prothorace canalimulato; antennis articulis duobus primis valde elongatis. One-coloured Cantharis, all black, hoary from pile; prothorax channelled : antennæ with the two first joints very long.

Length of the body 7 lines.

Taken in Canada by Dr. Bigsby.

\section{DESCRIPTION.}

Body black, hoary from numerous decumbent white hairs: antennæ subsetaceous, a little longer than the prothorax; two first joints very long, the first curved and nearly twice the length of the second; and the second as long as the three following ones together: prothorax rather bell-shaped, channelled: wings embrowned.

This species seems to come near to the Lytta immaculata of Say, ${ }^{4}$ but the relative lengths of the joints of the antennæ differ, the palpi of our insect are black, and it is much smaller.

CXXXIV. Genus MELOE. Linn.

'This genus appears to be one of the stepping stones to the Orthoptera, which is proved not only by its galeate maxillæ, but, by its elytra lapping over each other, and its vertical and often inflexed head, in this respect resembling the Blattina. 
M. (impressa) violacea; antennis irregularibus, prothorace postice longitudinaliter impresso.

Impressed Meloe, violet-coloured : antennæ irregular: prothorax with a longitudinal posterior impression.

Length of the body $5 \frac{1}{4}$ lines.

A single specimen taken in Lat. $65^{\circ}$.

DESCRIPTION.

Nearly related to Meloe violacea, but very much smaller. Body violet-coloured. Head with scattered but not large punctures; front between the antennæ transversely and obtusely elevated; antennæ irregular: prothorax not much narrower than the head, anteriorly rounded, posteriorly narrower and emarginate, towards the base with a deepish impression, with several scattered but not large punctures, and two little transverse oblique crescents formed of punctures: elytra wrinkled: outer claws and spurs rufo-piceous, inner claws paler.

2. Meloe vigra. Black Meloe.

M. (nigra) nigra, punctulata; antennis irregularibus, basi, tibiis, tarsisque violaceis; prothorace postice impresso.

Black Meloe, black, minutely purctured; antennæ irregular, at the base violct-coloured, as is also tbe ivhole of the tibire and tarsi ; prothorax impressed behind.

Length of the body 6 lines.

A single specimen taken in Lat. $65^{\circ}$.

DESCRIPTION.

Extremely similar to the preceding species, but the body is all black with no tint of violet, except the base of the antennæ below the band and the tibiæ and tarsi: the head and prothorax are more thickly punctured, and the claws and spurs are ferruginous.

\section{MALACODERMA. Lat.}

The Malacoderma of Latreille by the soft substance of their elytra, and their reticulations in some species of Lycus, seem to make an approach to the Orthoptera. 'They appear to branch off from the Elateridans by Campylus to Cebrio, and therefore we must now be regarded as retracing our steps to take a fresh route from that family in a new direction towards the Orthoptera. 


\section{Fanily MELYRIDE. Melyridans.}

CXXXY. Genus DASYTES. Payk.

D. (foveicollis) atro-ceruleus, subhirhus, capite protharacequc punctatis, hoe antice bifoveato.

Pit-necked Dasytes, black-blue, somewhat lairy: head and prothorax punctured ; the latter with two anteriorimpressions.

Length of the body $2 \frac{3}{4}$ lincs.

A single specimen taken in the Journey from New York to Cumberland-honse.

DESCRIPTION.

Body somewhat hairy, underneath black and glossy; above with a blue tint. Head glossy, punctured with largish scattered punctures; front with two impressions: prothorax nearly square, with the sides a little curved, punctured at the head, with a pair of transverse anterior inpressions; sides and base margined, margin reflexed : elytra less glossy than the rest of the body, minutely, but not conspicuously, punctured.

This species answers in almost every respeet to Major Gyllenhal's description of Dasytes cceruleus, but as he does not notice the impressions in the prothorax, which so minute a describer would scarcely have overlooked, I apprehend it as a distinct species. What we have in England under the name of D. corruleus is the Lagria viridis of Rossi, a fine green insect, first taken I believe on the Sussex coast by Sir W. T. Hooker. It differs from D. caruleus not only in its colour, but also by having the prothorax much more thickly punctured.

\section{Family CLERIDE. Cleridans.}

CXXXVI. Genus NECROBIA. Olis.

(332)

\section{Necrobia violacea. Violet-coloured Necrobia.}

Necrobia violacea. Lat. Hist. Nat. ix, 156, t. Ixxrii, f. 5; Gen. i, 274, 1; Crust. Arachn. et Ins. i, $479 . \quad$ Olir. Ent. iv, 76, bis. 5, 1. Stepb. Mllustr. Mandib. iii, 327, 1.

Dermestes violaceus. Linn. Fn. Suec. 422; Syst. Nat. ii, 563, 13. Fab. Syst. Ent. 57, 10; Eut. Syst. i, 230, 16. Panz. Fn. Germ. v, t. 6; Ent. Germ. i, 98, 18. Ced. Fn. Ingr. 129. Schrank Enum. 26, 45; Fn. Boic. i, 516, 595.

Clerus Quadra. Marsh. Ent. Brit. i, 3223, 4.

- nigro-cærulens. Geoff. Ins. i, 304, 2.

Corynetes violaceus. Payk. Fn. Suec. i, 275, 1. Fab. Syst. Elcuth. i, 285, 1.

Length of the body $2 \frac{1}{3}$ lines.

Taken abundantly on the Journer. 
DESCRIPTION.

Body dark blue, glossy, minutely punctured, rather hairy. Punctures on the head and prothorax nearly confluent and larger than those of the underside of the body; antennæ black, last joint subquadrangular: sides of the prothorax obtusangular: scutellum black: longer punctures of the anterior half of the elytra arranged in rows with the interstices minutely punctured, the rows then disappear, and the whole of the apex is indiscriminately and minutely punctured: legs black with a tint of brown.

On the continent this insect has been universally confounded with the Clerus violaceus of Mr. Marsham, which Mr. Stcphens considers as a distinct genus and as synonymous with Corynetes violaceus of Paykull: but as the latter has evidently in his description of the palpi had in view those of Necrobia, and assigns the habitat of that genus to his Corynetes, it scems clear that it is synonymons with Olivier's genus. The latter author has evidently confounded the two as well as Latreille. Thinking those found in carrion synonymous with those creeping about the windows of our houses early in the year, hc took his figure from one of the latter, as is evident from his sketch of the palpi and antennæ which are not those of Necrobia, but belong to Corynetes. Linné himself appears to have confounded these two insects; for his short description belongs rather to Corynetes violaceus than to Necrobia violacea; the character, thurax villosus, belonging more to the former than to the latter, the prothorax of which is much less hairy; but the terms in which he describes its habitat in the Systema Natura, cadaveribus inhians, indicates the latter. I believe I was the first who pointed out the difference between the two to the late Mr. Marsham, and the trivial name he adopted, Clerus Quadra, was suggested by me.

There seems to be some tendency in this genus to Cryptophagus, \&c.

CXXXViI. Genus THANASIMUS. Lat.

(333) 1. * Thanasimus abdominalis. Abdominal Thanasimus.

T. (abdominalis) niger, pubescens: abdomine testaceo; antennis pedibusque rufis; elytris fasciis duabus undulato-angulatis piloso-albis.

Abdominal Thanasimus, black, downy; abdomen testaceous; antennæe and legs rufous; elytra with two undulato-angulated hairy white bands.

PLATE II, FIG. 5.

Length of the body $4 \frac{1}{2}$ lines.

Several specimens taken in Lat. $65^{\circ}$.

DESCRIPTION.

Body black, hairy, with longish white and some black hairs. Head punctured with two posteriorly converging impressed lines between the eyes; palpi and antennæ dull rufous, last joint of the labial palpi, which are more than twice the length of the maxillary, very large and semicordate; last joint of the antennx, which are shorter than the prothorax, ovate and subacuminate; eyes kidney- 
shaped, rufous, with a golden lustre: prothorax thickly punctured, not wider and not much longer than the head, constricted behind, and anteriorly with a pair of oblique impressions, one on each side: elytra minutely puncturel, with larger punctures arranged in five rows, the two exterior ones reaching from the shoulder to the mildle, and the interior ones not so far ; the elytra are traversed by a pair of white undulato-angular bands formed of decumbent hairs; the first begins at the base below the scutellum, and ruming down along the suture for a little way then diverges and forms the band which is broadest at the lateral margin; the other band is near the apex, broad, and projects anteriorly into an angle: the legs are dull-rufous: the abdomen is between testaceous and orange with the tips of the segments paler.

\title{
Family CYPHONIDAE. Cyphonidans.
}

CXXXVIII. Genus CYPHON. Fab.

$(334)$

\author{
1. Crphor fusciceps. Broun-headed Cyphon. \\ C. (fusciceps) luridus, pubescens: capite, antcnnis, abdomine, femoribusque fuscis. \\ Brown-headed Cyphon, lurid, puhescent : head, antenne, abdomen, and thighs brown.
}

Length of the body $1 \frac{8}{4}$ line.

A single specimen taken.

DESCRIPTION.

Body lurid, downy. Head brown, mouth lurid; antenna mutilated in the specimen, but what remains is brown: prothorax very short, transverse, slightly bisinuate both anteriorly and posteriorly ; disk embrowned: clytra very minutely and thickly punctured: breast and belly brown: thighs embrowned.

\section{Family TELEPHORIDÆ. Telephoridams.}

CXXXIX. Genus TELEPHORUS. Schæef.

$(335)$

1. Telephorus ater. Black Telephorus.

Telephorus ater. Oliv. Ent. ii, 26, 13, 12, t. i, f. 3. Stepl. Illustr. Mandib. iii, 294, 5.

Cantharis atra. Jinn. Syst. Nat. ii, 649, 16. Fab. Syst. Ent. 206, 5; Syst. Elcuth. i, 297, 18. Gyll. Ins. Suec. i, 3336, 10. Fall. Canth. 12, 9. Illig. Kaf. Preuss. i, 301, 10. Panz. Ent. Germ. i, 90, 7.

Length of the body $2 \frac{3}{6}$ lines.

$\Lambda$ single specimen taken in the Journey from New York to Cumberland-house. 


\section{DESCRIPTION.}

Body black, rather hairy. Head suborbieular, obsoletely ehannelled : mouth, palpi, and base of the antennæ, rufous : prothorax rather wider than long, very glossy; disk obsoletely channelled and a little elevated on eaeh side the ehaunel; anterior angles rounded: elytra minutely and confluently punctured, when elevated from the body they appear embrowned: tip of the thighs, tibix, and tarsi, rufous.

\section{2. * Telephorus Westwoodi. Westwood's Telephoms.}

T. (Westwoodii) niger, capite rufo fascia nigra tridentata, antennis basi, therace, anoque rufis.

Westwood's Telephorus, black, head rufous with a black tridentated band; antennæ at the base, thorax, and anus, rufous.

Length of the body $5 \frac{1}{4}$ lines.

A single specimen taken in Lat. 65 .

\section{DESCRIPTION.}

Body blaek, downy. Head suborbieular, rufous with a black anteriorly tridentate band between the eyes; mandibles and palpi dusky at the tip; antennæ shorter than the body with the scape and the base of the pedicel, or second joint, rufous: prothorax rufous, rather wider than long, anteriorly rounded, posteriorly transverse with the margin much reflexed; disk slightly channelled: elytra obsoletely punctured, or wrinkled, with three obsolete longitudinal elevated lines, the outer one abbreviated at both ends; legs dusky, base and apex of the four anterior thighs rufous; posterior thighs rufous, dusky at the tip.

\section{3. * Telephorus Samouellit. Samouelle's Telephorus.}

T. (Samouellii) niger; capite, prothorace, scutello, pedibus, ventreque segnentis apice lateribusque pallide, testaceis.

Samouelle's Telephorus, black; head, prothorax, scutellum, and legs testaceous : apex and sides of the ventral segments pale testaceous.

Length of the hody $5 \frac{1}{4}$ lines.

Taken in the Route from New York, in Lat. $65^{\circ}$. and in the Rocky Mountains. DESCRIPTION.

Very like T. Westwoodii, but the antennæ are dusky, pale at the base; between the eyes is a faint dusky eloud; the seutellum and the legs are testaeeous, as are the sides and tips of the ventral segments of the abdomen as well as the anus. 
T. (Curtisii) niger; capito rufo fascia interoculari nigra; prothorace elongato, scutcllo, pedibus, ventreque seymentis apice et luteribus, testaceis.

Curtis's Telephorus, black; hend rufous with an interocular black band; elongated prothorax, scutellum, legs, apex, and sides of the ventral segments, testaccons.

\section{Length of the body $4 \frac{1}{4}$ lines.}

Taken in Lat. $65^{\circ}$.

DESCRIPTION.

Very like the preceding speeies, but it is smaller, there is a black band between the eyes; the prothorax is considerably longer and narrower in proportion, the posterior angles are more acute, and the tarsi are black.

xxviii. * Subgenus Malchacus. Kirb.

Palpi with the terminal joint narrow and subtriangular.

Prothorax nearly square.

This subgenus differs from the genuine Telephori in the different shape of the terminal joint of its palpi.

\section{I. * Telephorus (Malthacus) puncticoldis. Puncture-necked T. Malthacus.}

T. M. (puncticollis) nigra capile rhomboidali; prothorace punctulato bigibbero, canaliculato, utrinque luteo; ore, elytrisque latere antice, pallidis; antcnnis basi subtus, cubitisque obscure rufis.

Puncture-necked T. Malthacus, black; head rhomboidal ; prothorax minutely punctured, two-hunched, channelled, reddish-yellow on each side, mouth and elytra anteriorly on the side, pallid; antennse at the base underneath and cubits, obscurely rufous.

$$
\text { PLATE VII, FIG. } 4 .
$$

Length of the body $2 \frac{1}{3}$ lines.

\section{A single specimen taken in Lat. $54^{\circ}$.}




\section{DESCRIPTION.}

Body black, rather hairy, with short decumbent white hairs. Head rhomboidal, lightly and minutely punctured; posteriorly obsoletely channelled; impressed between the eyes; pale-yellow below the antennæ; antennæ longer than the prothorax, three first joints underneath of a dull-red, second and third, taken together, scarcely longer than the fourth: prothorax nearly square, lightly and very minutely punctured; anterior angles rounded, posterior rectangular; disk channelled, and on each side the channel longitudinally elevated; sides luteous; posterior margin reflexed: elytra very minutely and thickly punctured; lateral margin anteriorly rather pale : legs black; troehanters and cubits dull-rufous.

\section{2. * Telephorus (Malthacus) Lavicoldis. Smooth-necked T. Malthacus.}

T. M. (lavicollis) niger, capite rhombuidali; antice, antennis basi, pedibusque luteis ; prothorace lavissimo disco canaliculato utrinque subelevato, angulis anticis obtusissimis luteis, posticis subrecurvis.

Smooth-necked T. Malthacus, black, bead rhomboidal, anteriorly, antennæ at the base, and legs, luteous : prothorax impunctured; disk channelled, somewhat elevated on each side; anterior angles very obtuse, luteous; posterior subrecurved.

Length of the body $3 \frac{1}{2}$ lines.

A single specimen taken in the Rocky Mountains.

DESCRIPTION.

Body black, somewhat hoary with decumbent hairs. Head impunctured, impressed transversely between the eyes; mouth and three first joints of the antennæ luteous; prothorax nearly square very glossy, impunctured; elytra less visibly punctured than in the preceding species; legs luteous, thighs brown at the base.

\section{3. * Telephorus (Malthacus) mandibularis. Mandibular T. Malthacus.}

T. M. (mandibularis) totus ater, mandibulis solis rufis.

Mandibular T. Maltbacus, entirely black, mandibles only rufous.

Length of the hody $2 \frac{3}{4}$ lines.

Several specimens taken in Lat. $65^{\circ}$.

DESCRIPTION.

Body all black, except the red mandibles, somewhat hoary with decumbent hairs. Hind-head received by the prothorax; eyes very prominent; antennæ longer than the prothorax; third joint nearly twice the length of the sccond: prothorax impunetured, scareely wider than long, all the angles rounded; disk channelled, less elevated on each side; posterior lateral margins somewhat reflexed: clytra black, minutely and confluently punctured.

This species, as to the insertion of its head, varies from the others, and comes ncarer to the typical Telepltori. 
xxix. "Subgenus Brachrótus. Kirb.

Prothorax transverse, short, anteriorly and posteriorly subemarginate.

'This subgenus has the palpi of Malthacus, but the prothorax is of a very different shape; it comes near to I'ygolampis, or Lampyris italica L.

\section{1. * Telephorus (Brachynotus) Benneti. Bemet's 'T'. Bruchynotus.}

T. B. (Bennetii) niger, naso prolhoraceque pallidis; hoc maeula discoidali nigro.

Bennet's T. Brachynotus, blaek; nose and protborax pale, the latter with a blaek discoidal spot.

Length of the body 6 lines.

Taken in Canada by Dr. Bigsby, and in Massachusets by Mr. Drake. DESCRIPTION.

Body black, hoary with decumbent hairs. Head suborbicular, punetured behind the antennæ; neek rufous; front, before the antcmnx, palc yellow; exterior margin of the nosc black; mandibles yellow at the base; antemn longer than the prothorax: prothorax pale yellow, disk elevated with a black irregular punctured spot: elytra minutely and confluently punetured, somewhat dilated externally; obsoletely tricarinate: legs black; knees rufous.

\section{Family LAMPYRID无. Lampyridans.}

CXL. Genus LAMPYRIS. Linn.

Lampyris corusca. Linn. Syst. Nat. ii, 64t, 2. Uddm. N. Sp. Ins. 47. Fal. Spec. Ins. i. 251, 3; Syst. Eleuth. ii, 100, 3. Oliv. Ent. ii, ㅇ, 19, 14, ८. ii, f. 14. Sturm. Ins. Cab. ii, t. xxii.

Length of the body $4 \frac{3}{4}$ lines.

Taken at New York and Cumberland-house Lat. 54º. In Canada by Dr. Bigsbỵ. DESCRIPTION.

Body oblong, pubescent, brown-black. Nose and mouth elongated: prothorax nearly semicircular, disk elevated; a rosc-coloured arched streak dilated and yellower anteriorly adjoins the elevated part on each side: elytra obsoletely carinated, most numerously and minutely punctured.

Linne gives this as a native of Finland and Russia, on the authority of Uddmann, but it has not sinee becn found there. Perhaps Uddmann might have mistaken American speeimens for European.

The Lampyride seem to lead towards the Blattina, I have therefore placed them last in the series of insects with soft elytra, as comnected with the Orthoptera in a different point from Meloe. Mr. Stephens has placed the Brachelytra next to the Dermaptera, and not without some appearance of reason, but their connection with Necrophorus and consequently with the Necrophaga, ${ }^{5}$ is so mucls more striking that I do not see how they ean be displaced without violating nature. 


\title{
ORDER ORTHOPTERA. Olir.
}

\author{
I. SALTATORIA. Lat. \\ Family LOCUSTID瓜. Locustidans.
}

CXLI. Genus LOCUSTA. Lcach.6

(344)

\section{Locusta leucostoma. White-mouthed Locusta.}

L. (leucostoma) rufescenti-nigricans; prothorace postice subcarinato; labro, palpis apice, mandibularumque macula magna, albis; antennis pedibusque rufescentibus.

White-mouthed Locust, blackish with a reddish tint ; prothorax subcarinated posteriorly; upper lip, apex of the palpi, and large spot of the mandibles, white; antennæ and legs reddish.

Length of the body $13 \frac{1}{2}$ lines.

A single specimen taken in Lat. $65^{\circ}$.

DESCRIPTION.

Body obscurely rufous, clouded with darker shades. Upper lip, and large spot of the mandibles, white; palpi reddish with the two last joints whiter, summit black; antennæ as long as the trunk, which on the upper side is subpubescent : last segment of the prothorax carinated: tegmina cinereons, with piceous and rufo-piceous nervures; and at the base is a longitudinal mesal series of black spots: the legs are rufo-testaceous, with the summit of the thighs and the spines black; the posterior thighs above are clouded with the same colour.

\section{Locusta verruculata. Warty Locust.}

L. (verruculata) cinerea, nigro obscure irrorata; prothorace toto rugoso, carinato, dorso verriculato; antennis pallidis apice nigris, thorace brevioribus.

Warty Locust, cinereous obscurely powdered and spotted with black; the whole of the prothorax is wrinkled and carinated; and its upper surface warty : antennæ pale, black at the tip, shorter than the thorax.

Length of the body $122_{4}^{2}$ lines.

A single specimen taken in Lat. $57^{\circ}$.

6 Gryllus Locusta 1. See Zool. Journ. ii, 431. 


\section{DESCRIJTION.}

Body cincreous sprinkled with black dots or punctures, and indistinct spots. Head punctured; palpi white at the tip; mandibles piccous; antemne shorter than the trunk, pale, black at the tip and longitudinally concavo-conrex : prothorax with an entire longitudinal dorsal ridge, wrinkled, and warty from the wrinkles: tegmina with a reddisls tint, irregularly reticulated; wings with a black mesal band, and reddish-yellow nervures: abdomen pale underneath.

The species of this genus, which admits of numerous subdivisions from the structure and characters of the thorax, are very numerous in most countries, though very little known. Probably they may amount to hundreds.

\section{Family ACRYDIADE. Acrydiadans.}

CXLII. Genus ACRYDIUM. Fab.

\section{Acridium granulatum. Gramulated Acrydium.}

A. (granulatum) ciriereum nigro obscure nebulosum; corpore toto punctulis elevatis albidis granulatum; prothoracc abdomine longiori tricarinato ; tibiis nufo-testaceis, albido olscure fasciatis.

Granulated Acrydium, cinereous, obscurely clouded with black, with the whole body granulated witb very minute elevated whitish points : prothorax longer than the abdomen, three-ridged; shanks reddish obscurely banded with white.

Length of the body 5 lines.

A single specimen taken in Lat. $65^{\circ}$.

DESCRIPTION.

Body black, sprinkled with numberless very minute elevated points or granules. Prothorax cincreous, clouded obscurely with black, three-ridged; with middle ridge straight, and the lateral oncs curved at the base: rudiments of the tegmina cinereous, ridged, punctured with excavated punctures: nervures of the wings black, those of the costal area white: the four anterior tibix are reddish obscurely banded or rather annulated with white.

N. B. The hind legs are wanting in the specimen.

This species belongs to Mr. Stephens's family $A$. 


\title{
ORDER NEUROPTERA. Linn.
}

\author{
I. LiBELLULINA. Mac I. \\ Family AGRIONID正. Agrionidans.
}

CXLIII. Genus AGRION. Fab.

$(347)$

1. Agrion Puella. Common Agriom.

Agrion Puella. Fab. Ent. Syst. ii, 387, 2. Ced. Fn. Ingr. 186, 57I. Stepb. Illustr. Mandib. vi, 73, 5. Iam. An. sans Vertèbr. iv, 229, 2. Lat. Crust. Arachn. et Ins. ii, 241. Ramd. Verdaung. Ins. 147, 5, t. xv, f. 4.

Libellula Puella. Iinn. Syst. Nat. ii, 905, 21; Fn. Suec. 1471. Scop. Carn.682. Schrank. Enum. 601. Vill. Ent. iii, 13, 26.

Mouff. Ins. 68, fig. infer. Rai. Hist. Ins. 5I, I5. Rös. Ins. ii, aquat. 2, t. x, f. 3, 4. Reaum. Ins. vi, t. xl. Sulz. Ins. $t$. xvii, $f$. 102. Geoff. Ins. ii, 224, 5. De Geer Ins. ii, 2, 60. H-s. Exp. t. xxix, f. 5, 6 ?

VARIETY B. Trunk sea-green, above black witn two sea-green longitudinal stripes: abdomen black, sea-green at the base, inscribed with black: legs black above, underneath sea-green or white; the stigma of the wings is blackish with a transparent margin.

C. Trunk black and white with two dorsal white longitudinal stripes; legs black; stigma of the wings black: abdomen mutilated.

Both taken in Lat. $65^{\circ}$.

II. PERLINA. Kirb.

Family PERLIDÆ.

CXLIV. Genus PERLA. Geoff.

\section{Perla bicaudata. Two-tailed Perla.}

Perla bicaudata. Lat. Hist. Nat. xiii, 49; Crust. Arachn. et Ins. ii, 258. Lam. An. sans Vertèbr. iv, 19I, 2. Steph. Illustr. Mandib. vi, 136, 3.

Perla fusca. Geoff. Ins. ii, 231, 1.

Phryganea bicaudata. Linn. Syst. Nat. ii, 908, I ; Fn. Suec. 1489. Schrank. Enum. 607. maxima. Scop. Carn. 705.

Semblis bicaudata. Fabr. Ent. Syst. ii, 73, 8. Ced. Fn. Ingr. 414.

Reaumar. Ins. iii, t. xiii, f. 12? iv, t. xi, f. 9, I0. Wagn. Helvet. 227-229. Sulz. Ins. $t$. xvii, $f .6$.

Length of the body about $7 \frac{1}{2}$ lines.

Several specimens taken in Lat. $68^{\circ}$. 
DESCRIPTION.

Body black, hairy. Antennx, tibix, tarsi, caudal setx, and wings dull testaceous; the vertex consists of al yellowish membranous spot: the joints of the eaudal antenniform organs are dark at the tip.

The larva is white unclemeath, fusco-cincrous above; head and thorax spotted with white, with a pale longitudinal line. More than one species seems to have passed under the name of Phryganea bicaudata. I will not affirm that the present species is not distinct: but as the specimens were not perfect, I thought it best to consider them as belonging to that type.

\section{ORDER 'TRICHOPTERA. Kirh.}

\section{Family PHRYGANID无.}

CXLV. Genus LIMNEPHILUS. Leach.

\section{1. * Limnephilus nebulosus. Clouded Limnephilits.}

I. (nebulosus) niger; alis superioribus testaceis, albido maculatis irroratisque, area costali immaculata; inferioribus albidis : neuris testaceis.

Clouded Limnephilus, black with the upper wings dusky-testaceous spotted and dotted with white, the costal area being without spots; under wings whitish with testaceous nervures.

Length of the body 7 lines.

\section{A single specinien taken in Lat. 65.}

\section{DESCRIPTION.}

Body black, hairy with whitish hairs. Antennæ are mutilated in the specimen, but the base is black: scutellum testaccous: upper wings testaceous spotted and dotted with white cxcept the costal arca, which is without any of that colour; under wings white with testaceous nervures: legs testaccous.

\section{2. * Limephilus femoralis. Femoral Limmephilus.}

I. (femoralis) nigcr, alis superioribus dilute testaceis albo maculatis irroratisque; inferioribus albis neuris testaceis : pedibus testaceis femoribus nigris.

Femoral Limnephilus, black, with the upper wings pale testaceous, spotted and dotted with white; under wings white with testaceous nervures; legs testaccous with black thighs.

Length of the body $6 \frac{1}{2}$ lines.

Taken with the preceding.

DESCRIPTION.

Very like the preceding species, but palcr, with black scutellum and thighs. 


\section{ORDER HYMENOPTERA. Linn.}

\section{TEREBRANTIA.}

i. Securifera. Lat.

\section{Family CIMBICIDÆ. Cimbicidans.}

CXLVI. Genus CIMBEX. Oliv.

\section{1. Сimbex femorata. Large-thighed Cimbex.}

Cimbex femorata. Fab. Syst. Piezat. 15, 1. Stepb. Illustr. Mandib. vii, 6, 1. Lat. Crust. Arach. et Ins. ii, $272 . \quad$ St. Farg. Tenthred. 31, 83. Lam. An. sans Vertèbr. iv, 176, 1. Walck. Fn. Paris 2, 32, 1.

Europea. Sam. Compend. 262, 1.

Tentluredo femorata. Linn. Syst. Nat. ii, 120, 1; Fn. Suec. 1533. Fab. Ent. Syst. ii, 104, 1. Ced. Fn. Ingr. 455.

Vill. Ent. iii, 78, 1. Panz. Fn. Germ. xxvi, t. 20. De Geer Ins. ii, 944, 2, t. xxxiv, f. 1-6. Jur. Hymen. 47.

Crabro femorata. Geoff. Ins. ii, 263, 3, t. xiv, f. 4. Scop. Ann. Hist. Nat. v, 120, 142. Sulz. Ins. t. xxvi, f. 4. Schæeff. Icon. $t$. civ, f. 1, 2. Alb. Ins. 69 .

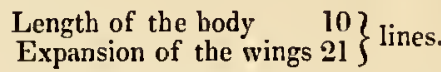

A single specimen taken in Lat. $65^{\circ}$.

DESCRIPTION.

q

Body very black, hairy. Antennæ yellow, brown at the base: legs blue-black; tarsi yellow: wings hyaline with yellow nervures, brown at the tip, with a brown cloud in the middle areolet adjoining the costa.

CXLVII. Genus TRICHIOSOMA. Leach. 1. * Trichiosoma Triangulum. Triangle Trichiosoma.

T. (Triangulum) nigrum, cinereo-lanuginosum; antennis articulis tribus clavo proximis, alis, tibiis tarsisque, testaceis; femoribus atro-ceruleis; abdomine ferrugineo, dorso triangulo isosceli nigro insigni.

Triangular Trichiosoma black, bairy, with cinereous lanuginous hairs; antennæ with the three joints next the knob, the wings, and the tibiæ and tarsi, testaceous; thighs black-blue; abdomen ferruginous, with a dorsal black isosceles triangle.

Length of the body 9 lines.

A single specimen taken in Lat. 650. Another was also sent me from Canada by Dr. Bigsby. 
DESCRIPTION.

Body black, shining, covered with soft and woolly whitish hairs, punctured more or less. Head, excluding the mandibles, depressed, orbicular, as wide as the trunk; mandibles crossed, very sharp, black; upper lip subpentagonal, flat with a longitudinal elevation in the middle, bairs on this part black; anterior margin of the nose wavy, emarginate in the middle; antennx with the fourth, fifth, and sixth joints testaceous; three eyelets behind the antenna arranged in a triangle; eyes oval, prominent; vertex square, marked out by a ridge on each side: trunk subglobose: prothorax with a longitudinal furrow: thighs and coxa black-blue; under a strong magnifier beautifully and most minutely reticulated which gives them a silky lustre; the rest of the leg is testaceous; the two posterior pair of thighs are thicker than the others and armed at the apex with a short tooth on each side, between which is a cavity to receive the shank when folded; tarsi with a sucker underneath at the apex of the four first joints: wings testaceous with piceous nervures, and at cloud at the tip; abdomen ferruginous with a dorsal triangular black spot, extending from the base towards the apex, but not entering the last segment; the basilar ventral segments are spotted with brown.

I at first regarded this insect as a variety of Cimbex Vitelline, but the colour of the antennx and legs differs; and what Linne meant by the words labio caret, is not clear-but as the upper lip is very conspicuous, though entirely black, it cannot be supposed to agree in that respect; unless we interpret his words as meaning that it had not a white lip like $C$. Amerina, the next species, which seems not very probable. St. Fargeau, in his Monograph on the Saw-flies (Tenthredinete,) has a Cimbex Vitelline, but his description does not agree with that of Limné. 2. Trichiosoma Lucorum. (Leach.) Trichiosoma of the groves.

Trichiosoma Lucorum. Leach. Zool. Misc. iii, xxviii, 110, 5. Stepb. Illustr. Mandib. vii, 10, 4 Cimbex Lucorum. Fab. Syst. Piezat. 16, 2. St. Farg. Tenthred. 33, 89.

Tenthredo Lucorum. Linn. Syst. Nat. ii, 921, 6; Fn. Suec. 1537. Fab. Ent. Syst. ii, 105, 2. Vill. Ene. iii, 8I, 6.

$$
\left.\begin{array}{l}
\text { Length of the body } 7 \\
\text { Expansion of the wings I5 }
\end{array}\right\} \text { lines }
$$

A single specimen taken in $\mathrm{Lat}^{\circ} .65$.

\section{DESCRIPTION.}

Body black with a very slight æneous tint; glossy, hairy with cinerascent hairs, those of the trunk long. Head orbicular, scarcely so wide as the trunk; upper lip small, convex, orbicular, punctured; antennæ black: wings subhyaline with a cloud at the tip; nervures some piceous and others rufous: thighs black with a very slight tint of blue; posterior pair armed with a tooth: abdomen short, subovate, black, covered more or less with short decumbent down; black above, underneath reddish at the tail. 


\section{Family TENTHREDINIDÆ. Tenthredinidans.}

CXLVIII. Genus ALLANTUS. Panz.

\section{Allantus meucostoma. White-mouthed Allantus.}

A. (leucostoma) atra, nitida, glabra; antennis thorace subbrevioribus ; naso emarginato; labro, palpis, mandibulisque basi, albis ; pcdibus flavis; tarsis posticis tibiarumque apice nigris.

White-mouthed Allantus, very black, glossy, naked; antennæ somewbat shorter tban the thorax, with the notched nose, upper lip, feelers, and base of the mandibles, white; legs yellow; with the posterior tarsi, and apex of the posterior tibiz, black.

Length of the body 6 lines.

One specimen taken in Lat. $65^{\circ}$.

DESCRIPTION.

Body narrow, black, glossy, without hairs. Head searcely so wide as the trunk, wedge-shaped; palpi, suborbieular upper lip, emarginate nose, and base of the mandibles, white; apex of the latter rufous; antennæ a little shorter than the trunk, nine-jointed, with the third joint longer than any of the others; neck eonstricted: tegulæ testaceous: wings subliyaline with piceous nervures: legs yellow, with the apex of the tibiæ, and the whole of the tarsi of the posterior legs, black: abdomen linear, aeute at the anus.

This speeies comes near Allantus ater, but the mandibles are rufous at the apex; the palpi are whiter; and the legs of a different colour.

\section{UROCERATA. Lat.}

\section{Family SIRICIDAE. Siricidans.}

CXLIX. Genus SIREX. Linn.

1. Sirex bizonatus. (Stephens.) Two-zoned Sirex.

Sirex bizonatus. Stepb. Cat. 342, 3998; Illustr. Mandib. vii, 114, 2, t. xxxvi, f. 1.

$\left.\begin{array}{l}\text { Length of the body } 18 \\ \text { Expansion of the wirugs } 27\end{array}\right\}$ lines.

Taken in Lat. $65^{\circ}$. and in the Journey from New York. 


\section{DESCRIPTION.}

Body very black, covered with innumerable punctures from each of which proceeds a black upright hair. Head narrower than the trunk; mandibles incumbent; palpi rufo-piceous: antennæ as long as the trunk, yellow; behind each cye is a large oval yellow eyc-like spot perfectly naked and smooth: legs and tip of the thighls yellow: wings yellowish with dark nervures: abdomen with the second, seventh, and eighth segments luteous: anal mucro linear, yellow, terminating in a point : ovipositor black.

The specimens of this spccies, which Mr. Stephens found near London, might probably have heen imported in fir timber from C'anada.

Sirex Juvencus. Linn. Syst. Nat. ii, 929, 4; Fn. Suec. $1575 . \quad$ Fab. Ent. Syst. ii, 126, $9 ;$ Syst. Piez. 50, $9 . \quad$ Klug. Sir ic. 36, 4, t. iii, f. 4, 5. Panz. Fn. Germ. lii, t. 17. Sulz. Ins. t. xxvi, f. 9, 10. Schæff. Icon. t. cev, f. 3. Walck. Fn. Paris. ii, 45, 3. Vill. Ent. iii, 128, 3. Ced. Fn. Ingr. 474. Steph. Illustr. Mandib. vii, 114, 4. Spin. Ins. Ligur. i, 60, 2. Curtis Brit. Ins. vi, $t$. ccliii.

Urocerus Juvencus. Lat. Gen. iii, $244,3$.

Iclneumon. De Geer Ins. i, 568, t. xxxvi, f. 7 .

Ichneumon Juvencus. Scop. Carn. 741 .

Torvus. H-s Exp, t. xxviii. Sirex $f$. I.

$\left.\begin{array}{l}\text { Length of the body, mucro included } 11 \\ \text { Expansion of the wings . . . 20 }\end{array}\right\}$ lines.

One specimen taken in Lat. $65^{\circ}$.

\section{DESCRIPTION.}

Body black-blue, glossy, punctured very thickly on the head and trunk, in which from each puncture proceeds a black hair. Head between globose and triangular, very hairy with a naked spot behind the eyes; cheek terminating in a tooth or point as in the other species of the genus; vertex blue-green : antennæ black, shorter than the thorax; palpi piceous: trunk subglobose, with the central part of the thorax, and the part between the four anterior legs tinted witl green: legs rufous with the coxæ and trochanters black: wings hyaline with piceous nervures: abdomen naked, terminated by a subtriangular acuminated mucro or horn; ovipositor piceous.

In this specimen the ovipositor is longer and gocs further beyond the anal horn than in the European ones, and the horn itself is more dilated at the base. 
III. PARASITA. Kirb.

i. Pupivora. Lat.

\section{Family FOENIDZE. Fonidans.}

CL. Genus FCENUS. Fab.

$(357)$

\section{Fonus Jaculator. Aicher Fonus.}

Fœenus Jaculator. Panz. Fn. Germ. xevi, t. 16. Fab. Ent. Syst. Suppl. 241 ; Syst. Piez. 141, 1. Walck. Fu. Paris. ii, 75, 1. Lat. Hist. Ins. iii, 329; Gen. 253, 1. N. D. D. H. N. xi, 581. Lam. An. sans Vertèb. iv, 148, $1 . \quad$ Sam. Compend. 268, 1. Steph. Illustr. Mandlb. vii, 120, 1. Jur. Hymenopt. 58, 1.

Ichneumon Jaculator. Linn. Syst. Nat. ii, 937, 52; Fn. Suec. 1626. Fab. Ent. Syst. Em. ii, 177, 183̇. Vill. Ent. iii, 173, 117. Ced. Fn. Ingr. 505.

Reaum. Ins. iv, 157, t. x, f. 14, 15. De Geer Ins. i, 560, t. xxxvi, f. 10.

Two specimens taken in Lat. $65^{\circ}$.

DESCLIPTION.

The American specimens differ from those of Europe, which also vary, in having the red segments of the abdomen marked with a large black basilar dorsal spot, the former having mostly only a darker cloud. Panzer's figure, however, comes very near the American.

ii. Larvivora. Kirb.

Family ICHNEUMONID无

CLI. Genus ICHNEUMON. Linn.

\$ ix. Scutello nigro, abdomine vel toto rufo, vel rufo et nigro. Ġrav. 1. * Ichneumon Ferrugator. Rusty Icheumom.

I. (Ferrugator) ater, punctulatissinus, palpis, tibiis anticis, tarsisque omnibus, abdomine segmentis, excepto antico nigro, rufescentibus.

Rusty Ichneumon, thickly and minutely punctured, with the palpi, anterior tibiæ, all the tarsi, the wings, the abdominal segments except the first which is black, more or less red.

Length of the body 7 lines.

Taken in the Expedition, but no locality stated. 


\section{DESCRIPTION.}

Abdomen black, rather glossy, very thickly punctured with minute and often confluent punctures. Head transverse, triangular, not quite so wide as the middle of the trunk; anterior margin of the face rounded; palpi reddish ; eyes long, subclliptical; antennæ shorter than the trunk, spirally convoluted: trunk oblong, subcompressed; scutellum subtriangular, rounded at the apex; metathorax armed on each side with a short tooth, with several elevated longitudinal and oblique lines; legs with decumbent whitish hairs, anterior tibia obscurcly, and all the tarsi, rufous; wings embrowned with a rufous tint, nervures darker: abdomen lineari-lanceolate, rufo-ferruginous, with the first joint, which is dilated at the apex, black; footstalk channelled longitudinally on each side.

\section{Family CRYPTIDE. Cryptidans.}

CLII. Genus CRYPTUS. Fab. Grav.

§ii. Scutello pallido, abdomine nigro. Grav.

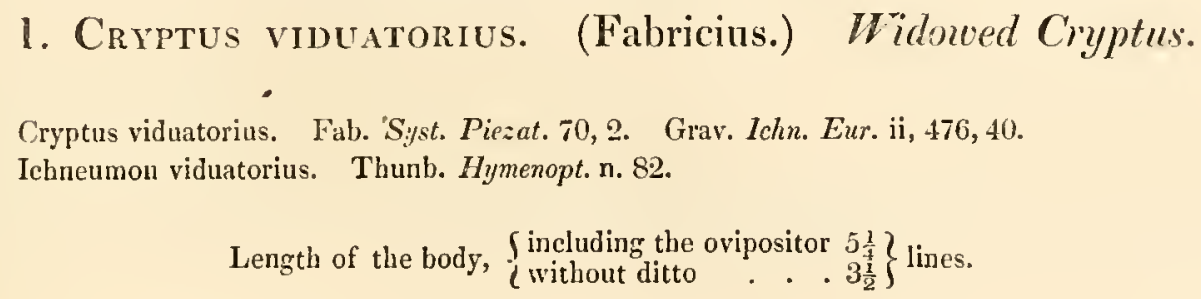

One specimen taken in Lat. $54^{\circ}$.

\section{DESCRIPTION.}

Body black. Head subtriangular, transverse, very minutely and thickly punctured; palpi pale rufous; face plane with two elevations in the middle; eyes large, oval ; antennæ shorter than the trunk, rather slender, involute, black with a white band in the middle; orbit of the eyes behind with a very indistinct white line: trunk oblong, cubical, gibbous, very thickly and confluently punctured except on the back; tegulæ whitc; metathorax armed with two minute teeth on each side, one in the middle and the other at the base, forming the terminal angle, marked out into three areas by elevated lines: legs red with coxæ, trochanters, and posterior tarsi black; wings subtestaceous with the larger nervures black: abdomen, excluding the ovipositor, scarcely so long as the trunk; first segment impunctured, glossy, dilated at the apex, which is subquadrangular; footstalk flat; second and third segments very large, with their gloss obscured by infinitely minute punctures; ovipositor shorter than the abdomen; borer red. 


\section{Genus CRYPTOCENTRUM. Kirb.}

Head betwcen transverse and globose; face quadrangular, with the anterior margin crenate; palpi long, filiform: antennæ slender, first joint thick; second minute; third longer than the rest: trunk ovate-oblong, subcompressed; neck moderately long; scutellum trapezoidal; legs slender, posterior pair elongated : upper wings-apical areolets three; middle four, viz. 2, 2, without a cellule ; basilar threc; under wings-areolets seven, viz. $4,3:^{8}$ abdomen sessile, smooth, subcompressed, in the female clubbed at the apex; four first segments longer than the rest, the first curved, rather wider at the apex; the three next are wider than long, the last is minute and triangular; at the extremity the tail is cleft for the passage of the ovipositor, this cleft is formed by the turning up of the sides of the last ventral segment; ovipositor very short; the four last ventral segments, at least in the dead insect, project so as to form an elevated ridge in which the ovipositor is concealed.

The insect from which I have taken the characters of this genus does not appear to arrange under any of those of Gravenhorst; its place would be near Accenites. 1. * Cryptocentrum hineolatum. Limeolate Ciyptocentrum.

C. (lineolatum) atrum, subnitidum; facie, palpis, antennis scapo extrorsum, oculorum orbita utrinque, pedibus quatuor anticis basi, scutello lineolis duabus transversis, abdominisque segmentis apice, posterioribus interrupte, niveis.

Lineolate Cryptocentrum. black, rather glossy; with the face, feelers, scape of the antennæ externally, orbit of the eyes on each side, the four anterior legs at the base, two transverse streaks of the scutellum, and the apex of the abdominal segments, in the posterior ones interruptedly, snowy-white.

PLATE VI, FIG. 1.

Length of the body 6 lines.

A single specimen taken in Lat. $65^{\circ}$.

DESCRIPTION.

Body very black, somewhat glossy, sprinkled with whitish decumbent hairs. Head subtrausverse, hollowed out behind to receive the neck; face with a streak on each side the eyes; feelers and scape of the antennæ on the outside white: antennæ slender, black, externally obscurely testaceous, with a white annulet below the middle; trunk compressed; margin of the collar on each side, tegulæ, and two transverse elevated streaks on the scutellum, white: four anterior legs with the coxæ and trochanters, tip of the thigh and under side of the tibix, white; the thighs, except the tip, testaceous; upper side of the tibiæ and tarsi, and long posterior legs, black: wings hyaline with black nervures: abdomen sessile, with the last segments dilated for the reception of the ovipositor; the apical margin of all the segments but the two first is interruptedly white; but in those segments the interruption is not perfect.

7 By this name Mr. Stephens distinguishes an areolet which Jurine calls the petiolated cubital cell $(39, t . i, f .3, b$.$) and$ Gravenhorst the arcolet.

${ }^{8}$ Introd. to Ent. iii, 630-. 


\section{Family BRACONIDE. Braconidans.}

CLIV. Genus BRACON. Fab.

$(361)$

1. Bracon crocator. Saffiron-coloured Bracom.

B. (crorator) ater, nitidus ; abdomine croceo; alis infuscatis ; ovipositore corpore vix breviore.

Saffron-coloured Bracon, very black, glossy; abdomen saffron-coloured; wings embrowned; ovipositor scarcely shotter than the body.

Length of the body without the ovipositor 3 lines.

A single specimen taken in Lat. $65^{\circ}$.

DESCRIPTION.

Body very black, glossy. Head subglobose, with the segment of a circle taken out behind; eyes between oval and round; antennæ as long as the trunk; trunk oblong, widest between the wings; scutellum rather large, rounded at the apex; metathorax obsoletely transversely wrinkled, sloping towards the abdomen: posterior legs rather robust: wings embrowned, middle areolets four, viz. 3 and 1 , all quadrangular; stigma very large: abdomen lanceolate-ovate, as long as the trunk, saffron coloured, paler towards the apex; the three first segments are emarginate, and marked with two longitudinal faint furrows, the first pair being curvilinear: ovipositor longer than the body, borer red.

IV. ACULEA'TA. Lat

i. Heterogrina. Lat.

a. Philopona. Kirb.

\section{Family FORMICID正. Formicidans.}

I consider the Heterogyna of Latreille as consisting of two races.

1. The Philopona containing all those genera, that constitute Linnés genus Formica, distinguished by their admirable industry, their wonderful economy, and the nests they construct.

2. The Misopona consisting of Linné's genus Mutilla, affording no such examples. 
CLV. Genus FORMICA. Linn.

\section{1. * Formica semipunctata. Semipmetured Formica.}

F. (semipunctata) nigra, glabra; abdomine pubescente, punctato; segmentis apice membranaceis rufescentibus, intermediis basi levibus.

Semipunctured Formica, black, naked; abdomen downy, punctured; segments membranous at the apex and reddish ; the intermediate ones impunetured at the base.

Length of the body $7 \frac{3}{4}$ lines.

\section{Several taken in the Journey from New York to Cumberland-house.}

\section{DESCRIPTION.}

Body black, glossy. Head something wider than the trunk, subtriangular: antennæ piceous with the scape black; wings cast in all the specimens $;^{9}$ scale vertical between the trunk and abdomen, sloping to a thin edge upwards, where it is very slightly emarginate: abdomen oblong, subcylindrical, minutely punctured with the punctures piliforous; hairs decumbent with those of the margin of the segments and the anus, longer; margin of both abdominal and ventral segments membranous, membrane reddish; base of the three intermediate segments not punctured.

This species a good deal rescmbles the Formica herculanea of Linné (F. ligniperda Latr.) but it is proportionably more narrow, and entirely black save the legs and upper portion of the antennæ. I at first took it for a variety of $F$. pubescens of Latreille, ${ }^{1}$ but in his description of that species, he makes no mention of the punctures of the abdomen, nor of the rufescent membranous margin of the abdominal segments, circumstances also which distinguish it from $F$. pennsylvanica of De Geer, and which, from the figure of that author, is evidently a much smaller insect. ${ }^{2}$

(363)

\section{Formica fusca. (Linné.) Brown Formica.}

Formica fusca. Linn. Syst. Nat. ji, 963, 4.; Fn. Suec. 1722. Fab. Ent. Syst. ii, 352, 11 ; Syst. Piez. 399, 13. De Geer Ins. ii, 1050, 1082, 3, t. xlii, f. 12 . Lat. Fourmis. 159, 35, t. vi, f. 32; N. Dict. D'H. Nat. xii. Article Fourmis. Crust. Arachn. et Ins. ii, 312. Geoff. Ins. ii, 428, 5. De Geer Ins. ii, 1050, 1082, 3, t. xlii, f. 12. Miill. Fn. Frid. 657; Linn. Nat. v, 913. Oliv. Encycl. vi, 433. Schrank. Enum. 833. Vill. Ent. iii, 334, 3. Berk. Syn. j, 159. Ced. Fn. Ingr. 557. Walck. Fn. Paris. ii, 162, 7. Stew. Elem. ii, 248. Jur. Hymenopt. 272. Kirb. and Sp. Introd. to Ent. ii, 62. Lam. An. sans Vertèbr. iv, 9, 5. Steph. Cat. i, 357, 1846, 8.

Formica media nigro colore splendeus Rai. Hist. Ins. 69.

The small Black Ant. Gould. Ants, $2,3$.

Formica flavipes. Fourc. Ent. Par. ii, 52.

- libera. Scop. Carn. 835 ?

Fournis noir cendrée. Hub. Fourm. 159, 35, t. vi, f. 32, A.

Length of the body $1 \frac{3}{4}$ line.

One specimen taken in Lat. $65^{\circ}$.

9 Introd. to Ent. i, 370.

1 IIist. Nat. de Fourmis. 96, t. i, f. 2, А, в.

2 De Geer, Ins. iii, 603, 4, t. xxxi, f. 9, 10. 


\section{DESCRIPTION.}

9

Body black, but not inteusely, glossy, subcinereous from down. Head triangular, large, much wider than the trunk; antenna with the seape, the three following joints, and the terminal one, rufous, the other joints are darker: trunk oblong, compressed, anteriorly elevated and wider; the prothorax with the seutellum forming a rlomboid; scutellum large, trapezoidal, subrufous; scale subtriangular, subemarginate; legs rufous; thighs embrowned; abdomen subglobose, more hairy than the rest of the body, especially towards the anus.

\section{ij. Lestica. \\ a. Diploptrirga. ${ }^{2}$ \\ Family VESPIDE. Vespidans.}

\section{Genus VESPA. Linn.}

(364)

\section{Vespa vulgaris. Common Vespa.}

Vespa vulgaris. Linı. Syst. Nat. ii, 914, 4; Fn. Suec. 1671. Fab. Ent. Syst. ii, 256, 10; Syst. Piez. 255, 9. Rui. IHist. Ins. 250. Scop. Carn. 825. Geoff. Ins. ii, 360, 2. Müll. Linn. Nat. v, 880. Frisch. Ins. 9, $t$. xii, f. 2. Schæetf. Elem. t. cxxx, Icon. $t$. xxxv, f. 4. De Geer Ins. ii, 766, 2, t. xxvi, f. 5-7. H-s. Expos. 128, $t$. xxxvii, f. 5 . Amo. Ins. venim 251, $t$. ii, $f .13 . \quad$ Sclirank. Enum. 787. Vill. Ent. iii, 263, 2. Christ. Hymenopt. 236, $t$. xxii, f. 2. Don. Brit. Ins. vii, t. cexxvi." Berk. Syn. i, 158. Ced. Fn. Ingr. 521. Walck. Fn. Paris, ii, 9], 4. Stew. Elem. ii, $23 \mathrm{~S}$. Bingl. An. Bi. iil, 34l. Panz. Fn. Germ. xlix, t. 19. Shaw. Gen. Zool. vi, 285, $t$. xev. Jur. Hymenopt. 168. Lat. N. D. D'H. N. xiv, 8; Crust. Arachn. et Ins. ii, 340. Lam. An. sans Vertèbr. iv, 88, 2. Sam. Compend. 280, ‥ Kirb. and Sp. Introd. to Ent. ii, 106. Steph. Cat. i, 374, 5029, 2. Ramd. Verdaung Ins. 132, 1, $t$ xii.

Vespa. Mouff. Ins. 45.

major. Schwenck. Theriotr. 561.

flava major. Merr. Pinax. 196.

Aristot. Hist. Anim. 1, ix, c, 41. Plin. Hist. Nat. 1, xi, r.. 21. Swamm. Bibl. Nut. t. xxvi, f. 8. Reaum. Ins. vi, t. xiv, f. $1-7$.

Dength of the body $6 \frac{1}{2}$ lines.

\section{A single specimen taken in Lat. $65^{\circ}$.}

3 Latreille names this section Diploptera, but the termination ptera being consecrated to the Orders of insects. I bave changed the term for another of the same meaning. 


\section{DESCRIPTION.}

i

Body black, variegated with yellow. Head and trunk thickly clothed with long woolly down of a grayish colour; face with threc yellow spots placed in a transverse line behind the antennæ, the two lateral ones subtriangular, the intermediate one subquadrangular, with a reddish cloud on its disk; the nosc below the antennæ is ycllow, inclining to red round the margin; it has also three black dots placed in a triangle in the disk, the two lower ones being very minute; the vertex of the nose is also black; the mandibles are yellow with black tips; on the outside the orbit of the eyes is reddislı-yellow : the trunk is black underneath; above the posterior upper margin of the collar, the tegula which cover the base of the wings, and a triangular spot underneath them, are yellow; on the metathorax and scutellum are six ycllow spots placed in a doublc series, the upper and lower pairs being subtriangular, and the intermediate pair crescent-shaped: the thighs are black at the base, but their apex, and the rest of the leg, and a small triangular spot on the inner side of the four posterior trochanters, are yellow; the wings are yellowish red with red nervures: the abdomen, except at the base, is less hairy than the rest of the body; it is yellow with all the segments, black at the base; though the blackness in the terminal ones is chiefly concealed by the antecedent scgments; in all in the middle it projects into a triangle; the four intermediate ones have also each a round-headed small black spot, the connection of which with the blackness of the base is interrupted in the second segment; on the under side of the abdomen the base of the segments is black, and the intermediate nes have cach a pair of rather crescent-shaped black spots not connected with the blackness of the base.

From this minute description, it will be seen that the American specimon which is very small, differs in several respects from the European wasps of the common specics, especially the spots on the vertex, and the six, instead of four spots, on the scutellum and metathorax: but as it exhibits nearly all the other characters ascribed by Linné to his $V$. vulgaris, I have judged it best, as there was only a single spccimen, to consider it as forming a variety rather than a species. I imaginc Aristotle's two species of wasp, one of which forms its nest in the oaks of the mountains, and the other underground, are the Vespa crabro and vulgaris of Linné; Pliny mentions his Vespe and Crabrones, the former as building their nest on high, and the latter as selecting caverus and subterraneous cavities; whence it seems probable that the last is the real $V$. vutlgaris. He mentions in the same chapter Vespee which are called Ichneumones, which carry spiders into their nest, from which circumstance it seems probable that these belonged to the modern genus Pompilus or the Spiderwasp.

\section{2. * Vespa borealis. Boreal Vespa.}

V. (borealis) nigra, antennis subtus luteis, capite flavo, trunco albido, maculatis; femoribus apice, tibiis tarsisque flavis ; abdominc subcordato flavo, segmentis basi nigris, omnibus, primo excepto, puncto libero nigro.

Boreal Wasp, black, antennæ underneath luteous, head spotted with yellow and the trunk with white; thighs at the tip and rest of the leg yellow; abdomen rather heart-shaped, yellow, with the segments black at the base and each, except the basal one, with two black discoidal dots.

Length of the body $7 \frac{1}{5}$ lines.

A single specimen taken with the last. 


\section{DESCRIPTION.}

Body black, downy, especially the head and trunk, with gray hairs. Nose trapezoidal, ycllow with a black floriform discoidal spot; anterior margin with three sinuses taken out; vertex with a trapezoidal yellow spot just above the base of the antennx; antennx black, lutcous undemeath; extcrnal orbit of the eyes and mandibles yellow: lateral margin of the collar, a triangular small spot under each wing, two narrow transverse and internally acute spots on the scutellum, and two similar ones below them on the metathorax, all white: tegule white with a brownish spot in the disk: legs yellow; thighs black at the base: wings testaceous: abdomen heart-shaped, with the bases of the segments where uncovered, and two dots on each except the first, black; the middle part of the black basal bands projects into a triangular tooth; the underside is nearly similar, but the projections form a longitudinal stripe.

$(366)$ 3. * Vespa marginata. Bordered Vespa.

$V$. (marginata) nigra, pubescens, ore, frontis maculis, antennis scapo subtus, thoracis linea utrinque ante alas, scutelli punctis duobus obscuris, abdominisque segmentis margine, albidis : pedibus rufescentibus basi nigris.

Bordered wasp, black, downy; with the mouth, spots of the front, scape of the antennæ below, line of the thorax before the wings, two obscure dots of the scutellum, and margin of the abdominal segments, all white; legs rufescent, black at the base.

PLATE VI, FIG. 2.

Length of the body $7 \frac{1}{2}$ lines.

Taken in the Ronte from New York, and again in Lat. 65\%.

DESCRIPTION.

i

Body black, punctured, downy from a mixture of black and gray hairs. Mandibles white with a black margin; palpi reddish; nose white with a flask-shaped longitudinal black spot in the disk; just above the antennæ is a bilobed white spot, between which and the eyc is a white line, and another external one above it; antennæ short, not much exceeding the head, black with the scape white underneath; in one of the specimens there is a reddish spot underneath on the four or five last joints, which is not discernible in the others: the external margin of the collar, before each wing, and a small triangular spot on each side of the scutellum, are white: wings cmbrowned with darker ncrvures, but the costal nervure, and tegulæ are ferruginous; legs testaceous, black at the base: abdomen with the apex of the dorsal and ventral segments white; anal segment black with a pair of white spots; the white margin of the dorsal segments receives an intermediate triangular point, and on each side of it a rounded lobe from the black base. 


\section{Vespa maculata. (Linné.) Spotted Vespa.}

Vespa maculata. Linn. Amcen. Acad. vi, 412, 91 ; Syst. Nat. ii, 948, 2. Fab. Ent. Syst. ii, 258, 18; Syst. Piez. Д5̃7, 17. De Geer Ins. iii, 584, 9, t. xxix, $f .13$. americana. Christ. Hymcnopt. 239.

Length of the body 10 lines.

A single specimen taken in Lat. $65^{\circ}$.

\section{DESCRIPTION.}

\section{$\cdot 9$}

Body black, downy, with grayish down, punctured. Mandibles very large, white; nose white with the whiteness divided longitudinally by a black stripe; front with three white spots placed transversely; the intermediate one trapezoidal and bilobed, the lateral ones curved and entering the sinus of the eyes; externally the eyes are bordered by a white stripe: collar with an L-shaped white line before the wings, below which is a triangle of the same colour; the black base-covers have a white dot; the scutellum and post-scutellum have each two lateral crescent-shaped white spots at their anterior margin : the three last segments of the abdomen have each a pair of white spots, which in the penultimate and antepenultimate segments are bilobed, and in the last segment triangular: all the ventral segments, except the first, have a white dot or spot on each side : the antennæ are broken off in the specimen, except the scape and two following joints, which are whitish underneath: the anterior legs are black and white, the intermediate have the apex of the thighs, and an external streak on the first joint of the tarsus, white; the posterior legs are black; the wings are embrowned.

De Geer describes the parts here stated to be white, as straw-coloured.

iii. Anthophila. Lat.

a. Brachyglossa. ${ }^{4}$ Kirb.

\section{Family PROSOPIDÆ. Prosopidans.}

CLVII. Genus PROSOPIS. Jurine.

(368)

1. * Prosopis elliptica. Elliptical Prosopis.

P. (elliptica) atra, subpubescens, nasi apice, fronte intus ad oculos, thoracisque tuberculo ante alas, albis; tibiis posticis albido annulatis; abdomine elliptico, nitido.

Elliptical Prosopis, body very black, a little downy; apex of the nose, front internally at the eyes, and the tubercle of the thorax before the wings, all wbite; posterior tibiæ annulated with white; abdomen elliptical, glossy.

Length of the body 3 lines.

Three specimens taken in Lat. $65^{\circ}$.

${ }^{4}$ I distinguish by this nane the genus Melitta of the Monographia Apam Anglia. 
DESCRIPTION.

Body very black, slightly downy, minutely punctured. Apex of the nose white, whiteness lobed; inner orbit of the eyes below the antenna white; vertex channelled below the eyelets; antennæ scarcely longer than the head: the projecting lobes of the collar terminate in a white tubercle; base-covers piceous; wings liyaline with dark nervures: metatlorax longitudinally wrinkled: posterior tibix annulated at the base with white: abdomen more glossy than the rest of the body, almost naked, and scarcely punctured; it is narrower and more elliptical than in any other known species of the genus.

\section{Family ANDRENID无. Andrenidans.}

CLVIII. Genus HALICTUS. Walck.

\section{Halictus rubicundus. Rubicund Halictus.}

Halictus rubicundus. Steph. Cat. 5249,5.

A pis rubicunda. Christ. Hymenopt. 190, t. xvi, f. 10.

Melitta rubicunda. Kirb. Mon. Ap. Angl. ii, 53, 14.

A pis flavipes. Panz. Fn. Germ. Ivi, t. 17.

Length of the body 5 lines.

Four specimens taken in the Expedition. Locality not stated.

DESCRIPTION.

q

Body black, downy. Head suborbicular, down grayish; space between the eyes broad: down on the thorax thicker, ferruginous: base-covers rufo-piccous: wings subhyaline; nervures and stigma testaceous; post-costal nervure black: legs thickly set with yellow hairs which shine like gold; tarsi testaceous : abdomen elliptical, downy with decumbent hairs; margin of the segments fringed with white hairs, the two first subinterruptedly; the ventral segments are similarly fringed, but the hairs are shorter.

$$
\text { 2. Halictus crassicornis. Thick-horned Halictus. }
$$

H. (crassicornis) niger jube cinerascenti-pallida ; abdonine lavi nitidissimo; antemuis crassiusculis; thorace dorso subcanaliculato, minutissime punctulatissimo.

Thick-horned Halictus, covered more or less with subcinereous or whitish down; abdomen without punctures, very glossy; antennæ rather thick; back of the thorax slightly channelled and covered with innumerable very minute punctures.

Length of the body 3 lines.

A single specimen taken in Lat. $54^{\circ}$. 
DESCRIPTION.

q

This little insect is so extremely like Halictus lavis, ${ }^{5}$ that at first I regarded it merely as a variety of that species, but upon a closer inspection they appear to me distinct. In H. crassicornis the antemna are proportionally more robust, but the principal difference lies in the sculpture of the thorax. In H. lavis that part is visibly punctured with scattered punctures, but in the insect I am describing, under a common lens, the punctures are scarcely discernible, but under a higher power, besides a slight channel drawn longitudinally, innumerable very minute punctures appear. In the former also the stigma of the upper wings is piceous, while in the latter it is testaceous. In other respects they are perfectly similar.

CLIX. Genus ANDRENA. Fab.

1. * Andrena impuncta. Impunctured Andrenu.

A. (impuncta) nigra albilo villosa; tibiis posticis scopa alba; abdomine lavi, antice albido, postice nigro, pilosa. Impunctured Andrena, black with white hairs, brush of the posterior tibix white; abdomen impunctured, anteriorly cloathed with white hairs and posteriorly with black.

Length of the body $5 \frac{1}{2}$ lines.

A single specimen taken in the Journey from New York to Cumberland-house. DESCRIPTION.

ㅇ

Body black, cloathed with rather long whitish hairs, especially the face below the antennæ; hairs of the thorax rufescent; wings subhyaline a little darker at the tip; nervures testaceous, post-costal black; brush of the posterior tibia white: abdomen impunctured with the hairs of its anterior half white; the other hairs above and below black.

This species a good deal resembles Andrena nitida, ${ }^{6}$ but the abdominal segments of that species are minutely punctured at the base, which is not the case with this, and the brush of the posterior tibia is of a different colour.

\section{Andrena varians. Varying Andrena.}

Apis varians. Ross Fn. Etrusc. Mant. 142, 317. Panz. Fn. Gern. lvi, t. 12 Melitta varians. Kirh. Men. Ap. Engl. ii, 117, 58.

Andrena varians. Stepb. Cat. i, 300, 5179, 24.

Length of the body $5 \frac{1}{2}$ lines.

Three specimens taken in the Expedition. Locality not stated.

5 Kirb. Mon. Ap. Angl. ii, 65, 24

6 Ibid. ii, 104, 51. 


\title{
DESCRIPTION.
}

웅

Very like the species just described, but the head is cloathed with black hair; that of the thorax aud base of the abdomen is tawny-red: the brush of the posterior tibia is changeable, as the site varies, from black to white; the hairs of the underside of the body and of the last abdominal segment above are black, except those on the posterior thighs forming the flocculus, which are whitish, as are those of the anterior part of the abdomen.

\author{
b. Macroglossa. Kirb. ${ }^{7}$ \\ a. Solitaria. Kirb. \\ a. Cuculina. Kirb.
}

\section{Family NOMADIDE. Nomadidans.}

CLX. Genus NOMADA. Scopoli.

N. (Americana) ferruginea, thoracis linea dorsali nigra; abdomine basi nigra, segmentis tribus primis apice fuscis.

American Nomada, ferruginous, dorsal line of the thorax black; abdomen black at the base, with the three first segments brown at the tip.

$$
\text { PLATE VI, FIG. } 3 .
$$

Length of the body $4 \frac{1}{2}$ lines.

\section{A single specimen taken in Lat. $65^{\circ}$.}

\section{DESCRIPTION.}

Body dark-ferruginous. Thorax with a longitudinal mesal black line, less distinct on the metathorax: breast with a black spot on cach side: wings, as in the rest of the genus, embrowned with a white spot near the tip thighs black at the base on the underside: first segment of the abdomen black at the base, and, with the second and third, brown at the apex.

This is the only American Nomada I ever saw, and Fabricius describes none from that country. lt comes near Nomada ruficornis and striata, but it has only a single black stripe on the thorax.

- This tribe, to wbich the modern genera Ammobates, Phileremus, Epeolus, Nomadu, Pusites, Melecta, Crocisa, and Oxrea belong, includes those bees that, like the cuckoo, deposit their eggs in the nest of other bees. See Mon. Ap. Angl. i, ljo, and $N$. D. D'H. N. xxiii, Article Nomada. 
B. Dasigastra.8 Kirb.

\section{Family CHELOSTOMIDE. Chelostomidans.}

CLX1. Genus CHELOSTOMA. Lat.

\section{1. * Chelostoma albifrons. White-fronted Chelostoma.}

C. (albifrons) atra, pubescens, fronte sub antennis argenleo-alba; thorace cinereo, abdomine nigro hirsutis; hoc segmentis niveo ciliatis.

White-fronted Chelostoma, black downy; front below the antennæ silver-white; thorax hirsute with cinereous hairs and abdomen with black; in the latter the segments are fringed with snowy ones.

Length of the body $4 \frac{1}{2}$ lines.

\section{A single specimen taken in Lat. $65^{\circ}$.}

\section{DESCRIPTION.}

\section{$\sigma^{\pi}$}

Body black, thickly punctured. Mouth bearded with white; mandibles carinated above, armed with two strong terminal teeth; nose square, flat, cloathed with decumbent silver pile; antennæ filiform; scape black; the other joints are rufo-piceous underneath : trunk very hirsute with white or subcinereous hairs : wings a little embrowned, with black veins and base-covers: legs hairy : abdomen subcylindrical, hirsute with black hairs, ineurved with the apex of the four intermediate segments fringed with white hairs; anal joint with a concavity above, obtuse; last ventral segment forcipate, rufo-piceous.

\section{Family MEGACHILID无. Megachilidans.}

CLXII. Genus MEGACHILE. Lat.

\section{Megachile maritima. Maritime Megachile.}

Megachile maritima. Curtis Brit. Ent. v, 1218. Steph. Cat. i, 373, 5059, 6. Apis maritima. Kirb. Mon. Ap. Angl. ii, 242, 43.

Length of the body 7 lines.

\footnotetext{
${ }^{3}$ I include in this tribe all those solitary bees, the underside of whose abdomen in the females is covered with a pol-
} liniferous brush. 


\title{
DESCRIPTION.
}

Body black, pubescent, thickly and minutely punctured. Mandibles very large, triangular, protended, not crossing each other, armed with four terminal tecth: face between the eyes thickly cloathed with brown hairs, which grow tawny towards the mouth: antenna filiform: back of the trunk cloathed with brown hairs less thickly in the disk; wings a little embrowned especially at the apex; nervures dusky; base-covers piceous : legs hairy with pale hairs: abdomen subovate with the three last segments fringed with pale hairs intermixed with black; the ventral hairs are tawny, paler towards the base, and darker towards the apex.

\section{$\%$. Lelogastra.}

\section{Family ANTHOPHORIDE. Anthophoridars.}

\author{
CLXIII. Genus ANTHOPHORA.
}

A. (bomboides) lirsuto-pallida, pedilus, abdominis ano ventreque hirsutie atra; fronte infra antennas alba: plantis posticis intus dente valido acuto armatis.

Humble-bee Anthophora, hirsuties pale, with that of the legs, the tail, and underside of the abdomen, black; front below the antennæ white; first joint of the posterior tarsi armed on the inside with a strong sharp tooth.

Length of the body 6 lines.

A single specimen taken in Lat. $65^{\circ}$.

DESCRIPTION.

Body black, thickly punctured, cloathed like that of a humble-bee with dense pallid hairs. Head triangular, upper lip subquadrangular, white with a black dot at each upper angle; nose white, naked; a bunch of whitish hairs conceals the base of the antennæ; antennæ filiform, scarcely longer than the head; vertex with some black hairs thinly scattered; occiput fringed with whitish ones: trunk subglobose, set with longish white hairs: hairs of the legs mostly black; tarsi piceous; the first or dilated joint is armed with a strong and sharp tooth on the inner side at the base: wings subliyaline with black nervures: abdomen between globose and triangular, with the three first clorsal segments cloathed with long whitish hairs, and the tail and ventral segments with black. 
b. Gregaria. Kirb.

\section{Family BOMBIDE. Bombidans.}

CLXIV. Genus BOMBUS. ${ }^{9}$ Lat.

\section{1. * Bombus sylvicola. Wood-frequenting Bombus.}

B. (sylvicola) supra hirsuto-flavicans; thorace fascia nigra; abdomine fascia ferruginea.

Wood-frequenting Bombus, hirsute-yellowish; thorax with a black, abdomen with a ferruginous, band.

Length of the body 7 lines.

\section{A single specimen taken in Lat. $65^{\circ}$.}

\section{DESCRIPTION.}

General hirsuties of the upper side of the body yellowish. Head with a tuft of the same colour below the antennæ, and another at the vertex: trunk with a broad black band between the wings: hairs of the thighs yellowish; those of the tibiæ black; tarsi more or less covered with short decumbent pale hairs; wings somewhat embrowned, with black nervures : abdomen with a broad, mesal, ferruginous band.

This species comes very ncar Bombus Sylvarum.1

\section{2. * Bombus borealis. Northern Bombus.}

B. (borealis) supra hirsuto-fulva; thorace inter alas, anoque nigris.

Northern Bombus, hirsuto-tawny; with the thorax between the wings, and the anus, black.

Length of the body 8 lines.

\section{Several taken with the preceding.}

9 In the first volume of my Monographia Apam Anglia (p. 209) I gave the characters of a tribe of bumble-bees which differ so much in their cbaracters as to indicate an important difference in their economy, and to entitle them to the rank of a genus. Their labrum is obtusangular; their mandibles obliquely truncated; their posterior tibiæ and plantæ are without any apparatus for carrying and kneading the pollen; their abdomen is inflexed and the last ventral segment projects on each side so as to form an angle; all characters not to be found in the other Bombi, no writer seems to have noticed this tribe, unless Klug's Ptilopus be synonymous with it, which I have not the means of ascertaining, if not already named I would call the genus by Jurine's name Bremus. Apis campestris, Barbutella, vestalis and rupestris, Mon. Api. Angl. belong to it.

1 Apis Sylvarum, Mon. Ap. Angl. ii, 326, 82. 


\section{DESCRIPTION.}

Body cloathed underneath with black, above with tawny, hairs. Face and vertex with a tuft of yellowish ones: thorax, between the wings, with a black hairy band; wings somewhat embrowned with black nervures: legs black: abdomen above with a thick coat of tawny hairs palest at the base; anus black.

\section{Bombus 'Terricola. Ground-frequenting Bombus.}

B. (Terricola) hirsuto-atra; thorace fascia antica, abdomineque magna media, flavis, ano albido.

Ground-frequenting Bombus, hirsuto-black; thorax with an anterior yellow band, and abdomen with a large middle one; anus whitish.

$$
\text { PLATE VI, FIG. } 4 .
$$

Length of the body 9 lines.

\section{Taken with the preceding.}

\section{DESCRIPTION.}

This species approaches very near to B. terrestris, but the whole upper surface of the abdomen is cloathed with yellow hairs, with the exception of the first segment the hair of which, and a band near the anus, are black; the extremity only of the latter is dirty-white; there are a few yellow hairs on the metathorax; and the wings are embrowned. In B. terrestris the abdomen is black, with a yellow band, and the two last anal segments are white; there are no ycllow hairs on the metathorax, and the wings are much clearer.

\section{Bombus Derhamellus. Derham's Bombus.}

Bombus Derhamellus. Sam. Compend. 414. Steph. Cat. i, 381, 5150, 38.

Apis Derhamella. Kirb. Mon. Ap. Angl. ii, 363, 105.

Length of the body 8 lines.

\section{Taken with the preceding.}

\section{DESCRIPTION。}

Body hairy, black. Head with a tuft of yellowish hairs on the vertex: thorax yellow, black between the wings; wings more embrowned than in the male: abdomen yellow at the base with a black posterior band; anus ferruginous. 
(381)

\section{5. * Bombus Praticola. Meadow Bombus.}

B. (Praticola) hirsuto-flavicans; thorace inter alas nigro; ano ferrugineo.

Meadow Bombus, hirsute-yellowish; thorax black between the wings; anus ferruginous.

Length of the body 7 lines.

Taken with the preceding.

\section{DESCRIPTION.}

o

Body black, cloathed above with yellowish hairs. Head with a tuft of yellowish hairs below the antennæ, and on the vertex: thorax black between the wings, which are embrowned: legs with yellow hairs at the base: anterior half of the abdomen yellow, posterior ferruginous.

Bombus virginicus. Fab. Syst. Piez. 346, 14.

A pis virginica. Linn. Mant. i, 540; Syst. Nat. Gmel. v, 2784, 113. Fab. Ent. Syst. ii, 318, 5. Drury Ins. t. xliii, f. 1. Length of the body $8 \frac{1}{2}$ lines.

\section{Locality uncertain.}

\section{DESCRIPTION}

i

Hairs of the body in general black, except a tuft on the vertex behind the antennx, the anterior and posterior extremities, and sides of the thorax, and the first segment of the abdomen, which are cloathed with yellowish hairs: between the wings the thorax is black: the tarsi are rufous: the wings are rather embrowned, most so at the apex; nervures black. 


\section{SUBCLASS HAUSTELLATA. Clair.}

\section{ORDER HEMIPTERA. Lat.}

\section{GEOCORISA. Lat. \\ Family PENTATOMIDE. Pentatomidans.}

We are now arrived at the second great subdivision of the class Insecta, those that take their food by suction, which may be regarded as forming a series of Orders parallel with those of the first. ${ }^{2}$

Under this view I shall, with Dr. Leach and Mr. Stephens, consider the Hemiptera of Linné as restricted by Latreille, as really forming two Orders, analogous to the two first Orders of the Mandibulata, the Coleoptera, and the Orthoptera, calling, with them, the first of them by the old appellation Hemiptera, and the second Homoptera.

CLXV. Genus PENTATOMA. Oliv.

(383)

1. Pentatoma carnifex. Executioner Pentatoma.

Cimex carnifex. Fab. Syst. Ent. Suppl. 535, 162; Syst. Rhyng. 177, 113. Coq. Ins. ii, t. xix, f. 3. Length of the body $2 \frac{1}{2}$ lines.

Several specimens taken in the road from New York to Cumberland-house.

DESCRIPTION.

Very near P. oleracea, and probably its American representative. Body black, a little bronzed; grossly and thickly punctured, the punctures on the upper surface the deepest. Head subtrapezoidal; promuscis pale in the middle; antennæ longer than the head: prothorax wider than long, with the lateral angles obtuse; signed with a sanguine cross, the arns of which extend from angle to angle; lateral margin, as well as that of the hemelytra and abdomen, white: scutellum longer than the thorax, obtuse witl a subtriangular sanguine spot on each side near the apex : penultimatc ventral segment of the abdomen margined with white : membrane white.

The specimens collected in the Expedition differ from the description of Fabricius in having the margin of the abdomen and that of the elytra white instead of sanguineous; but as the sexes of $P$. oleracea differ in the colour of their spots, this may be a sexual distinction. I received a specimen from Dr. Mac Culloch which agreed with the Fabrician description. In one specimen the markings and spots of the elytra and scutellum are very pale. 


\section{2. * Pentatoma variegata. Variegated Pentatoma.}

$P$. (variegata) albo, sanguineo, nigroque variegata; prothorace subincarnato fasciis duabus nigris, posteriori basilari subinterrupta ; capite antice, scutello hemelytrisque margine laterali, albis; ventre macula magna biloba nigra, intus utrinque pubescente-cinerea.

Variegated Pentatoma, body variegated with white, sanguine, and black; prothorax inclining to flesh-colour, with two black bands, the posterior basilar, subinterrupted; the head anteriorly, lateral margin of the scutellum and hemelytra, white; underside of the abdomen with a large bilobed black discoidal spot, internally on each side pubescent with ash-coloured down.

Length of the body 3 lines.

\section{A single specimen taken in the road from New York to Cumberland-house.}

\section{DESCRIPTION.}

Upper surface of the body punctured. Head, excluding the prominent eyes, subtrapezoidal, black, with the margin bclow the eyes, white; promuscis extending to the base of the hind legs, pallid, black at the tip; antennæ black : prothorax transverse with latcral angles obtuse; pallid with a tint of flesh-colour especially at the angles, with a broad anterior and narrow posterior black band, both abbreviated on each side, and the latter almost divided into two; scutellum an isosceles triangle obtuse at the apex, black with the lateral margin pallid: hemelytra black with a pallid lateral margin, membrane embrowned: underside of the trunk black spotted with pallid and sanguine, punctured: tibix and apex of the thighs hlack; base of the thighs sanguine: abdomen below punctured at the sides, sanguine, with a large black discoidal spot, rather nearer the anus; nearly divided into two; on the sides and at the base naked, but a quadrangular space of the inner side of each division, is covered with decumbent subcinereous pilc.

N. B. The antepectus is entirely pallid, but the socket, if it may be so called, of the legs is redider at the margin than the rest.

xxx. * Subgenus Neotriglossa.

Nose shorter than the cheeks.

Bed of the promuscis elevated on each side at the base.

In the typical Pentatome the part which I regard as analogous to a nose is of the same length with the two lateral lobes of the front, and the base of the cavity in which the promuscis reposes when unemployed is not so clevated.

\section{3. * Pentatoma (Neottiglossa) trilineata. Three-lined P. Neottiglossa.}

P. N. (trilineata) nigro-cenea, punctatissima; supra lurida punctis nigris; prothoracis lateribus, cum scutelli linea intermedia longitudinali, albis.

Three-lined P. Neottiglossa, nigro-æneous, thickly punctured; above lurid with the punctures black; the sides of the prothorax and a longitudinal intermediate line common to it and the scutellum, white.

PLATE VI, FIG. 6.

Length of the body 3 lines.

One specimen taken with the preceding. 
DESCRIPTION.

Body underneath and the head black, a little bronzed; thickly punctured with rather deeply impressed punetures; autennx reddish at the base, with the two last elongated and inerassated joints black: prothorax black anteriorly, posteriorly lurid with the lateral margin and an intermediate longitudinal impunctured line, which extends nearly through the scutellum, white; the scutellum has also a white linear spot and dot on each side at the base: the punctures of the thorax, scutellum, and hemelytra are black; the membrane of the latter is white: the legs and sides of the breast are lurid spotted or punetured with black: the elevated basilar portion ${ }^{3}$ of the bed of the rostrum is concave and has a semicircular ontline, and its margin, viewed under a strong magnifier, is minutely serrulate.

\section{Fanily EDESSIDÆ.}

CLXVI. Genus EDESSA. Fab.

(386) 1. Edessa nebulosa. Clouded Edessa.

E. (nebulosa) pallida, nigro punctata; supra fusco subnebulosa ; abdominis margine nigro maculato.

Clouded Edessa, pale, punctured with black; above clouded with brown; sides of the abdomen spotted with black.

Length of the body $3-4$ lines.

Three specimens taken in the Journey from New York to Cumberland-house and in Lat. $65^{\circ}$.

\section{DESCRIPTION.}

Body pale yellowish, sprinkled with black impressed punetures, most numerous and largest on its upper surface, which is clouded with reddish-brown, or blackish shades; the antennæ are of a reddish-yellow: the lateral angles of the prothorax are more acute than in the Pentatome; the scutellum is acuminate or attenuated at the apex: the lateral margin of the abdomen has a black spot on each segment, which sometimes appears on the ventral segments.

VAR1ETr B. Smaller, with the ventral sesgments of the abdomen rufescent, and the clouding of the upper surface of the body blacker: the thorax also is black posteriorly.

\section{Fanily CAPSIDÆ. Capsidans.}

CLAVII. Genus MIRIS. Fab.

$(38 \pi)$

1. * Miris punctulatus. Punctured Miris.

11. (punctulatus) lurido-subvirens; antennis brevioribus; subtestaceis : articulis duobus cxtimis nigris.

Punctured Miris, lurid with a slight tint of green; antennæe shorter than the body, subtestaceous, with the two last joints black.

Length of the body 3 lines.

Two specimens taken in Lat. $65^{\circ}$. 


\section{DESCRIPTION.}

Body oblong, pale, somewhat lurid with a very slight tint of green. Head triangular, impunetured; eyes a little embrowned, prominent; antennæ as long as the prothorax, subtestaceous with the two last joints and the underside of the first black : thorax, scutellum, and bemelytra very minutely punctured; a small portion of the prothorax adjoining the lhead is separated from the rest by an impressed sinuous line and is not punctured: legs pale; abdomen subpyramidal, black above, pale underneath. This appears to be the American representative of $M$. pabulinus.

M. (ventralis) pullidus; hemelytris nigro subnebulosis; abdomine supra et infra nigro; ventre vittis duabus rufescentibus. Ventral Miris, pale; with the hemelytra faintly clouded with black; abdomen black above and below, with two ventral abbreviated reddish longitudinal stripes.

Length of the hody 3 lines.

Taken with the preceding.

\section{DESCRIPTION.}

Very similar to $M$. punctulatus, and perhaps only a variety, but the hemelytra are faintly clouded with black, the underside of the abdomen is dusky with two longitudinal reddish spots or stripes.

\section{Family ACANTHIADE. Acanthiadans.}

CLXVIII. Genus ARADUS. Fab.

1. * Aradus tuberculifer. Tubercle-bearing Aradus.

A. (tuberculifer) niger, prothorace antice lobato, supra sexcarinato, scutello margine rẹflcxo, disco tuberculum subhemispharicum gerente.

Tubercle-bearing Aradus, black; prothorax lobed anteriorly, above six-ridged ; margin of the scutellum reflexed, bearing a subbemispherical tubercle on its disk.

PLATE VI, FIG. 5.

Length of the body $3 \frac{3}{4}$ lines.

A single specimen taken with the preceding. 
DESCRIP'IION.

Body dull blaek, very flat. Head with the nose prominent and obtuse, and the front armed with a sharp tooth on each side; antennx black with the seeond joint rufous all but the tip; the last joint white at the tip : prothorax with a short anterior truncated lobe, widest in the middle where the sides form a rounded angle; emarginate posteriorly; edge very minutely serrulate; six longitudinal ridges oceupy the disk of the thorax, the two external ones are abbreviated and rather obtuse; scutellum with a reflexed margin, and bearing on its disk a large subhemispherical tuberele: hemelytra reticulated with einereous, espeeially the membrane: abdomen with a loroad margin, and the last segment bilobed with incurved lobes.

This speeies appears to be related to A. depressus and elevatus Fabr. and to A. quadrilineatus of Say. ${ }^{4}$

$$
\text { 2. Aradus affinis. Kindred Aradus. }
$$

A. (afpinis) niger, prothorace non lobato; postice dilatato angulis obtusis; disco sexcarinato; scutello vix tuberculato.

Kindred Aradus, black with the prothorax not lobed; dilated posteriorly with obtuse angles; disk six-ribbed; scutellum scarcely tuberculated.

Length of the body $2 \frac{1}{2}$ lines.

Several taken with the precerling.

DESCRIPTION.

Extremely similar to $A$. tuberculifer, but much smaller. Antennx entirely black: prothorax not extended anteriorly, so as to form a lobe; lateral abbreviated ridge more obtuse, resembling a tubercle: margin of the abdomen with a white point at the apex of each segment; anus not lobed.

\section{Family REDUVIAD无. Reduviadans.} CLXIX. * Genus REDUVIOLUS. Kirb.

Body linear-oblong.

Promuscis slender, inflexed, not reaehing beyond the base of the anterior legs.

Antenne inserted below the eyes, subsetaeeous, five-jointed? penultimate joint the longest.

Stemmata small, sessile.

Eyes hemispherieal.

Prothorax bilobed.

N.B. In Reduvius the promuseis is thick; the antemre are inserted between the eyes; the eyes are kidney-shaped; the stemmata are large and set in a tuberele; and the borly is oblong. 
R. (inscriptus) pallidus; capite prothoracisque lobo antico nigro inscriptis; scutello nigricanti, apice callis duobus elevatis albis; abdomine supra nigro, subtus vittis tribus nigris.

Inscribed Reduviolus, pale, with bcad and anterior lobe of the prothorax inscribed with black; scutellum blackish with two white elevated callosities at the apex; abdomen black above, underneath with three black stripes.

PLATE VI, FIG. 7.

Nabis obsoletus. Steph. Cat. ii, 351,9701,6?

Length of the body 3 lines.

\section{A single specimen taken with the preceding.}

\section{DESCRIPTION.}

Body of a pale or yellowish white, lineari-oblong, widest posteriorly. Antennæ shorter than the body, rufous, three last joints very slender: head and prothorax streaked and dotted with black; with the anterior lobe of the latter constricted next the head, separated from the posterior by an impressed simuated black line; scutellum black with two pale longitudinal elevations, thiekest anteriorly: hemelytra with the nervures whiter than the rest of their substance; with three blackish discoidal dots arranged longitudinally from the middle to the membrane: thighs dotted with black, the anterior pair being incrassated and thicker than the intermediate, and these than the posterior, which are not incrassated: back of the abdomen black, with a white lateral margin, underneath with three longitudinal black stripes.

CLXX. * Genus CHIROLEPTES. Kirb.

Promuscis inflexed, slender, naked, reaching the base of the first pair of legs.

Antenne capillaceous with the scape inerassated, second joint very long, inserted before the eyes.

Stemmata small, sessile.

Body linear: head setting on an elongated neck.

Prothorax bilobed, bell-shaped, posteriorly dilated; arms raptorious.

This genus differs from Zelus, Fab. principally in its slenderer promuscis the flexure of which is a very acute angle; its stemmata also are sessile, but more particularly in having its arms raptorious ${ }^{5}$ like those of a Mantis, Zelus femoratus belongs probably to this genus. 
C. (Raptor) niger, nitilus; prothorace hemelytrisque obscuris; lis nigro-fuscis, albido lineatis et marginutis; seutello upice albo; pedibus pallidis; humeris apice nigricantibus.

Robber Chiroleptes, black, shining; prothorax and hemelytra dull; the latter black-brown, with wlite lateral margin and lines; scutellum white at the tip; legs pale, shoulders blackish at the tip.

Length of the body nearly 4 lines.

Two specimens taken in the road from New York to Cumberland-house.

DESCRIPTION.

Body black and slining. Head subrlomboidal, connected with the prothorax by a long cylindrieal and transversely wrinkled neck, which altogether gives the animal a serpentine aspect: legs pale; shoulders much incrassated, blackish at the tip, armed below with several strong spines; cubits with a single intermediate one: prothorax bell-shaped, black, dull from inconspicuous pubescence: scutellum dull, white at the tip: hemelytra dull from pubescence, blackish-brown, with paler lines which extend into the membrane; lateral margin white: abdomen black, with the ventral lateral margin white.

This species approaches very near to Say's Reduvius raptorius, ${ }^{6}$ but it is distinct.

\section{CLXXI. * Genus NABICULA. Kirb.}

Promuscis inflexed, not arched, slender, reaching to the intermediate legs, naked, first joint elongated.

Antennce mutilated in the specimen, inserted before the eyes; scape elongated.

Stemmata obsolete.

Eyes hemispherical.

Body apterous, linear, head elongated, subtriangular: prothorax bilobed, anterior lobe bell-shaped; posterior short, flat, scarcely dilated: hemelytra with a very narrow membrane : arms raptorious.

This genus differs from Nabis, as Reduvioltes from Reduvius and Chiroleptes from Zelus, in not having an arched promuscis; the first joint of which is longer than it is in Nabis, and naked; the stemmata are not visible under a common lens, and the arms are raptorious. 


$$
\text { 1. * Nabicula subcoleoptrata. Subcoleoptrate Nabicula. }
$$

N. (subcoleoptrata) aptera, nigra, obscura; elytris punctatis margine laterali, antennis, pedibusque, rufis.

Subcoleoptrate Nabicula, without wings, dull-black; elytra punctured with their lateral margin, and the antennæ and legs, rufous.

Length of the body 4 lines.

Taken with the preceding.

DESCRIPTION.

Body apterous, black, without any gloss. Head subtriangular, antenuæ rufous: thorax bilobed, first lobe thrice as long as the last, bell-shaped; last a little wider than the first, flattish : hemelytra a little shorter than the abdomen, brownish-black, punctured; lateral margin obscurely rufous; membrane scarcely differing in substanee or colour from the rest of the hemelytrum: legs rufous? abdomen obtnsangular underneath.

\section{Family HYDROMETRIDE. Hydrometridans.}

CLXXII. Genus GERRIS. Lat.

\section{Gerris rufo-scuteliata. Red-scutellum Gerris.}

Gerris rufo-scutellata. Lat. Gen. Crust. et Ins. iii, 134, 2. Steph. Cat. ii, 352, 9721, 3.

La Punaise coureuse d'eau. Stoll. Cimic. 64, 108, t. xv, 108, \&c. A.

Length of the body $6 \frac{1}{3}$ lines.

One specimen taken in Lat. $65^{\circ}$.

DESCRIPTION.

Body underneath blaek, covered with silver pile. Head brown-black, subpilose; two first joints of the promuscis black and robust, the remainder rufous and more slender; antennæ rufous with the last joint black; eyes large, subhemispherical, brown: prothorax dull-ferruginous, with the lateral margin, a dorsal subelevated line, and the scutellum, paler; legs rufous, pale at the base; hemelytra dull-ferruginous, with the lateral margin and nervures black: the bead that forms the lateral margin of the abdomen, and the two last segments, are rufous; the anal spines are very little shorter than the tail.

The American specimen seems to vary a little from the deseription of the European ones, but not sufficiently to warrant its being deseribed as a new speeies. 
Gerris lacustris. Fab. Ent. Syst. iv, 187, 1. Lat. Hist. Nat. xii, 275, t. xcr, f. 7; Gen. iii, 134, 3. Lam. An. sans Vertèbr. iii, 514, 3. Steph. Cat. ii, 352, 9723, 5. Kirb. and Sp. Intrad. to Ent. ii, 360.

Cimex lacustris. Limn. Syst. Nat. ii, 732, 117; Fn. Suec. 970. Geoff. Ins. i, 463, 59. Scop. Carn. 394. Vill. Emt. i, 537, 203. Schrank. Enum. 557.

Hydrometra lacustris. Fub. Syst. Rhyng. 256, I. Walck. Fn. Paris, ii, 350, 1.

Cimex Naias. De Geer Ins. iii, 311, 39, t. xvi, f. 7.

La punaise Nayade. Geoffi. Ins. i, 463, 59. Stoll. Pun. 42, t. ix, f. 63.

Rat. Hist. Ins. 57, No. 6. Bauh. Boll. 213, f. 1. List. Mut.t. v, f. 4, 5. Bradl. Nat. t. xxvi, f. 2, D. Sulz. Ins. t. xi, f. 78 .

'There were three pupæ of this species taken, which do not appear to differ from the European specimens.

\section{HYDROCORISA. Lat.}

\section{Family CORIXID隹. Corixidons.}

CLXXIII. Genus CORIXA. Geoff.

\section{Corixa striata. Streaked Corixa.}

Corixa striata. Lat. Hist. Nat. xii, 289; Gen. iii, 151, 1. Lam. An. sans Vertèbr. iii, 521, 1. Leach Linn. Trans. xii, 16, 2. Sam. Compend. 228, 2. Steph. Cat. ii, 354, 9739, 5.

Sigara striata. Fab. Ent. Syst. iv, 60, 2; Syst. Rhyng. 104, 2. Schellenb. Cimic. t. xi. Ced. Fn. Ingr. 840.

Notonceta striata. Linn. Syst. Nat. ii, 712, 2; Fn. Suec. 904. Vill. Ent. i, 475, 2. Scop. Carn. 349.

Nepa striata. De Geer Ins. iii, 389.

Pet. Gazoph. t. Ixxii, f: 7. Rüs. Ins. App. i, 177, t. xxix. Joblot. Micr. i, 1, t. vii, f. 2, 3. Schæff. Elem. t. 1. Stol!. Cimic. 65, $t$. xiii, B.

Length of the body $3-3 \frac{1}{4}$ lines.

Many specimens taken with the preceding.

DESCRIPTION.

Body yellowish, depressed, naked, smooth. Head inflexed, obtuse; eyes brownish, triangular: antennæ inserted before the eyes under the lateral margin; seape incrassated; remaining joints together are setiform: prothorax subtriangular, with the hemelytra, brown, streaked transversely, with irregular ycllow streaks; epipleura not streaked, pale-yellow; breast black, spotted with yellow on the sides: legs yellow; anterior and posterior tarsi natatory; the latter longer than the tibix: abdomen with the first ventral segment, and an abbreviated basilar band of the second, black.

Varietr 13 . With the first joint of the posterior tarsi black at the tip. This may be a distinct species, there were seven specimens distinguished by a black annulet surrounding the terminal half of the first dilated joint of the tarsus in question. 


\section{2. * Corixa carinata. Ridged Corixa.}

C. (carinata) corpore subtus, capite, pedibusque, flavidis ; occipite postice medio transverse, verticeque langitudinaliter, obtusangulis ; prothorace carinato nigricanti, flavido transverse lineato; hemelytris nigricantibus flavido irroratis.

Ridged Corixa, with the body underneath, head, and legs pale-yellow; the hind-head posteriorly in the middle transversely, and the vertex longitudinally, obtusangular; prothorax ridged, brownish-llack, transversely streaked with yellowish ; elytra brownish-black sprinkled with yellowish.

Length of the body 4 lines.

Two specimens taken with the preceding species.

DESCFIPTION.

This species appears to come very near to Geoffroy's Corise, ${ }^{7}$ which is evidently not $C$. striata ; and also to $C$. stagnalis of Dr. Leach ; but as neither of these authors mention the ridge of the thorax, which is conspicuous, it appears to be distinct. Body yellow underneath, embrowned at the insertion of the legs. Head yellow; front broad and flat; labrum transversely tricarinate ; occiput obtusangular; vertex with an obsolete longitudinal ridge issuing from the angle of the occiput: prothorax with a longitudinal intermediate ridge, transversely streaked witl yellow and brownishblack: hemelytra sprinkled, and towards the base almost streaked, with black and yellow. In other respects this species resembles $C$. striata.

3. * Corixa planifrons. Flat-fronted Corixa.

C. (planifrons) subtus nigra, utrinqne flavido maculata; occipite medio obtusangulo; fronte retusa ; prothorace carinato, nigricanti, flavido transverse lineato; hemelytris nigricantibus flavido irroratis.

Flat-fronted Corixa, underneath hlack, with the sides spotted with pale-yellow; occiput obtusangular in the middle ; front blunt; prothorax carinated, brownish-black, transversely streaked with pale yellow; hemelytra brownish-black sprinkled with yellow.

Length of the body 4 lines.

Two specimens taken with the preceding.

DESCRIPTION.

This species differs from the preceding in having the under side of the body black, with two pale spots on each side of the breast, and the anal half of the abdomen pale-yellow. The head is yellow, the vertex is ridged longitudinally and separated from the front by a transverse curvilinear ridge; and from which the anterior part of the face is inflexed, plane or slightly concave; in other

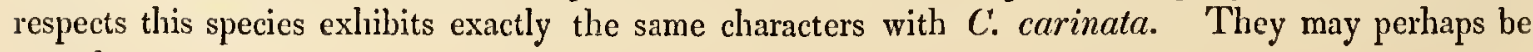
sexual varieties.

$$
7 \text { Ins. i, 478, 1, t. ix, f. } 7 . \quad{ }^{8} \text { Linn. Trans. xii, } 16 .
$$




\section{Fanily NO'TONECTIDE. Notonectidans.}

CLXXIV. Genus NOTONECTA. Linn.

$(399)$

1. * Notonecta insulata. Islet Notonecta.

$\boldsymbol{N}$. (insulata) subtus nigra, supra flavida; hemelytris margine laterali fusco flavido maculato, apice nigris naculis aluabus insulatis albidis anteriori triangulari, posteriori reniformi.

Islet Notonecta, underneath black, above yellowish; lateral margin of the bemelytra brown spotted with yellow; apex black with two insulated whitish spots, the anterior one triangular and the posterior kidney-shaped.

Length of the body $6 \frac{2}{3}$ lines.

A single specinen taken.

DESCRIPTION.

Body underneath black, above yellowish. Head yellowish, with a brownish longitudinal stripe between the eyes, which are reddish: scutellum very black, velvetty: hemelytra with the lateral margin brown spotted with yellow; the posterior balf of the hemelytra is brown anteriorly, blackbrown in the middle, fuliginous at the apex; in this darkened portion anteriorly is a yellowish triangle connected with the last marginal spot, and posteriorly is a white kidney-shaped spot followed by the sooty apex: breast very hairy with longish fuliginous hairs: legs yellowish.

\section{ORDER HOMOPTERA. Leach.}

ii. Ranatra. Linn.

\section{Family CERCOPIDE. Cercopidans.}

CLXXV. Genus CERCOPIS. Fab.

(400) 1. Cercopis marginelua. (Fabricius.) Red-bordered Cercopis.

Cereopis marginella. Fab. Syst. Rhyng. 96, 44.

lateralis. Fab. Suppl. 524, 24. Coq. Ins. i, 35, t. ix, f. 3.

Length of the body $3 \frac{1}{4}$ lines.

Taken with the preceding and at Carlton-house in April.

DESCRIPIION.

Body black, dotted and inseribed with white. Hemelytra embrowned; nervures black; Iateral margin sanguine : margin of the abdomen edged with white. 


\title{
ORDER LEPIDOP'TERA.
}

\author{
I. DIURNA. Lat. \\ Family PAPILIONIDE. Papilionidans.
}

CLXXVI. Genus PAPILIO. Linn.

\section{Papilio Turnus. Turmes Papilio.}

Papilio Turnus. Linn. Mant. i, 536; Syst. Nat. Gmel. v, 243, 338 . Fab. Ent. Syst. iii, 29, 86. Say. Amer. Ent. iii, t. xl.

Alcidamas. Cram. Pap. iv, $t$. xxxvii, $f$. A. B.

Mouff. Ins. 98? Jonst. Ins. t. v, f. 1 ? Rai. Hist. Ins. iii, 2? Cates. Carol. t. xcvii.

Expansion of the wings $3 \frac{3}{4}$ inches.

Taken in Canada by Dr. Bigsby.

DESCRIITION.

Body yellow. Head above black, below tufted with yellow : trunk and abdomen striped with black and yellow: wings yellow; primaries with five abbreviated black subangular bands; the two inner ones being common to both wings, the innermost of these bands is marginal and its lower attenuated extremity converges with that of the penultimate band, reekoning from the tip; the anterior margin of the primary wings is edged with black, with yellow scales intermixed, and two longitudinal yellow streaks between the middle and the apex; the posterior margin has a broad black stripe with an articular ${ }^{9}$ yellow band; in the secondary wings the discoidal basilar area is distinguished by a black streak at the apex; the posterior margin has a broad black band with a double transverse series of erescents, each series consisting of four spots, the internal series being bluish, and the external yellow; there is besides an orange spot at the anal angle, and another at the external margin; this margin is indented, with the coneavities fringed with yellow; the angle between the fourth and fifth indentures projects into a short tail ; the underside of the wings is yellow, but paler than the upperside; there are also the five black bands: the posterior margin of the primary wings has an interior ash-eoloured band and exterior yellow one, included between three narrow blaek ones: the underside of the seeondary wings is not very different from the upper, except that the posterior margin is not nearly so black; and at the anal angle there is a spurious ocellus consisting of a black semieircle, a blue crescent, a black, and lastly an orange transverse spot. The legs of this species are black, as are also the nervures of both wings.

Fabricius says that this speeies is thrice the size of P. Machaon, but the specimens I received, of which there were several, were of the same size. In Mouffet's figure, referred to by Ray, which appears to belong to the inseet here deseribed, the expansion of the wings is eight inches, but his imagination has evidently been employed in drawing that figure, whielı is represented with faleated primary wings. Probably it was drawn from a mutilated specimen. He has made the blue spots of the secondary wings eireular, looked at in certain lights they appear so. Probably those in the warmer parts of Ameriea may be larger than the northern ones. 


\section{Family COLIAD无. Colindans.}

CLXXVII. Genus COLIAS. Fab.

\section{Colias Edusa. (Fabricius.) Eilusta Colias.}

Colias Edusa. Fab. Syst. Glossat. in Illig. MIag. Steph. Illestr. Haustell. i, 12, 3. Jorm. Butt. S9. Dun. Butt. (Nat. Libr. Ent. iii, 103), t. v, f. 2.

Aurora. MIeig. Schmett. i, 26, 2, t. viii, $f$. 1.

Papilio Edusa. Fab. Ent. Syst. iii, 206, 643. Hubn. Schmett. t. Ixxxv, f. 429, 430, ð 431, 9 . Panz. Fu. Germ. 1. t. 17. Don. Brit. Ins. iii. 60, t. ccxxxviii, f. 2, ․ Bork. Rhein. Mag. i, 231, 4. Haw. Lep. 11, 10. Stew. Elem. ii, 121. Vill. Ent. iv, 25. Ochs. Schmett. ii, 173, 1.

Papilio Hyale. Wienn. Verz. 165, 3. Scop. Carn. 45j. Schæff. Icon. $t$. cxlix, f. 1-3. Rüs. Ins. iii, $t$. xlvi, $f .4,5$. Esp. Schmett. i, t. iv, f. 3, \&c. Herbst. Schmett. t. exiv, f. 1-4. Berg. Ins. t. xvi, f. 3, 4, t. xxxii, f. 1 . Fuess. Ins. 20, 554. Cram. Pap. t. cccli, fig. E-11. Bork. Schmett. 119, 254, 3. Schneid. Schmett. 64, 11. Lang. Schmctt. ii, 13, 69-72. Ross. Fr. Etrusc. ii, 977. Schrank. Fr. Boic. 1296.

Papilio Electra. Lew. Pap. t. xxxii, f. I-3.

Le Souci. Geoffr. Ins. ii, 75, 58. Ernst. Pap. i, 226, $t$. liv, $f .111$, \&c.

Expansion of the wings 2-21 inches.

\section{Several specimens from North America.}

\section{DESCRIPTION.}

\section{ठำ}

Antennæ rose-coloured with the club somewhat embrowned: primary wings above saffron-coloured with a broad, deep-brown margin, a little indented internally with the nervures, especially those wext the apex, and the fringe, pale yellow; a black oblong spot marks the disk nearer the anterior than the posterior margin; anterior margin paler than the rest of the wing; underneath this wing is paler, the black discoidal submarginal spot has a minute white pupil, and there is a series of about six black spots inereasing in size as they approach the interior margiu parallel to the posterior one; the three first of these little spots are very indistinct: the sccondary wing is also saffron-coloured and has usually a spot of a deeper colour in the disk; the margin is also deep-brown, the brown colour terminating in a point short of the anal angle; parallel with the abdomen both wings are embrowned; beneath this wing is of the same colour with the primary, and has a series of indistinct black spots parallel with the margin; in the middle of this side of the wing is a sesquialterous compound eyelet, ${ }^{1}$ the exterior circle or atmosphere ${ }^{2}$ of which is composed of rusty brown scattered scales, which to form the iris are more condensed, while the pupil is formed of silvery ones.

VAnETY B. With the dark brown marginal band of the primary wings rather narrower, and the lesser eyelet of the under side of the sccondary one without a silvery pupil. C. Like the preeeding, with the eyelet just named single; these two varieties are smaller than $\mathrm{A}$. 
우

Brown marginal band of the primaries broader, internally more deeply indented than those of the male, and spotted irregularly with yellow.

The American specimens of $C$. Edusa seem to vary from the English as described by Mr. Stephens, in having the black discoidal spot on the underside of the primary wings ocellated, and from that described by Latreille, ${ }^{3}$ in having the series of marginal spots on the underside of the secondaries blind.

In the two varieties of the male above described, the passage to a simple eyelet on that wing from the sesquialterous one, is by the disappearance of the silvery pupil in B.

CLXXVIII. Genus PONTIA. Fab.

\section{1. * Pontia casta. Chaste Pontia.}

$P$. (casta) alis rotundatis integerrimis albis ; primoribus basi costa nigricanti.

Chaste Pontia, wings rounded, very intire, white; the primary with the costal nervure blackish at the base.

PLATE III, FIG. 1 .

Expansion of the wings 2 inches.

Three specimens taken in Lat. $65^{\circ}$.

DESCRIPTION.

Antennæ black annulated with white: wings white, the primaries at the anterior margin sprinkled with blackish scales; secondaries underneath with a few scattered black scales accompanying the nervures; the wings are rounded and very intire.

I received a species of this genus from Dr. Harris under the name of Pontia oleracea which $P$. casta approaches, but that is more strongly marked; its secondaries are pale-yellow underneath, and, as in $P$. Napi, accompanied on both sides by a broad greenish line.

${ }^{3}$ N. D. D'H. N. vii, 338 . 


\section{Family NYMPHALID无. Nymphalidans.}

CLXIIX. Genus MELITAA. Fab.

\section{Melitea Selenis. Ciescent Melitea.}

Melitæe Tharos. Drury. Illustr. ii, $t$. Ixxi, $f .5,6$ ?

11. (Selenis) alis integerrimis: primoribus supra nigro-fuscis fulvo maculatis at subfasciatis, subtus fulvis nigro et pallido maculatis; secundariis supra nigris fulvo maculatis, macula magna discoidali irregulari fulvo; subtus pallidis fulvo subfasciatis et nebulosis; lumula marginali albida.

Crescent Melitæa, wings very entire; primaries above black-brown, spotted and partially banded with tawny; underneath tawny, with black and pallid spots; secondaries above black spotted with tawny, with a large discoidal irregular orange-tawny spot; underneath pallid, clouded and partially banded with tawny, with a whitish marginal crescent.

Expansion of the wings 1 inch and 5 lines.

\section{Taken in North America.}

\section{DESCRIPTION.}

Antennæ black, annulated with white; linob black, compressed: primary wings dark-brown, spotted, and partially banded, with fulvous deeper or paler, viz. a series of five irregular spots, the mesal one the largest and palest; a transverse discoidal angular forked band, and a pale marginal crescent; the margin is marked with very indistinct whitish crescents: secondaries above brown, with a large discoidal tawny-orange spot, in which anteriorly two areas are formed by confluent brown lines; and posteriorly there is a series of round black spots, those nearest the anal angle being the largest; in the brown margin are five whitish crescents, three of which are evanescent; the two ncarest the above angles being most conspicuous. The underside of the primaries is tawny-orange with paler spots at the apex of the wing; next the interior margin is a sesquialterous black spot; next the anterior is an abbreviate macular band of the same colour, consisting of four black spots ; and adjoining the anal angle is an angular, abbreviated, black band; parallel with the posterior margin is an indented orange line. The underside of the secondaries is tawny, at the base reticulated and clouded by darker lines and spots; the apex also is clouded, and at the angles reticulated; parallel with the posterior margin is a series of brownish-black spots; at the margin, between the fifth and sixth nervures, is a whitish crescent, two or threc pale evanescent ones are observable also near the posterior or external angle.

CLXXX, Genus ARGYNNIS. Fab.

1. Argrixis Crbele. Cybele Argymis.

Argynnis. Fabr, Syst. Glossat. in Illig. Mag.

Papilio Cybele. Fabr. Ent. Syst. iii, 145, 445.

- Daphnis. Cram. Pap. v, t. 57, f. E. F.

Expansion of the wings 3 inches.

Taken in Canada by Dr. Bigsby. 


\title{
DESCRIPTION.
}

Wings entire, tawny: primaries above brown-black, at the base reticulated with the same colour; in the disk is a transverse macular submarginal band, consisting of eight round black spots; next follows a marginal internally dentated black band including in it a macular one, consisting of eight oblong pale spots, those nearest the anal angle being tawny; on the underside this wing is tawny, similarly reticulated and spotted with the upper side, only the tecth of the dentated band are very acute, the seven external ones including a silver triangular spot; there are also three silver spots in a triangle just above the other near the costa, the intermediate one being the largest: the basilar half of the secondaries is brown-black, the apical tawny with six black dots arranged transversely in a curve, followed by six black crescents, a line of the same colour, and a black and tawny marginal band; on the under side there are twenty-two silver spots, viz. six triangular ones forming a band near the margin; seven subquadrangular, forming an angular band in the disk, and nine varying in shape and size placed irregularly at the base, making in all thirty-two silver spots: the fringe is white, barred with black.

\section{Arginnis Mrrina. Myrina Argymis.}

Papilio Myrina. Fab. Ent. Syst. iii, 145, 444. Cram. Pap. xvi, t. clxxxix, f. в. c. Melitæ Myrina. Say. Am. Ent. iii, $t$. xlvi.

Expansion of the wings $1 \frac{1}{2}$ inch.

\section{Taken in Canada by Dr. Bigsby.}

\section{DESCRIPTION.}

Wings above tawny-orange, anteriorly reticulated with black; a submarginal macular band is formed on each wing of six round black spots; there is also an acutely dentated marginal band, each tooth inclosing a tawny spot: primaries undemeath inscribed with costal black bars expressing the number 130, with nine irregular black spots on the disk; with eight silver ones in the margin, above which are two others : the secondaries underneath are ferruginous with paler spots and twentyone silver ones arranged in bands; at the base is an area surrounded by silver spots in the centre of which is an eyelet with a pale narrow iris and black pupil; there is also a series of black spots between the two first bands of silver spots.

\section{Argunnis Aphrodite. (Fabricius.) Aphrodite Argymis.}

Argynnis Aphrodite. Fab. Ent. Syst. iii, 144, 443.

Expansion of the wings $2 \frac{1}{4}-2 \frac{1}{2}$ inches.

\author{
Taken in Canada by Dr. Bigsby.
}




\section{DESCRIPTION.}

Primary wings tawny-orange, brown at the base; spotted, inscribed and reticulated with black; at the posterior margin is a deep orange band edged with black; above this a series of black crescents succeeded by one of round spots; the eostal margin is barred with black, the three anterior bars being angular, and the fourth shaped like the letter $\mathrm{P}$; this is followed by three others less distinet; the reticulations of the disk terminate posteriorly in a zigzag black band; underneath at the external angle are five, silver, marginal triangles surmounted with black, and above them near the costa two others: the secondaries have a marginal series of black erescents; above which the wing is spotted with black, with a few paler spots surmounted by a black crescent: underneath they are reddish-brown, with a pale tawny marginal band; a marginal scries consisting of seven silver triangular spots edged with black next follows, and a secend scries consisting of the same number, differing in slape, edged also with black, the intermediate one being the smallest; a third series succeeds of four spots, that next the costa is crescent-shaped, the second is subtriangular divided by a black line, the third is oblong and the fourth minute; at the base are five spots varying in form, on the shoulders is also a silver spot, and the inner margin is silvered but less conspicuously: fringe pale, barred with black.

Fabricius cloes not mention the two costal silver spots of the prone surface of the primaries, in some specimens these appear not silvered.

In the smaller specimen the marginal band of the primaries is nearly black, the tawny colour being nearly evanescent.

\section{Arginis Freya. Freya Argymis.}

Argynnis Freya. God. Encycl. Method. ix, 273,37.

Papilio Freya. Hubu. Sclmett. 2, 13, t. x, f. 55, t. xi, f:560. Herbst. Schmett.x, 129, t. cclxxii, f. 7-10. Thunb. Diss. Ins. Succ. iii, 49, t. v, f. 14. Schneid. Mog. i, 420. Illig. Mag. i, 452, iii, 195. Ochs. Schmett. i, 78, 11. Esp. Schmett. contin. $t$. cis.

Papilio Dia lapponica. Esp. Sclmett. i, t. xcvii, cont. t. lii, f. 3 .

Expansion of the wings $1 \frac{1}{2}$ inches.

'Three specimens taken near Cumberland-house, Lat. 54\%.

DESCRIPTION.

Stalk of the antenna yellow with a large compressed dark-brown knob, red underneath at the base and tip: wings tawny, dark-brown at the base, with a narrow black band occupying the pos-. terior margin, followed by a series of black arrow-headed spots; next to which in the primaries is a zigzag angular discoidal black band, and at the anterior margin five transverse spots of the same colour; the underside of these wings is tawny variegated with black and white spots and lines: the secondaries are underneath reddish-brown variegated with white and yellow spots and bands, with a discoidal arrow-headed white spot in the centre; the fringe of the wings is alternately white and yellow. 


\section{Family VANESSID龙. Vanessidans.}

CLXXXI. Genus VANESSA. Fab.

xxxi. Subgenus Grapta K. Polygonia Hubn.

Secondary wings inscribed underneath.

(409)
1. *VANESSA
(Grapta)
C. Argenteum.
Silver C. V. Grupta.

V. G. (C. argenteum) alis angulatis fulvis nigro maculatis, subtus nigro cinereoque marmoratis tt nebulosis; secundariis $C$ argenteo inscriptis.

Silver C. Vanessa (Grapta) with angulated tawny wings, underneath marbled and clouded with black and cinereous; the secondary inseribed with a silver $C$.

PLATE III, FIG. 6, 7.

Expansion of the wings 2 inches.

A single specimen taken in Lat. 54 .

DESCRIPTION.

Antennæ brown above, pale below; knob pale at the tip: wings angular, cut out into sinuses which are dentated: primaries above orange-tawny, with five black round spots forming a rightangled triangle with each other; two triangular costal bars and posterior margin black; above the black marginal band is a series of paler tawny triangular spots; underncath the wings are veined, marbled and clouded with black, brown, and cinereous; the primaries have a very broad paler band near the margin: secondaries above dull-orange, at the base with a black spot or two near the anterior margin; the other half is black with a transverse series of triangular pale spots, the interior ones being nearly obsolete; the disk is inscribed with a slender silver somewhat obtusangular $\mathrm{C}$, with the concavity towards the anterior margin.

2. * Vanessa furcillata. (Say.) Furcillate Vamessa.

Vanessa furcillata. Say $A n$. Ent. ii, $t$. xxvii.

Expansion of the wings 2 inches.

'Taken in Canada by Dr. Bigsby.

Common in the N. West Territory and the vicinity of Fort William. 


\section{DESCRIPTION.}

Very near $V$. Urtice, but distinet. Antennx black; knob pale at the tip; a white spot at the base of each joint: wings angular, subsinuated and dentated, black-brown, above with a marginal ormge-tawny band common to both, which at the anterior extremity terminates in a fork, or two branches tipped with white, or pale; there are also two orange-tawny bars at the anterior margin of the primaries: the secondary wings have a series in the margin consisting of five blue crescents; underneath, at the base they are brown-black, inscribed with black transverse wavy lines, and the brown part is edgel with a black line; towards the posterior margin the brown of the wings is paler and marbled, so as to form a broad marginal sinuated band.

\section{Vanessa Antiopa. Antiopa Vamessa.}

Vanessa Antiopa. Kirb. and Sp. Introd. to Ent. iv, 499. Steph. Haustell. i, 45, 5. Jerm. Butt. 68, 113. Sam. Comp. 238, 3. Leach E. E. ix, 128. Curtis Brit. Ins. ii, t. xcvi. God. Lepidopt. i, 5, 1. Lat. Crust. Arachn. et Ins. ii, 380. Meig. Schmett. ii, 75, 3, t. xvii, $f$. 3. Dun. Butt. (Nat. Libr. Ent. iii, 168, ) t. xviii, f. 2.

Papilio Antiopa. Linn. Syst. Nat. ii, 776, 165; Fn. Suec. 1056. Fab. Ent. Syst. iii, 115, 355. Scop. Carn. 419. I Iubn. Schmett. 15, 4, t. xvi, f. 79. Wienn. Verz. 175, 4. Illig. Mag. iii, 185. Lew. Pap. t. i, f. 1-5. Don. Ins. iii, 45, t. Lxxxix. Berk. Synn. i, 126. Haw. Lepidopt. i, 27, 32. Stew. Elem. ii, 126. Sulz. Ins. t. xiv, f. 85. Esp. Schmett. t. xii, f. 2. Herbst. Schmett. t. clxvii, f. 5, 6. Ernst. Pap. i, $t$. i. Berg. Ins. $t$ xxxix. Panz. Fr. Germ. lxxxix, $t .23$. Bork. Schmett. i, 195, 3. Rhein. Mag. i, 258, 48. Schneid. Schmett. 156, 83, t. i, f. 4, 6. Miüll. Zool. Dan. 1295; Fu. Frid. 54, 319. Brahm. Ins. Kal. 17, 8. Ross. Fn. Etrusc. ii, 150, 1016. Fuess. Ins. 30, 572. Lang. Schmett. 34, 252-256. Schwarz. Raupen-kal. 162, 342, 486, 619. Schrank. Fn. Boic. 1333. Fourc. Ent. Par. 233, 1. Vill. Ent. 11, 41, 72. Ced. Fn. Ingr. 615. Ochs. Schmett, i, 110, 4. Lett. Nat. Comp. Frontisp. Wilks. Butt. 58, t. cxiii.

- Norio. Linn. Fu. Suec. 1st Ed. 772. Geoff. Ins. i, 35, 1.

Jonst. Ins. t. v. Pet. Gaz. t. xii, f. 10 . Rai. Hist. Ins. 135. Papilio maxima, \&c. Rös. Ins. i, t. i, f. 1. Seba. Thes. iv, 32, f. I, 2, 5, 6. Hoffn. Ins. $t$. iii, $f .2$, and $t$. vi, $f .3$. De Geer Ins. i, 305, t. xxi, $f, 8,9$. H-s. Aurel. t. xii, d.e. Schæff. Elem. t. xciv, $f .1$; Icon.t. lxx, f. 1,2 .

Expansion of the wings 3 inches.

\section{Taken in Canada by Capt. Sheppard.}

DESCRIPTION.

Borly brown-black, with a reddish tint. Antennæ externally with a white spot on each joint, underneath reddish; knob not much incrassated, pale at the tip: legs, execpt the thighs which are of the colour of the body, pale: wings of a rich reddish brown-black, with a buff-coloured posterior margin dusted here and there with black; parallel with the margin is a macular band consisting of blue spots: in the primaries the costal nervure is marbled with buff-colour, and there are two transverse angular bars of the same colour near the apex; underneath the wings have a marginal pale band, more dusted with black than the upper one; the remainder of this surface is of a cinerascent, but not pale, brown transversely marbled with black lines; it exhibits the two marginal costal bars, but smaller and less distinct, and there is a paler dot on the disk of each wing; the marginal band is internally angular, and the margin of the wings is sinuato-angular, with the rudinents of two tails.

In the European specimens the marginal band is usually white. 


\section{Vanessa Atalanta. Atalamta Vamessa.}

Vanessa Atalanta. Kirb, and Sp. Introd. to Ent. iii, 84, 114. Stepb. Illustr. Haustell. i, 46, 6. Jerm. Butt. 66, 111. Sam. Compend. 238, 1. Leach E. E. ix, 138. God. Lepidopt. i, 6, 1. Latr. Crust. Arachn. et Ins. ii, $380 . \quad$ Meig. Schmett. ii, 74, 2, t. xvii, f. 2. Dun. (Nat. Libr. Ent. iii, 170,) t. xx, f. 1.

Papilio Atalanta. Linn. Syst. Nat. ii, 779, 175; Fn. Suec. 1060. Fab. Ent. Syst. iii, 118, 362. Scop. Carn. 424. Hubn. Schmett. $t . x v, f .75,76$. Wienn. Schmett. 174, 1. Illig. Mag. iii, 187. Schæff. Icon. t. cxlviii, f. 1, 2. Lew: Pap. t. vii, f. 1-4. Don. Ins. t. cclx. Berk. Sun. i, 127, 23. Haw. Lepidopt. i, 28, 33. Stew. Elem. ii, 127. Esp. Schnett. $t$. xiv, $f$. ]. Enst. Pap. i, $t$. vi, f. 6. Herbst. Schmett.t. clxxx. Berg. Ins. $t$. xx, f. 1-11. Panz. Fn. Germ. xxii, t. 20. Petagn. Inst. Ent. ii, 465, t. vii, f. 6. Hüf. Berl. Mag. 58, 4. Müll. Zool. Dan. 1300 ; Fn. Frid. 45, 323. Bork. Sclmett. i, 12, 196, 4. Rhein. Mag. i, 256, 95. Schneid. Sclmett. 154, 82. Brahm. Ins. Kal. 148, 314. Ross. Fn. Etrusc. 1017. Fuess. Ins. 30, 576. Lang. Sehmett. 33, 243-246. Schwartz. Raupen-kal. 169, $343,623$. Schrank. Fn. Boic. 1330. Ochs. Selunett. i, 104, 2. Ced. Fn. Ingr.616. Vill. Ent. 11, 45, 76. Brit. Butt. 18. t. x. f. infim. Wilks. Pap. 55, t. cv. Ramd. Verdaung $161,2$.

Lybithea Atalanta. Lam. An. sans Vertebr. iv, 29, 4.

Mouff. Ins. 100, f. 3, 4. Aldrov. Ins. t. ccxliv, f. 3, 4. Jonst. Ins. t. vii, f. 6. 7 ? Rai. Hist. Ins. 126, 1. Pet. Mus. 35, 327. Goed. Ins, i, t. xxvi. Ed. List. $t$. 1, f. 4. H-s. Ins. 12, $t$. vi, $f$. a, b. Blank. Ins. $t$. xviii, $f .2$, A. D. Mer. Europ. 91 ; Eruc. ii, $t$. xli. Alb. Ins.t. iii, f. 4. Reaum. Ins. i, $t . x, f$. 89 . De Geer Ins. i, $t$. xxii, f. 5 . Geoff. Ins. ii, 40, 6. Rös. Ins. i Pap. i, t. vi. Adm. Ins. t. xxiv. Pod. Ins. Grac. 72, t. ii, f. 3. Pet. Mus. 327 ; Pap. t. ii, f. 11. H-s. Aurel. t. vi, f. a, b; Jepidopt. 2. Sepp. Neder. Ins.t. i. Seb. Thes. 4, 1, D.

Expansion of the wings 2 inches and 4 lines.

\section{Several taken in Canada.}

\section{DESCRIPTION.}

Body black above, grayish beneath. Palpi brown on the upper and pale on the under side; antennæ internally rufous, extemally white, but eaeh joint is black at the tip; knob black, tipped with pale: wings subdentated, brown-black, silky: primaries with an oblique subangular mesal orange band, incurved at the lower extremity; between this band and the apex are several white spots and dots; in the posterior margin of these wings is a sinus, and the fringe is alternately black and white, so as to form white creseents; underneath, at the base, the costa is alternately barred with blue-gray and black; the transverse band is more red, at the costa it is tipped with white, and at the anal angle witl pale-yellow; between it and the base are two red streaks, the inner one branching from the band; beneath these is an indistinet eyelet with a black pupil and gray iris; above the band near the costa is an irregular angular eyelet, or two blue lines confluent at each extremity and including a black islet, then follow the white spots of the upper side but less distinet and near the apex three imperfect eyelets: the secondaries have a marginal broad orange band which almost unites with the band of the primaries, it is marked with four black dots between the nervures and at the anal angle is a double eyelet, with a black iris and blue pupil; fringe alternately black and white; under side clouded, marbled and spotted with bluish, gray, black and white in the middle, at the costa ia a triangular white spot, dusted with black in the centre, near the posterior margin is a band of indistinet cordiform or reniform eyelets with a black iris and bluish pupil, between these and the margin is another band of imperfect eyelets in which the iris is gray and the pupil light brown: at the edge of the wing is a macular band of black creseents.

This beautiful though common butterfy, to judge from the shape of its wings, seems rather to belong to the genus, or perliaps subgenus, Cynthia; at any rate it forms a connecting link between it and Vanessa. 
CLXXXII. Genus CYNTHA. Fabr.

(ynthia Cardui. Kirb. and Sp. Introd. to Ent. ii, 437, iii, 458, 460. Jerm. Butt. 66, 109. Stepl.. Illustr. IIaustell. i, 47, 1. Brit. Butt. 19, t. xi. Dun. (Nat. Lib. Ent. iii, 174,) t. xix, f. 2.

Vanessa Cardui. God. Lepielopt. i, 5, 2; Encycl. Method. t. liv. 1. Lat. Crust. Araehn. et Ins. ii, 380, 3. Mleig. Schmett. ii, 73, , t, t. xvii, $f .1$.

Libythea Cardui. Lam. An. sans Vertibr. iv, $29,5$.

Papilio Cardui. Linn. Syst. Nat. ii, 774, 157; Fr. Succ. 1034. Fal. Ent. Syst. iii, 104, 320. Scop. Carn. 426. Huibn. Schmett. 14, 1, t. xv, f. 73-74. Wienn. Sclmett. 175, 2. Illig. Mag. iii, 1, 104, 320. Lew. Pap. t. vi, f. 1, 4. Don. Ins. ix, 9, t. ccxcii. Berk. Syn. i, 126. Haw. Lepidopt. i, 20, 22. Stew. Elem. ii, 125. Shaw. Nat. Misc. xi, t. ccccxxx. Miill. Zool. Dan. 1299; Fn. Frid. 518. Esp. Schmett. i, 133, t. x, f. 3. Ernst. Pap. i, 20, t. vii,f. 7. Berg. Ins. 20, t. 1xii, f. 1-6. Icon. Pap. ii, t. x, f. 1-7. Höf. Berl. Mag. ii, 64, 13. Panz. Fn. Germ. xxii, t. 19. Bork. Selnnett. i, 13, 199, 6. Rhein. Mlag. 255, 44. Scluneid. Schmett. 153, 81. Ross. Fn. Etrusc. 1i, 1013. Fuess. Ins. 29, 569. Lang. Verzeich. ii, A, 33, 237-39. Schwarz. Raupen-kal. 156,342, 485, 624. Schrank. Fn. Boic. 1331. Wilks. Pap. 56, t. crii, f. 1. Vill. Ent. ii, 32, 45. Fourc. Ent. Par. 235, 7. Ced. Fn. Ingr. 613.

Papilio Carduelis. Cram. Pap. t. xxvi, $f$. E, F.

Mouft. Ins. 101,f.9, 10. Pet. Gazopl. t. iv, f. 21, 22; Mus. 35, 326. Rai. Hist. Ins. 122, 13. Alb. Ins. t. lvi. Seb. Thes. 4, 1, E. Gocd. Ins. 3, t. A; Ed. List.t. i, f. 6 . Schref. Icon. $t$. xcvii, f. 5, 6. Rüs. Ins. i, 57, $t . x$. Mer. Eruo. iii, t. xv. Geoff. Ins. ii, 4l, 7. Reaum. Ins. t. xxvi, f. 11, 12. H-s. Aurel. t. xi, f. e. f.

Expansion of the wings 2 inches and 7 lines.

\section{Taken in North America. Canada?}

\section{DESCRIPTION.}

Body underneath white, above brown. Antennæ long, reddish on the under side, on the upper alternately brown and white; knob brown, tipped with pale-yellow, with a mucro at the summit: wings brown at the base, dusted with tawny-yellow: primaries dark-brown, sometimes almost black, at the apex barred, spotted and dotted with white, the interior portion is tawny with an oblique band of black angular spots: at the apex is a double transverse series of indistinct white crescents: underneath these wings are gray at the base with a black spot; the costal area is gray barred with black; the disk is tawny with a macular abbreviated band consisting of four black spots, the last transverse and angular not reaching the interior margin, above this band at the costa is a white bar; the apex of the wing is grayish-brown spotted with white; the spots corresponding with those on the upper side, only the dots and spot form indistinct eyelets: the fringe is alternately white and brow1 on both sides: the secondaries are tawny, dark-brown or brownish-black at the base and the costa, with a whitish discoidal transverse spot: at the posterior margin is a triple series of black spots, the first consists of five subocellated round ones, with an indistinct white pupil; the sccond of six crescents; the third of as many subtriangular spots: underneath these wings are paler, grayish-brown, clouded, spotted, and streaked, with white or buff-colour; parallel with the posterior margin are five eyelets; that nearest the anal angle is the largest and consists of a black atmosphere, a buff-coloured iris, the pupil above is blue edged with red, and below black dusted with whitc; the three next eyelets are smaller, in the sccond the iris which is pale is edged on one side with black, and the pupil is black dusted and edged above with white; in the third there is no atmosphere, and the 
pale iris is extended a little above; in the fourth the black atmosphere appears again and the pupil is dusted with blue; the fifth eye is imperfect, the pupil is a small black spot, round which the pale iris expands, particularly above; between these eyelets and the margin is a concatenated series of brown crescents dusted with blue; in some specimens they are quite covered with blue scales; these are followed by a white undulated line, succeeded by another series of less distinct crescents; and the margin terminates with a pale yellow line edged with black: the fringe is white, but brown where the nervures terminate.

\section{Cynthia Huntera. (Fabricius.) Hunter's Cynthia.}

Cynthia. Fab. Syst. Glossat. in Illiger's Mag.

Papilio Huntera. Fab. Ent. Syst. iii, 104, 321. Smith Georg. i, 17, t. ix.

—_Cardui Virginiensis. Drur. Ins. i, $t . v, f .1$.

Jole. Cram. Pap. i, t. xii, f. E, F.

Pet. Gazoph. Dec. iv, t. xxxiii, 5.

Vanessa Huntera. Drury. Hist. Nat. i, 1, t. $x$.

Expansion of the wings 2 inches and $7 \frac{3}{4}$ lines.

Taken in Canada by Dr. Bigsby. Inhabits the Graphalium obtusissimum. Abbott.

\section{DESCRIPTION.}

Wings brown at the base, thickly dusted with tawny scales : primaries orange-tawny in the disk, somewhat reticulated with black lines, band, and spots; costal margin brown; apex of the wing brownish-black, with a pale costal bar or crescent, within which and the tip are first two distant white spots and next a pair of white dots uear each other; parallel witl the posterior margin is a faint palish linear band: the fringe is alternately brown and white: underneath the primaries are red in the disk, banded, barred, and spotted with black; the costal area is white at the base barred with black; the apex of the wing is brown with a triangular, and angular white abbreviated band; between the latter and the apex is a didymous eyelet, or two confluent eyelets with a blackish pupil including an indistinct blue and white spot, the iris is pale and the atmosphere black; in the other the pupil is brown crowned witl a white spot, and has a middle blue crescent; next the costal margin is a pair of black subtriangular spots; the posterior margin is blue, gray, and whitish, with two black crescents next the anal angle; and a black line running parallel with the margin, terminating at some distance from the apical angle in an oblong black spot: the secondary wings are orangetawny with four black eyelets in a series parallel with the posterior margin, with blue pupils, next these is a macular band consisting of concatenated black crescents, terminating at the anal angle in a straight black line including a blue one; underneath these wings are brown at the base, almost reticulated with paler lines and bands; in the disk are two eye-like spots, the innermost round, and the ontermost elliptical; then follows a whitish broad angular band, dusted with black, and widest nest the abdomen: the posterior part of these wings exhibits first a broad brown anteriorly bilobed 
band, including two large eyelets; that next the anal angle, which is the largest, consists first of a narrow black atmosphere, next is a broad brown iris edged with white, and a white, brown, and blue, round pupil, the white part of which is dusted with blue; the other eyelet has the same external eircles, but the pupil is dark and elged with some blue scales; the brown band is edged with pale; between it and the posterior margin is an indented blue band consisting of concatenated crescents, and edged with black; to this suceeds a grayish white band divided into two by a narrow black line and terminated by a marginal one; fringe brown and white.

\section{Family HIPPARCHIADÆ. Hipparchiadens.}

CLXXXIII. Genus HIPPARCHIA. Fab.

\section{Hipparchia Nephele. Cloud Hipparchia.}

H. (Nephele) alis omnibus fuscis; primoribus supra et infra fascia pallidiori ocellos binos includentc; secundariis subtus apicen versus pallidioribus; ocellis sex minutis duplici serie.

Cloud Hipparchia, with all the wings dentated, brown; primaries both above and below with a paler band including in it a pair of eyelets; secondaries paler towards the apex with six minute eyelets, arranged in two rows.

Expansion of the wings $2 \frac{1}{2}$ inches.

\section{Taken in Canada by Dr. Bigsby.}

\section{DESCRIPTION.}

Antennæ brown annulated with white, rufous at the end; knob slender: wings brown: primaries both above and below with a paler submarginal broad band including two eyclets; the upper ones surrounded by a paler atmosphere, with a black iris and white pupil; on the under side the atmosphere of the eyelets is more distinct and forms a kind of glory round them; the pupil is snowywhite with some blue scales scattered round it; the under side of hoth wings, above the band, is marbled with transverse deeper coloured streaks: the secondarjes are dentated but not the primaries, which at the margin have two transverse black parallel lines; in the former there is anteriorly a costal paler bar, and the posterior laalf of the wing is paler; between the bar and the marginal paler band, are three minute eyelets, with a black iris and bluish pupil, arranged transversely in a triangle; and three more similar ones arranged obliquely, the extemal one minute, in the paler part, the internal one pointing to the anal angle. 


\section{2. * Hipparchia discoidalis. Discoidal Hipparchice.}

H. (discoidalis) fusca, alis integerrimis, primoribus vitta discoidali fulva; secundarïs subtus albido marmoratis et nebulosis. Discoidal Hipparchia, brown with very entire wings; the primaries with a discoidal tawny stripe ; the secondaries underneath marbled and clouded with white.

PLATE III, FIG. 2, 3.

Expansion of the wings $1 \frac{3}{4}-2$ inches.

\section{Several specimens taken at Cumberland-house, Lat. 54º.}

\section{DESCRIPTION.}

Body brown. Antennæ annulated with white : wings very entire, brown; costa spotted with gray; a triangular obscure reddish-tawny discoidal stripe extends from the base to the posterior margin of the primaries, and is discoverable also on the under side where the wing is faintly clouded with gray at the tip: the secondaries underneath are indistinctly marbled and clouded with gray or whitish scales; fringe whitish and brown alternately.

\section{Family LYCENID王. Lycenidans.}

CLXXXIV. Genus THECLA. Fab.

\section{1. * Thecla Augustus. Augustus Thecla.}

T. (Augustus) alis integerrimis, basi nigris, disco ferrugineis; secundariis subtus basi nigris, apice cinereis; serie transversa punctorum nigrorum.

Augustus Thecla, wings very entire, hlack at the base, ferruginous in the disk; secondaries underneath black at the base cinereous at the apex, with a transverse series of black spots.

PLATE III, FIG. 4, 5 .

Expansion of the wings 1 incb.

Taken in Lat. $54^{\circ}$.

\section{DESCRIPTION.}

Antenıæ annulated with white; knob elongated: wings dusky black, with a dull ferruginous disk; fringe alternately black and white: secondaries underneath black at the base; at the apex dusky ash-coloured, with a transverse series of about eight black spots; rudiments of which appear on the same surface of the primaries.

Named after the Esquimaux Augustus. 
CLXXXV. Genus LYCANA. Fab. Lat.

L. (Dorcas) alis supra fusco-ferrugincis nigro punctatis et maculatis; subtus fulvis; primoribus punctis lunulisque nigris; secundariis subtus nigro obsolcte punctatis; apice lunulis obsoletis aurantiis.

Dorcas Lycena, wings above brown-ferruginous dotted and spotted with black ; beneatl tawny; primaries with black spots and crescents; secondaries obsoletely dotted with black; marked at the apex with obsolete orange crescents.

PLATE IV, FIG. 1.

Expansion of the wings 1 inch.

Taken in Lat. $54^{\circ}$.

\section{DESCRIPTION.}

Body black above, white underneath. Antennæ black, annulated with white; knob tipped with orange : wings brown with a reddish tint, underneath tawny : primaries with an angular band formed of faint black spots; behind these nearer the costa is a black bar, above which are two more spots; between the hand and the posterior margin are three more black spots arranged transversely, and above the base are three spots forming a triangle: the secondaries have a slight sinus near the anal angle, the fringe of which projects so as to assume the appearance of a short tail; cross the disk runs an angular band formed of faint black spots, above which is a crescent of the same colour; at the anal angle is an orange coloured angular bar, or abbreviated band; underneath, these wings have several indistinct black dots, the three external ones of which form an obtuse angle with the four internal ones.

This species secms the American representative of L. Phlaas, but its colour is much less vivid.

CLXXXVI. Genus POLYOMMATUS. Lat. 1. Polyomatus Lucia. Lucia Polyommutus.

P. (Lucia) alis supra argenteo-carulcis margine tenuissime nigro; primoribus subtus cinerascentibus, ocellis quatuar marginalibus indistinctis; fascia maculari, lunulaque disci, nigris, albidocinetis; secundariis subtus fusco-cinereis, albido nigrcque maculatis; ocellis in margine quinque.

Iucia Polyommatus, wings above silvery-blue, with a very slender black margin; primaries underneath cinerascent with four indistinct eyelets in the margin; with a macular band and crescent in the disk black edged with white; secondaries underneath brownish ash-colour, spotted with black and white; with five eyelets in the margin.

PLATE III, FIG. 8, ?.

Expansion of the wings l inch.

One specimen taken with the preceding. 


\section{DESCRIPTIOR.}

Wings above silvery-bluc, terminating, especially at the posterior margin, in a very slender black line : fringe white barred with black: primaries underneath ash-coloured mottled with white; in the disk is a black crescent and a curved macular band, consisting of, mostly, oblique black crescents edged with white, especially on their under side; the wing terminates posteriorly in a broadish, brown band, formed chiefly by obsolete eyelets: the secondaries are brown; underneath spotted and striped with black and white; towards the posterior margin the white spots are arranged in a transverse band parallel with it; and, as in the primaries, the wing terminates in several obsolete eyelets.

\section{Family HESPERIAD正. Hesperiadans.}

CLXXXVII. Genus HESPERIA. Fab.

\section{1. * Hesperia Peckius. Peck's Hesperia.}

H. (Peckius) fusca, alis supra fascia communi articulata angulata; secundariis subtus nacula magna didynia, luteo-pallidis. Peck's Hesperia, brown, wings above with an angular band common to both; secondaries underneath witb a large, didymous, irregular spot; both of pale yellow.

PLATE IV, FIG. 2, 3.

Expansion of the wings 1 inch and $\frac{1}{2}$ a line.

Taken with the preceding, and also by Professor Peck.

DESCRIPTION.

Body brown, paler on the under side. Antennæ rufous above, below the joints have a patcls of white scales: kuob fusiform, hooked: wings above tawny-brown, with an articulate angular band, common to both wings, of pale yellow: primaries striped and streaked with the same colour near the base, and in the costal area: underneath the wings are paler; the primaries have nearly the same marks as above but more conspicuous: on the secondaries the angular band is surmounted by another irregular spot, so as to form two contiguous spots, or rather une large irregular didymous one.

This species does not appear to belong to either Thymele or Pamphila of Fabricius, as their characters are detailed by Mr. Stephens in his excellent Illustrations of British Entomology ${ }^{4}$ In both of these the palpi are thickly cloathed with hair and the terminal joint is obtuse; but in $H$. Peckius the palpi may be described as thickly cloathed with elongated divergent scales, with the terminal joint emerging, naked, and acute.

${ }^{4}$ Haustellat. i, 97, 99 . 
II. CREPUSCULARIA. Lat.

\title{
Family ZYGANIDE. Zyganidams.
}

CLXXXVIII. Genus ALYPIA. Hubn.

1. * Alypia Mac Cullochil. Mac Culloch's Alypia.

A. (Mac Cullochii) aterrima alarum maculis quatuar punctoque, nivcis; illis nigro striatis.

Mac Culloch's Alypia, very black, with four spots of the wings and a dot pure white, the former streaked with black.

PLATE IV, FIG. 5.

Expansion of the wings $1 \frac{1}{8}$ inch.

Taken in Nova Scotia by Dr. Mac Culloch, and in Canada by Dr. Bigsby. DESCRIPTION.

Body and wings very black. Orbit of the eyes externally cloathed with white hairs: base-covers or tippets whitish: primary wings with three very white spots, one near the base oblique, obversely wedge-sliaped, divided into two by a longitudinal black line; next, at a little distance from the anterior margin, is a subtrapezoidal, small, white spot, between which and the posterior margin is an articulate baud, abbreviated at eacls end, of the same colour, consisting of six spots divided by black lines; the same spots distinguish the under surface of these wings, and besides there is a whitish longitudinal one in the costal area: in the secondaries are also three white spots on both surfaces, viz. a large rectangular one near the base clivided longitudinally into four; a longitudinal undivided one at the anterior margin; and an articulate posterior abbreviated band, divided into five spots: the longitudinal costal streak may almost be regarded as forming a sixth as the lower end is parallel with the last spot of the band: the four anterior legs are externally covered with long orange coloured hairs, which character is also found in $A$. octomaculata.

\section{Family SPHINGID正. Sphingidans.}

\author{
CLXXXIX. Genus SMERINTIIUS. Lat. \\ 1. * Smerinthus Cerisyi. Cerisy's Smerinthis.
}

S. (Cerisyi) alis primoribus angulatis fusco-cinereis; fusco albidoque fasciatıs et ncbulosis ; linea transversa anguluta albida; secundariis rubcntibus; apud angulum ani, ocello pupilla, atmospharaque atris, iride carulea interrupto.

Cerisy's Smerinthus, primaries angulated, dusky-cinereous, banded and clouded with brown and whitish; with a transverse, angular, white line; secondarics rose-coloured, with an eyelet near the anal angle, formed by a black pupil and atmosphere, and a blue interrupted iris.

PLATE IV, FIG. 4.

Expansion of the wings $2 \frac{3}{1}$ inches.

Taken in North America, locality not stated. 


\section{DESCRIPTION.}

Body ash-coloured: thorax with a large trapezoidal brown spot dilated next the abdomen: primaries angulated, ash-coloured, with a transverse series of brown submarginal crescents in a paler band, between which and the posterior margin is another obsolete paler one; above the crescents is a straight whitish band, and a linear angular forked one under the internal sinuses of which the wings are clouded with dark brown; underneath the above markings of the wing are very indistinct: the secondaries are rose-colour, paler at the costal and posterior margins; underneath they are duskycinereous, with a whitish band coinciding with that of the primaries, a transverse series of crescents and a dentated brownish band, all rather indistinct: but the most conspicuous character of the secondaries is a large eyelet situated at the anal angle, consisting of a black pupil, nearly but not quite surrounded by a blue iris, and situated in a black triangular spot or atmosphere, which extends to the anal angle, and is surmounted by some blue scales: the abdomen above is dusky asl-coloured.

This insect appears to be the American representative of $S$. ocellatus, from which however it differs considerably. It comes very near to $S$. geminatus (Say Am. Ent. i, $t$. xii,) but in that the eyelet has two blue pupils.

CXC. Genus DEILEPHILA. Ochs.

\section{1. * Deilephila intermedia. Intermediate Deilephila.}

D. (intermedia) olivacea; alis primoribus vitta intermedia antice pallide rosea postice nigra; secundarïs nigris fascia rosea. intus, et ciliis, allis.

Intermediate Deilephila, olive-coloured; primary wings with an intermediate stripe anteriorly pale rose-colour, posteriorly. black ; secondaries black with a rose-coloured band which internally, as well as the fringe, 'is white.

Expansion of the wings $2 \frac{1}{2}$ inches.

\section{Taken in North America.}

\section{DESCRIPTION.}

This species is intermediate between D. Euphorbice and D. Galii, which last it most resembles, but the anterior portion of the mesal stripe of the primary wings is pale rose-colour; the fringe of their inner margin, and of the posterior of the secondaries is white: there is no series of white dots on the back of the abdomen and the ventral segments are fringed at the apex with white hairs. This description was taken from an old specimen apparently somewhat faded. 


\section{Family SESIAD无.}

CXCI. Genus SESIA. Fab.

\section{I. * Sesia ruficaudis. Red-tailed Sesiu.}

S. (ruficaudis) olivacea, abdomine scgmentis duobus intermediis atris; sequentibus rufis; alis nigricantibus disco hyalinis; sccundariis basi intus ferrugineis extus luteis.

Red-tailed Sesia, olive-coloured; abdomen with the two intermediate segments black; the subsequent ones rufous; wings black with a lyyaline disk; secondaries at the base internally ferruginous, externally yellow.

Sphinx Pelasgus. Cram. Pap. iii, $t$. ccxlviii, $f . \mathrm{B}$ ?

Expansion of the wings $2 \frac{1}{8}$ inches.

Taken in Canada by Dr. Bigsby, and in New Jersey by Mr. Drake.

DESCRIPTION.

Body yellow-olive, underneath pale-yellow. Antennæ black: primaries reddish-brown, hyaline in the disk, with the hyaline part half divided towards the base with a costal bar, covered with yellowolive hairs at the base; underneath the costa, the posterior margin, and the nervures are dark ferruginous; there is also a yellow stripe on the inner side of the base: secondaries byaline in the disk; base exterually and costa yellow; internally the base is ferruginous; underneath the dark part of the wing is ferruginous, and the base pale-yellow: two first segments of the abdomen yellowolive, two next black, the rest ferruginous with pale-yellow lateral spots.

This species appears to be the American representative of Sesia fuciformis, which it greatly resembles, but differs in the colour of the tail and the base of the secondaries.

III. NOCTURNA. Lat.

\section{Family LI'THOSIAD无. Lithosiadam.}

CXCII. Genus CALLIMIORPHA. Lat.

1. Callinorpha Parthenice. Maiden Callimorpha.

C. (Parthenice) alis primoribus nigris; rivulis incarnato-pallidis; sccundariis rubris thoraeeque maculis quinque nigris.

Maiden Callimorpha, primary wings black with pinkish-pale rivulets; red secondaries and the tborax each with five black spots.

Expansion of the wings $1 \frac{3}{4}$ inch.

Taken in North America. 


\section{DESCRIPTION.}

$\delta$

Antemnæ black, bipectinated : thorax flesh-coloured with two anterior, and three posterior, oblong, black spots, the latter being the largest : primary wings black, with the so-called rivulets pale with a slight pinkish tint; the main streams, especially towards the apex of the wing, form several islets, most of which are divided by slenderer ones which do not appear on the under side of the wing: the secondaries are of the colour of red lead, with five black spots towards the posterior margin, the intermediate three forming a macular band, above which is onc smaller one and below it another: underneath there is also a small spot, at the costal margin, above the others.

\section{2. * Callimorpha Virguncula. Little-maiden Callimorpha.}

C. (Virguncula) alis primoribus rivulis carneo-pallidis, apice radiantibus; sccundariis luteis, nigro maculatis; thorace' maculis quinque nigris.

Little-maiden Callimorpha, primary wings black with pinkish-pale rivulets, forming rays at the apex : secondaries yellow spotted with black; thorax yellow with five black spots.

PLATE IV, FIG. 6.

Expansion of the wings $1 \frac{1}{2}$ inch.

\section{Taken in Canada by Dr. Bigsby.}

\section{DESCRIPTION.}

Head pallid; orbit of the eyes, and the mouth, black; antennæ black, serrato-pectinate : thorax pallid, with five lanceolate black spots, the posterior ones being the largest: primary wings black, with pallid rivulets, which are formed by the scales that clothe the nervures, and produce the rays at the apex of these wings, where the lines are traversed by a transversc, angulated band; underneath they are pale, with the black parts less distinct, except at the apex; there is a black spot in the disk near the costal margin: the secondaries are orange-tawny, spotted at the apex with black: abdomen tawny above, bclow pale, with a dorsal, and on each side a double, lateral, black, macular stripe: trunk underneath black, with pale hairs intermixed: legs black; tibiæ pale above; thighs with a pale spot at the base and apex.

This is nearly related to the preceding species, but is much smaller; and the painting and spotting of the wings differ materially. 
CxCIII. Genus LITHOSIA. Fab.

1. * Lithosia miniata. Red-striped Lithosia.

L. (miniata) miniata ; alis primoribus vittis tribus; posticis apice abdomineque medio, schisticoloribus.

Red-striped Lithosia, miniatous; primary wings with three stripes; secondary at the apex, and abdomen in the middle, slate-coloured.

Expansion of the wings $1 \frac{1}{2}$ inch.

Taken in Canada by Dr. Bigsby.

DESCRIPTION.

Head, trunk, base and apex of the abdomen, costal and anal margin, mesal forked stripe of the primary wings, and base of the secondary, miniatous or of the colour of red lead; two longitudinal stripes and the space between the apical fork of the primaries, apex of the secondaries, and midlle of the abdomen, slate-coloured.

\section{Family CTENUCHIDÆ. Ctemuchidans.}

CXCIV. "Genus CTENUCHA. Kïb.

Palpi longer than the head, three-jointed: joints covered with shortish scales, first and second equal in size and length, the third a little shorter and small, but not minute.

Antenne of both sexes bipectiuate, but the teeth are very long in the male.

Legs, posterior tibice with a pair of spurs in the middle as well as at the apex.

Wings depressed: primaries incumbent; oblong, apical and anal angles rounded: secondaries plicatile. Anus tufted.

\section{Ctenucha Latreillana. Latreillian Ctenucha.}

C. (Latreillana) fusca, capite, alarumque primorum humeris, aurantiis; trunco cyaneo; antennis nigris.

Latreillian Ctenucha, brown; with the head, and the shoulders of the primary wings, orange; the trunk cyaneous; and the antennæ black.

Expansion of the wings $2 \frac{1}{8}$ inches.

Taken by Dr. Bigsbly in Canada, and Dr. Mac Culloch in Nova Scotia. 


\section{DESCRIPTION.}

Body, and primary wings, light-brown. Antenıx and anal hairs black; head and base of the primaries, bright orange : trunk, back of the abdomen, and outside of the thighs, cyaneous or bluegreen; fringes of the wings white, but in the middle of the posterior margin brown: secondaries short.

\section{Family NOCTUIDE. Noctuidans.}

CXCV. Genus PLUSIA. Ochs.

1. * Plusia rectangula. Rectangular Noctua.

P. (rectangula) alis primoribus cinereis, nigro nebulosis; macula discoidali nivea, rectangula, subramosa.

Rectangular Plusia, primary wings ash-coloured, clouded with black, with a rectangular, subramose, snowy-white, discoidal spot.

Expansion of the wings $1 \frac{1}{2}$ inch.

Taken in Canada by Dr. Bigsby.

\section{DESCRIPTION.}

Body cinerous, underneath whiter. Antennæ testaceous: thorax crested? as the scales are mostly rubbed off this cannot however be positively asserted; wings incumbent; primaries with a subcrenate edge; inclining to ash-coloured, clouded with black, with a subramose rectangular somewhat silvery spot, extending from near the base to the middle of the wing; between which and the apex is a narrow white wavy band, edged with black; and still nearer the margin a zigzag transverse black line: the secondary wings are plicatile, cinereous, and dusted at the apex with brown.

N.B. The silvery rectangular spot in the primary wings of this insect, when they are brought near to each other, forms a quadrangular area very much resembling a picture in a silver frame. 
Plusia Gamma. Ochs. Schmett. Tr. viii, 185, 21. Steph. Illustr. IIaustell. iii, 103, 5.

Noctua Gamma. Fab. Ert. Syst. iii, p. 2, 79, 228. Hübn. Noct. t. lviii. f. 283 ; Larv. Lep. iv, Noct. iii, A. c. f. 1, a. b. Wienn. Schmett. 93, 5. Esp. Selmett. iv, t. cxi ; Noct. 32, f. 1-4, t. cxxv; Noct. 46, f. 1-4. Ced. Fn. Ingr. 713. Illig. N. Ausg. dess. 350, 5. Walck. Fn. Paris, ii, 298, 9. Lat. N. D. D'H. N. xxiii, 37, 2. Crust. Arachn. et Ins. ii, 411. Kïb. and Sp. Introd. to Ent. iii, 254. Vieweg. Schmett. ii, 44, 63. Höf. Berl. Magaz. iii, 2, 212, 14.

Campæa Gamma. Lam. An. sans Vertèbr. iii, 569, 3.

Phytometra Gamma. Haw. Lepidopt. 256, 6.

Phalæna Noctua Ganma. Linn. Syst. Nat. ii, 843, 127; Fn. Succ. 117l. Vill. Ent. ii, 213, 189. Don. Ins. viii, t. cclxv. f. 2. Berk. Syn. i, 14l. Schrank. Fn. Boic. 1597. Stew. Elent. ii, 186.

Camma. Scop. Carn. 523. Wilks Moth. Sc. 34, t. lxix; Butt. t. xi, f. 3.

gammina. Haw. Prodr. 16.

Lambda. Petiv. Gazoph.t. lxiv, f.6. Geoffr. Ins. ii, 156, 92. Müll. Fn. Frid. 41, 448; Zool. Dan. 1395.

Ernst. Pap. viii, 134, t. ccxxxviii, f. 594 .

Goed. Belg. ii, 83, t. lxxxi ; Ed. List. t. ii, f. 14. Blank. Belg. 54, t. viii, f. N. o. p. Alb. Eng. Ins. t. Ixxxiv, f. e-h. Rai. Hist. Ins. 163, 17. Mer. Europ. t. lxxxii. Reaum. Ins. ii, t. xxvii, f. 4, 5. Sepp. Nederl. Ins. v, t. i, f. 6. Rüs. Ins. i, t. v, f. 1-4. Schæff. Ic. t. lxxxiv, f. 5. Frisch. Ins. i, 5, 37, t. xr. Pod. Mus. Grac. 91. H-s. Lepidopt. 59. Fuess. Ins. 715. Bork. Schmett. iv, 782, 358. Lang. Schmett. 1117. Brahm. Ins. Kul. ii, 211, 109. Rossi. Fn. Etrusc. ii, 1126. Goeze. Beitr. iii, 3, 124, 127.

Expansion of the wings $1 \frac{1}{2}$ inch

Taken in Canada by Dr. Bigsby.

\section{DESCRIPTION.}

Head, crests of the thorax and abdomen gray, these crests are edged with white and in the anterior ones the margin is formed by a black and white line: abdomen cinereous : antennæ above testaceous, underneath white banded with brown: the primary wings are shaded and elouded with black, brown and white, and towards the apex have three indistinet bands, the first white internally abbreviated, the second dark-brown, and the marginal one gray including a transverse series of black crescents, in the disk of the wing is a pallid silvery signature, representing the Greek letter gamma, or the Roman $\mathrm{Y}$, the forked part pointing to the costal margin; from the upper point of the fork a white curving line runs obliquely to the anal margin of the wing near its base: secondary wings light brown, or drab, with the nervures, and posterior margin broadly, dark-brown; fringe alternately dark and light: underneath the wings are cinereous, darker at the apex. 


\section{3. * Plusia falcifera. Sickle-bearing Plusia.}

$P$. (falcifera) grisea; alis primoribus nebula magna fusca falculam argenteam inchudente, extus ramulum emittente.

Sickle-bearing Plusia, grizzled, primary wings with a Jarge brown cloud including a silver sickle-shaped streak, which sends forth on the outside a little branch.

Expansion of the wings $I_{\frac{1}{2}}$ inch.

\section{Taken in Nova Scotia by Dr. Mac Culloch.}

\section{DESCRIPTION.}

Body gray. Antenna and thorax, when laid bare, testaceous : primary wings gray with a faint reddish tint, a broad brown spot, or cloud, almost triangular, traverses the middle of the wing, which partly includes, and is partly edged, by a sickle-shaped silvery streak; the part representing the handle of the sickle, being broader than the rest, and sending forth externally near its apex a short branch, which, with the internal apex of the handle, forms a fork; the inner tine, or branch, of which terminates in a slender line running in a curve to the costal margin where it touches the scutellum; a brown indistinct cloud, or band, also runs obliquely from the anal to the apical angle of the wing; a very minute, pale streak marks it just transversely above the former angle; the posterior margin is slightly indented: the secondary wings are reddish-brown, with an obsolete, pale, submarginal, band.

\section{Plusia Iota. Iota Plusia.}

PJusia Iota. Ochs. Schmett. Tr. viii, 181, 20. Steph. Cat. 105, 6375, 1 ; Illust. Haustell. iii, $100,1$.

Noctua Iota. Linn. Syst. Nat. ii, 844, 130. Fab. Ent. Syst. III, ii, 81, 237. Hubn. Noct.t. lviii, f. 282. Berk. Sclmett. iv, 79, 362. Vill. Ent. ii, 215, 192. Fuess. Schmett. 38, 717. Vieweg. Schmett. ii, 64, 64. Ross. Fn. Etrusc. ii, 1127. Goeze. Beitr. iii, $t$. iii, 127, 130, v.

- Protea. Cram. Pap. Exot. iv, 244, $t$. cccc, $f$. M.

Interrogationis. Bork. Schmett. 792, 363. Esp. Schmett. iv, 225, $t$. cxiii, f. 1, 2.

- Gamma. Müll. G. L. Naturf. $t$. ii, 5,6 .

Phytometra Iota. Haw. Lepidopt. 256, 5.

Le V. D'or. Ernst. Pap. D' Eur. viii, 129, t. ccexxxvi, f. 592.

Expansion of the wings $1 \frac{3}{4}$ incl.

Taken in Nova Scotia by Dr. Mac Culloch and in Canada by Dr. Bigsby. 


\section{DESCRIPTION.}

Body, legs, and autcmin, fawn-coloured, as are likewise the paler parts of the wings : primaries clonded and streaked with dark, and reddish-brown; the disk of these wings is occupied by a large cloud of this colour inseribed with two, sometimes silvery, and sometimes golden, brilliant metallic spots, tending to form an obtuse angle with each other: the upper one, or that nearest the base of the wing being acuminated towards that part, rounded towards the apex, and sending forth two branches towards the costal area; the lower spot is subtriangular or V-shaped, with the point towards the base of the wings: the two together form, in some sort, a semicolon reversed : between the lower or ovate spot and the costa, is a rather indistinct circlet of gold or silver, and two strcaks of the same lustre may be traced lower down between it and the inner margin of the wing; the disk near the apex is bronzed; from the brown cloud mentioned above runs a wavy brown streak to the external apical angle, the apex itself is terminated by a band formed by indistinct black crescents; and above the streak is a transverse band formed by two faint lines of clark indistinct crescents including a pale band: secondary wings darker at the apex.

N.B. In the Nova Scotia specimens the discoidal spots are silvery, while in that from Canada their lustre is golden. The synonymy of this species seems very doultful: the metallic signature can scarcely be said to represent either a mark of interrogation, or a greck Iota reversed; they most resemble a semicolon.

\section{ORDER DIPTERA. Linn.}

I. NEMOCERA. Lat.

\section{Family CULICID无. Culicidans.}

CXCVI. Genus CULEX. Linn. 1. *ulex P'unctor. Pungent Culex.

C. (Punctor) nigra; pedibus, alarumque, albarum neuris, testaceis.

Pungent Culex, black with the legs, and nervures of the white wings, testaceous.

Length of the body $3 \frac{1}{3}$ lines.

\section{Two specimens taken in Lat. $65^{\circ}$.}

\section{DESCRIPTION.}

Body black. Proboscis longer than the trunk; sheath black; valvules and lancets testaceous: palpi somewhat incrassated towards the apex; antennæ broken off in both specimens: wings white, iridescent, with testaccous nervures, without scales, hairs, and fringe: legs testaceous. 


\section{Family TIPULIDÆ. Tipulidans.}

CXCVII. Genus TIPULA. Linn.

\section{1. * Tipula Pratorum. Tipula of the Meadows.}

T. (Pratorum) schisticolor; prothorace fusco, quadrilineato; abdamine favo, lineis tribus langitudinalibus anoque, fuscis; pedibus, antennisque basi, testuceis; alis nebulosis.

Tipula of the Meadows, slate-coloured; prothorax with four brown stripes; abdomen yellow, with three longitudinal lines and the anus brown; legs and antennæ testaceous at the base; wings clouded.

Length of the body 7 lines.

Taken with the preceding.

\section{DESCRIPTION.}

ठ઼

Head and trunk slate-coloured. Antenna black, with the scape yellow : thorax with four brown stripes, the lateral ones abbreviated : wings embrowned, clouded with white; nervures black, but those at the base of the wing are testaceous; there is a black dot or two near the anterior margin; and the stigma, or what represents it, is black; the poisers are pale but black at the tip: legs obscurely tcstaceous; thighs and shanks black at the tip; tarsi black: abdomen clubbed, yellow, with a longitudinal dorsal brown stripe; anal club black.

Wings not spotted with white: legs distinctly testaceous, black at the joints; last joints of the tarsi black : abdomen lauceolate, yellow, with a dorsal, ventral, and on each side a lateral, brown stripe.

\section{Family BIBIONIDÆ. Bibionidans.}

CXCVIII. Genus ASPISTES. Hoff.

xxxii. Subgenus Arthria. Kirb.

Antenne novemarticulatæ, ultimis articulis vix distinctis.

Oculi reniformes, antennarum basin cingentes.

Stemmata tria.

Femora antica incrassata.

The little insect which forms the type of this subgenus differs chiefly from Aspistes of Count Hoffmanscgg, ${ }^{5}$ in having one joint more in the antennæ; the three terminal ones are closely imbricated so as to be scarcely distinguishable; and the last is of a different form. ${ }^{6}$ The neuration of the wings, in both, is precisely the same; and in both the anterior tibia terminates in a spine. 
A. A. (analis) atra ; trunci lateribus, pedibus, anoque, testaceis ; alis corpore longioribus.

Anal A. Arthria, black; with the sides of the trunk, legs, and amus, testaceous ; wings longer than the body.

PLATE VI, FIG. 8.

Length of the body, $\left\{\begin{array}{l}\text { excluding the wings, } 2 \\ \text { including the wings, } 3\end{array}\right\}$ lines.

Several taken in Lat. $65^{\circ}$.

DESCRIPTION.

Body black, naked. Head very small: trunk with a dorsal area marked ont by a ridge; on each side is a reddish-yellow line drawn from the collar to the base of the wing; but in some specimens this is very indistinet; poisers white; wings lyaline, iridescent, much longer than the body; costal area divided into three areolets, with testaceous nervures, terminating in a black stigma; there are four spurious nervures, the first abbreviated, and the anal one bent towards the margin: the legs are reddish-yellow exeept the apex of the tarsi which is blaek; the intermediate pair are smaller and shorter than the others; anterior thighs are much incrassated, and the tibix terminate in a spine; the posterior thighs are elongated; abdomen flat above; anus yellow, as is sometimes the margin of the ventral segments.

\section{TANYSTOMA.}

\section{Family EMPID无. Empidans.}

CXCIX. Genus EMPIS. Lin.

1. Empis luctuosa. Monming Empis.

E. (luctuosa) atra; alis infuscatis, stigmate magno; halteribus nigris, capitulo magno; proboscide vix capite longiori.

Mourning Empis, black; wings embrowned with a large stigma; poisers black with an ample bead; proboscis scarcely longer than the head.

Length of the lody, wings included, 3 lines.

Taken with the preceding.

DESCRIPTION.

Body entirely black. Proboscis very little longer than the head: wings a little embrowned. with a large black stigma, iridescent, nervures black. 


\section{Empis geviculata. White-lineed Empis.}

E. (geniculata) nigricans; pedum geniculis albidis; proboscide capite longiori; alis amane iricoloribus. White-kneed Empis, blackish; knees white, proboscis longer than the head; wings beautifully iridescent.

Length of the body 3 lines.

Taken with the preceding.

\section{DESCRIPTION.}

Very similar to the preceding, but not so black: wings slightly embrowned, beautifully iridescent; legs, where the shank is united to the thigh, white; proboscis nearly as long as the thorax.

\section{Family BOMBYLIAD无. Bombyliadans.}

CC. Genus BOMBYLuUS, Lin.

\section{Bombylius major.}

Bombylius major. Linn. Syst. Nat. ii, 1009, 1; Fn. Suec. 1918. Fab. Ent. Syst. iv, 407, 1; Syst. Antl. 128, 1. Schrank. Enum. 1002. Vill. Eut. iv, 605, 1. Berk. Syn. i, 167. Don. ii, 79, t. lxvi. Stew. Elem. ii, 273. Ced. Fn. Ingr. 1052. Ramdohr. Verdaung. Ins. 183, 13, t. xx, f. 2-5. Schel]. Dipt. 90, t. xxxiv, f. 2. Herbst. Naturg. ii, t. cccxlvii, $f$. 1. Fall. Dipt. Succ. Bombyl. 9, 1. Lat. Consid. Gèner. 443. Meig. Dipt. ii, 190, 5.

Bombylius varicgatus. De G. Ins. vi, $268,1, t . x v, f .10$.

- sinuatus. Mik. Bomb. 35, t. ii, f. 4. Meig. Klossif. d. Sweif. i, 179, 4.

Aldr. Ins. 330, f. 10. Musca X. Mouff. Ins. 65; Sinistr. f. 5. Höf. Jun? t. viii, f. 5 . Pet. Gaz. v, t. xxxvi, f. 5. Schæff. Elem. t. xxvii. f. 1 ; Icon. t. xxi, f. 5. H-s. Expos. t. xvii, f. 2 ? Müll. Linn. Nat. v, 1007 ; Fn. Frid. 790. Wied. Mag. i, 2, 20.

$$
\text { Length of the body, }\left\{\begin{array}{l}
\text { including the proboscis, } 7 \\
\text { excluding the proboscis, } 5
\end{array}\right\} \text { lines. }
$$

Taken in Lat. $65^{\circ}$.

Expansion of the wings 1 inch to $\frac{3}{4}$ inch.

Linné under this species refers to one noticed by Ray $;^{7}$ bnt Ray describes the wings as "punctis nigris creberrimis picte," words which evidently refer to $B$. medius; Mr. Samouelle, perhaps induced by this reference, has figured the latter insect ${ }^{8}$ as B. major. The reference in Syst. Nat. also to Geoffroy ${ }^{9}$ appears to be incorrect, for Linné describes the wing of this species not as basi fusca as Geoffroy does; but in these words "ala dimidium longitulinaliter fuscum." Geoffroy, as well as Reaumur, who is also quoted by more authors for this species, probably had the B. minior in their cye, the wings of which Linné describes as "antice versus basin obsolete fuscescentes."2

\footnotetext{
I Hist. Ins. 273, Musca bombyliiformis, \&c.

9 ii, 466, Ins. Asilus. 1. Le Bèchon. $\quad 1$ Ins, iv, t. viii, f. 11-13.

$s$ Compend. t. ix, f. 10.

${ }^{2}$ Fn. Suec. 1920.
} 


\section{DESCRIPTION.}

Body black, thickly covered above with yellowish, soft, but erect hairs; underneath the hairs are whiter, but those on the breast, at the origin of the legs, are black: wings with the anterior half longitudinally black-brown, the dark colour on the inner side being sinuated or uneven; the posterior half of the wings is transparent with black nervures: the legs are long, and pale-yellow; but the tarsi are reddish-black at the extremity: the eyes are triangular.

Bombylits pygmæus. Fab. Ent. Syst. iv, 411, 19; Syst. Antl. 135, 32. Wied. Dipt. Ex. 175, 29.

Length of the body, $\left\{\begin{array}{l}\text { including the proboscis, } 5 \\ \text { excluding the proboscis, } 3\end{array}\right\}$ lines.

Expansion of the wings 9 lines.

Taken with the preceding.

DESCRIPTION.

Body black, hairy. Hair below the eyes black; eyes meeting at the vertex; behind the eyes the hairs are gray; those on the thorax are tawny or reddish with a white tuft on each side at the anterior and posterior margin : the wings are longitudinally dusky at the anterior margin; more than the posterior half is hyaline, with several scattered black dots, the interior ones being the largest: the legs are testaceous, but black at the tip: the abdomen is covered by reddish hairs with dark ones intermingled; those at the anus are whitish.

\section{Family TABANIDEE. Tabanidans.}

CCI. Genus TABANUS. Linn.

\section{1. * Tabanus affinis. Kindred Tubanus.}

T. (affinis) niger; proboscide, palpis, antennis basi, abdomineque segmentis tribus primis utrinque, quarto pknctis duobus dorsulibus, tibiisque quatuor posticis, rufis.

Kindred Tabanus, black, with the proboscis, feelers, antennx at the base, abdomen with the three first segments on each side, two dorsal dots of the fourth, and four posterior tibix, red.

Length of the body $7 \frac{3}{4}$ lines.

Taken with the preceding. 
DESCRIPTION.

Body black with hoary down. Proboscis, palpi, and base of the antennæ obscurely, all red : down on the trunk very thin, mixed with a few black hairs: tubercles before the wings, winglets and knob of the poisers, pale testaceous: legs black with the four posterior tibix rufous: wings embrowned, with darker nervures: three first segments of the abdomen rufous, each with a black dorsal spot; margin of the segments pale with a whitish fringe; the fourth segment has a pair of round, red, dorsal, spots.

VARIETy B. Antennæ all black.

This species is nearly related to T. tropicus, solstitialis, and gracus, but appears distinct.

\section{2. * Tabanus zonalis. Zoned Tabamus.}

T. (zonalis) niger, subpubescens, antennis basi, tibiis, tarsis, et femoribus apice, rufis; abdomine segmentis margine albidis. Zoned Tabanus, black; a little downy; antennæ at the base, tibiæ and tarsi, and thighs at the apex, red: margin of the abdominal segments white.

Length of the body $7 \frac{1}{2}$ lines.

Taken with the preceding species.

DESCRIPTION.

Body black, with a few hairs of the same colour, especially at the sides of the trunk. Antennæ reddish at the base; sheath of the proboscis, and palpi, black; haustellum testaceous: breast whitish from inconspicuous down; tubercles before the wings subferruginous: wings subtestaceons with some of the nervures black; knob of the poisers reddish: thighs black, reddish at the tip; tibix, and tarsi, except the anterior pair which are black, as well as the apex of the anterior tibix, red : abdominal segments above and below margined with white decumbent down and fringe.

CCII. Genus CHRYSOPS. Meig. 1. Chrysops sepulchralis. Sepulchral Chrysops.

Chrysops sepulchralis. Fab. Ent. Syst. iv, 374, 48; Syst. Antl. 113, 12. Meig. Dipt. ii, 74, 10. Length of the body 6 lines.

Taken with the preceding. 
DESCRIPTION.

Body black, slightly downy. Head hoary from pubescence; proboscis with a black sheath and testaceous haustellum; feclers black: antennæ red at the base; below the antennæ is an obtriangular levigated, and naked space, witl rounded angles, and somewhat elevated; behind the antennæ in the frontal space, between the eyes, the ordinary levigated and naked areas, which in Tabanus are longitudinal, in Chrysops are transverse: sides of the trunk hairy with black erect hairs, it is also marked above with four longitudinal hoary stripes formed by invisible pubescence; underneath the trunk is covered with down of the same description and colour, and set with tufts of longer hairs: wings white, with the costal margin and a middle abbreviated band, and nervures brown: legs and abdomen black; and extremity whitish from down.

\section{ATHERICERA. Lat. Family SYRPHIDE. Syrphidans.}

CCIII. Genus SCÆVA. Fab.

\section{Sczeva Ribesit. (Fabricius.) Currant Scceva.}

Scæra Ribesii. Fab. Syst. Antl.248, 1. Fall. Dipt. Suec. Syrph, 40,6. Steph. Cat. ii, 285, 858, 10.

Syrphus Ribesii. Fal. Spec. Ins. ii, 432, 57 ; Ent. Syst. iv, 304, 100. Lat. Crust. Araclut. et Ins. ii, 494. Meig. Dipt. iii, 306, 49. Ced. Fn. Ingr.961. Kirb. and Sp. Introd. to Ent. iii, 299. Walck. Fn. Par. ii, 389, 15. Ramd. Verdaung. Ins. 177.

Musca Ribesii. Linn. Syst. Nat. ii, 987, 50; Fn. Suec. 1816. Schrank. Enum. 905; Fn. Boic. iii, 2408. Vill. Ent. iii, 446, 99. De G. Ins. vi, 103, 4, t. vi, f. 3-13; Act. Upsal. 1736, 32, 41. Don. Ins. xii, 21, t. cecci, f. 3. Stew. Elem. ii, 266.

Rai. Hist. Ins. 269 1. Goed. Ins. i, t. xli, Ed. List. f. 133. MIer. Eruc. $t$. vi. Geoff. Ins. ii, $511,37 . \quad$ H-s. Exp. t. $\operatorname{xxxii}, f .38$.

Length of the body 4 lines.

\section{A single specimen taken with the preceding.}

\section{DESCRIPTION.}

Head concavo-convex; underneath black, with the edge fringed with whitish hairs; vertex black: face bclow the antenne yellowish; hoary from decumbent hairs next the cyes; antennæ ycllowish with a darker cloud: trunk bronzed with a greenish tint, dewny especially on the sides, down whitish: wings hyaline, longer than the body, with black nervures, but those of the costal area arc ferruginous: scutcllum large, yellow: legs luteous, coxæ and trochanters dark-brown, postcrior tarsi black, first joint below with a brush of golden coloured bristles: abdomen depressed, above black with five yellow bands, viz. one consisting of two crescents, forming an interrupted band, 
traversing the middle of the first segment; then a broadish subinterrupted onc traversing the base of the second and third; and lastly the margin of the two last segments is also yellow, as is the under side of the abdomen.

Ray, I suppose, has not hitherto been referred to as describing this species, because in his clefinition he mentions only three yellow bands, or annuli, as he calls them; yet in his description he mentions a fourth narrower one.

\section{Family MUSCIDE. Muscidans.}

CCIV. Genus MUSCA. Linn.

\section{1. * Musca Cadaverum. Carcase Musca.}

M. (Cadaverum) rigra; prothorace abdomineque ex viridi atro-caruleis; fronte versicolori; palpis subferrugineis ; alulis albis. neura cingente testacea.

Carcase Musca, black; thorax and abdomen black-blne with a green tint; front changeable; palpi subferruginous; winglets white, surrounded with a testaceous nervure.

\section{Length of the body $4 \frac{3}{4}$ lines.}

\section{A single specimen taken in Lat. $65^{\circ}$.}

\section{DESCRIPTION.}

Body black, with black hairs and briștles. Antenna plumate; eyes brown; the cheeks and front in certain lights appear hoary or silvery from ineonspicnous down, in others black; feclers subferruginous: trunk and abdomen black-blue with a greenish tint: wings hyaline; intermediate areolet obtusangular: winglets white, bordered with a testaceous nervure.

This species approaches very near to $M$. cadaverina, but the front, winglets, and palpi are of a different colour.

\section{Musca hortisequa. Funereal Musca.}

M. (mortisequa) thorace obsolete trivittato; abdomine caruleo, nitido; ore ferrugineo, palpis pollide rufis; alulis magnis albis; alis areola intermedia acutangula.

Funereal Musca, thorax with three obsolete stripes; abdomen blue, glossy; front ferruginous; feelers pale-red; winglets large, white; wings with the intermediate areolet acutangular.

Length of the body $5 \frac{1}{2}$ lines.

Several taken with the preceding. 


\title{
DESCRIPTION.
}

Body black, with black hairs and bristles. Eyes brown; cheek and front forruginous, in certain lights exhibiting something of a golden lustre: feelers long, slender, reddish-yellow : trunk slightly loary, with three very indistinct black dorsal stripes: wings hyaline, with the intermediate areolet projecting internally into an acute angle: winglets white terminated by a white nervare: abdomen heart-shaped, glossy, blue with a slight tint of green.

This seems to be the American representative of $M$. vomitoria, from which it differs chiefly in having three obsolete black stripes between the wings; in the anterior spiracles not being of a different colour from the rest of the trunk; in having white winglets and not black edged with white; and in the abclomen exhibiting no changeable appearance of eliequer-work.

VARIETY B. with a green abslomen.

C. with chalybeous abdomen.

\section{ORDER HOMALOPTERA. Leach.}

\author{
PUPIPARA. Lat. \\ Family HIPPOBOSCIDE. Hippoboscidans.
}

CCV. Genus hippoboscA. Linn.

\section{Hippobosca equina. Equine Hippoboscu.}

Hippobosca equina. Linn. Syst. Nat. ii, 1010, 1; Fn. Suec. 1921. Fab. Ent. Syst. iv, 415, 1; Syst. Antl. 337, 2. Lat. N. D. D'H. N. xiv, 483.; Crust. Arachn. et Ins. ii, 543. Pod. Mus. Grec. t. cxx. Scop. Curn. 1022. Frisch. Ins. v. t. xx? Schrank. Enum. 1007. De G. vi, 275, 1, t. xvi, $f .1$, 2. Schæff. Icon. $t$. clxxix, f. 8, 9. Müll. Fr. Frid. 729. Schell. Dipt. 92, t. xlii, f. 1. Stew. Elem. ii, 274. Panz. Fn. Germ. vii, t. 23. Shaw. Zool. vi, 401, t. cxiv. Leach Encycl. ix, 130; Eprob. 9, t. xxvi, f. 4-7. Sam. Compend. 302, t. ix, f. 11 . Kirb. and Sp. Introd. to Ent. i, :2027. Lam. An. sans Vertèbr. iii, 347, 1.

Ilouff. Ins. 59? Reaum. Ins. vi, 569, t. xlviii. Sulz. Ins. t. xii, f. 141. Gcoff. Ins. ii, 547, 1, t. xviii, f. 6.

Length of the body $\left\{\begin{array}{l}\text { excluding wings, } 4 \\ \text { including wings, } 5\end{array}\right\}$ lines.

\section{Locality not mentioned.}

DESCRIPTION.

Body flat; subpubescent, dirty-yellow, spotted with brown, with whitish signatures. On the forehead, between the eyes, is a brown quadrangular spot shaped like what are called skates eggs, with four projecting points at the angles: abdomen underneath pale, anus hairy: tarsi with four black claws, the inner ones shorter and truneated: wings much longer than the body.

One of the characters assigned to this genus by Fabricius is the want of stemmata, but if the present species is examined under a powerful magnifier, one will be diseovered at the posterior internal angle of each eye. 


\section{ORDER APHANIPTERA. Kirb.}

\section{Family PULICIDAt. Pulicidans.}

CCVI. Genus PULEX. Linn.

$$
\text { 1. * Pulex Gigas. Giunt Pulex. }
$$

P. (Gigas) ovatus, luteo-testaceus, nigro setosus; thoracis segmento primo apice setis pectinato; secundibasi nigra ; antennis brevissimis, conicis : femoribus compressis, subovatis, latissimis.

Giant Pulex, ovate, yellowish-red; bristles black; first segment of the thorax pectinated with bristles ; second blaek at the base; antennæ very short, conical ; thighs compressed, rather ovate, very broad.

PLATE VI, FIG. 9.

Length of the body 2 lines.

Two specimens taken in Lat. $65^{\circ}$.

\section{DESCRIPTION.}

Body ovate, reddish-yellow: segments, particularly the first of the trunk, pectinated with black bristles; antennæ though short very distinct, standing out from the head, they seem to consist of two joints, the last conical and obtuse; the base of the second segment of the trunk is black; the thighs are very flat and wide, inclining to ovate; tibia armed with long black bristles.

This I believe is the largest flea known, but $\mathrm{I}$ have not been able to aseertain upon what animal it was captured. 


\section{N D E X.}

The references to groups, whose characters are given in the text, are in small caprtals. Those to the species described are given so fully, in the table of contents prefixed to the volume, that it is unnecessary to repeat them. Synonymes and groups or species incidentally noticed are in Italics. Where Roman claracters are used to indicate any Trivial name, they imply that the species is described under that name in the work.

N.B. In the text of this volume an asterisk (*) prefixed to a genus or species, signifies that it is non-descript: an obelus $(t)$ prefixed to a word, that it is a subgenus.

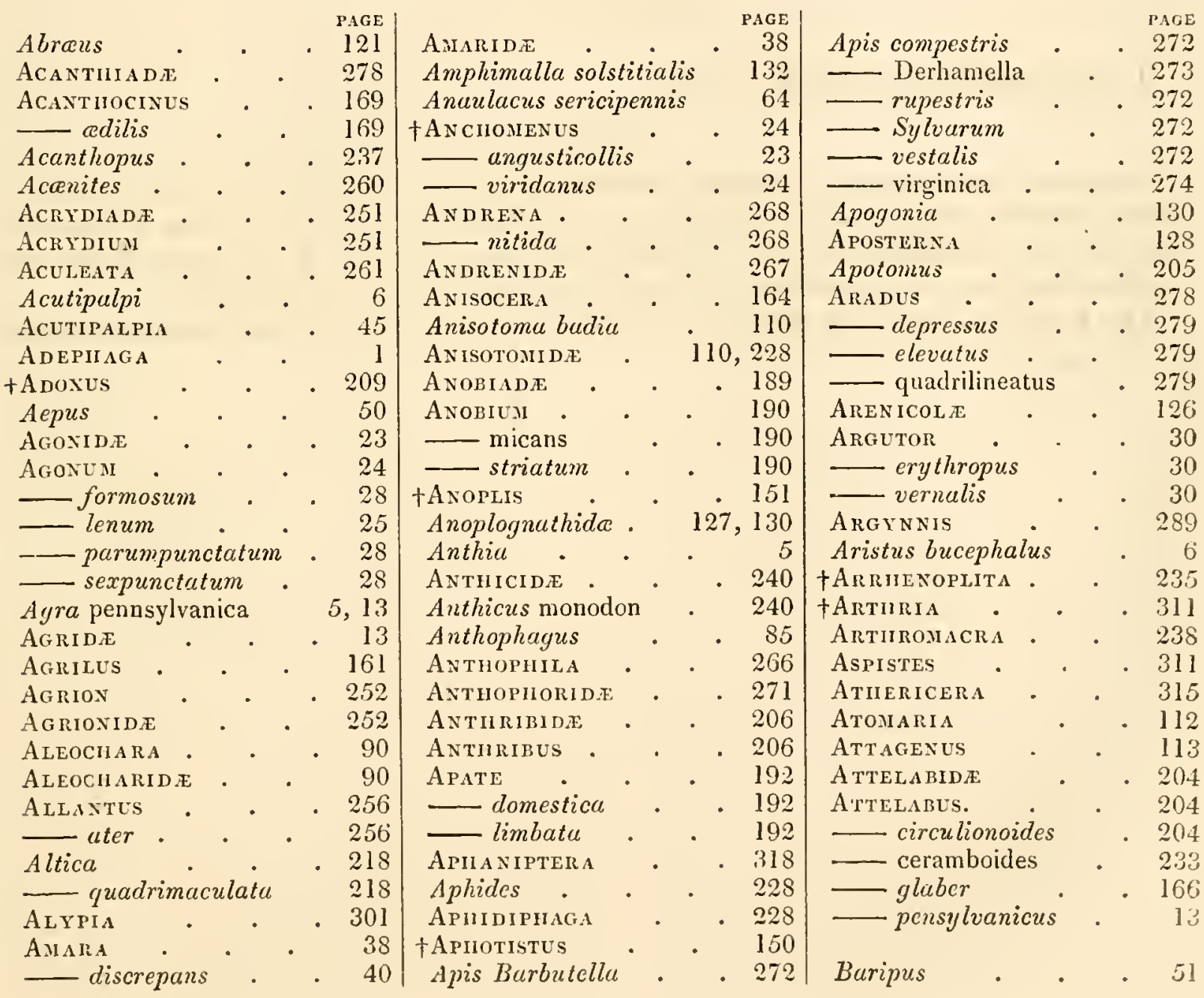


INDEX.

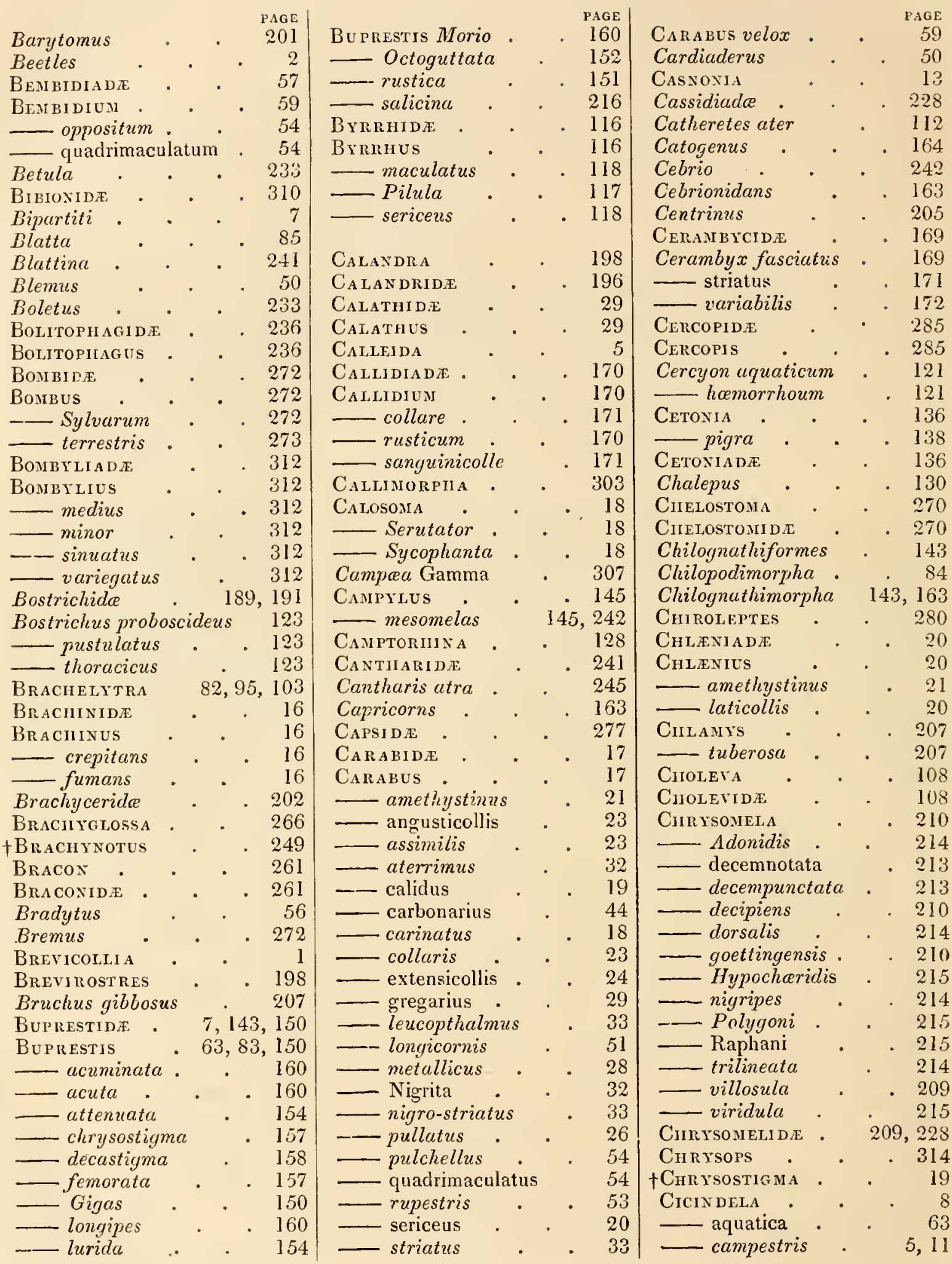




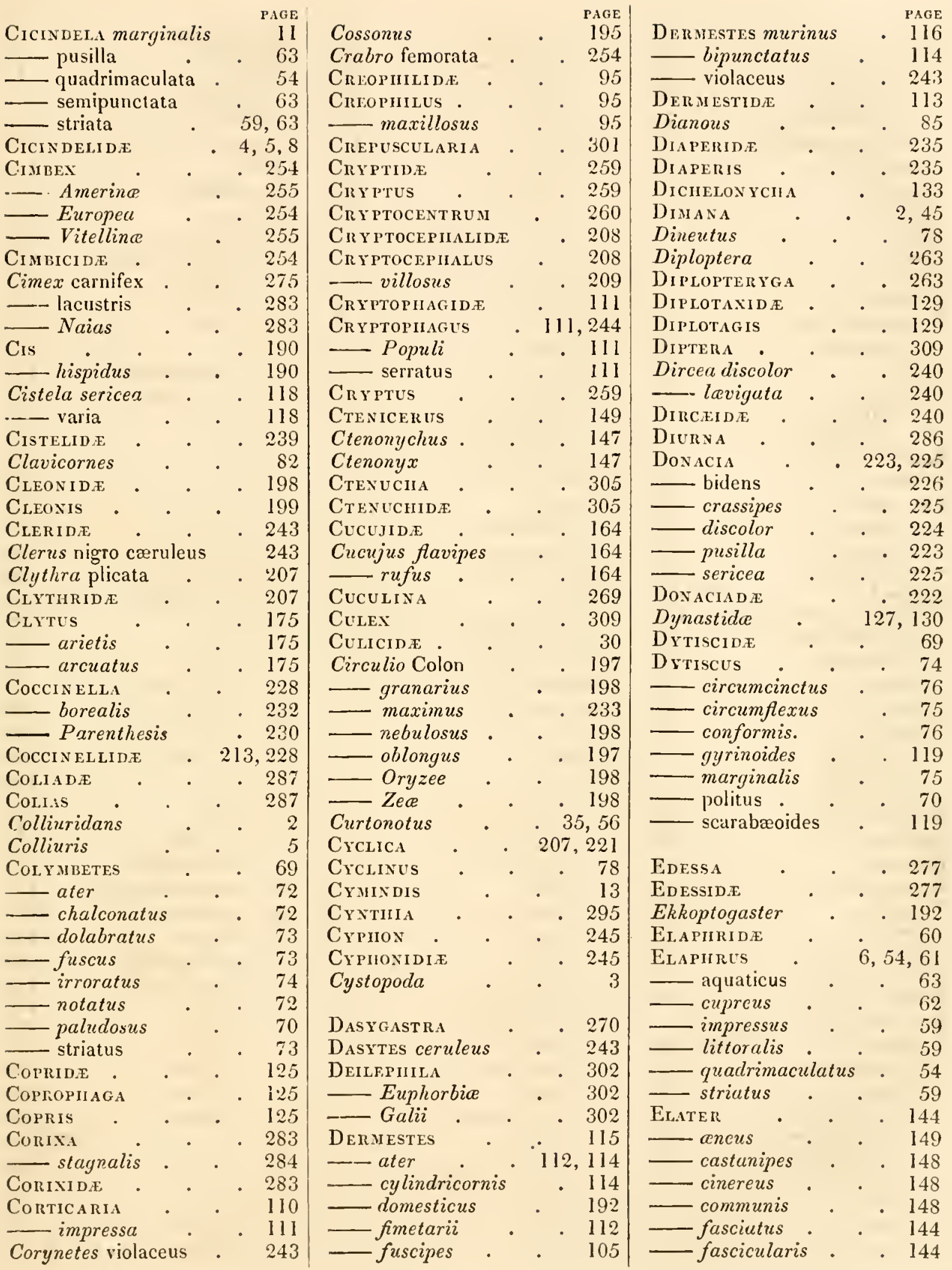




\begin{tabular}{|c|c|c|c|c|c|c|c|c|}
\hline & & & & & & & & \\
\hline Elater flabellico & rnis & 144 & Formica herculanea & & 262 & HEMIPTER A & . & 275 \\
\hline fulgens . & & 144 & — libera . & & 262 & Hemirlipus & & 144 \\
\hline fulvipes & & 147 & - ligniperda. & & 262 & HEsperia & & 300 \\
\hline -fuscipes . & & 144 & - pennsylvanica & & 262 & HESPERIade & & 300 \\
\hline - fuscus major & & 148 & - pubescens. & & 262 & HETEROGENEA & & 89 \\
\hline - Gigas . & & 144 & ForMICIDE & - & 261 & HETEROGYNA & & 261 \\
\hline _ impressus & - & 149 & & & & HET EROMERA & & 143 \\
\hline - ligneus & & 144 & GaLlERUCA & & 216 & HIERENTOMA & & 125 \\
\hline - linearis & • & 145 & — Caroliniana & • & 217 & HipPaRCHIA & & 297 \\
\hline major & & 148 & - quadrimaculata & & 218 & HIPPARCHIADE & & 297 \\
\hline - mesomelus & & 144 & - Salicis & . & 216 & Нip РововсA & & 317 \\
\hline - murinus & & 149 & - Vitellinæ & & 216 & HIPPOE & & 317 \\
\hline niger & & 144 & Galler ucide & & 218 & Hispa & & 227 \\
\hline - noctilucus & & 144 & EADEPHAGA & & 3,118 & atra & & 227 \\
\hline $\begin{array}{l}\text { - obscurus } \\
\text { - pectinicornis }\end{array}$ & s & $\begin{array}{l}144 \\
144\end{array}$ & $\begin{array}{l}\text { Geocorisa } \\
\text { GERRIS }\end{array}$ & & $\begin{array}{r}275 \\
. \quad 282\end{array}$ & $\begin{array}{l}\text { - bicornis } \\
\text { erinacea }\end{array}$ & . & $\begin{array}{l}235 \\
227\end{array}$ \\
\hline - ruficaudis & . & 144 & Gnathophorus & • & 166 & HISPIDE . & & 227 \\
\hline - rugosus & & 148 & Goliathus . & & - 139 & Hister . & & . $\quad 123$ \\
\hline - sanguineus & • & 149 & GoNatocera & & 196,202 & HISTERIDE & & 121,122 \\
\hline Spectator & & 144 & tGraPIIISURUS & & . 169 & Hololepta maxillos & & . 141 \\
\hline suturalis & & 144 & †GRAPTA & & 292 & HOMALOPTERA. & & 317 \\
\hline unguliserris & & 147 & Gregaria & & - 272 & & & 275,285 \\
\hline ERIDE & . & 144 & Gryllus Locusta & & 250 & †HYDA & & . 73 \\
\hline ledona cornuta & & 236 & GYMNODUS . & & 140 & DEPHAGA & . & 6,65 \\
\hline lytra & - & . 7,62 & GYP & & 78 & IUS . & & 120 \\
\hline $\mathrm{D} \approx$ & & 311 & Grrinus . & & 78 & etra lacust & tris & 283 \\
\hline MPIS & & 311 & —americanus & & 79 & HYDROMETRIDE & & 282 \\
\hline GI DE & & 107 & - bicolor & & 81 & HYDR & & 119 \\
\hline STAPIIIA & & 95 & -Kirbii & & 81 & Hydrophilus & 82 , & $, 119,120$ \\
\hline ndoxus & & 209 & - marinus & & 79 & _ dermestoides & & . 121 \\
\hline Eaphius & & 50 & - Natator & & 81 & — fuscipes . & & 119 \\
\hline MUS & & 55 & GYROIIYPNIDE & & 88 & — hamorrhoida & & 121 \\
\hline UMOLPUS & & 209 & GyroIIYPNIS ochrace & eus & 88 & __ marginellus & & 120 \\
\hline - ignitus & & 209 & GyroneCha & & 78 & - margipallens & & 120 \\
\hline NECHA & & - 65 & & & & _ melanocep & & 120 \\
\hline $\mathrm{ODA}$ & & 207,221 & HEMONIA & & 222 & - minutus & & 120 \\
\hline TERA & & & -Equiseti & & 222 & - quadripuncto & atus & 120 \\
\hline rhinus . & & . $\quad 205$ & - Zosterce & & 222 & - - Scarabaoides & & 119 \\
\hline UTRECIIA & & $5,7,13$ & $\begin{array}{l}\text { HaLICTUS } \\
\text { lavis }\end{array}$ & & $\begin{array}{l}267 \\
268\end{array}$ & $\begin{array}{l}\text { Hydroporus } \\
\text { picipes }\end{array}$ & & \\
\hline ronia & & 24 & HALI PLI DE & & 65 & HYGRADEPIIAGA & & 6,45 \\
\hline ripennis & • & & HaLiplus & & 65,222 & & & 163,192 \\
\hline - extensicollis & & & HaLtica & & . 217 & BIADE & & . 196 \\
\hline — gregaria & & & - alternata & & 21 & G US & & 195 \\
\hline _Longicornis & & $\begin{array}{l}51 \\
22\end{array}$ & $\triangle$ LTICIDE & & $\begin{array}{l}217 \\
178\end{array}$ & HYMENOPTERA & & 254 \\
\hline Nigrita & & - $\quad 33$ & & & $\begin{array}{l}178 \\
1119\end{array}$ & & & \\
\hline $\begin{array}{l}\text { Filipalpia } \\
\text { Fissicollia }\end{array}$ & & $\begin{array}{r}45,60 \\
1\end{array}$ & $\begin{array}{l}\text { HARPALIDÆ } \\
\text { HARPALUS }\end{array}$ & & $\begin{array}{r}41,222 \\
. \quad 41\end{array}$ & -_J Jaculator & & 258 \\
\hline ABRA & & 91 & - angusticollis & & $\begin{array}{l}71 \\
23\end{array}$ & Juvencus . & & 257 \\
\hline ENIDE & & 258 & - Nigrita & & 32 & — viduatorius & & 259 \\
\hline ENUS & • & 258 & - tardus & & 41 & ICHNEUMONIDE & & 258 \\
\hline ot cushions & & 3 & A USTELLATA & & 275 & IPS & . & 107 \\
\hline$a$ & & 85 & HELOBIA & & 20 & — impressa & & 111 \\
\hline & & 261 & Helopians . & & 164 & & . & $\begin{array}{r}164 \\
40\end{array}$ \\
\hline$-f l a$ & • & 262 & HELOPIDE & & 231 & OPLEURIDÆ & & \\
\hline
\end{tabular}




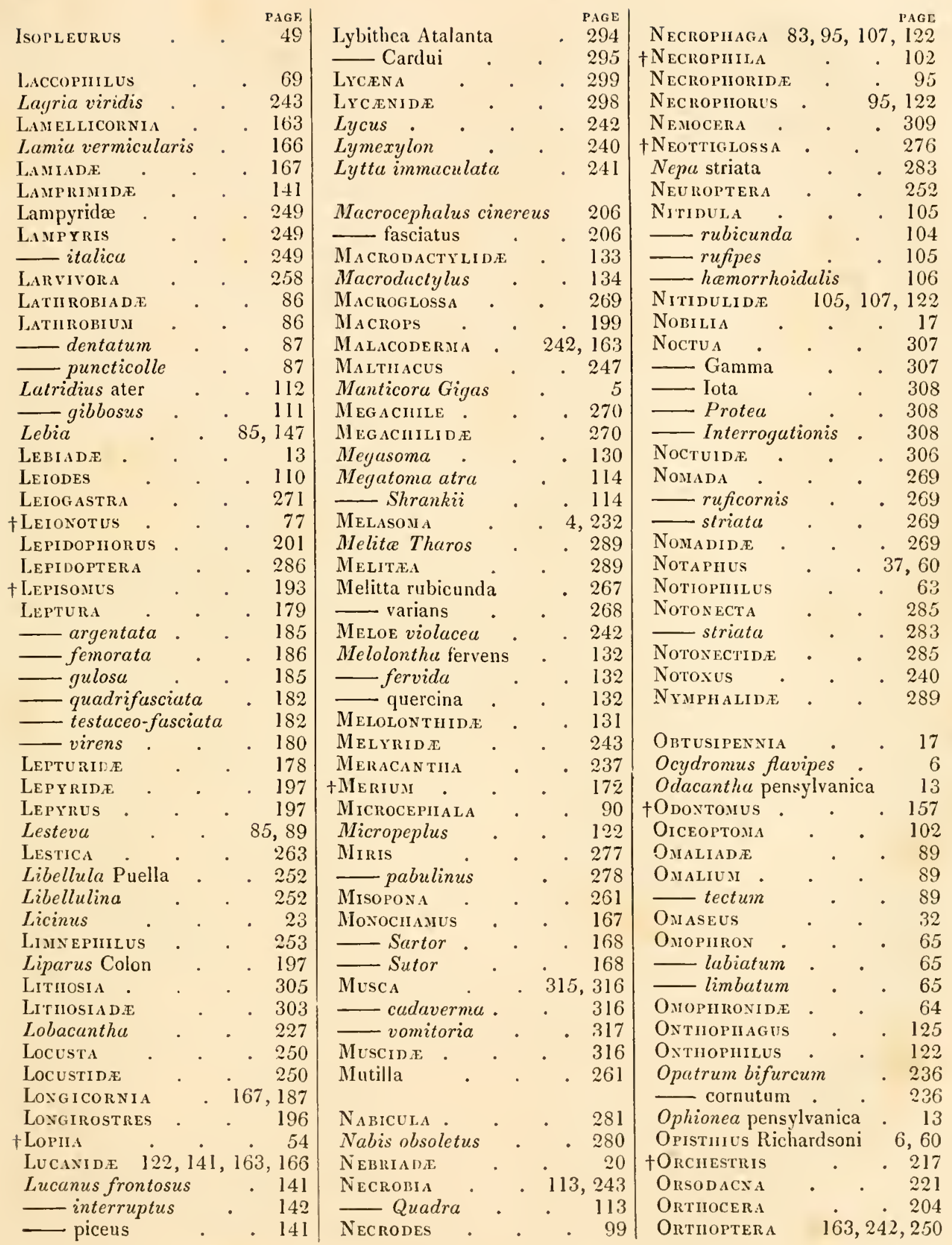


INDEX.

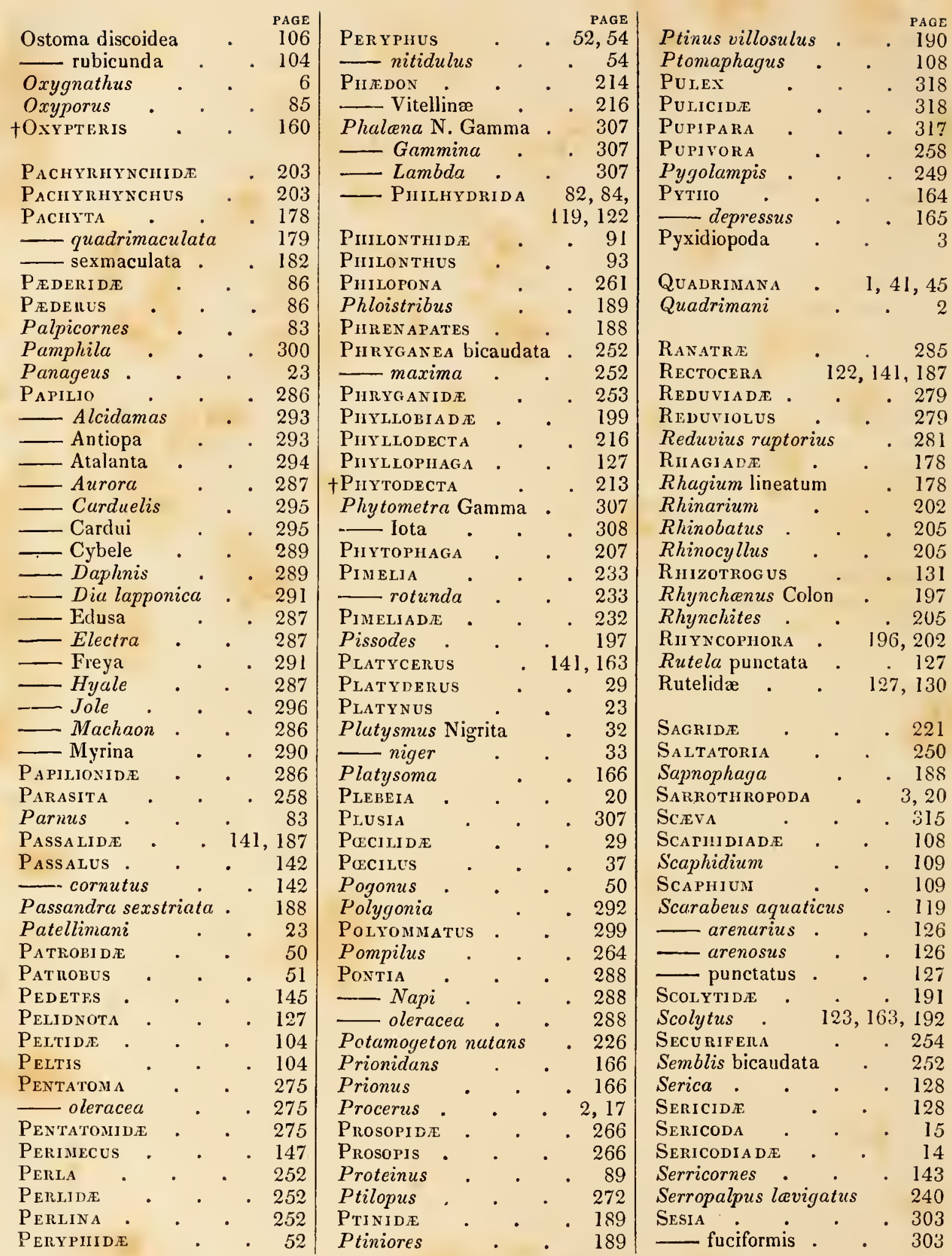




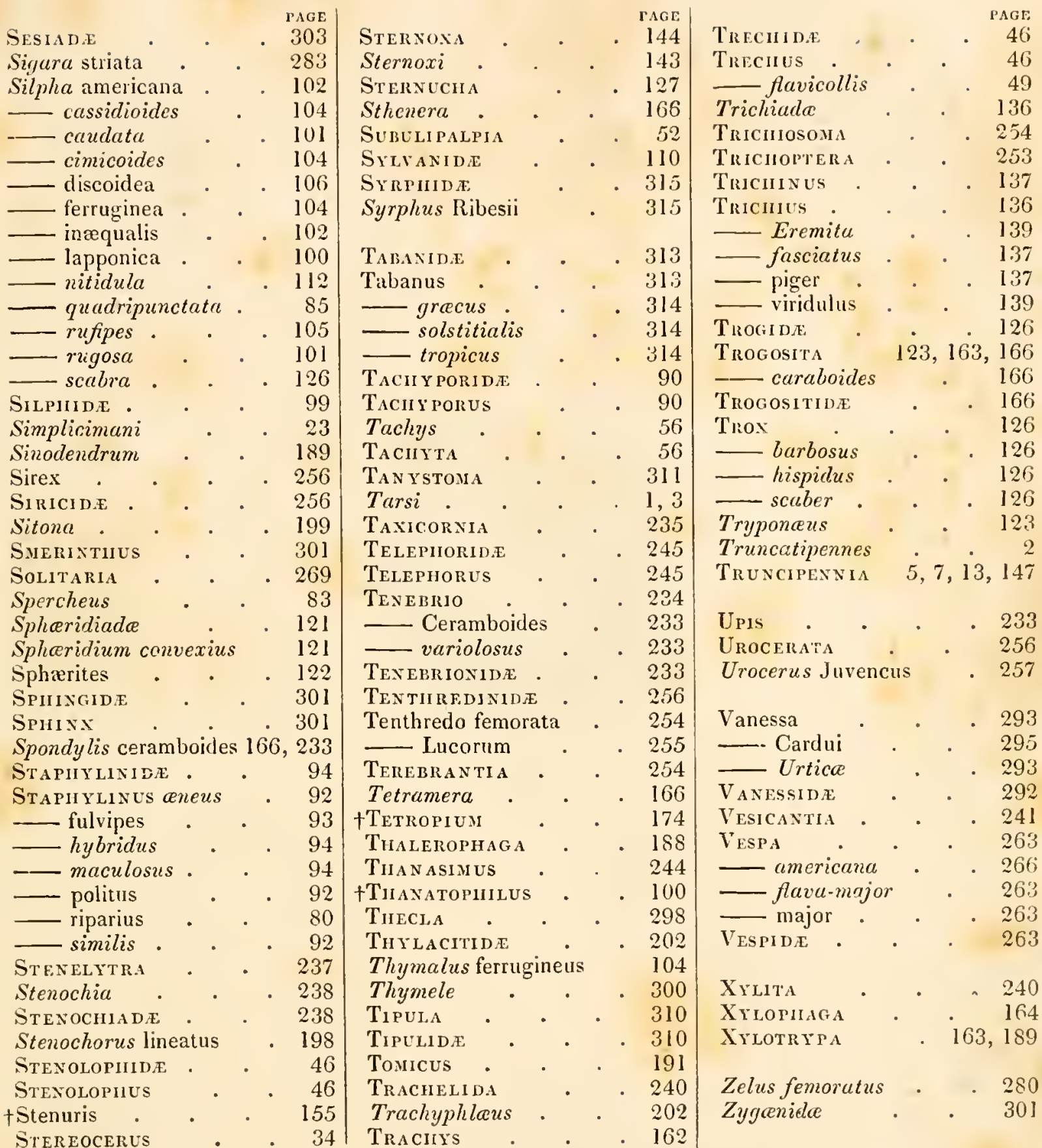




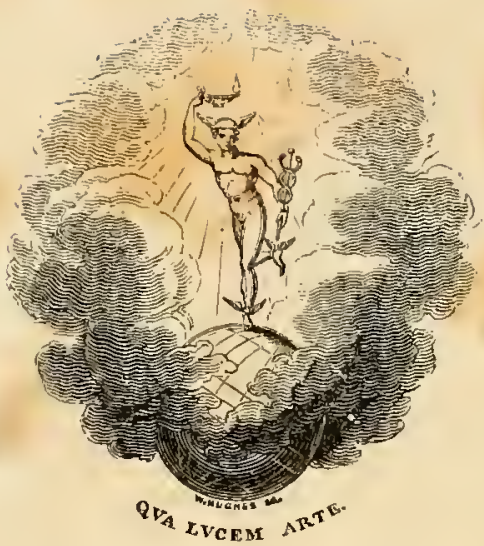

\$arivity :

PRINTED BY J. FLETCHER, UPPER HAYMARKET. 

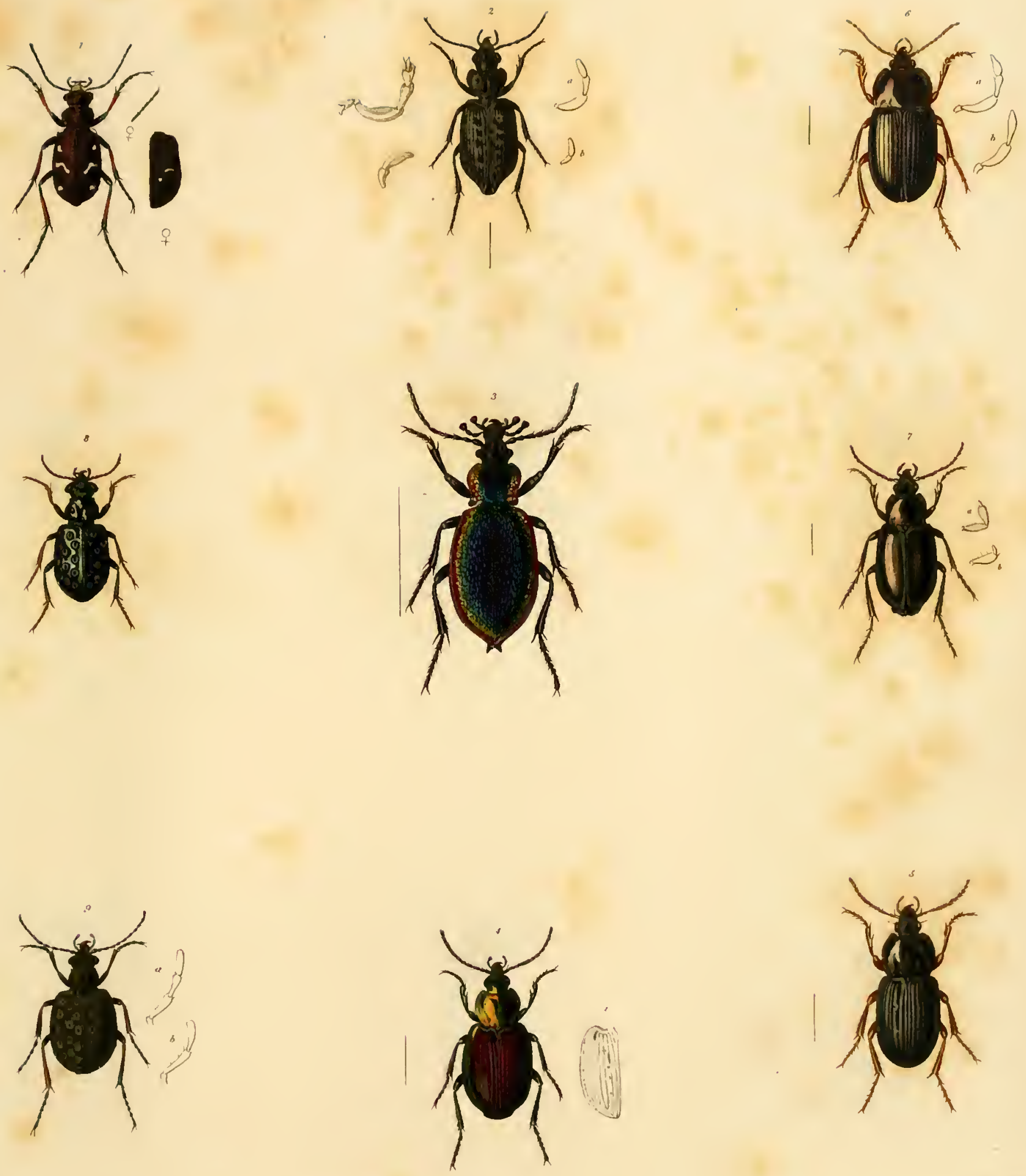


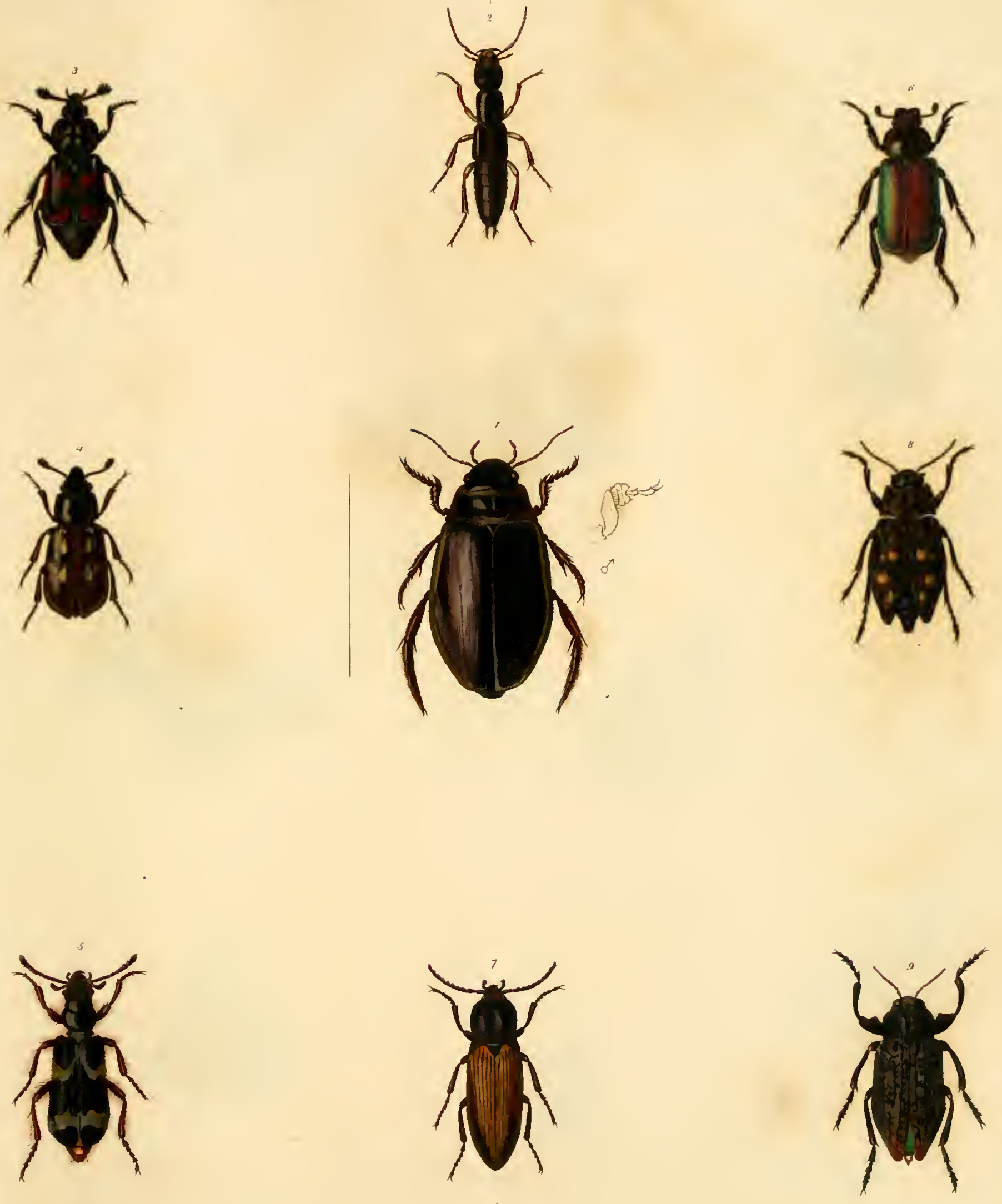


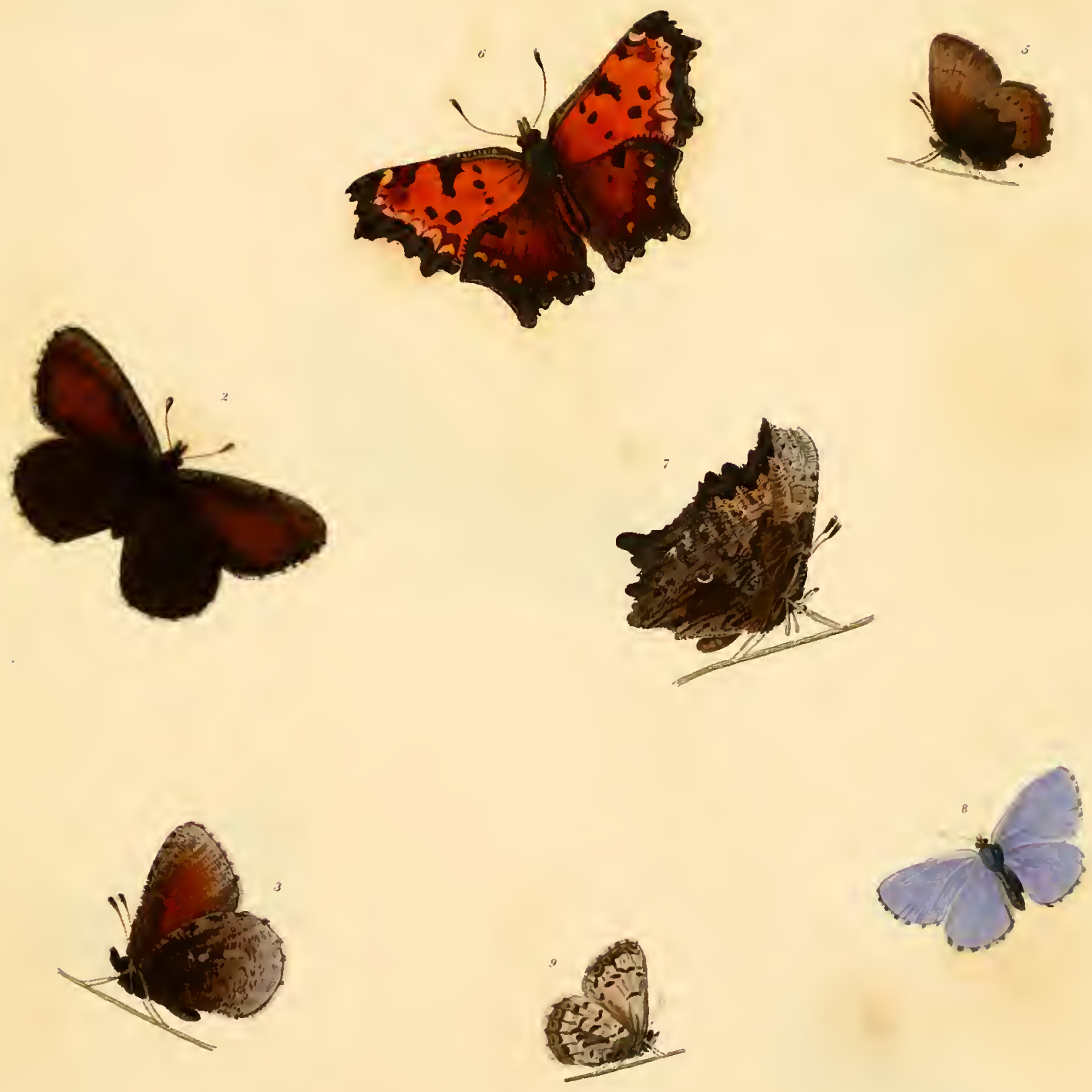


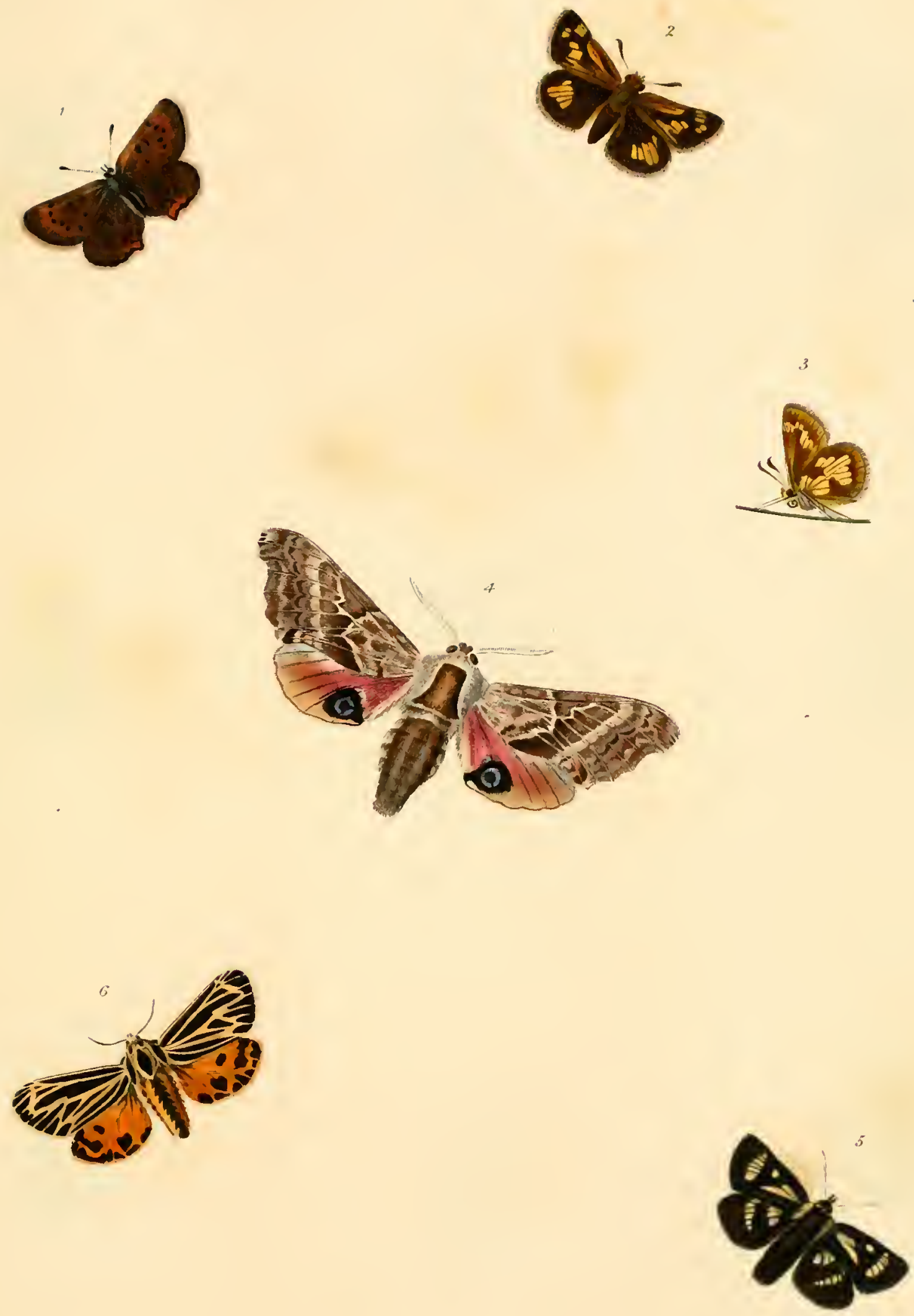

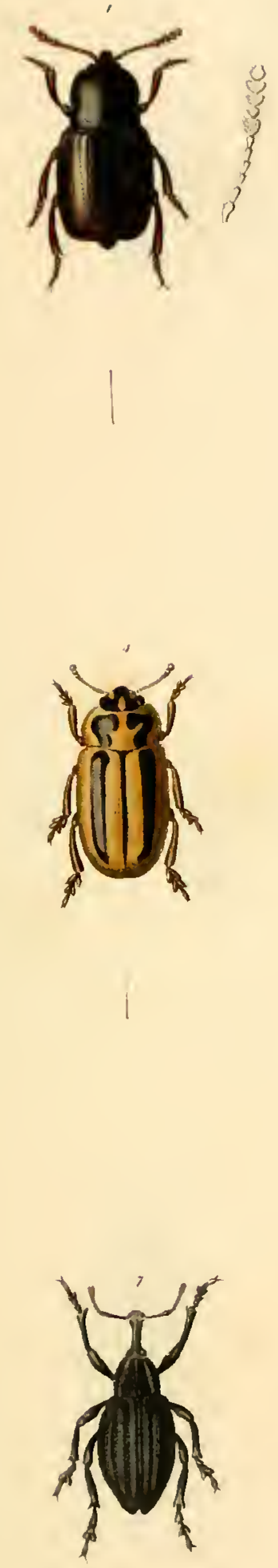
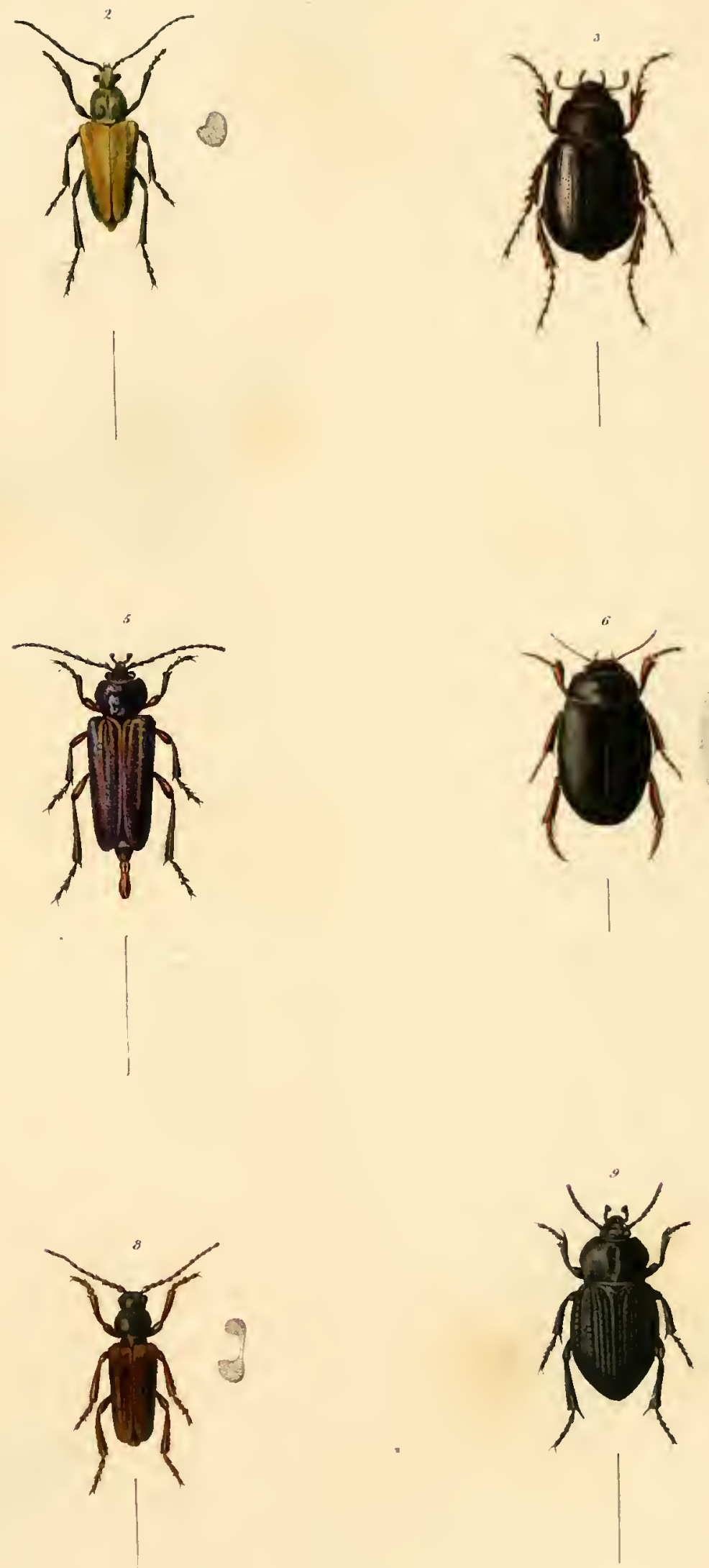



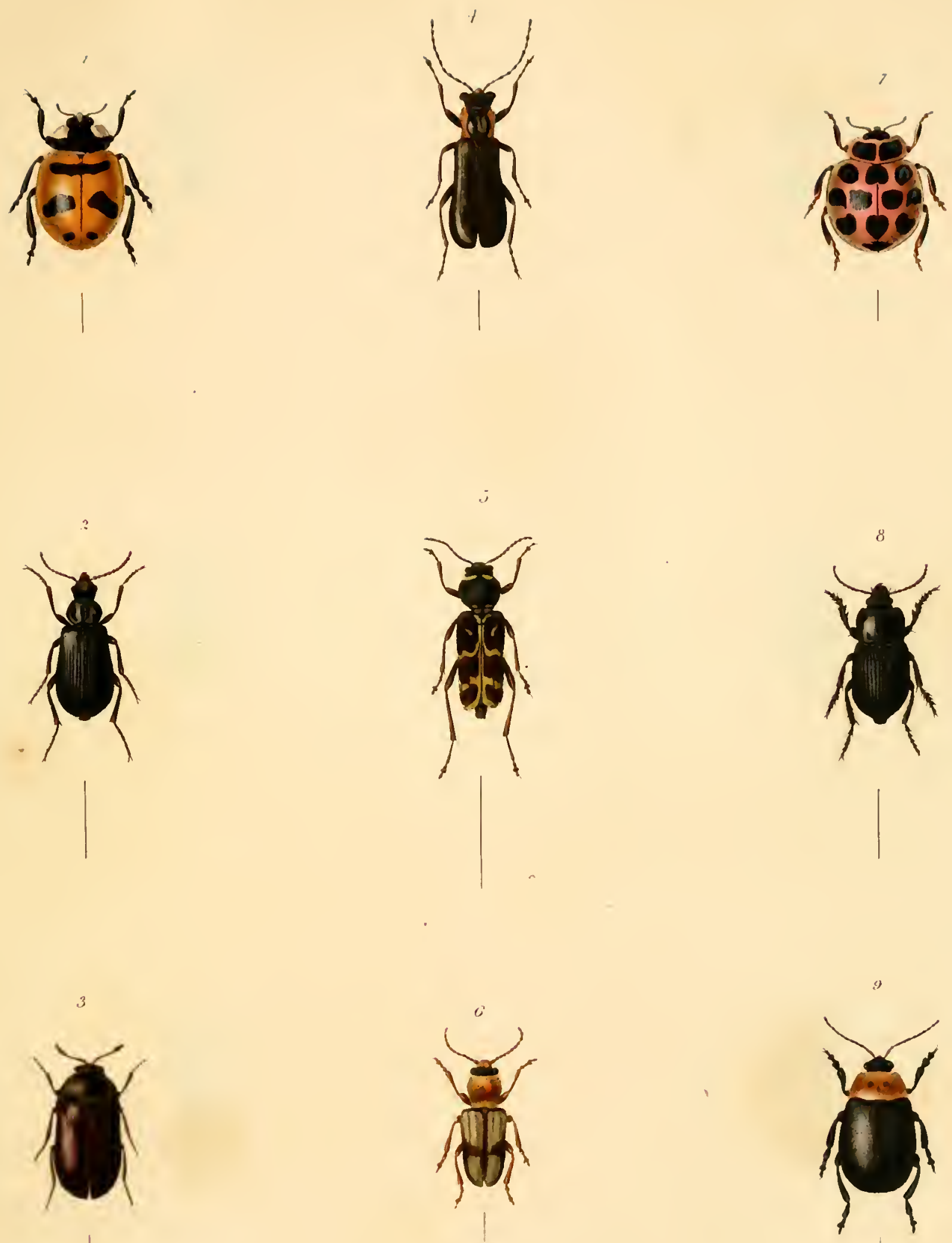


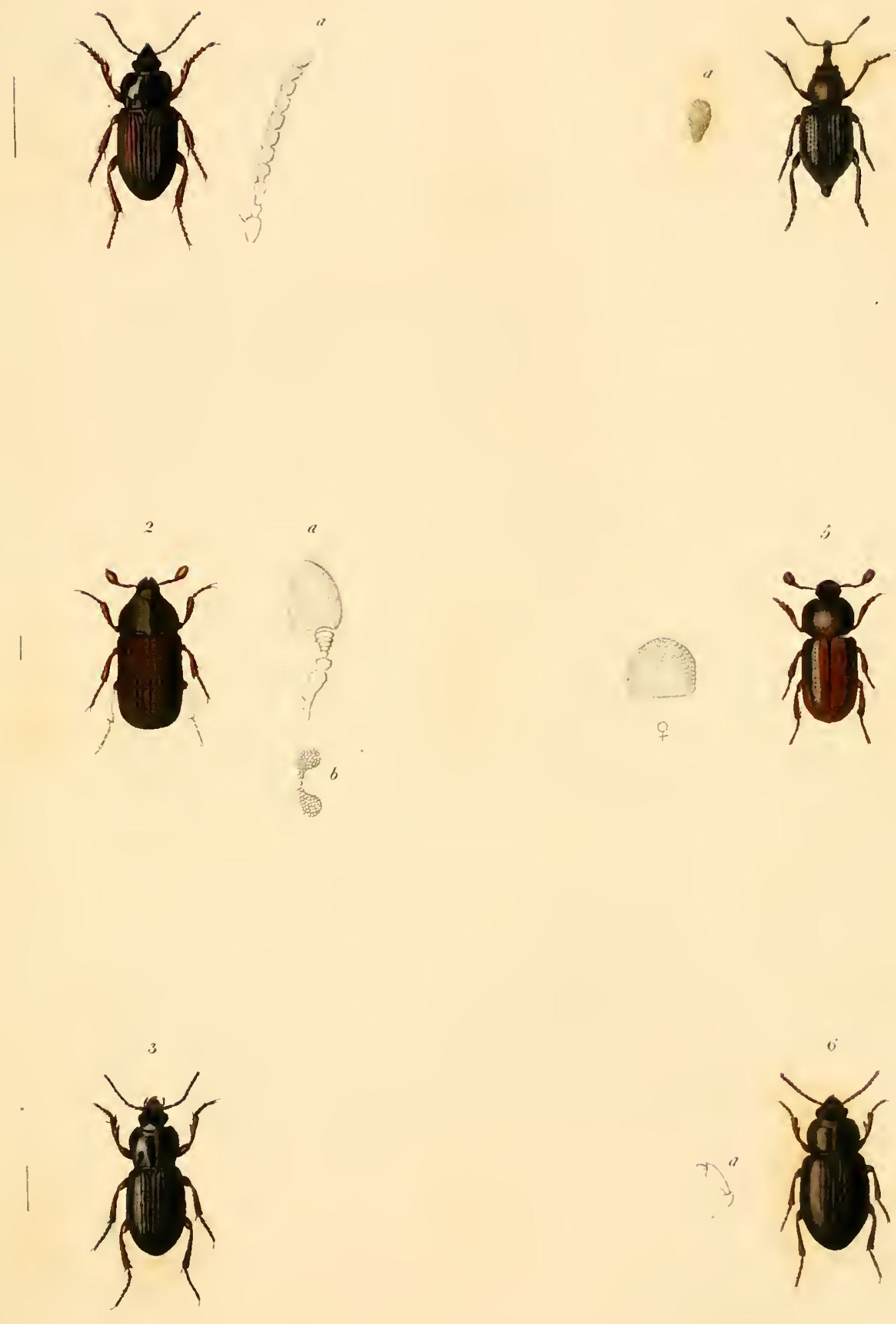


\section{ERRATA.}

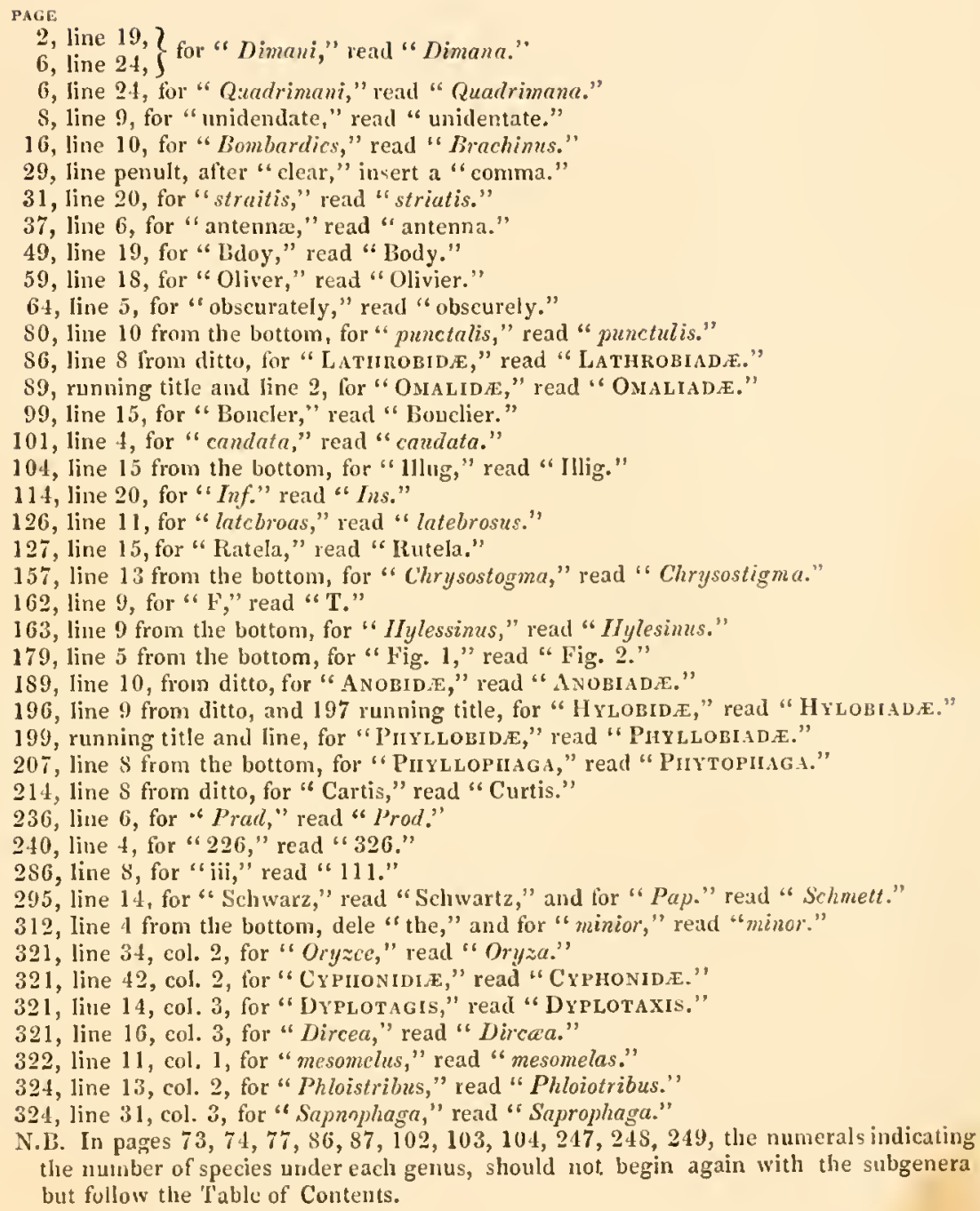





Gey R. Browl

Bonkblind 2030 Srovth 18th S".

Pmisturgh $3, P_{2}$ 
